\title{
Dinoflagellate Taxonomy and Biostratigraphy of the Mid- to Late Eocene and Early Oligocene of New Zealand
}

by

Christopher Dennis Clowes

\author{
A thesis \\ submitted to the Victoria University of Wellington \\ in fulfilment of the \\ requirements for the degree of \\ Doctor of Philosophy \\ in Geology \\ Victoria University of Wellington \\ 2009
}




\section{Dinoflagellate Taxonomy and Biostratigraphy of the Mid- to Late Eocene and Early Oligocene of New Zealand}




\section{Abstract}

This document presents results from a study of the Mid- to Late Eocene and earliest Oligocene marine palynomorphs from on-shore and near-shore New Zealand. Eighty samples of appropriate age from across mainland New Zealand were examined for fossil dinoflagellates. Acritarchs encountered in the study are described, also, and the phenetic taxonomy of the Acritarcha provides an interesting contrast to the present 'mixed' state of dinoflagellate taxonomy: phylogenetic above the genus rank, and arguably below it, but predominantly phenetic at the genus rank.

Extensive single mount collections were harvested from a number of samples which were found to be especially rich, well preserved, or which contained new taxa. The outcome has included descriptions of 25 new species, in addition to two (Corrudinium regulare and Corrudinium otagoense) published in an earlier paper (Clowes \& Wilson 2006), namely:

Achilleodinium echinatum

Achilleodinium improcerum

?Areoligera hampdenensis

Batiacasphaera perforata

Chlamydophorella neopilata

Chlamydophorella pilata

Corrudinium bujakii

Deflandrea totara

Disphaerogena morgansii
Graptodinium inconditum Graptodinium reticulatum Nummus inornatus

Operculodinium crouchii

Operculodinium schioleri

Operculodinium pulcher

Operculodinium vulgare

Phthanoperidinium aculeatum

Phthanoperidinium australe
Phthanoperidinium dentatum Phthanoperidinium granulatum Phthanoperidinium spumosum Phthanoperidinium tenuimurum Pyxidinopsis mundus Pyxidinopsis teuriensis Samlandia tenuis

Although there remain some difficulties where the adopted suprageneric phylogeny meets the traditionally phenetic generic constructs, adopting an explicitly phylogenetic approach to dinoflagellate taxonomy was found to be a fruitful approach. Investigation into some of the new taxa described herein was first prompted by geographic or temporal occurrence criteria which hinted that relationships might be other than those immediately suggested by gross morphology. Only upon closer inspection were subtler morphological distinctions noticed.

To adopt a wholly phylogenetic approach almost certainly requires the abandonment of taxa, particularly genera, which are uniquely defined by mutually exclusive morphological criteria. Other clues to phylogeny, such as stratigraphic and regional occurrence data, may also have to be recognised. Notwithstanding, all taxa described herein are, in fact, defined by means of conventional morphological distinctions. This study does not take the bold step to suggest a new taxon based wholly on geographical and temporal criteria. Doing so, however, is clearly a rational extension to the ideas presented herein, and is thought worthy of further investigation.

A subordinate goal of this study was to further refine the younger part of Wilson's dinoflagellate biozonation for New Zealand (Wilson 1984d, 1987, 1988; Morgans et al. 2004), to:

- improve resolution, if possible;

- clarify an ambiguous boundary remaining in the literature, between the Wetzeliella hampdenensis and Wilsonidium tabulatum zones;

- incorporate more common taxa, which are not restricted to particular ecological settings.

This has been progressed by a number of measures, including adopting a consistent approach to defining zone boundaries; replacement of the Wilsonidium echinosuturatum and Wilsonidium lineidentatum Zones with three new zones, Deflandrea convexa (early Porangan - late Porangan), Graptodinium inconditum (late Porangan - early Bortonian), and Impagidinium elegans (early Bortonian - late Bortonian); and the establishment of an additional new zone, the Stoveracysta kakanuiensis Zone, straddling the EoceneOligocene boundary. 
Since phylogenetic concepts played no role in formulating the classification [of Sarjeant \& Downie 1966, 1974], one should be cautious in criticizing its authors for seeming to suggest relationships at suprageneric levels when that was not intended. However, one can also question whether, under such circumstances, a detailed family-like classification of "non-families" is any more useful than an alphabetical listing or some other systematic but frankly arbitrary ordering.

— Evitt 1985, p. 278

This contribution is dedicated to the founder and uncontested doyen of fossil dinoflagellate studies in New Zealand,

Dr. Graeme J. Wilson

of GNS Science (formerly the New Zealand Geological Survey) until his retirement at the end of 2007.

A wonderful mentor, field-trip companion, and kind friend.

Thanks Graeme! 


\section{Table of Contents}

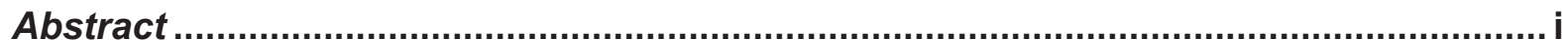

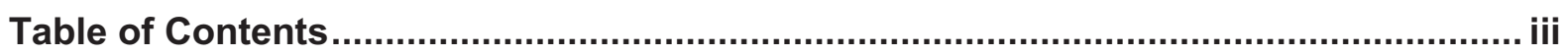

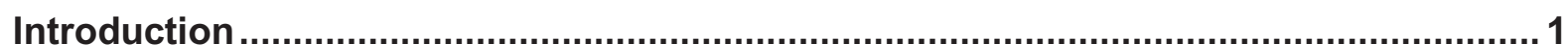

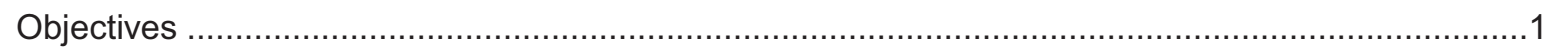

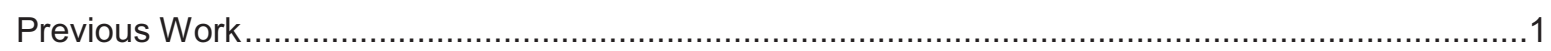

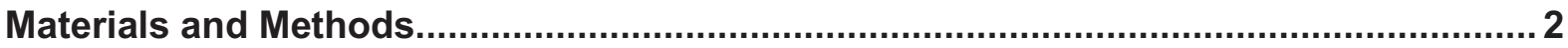

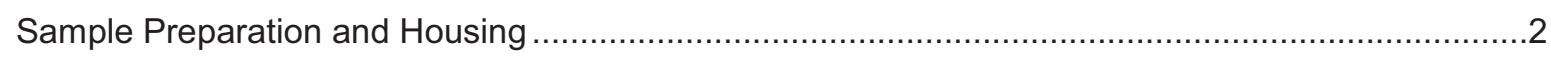

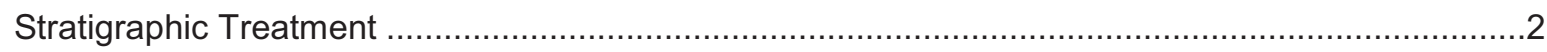

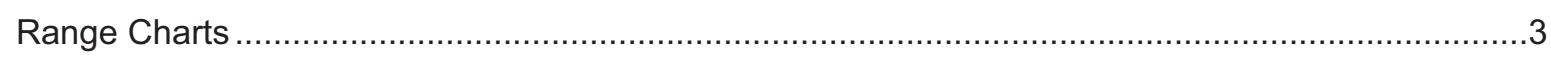

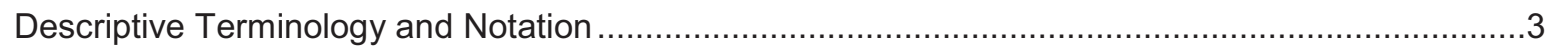

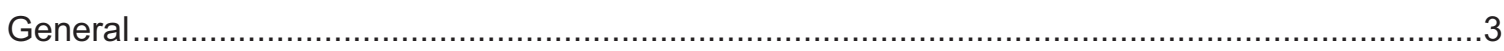

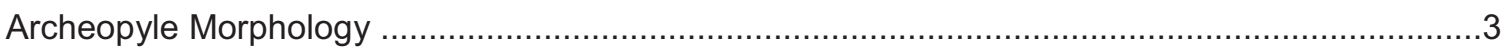

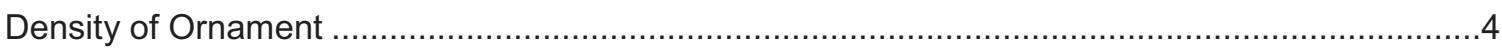

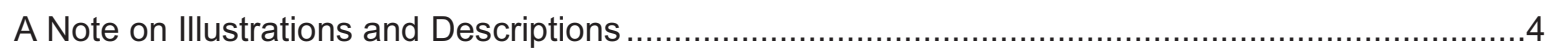

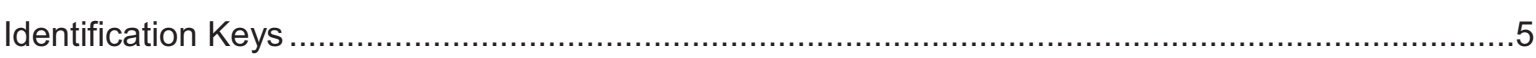

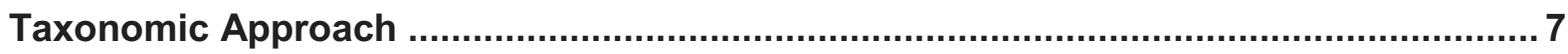

Scope

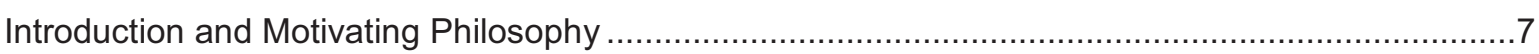

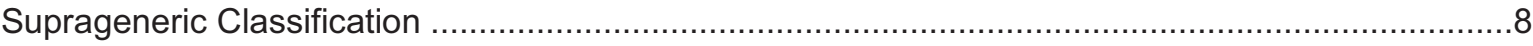

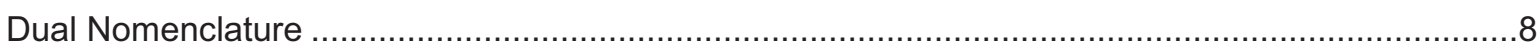

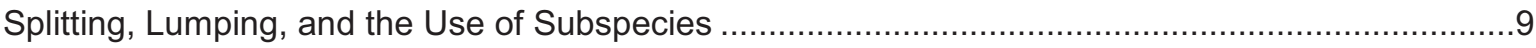

Presentation of Findings .................................................................................. 11

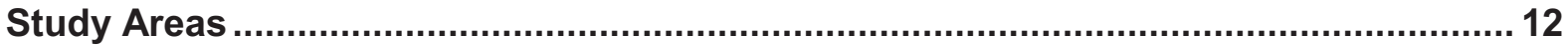

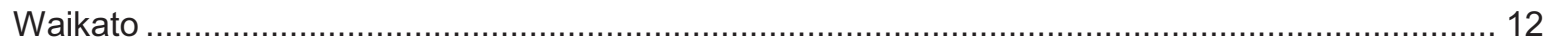

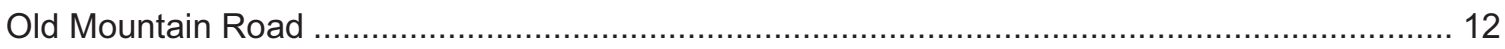

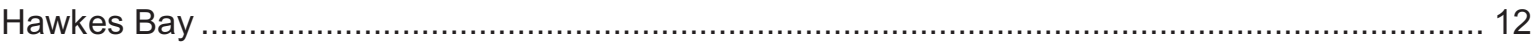

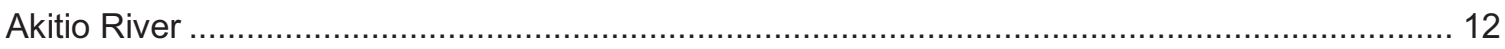

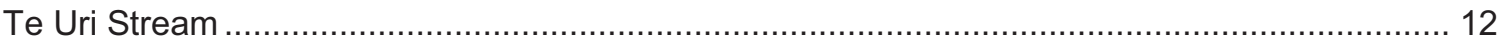

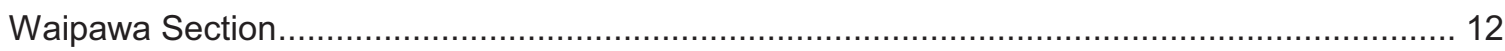

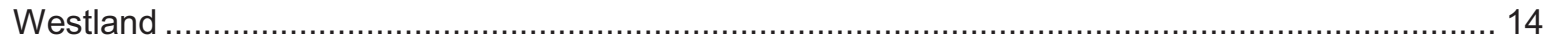

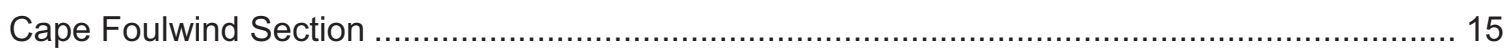

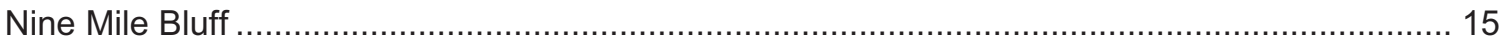

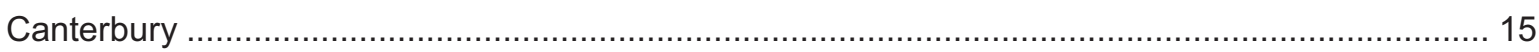

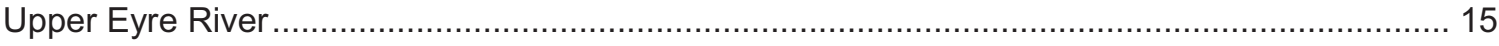

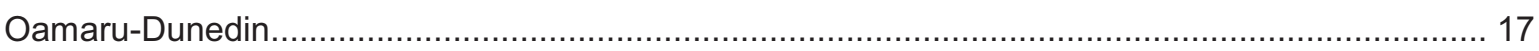

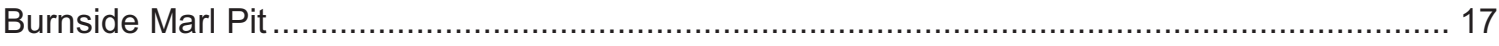

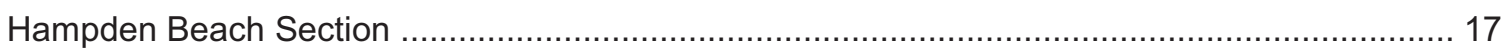

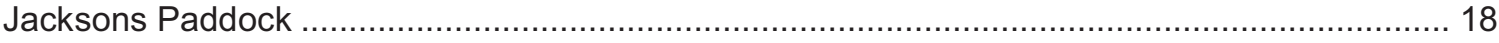

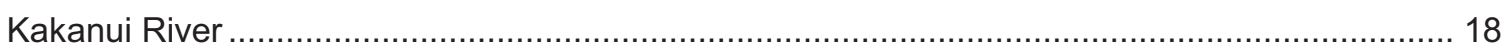

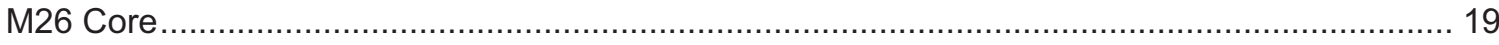

Puketeraki Core

Tumai 


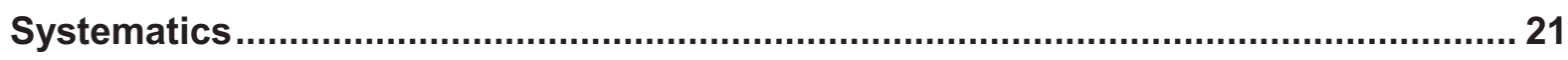

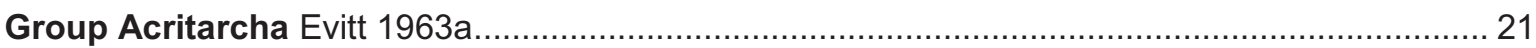

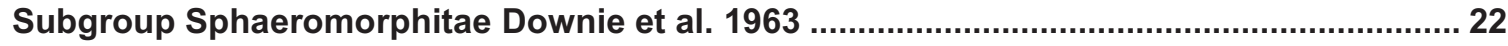

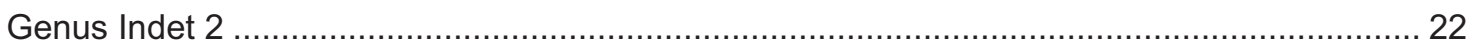

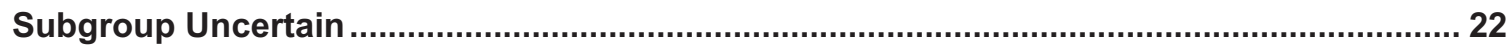

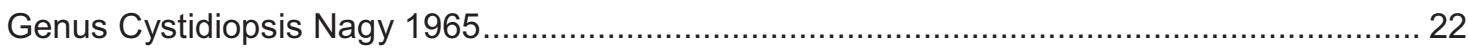

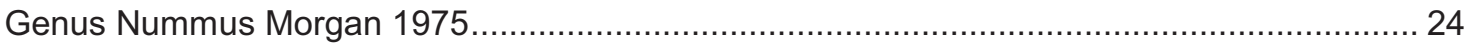

Genus Paucilobimorpha De Coninck 1986b emend. Prössl 1994 .................................... 25

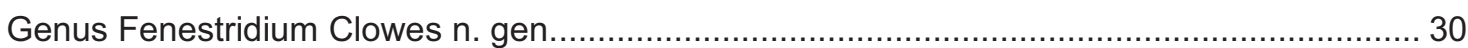

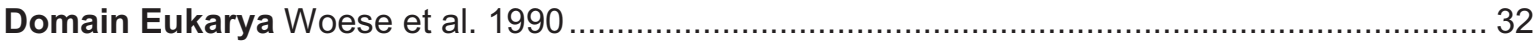

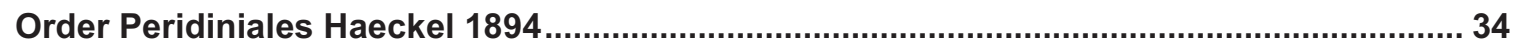

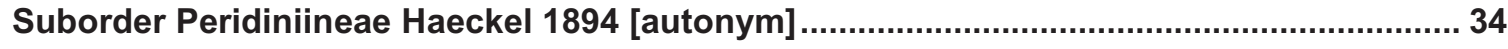

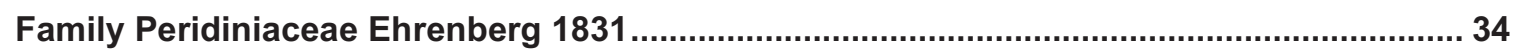

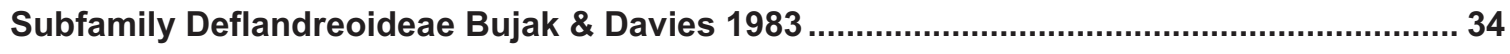

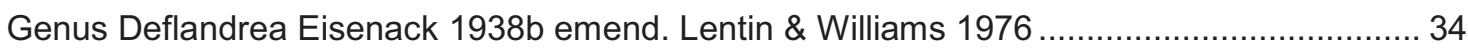

Genus Alterbidinium Lentin \& Williams 1985 emend. Khowaja-Ateequzzaman et al. 1991 ..... 46

Genus Cerodinium Vozzhennikova 1963 emend. Lentin \& Williams $1987 \ldots \ldots \ldots \ldots \ldots \ldots \ldots \ldots \ldots . \ldots 7$

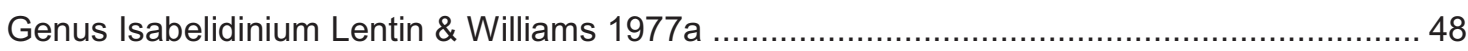

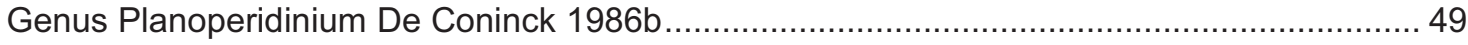

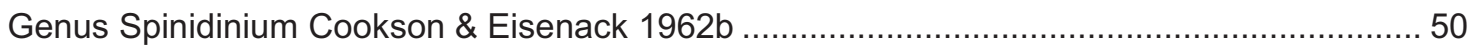

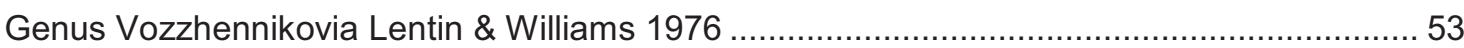

Subfamily Palaeoperidinioideae (Vozzhennikova 1961) Bujak \& Davies 1983 .................... 55

Genus Phthanoperidinium Drugg \& Loeblich Jr. 1967 emend. Clowes .............................. 55

Subfamily Wetzelielloideae (Vozzhennikova 1961) Bujak \& Davies 1983 ........................... 65

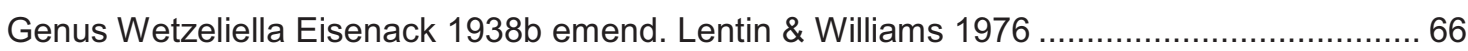

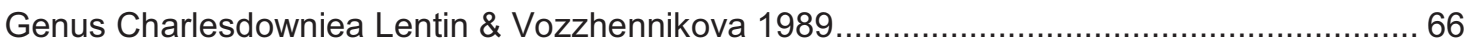

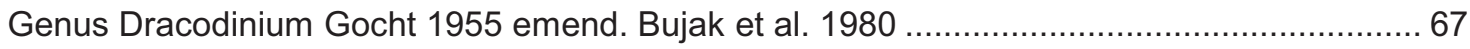

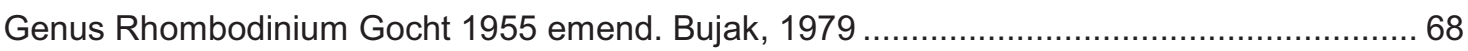

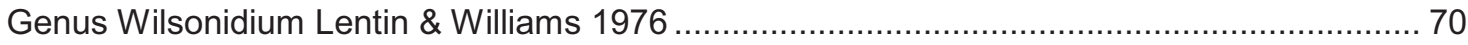

Family Protoperidiniaceae Bujak \& Davies 1983 ............................................................... 72

Subfamily Protoperidinioideae Bujak \& Davies 1983 [autonym]........................................ 72

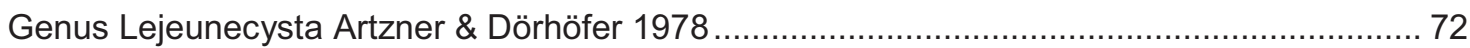

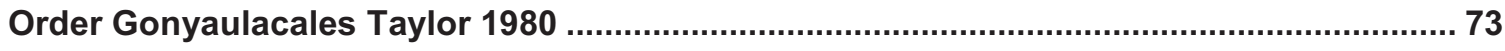

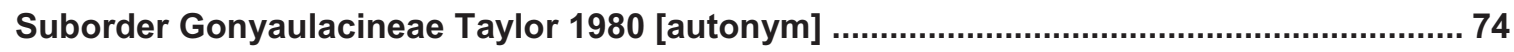

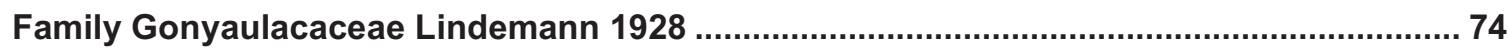

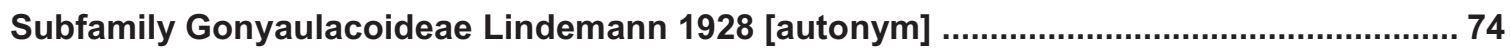

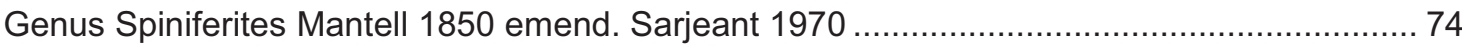


Genus Achomosphaera Evitt 1963a

Genus Hafniasphaera Hansen 1977 ......

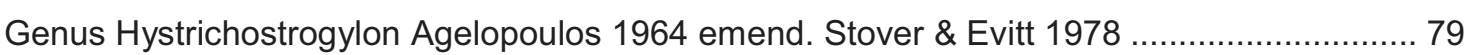

Genus Nematosphaeropsis Deflandre \& Cookson 1955 emend. Wrenn 1988 ...................... 80

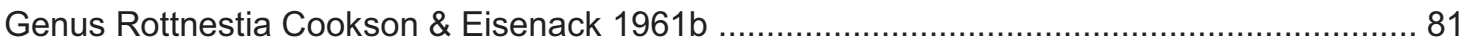

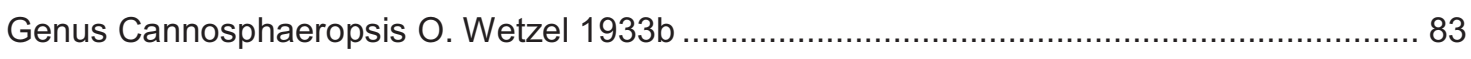

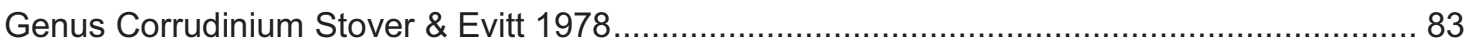

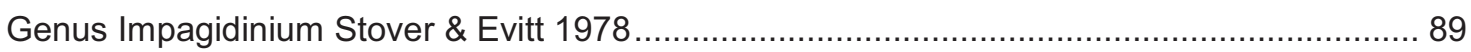

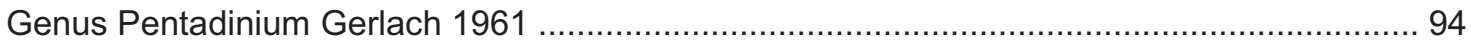

Genus Tectatodinium Wall 1967a emend. Head 1994a............................................ 95

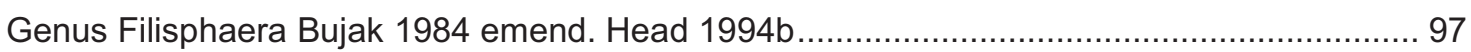

Subfamily Cribroperidinioideae Fensome et al. 1993b .................................................... 98

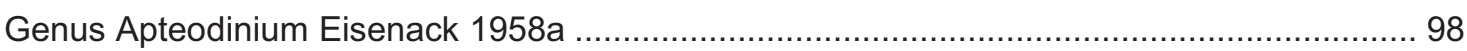

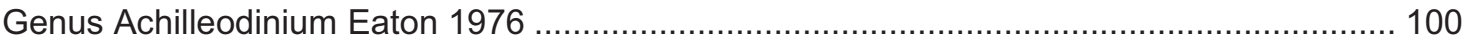

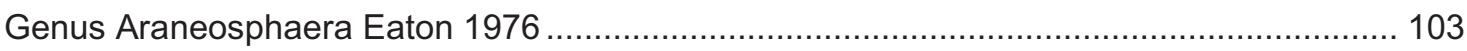

Genus Cordosphaeridium Eisenack 1963b emend. Davey 1969c................................ 104

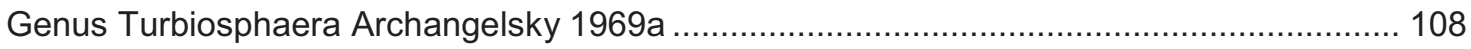

Genus Disphaerogena O. Wetzel 1933b emend. Sarjeant 1985b ................................ 109

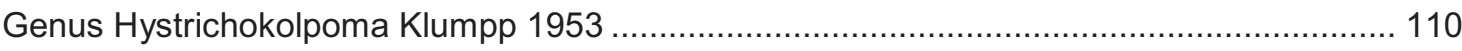

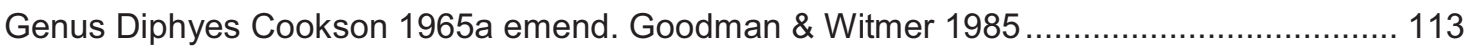

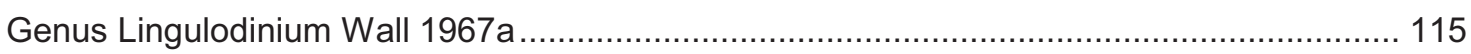

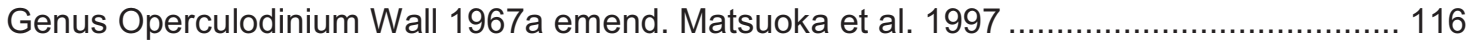

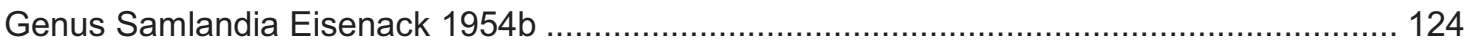

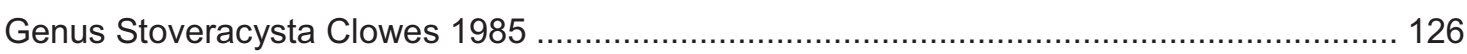

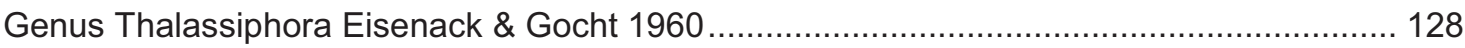

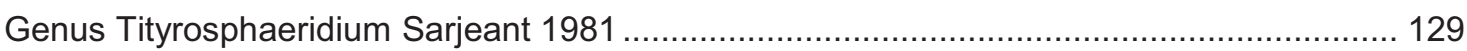

Subfamily Leptodinioideae Fensome et al. 1993b ...................................................... 130

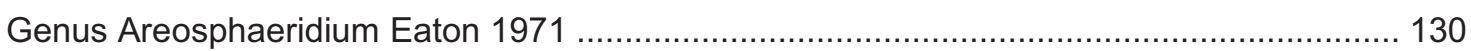

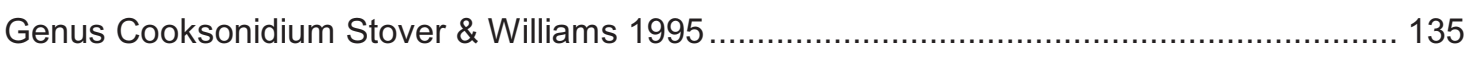

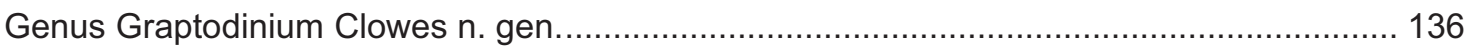

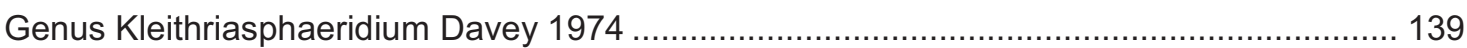

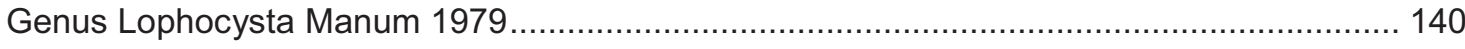

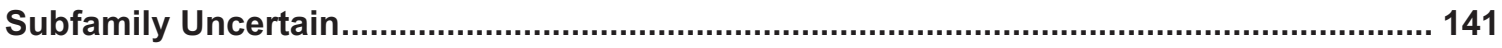

Genus Aireiana Cookson \& Eisenack 1965a............................................................ 141 
Genus Fibrocysta Stover \& Evitt 1978

Genus Pyxidinopsis Habib 1976.

Family Areoligeraceae Evitt 1963b

Genus Areoligera Lejeune-Carpentier 1938a.

Genus Cleistosphaeridium Davey et al. 1966 emend. Eaton et al. 2001.

Genus Cyclonephelium Deflandre \& Cookson 1955 emend. Stover \& Evitt 1978 153

Genus Glaphyrocysta Stover \& Evitt 1978 153

Genus Membranophoridium Gerlach 1961 emend. Stover \& Evitt 1978 154

Genus Riculacysta Stover 1977 155

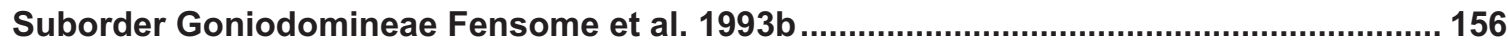

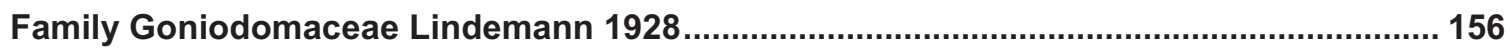

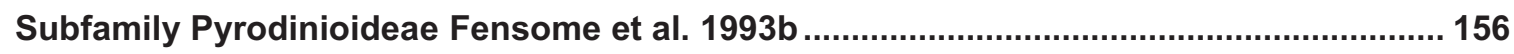

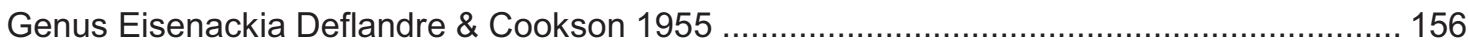

Genus Homotryblium Davey \& Williams 1966b ................................................. 157

Genus Hystrichosphaeridium Deflandre 1937b emend. Davey \& Williams 1966 ................ 158

Suborder Uncertain ...................................................................................................... 160

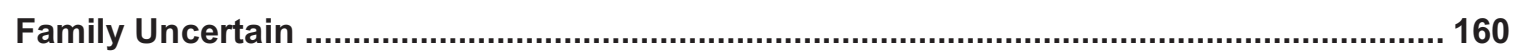

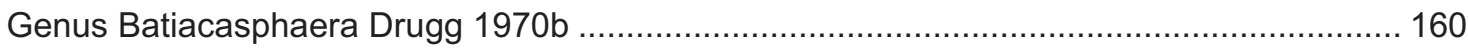

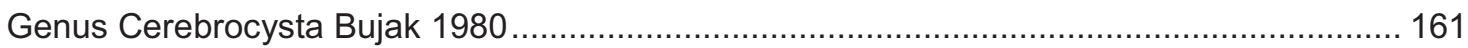

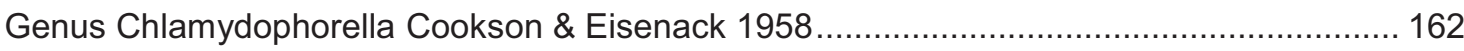

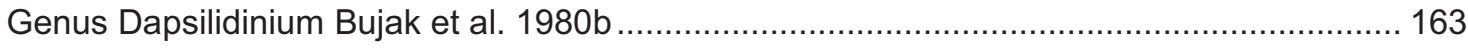

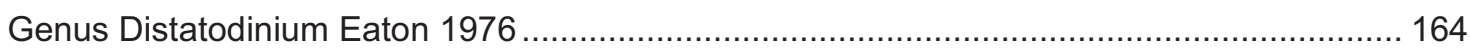

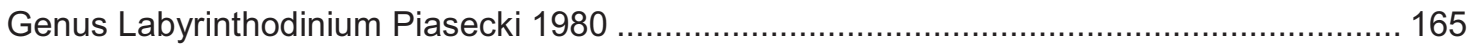

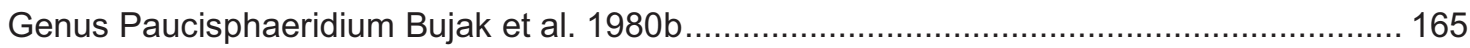

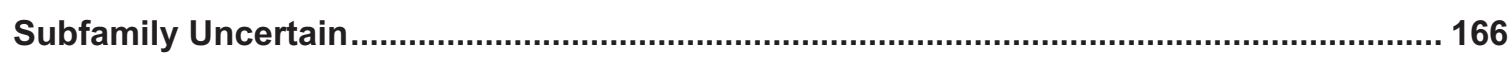

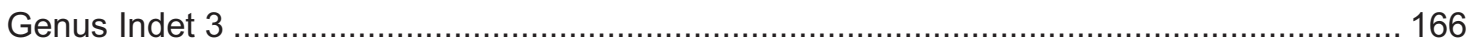

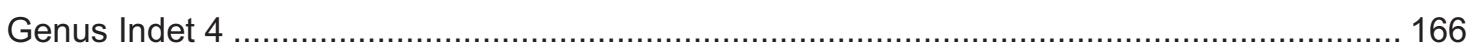

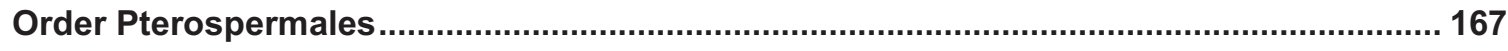

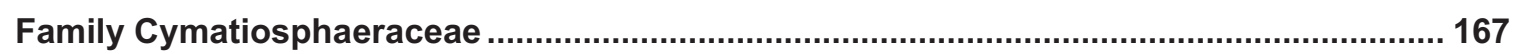

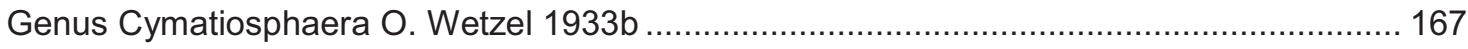

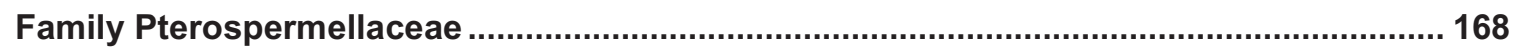

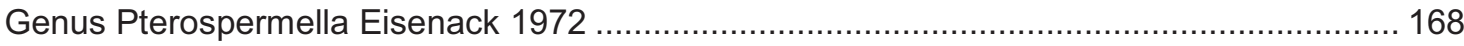

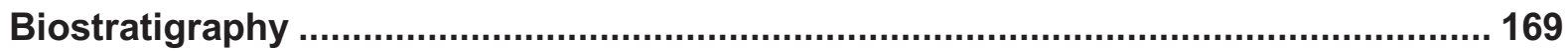

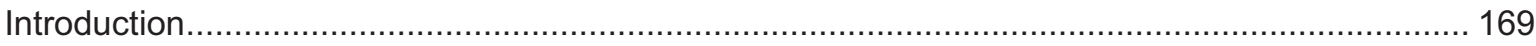

Zonal Scheme for the Mid-Late Eocene to Early Oligocene .................................................... 169

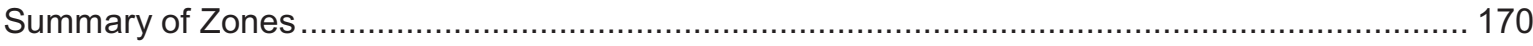




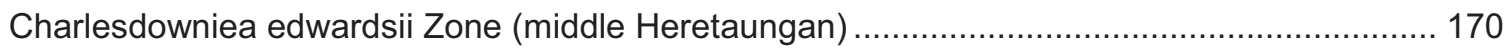

Membranophoridium perforatum Zone (late Heretaungan - earliest Porangan?) ...................... 170

Deflandrea convexa Zone n. zone (early Porangan - late Porangan)....................................... 171

Graptodinium inconditum Zone n. zone (late Porangan - early Bortonian) ................................ 171

Impagidinium elegans Zone n. zone (early Bortonian - late Bortonian) ................................... 171

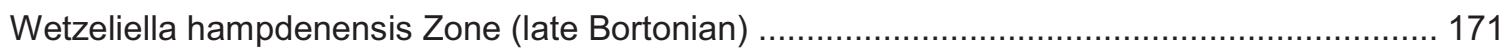

Rhombodinium glabrum Zone n. zone (late Bortonian - Kaiatan) ........................................ 171

Deflandrea phosphoritica Zone (late Kaiatan - latest Runangan) ........................................ 171

Stoveracysta kakanuiensis Zone n. zone (latest Runangan - early Whaingaroan) ................... 172

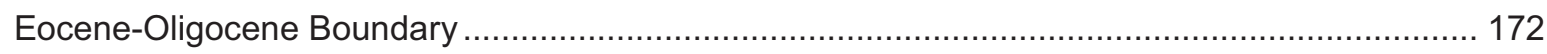

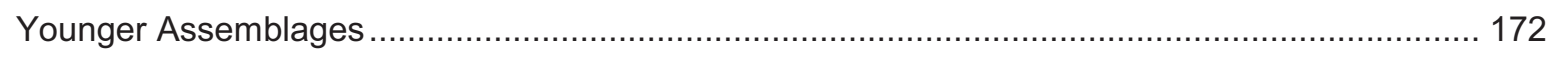

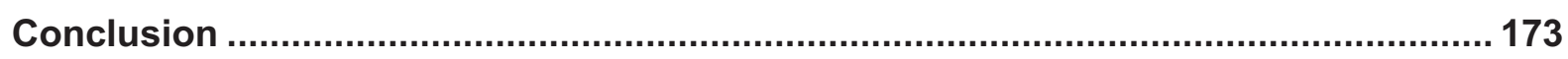

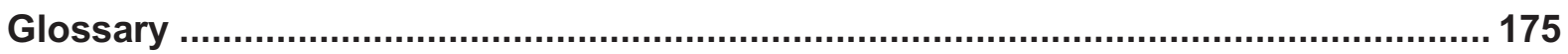

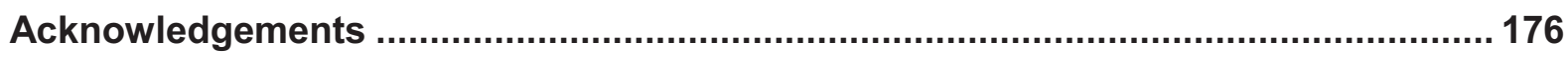

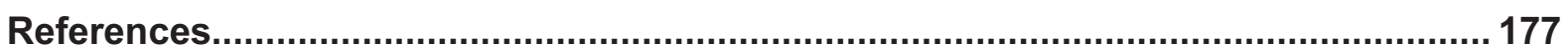

Appendix 1. List of Samples and Preparations ........................................................... 193

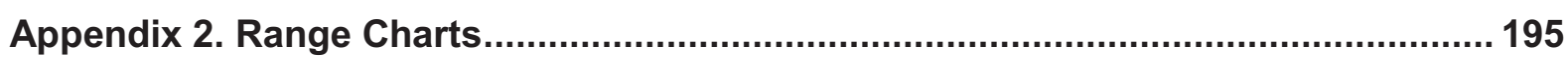

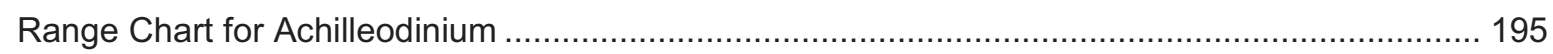

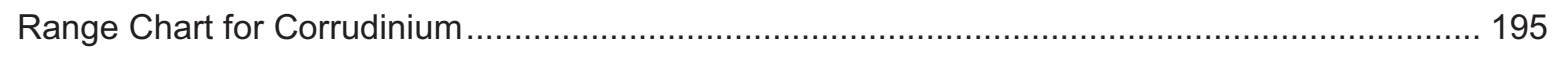

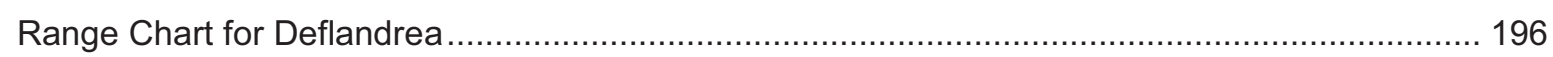

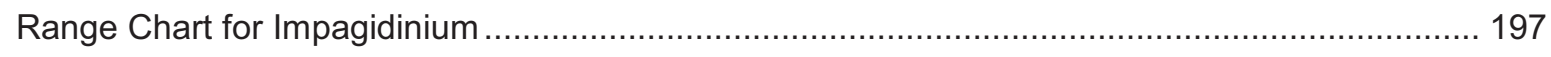

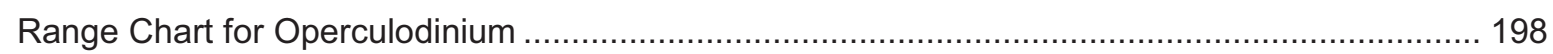

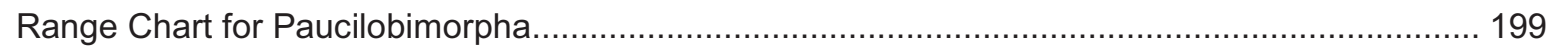

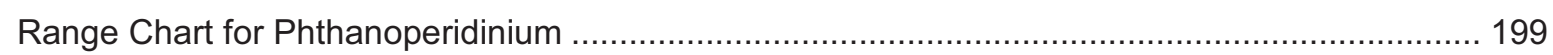

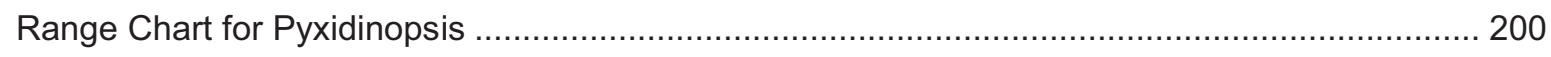

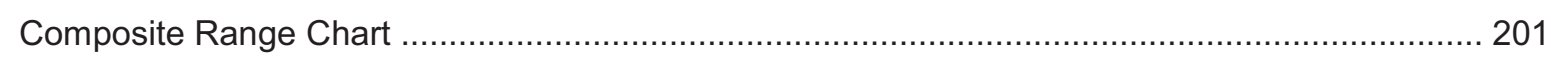

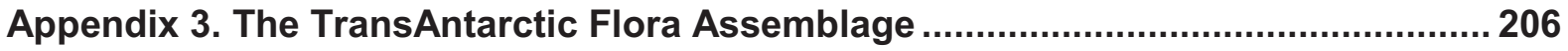

Appendix 4. Other Species of Phthanoperidinium ................................................... 207

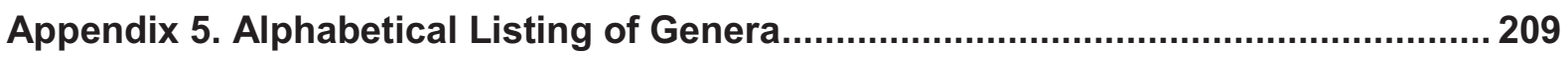

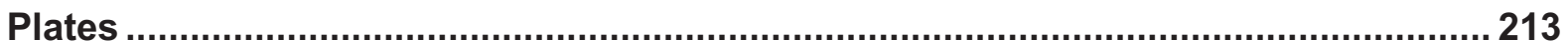




\section{Introduction}

\section{Objectives}

This document presents results from a study of the Mid- to Late Eocene and earliest Oligocene acritarchs and dinoflagellates from on-shore and near-shore New Zealand. The focus is primarily taxonomic, but effort is also made to characterise and compare whole assemblages, with emphasis upon refining the biozonation scheme for the interval.

Some specific objectives of the present study are:

1. First and foremost, this study aims to evaluate the effectiveness of having adopted an explicitly phylogenetic approach to dinoflagellate taxonomy.

The background, motivation, and evaluation of this approach are explored further in the section entitled Taxonomic Approach.

2. The approach was trialled by applying it to "genuine" (i.e., not a contrived experiment) taxonomic research, which was expected to further elucidate the taxonomy of the middle Eocene to early Oligocene dinoflagellate cyst biota of New Zealand. This is the second objective.

The resulting systematic descriptions, including 25 new taxa, are documented in the systematic section.

3. A third goal is to further refine the younger part of Wilson's (1984d ${ }^{1}, 1987,1988$; Morgans et al. 2004) dinoflagellate biozonation for New Zealand, to:

- improve resolution, if possible;

- clarify an ambiguous boundary occurring between the Wetzeliella hampdenensis and Wilsonidium tabulatum zones (Morgans et al. 2004, p. 149);

- incorporate more common taxa, which are not restricted to particular ecological settings.

This goal has been progressed (I would not claim to have written the final word on any part of the zonation) by replacing the Wilsonidium echinosuturatum and Wilsonidium lineidentatum Zones with three new zones and the establishment of a new zone straddling the Eocene-Oligocene boundary, as discussed in the Biostratigraphy section.

\section{Previous Work}

Previous accounts of Paleogene dinoflagellate cysts from mainland and near-shore New Zealand include Deflandre 1933, Couper 1960, Wilson 1967c, 1968, 1977, 1978, 1982a, 1982b and 1982c, Clowes \& Morgans 1984, Wilson 1985, Clowes 1985, Wilson 1988, Beggs et al. 1992, Strong et al. 1995, Wilson \& McMillan 1996, Edbrooke et al. 1998, Crouch 2001, Willumsen 2003, Morgans et al. 2004, Willumsen 2004, Hollis et al. 2005 and Clowes \& Wilson 2006. The majority of the publications describe material from localities in eastern New Zealand ranging from Hawkes Bay to Otago, although Beggs et al. 1992 deals exclusively with material from petroleum exploration wells in the offshore Taranaki Basin west of North Island.

Of the several papers dealing with detailed taxonomy, the two most significant contributions are Wilson 1967c and Wilson 1988 which together include full systematic descriptions and stratigraphic ranges for over 35 dinoflagellate species. These form the basis of the current New Zealand-wide dinoflagellate zonation for the Paleocene and Eocene, part of which is also used in Australia (Wilson 1984d, 1985, 1987, Partridge \& Dettmann 2003, Morgans et al. 2004). Recent refinements to parts of the scheme have resulted from the doctoral research studies of Crouch (2001) and Willumsen (2003).

However, the Late Eocene and Early Oligocene dinoflagellate cyst fossils of New Zealand have been relatively little documented compared to older sections. The earliest publication is Deflandre 1933, in which a siliceous dinoflagellate, Lithoperidinium (now Peridinites) oamaruense, is described from an Oamaru diatomite, and then there is a hiatus until a small string of publications by Wilson (1982a, 1982b, 1982c, 1985, Beggs et al. 1992, Wilson \& McMillan 1996) and the present writer (Clowes \& Morgans 1984, Clowes 1985, Clowes \& Wilson 2006).

\footnotetext{
1 References are cited without commas separating the authors' names and dates of publication. Where a researcher is referred to in person, any supporting references are listed in parentheses, generally without repreating the author's name.
} 


\section{Materials and Methods}

\section{Sample Preparation and Housing}

The fossil locality numbers, denoted by "f" and recorded in the New Zealand Fossil Record File, refer to the NZMS 260 Topographical Map Series.

Standard preparation techniques - comprising hydrofluoric acid digestion, heavy liquid flotation $(S G=2.0)$, and oxidation in Schulze's reagent - were used throughout. The practice of oxidation is now thought to selectively remove certain cysts, and is used with more caution than in the past. Most (all but eight) of the samples used in this study, however, were prepared long ago: many as early as the 1970s, and are likely to have been treated to approximately 15 minutes or more of oxidation. Moreover, it remains true, even today, that oxidation is a simple, practical technique which yields good results.

Strew slides are identified by a laboratory preparation number prefixed by the letter 'L.' Single grain mounts were prepared, wherever possible, to obtain clean, oriented specimens for photography. These were hand-picked from glycerine jelly with a mounted needle and are identified by a serial number prefixed by the letters 'SM.'

$\mathrm{L}$ and SM numbers refer to the corresponding catalogues maintained by GNS Science, Lower Hutt, New Zealand. All rock samples, palynological residues and prepared slides will be deposited in the collections of GNS Science.

\section{Stratigraphic Treatment}

In the pioneer days of New Zealand geology, Thomson formulated a system of local stages for the New Zealand marine sequence (Thomson 1916). The philosophy represented by this paper is at once the greatest single advance and the greatest impediment to further progress in New Zealand biostratigraphy today. The scheme allows for the convenient pigeonholing of New Zealand sediments into an overall succession, with a resolution at least equal to that of the international standard. However, the wholesale continued use of Thomson's stages could lead us into a parochial science, born and bred in isolation.

Globally, biostratigraphic data are increasingly reported in international units - stages anchored to GSSPs or magnetostratigraphic chrons - and this trend appears to be gaining some acceptance locally as well. Cooper 2004 represents a major milestone in our coming of age. Following this major undertaking, it is now possible to correlate almost any local stratigraphic datum with the international chronology (Table 1). Thus, a major objective of this study has been to relate the New Zealand stage material to more regional data.

However, to me, there seems little point in simply substituting one set of problematic units for another worse, indeed, because at least the New Zealand stages are relatively well-agreed by practising geologists and defined by the paleontology of relatively few organisms (most New Zealand Cenozoic stages are essentially foraminiferal zones) whereas definitions for many international stages are still being agreed.

The samples used in the present study are all dated independently of the study itself, generally by means of foraminifera (or interpolation from other samples which are dated by foraminifera), although palynological results are also important (e.g. in the Puketeraki section).

Although the distinction rarely surfaces in the text, the underlying data for this study consistently distinguishes between "sections" (a delimited sequence of sediments at a particular locality) and "collections" (a sampling made from a particular section, made on a given day or

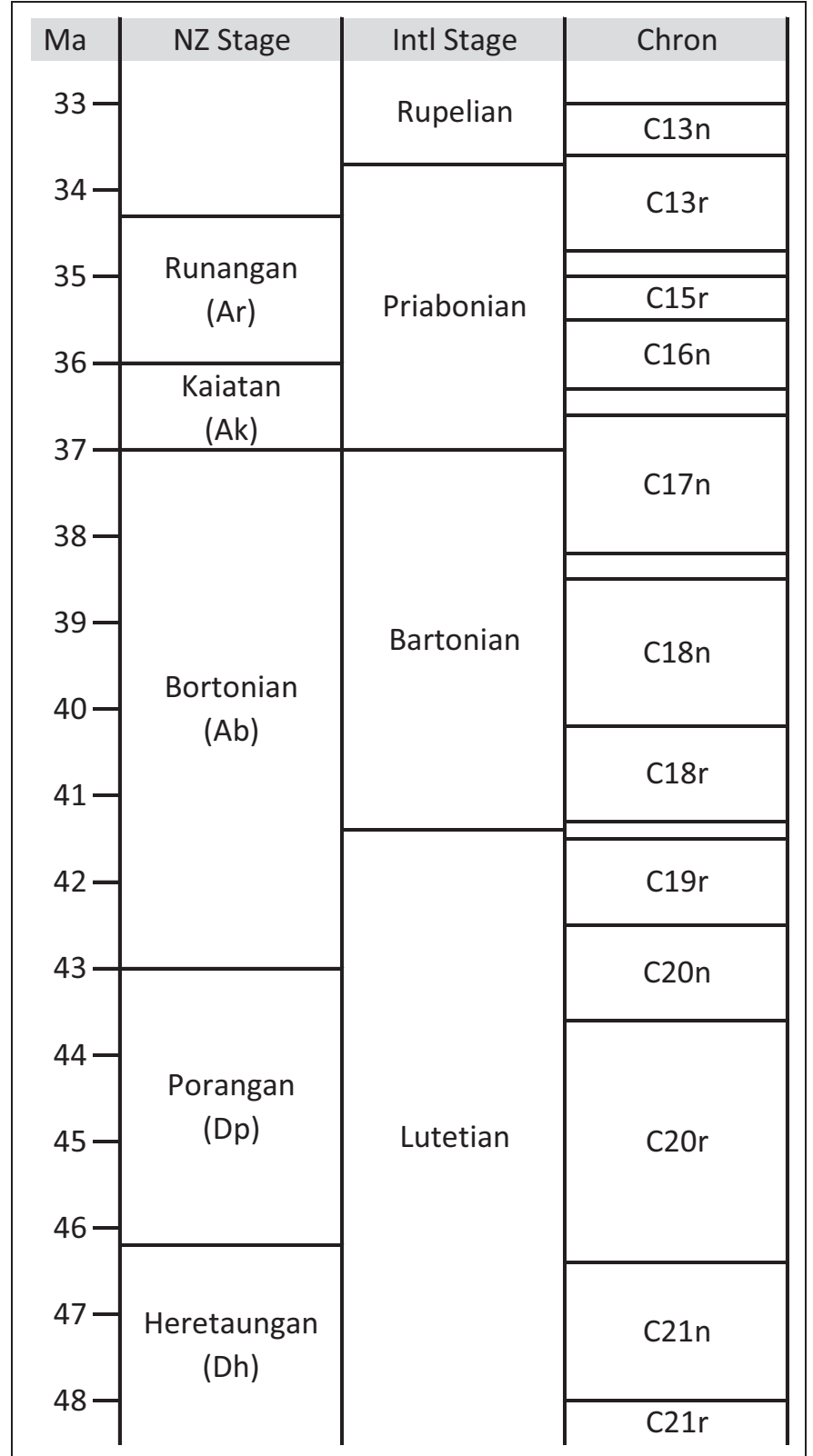

Table 1: Approximate correlations between New Zealand and international stages; after Cooper 2004. 
a few successive days). It is assumed that the sequence of samples from a single collection is precisely known. But, because different collections may be made years apart, and even the most reliable of landmarks can change over time, it is not assumed that the exact ordering of samples combined from different collections can be exactly known. Thus, for example, when a composite section was assembled for the main species range chart given in Appendix 2, only a single collection from each section was utilised, so as to avoid the uncertain ordering of samples from overlapping collections.

\section{Range Charts}

The stratigraphic ranges of various taxa are presented (Appendix 2) as a series of range charts. Individual charts are presented for a handful of genera, for which the member species are sufficiently numerous, common, and distinctive to make it worthwhile to do so. These are referenced from the appropriate systematic sections.

Additionally, a composite range chart is provided for all taxa which have been found to be stratigraphically useful in the studied interval. The column for this chart was assembled from various sections by hand. Samples were selected so as to avoid uncertain correlations. As noted above, only a single collection (generally the most extensive) from each section was utilised, so as to avoid the uncertain ordering of samples collected on different occasions.

In all cases, the charts were prepared programmatically from raw occurrence records, ignoring identifications marked as uncertain. Rows in the charts, corresponding to individual samples, were omitted if they contained neither a FAD nor a LAD for any taxon included in the chart.

\section{Descriptive Terminology and Notation}

\section{General}

Descriptive terminology generally follows Evitt et al. 1977, Stover \& Evitt 1978, Evitt 1985, and Fensome et al. 1993b, extended by a small number of additions proposed by subsequent authors. A schematic diagram, illustrating the most fundamental features of dinoflagellate morphology is reproduced in Text-Fig. 1, and many of the important individual terms employed here are defined in the glossary.

This contribution adopts the recommendation of Norris (1978a) to omit the unnecessary para- prefix from terms such as paraplate, parasuture, and so on.

It adopts the most popular of the tabulation notation systems, based on Kofoid's original, because it is a strictly descriptive notation system. Although there are others, such as the Evitt-Taylor and Edwards systems, and no doubt each has some advantages (e.g. see Fensome et al. 1996), they share a common failing in attempting to codify presumed plate homologies within the notation itself. While there may yet come a day when these homologies are so well-understood that they acquire near-factual status, for the present they remain interpretive, and interpretation has no place in a descriptive notation.

\section{Archeopyle Morphology}

Detailed archeopyle morphology is nowadays considered less important than it once was ("highly overrated" in the words of Evitt 1985, p. 280). Nevertheless, it still has its place and many genera in widespread use today are distinguished by archeopyle

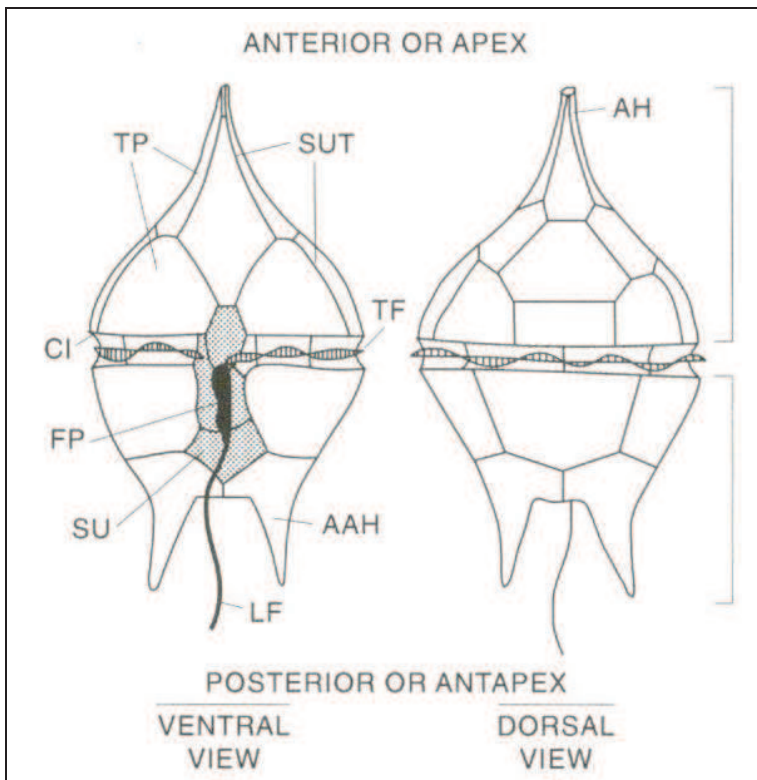

Text-Fig. 1: Schematic diagram, illustrating the most fundamental features of dinoflagellate morphology. $\mathrm{AH}=$ apical horn; $\mathrm{AAH}=$ antapical horn; $\mathrm{TP}=$ plates; SUT = sutures; $\quad \mathrm{Cl}=$ cingulum; $\quad \mathrm{TF}=$ transverse flagellum (not fossilised); FP = flagellar pore; $\mathrm{SU}=$ sulcus $\quad$ (shaded $\quad$ area); $\quad$ LF = longitudinal flagellum (not fossilised). The upper or portion of the cysts, anterior to the cingulum, is known as the episome, and the posterior portion as the hyposome. [After Fensome et al. 1996] characteristics and little else (e.g. Cerebrocysta and Pyxidinopsis). Indeed, the rather fragile distinction between the subfamilies Deflandreoideae and Palaeoperidinioideae is entirely based upon archeopyle characteristics (Fensome et al. 1993b, p. 129, text-fig. 133) with the genus Phthanoperidinium uncomfortably straddling both.

Two particular points are noted here:

1. An archeopyle metric widely employed in the description of peridiniaceans is the transverse archeopyle index (width of the widest part of the archeopyle divided by the total width of the cyst at the same "latitude").

Lentin \& Williams 1976 (p. 22) also defines a "transverse archeopyle ratio" (not to be confused with the unqualified term, archeopyle ratio, e.g. as defined in Evitt 1985, p. 133) but Lentin \& Williams's ratio is 
algebraically equivalent to the index $[1 / R=(1 / I)-1]$ and so it adds no new information. Specifically, it should not be used (e.g. as in Lentin \& Williams 1976, table 7) to provide a second dimension on a scatter plot. It is here proposed that use of the transverse archeopyle ratio metric be discontinued altogether.

All of the numeric archeopyle metrics presented herein are transverse archeopyle indices.

2. Here, and in a previous study (Clowes \& Wilson 2006), certain species attributed to Pyxidinopsis and Corrudinium were observed to possess a distinctive plate 3 " which is very narrow at the top, lending a roughly triangular appearance to the archeopyle. The term "subtriangular" is applied to this morphology, and "pentagonal" to the usual, Gonyaulax-style of precingular archeopyle, in which the top margin is broader and typically angled where the suture between plates 2 ' and 3 ' connects.

\section{Density of Ornament}

A common characteristic of several different kinds of surface ornament - whether a reticulum, or rugulum, or whatever - is the density of the ornamental features. Typically in the literature, ornament is described using absolute measurements. However, ornamental features often scale in proportion to the overall cyst diameter. Recognising this, an approach experimentally used in this study is to count the number of ornamental "units" across the visible diameter of the cyst.

The approximate measure is obtained simply by counting across a number of radii and averaging the counts for tround forms; across the cingulum for peridinioids. l'll revisit the wording of this section to address any ambiguity.

It might be expected that this number becomes difficult to ascertain as one approaches the ambitus, or limb, of the cyst, where the surface retreats until it becomes perpendicular to the observer. In practise, however, an approximate measure is easy to obtain, quicker than absolute measurement, and automatically compensates for differences between small and large individuals. It has been found to have considerable merit.

\section{A Note on IIlustrations and Descriptions}

A principle adopted in the preparation of this document is that illustrations without accompanying descriptions are completely useless, and descriptions without accompanying illustration are not greatly better. Accordingly, descriptions have been provided for many taxa, even if they be well-described already, and supposedly wellunderstood. Any taxonomist who has tried to assemble a dataset for cladistic analysis - even for such as a wellknown taxon as Deflandrea, for example - is well-aware that observations for corresponding characters of most species are difficult to locate in the literature. Comparable descriptions of even a few taxa are difficult to come by, and broad datasets, including many taxa, rare indeed.

As a consequence of the second part of the proposition, almost all of the taxa identified during the study have been illustrated by at least one specimen, the result being something in the order of 90 plates. The intention is that all of my identifications can be readily verified by the reader, who may then make an informed decision whether or not to include the occurrences reported here into their own synonymies. Merely listing a taxon name as "present" does not afford such confidence.

In respect of the photographs themselves, digital images were cropped and sometimes rotated, using Adobe Photoshop. However, no images have been enhanced by any means - including brightness, contrast or sharpness manipulation - nor has any debris close to the imaged specimens been masked. I have attempted to produce published images as close as possible to the first-hand experience of seeing the specimens down a microscope.

Many of the dinoflagellate descriptions provided below are computer generated. This is an approach to taxonomic description which is becoming increasingly popular. Observations are collected in some kind of database - perhaps something as simple as a spreadsheet - and computer generate the description text, or at least a draft of it, from there. Some of the practical advantages of this technique are that it ensures consistency of the format and coverage of features, and, because the author is typically compiling descriptions from raw data in a database anyway, reduces the likelihood of copying errors.

A similar approach was attempted here, with the dinoflagellate descriptions only. Results were mixed.

I took some pains to generate text in an acceptable final form. Once computer-generated text (of any kind) has been hand-edited, it can no longer be recreated if a new observation requires a change to be made to the base data, unless one also reapplies the manual changes. This requires keeping a record of all such manual changes which, for a large database, is a considerable overhead., which does not require subsequent hand-editing. In practice, however, I found that fully computer-generated descriptions were often inferior to those that were "hand written" and some manual editing was necessary in many cases. Notwithstanding these few shortcomings, the computer generated descriptions provided a useful place to start, and, I believe, saved a great deal of time.

Rather than a series of observations ("character states") being attached to fixed set of morphological features ("characters"; think of columns in a spreadsheet), the characters themselves are also defined in a table, together with various annotations describing their relationship to one another. This nuance permitted new characters to be defined, or existing characters to be modified, without any requirement to change the programme which generates the descriptions, and was found to be very effective. 
Exactly the same table of characters and character states was also used to generate the keys described below. This approach ensured consistency between the descriptions and the keys, and, assuming the keys are able to resolve of all taxa, further ensured that the descriptions are truly diagnostic - at least within the context of taxa defined in the tables. Certain character states are flagged as unsuitable for use in the keys. Typically, exact plate counts, especially of minor series such as the sulcal plates, are not useful in keys, either because they are variable between individuals which we would otherwise recognise as belonging to the same species, or because they are too difficult to observe in all but the most perfect specimens. The keys are discussed further, below.

\section{Identification Keys}

Identification keys are common in modern floras, yet, despite an early outing in the influential Evitt 1985, and some notable exceptions such as Jan du Chêne et al. 1986a, for some reason the technique does not seem to have become widespread practice in palynological studies. Some limited use of keys for selected genera and higher taxa has been introduced in the present endeavour. Some, typically those for supra-generic taxa have been assembled by hand; others are computer-generated from the table of morphological features ("characters") and observations ("character states") for each species.

A key comprises a number of questions, or decision points ("is the operculum free or attached?") known as nodes, from which arise one or more branches, depending upon the answer. Near the beginning of a typical key, most branches will lead to further questions. Later, though, the branches will lead to answers from which no further branches arise ("leaves"). Ideally, most of these will provide resolved identifications.

At the first node in a key, and at each subsequent node, are assembled one or more taxa, each taxon having one or more characteristics and its associated character state. An artificially simplified set for a key to subspecies of Hystrichosphaeridium tubiferum might look something like this:

\begin{tabular}{|l|l|l|}
\hline Taxon & Character & Character State \\
\hline \multirow{3}{*}{ H. tubiferum subsp. brevispinum } & archeopyle type & apical \\
\cline { 2 - 3 } & operculum attachment & free \\
\cline { 2 - 3 } & length of processes & less than diameter of body \\
\hline \multirow{2}{*}{ H. tubiferum subsp. tubiferum } & archeopyle type & apical \\
\cline { 2 - 3 } & operculum attachment & free \\
\cline { 2 - 3 } & length of processes & more than diameter of body \\
\hline
\end{tabular}

In the special case where there is only a single species present, then we have arrived at a leaf and the only task required is to write down the "answer."

In the case of non-leaf nodes, however, we have a more complex task. The first decision is which character is best to distinguish between the taxa. One approach would be to calculate the outcomes of using each character in turn, potentially carrying this calculation forward through many nodes, and choose the best approach in retrospect. Where there is only a small number of taxa and characters, it might even be possible make an exhaustive calculation of every possible key. Many chess- and other game-playing programmes use some variation of this technique.

The computer programme employed here, though, takes a different approach. Instead of calculating many outcomes, and retrospectively choosing the best character, a heuristic is used to try to predict the best character to use. This approach may occasionally produce suboptimal results, but it is no less "accurate" in the sense that it doesn't make actual errors, and keys are able to be constructed much more quickly. The entire systematics section of this thesis, together with all keys, descriptions, references, range charts, text-figures and plates, is generated in three or four minutes on a regular desktop PC.

The best character to use at a given node is chosen by scoring all characters using a handful of criteria, as follows:

- The choice of a specific character divides the taxa into one or more groups, depending upon the states each has for that character. Dichotomous keys require that the taxa at each node are always divided into two groups (i.e., that the node has two outgoing branches); polytomous keys (as these are) do not have that restriction. One outcome which is useless, however, is where a character produces only a single group; i.e., it cannot differentiate between any of the taxa. Such characters are assigned a high (effectively infinite) negative "score".

- In both dichotomous and polytomous keys, it is considered best for the groups to be of approximately equal size. This criterion promotes shorter keys. The programme handles this criterion by calculating the difference between the sizes of the smallest and largest group, multiplying by a weighting factor, and setting the resulting number as a negative score against the character being assessed.

- The overall number of groups is also multiplied by a weighting factor, and set as a negative score against the character being assessed. This criterion favours characters which divide the taxa into fewer groups: 
ideally two (producing a dichotomous node) but the weighting is not overwhelming. Nodes with three or four outgoing branches are common in the following keys.

- Finally, the number of "unknown" character states is multiplied by a high weighting factor, and set as a negative score against the character being assessed, so as to favour characters for which the data are complete, at the expense of characters which are poorly understood. (Characters which are ambiguous, difficult to determine, or problematic in some other way, are simply not made available to the key generating programme in the first place.)

Having evaluated each character against all criteria, the one with the best score is chosen for use at the current node, and taxa are divided into groups depending on their states for the chosen character. In cases where the state is variable ("the operculum is free or attached"), both character states are evaluated. Thus it is possible for a single taxon to pass down two (or more) branches from a node and so appear at more than one leaf in a key. Then, taking each group in turn, the programme invokes itself (an operation known as "recursion") to consider the subset of taxa, characters, and character states for that group. The idea of recursion can seem astonishing to non-programmers, but in fact it is standard practice in cases where a large data set is to be broken into subsets, and each subset treated the same way in turn.

The programme terminates successfully when a leaf is reached. Here, it simply prints out the name of the remaining taxon and "returns" without invoking itself further.

However, there is also an "unsuccessful" termination, which arises when there is more than one taxon left, but no character can be found to differentiate between them. This situation arises when there is insufficient morphological data available to differentiate between genuinely different forms, and also in the case of true synonyms. The programme explicitly checks for this possibility and simply treats it as a special kind of leaf. It prints out a list of the undifferentiated taxa, and returns. Some of these cases have been picked up in earlier drafts of this document, and additional characters defined so as to permit full resolution.

In practice, the keys so produced were found to of highly variable quality, and the majority are omitted in the following text. Only a few have been retained where they seem to make a useful contribution to the discussion. In other cases, minor problems have been overlooked or corrected by hand, this being a primarily taxonomic study rather than a computer science project. Before persisting any further with this initiative, I believe it would be necessary to improve the computer programme considerably, so as to better accommodate multiple character states, and to support both phylogenetic and phenetic keys. 


\section{Taxonomic Approach}

\section{Scope}

Although fossil palynomorphs are taxonomically diverse, in practice, individual taxonomists do tend to specialise. In New Zealand, at least, the tradition has been for our researchers to specialise in either terrestrial pollen and spores, or marine acritarchs, dinoflagellates and various "algae".

A variety of palynomorphs has been encountered during this study. I have not attempted to report them all. Only dinoflagellates, acritarchs, and a handful of Pterospermatales have been studied.

\section{Introduction and Motivating Philosophy}

Sir Earnest Rutherford, who was born in Nelson, near what is now Brightwater, before travelling to Manchester and discovering the atomic nucleus" ${ }^{2}$, once famously proclaimed that "All science is either physics or stampcollecting" (e.g. Gallagher \& Appenzeller 1999). While strongly disagreeing with this assessment, it is nevertheless true that, without some unifying theory behind it-evolution, obviously-a catalogue of dinoflagellate taxa is, indeed, little more than a stamp album. Describing and illustrating taxa has its uses, certainly, but alone it is only part of the story. It is phylogeny that breathes meaning into the names, and makes the pictures tell a story. In my first period of working with dinoflagellates, some twenty or more years ago, I was unsettled by the lack of it (the words "gonyaulacacean lineage" on p. 29 of Clowes 1985 were a poor attempt to fill a perceived vacuum) and in the present study, I was determined to try out the new developments which have been made since then.

The science of biological taxonomy has undergone a revolution during the past 50 or so years, initiated at least in part by ideas published by Hennig in 1950 and 1966, and the last of the dust has yet to settle, even now. Some cherished morphological constructs have been eroded as the cladistic movement has gained traction and brought the phylogenetic world-view into collision with established form-taxonomy.

The debate has been robust, intemperate at times, and the cladists have - easily, in my view - won the high ground from a purely theoretical standpoint. There have even been proposals to eventually replace the Linnaean nomenclatural system currently in use (see, for example, Brochu \& Sumrall 2001 and references therein). But, although few have been brave enough to challenge the logic of adopting a phylogenetically-based taxonomy on theoretical grounds, some grass-roots dinoflagellate (and other) paleontologists have simply refused to acknowledge that anything is fundamentally different; they have continued organising their material exactly as they have always done or, arguably worse, have adopted phylogenetic frameworks merely as an alternative to alphabetical or some other arbitrary order.

One referee of a recent paper of mine asked, rhetorically, whether it would ever be possible to truly know the phylogenetic relationships between our taxa. Insofar as fossils are our objects of study, it can be said that morphology is the only objective evidence we have available, but this argument is a more than a little disingenuous: We can certainly deduce phylogeny in some cases, perhaps many. One of the earliest attempts along these lines was that of Eaton (1971), who examined some sequences of Areosphaeridium and close allies. Eaton's sequences have been dismissed as "not phyletic" by some subsequent authors (e.g. Damassa et al. 1994, p. 4-5), because the break-up of the genus Areosphaeridium by Stover \& Williams 1995, dispersed several of the species across two or three genera which are purported to belong to different families. It will later be contended herein that the analysis of Stover \& Williams 1995 is fundamentally flawed, and that many of the species are not greatly different. Eaton's lineages may yet prove to be phyletic, after all. However, whether they are or are not, in this particular case, is beside the point: As long ago as 1971 - more than thirty years ago Eaton was able to propose a plausible evolutionary succession of fossil dinoflagellate cyst taxa. It is surely not beyond our means to effect similar work today.

Some other well-known papers which make the attempt to deduce the phylogeny of various dinoflagellate cysts are Davey 1969c (Amphorosphaeridium and Cordosphaeridium), Bujak 1976 (Areosphaeridium and close allies), Bujak 1979 (Rhombodinium and Gochtodinium), Costa \& Downie 1979a (Wetzeliellaceae), and Dörhöfer \& Davies 1980 (Rhaetogonyaulacineae). However correct or otherwise the proposed lineages are eventually determined to be, these examples should be inspirational. They prove that we can deduce phylogeny, with sufficient application. We certainly can do much better than we have done to date.

There are very pragmatic reasons to eschew a single-mindedly morphological taxonomy of dinoflagellates too. A key failing of any form-taxonomy to the working stratigrapher is that form-taxa have no general stratigraphic value: ranges can be discontinuous or of a length which defies credibility. Any stratigraphic relationship between form-taxa is coincidental. Consider the following real-world situation: A form-taxonomic group - say the dinoflagellate genus Pyxidinopsis - contains species ranging geographically from the North Atlantic to New

2 "Geiger recalled that, early in 1911, 'one day Rutherford, obviously in the best of spirits, came into my room and told me that he now knew what the atom looked like and how to explain the large deflections of alpha particles'" (Weinberg 1993, p. 127). 
Zealand, and temporally from Late Jurassic to Quaternary. The taxon thus defined has very little to offer the practising paleontologist. Identifying a specimen as belonging to this genus leaves the researcher none the wiser. (Of course there are some dinoflagellate genera which are genuinely, and perhaps unavoidably, like this, though Pyxidinopsis isn't one of them - refer to the Systematic section.)

It is obvious (or, at any rate, it will adopted as such in the following text) that the phylogenetic approach has the greater interpretative and predictive value. As noted in Grimaldi \& Engel 2005, p. 15: "Besides identifying lineages of organisms, [a phylogeny] can record the success and demise of those lineages, and perhaps even provide explanations for these outcomes. Phylogenies also allow the interpretation of evolutionary patterns. Another salient scientific advantage to understanding phylogeny, though, is that it allows predictions. Armed with knowledge about the closest relatives, accurate predictions can be made about any species, and so phylogenies explain very well. There are many ways to classify organisms - things good to eat, bad to eat, things that sting but a phylogenetic classification, one that reflects and summarises phylogeny, is the most useful and a goal of modern systematists."

While far from blind to the practical difficulties and shortcomings of the phylogenetic scheme followed herein (Fensome et al. 1993b), it seems to me to offer the greatest hope for the future. Developing a better formtaxonomic framework, perhaps something analogous to Potonié's turma concept (Traverse 1988) used for pollen, might yield better short-term results, but to me it seems backward-looking and carries the additional risk that it may simply detract from the collective effort even further. Working with the phylogenetic philosophy and evaluating its contribution to (or detraction from) the study is the key element of this research project.

\section{Suprageneric Classification}

Over the past few decades, a number of authors have attempted to synthesise suprageneric classification schemes for all or part of the Dinoflagellata. A handful of examples, by no means comprehensive, are Eisenack 1961, Sarjeant \& Downie 1966, Norris 1978a, b, Bujak \& Davies 1983, Taylor 1987d, 1990. Some of these schemes were early attempts at a phylogenetic approach; others phenetic (i.e., presenting a form taxonomy). Some considered only fossil cysts, or considered modern and fossil dinoflagellates separately; others attempted to unify fossil and modern classifications.

By far the most comprehensive attempt to date is Fensome et al. 1993b. (A number of the authors of earlier attempts, mentioned above, are bundled up in the "et al.") This landmark work provides a suprageneric classification for both modern and fossil dinoflagellates which is explicitly phylogenetic.

In this work, the Dinoflagellata is divided into two subdivisions (subphyla) and three classes, primarily on characteristics of the nucleus (obviously a neontological feature). Lower taxa-comprising five subclasses, fourteen orders, ten suborders and fifty six families - are recognised on the basis of tabulation patterns, which can, at least in principle, be recognised in both fossil and modern material. Below the level of family, a broader variety of features is employed. This is the part of the scheme which is least systematised, and, one gets the impression, most likely to be modified in the future for that reason.

The phylogenetic philosophy underpinning the entire Fensome et al. work is made explicit as early as the third paragraph of the abstract, which is worth quoting in its entirety:

The classification, and the phylogenetic hypothesis that derives from it, supports the following premises: 1) that below the rank of class, amphiesmal structure, especially tabulation, is the most valuable and meaningful criterion in classifying dinoflagellates; 2) that the use of cell or cyst habit (i.e. general shape or morphology) in classifying dinoflagellates should be restricted in its use primarily to subfamily and, less commonly, higher rank; 3) that, although incomplete and despite the sporadic evidence of Paleozoic dinoflagellates, the fossil record supports a major adaptive radiation of dinoflagellates during later Triassic and earlier Jurassic times; 4) that the majority of living thecate dinoflagellate[s] can be interpreted as having either a peridinialean or gonyaulacalean tabulation, and that these tabulations, and hence the orders Gonyaulacales and Peridiniales, have been separate since at least the Early Jurassic.

A corollary to their premise is that ornamental features, per se, have less significance than plate topologies. This is an observation which deserves explicit recognition: It is quite evident that gross ornamental morphologies, such as spinose processes or whatever, recur again and again in taxa which are as distantly related as peridiniaceans and gonyaulacaceans. These kinds of features, while useful species-level distinctions, offer little insight at higher taxonomic levels. Indeed, it seems likely that ecological considerations exert as much control over the development of these features as do genomics.

It is with these concepts firmly in mind that the present study was undertaken.

\section{Dual Nomenclature}

It is quite contrary to the spirit of a phylogenetic classification to retain a dual nomenclature for motile and cyst forms of the same taxon. However, two major methodological difficulties stand in the way of a unified approach at present: 
1. Although Fensome et al. 1993b does much to reconcile the higher taxa, there is still no usable correspondence between thecal and cyst taxonomies at the generic level.

2. In most cases the association of cysts, particularly of older fossil cysts, with motile forms is not convincingly established. It is this uncertainty which, for example, led Matsuoka et al. (1997) to recommend the retention of 'Hystrichosphaeridium' centrocarpum and similar forms within the cyst genus Operculodinium, rather than in the thecal genus Protoceratium.

Consequently (and with some misgivings) I have followed the standard practice of using exclusively cyst taxa at the generic and species rank.

\section{Splitting, Lumping, and the Use of Subspecies}

Authorities differ in their interpretations of taxonomic boundaries, and no doubt always will. Those favouring fine division are colloquially known as splitters; the opposite extreme as lumpers. This contribution adopts the philosophy set out below.

Morphological breaks, or discontinuities, between taxa are sampling artefacts. If every organism that ever lived could be called to heel, it would be possible to assemble an insensible gradation from elephants to pond-scum. In the more prosaic phrasing of Brochu \& Sumrall (2001, p. 754), "An evolutionary group exists because of common ancestry. The only natural boundaries for these groups are [splitting of lineages] and extinction." Richard Dawkins (2004) hammers home a final nail with a sledgehammer: "[W]e have a continuous historical lineage in evolution. At the borderline between any fossil species and its immediate predecessor, there must be some individuals about whom it is absurd to argue, since the reductio of such an argument must be that parents of one species gave birth to a child of the other. It is even more absurd ... [in the case of higher taxa]. These are evolutionary regions into which our zoological naming conventions were never designed to go" (p. 69).

A widespread though erroneous impression of the punctuated equilibrium hypothesis (Eldredge \& Gould 1972) is that it conceives of evolution as proceeding in a series of quantum jumps, or saltations. In fact, punctuated equilibrium isn't, and never was, a theory of saltations. For authenticity, this is perhaps best explained by one of its original authors: "Our theory entails no new or violent mechanism, but only represents the proper scaling of ordinary events into the vastness of geological time. An isolated population may take a thousand years to speciate, and its transformation would therefore appear glacially slow if measured by the irrelevant scale of our personal lives. But a thousand years, appropriately recorded in geological time, is only an unresolvable moment, usually preserved on a single bedding plane, in the lifetime of species that often live for several million years in stasis" (Gould 1992; italics added).

Punctuated equilibrium is not relevant to the present study - it is concerned with the allopatric speciation of sexually reproducing metazoans (Eldredge \& Gould 1972, p. 94) - but, even if it were, it would not represent a contradiction to the view presented in the preceeding paragraphs. Notwithstanding one or two real saltations, if there are such things, as paleontologists we all believe in evolution, and we are all aware of transitional forms between neatly circumscribed taxa. Thus, whether they arise slowly or quickly, punctuated by stasis or not, divisions between taxa - morphospecies - are gradational and arbitrary. Published fossil taxa are simply convenient, though somewhat random, "signposts" scattered over a phylogenetic tree. The presence or otherwise of known intermediates has no phylogenetic meaning. Specifically, it is irrational to combine - to lump - taxa simply because intermediates are observed, rather than lying undiscovered in some rock we have yet to examine. In this respect I am an unapologetic splitter and quite reconciled to living with the imprecision inherent in gradational boundaries between taxa.

It is a commonly held view that taxa should be distinguished - split - where they have stratigraphic value; left combined otherwise. But this idea is equally absurd since we cannot know, a priori, which taxa will have future stratigraphic value, and which will not. Where consistent morphological differences exist, they should be recognised, and that's all there is to it. The reverse argument does have some merit, though. Different taxa, whose occurrences are widely separated in time or space, should not be lumped, in my opinion, even if morphologically very similar.

If we accept that species will be recognised, even where they may intergrade with one another, then the manner in which we employ subspecies suggests itself for review. Given that we are dealing with fossils, we are deprived of the semi-objective (at best) fertility and genome criteria available to neontologists. We must recognise that our decision is almost entirely arbitrary: practical usability alone can be our guide.

In the past, implementation of the subspecies construct has been quite inconsistent, with some authorities making extensive use of the concept and others ignoring it. Where it has been used, there may be some implied phylogenetic relationship, generally absent from our present use of higher order taxa. Developments of the past few years, however, have seen an increasing phylogenetic philosophy brought to bear above the genus level. Although that work is still far from complete, the new front line in our battle to understand these organisms more fully, lies at the level of genera and species. We must pick apart the old catch-all genera which have been used as dumping places for species with superficial resemblance, but no seriously implied kinship, and assemble a new taxonomy of genera reflecting true (or, at least, hypothesised) phylogenetic relationships. In that endeavour, subspecies are something of a distraction. Their time may yet come, but for the moment I have chosen to ignore the construct. 
Nor have I yielded to the temptation to assign difficult forms to "complexes" or superspecies. Some specimens exhibit morphologies which are intermediate - sometimes in different and conflicting degrees for different characteristics - between neatly circumscribed taxa. They are difficult to identify, and that is just a fact of life. The taxonomist still has to stand up and commit to a view: otherwise his discipline becomes, indeed, "just stampcollecting." 


\section{Presentation of Findings}

The findings of the study are presented as follows:

- A brief review - essentially annotated references to the available literature - of the localities and geology of the sections from which the samples were drawn is provided next. The localities occur across the country, including both North and South Islands; both west and east coasts.

A list of the 80 or so individual samples examined in this study is provided in Appendix 1.

- Next, the Systematics section describes almost all of the acritarch and dinoflagellate taxa encountered in the study, including a small number which could not be identified to even generic level. Only the poorest and most ambiguous material is omitted from the Systematics section entirely.

An extensive collection of more than 1000 individually mounted specimens was harvested from a number of samples which were found to be especially rich, well preserved, or which contained new taxa.

Where sufficient material, of sufficient quality, was found, new taxa have been described. If the material was too sparse, or poor, to be reliable, informal tags are provided. (As the writer encountered new forms during the study, informal tags were applied consecutively. Subsequent identification or description, however, means they are no longer so.) The outcome has included descriptions of 25 new taxa, including two (Corrudinium regulare and Corrudinium otagoense) published in an earlier paper (Clowes \& Wilson 2006).

It is recognised that description in a limited-run thesis does not constitute effective publication in the sense of the Internation Code of Botanical Nomenclature (Article 29). However, it is intended to publish the present text with minimal modification as soon as practical, so the usual trappings of formal publication (specifying holotypes, repository, etc.) have been provided in preference to using manuscript names.

All taxa are described by means of morphological distinctions. As further elaborated in the Conclusion section, this study does not take the bold step to suggest a new taxon based wholly on geographical and temporal criteria. Doing so, however, is clearly a rational extension to the present ideas, and such an approach is advocated as worthy of further investigation.

- A Biostratigraphy section discusses the dinoflagellate biozonation for New Zealand, as it is presently known, and presents a number of proposals to refine the scheme, including:

a. redefining zone boundaries using the lower boundary only, so as to eliminate the possibility for gaps or overlaps to arise;

b. replacing the Wilsonidium echinosuturatum and Wilsonidium lineidentatum Zones with three new zones;

c. replacing the Wilsonidium tabulatum Zone with an approximate equivalent defined by the more commonly found Rhombodinium glabrum; and

d. defining a new zone marked by the FAD of Stoveracysta kakanuiensis at or very close to the EoceneOligocene boundary.

- Finally, a concluding section revisits the principal taxonomic theme of the study, and summarises the major findings.

Appendices and plates complete the document. 


\section{Study Areas}

A map locating the broad study areas described below, is provided in Text-Fig. 2.

\section{Waikato}

Basement in the region is provided by the massive, largely undifferentiated graywackes of the Torlesse Supergroup. Graywackes of the Manaia Hill Group, ranging in age up to late Jurassic, crop out east of the Waipa Fault. Over this, a transgressional sequence, the Te Kuiti Group, comprises basal coal measures overlain by marine sediments, deposited as the early Cenozoic shoreline moved south and westward.

The economically significant Waikato Coal Measures are of Arnold age; further south, the coals are Landon: possibly as young as Duntroonian at Tongariro National Park (Suggate et al. 1978, p. 449). The oldest marine beds are Whaingaroan.

\section{Old Mountain Road}

The Old Mountain Road site (Text-Fig. 3) is located at grid reference S14/937707, below a prominent bluff, $60 \mathrm{~m}$ south west of the summit of Old Mountain Road, situated approximately half way between Hamilton and Raglan, Waikato, North Island, New Zealand.

\section{Hawkes Bay}

Rocks of the Hawkes Bay area comprise predominantly marine sediments ranging from about mid-Cretaceous to Quaternary in an almost complete sequence.

General accounts of the geology of the area include Kingma 1971.

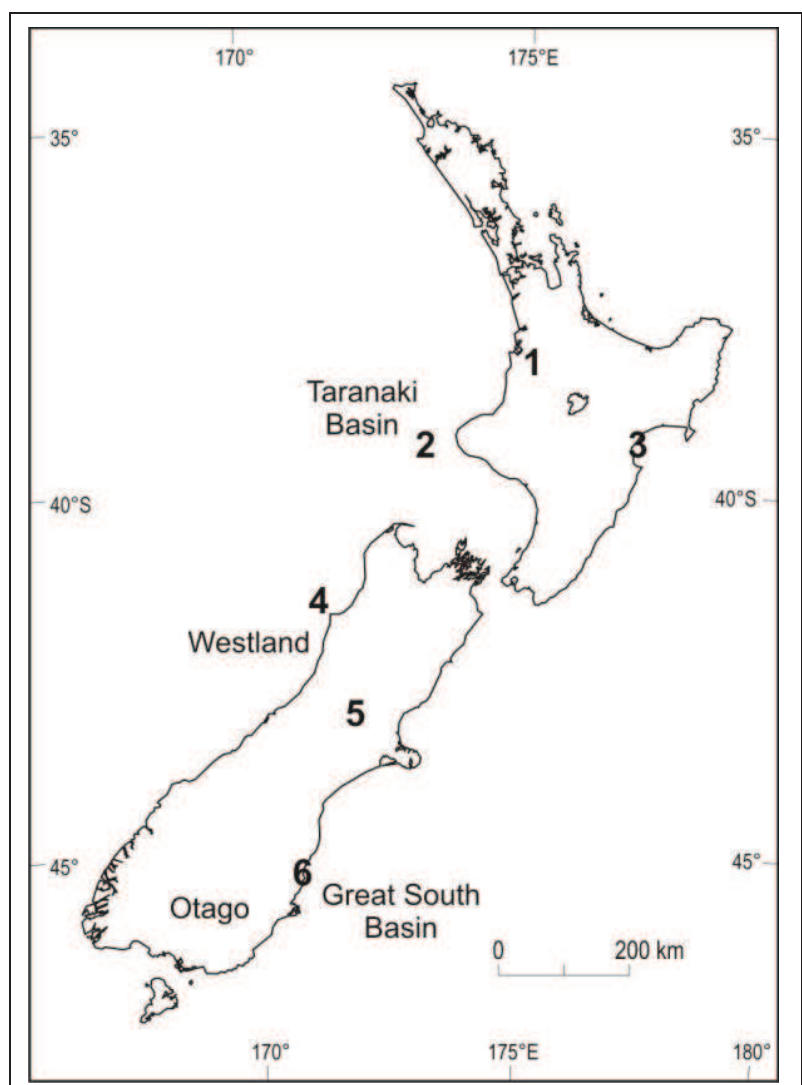

Text-Fig. 2: Map of New Zealand locating the broad study areas discussed herein:

(1) Waikato, (2) Taranaki Basin, (3) Hawkes Bay, (4) Cape Foulwind, (5) Central Canterbury, (6) OamaruDunedin area, including Kakanui River mouth, Hampden Beach, Puketeraki, and Abbotsford.

Pre-Cretaceous greywacke basement is overlain throughout the region by sediments laid down in a shallow synclinal setting. Material was apparently derived from the east and southeast during the Cretaceous, and afterwards from the west. The rate of deposition was slow prior to the Miocene; sediments are generally thin, fine grained, and conformable throughout the Eocene and early Oligocene.

\section{Akitio River}

The Akitio River flows through the east cost ranges of north Wairarapa, New Zealand. The general geology of the Akitio area is described in Neef 1992. The locality for the sample analysed in the present study is shown in TextFig. 4.

\section{Te Uri Stream}

Te Uri Stream is located on the southern flank of the Whangai Range in southern Hawkes Bay, North Island, New Zealand.

The type Porangan material analysed in this study was collected from between grid reference U24/031959 and U24/032959 (Text-Fig. 5). It is the original stratotype for the entire Dannevirke Series, although exposures are often poor and stage boundaries seldom available for close study.

\section{Waipawa Section}

Waipawa township is located on State Highway 2, north of Waipukurau, North Island, New Zealand.

The area was mapped by Kingma 1971. The section itself is a standard for the Dannevirke Series, supplementing the incomplete type section at Te Uri Stream (Hornibrook \& Harrington 1957, Wilson 1988). Columns and a taxon range chart for Waipawa Section are provided in Wilson 1988.

The section has been extensively studied for foraminifera (Hornibrook \& Harrington 1957; Hornibrook 1971; Jenkins 1971), calcareous nannofossils (Edwards 1971), and palynomorphs. Couper 1960 describes some terrestrial palynomorph taxa from the section but, of marine taxa, he records only the presence of unspecified 
microplankton. The earliest dinoflagellate taxonomy from the section is Wilson 1967c and the definitive account is provided by Wilson 1988.

The locality for the sample analysed in the present study is shown in Text-Fig. 6.
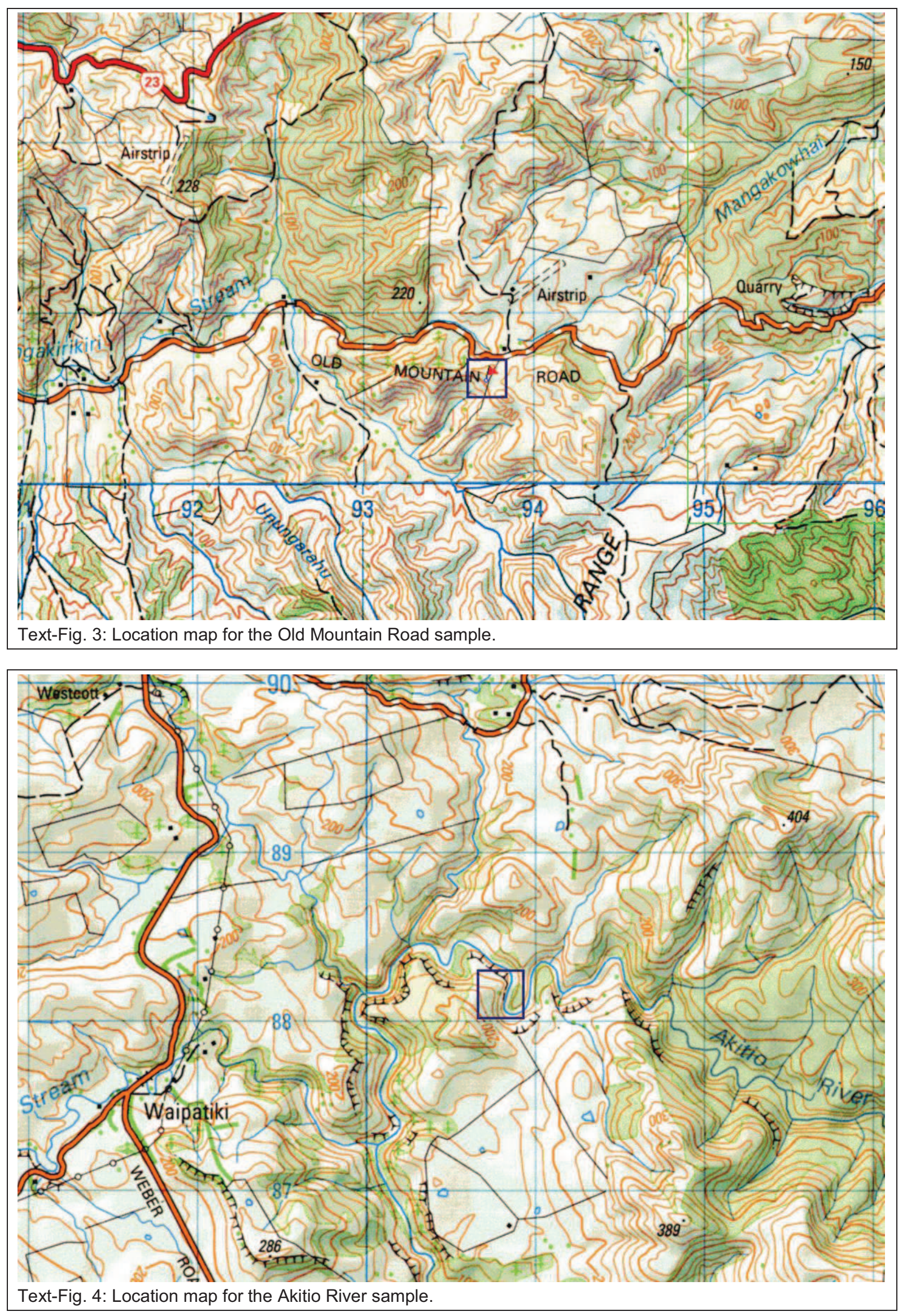

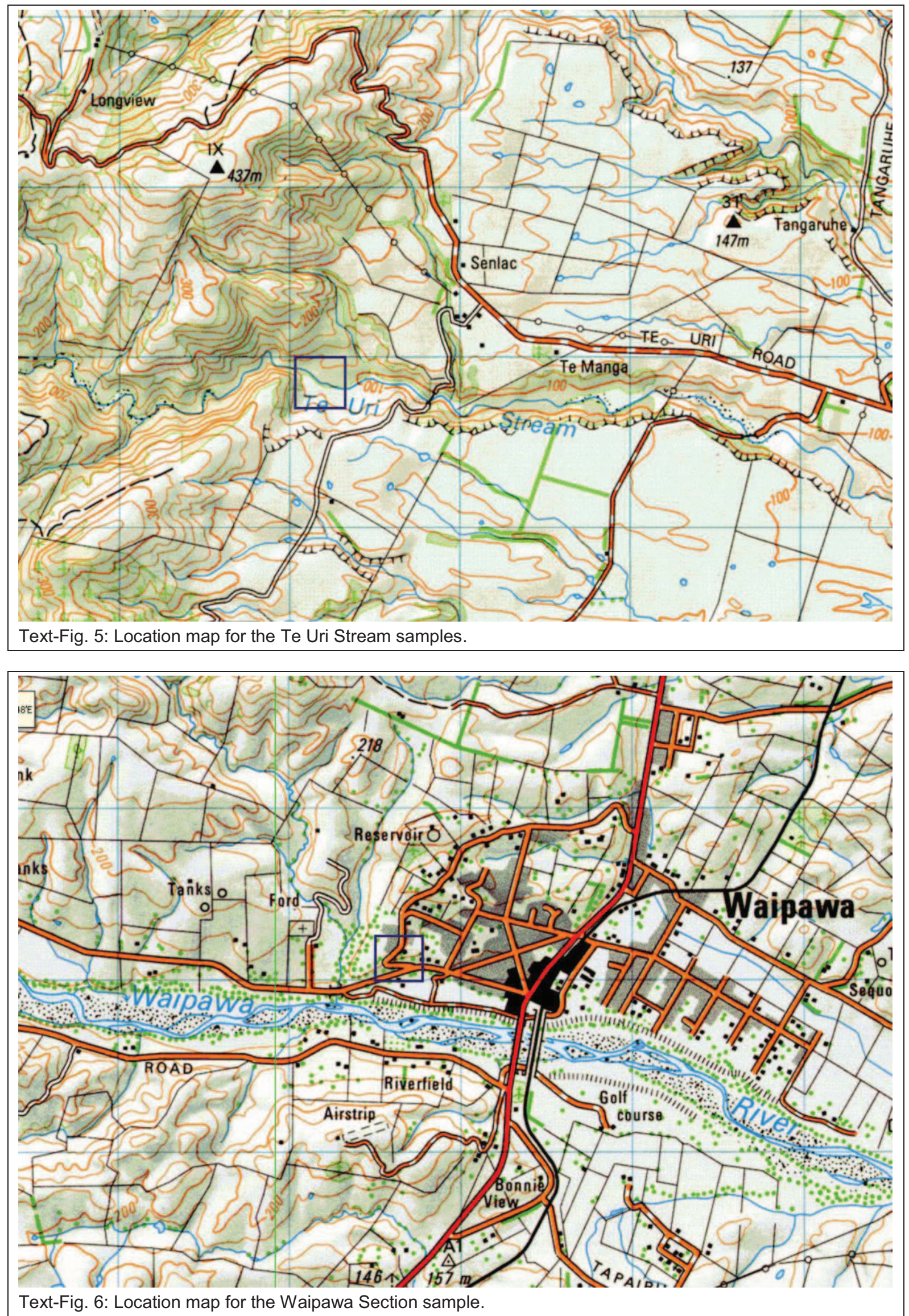

\section{Westland}

Upper Cretaceous coals are overlain, after a (probably region-wide) break, by Cenozoic sediments laid down in a transgression which lasted through to the Oligocene, when limestone (e.g., the Cobden Limestone) was 
deposited in most areas, followed by a regressional sequence (e.g., the Miocene to Pliocene Blue Bottom Formation).

The transgressional sequence commences with coals, which generally young to the north (Suggate 1950, Couper 1960, p. 13-14), and include the economically significant Brunner Coal Measures, overlain by marine sediments ranging in age from ?Teurian upwards. The earliest marine sediments are Bortonian in the Greymouth Coalfield, Kaiatan in the Buller Coalfield. The Kaiata Siltstone may be wholly Kaiatan.

\section{Cape Foulwind Section}

Cape Foulwind forms a prominent headland on the west coast of the South Island, New Zealand (Text-Fig. 2). The section crops out along the base of the sea cliffs extending south from the headland, roughly between grid references K29/829386 and K29/834388 (Text-Fig. 7).

The sea cliffs along the west and north coasts of Cape Foulwind provide key reference sections through the Runangan and Lower Whaingaroan Stages.

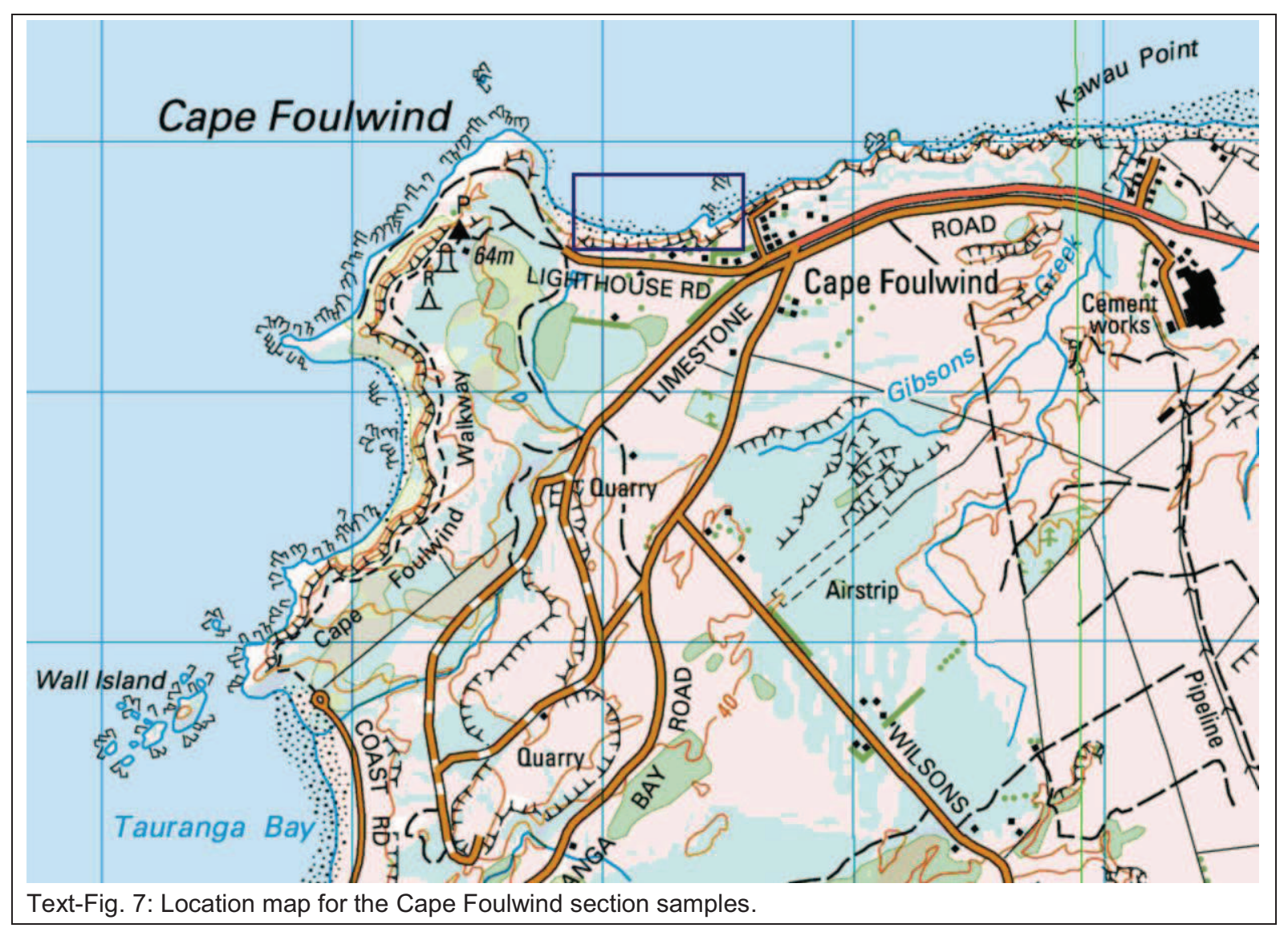

\section{Nine Mile Bluff}

Nine Mile Bluff, where marine sandstones of probable Kaiatan age overlie brown coal, is located north of Point Elizabeth and the Grey River mouth, on the Westland coast (Text-Fig. 8).

\section{Canterbury}

Principal accounts of the general geology of the area include Gair 1959, Wilson 1956, and Wilson 1963.

Base comprises indurated Triassic or Jurassic rocks of the Torlesse Supergroup, overlain by late Cretaceous and early Cenozoic basal coals and marine sediments laid down as the shoreline migrated generally west and south. Transgression reached a maximum in the Oligocene, followed by regression associated with uplift of the alpine range.

\section{Upper Eyre River}

The headwaters of the Eyre River lie in the Puketeraki Ranges, north of the Waimakariri River and to the west of Oxford, central Canterbury, South Island, New Zealand (Text-Fig. 9).

The geology of the area is mapped by Gregg 1964 and further described in MacPherson 1947, McLennan 1981, and Wilson 1982c. 
Dinoflagellate assemblages from two samples recovered from the area, at grid reference L34/294700, are described in Wilson 1982c.
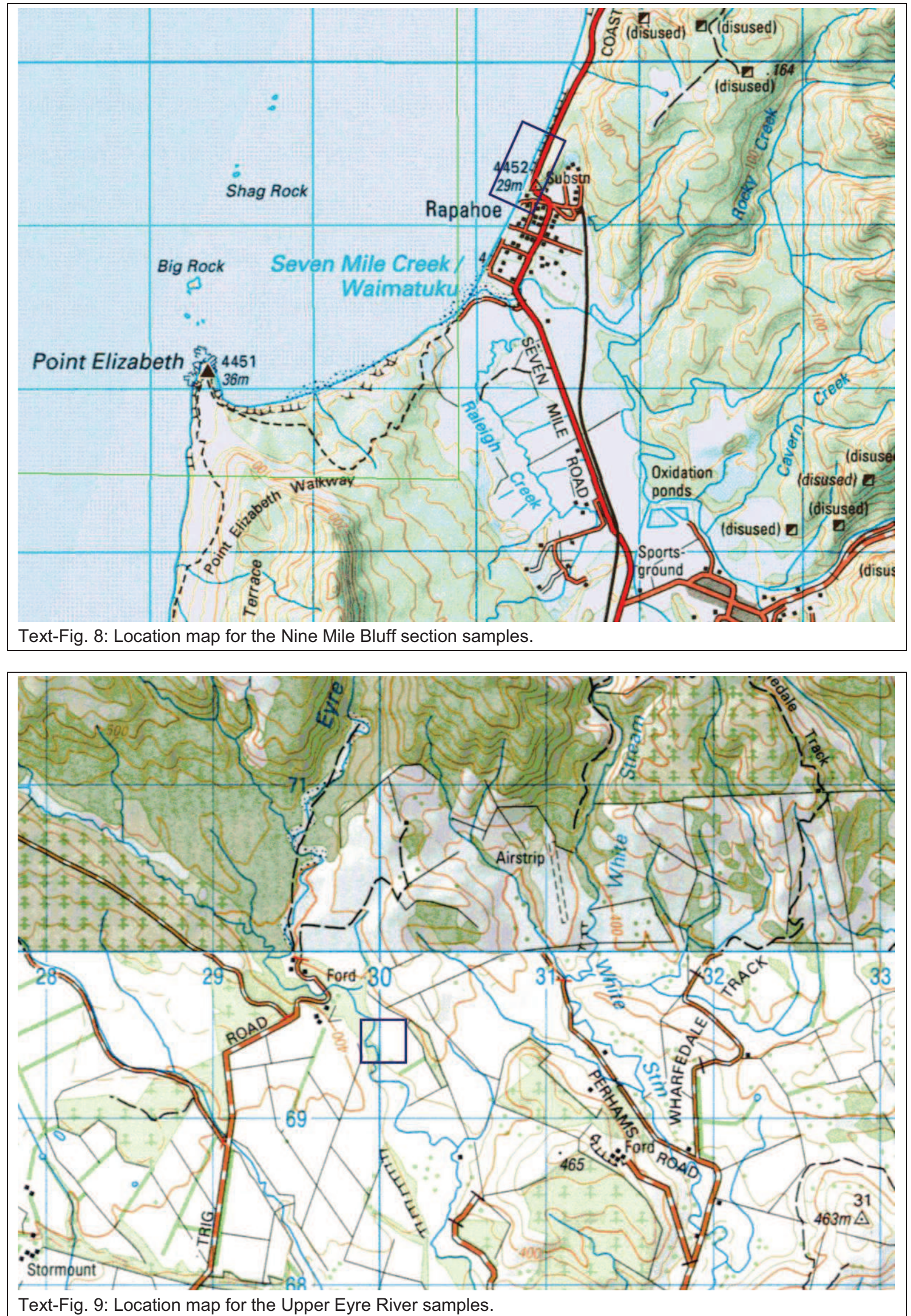


\section{Oamaru-Dunedin}

The Great South Basin and the on-shore correlative sediments of coastal Otago range from Late Cretaceous to mid-Miocene.

General accounts of the geology of the Oamaru area include Park 1918, Gage 1957, and Mutch 1963. A detailed allostratigraphic analysis is provided by McMillan \& Wilson 1997.

Basement in northern Otago comprises a ?Cretaceous peneplain, principally of schist, which became inundated from the north, beginning in the latest Cretaceous, allowing the accumulation of marginal coals and fully marine sediments. Sedimentation appears to have ceased for a time early in the Eocene, and been reversed by erosion in places (Gage 1957, p. 16) before recommencing. Intermittent basaltic intrusion marked the late Eocene-early Oligocene interval, followed by slowing sedimentation through to the middle or late Oligocene, when sediment accumulation increased again.

\section{Burnside Marl Pit}

The Burnside Marl Pit (or Burnside Quarry) is located to the west of central Dunedin, South Island, New Zealand (Text-Fig. 10).

The section is described in Benson 1968.

A column and description of the sequence exposed in the Pit are provided in Wilson \& McMillan 1996 (p. 4-5, figs. 8-11).

Descriptions of foraminifera (p. 5, 133) and dinoflagellate (p. 5, 128-132) assemblages for this section are provided in Wilson \& McMillan 1996

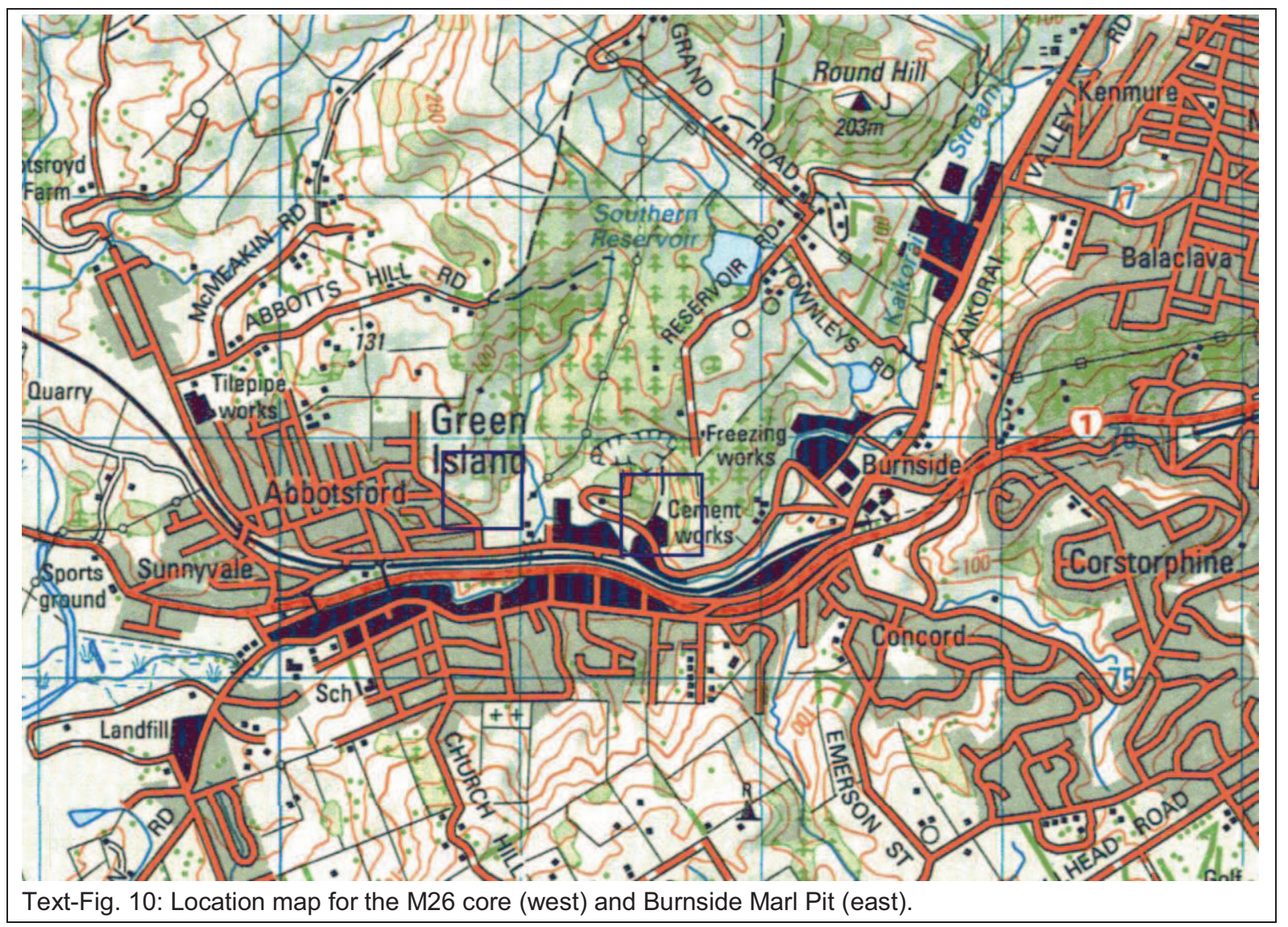

\section{Hampden Beach Section}

Hampton Beach is located to the north of Hampden township, south of Oamaru, South Island, New Zealand (Text-Fig. 11).

The Hampden Beach area is mapped by Brown 1938 and the section has been well-known and repeatedly studied for many years, acquiring the working status of Bortonian stage lectostratotype (Cameron \& Waghorn 1985, Wilson 1985, Hornibrook et al. 1989) owing to the poor exposure and fossil content of the original stratotype at Bortons, in the Waitaki River valley. 
Low coastal cliffs expose an extensive section, ranging from possibly Teurian (Wilson \& McMillan 1996, p. 13) to at least Bortonian. A stratigraphic column for the Hampden Section is provided by Jenkins based on unpublished work by D.A. Brown (Jenkins 1971, Column 3).

Previous paleontological studies include Finlay \& Marwick 1940, Jenkins 1971 and Edwards 1971. Dinoflagellates are recorded from the section in Wilson 1967c, Wilson 1977, and, more expansively, in Wilson 1985 and Wilson \& McMillan 1996.

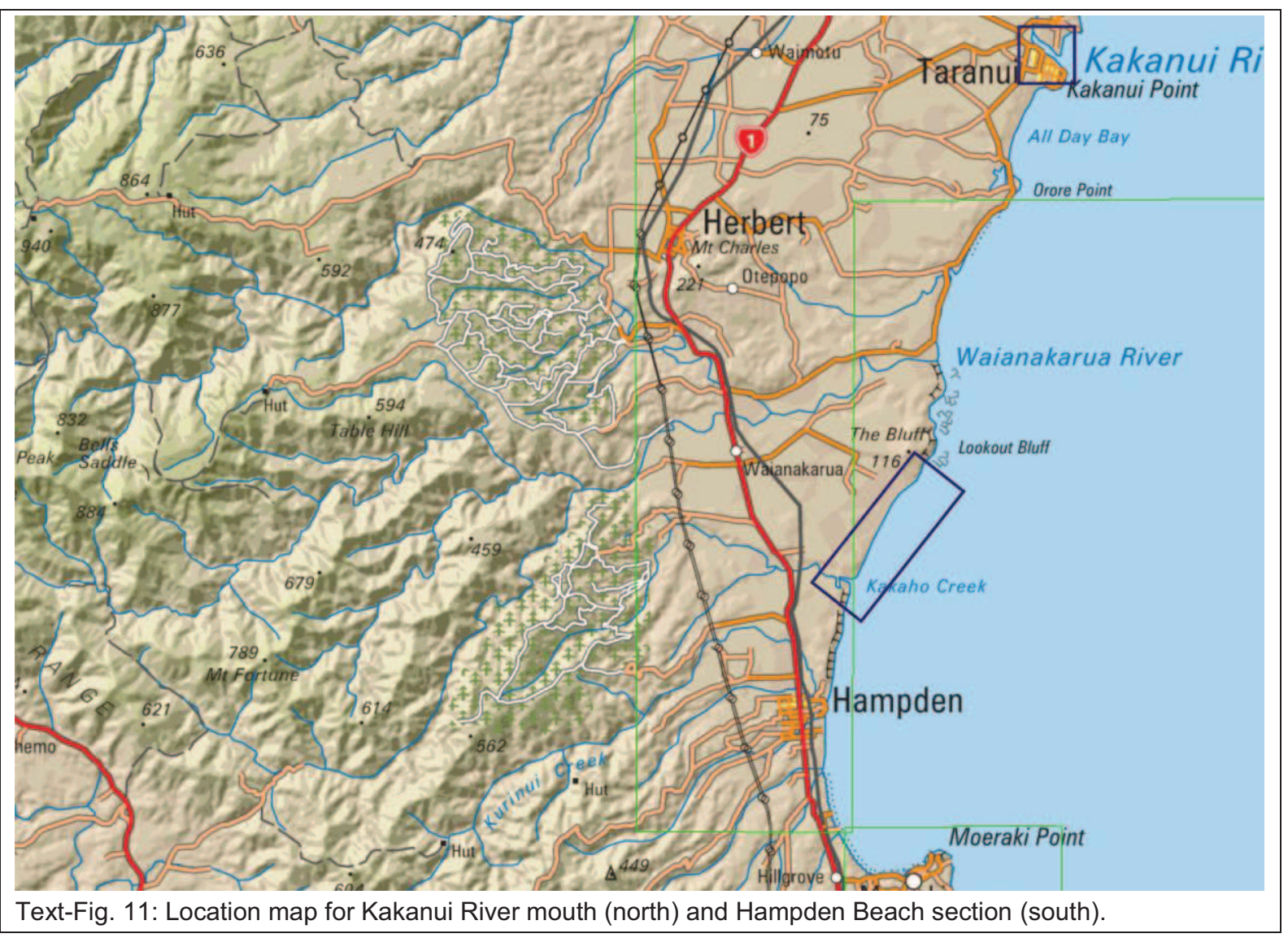

\section{Jacksons Paddock}

Jacksons Paddock is located near Cormacks, to the west of Oamaru, north Otago, South Island, New Zealand (Text-Fig. 12).

Relevant stratigraphic details for the Waiareka Volcanic Formation are provided by Gage (1957).

"Lithoperidinium oamaruense" of Deflandre (1933) is from a sample from Cormacks Top, near the Jacksons Paddock locality and probably from the same stratigraphic horizon. Organic-walled dinoflagellates from sample S136/f914, recovered from immediately below 'basalt' $20 \mathrm{~m}$ below diatomite in an exposure at Jacksons Paddock, is dated as Lower Runangan (Upper Eocene) on foraminifera and nannoplankton (Wilson 1982b).

\section{Kakanui River}

The Kakanui River section is well-exposed for $~ 300$ metres along the south bank of Kakanui River, south of Oamaru, South Island, New Zealand (Text-Fig. 11), approximately 300 metres inland from a sand bar across the river mouth, grid reference $\mathrm{J} 42 / 446558$.

The section includes a Runangan-Whaingaroan boundary, and maybe also an Eocene-Oligocene boundary within the early Whaingaroan (Clowes \& Morgans 1984). Early reports include studies of the section's macrofauna (Gage 1957) and microfauna (Jenkins 1971).

The section exposes the Totara Limestone formation, comprising Runangan aged thin-banded calcareous tuffs and marls, passing up into a Whaingaroan polyzoan limestone, overlain by the coarse grey and brown tuffs of the Deborah Volcanics (Gage 1957, column S136/1; Clowes \& Morgans 1984, text-fig. 2).

Previous dinoflagellate studies are reported in Wilson 1982b, Clowes \& Morgans 1984, and Clowes 1985. 

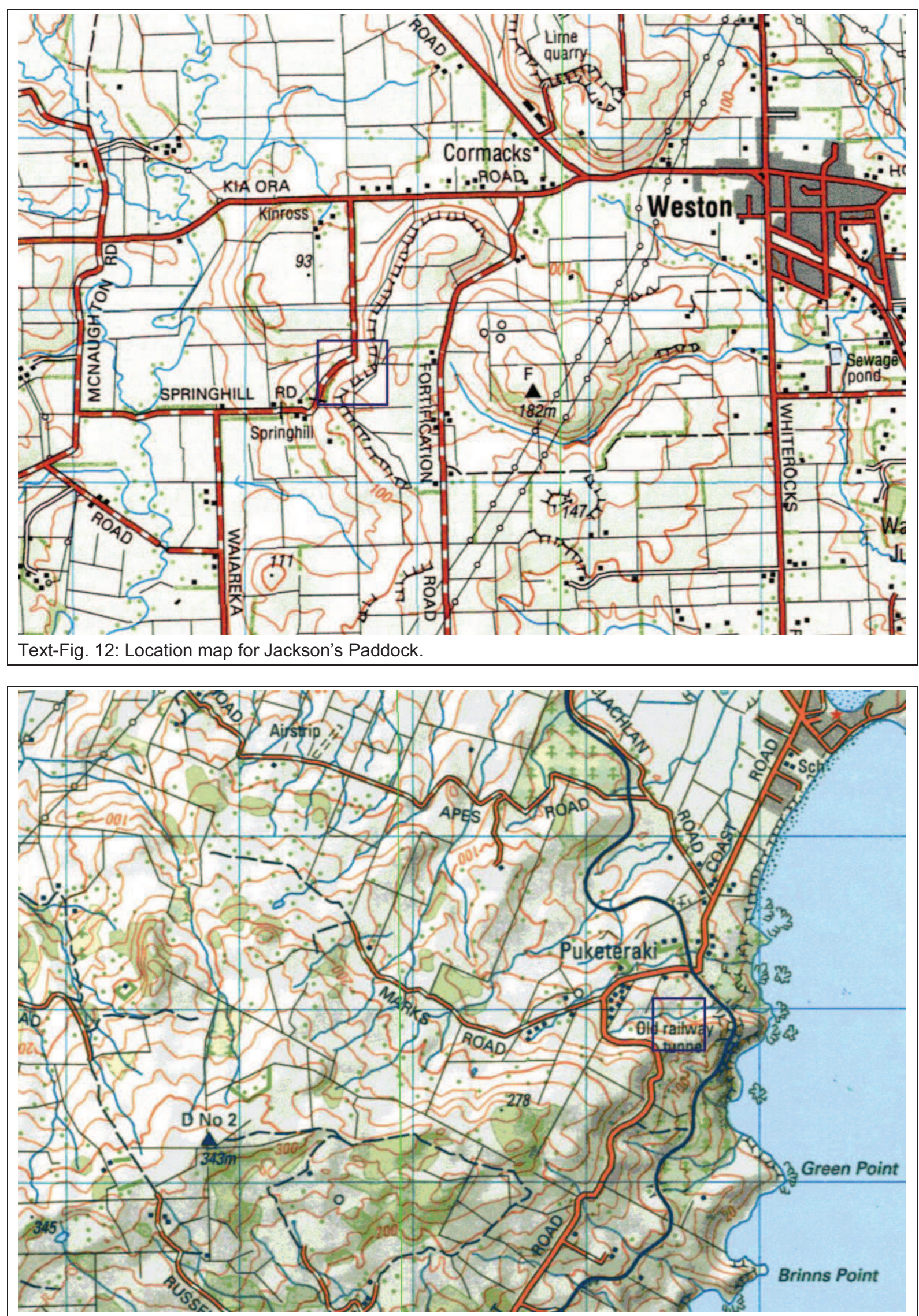

Text-Fig. 13: Location map for the Puketeraki core.

\section{M26 Core}

The M26 core, grid-reference 144/109760, was the longest of 30 cores recovered from holes drilled in the Abbotsford area (Text-Fig. 10) following the landslide of August 1979 which damaged homes and required the permanent evacuation of a small residential subdivision. 
Terrestrial palynomorphs from the core are provided in preliminary (Mildenhall 1979a) and expanded reports (Mildenhall 1979b) from the time of the landslide. Foraminifera and dinoflagellate assemblages from M26 are discussed in Wilson \& McMillan 1996.

\section{Puketeraki Core}

Puketeraki is located on the coast, north of Dunedin, South Island, New Zealand (Text-Fig. 13). The Puketeraki core was drilled in 1993 at grid reference 143/26550313, in the course of an investigation into landslides affecting the main trunk railway line in the area (Glassey 1994, Wilson \& McMillan 1996).

The majority of the core comprises "alternating zones of silty claystone and claystone of variable thickness" (Wilson \& McMillan 1996, fig. 21) of the Burnside Formation. The lowest $\sim 65 \mathrm{~m}$. are of late Bortonian-age, separated from overlying Kaiatan sediments by a discontinuity, those in turn separated from overlying Runangan sediments by a second discontinuity. Discontinuously overlying the Burnside Formation is ?Waitakian-aged Concord Greensand and Otaian Caversham Sandstone.

Dinoflagellate assemblages from the Puketeraki Core are reported in Wilson \& McMillan 1996.

\section{Tumai}

The section exposed at the Tumai Overbridge, just south of Goodwood, South Island, New Zealand (Text-Fig. 14), "is known for its exposure of the rarely observed contacts of the Burnside Formation, Concord Greensand and Caversham Sandstone outside of the immediate Dunedin area" (Wilson \& McMillan 1996, p. 16).

Foraminifera (two samples) and dinoflagellate (one sample) assemblages from Tumai are reported in Wilson \& McMillan 1996, p. 16-17, 89-91).

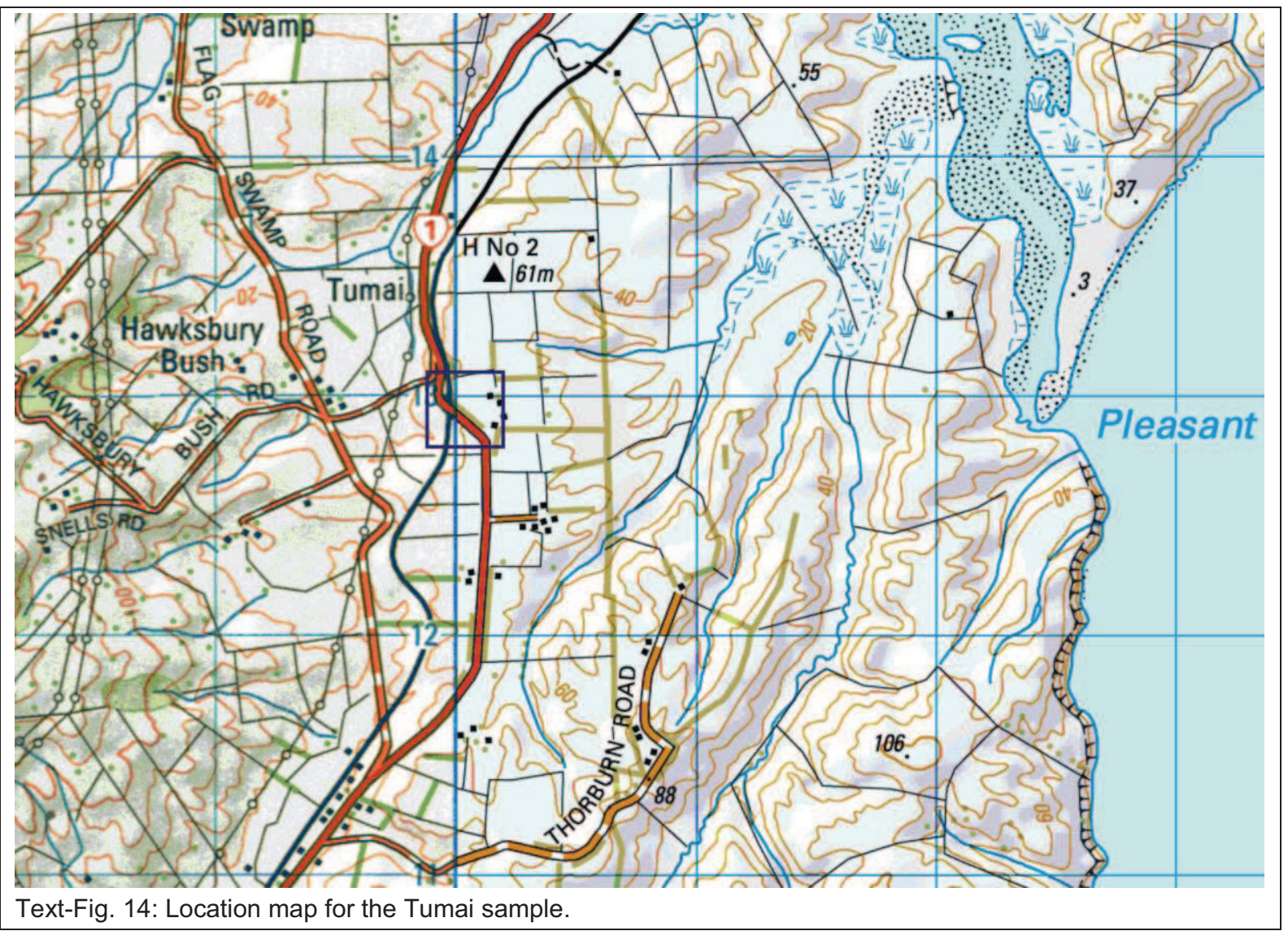




\title{
Systematics
}

In the subsequent systematic text, the following points apply.

The sequencing of the taxa is, first of all, determined by the suprageneric classification of Fensome et al. 1993, updated where appropriate. Genera are arranged within subfamilies, and species within genera, so as to position the most similar forms together, wherever possible. The type, if it is represented within the study material, appears first, followed by any other taxa. There is no concession to alphabetical order, and the reader is directed to Appendix 5 to locate individual taxa alphabetically.

The synonymies are not exhaustive, and are not intended to be. Various databases are available for readers wishing to locate all citations of a particular name in the literature. Necessarily, these lists are constantly growing, and any printed version is doomed to obsolescence as soon as the ink dries. There is limited value in such an activity.

Instead, the synonymies presented below include two types of entry:

1. Important orthographic or nomenclatural variations have been captured.

2. Other entries are "just" citations from the literature, but with the added distinction that each has been individually examined, to determine that the cited occurrence does indeed correspond to my own view of the taxon circumscription. Of course I could be as easily mistaken as the next person, but the reader may be assured that the presence of a citation in one of the following synonymies implies more than just the mention of a name.

For both types of entry, I have relocated the original reference in nearly all cases, and attempted to reproduce the citation exactly, including any misspellings or other typographical irregularity.

Occurrences listed in the Distribution section for each species may include a few from the literature; typically those also listed in the synonymy. As for the synonymy, these are not intended to be exhaustive, nor even representative of the global distribution.

Distribution lists for each taxon include only the FAD and LAD from each collection (not section) and intervening occurrences are omitted.

The lists are ordered approximately by the age/stage for the occurrence, as far as can be determined. Ages for occurrences derived from the literature are reproduced in their original terms; not converted to New Zealand ages. The sample reference column in the distribution table provides previously published references to the sample, if one exists. Note these are references to the sample, not necessarily to the taxon.

\section{Group Acritarcha Evitt 1963a}

\author{
1963a Acritarchs Evitt, p. 158 \\ 1963b Acritarchs Evitt, p. 300-302 \\ 1963 Acritarcha Evitt 1963; Downie et al., p. 7
}

Remarks: Evitt (1963a, p. 158) proposed the name acritarchs be applied to a "new informal group of microfossils of organic composition and unknown affinity". Later (1963b, p. 300-301) he elaborated his vision of the group in two important ways, (1) noting that the group is polyphyletic, and (2) restricting his definition, morphologically, to microfossils having "a central cavity enclosed by a wall of single or multiple layers and of chiefly organic composition; symmetry, shape, structure, and ornamentation varied; central cavity closed or communicating with the exterior by varied means, for example: pores, a slitlike or irregular rupture, a circular opening (the pylome)."

The characteristic of polyphyletic and unknown affinity necessitates a wholly morphological (phenetic) form taxonomy for the group as a whole: Acritarchs are acritarchs precisely because we do not know their phylogenetic affiliations. Of course, that need not preclude us from attempting to assemble groups of species into "genera" that are at least potentially phylogenetic units, although any such approach is necessarily constrained. Thus, for example, it was perfectly reasonable for Prössl (1994) to recognise the essential similarity between Paucilobimorpha and Tritonites and to combine the species into a single form-genus. More stands to be gained from considering them together than separately.

Before the dinoflagellate affinities of many fossil cyst taxa had been convincingly demonstrated, several acritarchs and dinoflagellate cysts were collectively known as "hystrichospheres" - an informal term derived from the now disused family name, Hystrichosphaeridae O. Wetzel 1933b (p. 32). The type genus and species of Hystrichosphaeridae, Hystrichosphaera furcata, is nowadays considered a junior synonym of Spiniferites ramosus (Lentin \& Williams 1973, p. 128-129), a dinoflagellate. The Hystrichosphaeridae was effectively dismantled by Evitt (1963a, b) and various members transferred to either the acritarchs or to "Peridiniales" (= dinoflagellates, in the sense Evitt meant it), as appropriate. Since then, a number of taxa have continued to shuffle back and forth between the two groups, as various workers have observed, or thought they observed, characteristics diagnostic of a dinoflagellate affinity. Most often, a clearly polygonal shape to the archeopyle, 
taken to indicate boundaries with surrounding plates and, by implication, the existence of the plates themselves, has been considered to be strong enough evidence of a dinoflagellate affinity, provided, of course, that size, shape, etc., are within the appropriate ranges. This is the standard of "proof" adopted herein, also. As further discussed below, the form known as Membranilarnax (or Valensiella) clathroderma, and usually grouped with the dinoflagellates, fails this test and is herein treated as an acritarch.

\title{
Subgroup Sphaeromorphitae Downie et al. 1963
}

\section{Genus Indet 2}

Remarks: A number of unidentified sphaeromorphs have been encountered. Two of the more striking forms are grouped together below.

\section{Indet 2 sp. 1}

$$
\text { PI. 1, figs. 1-3 }
$$

Description: Small, thick-walled, prolate to more or less spherical cyst, with a broad pylome in the "precingular" position; evidence of thickened ridges on the wall do not appear to delineate any kind of tabulation.

Size Range: Length = 23 (29) $35 \mu \mathrm{m}$ (2 measurements). Width = $21 \mu \mathrm{m}$ (one measured specimen).

Distribution:

$\begin{array}{llll}\text { Age/Stage } & \text { Location } & \text { Sample } & \text { Sample Reference } \\ \text { early Whaingaroan } & \text { Kakanui River, Oamaru-Dunedin, New Zealand } & \text { J42/f096 (L10951) } & \text { Clowes \& Morgans 1984 } \\ \text { Bortonian } & \text { Puketeraki Core, Oamaru-Dunedin, New Zealand } & \text { I43/f091 (L16339) } & \text { Wilson \& McMillan 1996 }\end{array}$

Indet 2 sp. 2

$$
\text { PI. 1, figs. 4-6 }
$$

Description: Small, thick-walled, prolate to more or less spherical cyst, with an almost circular pylome in the "precingular" position, showing evidence of splitting below the posterior margin, as if splitting along the two sutures lateral to a plate $3 "$ analogue.

Size Range: Length $=20 \mu \mathrm{m}$ (one measured specimen). Width $=20 \mu \mathrm{m}$ (one measured specimen).

Distribution:

\begin{tabular}{llll}
\hline Age/Stage & Location & Sample & Sample Reference \\
early Whaingaroan & Kakanui River, Oamaru-Dunedin, New Zealand & J42/f096 (L10951) & Clowes \& Morgans 1984
\end{tabular}

Remarks: A very tiny form which could, conceivably, be a fungal spore or similar.

\section{Subgroup Uncertain}

Genus Cystidiopsis Nagy 1965

\author{
1965 Cystidiopsis Nagy, p. 209 \\ 1978 Cystidiopsis Nagy 1965; Stover \& Evitt, p. 291 \\ 1990 Cystidiopsis Nagy, 1965b, p. 209; Fensome et al., p. 178
}

Type Species: Cystidiopsis certa Nagy 1965, p. 209-210, pl. 5, figs. 27-30 [Mid Miocene]

Original Description: Regularly arranged cysts on the globular central body (E. Nagy, p. 209).

Remarks: This genus of small but distinctive acritarchs is seldom reported, though it is apparently cosmopolitan. 


\title{
Cystidiopsis certa Nagy 1965
}

\author{
PI. 1, figs. 7-9
}

\author{
?1960 Dinoflagellata cyst; Kuprijanova, p. 78, pl. 14, fig. 1 \\ 1965 Cystidiopsis certa Nagy, p. 209-210, figs. 27-30, text-fig. 8 \\ 1977 Litosphaeridium? mamellatum De Coninck, p. 42, pl. 6, figs. 8-13 \\ 1990 Cystidiopsis certa Nagy, 1965b, p. 209-210; pl. 5, figs. 27-30; Fensome et al., p. 178 \\ 2002 Litosphaeridium? mamellatum De Coninck, 1977; De Coninck, pl. 8, figs. 21-22
}

Original Description: [Diagnosis] Shell $21 \mu$ in diameter, its globular central body is $12 \mu$ large covered with a smooth cyst of roughly $1 \mu$ thickness. To this cyst from outside, around and in groups of three about twelf [sic] smooth-walled vesicles of $1 \mu$ [sic] seize [sic] adhere, each of which has an approximately $8 \mu$ long appendage ending in a point....

[Remarks] An entirely identical form was published by Kuprijanova (1960, Pollen et Spores, p. 78, Table 14, Fig. 1) from the Lower Oligocene of West-Kazakhstan.... Beside the holotype one more specimen was found so far in the sample from 755 to $757 \mathrm{~m}$. depth of the [Zengövárkony] bore-hole No. 59 at Hidas [Mecsek Mountains, southern Hungary]. Both samples are of maritime origin... (Nagy 1965, p. 209-210).

Size Range: Length including any processes $=20$ (31) $42 \mu \mathrm{m}$ (5 measurements). Width including any processes $=25 \mu \mathrm{m}$ (one measured specimen).

Distribution: Rare. To date, recorded in New Zealand from the Bortonian only.

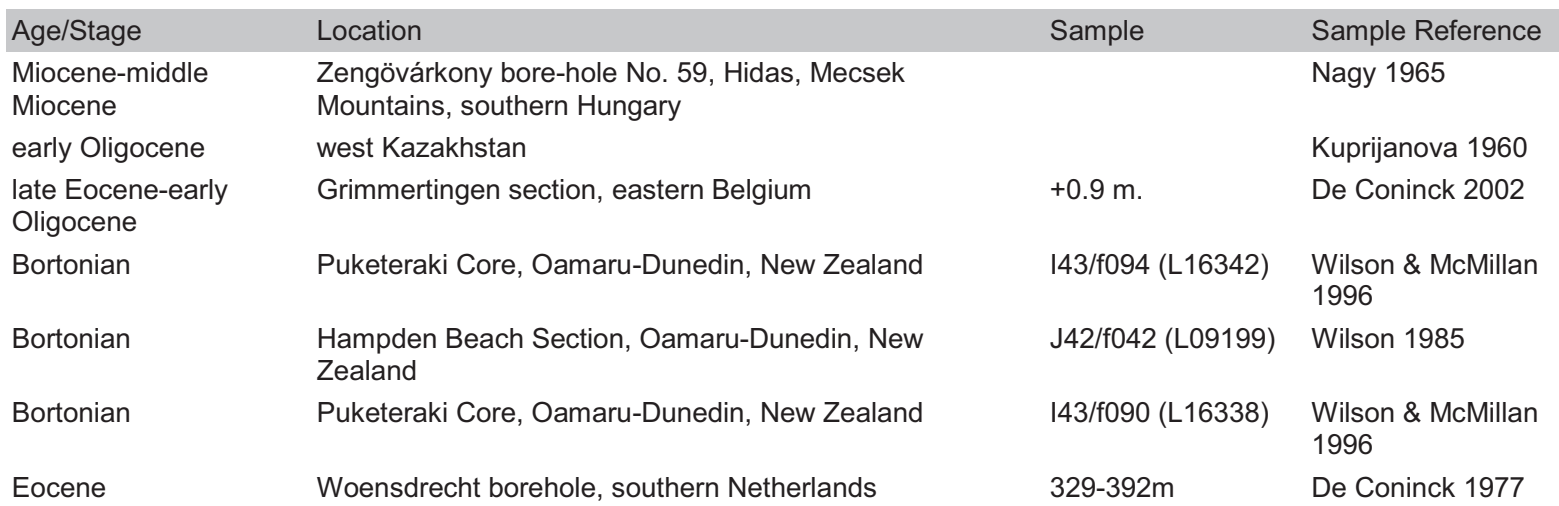

Remarks: The holotype is from 30.9 to $34.0 \mathrm{~m}$. in Zengövárkony borehole No. 59 and is stated to be Middle Miocene. The paper does not specifically state the age of another specimen occurring in the 755 to $757 \mathrm{~m}$. interval, other than noting (p.199) that the entirety of the core is Miocene. The examples encountered in this study, however, are late Middle Eocene (Bortonian).

De Coninck 1977 (re)described this form as ?Litosphaeridium mamellatum noting that "about 13" of the inflated, ribbed processes "seem to communicate with the interior of the central body" and have a small opening at the distal extremity.

New Zealand specimens seem identical to the type material.

\section{?Cystidiopsis sp. 1}

$$
\text { Pl. 1, figs. 10-12 }
$$

1988 Hystrichosphaeridium cf. H. astartes Sannemann 1955; Wrenn \& Hart, p. 354, fig. 24, 4-5

Description: Small cysts constructed as a collection of 25 or so, straight to gently convex-sided, cones joined at their wide ends to form a polyhedral vesicle.

Size Range: Length including any processes $=30 \mu \mathrm{m}$ (one measured specimen). Width including any processes $=28$ (29) $30 \mu \mathrm{m}$ (2 measurements). 
Distribution: Rare. Apparently confined to the Bortonian in New Zealand.

$\begin{array}{llll}\text { Age/Stage } & \text { Location } & \text { Sample } & \text { Sample Reference } \\ \text { Bortonian } & \text { Puketeraki Core, Oamaru-Dunedin, New Zealand } & \text { 143/f093 (L16341) } & \text { Wilson \& McMillan } 1996 \\ \text { Bortonian } & \text { Puketeraki Core, Oamaru-Dunedin, New Zealand } & \text { I43/f089 (L16337) } & \text { Wilson \& McMillan 1996 } \\ \text { late early Eocene } & \text { northern Seymour Island, West Antarctica } & 8462 & \text { Wrenn \& Hart 1988 }\end{array}$

Comparison: This form differs from Cystidiopsis certis in possessing processes which are more acutely conical than the lower, more rounded processes of $C$. certis.

\section{Genus Nummus Morgan 1975}

1975 Nummus Morgan, p. 163

1978 Nummus Morgan 1975; Stover \& Evitt, p. 295

1989 Nummus Morgan, 1975, p. 163; Lentin \& Williams, p. 258

1990 Nummus Morgan, 1975, p. 163, emend. Backhouse, 1988, p. 112; Fensome et al., p. 367

Type Species: Nummus monoculatus Morgan 1975, p. 163, pl. 3, figs. 1a-d, 4a-c [Aptian]

Original Description: Lenticular fossil is single-walled, with a slight thickening around the margin in dorsal-ventral view. A subcircular to rounded angular pylome is located in an "intercalary" position, and most of the "ventral" wall is lost, apparently by disintegration (Morgan 1975, p. 163).

Comparison: Nummus superficially resembles Cyclopsiella, but differs in being single-walled and in lacking an ambital thickening or flange. Additionally, it commonly appears to lose the majority of its ventral wall, leaving a construction reminiscent of the periphragm of Thalassiphora, though the significance of this characteristic is enigmatic, to say the least.

Nummus inornatus Clowes n. sp.

PI. 2, figs. 1-6

?2004 Cyclopsiella sp. A; Ramírez, pl. 9, fig. 3

?2005 Cyclopsiella sp. 1; Schiøler, pl. 6, fig. 7

Derivation of Name: Latin, inornatus, unadorned or uncelebrated; with reference to the lack of distinctive surface ornament.

Holotype: Sample 143/f093, slide L16341/SM100; Burnside Formation, Puketeraki Core (Bortonian); PI. 2, figs. 1 3

Description: Vesicle elliptical in outline. Wall apparently single layered; typically lacking from most of the central ventral surface, the rim being relatively smooth; thin $(\sim 0.5 \mu \mathrm{m}$ or less) and hyaline; lacking any thickened ambital flange. Surface irregularly and very shallowly wrinkled, especially near the ambitus, sparsely punctate; otherwise apparently completely smooth. Pylome subapical, circular to ellipsoidal; pylome rim thickened ( 1.5 to $2 \mu \mathrm{m})$, slightly irregular or wrinkled. No operculum has been observed.

Although the rim of the ventral "opening" exhibits occasional tears, it is generally quite smooth, suggesting that the ventral surface separates along some kind of pre-formed line of weakness rather than tearing away at random.

Size Range: Length including any processes $=80$ (94) $120 \mu \mathrm{m}$ (6 measurements). Width including any processes = 68 (87) $122 \mu \mathrm{m}$ (5 measurements).

Distribution: Rare.

\begin{tabular}{|c|c|c|c|}
\hline Age/Stage & Location & Sample & Sample Reference \\
\hline Rupelian-Burdigalian & Alma-1X well, Danish North Sea & LVR23764 & Schiøler 2005 \\
\hline early Whaingaroan & Cape Foulwind Section, Westland, New Zealand & K29/f178 (L11927) & \\
\hline Runangan & Cape Foulwind Section, Westland, New Zealand & K29/f128 (L11939) & \\
\hline Kaiatan & Puketeraki Core, Oamaru-Dunedin, New Zealand & I43/f096 (L16344) & $\begin{array}{l}\text { Wilson \& McMillan } \\
1996\end{array}$ \\
\hline Bortonian & Puketeraki Core, Oamaru-Dunedin, New Zealand & |43/f093 (L16341) & $\begin{array}{l}\text { Wilson \& McMillan } \\
1996\end{array}$ \\
\hline Porangan-Bortonian & Hampden Beach Section, Oamaru-Dunedin, New & J42/f301 (L23131) & \\
\hline
\end{tabular}




$\begin{array}{lll} & \text { Zealand } & \\ \text { Porangan-Bortonian } & \begin{array}{l}\text { Hampden Beach Section, Oamaru-Dunedin, New } \\ \text { Zealand }\end{array} & \text { J42/f485 (L23120) } \\ \text { middle Eocene-late } & \text { north west Venezuela } & \text { Pica-1X, 2119 ft. Ramírez 2004 } \\ \text { Eocene } & \end{array}$

Comparison: This taxon differs from Nummus similis (Cookson \& Eisenack 1960b) Burger 1980b, in possessing a relatively smooth rather than a granular wall, and from Nummus monoculatus Morgan 1975 in having a smaller pylome which is noticeably thickened around the rim and in the relatively smooth rather than a "granulo-punctate" wall.

\title{
Genus Paucilobimorpha De Coninck 1986b emend. Prössl 1994
}

\author{
1986b Paucilobimorpha De Coninck, p. 22 \\ 1988 Tritonites Marshall \& Partridge, p. 244-245 \\ 1990 Paucilobimorpha De Coninck, 1986b, p. 22; Fensome et al., p. 387 \\ 1990 Tritonites Marshall and Partridge, 1988, p. 244-245; Fensome et al., p. 496-497 \\ 1994 Paucilobimorpha De Coninck 1986b emend. Prössl, p. 400
}

Type Species: Paucilobimorpha triradiata De Coninck 1986b, p. 23, pl. 11, figs. 19-20 [Eocene (Bartonian)]

Original Description: The vesicle is single-layered and consists of a few hollow lobes diverging from a common centre. Each lobe may eventually terminate distally in a few, more or less pronounced bulbous parts. The vesicle wall may be smooth or granular and/or ornamented with short spines (De Coninck 1986b, p. 22).

Remarks: Prössl 1994 emends Paucilobimorpha and considers Tritonites Marshall \& Partridge 1988 to be a junior synonym.

Prössl included two Late Cretaceous forms (?P. apiculata and $P$. extrema, both described in Cookson \& Eisenack 1962a) within Paucilobimorpha. They seem unusual because their age is very different from those of the Eocene species comprising the majority of the genus.

- ?P. apiculata appears to be a typical Paucilobimorpha, somewhat like $P$. incurvata with the addition of a small "apical" projection. Only a single specimen is illustrated (presumably the holotype, though neither the description nor the figure caption states this to be the case) and only the holotype is measured. It is not clear that additional specimens have ever been found. The photograph is tiny (12 mm high) and grainy; as far as can be seen, the apical projection could be the result of mechanical damage.

- P. extrema appears (Cookson \& Eisenack 1962a, pl. 37, fig. 10) to possess an extensively folded and otherwise textured wall which is quite atypical for the genus, however, and might have been better left in Horologinella.

A range chart for the species of Paucilobimorpha encountered in this study is provided in Appendix 2, chart 6.

Paucilobimorpha inaequalis (Marshall \& Partridge 1988) Prössl 1994

PI. 2, figs. 7-12, PI. 3, figs. 1-3

\author{
1988 Tritonites inaequalis Marshall \& Partridge, p. 251, fig. 11A-U \\ 1990 Tritonites inaequalis Marshall and Partridge, 1988, p. 251, figs. 11A-U; Fensome et al., p. 497 \\ 1994 Paucilobimorpha inaequalis (Marshall \& Partridge 1988) Prössl, p. 402, figs. 6a-b
}

Original Description: Vesicle consisting of 3 lobes; longitudinal axes of lobes generally coplanar and symmetrically arranged around common junction. Lobe tips expanded into rounded subtriangular shapes.... One triangular expansion approximately in same plane as the 3 longitudinal axes; the other 2 near $90^{\circ}$ to this plane. Distal lobe margins flattened or, more commonly, concave. On specimens with markedly concave distal margins, lobe termini bifurcate with branches forming 2 rounded bulges. Wall usually single layered, $0.5-1 \mu \mathrm{m}$ thick; occasionally with diaphanous inner layer $0.3 \mu \mathrm{m}$ thick evident where detached from outer wall near lobe tips.... Wall thinning on rare specimens at tip of one lobe. Surface ornamented with granules, bacula, and spines up to $2.5 \mu \mathrm{m}$ high, $1.5 \mu \mathrm{m}$ in diameter, and usually more than $\mu \mathrm{m}$ apart. Spine bases usually rounded, occasionally stellate with 4-5 points; spines may be hollow. Ornament concentrated towards lobe tips (Marshall \& Partridge 1988 , p. 251; ellipses replace figure references in the original).

Description of Study Material: Vesicle constructed as two pairs of lobes, here referred to as apical and antapical, separated by a constricted waist; the apical pair of lobes characteristically poorly developed, in extreme cases 
barely distinguishable as a pair at all; the overall outline resembling a thickly formed, inverted, letter T, with varying degrees of lateral expansion evident at the apex; approximately $20 \mu \mathrm{m}$ high. Lobes closed and rounded distally; more or less tubular, neither attenuating nor expanding greatly; the antapical pair essentially equal in size, though rarely exactly so. The waist is typically constricted to around a third of the width of the antapical pair of lobes. Walls either single layered or comprising two indistinguishable layers, approximately $1 \mu \mathrm{m}$ thick; hyaline; generally not folded; completely smooth over most of the surface except for sparse spines ornamenting the distal surfaces of the lobes. Spines small and conical, in the order of $0.5 \mu \mathrm{m}$ diameter and $1 \mu \mathrm{m}$ high; apparently solid, and hyaline like the wall itself.

Size Range: Length including any processes $=18(26) 33 \mu \mathrm{m}(10$ measurements). Width including any processes $=15$ (24) $27 \mu \mathrm{m}$ (9 measurements).

Distribution: Rare. Recorded from the ?latest Porangan at Hampden Beach, and several Bortonian locations. Not recorded from the type Porangan at Te Uri Stream, which may be a little older than the Porangan at Hampden Beach.

\begin{tabular}{|c|c|c|c|}
\hline Age/Stage & Location & Sample & Sample Reference \\
\hline Bortonian & $\begin{array}{l}\text { Hampden Beach Section, Oamaru-Dunedin, New } \\
\text { Zealand }\end{array}$ & J42/f055 (L09212) & Wilson 1985 \\
\hline Bortonian & Puketeraki Core, Oamaru-Dunedin, New Zealand & l43/f093 (L16341) & $\begin{array}{l}\text { Wilson \& McMillan } \\
1996\end{array}$ \\
\hline Bortonian & Puketeraki Core, Oamaru-Dunedin, New Zealand & l43/f089 (L16337) & $\begin{array}{l}\text { Wilson \& McMillan } \\
1996\end{array}$ \\
\hline $\begin{array}{l}\text { Porangan- } \\
\text { Bortonian }\end{array}$ & $\begin{array}{l}\text { Hampden Beach Section, Oamaru-Dunedin, New } \\
\text { Zealand }\end{array}$ & J42/f302 (L23132) & \\
\hline $\begin{array}{l}\text { Porangan- } \\
\text { Bortonian }\end{array}$ & $\begin{array}{l}\text { Hampden Beach Section, Oamaru-Dunedin, New } \\
\text { Zealand }\end{array}$ & J42/f301 (L23131) & \\
\hline
\end{tabular}

\section{Paucilobimorpha incurvata (Cookson \& Eisenack 1962a) Prössl 1994}

$$
\text { Pl. 3, figs. 4-6 }
$$

1962a Horologinella incurvata Cookson \& Eisenack, p. 272, pl. 37, fig. 5

1982b Horologinella incurvata Cookson \&Eisenack; Wilson, p. 7, pl. 1, fig. 15

1994 Paucilobimorpha incurvata (Cookson \& Eisenack 1962) Prössl, p. 402-403

Original Description: Shell small, without fields and apical projection approximately isodiametric with deeply concave sides, no opening observed. Wall relatively thick, surface smooth (Cookson \& Eisenack 1962a, p. 272).

Description of Study Material: Vesicle comprising two pairs of lobes, essentially indistinguishable, separated by a variably constricted waist; the outline of the upper and lower surfaces generally convex, strongly concave at the sides; approximately $13 \mu \mathrm{m}$ high. The shape in polar view (i.e., whether the solid form is dorso-ventrally flattened or essentially cylindrical) has not been determined. Lobes closed and rounded distally. Walls either single layered or comprising two indistinguishable layers, approximately $1 \mu \mathrm{m}$ thick; hyaline; generally not folded; surface completely smooth.

A very small species: the holotype is just $16 \mu \mathrm{m}$ high and the same broad, and the New Zealand specimens encountered in this study slightly smaller. The overall shape can vary somewhat (e.g. contrast PI. 3 , fig. 5 and PI. 3, fig. 6).

Size Range: Length including any processes $=12$ (15) $27 \mu \mathrm{m}$ (9 measurements). Width including any processes $=13$ (16) $23 \mu \mathrm{m}$ (5 measurements).

Distribution: Rare. Cookson \& Eisenack's type material is recorded as "probably lower Eocene" but in New Zealand it seems to be one of the younger species of Paucilobimorpha, persisting possibly as late as the Oligocene.

\begin{tabular}{|c|c|c|c|}
\hline Age/Stage & Location & Sample & Sample Reference \\
\hline $\begin{array}{l}\text { early } \\
\text { Whaingaroan }\end{array}$ & Cape Foulwind Section, Westland, New Zealand & K29/f097 (L10914) & \\
\hline Kaiatan & $\begin{array}{l}\text { Hampden Beach Section, Oamaru-Dunedin, New } \\
\text { Zealand }\end{array}$ & J42/f064 (L09221) & Wilson 1985 \\
\hline Kaiatan & Puketeraki Core, Oamaru-Dunedin, New Zealand & I43/f096 (L16344) & Wilson \& McMillan 1996 \\
\hline Bortonian & Burnside Marl Pit, Oamaru-Dunedin, New Zealand & |44/f080 (L08947) & Clowes \& Wilson 2006 \\
\hline Bortonian & $\begin{array}{l}\text { Hampden Beach Section, Oamaru-Dunedin, New } \\
\text { Zealand }\end{array}$ & J42/f048 (L09205) & Wilson 1985 \\
\hline Bortonian & Puketeraki Core, Oamaru-Dunedin, New Zealand & I43/f089 (L16337) & Wilson \& McMillan 1996 \\
\hline
\end{tabular}




\title{
Paucilobimorpha panda (Marshall \& Partridge 1988) Prössl 1994
}

$$
\text { Pl. 3, figs. 7-12 }
$$

1988 Tritonites pandus Marshall \& Partridge, p. 248-250, fig. 10A-W

1990 Tritonites pandus Marshall and Partridge, 1988, p. 248-251, figs. 10A-W; Fensome et al., p. 497

1994 Paucilobimorpha panda (Marshall \& Partridge 1988) Prössl, p. 403, fig. 1

Original Description: Vesicle with 2 arcuate lobes forming a horseshoe shape. Lobes planar or more frequently distal tips of lobes twisted above and below this plane...; tips occasionally overlap.... Vesicle outline in side view (i.e., normal to plane containing the lobes) subcircular, oval, subrectangular, to slightly v-shaped..., with outer margin along which lobes connect nearly straight to concave. Lobes circular in cross-section, of fairly uniform diameter on individual specimens, tips rounded to slightly bulbous. Wall single-layered, 0.5-1.5 $\mu \mathrm{m}$ thick, thinning on most specimens at tip or on inward-facing side of one lobe, where wall is flattened..., wrinkled..., or ruptured. Surface with granules; straight to arcuate rugulae, bacula, and spines up to $2 \mu \mathrm{m}$ high and $0.5 \mu \mathrm{m}$ in diameter. Elements usually $1 \mu \mathrm{m}$ apart, distributed on outward-facing surfaces of lobes and concentrated towards tips, occasionally arranged in discontinuous rows (Marshall \& Partridge 1988, p. 248; ellipses replace figure references in the original).

Size Range: Length including any processes $=15$ (18) $20 \mu \mathrm{m}$ (7 measurements). Width including any processes $=17$ (19) $21 \mu \mathrm{m}$ (4 measurements).

Distribution: Infrequent. This species appears to be the earliest appearing Paucilobimorpha, possibly occurring as early as the Heretaungan.

\begin{tabular}{|c|c|c|c|}
\hline Age/Stage & Location & Sample & Sample Refe \\
\hline Bortonian & $\begin{array}{l}\text { Hampden Beach Section, Oamaru-Dunedin, New } \\
\text { Zealand }\end{array}$ & J42/f055 (L09212) & Wilson 1985 \\
\hline Bortonian & $\begin{array}{l}\text { Hampden Beach Section, Oamaru-Dunedin, New } \\
\text { Zealand }\end{array}$ & J42/f489 (L23124) & \\
\hline Bortonian & $\begin{array}{l}\text { Hampden Beach Section, Oamaru-Dunedin, New } \\
\text { Zealand }\end{array}$ & J42/f040 (L09197) & Wilson 1985 \\
\hline Porangan & $\begin{array}{l}\text { Hampden Beach Section, Oamaru-Dunedin, New } \\
\text { Zealand }\end{array}$ & J42/f299 (L23129) & \\
\hline Porangan & Te Uri Stream, Hawkes Bay, New Zealand & U24/f419 (L23127) & \\
\hline $\begin{array}{l}\text { Heretaungan- } \\
\text { Porangan }\end{array}$ & $\begin{array}{l}\text { Hampden Beach Section, Oamaru-Dunedin, New } \\
\text { Zealand }\end{array}$ & J42/f298 (L23128) & \\
\hline
\end{tabular}

Remarks: New Zealand forms, while falling within the range of the type material, are quite variable in overall shape (contrast, for example, PI. 3, figs. 7-8 and PI. 3, figs. 11-12). Further, some specimens seem completely smooth, whereas others carry small spines (e.g. PI. 3, fig. 9).

\section{Paucilobimorpha spinigera (De Coninck 1969) Prössl 1994}

$$
\text { PI. 4, figs. 1-3 }
$$

\author{
1969 Diacrocanthidium spinigerum De Coninck, p. 43-44, pl. 13, figs. 11-13 \\ 1988 Tritonites bilobus Marshall \& Partridge, p. 247, fig. 8A-O \\ 1990 Tritonites bilobus Marshall and Partridge, 1988, p. 247, figs. 8A-O; Fensome et al., p. 497 \\ 1994 Paucilobimorpha spinigerum (De Coninck 1969) Prössl, p. 403, fig. 2
}

Original Description: The organism consists of a small elongated body with inflated ends on which are a variable number of short spines (De Coninck 1969, p. 43-44).

Description of Study Material: Vesicle apparently constructed as two pairs of lobes separated by a constricted waist, as in other species of Paucilobimorpha, but each pair of lobes reduced to a mere swelling; approximately $25 \mu \mathrm{m}$ high. Vesicle closed, presumed to be more or less circular in cross-section. Walls either single layered or comprising two indistinguishable layers, approximately $1 \mu \mathrm{m}$ thick; hyaline; generally not folded; completely smooth over most of the surface except for scattered spines ornamenting the apical and antapical lobes. Spines relatively elongated, in the order of $0.5 \mu \mathrm{m}$ diameter and up to $5 \mu \mathrm{m}$ high; apparently solid, and hyaline like the wall itself. 
Size Range: Length including any processes $=23 \mu \mathrm{m}$ (one measured specimen). Width including any processes $=15 \mu \mathrm{m}$ (one measured specimen).

Distribution: Very rare. Occurs low in the Bortonian (Hampden Beach) in New Zealand and at the early/middle Eocene boundary in the Gippsland Basin, according to Marshall \& Partridge 1988.

$\begin{array}{llll}\text { Age/Stage } & \text { Location } & \text { Sample } & \text { Sample Reference } \\ \text { Bortonian } & \text { Hampden Beach Section, Oamaru-Dunedin, New Zealand } & \text { J42/f303 (L23133) }\end{array}$

\section{Paucilobimorpha spinosa (Cookson 1965a) Prössl 1994}

$$
\text { PI. 4, figs. 4-6 }
$$

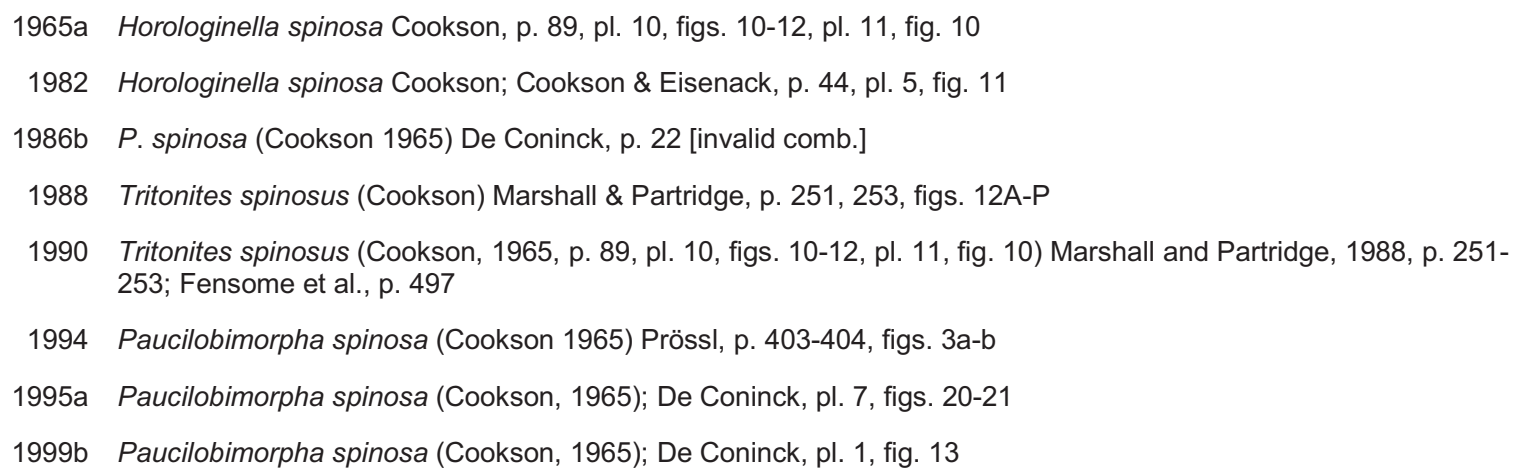

Original Description: Cyst without fields, with deeply concave sides and straight to slightly concave ends (cf. $H$. incurvata ...). Wall c. $0.5-1 \mu$, thick mainly smooth, except at the distal rounded ends of the 4 arms where it is ornamented with small, solid, spine-like projections. One of the arms at the 'anterior' end is slightly longer than the other 3 and sometimes narrows slightly towards the apex. In 2 examples ... the apex of the longer arm is open, apparently as the result of a natural transverse break (Cookson 1965a, p. 89; ellipses replace figure references in the original).

Description of Study Material: Vesicle comprising two pairs of lobes, here referred to as apical and antapical, separated by a constricted waist, the outline thus resembling a thickly formed letter $\mathrm{H}$ laid on its side; generally concave on all sides, strongly so at the waist; approximately 25-30 $\mu \mathrm{m}$ high. The two pairs of lobes are almost but usually not quite, coplanar, being slightly rotated with respect to one another about an imaginary polar axis. Lobes closed and rounded distally; more or less tubular, neither attenuating nor expanding greatly; very close to being equal in size, but rarely exactly so, the slightly smaller pair herein referred to (and oriented in the figures) as the apical pair. The waist is typically constricted to around a third of the width of the lobes. Walls either single layered or comprising two indistinguishable layers, approximately $1 \mu \mathrm{m}$ thick; hyaline; generally not folded; completely smooth over most of the surface except for the characteristic sparse spines ornamenting the distal surfaces of the lobes. Spines small and conical, in the order of $0.5 \mu \mathrm{m}$ diameter and $1 \mu \mathrm{m}$ high; apparently solid, and hyaline like the wall itself.

Size Range: Length including any processes $=23(28) 35 \mu \mathrm{m}$ (17 measurements). Width including any processes $=25$ (29) $33 \mu \mathrm{m}$ (3 measurements).

Distribution: Frequent. Occurs widely, though it is never common, from the Bortonian to at least the early Whaingaroan in New Zealand.

$\begin{array}{llll}\text { Age/Stage } & \text { Location } & \text { Sample } & \text { Sample Reference } \\ \text { early Whaingaroan } & \begin{array}{l}\text { Cape Foulwind Section, Westland, New } \\ \text { Zealand }\end{array} & \text { K29/f097 (L10914) } \\ \text { early Whaingaroan } & \begin{array}{l}\text { Cape Foulwind Section, Westland, New } \\ \text { Zealand }\end{array} & \text { K29/f114 (L11050) } \\ \text { Carly Whaingaroan } & \begin{array}{l}\text { Cape Foulwind Section, Westland, New } \\ \text { Zealand }\end{array} & \text { K29/f182 (L11931) } \\ \text { Kakanui River, Oamaru-Dunedin, New } & \text { J42/f096 (L10951) } & \text { Clowes \& Morgans } \\ \text { early Whaingaroan } & \begin{array}{l}\text { Zealand } \\ \text { Cape Foulwind Section, Westland, New }\end{array} & \text { K29/f171 (L11920) } & \text { 1984 } \\ \begin{array}{l}\text { Runangan-early } \\ \text { Whaingaroan }\end{array} & \begin{array}{l}\text { Zealand } \\ \text { late Eocene-early }\end{array} & \text { Kallo borehole, north-western Belgium } & \text {-110 m. - slide 3 } \\ \text { Oligocene } & \text { Cape Foulwind Section, Westland, New } & \text { K29/f099 (L11035) } & \text { De Coninck 1999b } \\ \text { ?Kaiatan-Runangan } & \begin{array}{l}\text { Zealand } \\ \text { Puketeraki Core, Oamaru-Dunedin, }\end{array} & \text { I43/f096 (L16344) } \\ \text { Kaiatan } & \text { New Zealand } & & \text { Wilson \& McMillan } \\ & & \end{array}$




\begin{tabular}{llll} 
Age/Stage & Location & Sample & Sample Reference \\
Bartonian-early Rupelian & Kallo borehole, north-western Belgium & $\begin{array}{l}-115 \text { m. - lame 1; -115 m. - } \\
\text { lame 2 }\end{array}$ & De Coninck 1995a \\
\cline { 2 - 3 } Bortonian & $\begin{array}{l}\text { Puketeraki Core, Oamaru-Dunedin, } \\
\text { New Zealand }\end{array}$ & l43/f089 (L16337) & Wilson \& McMillan \\
& & & 1996
\end{tabular}

Remarks: Marshall \& Partridge 1988 (p. 251) describe the lobes of Paucilobimorpha (as Tritonites) spinosa as "planar" and subsequently refer to a "plane containing the lobes." Although this is approximately the case, neither their figures (see especially their figs. 12E-G) nor the specimens observed in this study possess lobes which are exactly coplanar. Instead, as noted in the foregoing description, the apical and antapical (insofar as we may recognise those concepts) pairs are usually slightly rotated with respect to one another, about an imaginary polar axis. Marshall \& Partridge 1988 also observed "a diaphanous inner layer $0.2 \mu \mathrm{m}$ thick, which is only clear where detached from the outer wall near lobe tips" (p. 251, fig. 12K). Nothing similar was encountered in the present study.

De Coninck (1986b) published the combination "P. spinosa (Cookson 1965)" without further elaboration, thus failing to meet the requirements of Art. 33.2 for valid publication of a new combination.

Paucilobimorpha tricornus (Marshall \& Partridge 1988) Clowes n. comb.

PI. 4, figs. 7-12

1985 Incertae Sedis sp. B in De Coninck 1976; De Coninck, p. 69, pl. 2, fig. 19 (not 18)

1988 Tritonites tricornus Marshall \& Partridge, p. 245-247, figs. 6A-U

1990 Tritonites tricornus Marshall and Partridge, 1988, p. 245-247, figs. 6A-U; Fensome et al., p. 497

Original Description: Vesicle of 3 arcuate lobes extending from their common junction. Lobes radial and symmetrical about axis normal to plane in which they join. Lobes diverging from proximal junction, subparallel or convergent distally. Vesicle outline subcircular when viewed normal to axis of symmetry.... Lobes circular in cross-section, of constant diameter or tapering slightly distally, tips rounded. Wall single-layered, c. $0.5 \mu \mathrm{m}$ thick, frequently thinning slightly towards inward-facing side of tip of one lobe...; this lobe usually slightly flattened, rarely ruptured. Surface bearing rugulae, bacula, and spines up to $2.5 \mu \mathrm{m}$ high, $1.5 \mu \mathrm{m}$ in diameter, and usually more than $1.5 \mu \mathrm{m}$ apart. Projections usually solid, occasionally hollow. Spine bases usually circular, occasionally star-shaped. Ornament distributed over outward facing convex surfaces; concentrated towards tips (Marshall \& Partridge 1988, p. 245).

Description of Study Material: Vesicle comprising three, approximately equal-sized and equally spaced, lobes which radiate from their common centre in a plane, then curve inwards. Sometimes this curvature is strong enough that the lobes almost touch at their tips, though generally it is less so; the approximate sphere thus formed being about 20-25 $\mu \mathrm{m}$ in diameter. Lobes closed and rounded distally; more or less tubular, neither attenuating nor expanding greatly. Walls either single layered or comprising two indistinguishable layers, approximately $1 \mu \mathrm{m}$ thick; hyaline; generally not folded; completely smooth over most of the surface except for the characteristic sparse (PI. 4, figs. 7-9) to fairly dense (PI. 4, fig. 12) spines ornamenting the distal or, less frequently, more proximal surfaces of the lobes. Spines small and conical, in the order of $0.5 \mu \mathrm{m}$ diameter and $1 \mu \mathrm{m}$ high; apparently solid, and hyaline like the wall itself.

Size Range: Length including any processes $=18$ (21) $23 \mu \mathrm{m}$ (5 measurements). Width including any processes $=20$ (22) $23 \mu \mathrm{m}$ (4 measurements).

Distribution: Infrequent. Somewhat less common than $P$. tripa (see below) though the stratigraphic range is broadly similar in New Zealand.

\begin{tabular}{llll}
\hline Age/Stage & Location & Sample & Sample Reference \\
\hline Bortonian & Hampden Beach Section, Oamaru-Dunedin, New Zealand & J42/f041 (L09198) & Wilson 1985 \\
Porangan-Bortonian & Hampden Beach Section, Oamaru-Dunedin, New Zealand & J42/f302 (L23132) & \\
Porangan-Bortonian & Hampden Beach Section, Oamaru-Dunedin, New Zealand & J42/f301 (L23131) & \\
Porangan & Te Uri Stream, Hawkes Bay, New Zealand & U24/f419 (L23127) & \\
Porangan & Te Uri Stream, Hawkes Bay, New Zealand & U24/f418 (L23126) & \\
middle Eocene & Sands of Lede, Mol borehole, Belgium & $-319.8 m-$ prep. 1 & De Coninck 1985
\end{tabular}

Remarks: Considered to be a junior synonym of $P$. tripa by Prössl 1994 (p. 404) as it may yet prove to be; see further remarks under $P$. tripa. 


\title{
Paucilobimorpha tripa De Coninck 1986b
}

\author{
PI. 5, figs. 1-6
}

\author{
?1982b ?Horologinella spinosa Cookson; Wilson, p. 7, pl. 1, fig. 14 \\ 1986b Paucilobimorpha tripus De Coninck, p. 23, pl. 11, fig. 25 \\ 1990 Paucilobimorpha tripus De Coninck, 1986b, p. 23, pl. 11, fig. 25; Fensome et al., p. 387 \\ 1994 Paucilobimorpha tripa De Coninck 1986; Prössl, p. 404, figs. 5a-b
}

Original Description: The vesicle consists of three lobes diverging from a common centre, but curving to one side as the legs of a tripos (three-legged stool) (latin: tripus -odis). The vesicle wall is single-layered and ornamented with short spines irregularly scattered all over the vesicle (De Coninck 1986b, p. 23).

Description of Study Material: Vesicle comprising three, approximately equal-sized and equally spaced, lobes which radiate from their common centre in a plane, then curve inwards, the approximate diameter of the whole being about $20-25 \mu \mathrm{m}$. Sometimes the curvature of the lobes is very weak (PI. 5, figs. 1-3, PI. 5, figs. 4-5); at other times it is much stronger (PI. 5, fig. 6) though rarely sufficient to bring the lobe tips close to touching. Lobes closed and rounded distally; more or less tubular, neither attenuating nor expanding greatly. Walls either single layered or comprising two indistinguishable layers, approximately $1 \mu \mathrm{m}$ thick; hyaline; generally not folded. The surface varies from almost completely smooth (PI. 5, figs. 4-5), through somewhat granular (PI. 5, figs. 1-3) to quite densely spinose (PI. 5, fig. 6); the spines, when present, small and conical, in the order of $0.5 \mu$ m diameter and $1 \mu \mathrm{m}$ high; apparently solid, and hyaline like the wall itself.

Size Range: Width $=25 \mu \mathrm{m}$ (one measured specimen). Length including any processes $=15$ (22) $31 \mu \mathrm{m}(8$ measurements). Width including any processes $=17$ (25) $37 \mu \mathrm{m}$ (5 measurements).

Distribution:

$\begin{array}{llll}\text { Age/Stage } & \text { Location } & \text { Sample } & \text { Sample Reference } \\ \text { Bortonian } & \text { Hampden Beach Section, Oamaru-Dunedin, New Zealand } & \text { J42/f055 (L09212) } & \text { Wilson } 1985 \\ \text { Bortonian } & \text { Hampden Beach Section, Oamaru-Dunedin, New Zealand } & \text { J42/f489 (L23124) } & \\ \text { Bortonian } & \text { Hampden Beach Section, Oamaru-Dunedin, New Zealand } & \text { J42/f303 (L23133) } & \\ \text { Bortonian } & \text { Hampden Beach Section, Oamaru-Dunedin, New Zealand } & \text { J42/f040 (L09197) } & \text { Wilson 1985 } \\ \text { Porangan } & \text { Te Uri Stream, Hawkes Bay, New Zealand } & \text { U24/f419 (L23127) } & \\ \text { Porangan } & \text { Hampden Beach Section, Oamaru-Dunedin, New Zealand } & \text { J42/f300 (L23130) } & \end{array}$

Comparison: A more "gracile" version of P. tricornus (Marshall \& Partridge), as noted in Prössl 1994 (p. 404), although the two may yet prove to be conspecific (as regarded by Prössl). For the present, however, I prefer to retain them separately because they are usually readily distinguished (although some intermediates are difficult) and their ranges, though similar, do not seem to be identical.

\section{Genus Fenestridium Clowes n. gen.}

Derivation of Name: Latin, fenestra, window; with reference to the window-like areas occurring on the outer wall of the type species.

Type Species: Fenestridium clathrodermum (Deflandre \& Cookson 1955) Clowes n. comb.

Description: Cyst comprising two, concentric, more or less spherical bodies, connected together by numbers of membranous lamellae. Where the lamellae connect to the outer wall they divide the surface up into numerous polygonal fields within which are typically one or a small number of fenestrae.

Remarks: The genus Membranilarnax O. Wetzel 1933b (p. 51) has long been recognised as a problematic taxon: Stover \& Evitt 1978 (p. 295) considered it to be an acritarch genus, whereas Sarjeant 1985b (p. 149, 151-152) considered it to be a skolochorate dinoflagellate cyst. In fact, however, the genus is quite likely to be polyphyletic and a more tractable approach might be to consider the various species individually. The species, 'Membranilarnax' clathroderma, is almost certainly not a dinoflagellate. As noted in Clowes \& Morgans 1984, p. 37 , the unusual ramifying lamellae between the wall layers, apparent lack of an archeopyle (a fact also noted by Stover \& Evitt 1978, p. 86), and surface pattern inconsistent with any obvious dinoflagellate tabulation, fail to provide any support for an affinity with the dinoflagellates (although one might argue that the structure of the wall layers has an approximate analogue in Samlandia).

It is, however, a very distinctive element of southern palynofloras around the Eocene-Oligocene boundary. The new genus, Fenestridium, is here proposed to accommodate this form, which bears no apparently close relationship with the type species of either Membranilarnax (M. pterospermoides, Late Cretaceous) or Valensiella (V. ovulum, Middle Jurassic). 
Fenestridium clathrodermum (Deflandre \& Cookson 1955) Clowes n. comb.

\author{
PI. 5, figs. 7-12, PI. 6, figs. 1-6
}

\author{
1955 Membranilarnax clathroderma Deflandre \& Cookson, p. 290, pl. 7, fig. 6, text-fig. 51 \\ 1963a Valensiella clathroderma (Deflandre \& Cookson 1955, p. 290, pl. 7, fig. 6, text-fig. 51) Eisenack, p. 101 \\ ?1974 Membranilarnacia densa Cookson \& Eisenack, p. 71, pl. 25, fig. 19; pl. 29, fig. 19 \\ 1978 Valensiella? clathroderma (Deflandre \& Cookson 1955) Eisenack 1963a; Stover \& Evitt, p. 86 \\ 1984 'Valensiella' clathroderma (Deflandre \& Cookson 1955); Clowes \& Morgans, p. 37, pl. 2, figs. 19-20 \\ ?1986b Valensiella? clathroderma (Deflandre \& Cookson 1955); De Coninck, pl. 10, figs. 26-27 \\ 2002 Valensiella? clathroderma Deflandre \& Cookson, 1955; De Coninck, pl. 10, figs. 8-10
}

Original Description: Shell practically spherical with an angular outline and thin wall surrounded by a 2nd very fine membrane that is indistinctly punctate and perforated with relatively large rounded holes. External membrane attached to the shell, not by individual processes but by membranaceous lamellae, which form a kind of widemeshed reticulate surface design wholly independent of the above-mentioned holes. External outline irregularly rounded, not exactly concentric with the shell (Deflandre \& Cookson 1955, p. 290).

Description of Study Material: Cyst comprising an approximately central, more or less spherical inner body, connected to a more polygonal outer wall by numbers of membranous lamellae. Where the lamellae connect to the outer wall they divide the surface up into numerous polygonal fields within which are typically one large or several smaller fenestrae.

Size Range: Length including any processes = 45 (54) $65 \mu \mathrm{m}$ (12 measurements). Width including any processes $=42$ (49) $60 \mu \mathrm{m}$ (5 measurements).

Distribution:

\begin{tabular}{|c|c|c|c|}
\hline Age/Stage & Location & Sample & Sample Reference \\
\hline early Whaingaroan & $\begin{array}{l}\text { Cape Foulwind Section, Westland, New } \\
\text { Zealand }\end{array}$ & K29/f097 (L10914) & \\
\hline early Whaingaroan & $\begin{array}{l}\text { Cape Foulwind Section, Westland, New } \\
\text { Zealand }\end{array}$ & K29/f116 (L11052) & $\begin{array}{l}\text { Clowes \& Wilson } \\
2006\end{array}$ \\
\hline early Whaingaroan & $\begin{array}{l}\text { Cape Foulwind Section, Westland, New } \\
\text { Zealand }\end{array}$ & K29/f184 (L11933) & \\
\hline ?early Whaingaroan & Kakanui River, Oamaru-Dunedin, New Zealand & J42/f097 (L10952) & $\begin{array}{l}\text { Clowes \& Morgans } \\
1984\end{array}$ \\
\hline early Whaingaroan & $\begin{array}{l}\text { Cape Foulwind Section, Westland, New } \\
\text { Zealand }\end{array}$ & K29/f114 (L11050) & \\
\hline Runangan-early Whaingaroan & $\begin{array}{l}\text { Cape Foulwind Section, Westland, New } \\
\text { Zealand }\end{array}$ & K29/f169 (L11918) & \\
\hline late Eocene-early Oligocene & Grimmertingen section, eastern Belgium & $+2.15 \mathrm{~m}$ & De Coninck 2002 \\
\hline Priabonian (Tongrien) & $\begin{array}{l}\text { Sands of Asse, Woensdrecht borehole, } \\
\text { southern Netherlands }\end{array}$ & $263 m$ & De Coninck 1986b \\
\hline $\begin{array}{l}\text { latest Bartonian-Priabonian } \\
\text { (Tongrien) }\end{array}$ & $\begin{array}{l}\text { Sands of Asse, Woensdrecht borehole, } \\
\text { southern Netherlands }\end{array}$ & $277 \mathrm{~m}$ & De Coninck 1986b \\
\hline
\end{tabular}

Remarks: The fossil taxon Membranilarnax clathroderma was described by Deflandre \& Cookson (1955, p. 290) who regarded it as a dinoflagellate cyst. Despite the apparent lack of an archeopyle or any other indications of a dinoflagellate tabulation, it has continued to be treated as a dinoflagellate cyst by most subsequent authors. For many years it has been assigned Valensiella. However, the non-dinoflagellate nature of 'Membranilarnax' clathroderma was recognised at least 30 years ago (e.g. Stover \& Evitt 1978, p. 86).

As far as can be judged from the single, somewhat poor figure of the holotype provided in Deflandre \& Cookson 1955 (pl. 7, fig. 6), the New Zealand forms encountered in the present study are conspecific.

Membranilarnacia densa Cookson \& Eisenack 1974 is regarded as a junior synonym in Stover \& Evitt 1978 (p. 86) though I'm not convinced myself. The original illustrations of this taxon depict only mid-section foci and show no evidence of the characteristic fenestrae. 


\title{
Kingdom Alveolata Cavalier-Smith 1991
}

\section{Phylum Dinoflagellata Bütschli 1885}

\author{
1831 Peridiniaea Ehrenberg, p. 32 \\ 1885 Dinoflagellata Bütschli \\ 1914 Pyrrophyta Pascher \\ 1981 Dinozoa Cavalier-Smith, table 10 \\ 1985 Pyrrhophyta; Evitt, p. 26 \\ 1993b Dinoflagellata (Bütschli 1885) Fensome et al., p. 39
}

Remarks: Dinoflagellates are protists - neither plants nor animals. The botanical code of nomenclature has been settled upon for naming dinoflagellates, more or less by historical accident. Botanists frequently refer to the phylum-level taxonomic rank as a "division".

Key to classes (principally after Fensome et al. 1998):

1 Dinoflagellates possessing a nucleus rather than a dinokaryon

Dinoflagellates possessing a dinokaryon during at least one stage of the life cycle

Class Syndiniophyceae - Dinoflagellates with motile cells (dinospores or gametes) with a dinokont arrangement of flagella, and in which the nucleus possesses histones (Fensome et al. 1998); intracellular parasites without known fossil record (Evitt 1985, p. 27).

Class Dinophyceae - Dinoflagellates with a dinokaryon throughout their entire life-cycle (Fensome et al. 1998).

Parasitic dinoflagellates with non-vacuolated cells

Non-parasitic dinoflagellates with vacuolated cells

Class Blastodiniphyceae - Parasitic dinoflagellates having a dinokaryon during part of the lifecycle only. Cells are not highly vacuolated (Fensome et al. 1998).

7

Class Noctiluciphyceae - Dinoflagellates with a dinokaryon during part of the life-cycle only. The principal life-cycle stage comprises a large free-living motile cell inflated by vacuoles (Fensome et al. 1998).

Note: The key to classes does not include the problematic class Ebriophyceae - non-photosynthetic, biflagellate, free-living organisms, variously classified as dinoflagellates, protozoans and incertae sedis - which lack a resistant external covering but having an internal siliceous skeleton which can fossilise. Examples are known from at least the Paleocene.

Only the class Dinophyceae is considered further herein.

\section{Class Dinophyceae (Bütschli 1885) Pascher 1914}

Dinoflagellates with a dinokaryon throughout their entire life-cycle (Fensome et al. 1998); in which one flagellum is whip-like and extends longitudinally, while the second is ribbon-like and follows a circular path in a plane about at right angles to the first (Evitt 1985, p. 26).

Key to subclasses (principally after Fensome et al. 1998):

1 Cysts tabulate....

Cysts non-tabulate

Plates not arranged into latitudinal series 
Subclass Peridiniphycidae - Dinophyceans with a tabulation which accords with, or derives from, a pattern in which there are five or six latitudinal plate series; sagittal suture lacking (Fensome et al. 1998); includes by far the majority of fossil dinoflagellate cysts, see below.

$5 \quad$ Episome and hyposome separated by a cingulum

Cingulum absent; tabulation comprising two large lateral plates plus a small apically located cluster of periflagellar platelets in a periflagellar area

Subclass Prorocentrophycidae - Dinophyceans in which the flagella are inserted apically and in which there is no cingulum or sulcus; thecal plates and a wavy flagellum, the latter being clearly homologous to the transverse flagellum of other dinoflagellates, are present (Fensome et al. 1998); no fossil record is known for this group.

7 Numerous plates, arranged in no obvious tabulation pattern other than division into episome, cingulum and hyposome

Relatively few plates; episome divisible into two latitudinal series of plates and an apical pore complex; hyposome divided into two large lateral plates by a sagittal suture

Subclass Gymnodiniphycidae - Dinophyceans in which: 1) amphiesmal vesicles are numerous and arranged nonserially or in more than six latitudinal series; or 2) the pellicle is the principal amphiesmal element; or 3) the amphiesmal structure is uncertain but does not comprise a theca divisible into six or fewer latitudinal series (Fensome et al. 1998); comprises the Gymnodiniales, Ptychodiscales, and Suessiales, all of which include fossil members though none have been encountered in the present study.

Subclass Dinophysiphycidae - Dinophyceans which possess a cingulum, sulcus and sagittal suture (Fensome et al. 1998); normally exhibits moderate to strong lateral compression; comprises the Dinophysiales, which have no certain fossil record, and the Nannoceratopsiales, which are known only from the Jurassic.

Note: The key has been constructed using only preservable characteristics, so cannot be applied to extant taxa, and without consideration of a few problematic fossil genera including Cobricosphaeridium, Prolixosphaeridium, Suibindia and Xylochoarion.

Only the subclass Peridiniphycidae includes members which are considered further herein.

\section{Subclass Peridiniphycidae Fensome et al. 1993b}

Dinophyceans with a tabulation which accords with, or derives from, a pattern in which there are five or six latitudinal plate series; sagittal suture lacking.

Key to orders (principally after Fensome et al. 1998):

1 Cells with two more or less symmetrical fundital (antapical) plates, neither being clearly dorsal to the other

Cells in which one fundital (antapical) plate is clearly in a more dorsal than the other

Order Peridiniales Haeckel 1894 - Tabulation with one or both of the following arrangements: (a) the first apical plate is symmetrical, the left lateral triple junction or pair of left lateral triple junctions being essentially level with the right lateral triple junction or pair of right lateral triple junctions; (b) there are two antapical plates, placed more or less symmetrically about the midventral (middorsal) plane. (Fensome et al. 1998)

3 Order Gonyaulacales Taylor 1980 - Tabulation with one or both of the following arrangements: (a) the first apical plate is asymmetrical, its left lateral triple junction being higher (i.e. more anterior) than the right lateral triple junction; (b) there are two to four fundital plates - always the posterior intercalary plate (1p) and first antapical plate (1'”'), sometimes the posterior sulcal homologue ( $\left.{ }^{*} \mathrm{ps}\right)$, and possibly in rare cases also the right sulcal homologue ( ${ }^{*} \mathrm{rs}$ ) or subdivisions of these plates. Among the fundital plates, 1 "'” is almost always larger and is in a clearly more dorsal position than the other(s). (Fensome et al. 1998) 


\title{
Order Peridiniales Haeckel 1894
}

\section{Suborder Peridiniineae Haeckel 1894 [autonym]}

\section{Family Peridiniaceae Ehrenberg 1831}

\section{Subfamily Deflandreoideae Bujak \& Davies 1983}

Genus Deflandrea Eisenack 1938b emend. Lentin \& Williams 1976

\author{
1938b Deflandrea Eisenack, p. 187 \\ 1966c Deflandrea Eisenack 1938 emend. Williams \& Downie, p. 231 \\ 1974 Deflandrea Eisenack 1938 emend. Stover, p. 169-170 \\ 1976 Deflandrea Eisenack 1938 emend. Lentin \& Williams, p. 35-36 \\ 1978 Deflandrea Eisenack 1938 emended Lentin \& Williams 1976; Stover \& Evitt, p. 99-101
}

Type Species: Deflandrea phosphoritica Eisenack 1938b, p. 187, text-fig. 6 [Late Eocene-Early Oligocene]

Original Description: [Given for the type species.] Deflandrea phosphoritica is characterized by its rounded inner body in apical view, oval in cross section, provided with a transverse band within its flattened, characteristically three pointed outer shell (translation from Eisenack 1938, p. 187, by Stover \& Evitt 1978, p. 99).

Remarks: Deflandrea and related genera were the subjects of a major revision by Lentin \& Williams 1976 (p. $35-$ 45 ) in which the diagnostic value of the archeopyle shape was explored thoroughly. In particular, the broad hexa style archeopyle (Text-Fig. 15) lends this genus a characteristically high transverse archeopyle index.

It seems to me, though, that Deflandrea is still in need of further work. For the present purposes, I have grouped together the species which appear similar and, indeed, to intergrade in at least some cases, such as $D$. phosphoritica and $D$. heterophlycta. I have stopped short of proposing new genera or subgenera to formalise such groupings, however. Doing so may be a very good idea, but will require a broader study than that attempted here.

The ventral episome appears to have an ortho-style configuration (Text-Fig. 16) for most Deflandrea species, and a more ambitious reassessment of the genus could make this feature a starting point for an emended diagnosis, as is attempted below for Phthanoperidinium. Although this feature is subtle and often difficult to observe, there seems no reason, in principle, to regard it as any less significant than, say, the L-type versus S-type ventral dichotomy used to classify gonyaulacaceans.

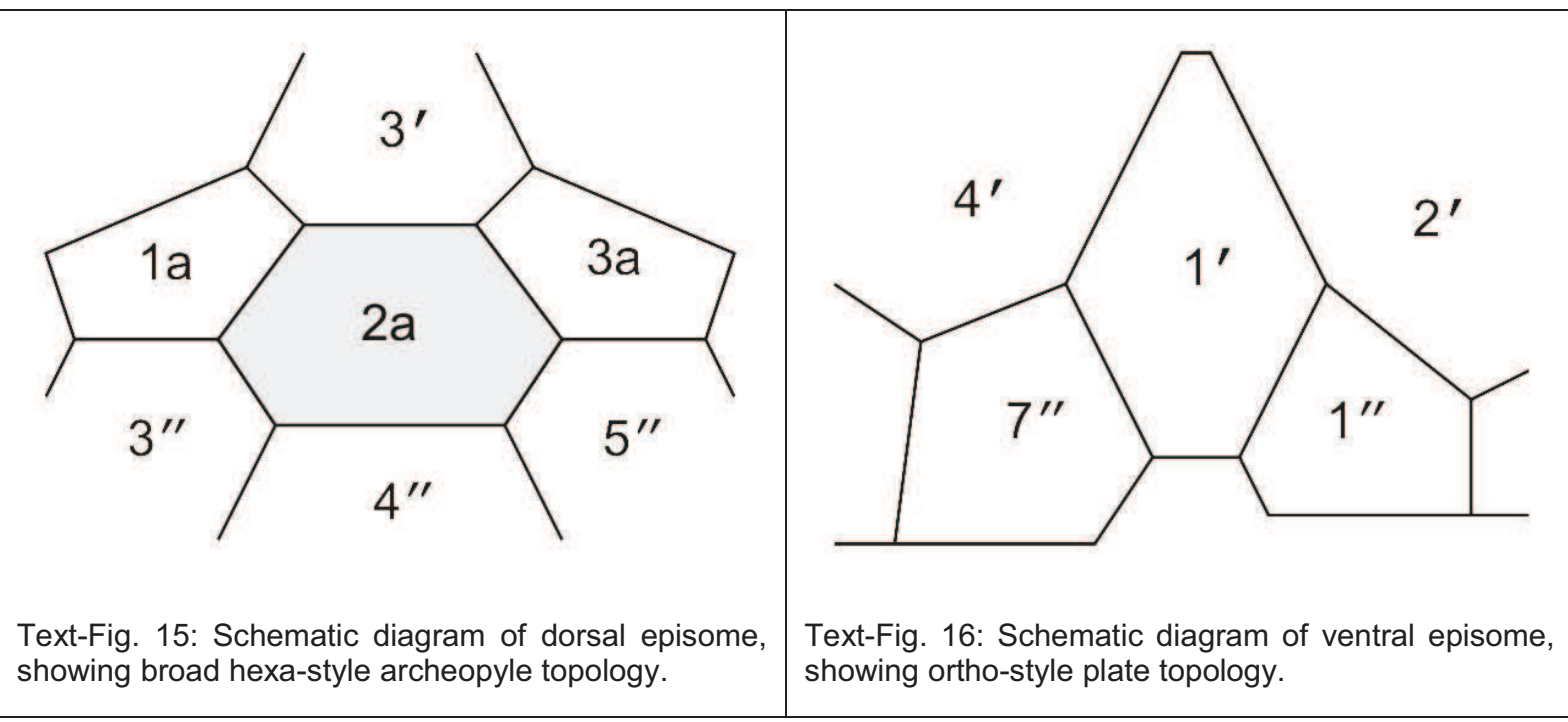

Several Australian species of Deflandrea which also occur in New Zealand are analysed in Stover 1974.

A range chart for species of Deflandrea is provided in Appendix 2, chart 3. 


\title{
Deflandrea phosphoritica Eisenack 1938b
}

\author{
PI. 6, figs. 7-12, PI. 7, figs. 1-9
}

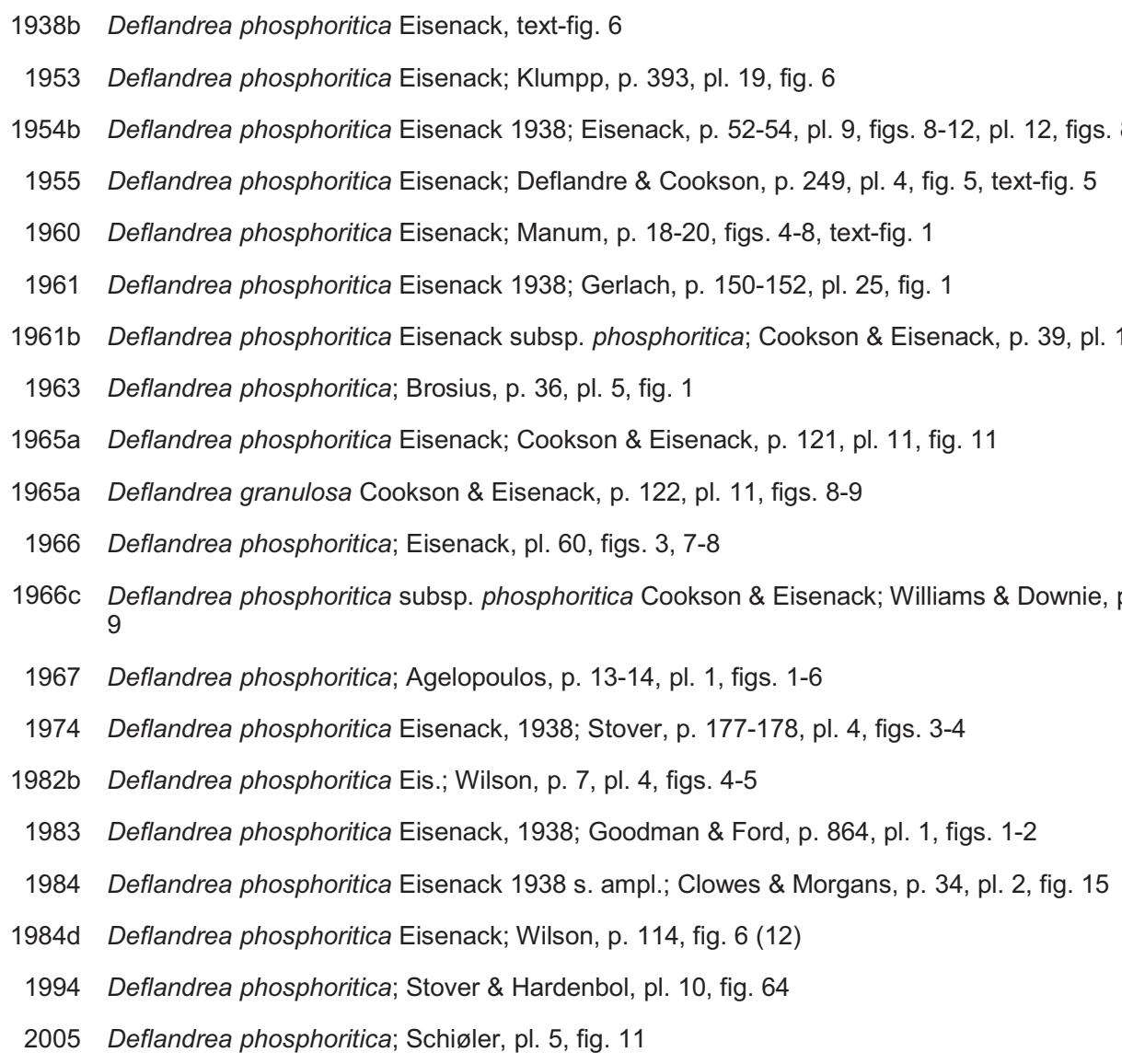

Original Description: Deflandrea phosphoritica is characterized by its rounded inner body in apical view, oval in cross section, provided with a transverse band within its flattened, characteristically three pointed outer shell (translation from Eisenack 1938, p. 187, by Stover \& Evitt 1978, p. 99).

Description of Study Material: Pericyst fairly large, with pointed apical horn and two relatively pointed antapical horns. Periphragm thin; surface ornamented with scattered grana which may be clustered or linear. Endophragm thicker, up to $2.5 \mu \mathrm{m}$; smooth. Intercalary archeopyle broad, up to $45 \mu \mathrm{m}$; operculum free, inner and outer layers adherent. Pericingulum apparent to well-defined by parallel rows of grana and by straight to concave profile in dorso-ventral view; width $\sim 7 \mu \mathrm{m}$. Sulcus prominent, broad, largely confined to hypocyst. Tabulation peridiniacean, indicated by archeopyle, cingulum, and occasionally by intratabular or penitabular clusters of grana on the pericyst; inferred formula: 4', 3a, 7", Xc, 5"', 0ps, 2"', 0-5s.

Size Range: Length = 110 (131) $175 \mu \mathrm{m}$ (29 measurements). Width = 87 (104) $117 \mu \mathrm{m}$ (9 measurements).

Distribution: Common.

The published stratigraphic range for Deflandrea phosphoritica is broad: at least early Ypresian to early Aquitanian. Previously, however, in New Zealand (pers. obs.; Graeme Wilson pers. comm.) and also in Australia (Alan Partridge pers. comm.), Deflandrea phosphoritica has generally been regarded as confined to the Middle Eocene (no older than Bartonian) and younger. Of course the first and last appearances of this, or any, taxon may be strongly diachronous, but in the case of $D$. phosphoritica there are also likely to be questions of taxonomic interpretation complicating the picture (see Remarks, below) and we must look more deeply.

For example, Crouch 2001, p. 36, records Deflandrea phosphoritica first appearing in her NZE1b subzone (early Waipawan/early Ypresian, C24r), further noting (p. 44) "[a]t Tawanui, Deflandrea phosphoritica first occurs at the $\mathrm{P} / \mathrm{E}$ boundary. This is earlier than recorded from northwest Europe, where is first occurs within the lower part of calcareous nannoplankton Zone NP10 (Bujak and Brinkhuis 1998); this suggests the species may have evolved in a Southern Hemisphere region." Whereas Crouch's pl. 3, fig. 2 (p. 52) could conceivably be dismissed as Deflandrea scabrata, which is to be expected in sediments of that age, her pl. 3, fig. 1 is much harder to ignore.

The top of its range was not pin-pointed in this study, but may occur in the lowest Oligocene (lower Rupelian) in New Zealand. 


\begin{tabular}{|c|c|c|c|}
\hline Age/Stage & Location & Sample & Sample Reference \\
\hline $\begin{array}{l}\text { middle Oligocene-middle } \\
\text { Miocene }\end{array}$ & north west Germany & $\operatorname{Pr} 1170 / 1,77$ & Gerlach 1961 \\
\hline early Oligocene & Samland, Germany & $\mathrm{Ph} 7$ & Eisenack 1954b \\
\hline early Whaingaroan & $\begin{array}{l}\text { Cape Foulwind Section, Westland, New } \\
\text { Zealand }\end{array}$ & K29/f097 (L10914) & \\
\hline early Whaingaroan & $\begin{array}{l}\text { Cape Foulwind Section, Westland, New } \\
\text { Zealand }\end{array}$ & K29/f116 (L11052) & $\begin{array}{l}\text { Clowes \& Wilson } \\
2006\end{array}$ \\
\hline early Whaingaroan & $\begin{array}{l}\text { Cape Foulwind Section, Westland, New } \\
\text { Zealand }\end{array}$ & K29/f184 (L11933) & \\
\hline early Whaingaroan & Kakanui River, Oamaru-Dunedin, New Zealand & J42/f096 (L10951) & $\begin{array}{l}\text { Clowes \& Morgans } \\
1984\end{array}$ \\
\hline $\begin{array}{l}\text { Runangan-early } \\
\text { Whaingaroan }\end{array}$ & $\begin{array}{l}\text { Cape Foulwind Section, Westland, New } \\
\text { Zealand }\end{array}$ & K29/f169 (L11918) & \\
\hline Runangan & $\begin{array}{l}\text { Cape Foulwind Section, Westland, New } \\
\text { Zealand }\end{array}$ & K29/f261 (L13543) & \\
\hline Runangan & North Otago, New Zealand & SM422 & Wilson 1984d \\
\hline Runangan & $\begin{array}{l}\text { Cape Foulwind Section, Westland, New } \\
\text { Zealand }\end{array}$ & K29/f102 (L11038) & \\
\hline Runangan & Kakanui River, Oamaru-Dunedin, New Zealand & J42/f098 (L10953) & $\begin{array}{l}\text { Clowes \& Morgans } \\
1984\end{array}$ \\
\hline Runangan & $\begin{array}{l}\text { Cape Foulwind Section, Westland, New } \\
\text { Zealand }\end{array}$ & K29/f262 (L13546) & \\
\hline late Eocene & Wöhrden & W-622-a & Klumpp 1953 \\
\hline Bortonian & $\begin{array}{l}\text { Hampden Beach Section, Oamaru-Dunedin, } \\
\text { New Zealand }\end{array}$ & J42/f057 (L09214) & Wilson 1985 \\
\hline Bortonian & $\begin{array}{l}\text { Puketeraki Core, Oamaru-Dunedin, New } \\
\text { Zealand }\end{array}$ & I43/f093 (L16341) & $\begin{array}{l}\text { Wilson \& McMillan } \\
1996\end{array}$ \\
\hline Bortonian & $\begin{array}{l}\text { Hampden Beach Section, Oamaru-Dunedin, } \\
\text { New Zealand }\end{array}$ & J42/f048 (L09205) & Wilson 1985 \\
\hline Bortonian & $\begin{array}{l}\text { Puketeraki Core, Oamaru-Dunedin, New } \\
\text { Zealand }\end{array}$ & I43/f089 (L16337) & $\begin{array}{l}\text { Wilson \& McMillan } \\
1996\end{array}$ \\
\hline
\end{tabular}

Remarks: Deflandrea phosphoritica is at once one of the most familiar dinoflagellate cyst species - almost every study of Eocene material reports it - and one of the most problematic. One source of confusion extends back to at least 1954 when Eisenack incorrectly nominated, as the holotype, a specimen other than that illustrated in his original 1938 publication of the name. Nomenclatural rules require that the holotype of $D$. phosphoritica is the specimen illustrated in Eisenack 1938b, text-fig. 6, and Eisenack 1954b, pl. 9, fig. 11, rather than the specimen Eisenack explicitly designated subsequently (Eisenack 1954b, pl. 9, fig. 8; refer to his figure caption on p. 91).

The distinction is important because there may be more than one species involved. It is quite clear that Eisenack favoured forms with a broad pentagonal "jodhpur" outline to the periphragm as best exemplifying this taxon (e.g. Eisenack 1954b, p. 52-54, pl. 9, fig. 8; Eisenack 1966, pl. 60, figs. 3, 7-8; also see Text-Fig. 17, herein). This particular form differs from the New Zealand pentagonal forms attributed herein to Deflandrea phosphoritica, in possessing a seemingly perfectly smooth periphragm and a periarcheopyle which extents upwards almost to the tip of the apical horn, but is otherwise the same.

Another source of difficulty is immediately apparent from a review of the plates. It is evident that $D$. phosphoritica intergrades with several other forms in shape and in the ornamentation of the endocyst.

So, what is Deflandrea phosphoritica? And is it confined to only the uppermost Eocene and early Oligocene or does it extend into older rocks? Several dimensions of the variation discussed above are represented in Text-Fig. 18. There may be some agesignificance in this variation, though it is not easy to discern any linear trends.

Deflandrea granulosa is identified as a junior synonym by Stover 1974 (p. 177). Observations made in the

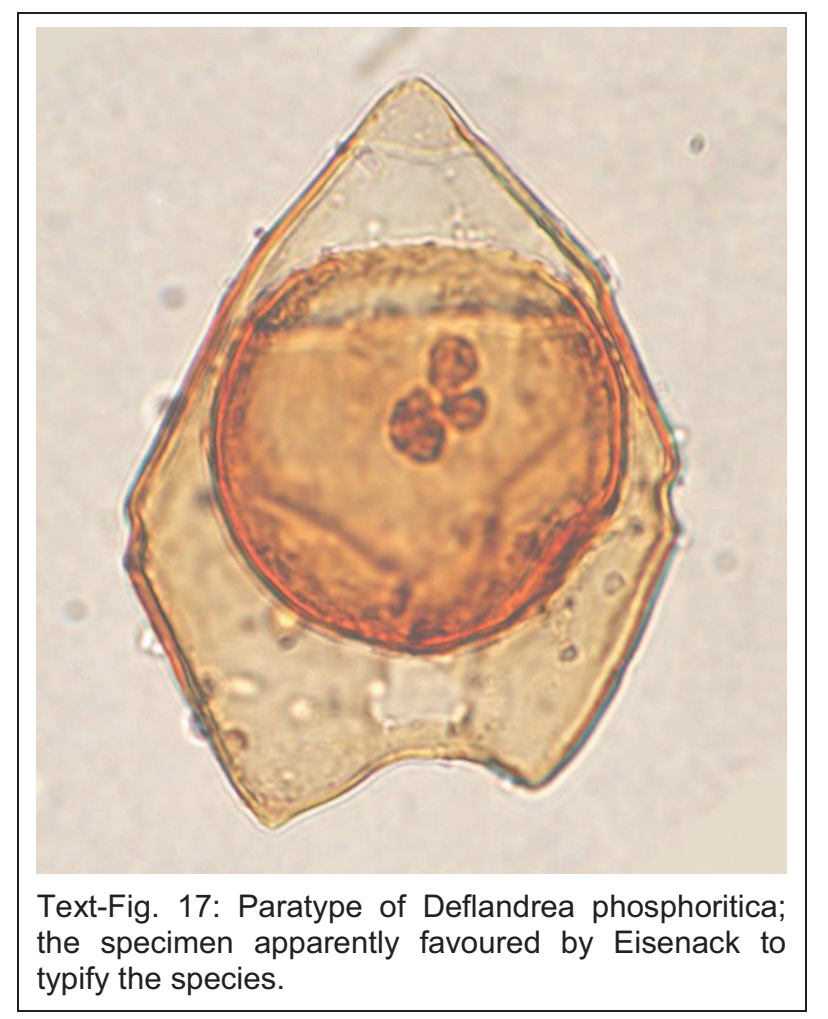


course of this study are quite consistent with this view.

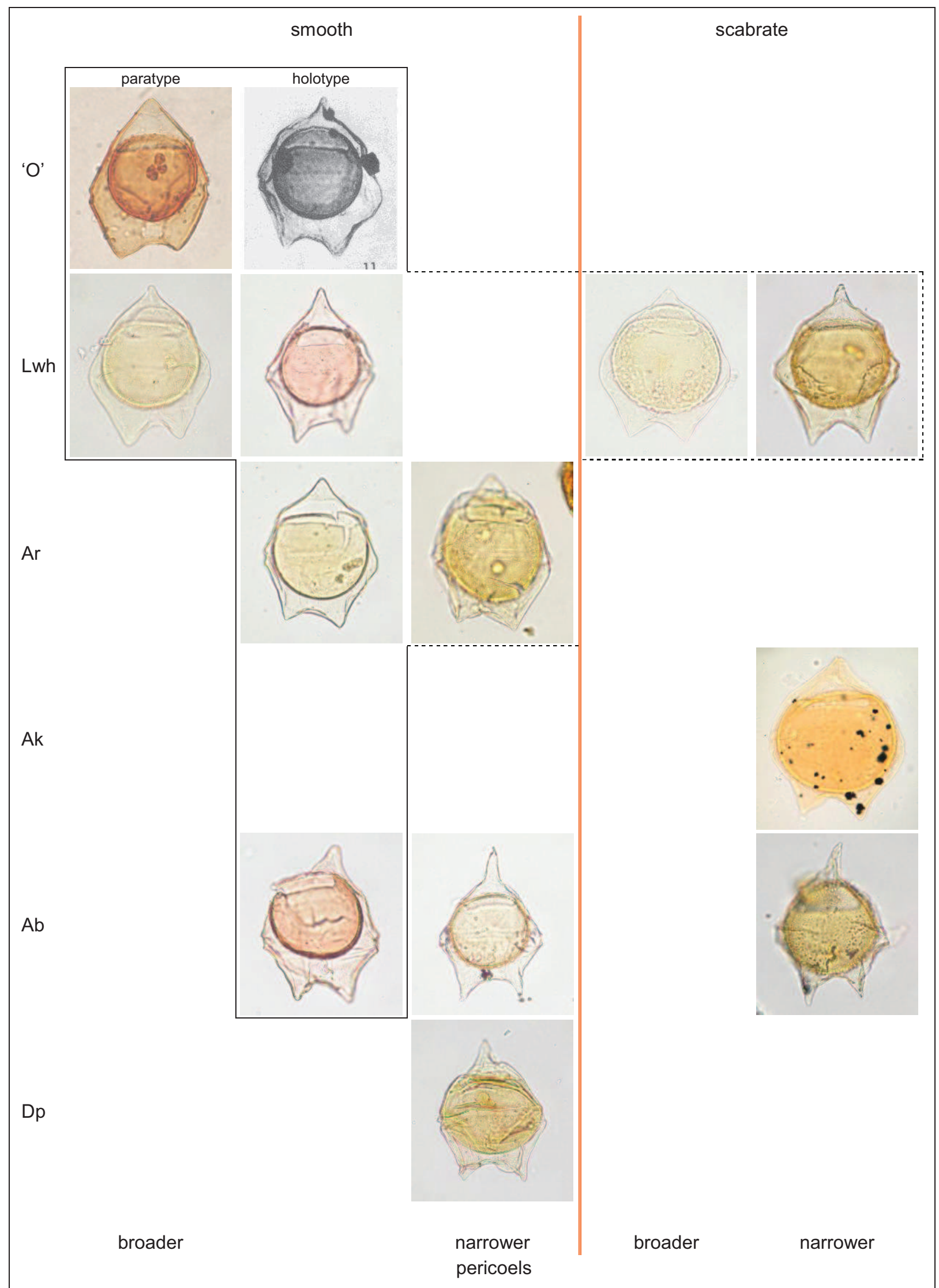

Text-Fig. 18: Diagram showing variation in forms resembling Deflandrea phosphoritica. 
2005 Deflandrea heterophlycta Deflandre \& Cookson 1955; Heilmann-Clausen \& Van Simaeys, pl. 3, fig. 10

Description of Study Material: Cysts large, proximate, only slightly dorso-ventrally compressed, outline peridinioid, with one apical and two antapical horns; episome and hyposome more or less equal in length. Apex more or less conical, episome more or less straight-sided; antapical horns strongly developed. Lateral pericoels strongly developed. Archeopyle intercalary, type I (2a); eurydeltaform. Surface of endophragm verrucate. Tabulation peridiniacean, inferred formula: 4', 3a, 7", Xc, 5"', 0ps, 2'"', 0-5s. Cingulum moderately expressed, indicated by folds in the periphragm, 10-12 $\mu \mathrm{m}$ wide; offset not readily visible on ventral surface.

Size Range: Length including any processes $=123$ (134) $149 \mu \mathrm{m}$ (6 measurements). Width including any processes $=102$ (109) $117 \mu \mathrm{m}$ (6 measurements).

\section{Distribution:}

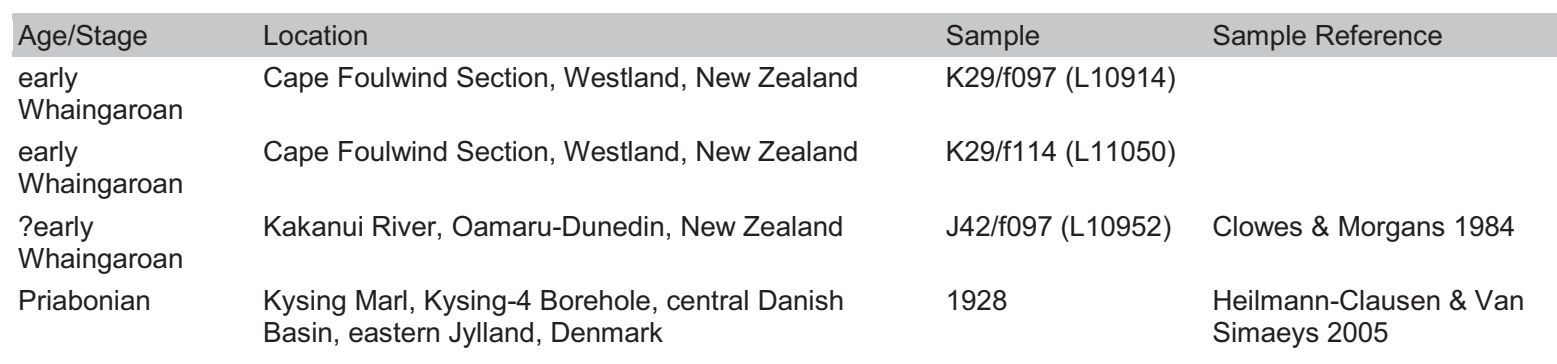

Remarks: A ?variety of Deflandrea phosphoritica having a scabrate endocyst, but retaining all other characters of the species, notably the characteristic periphragm outline and associated relative development of the pericoels (cf. D. heterophlycta).

Cookson \& Eisenack 1965a, p. 121, comments "Specimens with the general characteristics of D. phosphoritica, but with tuberculate thickenings on the wall of the capsule, similar to, but less prominent than those of $D$. heterophlycta, are not uncommon in the upper beds of the Browns Creek section. Furthermore, the shape of the shell differs from that of the holotype of $D$. heterophlycta and more particularly that of additional specimens of this species recently isolated from the type locality at Castle Cove, Victoria."

The authors were clearly making a distinction between a scabrate $D$. phosphoritica and $D$. heterophlycta, most usefully on the basis of its different periphragm shape. Such a distinction is supported by observations from the present study, but, although some specimens of the "scabrate $D$. phosphoritica" differ markedly from $D$. heterophlycta in possessing a far more pronounced cingulum underlain by well-developed pericoels, it will be seen that many intermediates (e.g. PI. 8, figs. 1-3) provide an insensible gradation from one to the other.

\section{Deflandrea ?heterophlycta Deflandre \& Cookson 1955}

$$
\text { PI. 8, figs. 7-12, PI. 9, figs. 1-9 }
$$

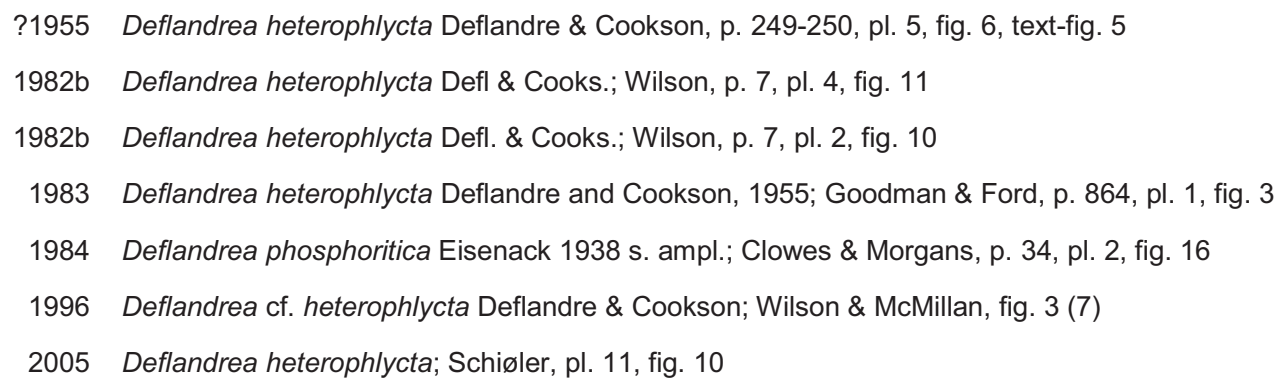

Original Description: Epitheca broadly conical with slightly convex flanks and a somewhat rounded, unthickened apex; hypotheca a little smaller than the epitheca and provided with 2 short, blunt, slightly divergent horns. Transverse girdle clear but shallow. Cyst spheroidal, ornamented with irregularly dispersed tubercles more numerous and coarser towards the poles. Cyst membrane finely punctate. Opening laterally extended situated towards the apical pole. Membrane of theca very finely and sparsely punctate (Deflandre \& Cookson 1955, p. 249-250).

Description of Study Material: Cysts large, proximate, only slightly dorso-ventrally compressed, outline peridinioid, with one apical and two antapical horns. Apical horn well developed, apex more or less conical to 
pointed, episome somewhat attenuated to markedly attenuated; antapical horns strongly developed, relatively pointed. Cyst wall two-layered; circumcavate, lateral pericoels developed to strongly developed; endophragm thicker than periphragm, up to $2.5 \mu \mathrm{m}$ in thickness. Archeopyle intercalary, type I (2a); eurydeltaform; operculum free, inner and outer layers adherent. Processes lacking; surface ornament present, non-tabular, comprising scattered grana; occasionally forming lineations, especially along the margins of the cingulum. Surface of endophragm scabrate to tuberculate, often coarser below the cingulum. Tabulation weak to lacking, peridiniacean, inferred formula: 4', 3a, 7", Xc, 5"', 0ps, 2"'", Xs. Cingulum clearly expressed, indicated by shape of the periphragm, 8-10 $\mu \mathrm{m}$ wide. Sulcus clearly expressed, indicated by depression of the periphragm; largely confined to the hyposome.

Size Range: Length including any processes $=98$ (118) $153 \mu \mathrm{m}$ (33 measurements). Width including any processes $=82(90) 100 \mu \mathrm{m}$ (8 measurements).

Distribution:

\begin{tabular}{|c|c|c|c|}
\hline Age/Stage & Location & Sample & Sample Reference \\
\hline early Whaingaroan & Cape Foulwind Section, Westland, New Zealand & K29/f115 (L11051) & \\
\hline early Whaingaroan & Cape Foulwind Section, Westland, New Zealand & K29/f114 (L11050) & \\
\hline $\begin{array}{l}\text { Runangan-early } \\
\text { Whaingaroan }\end{array}$ & Kakanui River mouth & & $\begin{array}{l}\text { Clowes \& Morgans } \\
1984\end{array}$ \\
\hline Bortonian & $\begin{array}{l}\text { Hampden Beach Section, Oamaru-Dunedin, New } \\
\text { Zealand }\end{array}$ & J42/f061 (L09218) & Wilson 1985 \\
\hline Bortonian & Puketeraki Core, Oamaru-Dunedin, New Zealand & I43/f094 (L16342) & $\begin{array}{l}\text { Wilson \& McMillan } \\
1996\end{array}$ \\
\hline Bortonian & $\begin{array}{l}\text { Hampden Beach Section, Oamaru-Dunedin, New } \\
\text { Zealand }\end{array}$ & J42/f055 (L09212) & Wilson 1985 \\
\hline Bortonian & Puketeraki Core, Oamaru-Dunedin, New Zealand & I43/f089 (L16337) & $\begin{array}{l}\text { Wilson \& McMillan } \\
1996\end{array}$ \\
\hline
\end{tabular}

Remarks: Deflandre \& Cookson 1955 illustrates the holotype of Deflandrea heterophlycta with a line drawing (text-fig. 5). The specimen appearing in the plates (pl. 5, fig. 6) is a paratype: an isolated endocyst. To the best of my knowledge, there is no published photograph of the holotype. Topotype material (Castle Cove, Victoria, Australia) subsequently illustrated by Cookson \& Eisenack 1965a (pl. 12, figs. 1-4), however, appears quite similar to the line drawing of the holotype.

As noted above, Cookson \& Eisenack 1965a, p. 121, distinguished between scabrate forms of Deflandrea phosphoritica and $D$. heterophlycta, the former having "tuberculate thickenings on the wall of the capsule, similar to, but less prominent than those of $D$. heterophlycta" and a different shape to the periphragm. As noted above, the periphragm shape is continuously variable across both smooth and scabrate/tuberculate forms. Subsequent studies suggest that the prominence of the tuberculae may be highly variable and, in fact, those of the Castle Cove (holotype and topotype) specimens appear quite extreme compared to most other published material. Specimens of $D$. heterophlycta recovered from the Gippsland Basin rarely exhibit tubercles as tall as those of the type, more typically resembling the present form (Alan Partridge pers. comm.)

The present material is considerably less tuberculate than the Castle Cove specimens, but agrees in other respects with the concept of $D$. heterophlycta as usually applied in Australasia.

Deflandrea ?heterophlycta differs from Deflandrea scabrata Wilson 1988 in lacking the thick (up to $6 \mu \mathrm{m}$ ), spongy endocyst.

\section{Deflandrea sp. 3}

$$
\text { PI. 9, figs. 10-12, PI. 10, figs. 1-9 }
$$

Description: Cysts large, proximate, only slightly dorso-ventrally compressed, outline peridinioid, with one apical and two antapical horns; episome and hyposome more or less equal in length. Apex more or less attenuated, episome more or less straight-sided; antapical horns strongly developed and also somewhat attenuated. Lateral pericoels moderately to strongly developed. Archeopyle intercalary, type I (2a); eurydeltaform. Surface of endophragm finely to moderately scabrate. Tabulation peridiniacean, inferred formula: 4', 3a, 7", Xc, 5"', 0ps, 2"'", $0-5 \mathrm{~s}$. Cingulum well expressed by folds in the periphragm, $\sim 10 \mu \mathrm{m}$ wide; offset not readily visible on ventral surface.

Size Range: Length including any processes $=127$ (127) $127 \mu \mathrm{m}$ (3 measurements). Width including any processes $=82(85) 88 \mu \mathrm{m}$ (3 measurements).

Distribution: Infrequent.

$\begin{array}{llll}\text { Age/Stage } & \text { Location } & \text { Sample } & \text { Sample Reference } \\ \text { Bortonian } & \text { Puketeraki Core, Oamaru-Dunedin, New Zealand } & \text { I43/f089 (L16337) } & \text { Wilson \& McMillan } 1996\end{array}$




$\begin{array}{llll}\text { Age/Stage } & \text { Location } & \text { Sample } & \text { Sample Reference } \\ \text { Porangan } & \text { Hampden Beach Section, Oamaru-Dunedin, New Zealand } & \text { J42/f300 (L23130) }\end{array}$

Remarks: Differs from Deflandrea phosphoritica in its longer, more attenuated horns, especially the apical horn, and from Deflandrea oebisfeldensis in having a smaller antapical pericoel which is more wholly incorporated into the antapical horns.

\section{Deflandrea cygniformis Pöthe de Baldis 1966}

$$
\text { PI. 10, figs. 10-12, PI. 11, figs. 1-3 }
$$

1966 Deflandrea cygniformis Pöthe de Baldis, p. 221, pl. 2, fig. c

1975 Deflandrea cygniformis Pöthe de Baldis; Haskell \& Wilson, pl. 1, fig. 14

cf. 1984b Deflandrea cf. D. cygniformis Pöthe de Baldis, 1966; Helenes, p. 94, 104, pl. 5, figs. 15-16

1988 Deflandrea cygniformis Pöthe de Baldis 1966 Wrenn \& Hart, p. 350, fig. 20, 2-5, fig. 21, 1-4, fig. 42, 3-5, fig. 44,

?2000 Deflandrea cf. D. cygniformis Pöthe de Baldis, 1966; Levy \& Harwood, p. 206, pl. 3, figs. d-e

Original Description: [Diagnosis] Theca fusiform and elongated, surface finely granulated. Epitheca three times larger than the hypotheca. Hypotheca with poorly defined antapical appendages, which terminate in an irregular edge. Cyst sub-rounded, large, occupying a little more than half of the specimen. The opening of the dorsal face is also large and ovoid. The cingulum is narrow, poorly demarcated with a smooth edge.

[Description] All specimens examined possess, in general, the same characteristics, although some variations exist with respect to the length of the epitheca with respect to the rest of the theca, but nevertheless maintaining this variation within specific characters. The theca has a pentagonal outline, is fusiform, and may exhibit either granulate or somewhat plain surface. The epitheca is much higher than the hypotheca. After separating itself from the cyst, the epitheca converges smoothly and uniformly, forming a long neck. In its lower part the epitheca is separated a little from the cyst, whereas the hypotheca is found completely separated from it. The cingulum is excavated and its border is plain or very finely granulate. The cyst is of oval form, and its larger diameter is the transverse. In all the samples observed one does not observe a good development of the antapical appendages, from which it is believed that the form in which they are found is their typical form. The antapical appendages are united, forming an irregular border (translated from Pöthe de Baldis 1966, p. 221).

Description of Study Material: Cysts large, proximate, not appreciably dorso-ventrally compressed, outline peridinioid, with one apical horn; episome much longer than hyposome. Apical horn extraordinarily developed, apex pointed, episome markedly attenuated; antapical horns weak to lacking. Lateral pericoels developed. Archeopyle intercalary, type I (2a); eurydeltaform. Tabulation peridiniacean, inferred formula: 4', 3a, 7", Xc, 5"', 0ps, 2"'", 0-5s. Cingulum clearly expressed, indicated by shape of the periphragm. Sulcus weakly expressed to moderately expressed, indicated by folds in the periphragm.

Size Range: Length including any processes $=120 \mu \mathrm{m}$ (one measured specimen). Width including any processes $=72 \mu \mathrm{m}$ (one measured specimen).

Distribution: Very rarely encountered in this study. The global distribution of $D$. cygniformis includes a number of southern and, possibly, Pacific localities, and at least some correspondence with elements of the Trans-Antarctic assemblage (Appendix 3).

$\begin{array}{llll}\text { Age/Stage } & \text { Location } & \text { Sample } & \text { Sample Reference } \\ \begin{array}{l}\text { late middle Eocene-late } \\ \text { Eocene }\end{array} & \text { northern Seymour Island, West Antarctica } & 8455 & \text { Wrenn \& Hart 1988 } \\ \text { late middle Eocene-late } & \text { northern Seymour Island, West Antarctica } & 8479 & \text { Wrenn \& Hart 1988 }\end{array}$

Eocene

Bortonian Hampden Beach Section, Oamaru-Dunedin, New

J42/f488 (L23123) Zealand

Lutetian Bateque Formation; Sebastian Vizcaino Basin, Baja California

Eocene erratics, McMurdo Sound, Antarctica

MTD 42

Helenes 1984b

Levy \& Harwood 2000

Remarks: A distinctive taxon, though apparently very rare on mainland New Zealand.

Wrenn \& Hart 1988 (p. 350) notes that " $D$. cygniformis is similar to $D$. antarctica and may prove to be an evolutionary offshoot of that species." To me, however, they look no more similar than any other pair of Deflandrea species, and less so than many. 


\title{
Deflandrea sp. 4
}

\section{PI. 11, figs. 4-6}

Description: Cysts large, proximate, somewhat dorso-ventrally compressed, outline peridinioid, with one apical and two antapical horns; episome slightly longer than the hyposome. Apex slightly attenuated; antapical horns well developed, rounded, sub-equal. Pericoels characterised by numerous lamellae apparently connecting the endocoel with the periphragm, imparting a reticulate pattern to the latter when viewed end-on; lateral pericoels well developed. Archeopyle intercalary, type I (2a); eurydeltaform. Surface of endophragm smooth to finely scabrate (the described specimen may be somewhat corroded). Tabulation not indicated by any surface features or by the pericoel lamellae; assumed to be peridiniacean. Cingulum moderately expressed by folds in the periphragm, $\sim 12 \mu \mathrm{m}$ wide; offset not readily visible on ventral surface.

Size Range: Length including any processes $=117 \mu \mathrm{m}$ (one measured specimen). Width including any processes $=92 \mu \mathrm{m}$ (one measured specimen).

Distribution: Extremely rare. Known from a single specimen only.

\begin{tabular}{llll}
\hline Age/Stage & Location & Sample & Sample Reference \\
early Whaingaroan & Cape Foulwind Section, Westland, New Zealand & K29/f114 (L11050) &
\end{tabular}

Remarks: The single specimen of this form is remarkable for highly unusual infilling between the endocyst and periphragm. It is unknown if it is a genuine character or a taphonomic effect.

\section{Deflandrea antarctica Wilson 1967a}

\section{PI. 11, figs. 7-12}

\author{
1967a Deflandrea antarctica Wilson, p. 58, 60, figs. 23-24, 26-27 \\ 1975 Deflandrea antarctica Wilson; Haskell \& Wilson, pl. 1, fig. 12 \\ 1982c Deflandrea antarctica Wilson; Wilson, p. 4, pl. 1, figs. 1-4 \\ 1983 Deflandrea antarctica Wilson, 1967; Goodman \& Ford, p. 864, pl. 1, figs. 4-6 \\ 1988 Deflandrea antarctica Wilson 1967; Wrenn \& Hart, p. 349, fig. 19, 1-4, fig. 44, 3 \\ 1989 Deflandrea antarctica Wilson; Wilson, pl. 1, fig. 1 \\ 2000 Deflandrea antarctica Wilson, 1967; Levy \& Harwood, p. 204, 206, pl. 2, figs. c-e, pl. 3, figs. a-c
}

Original Description: Test peridinioid in shape, bi-layered, divided into epitheca and hypotheca by a slightly laevorotatory transverse girdle. Apical horn broad at base, narrow at apex which is usually capped with a small papilla; antapical horns short, approximately equal in size. Outer cyst usually covered with numerous granules forming a dotted pattern. Inner cyst fairly thick-walled, smooth, and approximately circular in outline. Archeopyle broad, intercalary, subhexagonal. Operculum free, bi-layered; inner layer smaller, denser, and of more regular shape than the membranous outer layer; the large and small layers of the operculum represent segments of the outer and inner cysts respectively.... Apparently atabulate, although granules sometimes concentrated into polygonal clusters possibly indicative of reflected tabulation (Wilson 1967a, p. 58, 60; ellipses replace figure references in the original).

Description of Study Material: Cysts large, proximate, not dorso-ventrally compressed, outline peridinioid, with one apical horn; episome longer than hyposome. Apex with nipple-like projection, episome inflated (more or less bell-shaped); antapical horns weak to lacking. Lateral pericoels weakly developed. Archeopyle intercalary, type I (2a); eurydeltaform; operculum free. Tabulation peridiniacean, inferred formula: 4', 3a, 7", Xc, 5"', 0ps, 2"'", 0-5s. Cingulum moderately expressed, indicated by shape of the periphragm.

Size Range: Length including any processes = 105 (115) $125 \mu \mathrm{m}$ (4 measurements). Width including any processes $=65 \mu \mathrm{m}$ (one measured specimen).

Distribution: The strict form of $D$. antarctica (see remarks provided under $D$. aff. antarctica, below), though widely reported from Antarctica and environs, is apparently quite rare on the New Zealand mainland.

$\begin{array}{llll}\text { Age/Stage } & \text { Location } & \text { Sample } & \text { Sample Reference } \\ \text { Bortonian } & \text { Hampden Beach Section, Oamaru-Dunedin, New Zealand } & \text { J42/f048 (L09205) } & \text { Wilson 1985 } \\ \text { Bortonian } & \text { Hampden Beach Section, Oamaru-Dunedin, New Zealand } & \text { J42/f488 (L23123) } & \\ \text { mid Eocene } & \text { DSDP Leg 71, Falkland Plateau, south Atlantic Ocean } & \text { 512-18-3, 14-16 cm } & \text { Goodman \& Ford 1983 } \\ \text { Heretaungan } & \text { Hampden Beach Section, Oamaru-Dunedin, New Zealand } & \text { J42/f039 (L09196) } & \text { Wilson 1985 } \\ \text { late early Eocene } & \text { northern Seymour Island, West Antarctica } & 8465 & \text { Wrenn \& Hart 1988 }\end{array}$




$\begin{array}{llll}\text { Age/Stage } & \text { Location } & \text { Sample } & \text { Sample Reference } \\ \text { late early Eocene } & \text { northern Seymour Island, West Antarctica } & 8506 & \text { Wrenn \& Hart 1988 } \\ \text { Mangaorapan } & \text { Oxford area, central Canterbury, New Zealand } & \text { SM1556, 1645 } & \text { Wilson 1982c } \\ \text { Eocene } & \text { CIROS-1 drillhole, McMurdo Sound, Antarctica } & \text { SM3781 } & \text { Wilson 1989 } \\ \text { Eocene } & \text { erratics near Minna Bluff, McMurdo Sound, Antarctica } & \text { L4737 } & \text { Wilson 1967a } \\ \text { Eocene } & \text { erratics, McMurdo Sound, Antarctica } & \text { MTD 1B } & \text { Levy \& Harwood 2000 } \\ \text { Eocene } & \text { erratics, McMurdo Sound, Antarctica } & \text { MTD 42 } & \text { Levy \& Harwood 2000 }\end{array}$

\title{
Deflandrea aff. antarctica
}

PI. 12, figs. 1-3

\author{
1967 Deflandrea oebisfeldensis Alberti; Cookson \& Cranwell, p. 205, pl. 1, figs. 1-4 \\ 1988 Deflandrea antarctica Wilson, 1967; Wilson, p. 17, pl. 5, figs. 5-7
}

Description: Cysts large, proximate, outline peridinioid, with one apical and two antapical horns; episome much longer than hyposome. Apex more or less conical, episome more or less straight-sided; antapical horns weak to lacking. Lateral pericoels weak to lacking. Archeopyle intercalary, type I (2a); eurydeltaform. Inferred formula: 4', $3 \mathrm{a}, 7$ ", Xc, 5"', Ops, 2"', 0-5s. Cingulum moderately expressed, indicated by folds in the periphragm.

Description of Study Material: Cysts large, proximate, outline peridinioid, with one apical and two antapical horns; episome much longer than hyposome. Apex more or less conical, episome more or less straight-sided; antapical horns weak to lacking. Lateral pericoels weak to lacking. Archeopyle intercalary, type I (2a); eurydeltaform. Tabulation peridiniacean, inferred formula: 4', 3a, 7", Xc, 5"', 0ps, 2"', 0-5s. Cingulum moderately expressed, indicated by folds in the periphragm.

Size Range: Length including any processes $=123$ (137) $150 \mu \mathrm{m}$ (7 measurements). Width including any processes $=68 \mu \mathrm{m}$ (one measured specimen).

Distribution: Common.

\begin{tabular}{|c|c|c|c|}
\hline Age/Stage & Location & Sample & Sample Reference \\
\hline $\begin{array}{l}\text { late Eocene- } \\
\text { Oligocene }\end{array}$ & $\begin{array}{l}\text { Leña Dura Formation, Río Leña Dura valley, SW of } \\
\text { Punta Arenas, Chile }\end{array}$ & JSB-56 & $\begin{array}{l}\text { Cookson \& Cranwell } \\
1967\end{array}$ \\
\hline Bortonian & $\begin{array}{l}\text { Hampden Beach Section, Oamaru-Dunedin, New } \\
\text { Zealand }\end{array}$ & J42/f048 (L09205) & Wilson 1985 \\
\hline Porangan-Bortonian & $\begin{array}{l}\text { Hampden Beach Section, Oamaru-Dunedin, New } \\
\text { Zealand }\end{array}$ & J42/f301 (L23131) & \\
\hline Porangan-Bortonian & $\begin{array}{l}\text { Hampden Beach Section, Oamaru-Dunedin, New } \\
\text { Zealand }\end{array}$ & J42/f485 (L23120) & \\
\hline Porangan & Te Uri Stream, Hawkes Bay, New Zealand & U24/f419 (L23127) & \\
\hline Porangan & Te Uri Stream, Hawkes Bay, New Zealand & U24/f418 (L23126) & \\
\hline Porangan & Waipawa standard section, Hawkes Bay, New Zealand & V22/f7401 (L976) & Wilson 1988 \\
\hline Heretaungan & $\begin{array}{l}\text { Hampden Beach Section, Oamaru-Dunedin, New } \\
\text { Zealand }\end{array}$ & J42/f039 (L09196) & Wilson 1985 \\
\hline Waipawan & Waipawa standard section, Hawkes Bay, New Zealand & V22/f7400 (L12098) & Wilson 1988 \\
\hline
\end{tabular}

Remarks: Deflandrea antarctica s.s. (erratics, Minna Bluff, Antarctica; Wilson 1967a) is characterised by an inflated, bell-shaped episome capped by a small, nipple-like horn, which is very distinctive. Later, however, Wilson (1988) illustrated a slightly different form, also under the name $D$. antarctica, which differs from the type material in possessing an essentially straight-sided, conical episome. He explained his identification of the two morphotypes by noting that "[t]he type Antarctic material possesses a more rounded epicyst with a short apical horn, although that material varies more than is indicated by the illustrated specimens (Wilson 1967a and unpublished data)" (Wilson 1988, p. 17).

Between Deflandrea antarctica s.s. and D. antarctica sensu Wilson 1988 lies a range of forms, here recorded as Deflandrea aff. antarctica, in which the shape of the episome varies, apparently continuously, between the two extremes. It is difficult to assign any age significance to the difference, owing to continuing uncertainty over exact age correlation between assemblages from Antarctica (typically confused by wholesale reworking) and those from lower latitudes, including New Zealand.

Wilson 1988, p. 17 , notes that Deflandrea antarctica - both s.s. and s.l. varieties - "is possibly conspecific with" Deflandrea flounderensis Stover 1974. However, he did not formally propose synonymy.

As further noted by Wilson (1988, p. 17), "Deflandrea medcalfii Stover is similar in many respects but differs in having a longer and narrower apical horn, a smooth and thinner endophragm, and by having distinctly separated, longer, antapical horns." 


\title{
Deflandrea convexa Wilson 1988
}

\author{
PI. 12, figs. 4-12
}

1988

Deflandrea convexa Wilson, p. 17, pl. 6, figs. 3-5

Original Description: Pericyst intermediate to large, ovoidal, elliptical to almost circular in dorso-ventral view with a subrounded apex and broadly convex antapical margin lacking horns. Surface finely reticulate, 1-1.5 $\mu \mathrm{m}$ thick. Paracingulum may be defined by lineation of reticulum; on other specimens it is not seen. Parasulcus defined by narrow smooth area on ventral surface of some specimens. Endocyst circular, smooth, slightly thicker walled than pericyst $(2-3 \mu \mathrm{m})$. Narrow pericoels (length up to $12 \mu \mathrm{m})$ are developed only at the apex and antapex. Intercalary archeopyle broad (width $37-42 \mu \mathrm{m}$ ), hexagonal; operculum free and comprises two adherent pieces from periphragm and endophragm (Wilson 1988, p. 17).

Description of Study Material: Cysts of intermediate size, proximate, somewhat dorso-ventrally compressed, outline peridinioid, with one apical horn; episome longer than hyposome. Apex rounded to subconical, episome more or less straight-sided; antapical horns weak to lacking. Lateral pericoels absent. Archeopyle intercalary, type I (2a); eurydeltaform. Tabulation not indicated by surface features; assumed to be peridiniacean. Generally not indicated.

Size Range: Length including any processes $=66$ (91) $105 \mu \mathrm{m}$ (15 measurements). Width including any processes $=61(80) 98 \mu \mathrm{m}(11$ measurements $)$.

Distribution: Infrequent. Generally infrequent, but one notable sample (L23126, U24/f418) is dominated by the species.

\begin{tabular}{llll}
\hline Age/Stage & Location & Sample & Sample Reference \\
Bortonian & Hampden Beach Section, Oamaru-Dunedin, New Zealand & J42/f061 (L09218) & Wilson 1985 \\
Bortonian & Puketeraki Core, Oamaru-Dunedin, New Zealand & I43/f093 (L16341) & Wilson \& McMillan 1996 \\
Bortonian & Puketeraki Core, Oamaru-Dunedin, New Zealand & I43/f090 (L16338) & Wilson \& McMillan 1996 \\
Porangan & Hampden Beach Section, Oamaru-Dunedin, New Zealand & J42/f300 (L23130) & \\
Porangan & Te Uri Stream, Hawkes Bay, New Zealand & U24/f418 (L23126) &
\end{tabular}

Remarks: The strict form is relatively old - Porangan to perhaps earliest Bortonian - but there is also a younger form higher in the Bortonian (PI. 12, figs. 10-12) which looks very similar but may differ systematically in possessing a hypopericoel which extends up and laterally as far as the cingulum.

\section{Deflandrea ?leptodermata Cookson \& Eisenack 1965a}

\section{PI. 13, figs. 1-3}

\author{
?1965a Deflandrea leptodermata Cookson \& Eisenack, p. 121-122, pl. 11, figs. 6-7 \\ 1974 Deflandrea leptodermata Cookson \& Eisenack, 1965; Stover, p. 177, pl. 5, figs. 1a, 1b \\ 1984 Deflandrea aff. 'leptodermata' sensu Stover 1974; Clowes \& Morgans, p. 34, pl. 2, fig. 14 \\ 2005 Deflandrea leptodermata; Schiøler, pl. 15, fig. 11-12
}

Original Description: Shell untabulated, longer than broad with strongly convex sides, a short blunt apical horn and two short, broad, slightly pointed antapical horns. Girdle usually not indicated. Wall of shell thin, distinctly granular. Capsule large, circular in outline, almost filling the shell, wall very thin and densely granular. Archeopyle usually indistinctly outlined, broader than long, possibly 6-sided. In the specimen shown in PI. 11, fig. 7 [the single paratype, like the holotype, apparently badly corroded] the basal suture of the archeopyle is evident as a fine line crossing the upper part of the shell at a right angle (Cookson \& Eisenack 1965a, p. 121-122).

Description of Study Material: Cysts large, proximate, somewhat dorso-ventrally compressed, outline peridinioid, with one apical and two antapical horns; episome longer than hyposome. Apex rounded to subconical, episome more or less straight-sided; antapical horns developed. Lateral pericoels weakly developed. Archeopyle intercalary, type I (2a); eurydeltaform. Tabulation not indicated by surface features; assumed to be peridiniacean. Cingulum weakly expressed, indicated by shape of the periphragm.

Size Range: Length including any processes = 97 (115) $138 \mu \mathrm{m}$ (6 measurements). Width including any processes $=98(100) 101 \mu \mathrm{m}$ (2 measurements).

Distribution: Occurs infrequently in the present study material. The type material from the Browns Creek Clays, southwest Victoria, Australia, is recorded as "Upper Eocene" Cookson \& Eisenack 1965a) but this date is not well-constrained. 


\begin{tabular}{|c|c|c|c|}
\hline Age/Stage & Location & Sample & Sample Reference \\
\hline $\begin{array}{l}\text { Runangan-early } \\
\text { Whaingaroan }\end{array}$ & Kakanui River mouth & & $\begin{array}{l}\text { Clowes \& Morgans } \\
1984\end{array}$ \\
\hline Runangan & Kakanui River, Oamaru-Dunedin, New Zealand & J42/f098 (L10953) & $\begin{array}{l}\text { Clowes \& Morgans } \\
1984\end{array}$ \\
\hline Runangan & Cape Foulwind Section, Westland, New Zealand & K29/f261 (L13543) & \\
\hline Bortonian & Puketeraki Core, Oamaru-Dunedin, New Zealand & |43/f092 (L16340) & $\begin{array}{l}\text { Wilson \& McMillan } \\
1996\end{array}$ \\
\hline Bortonian & Puketeraki Core, Oamaru-Dunedin, New Zealand & I43/f090 (L16338) & $\begin{array}{l}\text { Wilson \& McMillan } \\
1996\end{array}$ \\
\hline
\end{tabular}

Remarks: As noted in Clowes \& Morgans 1984, p. 34, the forms attributed to D. leptodermata by Stover 1974, p. 177 , pl. 5, figs. 1a-b, possess a very broad archeopyle, "a feature which is not apparent from the holotype illustration" of Cookson \& Eisenack 1965a (pl. 11, fig. 6). It is assumed that Stover may have been able to determine the archeopyle width from his re-examination of the type material, but some uncertainty surely remains.

\section{Deflandrea micropoda Cookson \& Eisenack 1974}

$$
\text { PI. 13, figs. 4-6 }
$$

1974 Deflandrea micropoda Cookson \& Eisenack, p. 49, pl. 27, fig. 11

?1975 Deflandrea cornumammillata Jan du Chêne \& Chateauneuf, p. 31-32, 34, pl. 2, figs. 1-13

Original Description: Overall shape is oval, with an apex shaped in the form of a slight arch and a straight-edged antapex, with two nearly equal, widely separated and very short antapical horns, no indication of a girdle or a longitudinal furrow. Periphragm is smooth and transparent with thin walls. The endophragm has a somewhat elliptical outline, is also smooth but has thick walls, crossing the archeopyle in its centre in the epitract, in the hypotract a narrow zone is left free at the antapex.

Archeopyle in the periphragm close under the apex, wide hexagonally rounded. Cap still in situ (Cookson \& Eisenack 1974, p. 49).

Description of Study Material: Cysts of intermediate size, proximate, somewhat dorso-ventrally compressed, outline peridinioid, with one apical and two antapical horns, characterised by small, nipple-like thickenings of the periphragm at the tips; episome and hyposome more or less equal in length. Apex rounded to subconical, episome more or less straight-sided; antapical horns weak to lacking. Lateral pericoels developed below the cingular region. Archeopyle intercalary, type I (2a); eurydeltaform. Tabulation not indicated by surface features; assumed to be peridiniacean. Cingulum weakly indicated.

Size Range: Length including any processes $=100 \mu \mathrm{m}$ (one measured specimen). Width including any processes $=80 \mu \mathrm{m}$ (one measured specimen).

Distribution: Very rare. Only one specimen found in the present study.

$\begin{array}{llll}\text { Age/Stage } & \text { Location } & \text { Sample } & \text { Sample Reference } \\ \text { Bortonian } & \text { Puketeraki Core, Oamaru-Dunedin, New Zealand } & \text { I43/f093 (L16341) } & \text { Wilson \& McMillan } 1996\end{array}$

Remarks: Considered to be a junior synonym of Deflandrea leptodermata by Stover \& Evitt 1978 (p.101), and there appears some substance to this view. Other than papillae terminating the antapical horns there seems little to distinguish them; the one specimen found in the present study may very well be an outlier of $D$. leptodermata.

\section{Deflandrea sp. 1}

Pl. 13, figs. 7-9

Description: Cysts of intermediate size, proximate, somewhat dorso-ventrally compressed, outline peridinioid, with one apical and two weakly developed antapical horns; episome and hyposome more or less equal in length. Apex rounded to subconical, episome more or less straight-sided; antapical horns small and bluntly rounded. Lateral pericoels developed below the cingular region. Archeopyle intercalary, type I (2a); eurydeltaform. Tabulation not indicated by surface features; assumed to be peridiniacean. Cingulum very weakly indicated. 
Distribution: Extremely rare. Only one encountered in the present study.

\begin{tabular}{llll}
\hline Age/Stage & Location & Sample & Sample Reference \\
Runangan-early Whaingaroan & Cape Foulwind Section, Westland, New Zealand & K29/f106 (L11042) &
\end{tabular}

Remarks: This form, which is known from a single specimen, is nevertheless highly distinctive, and included in the hope that further specimens may be encountered.

Deflandrea totara Clowes n. sp.

PI. 13, figs. 10-12, PI. 14, figs. 1-3

1984 Deflandrea sp. 2; Clowes \& Morgans, p. 37, pl. 2, figs. 17-18

Derivation of Name: Named after the type formation: the Totara Limestone.

Holotype: Sample J42/f096, slide L10951/SM091; Totara Limestone, Kakanui River (early Whaingaroan); PI. 13, figs. 10-11

Description: Cysts large, proximate, somewhat dorso-ventrally compressed, outline peridinioid, with one apical and two antapical horns; episome longer than hyposome. Apex more or less conical, episome more or less straight-sided; antapical horns developed. Lateral pericoels weak to lacking. Archeopyle intercalary, type I (2a); eurydeltaform; ratio (AR) about 0.5 ; operculum free. Tabulation not indicated by surface features; assumed to be peridiniacean. Cingulum clearly expressed, indicated by folds in the periphragm. Sulcus weakly expressed to moderately expressed, indicated by folds in the periphragm.

Size Range: Length including any processes $=112$ (124) $135 \mu \mathrm{m}$ (9 measurements). Width including any processes $=92$ (96) $98 \mu \mathrm{m}$ (5 measurements).

Distribution: Common. Apparently of limited stratigraphic occurrence, nevertheless, it is often occurs commonly where it occurs at all.

\begin{tabular}{|c|c|c|c|}
\hline Age/Stage & Location & Sample & Sample Reference \\
\hline $\begin{array}{l}\text { early } \\
\text { Whaingaroan }\end{array}$ & Kakanui River, Oamaru-Dunedin, New Zealand & J42/f096 (L10951) & $\begin{array}{l}\text { Clowes \& Morgans } \\
1984\end{array}$ \\
\hline Kaiatan & $\begin{array}{l}\text { Hampden Beach Section, Oamaru-Dunedin, New } \\
\text { Zealand }\end{array}$ & J42/f064 (L09221) & Wilson 1985 \\
\hline Bortonian & Puketeraki Core, Oamaru-Dunedin, New Zealand & |43/f090 (L16338) & Wilson \& McMillan 1996 \\
\hline Bortonian & $\begin{array}{l}\text { Hampden Beach Section, Oamaru-Dunedin, New } \\
\text { Zealand }\end{array}$ & J42/f061 (L09218) & Wilson 1985 \\
\hline
\end{tabular}

Comparison: Deflandrea totara most closely resembles $D$. leptodermata, but differs in possessing a narrower archeopyle, a higher, more conical apical horn, and a periphragm which is more closely appressed to the endocyst laterally. It is readily distinguished from $D$. phosphoritica and similar forms with well-developed welldeveloped pericoels below the cingulum, because it typically possesses almost none, and from $D$. antarctica in its shorter, less inflated apical horn.

\section{Deflandrea sp. 2}

\section{PI. 14, figs. 4-6}

Description: Cysts large, proximate, somewhat dorso-ventrally compressed, outline peridinioid, with one apical and two antapical horns; episome and hyposome or more or less equal length. Apex quite pointed and more or less conical, episome more or less straight-sided; antapical horns also quite pointed, developed unequally. Lateral pericoels developed below the cingular region. Archeopyle intercalary, type I (2a); eurydeltaform; ratio (AR) about 0.5 ; operculum free. Tabulation not indicated by surface features; assumed to be peridiniacean. Cingulum moderately well expressed, indicated by folds in the periphragm. Sulcus weakly expressed to moderately expressed, indicated by folds in the periphragm.

Distribution: Very rare; only a single specimen recorded in the present study.

$\begin{array}{llll}\text { Age/Stage } & \text { Location } & \text { Sample } & \text { Sample Reference } \\ \text { Runangan } & \text { Cape Foulwind Section, Westland, New Zealand } & \text { K29/f102 (L11038) }\end{array}$


Genus Alterbidinium Lentin \& Williams 1985 emend. Khowaja-Ateequzzaman et al. 1991

1967 Albertia Vozzhennikova, p. 150-151
1976 Alterbia Lentin \& Williams, p. 47-48
1978 Alterbia Lentin \& Williams 1976; Stover \& Evitt, p. $92-93$
1985 Alterbidinium Lentin \& Williams, p. 14
1991 Alterbidinium Lentin \& Williams 1985 emend. Khowaja-Ateequzzaman et al., p. 38

Type Species: Alterbidinium recticorne (Vozzhennikova 1967, p. 151-152, pl. 77, figs. 1-4; pl. 78, figs. 1-3; pl. 79, figs. 1-2) Harker \& Sarjeant 1990, p. 104 [Cretaceous (Turonian)]

Original Description: Theca pentagonal, rhomboid, subdivided into almost equal parts [presumably by the cingulum]. Epitheca bell-shaped, triangular with a small apical horn. Hypotheca with one or two unequal antapical horns. Transverse furrow equatorial, annulate; longitudinal furrow situated on hypotheca and extends to the antapex. Internal body has the same outline of that of the theca. Pylome triangular with rounded or truncated angles, thus appearing somewhat trapeziform (translated from Vozzhennikova 1967, p. 150-151, by Lees 1971, reproduced in Stover \& Evitt 1978, p. 92).

Remarks: Alterbidinium (as Alterbia) and related genera were the subjects of a major revision by Lentin \& Williams 1976 (p. 47-50) in which the diagnostic value of the archeopyle shape was explored. Note, however, that the transverse archeopyle ratio value given for Alterbia in text-fig. $5 \mathrm{~A}$ is incorrect $[R$ is given as 0.92 ; it should be 0.86] and in tables $6 \& 7$ the transverse archeopyle index and ratio values are mutually inconsistent [if $I$ is 0.33 , then $\mathrm{R}$ must be 0.49 , not 0.57 , whereas if $\mathrm{R}$ is 0.57 , then I must be 0.36 , not 0.33 ].

Stover \& Evitt 1978, p. 93, notes that Alterbidinium differs from Senegalinium in having an epipericoel which is in communication with the exterior through the archeopyle, and in having a reduced or absent right antapical horn instead of two nearly equally developed antapical horns. However, Goodman \& Ford 1983 reports populations of Alterbidinium distinctum (as Alterbia distincta) from the upper Eocene of the Falklands Plateau (DSDP Hole 511) which display archeopyles where communication between the epipericoel and the exterior is variable. Goodman \& Ford go on to suggest that "archeopyle morphology should possibly be treated as an intergeneric variable rather than a generic character for these taxa" (p. 864). Although this cautious statement stops short of proposing any synonymy, it definitely amounts to a warning shot across the bows. (Note also that Herngreen 1975, p. 6061, considers Senegalinium to be a junior synonym of Deflandrea.)

Eucladinium is also similar to Alterbidinium in having a reduced right antapical horn, but is mainly epicavate rather than circumcavate (Stover \& Evitt 1978, p. 93).

Alterbidinium cf. acutulum (Wilson 1967b) Lentin \& Williams 1985

PI. 14, figs. 10-12

Original Description: Test narrow, bi-layered, comprising smooth outer cyst tapering at poles, and small inner cyst. Apical horn long $(I=22-32 \mu)$. bluntly terminated. Right antapical horn long $(I=14-36 \mu)$, pointed. Left antapical horn absent, but position represented by minor angularity in margin of outer cyst. Archeopyle long, narrow. intercalary, situated on dorsal epitheca; operculum hinged to shell by posterior margin. Spiral transverse girdle represented by a folding of outer cyst (Wilson 1967b, p. 225-226).

Size Range: Length including any processes $=57$ (64) $70 \mu \mathrm{m}$ (2 measurements). Width including any processes $=45$ (48) 51 um (2 measurements).

Distribution: Rare.

$\begin{array}{llll}\begin{array}{l}\text { Age/Stage } \\ \text { Kaiatan }\end{array} & \text { Location } & \text { Sample } & \text { Sample Reference } \\ & \text { Puketeraki Core, Oamaru-Dunedin, New Zealand } & \text { I43/f096 (L16344) } & \text { Wilson \& McMillan } \\ \text { Porangan- } & \text { Hampden Beach Section, Oamaru-Dunedin, New } & \text { J42/f486 (L23121) } \\ \text { Bortonian } & \text { Zealand } & \\ \begin{array}{l}\text { Porangan- } \\ \text { Bortonian }\end{array} & \text { Hampden Beach Section, Oamaru-Dunedin, New } & \text { J42/f485 (L23120) } \\ \text { Porangan } & \text { Zealand } & \text { U24/f419 (L23127) }\end{array}$

Remarks: A few specimens resembling A. acutulum, at least superficially, were encountered in the present study. However, the identification seems unlikely: if they really are $A$. acutulum, then they would extend the known stratigraphic range of that species from the Late Cretaceous to the Eocene. 
Genus Cerodinium Vozzhennikova 1963 emend. Lentin \& Williams 1987

\author{
1963 Cerodinium Vozzhennikova, p. 181 \\ 1963 Ceratiopsis Vozzhennikova, p. 181 \\ 1980b Ceratiopsis Vozzhennikova, 1967 [sic] emend. Bujak et al., p. 27 \\ 1987 Cerodinium Vozzhennikova 1963 emend. Lentin \& Williams, p. 114 \\ 1988 Ceratiopsis Vozzhennikova, 1963 emend. Bujak et al., 1980c; Wilson, p. 15
}

Type Species: Cerodinium sibiricum Vozzhennikova 1963, p. 181, text-figs. 9-10 [Paleocene-Eocene]

Original Description: Cells spherical or lenticular, with one apical and two widely spaced antapical horns. Girdle annular; longitudinal furrow present on hypovalve. Width of furrow varies. Membrane thin, delicate, smooth hyaline. Internal body occupies the whole cell cavity, which is darker than the membrane (translation from Vozzhennikova 1963, p. 181, by Lentin \& Williams 1976, p.154).

Remarks: Cerodinium is treated as a junior synonym of Deflandrea by, for example, Lentin \& Williams 1976 (p.154) which notes similarities between the type species, C. sibiricum and Deflandrea oebisfeldensis. This treatment was followed for some years, for example by Stover \& Evitt 1978 (p. 99) and Lindgren 1984 (p. 153).

A subsequent analysis by Lentin \& Williams (1977b, p. 20) reinstated Ceratiopsis and transferred the former Cerodinium species, C. sibiricum and C. balticum, into that genus.

Lindgren (1984, p. 153-154) reverted to the earlier approach, regarding both Cerodinium and Ceratiopsis as junior synonyms of Deflandrea, and further pointing out that Ceratiopsis Vozzhennikova 1963 is a junior homonym of Ceratiopsis De Wildeman 1896, a fungus.

In 1987, however, Lentin \& Williams (p. 114) again resurrected the Cerodinium/Ceratiopsis concept, this time using Cerodinium as the name-bearer and, generally, the genus has remained in use since.

Lentin \& Williams 1987, p. 113, notes that: "Ceratiopsis and Cerodinium were considered to be congeneric by Lentin and Williams (1976) who gave priority to the name Ceratiopsis." In fact, the analyses of Ceratiopsis and Cerodinium provided in Lentin \& Williams 1976, on pages 153 and 154 respectively, do not reference one another at all, and both genera, as noted above, are considered to be junior synonyms of Deflandrea. It seems likely that this was a simple reference error, and that the authors mistakenly referenced Lentin \& Williams 1976 when they meant Lentin \& Williams 1977b, in which Cerodinium and Ceratiopsis are indeed interpreted as synonyms of one another, but distinct from Deflandrea (p. 22).

The convoluted nomenclatural history notwithstanding, the status of this genus remains unconvincing. Lentin \& Williams 1987, p. 114, concludes that Cerodinium differs from Deflandrea in possessing an isodeltaform rather than a latideltaform [= eurydeltaform] archeopyle. In preparing a dataset from which to build a key for Deflandrea species, however, archeopyle ratios for numerous similar taxa were compared and, at $\sim 0.85$, that of Cerodinium dartmoorium hardly stands out as remarkable.

Cerodinium medcalfii (Stover 1974) Lentin \& Williams 1987

PI. 15, figs. 1-6

1974 Deflandrea medcalfii Stover, p. 175-176, pl. 3, figs. 3a-c, text-fig. 3G, 6C

1976 Deflandrea dartmooria subsp. medcalfii (Stover 1974, p. 175-176, pl. 3, figs. 3a-c; text-figs. 3G, 6C) Lentin \& Williams, p. 39

1985 Ceratiopsis medcalfii (Stover 1974, p. 175-176, pl. 3, figs. 3a-c; text-figs. 3G, 6C) Heilmann-Clausen, p. 19

1987 Cerodinium medcalfii (Stover 1974, p. 175-176, pl. 3, figs. 3a-c; text-figs. 3G, 6C) Lentin \& Williams, p. 114

1988 Deflandrea medcalfii Stover, 1974; Wilson, p. 18, pl. 7, figs. 1-3

Original Description: Cysts are tricornate with an elongate, tapered apical horn and prominent antapical horns of about equal size and with narrowly rounded or pointed tips. Antapical horns separated by a broad medial concavity.

Lateral margins of periphragm are gently convex anterior to the cingulum, and straight to slightly concave posterior to the cingulum. Periphragm less than $1 \mu$ thick and clear except for areas with small coni. The species has a typical peridinioid tabulation of 4', 3a?, 7", 5", 2'"' with the size, shape, and position of the plates represented by the conate areas. Cingulum defined by transverse parallel ridges about $1 \mu$ high, $5-7 \mu$ apart, and fringed with coni, denticles, or spinules. On some specimens the cingulum is subdivided by longitudinal ridges 
and its floor is smooth or bears scattered coni. Sulcal margins generally indefinite, and on most specimens, a hook-shaped scar occurs in the sulcus near its junction with the cingulum and generally a little right of centre.

Endoblast is comparatively large, broadly elliptical to ovoid in dorso-ventral view, generally wider than long although on some specimens the reverse is true, and located about centrally with respect to the periphragm. Endoblast configuration approximates that of the periblast laterally but deviates apically and antapically. Endophragm is smooth and ca $0.5 \mu$ thick.

Archeopyle intercalary, large, irregularly hexagonal in outline, and with a narrower apical than antapical margin. Opening in endophragm corresponds with that in the periphragm. Operculum free.

Length of periphragm is $106-140 \mu$, width of periphragm is $68-75 \mu$ and the specimens have a length:width ratio between 1:0.53 and 1:0.73 (mean 1:0.64). Length of endophragm is $53-70 \mu$, width $58-76 \mu$. Apical horn is $22-34 \mu$ long; antapical horns 20-36 $\mu$ long. Measurements based on 12 complete specimens (Stover 1974, p. 175).

Description of Study Material: Cysts large, proximate, not dorso-ventrally compressed, outline peridinioid, with one apical and two antapical horns; episome longer than hyposome. Apical horn well developed, apex pointed, episome markedly attenuated; antapical horns strongly and approximately equally developed, relatively pointed. Cyst wall two-layered; bicavate, lateral pericoels absent; thin $(<1 \mu \mathrm{m})$ in thickness. Archeopyle intercalary, type I (2a); isodeltaform, large; operculum free. Surface ornament present, non-tabular, comprising coni; sometimes forming incomplete, apparently sutural, lineations. Tabulation peridiniacean, inferred formula: 4', 3a, 7", Xc, 5"', Ops, 2"', $0-5 \mathrm{~s}$. Cingulum clearly expressed, surface ornament and folds in the periphragm, 7-8 $\mu \mathrm{m}$ wide; offset only slightly.

Size Range: Length including any processes $=125$ (136) $155 \mu \mathrm{m}$ (7 measurements). Width including any processes $=72(80) 87 \mu \mathrm{m}$ (3 measurements).

Distribution: Frequent. The younger occurrences reported here represent a significant extension to the previously reported range of the species (Stover 1974, Wilson 1988).

$\begin{array}{llll}\text { Age/Stage } & \text { Location } & \text { Sample } & \text { Sample Reference } \\ \text { Bortonian } & \text { Hampden Beach Section, Oamaru-Dunedin, New Zealand } & \text { J42/f048 (L09205) } & \text { Wilson 1985 } \\ \text { Porangan } & \text { Te Uri Stream, Hawkes Bay, New Zealand } & \text { U24/f419 (L23127) } & \\ \text { Porangan } & \text { Te Uri Stream, Hawkes Bay, New Zealand } & \text { U24/f417 (L23125) } & \\ \text { Heretaungan } & \text { Hampden Beach Section, Oamaru-Dunedin, New Zealand } & \text { J42/f039 (L09196) } & \text { Wilson 1985 } \\ \text { Waipawan } & \text { Waipawa standard section, Hawkes Bay, New Zealand } & \text { V22/f8978 } & \text { Wilson 1988 } \\ \text { Teurian } & \text { Waipawa standard section, Hawkes Bay, New Zealand } & \text { V22/f8692 } & \text { Wilson 1988 }\end{array}$

Remarks: Cerodinium medcalfii appears to differ from C. dartmoorium principally in possessing a tabulation less well-delineated by linear sutural features.

\title{
Genus Isabelidinium Lentin \& Williams 1977a
}

\author{
1976 Isabelia Lentin \& Williams, p. 56 \\ 1977a Isabelidinium Lentin \& Williams, p. 167 \\ 1978 Isabelidinium Lentin \& Williams 1977a; Stover \& Evitt, p. 108-109
}

Type Species: Isabelidinium korojonense (Cookson \& Eisenack 1958, p. 27-28, pl. 4, figs. 10-11) Lentin \& Williams 1977a, p. 167 [Cretaceous (Campanian-Maastrichtian)]

Original Description: Pericyst: Ambitus commonly pentagonal, elongated in an anteroposterior direction, rarely rhomboidal or rectangular. Apex prolonged into a broad short apical horn which may merge imperceptibly into the epipericyst, or be developed into shoulders. Antapex produced into two symmetrically located short antapical horns, usually of unequal length. The left antapical horn is always the longer, the right is reduced or vestigial. The apical and two antapical horns sometimes reduced. There is usually a slight to prominent equatorial bulge in ambital view. Compression dorso-ventral.

Endocyst: Ambitus ovoidal with longest axis equatorially aligned to circular, to elongate ovoidal. May be equatorially in contact with endocyst. Pericoels: When endocyst and pericyst are appressed in precingular, cingular and postcingular regions, they are separated apically and antapically by a large apical and a large antapical pericoel, respectively. Alternatively the apical and antapical pericoels may be united by an ambital pericoel. Compression dorso-ventral, may be negligible.

Periphragm: Usually of constant thickness. Surface laevigate, scabrate, granulate or verrucate. Ornamentation nontabular. Endophragm: Surface laevigate to scabrate to granulate. Pericyst: Paratabulation indeterminate other than in the vicinity of the periarcheopyle. Pericingulum: Almost always absent or rudimentary and never complete, occasionally visible on the ambitus as an indentation. Perisulcus: Not observed. Endocyst: Paratabulation unknown. 
Periarcheopyle: Omegaform intercalary resulting from the partial detachment of the second anterior intercalary paraplate, $2 \mathrm{a}$, with perioperculum usually remaining along parasuture $\mathrm{H} 4$. Transverse periarcheopyle index is $0.33-0.55$. Transverse archeopyle ratio is $0.50-1.25$. Endoarcheopyle: Where observable appears to result from the loss of the second anterior intercalary paraplate $(2 a)$, or all three anterior intercalaries.

Archeopyle Formula: I/I (2a/2a) or I/3I (2a/1-3a) (Lentin \& Williams 1976, p. 56, 57).

Remarks: Isabelidinium is a substitute for the original name applied to this genus, Isabelia Lentin \& Williams 1976, which is a junior homonym of the orchid genus Isabelia Barbosa-Rodrigues 1877.

A number of older New Zealand species (or species occurring in New Zealand) previously assigned to this genus have been moved to other genera (e.g. I. haumuriense to Satyrodinium; I. druggii/seelandicum to Manumiella). The genus as currently defined dates back to at least the Paleocene: Wilson 1988 records $I$. bakeri and a new species, I. cingulatum, from the Teurian at Waipawa.

As far as I am aware, however, the following record is the youngest occurrence yet reported from New Zealand.

Isabelidinium cf. bakeri (Deflandre \& Cookson 1955) Lentin \& Williams 1977a

PI. 15, figs. 7-9

Original Description: [Description of $I$. bakeri] Cell generally but not always encysted. Theca widely fusiform, somewhat obliquely truncated posteriorly; transverse girdle faint, neither hollowed nor shallow, sometimes quite indistinct, dividing the theca into 2 unequal parts. Longitudinal furrow not observed. Epitheca larger than the hypotheca, widely conical or bell-shaped, surmounted by a short, more or less bluntly pointed, slightly thickened prominence. Hypotheca like a frustum of a cone, sometimes with 2 very short unequal horns and occasionally a 3rd submedian conical expansion, sometimes with the lower angles simple or 1 of the 2 rounded. In lateral view ... the encysted cells have an asymmetrical outline with, at the level of the cyst, 1 face plane and the other convex. This convexity does not seem to exist in the rare non-encysted examples that have been examined. The cyst also causes a slight frontal enlargement.

The cysts is ellipsoidal, more or less regular when viewed from the front, more asymmetrical in lateral view. The encysted cells have a rather regular polygonal aperture on the convex side of the epitheca (Deflandre \& Cookson 1955 , p. 251; ellipses replace figure references in the original).

Size Range: Length including any processes $=165 \mu \mathrm{m}$ (one measured specimen). Width including any processes $=96 \mu \mathrm{m}$ (one measured specimen).

Distribution: Extremely rare. Known from a single specimen.

$\begin{array}{llll}\text { Age/Stage } & \text { Location } & \text { Sample } & \text { Sample Reference } \\ \text { Kaiatan } & \text { Hampden Beach Section, Oamaru-Dunedin, New Zealand } & \text { J42/f063 (L09220) } & \text { Wilson 1985 }\end{array}$

Remarks: The present form closely resembles I. bakeri though, if it were truly conspecific, would represent a considerable extension to the stratigraphic range. It seems more probable that the specimen is reworked.

\section{Genus Planoperidinium De Coninck 1986b}

1986b Planoperidinium De Coninck, p. 18

Type Species: Planoperidinium gracile De Coninck 1986b, p. 18, pl. 6, fig. 44, pl. 8, figs. 1-10 [Oligocene (Rupelian)]

Original Description: Small, dorsoventrally flattened pericyst with peridinioid ambitus. Pericyst and endocyst separate from each other in the antapical horns and often in the apical horn as well unless it is very poorly developed. Between horns and cingulum peri and endocyst generally not separate; in some specimens however a narrow separation is visible. Cingulum mainly marked at the lateral margin. Sulcus generally invisible or slightly marked. The archeopyle is intercalary and relatively wide. No ornamentation of the periphragm, hence no tabulation indicated (De Coninck 1986b, p. 18).

\section{Planoperidinium ?gracile De Coninck 1986b}

$$
\text { Pl. 15, figs. 10-12, Pl. 16, figs. 1-3 }
$$


Original Description: The pericyst is dorsoventrally flattened. Its ambitus is peridinioid. The epicyst is generally a little longer than the hypocyst and has a more or less triangular outline. The apical horn is poorly developed and rounded. The cingular margins are marked on the ambitus by short protrusions between which the cingulum is represented by a shallow depression. Generally the cingulum and sulcus are invisible on the dorsal and ventral surfaces of the pericyst. The hypocyst is trapezium-shaped with two protruding antapical horns with a pointed, often flexuous tip. One of the antapical horns is a little longer than the other. Between the antapical horns the pericyst is concave. The surface of the pericyst in unornamented. The endocyst is generally appressed against the pericyst except in each of the antapical horns where the separation is clearly indicated. In the poorly developed apical horn, the separation of endo- and pericyst is not always marked. The archeopyle, generally not developed, is intercalary and relatively large (De Coninck 1986b, p. 18).

Description of Study Material: Cysts of intermediate size, proximate, dorso-ventrally compressed, outline peridinioid, with one apical and two antapical horns; episome slightly longer than hyposome. Apical horn moderately well-developed; antapical horns strongly developed, acuminate. Cyst wall two-layered; cornucavate. Archeopyle intercalary, type I (2a); large. Surface ornament lacking. Indicated by folds in the periphragm.

Size Range: Length including any processes $=78$ (82) $87 \mu \mathrm{m}$ (2 measurements). Width including any processes = 57 (63) $67 \mu \mathrm{m}$ (3 measurements).

Distribution:

\begin{tabular}{llll}
\hline Age/Stage & Location & Sample & Sample Reference \\
early Whaingaroan & Cape Foulwind Section, Westland, New Zealand & K29/f097 (L10914)
\end{tabular}

Remarks: The general outline and "over-size" archeopyle recall Lentinia. According to De Coninck (1986b, p. 18) Planoperidinium differs from Lentinia "by its extreme dorso-ventral flattened body" and, more obviously, by the "absence of any ornamentation and tabulation of the pericyst."

\title{
?Planoperidinium sp. 2
}

\author{
PI. 16, figs. 4-9
}

Description: Cysts of intermediate size, proximate, dorso-ventrally compressed, outline peridinioid, with one apical and two antapical horns; episome slightly longer than hyposome. Apical horn moderately well-developed; antapical horns strongly developed, acuminate. Cyst wall two-layered; cornucavate. Archeopyle intercalary, type I (2a); large. Surface ornament lacking. Cingulum indicated by folds in the periphragm.

Size Range: Length including any processes $=72(74) 75 \mu \mathrm{m}$ (2 measurements). Width including any processes $=50$ (52) $55 \mu \mathrm{m}$ (2 measurements).

Distribution: Rare.

\begin{tabular}{lll}
\hline Age/Stage & Location & Sample \\
early Whaingaroan & Cape Foulwind Section, Westland, New Zealand & K29/f097 (L10914)
\end{tabular}

Remarks: A few specimens, though apparently of Planoperidinium, differ from Planoperidinium gracile in lacking the characteristically delicate, very attenuated antapical horns.

\section{Genus Spinidinium Cookson \& Eisenack 1962b}

\author{
1962b Spinidinium Cookson \& Eisenack, p. 489 \\ 1978 Spinidinium Cookson \& Eisenack 1962b emended Lentin \& Williams 1976; Stover \& Evitt, p. 124-125
}

Type Species: Spinidinium styloniferum Cookson \& Eisenack 1962b, p. 489, pl. 1, figs. 1-5 [Cretaceous (AptianAlbian)]

Original Description: Shell longer than broad, concavo-convex, with straight or slightly convex slanting sides. Epitheca horned, hypotheca with a small projection on one side. Girdle equatorial, circular; longitudinal furrow more or less well developed. Wall of shell two-layered, the outer layer which is covered with small spines forming the apical horn and antapical projection. A pylome may develop on the dorsal surface of the epitheca (Cookson \& Eisenack 1962, p. 489).

Remarks: The ventral plate topology of the type species, Spinidinium styloniferum, appears to exhibit the same ortho-style arrangement as Deflandrea (Cookson \& Eisenack 1962b, pl. 1, fig. 4; Morgan 1975, pl. 2, fig. 1b). This topology is herein taken to be a diagnostic character for the genus as a whole.

Spinidinium has historically been distinguished from broadly similar forms, such as Phthanoperidinium, by various features of its intratabular ornament. As noted elsewhere, these sorts of ornamental distinctions have little 
phylogenetic meaning, and more profound distinctions should be sought at the generic and higher taxonomic ranks. It is more significant that Spinidinium has an attenuated to standard hexa-style plate 2a in the sense of Lentin \& Williams 1976 (text-fig. 4). In particular, that of the genoholotype is very narrow (Cookson \& Eisenack 1962b, pl. 1, fig. 2; Morgan 1975, pl. 2, fig. 1d), which distinguishes Spinidinium from Gippslandia, Lentinia, Phthanoperidinium, Vozzhennikovia, etc.

Spinidinium differs from Vozzhennikovia in possessing a deltaform archeopyle, as opposed a thetaform or even slightly omegaform archeopyle in V. apertura. Spinidinium further differs from Vozzhennikovia in possessing a tabulation which is a known, as a consequence of having the ornamentation arranged in penitabular rows or intratabular clusters, or both, rather than being nontabular.

It differs from Ginginodinium in having a type I rather than a type 3 I archeopyle (Stover \& Evitt 1978, p. 124).

\section{Spinidinium cf. styloniferum Cookson \& Eisenack 1962b}

$$
\text { PI. 16, figs. 10-12 }
$$

1962b Spinidinium styloniferum Cookson \& Eisenack, p. 489, pl. 1, figs. 1-5

Description of Study Material: Cysts small to intermediate, proximate, not dorso-ventrally compressed, more or less spherical to prolate, with one apical and one or two unequal antapical horns; episome and hyposome more or less equal in length. Apical horn well developed, apex rounded; antapical horns weakly developed, relatively pointed. Cyst wall two-layered; cornucavate. Archeopyle intercalary, type I (2a); ?stenodeltaform; operculum attached. Processes lacking; surface ornament present, intratabular, comprising coni; about 1-2 $\mu \mathrm{m}$ high. Crests sutural, low (less than about $1 \mu \mathrm{m}$ ), margins of crests smooth. Tabulation clearly expressed, peridiniacean, 3a, 7", 5"', ?ps, 2"'"; ventral organisation probably ortho-style. Cingulum clearly expressed, indicated by sutural septa; offset only slightly. Sulcus clearly expressed, indicated by sutural septa.

Size Range: Length including any processes $=30$ (43) $56 \mu \mathrm{m}$ (2 measurements). Width including any processes $=47 \mu \mathrm{m}$ (one measured specimen).

\section{Distribution: Rare.}

\begin{tabular}{llll}
\hline Age/Stage & Location & Sample & Sample Reference \\
Bortonian & Burnside Marl Pit, Oamaru-Dunedin, New Zealand & I44/f080 (L08947) & Clowes \& Wilson 2006 \\
Bortonian & Puketeraki Core, Oamaru-Dunedin, New Zealand & I43/f090 (L16338) & Wilson \& McMillan 1996
\end{tabular}

Remarks: One or two specimens have been encountered which superficially resemble Spinidinium styloniferum. This identification is unlikely, however, because the true $S$. styloniferum has not previously been reported from the Eocene.

\section{Spinidinium colemanii Wrenn \& Hart 1988}

PI. 17, figs. 1-9

1988 Spinidinium colemanii Wrenn \& Hart, p. 366-367, fig. 36, 1-2; fig. 39, 2

2000 Spinidinium colemanii Wrenn \& Hart, 1988; Levy \& Harwood, p. 208, 210, pl. 9, fig. a

Original Description: Shape: Cornucavate, subpentagonal to subelliptical dinocysts bearing one hundred or more penitabular spines. The paracingulum separates the epicyst from the hypocyst; the former is usually two to three times the length of the hypocyst. The paracingular area may bulge laterally, giving the dinocyst a subpentagonal shape.

Phragma: Both the endophragm and the periphragm are smooth. The wall layers are appressed except in the basal regions of the horns. The periphragm gives rise to capitate spines, whereas the endophragm lacks projections. The short apical horn is capped by two or more capitate spines. The right antapical horn is rarely evident, whereas the left horn is a long, spike-shaped projection bearing one or more accessory spines.

Paratabulation: A paratabulation of x', 3a, 7", xc, 5"', ?2"'" is delineated by penitabular capitate spines. The distribution and number of paraplates is obscured by the abundance of the closely spaced spines and by the presence of accessory rows of spines. The paracingulum and the parasulcus are not divided by rows of spines.

Paracingulum: Low folds capped with short capitate spines delimit the shallow excavation of the paracingulum. Paraplate divisions within the paracingulum were not observed.

Parasulcus: A broad, bare area bordered by rows of spines indicates the location of the parasulcus. Spines are usually absent within the parasulcal area, although isolated spines occur on some specimens. 
Archeopyle: The archeopyle is formed by the partial detachment of the 2a paraplate, and occasionally by the partial detachment of the 4" paraplate. The operculum is adnate along the H4 parasuture. A row of penitabular capitate spines occurs on each side of all archeopyle parasutures, except the H4 parasuture. The rows of spines along the $\mathrm{H} 2-\mathrm{H} 3$ and the $\mathrm{H} 5-\mathrm{H} 6$ parasutures of the $2 \mathrm{a}$ intercalary paraplate continue below the base of that paraplate and along the margins of the 4 " paraplate to the anterior margin of the paracingulum (Wrenn \& Hart 1988, p. 366-367).

Size Range: Length including any processes $=47$ (54) $60 \mu \mathrm{m}$ (2 measurements). Width including any processes $=37(40) 42 \mu \mathrm{m}$ ( 2 measurements).

Distribution: Very rare. Just two specimens resembling Spinidinium colemanii (one rather dubiously) were encountered in the type Porangan material from Te Uri Stream.

$\begin{array}{llll}\text { Age/Stage } & \text { Location } & \text { Sample } & \text { Sample Reference } \\ \text { Bortonian } & \text { Hampden Beach Section, Oamaru-Dunedin, New } & \text { J42/f488 (L23123) } & \\ & \text { Zealand } & \text { U24/f417 (L23125) } & \\ \text { Porangan } & \text { Te Uri Stream, Hawkes Bay, New Zealand } & \text { MB 181(2) } & \text { Levy \& Harwood } \\ \text { Eocene } & \text { erratics, McMurdo Sound, Antarctica } & & \text { 2000 } \\ \text { late early } & \text { northern Seymour Island, West Antarctica } & 8496 & \text { Wrenn \& Hart 1988 }\end{array}$

Paleocene

Remarks: This species differs from Spinidinium essoi and S. macmurdoense in its far coarser ornamentation and, rather more variably, a more prominent antapical horn.

Spinidinium essoi Cookson \& Eisenack 1967a

PI. 17, figs. 10-11

1967a Spinidinium essoi Cookson \& Eisenack, p. 135, pl. 19, figs. 1-8

2000 Spinidinium essoi Cookson \& Eisenack, 1967; Levy \& Harwood, p. 210, pl. 9, fig. b

Original Description: Shell small, somewhat flattened and oval in outline, with straight to convex sides, a relatively broad, circular, equatorial girdle with high ledges bearing short thin spines, a short blunt apical horn and a single sharply-pointed horn on the left-hand side of the antapex. Both surfaces of the shell are partially tabulated, the areas being delimited by short spines. On the ventral surface of the epitheca a small, roughly rectangular area outlined by small dot-like thickenings is usually clearly evident, and a wide furrow-like region, delimited by small spines, is typically present in the hypotheca. An intercalary, trapezoidal archeopyle is developed on the dorsal surface of the epitheca.

In one specimen ... a relatively thin-walled cyst-like body, circular in outline, occupies approximately threequarters of the cavity of the shell [this is either a different taxon or else an accidental superposition of some other palynomorph; it is difficult to determine from the published image - CC].

The wall of the shell, which is rather sparsely ornamented with pointed or knobbed spines, appears to consist of two closely opposed layers which separate from one another only at or near the bases of the horns, the position of the diaphragm varying in individual specimens. The apical horn tends to be straight-sided and its apex incurved; the antapical horn, which tapers to a sharp point, bears a few downwardly directed spines (Cookson \& Eisenack 1967a, p. 135).

Size Range: Length including any processes = 35 (45) $55 \mu \mathrm{m}$ (3 measurements). Width including any processes $=30$ (36) $42 \mu \mathrm{m}$ (3 measurements).

Distribution: Rare. Very seldom encountered in the present study, but known from older New Zealand sediments (Erica Crouch pers. comm.)

$\begin{array}{llll}\text { Age/Stage } & \text { Location } & \text { Sample } & \text { Sample Reference } \\ \text { Porangan } & \text { Te Uri Stream, Hawkes Bay, New Zealand } & \text { U24/f419 (L23127) } & \\ \text { Eocene } & \text { erratics, McMurdo Sound, Antarctica } & \text { MB 181(2) } & \text { Levy \& Harwood 2000 }\end{array}$

Spinidinium macmurdoense (Wilson 1967a) Lentin \& Williams 1976

PI. 17, fig. 12, PI. 18, figs. 1-3

1967a Deflandrea macmurdoensis Wilson, p. 60-62, figs. 2a, 11-16, 22

1975 Deflandrea macmurdoensis Wilson; Haskell \& Wilson, pl. 1, fig. 13 
Original Description: Test bi-layered, dorso-ventrally flattened, angular, bilaterally asymmetric. Outer cyst divided into fields by small spines $(I=5-9 \mu)$; smooth hyaline inner cyst closely follows outline of outer cyst. Horns formed by polar extensions of outer cyst; apical horn relatively long $(I=14-20 \mu)$ narrow, blunt-ended and bordered by very small spines; right antapical horn pointed $(I=13-17 \mu)$ and usually bordered with small spines; left antapical horn either non-existent or very small. Prominent slightly laevo-rotatory transverse girdle delimited by a double row of spines or sometimes, on dorsal surface, by a spiny ridge. Archeopyle intercalary, hoof-shaped or subhexagonal, located on dorsal epitheca; operculum always fixed to shell by its posterior margin; remainder of archeopyle perimeter bordered by a double row of spines, one on operculum, the other on outer cyst, with line of rupture between the two rows.... Tabulation uncertain, but that of dorsal epitheca apparently consistent with Gonyaulax... (Wilson 1967a, p. 60, 62; ellipses replace figure references in the original).

Size Range: Length including any processes $=55 \mu \mathrm{m}$ (one measured specimen). Width including any processes $=46 \mu \mathrm{m}$ (one measured specimen).

Distribution: Extremely rare in the present study; only a single specimen was recovered from Hampden Beach.

\begin{tabular}{|c|c|c|c|}
\hline Age/Stage & Location & Sample & Sample Reference \\
\hline Porangan-Bortonian & $\begin{array}{l}\text { Hampden Beach Section, Oamaru-Dunedin, New } \\
\text { Zealand }\end{array}$ & $\mathrm{J} 42 / \mathrm{f} 485(\mathrm{~L} 23120)$ & \\
\hline Eocene & erratics near Minna Bluff, McMurdo Sound, Antarctica & L4729 & Wilson 1967a \\
\hline Eocene & erratics, McMurdo Sound, Antarctica & MTD 153(1) & $\begin{array}{l}\text { Levy \& Harwood } \\
2000\end{array}$ \\
\hline late early & northern Seymour Island, West Antarctica & 8457 & Wrenn \& Hart 1988 \\
\hline
\end{tabular}

Genus Vozzhennikovia Lentin \& Williams 1976

\author{
1976 Vozzhennikovia Lentin \& Williams, p. 65-66 \\ 1978 Vozzhennikovia Lentin \& Williams 1976; Stover \& Evitt, p. 129-130
}

Type Species: Vozzhennikovia apertura (Wilson 1967a, p. 64-65, figs. 3-5, 8) Lentin \& Williams 1976, p. 65 [Paleocene-Oligocene]

Original Description: Pericyst: Ambitus rounded to ovoidal. Apex occasionally rounded, more frequently produced into a short apical horn which distally may be acuminate, oblate or invaginated. Antapex rounded or commonly with one eccentrically located left antapical horn. Rarely there are two symmetrically located antapical horns which are unequal in length, the right antapical horn being reduced or vestigial. Epipericyst and hypopericyst of more or less equal size or epipericyst somewhat larger. Ambital outline widest in pericingular region. Compression dorso-ventral, moderate to extreme.

Endocyst: Ambitus rounded to ovoidal, almost always appressed against pericyst apart from in the vicinity of the horns. Usually difficult to delineate, Compression dorso-ventral, often extreme. Pericoels: A small apical pericoel in the vicinity of the apical horn. If an antapical horn is present there may be a small antapical pericoel. Periphragm: Epipericyst and hypopericyst ornamented with nontabular echinae or processes rarely exceeding $10 \mu$ in length. The processes may be distally acuminate, oblate or invaginated. Processes often oriented in pericingular or perisulcal regions only.

Endophragm: Laevigate. Usually thin and difficult to delineate. Pericyst: Paratabulation never discernible other than in the vicinity of the periarcheopyle. Pericingulum: Generally present and indented. Planar or slightly helicoidal. Anterior and posterior parasutures delineated by a continuous or discontinuous row of echinae or processes. Area of pericingulum within parasutures is devoid of a surface ornamentation. Perisulcus: Commonly delineated by absence of ornamentation. Indented. Extending onto epipericyst but considerably longer and wider on the hypopericyst reaching almost to the antapex. Endocyst: Paratabulation not observed.

Standard hexa or broad hexa intercalary [archeopyle] resulting from the partial or complete detachment of the anterior intercalary paraplate $2 \mathrm{a}$. The operculum may be free or remain attached along parasuture $\mathrm{H} 4$. Since the endophragm and periphragm are appressed in the vicinity of the archeopyle, there is no separation of the endoperculum and perioperculum so that effectively there is one archeopyle and one operculum. Transverse archeopyle index is 0.33-0.50. Transverse archeopyle ratio is 0.50-1.0. 
Archeopyle Formula: I (Lentin \& Williams 1976, p.65-66).

Remarks: Vozzhennikovia differs from Spinidinium in possessing a broader, thetaform or slightly omegaform archeopyle, whereas that of Spinidinium is narrow and deltaform (q.v.), and also in generally lacking evidence of plate boundaries. The latter characteristic, while presenting methodological difficulties, of course, is not considered to have any phylogenetic significance per se. Ornament which fails to delineate the plate boundaries is still "just another kind" of ornament.

Vozzhennikovia differs from Dioxya in having two wall layers rather than an autophragm only, and in the shape of the antapex which clearly indicates two plates, although only one horn may be developed, rather than the single antapical projection of Dioxya which is less typical of peridiniaceans. Additionally, most Dioxya species appear confined to the Cretaceous, whereas most southern (Gondwana) species of Vozzhennikovia appear to be Eocene or younger. The Paleocene species, Vozzhennikovia spinulosa Wilson 1984c is somewhat atypical in this regard, although in all other respects its generic placement appears sound.

\section{Vozzhennikovia apertura (Wilson 1967a) Lentin \& Williams 1976}

$$
\text { Pl. 18, figs. 4-12 }
$$

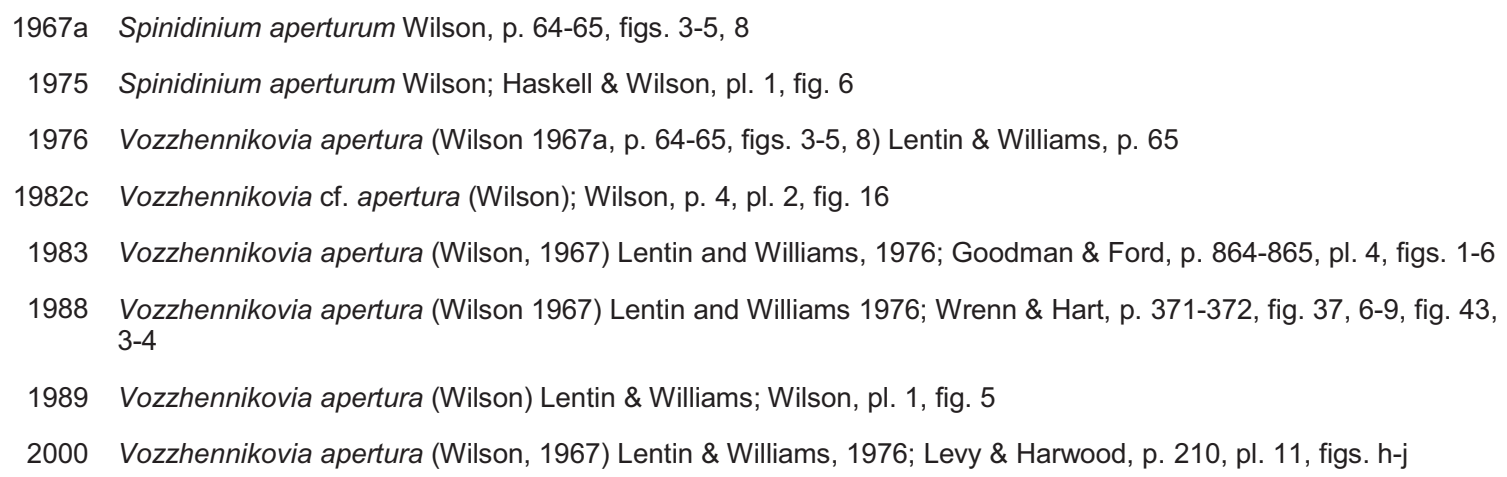

Original Description: Test broadly rounded to sub-angular, differentiated into two closely joined layers forming inner and outer cysts. Surface of outer cyst thickly covered with pointed or flat-tipped spines, evenly distributed over the dorsal and ventral surfaces except on transverse girdle and longitudinal furrow. Transverse girdle wide, deeply grooved, either non- spiral or very slightly laevo-rotatory, delimited by two parallel rows of closely spaced spines. Longitudinal furrow a very prominent deep groove devoid of spines. Apical horn relatively long $(I=8-10 \mu)$ rectangular and usually terminated by either one or two small spines; right antapical horn short $(I=2-3 \mu)$ pointed; left antapical horn absent but position defined by slight angularity in shell outline. Archeopyle very prominent, intercalary, hexagonal. located on dorsal epitheca. Operculum free, distinctive, often occurs totally separated from parent shell.... Atabulate (Wilson 1967a, p. 64-65).

Description of Study Material: Cysts small, proximate, somewhat dorso-ventrally compressed, with one apical horn; episome usually slightly longer than the generally rounded hyposome. Apical horn well developed, apex bluntly terminated; antapical horns small and weakly developed to completely lacking. Cyst wall two-layered; cornucavate. Archeopyle intercalary, type I (2a); eurythetaform to slightly euryomegaform; operculum free to attached, inner and outer layers adherent. Processes lacking; surface ornament comprising small non-tabular granules to short spines. Tabulation not expressed. Cingulum lacking to weakly expressed by surface ornament and folds in the periphragm. Sulcus generally moderately clear, expressed by an absence of surface ornament; more or less vertical; largely confined to the hyposome; lacking any clear indications of subdivision.

Size Range: Length including any processes $=33(38) 45 \mu \mathrm{m}$ (9 measurements). Width including any processes $=31$ (33) $35 \mu \mathrm{m}$ (3 measurements).

Distribution: Occurs infrequently in a handful of samples, although in one only (143/f092, L16340) specimens are common.

$\begin{array}{llll}\text { Age/Stage } & \text { Location } & \text { Sample } & \text { Sample Reference } \\ \text { Bortonian } & \text { Puketeraki Core, Oamaru-Dunedin, New Zealand } & \text { I43/f092 (L16340) } & \begin{array}{l}\text { Wilson \& McMillan } \\ 1996\end{array} \\ \begin{array}{l}\text { Porangan- } \\ \text { Bortonian }\end{array} & \begin{array}{l}\text { Hampden Beach Section, Oamaru-Dunedin, New } \\ \text { Zealand }\end{array} & \text { J42/f301 (L23131) } \\ \text { Eocene } & \text { northern Seymour Island, West Antarctica } & 8463 & \text { Wrenn \& Hart 1988 } \\ \text { Eocene } & \text { ClROS-1 drillhole, McMurdo Sound, Antarctica } & \text { SM3786 } & \text { Wilson 1989 } \\ \text { Eocene } & \text { erratics near Minna Bluff, McMurdo Sound, Antarctica } & \text { L4729 } & \text { Wilson 1967a } \\ \text { Eocene } & \text { erratics, McMurdo Sound, Antarctica } & \text { MB 109(1) } & \text { Levy \& Harwood 2000 } \\ & \text { erratics, McMurdo Sound, Antarctica } & \text { MTD 1B } & \text { Levy \& Harwood 2000 }\end{array}$


Remarks: The older forms included here, from the lower part of Hampden Beach (J42/f301, L23131; Porangan to ?Bortonian) have distinctly longer spines than the younger forms (and the Antarctic type material) and may represent a distinct species.

Vozzhennikovia rotunda is treated as a synonym of Vozzhennikovia apertura in Wrenn \& Hart 1988 (p. 371-372) on account of the existence of intermediates and the authors' observation that the two species are "end members of a morphologic continuum." As noted elsewhere herein, the existence of intermediates, per se, does not imply synonymy.

\title{
Subfamily Palaeoperidinioideae (Vozzhennikova 1961) Bujak \& Davies 1983
}

\author{
Genus Phthanoperidinium Drugg \& Loeblich Jr. 1967 emend. Clowes
}

\author{
1967 Phthanoperidinium Drugg \& Loeblich Jr., p. 182 \\ 1978 Phthanoperidinium Drugg \& Loeblich 1967; Stover \& Evitt, p. 118-119 \\ ?1980 Vectidinium Liengjarern et al., p. 490 \\ 1981 Phthanoperidinium Drugg \& Loeblich 1967 emend. Edwards \& Bebout, p. 36, 38 \\ 1982 Phthanoperidinium Drugg et Loeblich 1967 emend. Islam, p. 306 \\ 2004 Phthanoperidinium Drugg \& Loeblich Jr., 1967, p. 182; Fensome \& Williams, p. 524-526
}

Type Species: Phthanoperidinium amoenum Drugg \& Loeblich Jr. 1967, p. 182, pl. 1, figs. 1-5; text-fig. 1a-e [Oligocene]

Original Description: Proximate fossil cysts, more or less ovoidal in shape, with short apical projection. Tabulation 4', 3a, 7", 5'", 2'"'. Additional furrow platelets may be present. The archeopyle is formed by the removal of intercalary plate 2a. Sutures delimited by low ridges, crests, or lines of spines (Drugg \& Loeblich 1967, p. 182).

Emended Description: Small to medium sized peridinioid cysts; apical horn typically present though small, antapical horns either very much reduced or absent; cyst walls two-layered but with the layers closely appressed everywhere (acavate), except sometimes at horn bases (cornucavate); typically exhibiting a clear tabulation, formula 4', 3a, 7", X-6c, 5'”, 0p, 2'”', X-4s; dorsal epicyst topology broad hexa-style; ventral epicyst topology ortho-style; archeopyle primarily type I (2a) but sometimes involving additional plates 1a-3a and 3"-5", operculum or opercular pieces variably free or attached.

Remarks: The genus Phthanoperidinium was established by Drugg \& Loeblich Jr. 1967 (p. 182) to accommodate proximate peridinioid fossil cysts with a "more definite" tabulation, formula 4', 3a, 7", 5"', 2"'", and a single 2a intercalary archeopyle. The authors described but did not draw particular attention to the broad six-sided (hexastyle) archeopyle. Drugg \& Loeblich Jr. 1967, text-figure 1, depicts five cingular plates, although these are not enumerated in the text, and it is assumed that there are in fact six in the series (e.g. as noted by Stover \& Evitt 1978 , p. 118) but that plate 1c is not clearly differentiated from the sulcus (contrast Drugg \& Loeblich Jr. 1967, pl. 1 , fig. 5, with Evitt 1985, fig. 5.2A). It is clear there is no posterior intercalary plate; references to this plate in some older descriptions of Phthanoperidinium species are assumed to be misinterpretations.

The archeopyle is a broad hexa-style (Text-Fig. 15).

Goodman \& Ford 1983 draws attention to the importance of ventral epicyst plate topology in any analysis of Phthanoperidinium. Plate 1' of the type species, Phthanoperidinium amoenum, is clearly five-sided and in contact with plates 4', 2', 7", 1", and the anterior sulcal: a configuration known as the ortho-style (Text-Fig. 16). To my knowledge, however, this seminal suggestion has not previously been pursued with any enthusiasm, possibly because the diagnostic features are sometimes difficult to observe, even in specimens which can be studied at first hand, and all the more difficult when only published illustrations are available. Ignoring the practical difficulties, however, there is no reason to suppose there is any difference - in principle - between this distinction and other much better recognised distinctions, such as that between the L-type and S-type gonyaulacaceans.

Some species currently assigned to Phthanoperidinium are apparently ortho-style, some are not, and others are unknown. (Perhaps some are variable, but I am unaware of it. If that were found to be the case, the present emendation would be invalidated.) Observing that both ortho- and non-ortho types included within the genus, and believing the distinction to be important, has prompted this reappraisal of the genus.

In overall appearance, the genera most closely resembling Phthanoperidinium are Ginginodinium, Lentinia, Luxadinium, and Vectidinium among the Palaeoperidinioideae, and Gippslandia, Spinidinium, and Vozzhennikovia among the Deflandreoideae.

- Ginginodinium: Stover \& Evitt 1978 (p. 118) notes that Phthanoperidinium differs from Ginginodinium in having a Type I rather than the Type 3 I archeopyle of Ginginodinium, and in either lacking antapical horns or having a single, medial, antapical projection rather than two, more or less equally developed, antapical horns as in Ginginodinium. Subsequent studies have shown that most species of Phthanoperidinium are 
somewhat variable in respects of both plate involvement in the archeopyle, and in antapical horn formation, very much weakening the utility of these characteristics as differentiators. However, the fact remains that the type species of Ginginodinium is quite dissimilar in overall appearance, and is very much older than the core group of "good" Phthanoperidinium species which appear tightly knit in both morphology and in their Paleocene to mid-Oligocene stratigraphic ranges.

- Lentinia: The alignment of granules on the ventral epicyst of the genoholotype of Lentinia (Bujak 1980, pl. 18, fig. 9) strongly supports an ortho-style interpretation (Bujak 1980, text-fig. 18A, C). However, Lentinia differs from Phthanoperidinium in possessing two well and approximately equally developed antapical horns, and an unusually large archeopyle.

- Luxadinium: Luxadinium is variously described as cavate (Brideaux \& Mclntyre 1975, p. 36), bicavate, circumcavate, or "possibly cornucavate" (Stover \& Evitt 1978). Only the last condition is comparable with Phthanoperidinium, but this does appear to be the case for the holotype of the type species of Luxadinium, L. primulum. But, although there may be some mechanistic difficulty formulating a clear morphological distinction between these two genera, the wide separation in time between Luxadinium primulum (mid Albian) and Phthanoperidinium, as defined herein, militates against any proposal for synonymy.

- Vectidinium: Vectidinium was considered a junior synonym of Phthanoperidinium by Islam (1982), having reviewed the type material of the type and only species, Vectidinium stoveri. Although Lentin \& Williams 1985 (p. 364) and subsequent editions of the Catalogue, including the most recent (Fensome \& Williams 2004), retain Vectidinium, Islam's view is provisionally accepted here. Islam did not, however, re-describe the species in any detail, so no further comment is made.

The Deflandreoideae differ from Phthanoperidinium at the subfamilial level in possessing archeopyles which involve the intercalary plates only (Fensome et al. 1993b, p. 129). However, as noted above and in many previous works, this is often true for Phthanoperidinium and it is true for some other Palaeoperidinioideae genera also.

- Gippslandia: Gippslandia shares the broad, hexastyle archeopyle of Phthanoperidinium (and is in several respects reminiscent of Lentinia, also). The topology of the ventral epicyst is neither discussed nor clearly shown by any of the illustrations in the type species description (Stover 1974) and is not mentioned in the original generic diagnosis (Stover \& Williams 1987). Topotype material generously provided to the writer by Alan Partridge, although less than fully conclusive, includes several specimens with an alignment of granules that is entirely consistent with the ortho-style (Text-Fig. 19). Remaining distinctions between Gippslandia and Phthanoperidinium are that precingular plates are never involved in the archeopyle formation of Gippslandia, and the ornament type: sutural or penitabular in the case of Phthanoperidinium and intratabular in the case of Gippslandia. It is quite evident, however, that similar ornament types recur again and again in genera which are as distantly related as peridiniaceans and gonyaulacaceans; these kinds of features, while useful species-level distinctions, offer little insight at higher taxonomic levels.

- Spinidinium: Historically, Phthanoperidinium has been distinguished from Spinidinium by its possession of sutural features of various sorts, rather than intratabular ornament only. As noted

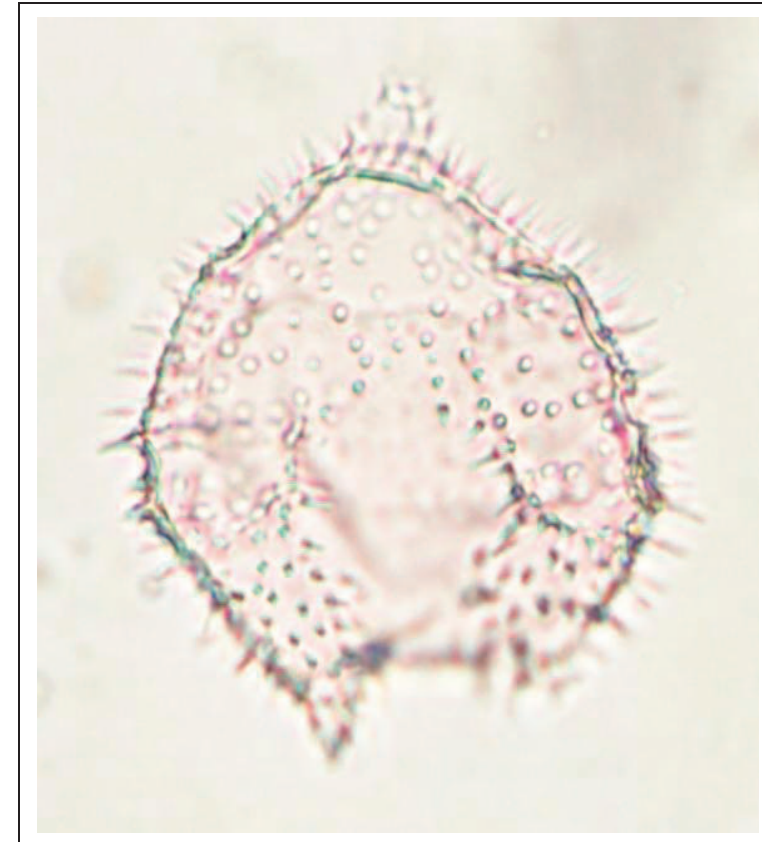

Text-Fig. 19: Topotype of Gippslandia extensa showing ventral surface of episome. The alignment of spines seems to indicate an ortho-style tabulation. above, these sorts of ornamental distinctions clearly have little phylogenetic meaning, so more profound distinctions are desirable at generic and higher taxonomic ranks. I consider it far more significant that Phthanoperidinium possesses a standard to broad hexa-style plate $2 \mathrm{a}$, whereas Spinidinium has an attenuated to standard hexa-style plate $2 a$ in the sense of Lentin \& Williams 1976 (text-fig. 4). That of the genoholotype of Spinidinium is very narrow (Cookson \& Eisenack 1962b, pl. 1, fig. 2; Morgan 1975, pl. 2, fig. 1d). The ventral plate topology of $S$. styloniferum appears to exhibit the same ortho-style arrangement as Phthanoperidinium (Cookson \& Eisenack 1962b, pl. 1, fig. 4; Morgan 1975, pl. 2, fig. 1b).

- Vozzhennikovia: Vozzhennikovia differs from all of the above in possessing non-tabular ornament and, in consequence, having a tabulation which is unknown apart from the archeopyle, which is clearly intercalary. However, as noted above, this is a methodological problem with no intrinsic phylogenetic significance at generic and higher taxonomic rank.

A range chart for species of Phthanoperidinium is provided in Appendix 2, chart 7. 
Key to selected species: The following key distinguishes most of the forms found in the present study; it is not intended to comprehensively address the entire genus.

\begin{tabular}{|c|c|c|}
\hline \multirow[t]{3}{*}{0.} & Surface ornament of very low relief (less than $\sim 1 \mu \mathrm{m}) \ldots$. & 1. \\
\hline & Surface ornament slightly elevated $(2-3 \mu \mathrm{m}) \ldots$. & 2. \\
\hline & Surface ornament of relatively high relief (a significant fraction of the cyst diameter) .... & 3. \\
\hline \multirow[t]{3}{*}{1.} & Sutural ridges present .... & 1.1. \\
\hline & Sutural plus penitabular ridges present .... & 1.2. \\
\hline & Surface ornament is non-tabular .... & 1.3. \\
\hline \multirow[t]{2}{*}{1.1.} & Intratabular areas smooth, or varying from shagreenate to vermiculate .... & 1.1.1. \\
\hline & Intratabular areas distinctly scabrate .... & 1.1.2. \\
\hline 1.1.1. & \multicolumn{2}{|l|}{ Phthanoperidinium amoenum } \\
\hline 1.1.2. & \multicolumn{2}{|l|}{ Phthanoperidinium granulatum } \\
\hline 1.2. & \multicolumn{2}{|l|}{ Phthanoperidinium geminatum } \\
\hline 1.3. & \multicolumn{2}{|l|}{ Phthanoperidinium spumosum } \\
\hline \multirow[t]{3}{*}{2.} & Surface ornament comprising low crests .... & 2.1. \\
\hline & Surface ornament comprising squat, non-tabular (or intratabular) echinae .... & 2.2. \\
\hline & Surface ornament comprising sutural or penitabular papillae .... & 2.3 \\
\hline \multirow[t]{2}{*}{2.1.} & Antapical horns absent or weak .... & 2.1.1. \\
\hline & A single antapical horn developed .... & 2.1.2. \\
\hline 2.1.1. & \multicolumn{2}{|l|}{ Phthanoperidinium ?crenulatum } \\
\hline 2.1.2. & \multicolumn{2}{|l|}{ Phthanoperidinium eocenicum } \\
\hline 2.2. & \multicolumn{2}{|l|}{ Phthanoperidinium dentatum } \\
\hline 2.3. & \multicolumn{2}{|l|}{ Phthanoperidinium echinatum } \\
\hline \multirow[t]{3}{*}{3.} & Spines very thin and delicate .... & 3.1. \\
\hline & Spines slender and sinuous .... & 3.2. \\
\hline & Spines robust and dagger-like .... & 3.3. \\
\hline 3.1. & \multicolumn{2}{|l|}{ Phthanoperidinium tenuimurum } \\
\hline 3.2. & \multicolumn{2}{|l|}{ Phthanoperidinium tritonium } \\
\hline 3.3. & \multicolumn{2}{|l|}{ Phthanoperidinium aculeatum } \\
\hline
\end{tabular}

Phthanoperidinium ?crenulatum (De Coninck 1975) Lentin \& Williams 1977b emend. HeilmannClausen 1985

PI. 19, figs. 1-6

1975 Peridinium crenulatum De Coninck, p. 96, pl. 17, figs. 5-7, 12-15

1977b Phthanoperidinium crenulatum (De Coninck, 1969, p. 96, pl. 17, figs. 5-7, 12-15) Lentin \& Williams, p. 131

1995a Phthanoperidinium crenulatum (De Coninck, 1969); De Coninck, pl. 7, figs. 3-5

Original Description: The outline of the body is roundly pentagonal. The archeopyle is intercalary. Serrated ridges (Latin: crenulatus) show the tabulation. I could see 7 precingular plates and 5 postcingular plates. The girdle is relatively large and helicoidal; The distance between the extremities is roughly equivalent to its width. The longitudinal furrow is larger than the girdle. There is a short horn on the apex on which the serrated ridges rise up. At the antapex the ridges become higher and suggest two weakly developed antapical horns (De Coninck 1975, p. 96).

Description of Study Material: Cysts of intermediate size, proximate, not dorso-ventrally compressed, prolate to peridinioid, usually with one apical horn; episome usually somewhat longer than hyposome. Apical horn variably developed up to about $5 \mu \mathrm{m}$; antapical horns weak to lacking. Cyst wall two-layered; acavate. Archeopyle intercalary, type I (2a). Processes lacking; surface ornament present, sutural, comprising crests; slightly elevated. Crests sutural, 2-3 $\mathrm{mm}$, margins of crests granulate. Inferred formula: 4', 3a, 7", 6c, 5"', ?ps, 2"'', X-5s; ventral organisation probably ortho-style. Cingulum clearly expressed, indicated by sutural septa; offset only slightly. Sulcus moderately expressed, indicated by sutural septa. 
Size Range: Length excluding any processes $=58 \mu \mathrm{m}$ (one measured specimen). Width excluding any processes $=47 \mu \mathrm{m}$ (one measured specimen). Length including any processes $=45(53) 61 \mu \mathrm{m}(9$ measurements). Width including any processes $=37$ (45) $53 \mu \mathrm{m}$ (4 measurements).

\section{Distribution:}

$\begin{array}{llll}\text { Age/Stage } & \text { Location } & \text { Sample } & \text { Sample Reference } \\ \text { Bortonian } & \text { Puketeraki Core, Oamaru-Dunedin, New Zealand } & \text { I43/f093 (L16341) } & \text { Wilson \& McMillan 1996 } \\ \text { Bortonian } & \text { Puketeraki Core, Oamaru-Dunedin, New Zealand } & \text { I43/f089 (L16337) } & \text { Wilson \& McMillan 1996 } \\ \text { Lutetian } & \text { Mol borehole, Belgium } & 309.8 \mathrm{~m} & \text { De Coninck 1995a }\end{array}$

Phthanoperidinium dentatum Clowes \& Wilson n. sp.

Pl. 19, figs. 7-12, PI. 20, figs. 1-3

1982b Phthanoperidinium cf. resistente (Morgenroth); Wilson, p. 7, pl. 1, figs. 4-6

1985 Spinidinium sp.; Wilson, p. 99, pl. 1, figs. 9-10

Derivation of Name: Latin, dentatus, toothed; with reference to the tooth-like processes.

Holotype: Sample J42/f8690, slide L06958/SM0382; Hampden Formation, Hampden Beach Section (Bortonian); PI. 19, figs. 7-12

Description: Cyst small, ellipsoidal, bilayered, with both layers closely appressed. A short relatively broad toothlike apical horn is present (length $\sim 4 \mu \mathrm{m}$ ) and a short narrow left antapical horn is sometimes present in the middle part of the antapical margin; the right antapical horn is not developed. Tabulation defined by parasutural rows of short solid tooth-like processes (length $\sim 2 \mu \mathrm{m}$ ), often joined proximally by low solid septa. Tabulation pattern peridiniacean: 4', 3a, 7", Xc, 5"', 2"'”, Xs. Isolated intratabular processes may be present in the central part of some plates; otherwise surface smooth. Archeopyle fairly prominent, intercalary type I; operculum generally free or may be partly attached. Cingulum relatively broad $(\sim 5 \mu \mathrm{m})$ and not generally segmented. Sulcus expressed as narrow midventral depression on the hypocyst; not usually differentiated into plates.

Size Range: Length including any processes $=40$ (42) $43 \mu \mathrm{m}$ (2 measurements). Width including any processes $=34$ (37) $40 \mu \mathrm{m}$ (2 measurements).

Distribution:

$\begin{array}{llll}\text { Age/Stage } & \text { Location } & \text { Sample } & \text { Sample Reference } \\ \text { Bortonian } & \text { Hampden Beach Section, Oamaru-Dunedin, New Zealand } & \text { J42/f8690 (L06958) } & \text { Wilson 1982b } \\ \text { Porangan-Bortonian } & \text { Hampden Beach Section, Oamaru-Dunedin, New Zealand } & \text { J42/f485 (L23120) }\end{array}$

Comparison: Phthanoperidinium dentatum is distinguished from other species mainly by its robust, tooth-like sutural processes. The spines of $P$. ?crenulatum occupy the same position on the cyst, but are far smaller; those of $P$. echinatum and $P$. geminatum are penitabular rather than sutural.

Remarks: At its type locality, the Hampden Beach section, Phthanoperidinium dentatum is associated with abundant Wetzeliella hampdenensis, a typical mid Bortonian species. (Also see Wilson 1985.)

Phthanoperidinium echinatum Eaton 1976

PI. 20, figs. 4-12

$\begin{aligned} 1976 & \text { Phthanoperidinium echinatum Eaton, p. 298-299, pl. 17, figs. 8-9, 12; text-fig. 23B } \\ 1980 & \text { ?Phthanoperidinium pseudoechinatum Bujak, p. 75-76, pl. 19, fig. 20, text-fig. 20c } \\ 1982 & \text { Phthanoperidinium echinatum Eaton 1976; Islam, p. 309, 311, pl. 1, fig. } 1 \\ 1995 a & \text { Phthanoperidinium echinatum Eaton, 1976; De Coninck, pl. 7, fig. } 6 \\ 2000 & \text { Phthanoperidinium echinatum Eaton 1976; Levy \& Harwood, p. 208, pl. 8, figs. g-I }\end{aligned}$

Original Description: Cyst body has a smooth surface, and a subcircular or rounded polygonal outline modified by a short blunt apical horn. Plate boundaries accentuated by a distinctive ornament concentrated at the plate margins, consisting of short hair-like projections [up to $3 \mu \mathrm{m}$ long], each with a bulbous spherical distal termination. Cingular zone clearly defined and slightly helicoid. Reflected tabulation 4', 3a, 7", 5"', 2"';; archeopyle intercalary, formed by displacement of plate 2a (Eaton 1976, p. 298). 
Description of Study Material: Medium sized, proximate cysts, prolate, usually with an apical horn, cingulum equatorial, most plates defined by coarsening of the surface ornament towards the sutures, immediately adjacent to which short capitate spines may be developed. An apical horn up to approximately $5 \mu \mathrm{m}$ long, and quite acute, may be developed; antapical horns lacking. Archeopyle intercalary; operculum free (not recognised). Cyst walls are not distinguishable into layers; assumed to comprise two layers closely appressed; thin $(\sim 1 \mu \mathrm{m})$. Ornament comprising small granules which are relatively small and sparse in the centres of the plates, coarsening and more frequent towards plate margins; the surface essentially smooth between granules. Immediately adjacent to the sutures, the ornament becomes roughly organised into a penitabular row where short (up to $\sim 2-3 \mu \mathrm{m}$ ) capitate spines are variably developed. The spines are typically straight or gently arcuate, unbranched, capitate, apparently solid and non-fibrous, more or less homogenous across the entire surface although it is possible those in the gonal areas may be somewhat larger. They delineate all plate series though the tabulation is not easily determined. The cingulum is about $6 \mu \mathrm{m}$ wide, laevorotatory, offset at the sulcus by approximately one width. The sulcus is variably delineated by alignment of relatively coarse ornamentation, having indications of division into plates.

Size Range: Length excluding any processes $=50 \mu \mathrm{m}$ (one measured specimen). Width excluding any processes $=40 \mu \mathrm{m}$ (one measured specimen). Length including any processes $=42(52) 65 \mu \mathrm{m}(10$ measurements). Width including any processes $=35$ (39) $45 \mu \mathrm{m}$ (4 measurements).

\title{
Distribution:
}

$\begin{array}{llll}\text { Age/Stage } & \text { Location } & \text { Sample } & \text { Sample Reference } \\ \text { late Eocene } & \text { Middle Barton Beds, Barton, Hampshire, southern England } & \text { V59898 } & \text { Bujak 1980 } \\ \text { Bartonian } & \text { Kallo borehole, Belgium } & 135.5 \mathrm{~m} & \text { De Coninck 1995a } \\ \text { Bortonian } & \text { Puketeraki Core, Oamaru-Dunedin, New Zealand } & \text { I43/f093 (L16341) } & \text { Wilson \& McMillan 1996 } \\ \text { Bortonian } & \text { Puketeraki Core, Oamaru-Dunedin, New Zealand } & \text { I43/f089 (L16337) } & \text { Wilson \& McMillan 1996 } \\ \text { middle Eocene } & \text { Middle Bagshot Beds, Shapley Heath, southern England } & \text { C1752(2) } & \text { Islam 1982 } \\ \text { Eocene } & \text { erratics, McMurdo Sound, Antarctica } & \text { MB 181(2) } & \text { Levy \& Harwood 2000 } \\ \text { Eocene } & \text { erratics, McMurdo Sound, Antarctica } & \text { MTD 42 } & \text { Levy \& Harwood 2000 }\end{array}$

Comparison: Phthanoperidinium echinatum differs from $P$. aculeatum and $P$. tritonium in having considerably shorter processes $(<4 \mu \mathrm{m}$ long), which are typically minutely capitate rather than attenuated, and which are arranged in two rows, one each side of but very close to the plate sutures, rather than in single file atop sutural crests.

Remarks: This species has been regarded as a junior synonym of $P$. stockmansii by De Coninck (1977, p. 40), "probably" by Edwards \& Bebout 1981 (p. 34), and by implication in Islam 1982 (p. 315; although Islam mistakenly considered $P$. echinatum to be the senior name). Unfortunately, the scant morphological details and tiny, coarse-grained photographs of $P$. stockmansii provided by the original description do not permit a confident determination. Pending a modern redescription of the type material, I have opted to refer the present material to Eaton's more expansively described taxon.

Phthanoperidinium pseudoechinatum is regarded as a junior synonym, as first proposed by Islam (1982, p. 309, 311 ), because the only difference in the original descriptions is the number of plates involved in archeopyle formation which is now believed to be a variable, possibly ecologically variable, character.

\section{Phthanoperidinium eocenicum (Cookson \& Eisenack 1965a) Lentin \& Williams 1973}

$$
\text { PI. 21, figs. 1-6 }
$$

\author{
1965a Peridinium eocenicum Cookson \& Eisenack, p. 119-120, pl. 11, figs. 1-5 \\ 1973 Phthanoperidinium eocenicum (Cookson and Eisenack, 1965a, p. 119-120, pl. 11, figs. 1-5) Lentin \& Williams, \\ p. 113 \\ 1982b Phthanoperidinium eocenicum (Cookson \& Eisenack); Wilson, p. 8, pl. 3, fig. 9
}

Original Description: Shell small, oval, tabulated and divided almost equally by a relatively broad, helicoid girdle. Both epitheca and hypotheca with a small, solid horn. Wall of shell finely granular with or without small dot-like thickenings of variable size on the surface of the plates... The borders of the girdle and the thin transparent ledges of the plates are lightly granular and their edges dotted with evenly spaced granules and small tubercles, or sparsely denticulate. Tabulation is of the Peridinium type, 4' ?, 3a, 7", 5'”, 1p, 2'”'. Plate 1' is kite-like in shape, the two upper sides of the 'rhomb' being shorter than the two lower. Plate 1'"' is very narrow. Intercalary strips are sometimes evident. The archeopyle is relatively large, hexagonal, and intercalary (Cookson \& Eisenack 1965a, p. 119; ellipses replace figure references in the original).

Description of Study Material: Cysts small, proximate, not dorso-ventrally compressed, prolate, with one apical and one antapical horn; episome and hyposome more or less equal in length. Apical horn moderately welldeveloped, apex pointed; antapical horns single antapical horn developed, relatively pointed. Cyst wall two- 
layered; acavate. Archeopyle intercalary, type I (2a). Processes lacking; sutural, comprising crests; 2-3 $\mu \mathrm{m}$ high. Margins of crests granulate. Tabulation weakly expressed, apparently peridiniacean, inferred formula: 4', 3a, 7", 6c, 5"', ?ps, 2"'", X-5s. Cingulum weakly expressed, indicated by sutural septa. Sulcus weakly expressed, indicated by sutural septa; lacking any clear indications of subdivision.

Size Range: Length including any processes $=42$ (48) $64 \mu \mathrm{m}$ (17 measurements). Width including any processes $=35$ (41) $45 \mu \mathrm{m}$ (3 measurements).

\title{
Distribution:
}

$\begin{array}{llll}\text { Age/Stage } & \text { Location } & \text { Sample } & \text { Sample Reference } \\ \text { Kaiatan-Runangan } & \text { Jacksons Paddock, Oamaru-Dunedin, New Zealand } & \text { J41/f8914 (L04979) } & \text { Wilson 1982b } \\ \text { Bortonian } & \text { Puketeraki Core, Oamaru-Dunedin, New Zealand } & \text { I43/f094 (L16342) } & \text { Wilson \& McMillan 1996 } \\ \text { Bortonian } & \text { Puketeraki Core, Oamaru-Dunedin, New Zealand } & \text { I43/f090 (L16338) } & \text { Wilson \& McMillan 1996 }\end{array}$

Remarks: Lentin \& Williams (1973, p.113) moved Peridinium eocenicum to Phthanoperidinium provisionally, as Phthanoperidinium ?eocenicum, without any comment as to why they regarded the assignment as provisional. The question mark over the assignment persists to this day in some publications (e.g. Fensome \& Williams 2004 p. 525) although, again, without any explicit rationale as far as I am aware. The ventral episome plate topology is clearly ortho-style (Cookson \& Eisenack 1965a, pl. 11, fig. 1) and in almost all other respects the species appears to be a "good" Phthanoperidinium. The majority of authors who have discussed Phthanoperidinium in some detail, including Edwards \& Bebout 1981, and Islam 1982, appear to have dismissed the only apparent anomaly - the mention of plate $1 p$ in the original description - as an error, and accepted eocenicum as a legitimate member of the genus. The interpretation followed here is that the "very narrow" plate 1"' of the original description is, in fact, a sulcal plate, and plate " $1 p$ " is 1 "'.

Stover \& Evitt (1978, p.119) considered Phthanoperidinium stockmansii and $P$. ?resistente to be possible junior synonyms of $P$. eocenicum. However, insofar as $P$. echinatum can be taken as a proxy for $P$. stockmansii, the two taxa are easily distinguished by the penitabular versus tabular arrangement of the ornament. Moreover, $P$. ?resistente is "very small": 33-42 $\mu \mathrm{m}$ long, $25-31 \mu \mathrm{m}$ broad, horns 3-4 $\mu \mathrm{m}$ (Morgenroth 1966a, p. 5), whereas $P$. eocenicum, by contrast, is significantly larger: 48-62 $\mu \mathrm{m}$ long, 33-48 $\mu \mathrm{m}$ broad (Cookson \& Eisenack 1965a, p. 120), and also differs in possessing noticeably finer-grained sculpturing. The New Zealand material does not particularly support the contention that $P$. ?resistente and $P$. eocenicum are synonyms; Edwards \& Bebout (1981, table 1) thought it "unlikely" also.

New Zealand specimens which appear identical to the Australian type material for this species.

\section{Phthanoperidinium geminatum Bujak 1980}

$$
\text { Pl. 21, figs. 7-12 }
$$

\author{
1980 Phthanoperidinium geminatum Bujak, p. 72, 74, pl. 19, figs. 8-12; text-figs. 20D, 22A \\ 2004 Phthanoperidinium geminatum; Eldrett et al., p. 111-112, pl. III, fig. 2 \\ 2005 Phthanoperidinium geminatum; Schiøler, pl. 13, fig. 9
}

Original Description: Pericyst ovoidal with one small apical horn and one or two unequal antapical horns, the right always being strongly reduced. An endocyst is rarely visible. The periphragm is chagrinate to granulate with parasutural rows of granules, short spines, or low crests. These delimit a paratabulation of 4', 3a, 7", xc, 5'”, 2'”'. Simulate rows or zones of similar ornament are always present and lie $1 \mu \mathrm{m}$ to $3 \mu \mathrm{m}$ inside the parasutures, except for those bordering the paracingulum on the precingular and postcingular paraplates. These typically merge with the cingular parasutures. An archeopyle is formed by the loss of paraplate 2a (Bujak 1980, p. 74).

Description of Study Material: Cysts small to intermediate, proximate, not dorso-ventrally compressed, prolate, with one apical and one or two unequal antapical horns; episome and hyposome more or less equal in length. Apical horn well developed; antapical horns unequal, the right strongly reduced or absent. Cyst wall two-layered; acavate; relatively robust, about $2 \mu \mathrm{m}$ in thickness. Archeopyle intercalary, type I (2a); operculum free. Processes lacking; sutural plus penitabular, comprising crests; very low (about $1 \mu \mathrm{m}$ or lower). Inferred formula: 4', 3a, 7", Xc, 5"', 2"'".

Size Range: Width excluding any processes = 35 (39) $43 \mu \mathrm{m}$ (3 measurements). Length including any processes $=42$ (48) $60 \mu \mathrm{m}$ (14 measurements). Width including any processes = 32 (40) $50 \mu \mathrm{m}$ (5 measurements).

\section{Distribution:}

$\begin{array}{llll}\text { Age/Stage } & \text { Location } & \text { Sample } & \text { Sample Reference } \\ \text { Bortonian } & \text { Puketeraki Core, Oamaru-Dunedin, New Zealand } & \text { I43/f093 (L16341) } & \text { Wilson \& McMillan 1996 } \\ \text { Bortonian } & \text { Puketeraki Core, Oamaru-Dunedin, New Zealand } & \text { I43/f092 (L16340) } & \text { Wilson \& McMillan 1996 }\end{array}$


?Phthanoperidinium ?granulatum Clowes \& Wilson n. sp.

PI. 22, figs. 1-6

Derivation of Name: Latin, granulatus, granulated; with reference to the granulate surface.

Holotype: Sample 143/f108, slide L16358/SM4832; Burnside Formation, Tumai (Runangan); PI. 22, figs. 1-6

Description: Cyst small, proximate, ellipsoidal, two layered, with both layers closely appressed. A short fairly broad apical horn (length $\sim 5 \mu \mathrm{m}$ ) with a blunt tip is usually present but the antapex is usually rounded without a horn. Tabulation defined by rows of low narrow smooth parasutural septa which are more prominent along the cingular borders. Tabulation pattern peridiniacean: 4', 3a, 7", Xc, 5"',2"', Xs. Surface of cyst covered with small low rounded granules. Archeopyle fairly prominent, intercalary type I; operculum generally free or may be partly attached. Cingulum relatively broad $(\sim 5 \mu \mathrm{m})$ and not generally segmented. Sulcus expressed as narrow midventral depression on the hypocyst; not usually differentiated into plates.

Size Range: Width excluding any processes $=43$ (45) $48 \mu \mathrm{m}$ (3 measurements). Length including any processes $=46$ (53) $61 \mu \mathrm{m}$ (4 measurements). Width including any processes $=35$ (44) $50 \mu \mathrm{m}$ (4 measurements).

Distribution:

$\begin{array}{llll}\text { Age/Stage } & \text { Location } & \text { Sample } & \text { Sample Reference } \\ \text { Runangan } & \text { Tumai, Oamaru-Dunedin, New Zealand } & \text { I43/f108 (L16358) } & \text { Wilson \& McMillan } 1996\end{array}$

Comparison: Phthanoperidinium granulatum is characterised by its granulate surface and smooth low sutural septa, in which respect it is broadly similar to the type species, Phthanoperidinium amoenum. However, it differs from Phthanoperidinium amoenum in having a generally more rounded shape, more prominent intratabular granules, and less clearly diamond shaped plate $1^{\prime}$. (Indeed, there must remain some doubt about the generic assignment of this species on this account.)

Phthanoperidinium ?resistente (Morgenroth 1966a) Eisenack \& Kjellström 1972

PI. 22, figs. 7-9

1966a Peridinium resistente Morgenroth, p. 5, pl. 2, figs. 1-2

1972 Phthanoperidinium resistente (Morgenroth, 1966a, p. 5, pl. 2, figs. 1-2) Eisenack \& Kjellström, p. 911

Original Description: [Diagnosis] A very small species of the genus Peridinium Ehrenberg with the following tabulation scheme: ?4', ?3a, 7", 5", 2"'. Stair-like pointed antapical horn. Two tiny antapical horns. Transverse furrow defined. Longitudinal furrow clear.

[Description] The small, pear-shaped theca consists of plates with a smooth surface, only occasionally can light granulation be detected. Granulation is greater on the plate sutures. Epitheca and hypotheca are similar sizes. The epitheca tapers off in a stair-like, pointed apical horn. The 3-4 $\mu$ wide, shallow cingulum runs in a counter clockwise spiral direction. Both ends are offset from each other by approximately 1 furrow width. The wide longitudinal furrow runs from the first apical plate to the antapex. Two tiny conical antapical horns protrude from both antapical plates, only one of which is indicated. The pylome is formed from the separation of plate $2 a$.

[Remarks] Peridinium resistente n. sp. is distinguished from other well-known fossil forms by its habitus, above all however by its small dimensions [ 40 $\mu \mathrm{m}$ long] (Morgenroth 1966a, p. 5).

Description of Study Material: Cysts small, proximate, not dorso-ventrally compressed, prolate. Antapical horns 2 tiny horns developed. Cyst wall two-layered; acavate. Archeopyle intercalary, type I (2a); operculum free. Surface ornament lacking to present, sutural, comprising granules; very low (about $1 \mu \mathrm{m}$ or lower). Inferred formula: 4', 3a, 7", 6c, 5"', ?ps, 2"', X-5s. Cingulum clearly expressed.

Size Range: Length including any processes = 43 (46) $48 \mu \mathrm{m}$ (2 measurements). Width including any processes $=35 \mu \mathrm{m}$ (one measured specimen).

Distribution:

\begin{tabular}{llll}
\hline Age/Stage & Location & Sample & Sample Reference \\
Bortonian & Puketeraki Core, Oamaru-Dunedin, New Zealand & I43/f093 (L16341) & Wilson \& McMillan 1996
\end{tabular}

Remarks: Morgenroth 1966a, p. 5, comments that the species is "very small". The dimensions given for the type material - 33-42 $\mu \mathrm{m}$ long, $25-31 \mu \mathrm{m}$ broad, horns $3-4 \mu \mathrm{m}$ - are somewhat smaller than is usual of Phthanoperidinium species, though not extremely so. Usefully, however, it is significantly smaller than P. eocenicum (48-62 $\mu \mathrm{m}$ long, 33-48 $\mu \mathrm{m}$ broad; Cookson \& Eisenack 1965a, p. 120), which it otherwise 
resembles somewhat. The sutural ornament of $P$. resistente appears more coarsely granular than that of P. eocenicum.

The present forms are intermediate between the two in size, but more coarsely ornamented than those herein attributed to $P$. eocenicum, and are assigned to $P$. resistente provisionally.

Phthanoperidinium spumosum Clowes n. sp.

PI. 22, figs. 10-12, PI. 23, figs. 1-3

Derivation of Name: Latin, spumosus, foaming or frothy; with reference to the surface texture.

Holotype: Sample 143/f093, slide L16341/SM078; Burnside Formation, Puketeraki Core (Bortonian); PI. 22, figs. 10-12, PI. 23, figs. 1-3

Description: Medium sized, proximate cysts, prolate, lacking horns, cingulum equatorial, most plates defined by alignment of the sculptural features above the sutures. Archeopyle intercalary; operculum attached. Sculpturing of the surface layer permits differentiation of the cyst walls into two layers when viewed in cross-section; the layers approximately equal in thickness; combined thickness $\sim 3 \mu \mathrm{m}$. Ornament comprising a reticulum in which the lacunae are small $(\sim 0.5$ up to, exceptionally, $\sim 3 \mu \mathrm{m})$ and circular. Alignments or coarsening of the reticulum at the sutures delineates most plate series though the tabulation is not easily determined. The cingulum is about $7 \mu \mathrm{m}$ wide. The sulcus is poorly delineated and does not exhibit division into plates.

Size Range: Length $=45 \mu \mathrm{m}$ (one measured specimen). Width $=37 \mu \mathrm{m}$ (one measured specimen).

Distribution: Rare, and resricted to only a few samples of Bortonian age, perhaps suggesting a narrow stratigraphic range.

$\begin{array}{llll}\text { Age/Stage } & \text { Location } & \text { Sample } & \text { Sample Reference } \\ \text { Bortonian } & \text { Puketeraki Core, Oamaru-Dunedin, New Zealand } & \text { I43/f093 (L16341) } & \text { Wilson \& McMillan } 1996 \\ \text { Bortonian } & \text { Puketeraki Core, Oamaru-Dunedin, New Zealand } & \text { I43/f089 (L16337) } & \text { Wilson \& McMillan 1996 }\end{array}$

Comparison: The rounded lacunae of the reticulum are quite distinctive and serve to distinguish $P$. spumosum from all other Phthanoperidinium known at this time.

Phthanoperidinium aculeatum Clowes n. sp.

$$
\text { PI. 23, figs. 4-9 }
$$

?1972 Phthanoperidinium sp.; Benedek, p. 20, pl. 4, fig. 9

Derivation of Name: Latin, aculeatus, prickly, stinging; with reference to the formidable-looking spinose ornament.

Holotype: Sample 143/f093, slide L16341/SM082A; Burnside Formation, Puketeraki Core (Bortonian); PI. 23, figs. 4-9.

Description: Cysts of intermediate size, proximochorate, prolate, with one apical horn; episome somewhat shorter than hyposome. Apical horn variably developed up to about $5 \mu \mathrm{m}$; antapical horns weak to lacking. Cyst wall twolayered; acavate; relatively robust, about $2 \mu \mathrm{m}$ in thickness. Archeopyle intercalary, type I (2a). Sutural, comprising spines. Nature of spines robust and dagger-like, length of spines generally less than about 12-13 $\mu \mathrm{m}$. Inferred formula: 4', 3a, 7", 6c, 5"', ?ps, 2"'", X-5s. Cingulum clearly expressed, indicated by surface ornament, about $4 \mu \mathrm{m}$ wide; offset strongly, by about 1 width. Sulcus clearly expressed, indicated by surface ornament; more or less vertical; showing indications of subdivision into individual plates.

Size Range: Length excluding any processes $=47$ (48) $50 \mu \mathrm{m}$ (2 measurements). Width excluding any processes $=32$ (35) $38 \mu \mathrm{m}$ (2 measurements). Length including any processes $=52$ (61) $70 \mu \mathrm{m}$ (2 measurements). Width including any processes $=42$ (50) $58 \mu \mathrm{m}$ (2 measurements).

\section{Distribution:}

$\begin{array}{llll}\text { Age/Stage } & \text { Location } & \text { Sample } & \text { Sample Reference } \\ \text { Bortonian } & \text { Puketeraki Core, Oamaru-Dunedin, New Zealand } & \text { I43/f093 (L16341) } & \text { Wilson \& McMillan 1996 } \\ \text { Bortonian } & \text { Puketeraki Core, Oamaru-Dunedin, New Zealand } & \text { I43/f089 (L16337) } & \text { Wilson \& McMillan 1996 }\end{array}$

Comparison: Phthanoperidinium aculeatum is readily distinguished by the other spinose forms discussed here, $P$. comatum, tritonium, and tenuimurum, by the more robust spines. 


\section{Phthanoperidinium tenuimurum Clowes n. sp.}

$$
\text { PI. 23, figs. 10-12 }
$$

Derivation of Name: Latin, tenuis, thin, slender, slight; plus murus, a wall; with reference to the very thin cyst walls.

Holotype: Sample S14/f8599, slide L10662/SM014; Waikato Coal Measures, Old Mountain Road (Runanganearly Whaingaroan); PI. 23, figs. 10-12

Description: Prolate cysts with slightly acute apex and antapex, antapical hemisphere much smaller than apical, round in cross section; cingulum represented by distinct folds and lacks significant laevorotatory offset; homogeneous, short, solid, non-fibrous, unbranched spines, 5-10 $\mathrm{mm}$, with simple, acute tips mostly (?always) arise, often in groups of two or three, from sutural crests of varying but consistently low height. Cyst walls twolayered, but the different layers are not clearly discernible, being thin (combined thickness $<\sim 0.5 \mu \mathrm{m}$ ) and very closely appressed. Archeopyle intercalary; with flat bottom edge, sides and top rounded; sometimes extending into splits between apical plates. Operculum free. A small $(\sim 1.5-7.5 \mu \mathrm{m})$ and sometimes indistinct apical horn is continuous with a crest which runs up the side of the sulcus and carries a cluster of four or five spines. Surface finely scabrate. Tabulation is apparent from the sutural crests, cingular folds and archeopyle; cingulum $\sim 1.5-5 \mu \mathrm{m}$ wide; the sulcus is indistinct. The precingular series is low to much lower than the $2 a$ intercalary plate. The pattern is peridiniacean, presumed formula 4', 3a, 7"', Xc, 5'”, 2"'”, Xs.

Size Range: Length excluding any processes $=43$ (53) $60 \mu \mathrm{m}$ (16 measurements). Width excluding any processes $=40(45) 53 \mu \mathrm{m}$ (17 measurements). Length including any processes $=51(61) 78 \mu \mathrm{m}(16$ measurements). Width including any processes $=48$ (57) $73 \mu \mathrm{m}$ (17 measurements).

Distribution: Although found in only two samples during the present study, the species is quite common in the type sample.

$\begin{array}{llll}\text { Age/Stage } & \text { Location } & \text { Sample } & \text { Sample Reference } \\ \begin{array}{l}\text { Runangan-early } \\ \text { Whaingaroan }\end{array} & \text { Old Mountain Road, Waikato, New Zealand } & \text { S14/f8599 (L10662) } & \\ \begin{array}{llll}\text { Bortonian } & \begin{array}{l}\text { Puketeraki Core, Oamaru-Dunedin, New } \\ \text { Zealand }\end{array} & \text { I43/f093 (L16341) } & \text { Wilson \& McMillan } \\ \end{array} & & 1996\end{array}$

Comparison: Distinguished by the other spinose forms discussed here, $P$. aculeatum, comatum and tritonium, by the very thin walls and delicate spines.

\section{Phthanoperidinium tritonium Eaton 1976}

$$
\text { Pl. 24, figs. 1-3 }
$$

1976 Phthanoperidinium tritonium Eaton, p. 299-300, pl. 17, figs. 2-3, 6-7, text-fig. 23c, 24

1980 'Phthanoperidinium tritonium' Eaton; Bujak, pl. 5, figs. 7-8

1980 Phthanoperidinium comatum (Morgenroth, 1966b) Eisenack and Kjellström, 1971; Bujak, p. 72

Original Description: Cyst body has a smooth surface, and a subcircular or rounded polygonal outline modified by a short blunt apical horn. Plate boundaries marked by thin smooth sutural crests of variable height, bearing erect or curved solid spines which may be distally simple of bifurcate. Cingular zone clearly defined and distinctly helicoid. Reflected tabulation 4', 3a, 7", 5"', 2"'”; archeopyle intercalary, formed by displacement of plate 2a (Eaton 1976, p. 299).

Description of Study Material: Cysts small to intermediate, proximochorate, not dorso-ventrally compressed, prolate, with one apical horn; episome usually somewhat longer than hyposome. Apical horn moderately welldeveloped, apex bluntly terminated; antapical horns lacking to weakly developed. Cyst wall two-layered; acavate; relatively robust, about $2 \mu \mathrm{m}$ in thickness. Archeopyle intercalary, type I (2a); operculum free to attached. Surface ornament present, intratabular, comprising granules; very low (about $1 \mu \mathrm{m}$ or lower); minute. Crests sutural, low (less than about $1 \mu \mathrm{m}$ ), margins of crests spinose; nature of spines slender, sinuous, length of spines generally less than about 12-13 $\mu \mathrm{m}$. Tabulation weakly expressed, apparently peridiniacean, inferred formula: 4', 3a, 7", 6c, 5"', ?ps, 2"'", X-5s; ventral organisation probably ortho-style. Cingulum clearly expressed, indicated by surface ornament. Sulcus weakly expressed to moderately expressed, indicated by surface ornament; more or less vertical.

Size Range: Length excluding any processes $=38$ (43) $45 \mu \mathrm{m}$ (5 measurements). Width excluding any processes $=35$ (36) $37 \mu \mathrm{m}$ (5 measurements). Length including any processes $=35$ (50) $70 \mu \mathrm{m}$ (44 measurements). Width including any processes $=40$ (47) $55 \mu \mathrm{m}$ (7 measurements). 


$\begin{array}{llll}\text { Age/Stage } & \text { Location } & \text { Sample } & \text { Sample Reference } \\ \text { early Whaingaroan } & \text { Cape Foulwind Section, Westland, New Zealand } & \text { K29/f114 (L11050) } & \\ \text { Kaiatan } & \text { Puketeraki Core, Oamaru-Dunedin, New Zealand } & \text { I43/f096 (L16344) } & \text { Wilson \& McMillan 1996 } \\ \text { Bortonian } & \text { Puketeraki Core, Oamaru-Dunedin, New Zealand } & \text { I43/f089 (L16337) } & \text { Wilson \& McMillan 1996 }\end{array}$

Comparison: Phthanoperidinium tritonium differs from $P$. comatum principally, and perhaps only, in possessing shorter spines: typically about 10 and up to $13 \mu \mathrm{m}$ in the case of $P$. tritonium and generally in the range 14-22 $\mu \mathrm{m}$ in the case of $P$. comatum (Eaton 1976, p. 300). Bujak (1980, p. 72) considered the two species conspecific because he observed the presence of intermediate forms which "possess spines whose lengths overlap that of both species" in his Barton Bed material. However, I am far more persuaded by the argument that a complete fossil record would undoubtedly exhibit an insensible intergradation between all dinoflagellate taxa (and, indeed, all taxa). The fact that some of these intermediates have been found, whereas others have not, is a sampling artefact having neither phylogenetic nor stratigraphic significance.

The spines of $P$. multispinum arise from penitabular rather than sutural crests (Bujak 1980, text-fig. 20F) and are noticeably shorter, reaching a maximum of 4-6 $\mu \mathrm{m}$ in $P$. multispinum (Bujak 1980, p. 74) but typically ranging up to around $10 \mu \mathrm{m}$ in the case of P. tritonium.

Phthanoperidinium polytrix (Benedek 1972) is possibly conspecific with $P$. tritonium, in which case it would be the senior synonym. Benedek's description is brief and inconclusive, and the original illustrations (pl. 6, figs. 1a-b) small and grainy. The holotype is reillustrated in Benedek \& Sarjeant 1981 (figs. 2-4, 2-6 and 6), however, which reveals the presence of low penitabular ridges not found in $P$. tritonium.

Another similar species is $P$. coreoides. The best available image of the $P$. coreoides holotype (Benedek \& Sarjeant 1981, fig. 3, numbers 2 and 4) depicts a cyst which has quite well-expressed tabulation and no discernable cavation. The line drawing in the same publication (fig. 5) shows a complete (fully expressed) tabulation, even showing 1a, 3a, 1c, and 7c, which I can't see in my specimens. Neither the line drawing nor the description hints at any cavation, whereas a small apical pericoel is easily in my material (PI. 24, fig. 1).

Eaton (1976) does not provide measurements for the thickness of the cyst wall though his illustrations (especially pl. 7, figs. 3, the holotype, and 7) give the appearance of a thin-walled cyst, though not as thin as $P$. tenuimurum. The form described above as $P$. aculeatum differs in possessing a more robust cyst wall.

Remarks: New Zealand forms appear indistinguishable from Eaton's type material, although bifid spine tips have not been observed.

Eaton 1976, p. 299-300, notes that archeopyle formation may sometimes involve incorporation, or partial incorporation, of plates 1a, 3a, and 4", which is consistent with many subsequent observations (e.g. Edwards \& Bebout 1981). This behaviour has not been observed in any of the New Zealand material, however, which exhibits type I (2a) archeopyle formation only.

Phthanoperidinium australe Clowes n. sp.

PI. 24, figs. 4-12

\author{
?1975 Palaeoperidinium sp.; Haskell \& Wilson, pl. 2, fig. 8 \\ ?1982a Phthanoperidinium cf. eocenicum (Cookson \& Eisenack); Wilson, pl. 1, fig. 10 \\ 1989 Phthanoperidinium sp. 1; Wilson, pl. 1, figs. 7-8
}

Derivation of Name: Latin, australis, southern; with reference to the species' (presently known) distribution.

Holotype: Sample 143/f090, slide L16338/SM002; Burnside Formation, Puketeraki Core (Bortonian); PI. 24, figs. 7-12

Description: Cysts small, proximate, not dorso-ventrally compressed, prolate, with one apical horn; episome and hyposome more or less equal in length. Apical horn lacking to poorly developed, apex bluntly terminated; antapical horns weak to lacking. Cyst wall two-layered; acavate; relatively robust. Archeopyle intercalary, type I (2a); operculum attached. Surface ornament present, sutural, comprising low septa; very low (about $1 \mu \mathrm{m}$ or lower). Margins of crests smooth. Tabulation clearly expressed, peridiniacean, inferred formula: 4', 3a, 7", 6c, 5"', ?ps, 2"', X-5s; ventral organisation probably ortho-style. Cingulum clearly expressed, indicated by sutural septa. Sulcus clearly expressed, indicated by sutural septa; more or less vertical.

Size Range: Length including any processes $=38$ (45) $52 \mu \mathrm{m}$ (9 measurements). Width including any processes $=33$ (34) 35 um (3 measurements). 
Distribution:

\begin{tabular}{|c|c|c|c|}
\hline Age/Stage & Location & Sample & Sample Reference \\
\hline $\begin{array}{l}\text { late Eocene-early } \\
\text { Oligocene }\end{array}$ & Chalky Island, Fiordland, New Zealand & & Wilson 1982a \\
\hline Kaiatan & $\begin{array}{l}\text { Puketeraki Core, Oamaru-Dunedin, New } \\
\text { Zealand }\end{array}$ & I43/f096 (L16344) & $\begin{array}{l}\text { Wilson \& McMillan } \\
1996\end{array}$ \\
\hline Bortonian & $\begin{array}{l}\text { Puketeraki Core, Oamaru-Dunedin, New } \\
\text { Zealand }\end{array}$ & I43/f089 (L16337) & $\begin{array}{l}\text { Wilson \& McMillan } \\
1996\end{array}$ \\
\hline Eocene & CIROS-1 drillhole, McMurdo Sound, Antarctica & SM3796 & Wilson 1989 \\
\hline
\end{tabular}

Comparison: $P$. australe is broadly similar to $P$. distinctum but differs in possessing less prominent sutures.

Consideration of the status of other species, previously or currently placed in Phthanoperidinium, is given in Appendix 4.

\section{Subfamily Wetzelielloideae (Vozzhennikova 1961) Bujak \& Davies 1983}

A series of lines drawings illustrating the major morphological differences between several Wetzeliella group genera is provided in Lentin \& Vozzhennikova 1989 (fig. 2; reproduced here as Text-Fig. 20).

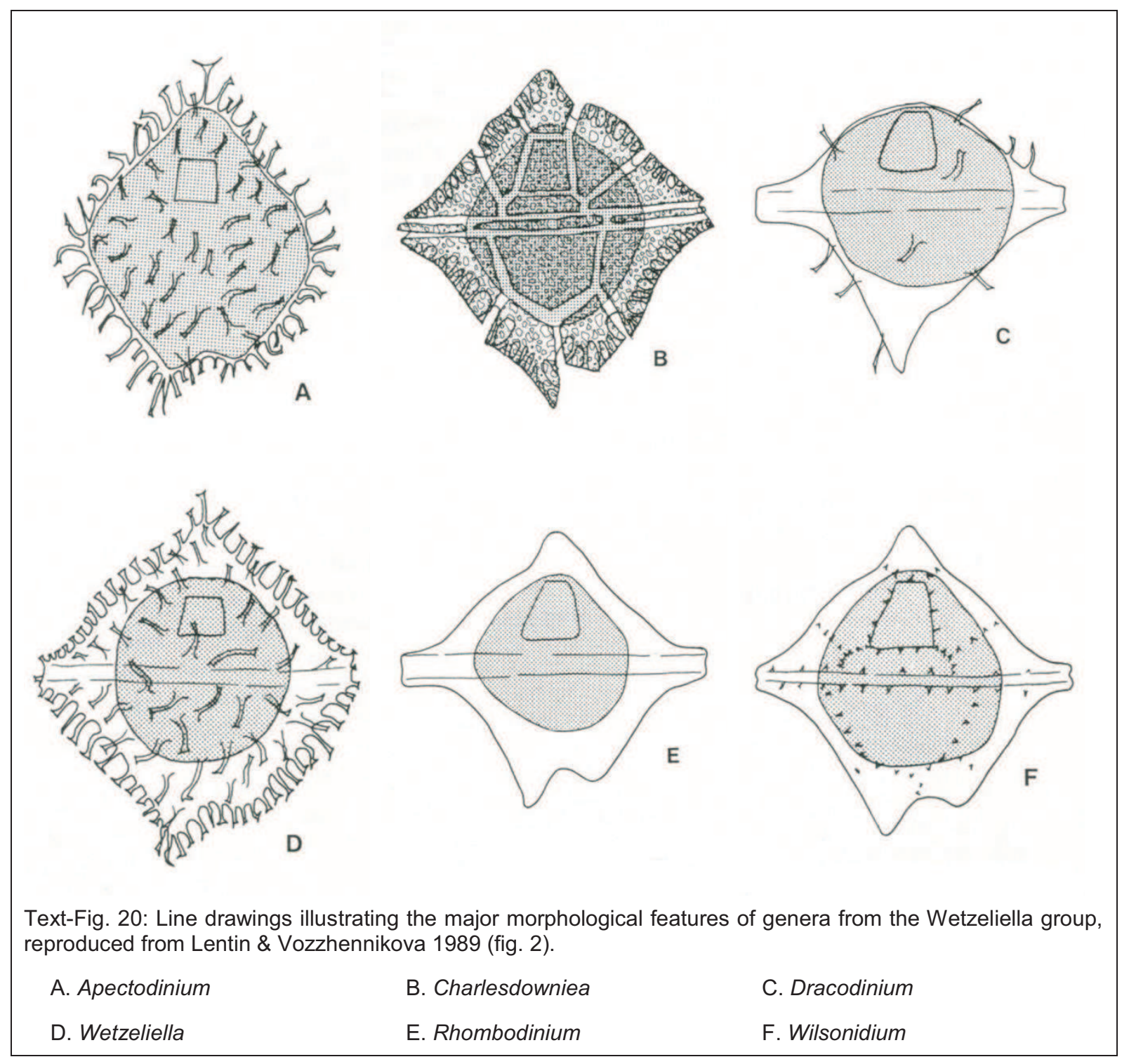


Genus Wetzeliella Eisenack 1938b emend. Lentin \& Williams 1976

\author{
1938b Wetzeliella Eisenack, p. 187 \\ 1976 Wetzeliella Eisenack, 1938b emend. Lentin \& Williams, p. 129-133 \\ 1978 Wetzeliella Eisenack 1938 emended Lentin \& Williams 1976; Stover \& Evitt, p. 130-131 \\ 1979a Wetzeliella Eisenack, 1938b emend. Lentin \& Williams, 1975; Costa \& Downie, p. 40
}

Type Species: Wetzeliella articulata Eisenack 1938b, p. 187; text-fig. 4 [Late Eocene-Early Oligocene]

Original Description: [Given for the type species.] Shell more or less flattened, rhomboidal to pentagonal or also more or less oval, usually with apical horn, lateral horns on both sides and two antapical horns, all of which can be strongly reduced, without tabulation, almost always ornamented with bristles or spines. Transverse and longitudinal furrows, respectively, not determinable as flagellar groove (the former perhaps indicated sometimes). Ellipsoidal capsule present interiorly (translated from Eisenack 1954b, p. 54, by Stover \& Evitt 1978, p. 130).

Remarks: Eisenack did not provide a separate generic description in his original publication of the genus (Eisenack 1938b).

\title{
Wetzeliella hampdenensis Wilson 1967c
}

\author{
PI. 25, figs. 1-3
}

1967c Wetzeliella (Wetzeliella) hampdenensis Wilson, p. 480-481, figs. 17, 19

1982b Wetzeliella hampdenensis Wilson; Wilson, p. 7, pl. 1, figs. 12-13

1984d Wetzeliella hampdenensis Wilson; Wilson, p. 114, fig. 6 (10)

1985 Wetzeliella hampdenensis Wilson 1967; Wilson, p. 100, pl. 1, fig. 1

Original Description: Periphragm outline pentagonal, asymmetric. Horns comparatively short apart from right antapical horn which is longer and more pointed than the others. Side horns broad, short, and blunt. Left antapical horn always present, substantially shorter than right antapical horn. Periphragm bordered by short, broad, sharply tapered aculeate processes (process length 3-9 $\mu$, bases 3-7 $\mu$, aculei length 2-5 $\mu$, number of aculei 3-6). The smallest processes occur on the horn margins. Processes of periphragm tapered (bases 2-7 $\mu$ ), aculeate, up to $16 \mu$ in length, and arranged in simulate complexes. Capsule sub-rhomboidal to sub-pentagonal; pericoel usually fairly well developed. Archeopyle trapezium-shaped. Tabulation apparently similar to Wetzeliella (W.) articulata (Wilson 1967c, p. 480-481; ellipses replace figure references in the original).

Size Range: Length including any processes $=97$ (119) $140 \mu \mathrm{m}$ (4 measurements). Width including any processes $=102 \mu \mathrm{m}$ (one measured specimen).

Distribution:

$\begin{array}{llll}\text { Age/Stage } & \text { Location } & \text { Sample } & \text { Sample Reference } \\ \text { Bortonian } & \text { Hampden Beach Section, Oamaru-Dunedin, New Zealand } & \text { J42/f055 (L09212) } & \text { Wilson 1985 } \\ \text { Bortonian } & \text { Hampden, Otago, New Zealand } & \text { S146/f690 } & \text { Wilson 1967c, 1984d }\end{array}$

Remarks: Considered a junior synonym of Wetzeliella articulata Eisenack 1938b by Costa \& Downie 1979a, p. 40. However, the 1981 and subsequent editions of the Lentin \& Williams catalogue (Lentin \& Williams 1981, et seq., Fensome \& Williams 2004) retained Wetzeliella hampdenensis, and the taxon remains in current use, at least in New Zealand (e.g. Wilson 1984d, 1985).

Wetzeliella hampdenensis is an index fossil for the mid Bortonian.

Genus Charlesdowniea Lentin \& Vozzhennikova 1989

1989 Charlesdowniea Lentin \& Vozzhennikova, p. 225, 227

2004 Charlesdowniea Lentin and Vozzhennikova, 1989, p. 225, 227; Fensome \& Williams, p. 117-119

Type Species: Charlesdowniea coleothrypta (Williams \& Downie 1966b, p. 185-186, pl. 18, figs. 8-9; text-fig. 47) Lentin \& Vozzhennikova 1989, p. 225 [Early Eocene]

Original Description: Dorso-ventrally compressed peridinioid cysts with one apical, two lateral and two antapical horns, the right of which may be reduced; circumcavate to cornucavate; endocyst broadly elliptical to round in outline; ectophragm incomplete, present over some or all intratabular areas and consistently absent over 
pandasutural areas. Endophragm smooth or lightly ornamented with features of low relief; periphragm ornamented with smooth tubular or solid processes arranged in intratabular clusters; processes may be reduced or absent on the mid-dorsal and/or mid-ventral surfaces. Pandasutural areas smooth to faintly ornamented. Ectophragm smooth, perforate, faintly ornamented or consisting of an open reticulum of trabeculae. Paratabulation indicated on the periphragm by intratabular processes and pandasutural zones without processes and by the shape of the ectophragm pieces whose outline tends to approximate the shape of the underlying paraplate; peridiniacean, formula 4', 3a, 7", Xc or 5c, 5"', 2"'", 0s or 2-4s. Archeopyle Type 1/I (quadra 2a only), operculum free or attached. Paracingulum indicated by the location of the lateral horns and/or transverse alignment of processes on the dorsal and ventral surfaces, and/or fine rectilinear intratabular groups of processes. Parasulcus not indicated or indicated by a shallow depression which may or may not have intratabular clusters of processes (Lentin \& Vozzhennikova 1989, p. 225-227).

Remarks: Charlesdowniea differs from Kisselovia in possessing processes and an ectophragm.

\title{
Charlesdowniea coleothrypta (Williams \& Downie 1966b) Lentin \& Vozzhennikova 1989
}

\section{PI. 25, figs. 4-6}

\author{
1966b Wetzeliella coleothrypta Williams \& Downie, p. 185-186, pl. 18, fig. 8, text-fig. 47 \\ 1967c Wetzeliella (Wetzeliella) coleothrypta Williams \& Downie; Wilson, p. 476, figs. 12-14 \\ 1976 Kisselevia coleothrypta (Williams \& Downie 1966b, p. 185-186, pl. 18, figs. 8-9; text-fig. 47) Lentin \& Williams, \\ p. 136 \\ 1984d Kisselovia coleothrypta (Williams \& Downie) Lentin \& Williams; Wilson, p. 114, fig. 6 (2) \\ 1989 Charlesdowniea coleothrypta (Williams \& Downie 1966b, p. 185-186, pl. 18, figs. 8-9; text-fig. 47) Lentin \& \\ Vozzhennikova, p. 225
}

Original Description: Thin walled periphragm characteristic pentagonal outline with each angle produced into horns, one apical, two lateral and two antapical; left antapical horn generally reduced. Pericoel totally enclosing endophragm. Processes arising from periphragm, hollow, connecting with pericoel. Distally processes of individual simulate complex united by finely perforate membrane assuming outline of underlying plate and extending over that plate as a replica of it. Processes commonly absent from pre- and postcingular plates on side lying nearest to cingulum. Reflected tabulation of 4', 3a, 7", 5c, 5"', 2" [sic], 3-4s (Williams \& Downie 1966b, p. 185).

Size Range: Length including any processes $=105 \mu \mathrm{m}$ (one measured specimen). Width including any processes $=97 \mu \mathrm{m}$ (one measured specimen).

\section{Distribution:}

$\begin{array}{llll}\text { Age/Stage } & \text { Location } & \text { Sample } & \text { Sample Reference } \\ \text { Porangan } & \text { Te Uri Stream, Hawkes Bay, New Zealand } & \text { U24/f418 (L23126) } & \text { Wilson 1967c } \\ \text { Heretaungan } & \text { Abbotsford Mudstone, Dunedin, New Zealand } & \text { S164/f533 } & \text { Wilson 1984d } \\ \text { Heretaungan } & \text { Otago, New Zealand } & \text { SM1002 } & \text { Wilson 1967c } \\ \text { Heretaungan } & \text { Waipawa } & \text { N141/f994 } & \text { Wilson 1967c }\end{array}$

Genus Dracodinium Gocht 1955 emend. Bujak et al. 1980

\author{
1955 Dracodinium Gocht, p. 87 \\ 1979a Dracodinium Gocht, 1955; Costa \& Downie, p. 43 \\ 1980b Dracodinium Gocht, 1955, emend. Bujak et al., p. 28
}

Type Species: Dracodinium solidum Gocht 1955, p. 88; text-figs. 3a-b, 4a-c, 5a-c [Eocene-Oligocene]

Original Description: Roughly kite-shaped dinoflagellates with well developed lateral horns and partially reduced antapical horns. Apex \pm rounded, occasionally slightly pointed (as distinct from Wetzeliella); only in exceptional cases is there any indication of a small apical cusp. The theca is untabulated and often has bristles; furrows are absent. Inside there is always a circular to \pm elliptical capsule (translation from Gocht 1955, p. 87).

Remarks: Considered to be a junior synonym of Wetzeliella by Lentin \& Williams 1976 and by Stover \& Evitt 1978 , but the genus differs in its rounded apex and has generally been found useful to retain (e.g. Costa \& Downie 1979, p.36, Bujak et al. 1980b, p.28, and Lentin \& Williams 1989, p.121). 
As noted in Bujak et al. 1980b, p. 28, Dracodinium differs from Rhombodinium in possessing a roughly subtriangular rather than a rhomboidal pericyst, an oval rather than subrhomboidal endocyst, and an operculum which is free rather than remaining attached anteriorly, along side Q1. The last distinction is considered unreliable, however — see Rhombodinium.

\section{Dracodinium granulatum (Wilson 1967c) Lentin \& Williams}

$$
\text { PI. 25, figs. 7-9 }
$$

1967c Wetzeliella (Rhombodinium) glabra var. granulata Wilson, p. 493, figs. 29-30

1973 Rhombodinium glabrum subsp. granulatum (Wilson 1967c, p. 493, figs. 29-30) Lentin \& Williams, p. 120

1981 Dracodinium granulatum (Wilson 1967c, p. 493, figs. 29-30) Lentin \& Williams, p. 92

Original Description: A variety of W. (Rh.) glabra with a coarsely granular periphragm. Granules sometimes aligned in rows indicating possible tabulation (Wilson 1967c, p. 493).

Size Range: Length including any processes $=87(98) 108 \mu \mathrm{m}(2$ measurements). Width including any processes = 95 (98) $100 \mu \mathrm{m}$ (2 measurements).

\section{Distribution:}

$\begin{array}{llll}\text { Age/Stage } & \text { Location } & \text { Sample } & \text { Sample Reference } \\ \text { Kaiatan } & \text { Raki Siltstone, Rakis Table, Oamaru, New Zealand } & \text { S136/f841 } & \text { Wilson 1967c } \\ \text { Bortonian } & \text { Puketeraki Core, Oamaru-Dunedin, New Zealand } & \text { I43/f094 (L16342) } & \text { Wilson \& McMillan 1996 } \\ \text { Bortonian } & \text { Puketeraki Core, Oamaru-Dunedin, New Zealand } & \text { I43/f093 (L16341) } & \text { Wilson \& McMillan 1996 }\end{array}$

Genus Rhombodinium Gocht 1955 emend. Bujak, 1979

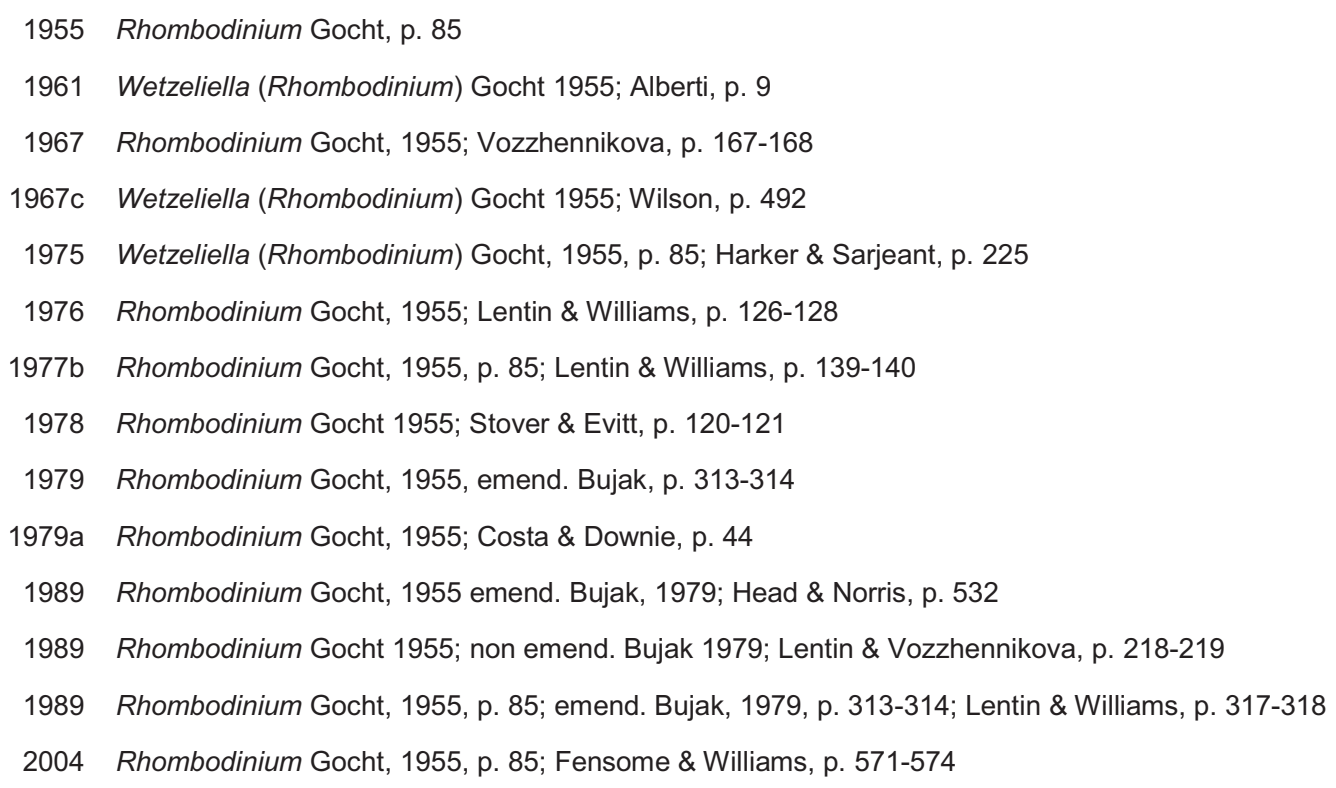

Type Species: Rhombodinium draco Gocht 1955, p. 86, text-figs. 1a-c [Mid Oligocene]

Original Description: Dinoflagellates with an approximately rhomboidal, kite-shaped, or quadrate outline, welldeveloped apical and lateral horns, and mostly reduced antapical horns. Shell untabulated, smooth, not ornamented with setae or spines (difference from Wetzeliella), without clearly recognizable transverse or longitudinal furrow. Shell always contains an inner capsule (translated from Gocht 1955, p. 85, by Stover \& Evitt 1978, p. 120).

Remarks: According to Bujak et al. 1980b, p. 28, Rhombodinium differs from Dracodinium in possessing a rhomboidal rather than a roughly subtriangular pericyst, a subrhomboidal rather than oval endocyst, and (following Bujak 1979, p. 313) an operculum which remains attached anteriorly, along side Q1, rather than becoming detached. Lentin \& Vozzhennikova (1989, p. 218), however, rejected Bujak's (1979) emendation, citing a personal communication from Gocht noting that the endoperculum is free in the genoholotype. Nor do the specimens of $R$. glabrum encountered in the present study support the notion that the operculum of Rhombodinium remains attached along edge Q1 (see PI. 25, figs. 10-12) or, indeed, at all (see PI. 26, figs. 1-2). 
Rhombodinium differs from Wetzeliella in having ornament of lower relief: a distinction of dubious merit at the generic level. Transitional forms are known (as lamented by several of the authors who have treated Rhombodinium as a subgenus of Wetzeliella).

It differs from Wilsonidium in lacking sutural features.

Rhombodinium glabrum (Cookson 1956) Vozzhennikova 1967

$$
\text { PI. 25, figs. 10-12, PI. 26, figs. 1-3 }
$$

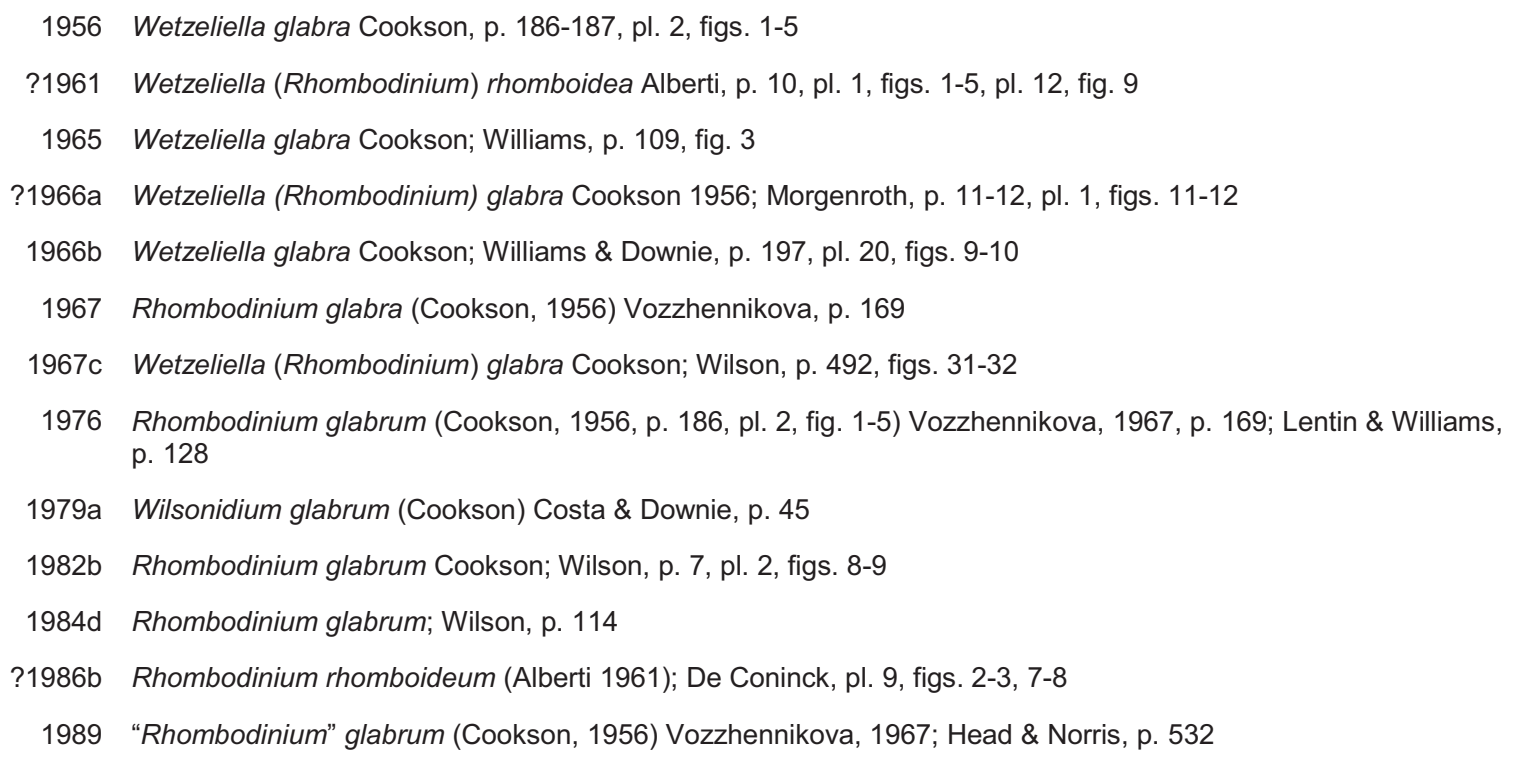

Original Description: Cell encysted, flattened, quadrangular in outline with an entire margin, divided equally by a transverse girdle into a triangular epitheca with a short, bluntly pointed apical horn and a hypotheca with 2 short, unequal horns. The girdle is most clearly evident in the position of the lateral horns. The cell membrane is finely granular and usually completely smooth; in the holotype a few minute teeth-like outgrowths are present in the region of the horns, particularly the apical horn.

The cyst, which is separated from the cell membrane by a wide space, is ellipsoidal and flattened, and has a moderately thick, roughened wall with a granular sculpture.... An approximately quadrangular opening has been present in all specimens, and the detached "lid" can sometimes be seen lying in the cell cavity (Cookson 1956, p. 186).

Size Range: Length including any processes $=100$ (120) $181 \mu \mathrm{m}$ (19 measurements). Width including any processes $=108(135) 160 \mu \mathrm{m}$ (8 measurements).

Distribution: Frequent. This form is the only truly "common" Wetzeliella-group taxon found in this study.

\begin{tabular}{|c|c|c|c|}
\hline Age/Stage & Location & Sample & Sample Reference \\
\hline ?Kaiatan & $\begin{array}{l}\text { Hampden Beach Section, Oamaru-Dunedin, } \\
\text { New Zealand }\end{array}$ & J42/f062 (L09219) & Wilson 1985 \\
\hline $\begin{array}{l}\text { latest Bartonian-Priabonian } \\
\text { (Tongrien) }\end{array}$ & $\begin{array}{l}\text { Sands of Asse, Woensdrecht borehole, } \\
\text { southern Netherlands }\end{array}$ & -263 to $-277 \mathrm{~m}$. & De Coninck 1986b \\
\hline Bortonian & $\begin{array}{l}\text { Burnside Marl Pit, Oamaru-Dunedin, New } \\
\text { Zealand }\end{array}$ & I44/f080 (L08947) & $\begin{array}{l}\text { Clowes \& Wilson } \\
2006\end{array}$ \\
\hline Bortonian & $\begin{array}{l}\text { Puketeraki Core, Oamaru-Dunedin, New } \\
\text { Zealand }\end{array}$ & I43/f094 (L16342) & $\begin{array}{l}\text { Wilson \& McMillan } \\
1996\end{array}$ \\
\hline Bortonian & $\begin{array}{l}\text { Hampden Beach Section, Oamaru-Dunedin, } \\
\text { New Zealand }\end{array}$ & J42/f061 (L09218) & Wilson 1985 \\
\hline Bortonian & $\begin{array}{l}\text { Puketeraki Core, Oamaru-Dunedin, New } \\
\text { Zealand }\end{array}$ & I43/f089 (L16337) & $\begin{array}{l}\text { Wilson \& McMillan } \\
1996\end{array}$ \\
\hline
\end{tabular}

Remarks: The forms described above, and in previous New Zealand publications such as Wilson 1967c, as a group, have slightly less strongly-developed lateral horns than the Australian type material, but appear otherwise identical. Regarded as a questionable generic assignment by Head \& Norris, who note that the "species was not discussed by Bujak (1979) in his emendation of Rhombodinium, but clearly it possesses a free, detached operculum (Cookson, 1956), which excludes it from Rhombodinium as emended by Bujak, and for which reason we have retained it only tentatively in this genus" (Head \& Norris 1989, p. 532). 
It is not completely clear (to me) that Dracodinium (formerly Rhombodinium) rhomboideum (Alberti 1961) differs meaningfully from this species.

\title{
Genus Wilsonidium Lentin \& Williams 1976
}

\author{
1976 Wilsonidium Lentin \& Williams, p. 138-139 \\ 1978 Wilsonidium Lentin \& Williams 1976; Stover \& Evitt, p. 132-133 \\ 1979a Wilsonidium Lentin \& Williams 1975; Costa \& Downie, p. 45
}

Type Species: Wilsonidium tabulatum (Wilson 1967c, p. 473-474, figs. 2a-b, 4-7, 10-11) Lentin \& Williams 1976 , p. 138,140 [Late Eocene]

Original Description: Pericyst: Ambitus rhomboidal to pentagonal (peridinioid). Apex rounded or more commonly prolonged into an apical horn. Two equal precingular horns usually present, occasionally reduced or absent. Antapex prolonged into one eccentrically located antapical horn, the left, or two unequal symmetrically located antapical horns, the left always being the longer, the right being reduced or vestigial. From the position of the pericingular horns, the epipericyst and hypopericyst may be equal in size, or unequal, in which case the hypopericyst is always the larger. Compression dorso-ventral, usually extreme.

Endocyst: Ambitus circular to ovoidal to ellipsoidal. Rarely may be completely appressed to the pericyst when it has the same shape. Generally only partially in contact with the pericyst and then in the interhorn areas. Compression dorso-ventral. Pericoels: When the endocyst and pericyst are in contact in the interhorn areas, there result an apical, two cingular and one or two antapical pericoels. Alternatively the pericoels may be united when the endocyst and pericyst are separated by a single ambital pericoel.

Periphragm: Thin (usually less than $2 \mu$ ) and of a constant thickness. Surface ornamented with parasutural granules, septa and/or processes. Intratabular ornamentation reduced or absent. Endophragm: $<1 \mu$ to several microns thick. Surface laevigate to granulate. Pericyst: The parasutures delineate a typical peridinioid paratabulation of 4', 3a, 7", 5"', 2"'' plus sulcals. In the apical series, paraplate I' is pentagonal, 2', 3' and 4' are considerably smaller. The $1 \mathrm{a}$ and $3 \mathrm{a}$ paraplates appear to be pentagonal and extend closer to the pericingulum than the quadra 2a. Of the precingulars 1" and 7" are rhomboidal with their longest axis parallel to the pericingulum, 2" and 6" are elongate narrow, 3" and 5" are four-sided, and 4" is six-sided with its longest axis parallel to the pericingulum. The width of the $4 "$ is greater than that of $2 a$. The postcingular paraplates consist of 1"' and 5"' which are four- sided and of more or less equal size, 2"' and 4"' which are likewise four-sided and of equal size, and the distinctive pentagonal 3"'. The two large antapicals are located primarily on the dorsal surface and are more or less equal in size. Pericingulum: Produced into two pericingular horns. Delineated by parasutural ornamentation, or apparently penetabular ornamentation as linear features. Commonly indented as can be seen at the distal extremity of the pericingular horns. Slightly helicoidal. Perisulcus: Clearly delineated. Large on both epipericyst and hypopericyst. Widening posteriorly and extending onto the antapical horns. The largest paraplate is the posterior sulcal. Flagellar pore imprints occasionally visible. Endocyst: Paratabulation indeterminate other than in the vicinity of the endoarcheopyle.

Periarcheopyle Quadra intercalary resulting from the partial or complete detachment of the second anterior intercalary paraplate 2a. Perioperculum free or remaining attached along the anterior parasuture. Endoarcheopyle: Quadra intercalary resulting from the loss of the second anterior intercalary paraplate 2a. Operculum usually free. May be of greater width than the periarcheopyle (Lentin \& Williams 1976, p. 138-139).

Remarks: Wilsonidium differs from Rhombodinium in possessing parasutural ornament. It differs from Wetzeliella in having sutural ornament and "generally reduced intratabular ornamentation" (Lentin \& Williams 1976, p. 139).

\section{Wilsonidium tabulatum (Wilson 1967c) Lentin \& Williams 1976}

\author{
1967c Wetzeliella (Wetzeliella) tabulata Wilson, p. 473-474, figs. 4-7, 10-11, text-fig. 2a-b \\ 1976 Wilsonidium tabulatum (Wilson 1967c, p. 473-474, figs. 2a-b, 4-7, 10-11) Lentin \& Williams, p. 138-140 \\ 1982b Wilsonidium tabulatum (Wilson); Wilson, p. 7, pl. 2, figs. 12-13 \\ 1984d Wilsonidium tabulatum (Wilson) Lentin \& Williams; Wilson, p. 114, fig. 6 (11)
}

Original Description: Periphragm outline pentagonal, bilaterally asymmetric, with well developed horns at each angle. Apical, lateral and right antapical horns all approximately equal in size; left antapical horn always shorter although still prominent. Polar horns tapered, pointed; lateral horns have a well defined notch at their extremities denoting the position of a transverse girdle. Periphragm divided into clearly defined fields by rows of slender nontapering solid spines $(I=2-8 \mu)$ which are occasionally united at their bases by a low ridge. Tabulation typical of genus.... Margin between horns concave, usually irregularly spinose, occasionally smooth. Capsule outline varies from circular to sub-angular. Archeopyle corresponds to 2a plate, shape square to rectangular; operculum often located within capsule. Transverse girdle clearly defined by double row of spines, slightly laevorotatory (Wilson 1967c, p. 473; ellipses replace figure references in the original). 
Size Range: Length including any processes $=125 \mu \mathrm{m}$ (one measured specimen).

Distribution: Rare. Only a single, poor, specimen was encountered in the present study.

$\begin{array}{llll}\text { Age/Stage } & \text { Location } & \text { Sample } & \text { Sample Reference } \\ \text { Kaiatan } & \text { Raki Siltstone, Rakis Table, Oamaru, Otago, New Zealand } & \text { J41/f8841 } & \text { Wilson 1967c } \\ \text { Bortonian } & \text { Puketeraki Core, Oamaru-Dunedin, New Zealand } & \text { I43/f093 (L16341) } & \text { Wilson \& McMillan 1996 }\end{array}$

Wilsonidium echinosuturatum (Wilson 1967c) Lentin \& Williams 1976

1967c Wetzeliella (Wetzeliella) echinosuturata Wilson, p. 477-479, figs. 22-25, text-fig. 3a-b

1976 Wilsonidium echinosuturatum (Wilson 1967c, p. 477-479, figs. 3, 22-25) Lentin \& Williams, p. 139

1984d Wilsonidium echinosuturatum (Wilson) Lentin \& Williams; Wilson, p. 114, fig. 6 (6)

?1985 ?Wilsonidium echinosuturatum (Wilson 1967); De Coninck, p. 69, pl. 3, figs. 8-12

Original Description: Periphragm surface punctate, outline pentagonal; sides more or less straight, rarely concave. Margin adorned with prominent capitate or oblate processes $(I=3-10 \mu)$. Right antapical horn invariably longer than left, although there is usually only a small difference, Ornament on periphragm comprised of very prominent ridges crested by oblate or capitate processes (/ up to $16 \mu$ ). The ridges correspond to sutures and define a clear peridinioid tabulation.... Pericoel large. Capsule finely granular, usually more or less circular, occasionally sub-rhomboidal. Archeopyle when formed is rectangular and replaces 2a plate (Wilson 1967c, p. 477, 479; ellipses replace figure references in the original).

Distribution: Rare. Only a single, poor, specimen was encountered in the present study.

$\begin{array}{llll}\text { Age/Stage } & \text { Location } & \text { Sample } & \text { Sample Reference } \\ \text { Bortonian } & \text { Hampden Beach Section, Oamaru-Dunedin, New Zealand } & \text { J42/f042 (L09199) } & \text { Wilson 1985 } \\ \text { Porangan } & \text { Waipawa, Hawkes Bay, New Zealand } & \text { N141/f1401 } & \text { Wilson 1967c } \\ \text { middle Eocene } & \text { Sands of Lede, Mol borehole, Belgium } & -323.9 m \text { - prep. 5 } & \text { De Coninck 1985 }\end{array}$

Wilsonidium cf. echinosuturatum (Wilson 1967c) Lentin \& Williams 1976

PI. 26, figs. 4-6

1975 Wetzeliella (Wetzeliella) echinosuturata Wilson; Haskell \& Wilson, pl. 1, fig. 2

Description of Study Material: Cysts of intermediate size, proximochorate, dorso-ventrally compressed, wetzeliellioid, with one apical, two lateral, and one or two unequal antapical horns; episome and hyposome more or less equal in length. Apical horn moderately well-developed, apex more or less conical, episome more or less straight-sided; antapical horns well developed, relatively pointed. Cyst wall two-layered; circumcavate, lateral pericoels strongly developed. Archeopyle intercalary, type I (2a); quadra-style. Processes lacking; surface ornament present, non-tabular, comprising sparse granules. Crests sutural, margins of crests granulate. Tabulation clearly expressed, peridiniacean, inferred formula: 4', 3a, 7", Xc, 5"', Ops, 2"', 0s. Cingulum moderately expressed, indicated by shape of the periphragm; offset only slightly.

Size Range: Length including any processes = 94 (94) $95 \mu \mathrm{m}$ (2 measurements). Width including any processes $=92 \mu \mathrm{m}$ (one measured specimen).

Distribution: Rare.

$\begin{array}{llll}\text { Age/Stage } & \text { Location } & \text { Sample } & \text { Sample Reference } \\ \text { Bortonian } & \text { Hampden Beach Section, Oamaru-Dunedin, New Zealand } & \text { J42/f303 (L23133) } & \\ \text { Bortonian } & \text { Hampden Beach Section, Oamaru-Dunedin, New Zealand } & \text { J42/f042 (L09199) } & \text { Wilson 1985 }\end{array}$

Remarks: This taxon is very similar to Wilsonidium echinosuturatum, but differs in having more rounded/subdued margins to the sutural crests.

Wilsonidium lineidentatum (Deflandre \& Cookson 1955) Lentin \& Williams 1976

PI. 26, figs. 7-9

1955 Wetzeliella lineidentata Deflandre \& Cookson, p. 253-254, pl. 5, fig. 5, text-fig. 17-18 
Original Description: Cell encysted, compressed, nearly quadrangular with a toothed margin. Epitheca imperfectly preserved, probably triangular, opening apparently quadrangular; hypotheca with 2 short unequal horns. Membranes of cyst thick, roughened. Cell membrane with lines of numerous short, blunt teeth, in surface view relatively widely spaced both equatorially and so as to delimit roughly polygonal areas analogous to the plates characterizing the Peridiniales (Cookson \& Deflandre 1955, p. 253).

Size Range: Length including any processes $=135 \mu \mathrm{m}$ (one measured specimen). Width including any processes $=95 \mu \mathrm{m}$ (one measured specimen).

Distribution: Rare.

$\begin{array}{llll}\text { Age/Stage } & \text { Location } & \text { Sample } & \text { Sample Reference } \\ \text { Bortonian } & \text { Hampden Beach Section, Oamaru-Dunedin, New Zealand } & \text { J42/f055 (L09212) } & \text { Wilson 1985 } \\ \text { Bortonian } & \text { North Otago, New Zealand } & \text { L9203/1 } & \text { Wilson 1984d } \\ \text { Bortonian } & \text { Hampden Beach Section, Oamaru-Dunedin, New Zealand } & \text { J42/f048 (L09205) } & \text { Wilson 1985 }\end{array}$

Remarks: Cookson 1956 (p. 186) indicates that this species was described a year earlier than is commonly supposed, in Deflandre \& Cookson 1954.

\title{
Family Protoperidiniaceae Bujak \& Davies 1983
}

\section{Subfamily Protoperidinioideae Bujak \& Davies 1983 [autonym]}

\section{Genus Lejeunecysta Artzner \& Dörhöfer 1978}

\author{
1961 Lejeunia Gerlach, p. 169 \\ 1972 Lejeunia Gerlach, 1961 emend. Kjellström, p. 467 \\ 1976 Lejeunia Gerlach, 1961, emend. Kjellström, 1972, emend. Lentin \& Williams, p. 68-71 \\ 1978 Lejeunecysta Artzner \& Dörhöfer, p. 1381 \\ 1978 Lejeunia Gerlach 1961 emended Lentin \& Williams 1976; Stover \& Evitt, p. 111-112
}

Type Species: Lejeunecysta hyalina (Gerlach 1961, p. 169-171, pl. 26, figs. 10-11) Artzner \& Dörhöfer 1978, p. 1381 [Late Oligocene]

Original Description: Theca bilaterally symmetrical-pentagonal, with apical horn and two antapical horns; without tabulation. Course of transverse furrow spiral, longitudinal furrow suggested (translated from Gerlach 1961, p. 169, by Stover \& Evitt 1978, p. 111).

Remarks: Gerlach's (1961) original name for this genus is a junior homonym of Lejeunia (later spelled Lejeunea) Libert 1820, a leafy liverwort (Hepaticae).

Lejeunecysta differs from Phelodinium in having an autophragm and convex rather than straight or slightly concave sides. In addition, the horns on most species of Phelodinium are considerably longer than those on Lejeunecysta (Stover \& Evitt 1978, p. 112).

Stover \& Evitt (1978, p. 112) further note that Lejeunecysta differs from Morkallacysta in having less welldeveloped apical and antapical horns. This doesn't seem a lot to go on; were it not for the uncertainty remaining about the exact form of the archeopyle in Morkallacysta, this distinction would probably not be worth maintaining. In view of this uncertainty, the assignment of additional species to the formerly monotypic Morkallacysta is unfortunate.

Lejeunecysta ?fallax (Morgenroth 1966b) Artzner \& Dörhöfer 1978

$$
\text { PI. 26, figs. 10-12 }
$$

\footnotetext{
1966b Lejeunia fallax Morgenroth, p. 2-3, pl. 1, figs. 6-7

1978 Lejeunecysta fallax (Morgenroth 1966b, p. 2-3, pl. 1, figs. 6-7) Artzner \& Dörhöfer, p. 1381
} 
Original Description: [No translation available] [Diagnosis] Eine Art der Gattung Lejeunia mit glatter derber Membran. Anstelle einer Gürtelfurche ist nur ein ?zirkulär verlaufender Grat vorhanden.

[Description] Die im Vergleich zu anderen Arten der Gattung kräftige Kapselmembran ist glatt. Streifungen sind nicht vorhanden. Die kegelförmige Epithek gipfelt in ein deutlich zugespiztes Apikalhorn. Eine Gürtelfurche ist nicht vorhanden. An ihrer Stelle befindet sich ein einfacher scharfer Grat, der \pm zirkulär verläuft. Ventral ist er durch eine angedeutete Längsfurche unterbrochen. Die hypothek zipfelt in 2 ungefähr gleich lange Antapikalhörner aus (Morgenroth 1966b, p. 3).

Description of Study Material: Cysts of intermediate size, proximate, dorso-ventrally compressed, pentagonal, with one apical and two antapical horns; episome and hyposome more or less equal in length. Apex pointed, episome more or less straight-sided; antapical horns 2 small, unequal horns developed, relatively pointed. Cyst wall single-layered. Archeopyle intercalary. Processes lacking; surface ornament present, non-tabular, comprising irregular, loose reticulum. Cingulum clearly expressed, indicated by folds in the autophragm; offset only slightly.

Size Range: Length including any processes $=72 \mu \mathrm{m}$ (one measured specimen). Width including any processes $=69 \mu \mathrm{m}$ (one measured specimen).

\section{Distribution:}

$\begin{array}{lll}\text { Age/Stage } & \text { Location } & \text { Sample } \\ \text { early Whaingaroan } & \text { Cape Foulwind Section, Westland, New Zealand } & \text { K29/f114 (L11050) }\end{array}$

\section{Order Gonyaulacales Taylor 1980}

Peridiniphycideans with a tabulation which accords with, or clearly derives from, a pattern in which one or both of the following arrangements occur:

- the first apical plate is asymmetrical, its left lateral triple junction being higher (i.e. more anterior) than the right lateral triple junction;

- there are two to four fundital plates - always the posterior intercalary plate and first antapical plate (or their homologues), sometimes the posterior sulcal plate, and possibly in rare cases also the right sulcal plate or subdivisions of these plates.

Among the fundital plates, 1 '"' is almost always larger and is in a clearly more dorsal position than the other(s).

Key to suborders (principally after Fensome et al. 1998):

$1 \quad$ Five or more climactal plates; three or more fundital plates

Generally four or more climactal plates; two fundital plates; partiform hyposome ...................... 3

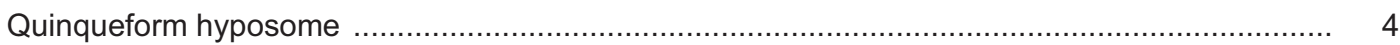

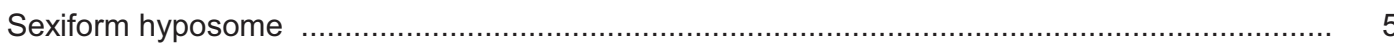

2 Suborder Rhaetogonyaulacineae Norris 1978a - Gonyaulacaleans in which there are at least three fundital plates, of which the dorsal-most does not contact the distal-most postcingular plate. There are more than five climactal plates. Secondary plate overgrowth may occur on all plate margins except those adjacent to the cingulum.

3 Subclass Cladopyxiineae Fensome et al. 1993b - Gonyaulacaleans in which the tabulation is partiform: that is, it accords with, or is derived from, a pattern in which the first antapical homologue ( ${ }^{*} 1$ "') $)$ contacts the distal-most postcingular plate $\left({ }^{*} 6\right.$ "') and in which the posterior sulcal homologue ( $\left.{ }^{*} \mathrm{ps}\right)$ is within the sulcus and extends further to the anterior than the posterior intercalary homologue $\left({ }^{*} 1 \mathrm{p}\right)$, thus contacting the first postcingular homologue $\left({ }^{*} 1 " '\right)$.

4 Goniodomineae Fensome et al. 1993b - Gonyaulacaleans with a tabulation which accords with, or derives from, a pattern in which there are two or three fundital plates - always the posterior intercalary homologue ( $\left.{ }^{*} 1 \mathrm{p}\right)$ and the first antapical homologue $\left({ }^{*} 1^{\prime \prime \prime \prime}\right)$, and sometimes also the posterior sulcal homologue ( $\left.{ }^{*} \mathrm{ps}\right)$. The first antapical homologue (*1"'") is the dorsal-most of the fundital plates, is five-sided (quinqueform) and does not contact the distal-most postcingular plate(s) - i.e. the sixth postcingular homologue ( $\left.{ }^{*} 6 " '\right)$ - and, when it is outside the sulcus, the right sulcal homologue $\left({ }^{*} r s\right)$. There are typically five or fewer climactal plates. Secondary plate overgrowth occurs only at overlapping plate margins.

No lateral horn

6 Ceratiineae Fensome et al. 1993b - Gonyaulacaleans having at least three horns, of which one or two are formed by contributions from postcingular plates, and in which the first antapical plate $(1 " ')$ contacts six or seven adjacent plates, including the distal-most postcingular plate. 
Gonyaulacineae Taylor 1980 [autonym] - Gonyaulacaleans in which the hyposomal tabulation is sexiform, i.e. in which the first antapical homologue $\left({ }^{*} 1\right.$ "') $)$ contacts the sixth postcingular homologue ( ${ }^{*} 6$ "') and in which the posterior intercalary homologue $\left({ }^{*} 1 p\right)$ extends further to the anterior than the posterior sulcal homologue $\left({ }^{*} p s\right)$. Distinctive postcingular horns are absent.

\title{
Suborder Gonyaulacineae Taylor 1980 [autonym]
}

Gonyaulacaleans in which the hyposomal tabulation is sexiform, i.e. in which the first antapical plate contacts the sixth postcingular plate and in which the posterior intercalary plate extends further to the anterior than the posterior sulcal plate. Distinctive postcingular horns are absent.

\section{Family Gonyaulacaceae Lindemann 1928}

Gonyaulacineans in which the sulcus is more or less midventral and may be straight, oblique from upper right to lower left, or sigmoidal. The antapical outline is more or less symmetrical and strong dorsoventral compression is lacking. There are six precingular plates.

\section{Subfamily Gonyaulacoideae Lindemann 1928 [autonym]}

\section{Genus Spiniferites Mantell 1850 emend. Sarjeant 1970}

\author{
1850 Spiniferites Mantell, p. 191 \\ 1866 Gonyaulax Diesing, p. 305, 382 \\ 1953 Hystrichokibotium Klumpp, p. 387 \\ 1966 Spiniferites Mantell, 1850, p. 191; Loeblich Jr. \& Loeblich III, p. 56-57 \\ 1970 Spiniferites Mantell, 1850, emend. Sarjeant, p. 75 \\ 1978 Spiniferites Mantell 1850 emended Sarjeant 1970; Stover \& Evitt, p. 189-191
}

Type Species: Spiniferites ramosus (Ehrenberg 1838, pl. 1, figs. 1-2, 5) Mantell 1854, p. 239 [Late Cretaceous]

Original Description: Subsperical shells with spiny processes in the shape given as characteristic for the family, but without the threefold metameric division of the body and without a closed aliform lamella, an outer shell membrane, or an outer network (translated from O. Wetzel 1933b, p. 33, description for Hystrichosphaera, by Stover \& Evitt 1978, 189).

Remarks: Loeblich Jr. \& Loeblich III 1966 (p. 56-57) appears to be the earliest publication to legally designate Spiniferites ramosus as the type species of Spiniferites.

Fensome et al. 1993b, p. 93, considers Spiniferites to be the possible senior synonym to Gonyaulax.

The genus Hystrichosphaera is usually treated as a junior synonym of Spiniferites, at least since the mid-1960s (e.g. Sarjeant $1964 a$, p. $174 ; 1970$, p. 74 ) although, to the best of my knowledge, the type species, H. furcata, has never been formally transferred into Spiniferites. According to Fensome \& Williams 2004, p. 619, the combination "Spiniferites" furcatus made in Lentin \& Williams 1973 (p. 128) is not validly published, because the combination was not intended by Lentin \& Williams, who, following Davey \& Williams 1966a, p. 29-33, considered Hystrichosphaera furcata to be a junior synonym of Spiniferites ramosus.

However, Ehrenberg's (1938) illustrations of the two forms which comprise the type species for Hystrichosphaera and Spiniferites, Xanthidium furcatum and Xanthidium ramosum respectively, look quite different to my eye: I don't think it is sufficient to simply pronounce the two synonymous because intermediates exist (LejeuneCarpentier 1937) or because Ehrenberg's types of Xanthidium furcatum cannot be relocated, as advocated by Davey \& Williams (1966a, p. 32).

It seems to me that a better solution, since Ehrenberg's type material for Xanthidium furcatum cannot be relocated, is simply to confine use of the furcatum epithet to the (lost) type material. By this means, the name Hystrichosphaera, while remaining validly published, also disappears from active use, other species of the genus already having been allocated elsewhere (e.g., see Lentin \& Williams 1973, p. 126-131).

Some authors (e.g. Davey \& Williams 1966a, Sarjeant 1970) have described Spiniferites as having processes which are sometimes (or "rarely" in Stover \& Evitt 1978, p. 190) hollow and open distally. Hollow processes have not been observed in the present study material, however, and only forms with solid process are assigned to Spiniferites herein.

Achomosphaera is considered a junior synonym of Spiniferites in Duxbury 1983 (p. 54-55) but herein I follow Lentin \& Williams 1989 (p. 3) and many subsequent authors who have retained Achomosphaera. 
Hafniasphaera has also been considered a junior synonym of Spiniferites (Stover \& Williams 1987, p. 117) but herein I follow Edwards 1996 (p. 989) and subsequent authors who have preferred to retain Hafniasphaera.

\title{
Spiniferites ramosus (Ehrenberg 1838) Mantell 1854
}

\section{PI. 27, figs. 1-6}

\author{
1838 Xanthidium? ramosum Ehrenberg, pl. 1, fig. 15 [not 1, 2 and 5] \\ 1854 Spiniferites ramosus (Ehrenberg 1838, pl. 1, figs. 1-2, 5) Mantell, p. 239 \\ 1937b Hystrichosphaera ramosa (Ehrenberg 1838, pl. 1, figs. 1-2, 5) Deflandre, p. 64 \\ 1961 Hystrichosphaera ramosa (Ehrenberg) O. Wetzel 1933; Gerlach, p. 175-176, pl. 27, fig. 3
}

Original Description: [No textual description provided.]

Size Range: Length excluding any processes $=36$ (52) $62 \mu \mathrm{m}$ (4 measurements). Width excluding any processes $=37(46) 57 \mu \mathrm{m}$ (4 measurements). Length including any processes = 55 (78) $105 \mu \mathrm{m}$ (18 measurements). Width including any processes $=56(80) 97 \mu \mathrm{m}$ (4 measurements).

Distribution:

\begin{tabular}{|c|c|c|c|}
\hline Age/Stage & Location & Sample & Sample Reference \\
\hline $\begin{array}{l}\text { middle Oligocene-middle } \\
\text { Miocene }\end{array}$ & north west Germany & $\operatorname{Pr} 1170 / 30$ & Gerlach 1961 \\
\hline Otaian & $\begin{array}{l}\text { Puketeraki Core, Oamaru-Dunedin, New } \\
\text { Zealand }\end{array}$ & I43/f101 (L16349) & $\begin{array}{l}\text { Wilson \& McMillan } \\
1996\end{array}$ \\
\hline early Whaingaroan & $\begin{array}{l}\text { Cape Foulwind Section, Westland, New } \\
\text { Zealand }\end{array}$ & K29/f097 (L10914) & \\
\hline early Whaingaroan & $\begin{array}{l}\text { Cape Foulwind Section, Westland, New } \\
\text { Zealand }\end{array}$ & K29/f116 (L11052) & $\begin{array}{l}\text { Clowes \& Wilson } \\
2006\end{array}$ \\
\hline early Whaingaroan & Kakanui River, Oamaru-Dunedin, New Zealand & J42/f096 (L10951) & $\begin{array}{l}\text { Clowes \& Morgans } \\
1984\end{array}$ \\
\hline $\begin{array}{l}\text { Runangan-early } \\
\text { Whaingaroan }\end{array}$ & $\begin{array}{l}\text { Cape Foulwind Section, Westland, New } \\
\text { Zealand }\end{array}$ & K29/f169 (L11918) & \\
\hline Runangan & $\begin{array}{l}\text { Cape Foulwind Section, Westland, New } \\
\text { Zealand }\end{array}$ & K29/f259 (L13545) & \\
\hline Runangan & $\begin{array}{l}\text { Cape Foulwind Section, Westland, New } \\
\text { Zealand }\end{array}$ & K29/f262 (L13546) & \\
\hline ?Kaiatan-Runangan & $\begin{array}{l}\text { Cape Foulwind Section, Westland, New } \\
\text { Zealand }\end{array}$ & K29/f099 (L11035) & \\
\hline Bortonian & $\begin{array}{l}\text { Hampden Beach Section, Oamaru-Dunedin, } \\
\text { New Zealand }\end{array}$ & J42/f489 (L23124) & \\
\hline Bortonian & $\begin{array}{l}\text { Hampden Beach Section, Oamaru-Dunedin, } \\
\text { New Zealand }\end{array}$ & J42/f042 (L09199) & Wilson 1985 \\
\hline Bortonian & $\begin{array}{l}\text { Puketeraki Core, Oamaru-Dunedin, New } \\
\text { Zealand }\end{array}$ & I43/f089 (L16337) & $\begin{array}{l}\text { Wilson \& McMillan } \\
1996\end{array}$ \\
\hline Porangan-Bortonian & $\begin{array}{l}\text { Hampden Beach Section, Oamaru-Dunedin, } \\
\text { New Zealand }\end{array}$ & J42/f302 (L23132) & \\
\hline Porangan-Bortonian & $\begin{array}{l}\text { Hampden Beach Section, Oamaru-Dunedin, } \\
\text { New Zealand }\end{array}$ & J42/f301 (L23131) & \\
\hline Porangan & Te Uri Stream, Hawkes Bay, New Zealand & U24/f417 (L23125) & \\
\hline
\end{tabular}

Remarks: Most commentators have unwittingly perpetuated the erroneous citation from Davey \& Williams 1966a, p. 33, which lists Xanthidium ramosum as appearing in figures 1, 2 and 5 of plate 1 from Ehrenberg 1838. In fact, it appears in fig. 15 only.

Spiniferites furcatus (as Xanthidium furcatum) also appears in Ehrenberg's plate 1 (figs. 12 and 14). As noted above, the illustrations of the two taxa are noticeably different, and the reasons usually cited to support synonymy (the existence of intermediates and loss of the type material for Spiniferites furcatus) do not convince me. If the two are indeed synonyms, however, no particular priority attaches to the earlier-appearing name in the publication: both names have the same publication date (implied, e.g. by Recommendation 30A.1, Voss et al. 1983, p. 30).

There appears to be an earlier mention, also, in Mittheilungen aus den Verhandlungen der Gesellschaft naturforschender Freunde zu Berlin, Viertes Quartal 1836, published in 1837 according to the cover page, in which Xanthidium furcatum, X. ramosum (p. 47), Peridinium pyrophorum and P. delitiense (p. 48) are all 
mentioned. The phrase "sie läfst sich mit dem Namen $X$. ramosum bezeichnen" (p. 47) may be significant (bezeichnen means "to define" or "designate").

Spiniferites gracilis (Davey \& Williams 1966a) n. stat.

$$
\text { PI. 27, figs. 7-9 }
$$

\footnotetext{
1966a Hystrichosphaera ramosa var. gracilis Davey \& Williams, p. 34-35, pl. 1, fig. 5; pl. 5, fig. 6

1973 Spiniferites ramosus var. gracilis (Davey \& Williams 1966a, p. 34-35, pl. 1, fig. 5; pl. 5, fig. 6) Corradini, p. 165

1973 Spiniferites ramosus ssp. gracilis (Davey \& Williams 1966a, p. 34-35, pl. 1, fig. 5; pl. 5, fig. 6) Lentin \& Williams, p. 130
}

Original Description: A variety of $H$. ramosa (Ehrenberg) with smooth, thin-walled central body bearing gonal and sutural processes. Processes solid or hollow and relatively long and slender. Crests proximal and extending along all processes often as far as the trifurcation. Gonal processes mainly trifurcate, sutural processes bifurcate, all but smallest terminating with a small trifurcation (Davey \& Williams 1966a, p. 34).

Size Range: Length excluding any processes $=25(28) 32 \mu \mathrm{m}$ (2 measurements). Width excluding any processes $=24$ (26) $28 \mu \mathrm{m}$ (2 measurements). Length including any processes $=45$ (61) $72 \mu \mathrm{m}$ (12 measurements). Width including any processes $=43(54) 60 \mu \mathrm{m}$ (4 measurements).

Distribution: Common, over a lengthy stratigraphic range.

$\begin{array}{llll}\text { Age/Stage } & \text { Location } & \text { Sample } & \text { Sample Reference } \\ \text { Otaian } & \text { Puketeraki Core, Oamaru-Dunedin, New Zealand } & \text { I43/f101 (L16349) } & \text { Wilson \& McMillan } 1996 \\ \text { ?Kaiatan-Runangan } & \text { Cape Foulwind Section, Westland, New Zealand } & \text { K29/f099 (L11035) } & \\ \text { Bortonian } & \text { Puketeraki Core, Oamaru-Dunedin, New Zealand } & \text { I43/f089 (L16337) } & \text { Wilson \& McMillan } 1996\end{array}$

Remarks: As noted in the introduction, the subspecies concept has not been found to be useful in this study. In a biological sense, the distinction between species and subspecies (reproductive isolation) has dubious applicability to asexual organisms, or to any fossils, and S. gracilis is no more or less similar to S. ramosus than some other full species.

\section{Spiniferites aff. mirabilis (Rossignol 1964) Sarjeant 1970}

$$
\text { PI. 27, figs. 10-12 }
$$

1964 Hystrichosphaera mirabilis Rossignol, p. 86-87, pl. 2, figs. 1-3; pl. 3, figs. 4-5

1970 Spiniferites mirabilis (Rossignol 1964, p. 86-87, pl. 2, figs. 1-3; pl. 3, figs. 4-5) Sarjeant, p. 76

Original Description: Large ovoid Hystrichosphaera with scarcely visible tabulation. Trifurcated processes at the junctions of three plates and bifurcated intercalary processes along the sutures, each branch finely bifurcated. At the antapical pole the processes of the antapical plate are embedded in a large common sheet until bi- or trifurcation occurs; the combined appearance is that of a fan (Rossignol 1964, p. 87).

Description of Study Material: Cysts of intermediate size, chorate, not dorso-ventrally compressed, more or less spherical to prolate, lacking horns. Cyst wall two-layered; acavate. Archeopyle precingular, type P (3"); pentagonal (standard Gonyaulax-type). Surface ornament lacking. Processes gonal + intergonal; non-fibrous, solid; proximally connected by sutural septa proximally, trifurcate distally; the antapical process broadly expanded, with several distal trifurcating points. Tabulation clearly expressed, gonyaulacacean, inferred formula: 3 to 4', 0a, 5-6", 6c, 5-6"', 1ps, 1"'", Xs; hyposome sexiform. Cingulum clearly expressed, indicated by sutural septa.

Size Range: Length excluding any processes $=46 \mu \mathrm{m}$ (one measured specimen). Width excluding any processes $=44 \mu \mathrm{m}$ (one measured specimen). Length including any processes $=91 \mu \mathrm{m}$ (one measured specimen). Width including any processes $=79 \mu \mathrm{m}$ (one measured specimen).

Distribution: Rare. The published range for Spiniferites mirabilis, s.s., is at least Aquitanian to Recent. If the present taxon were recognised as indeed belonging to Spiniferites mirabilis, it might represent a significant backward extension of this range.

$\begin{array}{llll}\text { Age/Stage } & \text { Location } & \text { Sample } & \text { Sample Reference } \\ \text { Bortonian } & \text { Puketeraki Core, Oamaru-Dunedin, New Zealand } & \text { I43/f093 (L16341) } & \text { Wilson \& McMillan 1996 } \\ \text { Bortonian } & \text { Puketeraki Core, Oamaru-Dunedin, New Zealand } & \text { I43/f092 (L16340) } & \text { Wilson \& McMillan 1996 }\end{array}$


Remarks: The New Zealand forms seem to be somewhat less densely ornamented than the type material, and the sutural septa are poorly developed (recalling Achomosphaera as much as Spiniferites) but is otherwise very similar.

\title{
Genus Achomosphaera Evitt 1963a
}

\author{
1963a Achomosphaera Evitt, p. 163 \\ 1978 Achomosphaera Evitt 1963; Stover \& Evitt, p. 138-139
}

Type Species: Achomosphaera ramulifera (Deflandre 1937b, p. 74, pl. 14, figs. 5-6, pl. 17, fig. 10) Evitt 1963, p. 163 [Late Cretaceous]

Original Description: Test consists of a spherical to ellipsoidal central body with precingular archeopyle and furcate, spinelike processes like those on Hystrichosphaera in both structure and distribution, but without sutural ridges or septa connecting their bases as in that genus. Tips of processes not interconnected. Wall two-layered; layers typically in close contact between bases of processes (Evitt 1963, p. 163).

Remarks: Achomosphaera was considered a junior synonym of Spiniferites by Duxbury 1983 (p. 54-55). However, beginning with Lentin \& Williams 1989 (p. 3), many subsequent authors have preferred to retain Achomosphaera. The difference, perhaps best articulated by Stover \& Evitt (1978, Appendix I, p. 283-284), is simply whether the gonal process bases are proximally linked by sutural features (Spiniferites) or not (Achomosphaera).

Whether two genera are maintained separately as a matter of convenience, or not, it seems inescapable that many of the species are closely related and some may even represent ecological variations of one another. Without a great deal of further analysis, the phylogenetic meaning of the Achomosphaera genus concept seems destined to remain unknown.

\section{Achomosphaera ?alcicornu (Eisenack 1954b) Davey \& Williams 1966a}

$$
\text { Pl. 28, figs. 1-6 }
$$

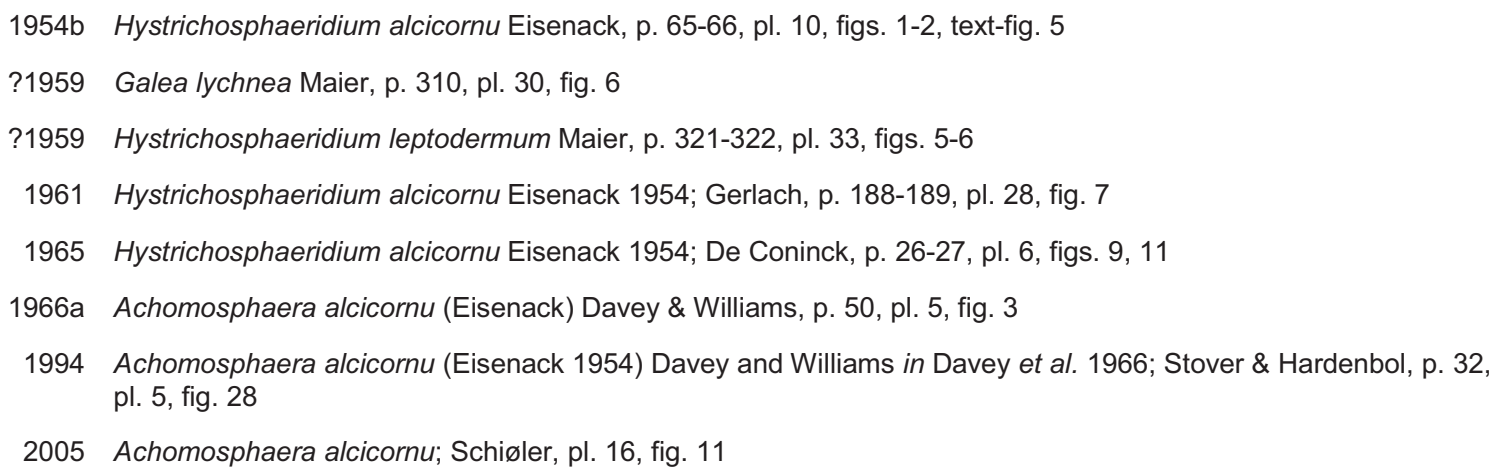

Original Description: [No translation available] Zentralkörper kugelförmig bis schwach oval, mit zahlreichen hohlen Anhängen versehen, die am Ende trichterartig erweitert sind. Diese Erweiterungen laufen in meist 3 , gelegentlich weiter unterteilte Spitzen aus, die bogig verbunden sind, so daß eine entfernte Ähnlichkeit mit einer Elchschaufel entsteht ... (Eisenack 1954b, p. 65; ellispses replace figure references in the original).

Description of Study Material: Cysts of intermediate size, chorate, not dorso-ventrally compressed, more or less spherical to prolate, lacking horns; episome and hyposome more or less equal in length. Cyst wall two-layered; acavate. Archeopyle precingular, type P (3"); pentagonal (standard Gonyaulax-type). Surface ornament lacking. Processes gonal; non-fibrous, branching, solid; not connected proximally, trifurcate distally. Tabulation weakly expressed by gonal processes, apparently gonyaulacacean. Sulcus indicated by a series of differentiated processes.

Size Range: Length excluding any processes $=45$ (48) $50 \mu \mathrm{m}$ (2 measurements). Width excluding any processes $=40 \mu \mathrm{m}$ (one measured specimen). Length including any processes $=78(86) 95 \mu \mathrm{m}$ (2 measurements). Width including any processes $=75 \mu \mathrm{m}$ (one measured specimen).

Distribution:

$\begin{array}{llll}\begin{array}{l}\text { Age/Stage } \\ \text { middle Oligocene-middle } \\ \text { Miocene }\end{array} & \text { Location } & \text { Sample } & \text { Sample Reference } \\ & \text { north west Germany } & \text { Pr 1170/44 } & \text { Gerlach 1961 }\end{array}$




$\begin{array}{llll}\begin{array}{l}\text { Age/Stage } \\ \text { middle Oligocene }\end{array} & \text { Location } & \text { Sample } & \begin{array}{l}\text { Sample Reference } \\ \text { Davey \& Williams } \\ \text { north west Germany }\end{array} \\ \begin{array}{l}\text { early Oligocene } \\ \text { Bortonian }\end{array} & \begin{array}{l}\text { Pr 1170/44 } \\ \text { Samland, Germany } \\ \text { Puketeraki Core, Oamaru-Dunedin, New } \\ \text { Zealand }\end{array} & \begin{array}{l}\text { Ph 4 } \\ \text { I43/f093 (L16341) }\end{array} & \begin{array}{l}\text { Wisenack 1954b } \\ \text { Wilson \& McMillan } \\ 1996\end{array} \\ \text { Bortonian } & \begin{array}{l}\text { Puketeraki Core, Oamaru-Dunedin, New } \\ \text { Zealand }\end{array} & \text { I43/f091 (L16339) } & \begin{array}{l}\text { Wilson \& McMillan } \\ 1996\end{array} \\ \text { Ypresian } & \text { Merelbeke, Belgium } & \text { Preparation 30 } & \text { De Coninck 1965 }\end{array}$

Remarks: The forms encountered in the study were generally poor and seem to be at least somewhat transitional with Achomosphaera ramulifera.

\section{Genus Hafniasphaera Hansen 1977}

1977 Hafniasphaera Hansen, p. 13-14

1982 Rivernookia Cookson \& Eisenack, p. 56

1987 Hafniasphaera Hansen 1977, p. 13; Stover \& Williams, p. 117

Type Species: Hafniasphaera hyalospinosa Hansen 1977, p. 14, figs. 7-8, 18A [Paleocene (Danian)]

Original Description: Chorate cysts with a subspherical or ovoid central body composed of two layers, endophragm and periphragm. One or both of these layers contain numerous evenly distributed vesicles (vacuoles). The vesicles are spherical or, if interconnected, they may form a fine reticulum internal in the cyst wall. Processes intertabular [sic], formed by the periphragm, with or without vesicles, solid or hollow, closed or open distally. Simple processes trifurcate (gonal processes) or bifurcate (sutural processes). Composite processes ramifying in more complex ways. Tips of furcae bifid. Archeopyle type $\mathrm{P}$, formed by loss of paraplate 3". Operculum becomes typically completely detached.

Paratabulation indicated by presence of sutural crests, weak bulges of the periphragm, by alignment of the vesicles, or by the arrangement of the processes only. Paratabulation of the plates 1'-3' (4'), 1"-6", 1c-6c, (1"') 2"'6"', (ps), (1p), 1"'. Paraplate 6" is triangular, 1"' very little if not absent. If present, paraplate 4' is situated between $1 "$ and 5", above 6" and parasulcus. Suture between $3 "$ " and $4 "$ "' is situated a little to the left of suture between 2" and 3", whereas suture between 4"' and 5"' is aligned with or slightly to the right of suture between 3 " and 4". Paracingulum disposed in a laevorotary spiral (Hansen 1977, p. 13).

Remarks: Considered a junior synonym of Spiniferites, according to Stover \& Williams (1987, p.117). Here, however, I have followed Edwards (1996, p.989) in retaining Hafniasphaera. The featureless, hyaline wall typical of most Spiniferites species, and the type species, Spiniferites ramosus, in particular, shows no signs of the "numerous evenly distributed vesicles" described by Hansen for Hafniasphaera, and nor does the type species of Hafniasphaera, H. hyalospinosa, at all resemble a typical species of Spiniferites.

\section{Hafniasphaera ?septata (Cookson \& Eisenack 1967b) Hansen 1977}

$$
\text { PI. 28, figs. 7-9 }
$$

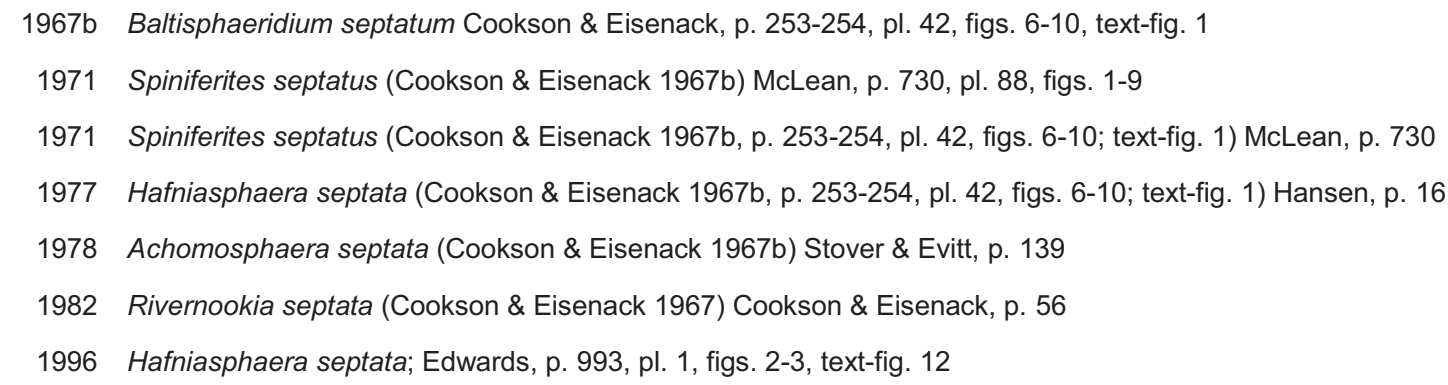

Original Description: Shell spherical, thin-walled with a closely and rather coarsely, apparently granular surface and a variable number of radially arranged appendages which approximate in length to the radius of the shell. A 'marginal zone' often present, giving the impression that the shell is thick-walled, is, in fact, due to compression.

The appendages vary in size, shape and structure. The majority narrow somewhat from a broadened base and divide distally into two or three straight or curved tapering branches with closed, pointed or minutely bifurcate tips. The larger appendages are typically hollow and septate throughout ...; in the finer to thread-like ones, on the contrary ... the degree of septation is often difficult to determine and their distal portions, at least, appear be 
solid. A few of the appendages are unbranched. A pylome has been seen in a few specimens ... (Cookson \& Eisenack 1967b, p. 253-254; ellipses replace figure references in the original).

Description of Study Material: Cysts of intermediate size, chorate, not dorso-ventrally compressed, prolate, lacking horns; episome and hyposome more or less equal in length. Cyst wall two-layered; acavate; thin, about $1 \mu \mathrm{m}$ in thickness. Archeopyle precingular, type P (3"); pentagonal (standard Gonyaulax-type); operculum free. Surface ornament present, non-tabular, comprising granules; very low (about $1 \mu \mathrm{m}$ or lower). Processes vacuolate, branching, solid; usually connected proximally, irregularly trifurcate distally. Tabulation weakly expressed, apparently gonyaulacacean, inferred formula: 4', 0a, 6", 6c, 6"', 1ps, 1"'", Xs; hyposome sexiform. Cingulum moderately expressed, indicated by surface ornament, about $6 \mu \mathrm{m}$ wide. Sulcus weakly expressed, indicated by surface ornament.

Size Range: Length excluding any processes $=44 \mu \mathrm{m}$ (one measured specimen). Width excluding any processes $=40 \mu \mathrm{m}$ (one measured specimen). Length including any processes $=70 \mu \mathrm{m}$ (one measured specimen). Width including any processes $=62 \mu \mathrm{m}$ (one measured specimen).

\title{
Distribution:
}

$\begin{array}{llll}\text { Age/Stage } & \text { Location } & \text { Sample } & \text { Sample Reference } \\ \text { Otaian } & \text { Puketeraki Core, Oamaru-Dunedin, New Zealand } & \text { I43/f101 (L16349) } & \text { Wilson \& McMillan } 1996 \\ \begin{array}{l}\text { Porangan } \\ \text { early Eocene }\end{array} & \text { Te Uri Stream, Hawkes Bay, New Zealand } & \text { U24/f419 (L23127) } & \\ & & & \text { Edwards } 1996\end{array}$

late Paleocene $\quad$ Aquia Formation, Virginia-Maryland coastal plain, USA SUPTC 10050-10051 McLean 1971

\section{Genus Hystrichostrogylon Agelopoulos 1964 emend. Stover \& Evitt 1978}

\author{
1964 Hystrichostrogylon Agelopoulos, p. 673-674
}

1978 Hystrichostrogylon Agelopoulos 1964 emend. Stover \& Evitt, p. 164-165

\section{Type Species: Hystrichostrogylon membraniphorum Agelopoulos 1964, p. 674; text-figs. 1-2 [Late Eocene]}

Original Description: Central shell spherical to oval, apparently slightly flattened, provided with forked spines, and enclosed by a delicate, transparent, only antapical developed, somewhat concentric outer shell that lies close to the inner shell ventrally and dorsally. Slender, long, hollow processes occur in the region of the apex which is indicated by a pylome, whereas wide, broad-surfaced processes are confined to the region of the antapex and therefore to the outer shell. The central shell within the outer shell possesses no processes (translated from Agelopoulos 1964, p. 673-674, by Stover \& Evitt 1978, p. 164).

Emended Description of Stover \& Evitt 1978: Shape. Endocyst subspherical; outline of periphragm varies in size and shape, consistent with degree of separation between endophragm and periphragm. Wall Relationships. Cysts camocavate; periphragm and endophragm always appressed dorsally, narrowly to widely separated elsewhere; size and shape of pericoel vary. Wail Features. Faint parasutural lines or ridges may be present on periphragm. Gonal and intergonal processes typically furcate, tips not interconnected; process shafts normally long where pericoel is least developed or not at all, short where pericoel is most developed. Endophragm and periphragm smooth or faintly ornamented. Paratabulation. Indicated by processes and additionally by faint parasutural lines or ridges; gonyaulacacean, formula: 3-4', 6", 6c, 5-6"', 0-1p, 1"'"; rarely expressed completely. Archeopyle. Precingular, Type P (3" only); operculum free. Paracingulum. Position indicated by locations of processes and, additionally, by faint parasutural lines or ridges. Parasulcus. Not indicated, or outlined by parasutural features. Size. Intermediate (Stover \& Evitt 1978, p. 164).

\section{Hystrichostrogylon membraniphorum Agelopoulos 1964}

$$
\text { PI. 28, figs. 10-12 }
$$

\footnotetext{
1964 Hystrichostrogylon membraniphorum Agelopoulos, p. 674, text-fig. 1-Feb

1967 Hystrichostrogylon membraniphorum Agelopoulos 1964; Agelopoulos, p. 43, pl. 9, figs. 7-8, pl. 12, figs. 1-2, pl. 13, fig. 8

1976 Achomosphaera membraniphora (Agelopoulos 1964) Eaton, p. 237-238, pl. 1, figs. 8-10, text-fig. 5

1978 Hystrichostrogylon membraniphorum Agelopoulos 1964; Stover \& Evitt, p. 165

1984b Hystrichostrogylon membraniphorum Agelopoulos, 1964; Helenes, p. 94, 104, pl. 5, figs. 13-14

2005 Hystrichostrogylon membraniphorum; Schiøler, pl. 1, fig. 12
} 
Original Description: [As for the genus.] Central shell spherical to oval, apparently slightly flattened, provided with forked spines, and enclosed by a delicate, transparent, only antapical developed, somewhat concentric outer shell that lies close to the inner shell ventrally and dorsally. Slender, long, hollow processes occur in the region of the apex which is indicated by a pylome, whereas wide, broad-surfaced processes are confined to the region of the antapex and therefore to the outer shell. The central shell within the outer shell possesses no processes (translated from Agelopoulos 1964, p. 673-674, by Stover \& Evitt 1978, p. 164).

Description of Study Material: Cysts of intermediate size, chorate, not dorso-ventrally compressed, lacking horns; episome and hyposome more or less equal in length. Cyst wall two-layered; camocavate, with the characteristic ventral pericoel well-developed. Archeopyle precingular, type P (3"); pentagonal (standard Gonyaulax-type); operculum free. Surface ornament lacking. Non-fibrous, solid; proximally connected by sutural septa proximally, trifurcate distally. Gonyaulacacean, inferred formula: 4', 0a, 6", 6c, 5-6"', 0 to 1ps, 1"', Xs; ventral organisation Stype; hyposome sexiform. Cingulum indicated by sutural septa, clearly expressed. Sulcus indicated by sutural septa, clearly expressed.

Size Range: Length excluding any processes $=57(68) 88 \mu \mathrm{m}$ (4 measurements). Width excluding any processes $=43(50) 60 \mu \mathrm{m}$ (4 measurements). Length including any processes $=72$ (89) $122 \mu \mathrm{m}$ (9 measurements). Width including any processes $=67(87) 110 \mu \mathrm{m}$ (5 measurements).

Distribution:

\begin{tabular}{|c|c|c|c|}
\hline Age/Stage & Location & Sample & Sample Reference \\
\hline late Eocene & Kieselton von Heiligenhafen, Holstein & Prb. 23, nr. 258 & Agelopoulos 1967 \\
\hline Kaiatan & Puketeraki Core, Oamaru-Dunedin, New Zealand & I43/f096 (L16344) & $\begin{array}{l}\text { Wilson \& McMillan } \\
1996\end{array}$ \\
\hline Bortonian & Puketeraki Core, Oamaru-Dunedin, New Zealand & |43/f091 (L16339) & $\begin{array}{l}\text { Wilson \& McMillan } \\
1996\end{array}$ \\
\hline Porangan & Te Uri Stream, Hawkes Bay, New Zealand & U24/f419 (L23127) & \\
\hline $\begin{array}{l}\text { middle Eocene-late } \\
\text { Eocene }\end{array}$ & Bracklesham Beds, Isle of Wight, southern England & V57764-57797 & Eaton 1976 \\
\hline Lutetian & $\begin{array}{l}\text { Bateque Formation; Sebastian Vizcaino Basin, Baja } \\
\text { California }\end{array}$ & & Helenes 1984b \\
\hline
\end{tabular}

Genus Nematosphaeropsis Deflandre \& Cookson 1955 emend. Wrenn 1988

\author{
1905 Pterococcus Lohmann, p. 47 \\ 1955 Nematosphaeropsis Deflandre \& Cookson, p. 268 \\ 1966c Nematosphaeropsis Deflandre \& Cookson 1955 [emend.] Williams \& Downie, p. 222 \\ 1970 Coccopterum Silva, p. 942 \\ 1978 Nematosphaeropsis Deflandre \& Cookson 1955 emended Williams \& Downie in Davey et al. 1966; Stover \& Evitt, \\ p. 176 \\ ?1980 Trabeculidinium Duxbury, p. 132-133 \\ 1988 Nematosphaeropsis Deflandre \& Cookson 1955 emend. Wrenn, p. 137, 139
}

Type Species: Nematosphaeropsis balcombiana Deflandre \& Cookson 1955, p. 268-269, pl. 8, fig. 5 [Middle Miocene]

Original Description: Shell globular, divided into fields by ridges, an equatorial series developed as in Hystrichosphaera. Branches of processes joined to one another by trabeculae or filaments as in the genus Cannosphaeropsis (Deflandre \& Cookson, p. 268).

Remarks: The extant genera Pterococcus Lohmann 1905 (an illegitimate name) and Coccopterum Silva 1970, are treated as junior synonyms of Nematosphaeropsis by Reid 1974 (p. 592) and Fensome et al. 1993b (p. 93).

Stover \& Williams (1987, p. 217) further regarded Trabeculidium Duxbury 1980 as a junior synonym, because they "could find no fundamental difference" between the description of Trabeculidium and Nematosphaeropsis as emended by Williams \& Downie 1966c (p. 222). Subsequently, Sarjeant (1989, p. 93) retained Trabeculidium. In this matter I am inclined to side with Sarjeant: my own view is that it requires more persuasive evidence than failing to find a "fundamental" difference between two authors' circumscriptions to motivate synonymy between genera whose type species are separated in time by the best part of 100 million years.

Ectosphaeropsis differs in possessing an ectophragm supported on the trabeculae (Londeix \& Jan du Chêne 1988, p. 252). 
Nematosphaeropsis balcombiana Deflandre \& Cookson 1955

PI. 29, figs. 1-6

1955 Nematosphaeropsis balcombiana Deflandre \& Cookson, p. 268-269, pl. 8, fig. 5
1984 Nematosphaeropsis balcombiana Deflandre \& Cookson 1955; Clowes \& Morgans, pl. 2, fig. 12
1988 Nematosphaeropsis balcombiana Deflandre \& Cookson 1955; Wrenn, p. 139-140, pl. 7, fig. 3

Original Description: Characters of the genus: shell slightly elliptical, with numerous processes of which the longest approaches half the diameter of the shell. Processes trifurcate, the extremities of the 3 branches joined to neighbouring processes by delicate filaments (Deflandre \& Cookson 1955, p. 268).

Description of Study Material: Cysts small, chorate, not dorso-ventrally compressed, more or less spherical, lacking horns; episome and hyposome more or less equal in length. Cyst wall single-layered. Archeopyle precingular, type P (3"); operculum free. Surface ornament lacking. Processes arising in gonal and intergonal positions; non-fibrous, solid; connected proximally by sutural septa, connected by well developed trabeculae distally. Tabulation clearly expressed, gonyaulacacean, inferred formula: 3 to 4', 0a, 5-6", 6c, 5-6"', 1ps, 1"'", Xs; ventral organisation S-type; hyposome sexiform; torsion neutral. Cingulum clearly expressed, indicated by sutural septa. Sulcus clearly expressed, indicated by sutural septa.

Size Range: Length excluding processes $=22$ (24) $27 \mu \mathrm{m}$ (2 measurements). Width excluding processes $=22$ (22) $22 \mu \mathrm{m}$ (2 measurements). Length including processes = 32 (39) $47 \mu \mathrm{m}$ (18 measurements). Width including processes $=40(43) 45 \mu \mathrm{m}$ (3 measurements).

Distribution: Generally uncommon, though it can be locally abundant in individual samples. The exact range in New Zealand requires more research, especially the upper boundary: I am not aware of any data to suggest that it doesn't extend well beyond the occurrences documented herein.

\begin{tabular}{|c|c|c|c|}
\hline Age/Stage & Location & Sample & Sample Reference \\
\hline early Whaingaroan & $\begin{array}{l}\text { Kakanui River, Oamaru-Dunedin, New } \\
\text { Zealand }\end{array}$ & J42/f096 (L10951) & $\begin{array}{l}\text { Clowes \& Morgans } \\
1984\end{array}$ \\
\hline $\begin{array}{l}\text { Runangan-early } \\
\text { Whaingaroan }\end{array}$ & $\begin{array}{l}\text { Cape Foulwind Section, Westland, New } \\
\text { Zealand }\end{array}$ & K29/f172 (L11921) & \\
\hline $\begin{array}{l}\text { Runangan-early } \\
\text { Whaingaroan }\end{array}$ & Kakanui River mouth & & $\begin{array}{l}\text { Clowes \& Morgans } \\
1984\end{array}$ \\
\hline $\begin{array}{l}\text { Runangan-early } \\
\text { Whaingaroan }\end{array}$ & $\begin{array}{l}\text { Cape Foulwind Section, Westland, New } \\
\text { Zealand }\end{array}$ & K29/f170 (L11919) & \\
\hline Bortonian & $\begin{array}{l}\text { Puketeraki Core, Oamaru-Dunedin, New } \\
\text { Zealand }\end{array}$ & I43/f089 (L16337) & $\begin{array}{l}\text { Wilson \& McMillan } \\
1996\end{array}$ \\
\hline
\end{tabular}

Remarks: N. balcombiana is treated as a junior synonym to N. labyrinthus (Ostenfeld 1903) by Reid 1974 (p. 592). However, as subsequently noted (see, for example, the discussion in Head \& Wrenn 1992b, p. 10-18), $N$. labyrinthus is a highly problematic taxon and considerable uncertainty surrounds its application to extant cysts from the North Atlantic type area, let alone fossils from half a world away. Herein, I prefer to follow (e.g.) Wrenn 1988 , p. 139 , in retaining $N$. balcombiana (though not, obviously, his further recommendation that the name be restricted to the holotype, p. 129).

Nor can I discern in the original images (Deflandre \& Cookson 1955, pl. 8, fig. 5) the "very broad-based, proximally branched processes" noted by Wrenn (1988, p. 136), at least not to the extent depicted by him (pl. 7 , fig. 3). The proximal process attachments of the forms assigned herein to $N$. balcombiana are essentially typical of most any species of Spiniferites or Achomosphaera.

\section{Genus Rottnestia Cookson \& Eisenack 1961b}

1961b Rottnestia Cookson \& Eisenack, p. 40, 42

1978 Rottnestia Cookson \& Eisenack 1961b; Stover \& Evitt, p. 185

Type Species: Rottnestia borussica (Eisenack 1954b, p. 62, pl. 9, figs. 5-7) Cookson \& Eisenack 1961 b, p. 42 [Early Oligocene]

Original Description: The shells consist, like those of a number of fossil dinoflagellates, of an internal body and a thin outer membrane. The internal body is clearly defined and oval in shape. The outer membrane is in contact with the internal body in the central region but extends beyond it both apically and antapically. The apical expansion is surmounted by a median conical or cylindrical horn; the antapical expansion is squarish in shape with sharp or rounded angles. The shell is crossed by a median helicoid girdle and a relatively broad longitudinal furrow runs obliquely across the ventral surface. The surface of the outer membrane is divided into pre- and post- 
equatorial fields the limits of which run into the edges supporting the apical and antapical expansions. Forked appendages may or may not be developed at the corners of the fields. A large elongate-trapezoid pylome develops on the dorsal side of the epitheca in both the internal body and outer membrane (Cookson \& Eisenack 1961b, p. 40, 42).

Remarks: The appendages of the type species, $R$. borussica, described as "forked" in the original description (Eisenack 1954b, p. 62), are depicted in text-fig. 1c, and especially 1d, as trifurcate, suggesting a possible affinity with Spiniferites.

The genus Hystrichosphaeropsis Deflandre 1935 also exhibits this general range of morphologies, having an apical horn but lacking or having only weakly developed gonal processes. However, in some specimens of $R$. borussica the gonal spines are absent, or almost, which compromises the distinction: the morphological ranges of Hystrichosphaeropsis ovum and R. borussica appear to overlap. Notwithstanding that, their stratigraphic ranges are quite different (Senonian versus Eocene), which militates very strongly against any idea of synonymy.

A re-examination of the original (or fresh topotype) material seems to be indicated. If found to be synonyms, Hystrichosphaeropsis is senior.

\title{
Rottnestia borussica (Eisenack 1954b) Cookson \& Eisenack 1961b
}

PI. 29, figs. 7-12

\author{
1954b Hystrichosphaera borussica Eisenack, p. 62, pl. 9, figs. 5-7 \\ ?1961 Hystrichosphaera ovum Deflandre 1937; Gerlach, p. 176-177, pl. 27, fig. 4 \\ 1961b Rottnestia borussica (Eisenack 1954b, p. 62, pl. 9, figs. 5-7) Cookson \& Eisenack, p. 42, pl. 1, figs. 8-10 \\ 1965 Rottnestia borussica (Eisenack) Cookson et Eisenack 1961; De Coninck, p. 19-20, pl. 3, fig. 9 \\ 1966a Triblastula borussica (Eisenack 1954b, p. 62, pl. 9, figs. 5-7) Morgenroth, p. 15-16, pl. 7, figs. 9-10 \\ 1966b Hystrichosphaeropsis borussica (Eisenack 1954b, p. 62, pl. 9, figs. 5-7) Sarjeant, p. 139 \\ 1967 Rottnestia borussica (Eisenack 1954); Agelopoulos, p. 24-25, pl. 7, figs. 2-4 \\ 1969a Rottnestia borussica (Eisenack 1954) Cookson \& Eisenack 1961; Eisenack, p. 105-108 \\ 1986a Rottnestia borussica (Eisenack 1954) Cookson \& Eisenack 1961; Jan du Chêne et al., p. 309
}

Original Description: The central body is oval, tabulated similarly to $H$. speciosa Defl. or $H$. wetzeli Defl., the lower pole is furnished with an extended system of membranous ridges that extends as far as the equatorial zone; however, in contrast to $H$. wetzeli, an upper pole is generally not present (Eisenack 1954b, p. 63).

Size Range: Length excluding any processes $=88 \mu \mathrm{m}$ (one measured specimen). Width excluding any processes $=45 \mu \mathrm{m}$ (one measured specimen). Length including any processes $=90 \mu \mathrm{m}$ (one measured specimen). Width including any processes $=54 \mu \mathrm{m}$ (one measured specimen).

Distribution: Very rare.

\begin{tabular}{|c|c|c|c|}
\hline Age/Stage & Location & Sample & Sample Reference \\
\hline $\begin{array}{l}\text { middle Oligocene-middle } \\
\text { Miocene }\end{array}$ & north west Germany & $\operatorname{Pr} 1170 / 31$ & Gerlach 1961 \\
\hline Bortonian & $\begin{array}{l}\text { Puketeraki Core, Oamaru-Dunedin, New } \\
\text { Zealand }\end{array}$ & I43/f093 (L16341) & $\begin{array}{l}\text { Wilson \& McMillan } \\
1996\end{array}$ \\
\hline
\end{tabular}

Remarks: Cookson \& Eisenack 1961b (p. 42 and in the caption to text-fig. 1) allude to variation which they consider to lie within their concept of Rottnestia borussica, embracing forms both with gonal processes and without, and both with an apical horn and without. This view seems at odds with modern fossil dinoflagellate taxonomic practice, at the species level, and, in particular, it is unlikely that the form illustrated in Cookson \& Eisenack 1961b, text-fig. 1a-b, would ordinarily be considered conspecific with that of text-fig. 1c-d.

Intermediate forms may have been present, though there is no explicit comment to this effect. Even if true, as noted elsewhere herein, the presence of intermediates does not necessarily imply conspecificity. There appear to be two distinct forms - or end-members - represented:

- The first is illustrated in Cookson \& Eisenack 1961b, pl. 1, figs. 8-10, and text-fig. 1c-d. This form possesses an apical horn and trifurcating gonal processes, and appears most like the original German type material. The specimen photographed for pl. 1, fig. 8 is "one of the original specimens from the Amber Formation, East Prussia" although those of pl. 1 figs. 9-10 are from the Rottnest Bore and similarly ornamented. The few specimens encountered in the present study (see PI. 29, figs. 7-12), are of this type.

- The second is illustrated in Cookson \& Eisenack 1961b, pl. 2, figs. 1-2, and text-fig. 1a-b. This form lacks an apical horn, possessing instead a convex though more or less smooth apical profile, and lacks gonal 
processes although the periphragm does appear to "peak" into sharp points at the gonal positions and one, at the left hand side of pl. 2, fig. 1, appears to be minutely ornamented (or it may be birefringence). This form has not been observed in the present study.

\title{
Genus Cannosphaeropsis O. Wetzel 1933b
}

\author{
1933b Cannosphaeropsis O. Wetzel \\ 1978 Cannosphaeropsis O. Wetzel 1933b emended Williams \& Downie in Davey et al. 1966; Stover \& Evitt, p. 143-144
}

Type Species: Cannosphaeropsis utinensis O. Wetzel 1933b, p. 6, pl. 3, figs. 9-17, text-fig. 12 [Cretaceous (Senonian)]

Original Description: Similar to the radiolarian Cannosphaera, from which it differs (also from Coelacantha) externally by the lack of a true pylome, by the number and arrangement of radial rods, as well as by the construction of the meshwork (translation from O. Wetzel 1933b, p. 6, by Stover \& Evitt 1978, p. 143).

\section{?Cannosphaeropsis sp. 1}

\section{PI. 30, figs. 1-3}

Description: Cysts of intermediate size, chorate, not dorso-ventrally compressed, more or less spherical, lacking horns; episome and hyposome more or less equal in length. Cyst wall single-layered. Archeopyle precingular, type P (3"); operculum free. Surface ornament lacking. Processes gonal; non-fibrous, solid; connected proximally by sutural septa, and distally by well developed trabeculae. Tabulation clearly expressed, gonyaulacacean, inferred formula: ?4', 0a, ?6", ?6c, ?5"', 1ps, 1"', Xs; ventral organisation S-type; hyposome sexiform; torsion neutral. Cingulum clearly expressed, indicated by sutural septa. Sulcus clearly expressed, indicated by sutural septa.

Size Range: Length excluding any processes $=38 \mu \mathrm{m}$ (one measured specimen). Width excluding any processes $=28 \mu \mathrm{m}$ (one measured specimen). Length including any processes $=59 \mu \mathrm{m}$ (one measured specimen). Width including any processes $=53 \mu \mathrm{m}$ (one measured specimen).

Distribution: Extremely rare. Only a single specimen has been encountered in the present study.

$\begin{array}{llll}\text { Age/Stage } & \text { Location } & \text { Sample } & \text { Sample Reference } \\ \text { Bortonian } & \text { Puketeraki Core, Oamaru-Dunedin, New Zealand } & \text { I43/f093 (L16341) } & \text { Wilson \& McMillan 1996 }\end{array}$

Remarks: The specimen is very faint (having taken up no stain) but otherwise looks perfect. It is fully inflated (3-dimensional) rather than flattened. Although it may be reworked, there is no physical evidence to indicate that is the case.

\section{Genus Corrudinium Stover \& Evitt 1978}

\author{
1978 Corrudinium Stover \& Evitt, p. 148-149 \\ 1993b Corrudinium Stover \& Evitt 1978; Fensome et al., p. 92 \\ 2004 Corrudinium Stover \& Evitt, 1978, p. 148-149; Fensome \& Williams, p. 159 \\ 2006 Corrudinium Stover \& Evitt 1978; Clowes \& Wilson, p. 400-401
}

Type Species: Corrudinium incompositum (Drugg 1970b, p. 810-811, figs. 1E-O, 2A) Stover \& Evitt 1978, p. 149 [Oligocene]

Original Description: Cysts proximate to proximochorate, subspherical, and without an apical horn or protrusion; paratabulation gonyaulacacean, indicated by parasutural ridges or septa; the accessory ridges or septa present on most paraplates tend to obscure paratabulation; archeopyle precingular, Type P (Stover \& Evitt 1978, p. 148).

Remarks: Corrudinium was separated from Impagidinium and Leptodinium in a revision of the latter by Stover \& Evitt (1978) on the basis of possessing accessory ridges or septa.

More significantly, as we now know, Corrudinium is distinguished from Leptodinium by the possession of a S-type ventral topology: Leptodinium and its allies have L-type ventral topology.

Impagidinium and Corrudinium share the S-type ventral topology common to the Gonyaulacoideae. Corrudinium differs consistently only in the possession of accessory ridges or septa. Impagidinium species may sometimes also exhibit a more prolate shape than Corrudinium. However, few would regard these features alone as defining anything more than a grouping of convenience for forms having a gross morphological similarity, but no seriously 
implied phylogenetic relationship; it seems likely there is considerably more work still to be completed before the phylogeny of these groups is in any way settled.

Ochetodinium Damassa 1979a is also broadly similar in outward appearance to some species of Corrudinium, especially Corrudinium otagoense, but can be readily distinguished by its characteristically perforate sutural ridges.

Corrudinium has been widely reported, both geographically and stratigraphically. However, I am of the view that the phylogenetically related "core" of species are confined to the Eocene and early Oligocene, or not much beyond it. A range chart for New Zealand occurrences of Corrudinium is provided in Appendix 2, chart 2.

Key to selected species:

\begin{tabular}{|c|c|c|}
\hline 0. & Septa very high $(\sim 8 \mu \mathrm{m}$ high $) \ldots$. & 1. \\
\hline & Septa prominent $(\sim 6 \mu \mathrm{m}$ high $) \ldots .$. & 2. \\
\hline & Septa generally very low $(<<5 \mu \mathrm{m}) \ldots$. & 3. \\
\hline 1. & \multicolumn{2}{|l|}{ Corrudinium otagoense } \\
\hline 2. & Sutural septa consistently higher than intratabular septa .... & 2.1. \\
\hline 2. & Sutural and intratabular septa of approximately similar height .... & 2.2. \\
\hline 2.1. & \multicolumn{2}{|l|}{ Corrudinium eyrense } \\
\hline 2.2. & \multicolumn{2}{|l|}{ Corrudinium obscurum } \\
\hline \multirow[t]{2}{*}{3.} & Surface ornament vermiculate; no evidence of tabulation .... & 3.1. \\
\hline & Surface ornament includes low sutural septa, indicating a gonyaulacacean tabulation .... & 3.2. \\
\hline 3.1 & \multicolumn{2}{|l|}{ ?Corrudinium vermiculatum } \\
\hline 3.2. & Cysts small $(<\sim 50 \mu \mathrm{m})$; thin-walled and frequently deformed $\ldots .$. & 3.2.1. \\
\hline 3.2 . & Cysts small $(<\sim 40 \mu \mathrm{m})$; walls relatively robust $\ldots .$. & 3.2.2. \\
\hline 3.2 . & Cysts larger ( $\sim 50 \mu \mathrm{m}$ and greater); walls relatively robust .... & 3.2.3. \\
\hline 3.2.1. & \multicolumn{2}{|l|}{ Corrudinium incompositum } \\
\hline 3.2 .2 . & \multicolumn{2}{|l|}{ Corrudinium bujackii } \\
\hline 3.2.3. & \multicolumn{2}{|l|}{ Corrudinium regulare } \\
\hline
\end{tabular}

\section{Corrudinium incompositum (Drugg 1970b) Stover \& Evitt 1978}

PI. 30, figs. 4-6

1970b Gonyaulacysta incomposita Drugg, p. 810-811, fig. 1E-O, 2A

1973 Leptodinium incompositum (Drugg 1970) Lentin \& Williams, p. 87

1978 Corrudinium incompositum (Drugg 1970) Stover \& Evitt, p. 148-149

1980 Corrudinium incompositum (Drugg 1970) L.E. Stover, W.R. Evitt 1978; Châteauneuf, p. 135, pl. 21, figs. 5-6

1983 Corrudinium incompositum (Drugg, 1970) Stover and Evitt, 1978; Goodman \& Ford, p. 865, pl. 5, figs. 1-2

1992 Corrudinium incompositum (Drugg) Stover and Evitt, 1978; Brinkhuis, pl. 2, figs. 11-12

1993 Corrudinium incompositum (Drugg) Stover and Evitt, 1978; Brinkhuis \& Biffi, p. 173, pl. 2, figs. 11-12

1994 Corrudinium incompositum (Drugg 1970) Stover and Evitt 1978; Stover \& Hardenbol, p. 32

?2003 Corrudinium incompositum; Brinkhuis, Munsterman, et al., p. 22

?2003 Corrudinium incompositum; Brinkhuis, Sengers, et al., fig. 155

2006 Corrudinium incompositum (Drugg 1970) Stover \& Evitt 1978; Clowes \& Wilson, p. 401, fig. 3A-F

Original Description: Tract small, ovoidal to spherical in shape. The tabulation ... is 3', 6", 6-7c, 6"', $1 \mathrm{p} . \mathrm{pl}, 1 \mathrm{p}$, 1 "'". The archeopyle is formed by the loss of plate $3 "$. The sulcus contains several small platelets. The cingulum is helicoidal and consists of six to seven cingular plates, some examples seemingly having six plates and some having seven plates. The sutures are in the form of low ridges. The wall is thin and often bears scattered grana. The ornamentation consists of random low ridges, which are often branched, and occasional small tubercles. The ridges usually originate from the sutures and project into the intratabular areas.... These ornamental ridges mimic sutural ridges and make the determination of the tabulation somewhat difficult. The tract diameter ranges from 25 
to $36 \mu$, most specimens being about $30 \mu$. (Drugg 1970, p. 810-811; ellipses replace figure references in the original.)

Description of Study Material: Cysts small, proximate, subspherical, lacking horns; the episome and hyposome roughly equal. Cyst wall single layered; thin and delicate, so that distorted and broken cysts are common. Archeopyle precingular, type P (3"); operculum free. Processes lacking; ornament comprising low parasutural and intratabular septa and often isolated granules; the cyst wall appearing smooth between these features. Parasutural septa low, forming a well-defined gonyaulacacean paratabulation, ?4', 0a, 6", 6c, 6"', 1p, 1"'"; hyposome sexiform, S-type ventral organisation, torsion neutral. Paracingulum and parasulcus clearly expressed by the parasutural septa; paracingulum with strong laevorotatory offset; parasulcus exhibiting considerable obliquity between contact with the cingular paraplates.

Size Range: Length including any processes $=30$ (41) $51 \mu \mathrm{m}$ (8 measurements). Width including any processes $=42 \mu \mathrm{m}$ (one measured specimen).

Distribution: Infrequent. Ignoring the Bartonian occurrence reported by Bujak (see C. bujakii, below), Corrudinium incompositum is thought to range from the New Zealand Bortonian (Middle Eocene) through to at least the middle or late Rupelian (Stover \& Hardenbol 1994; Brinkhuis, Munsterman, et al. 2003). Its occurrence in the Gippsland Basin, Australia, appears to be somewhat earlier, from latest Bartonian up to, but not crossing, the EoceneOligocene boundary (e.g. Partridge \& Dettmann 2003, table 22.12).

\begin{tabular}{|c|c|c|c|}
\hline Age/Stage & Location & Sample & Sample Reference \\
\hline C10r (Rupelian) & $\begin{array}{l}\text { ODP Site 1168, offshore western Tasmania, } \\
\text { Tasman Sea }\end{array}$ & $\begin{array}{l}\text { 189-1168A-73X-3, 57-59 } \\
\mathrm{cm} .\end{array}$ & $\begin{array}{l}\text { Brinkhuis, Munsterman, } \\
\text { et al. } 2003\end{array}$ \\
\hline middle Rupelian & Boom Clay Formation, northwest Belgium & $47-1$ and $S N-22$ & $\begin{array}{l}\text { Stover \& Hardenbol } \\
1994\end{array}$ \\
\hline Oligocene & Contessa Highway Section B, Italy & $\mathrm{CH} 24$ & Brinkhuis \& Biffi 1993 \\
\hline Oligocene & $\begin{array}{l}\text { Glendon Limestone and Mint Spring Marl, } \\
\text { Hinds County, Mississippi }\end{array}$ & $\begin{array}{l}2658-2(1) 28-96 \text { and } 2649- \\
1(3) 34-103\end{array}$ & Drugg 1970b \\
\hline early Oligocene & $\begin{array}{l}\text { DSDP Holes } 511 \text { and } 513 \text { A, Falkland } \\
\text { Plateau, southwest Atlantic Ocean }\end{array}$ & $71-511-9-2,102-104 \mathrm{~cm}$. & Goodman \& Ford 1983 \\
\hline early Oligocene & Red Bluff Clay, Wayne County, Mississippi & $30223(S) 28-100$ & Drugg $1970 b$ \\
\hline Rupelian & $\begin{array}{l}\text { ODP Site 1168, offshore western Tasmania, } \\
\text { Tasman Sea }\end{array}$ & $\begin{array}{l}189-1172 \mathrm{~A}-39 X-3,138-149 \\
\mathrm{~cm} .\end{array}$ & $\begin{array}{l}\text { Brinkhuis, Sengers, et a } \\
2003\end{array}$ \\
\hline Rupelian & Paris Basin & & Châteauneuf 1980 \\
\hline $\begin{array}{l}\text { early } \\
\text { Whaingaroan }\end{array}$ & $\begin{array}{l}\text { Cape Foulwind Section, Westland, New } \\
\text { Zealand }\end{array}$ & K29/f097 (L10914) & \\
\hline $\begin{array}{l}\text { early } \\
\text { Whaingaroan }\end{array}$ & $\begin{array}{l}\text { Cape Foulwind Section, Westland, New } \\
\text { Zealand }\end{array}$ & K29/f116 (L11052) & Clowes \& Wilson 2006 \\
\hline $\begin{array}{l}\text { early } \\
\text { Whaingaroan }\end{array}$ & $\begin{array}{l}\text { Cape Foulwind Section, Westland, New } \\
\text { Zealand }\end{array}$ & K29/f182 (L11931) & \\
\hline $\begin{array}{l}\text { early } \\
\text { Whaingaroan }\end{array}$ & $\begin{array}{l}\text { Cape Foulwind Section, Westland, New } \\
\text { Zealand }\end{array}$ & K29/f115 (L11051) & \\
\hline $\begin{array}{l}\text { early } \\
\text { Whaingaroan }\end{array}$ & $\begin{array}{l}\text { Cape Foulwind Section, Westland, New } \\
\text { Zealand }\end{array}$ & K29/f176 (L11925) & \\
\hline $\begin{array}{l}\text { late Eocene- } \\
\text { Oligocene }\end{array}$ & Massignano Section B, Italy & M8.70 & Brinkhuis \& Biffi 1993 \\
\hline $\begin{array}{l}\text { late Eocene- } \\
\text { Oligocene }\end{array}$ & Monte Cagnero Section A, Italy & CA111.6 & Brinkhuis \& Biffi 1993 \\
\hline Bortonian & $\begin{array}{l}\text { Puketeraki Core, Oamaru-Dunedin, New } \\
\text { Zealand }\end{array}$ & I43/f089 (L16337) & Wilson \& McM \\
\hline
\end{tabular}

Remarks: The oldest occurrences in the Puketeraki core are Bortonian, possibly early Bortonian. Although this seems to represent a slightly anomalous outlier to the more common occurrences in the very late Eocene-early Oligocene (e.g. at Cape Foulwind, this study, and at Falkland Plateau, Goodman \& Ford 1983; the type is also early Oligocene) the Puketeraki specimens have been re-examined carefully and cannot be distinguished from younger material.

Corrudinium bujakii Clowes $\mathrm{n} . \mathrm{sp}$.

PI. 30, figs. 7-9

1980 Leptodinium incompositum (Drugg, 1970) Lentin and Williams, 1973; Bujak, p. 72, pl. 19, figs. 1-2

?1986b Corrudinium incompositum (Drugg 1970); De Coninck, pl. 2, figs. 1-2

2005 Corrudinium incompositum; Schiøler, pl. 15, fig. 6-8 
Derivation of Name: Named after Dr. Jonathan Bujak.

Holotype: Sample 143/f090, slide L16338/SM053; Burnside Formation, Puketeraki Core (Bortonian); PI. 30, figs. 7-9

Description: Cysts small, proximate, not dorso-ventrally compressed. Cyst wall single-layered. Archeopyle precingular, type $\mathrm{P}\left(3^{\prime \prime}\right)$; pentagonal (standard Gonyaulax-type). Processes lacking; surface ornament present, sutural plus intratabular, comprising low septa, forming an incomplete reticulum; 2-3 $\mu \mathrm{m}$ high. Inferred formula: 3 to 4', 0a, 6", 6c, 5-6"', 0 to 1ps, 1"'", ?s; ventral organisation S-type; hyposome sexiform; torsion neutral. Cingulum clearly expressed, indicated by sutural septa. Sulcus clearly expressed, indicated by sutural septa.

Size Range: Length including any processes $=30$ (35) $40 \mu \mathrm{m}$ (7 measurements). Width including any processes $=33 \mu \mathrm{m}$ (one measured specimen).

Distribution:

\begin{tabular}{|c|c|c|c|}
\hline Age/Stage & Location & Sample & Sample Reference \\
\hline Priabonian (Tongrien) & $\begin{array}{l}\text { Sands of Asse, Woensdrecht borehole, southern } \\
\text { Netherlands }\end{array}$ & $263 m$ & De Coninck 1986b \\
\hline Bartonian-early Rupelian & $\begin{array}{l}\text { Horda \& Lark Formations, Alma-1X well, Danish } \\
\text { North Sea }\end{array}$ & $\begin{array}{l}\text { LVR24106 to } \\
26013\end{array}$ & Schiøler 2005 \\
\hline $\begin{array}{l}\text { early Bartonian-middle } \\
\text { Bartonian }\end{array}$ & Upper Barton Beds, Whitecliff Bay, Isle of Wight & V59992 & Bujak 1980 \\
\hline Bortonian & Puketeraki Core, Oamaru-Dunedin, New Zealand & I43/f090 (L16338) & $\begin{array}{l}\text { Wilson \& McMillan } \\
1996\end{array}$ \\
\hline Bortonian & Puketeraki Core, Oamaru-Dunedin, New Zealand & I43/f089 (L16337) & $\begin{array}{l}\text { Wilson \& McMillan } \\
1996\end{array}$ \\
\hline
\end{tabular}

Comparison: Corrudinium bujakii is distinguished from Corrudinium incompositum by its more robust, thickerwalled, construction. On average it is also slightly smaller, although the ranges overlap considerably and are generally not diagnostic.

Corrudinium eyrense Clowes \& Wilson 2006

PI. 30, figs. 10-12, PI. 31, figs. 1-3

2006 Corrudinium eyrense Clowes \& Wilson, p. 404, figs. 4J-L, 5A-C

Original Description: Cysts of intermediate size, proximate, spherical, lacking horns, with episome and hyposome of approximately equal size. Cyst wall single-layered and relatively thick (c. $3 \mu \mathrm{m})$. Archeopyle precingular, type $P$ $(3 ")$, relatively large, pentagonal; operculum free. Processes lacking; ornament comprising fairly prominent parasutural septa (up to $6 \mu \mathrm{m}$ in height) with smooth or undulating crests, and lower scattered intratabular septa. Parasutural septa define an apparent gonyaulacacean paratabulation which is difficult to fully determine. Secondary septa are often discontinuous but sometimes form small, somewhat circular, fields. Paracingulum and parasulcus expressed by parasutural septa; parasulcus often has somewhat reticulate appearance defined by secondary septa.

Size Range: Length including any processes $=53 \mu \mathrm{m}$ (one measured specimen). Width including any processes $=53 \mu \mathrm{m}$ (one measured specimen).

Distribution:

$\begin{array}{llll}\text { Age/Stage } & \text { Location } & \text { Sample } & \text { Sample Reference } \\ \text { Mangaorapan } & \text { Upper Eyre River, Canterbury, New Zealand } & \text { L34/f7538 (L06997) } & \text { Wilson 1982c } \\ \text { Mangaorapan } & \text { Upper Eyre River, Canterbury, New Zealand } & \text { L35/f7539 (L06998) } & \text { Wilson 1982c }\end{array}$

Corrudinium obscurum Wilson 1988

Pl. 31, figs. 5-6, 8-9

1988 Corrudinium obscurum Wilson, p. 16, pl. 4, figs. 3, 6

2006 Corrudinium obscurum Clowes \& Wilson, p. 404, 406, fig. 5D-E, G-H

Original Description: Cyst small to intermediate, subspherical, fairly thick-walled (c. $2 \mu \mathrm{m})$ without apical horn and apparently comprises autophragm only. Parasutural septa relatively low (up to $5 \mu \mathrm{m}$ in height), irregular and indistinct, especially on ventral surface. Intratabular ornament very prominent, comprises both irregular, discontinuous septa, and solid slender spines, apparently randomly distributed; cyst has a somewhat spongy 
reticulate pattern. Archeopyle relatively large, type P; operculum free. Paracingulum well defined on dorsal surface by relatively smooth, depressed area (width 3-4 $\mu \mathrm{m}$ ). Paratabulation poorly defined but the second, third and fourth precingular and postcingular paraplates can usually be recognised. Ventral paratabulation and parasulcus indistinct (Wilson 1988, p. 16).

Description of Study Material: Cysts of intermediate size, proximate, not dorso-ventrally compressed, more or less spherical, lacking horns; episome and hyposome more or less equal in length. Cyst wall single-layered. Archeopyle precingular, type P (3"); pentagonal (standard Gonyaulax-type); operculum free. Processes lacking; surface ornament present, sutural plus intratabular, comprising membranous septa, forming an incomplete reticulum; about $6 \mu \mathrm{m}$ high, sutural and intratabular septa approximately the same height. Inferred formula: 3 to 4', 0a, 6", 6c, 5-6"', 0 to 1ps, 1"'", ?s; ventral organisation S-type; hyposome sexiform.

Size Range: Length including any processes $=55$ (61) $67 \mu \mathrm{m}$ (2 measurements). Width including any processes $=55 \mu \mathrm{m}$ (one measured specimen).

\title{
Distribution:
}

$\begin{array}{llll}\text { Age/Stage } & \text { Location } & \text { Sample } & \text { Sample Reference } \\ \text { Porangan } & \text { Hampden Beach Section, Oamaru-Dunedin, New Zealand } & \text { J42/f299 (L23129) } & \\ \text { Porangan } & \text { Te Uri Stream, Hawkes Bay, New Zealand } & \text { U24/f419 (L23127) } & \\ \text { Heretaungan } & \text { Hampden Beach Section, Oamaru-Dunedin, New Zealand } & \text { J42/f039 (L09196) } & \text { Wilson 1985 } \\ \text { Mangaorapan } & \text { Wanstead Formation, Waipawa, Hawkes Bay, New Zealand } & \text { V22/f8991 } & \text { Wilson 1988 }\end{array}$

Comparison: Corrudinium obscurum is most similar to Corrudinium eyrense, but differs in having parasutural and intratabular septa of approximately similar height, whereas the parasutural septa of $C$. eyrense are consistently higher than the intratabular septa.

Remarks: The sutures of this species are difficult - often practically impossible - to discern, and in this respect it approaches a number of the Tertiary forms referred to Pyxidinopsis (q.v.), suggesting there is more work to be done to fully understand these two groups.

\section{Corrudinium otagoense Clowes \& Wilson 2006}

\author{
1982a Corrudinium sp.; Wilson, pl. 3, fig. 12 \\ 1982c Ochetodinium cf. romanum Damassa; Wilson, p. 4, pl. 1, fig. 11 \\ 1985 Pyxidinopsis sp.; Wilson, fig. 15 \\ 2006 Corrudinium otagoense Clowes \& Wilson, p. 402, fig. 4D-I
}

Original Description: Cysts of intermediate size, proximate, spherical, lacking horns; the episome and hyposome roughly equal in size. Cyst wall single layered; thick (c. $2 \mu \mathrm{m})$ and robust, so that the cysts are typically found either fully spherical or else fractured rather than distorted. Archeopyle precingular, type P (3"), relatively large, pentagonal; operculum free. Processes lacking; ornament comprising prominent (up to $8 \mu \mathrm{m}$ in height) parasutural and lower intratabular septa, with generally smooth crests. The paratabulation is apparently typical for the genus, though it is nearly impossible to discern among the multitude of folded septa. Paracingulum and parasulcus expressed by parasutural septa; parasulcus usually completely obscured by accessory ornament.

Description of Study Material: Cysts of intermediate size, proximate to proximochorate, not dorso-ventrally compressed, more or less spherical, lacking horns; episome and hyposome more or less equal in length. Cyst wall single-layered; relatively robust, about $2 \mu \mathrm{m}$ in thickness. Archeopyle precingular, type P (3"); pentagonal (standard Gonyaulax-type), large; operculum free. Processes lacking; surface ornament present, sutural plus intratabular, comprising membranous septa, forming a dense reticulum; about $8 \mu \mathrm{m}$ high. Margins of crests more or less smooth. Tabulation obscured among the multitude of folded septa, apparently gonyaulacacean. Cingulum weakly expressed to moderately expressed, indicated by sutural septa. Sulcus usually completely obscured by accessory ornament, indicated by sutural septa.

Size Range: Length excluding any processes $=42$ (44) $46 \mu \mathrm{m}$ (2 measurements). Width excluding any processes $=43(45) 47 \mu \mathrm{m}$ (2 measurements). Length including any processes $=42$ (56) $70 \mu \mathrm{m}$ (39 measurements). Width including any processes $=50$ (54) $60 \mu \mathrm{m}$ (6 measurements).

Distribution: Frequent. Occurs widely in the late Heretaungan (Lutetian) to Kaiatan (early Priabonian) interval of New Zealand.

$\begin{array}{llll}\text { Age/Stage } & \text { Location } & \text { Sample } & \text { Sample Reference } \\ \text { Kaiatan } & \text { Hampden Beach Section, Oamaru-Dunedin, New Zealand } & \text { J42/f064 (L09221) } & \text { Wilson 1985 } \\ \text { Kaiatan } & \text { Waiareka Volcanic Formation, Jacksons Paddock, Otago, } & \text { J41/f8914 } & \text { Wilson 1982a }\end{array}$




\begin{tabular}{|c|c|c|c|}
\hline Age/Stage & Location & Sample & Sample Reference \\
\hline & New Zealand & & \\
\hline Bortonian & Hampden Beach Section, Oamaru-Dunedin, New Zealand & J42/f303 (L23133) & \\
\hline Bortonian & Puketeraki Core, Oamaru-Dunedin, New Zealand & I43/f094 (L16342) & $\begin{array}{l}\text { Wilson \& McMillan } \\
1996\end{array}$ \\
\hline Bortonian & Puketeraki Core, Oamaru-Dunedin, New Zealand & l43/f089 (L16337) & $\begin{array}{l}\text { Wilson \& McMillan } \\
1996\end{array}$ \\
\hline $\begin{array}{l}\text { Porangan- } \\
\text { Bortonian }\end{array}$ & Hampden Beach Section, Oamaru-Dunedin, New Zealand & J42/f486 (L23121) & \\
\hline Porangan & Te Uri Stream, Hawkes Bay, New Zealand & U24/f419 (L23127) & \\
\hline Porangan & Hampden Beach Section, Oamaru-Dunedin, New Zealand & J42/f299 (L23129) & \\
\hline Heretaungan & Hampden Beach Section, Oamaru-Dunedin, New Zealand & J42/f039 (L09196) & Wilson 1985 \\
\hline Heretaungan & Hampden Beach Section, Oamaru-Dunedin, New Zealand & J42/f483 (L23118) & \\
\hline
\end{tabular}

Comparison: Corrudinium otagoense differs from Corrudinium incompositum in being distinctly larger, more spherical, and more robust; it differs from $C$. incompositum and $C$. regulare in having higher parasutural and intratabular septa, the latter obscuring the paratabulation. The surface ornament is distinctly denser than that of C. eyrense.

\title{
Corrudinium regulare Clowes \& Wilson 2006
}

$$
\text { PI. 32, figs. 4-9 }
$$

\author{
1975 Leptodinium sp.; Haskell \& Wilson, pl. 2, fig. 7 \\ 1983 Corrudinium sp.; Goodman \& Ford, p. 865, pl. 10, figs. 6-10 \\ 1996 Impagidinium sp.; Wilson \& McMillan, fig. 4 (4) \\ 2006 Corrudinium regulare Clowes \& Wilson, p. 402, fig. 3G-L, fig. 4A-C
}

Original Description: Cysts of intermediate size, proximate, spherical, lacking horns; the episome and hyposome roughly equal in size. Cyst wall single layered; thick and robust, so that the cysts are most commonly found either fully spherical or else fractured rather than distorted. Archeopyle precingular, type P (3"); operculum free. Processes lacking; ornament comprising low parasutural and intratabular septa, the latter forming an incomplete reticulum with features on a scale of $\sim 3$ microns; the cyst wall appears smooth within the lacunae. Parasutural septa low, rarely very low, forming a well-defined gonyaulacacean paratabulation, ?4', 0a, 6", 6c, 6"', 1p, 1'”'; hyposome sexiform, S-type ventral organisation ..., torsion neutral .... Paracingulum and parasulcus clearly expressed by the parasutural septa; paracingulum with strong laevorotatory offset; parasulcus exhibiting considerable obliquity between contact with the cingular paraplates (Clowes \& Wilson 2006, p. 402; ellipses replace figure references in the original).

Description of Study Material: Cysts of intermediate size, proximate, not dorso-ventrally compressed, more or less spherical, lacking horns; episome and hyposome more or less equal in length. Cyst wall single-layered; relatively robust. Archeopyle precingular, type P (3"); pentagonal (standard Gonyaulax-type), large; operculum free. Processes lacking; surface ornament present, sutural plus intratabular, comprising low septa, forming an incomplete reticulum; with features on a scale of 14-18 sculptural elements across the diameter; very low (about $1 \mu \mathrm{m}$ or lower) to slightly elevated (2-3 $\mu \mathrm{m})$. Margins of crests more or less smooth. Tabulation clearly expressed, gonyaulacacean, inferred formula: ?4', 0a, 6", 6c, 6"', 1ps, 1"'", Xs; ventral organisation S-type; hyposome sexiform; torsion neutral. Cingulum clearly expressed, indicated by sutural septa; offset strongly, by 2-3 widths. Sulcus clearly expressed, indicated by sutural septa; exhibiting considerable obliquity.

Corrudinium regulare exhibits a range of variation from relatively smooth (PI. 32, fig. 7 ) to deeply sculptured, almost comparable to C. otagoense (PI. 32, figs. 8-9).

Size Range: Length including any processes $=48$ (54) $75 \mu \mathrm{m}$ (26 measurements). Width including any processes = 51 (53) $55 \mu \mathrm{m}$ (2 measurements).

Distribution: Frequent. Corrudinium regulare occurs widely throughout the middle Eocene to early Oligocene interval in the southern hemisphere.

\begin{tabular}{|c|c|c|c|}
\hline Age/Stage & Location & Sample & Sample Reference \\
\hline Rupelian & $\begin{array}{l}\text { DSDP Hole 511, Falkland Plateau, southwest Atlantic } \\
\text { Ocean }\end{array}$ & $\begin{array}{l}71-511-15-1,38-40 \\
\mathrm{~cm} .\end{array}$ & $\begin{array}{l}\text { Goodman \& Ford } \\
1983\end{array}$ \\
\hline Runangan & Cape Foulwind Section, Westland, New Zealand & K29/f101 (L11037) & \\
\hline Runangan & $\begin{array}{l}\text { Caversham Sandstone, Burnside Quarry, Otago, New } \\
\text { Zealand }\end{array}$ & I44/f274 & $\begin{array}{l}\text { Wilson \& McMillan } \\
1996\end{array}$ \\
\hline $\begin{array}{l}\text { ?Kaiatan- } \\
\text { Runangan }\end{array}$ & Cape Foulwind Section, Westland, New Zealand & K29/f099 (L11035) & \\
\hline
\end{tabular}




\begin{tabular}{|c|c|c|c|}
\hline Kaiatan & $\begin{array}{l}\text { Hampden Beach Section, Oamaru-Dunedin, New } \\
\text { Zealand }\end{array}$ & J42/f063 (L09220) & Wilson 1985 \\
\hline Kaiatan & Puketeraki Core, Oamaru-Dunedin, New Zealand & I43/f096 (L16344) & $\begin{array}{l}\text { Wilson \& McMillan } \\
1996\end{array}$ \\
\hline ?Kaiatan & $\begin{array}{l}\text { Hampden Beach Section, Oamaru-Dunedin, New } \\
\text { Zealand }\end{array}$ & J42/f062 (L09219) & Wilson 1985 \\
\hline Bortonian & Burnside Marl Pit, Oamaru-Dunedin, New Zealand & I44/f080 (L08947) & $\begin{array}{l}\text { Clowes \& Wilson } \\
2006\end{array}$ \\
\hline Bortonian & Puketeraki Core, Oamaru-Dunedin, New Zealand & I43/f089 (L16337) & $\begin{array}{l}\text { Wilson \& McMillan } \\
1996\end{array}$ \\
\hline middle Eocene & $\begin{array}{l}\text { DSDP Leg 29, Site 283, Tasman Sea, east of } \\
\text { Tasmania }\end{array}$ & 283-7, CC & $\begin{array}{l}\text { Haskell \& Wilson } \\
1975\end{array}$ \\
\hline Lutetian & $\begin{array}{l}\text { DSDP Hole 512, Falkland Plateau, southwest Atlantic } \\
\text { Ocean }\end{array}$ & $\begin{array}{l}71-512-19-3,29-31 \\
\mathrm{~cm} .\end{array}$ & $\begin{array}{l}\text { Goodman \& Ford } \\
1983\end{array}$ \\
\hline
\end{tabular}

Comparison: Corrudinium regulare is distinctly larger, more spherical, more robust, the intratabular areas more densely ornamented, and the intratabular septa distinctly lower than the parasutural features on Corrudinium incompositum or Corrudinium bujakii. It differs from Corrudinium otagoense, typically, in possessing lower septa, and consistently in displaying a distinct paratabulation, even in variants where the intratabular ornament is abnormally high.

\title{
Genus Impagidinium Stover \& Evitt 1978
}

\author{
1978 Impagidinium Stover \& Evitt, p. 165-166
}

Type Species: Impagidinium dispertitum (Cookson \& Eisenack 1965a, p. 122-123, pl. 12, figs. 5-7) Stover \& Evitt 1978 , p. 165 [Late Eocene]

Original Description: Cysts proximochorate, acavate, subspherical to ellipsoidal, and typically without an apical projection or horn; paratabulation gonyaulacacean, indicated by parasutural septa only; paraplate 4' characteristically about as long as $1^{\prime}$ and contact with subtriangular paraplate 6" very short; archeopyle precingular, Type P (Stover \& Evitt 1978, p. 165).

Comparison: In a revision of the genus Leptodinium, Stover \& Evitt (1978) separated the new genus Impagidinium on the basis of having "the first and fourth apical paraplates of similar shape, of about equal length, and often imperfectly separated" (p. 165) and in the shapes and contacts of plate 6" which are today recognised as topological consequences of the L-type (Leptodinium) and S-type (Impagidinium) ventral patterns of the two genera.

Impagidinium and Corrudinium share the S-type ventral topology common to the Gonyaulacoideae. Corrudinium differs consistently only in the possession of accessory ridges or septa. Impagidinium species may sometimes also exhibit a more prolate shape than Corrudinium.

In overall appearance, Pterodinium is also similar, and is potentially a senior synonym. However, the detailed plate topology of the type remains uncertain and the genus is less commonly used than Impagidinium.

Remarks: A range chart for species of Impagidinium identified in this study is provided in Appendix 2, chart 4.

Key to selected species:

\begin{tabular}{|l|l|l|}
\hline 0. & Cysts proximochorate.... & 1. \\
\hline & Cysts proximate.... & 2. \\
\hline 1. & Overall shape more or less spherical.... & 1.1. \\
\hline & Overall shape noticeably prolate.... & 1.2. \\
\hline 1.1. & Margins of sutural septa smooth.... & 1.1 .1$. \\
\hline & Margins of sutural septa lacerate to irregularly incised.... & 1.1 .2$. \\
\hline 1.1 .1$. & Impagidinium aculeatum & \multicolumn{2}{|l|}{} \\
\hline 1.1 .2$. & Impagidinium elegans & 1.2 .1$. \\
\hline 1.2. & Sutural septa extended into spinose 'tails' in the gonal positions..... & \\
\hline & Sutural septa lacking gonal extensions.... & 2.1. \\
\hline 1.2 .1$. & Impagidinium aculeatum & \\
\hline 1.2 .2$. & Impagidinium waipawaense & \\
\hline 2. & Surface ornament sutural.... & \\
\hline
\end{tabular}




\begin{tabular}{|c|c|c|}
\hline & Surface ornament intratabular.... & 2.2. \\
\hline \multirow[t]{2}{*}{2.1.} & Crests - margins smooth.... & 2.1.1. \\
\hline & Crests - margins more or less smooth.... & 2.1 .2 . \\
\hline \multirow[t]{2}{*}{2.1 .1}$. & Sulcus divided by transverse septa into two or more plates longitudinally.... & 2.1.1.1. \\
\hline & Sulcus not divided by transverse septa.... & 2.1.1.2. \\
\hline 2.1.1.1. & \multicolumn{2}{|l|}{ Impagidinium dispertitum } \\
\hline 2.1.1.2. & \multicolumn{2}{|l|}{ Impagidinium victorianum } \\
\hline 2.1 .2$. & \multicolumn{2}{|l|}{ Impagidinium waipawaense } \\
\hline \multirow[t]{3}{*}{2.2.} & Sutural septa entire; ornament comprising light 'dotting'.... & 2.2.1. \\
\hline & Sutural septa entire; ornament distinctly scabrate.... & 2.2 .2 \\
\hline & Sutural septa distinctively perforate.... & 2.2 .3$. \\
\hline 2.2.1. & \multicolumn{2}{|l|}{ Impagidinium maculatum } \\
\hline 2.2 .2 . & \multicolumn{2}{|l|}{ Impagidinium cf. maculatum; } \\
\hline 2.2.3. & \multicolumn{2}{|l|}{ Impagidinium waipawaense } \\
\hline
\end{tabular}

Impagidinium dispertitum (Cookson \& Eisenack 1965a) Stover \& Evitt 1978

PI. 32, figs. 10-12

\begin{abstract}
1965a Leptodinium dispertitum Cookson \& Eisenack, p. 122-123, pl. 12, figs. 5-7
1977 Leptodinium dispertitum? Cookson \& Eisenack 1965; De Coninck, p. 42, pl. 4, fig. 10

1978 Impagidinium dispertitum (Cookson \& Eisenack 1965a, p. 122-123, pl. 12, figs. 5-7) Stover \& Evitt, p. 165

1988 Impagidinium dispertitum (Cookson \& Eisenack, 1965a) Stover \& Evitt, 1978; Wilson, p. 23-24, pl. 12, fig. 4

1994 Impagidinium dispertitum (Cookson and Eisenack 1965) Stover and Evitt 1978; Stover \& Hardenbol, p. 32, pl. 8, fig. 50
\end{abstract}

Original Description: Shell small, oval, without a horn, tabulated, and divided equally by a relatively broad, helicoid girdle consisting of six plates. Plates smooth or faintly granular, bordered by transparent ledges. The longitudinal field on the ventral surface (representative of a longitudinal furrow), which extends from the apical plates to the antapical plate, is typically marked by three large plates; very occasionally the transverse wall between the two upper ones is incomplete. Archeopyle formed by the removal of plate 3" (Cookson \& Eisenack 1965a, p. 122-123).

Description of Study Material: Cysts small to intermediate, proximate, not dorso-ventrally compressed, prolate, lacking horns; episome and hyposome more or less equal in length. Cyst wall single-layered. Archeopyle precingular, type P (3"); pentagonal (standard Gonyaulax-type); operculum free to attached. Processes lacking; surface ornament present, sutural, comprising low septa. Septa sutural, with smooth margins. Tabulation clearly expressed, gonyaulacacean, inferred formula: 3 to 4', 0a, 5-6", 4-6c, 5-6"', 0 to 1ps, 1'"', 0-3s; ventral organisation S-type; hyposome sexiform. Cingulum clearly expressed, indicated by sutural septa. Sulcus clearly expressed, indicated by sutural septa.

Size Range: Length including any processes = 35 (48) $85 \mu \mathrm{m}$ (8 measurements). Width including any processes $=36 \mu \mathrm{m}$ (one measured specimen).

Distribution: Infrequent. There are many described species having a generally similar morphology to Impagidinium dispertitum, and a thorough overhaul of Impagidinium would be a useful contribution to the field.

$\begin{array}{llll}\text { Age/Stage } & \text { Location } & \text { Sample } & \text { Sample Reference } \\ \text { Runangan } & \text { Cape Foulwind Section, Westland, New Zealand } & \text { K29/f261 (L13543) } & \\ \text { Bortonian } & \text { Puketeraki Core, Oamaru-Dunedin, New Zealand } & \text { I43/f094 (L16342) } & \text { Wilson \& McMillan } 1996 \\ \text { Bortonian } & \text { Hampden Beach Section, Oamaru-Dunedin, New Zealand } & \text { J42/f042 (L09199) } & \text { Wilson 1985 } \\ \text { Bortonian } & \text { Puketeraki Core, Oamaru-Dunedin, New Zealand } & \text { I43/f090 (L16338) } & \text { Wilson \& McMillan } 1996 \\ \text { Porangan } & \text { Te Uri Stream, Hawkes Bay, New Zealand } & \text { U24/f417 (L23125) } & \\ \text { Porangan } & \text { Waipawa Section, Hawkes Bay, New Zealand } & \text { V22/f7401 } & \text { Wilson } 1988 \\ \text { Heretaungan } & \text { Hampden Beach Section, Oamaru-Dunedin, New Zealand } & \text { J42/f039 (L09196) } & \text { Wilson } 1985 \\ \text { Eocene } & \text { Woensdrecht borehole, southern Netherlands } & 369 m & \text { De Coninck } 1977\end{array}$

Remarks: In their comparison with Impagidinium maculatum, Cookson \& Eisenack (1965a, p. 123) note that the "longitudinal field is usually divided, not continuous and furrow-like". 
PI. 33, figs. 1-9

\author{
1965a Leptodinium victorianum Cookson \& Eisenack, p. 123, pl. 12, figs. 8-9 \\ 1978 Impagidinium victorianum (Cookson \& Eisenack 1965a) Stover \& Evitt, p. 166 \\ 1983 Impagidinium victorianum Cookson and Eisenack, 1965) Stover and Evitt, 1978; Goodman \& Ford, p. 866, pl. 6, \\ figs. 1-6 \\ 1984 Impagidinium victorianum (Cookson \& Eisenack 1965); Clowes \& Morgans, p. 32, pl. 2, figs. 5-7
}

Original Description: Shell nearly spherical, clearly tabulated, borders of plates, including those of girdle distinct, thin and transparent. Girdle strongly helicoid, represented by six plates, the lower borders of the two plates adjacent to the longitudinal field usually missing. Longitudinal field partially divided into three plates, the two upper ones always incompletely separated, the third adjacent to plate 1'"' clearly delimited. Archeopyle formed by the detachment of plate 3" (Cookson \& Eisenack 1965a, p. 123).

Description of Study Material: Cysts small to intermediate, proximate, not dorso-ventrally compressed, prolate, lacking horns; episome and hyposome more or less equal in length. Cyst wall single-layered. Archeopyle precingular, type P (3"); pentagonal (standard Gonyaulax-type); operculum free to attached. Processes lacking; surface ornament present, sutural, comprising low septa. Crests sutural, margins of crests smooth. Tabulation clearly expressed, gonyaulacacean, inferred formula: 3 to 4', 0a, 5-6", 4-6c, 5-6"', 0 to $1 \mathrm{ps}, 1$ "'", $^{-3}$-3s; ventral organisation S-type; hyposome sexiform. Cingulum clearly expressed, indicated by sutural septa. Sulcus clearly expressed, indicated by sutural septa.

Size Range: Length including any processes $=43(69) 82 \mu \mathrm{m}$ (4 measurements). Width including any processes $=68$ (73) $78 \mu \mathrm{m}$ (3 measurements).

\title{
Distribution:
}

\begin{tabular}{|c|c|c|c|}
\hline Age/Stage & Location & Sample & Sample Reference \\
\hline early Whaingaroan & $\begin{array}{l}\text { Cape Foulwind Section, Westland, New } \\
\text { Zealand }\end{array}$ & K29/f180 (L11929) & \\
\hline early Whaingaroan & $\begin{array}{l}\text { Kakanui River, Oamaru-Dunedin, New } \\
\text { Zealand }\end{array}$ & J42/f096 (L10951) & $\begin{array}{l}\text { Clowes \& Morgans } \\
1984\end{array}$ \\
\hline $\begin{array}{l}\text { Runangan-early } \\
\text { Whaingaroan }\end{array}$ & Kakanui River mouth & & $\begin{array}{l}\text { Clowes \& Morgans } \\
1984\end{array}$ \\
\hline $\begin{array}{l}\text { Runangan-early } \\
\text { Whaingaroan }\end{array}$ & $\begin{array}{l}\text { Cape Foulwind Section, Westland, New } \\
\text { Zealand }\end{array}$ & K29/f169 (L11918) & \\
\hline Bortonian & $\begin{array}{l}\text { Puketeraki Core, Oamaru-Dunedin, New } \\
\text { Zealand }\end{array}$ & I43/f093 (L16341) & $\begin{array}{l}\text { Wilson \& McMillan } \\
1996\end{array}$ \\
\hline
\end{tabular}

Remarks: Impagidinium victorianum differs from I. dispertitum in being larger and in "the constant absence of the transverse dividing [septum] between the upper two plates of the ventral field [sulcus]" (Cookson \& Eisenack 1965a, p. 123).

Impagidinium aculeatum (Wall 1967a) Lentin \& Williams 1981

$$
\text { PI. 33, figs. 10-12, PI. 34, figs. 1-3 }
$$

\footnotetext{
1967a Leptodinium aculeatum Wall, p. 104-105, pl. 14, figs. 18-19, text-fig. 3C-D

1981 Impagidinium aculeatum (Wall 1967, p. 104-105, pl. 14, figs. 18-19; text-figs. 3C-D) Lentin \& Williams, p. 153

?1982 Spiniferites cingulatus var. intermedius zu Sp. cingulatus cingulatus; Cookson \& Eisenack, p. 48, pl. 7, figs. 4-5

2003 Impagidinium aculeatum; Brinkhuis, Munsterman, et al., pl. 1, figs. 69-70

2005 Impagidinium aculeatum; Schiøler, pl. 9, fig. 15
}

Original Description: A relatively small, ovoid species with a relatively wide girdle zone and extensive ventral area; test hyaline with sutural septa most strongly developed in the posterior intercalary area; precingular platearea 6" very narrow (Wall 1967, p. 104).

Description of Study Material: Cysts small to intermediate, proximochorate, not dorso-ventrally compressed, more or less spherical to prolate, lacking horns; episome and hyposome more or less equal in length. Cyst wall singlelayered. Archeopyle precingular, type P (3"); pentagonal (standard Gonyaulax-type); operculum free to attached. Surface ornament lacking. Processes gonal; non-fibrous, unbranched, solid; proximally connected by sutural 
septa proximally, tapering to a more or less acute point distally. Crests sutural, margins of crests smooth. Inferred formula: 3 to 4', $0 \mathrm{a}, 5-6 ", 4-6 \mathrm{c}, 5-6 " ', 0$ to $1 \mathrm{ps}, 1$ '"', $0-3 \mathrm{~s}$; ventral organisation S-type; hyposome sexiform. Cingulum clearly expressed, indicated by sutural septa. Sulcus clearly expressed, indicated by sutural septa.

Size Range: Length excluding any processes = 28 (29) $30 \mu \mathrm{m}$ (2 measurements). Width excluding any processes $=27$ (28) $28 \mu \mathrm{m}$ (2 measurements). Length including any processes $=40$ (45) $52 \mu \mathrm{m}$ (9 measurements). Width including any processes $=43(46) 49 \mu \mathrm{m}$ (3 measurements).

\title{
Distribution:
}

$\begin{array}{llll}\text { Age/Stage } & \text { Location } & \text { Sample } & \text { Sample Reference } \\ \text { early Whaingaroan } & \text { Kakanui River, Oamaru-Dunedin, New Zealand } & \text { J42/f096 (L10951) } & \text { Clowes \& Morgans } 1984 \\ \text { Bortonian } & \text { Puketeraki Core, Oamaru-Dunedin, New Zealand } & \text { I43/f094 (L16342) } & \text { Wilson \& McMillan } 1996 \\ \text { Bortonian } & \text { Puketeraki Core, Oamaru-Dunedin, New Zealand } & \text { I43/f089 (L16337) } & \text { Wilson \& McMillan 1996 }\end{array}$

Remarks: Impagidinium aculeatum is a small taxon; Wall (1967a) records the type material at around 28-38 $\mu$ m.

\section{Impagidinium elegans (Cookson \& Eisenack 1965a) Stover \& Evitt 1978}

$$
\text { PI. 34, figs. 4-12, PI. 35, figs. 1-3 }
$$

\author{
1965a Leptodinium elegans Cookson \& Eisenack, p. 123-124, pl. 12, 10-13 \\ 1978 Impagidinium elegans (Cookson \& Eisenack 1965a, p. 123-124, pl. 12, figs. 10-13) Stover \& Evitt, p. 165 \\ 1982b Impagidinium elegans (Cookson \& Eisenack); Wilson, p. 8, pl. 3, fig. 11
}

Original Description: Shell spherical, thick walled (c. 3-5 $\mu$ ), girdle equatorial, strongly helicoid, clearly defined and plated on the dorsal surface, only slightly so on the ventral surface. Borders of plates including those of girdle, high, transparent, and granular with wavy or dotted edges. The longitudinal field wide and only partially plated and bordered. The plate adjacent to the antapex is always present as is the right-hand border of the field; the left-hand border is restricted to the hypotheca. The archeopyle is formed by the detachment of a portion of plate 3"' (Cookson \& Eisenack 1965a, p. 123).

Description of Study Material: Cysts intermediate to large, proximochorate, not dorso-ventrally compressed, more or less spherical, lacking horns; episome and hyposome more or less equal in length. Cyst wall single-layered. Archeopyle precingular, type P (3"); pentagonal (standard Gonyaulax-type); operculum free to attached. Surface ornament present, sutural, comprising membranous septa. Crests sutural, margins of crests lacerate to irregularly incised. Tabulation clearly expressed, gonyaulacacean, inferred formula: 3 to 4', 0a, 5-6", 4-6c, 5-6"', 0 to 1 ps, 1"', 0-3s; ventral organisation S-type; hyposome sexiform. Cingulum clearly expressed, indicated by sutural septa. Sulcus clearly expressed, indicated by sutural septa.

Size Range: Length excluding any processes $=63(75) 82 \mu \mathrm{m}$ (6 measurements). Width excluding any processes $=68$ (74) $79 \mu \mathrm{m}$ (6 measurements). Length including any processes = 65 (96) $122 \mu \mathrm{m}$ (45 measurements). Width including any processes $=88(98) 112 \mu \mathrm{m}$ (7 measurements).

Distribution:

\begin{tabular}{|c|c|c|c|}
\hline Age/Stage & Location & Sample & Sample Reference \\
\hline Otaian & Puketeraki Core, Oamaru-Dunedin, New Zealand & I43/f101 (L16349) & $\begin{array}{l}\text { Wilson \& McMillan } \\
1996\end{array}$ \\
\hline early Whaingaroan & Cape Foulwind Section, Westland, New Zealand & K29/f115 (L11051) & \\
\hline early Whaingaroan & Kakanui River, Oamaru-Dunedin, New Zealand & J42/f096 (L10951) & $\begin{array}{l}\text { Clowes \& Morgans } \\
1984\end{array}$ \\
\hline $\begin{array}{l}\text { Runangan-early } \\
\text { Whaingaroan }\end{array}$ & Kakanui River, Oamaru-Dunedin, New Zealand & J42/f125 (L11625) & \\
\hline Runangan & Cape Foulwind Section, Westland, New Zealand & K29/f259 (L13545) & \\
\hline Runangan & Cape Foulwind Section, Westland, New Zealand & K29/f262 (L13546) & \\
\hline ?Kaiatan & $\begin{array}{l}\text { Hampden Beach Section, Oamaru-Dunedin, New } \\
\text { Zealand }\end{array}$ & J42/f062 (L09219) & Wilson 1985 \\
\hline Bortonian & Puketeraki Core, Oamaru-Dunedin, New Zealand & I43/f089 (L16337) & $\begin{array}{l}\text { Wilson \& McMillan } \\
1996\end{array}$ \\
\hline
\end{tabular}

Remarks: The type illustrations show a strongly granulate surface to the periphragm. Whereas this may well be an artefact of preservation or processing, the present study has encountered both granulate and smooth-walled forms, otherwise attributable to Impagidinium elegans, which appear to be genuine differences in the taxa. Pending re-examination of the type material, both forms are referred to Impagidinium elegans for the present. 
A second morphological variable is evident in the edges of the sutural crests, which in some specimens are almost smooth (PI. 35, figs. 1-3) and in others are quite deeply and narrowly notched (PI. 34, figs. 4-6). However, as above, no attempt has been made to distinguish a separate taxon in the course of the present study.

Inconspicuous, slender, trifurcating processes can be discerned at the gonal positions on the margins of the cingulum of some specimens (e.g. Pl. 34, figs. 4-6).

Impagidinium maculatum (Cookson \& Eisenack 1961b) Stover \& Evitt 1978

$$
\text { PI. 35, figs. 4-12 }
$$

1961b Leptodinium maculatum Cookson \& Eisenack, p. 40, pl. 2, figs. 5-6

Original Description: Shell oval to nearly spherical, without a horn. Girdle equatorial, strongly helicoid and rather broad with low borders. Longitudinal furrow broad, elongate-rectangular, bounded antapically by a large plate. Plates strongly outlined, bordered by low, thin, hyaline ledges. Surface of the plates distinctly dotted. Pylome formed by removal of plate $3 "$. Tabulation 4', 6", 5"', $1 p, 1$ "'".

Description of Study Material: Cysts small to intermediate, proximate, not dorso-ventrally compressed, more or less spherical to prolate, lacking horns; episome and hyposome more or less equal in length. Cyst wall singlelayered. Archeopyle precingular, type P (3"); pentagonal (standard Gonyaulax-type); operculum free. Ornament intratabular, comprising minute granules. Crests sutural, margins of crests smooth. Inferred formula: 3 to 4', 0a, 5-6", 4-6c, 5-6"', 0 to 1ps, 1"'", 0-3s; ventral organisation S-type; hyposome sexiform. Cingulum clearly expressed, indicated by sutural septa. Sulcus clearly expressed, indicated by sutural septa.

Size Range: Length including any processes $=40$ (53) $83 \mu \mathrm{m}$ (11 measurements). Width including any processes $=37$ (41) $45 \mu \mathrm{m}$ (3 measurements).

\title{
Distribution:
}

\begin{tabular}{|c|c|c|c|}
\hline Age/Stage & Location & Sample & Sample Reference \\
\hline $\begin{array}{l}\text { early } \\
\text { Whaingaroan }\end{array}$ & Cape Foulwind Section, Westland, New Zealand & K29/f114 (L11050) & \\
\hline Bortonian & $\begin{array}{l}\text { Hampden Beach Section, Oamaru-Dunedin, New } \\
\text { Zealand }\end{array}$ & $\mathrm{J} 42 / \mathrm{f} 489$ (L23124) & \\
\hline Bortonian & Puketeraki Core, Oamaru-Dunedin, New Zealand & I43/f094 (L16342) & $\begin{array}{l}\text { Wilson \& McMillan } \\
1996\end{array}$ \\
\hline Bortonian & Puketeraki Core, Oamaru-Dunedin, New Zealand & I43/f089 (L16337) & $\begin{array}{l}\text { Wilson \& McMillan } \\
1996\end{array}$ \\
\hline Porangan & Te Uri Stream, Hawkes Bay, New Zealand & U24/f419 (L23127) & \\
\hline Heretaungan & $\begin{array}{l}\text { Hampden Beach Section, Oamaru-Dunedin, New } \\
\text { Zealand }\end{array}$ & J42/f483 (L23118) & \\
\hline
\end{tabular}

Remarks: The dimensions of the type are recorded as $52 \mu \mathrm{m} \times 50 \mu \mathrm{m}$. The type specimens occur with $R$. borussica in the Rottnest Island bore.

\section{Impagidinium cf. maculatum}

\author{
PI. 36, figs. 1-6
}

1978 Impagidinium maculatum (Cookson \& Eisenack 1961b, p. 40, pl. 2, figs. 5-6) Stover \& Evitt, p. 167

1988 Impagidinium maculatum (Cookson \& Eisenack, 1961) Stover \& Evitt, 1978; Wilson, p. 24, pl. 12, fig. 3

Description: Cysts small to intermediate, proximate, not dorso-ventrally compressed, more or less spherical to prolate, lacking horns; episome and hyposome more or less equal in length. Cyst wall single-layered. Archeopyle precingular, type $\mathrm{P}\left(3^{\prime \prime}\right)$; pentagonal (standard Gonyaulax-type); operculum free. Ornament intratabular, comprising granules. Crests sutural, margins of crests smooth. Inferred formula: 3 to 4', $0 \mathrm{a}, 5-6$ ", 4-6c, 5-6"', 0 to $1 \mathrm{ps}, 1$ "'", 0-3s; ventral organisation S-type; hyposome sexiform. Cingulum clearly expressed, indicated by sutural septa. Sulcus clearly expressed, indicated by sutural septa.

Size Range: Length including any processes $=45(60) 70 \mu \mathrm{m}$ (5 measurements). Width including any processes $=42$ (49) $63 \mu \mathrm{m}$ (3 measurements). 


\begin{tabular}{|c|c|c|c|}
\hline Age/Stage & Location & Sample & Sample Reference \\
\hline Bortonian & $\begin{array}{l}\text { Hampden Beach Section, Oamaru-Dunedin, New } \\
\text { Zealand }\end{array}$ & J42/f042 (L09199) & Wilson 1985 \\
\hline Bortonian & Puketeraki Core, Oamaru-Dunedin, New Zealand & I43/f092 (L16340) & $\begin{array}{l}\text { Wilson \& McMillan } \\
1996\end{array}$ \\
\hline $\begin{array}{l}\text { Porangan- } \\
\text { Bortonian }\end{array}$ & $\begin{array}{l}\text { Hampden Beach Section, Oamaru-Dunedin, New } \\
\text { Zealand }\end{array}$ & $\mathrm{J} 42 / \mathrm{f302}$ (L23132) & \\
\hline Porangan & Te Uri Stream, Hawkes Bay, New Zealand & U24/f419 (L23127) & \\
\hline Heretaungan & $\begin{array}{l}\text { Hampden Beach Section, Oamaru-Dunedin, New } \\
\text { Zealand }\end{array}$ & J42/f039 (L09196) & Wilson 1985 \\
\hline Mangaorapan & Waipawa Section, Hawkes Bay, New Zealand & V22/f8993 & Wilson 1988 \\
\hline
\end{tabular}

Remarks: Differs from Impagidinium maculatum in possessing markedly coarser ornament: it is definitely scabrate as opposed to "maculate" although intermediates can be difficult to allocate to one or other form (e.g. PI. 35, figs. 4-9).

Impagidinium waipawaense Wilson 1988

\author{
PI. 36, figs. 7-9
}

1988 Impagidinium waipawaense Wilson, p. 24, pl. 13, figs. 1a-b; pl. 14, figs. 1a-c, 2a-b

Original Description: Cyst subspherical, of intermediate size; autophragm characterised by perforate parasutural septa and smooth intratabular areas. Septa fairly prominent (height up to $4 \mu \mathrm{m}$ ) perforate (perforations 1-3 $\mu \mathrm{m}$ ) and generally smooth crested; base of septa relatively broad (up to $3 \mu \mathrm{m}$ ) and may be bordered by narrow perforate zone. Horn short (length 6-11 $\mu \mathrm{m}$ ) broad based (breadth up to $10 \mu \mathrm{m}$ ), somewhat perforate, with an irregular blunt apex. Paratabulation well defined by septa, gonyaulacacean, formula 4', 6"', 6c, 1p, 1"', 2-3s [sic]. Archeopyle relatively small (length $14 \mu \mathrm{m}$, breadth $17 \mu \mathrm{m}$ on holotype) Type P; operculum free. Paracingulum indicated by parallel, transverse ridges (breadth up to $8 \mu \mathrm{m}$ ) and usually comprises 6 paraplates. Parasulcus extends to epicyst and is somewhat broader on the hypocyst; up to three small sulcal paraplates present (Wilson 1988, p. 24).

Description of Study Material: Cysts intermediate to large, proximate to proximochorate, not dorso-ventrally compressed, prolate, with one apical horn; episome and hyposome more or less equal in length. Apical horn well developed, apex bluntly terminated; antapical horns lacking. Cyst wall single-layered. Archeopyle precingular, type P (3"); pentagonal (standard Gonyaulax-type); operculum free. Crests sutural, perforate, up to about $4 \mu \mathrm{m}$, margins of crests more or less smooth. Inferred formula: 3 to 4', 0a, 5-6", 4-6c, 5-6"', 0 to 1ps, 1"', 0-3s; ventral organisation S-type; hyposome sexiform. Cingulum clearly expressed, indicated by sutural septa. Sulcus clearly expressed, indicated by sutural septa.

Size Range: Length including any processes = 75 (89) $107 \mu \mathrm{m}$ (4 measurements). Width including any processes $=60 \mu \mathrm{m}$ (one measured specimen).

\title{
Distribution:
}

\begin{tabular}{|c|c|c|c|}
\hline Age/Stage & Location & Sample & Sample Reference \\
\hline Bortonian & Puketeraki Core, Oamaru-Dunedin, New Zealand & l43/f090 (L16338) & $\begin{array}{l}\text { Wilson \& McMillan } \\
1996\end{array}$ \\
\hline $\begin{array}{l}\text { Porangan- } \\
\text { Bortonian }\end{array}$ & $\begin{array}{l}\text { Hampden Beach Section, Oamaru-Dunedin, New } \\
\text { Zealand }\end{array}$ & J42/f485 (L23120) & \\
\hline Porangan & $\begin{array}{l}\text { Hampden Beach Section, Oamaru-Dunedin, New } \\
\text { Zealand }\end{array}$ & $\mathrm{J} 42 / \mathrm{f3} 00(\mathrm{~L} 23130)$ & \\
\hline Porangan & Te Uri Stream, Hawkes Bay, New Zealand & U24/f418 (L23126) & \\
\hline Porangan & $\begin{array}{l}\text { Hampden Beach Section, Oamaru-Dunedin, New } \\
\text { Zealand }\end{array}$ & J42/f299 (L23129) & \\
\hline Heretaungan & $\begin{array}{l}\text { Hampden Beach Section, Oamaru-Dunedin, New } \\
\text { Zealand }\end{array}$ & J42/f039 (L09196) & Wilson 1985 \\
\hline Heretaungan & $\begin{array}{l}\text { Hampden Beach Section, Oamaru-Dunedin, New } \\
\text { Zealand }\end{array}$ & J42/f483 (L23118) & \\
\hline
\end{tabular}

\section{Genus Pentadinium Gerlach 1961}

\author{
1961 Pentadinium Gerlach, p. 164-165 \\ 1978 Pentadinium Gerlach 1961; Stover \& Evitt, p. 179-180
}


1982 Pentadinium Gerlach 1961; Edwards, p. 105-106, 108

Type Species: Pentadinium laticinctum Gerlach 1961, p. 165-166, pl. 26, figs. 5-6; text-figs. 6-7 [Mid OligoceneMid Miocene]

Original Description: Theca spherical to polyhedral. Shell always with an oval or spherical inner body, wall tabulate: 5", 5"' and 1'"'. Number of apical plates 1' (?). Girdle helicoidal; longitudinal furrow between the displaced extremities of the girdle. External shell delicate, inner capsule robust (translated from Gerlach 1961, p. 164, by Stover \& Evitt 1978, p. 179).

\title{
Pentadinium sp. 1
}

$$
\text { PI. 36, figs. 10-12, PI. 37, figs. 1-3 }
$$

?1986b Impagidinium? sp. cf. I. multiplexum (Wall \& Dale 1968); De Coninck, pl. 4, figs. 19-20, $23-24$

Description: Cysts of intermediate size, proximate, not dorso-ventrally compressed, more or less spherical, lacking horns; episome and hyposome more or less equal in length. Cyst wall two-layered; suturocavate. Archeopyle precingular, type P (3"); operculum free to attached. Processes lacking; surface ornament lacking. Tabulation clearly expressed, gonyaulacacean, inferred formula: 4', 0a, 5-6", ?5c, 4-6"', 1ps, 1"', Xs; ventral organisation S-type; hyposome sexiform. Cingulum clearly expressed, indicated by the sutural pericoels..

Size Range: Length $=62$ (68) $75 \mu \mathrm{m}$ (5 measurements). Width $=65$ (68) $70 \mu \mathrm{m}$ (2 measurements).

Distribution: Infrequent.

$\begin{array}{llll}\text { Age/Stage } & \text { Location } & \text { Sample } & \text { Sample Reference } \\ \begin{array}{l}\text { Priabonian } \\ \text { (Tongrien) }\end{array} & \begin{array}{l}\text { Sands of Asse, Woensdrecht borehole, southern } \\ \text { Netherlands }\end{array} & \text { 263m } & \text { De Coninck } \\ \text { Porangan-Bortonian } & \text { Hampden Beach Section, Oamaru-Dunedin, New Zealand } & \text { J42/f302 (L23132) } \\ \text { Porangan-Bortonian } & \text { Hampden Beach Section, Oamaru-Dunedin, New Zealand } & \text { J42/f486 (L23121) } \\ \text { Porangan } & \text { Hampden Beach Section, Oamaru-Dunedin, New Zealand } & \text { J42/f299 (L23129) } \\ \text { Heretaungan } & \text { Hampden Beach Section, Oamaru-Dunedin, New Zealand } & \text { J42/f039 (L09196) } & \text { Wilson 1985 } \\ \text { Heretaungan } & \text { Hampden Beach Section, Oamaru-Dunedin, New Zealand } & \text { J42/f484 (L23119) }\end{array}$

Genus Tectatodinium Wall 1967a emend. Head 1994a

\author{
1967a Tectatodinium Wall, p. 112-113 \\ 1978 Tectatodinium Wall 1967; Stover \& Evitt, p. 193-194 \\ 1994a Tectatodinium Wall 1967 emend. Head, p. 306, 308
}

Type Species: Tectatodinium pellitum Wall 1967, p. 113, pl. 16, figs. 11-12 [Miocene-Holocene]

Original Description: Spherical to ovoid dinoflagellate cysts without apical, antapical, or any other form of projections. Test wall double (resembling tectate pollen), the outer layer being thicker and less compact or homogeneous than the inner. Test penetrated by a large dorsal precingular archeopyle representing the loss of one plate. A girdle or ventral sulcus rarely present (Wall 1967, p. 113).

Tectatodinium pellitum Wall 1967a emend. Head 1994a

$$
\text { PI. 37, figs. 4-9 }
$$

\footnotetext{
1967a Tectatodinium pellitum Wall, p. 113, pl. 16, figs. 11-12

?1972 Kugelige kapsel unbekannter zuordnung 2 Benedek, p. 56, pl. 12, figs. 10a-c

1977 Tectatodinium pellitum Wall 1967; Jan du Chêne, p. 105-106, pl. 1, figs. 5-6

?1982b Tectatodinium cf. pellitum Wall; Wilson, pl. 4, fig. 7

1984 Tectatodinium pellitum Wall 1967; Clowes \& Morgans, p. 32, pl. 2, fig. 9

1993 Tectatodinium grande Williams et al., p. 57

1994 Tectatodinium pellitum Wall 1967; Stover \& Hardenbol, p. 33, pl. 9, fig. 60

1994a Tectatodinium pellitum Wall 1967 emend. Head, p. 308-314, pl. 1-4, pl. 11, figs. 1-9

2005 Tectatodinium pellitum; Schiøler, pl. 6, fig. 11
} 
Original Description: The test is ovoid and thick-walled The latter is double-layered, the inner [pedium] being thin and homogeneous, the outer [luxuria] thicker and spongy; apparently it is formed by numerous, finely interwoven fibrils so that in optical section the focus is indistinct. In surface view the test appears microgranular. There is a large, dorsal, trapezoidal archeopyle but no girdle or ventral sulcus (Wall 1967a, p. 113).

Size Range: Length = 35 (49) $75 \mu \mathrm{m}$ (10 measurements). Width $=40$ (52) $68 \mu \mathrm{m}$ (5 measurements).

Distribution: Frequent.

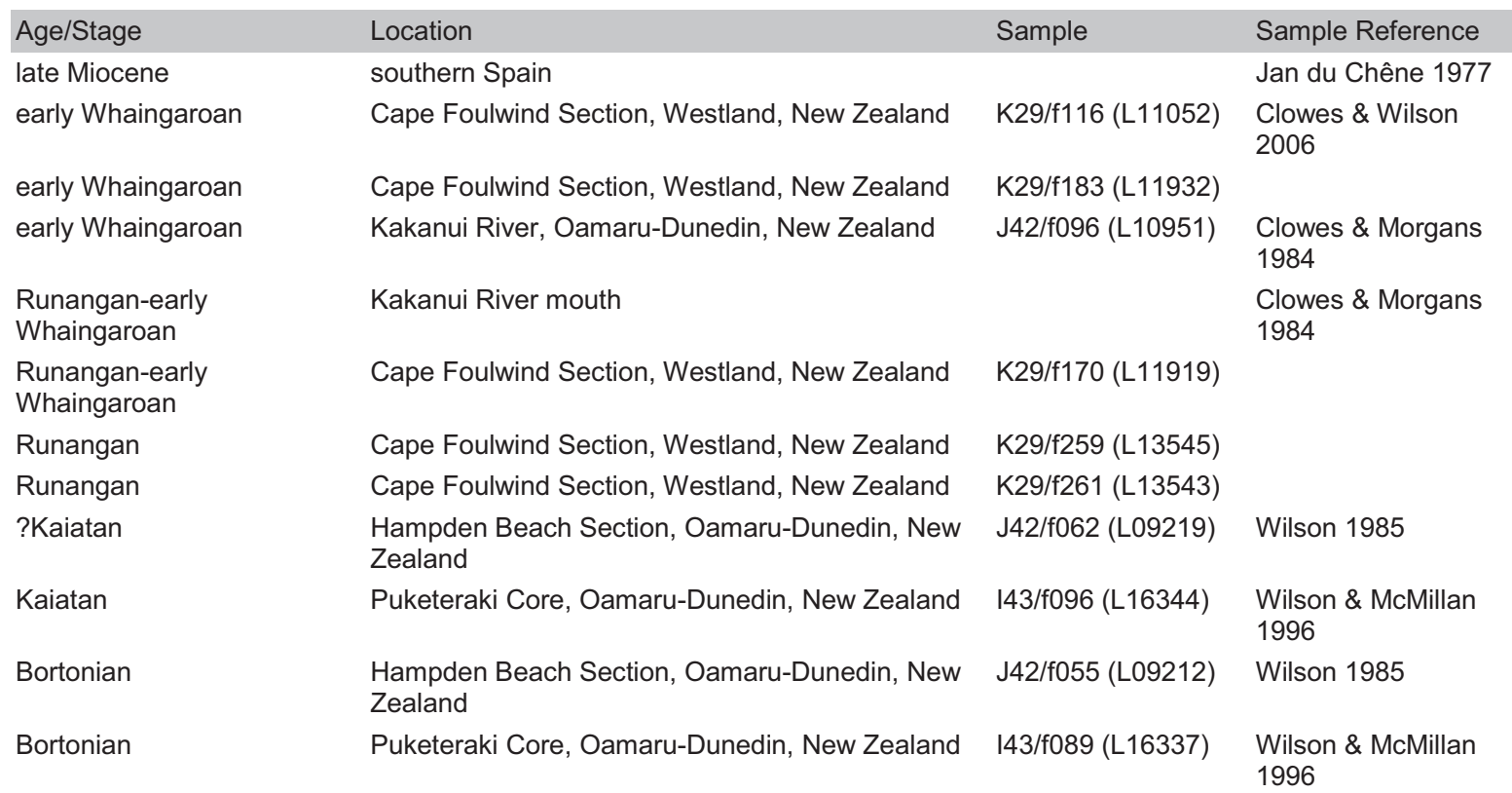

Remarks: The upper margin to the archeopyle in Wall's (1967a) fig. 11 is quite distinctly pointed. The specimens encountered in this study, notably from the Kakanui River site, differ very slightly from Wall's fig. 11 in having a rounded upper margin to the archeopyle.

\section{Tectatodinium sp. 1}

\section{PI. 37, figs. 10-12}

1984 Tectatodinium sp.; Clowes \& Morgans, p. 32, pl. 2, fig. 10

Description: Wall layers appressed, endophragm of constant thickness (about $1.5 \mu \mathrm{m}$ ) and homogeneous, periphragm varying in thickness (from less than $1 \mu \mathrm{m}$ up to about $4 \mu \mathrm{m}$ ) and spongy. Tabulation indicated by large precingular archeopyle and variably developed, undivided cingulum. Operculum free. Overall size range: 57-73 $\mu \mathrm{m}$ (Clowes \& Morgans 1984, p. 32).

Size Range: Length = 34 (61) $75 \mu \mathrm{m}$ (4 measurements). Width = 34 (62) $80 \mu \mathrm{m}$ (4 measurements).

Distribution: Rare.

$\begin{array}{llll}\text { Age/Stage } & \text { Location } & \text { Sample } & \text { Sample Reference } \\ \text { Runangan-early } & \text { Cape Foulwind Section, Westland, New } & \text { K29/f172 (L11921) } \\ \text { Whaingaroan } & \text { Zealand } & & \\ \text { Runangan } & \text { Kakanui River, Oamaru-Dunedin, New } & \text { J42/f098 (L10953) } & \text { Clowes \& Morgans } \\ & \text { Zealand } & & 1984\end{array}$

Remarks: This form is distinguished by the comparatively (for the genus) well-developed cingulum.

\section{Tectatodinium sp. 2}

PI. 38, figs. 1-6 
Description: Cysts small, generally markedly prolate, sometimes showing sign of a slight apical bulge but lacking true horns. Walls two-layered, closely appressed, lacking a prominent texture. Surface minutely scabrate. Lacking any indications of tabulation other than the type P (3") precingular archeopyle.

Size Range: Length = 38 (40) $41 \mu \mathrm{m}$ (2 measurements). Width = 30 (31) $32 \mu \mathrm{m}$ (2 measurements).

Distribution: Rare.

\begin{tabular}{|c|c|c|c|}
\hline Age/Stage & Location & Sample & Sample Reference \\
\hline $\begin{array}{l}\text { early } \\
\text { Whaingaroan }\end{array}$ & Cape Foulwind Section, Westland, New Zealand & K29/f182 (L11931) & \\
\hline Runangan & Kakanui River, Oamaru-Dunedin, New Zealand & J42/f098 (L10953) & $\begin{array}{l}\text { Clowes \& Morgans } \\
1984\end{array}$ \\
\hline late Eocene & $\begin{array}{l}\text { Mallee Cliffs bore } 36465,201-206 \text { m., central Murray Basin, } \\
\text { New South Wales, Australia }\end{array}$ & Slide 2829-1 & Martin 1993 \\
\hline late Eocene & $\begin{array}{l}\text { Mallee Cliffs bore } 36465,210-216 \text { m., central Murray Basin, } \\
\text { New South Wales, Australia }\end{array}$ & Slide $2830-1$ & Martin 1993 \\
\hline
\end{tabular}

Remarks: This form can resemble a thin-walled $T$. pellitum but is usually readily distinguishable by a markedly prolate shape.

\title{
Genus Filisphaera Bujak 1984 emend. Head 1994b
}

\author{
1984 Filisphaera Bujak, p. 185 \\ 1989b Muraticysta Head et al., p.458 \\ 1994b Filisphaera Bujak 1984 emend. Head, p. 234-235
}

Type Species: Filisphaera filifera Bujak 1984, p. 185, pl. 1, figs. 7-12 emend. Head 1994b, p. $235-236$ [Late Miocene-Early Pleistocene]

Original Description: Spherical to ovoidal dinoflagellate cysts, sometimes with small apical lobe. Cyst with thin inner wall and thicker outer wall composed of radiating fibers. Spines and other projections absent. Cingulum and sulcus absent. Archeopyle precingular, formed by loss or displacement of one or more plates (Bujak 1984, p. 185).

Emended Description of Head 1994b: Cysts spherical to ovoidal, sometimes with small apical lobe. Cyst wall formed of two closely appressed layers, a thin solid endophragm inner thicker periphragm of narrow, principally radiating, nontabular septa that form a microreticulum. Other projections absent or weakly expressed. Paracingulum and parasulcus absent or weakly expressed. Archeopyle precingular, with well developed angles, and formed by loss or displacement of one or more plates (Head 1994b, p. 235).

\section{Filisphaera sp. 3}

\section{PI. 38, figs. 7-9}

Description: Cysts small, more or less spherical, lacking horns. Walls two-layered, closely appressed, characterised by a prominent texture of radial fibrils. Surface minutely and densely maculate, where the fibrils are seen end-on. Lacking any indications of tabulation other than the large, square, type P (3") precingular archeopyle.

Size Range: Length including any processes $=38 \mu \mathrm{m}$ (one measured specimen). Width including any processes $=36 \mu \mathrm{m}$ (one measured specimen).

\section{Distribution: Rare.}

$\begin{array}{llll}\text { Age/Stage } & \text { Location } & \text { Sample } & \text { Sample Reference } \\ \text { early Whaingaroan } & \text { Cape Foulwind Section, Westland, New } & \text { K29/f183 (L11932) } \\ & \text { Zealand } & & \\ \text { Runangan-early } & \text { Kakanui River, Oamaru-Dunedin, New } & \text { J42/f125 (L11625) } \\ \text { Whaingaroan } & \text { Zealand } & & \\ \text { Runangan } & \text { Kakanui River, Oamaru-Dunedin, New } & \text { J42/f098 (L10953) Clowes \& Morgans } & \text { 1984 }\end{array}$

Remarks: This form is distinguished by the distinctive radially fibrous wall. 


\title{
Subfamily Cribroperidinioideae Fensome et al. 1993b
}

\section{Genus Apteodinium Eisenack 1958a}

\author{
1958a Apteodinium Eisenack, p. 385 \\ 1978 Apteodinium Eisenack 1958; Stover \& Evitt, p. 141-142
}

\section{Type Species: Apteodinium granulatum Eisenack 1958a, p. 386-387, pl. 23, figs. 8-14 [Cretaceous (Aptian)]}

Original Description: Shell globular, oval to ovoid, sometimes rounded diamond shaped, with a short pointed apical horn; without tabulation, without ornamentation (spines, crests). Epi- and hypovalve separated by a narrow, scarcely depressed (and then often visible with difficulty or not visible at all) unspiraled girdle. Longitudinal furrow not present. Pylome frequent, on dorsal side of epivalve below apical horn. Occasionally a small antapical horn occurs (translated from Eisenack 1958, p. 385, by Stover \& Evitt 1978, p. 141).

Remarks: Apteodinium is morphologically similar to Cribroperidinium. The genotypes of both genera are Cretaceous, though their ranges are not close in time. The principal distinction previously recognised between Cribroperidinium and Apteodinium is that Apteodinium lacks the sutural features which are a prominent characteristic of Cribroperidinium. It is not unusual, however, for subtle sutural features to be variably expressed within a single species or subspecies, so that a number of taxa have sat between the two genera, and some have been shuttled back and forth between them to no particular effect. There may be a case to be made for synonymy (Apteodinium would be the senior synonym) although the wall structures of the two genera seem to me to be significantly different. Further investigation of this issue, however, is beyond the scope of this paper.

Helenes 1984a recommends the reassignment of species from Apteodinium to Cribroperidinium as tabulation is discovered, and this advice has been appropriately adopted (for example, by Crouch 2001, in the generic assignment of her "Cribroperidinium sp. A"). This is a perfectly orthodox form-taxonomic approach. However, if we adopt a more phylogenetic perspective, we should be doing something different.

The Eocene forms assigned to Apteodinium in the present study, together with Apteodinium spiridoides Benedek 1972 and Apteodinium tectatum Piasecki 1980, are not considered likely to be phylogenetically related (at least not closely) to the Cretaceous genotype species, Apteodinium granulatum Eisenack 1958a. Nor does reassigning them to Cribroperidinium effect any improvement over the status quo. A new genus - "Neoapteodinium" perhaps - may be the way to solve the taxonomic problem, but will entail more investigation than I am able to include within the present study.

‘Apteodinium' australiense (Deflandre \& Cookson 1955) Williams 1978

$$
\text { PI. 38, figs. 10-12 }
$$

1955 Gymnodinium australiense Deflandre \& Cookson, p. 248-249, pl. 5, fig. 1

1965a Scriniodinium australiense (Deflandre \& Cookson 1955) Cookson \& Eisenack, p. 122, pl. 13, fig. 15

1967 Scriniodinium australiense (Deflandre \& Cookson 1955) Eisenack, p. 195

?1972 Gonyaulacysta cf. giuseppi (Morgenroth 1966); Benedek, p. 18-19, pl. 4, figs. 7a-b

?1972 Apteodinium conjunctum Eisenack \& Cookson 1960; Benedek, p. 4, pl. 1, fig. 2

?1976 Apteodinium cf. spiridioides Benedek, 1972; Manum, pl. 1, fig. 6

1977 Apteodinium australiense (Deflandre \& Cookson) Edwards, p. 114-115, pl. 1, figs. 2a-d, 4a-b

1978 Apteodinium australiense (Deflandre \& Cookson 1955) Williams, p. 794

1984 Apteodinium australiense (Deflandre \& Cookson 1955); Clowes \& Morgans, pl. 2, fig. 11

1994 Apteodinium australiense (Deflandre and Cookson 1955) Williams 1978; Stover \& Hardenbol, p. 32, pl. 8, fig. 51

?2005 Apteodinium australiense; Schiøler, pl. 1, fig. 5

Original Description: Cell globular, divided into 2 approximately equal parts by a narrow, rather shallow, strongly helicoidal girdle. A longitudinal furrow is visible on the hypotheca. The epitheca is surmounted by a short truncate process, the centre of which is frequently depressed. Usually the base of the process is distinctly mamillate. Hypotheca widely rounded; both parts or only the epitheca are bell-shaped. The membrane is finely punctate and sometimes indistinct lines suggestive of plates are apparent. The cell is generally encysted with a more or less quadrangular opening on the dorsal face of the epitheca (Deflandre \& Cookson 1955, p. 248).

Description of Study Material: Cysts of intermediate size, proximate, not dorso-ventrally compressed, more or less spherical, with one apical horn; episome and hyposome more or less equal in length. Apical horn moderately 
well-developed, apex bluntly terminated; antapical horns lacking. Cyst wall single-layered. Archeopyle precingular, type $\mathrm{P}\left(\mathrm{3}^{\prime \prime}\right)$; operculum free. Processes lacking. Tabulation not expressed; hyposome sexiform; torsion dextral. Cingulum moderately expressed, indicated by folds in the autophragm. Sulcus generally not evident.

Size Range: Length = 65 (76) $94 \mu \mathrm{m}$ (4 measurements). Width = 70 (80) $91 \mu \mathrm{m}$ (2 measurements).

Distribution:

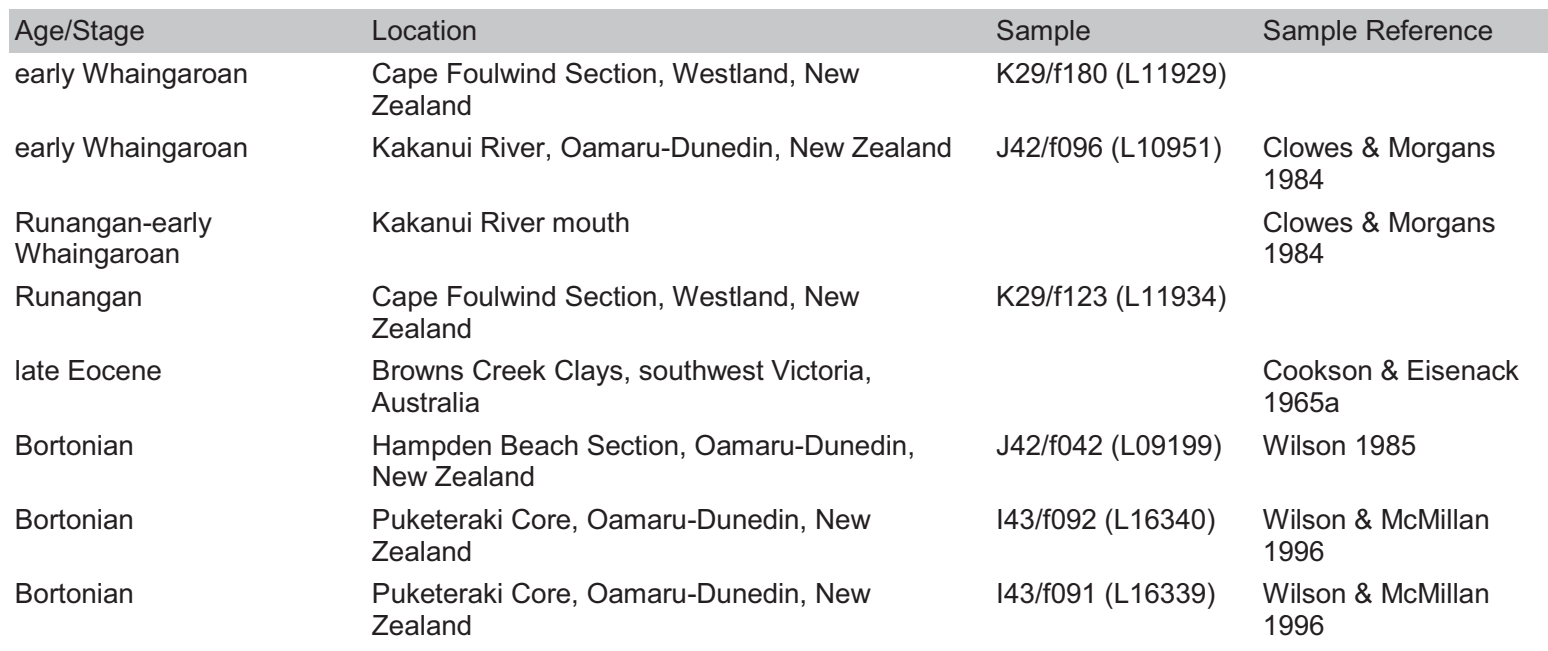

'Apteodinium' ?tenuitabulatum (Gerlach 1961) Clowes n. comb.

$$
\text { Pl. 39, figs. 1-9 }
$$

1961 Gonyaulax tenuitabulata Gerlach, p. 159-161, pl. 25, figs. 10-11, text-fig. 1-3

?1963 Gonyaulax cf. tenuitabulatum Gerlach 1961; Brosius, p. 37, pl. 1, fig. 5

?1969 Gonyaulacysta tenuitabulata (Gerlach, 1961) De Coninck, p. 23, pl. 5, figs. 9-10, 13-16

1978 Millioudodinium tenuitabulatum (Gerlach 1961) Stover \& Evitt, p. 174

1984a Cribroperidinium tenuitabulatum (Gerlach 1961) Helenes, p. 124

1984b Rhynchodiniopsis tenuitabulata (Gerlach, 1961) Sarjeant, p. 76

1985 Cribroperidinium tenuitabulatum (Gerlach 1961, p. 159, pl. 25, figs. 10-11; text-figs. 1-3) Helenes 1984, p. 124; Lentin \& Williams, p. 81

1994 Cribroperidinium tenuitabulatum (Gerlach 1961) Helenes 1984; Stover \& Hardenbol, p. 32, pl. 8, fig. 53

?2000 Cribroperidinium giuseppi; Levy \& Harwood, p. 222, pl. 2, figs. f-i

?2001 Cribroperidinium sp. A; Crouch, p. 44, pl. 2, figs. 8-9

?2003 Apteodinium australiense; Brinkhuis, Munsterman, et al., pl. 1, figs. 4-8

Original Description: Casing thin-walled, compactly spheroidal, with a short, blunt apical horn. Tabulation scheme: 4', 6", 6"', 1p, 1ppl, 1'”'. Plates are bound by low, narrow straps. Girdle furrow spiral with an offset of approximately $1 \frac{1}{2}$ furrow widths. Membrane is finely granular (translation from Gerlach 1961, p. 159-160).

Description of Study Material: Cysts of intermediate size, proximate, not dorso-ventrally compressed, more or less spherical, with one apical horn; episome and hyposome more or less equal in length. Apical horn moderately well-developed, apex bluntly terminated; antapical horns lacking. Cyst wall single-layered; about $1.5 \mu \mathrm{m}$, increasing towards the cingulum to about $2 \mu \mathrm{m}$ in thickness; sutural thickenings above and below the cingulum bring the combined thickness (wall plus sutural thickening) to about $4 \mu \mathrm{m}$. Archeopyle precingular, type P (3"); operculum free. Processes lacking; comprising low septa; very low (about $1 \mu \mathrm{m}$ or lower). Tabulation weakly expressed; hyposome sexiform; torsion dextral. Cingulum clearly expressed, indicated by sutural septa. Sulcus weakly expressed.

Size Range: Length = 58 (73) $95 \mu \mathrm{m}$ (44 measurements). Width = 63 (69) $74 \mu \mathrm{m}$ (8 measurements).

Distribution:

\begin{tabular}{|c|c|c|c|}
\hline Age/Stage & Location & Sample & Sample Reference \\
\hline middle Oligocene-middle & north west Germany & $\operatorname{Pr} 1170 / 10-12$ & Gerlach 1961 \\
\hline
\end{tabular}




$\begin{array}{llll}\begin{array}{l}\text { Miocene } \\ \text { Kaiatan }\end{array} & \begin{array}{l}\text { Puketeraki Core, Oamaru-Dunedin, New } \\ \text { Zealand }\end{array} & \text { I43/f096 (L16344) } & \begin{array}{l}\text { Wilson \& McMillan } \\ \text { Hampden Beach Section, Oamaru-Dunedin, }\end{array} \\ \text { Bortonian } & \text { J42/f061 (L09218) } & \text { Wilson } 1985 \\ & \begin{array}{l}\text { New Zealand } \\ \text { Hampden Beach Section, Oamaru-Dunedin, }\end{array} & \text { J42/f042 (L09199) } & \text { Wilson } 1985 \\ \text { Bortonian } & \begin{array}{l}\text { New Zealand } \\ \text { Puketeraki Core, Oamaru-Dunedin, New }\end{array} & \text { I43/f089 (L16337) } & \begin{array}{l}\text { Wilson \& McMillan } \\ \text { Zealand }\end{array} \\ \text { Bortonian } & & & \text { 1996 }\end{array}$

Remarks: Owing to the kind assistance of Jörg Pross, the writer was able to examine the holotype at Tübingen, on 21 May 2003. The material at the antapex of the specimen is an unrelated piece of debris, draped over the specimen: the antapex is rounded and entire. The specimen may have deteriorated, because the plates are not at all discernable. The only indications of tabulation I was able to observe were the archeopyle and cingulum. The wall is quite thick, as illustrated by Gerlach though in contrast to her description; $\sim 1.5 \mu \mathrm{m}$ on average increasing to $3 \mu \mathrm{m}$ or more at the cingulum. The apical horn is partly obscured, the overall length is $\sim 88 \mu \mathrm{m}$. The archeopyle is very large, $18.5 \mu \mathrm{m}$ high $\times 31 \mu \mathrm{m}$ wide at the cingular margin.

I have not had the opportunity to investigate the type material of Cribroperidinium giuseppei (Morgenroth 1966a, p. 5, pl. 2, figs. 3-6) Helenes 1984a, p. 121, but any distinctions between that and the present taxon are not clear to me from the illustrations alone.

\title{
Genus Achilleodinium Eaton 1976
}

\author{
1976 Achilleodinium Eaton, p. 234 \\ 1978 Achilleodinium Eaton 1976; Stover \& Evitt, p. 137-138
}

Type Species: Achilleodinium biformoides (Eisenack 1954b, p. 68, pl. 11, figs. 16-20) Eaton 1976, p. 234 [Late Eocene-Early Oligocene]

Original Description: Dinoflagellate cysts having a spherical or subspherical body bearing two types of intratabular processes: cylindrical processes, one per reflected plate area, hollow, circular to polygonal in crosssection, distally open or closed, variable in size; the larger processes occurring on the precingular and postcingular and antapical zones, the smaller on the apical zone. Slender processes, simple or bifurcate, distally open, restricted to the cingular and sulcal zones. Reflected tabulation 4', 6", 6c, 5"', 1p, 1"'; archeopyle precingular, formed by displacement of plate 3" (Eaton 1976, p. 234).

Remarks: Several species of Achilleodinium occur in the older part of the studied interval, from Heretaungan through to early Bortonian.

In overall appearance, Achilleodinium closely resembles Hystrichokolpoma. It differs, however, in possessing a precingular as opposed to an apical archeopyle. Florentinia, which is also somewhat similar, possesses a combination type $\mathrm{tA}+\mathrm{P}$ archeopyle.

A range chart for New Zealand occurrences of Achilleodinium is provided in Appendix 2, chart 1.

Achilleodinium biformoides (Eisenack 1954b) Eaton 1976

PI. 39, figs. 10-12, PI. 40, figs. 1-6

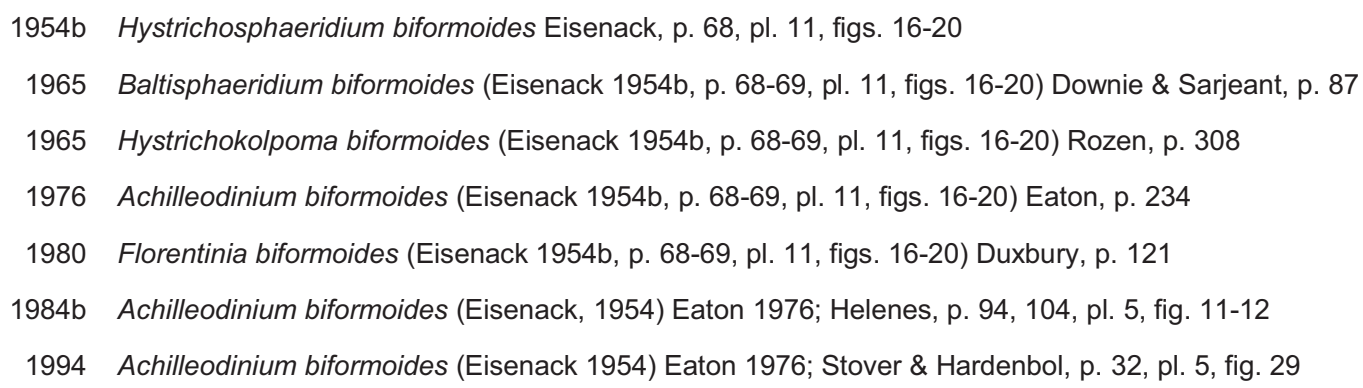

Original Description: Central body spheroid to slightly ovoid with dispersed, short and wide appendages furnished with secondary cusps. In between these appendages are irregularly distributed, thin, occasionally pointed, occasionally furcate or even outward-splaying appendages of approximately the same length as the first ones. Excystment holes are usually present (translation from Eisenack 1954b, p. 68-69). 
Description of Study Material: Cysts of intermediate size, chorate, not dorso-ventrally compressed, more or less spherical, lacking horns; episome somewhat shorter than hyposome. Cyst wall two-layered; acavate. Archeopyle precingular, type P (3"); operculum free. Surface ornament lacking. Processes intratabular; non-fibrous, inflated, hollow, closed, variable in length, sometimes broader than high; not connected proximally, with distal, secondary cusps. Tabulation clearly expressed by the processes, gonyaulacacean, inferred formula: 4', 0a, 6", 6c, 5"', 1ps, 1"', 3-5s; ventral organisation L-type; hyposome sexiform; torsion dextral. Cingulum clearly expressed, indicated by a series of differentiated processes. Sulcus clearly expressed, indicated by a series of differentiated processes.

Size Range: Length excluding any processes $=53(68) 88 \mu \mathrm{m}$ (3 measurements). Width excluding any processes $=46$ (51) $55 \mu \mathrm{m}$ (3 measurements). Length including any processes $=80$ (95) $112 \mu \mathrm{m}$ (11 measurements). Width including any processes $=63(78) 88 \mu \mathrm{m}$ (3 measurements).

\section{Distribution:}

\begin{tabular}{|c|c|c|c|}
\hline Age/Stage & Location & Sample & Sample Reference \\
\hline Bortonian & $\begin{array}{l}\text { Hampden Beach Section, Oamaru-Dunedin, New } \\
\text { Zealand }\end{array}$ & J42/f303 (L23133) & \\
\hline Bortonian & Puketeraki Core, Oamaru-Dunedin, New Zealand & l43/f094 (L16342) & $\begin{array}{l}\text { Wilson \& McMillan } \\
1996\end{array}$ \\
\hline Bortonian & Puketeraki Core, Oamaru-Dunedin, New Zealand & l43/f090 (L16338) & $\begin{array}{l}\text { Wilson \& McMillan } \\
1996\end{array}$ \\
\hline $\begin{array}{l}\text { Porangan- } \\
\text { Bortonian }\end{array}$ & $\begin{array}{l}\text { Hampden Beach Section, Oamaru-Dunedin, New } \\
\text { Zealand }\end{array}$ & J42/f485 (L23120) & \\
\hline Porangan & $\begin{array}{l}\text { Hampden Beach Section, Oamaru-Dunedin, New } \\
\text { Zealand }\end{array}$ & J42/f300 (L23130) & \\
\hline Heretaungan & $\begin{array}{l}\text { Hampden Beach Section, Oamaru-Dunedin, New } \\
\text { Zealand }\end{array}$ & J42/f483 (L23118) & \\
\hline
\end{tabular}

Remarks: New Zealand forms assigned to this species are somewhat variable, although the illustrated specimens compare very closely with the holotype and other types illustrated in Eisenack 1954b (pl. 11, figs. 16-20). The primary criterion used in this study for making specific distinctions within Achilleodinium is the relative length and degree of inflation of the large pre- and post-cingular processes, and the development of any secondary sculpturing on the distal parts of the large processes.

\section{Achilleodinium cf. biformoides}

\section{PI. 40, figs. 7-9}

Description: Cysts of intermediate size, chorate, not dorso-ventrally compressed, more or less spherical, lacking horns; episome somewhat shorter than hyposome. Cyst wall two-layered; acavate. Archeopyle precingular, type P (3"); operculum free. Surface ornament lacking. Processes intratabular; non-fibrous, inflated, hollow, closed, variable in length, sometimes broader than high; not connected proximally, with distal, secondary cusps distally. Tabulation clearly expressed, gonyaulacacean, inferred formula: 4', 0a, 6", 6c, 5"', 1ps, 1"', 3-5s; ventral organisation L-type; hyposome sexiform; torsion dextral. Cingulum clearly expressed, indicated by a series of differentiated processes. Sulcus clearly expressed, indicated by a series of differentiated processes.

Description of Study Material: Cysts of intermediate size, chorate, not dorso-ventrally compressed, more or less spherical, lacking horns; episome somewhat shorter than hyposome. Cyst wall two-layered; acavate. Archeopyle precingular, type P (3"); operculum free. Surface ornament lacking. Processes intratabular; non-fibrous, inflated, hollow, closed, variable in length, sometimes broader than high; not connected proximally, with distal, secondary cusps. Tabulation clearly expressed by the processes, gonyaulacacean, inferred formula: 4', 0a, 6", 6c, 5"', 1ps, 1"', 3-5s; ventral organisation L-type; hyposome sexiform; torsion dextral. Cingulum clearly expressed, indicated by a series of differentiated processes. Sulcus clearly expressed, indicated by a series of differentiated processes.

Size Range: Length excluding any processes $=86 \mu \mathrm{m}$ (one measured specimen). Width excluding any processes $=50 \mu \mathrm{m}$ (one measured specimen). Length including any processes $=107 \mu \mathrm{m}$ (one measured specimen). Width including any processes $=96 \mu \mathrm{m}$ (one measured specimen).

Distribution: Infrequent. Apparently co-occurring with A. biformoides s.s. though only in the older part of its range.

$\begin{array}{llc}\text { Age/Stage } & \text { Location } & \text { Sample } \\ \text { Porangan } & \begin{array}{l}\text { Hampden Beach Section, Oamaru-Dunedin, New } \\ \text { Zealand } \\ \text { M26 Core, Oamaru-Dunedin, New Zealand }\end{array} & \text { J42/f299 (L23129) } \\ \begin{array}{l}\text { Heretaungan- } \\ \text { Bortonian } \\ \text { Heretaungan }\end{array} & \text { Hampden Beach Section, Oamaru-Dunedin, New } & \text { I44/f240 (L15506) }\end{array}$


Remarks: This form is close to the type species, A. biformoides but differs in possessing longer, and generally broader processes.

Achilleodinium echinatum Wilson \& Clowes $\mathrm{n} . \mathrm{sp}$.

PI. 40, figs. 10-12, PI. 41, figs. 1-3

Derivation of Name: Latin, echinatus, prickly; originally from Greek, $\varepsilon \chi 1 v o \zeta$, meaning hedgehog; with reference to the spiny projections on the processes.

Holotype: Sample J42/f485, slide L23120/SM026; ?Hampden Formation, Hampden Beach Section (PoranganBortonian); PI. 40, figs. 10-12, PI. 41, figs. 1-3

Description: Cysts intermediate to large, chorate, not dorso-ventrally compressed, more or less spherical, lacking horns; episome and hyposome more or less equal in length. Cyst wall two-layered; acavate. Archeopyle precingular, type $\mathrm{P}\left(3^{\prime \prime}\right)$; operculum free. Ornament intratabular, comprising differentiated inflated hollow processes and simple spines. Non-fibrous, hollow, closed, up to about $30 \mu \mathrm{m}$; not connected proximally, with a small number of thin solid spines along the distal margins distally, sometimes joined by rare, thin trabeculae; apical process relatively short, up to $15 \mu \mathrm{m}$ and flat; antapical process up to $30 \mu \mathrm{m}$ and club-shaped to sub-ovoid; cingular and sulcal processes simple or bifurcate, simple spines. Tabulation clearly expressed, gonyaulacacean, inferred formula: 4', 0a, 6", 6c, 5"', 1ps, 1"', 5-6s; ventral organisation L-type; hyposome sexiform; torsion dextral. Cingulum clearly expressed, indicated by up to 12 simple or bifurcate processes. Sulcus clearly expressed, indicated by a series of differentiated processes.

Size Range: Length excluding any processes $=57 \mu \mathrm{m}$ (one measured specimen). Width excluding any processes $=50 \mu \mathrm{m}$ (one measured specimen). Length including any processes $=97 \mu \mathrm{m}$ (one measured specimen). Width including any processes $=100 \mu \mathrm{m}$ (one measured specimen).

\section{Distribution:}

\begin{tabular}{llll}
\hline Age/Stage & Location & Sample & Sample Reference \\
Porangan-Bortonian & Hampden Beach Section, Oamaru-Dunedin, New Zealand & J42/f485 (L23120) & \\
Porangan & Hampden Beach Section, Oamaru-Dunedin, New Zealand & J42/f299 (L23129)
\end{tabular}

Comparison: The species is distinguished by the distal process spines, generally smooth surface and by having some of the processes joined by trabeculae. It superficially resembles Hystrichokolpoma spinosum from the New Zealand Early-Mid Eocene but is readily distinguished from that species by having a precingular rather than apical archeopyle.

Remarks: A provisional description for this taxon appears in an unpublished manuscript prepared by Dr. Graeme Wilson shortly prior to his retirement from GNS Science (formerly the New Zealand Geological Survey), under the name Achilleodinium echinatum. Although the description has been amended somewhat to bring it into conformity with the other descriptions provided herein, and observations from additional material incorporated, Dr. Wilson's fundamental contribution is recognised in the authorship of the proposed name.

\section{Achilleodinium improcerum Wilson \& Clowes n. sp.}

$$
\text { Pl. 41, figs. 4-12, PI. 42, figs. 1-6 }
$$

?1993 Achilleodinium biformoides (Eisenack) Eaton, 1976; Brinkhuis \& Biffi, p. 173, pl. 5, fig. 9

Derivation of Name: Latin, improcerus, short; with reference to the processes.

Holotype: Sample J42/f484, slide L23119/SM020; Kurinui Formation, Hampden Beach Section (Heretaungan); PI. 41, figs. 4-6

Description: Cyst of intermediate size, subspherical to ellipsoidal, two-layered, bearing short hollow, box-like intratabular processes. Precingular and postcingular processes broad, polygonal, short (length to breadth ratio less than 1:2) with a narrower distal margin. Polar processes not well-developed. Cingular processes generally short and narrow, occasionally spinose, sometimes absent. Sulcal processes generally short, spinose. Tabulation apparently 1-4', 6", 6c, 5"', 1p, 1"'”, 3-5s. Periphragm surface between processes usually has widely dispersed granules. Archeopyle precingular, type P (3"); operculum free. Size Range: Holotype - overall length 91 microns, breadth 86 microns, length of endocyst 78 microns, length of processes up to 11 microns; range of 6 specimens - overall length 78-108 microns, breadth 68-87 microns. 
Size Range: Length excluding any processes $=60$ (77) $94 \mu \mathrm{m}$ (4 measurements). Width excluding any processes $=47$ (67) $83 \mu \mathrm{m}$ (4 measurements). Length including any processes $=72$ (94) $126 \mu \mathrm{m}$ (8 measurements). Width including any processes $=55$ (88) $112 \mu \mathrm{m}$ (4 measurements).

\title{
Distribution:
}

$\begin{array}{llll}\text { Age/Stage } & \text { Location } & \text { Sample } & \text { Sample Reference } \\ \text { early Priabonian } & \text { Massignano Section, northeast Italy } & \text { MS 7.20-01 } & \text { Brinkhuis \& Biffi 1993 } \\ \text { Bortonian } & \text { Puketeraki Core, Oamaru-Dunedin, New Zealand } & \text { I43/f093 (L16341) } & \text { Wilson \& McMillan 1996 } \\ \text { Bortonian } & \text { Hampden Beach Section, Oamaru-Dunedin, New Zealand } & \text { J42/f042 (L09199) } & \text { Wilson 1985 } \\ \text { Bortonian } & \text { Puketeraki Core, Oamaru-Dunedin, New Zealand } & \text { I43/f090 (L16338) } & \text { Wilson \& McMillan 1996 } \\ \text { Porangan } & \text { Te Uri Stream, Hawkes Bay, New Zealand } & \text { U24/f419 (L23127) } & \\ \text { Heretaungan } & \text { Hampden Beach Section, Oamaru-Dunedin, New Zealand } & \text { J42/f484 (L23119) } \\ \text { Heretaungan } & \text { Hampden Beach Section, Oamaru-Dunedin, New Zealand } & \text { J42/f483 (L23118) }\end{array}$

Comparison: The species is distinguished by its short, generally broad precingular and postcingular processes, and in lacking a distinctive antapical process. Wilson 1985 further notes the more polygonal in cross-section of the processes as a point of difference from the genotype, $A$. biformoides. It superficially resembles Hystrichokolpoma wilsonii (Wilson) Williams et al. 1998, but differs in having a precingular rather than an apical archeopyle. It also resembles Aireiana species, but differs in having two distinct process types.

Remarks: A provisional description for this taxon appears in an unpublished manuscript prepared by Dr. Graeme Wilson shortly prior to his retirement from GNS Science (formerly the New Zealand Geological Survey), under the name Achilleodinium improcerum. Although the description has been amended somewhat to bring it into conformity with the other descriptions provided herein, and observations from additional material incorporated, Dr. Wilson's fundamental contribution is recognised in the authorship of the proposed name.

\section{Genus Araneosphaera Eaton 1976}

\author{
1976 Araneosphaera Eaton
}

Type Species: Araneosphaera araneosa Eaton 1976, p. 240, 242, pl. 2, figs. 5-8, text-figs. 6A-D [Mid-Late Eocene]

Original Description: Dinoflagellate cysts having a spherical or subspherical body with a smooth or finely fibroreticulate surface. Processes intratabular, fibrous, simple or branched. A variable proportion of the processes are distally united by fibrous membrane. Processes invariably present on the apical, pre- and postcingular and antapical zones. Typically each reflected plate area has one process, sometimes more than one. Cingular zone usually, but not invariably, devoid of processes. Basic reflected tabulation 4', 6", 5-6"', 0-1p, 1"'"; archeopyle precingular, formed by displacement of plate 3" (Eaton 1976, p. 240).

\section{‘Araneosphaera’ stephanophora (Benedek 1972) Benedek \& Sarjeant 1981}

PI. 42, figs. 7-12, PI. 43, figs. 1-6

1972 Cordosphaeridium minimum (Morgenroth 1966) Benedek, pl. 9, fig. 3

1972 Hystrichosphaeridium stephanophorum Benedek, p. 30-31, pl. 9, fig. 6, text-fig. 10

1981 Araneosphaera stephanophora (Benedek, 1972) Benedek \& Sarjeant, p. 349-351, fig. $10(3,6)$

Original Description: [No translation available] Eine Art der Gattung Hystrichosphaeridium mit kleiner kugelföformiger Kapsel. Diese ist dünnwandig und hat eine glatte, ungefelderte Oberfläche. Sie wird locker von hohlen kurzen Fontsätzen besetzt, deren distale Erweiterungen verwaschsen sein können (Benedek 1972, p. 30).

Size Range: Length excluding any processes $=20$ (22) $27 \mu \mathrm{m}$ (6 measurements). Width excluding any processes $=18$ (22) $27 \mu \mathrm{m}$ (4 measurements). Length including any processes $=29$ (38) $47 \mu \mathrm{m}$ (8 measurements). Width including any processes $=32$ (37) $40 \mu \mathrm{m}$ (4 measurements).

Distribution:

$\begin{array}{llll}\begin{array}{l}\text { Age/Stage } \\ \text { Kaiatan }\end{array} & \text { Location } & \text { Sample } & \begin{array}{l}\text { Sample Reference } \\ \text { I43/f096 (L16344) }\end{array} \\ \text { Bortonian } & \text { Puketeraki Core, Oamaru-Dunedin, New Zealand } & \begin{array}{l}\text { WcMillan } \\ \text { Puketeraki Core, Oamaru-Dunedin, New Zealand }\end{array} & \begin{array}{l}\text { I43/f089 (L16337) } \\ \text { Wilson \& McMillan } \\ 1996\end{array}\end{array}$




$\begin{array}{lll}\text { Porangan- } & \text { Hampden Beach Section, Oamaru-Dunedin, New } & \text { J42/f486 (L23121) } \\ \text { Bortonian } & \text { Zealand } & \\ \text { Porangan } & \text { Hampden Beach Section, Oamaru-Dunedin, New } & \text { J42/f300 (L23130) } \\ & \text { Zealand } & \end{array}$

Remarks: 'Araneosphaera' stephanophora was first described (Benedek 1972) as a species of Hystrichosphaeridium. Included among the types were some specimens subsequently reattributed to Cordosphaeridium minimum in Benedek \& Sarjeant 1981, p. 350. (The comment that the reattributed specimens possess apical archeopyles is assumed to be an error since Cordosphaeridium has a precingular archeopyle.)

Strauss \& Lund 1992, p. 161-162, advances the proposition that this species is a member of super-specific group of forms they term the "aff. Cordosphaeridium minimum (Morgenroth) Benedek 1972-cyst complex" which is characterised by a small, subspherical, hollow central body with "probably" a type P (3") archeopyle and fibrous, distally expanded processes. These authors cite a continuous range of variation between typical Cordosphaeridium minimum types having no distal connections between processes, to others which are completely enveloped by an ectophragmal membrane. The continuous range of variation is somewhat supported in the present study. The abandonment of taxonomic duty by simply dumping the problem into a "complex", however, is not.

The generic assignment is here regarded as highly dubious because the archeopyle type of 'A.' stephanophora is quite uncertain (the reassurances in Benedek \& Sarjeant 1981 notwithstanding) and, even if it does prove to be precingular, the resemblance to the type species of Araneosphaera, A. araneosa Eaton 1976, remains slight. My own view is that by including all of these forms in Cordosphaeridium, Strauss \& Lund were closer to the mark.

\title{
Genus Cordosphaeridium Eisenack 1963b emend. Davey 1969c
}

\author{
1963b Cordosphaeridium Eisenack, p. 261 \\ 1969c Cordosphaeridium Eisenack 1963 emend. Davey, p. 35 \\ 1978 Cordosphaeridium Eisenack 1963b emended Davey 1969c; Stover \& Evitt, p. 146-147
}

Type Species: Cordosphaeridium inodes (Klumpp 1953, p. 391, pl. 18, figs. 1-2) Eisenack 1963b, p. 261 [Late Eocene]

Original Description: Hystrichospheres with spherical to (generally weakly) ellipsoidal shells, which are covered with approximately homogeneous and rather regularly distributed radial appendages, which appear cord-like, i.e., are formed of numerous thin, closely set fibres. A hollow space is, in general, not discernible; however, in some cases it can be present in relict fashion. Commonly the shell consists of two layers, of which the outer has a fibrous structure and (in all probability) the converging fibres constitute the processes. At the tips the fibres diverge in paintbrush-like fashion; however, they may also unite together in net like fashion (translated from Eisenack 1963b, p. 261, by Stover \& Evitt 1978, p. 146).

\section{Cordosphaeridium inodes (Klumpp 1953) Eisenack 1963b}

$$
\text { PI. 43, figs. 7-12, PI. 44, figs. 1-3 }
$$

\footnotetext{
1953 Hystrichosphaeridium truncigerum Deflandre; Cookson, p. 114, pl. 2, figs. 21-23

1953 Hystrichosphaeridium inodes Klumpp, p. 391, pl. 18, figs. 1-2

1955 Hystrichosphaeridium inodes Klumpp; Deflandre \& Cookson, p. 277-278, pl. 8, fig. 7

1963 Hystrichosphaeridium inodes Klumpp 1953; Brosius, p. 40, pl. 5, fig. 5

1963b C. (Hystrichosphaeridium) inodes (Klumpp 1953) Eisenack, p. 261

1965 Cordosphaeridium inodes (Klumpp 1953); De Coninck, p. 31, pl. 8, figs. 1-7, pl. 9, figs. 1, 2, 5

1966b Cordosphaeridium gracilis (Klumpp) Davey \& Williams, p. 83-84, pl. 3, fig. 9, text-fig. 18

1969 Cordosphaeridium inodes inodes (Klumpp 1953) Gocht, p. 41, pl. 1, figs. 11-12, pl. 4, fig. 14

1972 Cordosphaeridium inodes inodes (Klumpp 1953) Gocht 1969; Benedek, p. 25, pl. 7, fig. 10

1985 Cordosphaeridium inodes (Klumpp 1953) Eisenack 1963; Jan du Chêne \& Adediran, p. 12, pl. 12, fig. 7

2004 Cordosphaeridium inodes (Klumpp 1953) Eisenack 1963b emend. Morgenroth 1968 emend. Sarjeant 1981; Ramírez, p. 45, pl. 2, fig. 6
}

Original Description: A species of the genus Hystrichosphaeridium with the following characteristics: the enclosing membrane is double layered, the outer layer consists of short fibres vertically aligned with the surface. The processes are formed from this fibre layer and ravel out irregularly at the ends (Klumpp 1953, p. 391). 
Size Range: Length excluding any processes $=50$ (56) $60 \mu \mathrm{m}$ (3 measurements). Width excluding any processes $=50$ (50) $50 \mu \mathrm{m}$ (2 measurements). Length including any processes $=68$ (119) $173 \mu \mathrm{m}$ (18 measurements). Width including any processes $=84$ (128) $165 \mu \mathrm{m}$ (5 measurements).

\section{Distribution:}

\begin{tabular}{|c|c|c|c|}
\hline Age/Stage & Location & Sample & Sample Reference \\
\hline Bortonian & $\begin{array}{l}\text { Puketeraki Core, Oamaru-Dunedin, New } \\
\text { Zealand }\end{array}$ & I43/f094 (L16342) & Wilson \& McMillan 1996 \\
\hline Bortonian & $\begin{array}{l}\text { Hampden Beach Section, Oamaru-Dunedin, } \\
\text { New Zealand }\end{array}$ & J42/f042 (L09199) & Wilson 1985 \\
\hline Bortonian & $\begin{array}{l}\text { Puketeraki Core, Oamaru-Dunedin, New } \\
\text { Zealand }\end{array}$ & I43/f089 (L16337) & Wilson \& McMillan 1996 \\
\hline Bortonian & $\begin{array}{l}\text { Hampden Beach Section, Oamaru-Dunedin, } \\
\text { New Zealand }\end{array}$ & J42/f040 (L09197) & Wilson 1985 \\
\hline Porangan-Bortonian & $\begin{array}{l}\text { Hampden Beach Section, Oamaru-Dunedin, } \\
\text { New Zealand }\end{array}$ & J42/f302 (L23132) & \\
\hline Porangan & Te Uri Stream, Hawkes Bay, New Zealand & U24/f417 (L23125) & \\
\hline Porangan & $\begin{array}{l}\text { Hampden Beach Section, Oamaru-Dunedin, } \\
\text { New Zealand }\end{array}$ & J42/f300 (L23130) & \\
\hline $\begin{array}{l}\text { middle Eocene-late } \\
\text { Eocene }\end{array}$ & north west Venezuela & Pica-1X, $3818 \mathrm{ft}$. & Ramírez 2004 \\
\hline Heretaungan & $\begin{array}{l}\text { Hampden Beach Section, Oamaru-Dunedin, } \\
\text { New Zealand }\end{array}$ & J42/f484 (L23119) & \\
\hline Heretaungan & $\begin{array}{l}\text { Hampden Beach Section, Oamaru-Dunedin, } \\
\text { New Zealand }\end{array}$ & J42/f483 (L23118) & \\
\hline $\begin{array}{l}\text { late Paleocene-early } \\
\text { Eocene }\end{array}$ & Lokoja, Nigeria & & $\begin{array}{l}\text { Jan du Chêne \& Adediran } \\
1985\end{array}$ \\
\hline
\end{tabular}

Remarks: The holotype of C. inodes appears in a poor photograph (pl. 18, fig. 1) and a sketch (pl. 18, fig. 2) in Klumpp's original publication (Klumpp 1953). Unsurprisingly, given the date of the work, there is little useful diagnostic detail in these depictions, nor in the description.

A somewhat more recent sketch is provided in Jux 1968, text-fig. 1. Jux's sketch depicts the holotype in the identical orientation but, unlike Klumpp's, shows the outline of a fairly typical precingular archeopyle on the upper surface.

Sarjeant 1981, pl.1, fig. 1, provides a photograph of the holotype, "in oblique ventral view." In this figure, the specimen is recognisably the same, but the orientation is rotated approximately $90^{\circ}$ clockwise with respect to the earlier illustrations. The area shown as an archeopyle in Jux's illustration, is out of focus in Sarjeant's photograph. It could be anything, and there is no way for the reader to assess the orientation for themselves. Sarjeant's sketches (text-fig. 1) illustrate his interpretation of the archeopyle shape and position. Even allowing for the rotation and left-to-right reflection in his depiction of the dorsal surface, Sarjeant's sketch of the archeopyle cannot be reconciled with Jux's, and the shape of Sarjeant's archeopyle is unconvincing.

\section{Cordosphaeridium gracile (Eisenack 1954b) Davey \& Williams 1966b}

$$
\text { PI. 44, figs. 4-6 }
$$

1954b Hystrichosphaeridium inodes subsp. gracile Eisenack, p. 66, pl. 8, fig. 17; pl. 10, figs. 3-8; pl. 12, figs. 7, 21

1966b Cordosphaeridium gracilis (Eisenack) Davey \& Williams, p. 84-86, pl. 3, fig. 8, pl. 11, figs. 4, 6, 7, text-fig. 19

1969 Cordosphaeridium inodes gracilis (Eisenack 1954) Gocht, p. 41-42, pl. 1, figs. 1-9, 15

Original Description: A subspecies of $H$. inodes Klumpp 1953 with the following characteristics: The central body is spherical to oval, generally larger than the primary type, the appendages longer, significantly narrower and of even length (translation from Eisenack 1954b, p. 66).

Size Range: Length excluding any processes $=64(74) 85 \mu \mathrm{m}$ (2 measurements). Width excluding any processes $=60$ (70) $80 \mu \mathrm{m}$ (2 measurements). Length including any processes $=47$ (149) $175 \mu \mathrm{m}$ (13 measurements). Width including any processes $=117$ (148) $163 \mu \mathrm{m}$ (8 measurements).

\section{Distribution:}

\begin{tabular}{llll}
\hline Age/Stage & Location & Sample & Sample Reference \\
Kaiatan & Puketeraki Core, Oamaru-Dunedin, New Zealand & I43/f096 (L16344) & Wilson \& McMillan 1996 \\
Bortonian & Burnside Marl Pit, Oamaru-Dunedin, New Zealand & I44/f080 (L08947) & Clowes \& Wilson 2006 \\
Bortonian & Hampden Beach Section, Oamaru-Dunedin, New Zealand & J42/f055 (L09212) & Wilson 1985
\end{tabular}




\title{
Cordosphaeridium fibrospinosum Davey \& Williams 1966b
}

PI. 44, figs. 7-12

\author{
1966b Cordosphaeridium fibrospinosum Davey \& Williams, p. 86, pl. 5, fig. 5 \\ ?1969c Cordosphaeridium fibrospinosum Davey \& Williams 1966b emend. Davey, p. 36, pl. 3, fig. 4, pl. 4, fig. 5, text- \\ fig. 1 (5) \\ 1980a Cordosphaeridium fibrospinosum Davey and Williams; Bujak et al., pl. 7, figs. 3, 6 \\ 1981 Emmetrocysta? fibrospinosa (Davey \& Williams 1966b, p. 86, pl. 5, fig. 5) Sarjeant, p. 123 \\ 1986 Tityrosphaeridium? fibrospinosum (Davey \& Williams 1966b, p. 86, pl. 5, fig. 5) Jain and Garg, p. 121
}

Original Description: Ovoidal central body with wall up to $0.5 \mu$ thick, composed of smooth endophragm and fibrous periphragm. Processes fibrous, often very broad and ovoidal in cross-section, walls perforate. Processes open distally, with entire or undulose margin. One process per plate reflecting a tabulation typical of the genus. Archeopyle apical haplotabular [sic] (Davey \& Williams 1966b, p. 86).

Description of Study Material: Cysts large, chorate, not dorso-ventrally compressed, prolate, lacking horns; episome and hyposome more or less equal in length. Cyst wall two-layered; acavate. Archeopyle precingular, type P (3"); operculum free. Processes intratabular; fibrous, often perforate, variable, sometimes broader than high; not connected proximally, flaring distally. Inferred formula: 3 to 4 ', $0 \mathrm{a}, 6$ ", $6 \mathrm{c}, 5-6$ "', 0 to $1 \mathrm{ps}, 1{ }^{\prime \prime \prime}, 0-3 \mathrm{~s}$; hyposome sexiform; torsion dextral.

Size Range: Length excluding any processes $=75(78) 81 \mu \mathrm{m}$ (2 measurements). Width excluding any processes $=73$ (74) $75 \mu \mathrm{m}$ (2 measurements). Length including any processes $=37$ (101) $157 \mu \mathrm{m}$ (23 measurements). Width including any processes $=90(104) 120 \mu \mathrm{m}$ (4 measurements).

\section{Distribution:}

$\begin{array}{llll}\text { Age/Stage } & \text { Location } & \text { Sample } & \text { Sample Reference } \\ \text { Bortonian } & \text { Hampden Beach Section, Oamaru-Dunedin, New Zealand } & \text { J42/f061 (L09218) } & \text { Wilson } 1985 \\ \text { Bortonian } & \text { Puketeraki Core, Oamaru-Dunedin, New Zealand } & \text { I43/f094 (L16342) } & \text { Wilson \& McMillan } 1996 \\ \text { Bortonian } & \text { Puketeraki Core, Oamaru-Dunedin, New Zealand } & \text { I43/f089 (L16337) } & \text { Wilson \& McMillan } 1996 \\ \text { Porangan } & \text { Hampden Beach Section, Oamaru-Dunedin, New Zealand } & \text { J42/f300 (L23130) } & \end{array}$

\section{Cordosphaeridium aff. funiculatum}

$$
\text { Pl. 45, figs. 1-12 }
$$
1988 Cordosphaeridium cf. funiculatum Morgenroth 1966; Biffi \& Manum, pl. 10, figs. 13, 17
1989 Cordosphaeridium cf. funiculatum Morgenroth, 1966; Head \& Norris, pl. 8, figs. 13-14
1992 Cordosphaeridium funiculatum Morgenroth, 1966a emend. Brinkhuis, p. 97, pl. 1, fig. 6
1993 Cordosphaeridium funiculatum Morgenroth, 1966a Brinkhuis \& Biffi, p. 173, pl. 1, fig. 6
1993 Cordosphaeridium funiculatum Morgenroth, 1966a; Brinkhuis \& Biffi, p. 173, pl. 1, fig. 6
1994 Cordosphaeridium funiculatum Morgenroth, 1966a; Brinkhuis, pl. 4, figs. 1-3

Description: Cysts more or less spherical with an indistinct equatorial cingulum. Two wall layers; a very thick $(\sim 4$ to $5 \mu \mathrm{m}$ ) endocyst and thin, hyaline, minutely perforate (?) pericyst. Archeopyle precingular, Type P (3"), with a flat bottom margin and semicircular upper margin; operculum free, possessing one central process complex. Ornament comprises intratabular (and possibly some accessory features in gonal positions) process complexes of variable morphology, including fibrous or at least striated, hollow, essentially "closed" though variably perforate processes which range from thick spines to blunt and sometimes inflated cones. Sometimes the antapical process appears broader than the others. The processes are joined proximally by an irregular, coarse reticulum which appears minutely maculate, possibly perforate. Indistinct indications of a cingulum may be provided by intratabular or possibly gonal processes on the cingular plates, and possibly an extremely faint and erratic alignment of the reticulum. The sulcus is not discernible at all on most specimens; only one from the present collection shows a very faint indication (PI. 45, figs. 1-6). Tabulation is indicated by the archeopyle and process 
placement, unambiguously by the archeopyle only; presumed to be gonyaulacacean; formula 4', 6", ?5-6c, 5"', ?0-1p, 1"'".

Size Range: Length excluding any processes $=80$ (102) $127 \mu \mathrm{m}$ (3 measurements). Width excluding any processes $=82$ (98) $120 \mu \mathrm{m}$ (3 measurements). Length including any processes $=43(116) 175 \mu \mathrm{m}(6$ measurements). Width including any processes $=112$ (137) $177 \mu \mathrm{m}$ (3 measurements).

Distribution: Infrequent. Occurs in only a few samples, possibly indicating a narrow stratigraphic range, but can be locally abundant when it does occur.

Previous reports of this taxon have been from the Tethys; the present report provides a significant extension to the known geographic range of this taxon.

\begin{tabular}{|c|c|c|c|}
\hline Age/Stage & Location & Sample & Sample Reference \\
\hline early Whaingaroan & Cape Foulwind Section, Westland, New Zealand & K29/f115 (L11051) & \\
\hline early Whaingaroan & Cape Foulwind Section, Westland, New Zealand & K29/f183 (L11932) & \\
\hline early Whaingaroan & Cape Foulwind Section, Westland, New Zealand & K29/f114 (L11050) & \\
\hline latest Eocene & Monte Cagnero Section A, Italy & & Brinkhuis \& Biffi 1993 \\
\hline Runangan & Cape Foulwind Section, Westland, New Zealand & K29/f128 (L11939) & \\
\hline late Eocene & Contessa Highway Section B, Italy & & Brinkhuis \& Biffi 1993 \\
\hline late Eocene & Massignano Section, northeast Italy & MS 18.00-01 & Brinkhuis \& Biffi 1993 \\
\hline late Eocene & Massignano Section, northeast Italy & MS 18.00-01 & Brinkhuis 1992 \\
\hline late Eocene & Priabona Section, northeast Italy & PB24-02 & Brinkhuis 1994 \\
\hline Bortonian & Puketeraki Core, Oamaru-Dunedin, New Zealand & I43/f094 (L16342) & Wilson \& McMillan 1996 \\
\hline
\end{tabular}

Remarks: Brinkhuis (1992, p. 97) considered this form to be a variant of Cordosphaeridium funiculatum Morgenroth 1966a and emended the original description "to include forms that possess shorter and broader processes, such as those figured by e.g., Biffi and Manum (1988) and Head and Norris (1989)."

Brinkhuis 1992, p. 97, further notes that "representatives of the species exhibiting relatively short and broad processes are restricted to lower (paleo-) latitudes", though this is clearly not the case for the New Zealand material. Moreover, the forms with shorter and broader processes appear generally to be younger than Morgenroth's early Eocene type material from Katharinenhof on Fehmarn Island (northern Germany). Thus it is plausible to suggest that the reported occurrences trace the southward migration of a variant, or descendent, of Cordosphaeridium funiculatum sensu stricto.

C. aff. funiculatum appears to possess some characteristics which are closer to Aireiana than to the type species of Cordosphaeridium, C. inodes.

\title{
Cordosphaeridium minimum (Morgenroth 1966a) Benedek 1972
}

PI. 46, figs. 1-9

\author{
1966a Cordosphaeridium inodes Klumpp minimum Morgenroth, p. 24-25, pl. 5, figs. 6-7 \\ 1969 ?Cordosphaeridium inodes subsp. minimum Morgenroth, 1966; De Coninck, p. 31, pl. 8, figs. 20-22 \\ 1972 Cordosphaeridium minimum (Morgenroth 1966) Benedek, p. 25-26 \\ 1994 Cordosphaeridium minimum (Morgenroth 1966) Benedek 1972; Stover \& Hardenbol, p. 32, pl. 7, fig. 39
}

Original Description: [No translation available] Eine Art der Gattung Cordosphaeridium mit einem "inodes"ähnlichen Fortsatztyp. Fortsätze erweitern sich distal trompetenförmig und fasern auf. Keine Fortsatzverzweigungen. Kapseldurchmesser ca. $20 \mu$ kleiner als bei Cordosphaeridium inodes (Morgenroth 1966a, p. 24).

Description of Study Material: Cysts small, chorate, not dorso-ventrally compressed, more or less spherical, lacking horns; episome and hyposome more or less equal in length. Cyst wall two-layered; acavate. Archeopyle precingular, type P\&nbsp;(3"); operculum free to attached. Processes intratabular, straight or gently curved; ?fibrous, unbranched; not connected proximally, irregularly flaring distally. Inferred formula: 3 to 4', 0a, 6", 6c, 56"', 0 to $1 \mathrm{ps}, 1^{\prime \prime \prime}, 0-3 \mathrm{~s}$.

Size Range: Length excluding any processes $=17$ (21) $25 \mu \mathrm{m}$ (10 measurements). Width excluding any processes $=18(21) 23 \mu \mathrm{m}$ (4 measurements). Length including any processes $=30(38) 45 \mu \mathrm{m}(13$ measurements). Width including any processes $=33$ (37) $40 \mu \mathrm{m}$ (4 measurements).

Distribution: 


\begin{tabular}{|c|c|c|c|}
\hline Age/Stage & Location & Sample & Sample Reference \\
\hline Bortonian & $\begin{array}{l}\text { Hampden Beach Section, Oamaru-Dunedin, New } \\
\text { Zealand }\end{array}$ & J42/f488 (L23123) & \\
\hline Bortonian & Puketeraki Core, Oamaru-Dunedin, New Zealand & l43/f091 (L16339) & $\begin{array}{l}\text { Wilson \& McMillan } \\
1996\end{array}$ \\
\hline Bortonian & Puketeraki Core, Oamaru-Dunedin, New Zealand & I43/f089 (L16337) & $\begin{array}{l}\text { Wilson \& McMillan } \\
1996\end{array}$ \\
\hline Porangan-Bortonian & $\begin{array}{l}\text { Hampden Beach Section, Oamaru-Dunedin, New } \\
\text { Zealand }\end{array}$ & J42/f301 (L23131) & \\
\hline Porangan & Te Uri Stream, Hawkes Bay, New Zealand & U24/f419 (L23127) & \\
\hline $\begin{array}{l}\text { Heretaungan- } \\
\text { Porangan }\end{array}$ & $\begin{array}{l}\text { Hampden Beach Section, Oamaru-Dunedin, New } \\
\text { Zealand }\end{array}$ & J42/f298 (L23128) & \\
\hline Heretaungan & $\begin{array}{l}\text { Hampden Beach Section, Oamaru-Dunedin, New } \\
\text { Zealand }\end{array}$ & J42/f039 (L09196) & Wilson 1985 \\
\hline Heretaungan & $\begin{array}{l}\text { Hampden Beach Section, Oamaru-Dunedin, New } \\
\text { Zealand }\end{array}$ & J42/f483 (L23118) & \\
\hline
\end{tabular}

Remarks: There has been some confusion concerning the distinction between Cordosphaeridium minimum and 'Araneosphaera' stephanophora, presumably because they are both very small, occur together, and the ectophragm of 'A.' stephanophora is often incomplete, and possibly sometimes lacking. Refer to 'A.' stephanophora for further discussion.

The precingular archeopyle is clearly evident in the studied specimens of the present form (e.g. see PI. 46, fig. 1).

\title{
Genus Turbiosphaera Archangelsky 1969a
}

\author{
1969a Turbiosphaera Archangelsky, p. 408 \\ 1978 Turbiosphaera Archangelsky 1969a; Stover \& Evitt, p. 198 \\ 1984 Turbiosphaera; Damassa, p. 61-62
}

Type Species: Turbiosphaera filosa (Wilson 1967a, p. 66, figs. 2b, 31-32, 34) Archangelsky 1969a, p. $408-411$ [Paleocene-Oligocene]

Original Description: Subspherical to suboval chorate cysts, with two-layered central body. Periphragm forming typically taeniate processes reflecting a tabulation 1', 6", 6c, 6"', (1p), 1'"'. Apical and antapical processes bigger than the others; cingular processes smaller than the others. Archeopyle precingular with entire margins, formed by detachment of plate 3" (translated from Archangelsky 1969a, p. 408, by Stover \& Evitt 1978, p. 198).

Turbiosphaera filosa (Wilson 1967a) Archangelsky 1969a

PI. 46, figs. 10-12, PI. 47, figs. 1-3

\author{
1961 Forma F Evitt, p. 392 \\ 1967a Cordosphaeridium filosum Wilson, p. 66, figs. 2b, 31-32, 34 \\ 1969a Turbiosphaera filosa (Wilson 1967a, p. 66, figs. 2b, 31-32, 34) Archangelsky, p. 408-411 \\ 1982b Turbiosphaera filosa (Wilson); Wilson, pl. 2, figs. 14-15 \\ 1984 Turbiosphaera filosa; Damassa, p. 61-62, pl. 6, figs. 1-3 \\ 1989 Turbiosphaera filosa (Wilson) Archangelsky Wilson, pl. 1, fig. 18 \\ 2000 Turbiosphaera filosa (Wilson, 1967) Archangelsky, 1969a; Levy \& Harwood, p. 228, 230, pl. 10, figs. d-I
}

Original Description: Test bi-layered comprising fibrous outer cyst and smooth oval inner cyst. Outer cyst extended radially to form 20-24 broad, flat, non-tubular fibrous processes $(I=8-26 \mu)$ the longest and broadest being at the poles; processes of equatorial region about one half as long as polar processes; polar processes usually pointed, the others flat-tipped; ventral processes much smaller than those on dorsal surface. Laevorotatory transverse girdle clearly defined by whorl of 6-8 processes whose long, narrow bases are aligned parallel to! the equator. Archeopyle large, subrounded, precingular, located on dorsal epitheca ... (Wilson 1967a, p. 66; ellipses replace figure references in the original).

Size Range: Length excluding any processes $=92 \mu \mathrm{m}$ (one measured specimen). Width excluding any processes $=73 \mu \mathrm{m}$ (one measured specimen). Length including any processes $=137 \mu \mathrm{m}$ (one measured specimen). Width including any processes $=110 \mu \mathrm{m}$ (one measured specimen). 
Distribution:

\begin{tabular}{llll} 
Age/Stage & Location & Sample & Sample Reference \\
\hline Porangan & Te Uri Stream, Hawkes Bay, New Zealand & U24/f419 (L23127) & \\
Porangan & Te Uri Stream, Hawkes Bay, New Zealand & U24/f418 (L23126) & \\
Heretaungan & Hampden Beach Section, Oamaru-Dunedin, New Zealand & J42/f483 (L23118) & \\
Eocene & CIROS-1 drillhole, McMurdo Sound, Antarctica & L13177/1 & Wilson 1989 \\
Eocene & erratics near Minna Bluff, McMurdo Sound, Antarctica & L4737 & Wilson 1967a \\
Eocene & erratics, McMurdo Sound, Antarctica & MB 245 & Levy \& Harwood 2000 \\
Eocene & erratics, McMurdo Sound, Antarctica & MTD 1B & Levy \& Harwood 2000
\end{tabular}

\title{
Turbiosphaera sp. 1
}

Pl. 47, figs. 4-12

Description: Cysts intermediate to large, chorate, not dorso-ventrally compressed, prolate, lacking horns; episome and hyposome more or less equal in length. Cyst wall two-layered; acavate; fibrous. Archeopyle precingular, type P (3"); large; operculum free. Surface ornament present, non-tabular, comprising texture arising from the fibrous composition of the periphragm, forming an irregular reticulum. Processes intratabular; fibrous, unbranched, solid; flaring distally; sometimes separating into a small number of divisions, though not true branches, distally. Tabulation clearly expressed, gonyaulacacean, inferred formula: 1-4', 0a, 6", X-6c, 5-6"', 1ps, 1"', Xs; hyposome sexiform; torsion dextral. Cingulum clearly expressed, a differentiated, flattened, process series; offset only slightly. Sulcus moderately expressed, a few differentiated, spine-like processes.

Size Range: Length excluding any processes $=67 \mu \mathrm{m}$ (one measured specimen). Width excluding any processes $=54 \mu \mathrm{m}$ (one measured specimen). Length including any processes $=102 \mu \mathrm{m}$ (one measured specimen). Width including any processes $=97 \mu \mathrm{m}$ (one measured specimen).

Distribution:

$\begin{array}{lll}\text { Age/Stage } & \text { Location } & \text { Sample } \\ \text { Porangan-Bortonian } & \text { Hampden Beach Section, Oamaru-Dunedin, New Zealand } & \text { J42/f485 (L23120) }\end{array}$

Remarks: A form which differs from Turbiosphaera filosa and T. sagena in possessing relatively long, thin, processes, like some species of Cordosphaeridium, but retaining the "shelf-like" cingular process cross-sections characteristic of Turbiosphaera.

Genus Disphaerogena O. Wetzel 1933b emend. Sarjeant 1985b

\author{
1933b Disphaerogena O. Wetzel, p. 51 \\ 1976 Cyclapophysis Benson, p. 182 \\ 1978 Cyclapophysis Benson 1976; Stover \& Evitt, p. 150-151 \\ 1981 Plethysyrinx Sarjeant, p. 106
}

Type Species: Disphaerogena carposphaeropsis O. Wetzel 1933b, p. 51, pl. 4, fig. 34 [Late Cretaceous]

Original Description: Shell with irregular outer trelliswork round the central sphere (translation from O. Wetzel 1933b, p. 51, by Norris \& Sarjeant 1965, p. 26).

Emended Description of Sarjeant 1985b: Proximochorate to chorate, skolochorate cysts, of spheroidal to ovoidal or subpolygonal ambitus. Distinct apical and antapical processes are present, of variable absolute and relative length; these are surrounded by fibrous processes. The precingular and postcingular processes bend towards the cingulum, their tips linked by short trabeculae or fusing to form an equatorial tunnel round the cyst, though this may be interrupted at the sulcus. Paratabulation 4', 6", ?0c, 6-?7"', ?1p, 1"'.. Archeopyle single-plate precingular, type P, formed by loss of paraplate 3" (Sarjeant 1985b, p. 141).

Remarks: Effectively emended by Sarjeant 1985b, p. 140-141, in which Cyclapophysis is considered a junior synonym. 
Derivation of Name: Named after the micropaleontologist and occasional field-mate, who supplied numerous samples and foraminifera age controls for the present study, Hugh Morgans.

Holotype: Sample J42/f486, slide L23121/SM015; ?Hampden Formation, Hampden Beach Section (PoranganBortonian); PI. 48, figs. 1-6

Description: Cysts of intermediate size, chorate, subspherical to slightly prolate, epicyst considerably shorter than the hypocyst, lacking horns. Surface ornament present, comprising non-tabular, scattered small granules. Processes arising from precingular and postcingular plates generally more or less tubular, hollow, and open, but very variable, and connected by distal trabeculae. The cingular series is represented by shorter, flat or spinose processes, which are not connected distally, arising from the upper margin only. The antapical plate supports a large tubular process, apparently hollow and open though constricted distally, which is not joined by trabeculae. A thinner, less regular process arises from the ?posterior intercalary plate. Tabulation appears to be completely represented by the processes, gonyaulacacean, inferred formula 4', 6", 6c, 6"', 1p, 1"', xs; archeopyle precingular, type $\mathrm{P}\left(3^{\prime \prime}\right)$.

Size Range: Length excluding any processes $=60(64) 68 \mu \mathrm{m}$ (3 measurements). Width excluding any processes $=42$ (53) $63 \mu \mathrm{m}$ (3 measurements). Length including any processes $=103$ (105) $110 \mu \mathrm{m}$ (3 measurements). Width including any processes $=85$ (94) $99 \mu \mathrm{m}$ (3 measurements).

Distribution:

$\begin{array}{lll}\text { Age/Stage } & \text { Location } & \text { Sample } \\ \text { Porangan-Bortonian } & \text { Hampden Beach Section, Oamaru-Dunedin, New Zealand } & \text { J42/f486 (L23121) } \\ \text { Porangan-Bortonian } & \text { Hampden Beach Section, Oamaru-Dunedin, New Zealand } & \text { J42/f485 (L23120) } \\ \text { Porangan } & \text { Hampden Beach Section, Oamaru-Dunedin, New Zealand } & \text { J42/f300 (L23130) }\end{array}$

Comparison: Disphaerogena morgansii differs D. carposphaeropsis (a senior synomym of $D$. monmouthensis, according to Sarjeant 1985b) in lacking an apical horn and in possessing a much longer antapical process; and from $D$. irregularis and $D$. lemniscata in possessing cingular processes.

\section{Genus Hystrichokolpoma Klumpp 1953}

1953 Hystrichokolpoma Klumpp, p. 388

1978 Hystrichokolpoma Klumpp 1953 emended Williams \& Downie in Davey et al. 1966; Stover \& Evitt, p. 54-55

Type Species: Hystrichokolpoma cinctum Klumpp 1953, p. 389, pl. 17, figs. 3-4, 5a-d [Late Eocene]

Original Description: A genus possessing the characters of the family Hystrichosphaeridae and the following peculiarities: horn shaped appendices raised up from large plates between which are thin spines from a girdle and a particular field arrangement (translated from Klumpp 1953, p. 388).

Additionally, Stover \& Evitt (1978) provides the following translation of Klumpp's description: The shell is almost round, divided by a girdle-like zone into two separate halves. The lower [but note that the taxon is being described upside-down] consists of six plates with inflated processes, between which in the middle there is an opening. The upper part carries four humped plates adjacent to the girdle and one field with thin spines as on the girdle. A smaller plate with a hollow process, longer than the bags [i.e., bag-like inflated processes], forms the apical field (translated from Klumpp 1953, p. 388, in Stover \& Evitt 1978, p. 54).

Hystrichokolpoma cinctum Klumpp 1953

Pl. 49, figs. 1-3

1953

(1)

1956

1961 Hystrichokolpoma cinctum Klumpp 1953; Gerlach, p. 182-183, pl. 28, fig. 1

1963 Hystrichokolpoma cinctum Klumpp 1953; Brosius, p. 43, pl. 2, fig. 4

1966a Hystrichokolpoma eisenackii Williams \& Downie, p. 176-178, pl. 17, figs. 1-3, text-fig. 46 
Original Description: [Given for the genus] A genus possessing the characters of the family Hystrichosphaeridae and the following peculiarities: horn shaped appendices raised up from large plates between which are thin spines from a girdle and a particular field arrangement (translated from Klumpp 1953, p. 388).

Additionally, Stover \& Evitt (1978) provides the following translation of Klumpp's description: The shell is almost round, divided by a girdle-like zone into two separate halves. The lower [but note that the taxon is being described upside-down] consists of six plates with inflated processes, between which in the middle there is an opening. The upper part carries four humped plates adjacent to the girdle and one field with thin spines as on the girdle. A smaller plate with a hollow process, longer than the bags [i.e., bag-like inflated processes], forms the apical field (translated from Klumpp 1953, p. 388, in Stover \& Evitt 1978, p. 54).

Distribution: Infrequent.

\begin{tabular}{|c|c|c|c|}
\hline Age/Stage & Location & Sample & $\begin{array}{l}\text { Sample } \\
\text { Reference }\end{array}$ \\
\hline $\begin{array}{l}\text { middle Oligocene-middle } \\
\text { Miocene }\end{array}$ & north west Germany & $\operatorname{Pr} 1170 / 38$ & Gerlach 1961 \\
\hline ?Oligocene & Nelson Bore, Australia & $730 \mathrm{ft}$. & Cookson 1956 \\
\hline early Oligocene & Samland, East Prussia & & Eisenack 1954b \\
\hline early Whaingaroan & $\begin{array}{l}\text { Cape Foulwind Section, Westland, New } \\
\text { Zealand }\end{array}$ & K29/f184 (L11933) & \\
\hline Runangan & $\begin{array}{l}\text { Cape Foulwind Section, Westland, New } \\
\text { Zealand }\end{array}$ & K29/f101 (L11037) & \\
\hline Runangan & $\begin{array}{l}\text { Cape Foulwind Section, Westland, New } \\
\text { Zealand }\end{array}$ & K29/f125 (L11936) & \\
\hline late Eocene & Wohrden Bore, Holstein, Germany & & Klumpp 1953 \\
\hline Eocene & Nelson Bore, Australia & $992 \mathrm{ft}$. & Cookson 1956 \\
\hline
\end{tabular}

Hystrichokolpoma rigaudiae Deflandre \& Cookson 1955

PI. 49, figs. 4-9

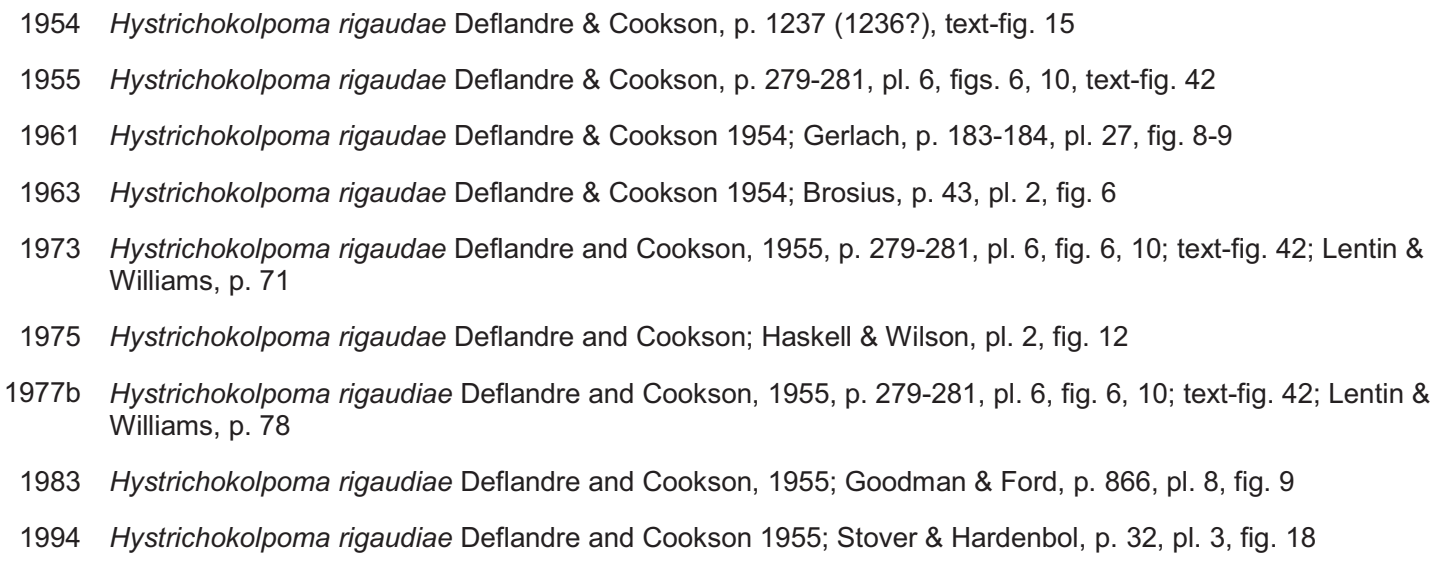

Original Description: Shell globular, more or less ellipsoidal, with approximately axial symmetry and processes of 2 kinds not communicating with the interior, disposed in parallel series starting from 1 pole considered as apical [in fact, though, the taxon is being described upside-down]. Antapical pole with a large aperture having a straight or angular margin. Bases of the large processes marked by lines forming quadrangular areas that give the impression of plates. Large processes always closed at their distal extremities, generally widened and provided with more or less numerous and sometimes relatively long horns. The large process situated at the apical pole is often longer than the others and is sometimes prolonged into a hollow horn.

The narrow tubular processes are slightly widened or divided at their extremities, which are either open or closed. Certain filiform processes seem to be solid throughout.

The narrow processes forming the equatorial series are about 10 in number, of which some may be paired. Between the equatorial series and the apex there is a circle of 4 large appendages and a space occupied by a small number (3-5) of narrow processes similar to those of the equatorial belt.

Below the equator there is a circle of 6 large processes, or in certain specimens 1 of these processes may, perhaps, be duplicated or replaced by several thinner appendages. Membrane of the shell smooth or indistinctly granular (Deflandre \& Cookson 1955, p. 280). 
Size Range: Length excluding any processes $=42$ (47) $55 \mu \mathrm{m}$ (4 measurements). Width excluding any processes $=30(41) 50 \mu \mathrm{m}$ (4 measurements). Length including any processes $=63$ (90) $124 \mu \mathrm{m}$ (5 measurements). Width including any processes $=48$ (68) $83 \mu \mathrm{m}$ (4 measurements).

\section{Distribution:}

\begin{tabular}{|c|c|c|c|}
\hline Age/Stage & Location & Sample & Sample Reference \\
\hline $\begin{array}{l}\text { middle Oligocene-middle } \\
\text { Miocene }\end{array}$ & north west Germany & $\operatorname{Pr} 1170 / 39$ & Gerlach 1961 \\
\hline $\begin{array}{l}\text { Runangan-early } \\
\text { Whaingaroan }\end{array}$ & Kakanui River, Oamaru-Dunedin, New Zealand & J42/f125 (L11625) & \\
\hline Kaiatan & $\begin{array}{l}\text { Puketeraki Core, Oamaru-Dunedin, New } \\
\text { Zealand }\end{array}$ & I43/f096 (L16344) & $\begin{array}{l}\text { Wilson \& McMillan } \\
1996\end{array}$ \\
\hline Bortonian & $\begin{array}{l}\text { Puketeraki Core, Oamaru-Dunedin, New } \\
\text { Zealand }\end{array}$ & I43/f090 (L16338) & $\begin{array}{l}\text { Wilson \& McMillan } \\
1996\end{array}$ \\
\hline Porangan & $\begin{array}{l}\text { Hampden Beach Section, Oamaru-Dunedin, } \\
\text { New Zealand }\end{array}$ & J42/f300 (L23130) & \\
\hline Heretaungan & $\begin{array}{l}\text { Hampden Beach Section, Oamaru-Dunedin, } \\
\text { New Zealand }\end{array}$ & J42/f484 (L23119) & \\
\hline
\end{tabular}

Remarks: The initial published appearance of the name, in Deflandre \& Cookson 1954, p. 1236 or 1237, did not validly establish the name, because the authors did not provide a description.

Deflandre \& Cookson's original spelling, rigaudae, without the second 'i', is an orthographic error (Voss et al. 1983, article 73.10). The error was overlooked in Lentin \& Williams 1973 (p. 71; -dae) but introduced in Lentin \& Williams 1977b (p. 78; -diae) in which the entry is annotated "O.C." indicating an orthographic change, though no further explanation is provided.

Hystrichokolpoma rigaudiae is apparently distinguishable from Hystrichokolpoma cinctum by the presence of secondary projections on the larger processes (Cookson 1956, p. 187-188).

\section{Hystrichokolpoma sp. 3}

PI. 49, figs. 10-12, PI. 50, figs. 1-3

?1965 Hystrichokolpoma rigaudae Deflandre et Cookson 1955; De Coninck, p. 27-28, pl. 7, figs. 7-16

Description: Cysts of intermediate size, proximate, not dorso-ventrally compressed, prolate, lacking horns; episome and hyposome more or less equal in length. Cyst wall two-layered; acavate. Archeopyle apical, type tA; operculum free. Surface ornament present, non-tabular, comprising granules; very low (about $1 \mu \mathrm{m}$ or lower); minute. Processes intratabular; non-fibrous, hollow, closed; with distal, secondary cusps distally; apparently formed by the coalescence of hollow spines, some of which may continue to project beyond the end of the processes. Tabulation clearly expressed, gonyaulacacean, inferred formula: ?4', 0a, 6", ?6c, 6"', ?1ps, 1"', Xs. Cingulum clearly expressed, indicated by a series of differentiated processes. Sulcus clearly expressed, a few differentiated, spine-like processes.

Size Range: Length excluding any processes $=31$ (34) $37 \mu \mathrm{m}$ ( 2 measurements). Width excluding any processes $=31$ (36) $40 \mu \mathrm{m}$ (2 measurements). Length including any processes $=55$ (56) $58 \mu \mathrm{m}$ (2 measurements). Width including any processes $=56$ (75) $94 \mu \mathrm{m}$ (2 measurements).

\section{Distribution:}

$\begin{array}{llll}\text { Age/Stage } & \text { Location } & \text { Sample } & \text { Sample Reference } \\ \text { Bortonian } & \text { Puketeraki Core, Oamaru-Dunedin, New Zealand } & \text { I43/f093 (L16341) } & \text { Wilson \& McMillan } 1996\end{array}$

Remarks: A few specimens of ?Hystrichokolpoma with digitate extensions to the pre- and postcingular processes closely resemble the most extreme cases of the Diphyes colligerum variant in which the pre- and postcingular processes are conjoined at their bases into intratabular process complexes. The decision (acknowledged as somewhat arbitrary) to assign the present forms to Hystrichokolpoma, is motivated by the amalgamation of thin processes into large hollow, intratabular, processes not just at their bases, but almost to their distal ends. 
The two forms may indeed intergrade. If substantiated, this observation suggests a connection between Diphyes and Hystrichokolpoma which cannot be readily explained by anagenesis or divergence of lineages, since it does not occur early in the stratigraphic range of either genus. An eventual explanation will have to consider possibilities such as whether Diphyes and Hystrichokolpoma are ecoforms of one another, or whether one or both genera are actually polyphyletic groups of species, and our current classification in fact disguises a true phylogenetic link between natural, but unrecognised, clades.

\title{
Hystrichokolpoma spinosum Wilson 1988
}

$$
\text { PI. 50, figs. 4-12, PI. 51, figs. 1-3 }
$$

1988 Hystrichokolpoma spinosum Wilson, p. 22, pl. 10, figs. 7a-b, 8

Original Description: Cyst of intermediate size, bi-layered, with thin smooth endophragm and periphragm; both layers in close contact except at base of intratabular processes. Precingular and postcingular processes fairly short, conical to polygonal, hollow with closed tips and adorned with thin solid spines (length up to $11 \mu \mathrm{m}$ ) at the distal extremity. Antapical process relatively large, conical, and adorned with numerous short spinules (length 2$3 \mu \mathrm{m})$. Paracingular and parasulcal processes simple or bifurcate, relatively long and thin. Apical process relatively long and spiny. Paratabulation 1-4', 6", 6c, 5-6"', 1p, 1"'", 5-6s. Archeopyle with zig-zag margin and deep parasulcal notch. Paracingulum indicated by up to 12 single or bifurcate processes, interrupted by parasulcus on ventral surface (Wilson 1988, p. 22).

Size Range: Length excluding any processes $=39$ (43) $48 \mu \mathrm{m}$ (3 measurements). Width excluding any processes $=37$ (39) $41 \mu \mathrm{m}$ (3 measurements). Length including any processes $=50$ (59) $70 \mu \mathrm{m}$ (3 measurements). Width including any processes $=60(65) 71 \mu \mathrm{m}$ (3 measurements).

Distribution:

\begin{tabular}{llll} 
Age/Stage & Location & Sample & Sample Reference \\
\hline Porangan-Bortonian & Hampden Beach Section, Oamaru-Dunedin, New Zealand & J42/f486 (L23121) \\
Heretaungan & Hampden Beach Section, Oamaru-Dunedin, New Zealand & J42/f483 (L23118)
\end{tabular}

Remarks: The present forms appear slightly less spinose than Wilson's (1988) type material, and may be closer to Hystrichokolpoma torquata Damassa 1984 , p. $825-826$, pl. 3, figs. 1-8, pl. 4, figs. 9-11, text-fig. 7, from the Eocene of northern California.

Genus Diphyes Cookson 1965a emend. Goodman \& Witmer 1985

\author{
1965a Diphyes Cookson, p. 85 \\ 1966b Diphyes Cookson 1965: 85 emend. Davey \& Williams, p. 95-96 \\ 1970b Lingulasphaera Drugg, p. 817 \\ 1978 Diphyes Cookson 1965a emended Davey \& Williams in Davey et al. 1966; Stover \& Evitt, p. 38-39 \\ 1985 Diphyes Cookson 1965 emend. Goodman \& Witmer, p. 76-77
}

Type Species: Diphyes colligerum (Deflandre \& Cookson 1955, p. 278-279, pl. 7, fig. 3) Cookson 1965a, p. 86-87 [Early Eocene]

Original Description: Shell composed of two parts, more or less unequal in size. The anterior part circular in outline with or without appendages. Archeopyle apical. The posterior part roughly bell-shaped to spherical with a small circular antapical opening and without typical appendages (Cookson 1965a, p.85).

Remarks: Many New Zealand examples of Diphyes species, especially Diphyes colligerum, exhibit proximally conjoined pre- and postcingular processes, clearly demonstrating a tabulation (though the exact formula may be obscure) and strongly suggestive of a close affinity with Hystrichokolpoma (notably Hystrichokolpoma sp. 3).

\section{Diphyes colligerum (Deflandre \& Cookson 1955) Cookson 1965a}

$$
\text { PI. 51, figs. 4-9 }
$$

\footnotetext{
1955 Hystrichosphaeridium colligerum Deflandre \& Cookson, p. 278-279, pl. 7, fig. 3

1965a Diphyes colligerum (Deflandre \& Cookson 1955, p. 278-279, pl. 7, fig. 3) Cookson, p. 86-87

1970b Lingulasphaera spinula Drugg, p. 817-818, figs. 10G, 11D-E, 12A-B
} 
1982c Diphyes cf. colligerum (Deflandre \& Cookson); Wilson, p. 4, pl. 2, figs. 1-3

1984b Diphyes colligerum (Deflandre and Cookson, 1955) Cookson, 1965; Helenes, p. 94, 104, pl. 3, fig. 16

Original Description: Shell globular, almost spherical; processes numerous, tubular, straight or slightly flexuous, with a conical base and a closed capitate or slightly furcate apex. At 1 pole of the shell there is a large, hollow, cylindro-conical outgrowth closed by a rounded conical apex. This outgrowth, like the small processes, does not communicate with the interior of the shell. It is frequently ornamented distally with a circle of short, blunt, hollow, conical knobs. Membrane of shell finely granular (Deflandre \& Cookson 1955, p. 278).

Emended Description of Goodman \& Witmer 1985: Skolochorate cysts with subspheroidal body bearing numerous nontabular or intratabular processes of nearly uniform size and a single large antapical process. Paratabulation gonyaulacacean; indicated by archeopyle, shape of the antapical process base, and rarely by the tendency of adjacent process bases to fuse into clusters apparently within the limits of individual paraplates. Archeopyle variable: Type (4A), (4A)P, 2P or P (Goodman \& Witmer 1985, p. 76).

Size Range: Length excluding any processes $=25$ (31) $35 \mu \mathrm{m}$ (4 measurements). Width excluding any processes $=30$ (36) $40 \mu \mathrm{m}$ (4 measurements). Length including any processes $=38$ (55) $64 \mu \mathrm{m}$ (11 measurements). Width including any processes $=40$ (62) $73 \mu \mathrm{m}$ (7 measurements).

Distribution:

\begin{tabular}{|c|c|c|c|}
\hline Age/Stage & Location & Sample & Sample Reference \\
\hline Bortonian & $\begin{array}{l}\text { Hampden Beach Section, Oamaru-Dunedin, New } \\
\text { Zealand }\end{array}$ & J42/f487 (L23122) & \\
\hline Bortonian & Puketeraki Core, Oamaru-Dunedin, New Zealand & l43/f093 (L16341) & $\begin{array}{l}\text { Wilson \& McMillan } \\
1996\end{array}$ \\
\hline Bortonian & Puketeraki Core, Oamaru-Dunedin, New Zealand & l43/f089 (L16337) & $\begin{array}{l}\text { Wilson \& McMillan } \\
1996\end{array}$ \\
\hline $\begin{array}{l}\text { Porangan- } \\
\text { Bortonian }\end{array}$ & $\begin{array}{l}\text { Hampden Beach Section, Oamaru-Dunedin, New } \\
\text { Zealand }\end{array}$ & J42/f302 (L23132) & \\
\hline Heretaungan & $\begin{array}{l}\text { Hampden Beach Section, Oamaru-Dunedin, New } \\
\text { Zealand }\end{array}$ & J42/f483 (L23118) & \\
\hline
\end{tabular}

\section{Diphyes aff. colligerum}

\section{PI. 51, figs. 10-12, PI. 52, figs. 1-9}

Description: Cysts of intermediate size, chorate, not dorso-ventrally compressed, more or less spherical, lacking horns. Cyst wall two-layered; acavate. Archeopyle apical, type tA; operculum free. Surface ornament lacking. Processes intratabular; non-fibrous, unbranched, hollow, closed; variably coalescent into intratabular groups proximally; the antapex carries a differentiated, large, variably inflated process; often with secondary cusps; and which may have a constricted distal opening. Hyposome sexiform; torsion dextral.

Size Range: Length excluding any processes = 39 (46) $52 \mu \mathrm{m}$ (2 measurements). Width excluding any processes $=38$ (39) $40 \mu \mathrm{m}$ (2 measurements). Length including any processes $=52$ (57) $62 \mu \mathrm{m}$ (2 measurements). Width including any processes $=58$ (67) $75 \mu \mathrm{m}$ (3 measurements).

Distribution: Frequent.

$\begin{array}{llll}\text { Age/Stage } & \text { Location } & \text { Sample } & \text { Sample Reference } \\ \text { Bortonian } & \text { Puketeraki Core, Oamaru-Dunedin, New Zealand } & \text { I43/f093 (L16341) } & \text { Wilson \& McMillan 1996 } \\ \text { Bortonian } & \text { Puketeraki Core, Oamaru-Dunedin, New Zealand } & \text { I43/f090 (L16338) } & \text { Wilson \& McMillan 1996 }\end{array}$

Remarks: Distinguished from D. colligerum s.s. by having pre- and postcingular processes which are proximally conjoined into process complexes. In extreme cases, this taxon more closely resembles Hystrichokolpoma than Diphyes, particularly Hystrichokolpoma sp. 3.

Diphyes ficusoides Islam 1983b 
Original Description: Cyst subspherical, skolochorate and biphragmal; phragma adpressed; periphragm chagrinate or reticulate; many nontabular tubular processes tapering from broad circular bases to narrow necks before ending in distal aculeation or wider rims, proximally closed, distally open but rarely a few processes closed, a few neighbouring pairs sometimes proximally joined; antapical process inflated, distinctively broad with biconvex ambitus in all lateral views with figlike appearance. Antapical process rises from a circular base, proximally closed, distally open but constricted with maximum width at base or mid-length; archeopyle apical type (tA) (Islam 1983, p. 338).

Size Range: Length excluding any processes $=38 \mu \mathrm{m}$ (one measured specimen). Width excluding any processes $=43 \mu \mathrm{m}$ (one measured specimen). Length including any processes $=69 \mu \mathrm{m}$ (one measured specimen). Width including any processes $=75 \mu \mathrm{m}$ (one measured specimen).

Distribution: Rare; reported from only a single location in New Zealand.

\begin{tabular}{llll}
\hline Age/Stage & Location & Sample & Sample Reference \\
Kaiatan-Runangan & Jacksons Paddock, Oamaru-Dunedin, New Zealand & J41/f8914 (L04979)
\end{tabular}

Diphyes brevispinum Bujak 1994

PI. 53, figs. 1-3

1994 Diphyes brevispinum Bujak, p. 121-123, pl. 2, figs. 4-6

Original Description: Cyst subspherical, skolochorate and biphragmal, endophragm and periphragm adpressed except beneath the processes. Periphragm smooth to chagrinate, forming numerous nontabular processes. Processes other than the antapical process less than $5 \mu \mathrm{m}$ in length, tubular, tapering from broader circular bases to narrow, open or closed terminations. Antapical process large, inflated, ovoidal to subspherical, with a closed circular base, and a constricted distal opening. Archeopyle apical; operculum tetraplacoid, contiguous (Bujak 1994, p. 123).

Size Range: Length excluding any processes $=40 \mu \mathrm{m}$ (one measured specimen). Width excluding any processes $=43 \mu \mathrm{m}$ (one measured specimen). Length including any processes $=60 \mu \mathrm{m}$ (one measured specimen). Width including any processes $=55 \mu \mathrm{m}$ (one measured specimen).

Distribution: This taxon is known from a single specimen in the present study.

$\begin{array}{llll}\text { Age/Stage } & \text { Location } & \text { Sample } & \text { Sample Reference } \\ \text { Kaiatan } & \text { Puketeraki Core, Oamaru-Dunedin, New Zealand } & \text { I43/f096 (L16344) } & \text { Wilson \& McMillan 1996 }\end{array}$

Remarks: The pre- and postcingular processes are at the long and of the published range $(\sim 5 \mu \mathrm{m})$ but it is otherwise apparently identical to Bujak's (1994) type material. It is, however, considerably younger: Kaiatan (early Priabonian) rather than Ypresian.

\title{
Genus Lingulodinium Wall 1967a
}

\author{
1967a Lingulodinium Wall, p. 109
}

Type Species: Lingulodinium machaerophorum (Deflandre \& Cookson 1955, p. 274, pl. 9, figs. 4, 8) Wall 1967, p. 109 [Miocene]

Original Description: Spherical to ovoid dinoflagellate cysts which, after dehiscence, possess a large, compound epithecal archeopyle representing the loss of either four or five precingular plate-areas. The remainder of the epitheca forms an elongate angular projection or lingula; this corresponds to several (apical, intercalary, and one precingular) plate-areas. The test wall is micro-granular to microreticulate and ornamented with numerous intratabular spines (Wall 1967, p. 109).

Remarks: The genus was subsequently emended by Wall \& Dale 1973, p. 24, to accommodate the observation that Lingulodinium species exhibit archeopyle types ranging from $\mathrm{P}$ to $5 \mathrm{P}$ and sometimes, though more rarely, incorporating the apical plates as well. This recommendation appears to have been widely adopted and is also used herein.

What is less clear, however, is their suggestion that the archeopyle sometimes includes intercalary plates, or that the genus even possesses intercalary plates. As noted in Stover \& Evitt 1978 (p. 172) for example, "the presence of anterior intercalary paraplates on the epicyst of Lingulodinium has not been documented. We have not, therefore, included this type of archeopyle in our analysis of the genus." Small plates occupying a dorsal "intercalary" position are known to occur in some gonyaulacaceans, however, and a large "supernumary" climactal plate possessed by Lingulodinium "may be homologous with one of the small intercalary plates, $\mathrm{Ci}$, of 
Mesozoic genera" although there is "no obvious stratigraphic connection" between them (Fensome et al. 1993b, p. 85).

Lingulodinium ?machaerophorum (Deflandre \& Cookson 1955) Wall 1967

$$
\text { PI. 53, figs. 4-9 }
$$

1955 Hystrichosphaeridium machaerophorum Deflandre \& Cookson 1955, p. 274, pl. 9, figs. 4, 8

1967a Lingulodinium machaerophorum (Deflandre and Cookson 1955) Wall, p.109

Description: Cysts of intermediate size, chorate, not dorso-ventrally compressed, more or less spherical, lacking horns. Cyst wall two-layered; acavate. Archeopyle precingular, type ?A+3P; operculum free. Surface ornament lacking. Processes non-tabular; non-fibrous, unbranched, apparently hollow, closed; somewhat sinuous. Tabulation not expressed.

Size Range: Length excluding any processes $=47 \mu \mathrm{m}$ (one measured specimen). Width excluding any processes $=48 \mu \mathrm{m}$ (one measured specimen). Length including any processes $=78 \mu \mathrm{m}$ (one measured specimen). Width including any processes $=73 \mu \mathrm{m}$ (one measured specimen).

\title{
Distribution:
}

$\begin{array}{llll}\text { Age/Stage } & \text { Location } & \text { Sample } & \text { Sample Reference } \\ \text { Bortonian } & \text { Puketeraki Core, Oamaru-Dunedin, New Zealand } & \text { I43/f093 (L16341) } & \text { Wilson \& McMillan } 1996\end{array}$

Remarks: May be conspecific with Lingulodinium machaerophorum. Although considerably older than the type, L. machaerophorum is known to extend back to the Eocene (Rob Fensome, pers. comm.)

Genus Operculodinium Wall 1967a emend. Matsuoka et al. 1997

\author{
1967a Operculodinium Wall, p. 110-111 \\ 1978 Operculodinium Wall 1967; Stover \& Evitt, p. 178-179 \\ 1997 Operculodinium Wall 1967 emend. Matsuoka et al., p. 22
}

Type Species: Operculodinium centrocarpum (Deflandre \& Cookson 1955, p. 272-273, pl. 8, figs. 3-4) Wall 1967, p. 111 [Miocene]

Original Description: Spherical to ovoid cysts possessing simple, dorsal precingular archeopyles (reflecting plate $3 ")$, and lacking polar structures. A weakly defined girdle and ventral sulcal depression often present. Cell wall double, the inner thin and outer thicker and microgranular or microreticulate. Elements of ornamentation variable, from small cones to long spines, but all with circular, minutely striated bases and often capitate extremities. Spine arrangement intratabular with several spines to each plate area, commonly arranged immediately within the reflected plate-area margins (Wall 1967, p. 110).

Emended Description of Matsuoka et al. 1997: Spherical to ovoid cysts possessing a 3" precingular archeopyle and lacking polar structures. A weakly defined girdle and ventral sulcal depression may or may not be present. Cell wall composed of a thin smooth endophragm and a thicker microgranular or microreticulate periphragm. Positive sculpturing varies from small cones to long processes with circular bases. Process bases may be striate or microreticulate. A variety of distal process shaft terminations may be present, including capitate, recurved, truncated or patulate, though usually one type per species. Processes distribution [sic] nontabular and/or intratabular, with several processes per paraplate area (Matsuoka et al. 1997, p. 22).

Remarks: The emended generic diagnosis provided by Matsuoka et al. (1997, p. 22), following their restudy of the genoholotype, expands the wording of the original, but adds little to either broaden or restrict the circumscription. The inclusion of non-tabular (as opposed to only intratabular) processes is moot: the plate boundaries are unknown, so there is no practical means to distinguish between the two kinds. The emendation adds "recurved, truncated or patulate" to the original capitate, as recognised process endings.

A range chart for species of Operculodinium is provided in Appendix 2, chart 5.

Operculodinium ?centrocarpum (Deflandre \& Cookson 1955) Wall 1967

$$
\text { PI. 53, figs. 10-12, PI. 54, figs. 1-3 }
$$


1961 Baltisphaeridium centrocarpum (Deflandre \& Cookson 1955, p. 272-273, pl. 8, figs. 3-4) Gerlach, p. 192-193

1965 Cordosphaeridium centrocarpum (Deflandre \& Cookson 1955, p. 272-273, pl. 8, figs. 3-4) De Coninck, p. 33

1966a Cordosphaeridium tiara (Klumpp 1953) centrocarpum (Deflandre \& Cookson 1955) Morgenroth, p. 26, pl. 5, fig. 12, pl. 6, fig. 1

1967a Operculodinium centrocarpum (Deflandre and Cookson 1955) Wall, p. 111, pl. 16, figs. 1-2, 5

1969 Cordosphaeridium microtriainum subsp. centrocarpum (Deflandre \& Cookson 1955, p. 272-273, pl. 8, figs. 3-4) De Coninck, p. 32

1978 Cleistosphaeridium centrocarpum (Deflandre \& Cookson 1955, p. 272-273, pl. 8, figs. 3-4) Jiabo, p. 61

1983 Operculodinium centrocarpum (Deflandre \& Cookson, 1955) Wall, 1967; Goodman \& Ford, p. 866, pl. 8, fig. 8

1997 Operculodinium centrocarpum (Deflandre \& Cookson) Wall 1967; Matsuoka et al., p. 22-23, pl. 1, figs. 1-6, pl. 2, figs. 1-9

2005 Operculodinium centrocarpum; Schiøler, pl. 3, fig. 3

Original Description: Shell globular, more or less ellipsoidal (probably by deformation), covered with numerous straight, slender processes placed irregularly or with a certain alignment. Processes solid, showing radiating fibrils at their point of insertion on the shell, which is clearly ornamented with a fine reticulum. The slightly widened apices of the processes are fringed with 10 or more small curved spines (this structure is only visible with a high-powered objective) (Deflandre \& Cookson 1955, p. 273).

Description of Study Material: Cysts of intermediate size, chorate, not dorso-ventrally compressed, more or less spherical, lacking horns. Cyst wall two-layered; acavate; thin, about $1 \mu \mathrm{m}$ in thickness. Archeopyle precingular, type P (3"); large. Surface ornament present, non-tabular, comprising spines. Capitate distally. Nature of spines short, sinuous, expanding proximally, length of spines 5-10 $\mu \mathrm{m}$. Cingulum lacking.

Size Range: Length excluding any processes $=35$ (43) $47 \mu \mathrm{m}$ (3 measurements). Width excluding any processes $=35$ (44) $50 \mu \mathrm{m}$ (3 measurements). Length including any processes $=54$ (57) $60 \mu \mathrm{m}$ (5 measurements). Width including any processes $=54(60) 63 \mu \mathrm{m}$ (3 measurements).

Distribution: Frequent. Noted by Goodman \& Ford (1983, p. 866) as having "little stratigraphic value."

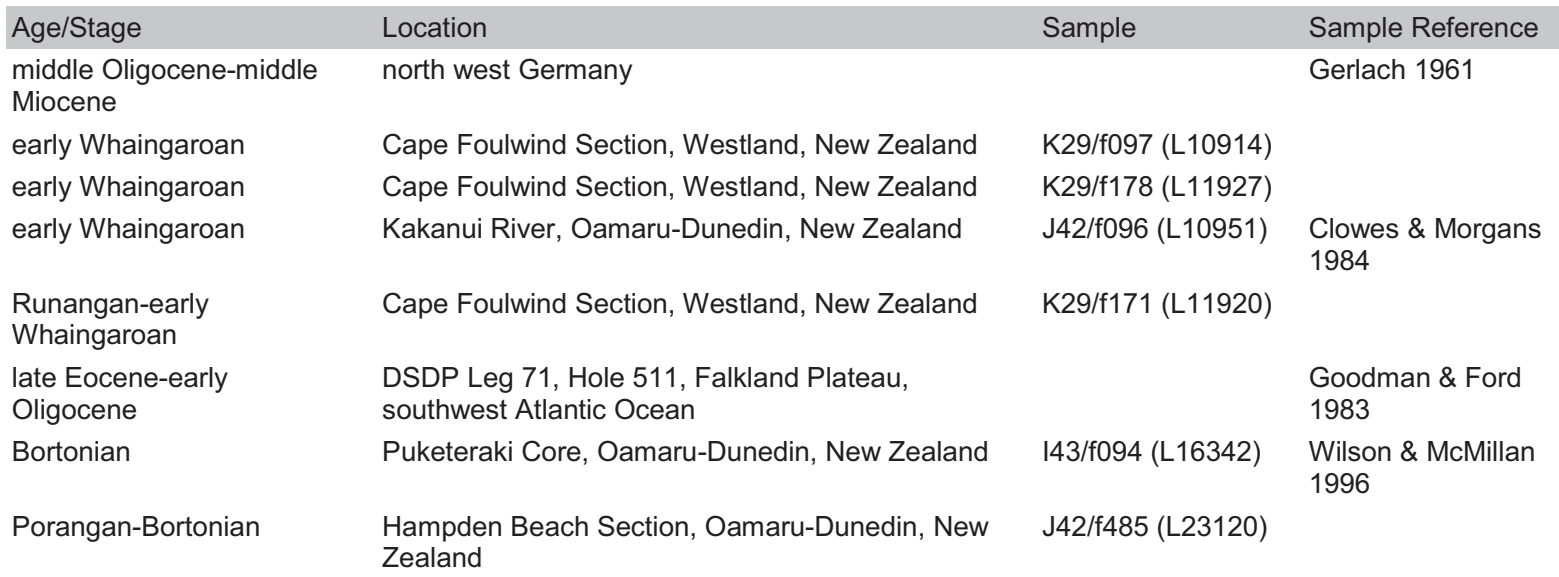

Remarks: The form encountered in this study quite closely resembles the type species of Operculodinium, $O$. centrocarpum, especially those specimens (e.g. PI. 54, figs. 1-3) with slightly longer processes.

Jux (1976) reports morphological variation in a Holocene population of $O$. centrocarpum ranging from proximate to chorate. Leaving aside the specific identity of Jux's Holocene material with Deflandre \& Cookson's (1955) Miocene type material, it is clear that real dinoflagellate populations exhibit considerable morphological variation, so it seems reasonable not to accord too much significance to the exact length of the processes alone.

Some Quaternary forms attributed to Operculodinium centrocarpum by Wall 1967b are further analysed in Matsuoka et al. 1997, which concludes they are a different species owing, principally, to a consistently smaller central body diameter and process lengths. [The "cyst diameter" referred to frequently in Matsuoka et al. 1997 is the diameter of the central body, excluding processes, though this important point is not made explicit.] The ratio between the dimensions they report, however, is very close to constant $(0.23$ versus 0.25$)$ so it is evident that the dimensions of central body and processes scale in proportion to the overall size. If preservational artefacts (e.g. greater compression, which would tend to squash a spherical object into a flattened disc with a greater diameter) cannot be ruled out, then the case for separating these forms reduces to process length, again, and appears very weak indeed.

The extant dinoflagellate, Protoceratium reticulatum (Claparéde \& Lachmann) Bütschli, forms cysts which apparently are virtually indistinguishable from Operculodinium centrocarpum. 
Operculodinium schioleri Clowes n. sp.

PI. 54, figs. 4-12

?2005

Operculodinium piaseckii; Schiøler, pl. 2, fig. 7

Derivation of Name: Named after the dinoflagellate palynologist, Poul Schiøler.

Holotype: Sample K29/f097, slide L10914/SM031; Port Elizabeth Member, Cape Foulwind Section (early Whaingaroan); PI. 54, figs. 4-9

Description: Cysts of intermediate size, chorate, not dorso-ventrally compressed, subspherical, lacking horns; episome and hyposome more or less equal in length. Cyst wall two-layered; acavate; quite thin, about $1 \mu \mathrm{m}$ in thickness. Archeopyle precingular, type P (3"). Processes ?gonal, spinose; ?fibrous, unbranched, apparently solid, generally less than about $12-13 \mu \mathrm{m}$; broadening proximally, capitate distally. Cingulum weakly expressed, indicated by the alignment of processes.

Size Range: Length excluding any processes $=60$ (88) $108 \mu \mathrm{m}$ (3 measurements). Width excluding any processes $=102(106) 110 \mu \mathrm{m}$ (2 measurements). Length including any processes $=80(112) 133 \mu \mathrm{m}(5$ measurements). Width including any processes $=110$ (118) $127 \mu \mathrm{m}$ (2 measurements).

\section{Distribution:}

\begin{tabular}{|c|c|c|c|}
\hline Age/Stage & Location & Sample & Sample Reference \\
\hline $\begin{array}{l}\text { early } \\
\text { Whaingaroan }\end{array}$ & Cape Foulwind Section, Westland, New Zealand & K29/f097 (L10914) & \\
\hline $\begin{array}{l}\text { early } \\
\text { Whaingaroan }\end{array}$ & Cape Foulwind Section, Westland, New Zealand & K29/f116 (L11052) & Clowes \& Wilson 2006 \\
\hline $\begin{array}{l}\text { early } \\
\text { Whaingaroan }\end{array}$ & Cape Foulwind Section, Westland, New Zealand & K29/f180 (L11929) & \\
\hline $\begin{array}{l}\text { early } \\
\text { Whaingaroan }\end{array}$ & Cape Foulwind Section, Westland, New Zealand & K29/f114 (L11050) & \\
\hline $\begin{array}{l}\text { early } \\
\text { Whaingaroan }\end{array}$ & Cape Foulwind Section, Westland, New Zealand & K29/f173 (L11922) & \\
\hline ?Kaiatan & $\begin{array}{l}\text { Hampden Beach Section, Oamaru-Dunedin, New } \\
\text { Zealand }\end{array}$ & J42/f062 (L09219) & Wilson 1985 \\
\hline Kaiatan & Puketeraki Core, Oamaru-Dunedin, New Zealand & 143/f096 (L16344) & $\begin{array}{l}\text { Wilson \& McMillan } \\
1996\end{array}$ \\
\hline
\end{tabular}

Comparison: This form bears a slight resemblance to Operculodinium piaseckii Strauss and Lund 1992 but is distinguished by being markedly larger and in possessing fewer processes, which apparent to be confined to the gonal areas.

Operculodinium sp. 10

\section{Pl. 55, figs. 1-3}

Description: Cysts large, chorate, not dorso-ventrally compressed, subspherical, lacking horns; episome somewhat shorter than hyposome. Cyst wall two-layered; acavate; quite thin, about $1 \mu \mathrm{m}$ in thickness. Archeopyle precingular, type P (3"); large. Processes ?gonal, spinose, somewhat sinuous; ?fibrous, unbranched, apparently solid, 20-30 $\mu \mathrm{m}$; broadening proximally, capitate distally. Cingulum weakly expressed to moderately expressed, indicated by the alignment of processes.

Size Range: Length excluding any processes $=92 \mu \mathrm{m}$ (one measured specimen). Width excluding any processes $=87 \mu \mathrm{m}$ (one measured specimen). Length including any processes $=117(121) 125 \mu \mathrm{m}(2$ measurements). Width including any processes $=122 \mu \mathrm{m}$ (one measured specimen).

\section{Distribution:}

\begin{tabular}{|c|c|c|c|}
\hline Age/Stage & Location & Sample & Sample Reference \\
\hline early Whaingaroan & Cape Foulwind Section, Westland, New Zealand & K29/f097 (L10914) & \\
\hline Bortonian & Hampden Beach Section, Oamaru-Dunedin, New Zealand & J42/f061 (L09218) & Wilson 1985 \\
\hline
\end{tabular}

Remarks: Operculodinium sp. 10 differs from the type species, O. centrocarpum, in possessing fewer, relatively longer, spines, which appear to occupy (or at least cluster towards) the gonal positions. It differs from the form described here as $O$. vulgare in possessing relatively shorter spines, though it is possible that the two forms represent members of the same population. The stratigraphic range of $O$. sp. 10 lies within that of $O$. vulgare. 
Operculodinium vulgare Clowes n. sp.

Pl. 55, figs. 4-9

?1982a Operculodinium sp.; Wilson, pl. 1, fig. 7

Derivation of Name: Latin, vulgaris, usual, commonplace, everyday; with reference to the taxon's ubiquity.

Holotype: Sample 143/f093, slide L16341/SM066; Burnside Formation, Puketeraki Core (Bortonian); PI. 55, figs. 4-6

Description: Cysts of intermediate size, chorate, not dorso-ventrally compressed, more or less spherical, lacking horns; episome and hyposome more or less equal in length. Cyst wall two-layered; acavate; quite thin, about $1 \mu \mathrm{m}$ in thickness. Archeopyle precingular, type P (3"); large; operculum free. Processes ?gonal, spinose, somewhat sinuous; non-fibrous, unbranched, apparently solid, 30-40 $\mu \mathrm{m}$; broadening proximally, capitate distally. Cingulum weakly expressed, indicated by the alignment of processes.

Size Range: Length excluding any processes $=52(71) 95 \mu \mathrm{m}$ (5 measurements). Width excluding any processes $=50$ (61) $87 \mu \mathrm{m}$ (4 measurements). Length including any processes $=40$ (93) $170 \mu \mathrm{m}$ (25 measurements). Width including any processes $=80$ (98) $135 \mu \mathrm{m}$ (9 measurements).

Distribution: Common. Widely found throughout a lengthy time range, from Bortonian (Bartonian) to early Whaingaroan (early Rupelian).

\begin{tabular}{|c|c|c|c|}
\hline Age/Stage & Location & Sample & Sample Reference \\
\hline early Whaingaroan & Cape Foulwind Section, Westland, New Zealand & K29/f097 (L10914) & \\
\hline early Whaingaroan & Cape Foulwind Section, Westland, New Zealand & K29/f116 (L11052) & $\begin{array}{l}\text { Clowes \& Wilson } \\
2006\end{array}$ \\
\hline early Whaingaroan & Cape Foulwind Section, Westland, New Zealand & K29/f184 (L11933) & \\
\hline early Whaingaroan & Kakanui River, Oamaru-Dunedin, New Zealand & J42/f096 (L10951) & $\begin{array}{l}\text { Clowes \& Morgans } \\
1984\end{array}$ \\
\hline Runangan & Cape Foulwind Section, Westland, New Zealand & K29/f261 (L13543) & \\
\hline Runangan & Cape Foulwind Section, Westland, New Zealand & K29/f102 (L11038) & \\
\hline Runangan & Cape Foulwind Section, Westland, New Zealand & K29/f125 (L11936) & \\
\hline Runangan & Cape Foulwind Section, Westland, New Zealand & K29/f262 (L13546) & \\
\hline $\begin{array}{l}\text { late Eocene-early } \\
\text { Oligocene }\end{array}$ & Chalky Island, Fiordland, New Zealand & SM1319 & Wilson $1982 a$ \\
\hline ?Kaiatan & $\begin{array}{l}\text { Hampden Beach Section, Oamaru-Dunedin, New } \\
\text { Zealand }\end{array}$ & J42/f062 (L09219) & Wilson 1985 \\
\hline Bortonian & $\begin{array}{l}\text { Hampden Beach Section, Oamaru-Dunedin, New } \\
\text { Zealand }\end{array}$ & J42/f489 (L23124) & \\
\hline Bortonian & Puketeraki Core, Oamaru-Dunedin, New Zealand & I43/f094 (L16342) & $\begin{array}{l}\text { Wilson \& McMillan } \\
1996\end{array}$ \\
\hline Bortonian & Puketeraki Core, Oamaru-Dunedin, New Zealand & I43/f089 (L16337) & $\begin{array}{l}\text { Wilson \& McMillan } \\
1996\end{array}$ \\
\hline
\end{tabular}

Comparison: Operculodinium vulgare somewhat resembles ?Hystrichosphaeridium paucifurcatum Cookson \& Eisenack 1961b in overall appearance. An implication of the generic placement of ?H. paucifurcatum is that it has an apical archeopyle (clearly different from the precingular archeopyle of $O$. vulgare) although the brief species description makes no specific mention of the archeopyle and the single illustration (Cookson \& Eisenack 1961b, pl. 2, fig. 15) shows a pale area near the apex which looks as if it might be a distorted precingular archeopyle. Pending some further work on the Australian material, I have elected to follow the recommendation in Stover \& Evitt 1978, p. 56, that the specific name H. paucifurcatum be restricted to the holotype.

Operculodinium vulgare differs from the type species, $O$. centrocarpum in possessing fewer, relatively longer, spines, which appear to occupy (or at least cluster towards) the gonal positions. It differs from the form informally listed here as $\mathrm{O}$. sp. 10 in possessing relatively longer spines.

Operculodinium ?janduchenei Head et al. 1989b

$$
\text { PI. 55, figs. 10-12, PI. 56, figs. 1-2 }
$$

\footnotetext{
?1977 Operculodinium sp. Jan du Chêne, p. 106, pl. 1, figs. 7-8

?1989b Operculodinium janduchenei Head et al., p. 459, pl. 4, figs. 7, 8, 12

?1993 Operculodinium janduchenei Head et al., 1989b Martin, p. 115, figs. 10A-F
} 
Original Description: [Diagnosis] Cysts small, proximochorate, with subspherical or broadly ellipsoidal body having a granulate wall surface. Processes are short conical and hollow, and may be distally closed or truncated and open. Distribution is apparently nontabular. Archeopyle precingular Type P (presumably Type P3). Operculum free. There is no other indication of paratabulation.

[Description] Wall surface varies from coarsely to faintly granulate, and some specimens may have short, solid, conical granules interspersed between processes, as described by Mudie (1987, p. 805). Processes are variable but most are open distally, although some specimens were observed with predominantly distally closed processes, and often specimens were found to possess a range of process morphologies. On the holotype, most processes are distally open, although some appear to be closed distally. Processes have a fairly regular distribution and appear to be nontabular. The archeopyle is presumably formed by loss of paraplate 3" (Head et al. 1989b, p. 459).

Description of Study Material: Cysts small, chorate, not dorso-ventrally compressed, more or less spherical, lacking horns; episome and hyposome more or less equal in length. Cyst wall two-layered; acavate. Archeopyle precingular, type P (3"); operculum free. Surface ornament present, non-tabular, comprising small clavae; densely covering the surface. Processes non-tabular, comprising short clavae; apparently solid, about $5 \mu \mathrm{m}$ long. Tabulation not expressed. Cingulum lacking to weakly expressed, indicated by the alignment of processes. Not expressed.

Size Range: Length excluding any processes $=44 \mu \mathrm{m}$ (one measured specimen). Width excluding any processes $=43 \mu \mathrm{m}$ (one measured specimen). Length including any processes $=48 \mu \mathrm{m}$ (one measured specimen). Width including any processes $=49 \mu \mathrm{m}$ (one measured specimen).

Distribution: Very rare in the present study.

\begin{tabular}{|c|c|c|c|}
\hline Age/Stage & Location & Sample & Sample Reference \\
\hline late Miocene & ODP Leg 105, Site 646, Labrador Sea & $\begin{array}{l}105-646 \mathrm{~B}-78 \mathrm{X}-\mathrm{CC} \\
1-3 \mathrm{~cm}\end{array}$ & Head et al. $1989 b$ \\
\hline Miocene & & & $\begin{array}{l}\text { Jan du Chêne } \\
1977\end{array}$ \\
\hline late Eocene & $\begin{array}{l}\text { Mallee Cliffs bore } 36465,183-187 \text { m., central Murray Basin, } \\
\text { New South Wales, Australia }\end{array}$ & Slide 2806-1 & Martin 1993 \\
\hline late Eocene & $\begin{array}{l}\text { Mallee Cliffs bore } 36465,192-197 \text { m., central Murray Basin, } \\
\text { New South Wales, Australia }\end{array}$ & Slide $2828-3$ & Martin 1993 \\
\hline late Eocene & $\begin{array}{l}\text { Mallee Cliffs bore 36465, 201-206 m., central Murray Basin, } \\
\text { New South Wales, Australia }\end{array}$ & Slide $2829-1$ & Martin 1993 \\
\hline $\begin{array}{l}\text { Porangan- } \\
\text { Bortonian }\end{array}$ & Hampden Beach Section, Oamaru-Dunedin, New Zealand & J42/f302 (L23132) & \\
\hline
\end{tabular}

Remarks: The identification is provisional because forms encountered in this study appear to possess granules which are slightly larger and more clavate than the type material. However, insufficient material has been recovered to give a reasonable indication of any variability within the population.

Operculodinium pulcher Clowes n. sp.

PI. 56, figs. 3-12

?1993 Operculodinium longispinigerum Matsuoka 1983; Martin, p. 115, figs. 10G-I

Derivation of Name: Latin, pulcher, beautiful, handsome; with reference to the delicate elegance of the processes.

Holotype: Sample 143/f093, slide L16341/SM042; Burnside Formation, Puketeraki Core (Bortonian); PI. 56, figs. 4-6

Description: Cysts of intermediate size, chorate, not dorso-ventrally compressed, more or less spherical, lacking horns. Cyst wall two-layered; acavate; quite thin, about $1 \mu \mathrm{m}$ in thickness. Archeopyle precingular, type P (3"); large. Processes non-tabular, spinose, straight; non-fibrous, unbranched, apparently solid, 10-15 $\mu \mathrm{m}$ in length; typically capitate distally; slender; process tips quite variable; from more or less acuminate to almost furcate. Cingulum not expressed.

Size Range: Length excluding any processes $=28$ (29) $30 \mu \mathrm{m}$ (6 measurements). Width excluding any processes $=28(29) 30 \mu \mathrm{m}$ (5 measurements). Length including any processes $=38$ (52) $58 \mu \mathrm{m}$ (9 measurements). Width including any processes $=45$ (57) $75 \mu \mathrm{m}$ (14 measurements).

Distribution: Locally common but encountered in only a few samples. 


\begin{tabular}{|c|c|c|c|}
\hline Age/Stage & Location & Sample & Sample Reference \\
\hline late Eocene & $\begin{array}{l}\text { Mallee Cliffs bore } 36465,183-187 \text { m., central Murray Basin, } \\
\text { New South Wales, Australia }\end{array}$ & Slide 2806-1 & Martin 1993 \\
\hline Bortonian & Puketeraki Core, Oamaru-Dunedin, New Zealand & l43/f093 (L16341) & $\begin{array}{l}\text { Wilson \& McMillan } \\
1996\end{array}$ \\
\hline Bortonian & Puketeraki Core, Oamaru-Dunedin, New Zealand & l43/f090 (L16338) & $\begin{array}{l}\text { Wilson \& McMillan } \\
1996\end{array}$ \\
\hline $\begin{array}{l}\text { Porangan- } \\
\text { Bortonian }\end{array}$ & Hampden Beach Section, Oamaru-Dunedin, New Zealand & J42/f302 (L23132) & \\
\hline
\end{tabular}

Comparison: Holistically, this taxon has a very similar appearance to Melitasphaeridium pseudorecurvatum (Morgenroth 1966a), but differs in possessing many more processes (approximately twice the number). Additionally, the processes of Melitasphaeridium are said to be hollow and open, whereas these do not seem to be so, although some specimens do appear to possess a minute sinus at the very base of the processes.

Remarks: The process tips exhibit quite a variety of development, from almost none (e.g. PI. 56, fig. 7) to very well-developed radial spinules (e.g. PI. 56, fig. 10). A specimen from the late Eocene of south-eastern Australia illustrated in Martin 1993 (fig. 10G-I) resembles the former (PI. 56, fig. 7).

\title{
Operculodinium sp. 5
}

\section{PI. 57, figs. 1-6}

Description: Cysts of intermediate size, chorate, not dorso-ventrally compressed, more or less spherical, lacking horns; episome and hyposome more or less equal in length. Cyst wall two-layered; acavate. Archeopyle precingular, type P (3"); large. Processes non-tabular, spinose, somewhat sinuous; non-fibrous, unbranched, apparently solid, 10-15 $\mu \mathrm{m}$ in length; capitate distally; slender. Cingulum not expressed. Sulcus not expressed.

Size Range: Length excluding any processes $=30$ (32) $34 \mu \mathrm{m}$ (2 measurements). Width excluding any processes $=30$ (30) $31 \mu \mathrm{m}$ (2 measurements). Length including any processes $=51$ (53) $55 \mu \mathrm{m}$ (2 measurements). Width including any processes $=45$ (48) $52 \mu \mathrm{m}$ (2 measurements).

Distribution: Rare.

$\begin{array}{llll}\text { Age/Stage } & \text { Location } & \text { Sample } & \text { Sample Reference } \\ \text { Porangan } & \text { Te Uri Stream, Hawkes Bay, New Zealand } & \text { U24/f419 (L23127) }\end{array}$

\section{Operculodinium sp. 7}

\author{
PI. 57, figs. 7-12
}

Description: Cysts of intermediate size, chorate, not dorso-ventrally compressed, prolate, lacking horns; episome and hyposome more or less equal in length. Cyst wall two-layered; acavate. Archeopyle precingular, type P (3"); operculum free. Surface ornament present, non-tabular, comprising a reticulum with angular lacunae. Processes ?gonal, spinose, straight or gently curved; non-fibrous, unbranched, apparently solid, highly variable, from about 5 to $15 \mu \mathrm{m}$ in length; acuminate distally. Tabulation not clearly expressed. Cingulum weakly expressed, indicated by a differentiated series of generally longer processes. Sulcus weakly expressed, alignment of processes; more or less vertical.

Size Range: Length excluding any processes $=33 \mu \mathrm{m}$ (one measured specimen). Width excluding any processes $=29 \mu \mathrm{m}$ (one measured specimen). Length including any processes $=44 \mu \mathrm{m}$ (one measured specimen). Width including any processes $=48 \mu \mathrm{m}$ (one measured specimen).

Distribution: Rare.

\begin{tabular}{llll}
\hline Age/Stage & Location & Sample & Sample Reference \\
Bortonian & Puketeraki Core, Oamaru-Dunedin, New Zealand & I43/f092 (L16340) & Wilson \& McMillan 1996
\end{tabular}

Operculodinium ?xanthium (Benedek 1972) Stover \& Evitt 1978

PI. 58, figs. 1-3

1972 Cordosphaeridium xanthium Benedek, p. 27-28, pl. 9, fig. 8, text-fig. 9

1978 Operculodinium xanthium (Benedek 1972) Stover \& Evitt, p. 179 
Original Description: [No translation available] Eine Art der Gattung Operculodinium, deren Kapseloberfläche eine von derben Fasern aufgebaute netzargige Struktur aufweist, aus der zahlreiche kleine und zugespitzte Fortsätze entspringen (Benedek 1972, p. 27).

Description of Study Material: Cysts of intermediate size, chorate, not dorso-ventrally compressed, more or less spherical, lacking horns. Cyst wall two-layered; acavate; relatively robust, about $2 \mu \mathrm{m}$ in thickness. Archeopyle precingular, type P (3"). Surface ornament present, non-tabular, comprising a dense reticulum. Processes nontabular, comprising short spines, straight or gently curved; non-fibrous, unbranched, apparently solid, about $5 \mu \mathrm{m}$ long. Cingulum not expressed. Sulcus not expressed.

Size Range: Length excluding any processes $=45 \mu \mathrm{m}$ (one measured specimen). Width excluding any processes $=45 \mu \mathrm{m}$ (one measured specimen). Length including any processes $=47(60) 78 \mu \mathrm{m}(3$ measurements). Width including any processes $=54(68) 83 \mu \mathrm{m}$ (2 measurements).

\section{Distribution:}

$\begin{array}{llll}\text { Age/Stage } & \text { Location } & \text { Sample } & \text { Sample Reference } \\ \text { Kaiatan } & \text { Nine Mile Bluff, Westland, New Zealand } & \text { J31/f9186 (L08325) } & \\ \text { Bortonian } & \text { Puketeraki Core, Oamaru-Dunedin, New Zealand } & \text { I43/f093 (L16341) } & \text { Wilson \& McMillan 1996 } \\ \text { Bortonian } & \text { Puketeraki Core, Oamaru-Dunedin, New Zealand } & \text { I43/f089 (L16337) } & \text { Wilson \& McMillan 1996 } \\ \text { Heretaungan } & \text { Hampden Beach Section, Oamaru-Dunedin, New Zealand } & \text { J42/f039 (L09196) } & \text { Wilson 1985 }\end{array}$

Remarks: This species appears very similar to, and may be conspecific with, Operculodinium xanthium (Benedek 1972) Stover \& Evitt 1978. A SEM image appearing in Brinkhuis, Sengers, et al. 2003 (pl. 1, fig. 196) appears similar, also.

Operculodinium ?xanthium differs from the type species, $O$. centrocarpum in possessing relatively shorter spines. The spines appear stiffer and less sinuous than those of the form informally described here as 0 . sp. 3 , though it is possible that the two forms represent members of the same population.

\section{Operculodinium sp. 3}

\section{PI. 58, figs. 4-6}

Description: Cysts of intermediate size, chorate, not dorso-ventrally compressed, more or less spherical, lacking horns; episome and hyposome more or less equal in length. Cyst wall two-layered; acavate; relatively robust about $2 \mu \mathrm{m}$ in thickness. Archeopyle precingular, type P (3"); large. Processes non-tabular, comprising short spines, usually curved; unbranched, apparently solid, 5-10 $\mu$ in length. Cingulum lacking to weakly expressed.

Size Range: Length excluding any processes $=55 \mu \mathrm{m}$ (one measured specimen). Width excluding any processes $=55 \mu \mathrm{m}$ (one measured specimen). Length including any processes $=53(62) 70 \mu \mathrm{m}(2$ measurements). Width including any processes $=65 \mu \mathrm{m}$ (one measured specimen).

\section{Distribution:}

\begin{tabular}{|c|c|c|c|}
\hline Age/Stage & Location & Sample & Sample Reference \\
\hline $\begin{array}{l}\text { early } \\
\text { Whaingaroan }\end{array}$ & Kakanui River, Oamaru-Dunedin, New Zealand & J42/f096 (L10951) & $\begin{array}{l}\text { Clowes \& Morgans } \\
1984\end{array}$ \\
\hline Bortonian & $\begin{array}{l}\text { Hampden Beach Section, Oamaru-Dunedin, New } \\
\text { Zealand }\end{array}$ & J42/f042 (L09199) & Wilson 1985 \\
\hline Bortonian & Puketeraki Core, Oamaru-Dunedin, New Zealand & I43/f090 (L16338) & Wilson \& McMillan 1996 \\
\hline
\end{tabular}

Remarks: Operculodinium sp. 3 differs from the type species, O. centrocarpum in possessing relatively shorter spines. The spines appear more flexible and sinuous than those of the form tentatively attributed to $O$. ?xanthium, though it is possible that the two forms represent members of the same population.

\section{Operculodinium sp. 6}

\section{PI. 58, figs. 7-9}

Description: Cysts of intermediate size, chorate, not dorso-ventrally compressed, more or less spherical, lacking horns. Cyst wall two-layered; acavate. Archeopyle precingular, type P (3"). Surface ornament lacking. Processes non-tabular, spinose, straight or gently curved; non-fibrous, unbranched, apparently solid, 10-15 $\mu \mathrm{m}$ in length. Tabulation not expressed. Cingulum not expressed. Sulcus not expressed.

Size Range: Length excluding any processes $=44 \mu \mathrm{m}$ (one measured specimen). Width excluding any processes $=40(44) 47 \mu \mathrm{m}(2$ measurements). Length including any processes $=60(68) 80 \mu \mathrm{m}(5$ measurements). Width including any processes $=60$ (64) $67 \mu \mathrm{m}$ (2 measurements). 
Distribution:

$\begin{array}{llll}\text { Age/Stage } & \text { Location } & \text { Sample } & \text { Sample Reference } \\ \text { Bortonian } & \text { Hampden Beach Section, Oamaru-Dunedin, New Zealand } & \text { J42/f057 (L09214) } & \text { Wilson 1985 } \\ \text { Bortonian } & \text { Puketeraki Core, Oamaru-Dunedin, New Zealand } & \text { I43/f090 (L16338) } & \text { Wilson \& McMillan } 1996 \\ \text { Heretaungan } & \text { Hampden Beach Section, Oamaru-Dunedin, New Zealand } & \text { J42/f483 (L23118) } & \\ \text { Heretaungan } & \text { Hampden Beach Section, Oamaru-Dunedin, New Zealand } & \text { J42/f039 (L09196) } & \text { Wilson 1985 }\end{array}$

Remarks: Operculodinium sp. 3 differs from the type species, O. centrocarpum in possessing relatively longer spines. Although it is possible that the two forms represent end members of the same population, O. Sp. 6 appears to be confined to the older part of their aggregate stratigraphic range.

\section{Operculodinium crouchii Clowes n. sp.}

$$
\text { PI. 58, figs. 10-12, PI. 59, figs. 1-12 }
$$

?1982a Operculodinium tiara (Klumpp); Wilson, p. 8, pl. 1, fig. 8

Derivation of Name: Named after the dinoflagellate palynologist, Dr. Erica Crouch.

Holotype: Sample J42/f302, slide L23132/SM019; Hampden Formation, Hampden Beach Section (PoranganBortonian); PI. 58, figs. 10-12

Description: Cysts of intermediate size, chorate, not dorso-ventrally compressed, more or less spherical, lacking horns; episome and hyposome more or less equal in length. Cyst wall two-layered; acavate. Archeopyle precingular, type P (3"); operculum free. Surface ornament present, non-tabular, comprising a dense reticulum. Processes non-tabular, spinose, somewhat sinuous; non-fibrous, unbranched, apparently solid, 10-15 $\mu \mathrm{m}$ in length; dolabrate distally. Tabulation not expressed. Cingulum not expressed. Sulcus not expressed.

Size Range: Length excluding any processes $=42$ (51) $59 \mu \mathrm{m}$ (7 measurements). Width excluding any processes $=40$ (48) $57 \mu \mathrm{m}$ (7 measurements). Length including any processes $=55$ (71) $82 \mu \mathrm{m}$ (7 measurements). Width including any processes $=50(67) 85 \mu \mathrm{m}$ (7 measurements).

Distribution:

\begin{tabular}{|c|c|c|c|}
\hline Age/Stage & Location & Sample & $\begin{array}{l}\text { Sample } \\
\text { Reference }\end{array}$ \\
\hline $\begin{array}{l}\text { late Eocene-early } \\
\text { Oligocene }\end{array}$ & Chalky Island, Fiordland, New Zealand & L6893 & Wilson $1982 a$ \\
\hline Bortonian & $\begin{array}{l}\text { Hampden Beach Section, Oamaru-Dunedin, New } \\
\text { Zealand }\end{array}$ & J42/f303 (L23133) & \\
\hline Porangan-Bortonian & $\begin{array}{l}\text { Hampden Beach Section, Oamaru-Dunedin, New } \\
\text { Zealand }\end{array}$ & J42/f301 (L23131) & \\
\hline
\end{tabular}

Comparison: Insofar as it is a thick-walled chorate cyst with a precingular archeopyle and reticulate surface ornament, Operculodinium crouchii resembles O. tiara (Klumpp 1953) Stover \& Evitt 1978. Klumpp's illustrations comprise a somewhat inferior photograph (pl. 17, fig. 8) and two line drawings (pl. 17, figs. 9-10) which depict a form with bluntly terminated processes (esp. pl. 17, fig. 9) but which reveal few diagnostic details.

Sarjeant (1981) redescribed a number of Klumpp's (1953) types held in the Kiel collections. For some reason, however, he failed to include "Hystrichosphaeridium" tiara among his redescriptions, and so there does not appear to be any more recent illustration of the holotype than Klumpp's own.

A few years later, Morgenroth (1966a), who presumably had access to Klumpp's types, provided an emended description for tiara. His illustrations (pl. 5, figs. 10-11), however, although seeming to portray a thick-walled chorate cyst of the Operculodinium type, are little more enlightening than Klumpp's line-drawings, and do not really convincingly resemble them.

In summary, although the present form is somewhat similar to O. tiara in overall appearance, the processes are typically acuminate, rather than truncated (albeit somewhat 'kinked' near the distal ends in the manner named dolabrate by Eaton et al. 2001). Unless or until the Kiel types are reassessed, the present material is treated separately. 


\title{
Operculodinium sp. 11
}

PI. 60, figs. 1-6

Description: Cysts of intermediate size, chorate, not dorso-ventrally compressed, more or less spherical, lacking horns. Cyst wall two-layered; acavate. Archeopyle precingular, type P (3"). Surface ornament lacking. Processes non-tabular, spinose, straight or gently curved; non-fibrous, unbranched, apparently solid, 10-15 $\mu \mathrm{m}$ in length. Tabulation not expressed. Cingulum not expressed. Sulcus not expressed.

Size Range: Length excluding any processes $=45$ (51) $57 \mu \mathrm{m}$ (2 measurements). Width excluding any processes $=40(46) 53 \mu \mathrm{m}$ (2 measurements). Length including any processes $=62$ (72) $82 \mu \mathrm{m}$ (2 measurements). Width including any processes $=60(70) 80 \mu \mathrm{m}$ (2 measurements).

\section{Distribution:}

\begin{tabular}{llll}
\hline Age/Stage & Location & Sample & Sample Reference \\
Bortonian & Puketeraki Core, Oamaru-Dunedin, New Zealand & I43/f090 (L16338) & Wilson \& McMillan 1996 \\
Bortonian & Puketeraki Core, Oamaru-Dunedin, New Zealand & I43/f089 (L16337) & Wilson \& McMillan 1996
\end{tabular}

Remarks: Compared with 0 . crouchii, this is a more robust form in which the spines appear more prominent. However, the two forms occur in the same area and with consistent stratigraphic ranges; it is possible they represent end members of the same population.

\section{Operculodinium sp. 12}

PI. 60, figs. 7-12

Description: Cysts of intermediate size, chorate, not dorso-ventrally compressed, more or less spherical, lacking horns. Cyst wall two-layered; acavate. Archeopyle precingular, type P (3"). Surface ornament lacking. Processes non-tabular, spinose, straight or gently curved; non-fibrous, unbranched, apparently solid, 10-15 $\mu \mathrm{m}$ in length. Tabulation not expressed. Cingulum not expressed. Sulcus not expressed.

Size Range: Length excluding any processes $=42$ (44) $47 \mu \mathrm{m}$ (2 measurements). Width excluding any processes $=32$ (38) $45 \mu \mathrm{m}$ (2 measurements). Length including any processes $=65$ (68) $70 \mu \mathrm{m}$ (2 measurements). Width including any processes $=50$ (59) $68 \mu \mathrm{m}$ (2 measurements).

\section{Distribution:}

$\begin{array}{llll}\text { Age/Stage } & \text { Location } & \text { Sample } & \text { Sample Reference } \\ \text { Bortonian } & \text { Hampden Beach Section, Oamaru-Dunedin, New Zealand } & \text { J42/f488 (L23123) } \\ \text { Porangan } & \text { Te Uri Stream, Hawkes Bay, New Zealand } & \text { U24/f417 (L23125) }\end{array}$

Remarks: Compared with $\mathrm{O}$. crouchii, this is a more gracile form in which the spines appear less prominent. However, the two forms are broadly similar and have overlapping geographic and stratigraphic ranges; it is possible they represent end members of the same population.

\section{Genus Samlandia Eisenack 1954b}

\author{
1954b Palmnickia Eisenack, p. 69 \\ 1954b Samlandia Eisenack, p. 76 \\ 1978 Samlandia Eisenack 1954; Stover \& Evitt, p. 185-186 \\ 1984 Samlandia; Damassa, p. 61
}

Type Species: Samlandia chlamydophora Eisenack 1954b, p. 76, pl. 11, figs. 12-15 [Early Oligocene]

Original Description: Central body spherical to slightly elliptical, surrounded by a thin second membrane which is connected to the inner shell by supports, whose cross sections form irregularly curved (vermiform) lines. Pylome at pole of the ellipsoid (translated from Eisenack 1954b, p. 76, by Stover \& Evitt 1978, p. 185). 


\title{
Samlandia reticulifera Cookson \& Eisenack 1965a
}

\author{
PI. 61, figs. 1-6
}

1965a Samlandia reticulifera Cookson \& Eisenack, p. 126-127, pl. 15, figs. 10-15

1982b Samlandia reticulifera C. \& E.; Wilson, p. 8, pl. 3, figs. 14-16

Original Description: Shell oval with a short, conical, apical and antapical projection and two lower, boarder and less clearly defined projections in an equatorial position, one on each side. Wall of shell 2-layered, the inner ornamented by a complete or incomplete reticulum. The relatively thick muri support short, thin, closely and vertically arranged appendages with broadened apices (P1. 15, fig. 15) which, by theft close approximation and possible coalescence, form the closely opposed outer thin layer of the wall. The archeopyle is sub-apical and the operculum approximately quadrangular or rectangular in outline (Cookson \& Eisenack 1965a, p. 126-127).

Size Range: Length including any processes $=102$ (104) $106 \mu \mathrm{m}$ (2 measurements). Width including any processes $=77(78) 78 \mu \mathrm{m}$ (2 measurements).

Distribution: Infrequent.

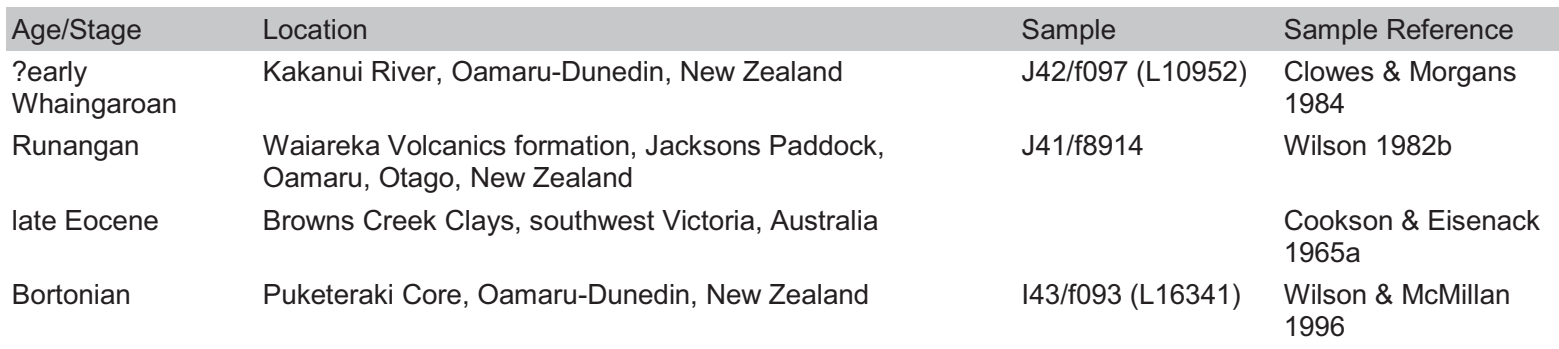

Remarks: Samlandia reticulifera Cookson \& Eisenack 1965a apparently differs from S. chlamydophora in "in the prominent reticulation of the inner layer of the wall and the close approximation of the enclosing membrane. In S. chlamydophora the outer membrane is widely separated from the inner wall and is supported by long unbranched lamenae" (Cookson \& Eisenack 1965a, p. 127).

Although not stated by Cookson \& Eisenack (1965a), it is also apparent that the endophragm is very much thinner in S. reticulifera than in S. chlamydophora. In this respect, it is very much closer to $S$. tenuis.

\section{Samlandia tenuis Clowes $\mathrm{n} . \mathrm{sp}$.}

$$
\text { PI. 61, figs. 7-12, PI. 62, figs. 1-3 }
$$

\author{
?1961 Palmnickia lobifera Eisenack 1954; Gerlach, p. 207-208, pl. 29, fig. 10 \\ 1982b Samlandia cf. chlamydophora Eis.; Wilson, p. 7, pl. 2, fig. 16, pl. 4, fig. 8 \\ 1984 Samlandia cf. chlamydophora; Damassa, p. 61, pl. 5, figs. 10-11 \\ 1993 Samlandia chlamydophora Eisenack, 1954; Brinkhuis \& Biffi, p. 177, pl. 9, fig. 7 \\ 1994 Samlandia chlamydophora Eisenack 1954; Stover \& Hardenbol, p. 33, pl. 8, fig. 54 \\ 2002 Samlandia chlamydophora Eisenack, 1954; De Coninck, pl. 13, figs. 3-5
}

Derivation of Name: Latin, tenuis, thin, slender, slight; with reference to the cyst walls which are much thinner than the otherwise similar species, Samlandia chlamydophora.

Holotype: Sample K29/f097, slide L10914/SM019; Port Elizabeth Member, Cape Foulwind Section, Westland, New Zealand (early Whaingaroan); PI. 61, figs. 7-12

Description: Cysts intermediate to large, proximate, not dorso-ventrally compressed, prolate, with one apical horn; episome and hyposome more or less equal in length. Apical horn well developed, apex rounded to subconical; antapical horns lacking. Cyst wall single-layered, with an ectophragm; the more or less continuous ectophragm is supported on numerous processes arising from the autophragm. Archeopyle precingular, type P (3"); operculum free. Surface ornament present, non-tabular, comprising coarse reticulum. Processes nontabular, arising from the muri of the reticulum, irregular; non-fibrous, apparently solid. Tabulation weakly expressed, apparently gonyaulacacean. Cingulum not expressed. Sulcus not expressed.

Size Range: Length = 50 (96) $139 \mu \mathrm{m}$ (33 measurements). Width = 65 (87) $100 \mu \mathrm{m}$ (9 measurements). 


\begin{tabular}{|c|c|c|c|}
\hline Age/Stage & Location & Sample & Sample Reference \\
\hline $\begin{array}{l}\text { middle Oligocene-middle } \\
\text { Miocene }\end{array}$ & north west Germany & $\operatorname{Pr} 1170 / 73$ & Gerlach 1961 \\
\hline late Rupelian & Monte Cagnero Section A, Italy & CA $114-01$ & $\begin{array}{l}\text { Brinkhuis \& Biffi } \\
1993\end{array}$ \\
\hline early Whaingaroan & Cape Foulwind Section, Westland, New Zealand & K29/f097 (L10914) & \\
\hline early Whaingaroan & Cape Foulwind Section, Westland, New Zealand & K29/f180 (L11929) & \\
\hline early Whaingaroan & Kakanui River, Oamaru-Dunedin, New Zealand & J42/f096 (L10951) & $\begin{array}{l}\text { Clowes \& Morgans } \\
1984\end{array}$ \\
\hline ?early Whaingaroan & Kakanui River, Oamaru-Dunedin, New Zealand & J42/f097 (L10952) & $\begin{array}{l}\text { Clowes \& Morgans } \\
1984\end{array}$ \\
\hline $\begin{array}{l}\text { Runangan-early } \\
\text { Whaingaroan }\end{array}$ & Cape Foulwind Section, Westland, New Zealand & K29/f108 (L11044) & \\
\hline $\begin{array}{l}\text { Runangan-early } \\
\text { Whaingaroan }\end{array}$ & Cape Foulwind Section, Westland, New Zealand & K29/f170 (L11919) & \\
\hline Runangan & $\begin{array}{l}\text { Totara Limestone formation, mouth of Kakanui River, } \\
\text { Oamaru, Otago, New Zealand }\end{array}$ & J42/6837 & Wilson 1982b \\
\hline Runangan & Cape Foulwind Section, Westland, New Zealand & K29/f102 (L11038) & \\
\hline $\begin{array}{l}\text { late Eocene-early } \\
\text { Oligocene }\end{array}$ & Grimmertingen section, eastern Belgium & $-3.3 \mathrm{~m}$. & De Coninck 2002 \\
\hline Kaiatan & $\begin{array}{l}\text { Raki Siltstone, Rakis Table, Oamaru, Otago, New } \\
\text { Zealand }\end{array}$ & $\mathrm{J} 41 / \mathrm{f} 8841$ & Wilson 1982b \\
\hline Bortonian & $\begin{array}{l}\text { Hampden Beach Section, Oamaru-Dunedin, New } \\
\text { Zealand }\end{array}$ & J42/f061 (L09218) & Wilson 1985 \\
\hline Bortonian & $\begin{array}{l}\text { Hampden Beach Section, Oamaru-Dunedin, New } \\
\text { Zealand }\end{array}$ & J42/f488 (L23123) & \\
\hline Bortonian & Puketeraki Core, Oamaru-Dunedin, New Zealand & I43/f094 (L16342) & $\begin{array}{l}\text { Wilson \& McMillan } \\
1996\end{array}$ \\
\hline Bortonian & $\begin{array}{l}\text { Hampden Beach Section, Oamaru-Dunedin, New } \\
\text { Zealand }\end{array}$ & J42/f042 (L09199) & Wilson 1985 \\
\hline Bortonian & Puketeraki Core, Oamaru-Dunedin, New Zealand & I43/f090 (L16338) & $\begin{array}{l}\text { Wilson \& McMillan } \\
1996\end{array}$ \\
\hline Heretaungan & $\begin{array}{l}\text { Hampden Beach Section, Oamaru-Dunedin, New } \\
\text { Zealand }\end{array}$ & J42/f483 (L23118) & \\
\hline
\end{tabular}

Comparison: This form has often been illustrated in the past (see synonymy) as Samlandia chlamydophora. Note, however, that S. chlamydophora possesses an extremely thick endophragm+periphragm: more than $4 \mu \mathrm{m}$, see Eisenack 1954b, especially pl. 11, figs. 12 and 13, and Text-Fig. 21 herein.

The present form possesses a very much thinner endophragm+periphragm; typically $2-3 \mu \mathrm{m}$, which serves to distinguish it readily. Moreover, other than the archeopyle, there are no indications of tabulation on S. chlamydophora whereas occasional discontinuities in the ectophragm of $S$. tenuis may indicate plate boundaries (e.g. see Williams et al. 1973, fig. 1, Damassa 1984, p. 61, pl. 6, figs. 4, 5).

Samlandia tenuis combines the wide spacing between endophragm+periphragm and ectophragm of Samlandia chlamydophora with the thin endophragm of Samlandia reticulifera.

\section{Genus Stoveracysta Clowes 1985}

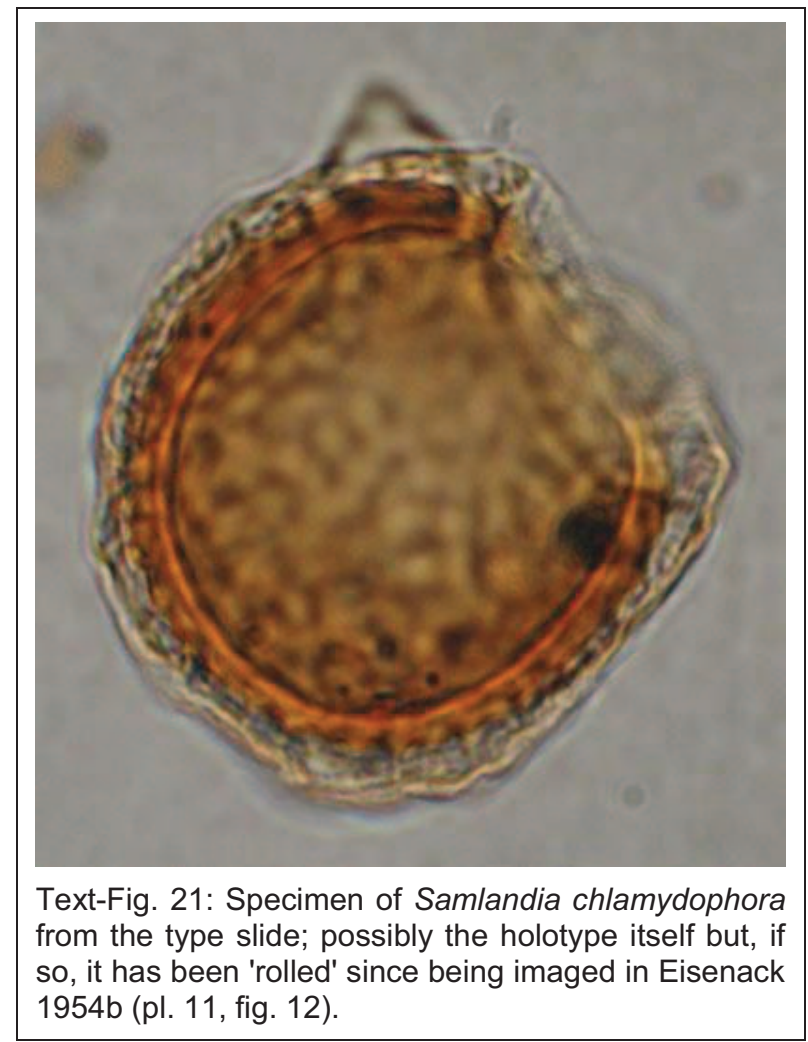


Type Species: Stoveracysta kakanuiensis Clowes 1985, p. 32, 34, pl. 1, figs. 1-12; pl. 2, figs. 1-12; text-figs. 4a-b [Early Oligocene]

Original Description: Proximate to proximochorate single layered cysts, subspherical in shape, lacking horns, ornamented by sutural to penitabular ridges or septa delineating a gonyaulacacean tabulation, formula: 4', 6", $X$ to $6 \mathrm{c}, 6$ "', $1 \mathrm{p}, 1$ '"', $X$ to $4 \mathrm{~s}$. The four plates of the apical series are developed subequally. The sulcal notch is not deep. Plate 1 "' is very small, poorly delimited, and intimately associated with the sulcus. Plates $1 p$ and ps are large. The antapical plate is clearly sexiform; it is in contact with plates 1p, 3"' through 6"', and ps. Archeopyle apical, type tA; operculum free (Clowes 1985, p. 29).

\title{
Stoveracysta kakanuiensis Clowes 1985
}

PI. 62, figs. 4-6

\author{
1984 Stoveracysta kakanuiensis Clowes (in prep.); Clowes \& Morgans, pl. 2, fig. 4 \\ 1985 Stoveracysta kakanuiensis Clowes, p. 32-34, pl. 1, figs. 1-12; pl. 2, figs. 1-12, text-fig. text-figs. 4a-b \\ 2003 Stoveracysta kakanuiensis; Brinkhuis, Sengers, et al., p. 21, figs. 137-138 \\ 2003 Stoveracysta kakanuiensis; Sluijs et al., p. 23, figs. 19-20 \\ 2004 Stoveracysta kakanuiensis Clowes 1985; Williams et al., pl. 9, figs. 17-18
}

Original Description: Proximate gonyaulacoid cysts, not dorso-ventrally compressed, prolate, lacking horns, consisting of a single wall layer. The ornament comprises low, incomplete, essentially sutural, septa which typically fail to develop on the upper margin of the cingulum, and minor intratabular granules. The archeopyle is apical, type $t A^{-}$; the operculum is free and ornamented with septa similar to those of the cyst body. These septa terminate a short distance from the absolute apex, thus leaving a small granular area at the pole. The full tabulation as defined by the ornament is gonyaulacacean, sexiform, formula: ?pr, 4', 6", X to 6c, 6"', 1p, 1"'", ?4s.

Size Range: Length $=65 \mu \mathrm{m}$ (one measured specimen). Width $=60 \mu \mathrm{m}$ (one measured specimen).

Distribution: Locally abundant although apparently confined to a narrow stratigraphic interval.

\begin{tabular}{|c|c|c|c|}
\hline Age/Stage & Location & Sample & Sample Reference \\
\hline early Whaingaroan & $\begin{array}{l}\text { Cape Foulwind Section, Westland, New } \\
\text { Zealand }\end{array}$ & K29/f180 (L11929) & \\
\hline early Whaingaroan & $\begin{array}{l}\text { Kakanui River, Oamaru-Dunedin, New } \\
\text { Zealand }\end{array}$ & J42/f096 (L10951) & $\begin{array}{l}\text { Clowes \& Morgans } \\
1984\end{array}$ \\
\hline early Whaingaroan & $\begin{array}{l}\text { Cape Foulwind Section, Westland, New } \\
\text { Zealand }\end{array}$ & K29/f176 (L11925) & \\
\hline $\begin{array}{l}\text { Runangan-early } \\
\text { Whaingaroan }\end{array}$ & $\begin{array}{l}\text { Cape Foulwind Section, Westland, New } \\
\text { Zealand }\end{array}$ & K29/f112 (L11048) & \\
\hline
\end{tabular}

Remarks: S. kakanuiensis occurs in an apparently narrow stratigraphic interval, close to the Eocene-Oligocene boundary in New Zealand.

It was correlated with Chron C13r at ODP Site 1172 by Sluijs et al. (2003) who go on to note that it "potentially provides an excellent regional correlation, conspicuously appearing at the time of the deepening of the Tasmanian Gateway" (p. 10).

Stoveracysta ?ornata (Cookson \& Eisenack 1965a) Clowes 1985

PI. 62, figs. 7-9

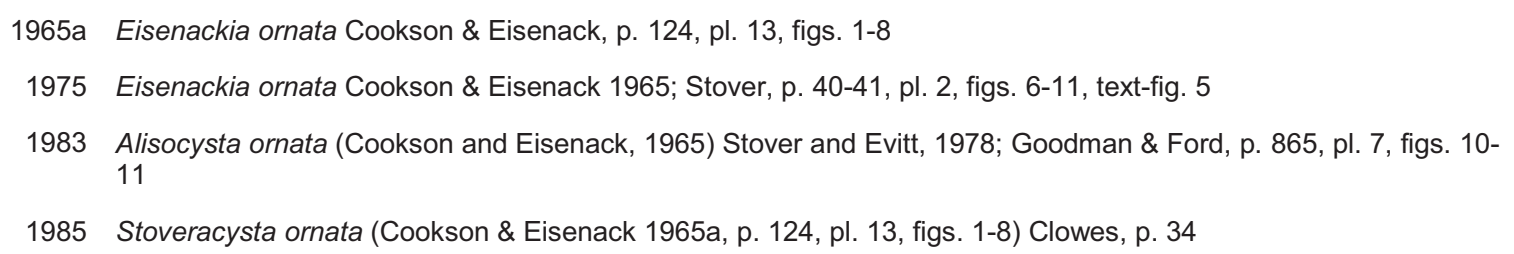

Original Description: Shell oval, apex slightly pointed, antapex with two short projections, girdle equatorial, broad, strongly helicoid, divided into six plates. Dorsal surface clearly tabulated, the plates which are outlined by low, 
transparent ledges ... being separated by distinct furrows. The ventral field, corresponding to the longitudinal furrow, is broadly oval and crossed by a varying number of irregularly arranged straight or curved low, narrow ridges of different lengths. The two antapical projections are situated at the ventral corners of the antapical plate. The surface of the shell is rather finely and closely granular. The shell opens by the detachment of a slightly hexagonal apical operculum ... (Cookson \& Eisenack 1965a, p. 124).

Size Range: Length = 43 (46) $49 \mu \mathrm{m}$ (2 measurements). Width = $60 \mu \mathrm{m}$ (one measured specimen).

Distribution: Rare.

$\begin{array}{lllc}\begin{array}{l}\text { Age/Stage } \\ \text { Runangan } \\ \text { late Eocene }\end{array} & \text { Location } & \text { Sample } & \text { Sample Reference } \\ & & \text { K29/f104 (L11040) } & \text { Stover 1975 } \\ \begin{array}{l}\text { Kaiatan } \\ \text { Bortonian }\end{array} & \begin{array}{l}\text { Puketeraki Core, Oamaru-Dunedin, New Zealand } \\ \text { Puketeraki Core, Oamaru-Dunedin, New Zealand }\end{array} & \text { I43/f096 (L16344) } & \text { Wilson \& McMillan 1996 } \\ & & \text { I43/f092 (L16340) } & \text { Wilson \& McMillan 1996 }\end{array}$

\section{Genus Thalassiphora Eisenack \& Gocht 1960}

1960 Thalassiphora Eisenack \& Gocht, p. 513

1978 Thalassiphora Eisenack \& Gocht 1960 emended Gocht 1968; Stover \& Evitt, p. 194-195

Type Species: Thalassiphora pelagica (Eisenack 1954b, p. 71, pl. 12, figs. 17-18) Eisenack \& Gocht 1960, p. 513-514 [Late Eocene-Early Oligocene]

Original Description: Central body spherical to ellipsoidal, hollow, firm-walled, surrounded by an equatorially placed helmet to bowl-shaped, wide, flexible membranous wing that never the less is double walled. The central body commonly has circular to horseshoe-shaped pylome (translated from Eisenack \& Gocht 1960, p. 153, by Stover \& Evitt 1978, p. 194).

Remarks: A supposed 1a intercalary plate was postulated by Gocht (1968). I am sceptical.

Thalassiphora pelagica (Eisenack 1954b) Eisenack \& Gocht 1960 emend. Benedek \& Gocht, 1981

PI. 62, figs. 10-12, PI. 63, figs. 1-12

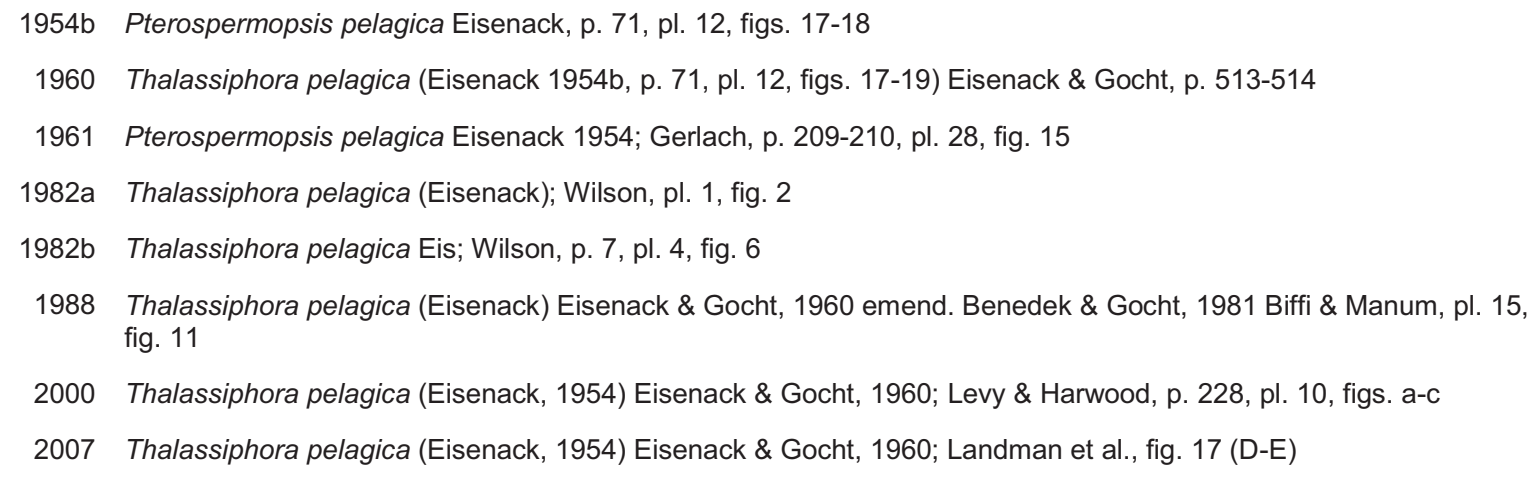

Original Description: A mostly ellipsoidal (rarely spherical) central body with fairly solid walls is suspended from or adheres to the middle of a double-walled helmet-shaped, flat shell-shaped or bell-shaped membranous wing in such a way that the longitudinal axis of the ellipsoid proceeds into the membrane. Usually a low, \pm sharp-edged wedge extends over the convex side of this membrane towards the longitudinal axis and ends in a short point at the rear edge of the membrane. Often an excystment hole has developed in the shape of a horseshoe in the front half of the outer (upper) side of the central body (Eisenack 1954b, p.71).

Size Range: Length = 98 (144) $200 \mu \mathrm{m}$ (5 measurements). Width = 112 (153) $225 \mu \mathrm{m}$ (5 measurements).

Distribution: Thalassiphora pelagica appears to be a long-ranging taxon, reported from (for example) the Maastrichtian of northeast USA (Landman et al. 2007) to the Miocene of Italy (Biffi \& Manum 1988) and New Zealand (herein).

$\begin{array}{llll}\text { Age/Stage } & \text { Location } & \text { Sample } & \text { Sample Reference } \\ \begin{array}{l}\text { middle Oligocene-middle } \\ \text { Miocene }\end{array} & \text { north west Germany } & \text { Pr 1170/75 } & \text { Gerlach 1961 } \\ \text { Otaian } & \text { Puketeraki Core, Oamaru-Dunedin, New Zealand } & \text { I43/f101 (L16349) } & \text { Wilson \& McMillan }\end{array}$




\begin{tabular}{|c|c|c|c|}
\hline Age/Stage & Location & Sample & Sample Reference \\
\hline & & & 1996 \\
\hline Oligocene-early Miocene & & & Biffi \& Manum 1988 \\
\hline early Whaingaroan & Cape Foulwind Section, Westland, New Zealand & K29/f174 (L11923) & \\
\hline $\begin{array}{l}\text { Runangan-early } \\
\text { Whaingaroan }\end{array}$ & Cape Foulwind Section, Westland, New Zealand & K29/f169 (L11918) & \\
\hline Bortonian & $\begin{array}{l}\text { Hampden Beach Section, Oamaru-Dunedin, New } \\
\text { Zealand }\end{array}$ & J42/f048 (L09205) & Wilson 1985 \\
\hline Bortonian & $\begin{array}{l}\text { Hampden Beach Section, Oamaru-Dunedin, New } \\
\text { Zealand }\end{array}$ & J42/f488 (L23123) & \\
\hline Porangan & Te Uri Stream, Hawkes Bay, New Zealand & U24/f419 (L23127) & \\
\hline Porangan & $\begin{array}{l}\text { Hampden Beach Section, Oamaru-Dunedin, New } \\
\text { Zealand }\end{array}$ & J42/f299 (L23129) & \\
\hline Heretaungan & $\begin{array}{l}\text { Hampden Beach Section, Oamaru-Dunedin, New } \\
\text { Zealand }\end{array}$ & J42/f484 (L23119) & \\
\hline Eocene & erratics, McMurdo Sound, Antarctica & MTD 42 & $\begin{array}{l}\text { Levy \& Harwood } \\
2000\end{array}$ \\
\hline Maastrichtian & $\begin{array}{l}\text { Manasquan River Basin, Monmouth County, New } \\
\text { Jersey, USA }\end{array}$ & & $\begin{array}{l}\text { Landman et al. } \\
2007\end{array}$ \\
\hline
\end{tabular}

Remarks: The long (and biostratigraphically unhelpful) range of Thalassiphora pelagica may be due in part to "lumping" of multiple taxa into the species. Nevertheless, it has proved difficult to discern any systematic differences between the oldest and youngest representatives in the present study. Perhaps this particular morphology is, indeed, exceptionally conservative.

\section{Genus Tityrosphaeridium Sarjeant 1981}

1981 Tityrosphaeridium Sarjeant, p. 120

1987 Tityrosphaeridium Sarjeant 1981, p. 120-121 Stover \& Williams, p. 213-214

Type Species: Tityrosphaeridium cantharellus (Brosius 1963, p. 40-41, pl. 6, fig. 1; text-fig. 2, nos. 11a-c) Sarjeant 1981, p. 120

Original Description: Cyst spheroidal to broadly ellipsoidal, skolochorate. Phragma two-layered, with processes typically or constantly formed by the periphragm only. Processes intratabular, essentially cylindrical in shape (solid or hollow), yet of very variable form - they may be bifid or branched and expanded distally, but are not linked by an enclosing membrane, partial or complete, or by trabeculae. The process walls are fibrous, with or without rootlike proximal extensions: parasutural or penitabular features are inconspicuous or lacking. Paratabulation gonyaulacacean, with the formula 3-4', 6", 5-7c, 5-6"', 0-1p, 0-?5s. The cingular processes may be slender or conspicuously elongate. The antapical processes may be larger and more conspicuous than the others. Archeopyle precingular: operculum free (Sarjeant 1981, p. 120).

Remarks: Tityrosphaeridium is considered a junior synonym of Cordosphaeridium, by to Lentin \& Williams 1985 , Stover \& Williams 1987, and Fensome \& Williams 2004. Quattrocchio \& Sarjeant 1996, retained the genus, and it is provisionally recognised here, thought there exists considerable doubt over its validity.

\section{? Tityrosphaeridium cantharellus (Brosius 1963) Sarjeant 1981}

$$
\text { PI. 64, figs. 1-12, PI. 65, figs. 1-3 }
$$

1963 Hystrichosphaeridium cantharellus Brosius, p. 40-41, pl. 6, fig. 1, text-fig. 2

1981 Tityrosphaeridium cantharellus (Brosius 1963, p. 40-41, pl. 6, fig.1; text-fig. 2, nos. 11a-c) Sarjeant, p. 120

1994 Cordosphaeridium cantharellum (Brosius 1963) Gocht 1969; Stover \& Hardenbol, p. 32, pl. 7, fig. 38

2005 Tityrosphaeridium cantharellus; Schiøler, pl. 5, fig. 5

Original Description: A species of the genus Hystrichosphaeridium with the following characteristics: The spherical to egg-shaped smooth central body supports about 15-20 hollow tree-like processes. These are mainly 
broadly cylindrical, narrowing in the middle somewhat and gently widening towards the end. They consist of fibres that are distally split and curled far back. Isolated reticulated protrusions also appear. The process ends always appear matted and only with strong magnification can the branching fibres be seen. Both narrow and wide processes can be found on the same specimen. A calotte can be separated to form an excystment hole (Brosius 1963, p. 40-41).

Size Range: Length excluding any processes $=20$ (29) $35 \mu \mathrm{m}$ (6 measurements). Width excluding any processes $=20$ (27) $35 \mu \mathrm{m}$ (6 measurements). Length including any processes $=35$ (55) $70 \mu \mathrm{m}$ (7 measurements). Width including any processes $=40$ (54) $70 \mu \mathrm{m}$ (6 measurements).

Distribution:

\begin{tabular}{|c|c|c|c|}
\hline Age/Stage & Location & Sample & Sample Reference \\
\hline early Whaingaroan & Kakanui River, Oamaru-Dunedin, New Zealand & J42/f096 (L10951) & $\begin{array}{l}\text { Clowes \& Morgans } \\
1984\end{array}$ \\
\hline $\begin{array}{l}\text { Runangan-early } \\
\text { Whaingaroan }\end{array}$ & Kakanui River, Oamaru-Dunedin, New Zealand & J42/f125 (L11625) & \\
\hline Bortonian & $\begin{array}{l}\text { Hampden Beach Section, Oamaru-Dunedin, New } \\
\text { Zealand }\end{array}$ & J42/f055 (L09212) & Wilson 1985 \\
\hline Porangan & $\begin{array}{l}\text { Hampden Beach Section, Oamaru-Dunedin, New } \\
\text { Zealand }\end{array}$ & J42/f300 (L23130) & \\
\hline Porangan & Te Uri Stream, Hawkes Bay, New Zealand & U24/f419 (L23127) & \\
\hline
\end{tabular}

Subfamily Leptodinioideae Fensome et al. 1993b

Genus Areosphaeridium Eaton 1971

\author{
1971 Areosphaeridium Eaton, p. 357 \\ 1978 Areosphaeridium Eaton 1971; Stover \& Evitt, p. 19-20 \\ 1995 Areosphaeridium Eaton 1971 emend. Stover \& Williams, p. 100, 102 \\ 1995 Enneadocysta Stover \& Williams, p. 108-109 \\ 2006 Enneadocysta Stover and Williams 1995 emend. Fensome et al., p. 394, 396
}

Type Species: Areosphaeridium diktyoplokum (Klumpp 1953, p. 392, pl. 18, figs. 3-7) Eaton 1971, p. $358-359$ [Eocene]

Original Description: Dinoflagellate cyst having a central body which is sub-circular to sub-quadrate in outline, with a finely granular surface, bearing solid, fibrous, intratabular processes. The process stems may be simple or branched, and frequently show fenestration. Distally the process stems are expanded and they terminate either as a distal bifurcation or a broad distal platform. Processes are invariably present on the apical, pre- and postcingular, and apical zones. Processes may or may not be present on the cingular zone. There is typically one process per plate, although some plates may be devoid of processes, and others may have two or three processes. The reflected paratabulation is 4', 5-6", 5-6"', $0-1 \mathrm{p}, 1$ '”'. The archeopyle is apical tetratabular (Eaton 1971, p. 357).

Comparison: Areosphaeridium differs from Hystrichosphaeridium and Oligosphaeridium in having solid, generally fibrous processes rather than tubular, nonfibrous processes (Stover \& Evitt 1978, p. 19-20). It is noteworthy, however, that Hystrichosphaeridium and Oligosphaeridium differ from one another in the respective presence and absence of cingular processes, which Areosphaeridium may or may not have.

The body and processes of Eatonicysta and Areosphaeridium are essentially identical, but Eatonicysta is readily distinguished by the ectophragm supported on the process tips.

Surculosphaeridium differs from Areosphaeridium in lacking fenestrate platform-like or arcuate features at the ends of the processes (Stover \& Evitt 1978, p. 20). Surculosphaeridium does have complex process tips, so this seems like a somewhat artificial distinction to me. However, the type species of Surculosphaeridium, $S$. cribrotubiferum, is ancient (Oxfordian; early Late Jurassic), so it is unlikely that the two genera are closely related.

A similar state of affairs pertains to Stiphrosphaeridium: it is morphologically quite similar to Areosphaeridium but the type species (Stiphrosphaeridium dictyophorum) ranges from Late Jurassic to Early Cretaceous and so seems unlikely to be a close relative. (Oddly, none of Davey 1982b, Stover \& Williams 1987, or Stover \& Williams 1995 provides a comparison between Stiphrosphaeridium and Areosphaeridium, despite the obvious morphological similarities.)

Remarks: Areosphaeridium was revised, and many Areosphaeridium species moved to a new genus, Enneadocysta, by Stover \& Williams (1995). The division into two genera is widely recognised today (e.g. Fensome \& Williams 2004, Fensome et al. 2006). However, as earlier noted by Brinkhuis, Sengers, et al. 
2003, p. 19, some and perhaps all species of Enneadocysta are "gonyaulacoid sexiform rather than partiform as suggested by Stover \& Williams (1995)." The supposed partiform hypocystal organisation of Enneadocysta is here regarded as "reading too much" into a slight dorso-ventral compression, and, accordingly, Enneadocysta is misplaced among the Cladopyxiaceae and belongs instead with Areosphaeridium (within the Leptodinioideae, as placed here, although Fensome et al. 2006 presents a good case for placing both close to Cleistosphaeridium, within the Areoligeraceae). Indeed, the validity of Enneadocysta must now stand in some doubt and it is simply treated as a junior synonym of Areosphaeridium herein.

The current conventional deployment of species variously allocated between these two genera is summarised in the following table, together with the significantly different treatment adopted herein.

\begin{tabular}{|c|c|c|}
\hline Original Epithet & Stover \& Williams 1995 & Herein \\
\hline $\begin{array}{l}\text { Cleistosphaeridium } \\
\text { actinocoronatum }\end{array}$ & - & Reticulatosphaera actinocoronata \\
\hline Areosphaeridium arcuatum & Enneadocysta arcuata & $\begin{array}{l}\text { Areosphaeridium arcuatum } \\
\text { Possibly a jnr. syn. of } A \text {. pectiniforme }\end{array}$ \\
\hline Areosphaeridium argentinense & $\begin{array}{l}\text { Surculosphaeridium? } \\
\text { argentiniense }\end{array}$ & - \\
\hline Areosphaeridium calcigerum & $\begin{array}{l}\text { Surculosphaeridium? } \\
\text { calcigerum }\end{array}$ & - \\
\hline Areosphaeridium capricornum & Cooksonidium capricornum & Cooksonidium capricornum \\
\hline- & Enneadocysta deconinckii & $\begin{array}{l}\text { ?Areosphaeridium deconinckii n. comb. } \\
=\text { Enneadocysta deconinckii Stover \& } \\
\text { Williams 1995, p. } 110\end{array}$ \\
\hline Areosphaeridium diktyoplokus & Areosphaeridium diktyoplokus & Areosphaeridium diktyoplokum \\
\hline Areosphaeridium dictyostilum & Enneadocysta? dictyostila & Areosphaeridium dictyostilum \\
\hline Areosphaeridium ebdonii & - & Areosphaeridium ebdonii \\
\hline Areosphaeridium fenestratum & Enneadocysta fenestrata & Areosphaeridium fenestratum \\
\hline- & Enneadocysta harrisii & $\begin{array}{l}\text { ?Areosphaeridium harrisii n. comb. } \\
=\text { Enneadocysta harrisii Stover \& } \\
\text { Williams 1995, p. } 111-112\end{array}$ \\
\hline Areosphaeridium michoudii & - & Areosphaeridium michoudii \\
\hline Areosphaeridium multicornutum & Enneadocysta multicornuta & Areosphaeridium multicornutum \\
\hline- & Enneadocysta partridgei & Jnr. syn. of $A$. dictyostilum \\
\hline Baltisphaeridium pectiniforme & Enneadocysta pectiniformis & Areosphaeridium pectiniforme \\
\hline Areosphaeridium polypetellum & $\begin{array}{l}\text { Cleistosphaeridium } \\
\text { polypetellum }\end{array}$ & - \\
\hline- & Enneadocysta robusta & $\begin{array}{l}\text { ?Areosphaeridium robustum n. comb. } \\
=\text { Enneadocysta robusta Stover \& } \\
\text { Williams } 1995, \text { p. } 115\end{array}$ \\
\hline Areosphaeridium suggestium & $\begin{array}{l}\text { Surculosphaeridium } \\
\text { suggestium }\end{array}$ & - \\
\hline
\end{tabular}


A key to understanding the genus Areosphaeridium is, of course, the nature and relationships of the type species, $A$. diktyoplokum. One myth that has grown up around this species is that the process fenestrae mostly or always exhibit smooth margins ("entire clypeate"; e.g. Goodman \& Ford 1983, p. 865; Fensome et al. 2006, p. 397, but not Stover \& Williams 1995, which notes variability of this feature on p. 102). However, the most casual glance at Klumpp's original illustrations (1953, pl. 18, figs. 3-7) shows four specimens, including the holotype, all with ragged margins.

There are certainly some southern hemisphere occurrences of cysts which, but for the lack of an entire margin, would be identified as $A$. diktyoplokum by almost anyone (e.g. Text-Fig. 22, from the Tasman Sea). Specimens from mainland/near-shore New Zealand, however, generally have less welldeveloped process tips, and have been assigned to Areosphaeridium dictyostilum in this study (e.g. PI. 65, figs. 4-9). There is little evidence to support a view that these are species of different genera, and the idea that they represent separate families unless perhaps caught in the act of divergence - is unsustainable.

[Note that the Gonyaulacaceae (Areosphaeridium) and the Cladopyxiaceae (the usual resting place for Enneadocysta, although the Areoligeraceae has also been suggested; see Eaton et al. 2001) diverged during the Mesozoic.]

\section{Areosphaeridium dictyostilum (Menéndez 1965) Sarjeant 1981 emend. Fensome et al. 2006}

$$
\text { PI. 65, figs. 4-12, PI. 66, figs. 1-3 }
$$

\footnotetext{
1965 Hystrichosphaeridium dictyostilum Menéndez, p. 11-12, pl. 2, fig .6; pl. 3, figs. 18-22

1967a Cordosphaeridium dictyoplokus (Klumpp) Eisenack; Wilson, p. 67, figs. 33, 35

1972 Oligosphaeridium? dictyostilum (Menéndez 1965, p. 11, 12, pl. 2, fig.6; pl. 3, figs. 18-22) Eisenack \& Kjellström, p. 845

1975 Areosphaeridium dictyoplokus (Klumpp); Haskell \& Wilson, pl. 1, fig. 1

1981 Areosphaeridium dictyostilum (Menéndez 1965, p. 11, 12, pl. 2, fig.6; pl. 3, figs. 18-22) Sarjeant, p. 115

1983 Areosphaeridium sp. cf. A. dictyoplokus (Klumpp, 1953) Eaton, 1971; Goodman \& Ford, p. 865, pl. 8, fig. 4

1988 Areosphaeridium dictyoplokum (Klumpp 1953) Eaton 1971; Wrenn \& Hart, p. 346-347, fig. 15, 6

1989 Areosphaeridium cf. dictyoplokus (Klumpp) Eaton; Wilson, pl. 1, fig. 16

1995 Enneadocysta? dictyostila (Menéndez 1965) Stover \& Williams, p. 109

1995 Enneadocysta partridgei Stover \& Williams, p. 113-114, pl. 4, figs. 4a-e, 5, pl. 5, figs. 1a-c, 2a-c, 3a-c, 4, 5a-b, textfig. 1D, J

2000 Enneadocysta partridgei Stover \& Williams, 1995; Levy \& Harwood, p. 222, 224, pl. 4, fig. h

2006 Enneadocysta? dictyostila (Menéndez 1965) Stover and Williams 1995, emend. Fensome et al., p. 396-397, pl. 3 , figs. 1-20, text-fig. 7 A-F, 8 A-R
}

Original Description: Body ellipsoid or ovoid, membrane almost smooth, tubular processes (17 or 18) distributed more or less radially, widened at the base, the free end broadly funnel-shaped with irregular branches or forming a reticulum (translation from Menéndez 1965, p. 11).

Emended Description of Fensome et al. 2006: [Diagnosis] A species of Enneadocysta with 6 precingular and 3-5 cingular processes and ragged clypeate to licrate process terminations.

[Description] Shape: Cyst chorate with a slightly dorsoventrally flattened, subspherical central body that may be symmetrical or slightly asymmetrical in outline. Wall relationships: Autophragm up to $1.5 \mu m$ thick. Wall features: Autophragm smooth to faintly granulate, occasionally pitted. The central body bears 22 to 23 processes, mostly mesotabular but at least three (two antapical and the posterior sulcal) apparently obtabular to 
penitabular, with 10 epicystal, 9 hypocystal, and 3-5 (usually 4) cingular. Processes predominantly simple, but may occasionally be branched or form a linear complex. Process stems are solid, occasionally faintly fibrous and may be perforate or fenestrate; they vary in width, cingulars being the narrowest. One of the dorsal apical processes (on the operculum) may have a wider stem or may be twinned. Occasionally, cingular processes are minute protuberances without distal expantions. Processes vary distally from bifid to most commonly ragged clypeate.... Archeopyle: Apical, type (tA), tetratabular, operculum simple, free. Tabulation. Indicated by processes and archeopyle margin. Each precingular plate has a mesotabular process, with first and sixth precingular processes and plates being of equal size. The anterior sulcal plate never has a process. Three to four, occasionally five, cingular plates have processes, which are located towards the ambitus. On the hypocyst, there are six postcingular processes, one per plate, a process that we interpret as the postcingular sulcal, and two antapical processes. The two antapical processes are interpreted as penitabular, located close to the lateral boundaries. Process formula: 4', 6", 3-5c, 6"', ps, 2"'" (interpreted as representing a single 1"'" plate, as discussed above). Dimensions. Range of 36 specimens except where noted: central body width 50 (54) $67 \mu \mathrm{m}$; central body length without operculum 40 (44) $58 \mu \mathrm{m}$ (30 specimens); central body length with operculum 57 (66) $75 \mu \mathrm{m}$ (2 specimens); processes length up to $17-30 \mu \mathrm{m}$; width at midlength of processes stems (excluding cingular

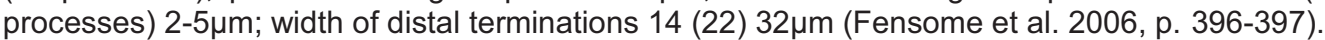

Size Range: Length excluding any processes $=45$ (57) $72 \mu \mathrm{m}$ (5 measurements). Width excluding any processes $=47(55) 62 \mu \mathrm{m}$ ( 6 measurements). Length including any processes $=77$ (97) $120 \mu \mathrm{m}$ (13 measurements). Width including any processes $=80$ (103) $125 \mu \mathrm{m}$ (7 measurements).

\section{Distribution: Common.}

\begin{tabular}{|c|c|c|c|}
\hline Age/Stage & Location & Sample & Sample Reference \\
\hline Whaingaroan & Akitio River, Hawkes Bay, New Zealand & U24/f201 (L12144) & \\
\hline $\begin{array}{l}\text { late Eocene-early } \\
\text { Oligocene }\end{array}$ & DSDP Hole 511 & & $\begin{array}{l}\text { Goodman \& Ford } \\
1983\end{array}$ \\
\hline Kaiatan & Puketeraki Core, Oamaru-Dunedin, New Zealand & |43/f096 (L16344) & $\begin{array}{l}\text { Wilson \& McMillan } \\
1996\end{array}$ \\
\hline Kaiatan & Nine Mile Bluff, Westland, New Zealand & J31/f9186 (L08325) & \\
\hline Bortonian & $\begin{array}{l}\text { Hampden Beach Section, Oamaru-Dunedin, New } \\
\text { Zealand }\end{array}$ & J42/f040 (L09197) & Wilson 1985 \\
\hline Bortonian & Puketeraki Core, Oamaru-Dunedin, New Zealand & I43/f089 (L16337) & $\begin{array}{l}\text { Wilson \& McMillan } \\
1996\end{array}$ \\
\hline Porangan-Bortonian & $\begin{array}{l}\text { Hampden Beach Section, Oamaru-Dunedin, New } \\
\text { Zealand }\end{array}$ & J42/f301 (L23131) & \\
\hline Eocene & $\begin{array}{l}\text { erratics near Minna Bluff, McMurdo Sound, } \\
\text { Antarctica }\end{array}$ & L4737 & Wilson 1967a \\
\hline Eocene & erratics, McMurdo Sound, Antarctica & MB 181(2) & $\begin{array}{l}\text { Levy \& Harwood } \\
2000\end{array}$ \\
\hline
\end{tabular}

Remarks: "Enneadocysta" partridgei is allegedly smooth or faintly granulate; 21 to 23 processes which are vasiform, simply branched or expanded distally; stems single, moderately wide and long; length about $1 / 3$ body diameter; 6" process present; as process absent; usually 4 cingular processes; medial or offset sulcal notch; 1 " = 6" (same size, presumably); 88-128 $\mu$ m overall diameter. I fully concur with Fensome et al. 2006 that it is a junior synonym of dictyostilum, whether it be called Areosphaeridium or Enneadocysta.

The holotype of "E." partridgei is from DSDP leg 29, site 283, core sample 11-3 $1119-121 \mathrm{~cm})$ (refer Haskell \& Wilson 1975).

Areosphaeridium ebdonii Bujak 1994

PI. 66, figs. 4-9

1994 Areosphaeridium ebdonii Bujak, p. 119-121, pl. 2, figs. 8-9

Original Description: Cysts skolochorate with subspherical bodies comprising an autophragm. Body typically with 17 intratabular processes, ten on the epicyst and seven on the hypocyst; areas between process bases smooth, or indistinctly ornamented, or finely and irregularly granulate. Processes less than $15 \mu \mathrm{m}$ in length. Process stems solid, with proximal fibrous ends expanded slightly and merging smoothly with the autophragm surface. Process stems expanded distally into vasiform or infundibular, fenestrate to reticulate process platforms with irregular to circular outlines. On some specimens the vasiform or infundibular distal terminations have irregular or entire margins. The processes reflect a paratabulation of 4',6", 0c, 5"', 1p, 1"', $0 \mathrm{~s}$, with the hypocystal paratabulation following the standard sexiform pattern. Paracingulum typically expressed by the absence of 
processes, but one or two narrow paracingular processes may be present. Parasulcal processes absent although a medial parasutural notch is frequently discernible. Archeopyle apical; operculum tetraplacoid, contiguous (Bujak 1994, p. 119-120).

Size Range: Length excluding any processes $=55 \mu \mathrm{m}$ (one measured specimen). Width excluding any processes $=55(56) 57 \mu \mathrm{m}$ (2 measurements). Length including any processes $=67$ (83) $105 \mu \mathrm{m}(4$ measurements). Width including any processes $=72$ (87) $102 \mu \mathrm{m}$ (3 measurements).

Distribution: Infrequent.

$\begin{array}{llll}\text { Age/Stage } & \text { Location } & \text { Sample } & \text { Sample Reference } \\ \text { Bortonian } & \text { Hampden Beach Section, Oamaru-Dunedin, New Zealand } & \text { J42/f303 (L23133) } & \\ \text { Bortonian } & \text { Hampden Beach Section, Oamaru-Dunedin, New Zealand } & \text { J42/f042 (L09199) } & \text { Wilson 1985 } \\ \text { Bortonian } & \text { Puketeraki Core, Oamaru-Dunedin, New Zealand } & \text { I43/f092 (L16340) } & \text { Wilson \& McMillan } 1996 \\ \text { Bortonian } & \text { Puketeraki Core, Oamaru-Dunedin, New Zealand } & \text { I43/f089 (L16337) } & \text { Wilson \& McMillan 1996 }\end{array}$

\title{
Areosphaeridium multicornutum Eaton 1971
}

$$
\text { PI. 66, figs. 10-12, PI. 67, figs. 1-3 }
$$

\author{
1971 Areosphaeridium multicornutum Eaton, p. 363-364, pl. 4, figs. 1-7, text-fig. 6 \\ 1995 Enneadocysta multicornuta (Eaton 1971, p. 363-364, pl. 4, figs. 1-7; text-fig. 6) Stover \& Williams, p. 109
}

Original Description: The central body has a sub-circular to sub-quadrate outline and a finely granular surface. The processes are intratabular and have solid fibrous stems of variable length and breadth. Each process is distally expanded and bifurcate; the attitude of the bifurcations varies from patulate to recurved. The bifurcations are of variable length, and they vary in breadth from slender with a denticulate distal margin, to broad, typically net-like, with an irregular distal margin. Fenestration is sometimes present in a few of the process stems and produces stem branches. The tabulation of 4', 6", 6"', $1 \mathrm{p}, 1^{\prime \prime \prime \prime}$ is not fully reflected by the Intratabular processes. On the apical zone there are 4 processes $\left(1^{\prime}-4^{\prime}\right)$. On the precingular zone there are five processes (1" - 5"), and plate 6" is devoid of processes. There are between four and seven cingular processes which are situated on the lateral margins of the cingular zone. On the postcingular zone there are five processes (1"'- 5 "'), and plate 6"' is devoid of processes. There is one process reflecting the posterior intercalary plate (1p). The antapex is typically offset to the right of the mid-ventral line and bears one process (1'”'). Between the postcingular processes and the antapical process there are between one and five additional processes. The archeopyle is apical, tetratabular.

The variation in the form of the processes in $A$. multicornutum is similar to that shown by $A$. arcuatum, including the frequent occurrence of broader processes reflecting plates 2"' and 4"' (pl. 4 fig. 2). The cingular processes in A. multicornutum are typically slender. Although they are restricted to the margins of the cingular zone, the cingular processes are not randomly distributed, but are arranged in a line approximately parallel to the pre- and postcingular zones. As with $A$. arcuatum the additional processes are probably postcingular or antapical rather than reflecting distinct plate areas. The number of cingular and additional processes quoted in the diagnosis for A. multicornutum is based on specimens from the Bracklesham Beds; specimens with a greater number of processes may occur (Eaton 1971, p. 363-364).

Size Range: Length excluding any processes $=45 \mu \mathrm{m}$ (one measured specimen). Width excluding any processes $=42(46) 48 \mu \mathrm{m}$ (3 measurements). Length including any processes = 65 (92) $107 \mu \mathrm{m}(9$ measurements). Width including any processes $=80$ (82) $85 \mu \mathrm{m}$ (4 measurements).

Distribution: Common.

\begin{tabular}{|c|c|c|c|}
\hline Age/Stage & Location & Sample & Sample Reference \\
\hline Bortonian & $\begin{array}{l}\text { Hampden Beach Section, Oamaru-Dunedin, New } \\
\text { Zealand }\end{array}$ & J42/f303 (L23133) & \\
\hline Bortonian & Puketeraki Core, Oamaru-Dunedin, New Zealand & I43/f094 (L16342) & $\begin{array}{l}\text { Wilson \& McMillan } \\
1996\end{array}$ \\
\hline Bortonian & Puketeraki Core, Oamaru-Dunedin, New Zealand & I43/f089 (L16337) & $\begin{array}{l}\text { Wilson \& McMillan } \\
1996\end{array}$ \\
\hline $\begin{array}{l}\text { Porangan- } \\
\text { Bortonian }\end{array}$ & $\begin{array}{l}\text { Hampden Beach Section, Oamaru-Dunedin, New } \\
\text { Zealand }\end{array}$ & J42/f302 (L23132) & \\
\hline
\end{tabular}

Areosphaeridium pectiniforme (Gerlach 1961) Stover \& Evitt 1978

PI. 67, figs. 4-12 
1963 Baltisphaeridium pectiniforme Gerlach 1961; Brosius, pp. 43-44, pl. 1, fig. 7, text-fig. 2 (9a-b)

1969 Cleistosphaeridium pectiniforme (Gerlach) Davey et al., p. 16

?1971 Areosphaeridium arcuatum Eaton, p. 360-363, pl. 3, figs. 1-9, text-fig. 4-5

1978 Areosphaeridium? pectiniforme (Gerlach 1961) Stover \& Evitt, p. 20

1982b Areosphaeridium arcuatum Eaton; Wilson, p. 7, pl. 2, fig. 7

1984b Areosphaeridium arcuatum Eaton, 1971; Helenes, p. 94, 104, pl. 5, figs. 5-6

?1995 Enneadocysta arcuata (Eaton 1971, p. 360-363, pl. 3, figs. 1-9; text-figs. 4-5) Stover \& Williams, p. 108, 109, textfigs. 1D, E

1995 Enneadocysta pectiniformis (Gerlach 1961) Stover \& Williams, p. 108, 114-115, pl. 6, figs. 1-4, text-figs. 1D, F

Original Description: [No translation available] Eine Art der Gattung Baltisphaeridium mit schlanken massiven Anhängen, die nach beiden Seiten weit ausladen und mit zahlreichen kleinen Häkchen besetzt sind. Form der Kapsel kreisförmig bis oval. Membran granuliert (Gerlach 1961, p. 195).

[Eaton's (1971) description of $A$. arcuatum] The central body has a sub-circular to sub-quadrate outline and a finely granular surface. The processes are intratabular and they have solid fibrous stems of variable length and breadth. Each process is distally expanded and bifurcate; the attitude of the bifurcations varies from patulate to recurved. The bifurcations are of variable length, and they vary in breadth from slender with a denticulate distal margin, to broad frequently net-like, with an irregular distal margin. Fenestration may be developed in the process stems producing stem branches which are sometimes distally free. The tabulation of 4', 6", 6"', 1p, 1"' is not always fully reflected by the processes. The processes reflecting plates 6", 6"' and $1 p$ are not always present. The cingular zone is typically devoid of processes although occasionally a process may occur on this zone. The antapex is typically offset to the right of the mid-ventral line and bears one process (1"'"). Between the postcingular processes and the antapical process there may be one or occasionally two additional processes. The archeopyle is apical, tetratabular (Eaton 1971, p. 360-361).

Size Range: Length excluding processes $=45$ (51) $55 \mu \mathrm{m}$ (3 measurements). Width excluding processes $=42$ (49) $58 \mu \mathrm{m}$ (3 measurements). Length including processes $=55$ (94) $110 \mu \mathrm{m}$ (20 measurements). Width including processes $=75$ (87) $112 \mu \mathrm{m}$ (10 measurements).

Distribution:

\begin{tabular}{|c|c|c|c|}
\hline Age/Stage & Location & Sample & Sample Reference \\
\hline $\begin{array}{l}\text { early } \\
\text { Oligocene }\end{array}$ & Emsburen Borehole-7, northwest Germany & Pr. $1170 / 53$ & Gerlach 1961 \\
\hline Bortonian & Puketeraki Core, Oamaru-Dunedin, New Zealand & I43/f093 (L16341) & $\begin{array}{l}\text { Wilson \& McMillan } \\
1996\end{array}$ \\
\hline Bortonian & Hampden Beach Section, Oamaru-Dunedin, New Zealand & J42/f042 (L09199) & Wilson 1985 \\
\hline Bortonian & Puketeraki Core, Oamaru-Dunedin, New Zealand & I43/f089 (L16337) & $\begin{array}{l}\text { Wilson \& McMillan } \\
1996\end{array}$ \\
\hline Lutetian & $\begin{array}{l}\text { Bateque Formation; Sebastian Vizcaino Basin, Baja } \\
\text { California }\end{array}$ & & Helenes 1984b \\
\hline
\end{tabular}

Remarks: Stover \& Evitt 1978, p. 20, notes that Areosphaeridium actinocoronatum, A. arcuatum, and A. pectiniforme might all be conspecific.

"Areosphaeridium" actinocoronatum is certainly different, many of the process tips being connected distally by a trabeculae. It has subsequently been reassigned to Reticulatosphaera, by Bujak \& Matsuoka 1986, p. 238, although this placement is contingent upon the assumption of a precingular archeopyle - refer to the discussion under that taxon.

Areosphaeridium pectiniforme allegedly differs from Areosphaeridium arcuatum in exhibiting 6 rather than 5-6 precingular processes, and in possessing an anterior sulcal process, for a total of 20 rather than 18-19 processes, and in having plate 1" smaller than plate 6", rather than larger as in A. arcuatum (Stover \& Williams 1995, table 1). To be meaningful, these differences have to be real, consistent, and phylogenetically significant. I am sceptical on all three counts.

Areosphaeridium michoudii Bujak 1994 was distinguished from various species of "Enneadocysta" on the basis of its sexiform hypocystal topology. If the present treatment of Enneadocysta as a junior synonym of Areosphaeridium is accepted, that distinction vanishes and the possibility arises that Areosphaeridium michoudii is a junior synonym of Areosphaeridium pectiniforme (or Areosphaeridium arcuatum, if the latter is itself distinct).

\section{Genus Cooksonidium Stover \& Williams 1995}


Type Species: Cooksonidium capricornum (Cookson \& Eisenack 1965a, p. 128-129, pl. 15, figs. 1-9) Stover \& Williams 1995, p. 107 [Late Eocene]

Original Description: Cysts skolochorate, central body subspherical and bears 16 to 18 intratabular processes and process complexes; process stems solid, smooth to fibroid, tips expanded distally, arcuate or rarely licrate or heart-shaped, ends free or connected by trabeculae; epicyst with 10 or 11 processes, hypocyst with six or seven processes arranged in the standard sexiform pattern, paracingular processes absent; archeopyle apical, operculum tetratabular, simple and free (Stover \& Williams 1995, p. 106).

Remarks: Cooksonidium appears to range from relatively late in the Bortonian through to the Kaiatan.

Cooksonidium capricornum (Cookson \& Eisenack 1965a) Stover \& Williams 1995

PI. 68, figs. 1-3

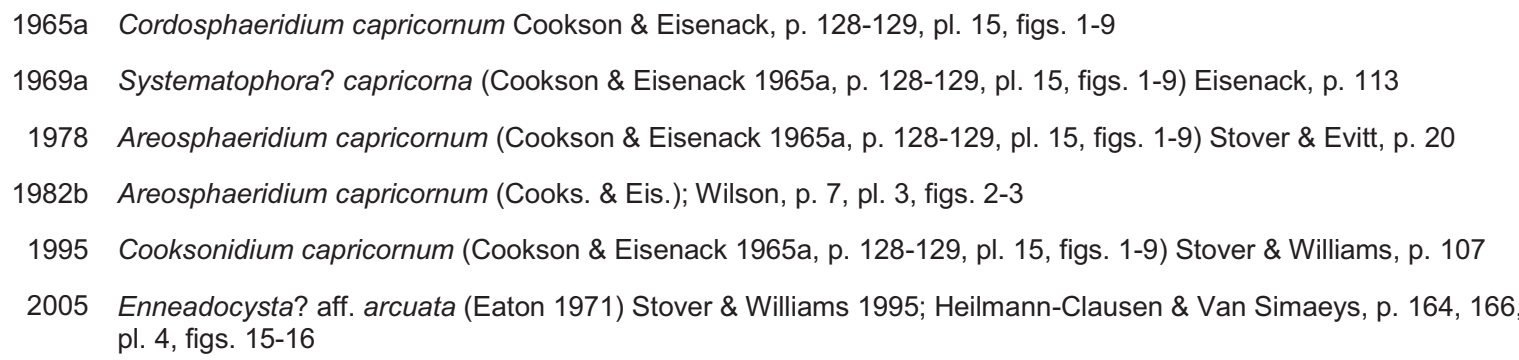

Original Description: Shell approximately spherical with numerous radially arranged appendages of characteristic form which vary in number in individual specimens and in size, form, and structure in one and the same specimen. All are solid; some are simple with unbranched or slightly branched apices or with terminal bifurcations which extend laterally and are upwardly or downwardly curved; others are broadly flattened and perforated to varying degrees with broad apices which narrow gradually as they curve backwards towards the shell. The upper surface of the apices and their extensions are consistently finely denticulate.... The bases of the larger appendages are semicircular to, occasionally, almost circular, and similarly the tips of the apical prolongations sometimes appear to touch but, in reality, are never connected. The appendages are sometimes faintly and longitudinally striated; shorter and more pronounced striations may be evident at or near their points of origin. The surface of the shell is faintly granular.

The archeopyle is apical, the operculum bearing four appendages, two relatively large and two small....

At the antapex an approximately circular area, outlined either completely ... or incompletely by a ridge to which a few small simple appendages mayor may not be attached, has been seen. Such an area is suggestive of an antapical field (Cookson \& Eisenack 1965a, p. 128-129).

Description of Study Material: Forms encountered in this study exhibit less well-developed trabeculae than the Australian types.

Size Range: Length excluding any processes $=32 \mu \mathrm{m}$ (one measured specimen). Width excluding any processes $=37 \mu \mathrm{m}$ (one measured specimen). Length including any processes $=52$ (74) $105 \mu \mathrm{m}(17$ measurements). Width including any processes $=57$ (81) $105 \mu \mathrm{m}$ (2 measurements).

Distribution:

$\begin{array}{llll}\text { Age/Stage } & \text { Location } & \text { Sample } & \text { Sample Reference } \\ \text { Kaiatan } & \text { Puketeraki Core, Oamaru-Dunedin, New Zealand } & \text { I43/f096 (L16344) } & \text { Wilson \& McMillan 1996 } \\ \text { Bartonian } & \begin{array}{l}\text { Søvind Marl Formation, Kysing Research Borehole, eastern } \\ \text { Jylland, central Danish Basin }\end{array} & 2661 & \text { Heilmann-Clausen \& Van } \\ \text { Bortonian } & \text { Puketeraki Core, Oamaru-Dunedin, New Zealand } & \text { I43/f092 (L16340) } & \text { Wilson \& McMillan 1996 }\end{array}$

Remarks: It is often difficult to place individual specimens within Areosphaeridium pectiniforme or Cooksonidium capricornum; the two taxa seem to intergrade in most samples, although the end points of the two populations are very clearly distinguishable. This intergradation may have been present in Cookson \& Eisenack's original Browns Creek Clay material, too: the specimen illustrated in their pl. 15, fig. 1, bears a strong likeness to Areosphaeridium pectiniforme as used here.

Genus Graptodinium Clowes n. gen.

Derivation of Name: Greek, $\gamma \rho \alpha \pi \tau \mathrm{c}$, written; with reference to the intratabular ornament which bears a fanciful resemblance to pictographic writing. 
Description: Cysts small, proximate, subspherical to distinctly prolate, lacking horns; the apical hemisphere slightly to considerably smaller than the antapical hemisphere. Cyst walls apparently single layered, ornamented by numerous short, sutural crests and characteristic intratabular accessory crests. Archeopyle apical, type tA; operculum free or attached; margin gently zig-zag; sulcal notch shallow and often inconspicuous. Processes lacking; ornament comprising low sutural and intratabular septa. Sutural septa clearly delineate a gonyaulacacean tabulation; formula ?4', $0 \mathrm{a}, 6$ "', 6c, 5 to 6'”, $1 \mathrm{ap}, 1$ 1'”; where only five postcingular plates are apparent, they are interpreted as representing plates 2"' to 6"'; torsion sinistral; ventral organisation L-type; antapical plate sexiform. Accessory septa forming an intratabular ornament, varying from discontinuous ridges and isolated granules to a fully developed reticulum. Cingulum and sulcus usually clearly expressed by the sutural septa; cingulum subdivided into transversely elongate plates; the ends of the cingulum not perceptibly offset but meeting the sulcus directly opposite one another.

Comparison: Directly opposite the apex of Graptodinium lies a single, large, six-sided antapical plate (the sexiform condition of Evitt 1985, p. 90), marking this form as a gonyaulacinean. The two genera with which Graptodinium cysts have commonly been identified in the past, Histiocysta and Microdinium, both exhibit a partiform hyposome and are thought to be Cladopyxiaceae. The hyposome condition, unfortunately, can be quite difficult to ascertain where specimens are few or inconveniently oriented, because the partiform and sexiform arrangements are topologically equivalent. They possess identical plate contacts and triple junctions. The only difference is the extent to which plate $1 p$ extends towards the antapical pole, which can only be seen in certain orientations.

Further morphological comparison with Histiocysta is difficult because the detailed morphology, particularly the tabulation pattern, of Histiocysta is rather poorly known, although the late Jurassic to Cretaceous Histiocysta) versus Eocene (Graptodinium) distribution is sufficient to avoid confusion for the practical purposes of daily identification.

Stover \& Evitt 1978, p. 65, 66) notes the occurrence of anterior intercalary plates in Microdinium; there is no evidence of anterior intercalary plates in Graptodinium.

Characters determining placement within the Leptodinioideae are the number of apical plates, ventral organisation, and torsion. Other Leptodinioideae (or possible Leptodinioideae) sharing an apical archeopyle, single wall-layer, and lacking processes, include Clathroctenocystis, Lanterna, Lithodinia, and Meiourogonyaulax. None closely resembles Graptodinium except Meiourogonyaulax, which can be distinguished by the more strongly helicoid cingulum, deep sulcal notch, and very different stratigraphic range.

Remarks: Graptodinium exhibits a morphological range which is here recognised by two species and an informal morphotype. The last, although equally distinctive, cannot be formally described with the material currently available.

The two formally described species are observed to (?almost) intergrade in some samples. Some authorities have taken the presence of intermediates as cue to "lump" taxa into a single species. However, as noted repeatedly throughout this paper, this urge is not rational: The discovery or otherwise of intermediates between phylogenetically related organisms is a sampling artefact, and thus an inappropriate motive for splitting or lumping taxa. Divisions between fossil morphotaxa are necessarily arbitrary and the imprecision of gradational boundaries between taxa is unavoidable.

Graptodinium inconditum Clowes n. sp.

$$
\text { PI. 68, figs. 4-12, PI. 69, figs. 1-6 }
$$

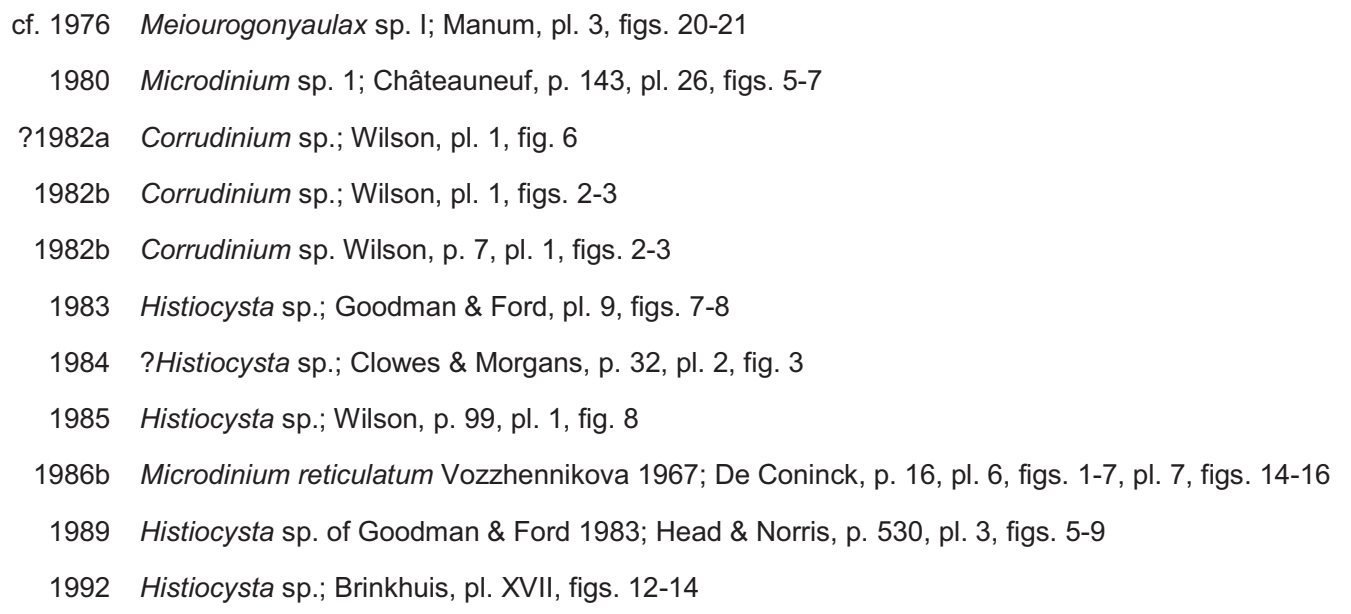


1994 Histiocysta sp.; Stover \& Hardenbol, pl. 2, figs. 13-14

1994 Histiocysta sp.; Stover \& Hardenbol, p. 32, pl. 2, fig. 13

1995 Stoveracysta sp. cf. S. ornata Cookson \& Eisenack 1974) Clowes 1985; Mao \& Mohr, p. 255, pl. 5, fig. 13

2005 Microdinium cf. reticulatum; Schiøler, pl. 13, fig. 11

2005 Microdinium sp. 1 of Châteauneuf (1980); Schiøler, pl. 17, figs. 14-15

Derivation of Name: Latin, inconditus, irregular, with reference to the intratabular ornamentation.

Holotype: Sample 143/f090, slide L16338/SM060; Burnside Formation, Puketeraki Core (Bortonian); PI. 68, figs. 4-9

Description: Cysts small, proximate, subspherical to slightly prolate, lacking horns; the apical hemisphere somewhat or, more usually, considerably smaller than the antapical hemisphere. Cyst walls apparently singlelayered. Archeopyle apical, type tA; operculum free or, more commonly, attached. Processes lacking; ornament comprising low, solid sutural and intratabular septa. Sutural septa approximately 2.5 to $4.5 \mu \mathrm{m}$ high, particularly distinct in equatorial view, forming a well-defined gonyaulacacean tabulation, ?4', 0a, 6", 6c, 6"', 1ap, 1'”'. Accessory septa comprising the irregular intratabular ornament forming an incomplete reticulum, sometimes continuous with the sutural septa, sometimes separated by a narrow clear area (Plate 1, figs. A, D). The floors of the muri appear smooth. Cingulum and sulcus clearly expressed by the sutural septa; cingulum broad $(\sim 5 \mu \mathrm{m})$ and typically subdivided, though not always clearly.

Size Range: Length = 28 (36) $45 \mu \mathrm{m}$ (77 measurements). Width = 30 (35) $40 \mu \mathrm{m}$ (11 measurements).

\section{Distribution:}

\begin{tabular}{|c|c|c|c|}
\hline Age/Stage & Location & Sample & Sample Reference \\
\hline ?late Whaingaroan & $\begin{array}{l}\text { Chalky Island Formation, Chalky Island, Fiordland, } \\
\text { New Zealand }\end{array}$ & $\begin{array}{l}\text { A45/f9553 (al. } \\
\text { S165/f553) }\end{array}$ & Wilson $1982 a$ \\
\hline Rupelian & Boom Clay Formation, north-western Belgium & 0.50 to $52.35 \mathrm{~m}$. & $\begin{array}{l}\text { Stover \& Hardenbol } \\
1994\end{array}$ \\
\hline early Rupelian & Lark Formation; Alma-1X well, Danish North Sea & 1825.8 to $1853.2 \mathrm{~m}$. & Schiøler 2005 \\
\hline early Rupelian & $\begin{array}{l}\text { Sands of Berg, Woensdrecht borehole, southern } \\
\text { Netherlands }\end{array}$ & $219 m$ & De Coninck 1986b \\
\hline early Whaingaroan & Kakanui River, Oamaru-Dunedin, New Zealand & J42/f096 (L10951) & $\begin{array}{l}\text { Clowes \& Morgans } \\
1984\end{array}$ \\
\hline ?early Whaingaroan & Kakanui River, Oamaru-Dunedin, New Zealand & J42/f097 (L10952) & $\begin{array}{l}\text { Clowes \& Morgans } \\
1984\end{array}$ \\
\hline $\begin{array}{l}\text { Runangan-early } \\
\text { Whaingaroan }\end{array}$ & Kakanui River, Oamaru-Dunedin, New Zealand & J42/f125 (L11625) & \\
\hline $\begin{array}{l}\text { Runangan-early } \\
\text { Whaingaroan }\end{array}$ & Kakanui River mouth & & $\begin{array}{l}\text { Clowes \& Morgans } \\
1984\end{array}$ \\
\hline Runangan & $\begin{array}{l}\text { Waiareka Volcanic Formation, Jacksons Paddock, } \\
\text { Otago, New Zealand }\end{array}$ & $\mathrm{J} 41 / \mathrm{f} 8914$ & Wilson $1982 b$ \\
\hline $\begin{array}{l}\text { late Eocene-early } \\
\text { Oligocene }\end{array}$ & Chalky Island, Fiordland, New Zealand & & Wilson 1982a \\
\hline Priabonian-Rupelian & Falkland Plateau, DSDP Leg 71, Hole 511 & $\begin{array}{l}511-17-1,102-104 \\
\mathrm{~cm}\end{array}$ & $\begin{array}{l}\text { Goodman \& Ford } \\
1983\end{array}$ \\
\hline ?Kaiatan-Runangan & Cape Foulwind Section, Westland, New Zealand & K29/f099 (L11035) & \\
\hline ?Priabonian & & & Brinkhuis 1992 \\
\hline Kaiatan & Puketeraki Core, Oamaru-Dunedin, New Zealand & I43/f096 (L16344) & $\begin{array}{l}\text { Wilson \& McMillan } \\
1996\end{array}$ \\
\hline ?Kaiatan & Hampden Beach section, Otago, New Zealand (LAD) & $\mathrm{J} 42 / \mathrm{f064}$ & Wilson 1985 \\
\hline ?Kaiatan & $\begin{array}{l}\text { Waiareka Formation; highest recorded occurrence in } \\
\text { Hampden Section, Otago, New Zealand }\end{array}$ & J42/f064 & Wilson 1985 \\
\hline ?late Bartonian & Horda Formation; Alma-1X well, Danish North Sea & $1862.3 \mathrm{~m}$. & Schiøler 2005 \\
\hline Bartonian & $\begin{array}{l}\text { Clay of Asse, Woensdrecht borehole, southern } \\
\text { Netherlands }\end{array}$ & $278 m$ & De Coninck 1986b \\
\hline Bortonian & $\begin{array}{l}\text { Hampden Beach Section, Oamaru-Dunedin, New } \\
\text { Zealand }\end{array}$ & J42/f061 (L09218) & Wilson 1985 \\
\hline Bortonian & $\begin{array}{l}\text { Hampden Beach Section, Oamaru-Dunedin, New } \\
\text { Zealand }\end{array}$ & J42/f303 (L23133) & \\
\hline Bortonian & Hampden Beach section, Otago, New Zealand & $\mathrm{J} 42 / \mathrm{f0} 44$ & Wilson 1985 \\
\hline Bortonian & $\begin{array}{l}\text { Hampden Formation, Hampden section, Otago, New } \\
\text { Zealand }\end{array}$ & $\mathrm{J} 42 / \mathrm{f} 8690$ & Wilson 1982b \\
\hline Bortonian & Hampden Beach Section, Oamaru-Dunedin, New & J42/f042 (L09199) & Wilson 1985 \\
\hline
\end{tabular}




$\begin{array}{llll}\text { Age/Stage } & \text { Location } & \text { Sample } & \text { Sample Reference } \\ \text { Zealand } & \begin{array}{l}\text { Zeaketeraki Core, Oamaru-Dunedin, New Zealand } \\ \text { Bortonian }\end{array} & \text { I43/f089 (L16337) } & \text { Wilson \& McMillan } \\ \text { Porangan-Bortonian } & \begin{array}{l}\text { Hampden Beach Section, Oamaru-Dunedin, New } \\ \text { Zealand }\end{array} & \text { J42/f301 (L23131) }\end{array}$

Comparison: The ornamentation of $G$. inconditum comprises discontinuous ridges and isolated granules, as opposed to the fully developed reticulum of G. reticulatum. Both taxa exhibit a range of morphologies which are quite distinct at their mid points in the samples examined as part of this study, though some intermediate specimens are less readily placed.

\title{
Graptodinium reticulatum Clowes $\mathrm{n} . \mathrm{sp}$.
}

$$
\text { PI. 69, figs. 7-12, PI. 70, figs. 1-3 }
$$

Derivation of Name: Latin, reticulus, a net or mesh; with reference to the surface texture.

Holotype: Sample 143/f093, slide L16341/SM071; Burnside Formation, Puketeraki Core (Bortonian); PI. 69, figs. 7-12

Description: Cysts small, proximate, subspherical to slightly prolate, lacking horns; the apical hemisphere somewhat or, more usually, considerably smaller than the antapical hemisphere. Cyst walls apparently singlelayered. Archeopyle apical, type tA; operculum free or, more commonly, attached. Processes lacking; ornament comprising low, solid sutural and intratabular septa. Sutural septa approximately 2 to $3 \mu \mathrm{m}$ high, particularly distinct in equatorial view, forming a fairly well-defined gonyaulacacean tabulation, ?4', 0a, 6", 6c, 5 to 6"', $1 \mathrm{ap}$, 1'”'. The dorsal postcingular series is particularly prominent. Accessory septa form an irregular intratabular reticulum, typically continuous with the sutural septa but more open and sometimes lacking immediately adjacent to sutures (Plate 1, fig. J). The floors of the muri appear smooth. Cingulum and sulcus clearly expressed by the sutural septa; cingulum broad $(\sim 5 \mu \mathrm{m})$ and typically subdivided, though not always clearly.

Size Range: Length = 29 (35) $45 \mu \mathrm{m}$ (9 measurements). Width = 26 (32) $37 \mu \mathrm{m}$ (2 measurements).

\section{Distribution:}

\begin{tabular}{|c|c|c|c|}
\hline Age/Stage & Location & Sample & Sample Reference \\
\hline $\begin{array}{l}\text { ?Kaiatan- } \\
\text { Runangan }\end{array}$ & Cape Foulwind Section, Westland, New Zealand & K29/f099 (L11035) & \\
\hline Bortonian & $\begin{array}{l}\text { Hampden Beach Section, Oamaru-Dunedin, New } \\
\text { Zealand }\end{array}$ & J42/f048 (L09205) & Wilson 1985 \\
\hline Bortonian & Puketeraki Core, Oamaru-Dunedin, New Zealand & I43/f093 (L16341) & $\begin{array}{l}\text { Wilson \& McMillan } \\
1996\end{array}$ \\
\hline Bortonian & $\begin{array}{l}\text { Hampden Beach Section, Oamaru-Dunedin, New } \\
\text { Zealand }\end{array}$ & J42/f042 (L09199) & Wilson 1985 \\
\hline Bortonian & Puketeraki Core, Oamaru-Dunedin, New Zealand & I43/f090 (L16338) & $\begin{array}{l}\text { Wilson \& McMillan } \\
1996\end{array}$ \\
\hline
\end{tabular}

Comparison: See G. inconditum, above.

\section{Genus Kleithriasphaeridium Davey 1974}

\author{
1974 Kleithriasphaeridium Davey, p. 55-56 \\ 1976 Diversispina Benson, p. 184 \\ 1978 Kleithriasphaeridium Davey 1974; Stover \& Evitt, p. 167-168
}

Type Species: Kleithriasphaeridium corrugatum Davey 1974, p. 56-57, pl. 5, figs. 1-5; text-fig. 3 [Cretaceous (Barremian)]

Original Description: The cysts are subspherical and bear one intratabular process per reflected plate area. The processes are hollow, open distally, and may be lightly striated; they vary in width with the smallest occupying the sulcal region (some of these may be solid). Rarely processes may be linked proximally by a membrane. The cyst wall beneath the processes is unusually thickened and granular. The reflected tabulation appears to be 3-4', 6", $6 \mathrm{c}, 5$ "', $1 \mathrm{p}$ ?, 1 "'" and 2 or more sulcal processes. The archeopyle is precingular formed by the loss of plate $3 "$ (Davey 1974, p. 55).

Remarks: In overall appearance, Kleithriasphaeridium exhibits an immediate similarity to Spiniferites. It differs, however, in that the processes seem essentially round in cross-section, are hollow, open, and distally they flare 
raggedly (somewhat similarly to Hystrichosphaeridium tubiferum) rather than being drawn into bi- or trifurcate points.

\title{
cf. Kleithriasphaeridium sp. 1
}

$$
\text { PI. 70, figs. 4-9 }
$$

Description: Cysts of intermediate size, chorate, not dorso-ventrally compressed, more or less spherical to prolate, lacking horns; episome and hyposome more or less equal in length. Archeopyle precingular, type P (3"). Surface ornament lacking. Processes ?gonal, spinose, straight; non-fibrous, hollow, open; proximally connected by sutural septa proximally, irregularly flaring distally. Tabulation clearly expressed, gonyaulacacean. Cingulum clearly expressed, indicated by sutural septa. Sulcus clearly expressed, indicated by sutural septa.

Size Range: Length excluding any processes $=72$ (72) $73 \mu \mathrm{m}$ (2 measurements). Width excluding any processes $=72$ (74) $75 \mu \mathrm{m}$ (2 measurements). Length including any processes $=80$ (101) $125 \mu \mathrm{m}$ (9 measurements). Width including any processes $=98$ (102) $107 \mu \mathrm{m}$ (2 measurements).

Distribution:

\begin{tabular}{|c|c|c|c|}
\hline Age/Stage & Location & Sample & Sample Reference \\
\hline early Whaingaroan & $\begin{array}{l}\text { Cape Foulwind Section, Westland, New } \\
\text { Zealand }\end{array}$ & K29/f114 (L11050) & \\
\hline Bortonian & $\begin{array}{l}\text { Puketeraki Core, Oamaru-Dunedin, New } \\
\text { Zealand }\end{array}$ & I43/f094 (L16342) & $\begin{array}{l}\text { Wilson \& McMillan } \\
1996\end{array}$ \\
\hline
\end{tabular}

Remarks: The processes of this form may be gonal, rather than intratabular, suggesting that placement in Kleithriasphaeridium is inappropriate. However, they also appear to be hollow and open distally, precluding placement in, say, Spiniferites.

The form identified as Spiniferites cf. ovatus Matsuoka 1983b by Ramírez (2004, pl. 4, figs. 11-12) from the Middle-Late Eocene of the east coast of the Maracaibo Lake, Venezuela, looks somewhat similar but seems to have shorter processes relative to the overall diameter.

\section{Genus Lophocysta Manum 1979}

\author{
1979 Lophocysta Manum, p. 238 \\ 1987 Lophocysta Manum 1979, p. 238; Stover \& Williams, p. 151-152
}

Type Species: Lophocysta sulcolimbata Manum 1979, p. 238, 240-242, pl. 1, figs. 1-11; text-figs. 1A-E [Early Miocene]

Original Description: Dinoflagellate cysts with apparent gonyaulacacean paratabulation; archeopyle pentagonal, precingular. Prominent periphragm expansion restricted to mid-ventral area and with ribs indicating paratabulation. Dorsal face with inconspicuous processes in gonal positions (Manum 1979, p. 238).

\section{Lophocysta ?sulcolimbata Manum 1979}

$$
\text { PI. 70, figs. 10-12, PI. 71, figs. 1-3 }
$$

1979 Lophocysta sulcolimbata Manum, p. 238, 240-242, pl. 1, figs. 1-11, text-fig. 1A-E

Original Description: Dinoflagellate cysts with pentagonal, precingular archeopyle. Central body ovoid, with a prominent ventral crest formed by an expanded periphragm along the entire midventral zone, extending from anterior end of archeopyle to posterior end of parasulcus; maximum crest height about 2/3 equatorial diameter of central body. The crest has a finely reticulate to striate texture and more prominent parasutural ribs. The entire parasulcus plus paraplates 1' and 4', 6", 6c, 1"' and 6"', and ip are represented in the crest.

Three conspicuous openings are in constant positions at the base of the periphragm crest: one in either side at the intersections between crest and paracingulum, the third - and largest - opening immediately below the paracingular opening in the left hand side. Two further openings - inconspicuous and sometimes fused - occur in a position interpreted as the left accessory sulcal paraplate. 
Inconspicuous processes, 1-3 $\mu \mathrm{m}$ high, occur in some - but not all - gonal positions of dorsal paraplates. Most consistent are two in posterior end of paraplate 4" and eight occupying gonal positions of cingular paraplates.

Dorsal cyst wall apparently unstratified and slightly under $2 \mu \mathrm{m}$ thick, surface entirely smooth (Manum 1979, p. 238).

Size Range: Length = 54 (58) $62 \mu \mathrm{m}$ (4 measurements). Width $=40$ (45) $52 \mu \mathrm{m}$ (3 measurements).

Distribution:

$\begin{array}{llll}\text { Age/Stage } & \text { Location } & \text { Sample } & \text { Sample Reference } \\ \text { Kaiatan } & \text { Puketeraki Core, Oamaru-Dunedin, New Zealand } & \text { I43/f096 (L16344) } & \text { Wilson \& McMillan 1996 } \\ \text { Bortonian } & \text { Puketeraki Core, Oamaru-Dunedin, New Zealand } & \text { I43/f089 (L16337) } & \text { Wilson \& McMillan 1996 }\end{array}$

\title{
Subfamily Uncertain
}

\section{Genus Aireiana Cookson \& Eisenack 1965a}

\author{
1965a Aireiana Cookson \& Eisenack, p. 127 \\ 1975 Aireiana Cookson \& Eisenack 1965; Stover, p. 43 \\ 1978 Aireiana Cookson \& Eisenack 1965a; Stover \& Evitt, p. 139 \\ 1984 Aireiana; Damassa, p. 60-61
}

Type Species: Aireiana verrucosa Cookson \& Eisenack 1965a, p. 127, pl. 14, figs. 11-13 [Late Eocene]

Original Description: Shell spherical, firm-walled, with an apical and antapical prominence and a number of irregularly distributed wart-like areas of variable size and construction. A smooth girdle-like zone and a similar unornamented longitudinal area may be indicated on the dorsal and ventral surfaces respectively. The shell opens by a sub-apical archeopyle (Cookson \& Eisenack 1965, p. 127).

Remarks: Aireiana differs from Cordosphaeridium and Kleithriasphaeridium in lacking cingular processes, and in having distally closed and generally shorter processes (after Stover \& Evitt 1978, p. 139).

\section{Aireiana salicta Damassa 1979a}

\section{PI. 71, figs. 4-9}

\section{9a Aireiana salicta Damassa, p. 817-818, pl. 1, figs. 4-9}

Original Description: [Diagnosis] Skolochorate cyst, ellipsoidal to spherical in shape, having fibrous intratabular processes formed by differentiation of outer part of autophragm. Processes tend to become fused in apical and sulcal regions. Paracingulum devoid of processes. Precingular archeopyle with rounded margin. (Description) Skolochorate cyst, ellipsoidal to spherical, overall diameter 54-60 microns, average 56 microns, of eight specimens. Diameter of holotype $=57$ microns. Wall consists of autophragm only. Total wall thickness $2-3$ microns. Twelve to fourteen fibrous intratabular processes, 13-35 microns in length, formed by differentiation of outer part of autophragm. Processes without a hollow interior. Processes tend to become fused in apical and sulcal regions. Longitudinal cross section of processes more or less rectangular; transverse cross section circular to irregular. Paracingulum devoid of processes; parasulcal processes variably distinct, but anterior and posterior sulcal processes generally can be distinguished. Precingular, postcingular and antapical processes large and generally well developed, although the first and second postcingular processes are fused with those of the parasulcus. Apex bears a single large process. Archeopyle Type $\mathrm{P}$, formed by loss of the third precingular paraplate. Margin of archeopyle rounded; operculum free. Surface of cyst similar to processes in appearance, fibrous and highly perforate at the surface. Process formula - 1', 5-6", 0c, xs, 1p, 6"', 1'”'. Inferred thecal tabulation - 4', 6"', 6c, xs, 1p, 6"', 1"',.

[Remarks] Aireiana salictum can be distinguished from A. verrucosa, the type species, by the length (13-35 vs. 610 microns, respectively) and fibrous nature of the processes (Stover 1975 [p. 43-44]). The number and shape of processes in the parasulcal region of A. salictum are highly variable. The sulcal paraplates are represented by an irregular mass from which several process tips arise. This group may include 1p, 1'", and 2"' as well. Clear indication of any paracingular processes is lacking in the specimens observed, although there is a possibility they may be represented as irregular thickenings on the adcingular side of the postcingular processes. The four apical paraplates are represented by a process complex which may have a divided tip, indicating fusion of several processes. The antapical process tends to be tapered and terminally rounded, a feature which aids in specimen orientation. In contrast, distal surfaces of the large precingular and postcingular processes are roughly parallel to the surface of the cyst (Damassa 1979, p. 817-818). 
Size Range: Length excluding any processes $=73(74) 75 \mu \mathrm{m}$ (2 measurements). Width excluding any processes $=75(76) 77 \mu \mathrm{m}$ (2 measurements). Length including any processes $=95$ (108) $122 \mu \mathrm{m}$ ( 2 measurements). Width including any processes $=102$ (115) $128 \mu \mathrm{m}$ ( 2 measurements).

Distribution: Very rare. In the present study, two specimens, only, were observed in a single sample.

$\begin{array}{llll}\text { Age/Stage } & \text { Location } & \text { Sample } & \text { Sample Reference } \\ \text { Bortonian } & \text { Puketeraki Core, Oamaru-Dunedin, New Zealand } & \text { I43/f090 (L16338) } & \text { Wilson \& McMillan } 1996\end{array}$

Remarks: Aireiana salicta can be distinguished from A. verrucosa by the length (13-35 vs. 6-10 $\mu$ m, respectively) of the processes (Damassa 1979a, p. 818).

\title{
Genus Fibrocysta Stover \& Evitt 1978
}

\author{
$1978 \quad$ Fibrocysta Stover \& Evitt, p. 155
}

Type Species: Fibrocysta bipolaris (Cookson \& Eisenack 1965b, p. 135, pl. 16, figs. 7-8) Stover \& Evitt 1978, p. 155 [Early Eocene]

Original Description: Cysts skolochorate; body ellipsoidal with small to long hornlike protrusions, generally one at each pole; body also bears numerous solid or hollow, normally nontabular processes; paratabulation usually indicated by precingular, Type P, archeopyle only (Stover \& Evitt 1978, p. 155).

\section{Fibrocysta bipolaris (Cookson \& Eisenack 1965b) Stover \& Evitt 1978}

$$
\text { PI. 71, figs. 10-12, PI. 72, figs. 1-3 }
$$

\author{
1965b Cordosphaeridium bipolare Cookson \& Eisenack, p. 135, pl. 16, figs. 7-8 \\ 1969 Lanternosphaeridium bipolare (Cookson \& Eisenack 1965b, p. 135, pl. 16, figs. 7-8) De Coninck, p. 38 \\ 1969 Lanternosphaeridium essentiale De Coninck, p. 38, pl. 11, figs. 7-8 \\ 1969c Amphorosphaeridium bipolare (Cookson \& Eisenack 1965b, p. 135, pl. 16, figs. 7-8) Davey, p. 35 \\ 1978 Fibrocysta bipolaris (Cookson \& Eisenack 1965b, p. 135, pl. 16, figs. 7-8) Stover \& Evitt, p. 155 \\ 1999a Fibrocysta essentialis (De Coninck, 1969); De Coninck, pl. 1, figs. 1-2 \\ 1999a Fibrocysta aff. essentialis (De Coninck, 1969); De Coninck, p. 150-151, pl. 1, figs. 3-4
}

Original Description: Shell typically oval, well-covered with narrow, solid, unbranched appendages of varying length and width. Usually the appendages narrow somewhat from broadish bases to widen distally to shallow funnel-shaped apices, the recurved edges of which may bear minute hair-like branches. In the larger appendages fine, longitudinal fibrils may be seen. The shell is bipolar, being characterized by the development of a distinctive apical and antapical appendage. The apical appendage is relatively short and broad, solid, densely granular and with a bluntish tip. It may be simple or with one or two short, slender, lateral branches. In the type specimen ... it appears to be connected with three broad, flattened, longitudinally striated appendages. The antapical appendage is longer than the neighbouring ones, unstriated, unbranched with approximately straight sides and a pointed tip.

The surface of the shell is densely granular with a linear arrangement evident near the bases of the appendages. A large archeopyle extends from close to the apical pole to the equatorial region of one surface (Cookson \& Eisenack 1965b, p. 135; ellipses replace figure references in the original).

Size Range: Length excluding any processes $=70(76) 83 \mu \mathrm{m}$ (2 measurements). Width excluding any processes = 63 (65) $67 \mu \mathrm{m}$ (2 measurements). Length including any processes $=108$ (122) $137 \mu \mathrm{m}$ (2 measurements). Width including any processes = 95 (96) $97 \mu \mathrm{m}$ (2 measurements).

\section{Distribution:}

\begin{tabular}{|c|c|c|c|}
\hline Age/Stage & Location & Sample & Sample Reference \\
\hline Bortonian & $\begin{array}{l}\text { Hampden Beach Section, Oamaru- } \\
\text { Dunedin, New Zealand }\end{array}$ & J42/f040 (L09197) & Wilson 1985 \\
\hline Bortonian & $\begin{array}{l}\text { Puketeraki Core, Oamaru-Dunedin, New } \\
\text { Zealand }\end{array}$ & I43/f090 (L16338) & $\begin{array}{l}\text { Wilson \& McMillan } \\
1996\end{array}$ \\
\hline Ypresian & Kallo borehole, Belgium & -374.5 m. - prep. 2 & De Coninck 1969 \\
\hline $\begin{array}{l}\text { late Paleocene-early } \\
\text { Eocene }\end{array}$ & Kallo borehole, Belgium & $\begin{array}{l}-272.5 \text { m. - lame } 1 ;-272.5 \text { m. - } \\
\text { lame } 2\end{array}$ & De Coninck 1999a \\
\hline late Paleocene-early & Knokke borehole, Belgium & -283 m. - lame 1; -284 m. - lame & De Coninck 1999a \\
\hline
\end{tabular}




\title{
Genus Pyxidinopsis Habib 1976
}

\author{
1976 Pyxidinopsis Habib, p. 382 \\ 1978 Pyxidinopsis Habib 1976; Stover \& Evitt, p. 183-184 \\ 1989c Pyxidinopsis Habib, 1976; Head et al., p. 494
}

Type Species: Pyxidinopsis challengerensis Habib 1976, p. 382, pl. 1, figs. 1a-b; pl. 3, figs. 1-2 [Cretaceous (Berriasian-Hauterivian)]

Original Description: Proximate dinoflagellate cysts. Outline in lateral, dorsal and ventral views oval to elliptical; longer than wide with rounded polar areas. Discrete apical and antapical horns lacking. Autoblast two-layered [sic] with periphragm and endophragm in contact. Evidence of cyst tabulation, cingulum or sulcus lacking. Archeopyle large and precingular, formed by loss of a single plate (Type P). Operculum simple and free. Periphragm texture variable, processes always wider or longer than high (Habib 1975, p. 382).

Remarks: Pyxidinopsis exists today as a kind of catch-all for any essentially spherical, proximate cyst with a type $P$ archeopyle, but lacking other indications of tabulation. Accordingly, it has accumulated an odd assortment of species, ranging in age from late Jurassic ( $P$. laminata Davies 1983) to Recent ( $P$. psilata Wall \& Dale $1973 ; P$. reticulata McMinn \& Sun 1994) and geographically from arctic Canada and the north Atlantic to New Zealand. The type species, $P$. challengerensis, hails from the early Cretaceous (Berriasian-Hauterivian) of the north Atlantic, and is most unlikely to have any phylogenetic affinity with many - or possibly any - of the other species.

Unfortunately, the genus is difficult to split apart precisely because it is so featureless. It is already divided into species according to ornament, and to separate it into multiple genera on that basis leaves us no better off. Even the occasional hint of a cingulum offers little hope: nobody seriously doubts that the thing has a cingulum, so unless we can get a very good indication of its end points on the ventral surface (e.g. to state with confidence whether the topology is L- or S-type) these mere hints of its existence avail us not at all. The only morphological features which do seem to offer some insight are the (a) size and (b) shape of the archeopyle.

Among the New Zealand Paleogene dinoflagellate species with single plate precingular archeopyles and few indications of tabulation, two distinct groups may be assembled, depending upon the size and shape of the archeopyle. The forms most similar to the type species of Pyxidinopsis, P. challengerensis, are those with large ("oversize") archeopyles having the standard Gonyaulax shape. Within this group, it is possible the lightly constructed forms with an open reticulum, such as $P$. delicata, may form a natural clade. A second group, as first noted in Clowes \& Wilson 2006, is denoted by a rather small ("undersize") archeopyle with a characteristically narrow apex, which lends it a triangular shape. This group includes $P$. waipawaensis and similar forms

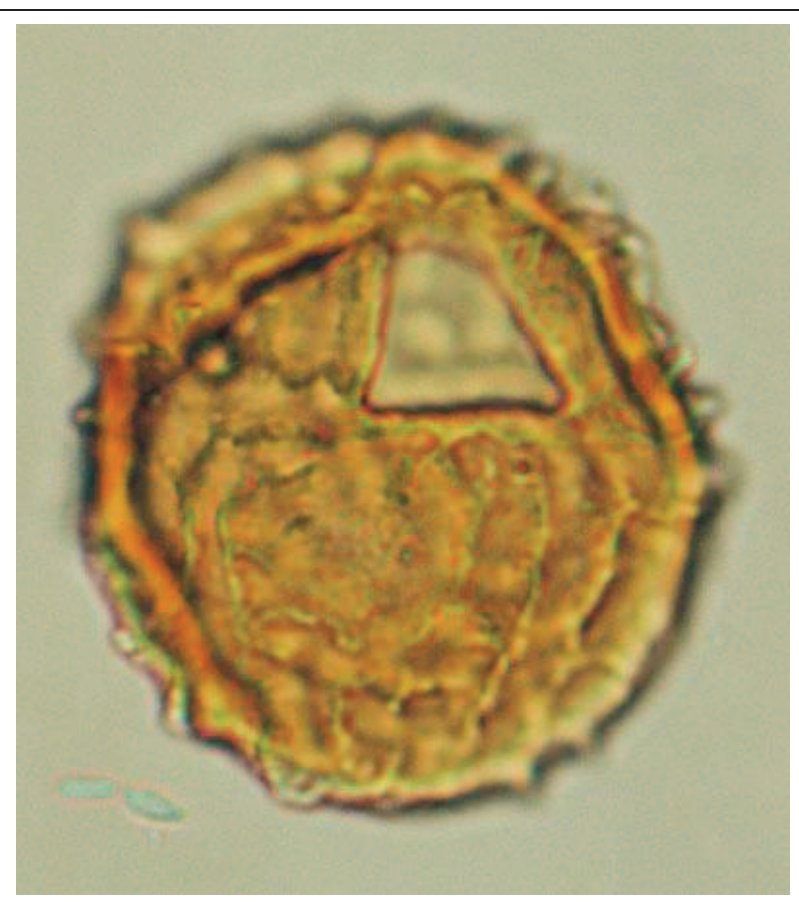

Text-Fig. 23: Holotype of ?Corrudinium vermiculatum (Wilson 1988) Clowes \& Wilson 2006, showing "undersized" sub-triangular precingular archeopyle. (PI. 75, figs. 1-3, PI. 75, figs. 4-5, PI. 75, fig. 6) as well as the enigmatic ?Corrudinium vermiculatum (TextFig. 23).

Beyond morphology alone, there may be some phylogenetic validity in dividing the genus on the basis of clustering of the species in space and time. For example, the New Zealand Tertiary forms are almost certainly not closely related to the type species, yet they may very well be related to one another.

A range chart for species of Pyxidinopsis is provided in Appendix 2, chart 8.

Key to selected species:

\begin{tabular}{|l|l|l|}
\hline 0. & Archeopyle small.... & 1. \\
\hline & Archeopyle large.... & 2. \\
\hline 1. & Archeopyle shape is narrow/subtriangular.... & 1.1. \\
\hline
\end{tabular}




\begin{tabular}{|c|c|c|}
\hline & Archeopyle is the standard Gonyaulax pentagonal shape.... & 1.2. \\
\hline \multirow[t]{2}{*}{1.1.} & Cingulum lacking.... & 1.1.1. \\
\hline & Cingulum weakly expressed.... & 1.1.2. \\
\hline 1.1 .1$. & \multicolumn{2}{|l|}{ Pyxidinopsis cf. waipawaensis (PI. 75, fig. 6) } \\
\hline 1.1.2. & \multicolumn{2}{|l|}{ ?Corrudinium vermiculatum } \\
\hline 1.2. & \multicolumn{2}{|l|}{ Pyxidinopsis waipawaensis } \\
\hline \multirow[t]{2}{*}{2.} & Surface ornament comprising a reticulum with angular lacunae.... & 2.1. \\
\hline & Surface ornament comprosing irregular ridges/rugulae.... & 2.2. \\
\hline \multirow[t]{4}{*}{2.1.} & Surface ornament density $8-12$ sculptural elements across the diameter.... & 2.1 .1$. \\
\hline & Surface ornament density $10-15$ sculptural elements across the diameter.... & 2.1.2. \\
\hline & Surface ornament density $14-18$ sculptural elements across the diameter.... & 2.1.3. \\
\hline & Surface ornament density $\sim 20$ sculptural elements across the diameter.... & 2.1.4. \\
\hline 2.1 .1$. & \multicolumn{2}{|l|}{ Pyxidinopsis cf. delicata } \\
\hline 2.1 .2$. & \multicolumn{2}{|l|}{ Pyxidinopsis sp. 3} \\
\hline 2.1.3. & \multicolumn{2}{|l|}{ Pyxidinopsis delicata } \\
\hline 2.1 .4 & \multicolumn{2}{|l|}{ Pyxidinopsis mundus } \\
\hline \multirow[t]{2}{*}{2.2} & Walls very thick.... & 2.2.1. \\
\hline & Walls relatively thinner ("normal” for the genus).... & 2.2.2. \\
\hline 2.2.1. & \multicolumn{2}{|l|}{ Pyxidinopsis crassimurata } \\
\hline 2.2 .2$. & \multicolumn{2}{|l|}{ Pyxidinopsis teuriensis } \\
\hline
\end{tabular}

\section{Pyxidinopsis crassimurata Wilson 1988}

PI. 72, figs. 4-6

1988 Pyxidinopsis crassimurata Wilson, p. 27, pl. 17, figs. 1a-b, 2, 3a-c

Original Description: Cyst subspherical, of intermediate size, with a thick two layered wall (total thickness c. $4 \mu \mathrm{m}$ ) comprising a thin smooth inner layer and a thick spongy (tectate) microreticulate outer layer, both layers being in close contact. Surface ornament also comprises thin solid irregular ridges (height up to $3 \mu \mathrm{m}$ ) which are linked to form a coarse macroreticulum superimposed upon the microreticulate outer layer; ridges apparently not related to a paratabulation. Archeopyle precingular type $\mathrm{P}\left(3^{\prime \prime}\right.$ only) relatively large, elongate, pentagonal; operculum free. Paratabulation indicated by archeopyle only, although the macroreticulation has a somewhat polygonal pattern which resembles paraplates. Paracingulum and parasulcus not generally indicated (Wilson 1988, p. 27)

Size Range: Length = 58 (76) $95 \mu \mathrm{m}$ (2 measurements). Width $=58 \mu \mathrm{m}$ (one measured specimen).

\section{Distribution:}

$\begin{array}{llll}\text { Age/Stage } & \text { Location } & \text { Sample } & \text { Sample Reference } \\ \text { Porangan } & \text { Te Uri Stream, Hawkes Bay, New Zealand } & \text { U24/f418 (L23126) } & \\ \text { Heretaungan } & \text { Hampden Beach Section, Oamaru-Dunedin, New Zealand } & \text { J42/f039 (L09196) } & \text { Wilson 1985 }\end{array}$

\section{Pyxidinopsis teuriensis Clowes n. sp.}

$$
\text { PI. 72, figs. 7-12, PI. 73, figs. 1-6 }
$$

Derivation of Name: Named after the type locality, Te Uri Stream.

Holotype: Sample J42/f484, slide L23119/SM031; Kurinui Formation, Hampden Beach Section (Heretaungan);

Description: Cysts of intermediate size, proximate, not dorso-ventrally compressed, more or less spherical, lacking horns. Cyst wall single-layered; relatively robust, about $2 \mu \mathrm{m}$ in thickness. Archeopyle precingular, type P (3"); pentagonal (standard Gonyaulax-type), large; operculum free. Processes lacking; surface ornament present, non-tabular, comprising irregular ridges/rugulae; with features on a scale of 14-18 sculptural elements across the diameter; 2-3 $\mu \mathrm{m}$ high. Cingulum not expressed. Sulcus not expressed. 
Size Range: Length $=61$ (72) $80 \mu \mathrm{m}$ (5 measurements). Width $=62$ (71) $77 \mu \mathrm{m}$ (5 measurements).

Distribution:

\begin{tabular}{|c|c|c|c|}
\hline Age/Stage & Location & Sample & Sample Reference \\
\hline Bortonian & Puketeraki Core, Oamaru-Dunedin, New Zealand & I43/f094 (L16342) & $\begin{array}{l}\text { Wilson \& McMillan } \\
1996\end{array}$ \\
\hline $\begin{array}{l}\text { Porangan- } \\
\text { Bortonian }\end{array}$ & $\begin{array}{l}\text { Hampden Beach Section, Oamaru-Dunedin, New } \\
\text { Zealand }\end{array}$ & J42/f301 (L23131) & \\
\hline $\begin{array}{l}\text { Porangan- } \\
\text { Bortonian }\end{array}$ & $\begin{array}{l}\text { Hampden Beach Section, Oamaru-Dunedin, New } \\
\text { Zealand }\end{array}$ & J42/f485 (L23120) & \\
\hline Porangan & Te Uri Stream, Hawkes Bay, New Zealand & U24/f419 (L23127) & \\
\hline Porangan & $\begin{array}{l}\text { Hampden Beach Section, Oamaru-Dunedin, New } \\
\text { Zealand }\end{array}$ & J42/f299 (L23129) & \\
\hline Porangan & Te Uri Stream, Hawkes Bay, New Zealand & U24/f418 (L23126) & \\
\hline Heretaungan & $\begin{array}{l}\text { Hampden Beach Section, Oamaru-Dunedin, New } \\
\text { Zealand }\end{array}$ & J42/f483 (L23118) & \\
\hline
\end{tabular}

Comparison: Pyxidinopsis teuriensis is most similar to $P$. crassimurata, in possessing a coarse reticulum, but is readily distinguished because it lacks the fine microreticulum visible in the lumina of crassimurata, and in its thinner cyst wall.

\section{Pyxidinopsis cf. delicata}

Pl. 73, figs. 7-12

?2005 Cerebrocysta bartonensis; Schiøler, pl. 19, figs. 10-11

Description: Cysts small to intermediate, proximate, not dorso-ventrally compressed, more or less spherical, lacking horns. Cyst wall single-layered; relatively robust, about $2 \mu \mathrm{m}$ in thickness. Archeopyle precingular, type P (3"); pentagonal (standard Gonyaulax-type), large; operculum free. Processes lacking; surface ornament present, non-tabular, comprising reticulum with angular lacunae; with features on a scale of 8-12 sculptural elements across the diameter; 2-3 $\mu \mathrm{m}$ high. Cingulum not expressed. Sulcus not expressed.

Size Range: Length = 40 (44) $47 \mu \mathrm{m}$ (2 measurements). Width $=52 \mu \mathrm{m}$ (one measured specimen).

Distribution:

$\begin{array}{llll}\text { Age/Stage } & \text { Location } & \text { Sample } & \text { Sample Reference } \\ \text { Bortonian } & \text { Puketeraki Core, Oamaru-Dunedin, New Zealand } & \text { I43/f091 (L16339) } & \text { Wilson \& McMillan 1996 } \\ \text { Bortonian } & \text { Puketeraki Core, Oamaru-Dunedin, New Zealand } & \text { I43/f090 (L16338) } & \text { Wilson \& McMillan 1996 }\end{array}$

Remarks: Compared with Pyxidinopsis delicata s.s., this form has (1) a relatively more open reticulum, 8-12 sculptural elements across the diameter as opposed to 14-18, and (2) a younger age range, Bortonian as opposed to Heretaungan to Porangan. However, the two forms are otherwise very similar (pers. obs.; GJ Wilson pers. comm.) It remains to be seen if these differences are consistent and are not just sampling artefacts.

\section{Pyxidinopsis delicata Wilson 1988}

1988 Pyxidinopsis delicata Wilson, p. 27-28, pl. 17, figs. 6, 7a-b

Original Description: Cyst subspherical, small to intermediate in size, fairly thick-walled (2-4 $\mu$ m), apparently comprising autophragm only with thin smooth inner layer and slightly thicker reticulate outer layer. Reticulum somewhat irregular with thin delicate, smooth or crenulate muri (height 2-3 $\mu \mathrm{m}$ ). Texture of lumina finely reticulate. Archeopyle small, polygonal (usually pentagonal or nearly square); operculum free or attached along posterior margin. Paratabulation indicated by archeopyle only. No trace of paracingulum or parasulcus (Wilson 1988, p. 28).

Description of Study Material: Cysts of intermediate size, proximate, not dorso-ventrally compressed, more or less spherical, lacking horns. Cyst wall single-layered; relatively robust, about $2 \mu \mathrm{m}$ in thickness. Archeopyle precingular, type P (3"); pentagonal (standard Gonyaulax-type), large; operculum free to attached. Processes lacking; surface ornament present, non-tabular, comprising reticulum with angular lacunae; with features on a scale of 14-18 sculptural elements across the diameter; 2-3 $\mu \mathrm{m}$ high. Cingulum not expressed. Sulcus not expressed.

Size Range: Length $=40$ (53) $72 \mu \mathrm{m}$ (24 measurements). Width $=50 \mu \mathrm{m}$ (one measured specimen). 


\begin{tabular}{|c|c|c|c|}
\hline Age/Stage & Location & Sample & Sample Reference \\
\hline Bortonian & $\begin{array}{l}\text { Hampden Beach Section, Oamaru-Dunedin, New } \\
\text { Zealand }\end{array}$ & J42/f061 (L09218) & Wilson 1985 \\
\hline Bortonian & Puketeraki Core, Oamaru-Dunedin, New Zealand & I43/f093 (L16341) & $\begin{array}{l}\text { Wilson \& McMillan } \\
1996\end{array}$ \\
\hline Bortonian & Puketeraki Core, Oamaru-Dunedin, New Zealand & I43/f089 (L16337) & $\begin{array}{l}\text { Wilson \& McMillan } \\
1996\end{array}$ \\
\hline $\begin{array}{l}\text { Porangan- } \\
\text { Bortonian }\end{array}$ & $\begin{array}{l}\text { Hampden Beach Section, Oamaru-Dunedin, New } \\
\text { Zealand }\end{array}$ & J42/f301 (L23131) & \\
\hline Porangan & Te Uri Stream, Hawkes Bay, New Zealand & U24/f418 (L23126) & \\
\hline Porangan & $\begin{array}{l}\text { Hampden Beach Section, Oamaru-Dunedin, New } \\
\text { Zealand }\end{array}$ & $\mathrm{J} 42 / f 300(\mathrm{~L} 23130)$ & \\
\hline Porangan & Te Uri Stream, Hawkes Bay, New Zealand & $\mathrm{U} 24 / \mathrm{f} 417$ (L23125) & \\
\hline Heretaungan & $\begin{array}{l}\text { Hampden Beach Section, Oamaru-Dunedin, New } \\
\text { Zealand }\end{array}$ & J42/f039 (L09196) & Wilson 1985 \\
\hline
\end{tabular}

Remarks: Pyxidinopsis delicata s.s. has a relatively fine reticulum and appears confined to the Porangan or older. A younger form ( $P$. cf. delicata) has a relatively more open reticulum.

Pyxidinopsis sp. 3

\section{PI. 74, figs. 1-3}

Description: Cysts of intermediate size, proximate, not dorso-ventrally compressed, more or less spherical, lacking horns. Cyst wall single-layered; relatively robust, about $2 \mu \mathrm{m}$ in thickness. Archeopyle precingular, type P (3"); pentagonal (standard Gonyaulax-type), large; operculum free. Processes lacking; surface ornament present, non-tabular, comprising reticulum with angular lacunae; with features on a scale of 10-15 sculptural elements across the diameter; 2-3 $\mu \mathrm{m}$ high. Cingulum not expressed. Sulcus not expressed.

Size Range: Length $=57 \mu \mathrm{m}$ (one measured specimen). Width $=55 \mu \mathrm{m}$ (one measured specimen).

Distribution:

$\begin{array}{llll}\text { Age/Stage } & \text { Location } & \text { Sample } & \text { Sample Reference } \\ \text { Porangan } & \text { Te Uri Stream, Hawkes Bay, New Zealand } & \text { U24/f419 (L23127) }\end{array}$

Pyxidinopsis mundus Clowes n. sp.

Pl. 74, figs. 4-12

Derivation of Name: Latin, mundus, elegant, tidy; with reference to the neat, even reticulum.

Holotype: Sample U24/f419, slide L23127/SM020; Wanstead, Te Uri Stream (Porangan); PI. 74, fig. 4

Description: Cysts of intermediate size, proximate, not dorso-ventrally compressed, more or less spherical, lacking horns. Cyst wall single-layered; relatively robust, about $2 \mu \mathrm{m}$ in thickness. Archeopyle precingular, type P (3"); pentagonal (standard Gonyaulax-type), large; operculum free. Processes lacking; surface ornament present, non-tabular, comprising reticulum with angular lacunae; with features on a scale of 20 sculptural elements across the diameter; 2-3 $\mu \mathrm{m}$ high. Cingulum not expressed. Sulcus not expressed.

Size Range: Length = 42 (51) $55 \mu \mathrm{m}$ (7 measurements). Width = 43 (49) $54 \mu \mathrm{m}$ (3 measurements).

Distribution:

\begin{tabular}{llll}
\hline Age/Stage & Location & Sample & Sample Reference \\
Bortonian & Hampden Beach Section, Oamaru-Dunedin, New Zealand & J42/f057 (L09214) & Wilson 1985 \\
Bortonian & Hampden Beach Section, Oamaru-Dunedin, New Zealand & J42/f042 (L09199) & Wilson 1985 \\
Porangan-Bortonian & Hampden Beach Section, Oamaru-Dunedin, New Zealand & J42/f485 (L23120) & \\
Porangan & Te Uri Stream, Hawkes Bay, New Zealand & U24/f419 (L23127) & \\
Heretaungan & Hampden Beach Section, Oamaru-Dunedin, New Zealand & J42/f483 (L23118) &
\end{tabular}

Comparison: Pyxidinopsis mundus is most similar to $P$. waipawaensis but differs in possessing a larger archeopyle, which, as noted above, may possibly have generic significance, and in the finer reticulum. 
Remarks: The alignment of ornamental features evident in PI. 74, fig. 6, which appears to hint at a faint tabulation, is not an artefact of the photograph: the features are also visible under the microscope. However, it is well-known that the human eye is adept at discerning patterns, even where they may not exist. Without the corroboration at least another specimen with similar features, it is probably premature to think of claiming a tabulation for Pyxidinopsis although most would agree it undoubtedly possesses one.

\section{Pyxidinopsis waipawaensis Wilson 1988}

PI. 75, figs. 1-6

1988 Pyxidinopsis waipawaensis Wilson, p. 28, pl. 17, figs. 4, 5a-b

Original Description: Cyst subspherical, small to intermediate in size, fairly thick walled (c. $2 \mu \mathrm{m}$ ), apparently comprising autophragm only, with a characteristically reticulate surface. Reticulation sharply defined by interconnected narrow muri (height c. 1-2 $\mu \mathrm{m}$ ) defining polygonal smooth lumina of variable size (average breadth range $0.5 \mu \mathrm{m}$ to $4 \mu \mathrm{m}$ ), but size of lumina rarely exceeding $5 \mu \mathrm{m}$. Occasional short non-interconnecting ridges project from muri. No other surface ornamentation present. Archeopyle relatively large, precingular, type P (3" only), somewhat rounded pentagonal, to almost quadrangular, typically bordered by low, narrow, ridge; operculum free. Paratabulation indicated by archeopyle only. No trace of paracingulum or parasulcus (Wilson 1988, p. 28).

Description of Study Material: Cysts of intermediate size, proximate, not dorso-ventrally compressed, more or less spherical, lacking horns. Cyst wall single-layered; relatively robust, about $2 \mu \mathrm{m}$ in thickness. Archeopyle precingular, type P(3"); pentagonal (standard Gonyaulax-type), small; operculum free. Processes lacking; surface ornament present, non-tabular, comprising reticulum with angular lacunae; with features on a scale of 24 30 sculptural elements across the diameter; about 1-2 $\mu \mathrm{m}$ high. Cingulum not expressed. Sulcus not expressed.

Size Range: Length = 58 (69) $80 \mu \mathrm{m}$ (2 measurements). Width = 56 (69) $82 \mu \mathrm{m}$ (2 measurements).

Distribution:

$\begin{array}{llll}\text { Age/Stage } & \text { Location } & \text { Sample } & \text { Sample Reference } \\ \text { Bortonian } & \text { Burnside Marl Pit, Oamaru-Dunedin, New Zealand } & \text { 144/f080 (L08947) } & \text { Clowes \& Wilson 2006 } \\ \text { Heretaungan } & \text { Waipawa Section, Hawkes Bay, New Zealand } & \text { V22/f8994 (L12118) } & \text { Wilson 1988 }\end{array}$

Remarks: Note that the holotype of Pyxidinopsis waipawaensis comes from sample V22/f8994, laboratory preparation number L12118, not preparation number L12121 as erroneously stated in Wilson 1988, p. 28. The paratype illustrated in Wilson 1988, pl. 17, fig. 4, is a single mount slide, registered as SM279, and comes from sample V22/f7401. This sample was prepared at least twice, the second time as laboratory preparation number L12121. Wilson 1988, Appendix 1 (p. 34) records the earlier preparation number as L976. However, that is incorrect according to the GNS Science L and SM catalogues, which attribute L976 to a different collection altogether, and do not record an L number for SM279. Notwithstanding the two clerical errors, which relate to the preparation numbers only, all accounts agree on the sample attribution, and the typification of the species is secure.

\section{Family Areoligeraceae Evitt 1963b}

Key to genera identified in this study:

\begin{tabular}{|l|l|l|}
\hline 0. & Cyst wall single-layered.... & 1. \\
\hline & Cyst wall two-layered (endophragm + periphragm).... & 2. \\
\hline 1. & Cysts chorate.... & 1.1. \\
\hline & Cysts proximochorate.... & 1.2. \\
\hline 1.1. & Processes rarely connected distally.... & 1.1 .1$. \\
\hline & Processes connected by well developed trabecula.... & 1.1 .3$. \\
\hline 1.1 .1$. & Processes dolabrate (see Remarks under Cleistosphaeridium).... & 1.1 .1 .1$. \\
\hline & Processes not dolabrate.... & 1.1 .1 .2$. \\
\hline 1.1 .1 .1$. & Cleistosphaeridium & \\
\hline 1.1 .1 .2 & Areoligera & \\
\hline 1.1 .3$. & Glaphyrocysta & \\
\hline 1.2 & Cyclonephelium & \\
\hline 2. & Chiropteridium; Membranophoridium; Senoniasphaera & \\
\hline
\end{tabular}




\title{
Genus Areoligera Lejeune-Carpentier 1938a
}

\author{
1938a Areoligera Lejeune-Carpentier, p. B164 \\ 1978 Areoligera Lejeune-Carpentier 1938; Stover \& Evitt, p. 17-19 \\ 2004 Areoligera Lejeune-Carpentier, 1938a, p. B164; Fensome \& Williams, p. 58-61
}

Type Species: Areoligera senonensis Lejeune-Carpentier 1938a, p. B164-B166, text-figs. 1-3 [Cretaceous (Senonian)]

Original Description: The shell is more or less hemispherical, showing a large convex face and another more or less depressed face of more reduced dimensions. This latter does not show in itself any particular ornament; it is bordered by a fringe of spiny laminae. On the other face are located large areas, each one encircled by a collarette; these areas are divided into two main groups by a line of much smaller elements forming a girdle. From the small areas as well as from the collarettes arise numerous spines, most of them long and slender, which may unite together at their distal extremity (translated from Lejeune-Carpentier 1938, p. 164, by Stover \& Evitt 1978, p. 17-18).

\section{?Areoligera hampdenensis Clowes $\mathrm{n} . \mathrm{sp}$.}

$$
\text { PI. 75, figs. 7-12, PI. 76, figs. 1-12 }
$$

1988 Systematophora placacantha (Deflandre \& Cookson, 1955) Davey et al., 1969, emend. May, 1980; Wilson, p. 31, pl. 22, figs. 1-4

2005 Heterosphaeridium heteracanthum; Schiøler, pl. 2, fig. 2

Derivation of Name: Named after the type locality, Hampden Beach.

Holotype: Sample J42/f483, slide L23118/SM005; Kurinui Formation, Hampden Beach Section (Heretaungan); PI. 75, figs. 7-12

Description: Cysts of intermediate size, chorate, dorso-ventrally compressed, lenticular, lacking horns. Cyst wall single-layered. Archeopyle apical, type tA; operculum free. Processes penitabular, spinose, somewhat sinuous; non-fibrous, commonly bi- and trifurcating, apparently solid, highly variable, from about 10 to $20 \mu \mathrm{m}$ in length; incompletely united into penitabular ridges proximally, capitate distally. Tabulation weakly expressed, apparently gonyaulacacean, inferred formula: 4', 0a, 6", X-6c, 5-6"', 1ps, 1'"', Xs. Cingulum not expressed. Sulcus weakly expressed, indicated by sutural septa.

Size Range: Length excluding any processes $=47$ (59) $72 \mu \mathrm{m}$ (14 measurements). Width excluding any processes $=43(58) 75 \mu \mathrm{m}$ (17 measurements). Length including any processes = 75 (96) $125 \mu \mathrm{m}(14$ measurements). Width including any processes $=70$ (89) $107 \mu \mathrm{m}$ (17 measurements).

Distribution: Frequent. Although apparently of limited stratigraphic range, within that interval it occurs frequently, and is common in some samples.

\begin{tabular}{|c|c|c|c|}
\hline Age/Stage & Location & Sample & $\begin{array}{l}\text { Sample } \\
\text { Reference }\end{array}$ \\
\hline Porangan-Bortonian & $\begin{array}{l}\text { Hampden Beach Section, Oamaru-Dunedin, New } \\
\text { Zealand }\end{array}$ & J42/f486 (L23121) & \\
\hline Porangan & $\begin{array}{l}\text { Hampden Beach Section, Oamaru-Dunedin, New } \\
\text { Zealand }\end{array}$ & J42/f300 (L23130) & \\
\hline Porangan & Te Uri Stream, Hawkes Bay, New Zealand & U24/f419 (L23127) & \\
\hline Porangan & Waipawa standard section, Hawkes Bay, New Zealand & V22/f7401 & Wilson 1988 \\
\hline Porangan & Te Uri Stream, Hawkes Bay, New Zealand & U24/f417 (L23125) & \\
\hline $\begin{array}{l}\text { Heretaungan- } \\
\text { Porangan }\end{array}$ & $\begin{array}{l}\text { Hampden Beach Section, Oamaru-Dunedin, New } \\
\text { Zealand }\end{array}$ & J42/f298 (L23128) & \\
\hline Heretaungan & Waipawa standard section, Hawkes Bay, New Zealand & V22/f8994 & Wilson 1988 \\
\hline Heretaungan & $\begin{array}{l}\text { Hampden Beach Section, Oamaru-Dunedin, New } \\
\text { Zealand }\end{array}$ & J42/f483 (L23118) & \\
\hline
\end{tabular}

Comparison: This taxon is broadly similar to the Cleistosphaeridium ancyrea-placacanthum group, but differs in possessing a more robust cyst, heterogeneous processes, and process tips which are not principally dolabrate.

The species described in Maier 1959 as Galea (now questionably assigned to Hystrichosphaeridium by Eisenack \& Kjellström 1975b) koryka somewhat resembles the present taxon (see especially Maier's pl. 30, fig. 7) and would obviously be the senior synonym if they are indeed the same. 
Remarks: As noted above, this taxon is broadly similar to the Cleistosphaeridium ancyrea-placacanthum group, but generic placement is tipped in favour of Areoligera by the heterogeneous processes, and nature of the process tips. The type of Heterosphaeridium differs from the present material in possessing a relatively straight margin to the archeopyle and "appendages of varying widths in one and the same specimen" (Cookson \& Eisenack 1968, p. 115).

In the absence of any plausible intermediate taxa, however, it seems unlikely to be closely related to the Cretaceous genotype species, Areoligera senonensis, which, if one is to adopt the phylogenetic viewpoint, is a reason to question the generic assignment.

\title{
?Areoligera sp. 2
}

PI. 77, figs. 1-9

Description: Cysts of intermediate size, chorate, dorso-ventrally compressed, lenticular, lacking horns; episome somewhat shorter than hyposome. Cyst wall single-layered. Archeopyle apical, type tA; operculum free. Processes penitabular, spinose, somewhat sinuous; non-fibrous, commonly bi- and trifurcating, apparently solid, highly variable, from about 10 to $20 \mu \mathrm{m}$ in length; incompletely united into penitabular ridges proximally, capitate distally. Tabulation clearly expressed, gonyaulacacean, inferred formula: 4', 0a, 6", X-6c, 5-6"', 1ps, 1"'", Xs. Cingulum moderately expressed, indicated by sutural septa. Sulcus weakly expressed, indicated by sutural septa.

Size Range: Length excluding any processes $=54$ (61) $68 \mu \mathrm{m}$ (2 measurements). Width excluding any processes $=62$ (62) $62 \mu \mathrm{m}$ (2 measurements). Length including any processes $=79$ (83) $87 \mu \mathrm{m}$ (2 measurements). Width including any processes $=77$ (84) $91 \mu \mathrm{m}$ (2 measurements).

Distribution:

$\begin{array}{lll}\text { Age/Stage } & \text { Location } & \text { Sample } \\ \text { Porangan } & \text { Hampden Beach Section, Oamaru-Dunedin, New Zealand } & \text { J42/f300 (L23130) } \\ \text { Porangan } & \text { Te Uri Stream, Hawkes Bay, New Zealand } & \text { U24/f417 (L23125) } \\ \text { Porangan } & \text { Hampden Beach Section, Oamaru-Dunedin, New Zealand } & \text { J42/f299 (L23129) } \\ \text { Heretaungan } & \text { Hampden Beach Section, Oamaru-Dunedin, New Zealand } & \text { J42/f484 (L23119) }\end{array}$

Remarks: A few specimens of ?Areoligera appear sufficiently dissimilar to those listed here as Areoligera sp. 1 to warrant separate consideration, but they are too few to merit formal description. Their processes are very heterogeneous, and some are more flattened.

Genus Cleistosphaeridium Davey et al. 1966 emend. Eaton et al. 2001

\author{
1966 Cleistosphaeridium Davey et al., p. 166 \\ 1978 Cleistosphaeridium Davey et al. in Davey et al. 1966; Stover \& Evitt, p. 31-32 \\ 2001 Cleistosphaeridium Davey et al. 1966 emend. Eaton et al., p. 176-177 \\ 2004 Cleistosphaeridium Davey et al., 1966, p. 166; Fensome \& Williams, p. 133-143 \\ 2006 Cleistosphaeridium Davey et al. 1966 emend. Eaton et al. 2001; Fensome et al., p. 410
}

Type Species: Cleistosphaeridium diversispinosum Davey et al. 1966, p. 167, pl. 10, fig. 7 emend. Eaton et al. 2001 [Early Eocene]

Original Description: Chorate dinoflagellate cysts having spherical to ovoidal central bodies bearing numerous processes, typically closed distally and without communication to endocoel. Number of processes typically exceeding 50; processes show no definite alignment, so that the tabulation is not determinable. Archeopyle apical, with zigzag margin (Davey et al. 1966, p. 166).

Remarks: The implication of the words "closed distally" in the original diagnosis is that the processes of Cleistosphaeridium are hollow, whereas, in fact, those of the type species, at least, are solid. This point is also noted in Islam 1993 (p. 82).

Islam 1993 (p. 88) further reports that the type species of Cleistosphaeridium, C. diversispinosum, sometimes has processes connected into penitabular areolae, and notes a partial tabulation, although no formula is derived. On the strength of this observation, Islam proposed Cleistosphaeridium to be a junior synonym of Systematophora, a recommendation which was adopted by a number of subsequent authors. However, as contended many times herein, the nature of the ornament - whether sutural, intratabular, subtly connected into areolae or not - has less phylogenetic significance at the generic level than the vast temporal gulf separating the type species of the two genera (Eocene in the case of Cleistosphaeridium diversispinosum, as opposed to Early Kimmeridgian for Systematophora areolata; a small matter of 100 million years). The only phylogenetically 
important distinction between intratabular and non-tabular ornament, per se, is that the former permits the deduction of a tabulation pattern whereas the latter does not, allowing cysts possessing an intratabular ornament to be more readily classified.

Accordingly, Cleistosphaeridium is retained here, recognised as a valid genus.

These considerations are echoed in Eaton et al. 2001, which also comments upon the "very different stratigraphic ranges" of the taxa (p. 171), and explores an interesting interpretation of the "pick-like" process terminations of Cleistosphaeridium, for which the authors coin the term "dolabrate" (p. 174, fig. 7).

I accept with enthusiasm the idea that an asymmetrical process tip is evidence of asymmetrical process placement within the plate - obtabular, parasutural or intratabular - and may thus distinguish between, for example, intratabular and non-tabular ornament. But do notionally non-tabular processes ever actually straddle sutures? If one can't tell, then the distinction is moot, anyway.

Downiesphaeridium and Polysphaeridium differ from Cleistosphaeridium in possessing hollow processes. Impletosphaeridium has solid processes and may yet prove to be a (senior) synonym of Cleistosphaeridium (Eaton et al. 2001, p. 173), being nominally distinguished only because there is no record of the type material exhibiting penitabular ridges joining some processes into process complexes. I am unaware of any comparison of the process tips. (The type material for the genotype, Impletosphaeridium transfodum Morgenroth 1966a is apparently lost; see Islam 1993, p. 85.)

The formal placement of Cleistosphaeridium within the Areoligeraceae is effected in Fensome et al. 2006 although, in the present writer's view, the authors of that paper draw a rather long bow at times, and, as noted elsewhere, I cannot concur with maintaining the distinction between Areosphaeridium and Enneadocysta on such slim evidence as the symmetry of the process tips.

The present writer's decision to place Cleistosphaeridium within the Areoligeraceae was prompted by the evident similarity with the species described herein as ?Areoligera hampdenensis, and further encouraged by the comment in Eaton et al. 2001, p. 173-174, that Cleistosphaeridium species generally show a preferred dorsoventral orientation and that the archeopyle margin sometimes exhibits an offset sulcal notch. (It must, however, also be mentioned that the emended description of the type species, Cleistosphaeridium diversispinosum, given in Eaton et al. 2001, p. 177-189, describes any dorso-ventral flattening as "only limited", p. 180.)

Cleistosphaeridium diversispinosum Davey et al. 1966 emend. Eaton et al. 2001

PI. 77, figs. 10-12

1966 Cleistosphaeridium diversispinosum Davey et al. 1966, p. 167, pl. 10, fig. 7

2001 Cleistosphaeridium diversispinosum Davey et al. 1966 emend Eaton et al., p. 177-188, figs. 1-7

Original Description: A Cleistosphaeridium with granular wall and polygonal archeopyle. Processes solid, taeniate or tubular, usually slender and proximally expanded. Distal end forked or expanded (Davey et al. 1966, p. 167).

Size Range: Length excluding any processes $=43 \mu \mathrm{m}$ (one measured specimen). Width excluding any processes $=32$ (38) $45 \mu \mathrm{m}$ (2 measurements). Length including any processes $=72 \mu \mathrm{m}$ (one measured specimen). Width including any processes $=52$ (63) $74 \mu \mathrm{m}$ (2 measurements).

Distribution:

$\begin{array}{llll}\text { Age/Stage } & \text { Location } & \text { Sample } & \text { Sample Reference } \\ \text { Bortonian } & \begin{array}{l}\text { Hampden Beach Section, Oamaru-Dunedin, New } \\ \text { Zealand }\end{array} & \text { J42/f303 (L23133) } & \\ \text { Bortonian } & \text { Puketeraki Core, Oamaru-Dunedin, New Zealand } & \text { I43/f093 (L16341) } & \text { Wilson \& McMillan } \\ & & & 1996 \\ \begin{array}{l}\text { Porangan- } \\ \text { Bortonian }\end{array} & \begin{array}{l}\text { Hampden Beach Section, Oamaru-Dunedin, New } \\ \text { Zealand }\end{array} & \text { J42/f302 (L23132) }\end{array}$

Cleistosphaeridium ancyreum (Cookson \& Eisenack 1965a) Eaton et al. 2001

PI. 78, figs. 1-6

1965a Systematophora ancyrea Cookson \& Eisenack, p. 126, pl. 14, figs. 1-3

1992 Systematophora placacantha var. ancyrea (Cookson \& Eisenack 1965a, p. 126, pl. 14, figs. 1-3) Strauss \& Lund, p. 173

2000 Systematophora ancyrea Cookson \& Eisenack, 1965a; Levy \& Harwood, p. 228, pl. 9, figs. j-I 
Original Description: Shell spherical or slightly oval with a rather thick, densely granular wall and numerous slender, flexuous, simple or occasionally forked appendages with capitate or slightly bifurcate apices. The appendages arise, mainly, from raised ridges which completely or incompletely delimit circular or polygonal areas. These areas are variable in size and are either separate from one another or coalescent. On one surface such areas tend to bound a narrow longitudinal apparently appendage-free surface. The shell opens by an apical archeopyle, the angular rim of which is suggestive of plates (Cookson \& Eisenack 1965a, p. 126).

Size Range: Length excluding any processes $=40 \mu \mathrm{m}$ (one measured specimen). Width excluding any processes $=35$ (39) $43 \mu \mathrm{m}$ (2 measurements). Length including any processes $=65 \mu \mathrm{m}$ (one measured specimen). Width including any processes $=41$ (52) $62 \mu \mathrm{m}$ (2 measurements).

Distribution:

$\begin{array}{llll}\text { Age/Stage } & \text { Location } & \text { Sample } & \text { Sample Reference } \\ \text { Bortonian } & \text { Hampden Beach Section, Oamaru-Dunedin, New Zealand } & \text { J42/f488 (L23123) } & \\ \text { Heretaungan } & \text { Hampden Beach Section, Oamaru-Dunedin, New Zealand } & \text { J42/f483 (L23118) } & \\ \text { Eocene } & \text { erratics, McMurdo Sound, Antarctica } & \text { MB 188G } & \text { Levy \& Harwood 2000 } \\ \text { Eocene } & \text { erratics, McMurdo Sound, Antarctica } & \text { MTD 42 } & \text { Levy \& Harwood 2000 }\end{array}$

Remarks: Cleistosphaeridium ancyreum is a morphological intermediary between C. diversispinosum, in which penitabular ridges are developed only very weakly or not at all, and C. placacanthum, in which penitabular ridges are complete and pronounced. Ridges are developed, but they are not continuous and sometimes not evident on every plate (Eaton et al. 2001, p. 188).

Cleistosphaeridium placacanthum (Deflandre \& Cookson 1955) Eaton et al. 2001

$$
\text { Pl. 78, figs. 7-9 }
$$

1955 Hystrichosphaeridium placacanthum Deflandre \& Cookson, p. 276-277, pl. 9, figs. 1-3

1965 Baltisphaeridium placacanthum (Deflandre \& Cookson 1955) Downie \& Sarjeant, p. 94

1965 Baltisphaeridium placacanthum (Deflandre \& Cookson 1955, p. 276-277, pl. 9, figs. 1-3) Downie \& Sarjeant, p. 94

1966a Impletosphaeridium placacanthum (Deflandre \& Cookson 1955) Morgenroth, p. 35-36, pl. 9, figs. 10-11

1969 Systematophora placacantha (Deflandre \& Cookson 1955, p. 276-277, pl. 9, figs. 1-3) Davey et al., p. 17

1972 Impletosphaeridium placacanthum (Deflandre and Cookson 1955) Morgenroth 1966; Benedek, p. 31, pl. 10, figs. 3a-c

?1983 Systematophora placacantha (Deflandre and Cookson, 1955) Davey et al., 1969; Goodman \& Ford, p. 866, pl. 8, figs. 6-7

2001 Cleistosphaeridium placacanthum (Deflandre \& Cookson 1955) Eaton et al., p. 190-191

2005 Cleistosphaeridium placacanthum; Schiøler, pl. 9, fig. 6

Original Description: Shell globular, circular or asymmetrical in outline, with a large number of processes that are aligned so as to divide the whole surface into more or less polygonal plate-like areas or fields. Each field is separated from its neighbours by an area devoid of appendages. Processes solid, of variable form, somewhat flexuous, simple or branched with pointed or hammer-shaped extremities, widening at the base. Sometimes the bases of 2 or more processes are connected by bridge-like strands; occasionally the apices may coalesce or be connected by a delicate thread as in Cannosphaeropsis (Deflandre \& Cookson 1955, p. 277).

Size Range: Length excluding processes $=47 \mu \mathrm{m}$ (one measured specimen). Width excluding processes $=$ $56 \mu \mathrm{m}$ (one measured specimen). Length including processes $=63$ (74) $84 \mu \mathrm{m}$ (2 measurements). Width including processes $=93 \mu \mathrm{m}$ (one measured specimen).

\section{Distribution:}

\begin{tabular}{|c|c|c|c|}
\hline Age/Stage & Location & Sample & Sample Reference \\
\hline Whaingaroan & Akitio River, Hawkes Bay, New Zealand & U24/f201 (L12144) & \\
\hline ?early Whaingaroan & Kakanui River, Oamaru-Dunedin, New Zealand & J42/f097 (L10952) & $\begin{array}{l}\text { Clowes \& Morgans } \\
1984\end{array}$ \\
\hline $\begin{array}{l}\text { Runangan-early } \\
\text { Whaingaroan }\end{array}$ & Cape Foulwind Section, Westland, New Zealand & K29/f106 (L11042) & \\
\hline Runangan & Cape Foulwind Section, Westland, New Zealand & K29/f102 (L11038) & \\
\hline
\end{tabular}


Remarks: Cleistosphaeridium placacantum is distinguished from Cleistosphaeridium ancyreum by possessing penitabular ridges which are complete and pronounced, as opposed to discontinuous to lacking on some plates (Cleistosphaeridium ancyreum) or barely evident at all (Cleistosphaeridium diversispinosum) (Eaton et al. 2001, p. 188).

\title{
Cleistosphaeridium sp. 1
}

\author{
PI. 78, figs. 10-12
}

Description: Cysts of intermediate size; more or less spherical; apparently single layered; with numerous, evenly and densely distributed, similar non-tabulate spines; spines solid, non-fibrous, some possibly vacuolated at the base; capitate, generally straight, and fairly stubby. Cyst surface between spines minutely, evenly and densely maculate. No indications of cingulum or sulcus. Archeopyle apparently apical; type tA. Tabulation indeterminate.

Size Range: Length excluding processes $=47$ (48) $50 \mu \mathrm{m}$ (2 measurements). Width excluding processes $=$ $40 \mu \mathrm{m}$ (one measured specimen). Length including processes $=45$ (59) $80 \mu \mathrm{m}$ (12 measurements). Width including processes $=60 \mu \mathrm{m}$ (one measured specimen).

\section{Distribution:}

$\begin{array}{llll}\text { Age/Stage } & \text { Location } & \text { Sample } & \text { Sample Reference } \\ \text { Runangan } & \text { Cape Foulwind Section, Westland, New Zealand } & \text { K29/f261 (L13543) } & \\ \text { Bortonian } & \text { Puketeraki Core, Oamaru-Dunedin, New Zealand } & \text { I43/f094 (L16342) } & \text { Wilson \& McMillan 1996 } \\ \text { Bortonian } & \text { Puketeraki Core, Oamaru-Dunedin, New Zealand } & \text { I43/f089 (L16337) } & \text { Wilson \& McMillan 1996 }\end{array}$

Remarks: The very straight, relatively short spines of this form are quite distinctive.

\section{Cleistosphaeridium sp. 3}

\section{PI. 79, figs. 1-6}

Description: Cysts small, chorate, dorso-ventrally compressed, lenticular, lacking horns; episome and hyposome more or less equal in length. Cyst wall single-layered. Archeopyle apical (?); operculum free. Surface ornament present, non-tabular, comprising a dense reticulum. Processes penitabular, spinose, somewhat sinuous; nonfibrous, occasionally branching, apparently solid; incompletely united into penitabular ridges proximally, dolabrate distally. Tabulation weakly expressed, apparently gonyaulacacean. Cingulum weakly expressed, indicated by the alignment of processes. Sulcus weakly expressed, indicated by the alignment of processes.

Size Range: Length excluding any processes $=40 \mu \mathrm{m}$ (one measured specimen). Width excluding any processes $=45 \mu \mathrm{m}$ (one measured specimen). Length including any processes $=52(70) 102 \mu \mathrm{m}(10$ measurements). Width including any processes $=65 \mu \mathrm{m}$ (one measured specimen).

Distribution:

\begin{tabular}{|c|c|c|c|}
\hline Age/Stage & Location & Sample & Sample Reference \\
\hline $\begin{array}{l}\text { early } \\
\text { Whaingaroan }\end{array}$ & Cape Foulwind Section, Westland, New Zealand & K29/f114 (L11050) & \\
\hline Bortonian & Puketeraki Core, Oamaru-Dunedin, New Zealand & I43/f094 (L16342) & $\begin{array}{l}\text { Wilson \& McMillan } \\
1996\end{array}$ \\
\hline Bortonian & Puketeraki Core, Oamaru-Dunedin, New Zealand & I43/f089 (L16337) & $\begin{array}{l}\text { Wilson \& McMillan } \\
1996\end{array}$ \\
\hline Porangan & $\begin{array}{l}\text { Hampden Beach Section, Oamaru-Dunedin, New } \\
\text { Zealand }\end{array}$ & $\mathrm{J} 42 / \mathrm{f3} 00$ (L23130) & \\
\hline
\end{tabular}

Remarks: I have to admit that I am far from confident that this taxon does not possess a large precingular archeopyle. There are many specimens, yet none show a precingular archeopyle face-on, yet, in the end, it was only the dolabrate processes which tipped me in favour of Cleistosphaeridium, with the implied apical archeopyle. 
Genus Cyclonephelium Deflandre \& Cookson 1955 emend. Stover \& Evitt 1978

\author{
1955 Cyclonephelium Deflandre \& Cookson, p. 285 \\ 1958a Tenua Eisenack, p. 410 \\ 1978 Cyclonephelium Cookson 1955 emend. Stover \& Evitt, p. 35-36
}

Type Species: Cyclonephelium compactum Deflandre \& Cookson 1955, p. 285, pl. 2, figs. 11-13; text-figs. 44-46 [Cretaceous (Albian-Santonian)]

Original Description: Shell spheroidal, flattened, with an equatorial ornamentation that extends for varying distances from the equator but never to the poles. The ornament is composed of processes that are either distinct or close and confluent and sometimes connected by more or less broad trabeculae. Shell often provided with large and ill-defined lateral opening (Deflandre \& Cookson 1955, p. 258).

\title{
Cyclonephelium membranophorum Cookson \& Eisenack 1962b
}

$$
\text { PI. 79, figs. 7-9 }
$$

1962b Cyclonephelium membranophorum Cookson \& Eisenack, p. 495, pl. 6, figs. 8-14

Original Description: Shell apparently concavo-convex ..., circular to subcircular in outline. Circumferential border zone delimited by two thin membranes of equal width, each of which is supported by rather widely spaced, equidistant, radial fibres. These fibres arise from the peripheral surfaces of the shell, and their bases are connected with one another tangentially. They are simple or capitate and relatively stout. Sometimes fine radial striae cross the width of the membranes, in which cases the edges appear to be very finely toothed. Occasionally a union between opposing fibres may occur, with the formation of wide funnel-like structures. The sculpture of the shell varies from very finely to coarsely granular (Cookson \& Eisenack 1962b, p. 495; ellipses replace figure references in the original).

Size Range: Length including processes $=87 \mu \mathrm{m}$ (one measured specimen). Width including processes $=95 \mu \mathrm{m}$ (one measured specimen).

Distribution: Extremely rare; known from a single specimen.

$\begin{array}{llll}\text { Age/Stage } & \text { Location } & \text { Sample } & \text { Sample Reference } \\ \text { Bortonian } & \text { Puketeraki Core, Oamaru-Dunedin, New Zealand } & \text { I43/f090 (L16338) } & \text { Wilson \& McMillan } 1996\end{array}$

Remarks: The form encountered in this study superficially resembles C. membranophorum, although the age is quite wrong (C. membranophorum is supposedly Albian; the present specimen is Bortonian.)

\section{Genus Glaphyrocysta Stover \& Evitt 1978}

\author{
1978 Glaphyrocysta Stover \& Evitt, p. 49-50
}

Type Species: Glaphyrocysta retiintexta (Cookson 1965a, p. 88, pl. 11, fig. 4) Stover \& Evitt 1978, p. 50 [Cretaceous (Senonian)]

Original Description: Cysts skolochorate, body lenticular with several annulate to arcuate penitabular process complexes; most complexes join to one another distally by a simple to intricate system of trabeculae; midventral and middorsal areas typically process-free or with reduced processes; archeopyle apical, Type tA; parasulcal notch offset (Stover \& Evitt 1978, p. 49).

\section{Glaphyrocysta cf. retiintexta}

PI. 79, figs. 10-12, PI. 80, figs. 1-12, PI. 81, figs. 1-9

?1965 Cyclonephelium exuberans Deflandre et Cookson 1955; De Coninck, p. 44-45, pl. 13, figs. 3-4, 6

cf. 1966b Cyclonephelium incultum Morgenroth, p. 9, pl. 2, fig. 5

1969b Cyclonephelium [retiintextum] Cookson; Archangelsky, p. 203-204, pl. 5, figs. 8-9

cf. 1978 Glaphyrocysta inculta (Morgenroth 1966b) Stover \& Evitt, p. 50 
Description: Cysts of intermediate size, chorate, dorso-ventrally compressed, lenticular, lacking horns. Cyst wall single-layered, with an ectophragm. Archeopyle apical, type tA; operculum free. Non-tabular, comprising minute granules; evenly covering the surface of the central body. Processes ?intratabular, straight or gently curved; nonfibrous, apparently solid, 20-30 $\mu \mathrm{m}$; sometimes incompletely connected proximally, connected by a well developed trabeculum distally. Tabulation weak to lacking. Cingulum lacking. Sulcus sometimes weakly expressed, indicated by incomplete sutural ridges.

Size Range: Length excluding processes $=45$ (53) $60 \mu \mathrm{m}$ (3 measurements). Width excluding processes $=50$ (53) $55 \mu \mathrm{m}$ (3 measurements). Length including processes $=72$ (85) $102 \mu \mathrm{m}$ (4 measurements). Width including processes $=70(94) 115 \mu \mathrm{m}$ (4 measurements).

Distribution:

\begin{tabular}{|c|c|c|c|}
\hline Age/Stage & Location & Sample & Sample Reference \\
\hline early Oligocene & Depold'sche Ziegelei, southern Helmstedt & $\mathrm{H} 2 / \mathrm{I}$ & Morgenroth 1966b \\
\hline Bortonian & Puketeraki Core, Oamaru-Dunedin, New Zealand & I43/f089 (L16337) & $\begin{array}{l}\text { Wilson \& McMillan } \\
1996\end{array}$ \\
\hline $\begin{array}{l}\text { Porangan- } \\
\text { Bortonian }\end{array}$ & $\begin{array}{l}\text { Hampden Beach Section, Oamaru-Dunedin, New } \\
\text { Zealand }\end{array}$ & J42/f486 (L23121) & \\
\hline $\begin{array}{l}\text { Porangan- } \\
\text { Bortonian }\end{array}$ & $\begin{array}{l}\text { Hampden Beach Section, Oamaru-Dunedin, New } \\
\text { Zealand }\end{array}$ & J42/f485 (L23120) & \\
\hline Porangan & $\begin{array}{l}\text { Hampden Beach Section, Oamaru-Dunedin, New } \\
\text { Zealand }\end{array}$ & $\mathrm{J} 42 / \mathrm{f} 300$ (L23130) & \\
\hline Eocene & Rio Turbio Formation, Santa Cruz Province, Patagonia & 720 & Archangelsky $1969 \mathrm{~b}$ \\
\hline Ypresian & Merelbeke, Belgium & Preparation 17 & De Coninck 1965 \\
\hline
\end{tabular}

Remarks: Glaphyrocysta cf. retiintexta has processes which are comparable to the diameter of the central body, ranging from perhaps a third to three quarters or more, often on a single specimen. In this respect it differs from G. retiintexta (Cookson 1965a) Stover \& Evitt 1978 s.s., and Glaphyrocysta semitecta (Bujak 1980), in which most processes appear to be relatively shorter.

It differs from the type illustrations of G. exuberans (Deflandre \& Cookson 1955) Stover \& Evitt 1978 in possessing fewer, less densely arranged processes, though it is quite similar to a number of reported specimens subsequently appearing under that name.

It resembles, at least superficially, the specimen illustrated as Membranilarnax cf. liradiscoides in Pastiels 1948, pl. 5, fig. 15, subsequently (and unwisely, in my view, because the description and figures were inadequate by the day's standards) designated Cyclonephelium (now Glaphyrocysta) pastielsi by Deflandre \& Cookson 1955. However, Sarjeant's (1986) re-illustrations of the holotype depict a cyst with considerably more numerous processes connecting the trabeculum with the central body. Additionally, his emended diagnosis indicates that the processes are probably relatively shorter as well: "less than $1 / 3$ the equatorial diameter of the cyst" (Sarjeant 1986, p. 28).

In respect of the length and density of its processes, the published species which Glaphyrocysta cf. retiintexta most closely resembles is Glaphyrocysta inculta (Morgenroth 1966b). It differs, however, in having a minutely granulate central body wall, rather than the relatively coarse granulation described by Morgenroth.

Genus Membranophoridium Gerlach 1961 emend. Stover \& Evitt 1978

1961 Membranophoridium Gerlach, p. 198

1978 Membranophoridium Gerlach 1961 emend. Stover \& Evitt, p. 64-65

Type Species: Membranophoridium aspinatum Gerlach 1961, p. 199-201, pl. 29, figs. 7-8 [Mid Oligocene]

Original Description: A genus with the characteristics of the Family Hystrichosphaeridae and the following distinctions: thecal outline oval or circular; however, dominantly semicircular owing to the loss of the apical polar cap. Lower, in contrast to upper side, bordered by two, parallel, more or less low, meridionally trending, thorny fringes that may be interrupted repeatedly. Fringes not joined at antapex, often drawn out into two long lobes of unequal length. Lower side of the theca weakly depressed longitudinally (translated from Gerlach 1961, p. 198, in Stover \& Evitt 1978, p. 64).

\section{Membranophoridium perforatum Wilson 1988}

$$
\text { PI. 81, figs. 10-12 }
$$


Original Description: Cyst lenticular, subspherical, bilayered, circumcavate, periphragm and endophragm in closest contact only in mid dorsal and mid ventral regions. Periphragm thin, generally folded, outline somewhat irregular to undulating, smooth with a sub-pointed apex and occasionally two poorly developed antapical lobations present. Perforations (diameter up to $10 \mu \mathrm{m}$ ) present in variable numbers, mainly around periphragm margin. Occasional solid slender processes (breadth up to $4 \mu \mathrm{m}$ ) sometimes connect periphragm to endophragm in antapical area. Endocyst thin walled, smooth, with a circular outline. Paratabulation indicated by archeopyle only, formula unknown. Archeopyle relatively broad, apical, type tA; principal archeopyle suture zig-zag, parasulcal notch indicating apical position of parasulcus. No indication of paracingulum (Wilson 1988, p. 26).

Size Range: Length $=83 \mu \mathrm{m}$ (one measured specimen). Width $=102 \mu \mathrm{m}$ (one measured specimen).

Distribution:

\begin{tabular}{llll}
\hline Age/Stage & Location & Sample & Sample Reference \\
Porangan-Bortonian & Hampden Beach Section, Oamaru-Dunedin, New Zealand & J42/f301 (L23131) & \\
Porangan & Hampden Beach Section, Oamaru-Dunedin, New Zealand & J42/f299 (L23129)
\end{tabular}

\section{Genus Riculacysta Stover 1977}

\section{Riculacysta Stover, p. 76-77}

Type Species: Riculacysta perforata Stover 1977, p. 77-78, pl. 2, figs. 22-31 [Mid to Late Oligocene]

Original Description: Cysts are chorate with a subspherical body that bears solid, normally isolated processes which arise from the ventrolateral and lateral surfaces and are typically lacking on the midventral and middorsal surfaces. Ventrolateral processes are longer than the lateral ones; all are connected distally by irregularly perforate to trabecular ectophragm that is close or appressed dorsally to the autophragm. Paratabulation indicated by apical type A archeopyle, by paracingulum, and less conspicuously by processes (Stover 1977, p. 76).

Remarks: Stover (1977) contrasted Riculacysta with Adnatosphaeridium, noting the distinction that the trabecular ectophragm of Riculacysta is close or appressed dorsally to the autophragm, and Cyclonephelium, noting that the processes of Riculacysta are of more or less equal length, regardless of their position. Although Stover \& Evitt (1978) did not contrast their new genus, Glaphyrocysta, with Riculacysta, the distinction with Cyclonephelium appears to hold true for Glaphyrocysta also.

\section{?Riculacysta sp. 1}

$$
\text { Pl. 82, figs. 1-12 }
$$

Description: Archeopyle apparently apical. Central body single-layered, apparently more or less spherical, although one specimen (see PI. 82, fig. 5) shows possible evidence for an antapical lobe-like structure. Surface ornamented with variable ridges and granules, forming a pattern which might approximately be called reticulate. A number of processes arise from ?intratabular areas, of variable width ranging from thin rod-like structures to (more commonly) broad, flattened, perforated-fenestrate sheets, often incorporating rod-like structures. The processes are connected distally by a perforate-fenestrate trabelculum, appearing essentially similar to the broader processes.

Size Range: Length excluding processes $=55$ (60) $67 \mu \mathrm{m}$ (4 measurements). Width excluding processes $=61$ (68) $80 \mu \mathrm{m}$ (4 measurements). Length including processes = 76 (86) $95 \mu \mathrm{m}$ (4 measurements). Width including processes $=82(92) 102 \mu \mathrm{m}$ (4 measurements).

\section{Distribution:}

$\begin{array}{lll}\text { Age/Stage } & \text { Location } & \text { Sample } \\ \text { Bortonian } & \text { Hampden Beach Section, Oamaru-Dunedin, New Zealand } & \text { J42/f488 (L23123) } \\ \text { Porangan } & \text { Te Uri Stream, Hawkes Bay, New Zealand } & \text { U24/f417 (L23125) }\end{array}$

Remarks: The present form bears some superficial resemblance to Glaphyrocysta but differs significantly in appearing to be essentially spherical rather than dorso-ventrally compressed, which suggests it may not belong with the Areoligeraceae. On some specimens, processes can be observed arising from all plate series, and it is not clear whether they are confined to the ambital plates.

Placement in Riculacysta is provisional because, although the middle Eocene forms described here possess a morphology which broadly resembles Riculacysta perforata, I know of no evidence for any geographic or temporal intermediates which might suggest a phylogenetic relationship. 


\title{
Suborder Goniodomineae Fensome et al. 1993b
}

\section{Family Goniodomaceae Lindemann 1928}

\section{Subfamily Pyrodinioideae Fensome et al. 1993b}

\section{Genus Eisenackia Deflandre \& Cookson 1955}

\author{
1955 Eisenackia Deflandre \& Cookson, p. 258 \\ 1978 Alisocysta Stover \& Evitt, p. 15-16 \\ 1978 Eisenackia Deflandre \& Cookson 1955 emended Sarjeant in Davey et al. 1966, Stover \& Evitt, p. 42 \\ 2003 Eisenackia Deflandre and Cookson, 1955, emend. Quattrocchio and Sarjeant, p. 144, 146
}

Type Species: Eisenackia crassitabulata Deflandre \& Cookson 1955, p. 258-261, pl. 5, fig. 2; text-figs. 6-16 [Paleocene-Early Eocene]

Original Description: Cell globular without appendages. Transverse girdle and longitudinal furrow not marked by a depression of the membrane which has a completely continuous outline. Transverse girdle delimited by the bases of the plates. Tabulation 2-3', 6", ?6g, 6"', 2p, 1"'”. The epitheca has, amongst others, an elongated ventral plate and the hypotheca a ventral area consisting of several small plates (Deflandre \& Cookson 1955, p. 258).

Remarks: Alisocysta is distinguished from Schematophora by the expression of intratabular ornament on the cingular series.

\section{Alisocysta aff. circumtabulata}

\section{Pl. 83, figs. 1-11}

\author{
1982c Alisocysta sp. Wilson, p. 4, pl. 2, figs. 5-7 \\ 1982c Alisocysta sp.; Wilson, p. 4, pl. 2, figs. 5-7 \\ 1988 Alisocysta circumtabulata (Drugg 1967) Stover and Evitt 1978; Wrenn \& Hart, p. 345, fig. 15, 1-3
}

Description: Cysts of intermediate size, chorate, not dorso-ventrally compressed, prolate, lacking horns; episome somewhat shorter than hyposome. Cyst wall single-layered. Archeopyle apical, type tA; operculum free. Ornament intratabular, comprising inflated, hollow processes. Processes intratabular, comprising high membranous septa; non-fibrous, open; somewhat ragged distally. Tabulation clearly expressed, gonyaulacacean. Cingulum clearly expressed, a differentiated, flattened, process series; offset only slightly. Sulcus clearly expressed, indicated by the alignment of processes; more or less vertical.

Size Range: Length excluding processes $=45$ (47) $49 \mu \mathrm{m}$ (3 measurements). Width excluding processes $=37$ (39) $41 \mu \mathrm{m}$ (3 measurements). Length including processes $=53$ (59) $62 \mu \mathrm{m}$ (6 measurements). Width including processes $=45(52) 57 \mu \mathrm{m}$ (6 measurements).

Distribution: Common.

\begin{tabular}{|c|c|c|c|}
\hline Age/Stage & Location & Sample & Sample Reference \\
\hline Bortonian & Puketeraki Core, Oamaru-Dunedin, New Zealand & I43/f094 (L16342) & $\begin{array}{l}\text { Wilson \& McMillan } \\
1996\end{array}$ \\
\hline Mangaorapan & $\begin{array}{l}\text { Eyre River, Oxford area, central Canterbury, New } \\
\text { Zealand }\end{array}$ & L34/f7538 & Wilson 1982c \\
\hline late early & northern Seymour Island, West Antarctica & 8497 & Wrenn \& Hart 1988 \\
\hline
\end{tabular}

Remarks: Alisocysta aff. circumtabulata resembles $A$. circumtabulata quite closely, but seems to differ consistently in possessing higher penitabular septa, sometimes developed to the extent (e.g. Pl. 83, figs. 7-11) that they could fairly be called intratabular processes. 


\title{
?Alisocysta cf. circumtabulata
}

PI. 83, fig. 12, PI. 84, figs. 1-3

Description: Cysts of intermediate size, chorate, not dorso-ventrally compressed, prolate, lacking horns; episome somewhat shorter than hyposome. Cyst wall single-layered. Archeopyle apical, type tA; operculum free. Ornament intratabular, comprising inflated, hollow processes. Processes intratabular, comprising high membranous septa; non-fibrous, open; somewhat ragged distally. Tabulation clearly expressed, gonyaulacacean. Cingulum clearly expressed, a differentiated, flattened, process series; offset only slightly. Sulcus clearly expressed, indicated by the alignment of processes; more or less vertical.

Size Range: Length excluding processes $=52 \mu \mathrm{m}$ (one measured specimen). Width excluding processes $=$ $47 \mu \mathrm{m}$ (one measured specimen). Length including processes $=70 \mu \mathrm{m}$ (one measured specimen). Width including processes $=61 \mu \mathrm{m}$ (one measured specimen).

Distribution: Rare.

$\begin{array}{llll}\text { Age/Stage } & \text { Location } & \text { Sample } & \text { Sample Reference } \\ \text { Bortonian } & \text { Puketeraki Core, Oamaru-Dunedin, New Zealand } & \text { I43/f090 (L16338) } & \text { Wilson \& McMillan 1996 } \\ \text { Bortonian } & \text { Puketeraki Core, Oamaru-Dunedin, New Zealand } & \text { I43/f089 (L16337) } & \text { Wilson \& McMillan 1996 }\end{array}$

Remarks: Alisocysta cf. circumtabulata resembles A. aff. circumtabulata quite closely, and A. circumtabulata more distantly, but in this case the septa/processes are even longer and more constricted - more "process-like" than either.

\section{?Alisocysta sp. cf. Hystrichokolpoma wilsonii}

$$
\text { PI. 84, figs. 4-12, PI. 85, figs. 1-3 }
$$

1988 Hystrichosphaeridium tubiferum subsp. brevispinum (Davey and Williams 1966) Lentin and Williams 1973; Wrenn \& Hart, p. 356, fig. 26, 7-9

?1995 Hystrichokolpoma salacia Eaton, 1976; Mao \& Mohr, pl. 5, figs. 3, 7

Description: Cysts of intermediate size, chorate, not dorso-ventrally compressed, prolate, lacking horns; episome somewhat shorter than hyposome. Cyst wall single-layered. Archeopyle apical, type tA; operculum free. Ornament intratabular, comprising inflated, hollow processes. Processes intratabular, comprising high membranous septa; non-fibrous, open; somewhat ragged distally. Tabulation clearly expressed, gonyaulacacean, inferred formula: 4', 0a, 6", 6c, 6"', 1ps, 1"', 2-5s. Cingulum clearly expressed, a differentiated, flattened, process series; offset only slightly. Sulcus clearly expressed, indicated by the alignment of processes; more or less vertical.

Size Range: Length excluding processes $=28$ (35) $43 \mu \mathrm{m}$ (3 measurements). Width excluding processes $=33$ (35) $36 \mu \mathrm{m}$ (3 measurements). Length including processes $=45$ (51) $57 \mu \mathrm{m}$ (3 measurements). Width including processes $=45$ (49) $51 \mu \mathrm{m}$ (3 measurements).

Distribution: Frequent.

\begin{tabular}{llll}
\hline Age/Stage & Location & Sample & Sample Reference \\
Bortonian & Hampden Beach Section, Oamaru-Dunedin, New Zealand & J42/f489 (L23124) & \\
Porangan & Te Uri Stream, Hawkes Bay, New Zealand & U24/f419 (L23127) & \\
late early Eocene & northern Seymour Island, West Antarctica & 8503 & Wrenn \& Hart 1988
\end{tabular}

Remarks: The processes are open and the cingular processes, although a strongly rectangular rather than square cross-section and, so, a different shape to the pre- and post-cingular processes, do not attain the thin, tubular form characteristic of Hystrichokolpoma s.s. The processes are of such a length as to fall outside the range normally attributed to Alisocysta, and the hyposomal topology has not been determined.

\section{Genus Homotryblium Davey \& Williams 1966b}

\author{
1966b Homotryblium Davey \& Williams, p. 100 \\ 1978 Homotryblium Davey \& Williams in Davey et al. 1966; Stover \& Evitt, p. 210
}

Type Species: Homotryblium tenuispinosum Davey \& Williams 1966b, p. 101-102, pl. 4, fig. 11; pl. 12, figs. 1, 5, 7; text-fig. 21 [Early Eocene] 
Original Description: Sub-spherical chorate cyst with central body composed of thin endophragm and surrounding periphragm which gives rise to processes. Processes intratabular, cylindrical to tubiform, open distally, reflecting a tabulation of 3', 6", 6c, 6"', $1 \mathrm{p}, 1$ '"' and 1 to $5 \mathrm{~s}$. Processes not in communication with the cavity of the central body. Archeopyle epitractal, suture running just above cingulum processes (Davey \& Williams 1966b, p. 100).

\section{Homotryblium sp. 2}

$$
\text { Pl. 85, figs. 4-6 }
$$

Description: Cysts small, apparently more or less spherical, lacking horns. Walls two-layered, acavate. Processes non-tabular, about $10 \mu \mathrm{m}$ in length, hollow, tapering from broad bases then distally aculeate, apparently open. Surface smooth and hyaline. No evidence of tabulation could be observed.

Size Range: Length excluding any processes $=35 \mu \mathrm{m}$ (one measured specimen). Width excluding any processes $=35 \mu \mathrm{m}$ (one measured specimen). Length including any processes $=45(51) 60 \mu \mathrm{m}(6$ measurements). Width including any processes $=45 \mu \mathrm{m}$ (one measured specimen).

Distribution: Very rare.

$\begin{array}{llll}\text { Age/Stage } & \text { Location } & \text { Sample } & \text { Sample Reference } \\ \text { Bortonian } & \text { Puketeraki Core, Oamaru-Dunedin, New Zealand } & \text { I43/f094 (L16342) } & \text { Wilson \& McMillan } 1996 \\ \text { Bortonian } & \text { Puketeraki Core, Oamaru-Dunedin, New Zealand } & \text { I43/f089 (L16337) } & \text { Wilson \& McMillan } 1996\end{array}$

Genus Hystrichosphaeridium Deflandre 1937b emend. Davey \& Williams 1966

1937b Hystrichosphaeridium Deflandre, p. 68

1978 Hystrichosphaeridium Deflandre 1937b emended Davey \& Williams in Davey et al. 1966; Stover \& Evitt, p. 55-57

Type Species: Hystrichosphaeridium tubiferum (Ehrenberg 1838, pl. 1, fig. 16) Deflandre 1937b, p. 68 [?Late Cretaceous]

Original Description: This genus comprises all the hystrichospheres totally destitute of an equatorial system of elongate plates and whose shell, in general, does not bear fields or plates limited by sutures. The shell, of a dimension greater than $20 \mu$, is most often spherical or spheroidal; some species, however, are more or less elongate (translated from Deflandre 1937b, p. 68, by Stover \& Evitt 1978, p. 55).

Hystrichosphaeridium tubiferum (Ehrenberg 1838) Deflandre 1937b

Pl. 85, figs. 7-12

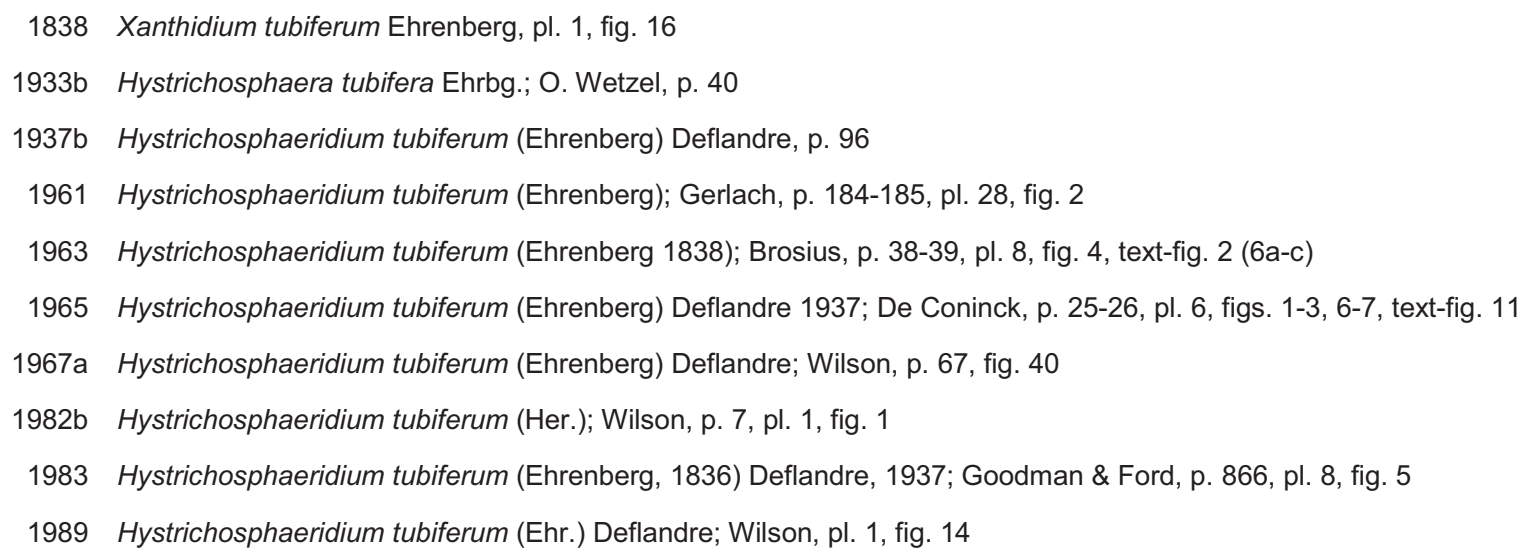

Original Description: [No textual description provided.]

Size Range: Length excluding processes $=38(42) 48 \mu \mathrm{m}$ (4 measurements). Width excluding processes $=32$ (34) $35 \mu \mathrm{m}$ (3 measurements). Length including processes $=47$ (88) $185 \mu \mathrm{m}$ (42 measurements). Width including processes $=68(83) 110 \mu \mathrm{m}$ (13 measurements).

Distribution:

$\begin{array}{llll}\text { Age/Stage } & \text { Location } & \text { Sample } & \text { Sample Reference } \\ \text { middle Oligocene-middle } & \text { north west Germany } & \text { Pr 1170/40 Gerlach 1961 } & \text { Page 158 }\end{array}$




\begin{tabular}{|c|c|c|c|}
\hline \multicolumn{4}{|l|}{ Miocene } \\
\hline Kaiatan & $\begin{array}{l}\text { Puketeraki Core, Oamaru-Dunedin, New } \\
\text { Zealand }\end{array}$ & I43/f096 (L16344) & $\begin{array}{l}\text { Wilson \& McMillan } \\
1996\end{array}$ \\
\hline Bortonian & $\begin{array}{l}\text { Hampden Beach Section, Oamaru-Dunedin, } \\
\text { New Zealand }\end{array}$ & J42/f057 (L09214) & Wilson 1985 \\
\hline Bortonian & $\begin{array}{l}\text { Hampden Beach Section, Oamaru-Dunedin, } \\
\text { New Zealand }\end{array}$ & $\mathrm{J} 42 / \mathrm{f489}(\mathrm{L} 23124)$ & \\
\hline Bortonian & $\begin{array}{l}\text { Hampden Beach Section, Oamaru-Dunedin, } \\
\text { New Zealand }\end{array}$ & J42/f303 (L23133) & \\
\hline Bortonian & $\begin{array}{l}\text { Hampden Beach Section, Oamaru-Dunedin, } \\
\text { New Zealand }\end{array}$ & J42/f040 (L09197) & Wilson 1985 \\
\hline Bortonian & $\begin{array}{l}\text { Puketeraki Core, Oamaru-Dunedin, New } \\
\text { Zealand }\end{array}$ & I43/f089 (L16337) & $\begin{array}{l}\text { Wilson \& McMillan } \\
1996\end{array}$ \\
\hline Porangan & Te Uri Stream, Hawkes Bay, New Zealand & U24/f418 (L23126) & \\
\hline Porangan & Te Uri Stream, Hawkes Bay, New Zealand & U24/f417 (L23125) & \\
\hline middle Eocene-late Eocene & DSDP Holes 511 and 512 & & $\begin{array}{l}\text { Goodman \& Ford } \\
1983\end{array}$ \\
\hline Heretaungan-Porangan & $\begin{array}{l}\text { Hampden Beach Section, Oamaru-Dunedin, } \\
\text { New Zealand }\end{array}$ & J42/f298 (L23128) & \\
\hline Heretaungan & $\begin{array}{l}\text { Hampden Beach Section, Oamaru-Dunedin, } \\
\text { New Zealand }\end{array}$ & J42/f483 (L23118) & \\
\hline Eocene & CIROS-1 drillhole, McMurdo Sound, Antarctica & SM3799 & Wilson 1989 \\
\hline Eocene & $\begin{array}{l}\text { erratics near Minna Bluff, McMurdo Sound, } \\
\text { Antarctica }\end{array}$ & L4737 & Wilson 1967a \\
\hline Ypresian & Merelbeke, Belgium & Preparation 20 & De Coninck 1965 \\
\hline
\end{tabular}

\section{Hystrichosphaeridium salpingophorum Deflandre 1935}

PI. 86, figs. 1-6

1935 Hystrichosphaeridium salpingophorum Deflandre, p. 232, pl. 9, fig. 1

1937b Hystrichosphaeridium salpingophorum Deflandre 1935, p. 232, pl. 9, fig. 1 ex Deflandre, p. 71

1965 Hystrichosphaeridium salpingophorum Deflandre 1937; De Coninck, p. 24-25, pl. 5, figs. 2, 3, 5-8, 11-12, textfig. 9-10

Original Description: ... H. salpingophora n. sp. ... body spherical or subspherical, ornamented with more or less flared tubular processes ... (translation from Deflandre 1935, p. 232).

Size Range: Length excluding processes $=40$ (44) $47 \mu \mathrm{m}$ (2 measurements). Width excluding processes $=38$ (39) $40 \mu \mathrm{m}$ (2 measurements). Length including processes = 73 (80) $87 \mu \mathrm{m}$ (2 measurements). Width including processes $=70(76) 81 \mu \mathrm{m}$ (2 measurements).

Distribution:

$\begin{array}{llll}\text { Age/Stage } & \text { Location } & \text { Sample } & \text { Sample Reference } \\ \text { Porangan-Bortonian } & \text { Hampden Beach Section, Oamaru-Dunedin, New Zealand } & \text { J42/f302 (L23132) } & \\ \text { Ypresian } & \text { Merelbeke, Belgium } & \text { Preparation 20 } & \text { De Coninck } 1965\end{array}$

Remarks: Hystrichosphaeridium salpingophorum supposedly differs from $H$. tubiferum in possessing processes which are more square in cross section than those of $H$. tubiferum. A few specimens encountered in the present study do have somewhat squarish cross sections, and are presented here. However, the distinction is not really convincingly supported by the present material.

Hystrichosphaeridium brevispinum (Davey \& Williams 1966b) Clowes n. stat.

$$
\text { PI. 86, figs. 7-12, PI. 87, figs. 1-3 }
$$

1966b Hystrichosphaeridium tubiferum var. brevispinum Davey \& Williams, p. 58, pl. 10, fig. 10

1973 Hystrichosphaeridium tubiferum subsp. brevispinum (Davey \& Williams 1966b, p. 58, pl. 10, fig. 10) Lentin \& Williams, p. 80

Original Description: A variety of Hystrichosphaeridium tubiferum with processes rarely exceeding one-third of the diameter of the central body (Davey \& Williams 1966b, p. 58). 
Size Range: Length excluding processes $=42$ (44) $46 \mu \mathrm{m}$ (4 measurements). Width excluding processes $=38$ (41) $47 \mu \mathrm{m}$ (5 measurements). Length including processes = 52 (70) $93 \mu \mathrm{m}$ (17 measurements). Width including processes $=60(71) 85 \mu \mathrm{m}$ (12 measurements).

Distribution:

$\begin{array}{llll}\text { Age/Stage } & \text { Location } & \text { Sample } & \text { Sample Reference } \\ \text { Bortonian } & \text { Hampden Beach Section, Oamaru-Dunedin, New Zealand } & \text { J42/f057 (L09214) } & \text { Wilson 1985 } \\ \text { Bortonian } & \text { Puketeraki Core, Oamaru-Dunedin, New Zealand } & \text { I43/f094 (L16342) } & \text { Wilson \& McMillan 1996 } \\ \text { Bortonian } & \text { Puketeraki Core, Oamaru-Dunedin, New Zealand } & \text { I43/f089 (L16337) } & \text { Wilson \& McMillan 1996 }\end{array}$

Remarks: Hystrichosphaeridium brevispinum is usually treated as a subspecies of $H$. tubiferum. However, there is no objective evidence to suggest it is more closely related or otherwise "similar" to $H$. tubiferum than other Hystrichosphaeridium species - notably $H$. salpingophorum - so it is herein considered as a species in its own right.

\title{
Suborder Uncertain
}

\section{Family Uncertain}

\section{Genus Batiacasphaera Drugg 1970b}

\author{
1970b Batiacasphaera Drugg, p. 813 \\ 1978 Batiacasphaera Drugg 1970b; Stover \& Evitt, p. 20-21
}

Type Species: Batiacasphaera compta Drugg 1970b, p. 813-814, figs. 6A-E, 7A-B [Late Eocene]

Original Description: Tract spherical to subspherical with an angular apical archeopyle. The ornamentation consists of rod-shaped elements, either separated or arranged to form a reticulum. In the latter case they may be fused (Drugg 1970b, p. 813).

Batiacasphaera perforata Wilson \& Clowes n. sp.

PI. 87, figs. 4-12, PI. 88, figs. 1-3

Derivation of Name: Latin, perforatus, perforated; with reference to the perforate autophragm.

Holotype: Sample 143/f089, slide L16337/SM102; Burnside Formation, Puketeraki Core (Bortonian); PI. 87, figs. 4-9

Description: Cysts of intermediate size, proximate, dorso-ventrally compressed, lenticular, lacking horns. Cyst wall single-layered. Archeopyle apical, type tA; operculum free. Processes lacking; surface ornament present, non-tabular, comprising circular perforations (diameter about $1 \mu \mathrm{m}$ ); with features on a scale of 20 sculptural elements across the diameter. Tabulation not expressed.

Size Range: Length including any processes $=53(60) 68 \mu \mathrm{m}$ (10 measurements). Width including any processes $=57$ (62) $67 \mu \mathrm{m}$ (2 measurements).

Distribution: Very rare.

$\begin{array}{llll}\text { Age/Stage } & \text { Location } & \text { Sample } & \text { Sample Reference } \\ \text { Kaiatan-Runangan } & \text { Jacksons Paddock, Oamaru-Dunedin, New Zealand } & \text { J41/f8914 (L04979) } & \text { Wilson 1982b } \\ \text { Bortonian } & \text { Puketeraki Core, Oamaru-Dunedin, New Zealand } & \text { I43/f089 (L16337) } & \text { Wilson \& McMillan 1996 }\end{array}$

Comparison: Batiacasphaera perforata is distinguished from all other similar species, known at this time, by its characteristic perforate autophragm.

Remarks: A provisional description for this taxon appears in an unpublished manuscript prepared by Dr. Graeme Wilson shortly prior to his retirement from GNS Science (formerly the New Zealand Geological Survey), under the name Batiacasphaera perforata. Although the description has been amended somewhat to bring it into conformity with the other descriptions provided herein, and observations from additional material incorporated, Dr. Wilson's fundamental contribution is recognised in the authorship of the proposed name. 


\title{
Genus Cerebrocysta Bujak 1980
}

\author{
1980 Cerebrocysta Bujak, p. 42 \\ 1987 Cerebrocysta Bujak in Bujak et al. 1980, p. 42; Stover \& Williams, p. 57
}

Type Species: Cerebrocysta bartonensis Bujak 1980, p. 42, pl. 13, figs. 4-11 [Late Eocene]

Original Description: Autocyst spherical to ovoidal, without apical, antapical, or other projections, except for an apparently random ornament of low crests. The crests occasionally suggest a paratabular arrangement. The archeopyle is formed by the loss of one (3") or more precingular paraplates (Bujak 1980, p. 42).

Remarks: According to Stover \& Williams (1987, p. 57), Cerebrocysta differs from Pyxidinopsis Habib 1976 in having discontinuous ridges and isolated granules rather than being reticulate, and in including forms having different archeopyle types whereas only forms with a simple precingular (type P) archeopyle are assigned to Pyxidinopsis.

The distinction from Pyxidinopsis on the basis of ornament is not considered significant; forms which possesses a reticulum rather than discontinuous ridges may still be considered a "good" Cerebrocysta. If this view is accepted, Cerebrocysta primarily differs from Pyxidinopsis in possessing a 2P (-3P) archeopyle, whereas Pyxidinopsis possesses a 1P archeopyle.

\section{Cerebrocysta sp. 1}

\section{PI. 88, figs. 4-9}

Description: Cysts small, proximate, not dorso-ventrally compressed, more or less spherical to prolate, lacking horns. Cyst wall single-layered. Archeopyle precingular, type ?P (3"); operculum free. Processes lacking; surface ornament present, non-tabular, comprising low membranous crests, forming an irregular reticulum; with features on a scale of 8-12 sculptural elements across the diameter; very low (about $1 \mu \mathrm{m}$ or lower). Tabulation not expressed. Cingulum not expressed. Sulcus sometimes weakly expressed, indicated by surface ornament; more or less vertical.

Size Range: Length = 20 (28) $33 \mu \mathrm{m}$ (17 measurements). Width = 22 (26) $29 \mu \mathrm{m}$ (5 measurements).

Distribution: Infrequent.

$\begin{array}{llll}\text { Age/Stage } & \text { Location } & \text { Sample } & \text { Sample Reference } \\ \text { Bortonian } & \text { Puketeraki Core, Oamaru-Dunedin, New Zealand } & \text { I43/f093 (L16341) } & \text { Wilson \& McMillan 1996 } \\ \text { Bortonian } & \text { Puketeraki Core, Oamaru-Dunedin, New Zealand } & \text { I43/f089 (L16337) } & \text { Wilson \& McMillan 1996 }\end{array}$

Cerebrocysta ?sp. 2

PI. 88, figs. 10-12

\author{
2001 Spongodinium? Sp. A; Crouch, p. 47, pl. 10, figs. 8-9 \\ 2003 Cerebrocysta bartonensis Brinkhuis, Munsterman, et al., pl. 1, figs. 32-33 \\ ?2003 Cerebrocysta bartonensis; Brinkhuis, Sengers, et al., pl. 1, fig. 24
}

Description: Cysts proximate, spherical, lacking horns; the apical and antapical hemispheres roughly equal. Cyst walls single layered $(\sim 1.5 \mu \mathrm{m}$ thick); walls delicate and flexible so that distorted cysts are common. Archeopyle precingular, type 2 (-3?) P; operculum free and the plates typically separated. Processes lacking; ornament comprising a low $(\sim 0.5 \mu \mathrm{m})$ nontabular reticulum; the cyst wall appearing completely smooth within the reticulae. Tabulation indicated only by the archeopyle and cingulum; formula unknown. Cingulum poorly expressed by alignment of reticulae and sometimes by folding of the cyst wall.

Size Range: Length $=60 \mu \mathrm{m}$ (one measured specimen). Width $=55 \mu \mathrm{m}$ (one measured specimen).

Distribution: Infrequent.

$\begin{array}{llll}\text { Age/Stage } & \text { Location } & \text { Sample } & \text { Sample Reference } \\ \text { Otaian } & \text { Puketeraki Core, Oamaru-Dunedin, New Zealand } & \text { I43/f101 (L16349) } & \text { Wilson \& McMillan 1996 } \\ \text { early Whaingaroan } & \text { Kakanui River, Oamaru-Dunedin, New Zealand } & \text { J42/f096 (L10951) } & \text { Clowes \& Morgans 1984 } \\ \text { Bortonian } & \text { Burnside Marl Pit, Oamaru-Dunedin, New Zealand } & \text { I44/f080 (L08947) } & \text { Clowes \& Wilson 2006 } \\ \text { Waipawan } & \text { Tawanui Section, Wairarapa, New Zealand } & & \text { Crouch 2001 }\end{array}$


Remarks: Cerebrocysta ?sp. 2 differs from Cerebrocysta bartonensis in being considerably larger ( 60 cf. $\sim 25 \mu \mathrm{m}$ ), in having a reticulate ornament rather than discontinuous ridges and isolated granules, and in an apparently less variable archeopyle. Another species possessing a reticulum resembling Cerebrocysta ?sp. 2 is Pyxidinopsis waipawaensis, which differs in being somewhat smaller $(\sim 50 \mu \mathrm{m})$, possessing a thicker, most robust wall $(\sim 2 \mu \mathrm{m})$, and in possessing a much smaller archeopyle which is quite clearly formed by the release of a single plate.

\title{
Genus Chlamydophorella Cookson \& Eisenack 1958
}

\author{
1958 Chlamydophorella Cookson \& Eisenack, p. 56 \\ 1978 Chlamydophorella Cookson \& Eisenack 1958; Stover \& Evitt, p. 27-28
}

Type Species: Chlamydophorella nyei Cookson \& Eisenack 1958, p. 56, pl. 11, figs. 1-3 [Cretaceous (AptianTuronian)]

Original Description: Shell enclosed in a delicate membrane that is supported by closely arranged, slender bifurcate spines of approximately equal length (Cookson \& Eisenack 1958, p. 56).

Cysts proximate, holocavate [sic], subspherical to elongate ellipsoidal, with or without an apical protrusion or horn; autophragm with numerous nontabular processes of essentially uniform height and covered by an ectophragm; archeopyle apical, Type tA (Stover \& Evitt 1978, p. 28).

Remarks: Stover \& Evitt 1978 (p. 28) applies the descriptor "holocavate" to Chlamydophorella. However, I am not convinced the term is correctly applied in this situation. Although it is frequent practice to treat the ectocoel as an analogue to the pericoel (e.g. Evitt 1985, p. 65), they are not homologous structures (in a developmental sense); personally, I restrict the cavation concept to spaces between the endophragm and periphragm of those two- or three-layered cysts possessing them.

Brideaux (1971, p. 98) remarked on the similarity between Gardodinium and Chlamydophorella and stated that "should both genera prove to have apical archeopyles [as is the case], it would be difficult to maintain two different names for the same concept." Stover \& Evitt 1978, however, regards Gardodinium as remaining distinct from Chlamydophorella "in always having a prominent apical horn, in having more slender, delicate, less densely distributed processes, and in showing faint indications of paratabulation other than the archeopyle" (p. 28). In any event, if the two are considered synonymous, Chlamydophorella is the senior name.

Chlamydophorella neopilata Clowes n. sp.

PI. 89, figs. 1-12

1984 Chlamydophorella sp.; Clowes \& Morgans, p. 32, pl. 2, figs. 1-2

Derivation of Name: Greek, $v \varepsilon o \zeta$, new, + pilata; with reference to the younger range than the similar taxon, Chlamydophorella pilata.

Holotype: Sample J42/f096, slide L10951/SM2952; Totara Limestone, Kakanui River (early Whaingaroan); PI. 89, figs. $1-4$

Description: Cysts subspherical to prolate, lacking horns; two-layered, the wall layers typically separated by numerous short $(\sim 2 \mu \mathrm{m})$ non-tabular processes. Archeopyle apical, type tA or $(\mathrm{tA})$; archeopyle margin quite ragged; operculum free though frequently adherent. Surface appearance granulate from the effect of seeing the non-tabular processes end-on. Other than the archeopyle there are no consistent indications of tabulation. However, it is occasionally possible to discern an imperfect alignment of the granulae suggesting a cingulum (e.g. Pl. 89, fig. 4).

Size Range: Length $=29$ (35) $43 \mu \mathrm{m}$ (15 measurements). Width $=28$ (30) $34 \mu \mathrm{m}$ (3 measurements).

Distribution: Ranges ?Bortonian to Whaingaroan, but commoner in the younger part of this range.

\begin{tabular}{|c|c|c|c|}
\hline Age/Stage & Location & Sample & Sample Reference \\
\hline early Whaingaroan & $\begin{array}{l}\text { Kakanui River, Oamaru-Dunedin, New } \\
\text { Zealand }\end{array}$ & J42/f096 (L10951) & $\begin{array}{l}\text { Clowes \& Morgans } \\
1984\end{array}$ \\
\hline ?early Whaingaroan & $\begin{array}{l}\text { Kakanui River, Oamaru-Dunedin, New } \\
\text { Zealand }\end{array}$ & J42/f097 (L10952) & $\begin{array}{l}\text { Clowes \& Morgans } \\
1984\end{array}$ \\
\hline $\begin{array}{l}\text { Runangan-early } \\
\text { Whaingaroan }\end{array}$ & $\begin{array}{l}\text { Kakanui River, Oamaru-Dunedin, New } \\
\text { Zealand }\end{array}$ & J42/f125 (L11625) & \\
\hline $\begin{array}{l}\text { Runangan-early } \\
\text { Whaingaroan }\end{array}$ & Kakanui River mouth & & $\begin{array}{l}\text { Clowes \& Morgans } \\
1984\end{array}$ \\
\hline Kaiatan & Puketeraki Core, Oamaru-Dunedin, New & I43/f096 (L16344) & Wilson \& McMillan \\
\hline
\end{tabular}




$\begin{array}{lll} & \text { Zealand } & 1996 \\ \text { Bortonian } & \begin{array}{l}\text { Puketeraki Core, Oamaru-Dunedin, New } \\ \text { Zealand }\end{array} & \text { I43/f089 (L16337) } \begin{array}{l}\text { Wilson \& McMillan } \\ 1996\end{array}\end{array}$

Comparison: Although some specimens of this taxon sometimes exhibit a very faint alignment of the pilae, suggesting sutural lineations, the lineations are both far less frequent and far less pronounced than in specimens of the older (Heretaungan to ?Bortonian) species, Chlamydophorella pilata.

\title{
Chlamydophorella pilata Clowes n. sp.
}

$$
\text { Pl. 90, figs. 1-12 }
$$

Derivation of Name: Latin, pila, pillar; with reference to the surface ornament which recalls a pilate pollen grain.

Holotype: Sample J42/f485, slide L23120/SM046; ?Hampden Formation, Hampden Beach Section (PoranganBortonian); PI. 90, figs. 1-6

Description: Cysts subspherical to prolate, lacking horns; two-layered, the wall layers typically separated by numerous short $(\sim 2 \mu \mathrm{m})$ non-tabular processes. Archeopyle apical, type tA or (tA); archeopyle margin quite ragged; operculum free though frequently adherent. Surface appearance granulate from the effect of seeing the non-tabular processes end-on. Tabulation is variably indicated by alignment or coarsening of the ornament into sutural lineations, especially along the margins of the cingulum.

Size Range: Length $=44$ (48) $56 \mu \mathrm{m}$ (3 measurements). Width $=33$ (34) $35 \mu \mathrm{m}$ (3 measurements).

Distribution:

$\begin{array}{lll}\text { Age/Stage } & \text { Location } & \text { Sample }\end{array}$

Comparison: This species differs from Chlamydophorella pilata in the stronger and more consistent development of sutural lineations.

Genus Dapsilidinium Bujak et al. 1980b

\author{
1980b Dapsilidinium Bujak et al., p. 27-28 \\ 1987 Dapsilidinium Bujak in Bujak et al. 1980, p. 27; Stover \& Williams, p. 69-71
}

Type Species: Dapsilidinium pastielsii (Davey \& Williams 1966b, p. 92-93, pl. 4, fig. 10) Bujak et al. 1980, p. 28 [Early Eocene]

Original Description: Chorate cysts with a subspherical to ovoidal central body bearing numerous processes. Processes intratabular, generally exceeding one per paraplate, mostly uniform in length but sometimes varying slightly in width. Processes hollow, open distally, tubiform or tapering. Periphragm ornament smooth, chagrinate, granulate or spinate, often extending on to the processes. Archeopyle apical, tetratabular. Operculum detached (Bujak et al. 1980, p. 27).

Remarks: Dapsilidinium differs from Cleistosphaeridium most obviously in the possession of hollow processes.

Dapsilidinium pseudocolligerum (Stover 1977) Bujak et al. 1980

$$
\text { PI. 91, figs. 1-6 }
$$

\footnotetext{
1961 Hystrichosphaeridium simplex (White 1842); Gerlach, p. 190, pl. 28, fig. 10, text-fig. 20-22

1971 Hystrichosphaeridium simplex (White 1842); Jux, pl. 26, figs. 7-14, text-fig. 1, 3d

1972 Hystrichosphaeridium simplex (White 1842) Gerlach 1961; Benedek, p. 29, pl. 9, fig. 11

1975 Polysphaeridium pastielsii Davey and Williams 1966; Williams \& Brideaux, pl. 24, fig. 3

1977 Polysphaeridium pseudocolligerum Stover, p. 74-75, pl. 1, figs. 14-19

1980b Dapsilidinium pseudocolligerum (Stover 1977, p. 74-75, pl. 1, figs. 14-19) Bujak et al., p. 28
} 
Original Description: Cysts are chorate with spherical to subspherical body from which arise 40 or more nontabular processes. Endophragm is typically thicker than the periphragm, and the wall layers are appressed between processes. Processes are nearly uniform in size and shape, hollow, generally slightly wider proximally than near their tips, more or less circular in cross-section, and expanded and open distally. Surface of processes is smooth, faintly granular or striate, and areas between processes are granular or punctoreticulate. Archeopyle is apical, type $A^{-}$, principal archeopyle suture only slightly angular and accessory sutures are rarely developed. Operculum is free and constituent apical plates are not delineated on its surface. Except for the archeopyle, indicators of paratabulation and parasulcus are lacking; paracingulum not expressed or indicated by equatorial alignment of processes. Overall size 60 to $92 \mu \mathrm{m}$; body 36 to $45 \mu \mathrm{m}$ in diameter; processes 15 to $23 \mu \mathrm{m}$ in length and 3 to $7 \mu \mathrm{m}$ in basal diameter (Stover 1977, p. 75).

Size Range: Length excluding processes $=30$ (39) $50 \mu \mathrm{m}$ (5 measurements). Width excluding processes $=38$ (40) $43 \mu \mathrm{m}$ (4 measurements). Length including processes $=45$ (61) $77 \mu \mathrm{m}$ (19 measurements). Width including processes $=25$ (64) $75 \mu \mathrm{m}$ (18 measurements).

Distribution: Common.

\begin{tabular}{|c|c|c|c|}
\hline Age/Stage & Location & Sample & Sample Reference \\
\hline $\begin{array}{l}\text { middle Oligocene-middle } \\
\text { Miocene }\end{array}$ & north west Germany & & Gerlach 1961 \\
\hline ?Kaiatan & $\begin{array}{l}\text { Hampden Beach Section, Oamaru-Dunedin, } \\
\text { New Zealand }\end{array}$ & J42/f062 (L09219) & Wilson 1985 \\
\hline Kaiatan & $\begin{array}{l}\text { Puketeraki Core, Oamaru-Dunedin, New } \\
\text { Zealand }\end{array}$ & I43/f096 (L16344) & $\begin{array}{l}\text { Wilson \& McMillan } \\
1996\end{array}$ \\
\hline Bortonian & $\begin{array}{l}\text { Hampden Beach Section, Oamaru-Dunedin, } \\
\text { New Zealand }\end{array}$ & J42/f048 (L09205) & Wilson 1985 \\
\hline Bortonian & $\begin{array}{l}\text { Puketeraki Core, Oamaru-Dunedin, New } \\
\text { Zealand }\end{array}$ & I43/f089 (L16337) & $\begin{array}{l}\text { Wilson \& McMillan } \\
1996\end{array}$ \\
\hline Porangan-Bortonian & $\begin{array}{l}\text { Hampden Beach Section, Oamaru-Dunedin, } \\
\text { New Zealand }\end{array}$ & J42/f302 (L23132) & \\
\hline Porangan-Bortonian & $\begin{array}{l}\text { Hampden Beach Section, Oamaru-Dunedin, } \\
\text { New Zealand }\end{array}$ & J42/f301 (L23131) & \\
\hline
\end{tabular}

\title{
Genus Distatodinium Eaton 1976
}

\author{
1976 Distatodinium Eaton, p. 262-263 \\ 1978 Distatodinium Eaton 1976; Stover \& Evitt, p. 39
}

Type Species: Distatodinium craterum Eaton 1976, p. 263-264, pl. 9, figs. 1-5 [Late Eocene]

Original Description: Dinoflagellate cysts in which the cyst body has an oval or elongate oval outline. Processes simple or branched, variable in breadth, flattened and blade-like in cross section, proximally expanded and frequently united by a membrane, distally expanded and ramified. Ramifications typically, but not invariably, complex. Occasionally, slender tubular processes are present. The number of processes varies from about 14 (in some specimens without an operculum) to about 60 or more. Processes aligned into rows parallel to the long axis of the cyst body, and apparently situated on or close to reflected plate boundaries; many are also arranged in a more or less circular manner around the cyst body. Archeopyle apical (Eaton 1976, p. 262).

Distatodinium apenninicum Brinkhuis et al. 1992

$$
\text { PI. 91, figs. 7-9 }
$$

1992 Distatodinium apenninicum Brinkhuis et al., p. 237-238, pl. 1, figs. 1-9; pl .8, figs. 1-4

Original Description: A species of Distatodinium that is characterized by the presence of 15 to 18 (including those on the operculum) intratabular, short, broad, tubular, hollow processes. Distally, the processes are closed and terminate in a complexly ramified, platform-like structure that may be recurved around its margin, or may be modified with interconnections developed between adjacent processes to produce an incomplete ectophragm. Proximally, the processes are flared and united by low ridges. Two apical processes may be united. A reflected gonyaulacean paratabulation of 4', 6", xc, 5"', 0-2p, 1"' is inferred. The surface ornament is smooth to scabrate or lightly reticulate. The apical archeopyle, which is invariably evident with a detached operculum, reflects the loss of all the apical paraplates (Brinkhuis et al. 1992, p. 237-238). 
Size Range: Length excluding processes $=68 \mu \mathrm{m}$ (one measured specimen). Width excluding processes $=$ $46 \mu \mathrm{m}$ (one measured specimen). Length including processes $=110 \mu \mathrm{m}$ (one measured specimen). Width including processes $=77 \mu \mathrm{m}$ (one measured specimen).

Distribution: Extremely rare; only one poor specimen was encountered in the present study.

$\begin{array}{llll}\text { Age/Stage } & \text { Location } & \text { Sample } & \text { Sample Reference } \\ \text { Bortonian } & \text { Puketeraki Core, Oamaru-Dunedin, New Zealand } & \text { I43/f091 (L16339) } & \text { Wilson \& McMillan } 1996\end{array}$

\section{Genus Labyrinthodinium Piasecki 1980}

1980 Labyrinthodinium Piasecki

Type Species: Labyrinthodinium truncatum Piasecki 1980, p. 67, 70, pl. 2, figs. 9-11, pl. 3, fig. 2, pl. 6, figs. 3-4 [Mid Miocene]

Original Description: Small chorate cysts with spherical main body and apical archeopyle. The cyst wall is two layered, and periphragma forms a closed or open reticulum of anastomosing crests. The smaller crests support the larger ones, which form membraneous processes of equal length (Piaseckii 1980, p. 67).

\section{?Labyrinthodinium sp. 1}

$$
\text { PI. 91, figs. 10-12, Pl. 92, figs. 1-3 }
$$

Description: Cysts small, proximochorate, not dorso-ventrally compressed, prolate, lacking horns. Cyst wall single-layered, with an ectophragm. Archeopyle apical (?); operculum free. Processes non-tabular; variable in length, sometimes broader than high; connected by an irregularly developed trabeculum distally. Tabulation not expressed. Cingulum not expressed. Sulcus not expressed.

Size Range: Length = 35 (37) $38 \mu \mathrm{m}$ (3 measurements). Width = 31 (34) $37 \mu \mathrm{m}$ (2 measurements).

Distribution: Rare: known from only a single sample, within which it occurs infrequently.

$\begin{array}{llll}\text { Age/Stage } & \text { Location } & \text { Sample } & \text { Sample Reference } \\ \text { Bortonian } & \text { Puketeraki Core, Oamaru-Dunedin, New Zealand } & \text { I43/f089 (L16337) } & \text { Wilson \& McMillan 1996 }\end{array}$

Remarks: The archeopyle could not be confidently discerned in the handful of specimens available; thus, generic placement remains provisional.

Genus Paucisphaeridium Bujak et al. 1980b

1980b Paucisphaeridium Bujak et al., p. 32

1987 Paucisphaeridium Bujak in Bujak et al. 1980, p. 30, 32; Stover \& Williams, p. 173

Type Species: Paucisphaeridium inversibuccinum (Davey \& Williams 1966b, p. 82, pl. 12, fig. 3) Bujak et al. 1980, p. 32 [Early Eocene]

Original Description: Chorate cysts with a spherical to subspherical body. The processes are proximally expanded, hollow, and constricted near the distal end. Process formula ?4', 6", 0c, 6"', 0"', xs. When present, the sulcal processes are slender. Archeopyle apical, presumably tetratabular. Operculum not observed (Bujak et al. 1980 , p. 30$)$.

?Paucisphaeridium inversibuccinum (Davey \& Williams 1966b) Bujak et al. 1980b

$$
\text { PI. 92, figs. 4-6 }
$$

1966b Paucisphaeridium inversibuccinum Davey \& Williams, p. 82, pl. 12, fig. 3

Original Description: The wall of the central body is usually thin, but thick walled specimens have occasionally been encountered. The processes are not in connection with the interior of the central body and seldom exceed 15 [sic]. The larger processes are sub-conical and may be up to $10 \mu$ wide at the base, rapidly decreasing in width to approximately $1.5-2 \mu$, before expanding distally into a denticulate or aculeate margin. In addition to these stout processes there are usually one or two slender ones which are possibly closed distally. The latter are probably 
sulcal processes. An apical tetragonal archeopyle was seen in one specimen, the archeopyle being surrounded by 6 precingular processes. However the remaining tabulation is obscure (Davey \& Williams 1966b, p. 82).

Size Range: Length excluding processes $=33 \mu \mathrm{m}$ (one measured specimen). Width excluding processes = $30 \mu \mathrm{m}$ (one measured specimen). Length including processes $=58 \mu \mathrm{m}$ (one measured specimen). Width including processes $=53 \mu \mathrm{m}$ (one measured specimen).

Distribution: Extremely rare.

$\begin{array}{llll}\text { Age/Stage } & \text { Location } & \text { Sample } & \text { Sample Reference } \\ \text { Bortonian } & \text { Puketeraki Core, Oamaru-Dunedin, New Zealand } & \text { I43/f093 (L16341) } & \text { Wilson \& McMillan 1996 }\end{array}$

\section{Subfamily Uncertain}

\section{Genus Indet 3}

\section{Indet 3 sp. 1}

Description: Cysts small, comprising a more or less spherical central body, which lacks surface ornament and from which arises numerous ?intratabular (though possibly gonal) processes. The processes are united distally by thin trabeculae which appear to be more numerous in the apical, cingular, and antapical regions, leaving the pre- and postcingular areas comparatively free. A projection, assumed to be antapical, which has no discernable analogue on the central body, is developed by the trabeculae, and there appears to exist a thin membrane covering parts of the trabeculae in this area (recalling Ectosphaeropsis).

Size Range: Length excluding processes $=33$ (36) $38 \mu \mathrm{m}$ (2 measurements). Width excluding processes $=29$ (32) $35 \mu \mathrm{m}$ (2 measurements). Length including processes $=68$ (72) $76 \mu \mathrm{m}$ (2 measurements). Width including processes $=64(67) 70 \mu \mathrm{m}(2$ measurements $)$.

Distribution: Very rare; only two specimens encountered in the present study.

$\begin{array}{llll}\text { Age/Stage } & \text { Location } & \text { Sample } & \text { Sample Reference } \\ \text { Heretaungan } & \text { Hampden Beach Section, Oamaru-Dunedin, New Zealand } & \text { J42/f484 (L23119) }\end{array}$

Remarks: If the archeopyle could be demonstrated to be precingular, this form would be a candidate for inclusion within Cannosphearopsis.

\section{Genus Indet 4}

Description: Proximate, tabulate cysts, with a distinctively tuberculate surface sculpturing.

Remarks: The rare specimens encountered in this study are invariably fragmented (suggesting a compound archeopyle?) making a more detailed description impossible at this time. However, the distinctive surface ornamentation makes the form easy to recognise when encountered, even in an extremely crushed or fragmentary state.

Indet 4 sp. 1

PI. 93, figs. 1-12, PI. 94, figs. 1-3

Description: [Refer genus].

Size Range: Length = 55 (65) $75 \mu \mathrm{m}$ (3 measurements). Width $=50$ (55) $60 \mu \mathrm{m}$ (3 measurements).

Distribution: Rare.

$\begin{array}{llll}\text { Age/Stage } & \text { Location } & \text { Sample } & \text { Sample Reference } \\ \text { Kaiatan } & \text { Puketeraki Core, Oamaru-Dunedin, New Zealand } & \text { I43/f096 (L16344) } & \text { Wilson \& McMillan } 1996 \\ \text { Bortonian } & \text { Hampden Beach Section, Oamaru-Dunedin, New Zealand } & \text { J42/f487 (L23122) } & \\ \text { Bortonian } & \text { Puketeraki Core, Oamaru-Dunedin, New Zealand } & \text { I43/f089 (L16337) } & \text { Wilson \& McMillan } 1996\end{array}$




\section{Order Pterospermales}

\section{Family Cymatiosphaeraceae}

[No translation available] Die hierhergehörigen Formen zeichnen sich meistens durch den Besitz lamellöser Außenhäute aus, die durch unregelmäßig verteilte, doch etwa radial angeordnete "Stäbchen" (= Verdickungen der Feldergrenzen?) gestützt werden. Mit ihrem Maschenwerk erinnern sie z. T. an die seinerzeit von Rüst im englischen Feuerstein gefundene Radiolarie Dictyospyris anglica Rüst 1885. Zugleich finden sich bei den vorliegenden Fossilien, ähnlich wie bei der vorigen Gruppe, Anklänge an die rezenten Pterospermacean Lohmann's (1904) bzw. an die Trochiscien Lemmermann's (1903), aber auch an rundliche Peridineen, insbesondere an solche mit Gürtellamelle und ohne große apikale Vorsprünge (O. Wetzel 1933b, p. 27).

Genus Cymatiosphaera O. Wetzel 1933b

1933b Cymatiosphaera O. Wetzel, p. 27

Type Species: Cymatiosphaera radiata O. Wetzel 1933b, p. 27, pl. 4, fig. 8

Original Description: The characteristics of the group [envelopes with less numerous and less uniform fields finer lines] also apply to the genus (translation from O. Wetzel 1933b, p. 27).

\section{?Cymatiosphaera sp. 1}

\section{PI. 94, figs. 4-6}

2000 Cymatiosphaera sp. E; Levy \& Harwood, p. 235, pl. 14, figs. a-c

2003 Cerebrocysta poulsenii; Brinkhuis, Munsterman, et al., p. 15, pl. 1, figs. 23-27

Description: Cysts small, tabulate though showing no apparently dinoflagellate tabulation, ornamented by low, smooth-edged crests in "sutural" positions on an otherwise smooth, hyaline surface. Viewed from above, the crests are characteristically sinuous.

Size Range: Length = 27 (29) $30 \mu \mathrm{m}$ (3 measurements). Width $=29 \mu \mathrm{m}$ (one measured specimen).

Distribution:

$\begin{array}{llll}\text { Age/Stage } & \text { Location } & \text { Sample } & \text { Sample Reference } \\ \text { Bortonian } & \text { Puketeraki Core, Oamaru-Dunedin, New Zealand } & \text { I43/f092 (L16340) } & \text { Wilson \& McMillan 1996 } \\ \text { Bortonian } & \text { Puketeraki Core, Oamaru-Dunedin, New Zealand } & \text { I43/f089 (L16337) } & \text { Wilson \& McMillan 1996 } \\ \text { Eocene } & \text { erratics, McMurdo Sound, Antarctica } & \text { MB 188B } & \text { Levy \& Harwood 2000 }\end{array}$

\section{?Cymatiosphaera sp. 2}

PI. 94, figs. 7-9

?2005 Cymatiosphaera sp. 1; Schiøler, pl. 4, fig. 9-10

Description: Cysts small, ornamented by high ( $15 \%$ of the overall diameter), smooth-edged crests in "sutural" positions on an otherwise smooth, hyaline surface. The crests delimit areas which might be called tabulae; the tabulation so defined is apparently not a dinoflagellate tabulation, although a narrow band on one specimen resembles a cingulum.

Size Range: Length = 27 (29) $30 \mu \mathrm{m}$ (3 measurements). Width = $29 \mu \mathrm{m}$ (one measured specimen).

Distribution:

$\begin{array}{llll}\text { Age/Stage } & \text { Location } & \text { Sample } & \text { Sample Reference } \\ \text { early Whaingaroan } & \text { Cape Foulwind Section, Westland, New Zealand } & \text { K29/f097 (L10914) } & \\ \text { Kaiatan } & \text { Puketeraki Core, Oamaru-Dunedin, New Zealand } & \text { I43/f096 (L16344) } & \text { Wilson \& McMillan } 1996\end{array}$




\section{Family Pterospermellaceae}

\section{Genus Pterospermella Eisenack 1972}

1972 Pterospermella Eisenack, p. 597

Type Species: Pterospermella aureolata (Cookson \& Eisenack 1958, p. 49, pl. 9, figs. 10-12) Eisenack 1972, p. 597

Original Description: Microfossils in organic matter that consist of a central body, which appears circular when viewed from above, eccentrically ovoid or occasionally circular in transverse section and has a concentrically and equatorially placed annular, double-walled and either smooth or jagged marginal wing. This can be flat or contain radial folds.

Its method of opening is still unknown (translation from Eisenack 1972, p. 597).

Pterospermella sp. 1

$$
\text { PI. 94, figs. 10-12 }
$$

Description: Cysts large, flattened, ovoidal; comprising an oval inner body supporting a large annual flange, marked by radial folds.

Size Range: Length including any processes $=110 \mu \mathrm{m}$ (one measured specimen). Width including any processes $=87 \mu \mathrm{m}$ (one measured specimen).

Distribution: Rare.

$\begin{array}{llll}\text { Age/Stage } & \text { Location } & \text { Sample } & \text { Sample Reference } \\ \text { Porangan } & \text { Te Uri Stream, Hawkes Bay, New Zealand } & \text { U24/f419 (L23127) }\end{array}$




\section{Biostratigraphy}

\section{Introduction}

A number of important biostratigraphic works, including Hornibrook 1961, Hoskins 1982, Wilson 1984a, Wilson 1988, and Cooper 2004, provide a solid foundation to move ahead towards a better understanding of the middle Eocene to early Oligocene interval in New Zealand.

In the following biostratigraphic analysis, homotaxial biostratigraphic events are preferred for correlations; first appearances are preferred to extinctions (ignoring contamination, an occurrence proves existence; absence proves nothing); acmes have not been used. Despite these precautions, however, many - or all - of the biostratigraphic data discussed below could, in principle, be diachronous, and in most cases we simply do not yet know.

I have persisted with a conventional zonal scheme, in the tradition of Wilson (e.g. 1984d; see more below) rather than adopting the increasingly common practise of simply listing key FADs and LADs. To some extent the distinction is moot, insofar as the zones I have adopted from Wilson's earlier work, and the new divisions proposed below, are based on single FADs or LADs, anyway.

However, I have considerable misgivings at the extent to which single events are being used today. We all know from our daily experience that FADs and LADs occur in different order in different sections, and various techniques, such as Shaw's graphic correlation, are employed to address precisely this problem. When choosing an event to define a zone, at least some thought goes into resolving these matters, and supporting assemblage data are available to assist our interpretations.

In the future, it will be better to tie local biostratigraphic events back to the only practically testable isochronous units available, the magnetostratigraphic chrons. This will not be completely straight-forward, of course. Pending fuller paleomagnetic or radiometric surveys of the sediments discussed herein, both local and international chronostratigraphic interpretations must be extrapolated from potentially diachronous biotic events.

\section{Zonal Scheme for the Mid-Late Eocene to Early Oligocene}

The earliest practical dinoflagellate zonal scheme for New Zealand sediments, of any age, was that of Wilson 1967c, an informal eight- or nine-fold division based upon Wetzelielloideae species. Extending this early work, Wilson later published a formal biozonation (Wilson 1984d) which proposed a sequence of thirteen zones extending from the Cretaceous-Tertiary boundary to the top of the Eocene. Subsequently, more detailed revisions were undertaken of the Cretaceous-Tertiary boundary (Wilson 1987) and of the mid-Paleocene to Middle Eocene interval (Wilson 1988, Morgans et al. 2004)

To this extent, a dinoflagellate zonation exists for the New Zealand Eocene. Its resolution is similar to, or slightly better than, that of the New Zealand marine stages (eleven dinoflagellate zones; seven stages) which are defined on foraminifera data. In the Eocene interval, the majority of dinoflagellate data are first and last appearances of Wetzeliella-group taxa. Unfortunately, these taxa are seldom common and may be ecologically constrained.

The zonation presented below for the late Middle Eocene (approximately middle Lutetian) to earliest Oligocene, is loosely based upon Wilson's (Wilson 1967c, 1984d, 1988, Morgans et al. 2004) with the following departures:

a. By analogy with best geochronologic practice, only the base of each zone is defined, the top being determined by the base of the next higher zone. Some of Wilson's (1984d) zones were separated by gaps where no zone was defined; the approach adopted here does not permit gaps.

b. The Wilsonidium echinosuturatum Zone is generally accounted in the literature to be of considerable duration, as much as $5 \mathrm{Ma}$ according to Cooper 2004. However, at its type section, Waipawa, it is represented by a single sample. Nor is the situation any better at Hampden, where Wilson 1985 again records only a single sample. Both it, and the following Wilsonidium lineidentatum Zone are further compromised by the scarcity of the index fossils defining their boundaries. Accordingly, they are herein replaced with three new zones: Deflandrea convexa, Graptodinium inconditum, and Impagidinium elegans.

c. The Wilsonidium tabulatum Zone is replaced by an approximate equivalent defined by a more commonly found taxon, Rhombodinium glabrum.

d. A new zone (marked by the FAD of Stoveracysta kakanuiensis) is introduced at the Eocene-Oligocene boundary.

The upper boundary of the last zone in the present scheme, the Stoveracysta kakanuiensis Zone, is not defined. This will require further study.

The relationships between Wilson's earlier (1984d, 1988, Morgans et al. 2004) zones, and those recognised below, are summarised in the following table. 


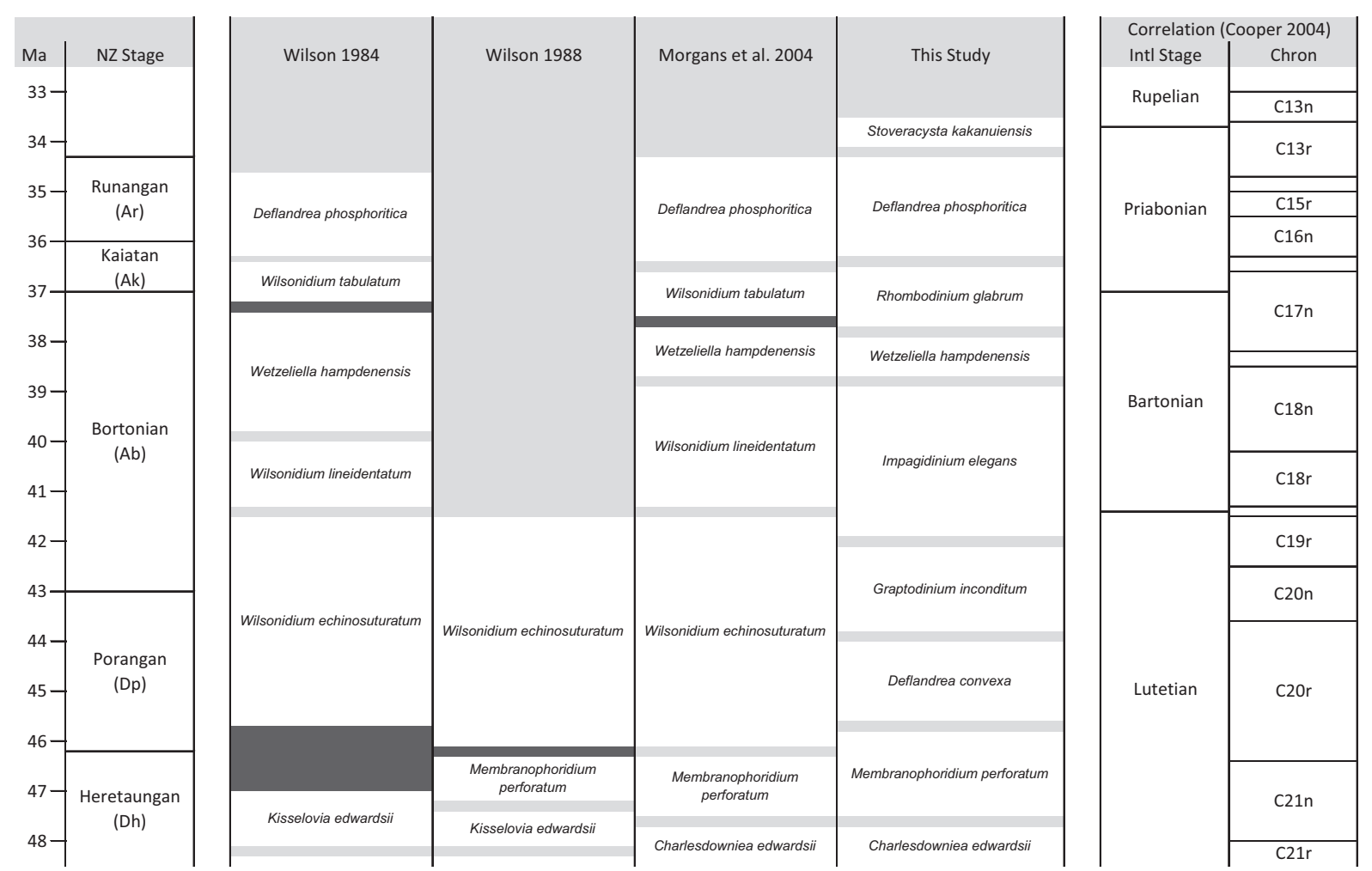

Table 2: Summary of stratigraphic relationships between several earlier New Zealand dioflagellate zonal schemes and those recognised herein. The darker markers between some zones indicate uncertain boundaries where there was a known hiatus or where different criteria were used to define the top of one zone and the base of next higer zone.

\section{Summary of Zones}

\section{Charlesdowniea edwardsii Zone (middle Heretaungan)}

The base of this zone is defined by LAD of Charlesdowniea coleothrypta.

It was originally described from the Waipawa Section, Hawkes Bay, where it is restricted to part of the Heretaungan Stage (Wilson 1984d, 1988) although the top of the zone is obscured by an unexposed interval at its type locality.

The zone correlates with part of the Globorotalia crater crater foraminiferal zone and the upper part of the Reticulofenestra dictyoda nannofossil zone (Wilson 1988).

Typical dinoflagellate species associated with the zone include Charlesdowniea edwardsii, Deflandrea scabrata, Damassadinium crassimuratum, Pyxidinopsis waipawaensis, Pyxidinopsis delicata, Cleistosphaeridium placanthum sensu Wilson 1988 (= Areoligera hampdenensis, as used here), Impagidinium parvireticulatum, and Impagidinium waipawaense.

The zone has been widely recorded from throughout New Zealand and the zone index has also been reported from the Gippsland Basin in Australia (Partridge 1976).

\section{Membranophoridium perforatum Zone (late Heretaungan - earliest Porangan?)}

The zone base is defined by the LAD of Charlesdowniea edwardsii.

It was originally recognised in the Waipawa Section, Hawkes Bay (Wilson 1988). Both the base and the top of the zone are obscured by unexposed intervals at the type locality and the zone includes upper Heretaungan and possibly lower Porangan Stages (Wilson 1988).

The Membranophoridium perforatum Zone correlates with the upper part of the Globorotalia crater crater foraminiferal zone and with the Discoaster elegans nannofossil zone (Wilson 1988).

Dinoflagellate species associated with the zone include Membranophoridium perforatum, Deflandrea scabrata, Damassadinium crassimuratum, Impagidinium waipawaense, Pyxidinopsis waipawaensis, Pyxidinopsis delicata, and Areoligera hampdenensis (see note above). Wetzeliella-group taxa are unknown from this zone (Wilson, pers. comm.) 


\section{Deflandrea convexa Zone n. zone (early Porangan - late Porangan)}

The zone base is defined by the FAD of Deflandrea convexa.

The type locality is Te Uri Stream section, Hawkes Bay, where the lower boundary has been observed at U24/2803190 6095920 (New Zealand Map Grid; sample U24/f418).

Characteristic associated species include Paucilobimorpha tricornus, Deflandrea aff. antarctica, Pyxidinopsis crassimurata, and Turbiosphaera filosa.

This zone replaces the lower part of the Wilsonidium echinosuturatum Zone (Wilson 1984d, 1988, Cooper 2004).

\section{Graptodinium inconditum Zone n. zone (late Porangan - early Bortonian)}

The zone base is defined by the FAD of Graptodinium inconditum.

The type locality is Hampden Beach section, Otago, where the lower boundary has been observed at J42/2339920 5542600 (New Zealand Map Grid; sample J42/f301).

Characteristic associated species include Paucilobimorpha tripa, Corrudinium otagoense, Glaphyrocysta cf. retiintexta, Impagidinium maculatum and I. cf. maculatum.

This zone replaces the middle to upper part of the Wilsonidium echinosuturatum Zone (Wilson 1984d, 1988, Cooper 2004).

\section{Impagidinium elegans Zone n. zone (early Bortonian - late Bortonian)}

The zone base is defined by the FAD of impagidinium elegans s.s.; it is noted that similar though recognisably different forms occur slightly earlier.

The type locality is Hampden Beach section, Otago, where the lower boundary has been observed at J42/2339920 5542610 (New Zealand Map Grid; sample J42/f302).

Characteristic associated species include Areosphaeridium pectiniforme, Hystrichosphaeridium brevispinum, Cordosphaeridium fibrospinosum and Cordosphaeridium gracile.

This zone replaces the uppermost part of the Wilsonidium echinosuturatum Zone (Wilson 1984d, 1988, Cooper 2004) and the Wilsonidium lineidentatum Zone (Wilson 1984d, Cooper 2004).

\section{Wetzeliella hampdenensis Zone (late Bortonian)}

The zone base is defined by the FAD of Wetzeliella hampdenensis.

The type locality for the zone is the Hampden section, North Otago (Wilson 1984, 1985).

The zone is correlated with the upper part of the Globigerapsis index index foraminiferal zone (Wilson 1984d).

Both Wetzeliella hampdenensis and Palaeocystodinium hampdenensis are restricted to this zone. Other characteristic species include Phthanoperidinium dentatum, Corrudinium otagoense, and an undescribed new species of Deflandrea.

The zone has been frequently reported throughout New Zealand.

\section{Rhombodinium glabrum Zone n. zone (late Bortonian - Kaiatan)}

The zone base is defined by the FAD of Rhombodinium glabrum.

The type locality is the Hampden section, North Otago (Wilson 1985).

The zone apparently lies mainly within the lower part of the Globorotalia inconspicua inconspicua foraminiferal zone, but further work needs to be completed to confirm this.

Typical dinoflagellate species associated with the zone include Rhombodinium glabrum, Dracodinium granulatum, Cooksonidium capricornum, and Wilsonidium tabulatum.

The Rhombodinium glabrum Zone is introduced to replace Wilson's (1984d) slightly shorter Wilsonidium tabulatum Zone because the index fossil, Rhombodinium glabrum, is far more common than W. tabulatum.

$$
\text { Deflandrea phosphoritica Zone (late Kaiatan - latest Runangan) }
$$

The zone base is re-defined by the LAD of Rhombodinium glabrum; Wilson's original concept of the zone was defined by the LAD of Wilsonidium tabulatum (see above). 
The type locality is the Kakanui River mouth section, Otago.

The zone lies mainly within the Globigerina linaperta and G. brevis foraminiferal zones (Wilson 1984d).

Deflandrea phosphoritica is abundant throughout the zone (Wilson 1984d), although the actual FAD for $D$. phosphoritica occurs much earlier, in the mid Bortonian (or possibly earlier; refer discussion in the systematic section). Other distinctive species include Impagidinium elegans, and several Phthanoperidinium species. Abundant Operculodinium species also occur near the top of the Deflandrea phosphoritica Zone; seemingly earlier in New Zealand than in southeastern Australia (cf. Partridge \& Dettmann 2003).

The zone is very common throughout New Zealand.

\section{Stoveracysta kakanuiensis Zone n. zone (latest Runangan - early Whaingaroan)}

The zone base is defined by the FAD of Stoveracysta kakanuiensis.

The type locality is the Kakanui River mouth section, Otago, where the age is basal Whaingaroan, very close to the Eocene-Oligocene boundary. The lower boundary has been observed at J42/2344600 5555800 (New Zealand Map Grid; sample J42/f096)

The zone appears to lie completely within the Globigerina brevis foraminiferal zone of Jenkins 1966.

It is associated with the last, or near last, appearances of the typically Paleogene species, including Chlamydophorella neopilata, Corrudinium incompositum, Deflandrea phosphoritica, Impagidinium victorianum, and Graptodinium inconditum. Additionally, species such as Nematosphaeropsis balcombiana, Operculodinium spp. and Spiniferites spp. become more prevalent.

The incoming of Stoveracysta kakanuiensis has been widely recognised in the Australasian region as appearing at or just below the Eocene-Oligocene boundary (e.g. Clowes \& Morgans 1984, Partridge \& Dettmann 2003, Sluijs et al. 2003). However, the event is probably diachronous, occurring first at lower paleolatitudes then migrating south. The initial work on mainland New Zealand, reported in Clowes \& Morgans 1984, indicates a FAD that is essentially indistinguishable from the Eocene-Oligocene boundary.

\section{Eocene-Oligocene Boundary}

The Runangan-Whaingaroan boundary is currently defined by the LAD of Globigerapsis index (Foraminifera, Orbulinidae) (Cooper 2004, p. 154). For the sake of convenience, this datum is generally assumed to be isochronous throughout New Zealand. (However, also see Hornibrook 1965, p. 1195 and Scott 1971, pp. 705706.) For example, Srinivasan \& Vella 1975 (p. 30) placed the Runangan-Whaingaroan boundary at Cape Foulwind, at the horizon where Globigerapsis index disappears.

The Eocene-Oligocene (Priabonian-Rupelian) boundary in New Zealand had earlier been assumed to coincide with the local Runangan-Whaingaroan boundary (e.g. Srinivasan 1965, Hornibrook \& Edwards 1978, Hoskins 1982). Jenkins, however, often contended that the Eocene-Oligocene boundary lies within the lower part of the Whaingaroan stage, although he also noted that the planktonic Foraminifera upon which he based his conclusions had not been described from the Eocene and Oligocene type sections (e.g. Jenkins 1971, p. 18; also 1963, p. 707 and 1974, p. 164).

The latter view has been increasingly adopted by subsequent writers (e.g. Clowes \& Morgans 1984, Clowes 1985) and prevails today. For example, Cooper 2004 places the Runangan-Whaingaroan boundary between 34.0 and $34.5 \mathrm{Ma}$ and the Eocene-Oligocene boundary between 33.5 and $34.0 \mathrm{Ma}$ (fig. 11.2). The absolute age of the Eocene-Oligocene GSSP has since been refined (to $33.9 \pm 0.1 \mathrm{Ma}$, Gradstein et al. 2004), and no doubt the ages of both data will be visited again, but the important recognition is that the Eocene-Oligocene boundary occurs some way - in the order of a million years - into the Early Whaingaroan.

\section{Younger Assemblages}

The upper boundary of the Stoveracysta kakanuiensis Zone is not defined, the dinoflagellates of the Whaingaroan being poorly studied, even after the present endeavour. It is expected that further research will define younger zones in such a way that the Stoveracysta kakanuiensis Zone will remain very short.

A significant reduction in diversity across the Eocene-Oligocene boundary is noticeable in both taxonomically and geographically dispersed groups of microplankton. It is observed in, for example, Carpathian foraminifera (Sotak et al. 2005) and it is certainly the case for New Zealand dinoflagellates. With few exceptions, the morphological diversity typical of the Eocene rapidly declines near the top of this zone, leaving impoverished assemblages dominated by a few species representing various chorate forms, notably Spiniferites and Operculodinium. 


\section{Conclusion}

The principal goal of this study has been to assess the utility of the phylogenetic approach to workaday fossil dinoflagellate cyst biostratigraphy and taxonomy. Difficulties were expected: The first comprehensive synthesis of fossil and neontological dinoflagellate data to be more or less universally adopted, Fensome et al. 1993b, is still quite new, compared with (to take one example) trilobite taxonomy, which has been phylogenetically based at least since Barande's publications of around 150 years ago (Barande 1852, 1872).

The suprageneric classification of Fensome et al. (1993b) is firmly based, as it should be, upon phylogenetic principles, whereas most fossil dinoflagellate cyst genera are form-taxonomic constructs and, to some extent, inevitably so. Notwithstanding that Fensome et al. provide morphological definitions for all of the suprageneric taxa which they recognise, we are left with a discontinuity in the underlying principles by which we define taxa when we "get down" to the generic level. It carries the potential to produce absurdities, such as genera which overlap two or more subfamilies. The only solution, if we are not to abandon phylogeny entirely, is to define, or redefine, where necessary, form-genera along phylogenetic lines.

How might we attempt this? Fossil taxa are characterised - indeed, could almost be defined - by the absence of genetic data. Morphological information is most of what we have left. Yet the richness of morphological data available to the palynologist, working with the ordinary tools we employ routinely, is poor indeed compared to one of Barande's trilobites.

If we are going to adopt a phylogenetic approach, we will almost certainly have to abandon our idea of genera which are uniquely defined by mutually exclusive morphological criteria. The Neocomian, Maastrichtian and Eocene member species of Pyxidinopsis, for example, are almost certainly not closely related, yet they are difficult to separate on morphology alone.

Ideally, we might reconstruct whole lineages thereby defining clades. As more fossil dinoflagellates are found and described, such an approach becomes more realistic and several well-known studies along these lines have been referenced already. At present, however, most lineages are too poorly known, so we must adopt other clues to phylogeny.

Stratigraphic and regional occurrence data are two possible indicators. Earlier reports of the taxon Graptodinium, to take another example, had usually attributed it to either Histiocysta or Microdinium. However, the genotype of Histiocysta, $H$. palla, is apparently confined to the early Cretaceous. The likelihood of any close phylogenetic relationship between $H$. palla and Graptodinium is small. Microdinium ornatum, the genotype of Microdinium, is a more likely relative but, again, the type and most other valid species of Microdinium occur in much older rocks: middle to late Cretaceous, although a few range into the Danian. Again, the likelihood of any close phylogenetic relationship with forms from the Cenozoic of New Zealand seems remote.

These were the clues which led to the hypothesis that Graptodinium inconditum was distinct from Histiocysta or Microdinium, at the generic level or higher, prompting a conscious search for new material to elucidate the detailed plate topology. I am confident that the new material described above amply confirms the hypothesis, and that the creation of a new genus is well-supported.

But this is still a morphological distinction. I have not (yet) been brave enough to suggest a new taxon based wholly on geographical and temporal criteria. However, this is clearly a rational extension to the present ideas, and is advocated as worthy of serious further investigation. There is a danger of tautology, of course, but this can be avoided with care.

My conclusion is that the difficulties of an explicitly phylogenetic approach do not seem insurmountable, and the rewards are profound.

A secondary goal of this study was to further refine the younger part of the dinoflagellate biozonation for New Zealand, as it is presently known. The current zonation is primarily based upon Wilson's (1984d, 1987, 1988; Morgans et al. 2004) work, which in turn had its origins in an earlier analysis of a succession of Wetzelielloideae species (Wilson 1967c).

Specific biostratigraphic objectives of the present study were:

- To improve the resolution of existing dinoflagellate zonal schemes, if possible.

This has been progressed by two measures. First, the long Wilsonidium echinosuturatum Zone and the following Wilsonidium lineidentatum Zone are herein replaced with three new zones. Second, a new zone (marked by the FAD of Stoveracysta kakanuiensis) is introduced at the Eocene-Oligocene boundary. The upper boundary of the Stoveracysta kakanuiensis Zone, is not defined. This will require further study.

- To clarify an ambiguous boundary remaining in the literature, between the Wetzeliella hampdenensis and Wilsonidium tabulatum zones.

To eliminate this (or any other) possibility for a gap or an overlap to occur between zones, only the base of each zone is defined in the scheme proposed here. The top of each zone is implicitly determined by the base of the next higher zone. 
- To incorporate more common taxa, which may be expected in more diverse ecological settings, than have been employed in the past.

Some progress was made here: the Wilsonidium tabulatum Zone is replaced by an approximate equivalent defined by a more commonly found taxon, Rhombodinium glabrum. It remains true that many of the New Zealand Eocene dinoflagellate zones are defined by quite rare, and perhaps ecologically constrained, index taxa. However, this was the only change thought to be well-supported by the present study.

It is hoped that further research will continue to improve both the resolution and the practical utility of the zonation. Further analysis of the range charts provided in the appendices may prove fruitful, perhaps by suggesting additional index taxa. However, I feel that the charts should be bolstered by the addition of sampling from many more sections, and ideally more granular sampling within sections, before such steps may be taken with surety. 


\section{Glossary}

aculeate The tip of a tubular process which flares into pointed serrations of constant or variable length. [Williams et al. 1973]

archeopyle The excystment aperture formed by the loss or displacement of one or a group of plates along pre-formed lines of weakness, usually the sutures surrounding the affected plates.

climactal The plates anterior to the precingular series, excluding those of the sulcus and apical pore complex.

dextral torsion The condition in which the hyposome is rotated so that the boundary between plates 4"' and 5"' lies middorsally and usually close to the boundary between 3 " and 4".

dinocyst A contraction of "dinoflagellate cyst", avoided herein

dolabrate "Pick" shaped bifurcating process terminations in which one bifurcation is clearly longer than the other. In extreme cases, the shorter bifurcation may be completely reduced, so that the process is apparently not bifurcate, but has a distinct angular bend at its extremity. [Eaton et al. 2001]

eurydeltaform Peridinioid archeopyle in which the archeopyle ration is less than 1 and the archeopyle signum is less than 1. [Evitt 1985]

fundital The plates posterior to the postcingular series, excluding those of the sulcus.

homotaxial occurring in the same order at diverse locations

isodeltaform Peridinioid archeopyle in which the archeopyle ration is approximately 1 and the archeopyle signum is less than 1. [Evitt 1985]

latideltaform Peridinioid archeopyle in which the archeopyle ration is less than 1 and the archeopyle signum is less than 1 (= eurydeltaform). [Evitt 1985]

L-type

A term so named because of the longitudinal nature of the sulcus. The sulcus is more or less straight. The sixth precingular plate (1i) is bounded to left and right by almost parallel sutures and anteriorly by a gabled margin due to its contact with both the fourth and first apical plates or their homologues $(A, 1 \mathrm{u})$. The fourth apical plate or its homologue $(A)$ is typically not long and narrow, and does not contact the anterior sulcal plate (ai). There is commonly a broad contact between the last precingular plate and the first apical plate or its homologue (1i/1u). See also S-type ventral organization. [Fensome et al. 1998]

Q1 The anterior edge of a quadra-style 2a plate, adjoining plate 3'. [Lentin \& Williams 1976]

S-type

A term so named because of the sigmoidal nature of the sulcus. The sixth precingular plate (1i) tends to have a triangular shape, with anteriorly converging lateral margins and a narrow, typically planate anterior margin. The fourth apical plate or its homologue (A) tends to be (but is not always) long and predominantly ventral, and contacts the anterior sulcal plate (ai). See also L-type ventral organization. [Fensome et al. 1998]

sinistral torsion The condition in which the hyposome is rotated so that the boundary between plates 4"' and 5"' is distant to the boundary between3" and 4" (refer dextral torsion).

topology The "layout" of the plates, including both consideration of the number of plates in each series, and also which vertices contact which edges of which plates.

transverse

archeopyle The maximum width of the archeopyle divided by the width of the epicyst measured along the same line. [Evitt 1985]

index

transverse

The width of a hexa $2 \mathrm{a}$ archeopyle at the widest point divided by the width of the epicyst less archeopyle ratio the archeopyle width. [Lentin \& Williams 1976] 


\section{Acknowledgements}

My profound thanks to Graeme Wilson for his mentoring and support throughout this project. Thanks also to my supervisor, Mike Hannah; to my friends at GNS, Hugh Morgans, John Simes, Roger Tremain, Erica Crouch, Poul Schiøler, Ian Raine, Dallas Mildenhall, and Chris Hollis, for encouragement, advice, and much practical assistance; to Alan Partridge, Jorg Pröss, Henk Brinkhuis, Geoff Eaton and Rob Fensome, for information and emails, to Kristina McGuiness-King, Quintin Ridgeway and Patrick Geddes for helping me limp through various European languages; and to my friends Claire Storkey and Nigel Sanders for keeping the pressure on.

Last, and foremost, even though I cannot properly express it, I thank my family, Joanne and Rebecca, for their patience with this endeavour over the past six years. 


\section{References}

Agelopoulos, J. 1964: Hystrichostrogylon membraniphorum n.g. n.sp. aus dem Heiligenhafener Kieselton (Eozän). Neues Jahrbuch für Geologie und Paläontologie, Monatshefte, no. 11: 673-675.

— 1967: Hystrichosphären, Dinoflagellaten und Foraminiferen aus dem eozänen Kieselton von Heiligenhafen, Holstein. Dissertation des Grades eines Dokters der mathematisch-naturwissenschaftlichen Fakultät der Eberhard-Karls-Universität, Tübingen, p. 1-74, pl. 1-14.

Alberti, G. 1961: Zur Kenntnis mesozoischer und alttertiärer Dinoflagellaten und Hystrichosphaerideen von Nordund Mitteldeutschland sowie einigen anderen europäischen Gebieten. Palaeontographica, Abteilung A 116: $1-58$, pl. 1-2.

Archangelsky, S. 1969a: Sobre el paleomicroplancton del Terciario inferior de Río Turbio, Provincia de Santa Cruz. Ameghiniana 5 (10): 406-416, pl. 1-2.

- 1969b: Estudio del paleomicroplancton de la Formacion Río Turbio (Eoceno), Provincia de Santa Cruz. Ameghiniana 6 (3): 181-218, pl. 1-5.

Artzner, D.G.; Dörhöfer, G. 1978: Taxonomic note: Lejeunecysta nom. nov. pro Lejeunia Gerlach 1961 emend. Lentin and Williams 1976 - dinoflagellate cyst genus. Canadian Journal of Botany 56: 1381-1382.

Barande, J. 1852: Système Silurien du Centre de la Bohéme: $1^{\text {ere }}$ Partie, Crustacés, Trilobites. Praha, Paris, v. 1: $1-935,51 \mathrm{pl}$

- 1872: Système Silurien du Centre de la Bohéme: $1^{\text {ere }}$ Partie, Supplement au Vol. 1. Trilobites, Crustacés divers et Poissons. Praha, Paris, 1-647, 37 pl.

Beggs, J.M.; Wilson, G.J.; Raine, J.I.; Pocknall, D.T. 1992: Biostratigraphic review of Cretaceous and Early Cenozoic section in Taranaki Basin exploration wells. DSIR Geology \& Geophysics Contract Report 1992/38: 1-182.

Benedek, P.N. von 1972: Phytoplanktonten aus dem Mittel- und Oberoligozän von Tönisberg (Niederrheingebiet). Palaeontographica, Abteilung B 137: 1-71, pl. 1-16.

Benedek, P.N. von; Sarjeant, W.A.S. 1981: Dinoflagellate cysts from the middle and upper Oligocene of Tönisberg (Niederrheingebiet): a morphological and taxonomic restudy. Nova Hedwigia 35 (2-3): 313-356, figs. 1-11.

Benson, D.G. 1976: Dinoflagellate taxonomy and biostratigraphy at the Cretaceous-Tertiary boundary, Round Bay, Maryland. Tulane Studies in Geology and Paleontology 12 (4): 169-233, pl. 1-15.

Benson, W.N. 1968: Geological map of Dunedin District, 1:50,000. New Zealand Geological Survey Miscellaneous Series Map 1. Department of Scientific and Industrial Research, Wellington, New Zealand, p.

Biffi, U.; Manum, S.B. 1988: Late Eocene-Early Miocene dinoflagellate cyst stratigraphy from the Marche Region (central Italy). Bollettino della Società Paleontologica Italiana 27 (2): 163-212, pl. 1-15.

Brideaux, W.W. 1971: Taxonomy of Upper Jurassic-Lower Cretaceous microplankton from the Richardson Mountains, District of Mackenzie, Canada. Geological Survey of Canada, Bulletin, no. 281: 1-89, pl. 1-16.

Brinkhuis, H. 1992: Late Eocene to Early Oligocene dinoflagellate cysts from central and northeast Italy. PhD thesis (published), University of Utrecht, p. 1-169, pl. 1-23.

- 1994: Late Eocene to Early Oligocene dinoflagellate cysts from the Priabonian type-area (northeast Italy): biostratigraphy and paleoenvironmental interpretation. Palaeogeography, Palaeoclimatology, Palaeoecology 107: 121-163, pl. 1-7.

Brinkhuis, H.; Biffi, U. 1993: Dinoflagellate cyst stratigraphy of the Eocene/Oligocene transition in central Italy. Marine Micropaleontology 22: 131-183.

Brinkhuis, H.; Munsterman, D.K.; Sengers, S.; Sluijs, A.; Warnaar, J.; Williams, G.L. 2003: Late EoceneQuaternary dinoflagellate cysts from ODP Site 1168, off western Tasmania. In Exon, N.F.; Kennett, J.P.; Malone, M.J. (eds.) 2003: Proceedings of the ODP, Scientific Results. U.S. Government Printing Office, Washington 189: 1-36.

Brinkhuis, H.; Powell, A.J.; Zevenboom, D. 1992: High resolution dinoflagellate cyst stratigraphy of the Oligocene/Miocene transition interval in northwest and central Italy. In Head \& Wrenn 1992. American Association of Stratigraphic Palynologists Foundation, p. 219-258, pl. 1-10.

Brinkhuis, H.; Sengers, S.; Sluijs, A.; Warnaar, J.; Williams, G.L. 2003: Latest Cretaceous-Earliest Oligocene and Quaternary dinoflagellate cysts, ODP Site 1172, East Tasman Plateau. In Exon, N.F.; Kennett, J.P.; 
Malone, M.J. (eds.) 2003: Proceedings of the ODP, Scientific Results. U.S. Government Printing Office, Washington 189: .

Brochu, C.A.; Sumrall, C.D. 2001: Phylogenetic nomenclature and paleontology. Journal of Paleontology 75: 754757.

Brosius, M. 1963: Plankton aus dem nordhessischen Kasseler Meeressand (Oberoligozän). Zeitschrift der Deutschen Geologischen Gesellschaft 114: 32-56, pl. 1-8.

Brown, D.A. 1938: Moeraki Subdivision. New Zealand Geological Survey Annual Report 32: 9-12.

Bujak, J.P. 1976: An evolutionary series of late Eocene dinoflagellate cysts from southern England. Marine Micropaleontology 1: 101-117, pl. 1-4.

- 1979: Proposed phylogeny of the dinoflagellates Rhombodinium and Gochtodinium. Micropaleontology 25: 308-324.

- 1980: V. Dinoflagellate cysts and acritarchs from the Eocene Barton Beds of southern England. In Bujak, J.P.; Downie, C.; Eaton, G.L.; Williams, G.L. 1980a: Dinoflagellate cysts and acritarchs from the Eocene of southern England. Special Papers in Palaeontology 24: 36-91.

- 1994: New dinocyst taxa from the Eocene of the North Sea. Journal of Micropalaeontology 13: 119-131, pl. 14.

Bujak, J.P.; Brinkhuis, H. 1998: Global warming and dinocyst changes across the Paleocene/Eocene epoch boundary. In Aubry et al. (eds.) 1998: Late Paleocene-early Eocene biotic and climatic events in the marine and terrestrial records. Columbia University Press, p. 277-295.

Bujak, J.P.; Davies, E.H. 1983: Modern and fossil Peridiniineae. American Association of Stratigraphic Palynologists Contributions Series 13: 1-203, 12 pl..

Bujak, J.P.; Downie, C.; Eaton, G.L.; Williams, G.L. 1980a: Dinoflagellate cysts and acritarchs from the Eocene of southern England. Special Papers in Palaeontology 24: 1-100.

- 1980b: IV. Taxonomy of some Eocene dinoflagellate cyst species from southern England. In - 1980a: Dinoflagellate cysts and acritarchs from the Eocene of southern England. Special Papers in Palaeontology 24: $26-36$

Bujak, J.P.; Matsuoka, K., 1986: Late Cenozoic dinoflagellate cyst zonation in the western and northern Pacific. American Association of Stratigraphic Palynologists Contributions Series 17: 7-25, pl. 1-3.

Burger, D. 1980b: Early Cretaceous (Neocomian) microplankton from the Carpentaria Basin, northern Queensland. Alcheringa 4: 263-279.

Bütschli, O. 1885: Dinoflagellata. In Protozoa (1880-1889), In Bronn's Klassen und Ordnungen des Tierreichs 1: 906-1029.

Cameron, A.A.; Waghorn, D.B. 1985: Bortonian/Kaiatan foraminifera and calcareous nannofossils from Hampden Beach and McCulloch's Bridge. In Cooper, R.A. 1985: Hornibrook Symposium 9, 1985, Christchurch, New Zealand, extended abstracts Hornibrook Symposium 9, 1985, Christchurch, New Zealand, extended abstracts, p. 18-20.

Cavalier-Smith, T. 1981: Eukaryote kingdoms, seven or nine? BioSystems 14: 461-481.

— 1991: Cell diversification in heterotrophic flagellates. In Patterson, D.J.; Larsen, J. (eds.) 1991: The biology of free-living heterotrophic flagellates. Oxford University Press, p. 113-131.

Châteauneuf, J.-J. 1980: Palynostratigraphie et paléoclimatologie de l'Eocène supérieur et de l'Oligocène du Bassin de Paris. Mémoires du Bureau de recherches géologiques et minières (BRGM) 116: 1-360, pl. 1-30.

Clowes, C.D. 1985: Stoveracysta, a new gonyaulacacean dinoflagellate genus from the Upper Eocene and Lower Oligocene of New Zealand. Palynology 9: 27-35, pl. 1, figs. 1-12, pl. 2, figs. 1-12, text-figs. 1-4.

Clowes, C.D.; Morgans, H.E.G. 1984: Micropaleontology of the Runangan-Whaingaroan (Eocene-Oligocene) Totara Limestone, Kakanui River, New Zealand. New Zealand Geological Survey Record 3: 30-40, pl. 1-2.

Clowes, C.D.; Wilson, G.J. 2006: Some new species of Corrudinium Stover \& Evitt 1978 (Dinophyceae) from the Eocene of New Zealand. New Zealand Journal of Geology and Geophysics 49: 399-408, figs. 1-5.

Cocozza, C.D.; Clarke, C.M. 1992: Eocene microplankton from La Meseta Formation, northern Seymour Island Antarctic Science 4 (3): 355-362.

Cookson, I.C. 1953: Records of the occurrence of Botryococcus braunii, Pediastrum and the Hystrichosphaerideae in Cainozoic deposits of Australia. National Museum, Melbourne, Memoir, no. 18: 107-123, pl. 1-2. 
- 1956: Additional microplankton from Australian Late Mesozoic and Tertiary sediments. Australian Journal of Marine and Freshwater Research 7 (1): 183-191, pl. 1-2.

- 1965a: Cretaceous and Tertiary microplankton from south-eastern Australia. Proceedings of the Royal Society of Victoria 78 (1): 85-93, pl. 9-11.

Cookson, I.C.; Cranwell, L.M. 1967: Lower Tertiary microplankton, spores and pollen grains from southernmost Chile. Micropaleontology 13 (2): 204-216, pl. 1-3.

Cookson, I.C.; Eisenack, A. 1958: Microplankton from Australian and New Guinea Upper Mesozoic sediments. Proceedings of the Royal Society of Victoria 70 (1): 19-79, pl. 1-12.

- 1960b: Upper Mesozoic microplankton from Australia and New Guinea. Palaeontology 2 (2): 243-261, pl. 3739.

— 1961b: Tertiary microplankton from the Rottnest Island Bore, Western Australia. Journal of the Royal Society of Western Australia 44: 39-47, pl. 1-2.

- 1962a: Some Cretaceous and Tertiary microfossils from Western Australia. Proceedings of the Royal Society of Victoria 75: 269-273, pl. 37.

- 1962b: Additional microplankton from Australian Cretaceous sediments. Micropaleontology 8 (4): 485-507, pl. $1-7$.

- 1965a: Microplankton from the Browns Creek Clays, SW. Victoria. Proceedings of the Royal Society of Victoria 79: 119-131, pl. 11-15.

- 1965b: Microplankton from the Dartmoor Formation, SW. Victoria. Proceedings of the Royal Society of Victoria 79: 133-137, pl. 16-17.

- 1967a: Some Early Tertiary microplankton and pollen grains from a deposit near Strahan, western Tasmania. Proceedings of the Royal Society of Victoria 80 (1): 131-140, pl. 17-21.

- 1967b: Some microplankton from the Paleocene Rivernook Bed, Victoria. Proceedings of the Royal Society of Victoria 80 (2): 247-257, pl. 39-42.

- 1968: Microplankton from two samples from Gingin Brook No. 4 Borehole, Western Australia. Journal of the Royal Society of Western Australia 51: 110-122.

- 1974: Mikroplankton aus australischen mesozoischen und tertiären Sedimenten. Palaeontographica, Abteilung B 148 (1-3): 44-93, pl. 20-29.

- 1982: Mikrofossilien aus australischen mesozoischen und tertiären Sedimenten. Zweiter Teil. Palaeontographica, Abteilung B 184 (1-3): 23-63, pl. 1-9.

Cooper, R.A. (ed.) 2004: The New Zealand geologic timescale. Institute of Geological and Nuclear Sciences Monograph 22: 1-284.

Corradini, D. 1973: Non-calcareous microplankton from the Upper Cretaceous of the northern Apennines. Bollettino della Società Paleontologica Italiana 11: 119-197, pl. 19-39.

Costa, L.I.; Downie, C. 1979: The Wetzeliellaceae; Palaeogene dinoflagellates. Proceedings of the 4th International Palynological Conference, Lucknow (1976-77) 2: 34-46.

Costa, L.I.; Downie, C. 1979a: The Wetzeliellaceae; Palaeogene dinoflagellates. IV International Palynological Conference, Lucknow (1976-1977) 2: 34-43.

Couper, R.A. 1953: Upper Mesozoic and Cainozoic spores and pollen grains from New Zealand. New Zealand Geological Survery Paleontological Bulletin 22: 1-77, pl. 1-9.

- 1960: New Zealand Mesozoic and Cainozoic plant microfossils. New Zealand Geological Survery Paleontological Bulletin 32: 1-87.

Crouch, E.M. 2001: Environmental change at the time of the Paleocene-Eocene biotic turnover. LPP Contributions Series 14: 1-216.

Damassa, S.P. 1979a: Eocene dinoflagellates from the Coastal Belt of the Franciscan Complex, northern California. Journal of Paleontology 53: 815-840, pl. 1-8.

Damassa, S.P. 1984: Morphologic variability and paraplate configuration of the dinoflagellate genus Danea Morgenroth 1968. Palynology 8: 51-69, pl. 1-6.

Damassa, S.P.; Williams, G.L.; Brinkhuis, H. 1994: Short course in Paleogene dinoflagellate cysts. Course Manual. Unpublished, p. . 
Davey, R.J. 1969c: The evolution of certain Upper Cretaceous hystrichospheres from South Africa. Palaeontologia Africana 12: 25-51, pl. 1-4.

- 1974: Dinoflagellate cysts from the Barremian of the Speeton Clay, England. In Unkn 1974 (ed.). Symposium on Stratigraphic Palynology; Birbal Sahni Institute of Palaeobotany, Special Publication, no. 3: 41-75, pl. 19.

- 1982b: Dinocyst stratigraphy of the latest Jurassic to Early Cretaceous of the Haldager No. 1 borehole, Denmark. Danmarks Geologiske Undersøgelse, Serie B, no. 6: 1-57, pl. 1-10.

Davey, R.J.; Downie, C.; Sarjeant, W.A.S.; Williams, G.L. 1966: Studies on Mesozoic and Cainozoic dinoflagellate cysts. British Museum (Natural History) Geology, Bulletin Supplement 3: 1-248, pl. 1-25, textfigs. 1-64.

Davey, R.J.; Downie, C.; Sarjeant, W.A.S.; Williams, G.L. 1969: Appendix to "Studies on Mesozoic and Cainozoic dinoflagellate cysts”. British Museum (Natural History) Geology, Bulletin Appendix to Supplement 3: 1-24.

Davey, R.J.; Williams, G.L. 1966a: IV. The genera Hystrichosphaera and Achomosphaera. In Davey, R.J.; Downie, C.; Sarjeant, W.A.S.; Williams, G.L. 1966: Studies on Mesozoic and Cainozoic dinoflagellate cysts. British Museum (Natural History) Geology, Bulletin Supplement 3: 28-52.

- 1966b: V. The genus Hystrichosphaeridium and its allies. In Davey, R.J.; Downie, C.; Sarjeant, W.A.S.; Williams, G.L. 1966: Studies on Mesozoic and Cainozoic dinoflagellate cysts. British Museum (Natural History) Geology, Bulletin Supplement 3: 53-106.

Davies, E.H. 1983: The dinoflagellate Oppel-zonation of the Jurassic-Lower Cretaceous sequences in the Sverdrup Basin, arctic Canada. Geological Survey of Canada, Bulletin, no. 359: 1-59, pl. 1-10.

Dawkins, R. 2004: The ancestors tale: a pilgrimage to the dawn of evolution. Houghton Mifflin, p. 1-688.

De Coninck, J. 1965: Microfossiles planctoniques du sable Yprésian à Merelbeke. Dinophyceae et Acritarcha. Mémoires de l'Académie royale des sciences, des lettres et des beaux-arts de Belgique, Classe des sciences, Collection in-8 36 (2): 1-55, pl. 1-14, text-figs. 1-12.

- 1969: Dinophyceae et Acritarcha de I'Yprésien du sondage de Kallo. Mémoires de IInstitut royal des sciences naturelles de Belgique, no. 161: 1-67, pl. 1-17.

- 1975: Microfossiles à paroi organique de I'Yprésien du Bassin Belge. Service géologique de Belgique, Professional Paper 1975 (12): 1-151, pl. 1-22.

- 1977: Organic walled microfossils from the Eocene of the Woensdrecht borehole, southern Netherlands. Mededelingen Rijks Geologische Dienst, Nieuwe Serie 28 (3): 33-64, pl. 1-8, text-figs. 1-3.

- 1985: Microfossiles à paroi organique dans les Sables de Lede (Eocene Moyen) du sondage de Mol (Belgique). Bulletin de la Société belge de Géologie 94 (1): 65-78, pl. 1-3, text-figs. 1-2.

- 1986b: Organic walled phytoplankton from the Bartonian and Eo-Oligocene transitional deposits of the Woensdrecht borehole, southern Netherlands. Mededelingen van de Rijks Geologische Dienst 40 (2): 1-49, pl. 1-11, text-figs. 1.

- 1995a: Microfossiles à paroi organique du Bartonien, Priabonian et Rupélien inférieur dans le sondage de Kallo; espèces significatives dans les sondages de Woensdrecht, Kallo et Mol. Mededelingen van de Rijks Geologische Dienst 53: 65-105, pl. 1-8, text-figs. 1-4.

- 1999a: Phytoplancton a paroi organique et phases transgressives vers la transition Paleocene-Eocene dans la partie méridionale du Bassin de la Mer du Nord. Bulletin de la Société belge de Géologie 105 (3/4): 139169, pl. 1-8, text-figs. 1-6.

- 1999b: Organic-walled phytoplankton biostratigraphy of the Eocene-Oligocene transition in the Kallo borehole and the Rupelian stratotype area (northwestern Belgium). Bulletin de la Société belge de Géologie 105 (3/4): 171-209, pl. 1-7.

- 2002: Organic-walled microfossils in the Oligocene Grimmertingen and Neerrepen Sand Members from the Grimmertingen type locality. Geological Survey of Belgium Professional Paper 2001/2 (294): 1-57, pl. 1-13, text-figs. 1-4.

Deflandre, G. 1933: Note préliminaire sur un péridinien fossile Lithoperidinium oamaruense n. g., n. sp. Bulletin de la Société zoologique de France 58: 265-273.

- 1935: Considérations biologiques sur les microorganisms d'origine planctonique conservés dans les silex de la craie. Bulletin biologique de la France et de la Belgique 69: 213-244, pl. 5-9.

- 1937b: Microfossiles des silex crétacés. Deuxième partie. Flagellés incertae sedis. Hystrichosphaeridés. Sarcodinés. Organismes divers. Annales de paléontologie 26: 51-103, pl. 11-18. 
Deflandre, G.; Cookson, I.C. 1954: Sur le microplancton fossile conservé dans diverses roches sédimentaires australiennes s'étageant du Crétacé inférieur au Miocène supérieur. Comptes rendus hebdomadaires des séances de IAcadémie des sciences 239: 1235-1238.

- 1955: Fossil microplankton from Australian Late Mesozoic and Tertiary sediments. Australian Journal of Marine and Freshwater Research 6 (2): 242-313, pl. 1-9.

Diesing, C.M. 1866: Revision der Prothelminthen, Abtheilung: Mastigophoren. Akademie der Wissenschaften zu Wien, Sitzungsberichte, Mathematisch-naturwissenschaftliche Klasse 52 (8): 287-401.

Dörhöfer, G.; Davies, E.H. 1980: Evolution of archeopyle and tabulation in rhaetogonyaulacinean dinoflagellate cysts. Life Sciences Miscellaneous Publications, Royal Ontario Museum, p. 1-91.

Downie, C.; Evitt, W.R.; Sarjeant, W.A.S. 1963: Dinoflagellates, hystrichospheres, and the classification of the acritarchs. Stanford University Publications, Geological Sciences 7: 1-16.

Downie, C.; Sarjeant, W.A.S. 1965: Bibliography and index of fossil dinoflagellates and acritarchs. Geological Society of America, Memoir 94: 1-180.

Drugg, W. S. 1970b: Some new genera, species, and combinations of phytoplankton from the Lower Tertiary of the Gulf Coast, U. S. A. Proceedings of the North American Paleontological Convention, Chicago, September 1969 September 1969: 809-843.

Drugg, W.S.; Loeblich, A.R. Jr. 1967: Some Eocene and Oligocene phytoplankton from the Gulf Coast, U.S.A. Tulane Studies in Geology 5 (4): 181-194, pl. 1-3.

Duxbury, S. 1980: Barremian phytoplankton from Speeton, east Yorkshire. Palaeontographica, Abteilung B 173 (4-6): 107-146, pl. 1-13.

- 1983: A study of dinoflagellate cysts and acritarchs from the Lower Greensand (Aptian to Lower Albian) of the Isle of Wight, southern England. Palaeontographica, Abteilung B 186 (1-3): 18-80, pl. 1-10.

Eaton, G.L. 1971: A morphogenetic series of dinoflagellate cysts from the Bracklesham beds of the Isle of Wight, Hampshire, England. In Farinacci, A. (ed.) 1971: Proc. 2nd Planktonic Conf. Rome, 1970 Proc. 2nd Planktonic Conf. Rome, 1970 (Edizioni Technoscienza) 1: 355-379, pl. 1-4.

- 1976: Dinoflagellate cysts from the Bracklesham Beds (Eocene) of the Isle of Wight, southern England. British Museum (Natural History) Geology, Bulletin 26: 227-332, pl. 1-21.

Eaton, G.L.; Fensome, R.A.; Riding, J.B.; Williams, G.L. 2001: Re-evaluation of the status of the dinoflagellate cyst genus Cleistosphaeridium. Neues Jahrbuch für Geologie und Paläontologie, Abhandlungen 219 (1/2): 171-205, figs. 1-9.

Edbrooke, S.W.; Crouch, E.M.; Morgans, H.E.G.; Sykes, R. 1998: Late Eocene-Oligocene Te Kuiti Group at Mount Roskill, Auckland. New Zealand Journal of Geology and Geophysics 41: 85-93.

Edwards, A.R. 1971: A calcareous nannoplankton zonation of the New Zealand Paleogene. In Farinacci, A. (ed.) 1971: Proc. 2nd Planktonic Conf. Rome, 1970 Proc. 2nd Planktonic Conf. Rome, 1970 (Edizioni Technoscienza) 1: 381-419.

Edwards, L.E. 1977: Range charts and chronostratigraphic hypotheses, with applications to Tertiary dinoflagellates [unpublished $\mathrm{PhD}$ thesis, University of California, Riverside]. Unpublished PhD thesis, University of California, Riverside, p. .

- 1982: Biostratigraphically important species of Pentadinium Gerlach 1961 and a likely ancestor, Hafniasphaera goodmanii n. sp. and from the Eocene of the Atlantic and Gulf coastal plains. Palynology 6: 105-117, pl. 1-4.

- 1996: 25. Analytical biostratigraphy and correlation. Introduction. In Jansonius, J.; McGregor, D.C. (eds.) 1996: Palynology: principles and applications. American Association of Stratigraphic Palynologists Foundation, vol. 1: p. 81-106 or is it vol. 3: 1249-1275.. American Association of Stratigraphic Palynologists Foundation 1: 81-106.

Edwards, Lucy E.; Bebout, John W. 1981: Emendation of Phthanoperidinium Drugg \& Loeblich 1967, and a description of $P$. brooksii sp. nov. from the Eocene of the mid-Atlantic outer continental shelf. Palynology 5: 29-41, pl. 1-2.

Ehrenberg, C.G. 1831: Animalia evertebrata. In Hemprich, P.C.; Ehrenberg, C.G. 1831: Symbolae physicae. Pars zoologica. , p. .

- 1838: Über das Massenverhältniss der jetzt lebenden Kiesel-Infusorien und über ein neues InfusorienConglomerat als Polierschiefer von Jastraba in Ungarn. Königlich Akademie der Wissenschaften zu Berlin, Abhandlungen, 1836 1: 109-135, pl. 1-2. 
Eisenack, A. 1938b: Die Phosphoritknollen der Bernsteinformation als Überlieferer tertiären Planktons. Schriften der Physikalisch-Ökonomischen Gesellschaft zu Königsberg 70 (2): 181-188.

- 1954b: Mikrofossilien aus Phosphoriten des samländischen Unteroligozäns und über die Einheitlichkeit der Hystrichosphaerideen. Palaeontographica, Abteilung A 105 (3-6): 49-95, pl. 7-12.

- 1958a: Mikroplankton aus dem norddeutschen Apt, nebst einigen Bemerkungen über fossile Dinoflagellaten. Neues Jahrbuch für Geologie und Paläontologie, Abhandlungen 106 (3): 383-422, pl. 21-27.

— 1961: Einige Erörterungen über fossile Dinoflagellaten nebst Übersicht über die zur Zeit bekannten Gattungen. Neues Jahrbuch für Geologie und Paläontologie, Abhandlungen 112 (3): 281-324, pl. 33-37.

- 1963a: Zur Membranilarnax-Frage. Neues Jahrbuch für Geologie und Paläontologie, Monatshefte 2: 98-103.

- 1963b: Cordosphaeridium n.g., ex Hystrichosphaeridium, Hystrichosphaeridea. Neues Jahrbuch für Geologie und Paläontologie, Abhandlungen 118: 260-265, pl. 29.

— 1966: Über einige probleme bei fossilen dinoflagellaten. Archiv Protistenkunde 109: 207-222, pl. 60, figs. 1-8, text-figs. 1-2.

- 1967: Katalog der Fossilen Dinoflagellaten, Hystrichosphären und Verwandten Mikrofossilien. Band I. Dinoflagellaten. 1. Ergänzungslieferung. E. Schweizerbart'sche Verlagsbuchhandlung, Stuttgart, Germany 3: 1-241.

- 1969a: Kritische Bemerkungen und Richtigstellungen im Gebiet der fossilen Dinoflagellaten und Acritarchen. Neues Jahrbuch für Geologie und Paläontologie, Abhandlungen 134 (2): 101-116.

- 1972: Kritische Bemerkung zur Gattung Pterospermopsis (Chlorophyta, Prasinophyceae). Critical remarks about Pterospermopsis. Neues Jahrbuch für Geologie und Paläontologie, Monatshefte, no. 10: 596-601.

Eisenack, A.; Gocht, H. 1960: Neue Namen für einige Hystrichosphären der Bernsteinformation Ostpreussens. Neues Jahrbuch für Geologie und Paläontologie, Monatshefte, no. 11: 511-518.

Eisenack, A.; Kjellström, G. 1972: Katalog der Fossilen Dinoflagellaten, Hystrichosphären und Verwandten Mikrofossilien. Band II. Dinoflagellaten. E. Schweizerbart'sche Verlagsbuchhandlung, Stuttgart, Germany, p. $1-1132$.

Eisenack, A.; Kjellström, G. 1975b: Katalog der Fossilen Dinoflagellaten, Hystrichosphären und Verwandten Mikrofossilien. Band II. Dinoflagellaten. 1. Ergänzungslieferung. E. Schweizerbart'sche Verlagsbuchhandlung, Stuttgart, Germany, p. 1-518.

Eldredge, N.; Gould, S.J. 1972: Punctuated equilibria: an alternative to phyletic gradualism. In: " Schopf, T.J.M. (ed.) 1972: Models in paleobiology. Freeman, Cooper \& Co, p. 82-115.

Eldrett, J.S.; Harding, I.C.; Firth, J.V.; Roberts, A.P. 2004: Magnetostratigraphic calibration of Eocene-Oligocene dinoflagellate cyst biostratigraphy from the Norwegian-Greenland Sea. Marine Geology 204: 91-127.

Evitt, W.R. 1961: Observations on the morphology of fossil dinoflagellates. Micropaleontology 7 (4): 385-420.

- 1963a: A discussion and proposals concerning fossil dinoflagellates, hystrichospheres, and acritarchs, I. Proceedings of the National Academy of Sciences, Washington 49: 158-164.

- 1963b: A discussion and proposals concerning fossil dinoflagellates, hystrichospheres, and acritarchs, II. Proceedings of the National Academy of Sciences, Washington 49: 298-302.

- 1985: Sporopollenin Dinoflagellate Cysts - Their Morphology and Interpretation. American Association of Stratigraphic Palynologists Foundation, p. 1-333.

Evitt, W.R., Lentin, J.K., Millioud, M.E., Stover, L.E.; Williams, G.L. 1977: Dinoflagellate cyst terminology. Geological Survey of Canada, Paper, no. 76-24: 1-11.

Exon, N.F.; Kennett, J.P.; Malone, M.J.; Brinkhuis, H.; Chaproniere, G.C.H.; Ennyu, A.; Fothergill, P.; Fuller, M.D.; Grauert, M.; Hill, P.J.; Janecek, T.R.; Kelly, D.C.; Latimer, J.C.; Nees, S.; Ninnemann, U.S.; Nürnberg, D.; Pekar, S.F.; Pellaton, C.C.; Pfuhl, H.A.; Robert, C.M.; McGonigal Roessig, K.L.; Röhl, U.; Schellenberg, S.A.; Shevenell, A.E.; Stickley, C.E.; Suzuki, N.; Touchard, Y.; Wei, W.; White, T.S. 2001: The Tasmanian Gateway: Cenozoic climatic and oceanographic development sites 1168-1172. Proceeding of Ocean Drilling Program, Initial Reports 189: 1-149.

Fensome, R.A.; Guerstein, G.R.; Williams, G.L. 2006: New insights on the Paleogene dinoflagellate cyst genera Enneadocysta and Licracysta gen. nov. based on material from offshore eastern Canada and southern Argentina. Micropaleontology 52 (5): 385-410, pl. 1-5, text-figs. 1-8.

Fensome, R.A.; MacRae, A.; Williams, G.L. 1998: DINOFLAJ Dinoflagellate Classification Database, version 1.1, October 1998. GSC Open File 3653. 
Fensome, R.A.; Riding, J.B.; Taylor, F.J.R. 1996: Chapter 6. Dinoflagellates. In Jansonius, J.; McGregor, D.C. 1996: Palynology: principles and applications. American Association of Stratigraphic Palynologists Foundation, vol. 1, p. 107-169.

Fensome, R.A.; Taylor, F.J.R.; Norris, G.; Sarjeant, W.A.S.; Wharton, D.I.; Williams, G.L. 1993b: A classification of fossil and living dinoflagellates. Micropaleontology Press Special Paper 7: 1-351.

Fensome, R.A.; Williams, G.L. 2004: The Lentin and Williams index of fossil dinoflagellates, 2004 edition. American Association of Stratigraphic Palynologists Contributions Series 42: 1-909.

Fensome, R.A.; Williams, G.L.; Barss, M.S.; Freeman, J.M.; Hill, J.M. 1990: Acritarchs and fossil prasinophytes: an index to genera, species and intraspecific taxa. American Association of Stratigraphic Palynologists Contributions Series 25: 1-771.

Finlay, H.J.; Marwick, J. 1940: The divisions of the Upper Cretaceous and Tertiary in New Zealand. Transactions of the Royal society of New Zealand 70 (1): 77-135.

Gage, M. 1957: The geology of the Waitaki Subdivision. New Zealand Geological Survey Bulletin ns 55: 1-135.

Gair, H.S. 1959: The Tertiary geology of the Pareora District, south Canterbury. New Zealand Journal of Geology and Geophysics 2: 265-296.

Gallagher, R.; Appenzeller, T. 1999: Beyond Reductionism. Science 284: .

Gerlach, E. 1961: Mikrofossilien aus dem Oligozän und Miozän nordwestdeutschlands, unter besonderer Berücksichtigung der hystrichosphaeren und dinflagellaten. Neues Jahrbuch für Geologie und Paläontologie, Abhandlungen 112 (2): 143-228, pl. 25-29, text-figs. 1-22.

Glassey, P.J. 1994: Puketeraki Landslide: Assessment of drilling and monitoring data and recommendations for remedial measures. Institute of Geological and Nuclear Sciences Client Report 94/91: 1-25.

Gocht, H. 1955: Rhombodinium und Dracodinium, zwei neue Dinoflagellaten-Gattungen aus dem norddeutschen Tertiär. Neues Jahrbuch für Geologie und Paläontologie, Monatshefte, no. 2: 84-92.

- 1968: Zur Morphologie und Ontogenie von Thalassiphora (Dinoflagellata). Palaeontographica, Abteilung A 129: 149-156, pl. 25-27.

- 1969: Formengemeinschaften alttertiären Mikroplanktons aus Bohrproben des Erdölfeldes Meckelfeld bei Hamburg. Palaeontographica, Abteilung B 126: 1-100, pl. 1-11.

Goodman, D.K.; Ford, L.N. 1983: 31. Preliminary dinoflagellate biostratigraphy for the Middle Eocene to Lower Oligocene from the southwest Atlantic Ocean. In Krasheninikov, V.A.; et al. 1983: Initial reports of the Deep Sea Drilling Project. U.S. Government Printing Office, Washington LXXI: 859-877.

Goodman, D.K.; Witmer, R.J. 1985: Archeopyle variation and paratabulation in the dinoflagellate Diphyes colligerum (Deflandre and Cookson, 1955) Cookson, 1965. Palynology 9: 61-83, pl. 1-6.

Gould, S.J. 1992: Life in a Punctuation. Natural History 101: 12-14.

Gregg, D.R. 1964: Sheet 18. Hurunui (1st ed). Geological Map of New Zealand 1:250,000. Department of Scientific and Industrial Research, Wellington, New Zealand, p. .

Grimaldi, D.; Engel, M.S. 2005: Evolution of the insects. Cambridge University Press, p. 1-755.

Habib, D. 1976: Neocomian dinoflagellate zonation in the western North Atlantic. Micropaleontology 21 (4): $373-$ 392, pl. 1-3.

Haeckel, E. 1894: Systematische Phylogenie. Entwurf eines natürlichen Systems der Organismen auf Grund ihrer Stammegeschichte, I. Systematische Phylogenie der Protisten und Pflanzen. Berlin, Reimer, p. 1-400.

Hansen, J.M. 1977: Dinoflagellate stratigraphy and echinoid distribution in Upper Maastrichtian and Danian deposits from Denmark. Bulletin of the Geological Society of Denmark 26: 1-26.

Harker, S.D.; Sarjeant, W.A.S. 1975: The stratigraphic distribution of organic-walled dinoflagellate cysts in the Cretaceous and Tertiary. Review of Palaeobotany and Palynology 20 (4): 217-315, pl. 1.

Haskell, T.R.; Wilson, G.J. 1975: Palynology of Sites 280-284, DSDP Leg 29, off southeastern Australia and western New Zealand. In Kennett, J.P., Houtz, R.E., et al. 1975: Initial Reports of the Deep Sea Drilling Project. U.S. Government Printing Office, Washington 29: 723-741.

Head, M.J. 1994a: Morphology and paleoenvironmental significance of the Cenozoic dinoflagellate genera Tectatodinium and Habibacysta. Micropaleontology 40: 289-321. 
Head, M.J. 1994b: A forum on Neogene and Quaternary dinoflagellate cysts. The edited transcript of a round table discussion held at the Third Workshop on Neogene and Quaternary dinoflagellates, with taxonomic appendix. Palynology 17: 201-239, pl. 1-11.

Head, M.J.; Norris, G. 1989: 28. Palynology and dinocyst stratigraphy of the Eocene and Oligocene in ODP Leg 105, Hole 647A, Labrador Sea. In Srivastava, S.P. et al. (eds.) 1989: Ocean Drilling Program, Proceedings, Scientific Results, Leg 105 Ocean Drilling Program, Proceedings, Scientific Results, Leg 105, College Station, Texas 105: 515-550, pl. 1-13.

Head, M.J.; Norris, G.; Mudie, P.J. 1989b: 26. New species of dinocysts and a new species of acritarch from the upper Miocene and lowermost Pliocene, ODP Leg 105, Site 646, Labrador Sea. In Srivastava, S.P. et al (eds.) 1989: Ocean Drilling Program, Proceedings, Scientific Results, Leg 105 Ocean Drilling Program, Proceedings, Scientific Results, Leg 105, College Station, Texas 105: 453-466, pl. 1-5.

Head, M.J.; Norris, G.; Mudie, P.J. 1989c: 27. Palynology and dinocyst stratigraphy of the Miocene in ODP Leg 105, Hole 645E, Baffin Bay. In Srivastava, S.P. et al. (eds.) 1989: Ocean Drilling Program, Proceedings, Scientific Results, Leg 105 Ocean Drilling Program, Proceedings, Scientific Results, Leg 105, College Station, Texas 105: 467-514, pl. 1-12.

Head, M.J.; Wrenn, J.H. (eds.) 1992b: A forum on Neogene and Quaternary dinoflagellate cysts. In Head, M.J.; Wrenn, J.H. (eds.) 1992a: Neogene and Quaternary dinoflagellate cysts and acritarchs. American Association of Stratigraphic Palynologists Foundation, p. 1-31.

Heilmann-Clausen, C. 1985: Dinoflagellate stratigraphy of the uppermost Danian to Ypresian in the Viborg I borehole, central Jylland, Denmark. Danmarks Geologiske Undersøgelse, Serie A, no. 7: 1-69, pl. 1-15.

Heilmann-Clausen, Claus; Van Simaeys, Stefan 2005: Dinoflagellate cysts from the Middle Eocene to ?lowermost Oligocene succession in the Kysing Research Borehole, central Danish Basin. Palynology 29: 143-204.

Helenes, J. 1984a: Morphological analysis of Mesozoic-Cenozoic Cribroperidinium (Dinophyceae), and taxonomic implications. Palynology 8: 107-137, pl. 1-5.

- 1984b: Dinoflagellates from Cretaceous to Early Tertiary rocks of the Sebastian Vizcaino Basin, Baja California, Mexico. In Frizzell, V.A. Jr. (ed.) 1984: Geology of the Baja California Peninsula. Pacific Section S.E.P.M. 39: 89-106.

Hennig, W. 1950: Grundzuge einer theorie der phylogenetischen systematik. Deutsche Zentralverlag, Berlin., p. .

— 1966: Phylogenetic systematics. University of Illinois Press, Urbana, p. .

Herngreen, G.F.W. 1975: Palynology of Middle and Upper Cretaceous strata in Brazil. Mededelingen Rijks Geologische Dienst, Nieuwe Serie 26: 39-91, pl. 1-5.

Hollis, C.J.; Field, B.D.; Jones, C.M.; Strong, C.P.; Wilson, G.J.; Dickens, G.R. 2005: Biostratigraphy and carbon isotope stratigraphy of uppermost Cretaceous-lower Cenozoic Muzzle Group in middle Clarence Valley, New Zealand. Journal of the Royal Society of New Zealand 35: 345-383.

Hornibrook, N. de B. 1961: Tertiary foraminifera from Oamaru District (N.Z.) Part 1 - Systematics and distribution. New Zealand Geological Survey Paleontological Bulletin 34 (1): 1-192, pl. 1-28.

- 1971: [no title] In Kingma, J.T. 1971: The geology of Te Aute Subdivision. New Zealand Geological Survey Bulletin 70:

Hornibrook, N. de B.; Brazier, R.C.; Strong, C.P. 1989: Manual of New Zealand Permian to Pleistocene foraminiferal biostratigraphy. New Zealand Geological Survey Paleontological Bulletin 56: 1-175.

Hornibrook, N. de B.; Harrington, H.J. 1957: The status of the Wangaloan stage. New Zealand Journal of Science and Technology, series B 38: 655-670.

Hoskins, R.H. 1982: Stages of the New Zealand marine Cenozoic: a synopsis. New Zealand Geological Survey Report 107: 1-74.

Islam, M.A. 1982: Archeopyle structure in the fossil dinoflagellate Phthanoperidinium. Review of Palaeobotany and Palynology 36: 305-316, pl. 1-2.

- 1983b: Dinoflagellate cyst taxonomy and biostratigraphy of the Eocene Bracklesham Group in southern England. Micropaleontology 29: 328-353, pl. 1-4.

- 1993: Review of the fossil dinoflagellate Cleistosphaeridium. Revista española de micropaleontología 25 (2): 81-94, pl. 1.

Jain, K.P.; R. 1986: Upper Paleocene dinoflagellate cysts and acritarchs from Vriddhachalam, Cauvery Basin, southern India. Palaeontographica, Abteilung B, 198: 101-132, pl. 1-6. 
Jan du Chêne, R. 1977: Étude palynologique du Miocène supérieur Andalou (Espagne). Revista española de micropaleontología 9: 97-114, pl. 1-2.

Jan du Chêne, R.; Adediran, S.A. 1985: Late Paleocene to Early Eocene dinoflagellates from Nigeria. Cahiers de micropaléontologie, Centre nationale de la recherche scientifique, no. 1984-3: 5-38, pl. 1-25.

Jan du Chêne, R.; Châteauneuf, J.-J. 1975: Nouvelles espèces de Wetzeliella et Deflandrea (Pyrrhophyta, Dinophyceae) de l'Eocène des Alpes occidentales. Revue de Micropaléontologie 18: 28-37, pl. 1-3.

Jan du Chêne, R.; Masure, E.; Becheler, I.; Biffi, U.; de Vains, G.; Fauconnier, D.; Ferrario, R.; Foucher, J.-C.; Gaillard, M.; Hochuli, P.; Lachkar, G.; Michoux, D.; Monteil, E.; Moron, J.-M.; Rauscher, R.; Raynaud, J.-F.; Taugourdeau, J.; Turon, J.-L. 1986a: Guide pratique pour la détermination de kystes de dinoflagellés fossiles. Le complexe Gonyaulacysta. Bulletin des Centres de recherches exploration-production ElfAquitaine, Mémoir, no. 12: 1-479, pl. 1-152.

Jenkins, D.G. 1966: Planktonic foraminiferal zones and new taxa from the Danian to Lower Miocene of New Zealand. New Zealand Journal of Geology and Geophysics 8: 1088-1126.

- 1971: New Zealand Cenozoic planktonic foraminifera. New Zealand Geological Survey Paleontological Bulletin 42: 1-278.

Jiabo 1978: On the Paleogene Dinoflagellates and Acritarchs from the Coastal Region of Bohai. Nanjing Institute of Geology and Palaeontology, Academia Sinica, Nanjing, China., p. 1-190, pl. 1-49.

Jux, U. 1968: Über den Feinbau der Wandung bei Cordosphaeridium inodes (Klumpp 1953). Palaeontographica, Abteilung B 122: 48-54, pl. 13-14, text-figs. 1.

- 1971: Über den Feinbau der Wandung einiger tertiärer Dinophyceen-Zysten und Acritarcha. Palaeontographica, Abteilung B 132: 115-128, pl. 25-28, text-figs. 1-2.

- 1976: Über den Feinbau der Wandung bei Operculodinium centrocarpum (Deflandre \& Cookson) Wall 1967 und Bitectatodinium tepikiense Wilson 1973. Palaeontographica, Abteilung B 155: 149-156, pl. 1-5, text-figs. 1.

Kemp, E.M. 1975: Palynology of Leg 28 drill sites, Deep Sea Drilling Project. In Hayes, D.E.; Frakes, L.A.; et al. 1975: Initial Reports of the Deep Sea Drilling Project reports of the Deep Sea Drilling Project, 28: 599-623. Initial Reports of the Deep Sea Drilling Project reports of the Deep Sea Drilling Project, 28: 599-623. 28: 599-623.

Khowaja-Ateequzzaman; Garg, R.; Jain, K.P. 1991: Some observations on dinoflagellate cyst genus Alterbidinium Lentin and Williams 1985. The Palaeobotanist 39 (1): 37-45, pl. 1-2.

Kingma, J.T. 1971: The geology of Te Aute Subdivision. New Zealand Geological Survey Bulletin ns 70: 1-173.

Kjellström, G. 1972: Archeopyle formation in the genus Lejeunia Gerlach, 1961 emend. Geologiska Föreningens i Stockholm Förhandlingar 94 (3): 467-469, figs. 1-2.

Klumpp, B. 1953: Beitrag zur Kenntnis der Mikrofossilien des mittleren und oberen Eozän. Palaeontographica, Abteilung A 103: 377-406.

Kuprijanova, L. 1960: Palynological data contributing to the history of Liquidambar. Pollen et Spores 2: 71-88.

Landman, N.H.; Johnson, R.O.; Garb, M.P.; Edwards, L.E.; Kyte, F.T. 2007: Cephalopods from the Cretaceous/Tertiary boundary interval on the Atlantic coastal plain, with a description of the highest ammonite zones in North America. Part III. Manasquan River Basin, Monmouth County, New Jersey. Bulletin of the American Museum of Natural History, New York, no. 303: 1-122, figs. 1-56.

Lejeune-Carpentier, M. 1937: L'étude microscopique des silex (4iè Note). Annales de la Société géologique de Belgique 61: 59-71.

- 1938a: L'étude microscopique des silex. Areoligera: nouveau genre d'Hystrichosphaeridée. (Sixième note.) Annales de la Société géologique de Belgique 62: B163-B174.

Lentin, J.K.; Vozzhennikova, T.F. 1989: The fossil dinoflagellate cysts Kisselovia emend. and Charlesdowniea gen. nov. Review of Palaeobotany and Palynology 58: 215-229, pl. 1-3.

Lentin, J.K.; Williams, G.L. 1973: Fossil dinoflagellates: Index to genera and species. Geological Survey of Canada, Paper 73-42: 1-176.

- 1976: A monograph of fossil peridinioid dinoflagellate cysts. Bedford Institute of Oceanography, Report Series, no. BI-R-75-16: 1-237.

— 1977a: Fossil dinoflagellate genus Isabelidinium nom. nov. Palynology 1: 167-168. 
— 1977b: Fossil dinoflagellates: index to genera and species, 1977 edition. Bedford Institute of Oceanography, Report Series, no. BI-R-77-8: 1-209.

- 1981: Fossil dinoflagellates: index to genera and species, 1981 edition. Bedford Institute of Oceanography, Report Series, no. BI-R-81-12: 1-345.

- 1985: Fossil dinoflagellates: index to genera and species, 1985 edition. Canadian Technical Report of Hydrography and Ocean Sciences 60: 1-451.

- 1987: Status of the fossil dinoflagellate genera Ceratiopsis Vozzhennikova 1963 and Cerodinium Vozzhennikova 1963 emend. Palynology 11: 113-116.

- 1989: Fossil dinoflagellates: index to genera and species, 1989 edition. American Association of Stratigraphic Palynologists Contributions Series, no. 20: 1-473.

Levy, R.H.; Harwood, D.M. 2000: Tertiary marine palynomorphs from the McMurdo Sound erratics, Antarctica. American Geophysical Union, Antarctic Research Series 76: 183-242.

Liengjarern, M.; Costa, L.; Downie, C. 1980: Dinoflagellate cysts from the Upper Eocene-Lower Oligocene of the Isle of Wight. Palaeontology 23: 475-499, pl. 53-54.

Lindemann, E. 1928: Abteilung Peridineae (Dinoflagellatae). In Engler, A.; Prantl, K. (eds.) 1928: Die Natürlichen Pflanzenfamilien nebst ihren Gattungen und wichtigeren Arten insbesondere den Nutzpflanzen. Zweite stark vermehrte und verbesserte Auflage herausgegeben von A. Engler. 2 Band. Zweite stark vermehrte und verbesserte Auflage herausgegeben von A. Engler. 2 Band. Leipzig, Wilhelm Engelmann, p. 3-104.

Lindgren, S. 1984: Acid resistant peridinioid dinoflagellates from the Maastichtian of Trelleborg, southern Sweden. Stockholm Contributions in Geology 39 (6): 145-201, figs. 1-23.

Loeblich, A.R.Jr.; Loeblich, A.R. III 1966: Index to the genera, subgenera, and sections of the Pyrrhophyta. Studies in Tropical Oceanography, no. 3: 1-94.

Lohmann, H. 1905: Eier und sogenannte Cysten der Plankton-Expedition. Anhang: Cyphonautes. Ergebnisse der Plankton-Expedition der Humboldt-Stiftung, Band IV. N. Lipsius und Tischer, Kiel, Germany, p. 1-61, pl. 1-7.

Londeix, L.; Jan du Chêne, R. 1988: Ectosphaeropsis, nouveau genre de dinoflagellé de la région stratotypique du Burdigalien Bordelais (France). Bulletin des Centres de recherches exploration-production Elf-Aquitaine 12 (1): 251-265, pl. 1-3.

MacPherson, E.O. 1947: The stratigraphy of Chalk Hill, Oxford Survey District, with notes on grading the chalk. New Zealand Journal of Science and Technology B28 (3): 164-172.

Maier, D. 1959: Planktonuntersuchungen in tertiären und quartären marinen Sedimenten. Ein Beitrag zur Systematik, Stratigraphie und Ökologie der Coccolithophorideen, Dinoflagellaten und Hystrichosphaerideen vom Oligozän bis zum Pleistozän. Neues Jahrbuch für Geologie und Paläontologie, Abhandlungen 107 (3): 278-340, pl. 27-33, text-figs. 1-4.

Mantell, G.A. 1850: Atlas of fossil remains consisting of coloured illustrations selected from Parkinson's "Organic Remains of a Former World." Henry G. Bohn, London, p. 1-207, pl. 1-74.

- 1854: The medals of creation; or, first lessons in geology and the study of organic remains, second edition. Henry G. Bohn, London, U.K., p. 1-930, pl. 1-6.

Manum, S.B. 1976: Dinocysts in Tertiary Norwegian-Greenland Sea sediments (Deep Sea Drilling Project Leg 38), with observations on palynomorphs and palynodebris in relation to environment. In Talwani, M.; Udintsev, G.; et al. (eds.) 1976: Initial Reports of the DSDP. U.S. Government Printing Office, Washington 38: 897-919.

- 1976: Some dinoflagellates and hystrichosphaerids from the Lower Tertiary of Spitsbergen. Nytt Magasin for Botanikk 8: 17-25, figs. 1-11.

- 1979: Two new Tertiary dinocyst genera from the Norwegian Sea: Lophocysta and Evittosphaerula. Review of Palaeobotany and Palynology 28: 237-248, pl. 1-2.

Mao, S.; Mohr, B. 1995: Middle Eocene dinocysts from Bruce Bank (Scotia Sea, Antarctica) and their paleoenvironmental and paleogeographic implications. Review of Palaeobotany and Palynology 86: 235263, pl. 1-7.

Marshall, N.G.; Partridge, A.D. 1988: The Eocene acritarch Tritonites gen. nov. and the age of the Marlin Channel, Gippsland Basin, southeastern Australia. Memoirs of the Association of Australasian Palaeontologists 5: 239-257.

Martin, H.A. 1993: Middle Tertiary dinoflagellate and spore/pollen biostratigraphy and palaeoecology of the Mallee Cliffs bore, central Murray Basin. Alcheringa 17: 91-124, figs. 1-13. 
Matsuoka, K. 1983: Late Cenozoic dinoflagellates and acritarchs in the Niigata district, central Japan. Palaeontographica, Abteilung B 187: 89-154.

Matsuoka, K.; McMinn, A.; Wrenn, J.H. 1997: Restudy of the holotype of Operculodinium centrocarpum (Deflandre \& Cookson) Wall (Dinophyceae) from the Miocene of Australia, and the taxonomy of related species. Palynology 21: 19-33.

McLean, D.M. 1971: Transfer of Baltisphaeridium septatum Cookson and Eisenack, 1967, from the Acritarcha to the Dinophyceae. Journal of Paleontology 45: 729-730, pl. 88.

McLennan, J.M. 1981: The Cretaceous-Tertiary rocks of Avoca, Oxford and Burnt Hill, central Canterbury. Unpublished thesis, University of Canterbury, p. 1-234.

McMillan, S.G.; Wilson, G.J. 1997: Allostratigraphy of coastal south and east Otago: a stratigraphic framework for interpretation of the Great South Basin, New Zealand. New Zealand Journal of Geology and Geophysics 40: 91-107, figs. 1-9.

McMinn, A.; Sun, X. 1994: Recent dinoflagellate cysts from the Chatham Rise, Southern Ocean, east of New Zealand. Palynology 18: 41-53, pl. 1-3.

Menéndez, C.A. 1965: Microplancton fósil de sedimentos Terciarios y Cretácicos del norte de Tierra del Fuego (Argentina). Ameghiniana 4 (1): 7-15, pl. 1-3.

Mildenhall, D.C. 1979a: Summary of the palynology of samples collected from the environs of the Abbotsford slip (metric sheet 144). New Zealand Geological Survey Palynology Section Report DCM 43/79, p. 1-3.

- 1979b: Palynology of samples collected from the area around the Abbotsford slip (metric sheet 144). New Zealand Geological Survey Palynology Section Report DCM 44/79, p. 1-10.

Morgan, R. 1975: Some Early Cretaceous organic-walled microplankton from the Great Australian Basin, Australia. Journal and Proceedings of the Royal Society of New South Wales 108: 157-167, pl. 1-3.

Morgans, Hugh E.G.; Beu, A.G.; Cooper, R.A.; Crouch, E.M.; Hollis, C.J.; Jones, C.M.; Raine, J.I.; Strong, C.P.; Wilson, G.J.; Wilson, G.S. 2004: Chapter 11, Paleogene (Dannevirke, Arnold and Landon Series). In Cooper, R.A. (ed.) 2004: The New Zealand geologic timescale. Institute of Geological and Nuclear Sciences Monograph 22: 1-284.

Morgenroth, P. 1966a: Mikrofossilien und Konkretionen des nordwesteuropäischen Untereozäns. Palaeontographica, Abteilung B 119 (1-3): 1-53, pl. 1-11.

— 1966b: Neue in organischer Substanz erhaltene Mikrofossilien des Oligozäns. Neues Jahrbuch für Geologie und Paläontologie, Abhandlungen 127: 1-12, pl. 1-2.

Mutch, A.R. 1963: Sheet 23, Oamaru (1st ed), Geological Map of New Zealand 1:250,000. Department of Scientific and Industrial Research, Wellington, New Zealand, p.

Nagy, E. 1965: The microplankton occurring in the Neogene of the Mecsek Mountains. Acta Botanica, Académiae Scientiarum Hungaricae 11: 197-216, pl. 1-6, text-figs. 1-9.

Neef, G. 1992: Geology of the Akitio area (1:50 000 metric sheet U25BD, east), northeastern Wairarapa, New Zealand. New Zealand Journal of Geology and Geophysics 35: 533-548.

Norris, G. 1978a: Phylogeny and a revised supra-generic classification for Triassic-Quaternary organic-walled dinoflagellate cysts (Pyrrhophyta). Part I. Cyst terminology and assessment of previous classifications. Neues Jahrbuch für Geologie und Paläontologie, Abhandlungen 155 (3): 300-317.

- 1978b: Phylogeny and a revised supra-generic classification for Triassic-Quaternary organic-walled dinoflagellate cysts (Pyrrhophyta). Part II. Families and sub-orders of fossil dinoflagellates. Neues Jahrbuch für Geologie und Paläontologie, Abhandlungen 156 (1): 1-30.

Ostenfeld, C.H. 1903: Phytoplankton from the sea around the Faeröes. Det Nordiske Forlag, Copenhagen, Denmark Part II: 558-612.

Park, J. 1918: The geology of the Oamaru District, North Otago (Eastern Otago Division). New Zealand Geological Survey Bulletin (n.s.) 20: 1-124.

Partridge, A.D.; Dettmann, M.E. 2003: Chapter 22.4.2 Plant microfossils. In Birch, W.D. (ed.) 2003: Geology of Victoria. Geological Society of Australia Special Publication 23: 643-652.

Pascher, A. 1914: Über flagellaten und algen. Deutsche Botanische Gesellschaft, Berichte 32: 136-160.

Pastiels, A. 1948: Contribution à l'étude des microfossiles de l'Éocène belge. Mémoires du Musée royal d'histoire naturelle de Belgique 109: 1-77, pl. 1-6. 
Piasecki, S. 1980: Dinoflagellate cyst stratigraphy of the Miocene Hodde and Gram Formations, Denmark. Geological Society of Denmark, Bulletin 29: 53-76, pl. 1-6.

Pöthe de Baldis, E.D. 1966: Microplancton del Terciario de Tierra del Fuego. Ameghiniana 4 (7): 219-228, pl. 1-2.

Prössl, K.F. 1994: Paucilobimorpha De Coninck 1986 and Tritonites Marshall \& Partridge 1988: two synonymous Eocene acritarch-genera. Neues Jahrbuch für Geologie und Paläontologie, Monatshefte 7: 399-406.

Quattrocchio, M.E.; Sarjeant, W.A.S. 2003: Dinoflagellates from the Chorrillo Chico Formation (Paleocene) of southern Chile. Ameghiniana 40 (2): 129-153.

Ramírez, R.A. 2004: Middle to Late Eocene dinoflagellate cysts and fungal spores from the east coast of the Maracaibo Lake, Venezuela. Unpublished PhD thesis, Eberhard-Karls-Universität Tübingen, p. 1-102, pl. 113.

Reid, P.C. 1974: Gonyaulacacean dinoflagellate cysts from the British Isles. Nova Hedwigia 25: 579-637, pl. 1-4.

Rossignol, M. 1964: Hystrichosphères du Quaternaire en Méditerranée orientale, dans les sédiments Pléistocènes et les boues marines actuelles. Revue de micropaléontologie 7 (2): 83-99, pl. 1-3.

Rozen, B. 1965: Contribution à l'étude des hystrichosphères et dinoflagellés du Bartonien belge. Bulletin de la Société belge de géologie, de paléontologie et d'hydrologie 73: 287-318, pl. 1-4.

Sarjeant, W.A.S. 1964a: Taxonomic notes on hystrichospheres and acritarchs. Journal of Paleontology 38 (1): 173-177.

- 1966b: Dinoflagellate cysts with Gonyaulax-type tabulation. In Davey, R.J.; Downie, C.; Sarjeant, W.A.S.; Williams, G.L. 1966: Studies on Mesozoic and Cainozoic dinoflagellate cysts. British Museum (Natural History) Geology, Bulletin Supplement 3: 107-156.

- 1970: The genus Spiniferites Mantell, 1850 (Dinophyceae). Grana 10: 74-78.

- 1981: A restudy of some dinoflagellate cyst holotypes in the University of Kiel Collections. II. The Eocene holotypes of Barbara Klumpp (1953); with a revision of the genus Cordosphaeridium Eisenack, 1963. Meyniana 33: 97-132, pl. 1-6.

- 1984b: Re-study of some dinoflagellate cysts from the Oligocene and Miocene of Germany. Journal of Micropalaeontology 3 (2): 73-94, pl. 1-4.

- 1985b: A restudy of some dinoflagellate cyst holotypes in the University of Kiel collections: VI. Late Cretaceous dinoflagellate cysts and other palynomorphs in the Otto Wetzel collection. Meyniana 37: 129185, pl. 1-7.

- 1986: A restudy of Pastiels' (1948) dinoflagellate cysts from the Early Eocene of Belgium. Bulletin de IInstitut royal des sciences naturelles de Belgique, no. 56: 5-43, pl. 1-5.

- 1989: Review: L.E. Stover and G.L. Williams. Analyses of Mesozoic and Cenozoic organic-walled dinoflagellates 1977-1985. American Association of Stratigraphic Palynologists, Contributions Series no.18, 1987. Micropaleontology 35 (1): 93-96.

Sarjeant, W.A.S.; Downie, C. 1966: The classification of dinoflagellate cysts above generic level. Grana Palynologica 6 (3): 503-527.

- 1974: The classification of dinoflagellate cysts above generic level: a discussion and revisions. Symposium on Stratigraphic Palynology, Birbal Sahni Institute of Palaeobotany, Special Publication, no. 3: 9-32.

Schiøler, Poul 2005: Dinoflagellate cysts and acritarchs from the Oligocene-Lower Miocene interval of the Alma1X well, Danish North Sea. Journal of Micropalaeontology 24: 1-37.

Silva, P.C. 1970: Remarks on algal nomenclature. IV. Taxon 19: 941-945.

Sluijs, A.; Brinkhuis, H.; Stickley, C.E.; Warnaar, J.; Williams, G.L.; Fuller, M. 2003: Dinoflagellate cysts from the Eocene-Oligocene transition in the Southern Ocean: Results from ODP Leg 189. In Exon, N.F.; Kennett, J.P.; Malone, M.J. (eds.) 2003: Proceedings of the ODP, Scientific Results. Proceedings of the Ocean Drilling Program, Scientific Results 189: 1-42.

Stover, L.E. 1974: Palaeocene and Eocene species of Deflandrea (Dinophyceae) in Victorian coastal and offshore basins, Australia. Geological Society of Australia, Special Publication 4: 167-188, pl. 1-5.

- 1975: Observations on some Australian Eocene dinoflagellates. Geoscience and Man 11: 35-45, pl. 1-3.

- 1977: Oligocene and Early Miocene dinoflagellates from Atlantic Corehole 5/5B, Blake Plateau. American Association of Stratigraphic Palynologists Contributions Series 5A: 66-89, pl. 1-3. 
Stover, L.E.; Evitt, W.R. 1978: Analyses of pre-Pleistocene organic walled dinoflagellates. Stanford University Publications, Geological Sciences 15: 1-300.

Stover, L.E.; Hardenbol, J. 1994: Dinoflagellates and depositional sequences in the Lower Oligocene (Rupelian) Boom Clay Formation, Belgium. Bulletin de la Société belge de Géologie 102 (1-2): 5-77.

Stover, L.E.; Williams, G.L. 1987: Analyses of Mesozoic and Cenozoic organic-walled dinoflagellates 1977-1985. American Association of Stratigraphic Palynologists Contributions Series 18: 1-243.

- 1995: A revision of the Paleogene dinoflagellate genera Areosphaeridium Eaton 1971 and Eatonicysta Stover and Evitt 1978. Micropaleontology 41: 97-141.

Strauss, C.; Lund, J.J. 1992: A Middle Miocene dinoflagellate cyst microflora from Papendorf near Hamburg, Germany. Mitteilungen Geologisch-Paläontologischen Institut der Universität Hamburg 73: 159-189, pl. 1-5.

Strong, C.P.; Hollis, C.J.; Wilson, G.J. 1995: Foraminiferal, radiolarian, and dinoflagellate biostratigraphy of Late Cretaceous to Middle Eocene pelagic sediments (Muzzle Group), Mead Stream, Marlborough, New Zealand. New Zealand Journal of Geology and Geophysics 38: 171-212.

Suggate, R.P. 1950: Quartzose coal measures of west Nelson and north Westland. New Zealand Journal of Science and Technology B31 (4): 1-13.

Suggate, R.P.; Stevens, G.R.; Te Punga, M.T. (eds.) 1978: The geology of New Zealand. Government Printer, Wellington, 2 vols., 1-820.

Taylor, F.J.R. 1980: On dinoflagellate evolution. BioSystems 13: 65-108.

- 1987d: Appendix. Taxonomy and classification. In Taylor, F.J.R. (ed.) 1987: The biology of dinoflagellates. Blackwell Scientific Publications, Botanical Monograph 21: 723-731.

— 1990: 24. Phylum Dinoflagellata. In Margulis, L., Corliss, J.O., Melkonian, M., Chapman, D.J.; McKhann, H.I. (editors) 1990: Handbook of Protoctista. Jones and Bartlett, p. 419-437.

Thomson, J.A. 1916: On stage names applicable to the divisions of the Tertiary in New Zealand. Transactions of the New Zealand Institute 48: 28-40.

Traverse, A. 1988: Paleopalynology. Unwin Hyman, London, p. 1-600.

Van Mourik, C.A.; Brinkhuis, H. 2005: The Massignago Eocene-Oligocene golden spike section revisited. Stratigraphy 2 (1): 13-30.

Voss, E.G.; Burdet, H.M.; Chaloner, W.G.; Demoulin, V.; Hiepko, P.; McNeill, J.; Meikle, R.D.; Nicholson, D.H.; Rollins, R.C.; Silva, P.C.; Greuter, W. 1983: International code of botanical nomenclature, adopted by the Thirteenth International Botanical Congress, Sydney, August 1981. Dr. W. Junk, The Hague/Boston 111: 1472.

Vozzhennikova, T.F. 1961: K voprosu o sistematike iskopayemykh Peridiney. Akademiya Nauk SSSR (Doklady Earth Science Sections) 139 (6): 1461-1462.

- 1963: Klass Peridineae (Dinoflagellateae). Peridinei, ili dinoflagellaty. In Kiselev, A. (ed.). Osnovy Paleontologii 14: $171-186$.

- 1967: Fossil peridineae from Jurassic, Cretaceous and Paleogene deposits of the USSR. Moscow, Nauka Publishers, p. 1-347.

Wall, D. 1967a: Fossil microplankton in deep-sea cores from the Caribbean Sea. Palaeontology 10 (1): 95-123, pl. 14-16.

- 1967b: The resting cysts of modern marine dinoflagellates and their palaeontological significance. Review of Palaeobotany and Palynology 2: 349-354, pl. 1.

Wall, D.; Dale, B. 1973: [Description of Pyxidinopsis psilata] In Wall, D.; Dale, B.; Harada, K. 1973: Descriptions of new fossil dinoflagellates from the Late Quaternary of the Black Sea. Micropaleontology 19: 22-23.

Weinberg, S. 1993: The discovery of subatomic particles. Penguin, 222 p., p. 1-222.

Wetzel, O. 1933b: Die in organischer Substanz erhaltenen Mikrofossilien des baltischen Kreide-Feuersteins mit einem sediment-petrographischen und stratigraphischen Anhang. Palaeontographica, Abteilung A 78: 1110, pl. 1-7.

Williams, G.L. 1965: Organic-walled microfossils aid oil research. Oil Gas Journal 63 (47): 108-112.

- 1978: Palynological biostratigraphy, Deep Sea Drilling Project Sites 367 and 370. In Lancelot, Y. et al., Deep Sea Drilling Project, Washington, Initial Reports, v. 41, p. 783-815, pl. 1-8. U.S. Government Printing Office, Washington 41: 783-815. 
Williams, G.L.; Brideaux, W.W. 1975: Palynologic analyses of upper Mesozoic and Cenozoic rocks of the Grand Banks, Atlantic Continental Margin. Geological Survey of Canada, Bulletin, no. 236: 1-163, pl. 1-47.

Williams, G.L.; Brinkhuis, H.; Pearce, M.A.; Fensome, R.A.; Weegink, J.W. 2004: Southern ocean and global dinoflagellate cyst events compared: index events for the Late Cretaceous-Neogene. In Exon, N.F.; Kennett, J.P.; Malone, M.J. (eds.) 2003: Proceedings of the ODP, Scientific Results. Proceedings of the Ocean Drilling Program, Scientific Results 189: .

Williams, G.L.; Downie, C. 1966a: The genus Hystrichokolpoma. In Davey, R.J.; Downie, C.; Sarjeant, W.A.S.; Williams, G.L. 1966: Studies on Mesozoic and Cainozoic dinoflagellate cysts. British Museum (Natural History) Geology, Bulletin Supplement 3: 176-181.

- 1966b: Wetzeliella from the London Clay. In Davey, R.J.; Downie, C.; Sarjeant, W.A.S.; Williams, G.L. 1966: Studies on Mesozoic and Cainozoic dinoflagellate cysts. British Museum (Natural History) Geology, Bulletin Supplement 3: 182-198.

- 1966c: Further dinoflagellate cysts from the London Clay. In Davey, R.J.; Downie, C.; Sarjeant, W.A.S.; Williams, G.L. 1966: Studies on Mesozoic and Cainozoic dinoflagellate cysts. British Museum (Natural History) Geology, Bulletin Supplement 3: 215-236.

Williams, G.L.; Sarjeant, W.A.S.; Kidson, E.J. 1973: A glossary of the terminology applied to dinoflagellate amphiesmae and cysts and acritarchs. American Association of Stratigraphic Palynologists, Contributions Series 2: 1-222.

Williams, G.L.; Stover, L.E.; Kidson, E.J. 1993: Morphology and stratigraphic ranges of selected MesozoicCenozoic dinoflagellate taxa in the Northern Hemisphere. Geological Survey of Canada, Paper, no. 92-10: 1-137.

Willumsen, P.S. 2003: Marine palynology across the Cretaceous-Tertiary boundary in New Zealand. PhD thesis in geology, Victoria University of Wellington. Unpublished $\mathrm{PhD}$ thesis in geology, Victoria University of Wellington., p. 1-387.

- 2004: Two new species of the dinoflagellate cyst genus Carpatella Grigorovich, 1969 from the CretaceousTertiary transition in New Zealand. Journal of Micropalaeontology 23: 119-125.

Wilson ,D.D. 1956: The Late Cretaceous and Early Tertiary transgression in South Island, New Zealand. New Zealand Journal of Science and Technology B37: 610-622.

— 1963: The geology of Waipara Subdivision. Bulletin of the New Zealand Geological Survey 64: 1-122.

Wilson, G.J. 1967a: Some new species of Lower Tertiary dinoflagellates from McMurdo Sound, Antarctica. New Zealand Journal of Botany 5: 57-83.

- 1967b: Microplankton from the Garden Cove Formation, Campbell Island. New Zealand Journal of Botany 5: 223-240.

- 1967c: Some species of Wetzeliella Eisenack (Dinophyceae) from New Zealand Eocene and Paleocene strata. New Zealand Journal of Botany 5: 469-497.

- 1968: Palynology of some Lower Tertiary coal measures in the Waihao district, South Canterbury, New Zealand. New Zealand Journal of Botany 6: 56-62.

- 1977: A new species of Svalbardella Manum (Dinophyceae) from the Eocene of New Zealand. New Zealand Journal of Geology and Geophysics 20: 563-566.

- 1978: The dinoflagellate species Isabelia druggii (Stover) and I. seelandica (Lange): their association in the Teurian of Woodside Creek, Marlborough, New Zealand. New Zealand Journal of Geology and Geophysics 21 (1): 75-80, figs. 1-13.

- 1982a: Early Tertiary dinoflagellates from Chalky Island, SW Fiordland. New Zealand Geological Survey Report PAL 56: 1-12, pl. 1, figs. 1-12.

- 1982b: Eocene and Oligocene dinoflagellate assemblages from the Oamaru area, North Otago, N.Z. New Zealand Geological Survey Report PAL 60: 1-20, pl. 1-4.

- 1982c: Early Tertiary dinoflagellate assemblages from the Oxford area, Central Canterbury and their bearing on the age of associated basaltic volcanics. New Zealand Geological Survey Report PAL 61: 1-10, pl. 1, figs. 1-16, pl. 2, figs. 1-16.

- 1984c: Some new dinoflagellate species from the New Zealand Haumurian and Piripauan stages (SantonianMaastrichtian, Late Cretaceous). New Zealand Journal of Botany 22: 549-556.

- 1984d: New Zealand Late Jurassic to Eocene dinoflagellate biostratigraphy - a summary. Newsletters on Stratigraphy 13: 104-117. 
- 1985: Dinoflagellate biostratigraphy of the Eocene Hampden Section, North Otago, New Zealand. New Zealand Geological Survey Record 8: 93-101, pl. 1, figs. 1-19.

- 1987: Dinoflagellate biostratigraphy of the Cretaceous-Tertiary boundary, mid-Waipara River section, North Canterbury, New Zealand. New Zealand Geological Survey Record 20: 8-15.

- 1988: Paleocene and Eocene dinoflagellate cysts from Waipawa, Hawkes Bay, New Zealand. New Zealand Geological Survey Paleontological Bulletin 57: 1-96.

- 1989: Marine palynology. In Barrett, P.J. (ed.) 1989: Antarctic Cenozoic history from the CIROS-1 drillhole, McMurdo Sound. Department of Scientific and Industrial Research, Wellington, New Zealand, Bulletin 245: 129-133, pl. 1, figs. 1-19.

Wilson, G.J.; McMillan, S.G. 1996: Late Cretaceous-Tertiary stratigraphic sections of coastal Otago, South Island, New Zealand: a summary of biostratigraphic and lithostratigraphic data. Institute of Geological and Nuclear Sciences Science Report 96/39: 1-182.

Woese, C.R.; Kandler, O.; Wheelis, M.L. 1990: Towards a natural system of organisms: proposal for the domains Archaea, Bacteria and Eucarya. Proceedings of the National Academy of Sciences of the USA 87: 45764579.

Wrenn, J.H. 1988: Differentiating species of the dinoflagellate cyst genus Nematosphaeropsis Deflandre \& Cookson 1955. Palynology 12: 129-150, pl. 1-7.

Wrenn, J.H.; Beckman, S.W. 1982: Maceral, total organic carbon, and palynological analyses of the Ross Ice Shelf Project Site J9 cores. Science 216: 187-189.

Wrenn, J.H.; Hart, G.F. 1988: Paleogene dinoflagellate cyst biostratigraphy of Seymour Island, Antarctica. Geological Society of America, Memoir 169: 321-447. 


\section{Appendix 1. List of Samples and Preparations}

The following table lists collection data for all illustrated specimens.

\begin{tabular}{|c|c|c|c|}
\hline Sample & Preparation & Provenance & Age \\
\hline 143/f089 & L16337 & Puketeraki Core & Bortonian \\
\hline 143/f090 & L16338 & Puketeraki Core & Bortonian \\
\hline 143/f091 & L16339 & Puketeraki Core & Bortonian \\
\hline 143/f092 & L16340 & Puketeraki Core & Bortonian \\
\hline 143/f093 & L16341 & Puketeraki Core & Bortonian \\
\hline I43/f094 & L16342 & Puketeraki Core & Bortonian \\
\hline 143/f096 & L16344 & Puketeraki Core & Kaiatan \\
\hline |43/f101 & L16349 & Puketeraki Core & Otaian \\
\hline |43/f108 & L16358 & Tumai & Runangan \\
\hline 144/f080 & L08947 & Burnside Marl Pit & Bortonian \\
\hline 144/f240 & L15506 & M26 Core & Heretaungan-Bortonian \\
\hline J31/f9185 & L08324 & Nine Mile Bluff & Kaiatan \\
\hline $\mathrm{J} 31 / \mathrm{f9} 966$ & L08325 & Nine Mile Bluff & Kaiatan \\
\hline J41/f8914 & L04979 & Jacksons Paddock & Kaiatan-Runangan \\
\hline J42/f039 & L09196 & Hampden Beach Section & Heretaungan \\
\hline $\mathrm{J} 42 / \mathrm{f0} 40$ & L09197 & Hampden Beach Section & Bortonian \\
\hline J42/f041 & L09198 & Hampden Beach Section & Bortonian \\
\hline $\mathrm{J} 42 / \mathrm{f0} 42$ & L09199 & Hampden Beach Section & Bortonian \\
\hline J42/f048 & L09205 & Hampden Beach Section & Bortonian \\
\hline $\mathrm{J} 42 / \mathrm{f055}$ & L09212 & Hampden Beach Section & Bortonian \\
\hline J42/f057 & L09214 & Hampden Beach Section & Bortonian \\
\hline J42/f061 & L09218 & Hampden Beach Section & Bortonian \\
\hline J42/f062 & L09219 & Hampden Beach Section & ?Kaiatan \\
\hline $\mathrm{J} 42 / \mathrm{f063}$ & L09220 & Hampden Beach Section & Kaiatan \\
\hline J42/f064 & L09221 & Hampden Beach Section & Kaiatan \\
\hline J42/f096 & L10951 & Kakanui River & early Whaingaroan \\
\hline J42/f097 & L10952 & Kakanui River & ?early Whaingaroan \\
\hline J42/f098 & L10953 & Kakanui River & Runangan \\
\hline $\mathrm{J} 42 / \mathrm{f} 125$ & L11625 & Kakanui River & Runangan-early Whaingaroan \\
\hline $\mathrm{J} 42 / \mathrm{f} 298$ & L23128 & Hampden Beach Section & Heretaungan-Porangan \\
\hline J42/f299 & L23129 & Hampden Beach Section & Porangan \\
\hline $\mathrm{J} 42 / \mathrm{f} 300$ & L23130 & Hampden Beach Section & Porangan \\
\hline $\mathrm{J} 42 / f 301$ & L23131 & Hampden Beach Section & Porangan-Bortonian \\
\hline $\mathrm{J} 42 / \mathrm{f302}$ & L23132 & Hampden Beach Section & Porangan-Bortonian \\
\hline $\mathrm{J} 42 / f 303$ & L23133 & Hampden Beach Section & Bortonian \\
\hline $\mathrm{J} 42 / f 483$ & L23118 & Hampden Beach Section & Heretaungan \\
\hline $\mathrm{J} 42 / f 484$ & L23119 & Hampden Beach Section & Heretaungan \\
\hline $\mathrm{J} 42 / f 485$ & L23120 & Hampden Beach Section & Porangan-Bortonian \\
\hline $\mathrm{J} 42 / f 486$ & L23121 & Hampden Beach Section & Porangan-Bortonian \\
\hline $\mathrm{J} 42 / f 487$ & L23122 & Hampden Beach Section & Bortonian \\
\hline $\mathrm{J} 42 / f 488$ & L23123 & Hampden Beach Section & Bortonian \\
\hline $\mathrm{J} 42 / f 489$ & L23124 & Hampden Beach Section & Bortonian \\
\hline J42/f8690 & L06958 & Hampden Beach Section & Bortonian \\
\hline K29/f097 & L10914 & Cape Foulwind Section & early Whaingaroan \\
\hline K29/f099 & L11035 & Cape Foulwind Section & ?Kaiatan-Runangan \\
\hline K29/f101 & L11037 & Cape Foulwind Section & Runangan \\
\hline
\end{tabular}




\begin{tabular}{|c|c|c|c|}
\hline K29/f102 & L11038 & Cape Foulwind Section & Runangan \\
\hline K29/f104 & L11040 & Cape Foulwind Section & Runangan \\
\hline K29/f106 & L11042 & Cape Foulwind Section & Runangan-early Whaingaroan \\
\hline K29/f108 & L11044 & Cape Foulwind Section & Runangan-early Whaingaroan \\
\hline $\mathrm{K} 29 / \mathrm{f} 112$ & L11048 & Cape Foulwind Section & Runangan-early Whaingaroan \\
\hline K29/f114 & L11050 & Cape Foulwind Section & early Whaingaroan \\
\hline K29/f115 & L11051 & Cape Foulwind Section & early Whaingaroan \\
\hline $\mathrm{K} 29 / \mathrm{f} 116$ & L11052 & Cape Foulwind Section & early Whaingaroan \\
\hline K29/f123 & L11934 & Cape Foulwind Section & Runangan \\
\hline $\mathrm{K} 29 / \mathrm{f} 125$ & L11936 & Cape Foulwind Section & Runangan \\
\hline K29/f128 & L11939 & Cape Foulwind Section & Runangan \\
\hline K29/f169 & L11918 & Cape Foulwind Section & Runangan-early Whaingaroan \\
\hline $\mathrm{K} 29 / \mathrm{f} 170$ & L11919 & Cape Foulwind Section & Runangan-early Whaingaroan \\
\hline $\mathrm{K} 29 / \mathrm{f} 171$ & L11920 & Cape Foulwind Section & Runangan-early Whaingaroan \\
\hline K29/f172 & L11921 & Cape Foulwind Section & Runangan-early Whaingaroan \\
\hline K29/f173 & L11922 & Cape Foulwind Section & early Whaingaroan \\
\hline $\mathrm{K} 29 / \mathrm{f} 174$ & L11923 & Cape Foulwind Section & early Whaingaroan \\
\hline K29/f176 & L11925 & Cape Foulwind Section & early Whaingaroan \\
\hline $\mathrm{K} 29 / \mathrm{f} 178$ & L11927 & Cape Foulwind Section & early Whaingaroan \\
\hline $\mathrm{K} 29 / \mathrm{f} 180$ & L11929 & Cape Foulwind Section & early Whaingaroan \\
\hline K29/f182 & L11931 & Cape Foulwind Section & early Whaingaroan \\
\hline K29/f183 & L11932 & Cape Foulwind Section & early Whaingaroan \\
\hline K29/f184 & L11933 & Cape Foulwind Section & early Whaingaroan \\
\hline K29/f259 & L13545 & Cape Foulwind Section & Runangan \\
\hline K29/f261 & L13543 & Cape Foulwind Section & Runangan \\
\hline K29/f262 & L13546 & Cape Foulwind Section & Runangan \\
\hline L34/f7538 & L06997 & Upper Eyre River & Mangaorapan \\
\hline L35/f7539 & L06998 & Upper Eyre River & Mangaorapan \\
\hline S14/f8599 & L10662 & Old Mountain Road & Runangan-early Whaingaroan \\
\hline U24/f201 & L12144 & Akitio River & Whaingaroan \\
\hline U24/f417 & L23125 & Te Uri Stream & Porangan \\
\hline U24/f418 & L23126 & Te Uri Stream & Porangan \\
\hline U24/f419 & L23127 & Te Uri Stream & Porangan \\
\hline V22/f8994 & L12118 & Waipawa Section & Heretaungan \\
\hline
\end{tabular}




\section{Appendix 2. Range Charts}

\section{Range Chart for Achilleodinium}

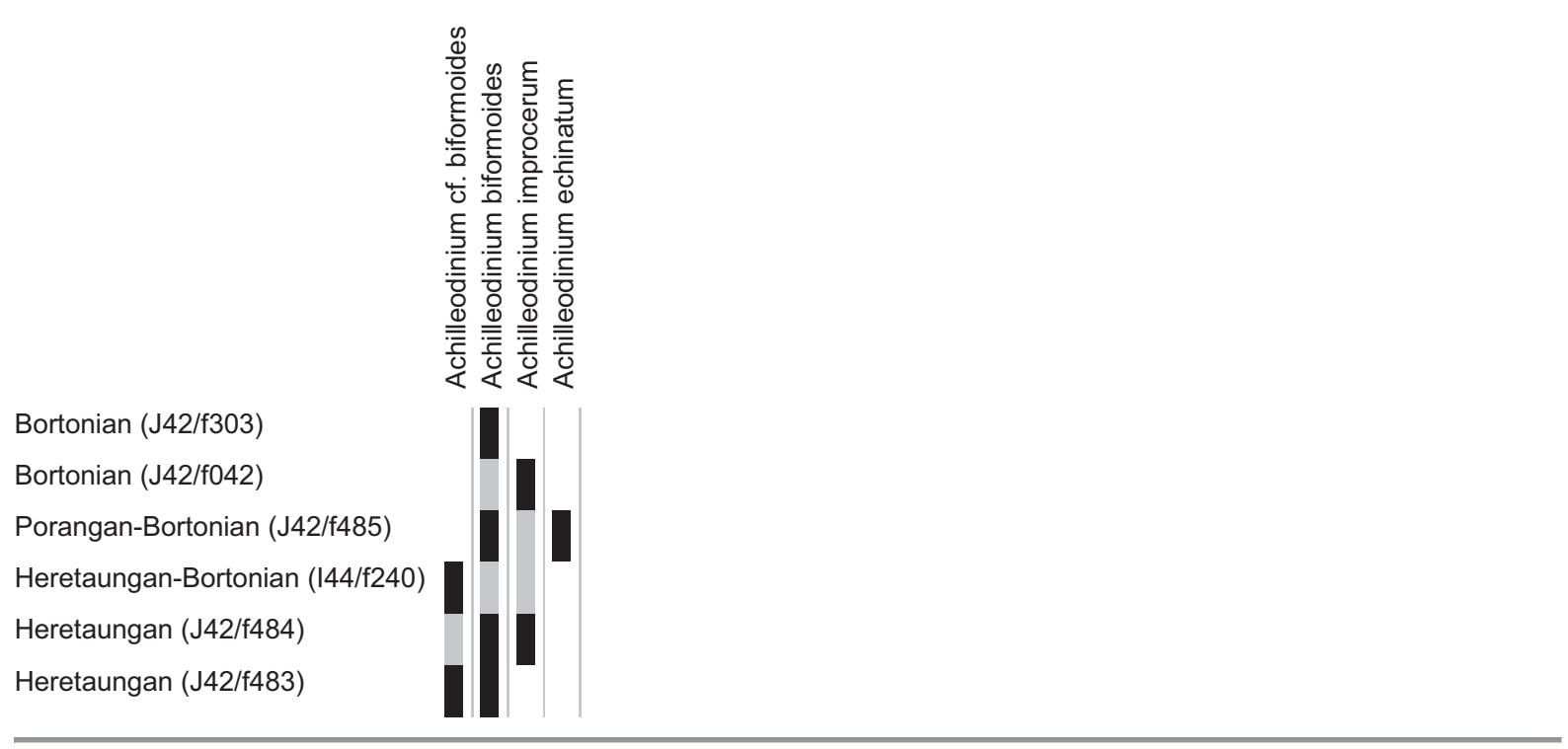

Chart 1: Range Chart for Achilleodinium.

\section{Range Chart for Corrudinium}

early Whaingaroan (K29/f182)

Runangan (K29/f101)

Kaiatan (J42/f063)

Bortonian (143/f090)

Bortonian (143/f089)

Porangan (U24/f419)

Porangan (J42/f299)

Heretaungan (J42/f039)

Mangaorapan (L35/f7539)

Mangaorapan (L34/f7538)
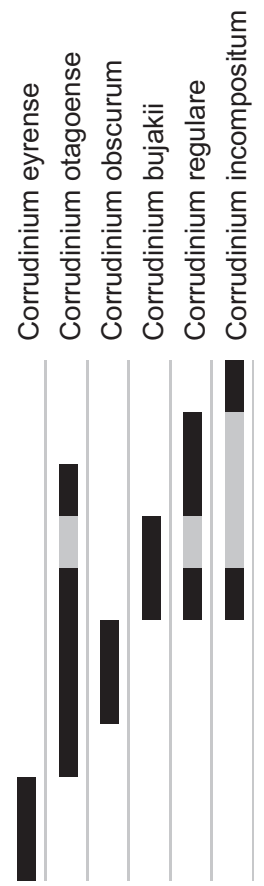

Chart 2: Range Chart for Corrudinium. 


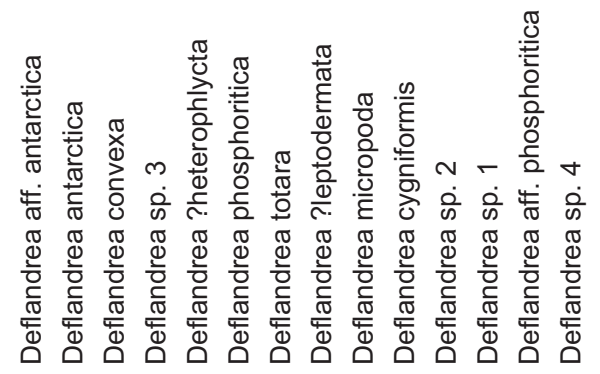

early Whaingaroan (K29/f184)

early Whaingaroan (K29/f115)

early Whaingaroan (K29/f114)

?early Whaingaroan (J42/f097)

early Whaingaroan (J42/f096)

Runangan-early Whaingaroan (K29/f106)

Runangan (K29/f260)

Runangan (K29/f102)

Bortonian (J42/f488)

Bortonian (J42/f061)

Bortonian (J42/f048)

Bortonian (143/f093)

Bortonian (143/f092)

Bortonian (143/f090)

Bortonian (143/f089)

Porangan (J42/f300)

Heretaungan (J42/f039)

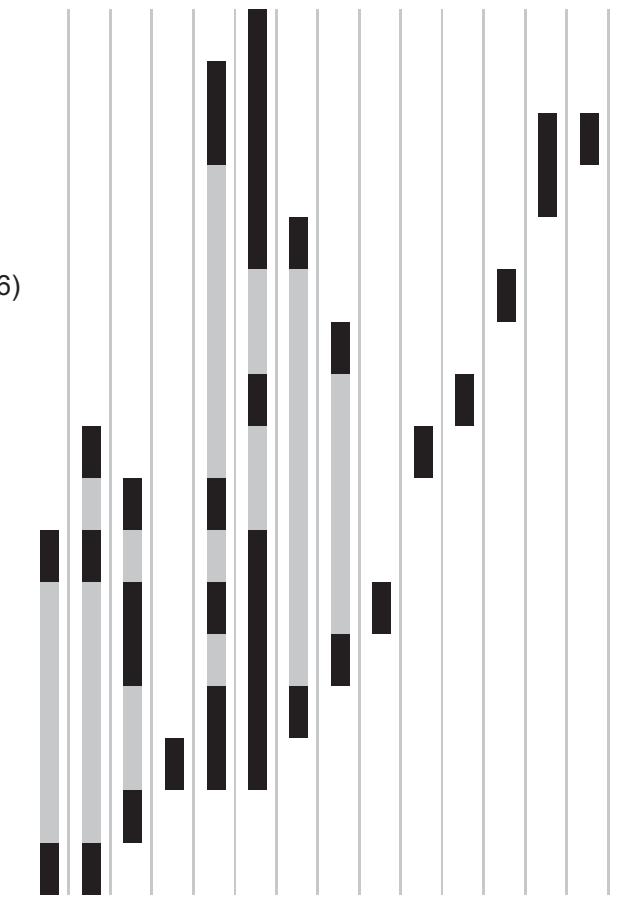

Chart 3: Range Chart for Deflandrea. 


\section{Range Chart for Impagidinium}

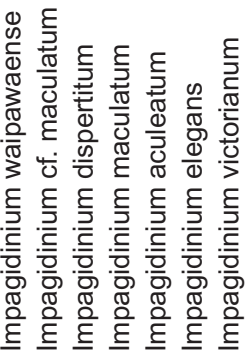

Otaian (143/f101)

early Whaingaroan (K29/f180)

Bortonian (J42/f042)

Bortonian (I43/f094)

Bortonian (143/f093)

Bortonian (143/f089)

Porangan-Bortonian (J42/f485)

Porangan (U24/f419)

Porangan (U24/f417)

Heretaungan (J42/f039)

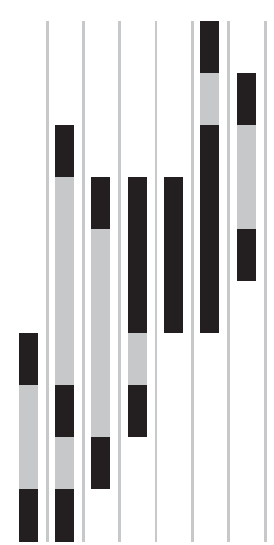

Chart 4: Range Chart for Impagidinium. 


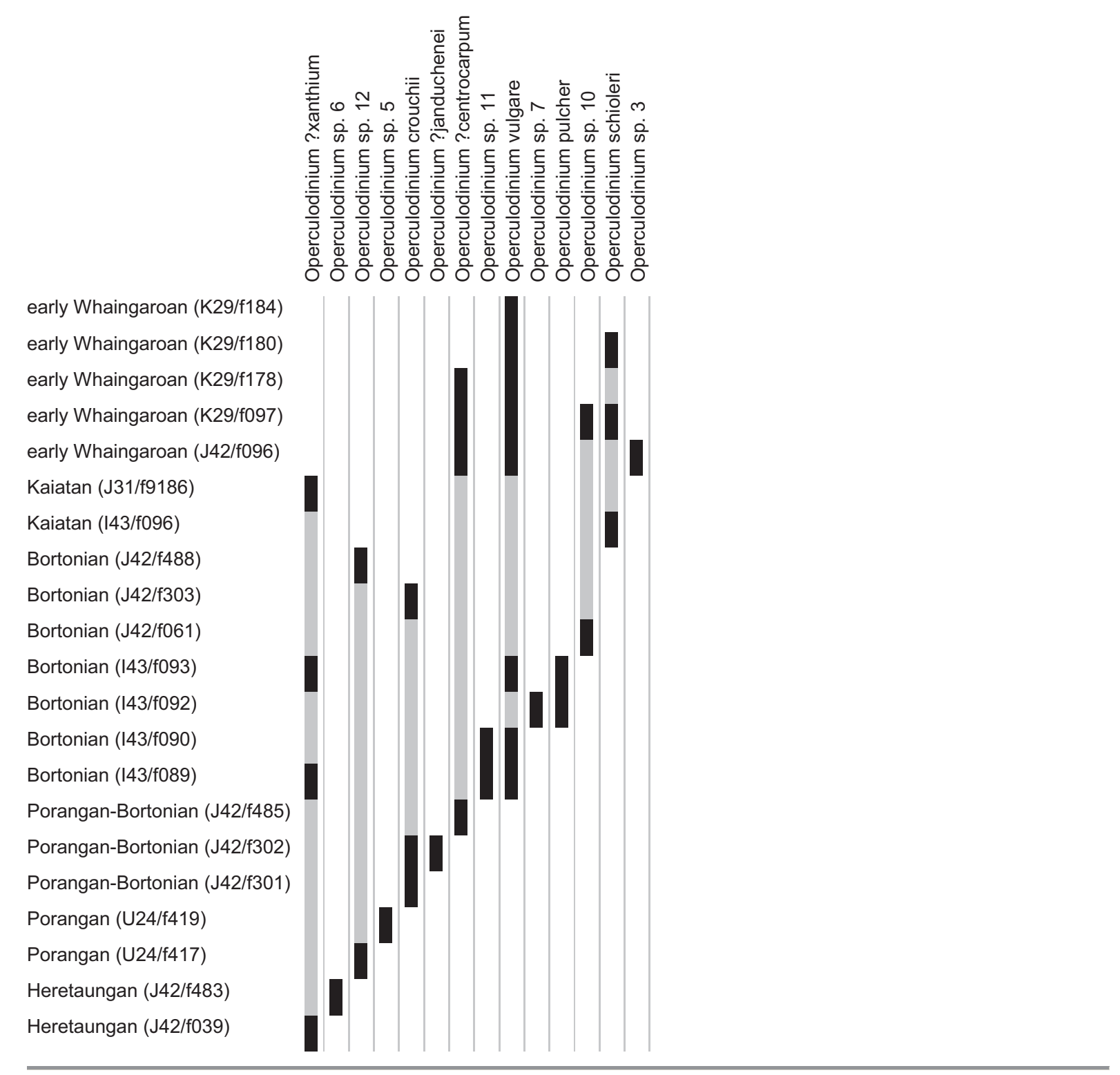

Chart 5: Range Chart for Operculodinium. 


\section{Range Chart for Paucilobimorpha}

early Whaingaroan (K29/f182)

early Whaingaroan (K29/f097)

Bortonian (J42/f489)

Bortonian (J42/f303)

Bortonian (J42/f055)

Bortonian (J42/f041)

Bortonian (I43/f089)

Porangan-Bortonian (J42/f301)

Porangan (U24/f418)

Porangan (J42/f300)

Heretaungan-Porangan (J42/f298)

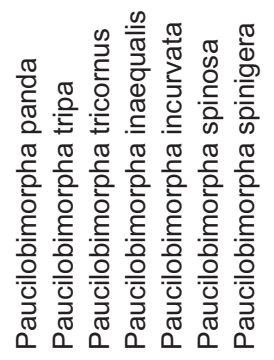

Chart 6: Range Chart for Paucilobimorpha

\section{Range Chart for Phthanoperidinium}

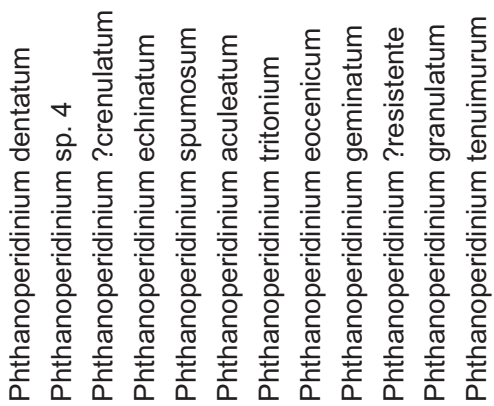

early Whaingaroan (K29/f114)

Runangan-early Whaingaroan (S14/f8599)

Runangan (I43/f108)

Kaiatan-Runangan (J41/f8914)

Bortonian (J42/f8690)

Bortonian (I43/f093)

Bortonian (143/f092)

Bortonian (143/f090)

Bortonian (143/f089)

Porangan-Bortonian (J42/f485)

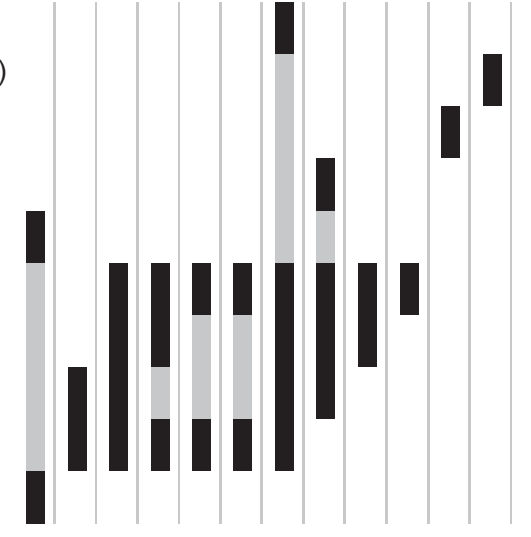

Chart 7: Range Chart for Phthanoperidinium. 


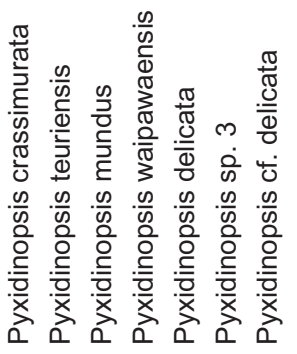

Bortonian (I43/f093)

Bortonian (I43/f091)

Bortonian (143/f090)

Porangan-Bortonian (J42/f485)

Porangan (U24/f419)

Porangan (U24/f418)

Porangan (J42/f300)

Heretaungan (V22/f8994)

Heretaungan (J42/f483)

Heretaungan (J42/f039)

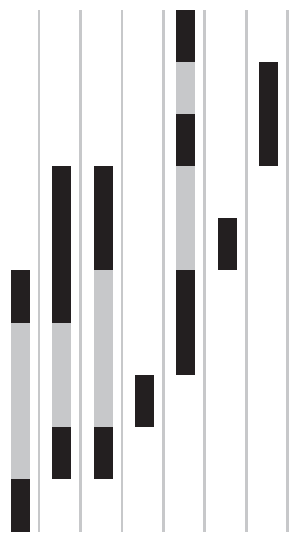

Chart 8: Range Chart for Pyxidinopsis. 


\section{Composite Range Chart}

early Whaingaroan (K29/f116) early Whaingaroan (K29/f115) early Whaingaroan (K29/f114)

Runangan-early Lwh (K29/f112) Runangan-early Lwh (K29/f108) Runangan-early Lwh (K29/f106) Runangan (K29/f104)

Runangan (K29/f102)

Runangan (K29/f101)

?Kaiatan-Runangan (K29/f099)

Kaiatan (143/f096)

?Kaiatan (J42/f062)

Bortonian (I43/f094)

Bortonian (I43/f093)

Bortonian (143/f092)

Bortonian (143/f091)

Bortonian (143/f090)

Bortonian (143/f089)

Bortonian (J42/ $/ 303)$

Porangan-Bortonian (J42/f302)

Porangan-Bortonian (J42/f301)

Porangan (J42/ $/ 300)$

Porangan (U24/f419)

Porangan (U24/f418)

Porangan (U24/f417)

Heretaungan-Porangan (J42/f298)

Heretaungan (J42/f484)

Heretaungan (J42/f483)
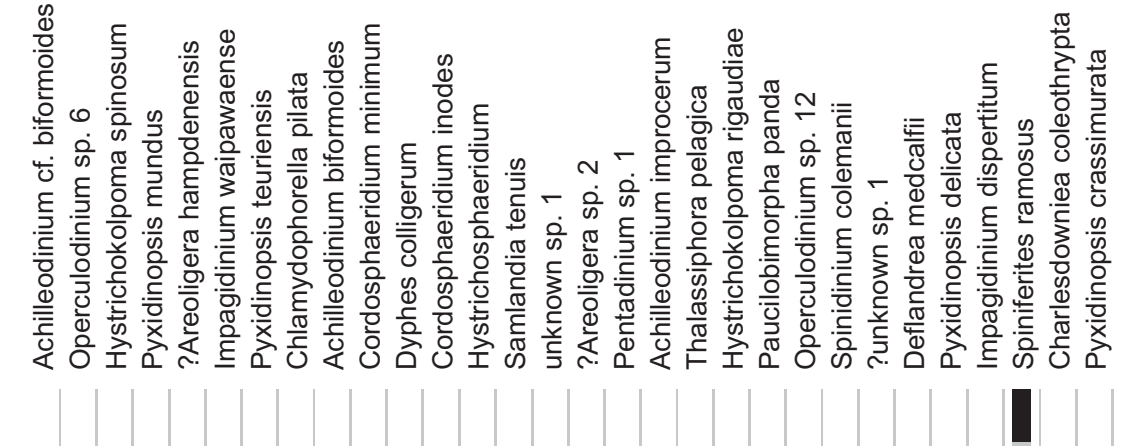

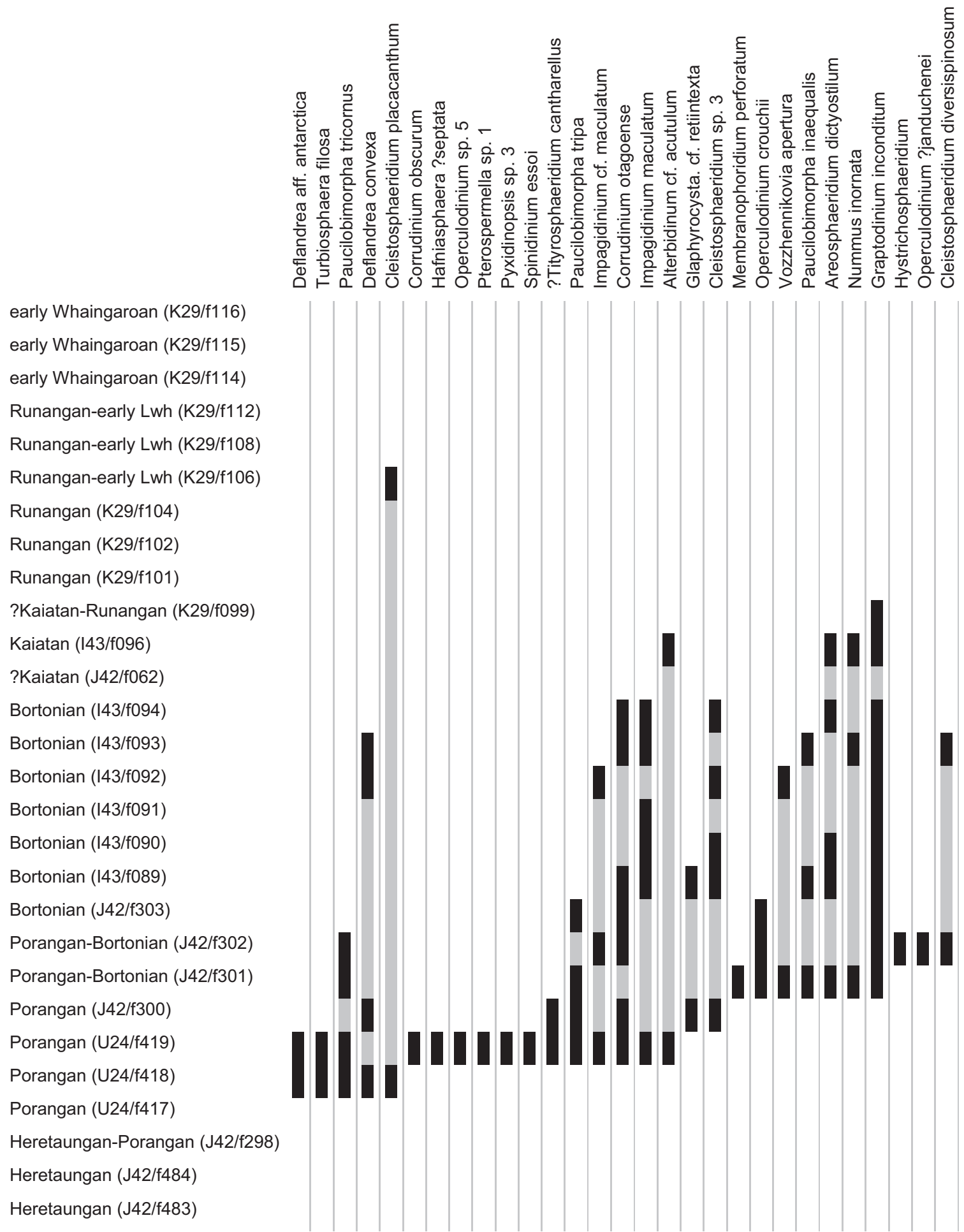

early Whaingaroan (K29/f116)

early Whaingaroan (K29/f114)

Runangan-early Lwh (K29/f112)

Runangan-early Lwh (K29/4108)

Runangan-early Lwh (K29/f106)

Runangan (K29/f104)

Runangan (K29/f102)

Runangan (K29/f101)

?Kaiatan-Runangan (K29/f099)

Kaiatan (143/f096)

Bortonian (143/f093)

Bortonian (143/f090)

Bortonian (143/f089)

Porangan-Bortonian (J42/f301)

Porangan (J42/f300)

(U24/†418)

Porangan (U24/f417)

Heretaungan (J42/f484)

Heretaungan (J42/f483) 
early Whaingaroan (K29/f116)

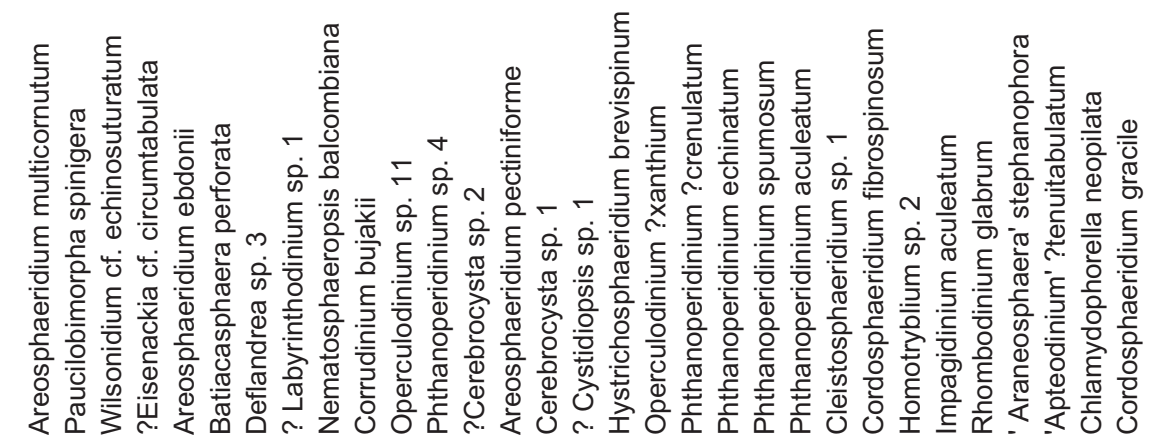

early Whaingaroan (K29/f115)

early Whaingaroan (K29/f114)

Runangan-early Lwh (K29/f112)

Runangan-early Lwh (K29/f108)

Runangan-early Lwh (K29/f106)

Runangan (K29/f104)

Runangan (K29/f102)

Runangan (K29/f101)

?Kaiatan-Runangan (K29/f099)

Kaiatan (143/f096)

?Kaiatan (J42/f062)

Bortonian (143/f094)

Bortonian (143/f093)

Bortonian (143/f092)

Bortonian (143/f091)

Bortonian (143/f090)

Bortonian (143/f089)

Bortonian (J42/f303)

Porangan-Bortonian (J42/f302)

Porangan-Bortonian (J42/f301)

Porangan (J42/f300)

Porangan (U24/f419)

Porangan (U24/f418)

Porangan (U24/f417)

Heretaungan-Porangan (J42/f298)

Heretaungan (J42/f484)

Heretaungan (J42/f483)

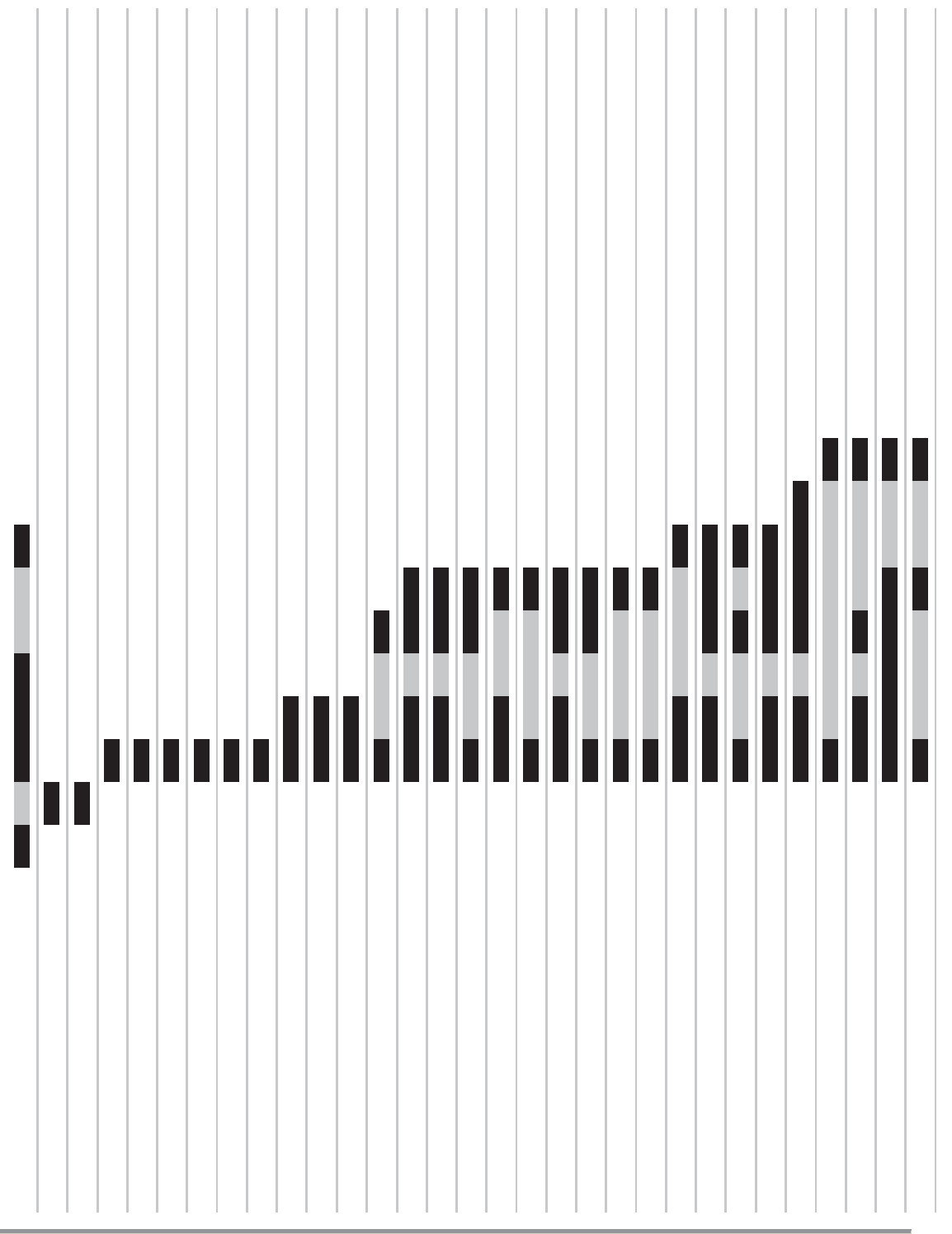




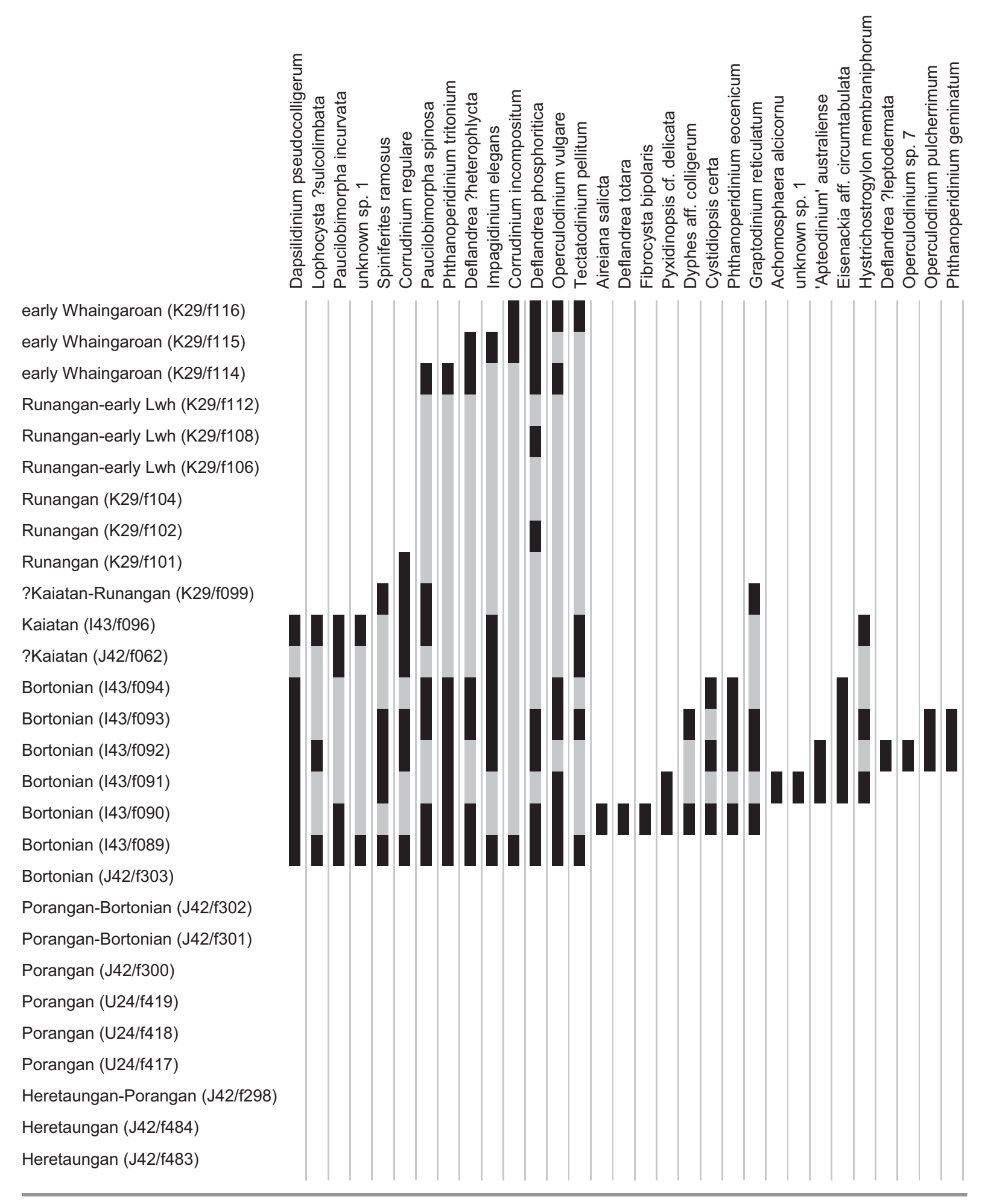


early Whaingaroan (K29/f116) early Whaingaroan (K29/f115) early Whaingaroan (K29/f114) Runangan-early Lwh (K29/f112) Runangan-early Lwh (K29/f108) Runangan-early Lwh (K29/f106) Runangan (K29/f104) Runangan (K29/f102) Runangan (K29/f101)

?Kaiatan-Runangan (K29/f099) Kaiatan (143/f096)

?Kaiatan (J42/f062)

Bortonian (I43/f094)

Bortonian (143/f093)

Bortonian (143/f092)

Bortonian (143/f091)

Bortonian (143/f090)

Bortonian (I43/f089)

Bortonian (J42/f303)

Porangan-Bortonian (J42/f302)

Porangan-Bortonian (J42/f301)

Porangan (J42/f300)

Porangan (U24/f419)

Porangan (U24/f418)

Porangan (U24/f417)

Heretaungan-Porangan (J42/f298)

Heretaungan (J42/f484)

Heretaungan (J42/f483)
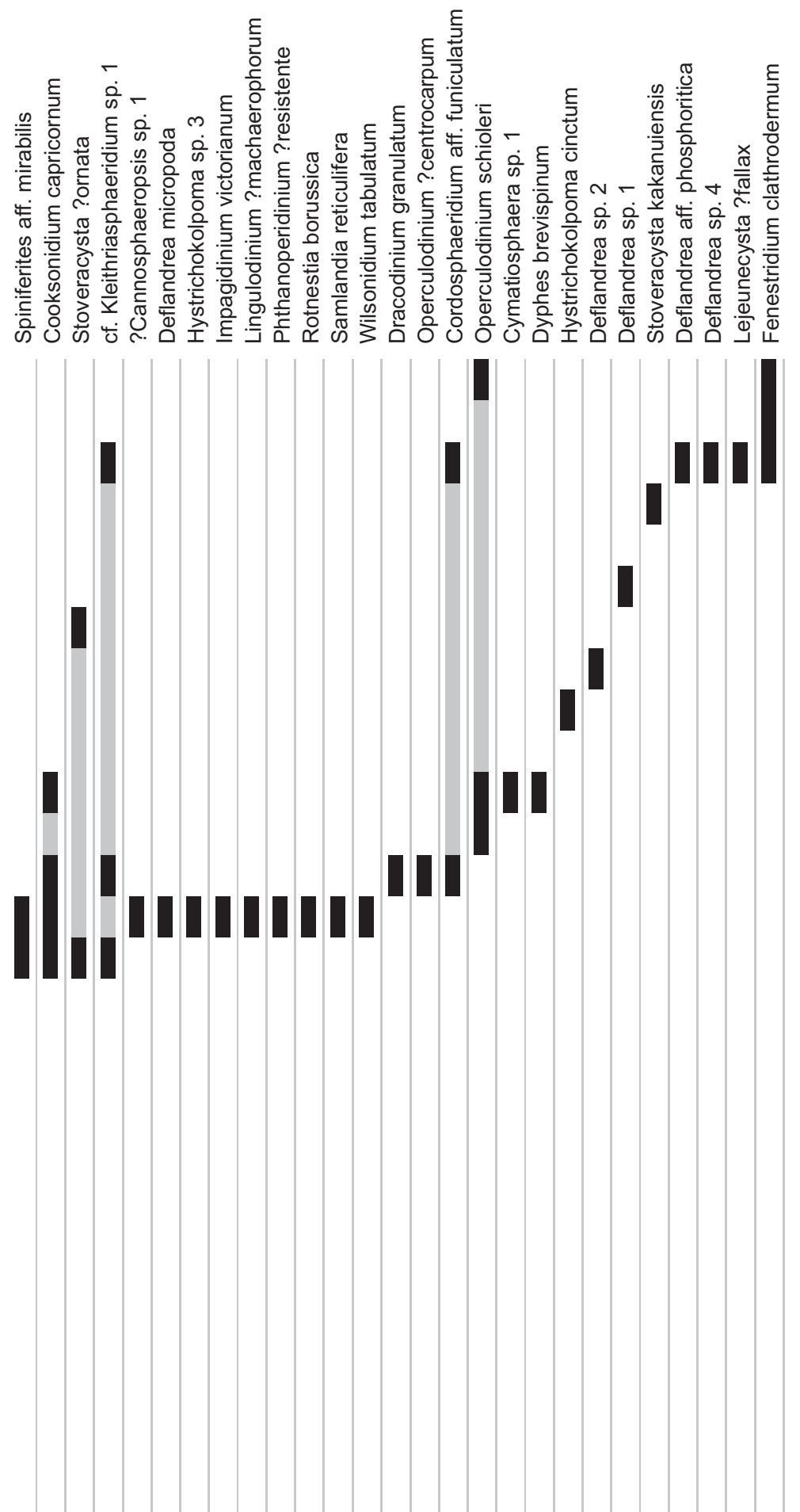

Chart 9: Range chart for composite stratigraphic section. 


\section{Appendix 3. The TransAntarctic Flora Assemblage}

The name "TransAntarctic Flora" (TAF) is due to Wrenn \& Beckman 1982 (p. 189), but, while some of us might believe we can recognise the TAF when we see it, there is no universally accepted "definition" of exactly which species comprise the flora, in the sense of which must essentially be present before we are sure we have it.

Perhaps the most straight-forward approach to this issue is to begin by listing who has found what. The species published in Wilson's (1967a) seminal account of the assemblage together with those species reported (or indicated to be characteristic of the TAF) by various subsequent authors are shown in the following table, excluding such cosmopolitan taxa as Hystrichosphaeridium tubiferum, Thalassiphora pelagica, etc. The tinted columns indicate studies from continental Antarctica or close islands (e.g. Seymour Island).

\begin{tabular}{|c|c|c|c|c|c|c|c|c|c|c|c|c|}
\hline Taxon & 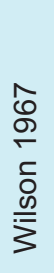 & 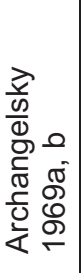 & 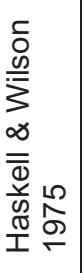 & 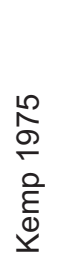 & 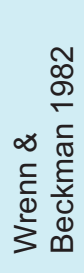 & 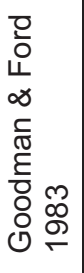 & 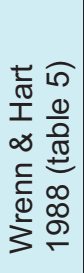 & 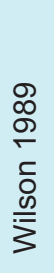 & 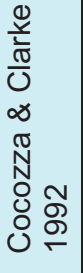 & 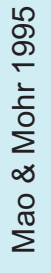 & 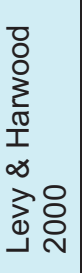 & 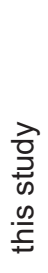 \\
\hline Alterbidinium asymmetricum $^{3}$ & $\mathrm{Y}$ & $\mathrm{Y}$ & $\mathrm{Y}$ & $\mathrm{Y}$ & & & & $\mathrm{Y}$ & $\mathrm{Y}$ & $\mathrm{Y}$ & Y & $x$ \\
\hline Alterbidinium ?distinctum & $\mathrm{Y}$ & & & & & Y & Y & Y & & & Y & $x$ \\
\hline Arachnodinium antarcticum & Y & Y & Y & Y & & & Y & Y & Y & $\mathrm{Y}$ & Y & $x$ \\
\hline Areosphaeridium dictyostilum & $\mathrm{Y}$ & Y & Y & Y & & Y & & Y & Y & $\mathrm{Y}$ & Y & $\checkmark$ \\
\hline Deflandrea antarctica & $\mathrm{Y}$ & & Y & & Y & Y & Y & Y & Y & $\mathrm{Y}$ & Y & $\checkmark$ \\
\hline $\begin{array}{l}\text { Deflandrea oebisfeldensis sensu } \\
\text { Cookson \& Cranwell } 1967\end{array}$ & & & & Y & & & Y & & & & & $x$ \\
\hline Deflandrea cygniformis & & & Y & & & & Y & & & $\mathrm{Y}$ & Y & $\checkmark$ \\
\hline Deflandrea granulata & & Y & & cf. & & & Y & cf. & & & & $x$ \\
\hline Graptodinium inconditum & & & & & & Y & & $?$ & & Y & $?$ & $\checkmark$ \\
\hline Spinidinium macmurdoense & $\mathrm{Y}$ & Y & & Y & Y & Y & Y & Y & Y & & Y & $\checkmark$ \\
\hline Turbiosphaera filosa & $\mathrm{Y}$ & Y & Y & $\mathrm{Y}$ & & & & $\mathrm{Y}$ & & & $\mathrm{Y}$ & $\checkmark$ \\
\hline Vozzhennikovia apertura & $\mathrm{Y}$ & & Y & Y & Y & Y & Y & Y & Y & $\mathrm{Y}$ & Y & $\checkmark$ \\
\hline Vozzhennikovia rotunda & $\mathrm{Y}$ & Y & Y & & Y & & & Y & & & & $x$ \\
\hline Wilsonidium echinosuturatum & & & Y & & & & Y & & & & & $\checkmark$ \\
\hline
\end{tabular}

The species having the broadest support among the reports, especially those from Antarctica itself, appear to be Alterbidinium asymmetricum, Alterbidinium ?distinctum, Arachnodinium antarcticum, Areosphaeridium dictyostilum (recorded under various aliases; refer to the systematic section), Deflandrea antarctica, which, at least in some cases, appears to be the same as the form reported as D. oebisfeldensis sensu Cookson \& Cranwell 1967, Spinidinium macmurdoense, and Vozzhennikovia apertura.

Age control over the Antarctic material itself has typically been weak. Instead, we have had to rely upon correlations with other high-latitude southern localities.

Although some elements of the TAF have been reported from the New Zealand mainland, others, including perhaps the most distinctive member, Arachnodinium antarcticum, have not. Of those which have, most are longranging, and of limited use in fixing a date to the assemblage. Only Wilsonidium echinosuturatum is useful, indicating an interval of Porangan to early Bortonian (middle to late Lutetian). However, it is open to debate whether this species really ought to be considered a fully paid up member of the TAF: it is not mentioned by the great majority of publications reporting occurrences of the assemblage.

Goodman \& Ford 1983 reports elements of the Trans-Antarctic Flora, including Vozzhennikovia apertura, Deflandrea antarctica and Spinidinium macmurdoense, ranging up into the Oligocene - indeed, beyond the local LAD of Deflandrea phosphoritica (fig. 2, occurrence data for DSDP Hole 511, on the eastern margin of the Falklands Plateau). In the present study, Vozzhennikovia apertura appears to be the TAF taxon exhibiting the youngest $L A D$, ranging into the later part of the Middle Eocene (Bortonian). However, the Falklands Plateau material of Goodman \& Ford 1983 conspicuously excludes Arachnodinium antarcticum; another hint that it is perhaps this species which most usefully characterises the TAF as a whole.

${ }^{3}$ Alterbidinium asymmetricum comb. nov., basionym = Deflandrea asymmetrica Wilson 1967a, p. 62-63, figs. $17-$ 21. 


\section{Appendix 4. Other Species of Phthanoperidinium}

Other species assigned at various times to Phthanoperidinium include the following, none of which has been reported from New Zealand at this time:

\section{Other Accepted Species}

Phthanoperidinium comatum (Morgenroth 1966b) Eisenack \& Kjellström 1972 - The plate topology of the ventral [or maybe the whole?] episome is not described, nor visible in the illustrations provided by the original description. However, on the assumption that it is the same as that of $P$. tritonium, $P$. comatum is retained in Phthanoperidinium until evidence emerges to the contrary.

Phthanoperidinium coreoides (Benedek 1972) Lentin and Williams, 1976 - this taxon was originally described with a perplexing yet distinctly gonyaulacacean tabulation formula, 4', ?1a, 6", 6c, 5-6", 1p, 0-1, 1'”'. However, Benedek \& Sarjeant 1981, pp. 327-330, provides a reinterpretation which is more or less consistent with conventional Phthanoperidinium, despite the plate 1' contacting plate 3a where 4' is expected (text-fig. 5).

Phthanoperidinium delicatum Michoux 1985

Phthanoperidinium filigranum (Benedek 1972) Benedek and Sarjeant 1981

Phthanoperidinium multispinum Bujak 1980

Phthanoperidinium obscurum Harland \& Sharp 1980

Phthanoperidinium pseudoechinatum Bujak 1980 - A junior synonym of $P$. stockmansii/echinatum according to Islam 1982, p. 309.

Phthanoperidinium stockmansii (De Coninck 1975) Lentin \& Williams 1977b

\section{Provisionally Accepted Species}

I have been unable to discern important diagnostic characters from published descriptions of the following species, and do not have material readily available to study at first hand. Pending future determinations, they are here regarded as provisionally accepted.

Phthanoperidinium alectrolophum Eaton 1976

Phthanoperidinium amiculum Liengjarern et al. 1980

Phthanoperidinium antarcticum Mao \& Mohr 1995

Phthanoperidinium bennettii Matsuoka \& Bujak 1988

Phthanoperidinium chalossense Michoux 1985

Phthanoperidinium clithridium Bujak 1994

Phthanoperidinium cornutum Heilman-Clausen \& van Simaeys 2005 - The photographs accompanying the original description depict a cyst which appears to possess a pericoel, which would place $P$. cornutum outside of our concept of Phthanoperidinium. However, the original description makes no mention of pericoels, so the species is provisionally retained in Phthanoperidinium for the present.

Phthanoperidinium crenulatum (De Coninck 1975) Lentin \& Williams 1977b

Phthanoperidinium distinctum Bujak 1994 - The holotype (Bujak 1994, pl. 4, figs. 7-8) appears to posses well developed pericoels, which is unlike the typically developed wall structure in Phthanoperidinium.

Phthanoperidinium flebile Lienjarern et al. 1980

Phthanoperidinium indistinctum Islam 1982 - The ventral view shown by Islam 1982, fig. 2, depicts a 1' plate which (ignoring any preapical contacts) is five-sided but not in any significant contact with plate 7". Although such an arrangement does not correspond exactly with the ortho-style of organisation, the species is provisionally retained in Phthanoperidinium, pending further research.

Phthanoperidinium levimurum Bujak 1980 - Published photographs of this species, particularly Bujak 1980, pl. 19, fig. 13 (of the holotype) depict a cyst which appears to possess an epipericoel, which would place $P$. levimurum outside of our concept of Phthanoperidinium. However, the original description makes no mention of pericoels, so the species is provisionally retained in Phthanoperidinium for the present.

Phthanoperidinium ovoideum He 1991

Phthanoperidinium paleocenicum Lucas-Clark 2006 - As noted above, the holotype of this species is also more strongly cornucavate and has more distinctly developed antapical horns than are ordinarily seen in Phthanoperidinium. 
Phthanoperidinium polytrix (Benedek 1972) Lentin \& Williams 1976 - Possibly conspecific with P. tritonium, in which case polytrix would be the senior synonym.

Phthanoperidinium regale Bujak 1994

Phthanoperidinium rhomboidale He 1991

Phthanoperidinium schizokeras (De Coninck 1975) Lentin \& Williams 1977 [b] — Note, however, that the principal diagnostic feature of this form, namely the "short [apical] horn which, starting from the base, is divided into two" (De Coninck 1975, p. 97), seems unlikely to have much diagnostic significance. The author's tiny illustrations of a single individual are unhelpful. Pending a modern redescription of the type material, it seems best to avoid using this name.

Phthanoperidinium stoveri (Lienjarern et al. 1980) Islam 1982

Phthanoperidinium tenellum Jin et al. 1989 [in He et al.]

\section{Not Accepted Species}

Phthanoperidinium brooksii Edwards \& Bebout 1981 - Possesses the meta-style of ventral epicyst topology and a cancellous pericoel filling, neither of which are typical Phthanoperidinium characteristics. This species may be better placed in another genus, possibly new.

Phthanoperidinium campoense Caro 1973 - Described from one specimen, refer Edwards \& Bebout 1981, table 1; additionally, the tabulation formula given in the description is not that of Phthanoperidinium, refer Stover \& Evitt 1978, p. 119; it is recommended the foregoing name be applied to the holotype specimen alone.

Phthanoperidinium coriciterium Islam 1982 - This species does not exhibit the diagnostic ortho-hexa arrangement of the epicyst; see Islam 1982, fig. 1.

Phthanoperidinium illustrans (O. Wetzel 1933a) Lentin \& Williams 1973 - Described from one specimen, refer Stover \& Evitt 1978, p. 119; it is recommended the foregoing name be applied to the holotype specimen alone.

Phthanoperidinium lambdoideum (E. Nagy 1966) Eisenack \& Kjellström 1972 - Considered unidentifiable, refer Stover \& Evitt 1978, p. 119; it is recommended the foregoing name be applied to the holotype specimen alone.

Phthanoperidinium powellii Bujak 1994 - The very wide pericoel and lack of clear differentiation into plates by either sutural or penitabular features suggest that it would be more appropriately placed in another genus such as Luxadinium. 


\section{Appendix 5. Alphabetical Listing of Genera}

Genus

Achilleodinium Eaton 1976

Achomosphaera Evitt 1963a

Aireiana Cookson \& Eisenack 1965a

Alterbidinium Lentin \& Williams 1985 emend. Khowaja-Ateequzzaman et al. 1991

Apteodinium Eisenack 1958a

Araneosphaera Eaton 1976

Areoligera Lejeune-Carpentier 1938a

Areosphaeridium Eaton 1971

Batiacasphaera Drugg 1970b

Cannosphaeropsis O. Wetzel 1933b

Cerebrocysta Bujak 1980

Cerodinium Vozzhennikova 1963 emend. Lentin \& Williams 1987

Charlesdowniea Lentin \& Vozzhennikova 1989

Chlamydophorella Cookson \& Eisenack 1958

Cleistosphaeridium Davey et al. 1966 emend. Eaton et al. 2001

Cooksonidium Stover \& Williams 1995

Cordosphaeridium Eisenack 1963b emend. Davey 1969c

Corrudinium Stover \& Evitt 1978

Cyclonephelium Deflandre \& Cookson 1955 emend. Stover \& Evitt 1978

Cymatiosphaera O. Wetzel 1933b

Cystidiopsis Nagy 1965

Dapsilidinium Bujak et al. 1980b

Deflandrea Eisenack 1938b emend. Lentin \& Williams 1976

Diphyes Cookson 1965a emend. Goodman \& Witmer 1985

Disphaerogena O. Wetzel 1933b emend. Sarjeant 1985b

Distatodinium Eaton 1976

Dracodinium Gocht 1955 emend. Bujak et al. 1980

Eisenackia Deflandre \& Cookson 1955

Fenestridium Clowes n. gen.

Fibrocysta Stover \& Evitt 1978

Filisphaera Bujak 1984 emend. Head 1994b

Glaphyrocysta Stover \& Evitt 1978

Graptodinium Clowes n. gen.

Hafniasphaera Hansen 1977

Homotryblium Davey \& Williams 1966b

Hystrichokolpoma Klumpp 1953

Hystrichosphaeridium Deflandre 1937b emend. Davey \& Williams 1966

Impagidinium Stover \& Evitt 1978

Indet 2

Indet 3

Indet 4

Isabelidinium Lentin \& Williams 1977a

Kleithriasphaeridium Davey 1974

Labyrinthodinium Piasecki 1980 
Membranophoridium Gerlach 1961 emend. Stover \& Evitt 1978

Nematosphaeropsis Deflandre \& Cookson 1955 emend. Wrenn 1988

Nummus Morgan 1975

Operculodinium Wall 1967a emend. Matsuoka et al. 1997

Paucilobimorpha De Coninck 1986b emend. Prössl 1994

Paucisphaeridium Bujak et al. 1980b

Pentadinium Gerlach 1961

Phthanoperidinium Drugg \& Loeblich Jr. 1967 emend. Clowes

Planoperidinium De Coninck 1986b

Pterospermella Eisenack 1972

Pyxidinopsis Habib 1976

Rhombodinium Gocht 1955 emend. Bujak, 1979

Riculacysta Stover 1977

Rottnestia Cookson \& Eisenack 1961b

Samlandia Eisenack 1954b

Spinidinium Cookson \& Eisenack 1962b

Spiniferites Mantell 1850 emend. Sarjeant 1970

Stoveracysta Clowes 1985

Tectatodinium Wall 1967a emend. Head 1994a 95

$\begin{array}{lr}\text { Thalassiphora Eisenack \& Gocht } 1960 & 128\end{array}$

$\begin{array}{lr}\text { Tityrosphaeridium Sarjeant } 1981 & 129\end{array}$

$\begin{array}{lr}\text { Turbiosphaera Archangelsky 1969a } & 108\end{array}$

Vozzhennikovia Lentin \& Williams 1976

Wetzeliella Eisenack 1938b emend. Lentin \& Williams $1976 \quad 66$

Wilsonidium Lentin \& Williams $1976 \quad 70$ 

Plates 
Plates 


\section{Plate 1}

\section{Indet 2 sp. 1}

Figure 1-3 Sample J42/f096, slide L10951/SM070; Totara Limestone, Kakanui River (early Whaingaroan); specimen measures $23 \times 21 \mu \mathrm{m}$

Indet 2 sp. 2

Figure 4-6 Sample J42/f096, slide L10951/SM105; Totara Limestone, Kakanui River (early Whaingaroan); specimen measures $20 \times 20 \mu \mathrm{m}$

\section{Cystidiopsis certa}

Figure 7-9 Sample 143/f094, slide L16342/1-1439-183; Burnside Formation, Puketeraki Core (Bortonian); specimen measures 25 × $25 \mu \mathrm{m}$

\section{?Cystidiopsis sp. 1}

Figure 10-12 Sample I43/f089, slide L16337/SM071; Burnside Formation, Puketeraki Core (Bortonian); specimen measures $30 \times 28 \mu \mathrm{m}$ 


\section{Plate 1}
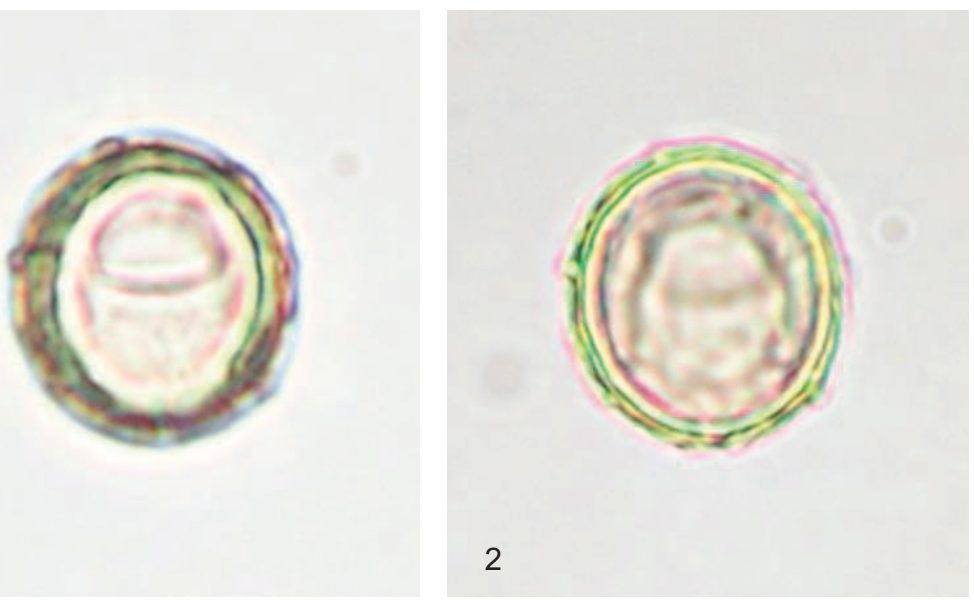

2

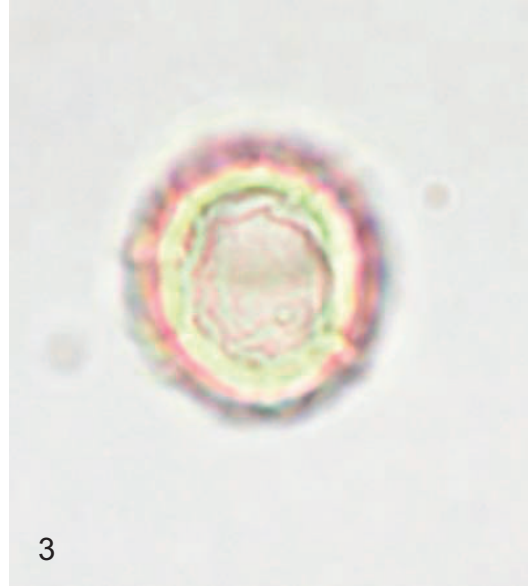

1
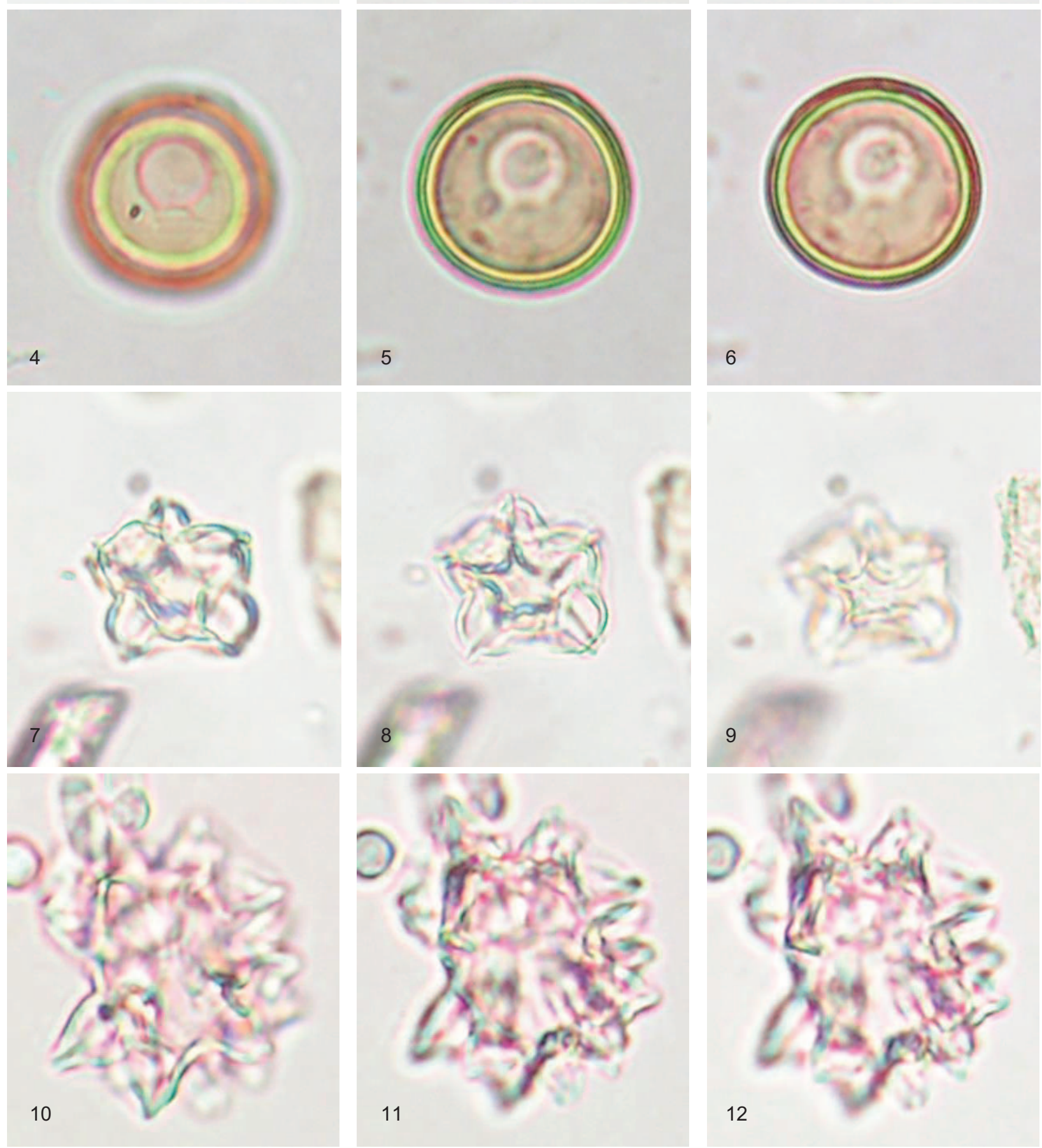


\section{Plate 2}

\section{Nummus inornatus}

Figure 1-3 Sample 143/f093, slide L16341/SM100; Burnside Formation, Puketeraki Core (Bortonian); x 475; specimen measures $96 \times 87 \mu \mathrm{m}$

Figure 4-6 Sample 143/f093, slide L16341/SM122; Burnside Formation, Puketeraki Core (Bortonian); x 350; specimen measures $120 \times 122 \mu \mathrm{m}$

\section{Paucilobimorpha inaequalis}

Figure 7-9 Sample J42/f301, slide L23131/SM003; Hampden Formation, Hampden Beach Section (Porangan-Bortonian); specimen measures $23 \times 22 \mu \mathrm{m}$

Figure 10-12 Sample 143/f089, slide L16337/SM072A; Burnside Formation, Puketeraki Core (Bortonian); specimen measures $27 \times 26 \mu \mathrm{m}$ 


0
8
83
83




\section{Plate 3}

\section{Paucilobimorpha inaequalis}

Figure 1-3 Sample 143/f093, slide L16341/SM124; Burnside Formation, Puketeraki Core (Bortonian); specimen measures $30 \times 27 \mu \mathrm{m}$

\section{Paucilobimorpha incurvata}

Figure 4 Sample 144/f080, slide L08947/SM009B; Burnside Formation, Burnside Marl Pit (Bortonian); specimen measures $27 \times 23 \mu \mathrm{m}$

Figure 5 Sample J42/f062, slide L09219/2-1431-032; Hampden Formation, Hampden Beach Section (?Kaiatan); specimen measures $13 \times 13 \mu \mathrm{m}$

Figure 6 Sample J42/f064, slide L09221/1-1341-164; Waiareka Volcanics, Hampden Beach Section (Kaiatan); specimen measures $15 \times 14 \mu \mathrm{m}$

\section{Paucilobimorpha panda}

Figure 7-8 Sample J42/f298, slide L23128/SM001; Kurinui Formation, Hampden Beach Section (Heretaungan-Porangan); specimen measures $17 \times 20 \mu \mathrm{m}$

Figure 9 Sample J42/f489, slide L23124/SM001; Hampden Formation, Hampden Beach Section (Bortonian); specimen measures $20 \times 21 \mu \mathrm{m}$

Figure 10 Sample U24/f419, slide L23127/SM097; Wanstead, Te Uri Stream (Porangan); specimen measures $19 \times 17 \mu \mathrm{m}$

Figure 11-12 Sample U24/f419, slide L23127/SM004; Wanstead, Te Uri Stream (Porangan); specimen measures $20 \times 17 \mu \mathrm{m}$ 
$\therefore 3 \cdot 83$

¿

(2) $\triangle 313$ 


\section{Plate 4}

\section{Paucilobimorpha spinigera}

Figure 1-3 Sample J42/f303, slide L23133/SM001; Hampden Formation, Hampden Beach Section (Bortonian); specimen measures $23 \times 15 \mu \mathrm{m}$

\section{Paucilobimorpha spinosa}

Figure 4-5 Sample J42/f096, slide L10951/SM103; Totara Limestone, Kakanui River (early Whaingaroan); specimen measures $30 \times 29 \mu \mathrm{m}$

Figure 6 Sample J42/f096, slide L10951/SM102; Totara Limestone, Kakanui River (early Whaingaroan); specimen measures $29 \times 33 \mu \mathrm{m}$

\section{Paucilobimorpha tricornus}

Figure 7-9 Sample J42/f301, slide L23131/SM005; Hampden Formation, Hampden Beach Section (Porangan-Bortonian); specimen measures $18 \times 20 \mu \mathrm{m}$

Figure 10-11 Sample U24/f419, slide L23127/SM096; Wanstead, Te Uri Stream (Porangan); specimen measures $20 \times 20 \mu \mathrm{m}$

Figure 12 Sample U24/f419, slide L23127/SM002; Wanstead, Te Uri Stream (Porangan); specimen measures $23 \times 23 \mu \mathrm{m}$ 


\section{Plate 4}
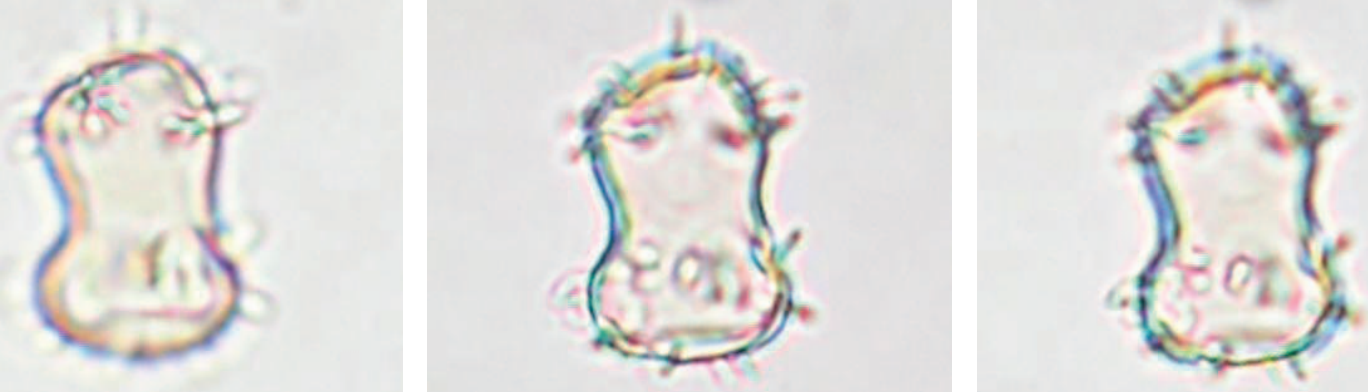

1

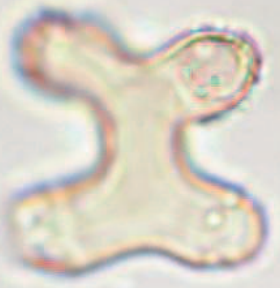

4

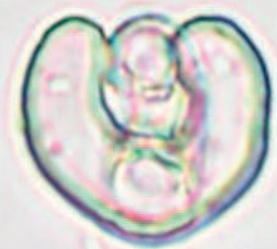

7

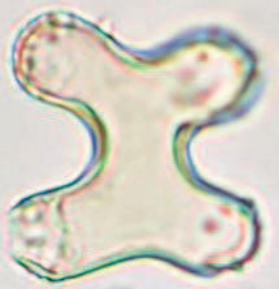

5

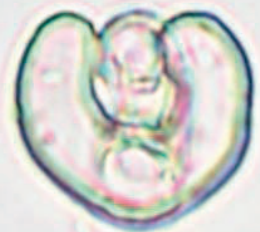

8

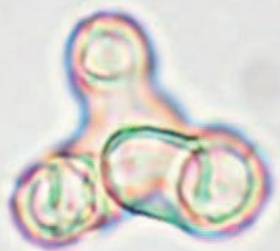

10

2

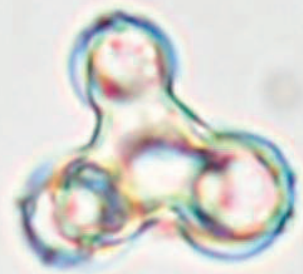

11

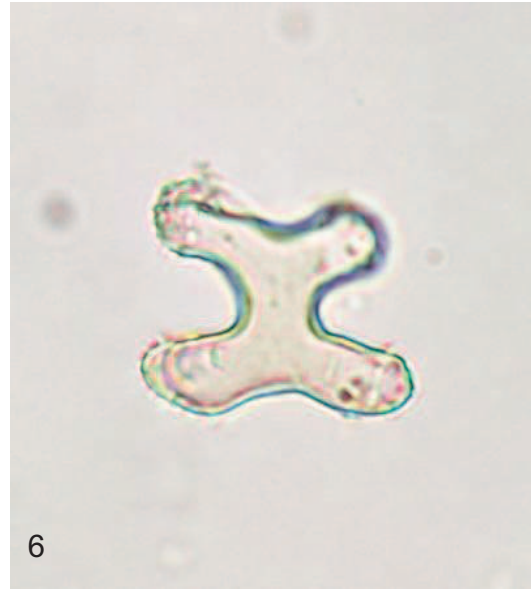




\section{Plate 5}

\section{Paucilobimorpha tripa}

Figure 1-3 Sample J42/f301, slide L23131/SM006A; Hampden Formation, Hampden Beach Section (Porangan-Bortonian); specimen measures $25 \times 25 \mu \mathrm{m}$

Figure 4-5 Sample J42/f041, slide L09198/1-1314-127; Hampden Formation, Hampden Beach Section (Bortonian); specimen measures $31 \times 37 \mu \mathrm{m}$

Figure 6 Sample J42/f489, slide L23124/SM003; Hampden Formation, Hampden Beach Section (Bortonian); specimen measures $19 \times 17 \mu \mathrm{m}$

\section{Fenestridium clathrodermum}

Figure 7-9 Sample J42/f097, slide L10952/SM2965; Totara Limestone, Kakanui River (?early Whaingaroan); x 875; specimen measures 53 x $48 \mu \mathrm{m}$

Figure 10-12 Sample J42/f097, slide L10952/SM013; Totara Limestone, Kakanui River (?early Whaingaroan); x 850; specimen measures 50 × $50 \mu \mathrm{m}$ 
Plate 5<smiles>[CH-]1CO1</smiles><smiles>c1c[cH-][cH-]1</smiles>

2

3

1<smiles></smiles>
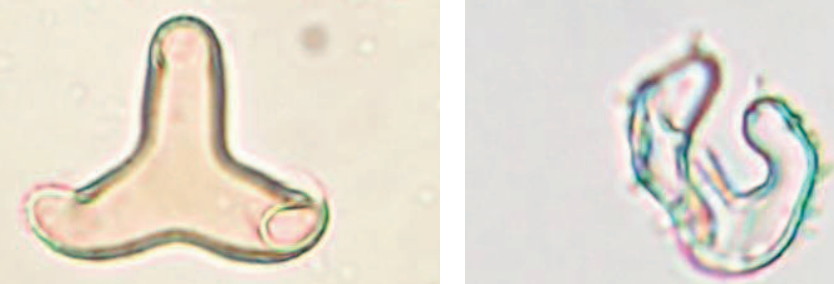

4

5

6

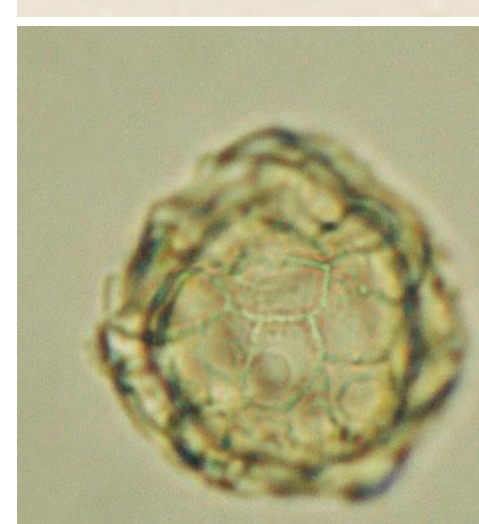

7

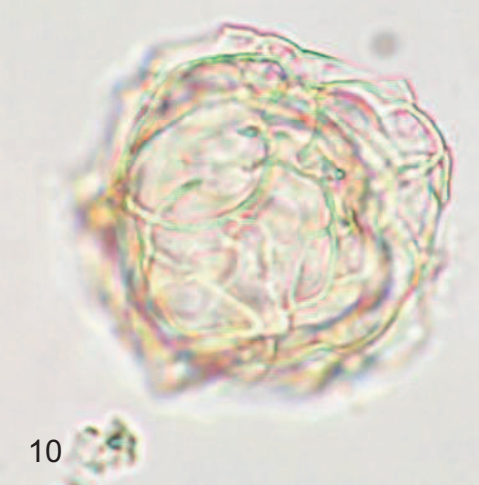

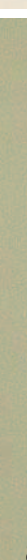

8
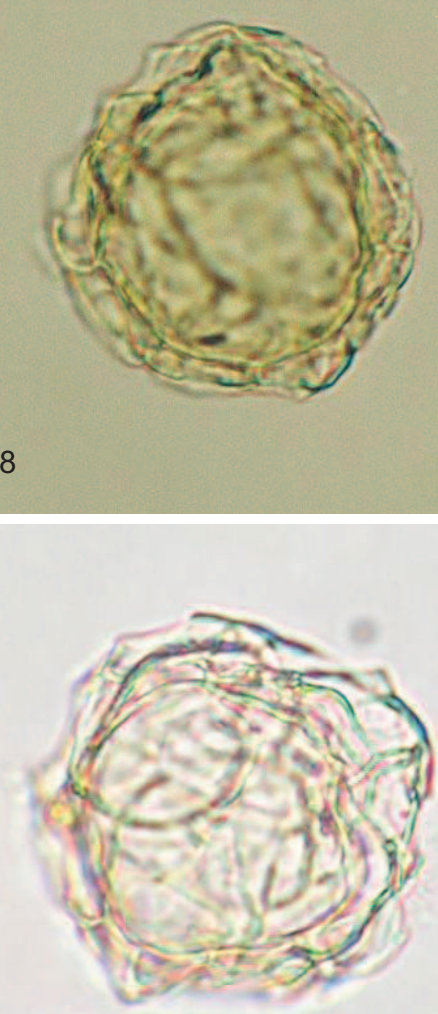

$11^{t}$

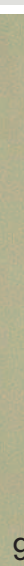

9

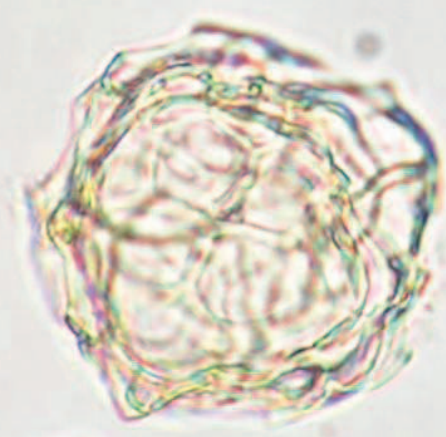

12

Page P11 


\section{Plate 6}

\section{Fenestridium clathrodermum}

Figure 1-3 Sample J42/f097, slide L10952/SM012; Totara Limestone, Kakanui River (?early Whaingaroan); x 1000; specimen measures 47 x $42 \mu \mathrm{m}$

Figure 4-6 Sample J42/f097, slide L10952/SM011; Totara Limestone, Kakanui River (?early Whaingaroan); x 975; specimen measures 45 x $43 \mu \mathrm{m}$

\section{Deflandrea phosphoritica}

Figure 7-9 Sample K29/f115, slide L11051/SM001; Port Elizabeth Member, Cape Foulwind Section (early Whaingaroan); x 325; specimen measures $142 \times 108 \mu \mathrm{m}$

Figure 10-12 Sample K29/f097, slide L10914/SM016; Port Elizabeth Member, Cape Foulwind Section (early Whaingaroan); x 325; specimen measures 150 x $105 \mu \mathrm{m}$ 


\section{Plate 6}
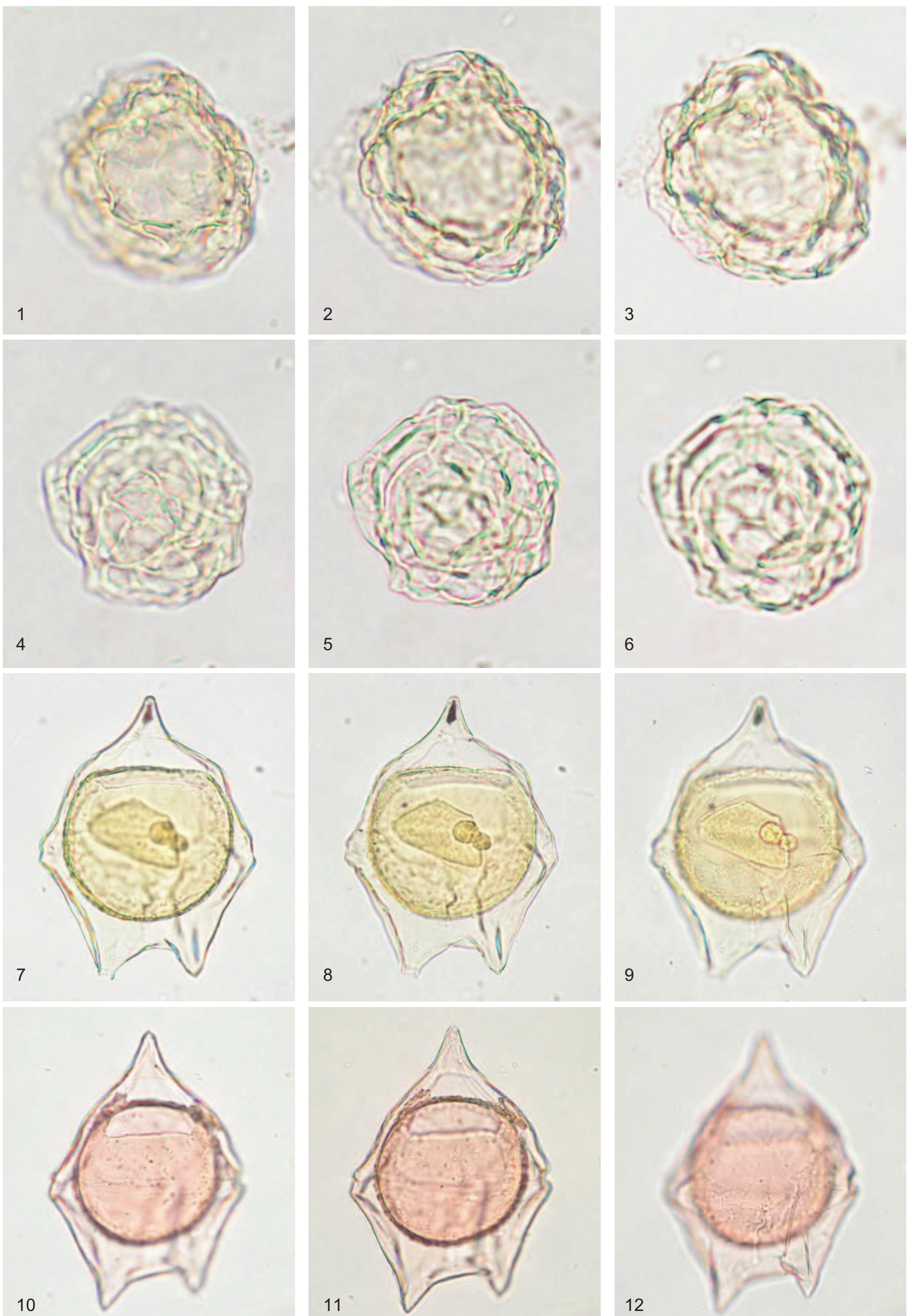

8
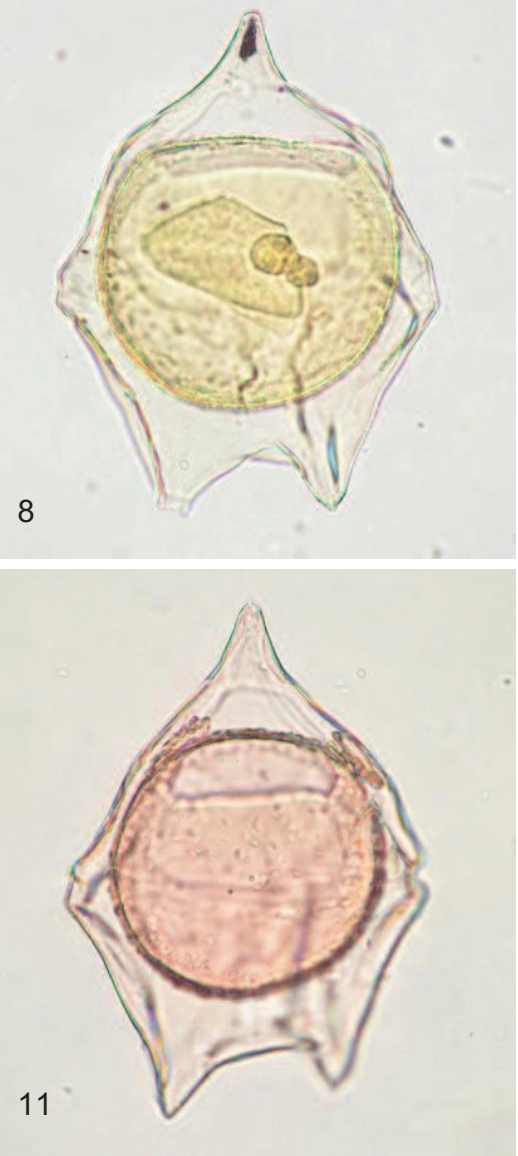

6

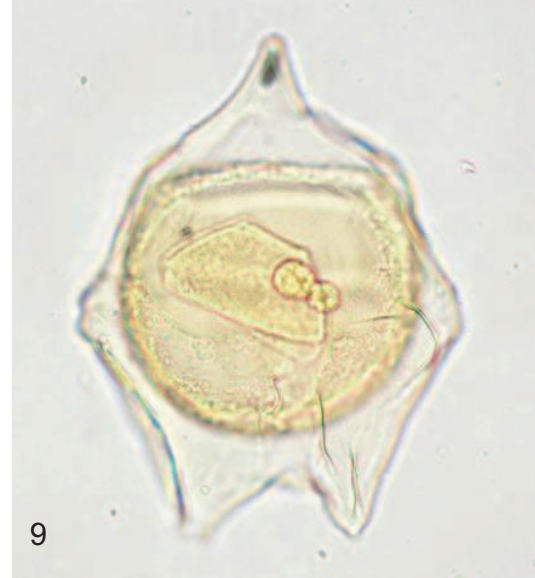

12

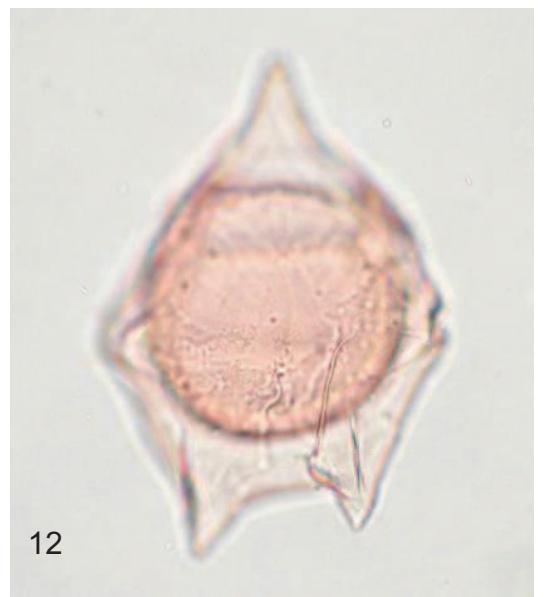




\section{Plate 7}

\section{Deflandrea phosphoritica}

Figure 1-3 Sample K29/f114, slide L11050/SM016; Port Elizabeth Member, Cape Foulwind Section (early Whaingaroan); x 325; specimen measures 148 x $117 \mu \mathrm{m}$

Figure 4-6 Sample K29/f115, slide L11051/SM002; Port Elizabeth Member, Cape Foulwind Section (early Whaingaroan); x 350; specimen measures 137 x $103 \mu \mathrm{m}$

Figure 7-9 Sample K29/f102, slide L11038/SM004; Kaiata Mudstone, Cape Foulwind Section (Runangan); x 350; specimen measures $130 \times 100 \mu \mathrm{m}$

\section{Deflandrea aff. phosphoritica}

Figure 10-12 Sample J42/f097, slide L10952/SM006; Totara Limestone, Kakanui River (?early Whaingaroan); x 325; specimen measures 142 x $110 \mu \mathrm{m}$ 


\section{Plate 7}
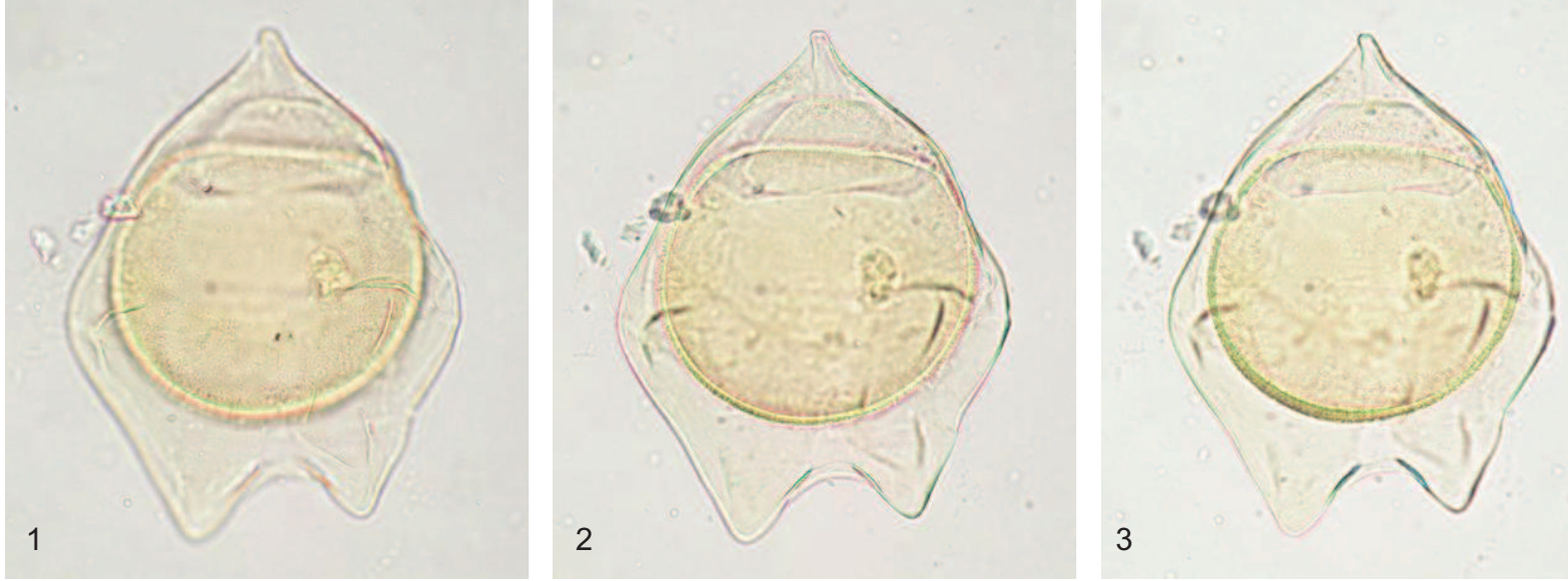

3

4
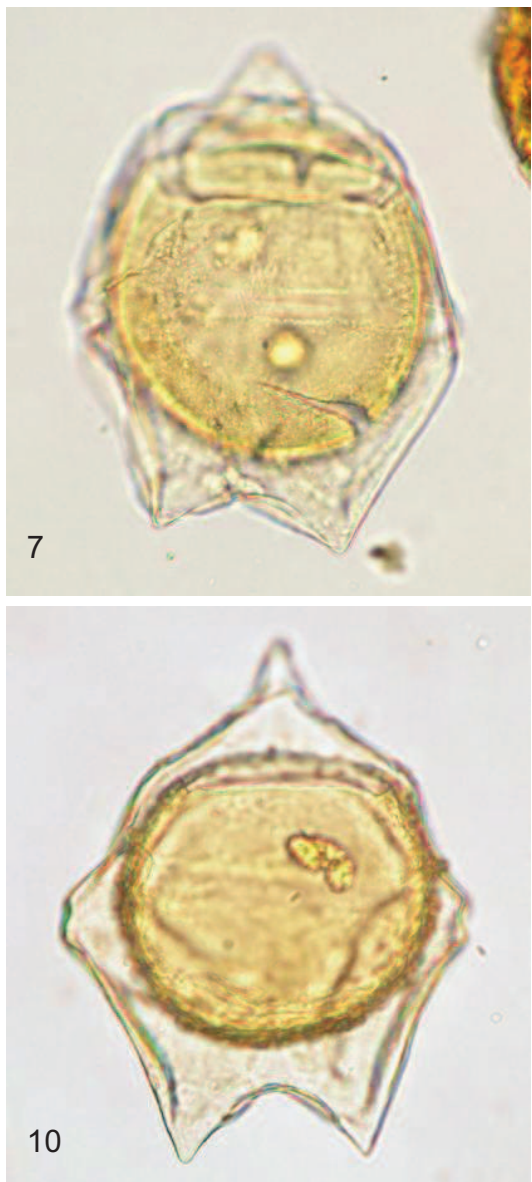

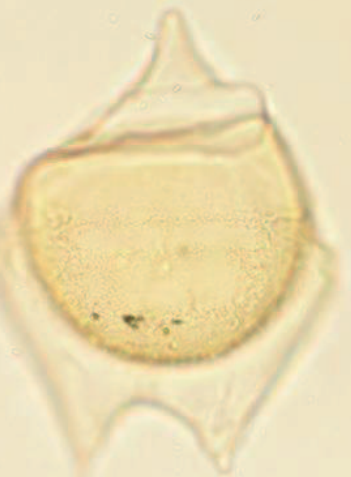

5
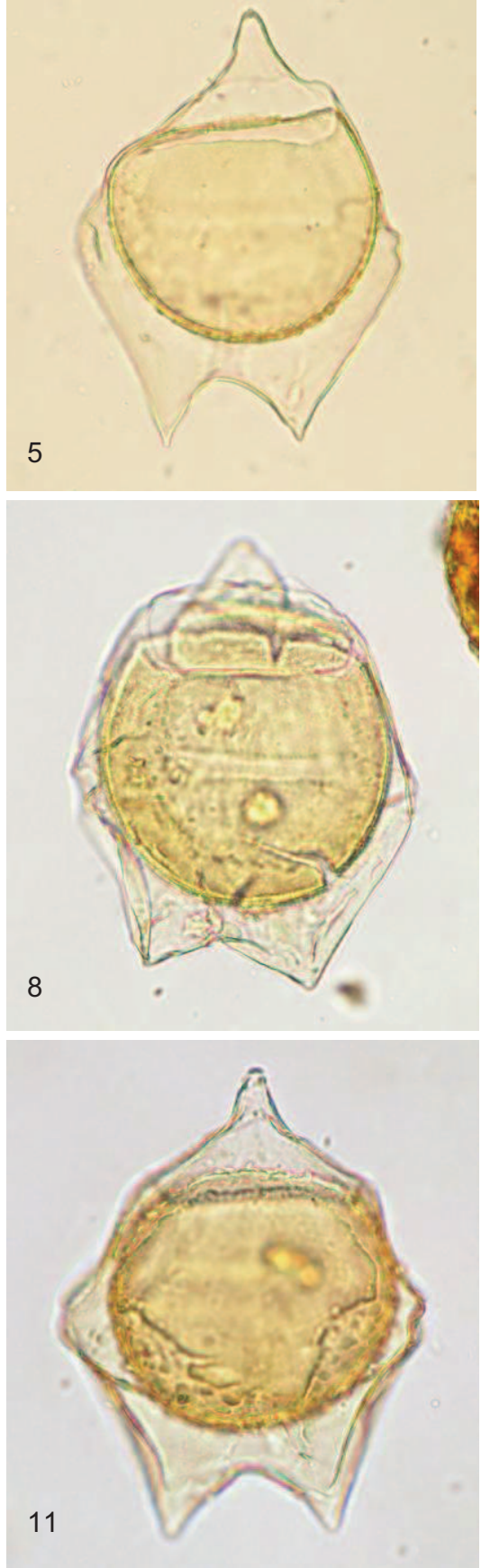

6

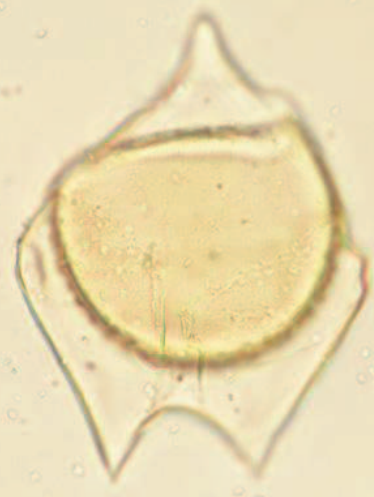

9
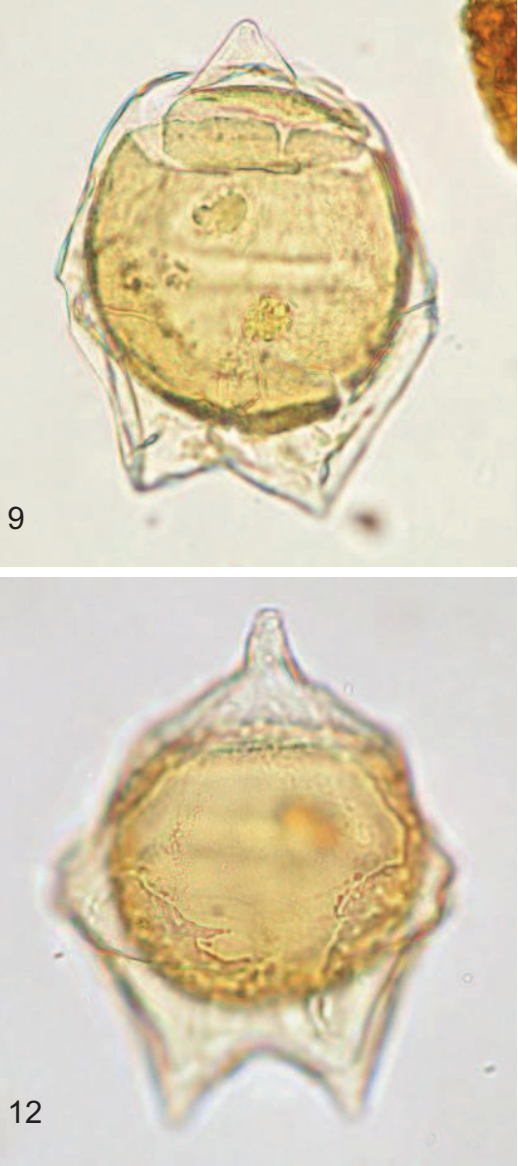


\section{Plate 8}

\section{Deflandrea aff. phosphoritica}

Figure 1-3 Sample J42/f097, slide L10952/SM2964; Totara Limestone, Kakanui River (?early Whaingaroan); $x 325$; specimen measures $149 \times 114 \mu \mathrm{m}$

Figure 4 Sample J42/f097, slide L10952/SM002; Totara Limestone, Kakanui River (?early Whaingaroan); x 375; specimen measures 125 x $105 \mu \mathrm{m}$

Figure 5 Sample K29/f114, slide L11050/SM024; Port Elizabeth Member, Cape Foulwind Section (early Whaingaroan); x 350; specimen measures 137 x $117 \mu \mathrm{m}$

Figure 6 Sample J42/f097, slide L10952/SM007; Totara Limestone, Kakanui River (?early Whaingaroan); x 350; specimen measures 130 x $108 \mu \mathrm{m}$

\section{Deflandrea ?heterophlycta}

Figure 7-12 Sample 143/f089, slide L16337/SM114; Burnside Formation, Puketeraki Core (Bortonian); x 350; specimen measures $130 \times 100 \mu \mathrm{m}$ 


\section{Plate 8}
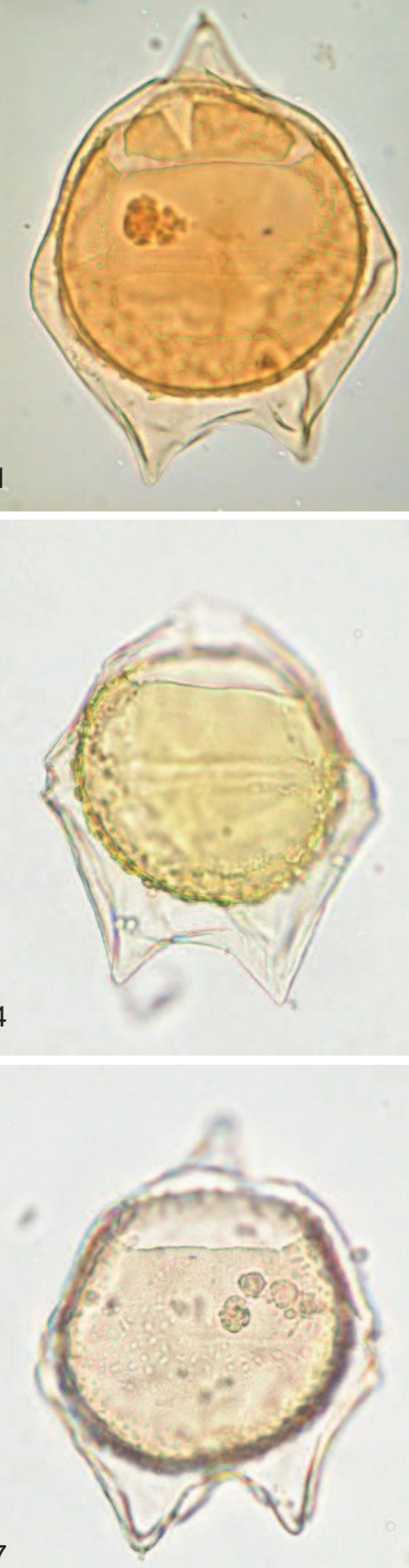

(20)

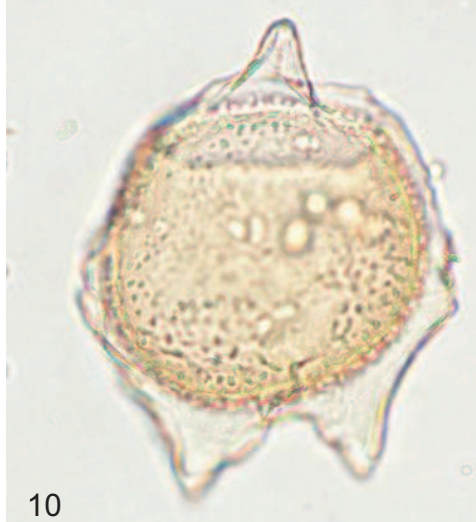

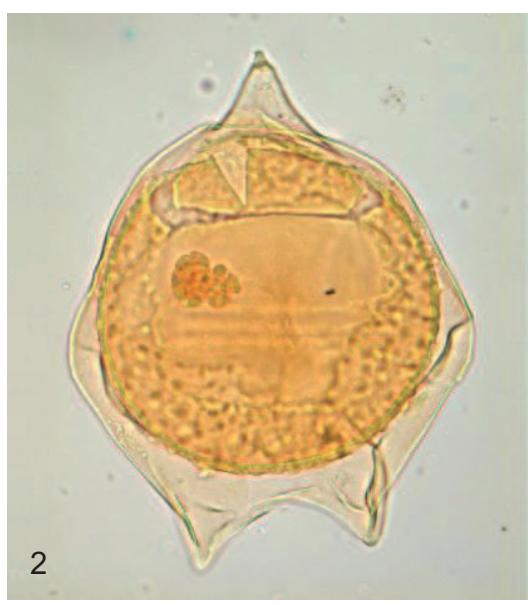

3
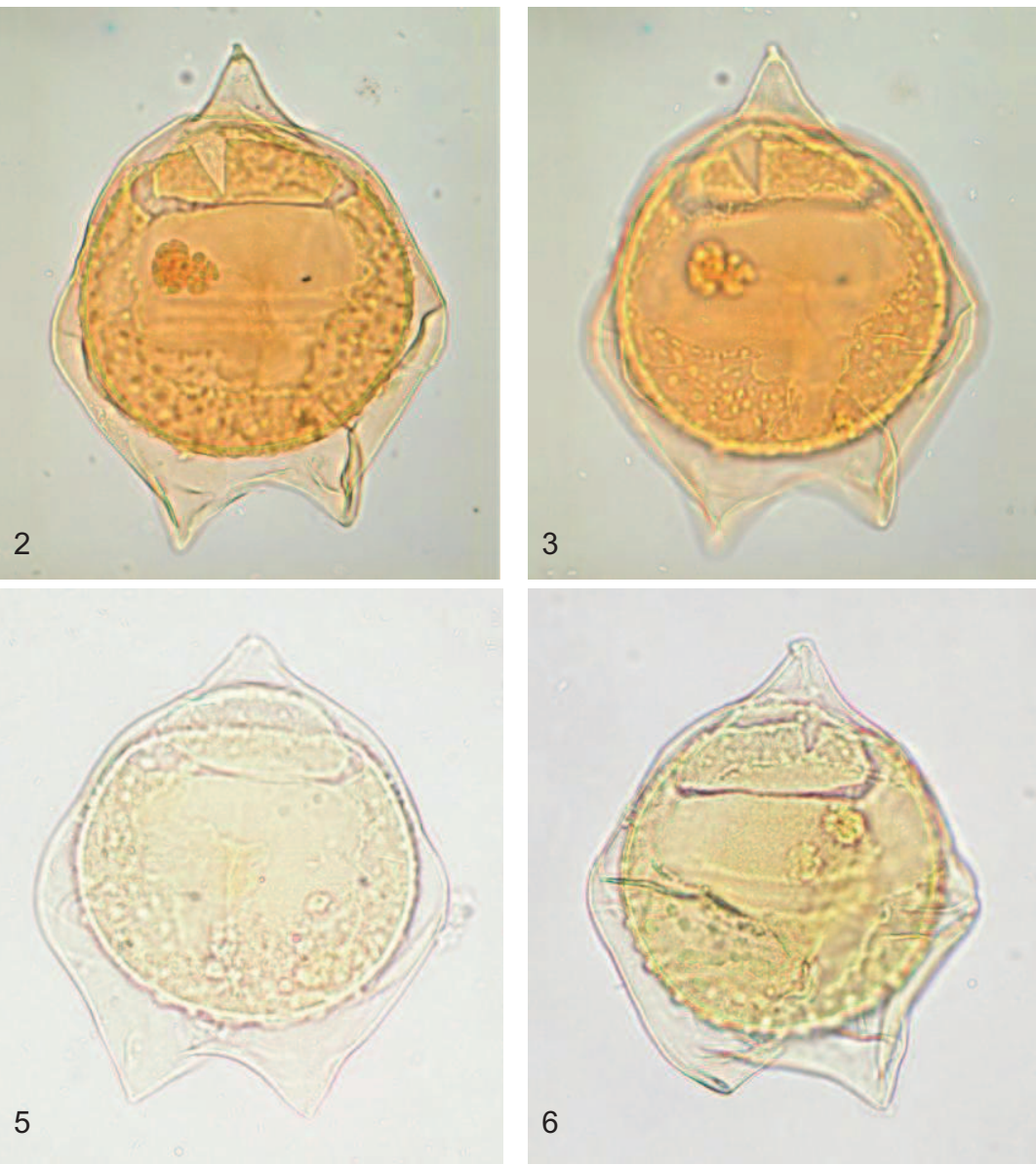

6
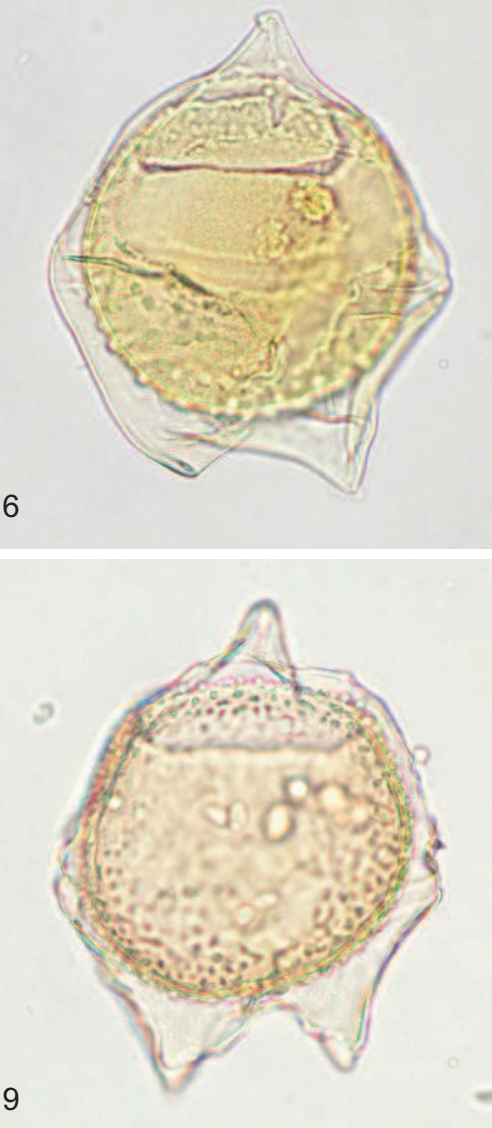

8
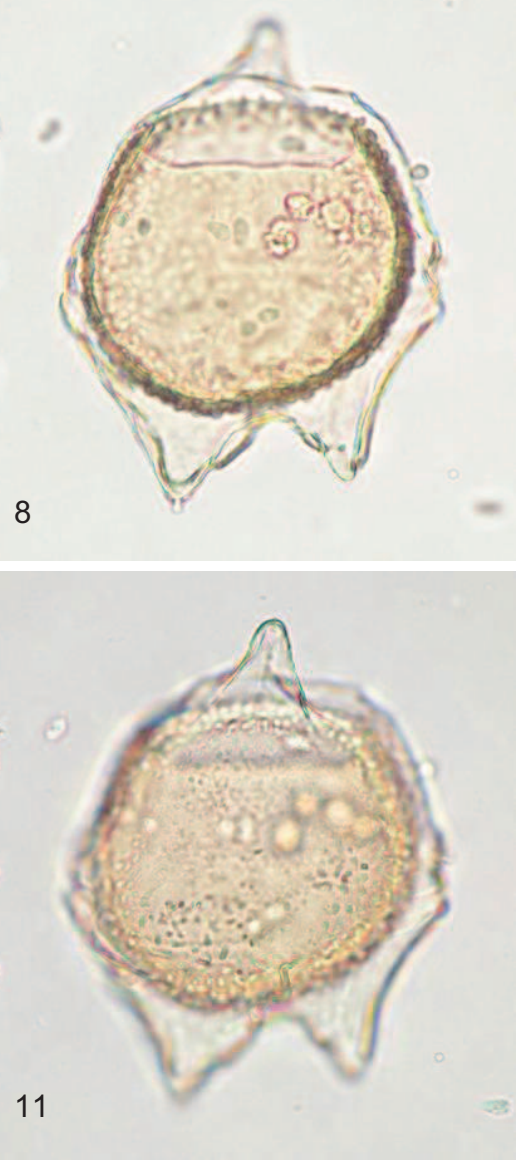

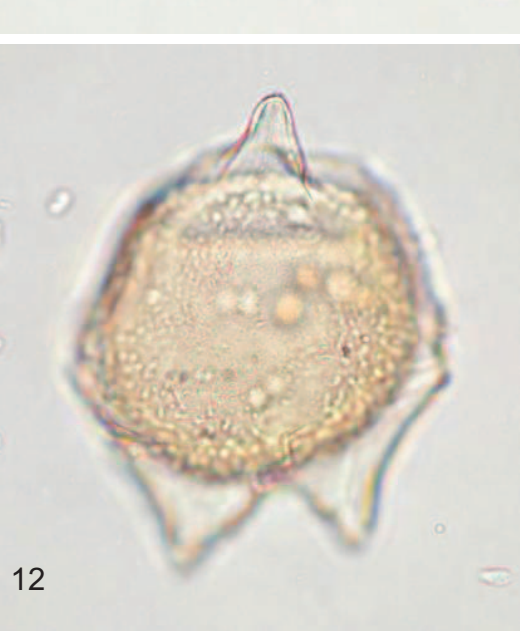




\section{Plate 9}

\section{Deflandrea ?heterophlycta}

Figure 1-6 Sample 143/f090, slide L16338/SM012; Burnside Formation, Puketeraki Core (Bortonian); x 400; specimen measures $115 \times 82 \mu \mathrm{m}$

Figure 7-9 Sample 143/f089, slide L16337/SM033; Burnside Formation, Puketeraki Core (Bortonian); x 375; specimen measures 127 x $98 \mu \mathrm{m}$

\section{Deflandrea sp. 3}

Figure 10-12 Sample I43/f089, slide L16337/SM081; Burnside Formation, Puketeraki Core (Bortonian); x 375; specimen measures 127 x $88 \mu \mathrm{m}$ 


\section{Plate 9}
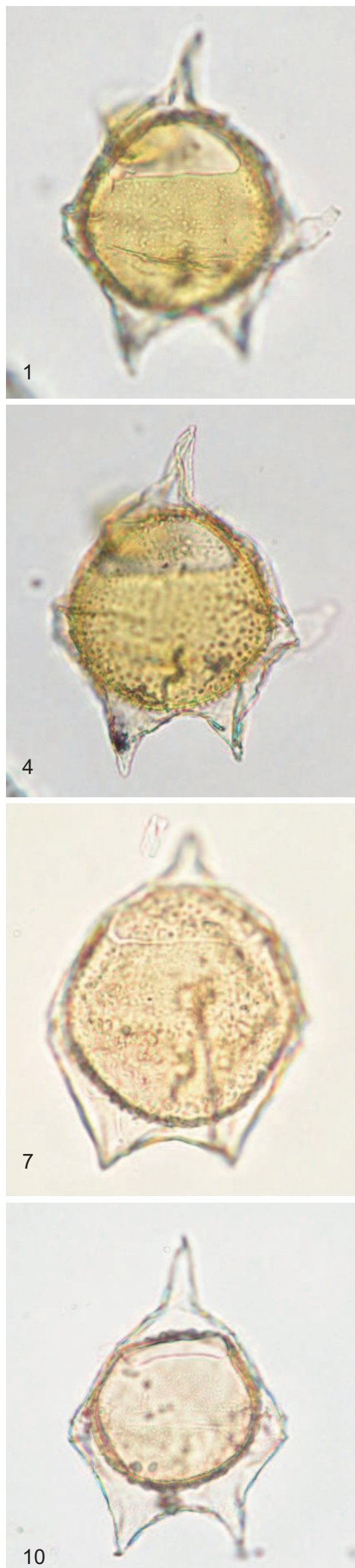
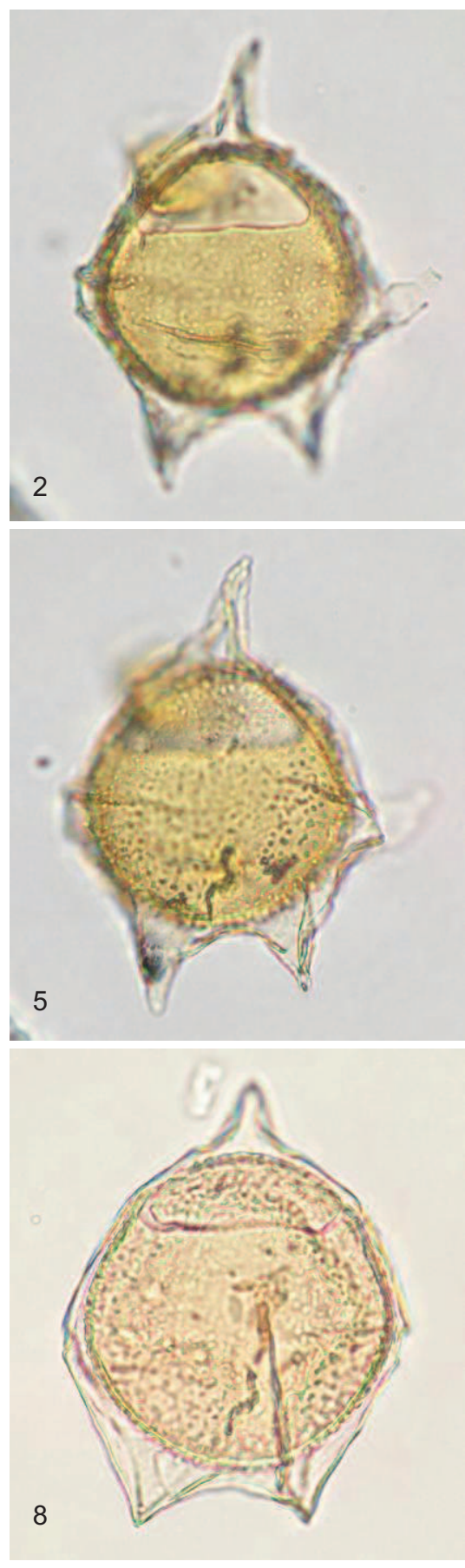

6
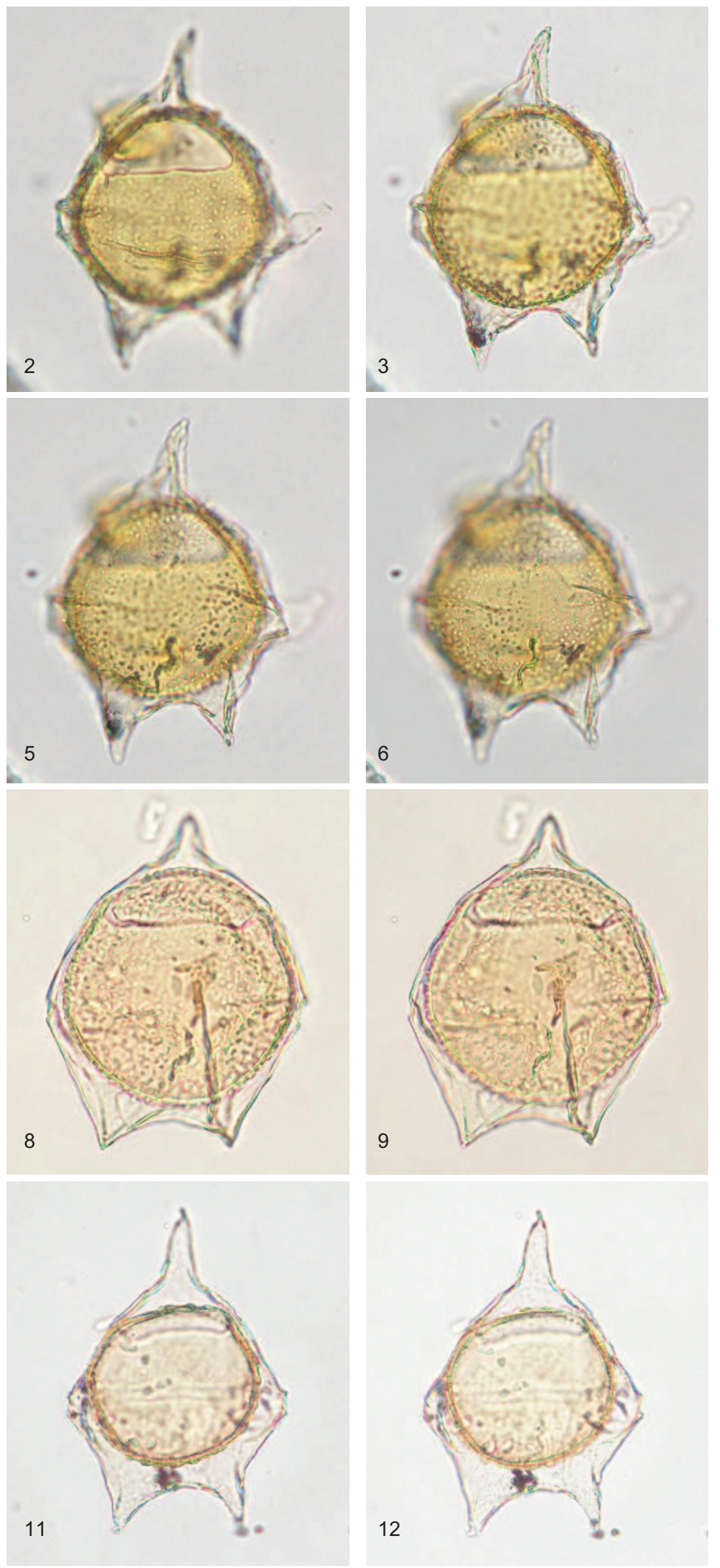


\section{Plate 10}

\section{Deflandrea sp. 3}

Figure 1-3 Sample 143/f089, slide L16337/SM081; Burnside Formation, Puketeraki Core (Bortonian); x 375; specimen measures $127 \times 88 \mu \mathrm{m}$

Figure 4-9 Sample 143/f089, slide L16337/SM031; Burnside Formation, Puketeraki Core (Bortonian); x 375; specimen measures $127 \times 82 \mu \mathrm{m}$

\section{Deflandrea cygniformis}

Figure 10-12 Sample J42/f488, slide L23123/SM006; Hampden Formation, Hampden Beach Section (Bortonian); x 400; specimen measures $120 \times 72 \mu \mathrm{m}$ 


\section{Plate 10}

1
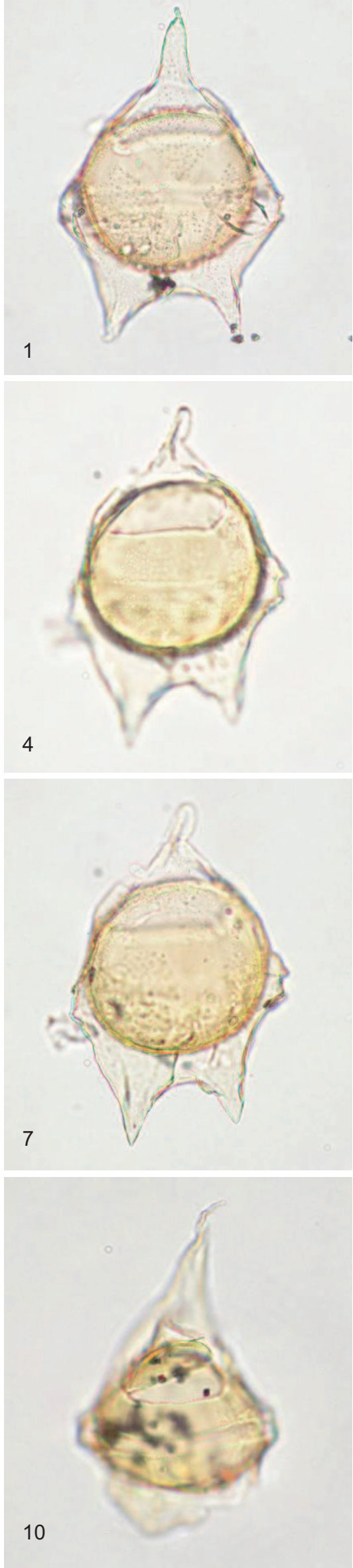

2

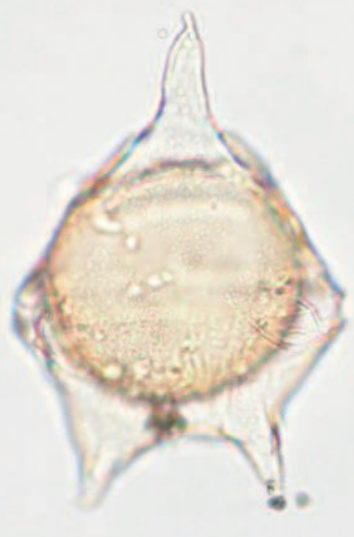

5

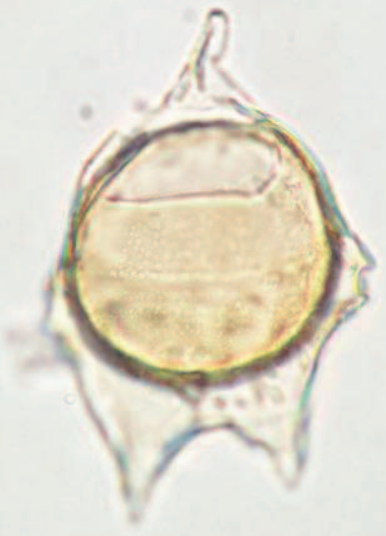

8
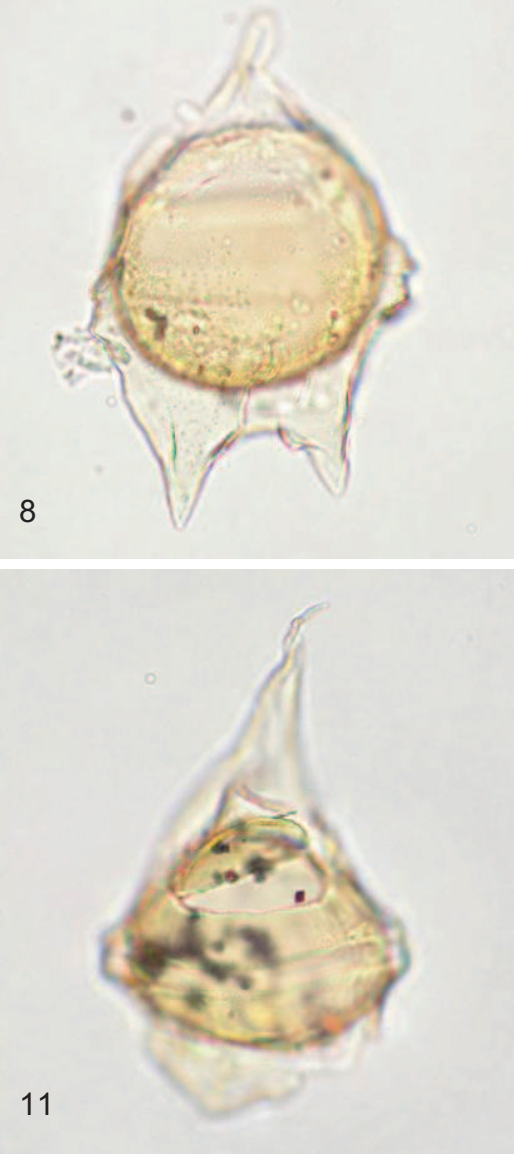

3

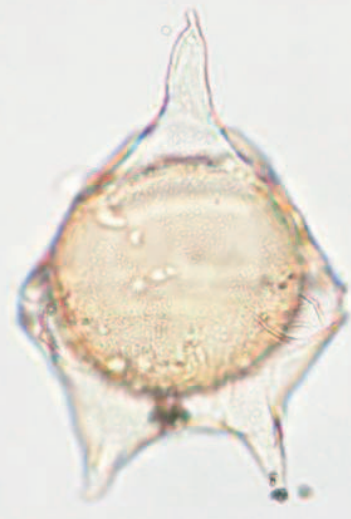

6

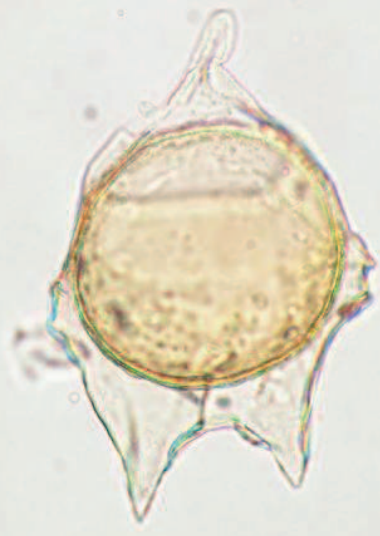

9

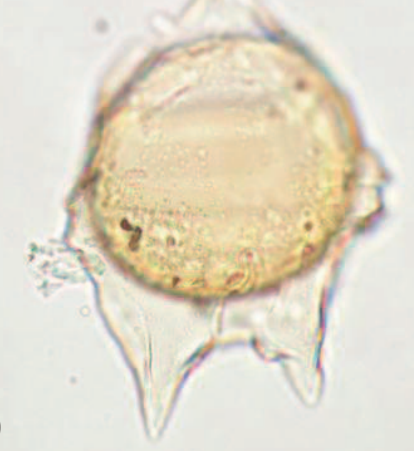

12

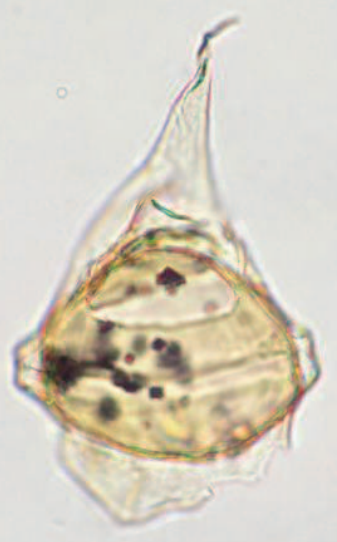




\section{Plate 11}

\section{Deflandrea cygniformis}

Figure 1-3 Sample J42/f488, slide L23123/SM006; Hampden Formation, Hampden Beach Section (Bortonian); x 400; specimen measures $120 \times 72 \mu \mathrm{m}$

\section{Deflandrea sp. 4}

Figure 4-6 Sample K29/f114, slide L11050/SM025; Port Elizabeth Member, Cape Foulwind Section (early Whaingaroan); x 400; specimen measures 117 x $92 \mu \mathrm{m}$

\section{Deflandrea antarctica}

Figure 7-12 Sample J42/f488, slide L23123/SM004; Hampden Formation, Hampden Beach Section (Bortonian); x 425; specimen measures 108 x $65 \mu \mathrm{m}$ 


\section{Plate 11}
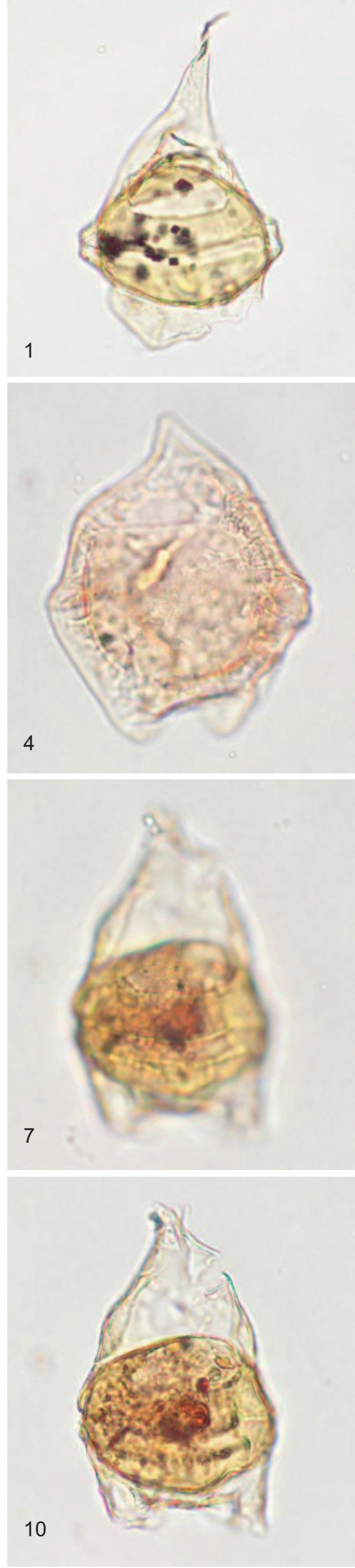
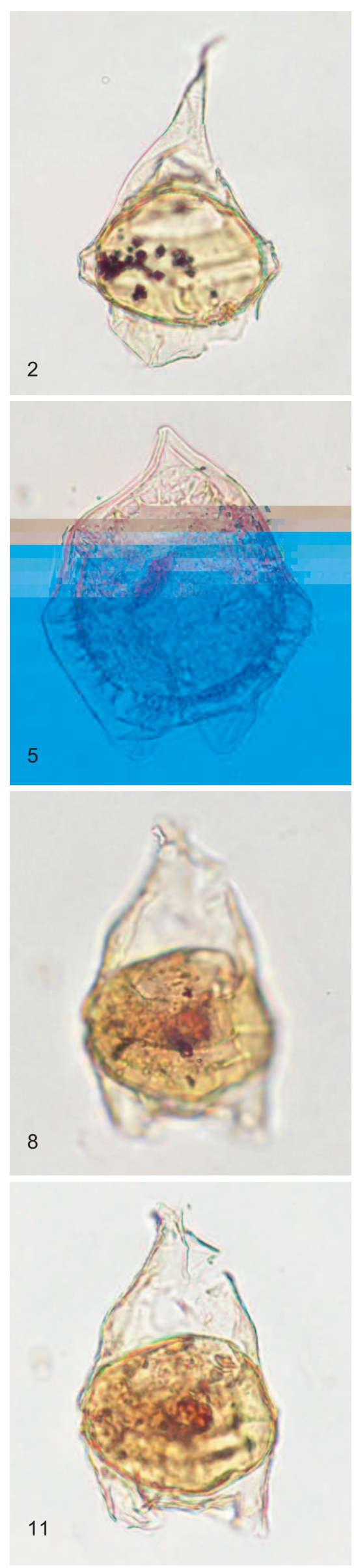
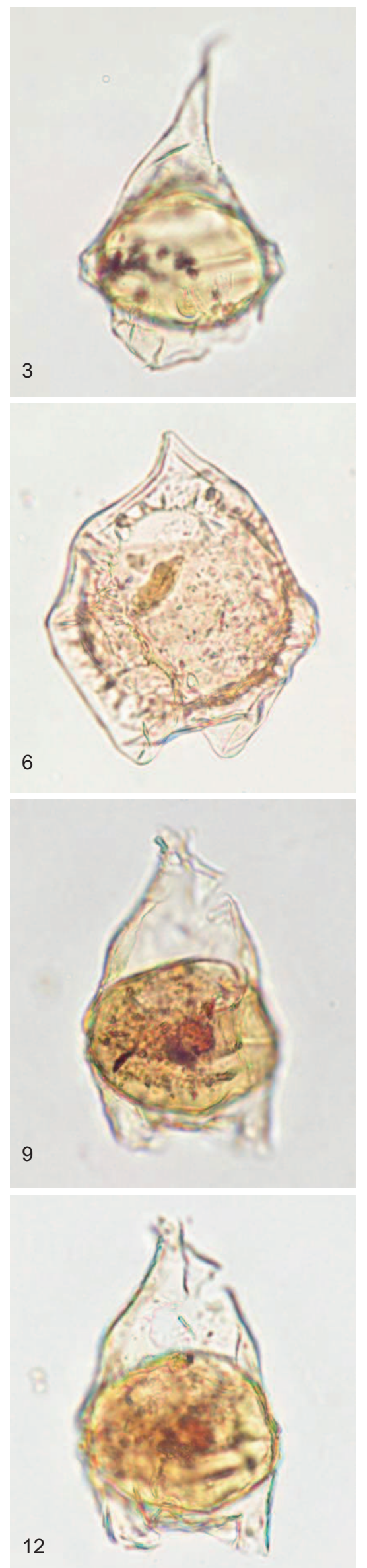


\section{Plate 12}

\section{Deflandrea aff. antarctica}

Figure 1-3 Sample U24/f419, slide L23127/SM005B; Wanstead, Te Uri Stream (Porangan); x 375; specimen measures $123 \times 68 \mu \mathrm{m}$

\section{Deflandrea convexa}

Figure 4-6 Sample U24/f418, slide L23126/SM006; Wanstead, Te Uri Stream (Porangan); x 550; specimen measures $80 \times 75 \mu \mathrm{m}$

Figure 7-9 Sample U24/f418, slide L23126/SM007; Wanstead, Te Uri Stream (Porangan); x 475; specimen measures $97 \times 80 \mu \mathrm{m}$

Figure 10-12 Sample 143/f090, slide L16338/SM014; Burnside Formation, Puketeraki Core (Bortonian); x 450; specimen measures $103 \times 85 \mu \mathrm{m}$ 


\section{Plate 12}

1
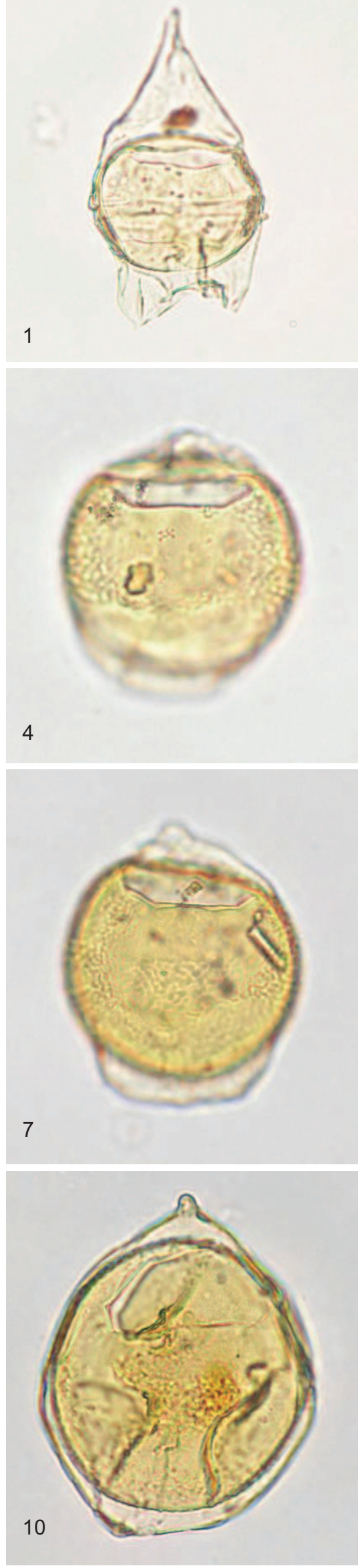
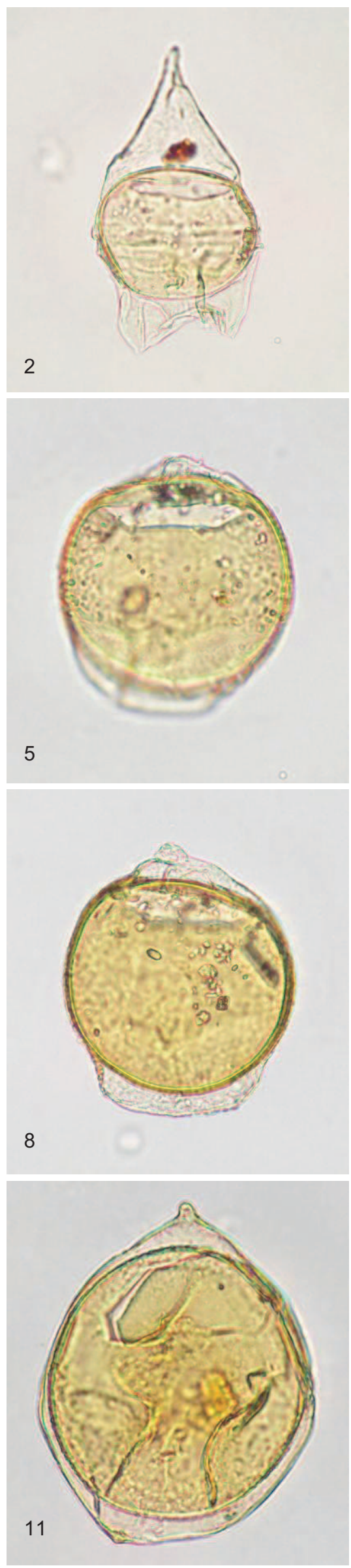

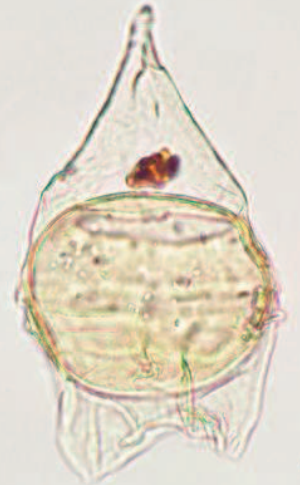

3

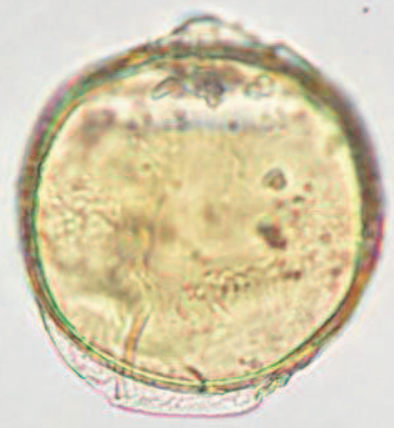

6

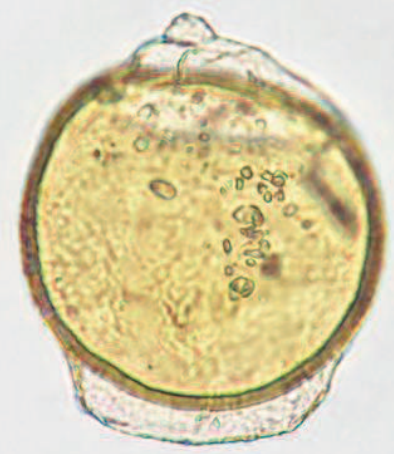

9

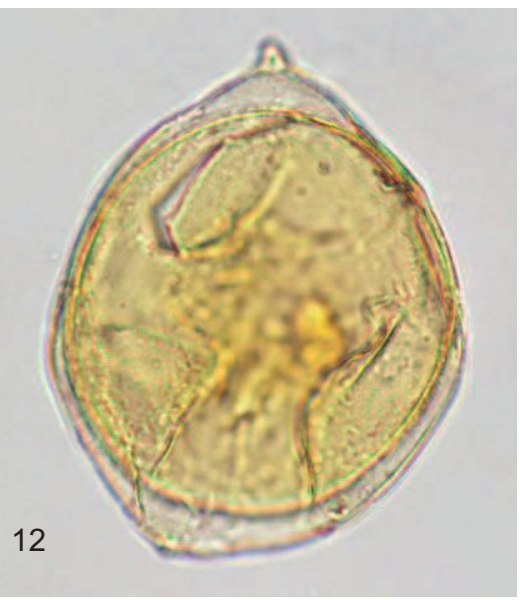




\section{Plate 13}

\section{Deflandrea ?leptodermata}

Figure 1-2 Sample J42/f098, slide L10953/SM004; Totara Limestone, Kakanui River (Runangan); x 400; specimen measures $115 \times 98 \mu \mathrm{m}$

Figure 3 Sample J42/f098, slide L10953/SM2967; Totara Limestone, Kakanui River (Runangan); x 350; specimen measures $138 \times 101 \mu \mathrm{m}$

\section{Deflandrea micropoda}

Figure 4-6 Sample 143/f093, slide L16341/SM127; Burnside Formation, Puketeraki Core (Bortonian); x 475; specimen measures $100 \times 80 \mu \mathrm{m}$

\section{Deflandrea sp. 1}

Figure 7-9 Sample K29/f106, slide L11042/SM001; Kaiata Mudstone, Cape Foulwind Section (Runangan-early Whaingaroan)

\section{Deflandrea totara}

Figure 10-11 Sample J42/f096, slide L10951/SM091; Totara Limestone, Kakanui River (early Whaingaroan); x 375; specimen measures 126 × $92 \mu \mathrm{m}$

Figure 12 Sample J42/f096, slide L10951/SM086; Totara Limestone, Kakanui River (early Whaingaroan); x 350; specimen measures 135 x $95 \mu \mathrm{m}$ 


\section{Plate 13}
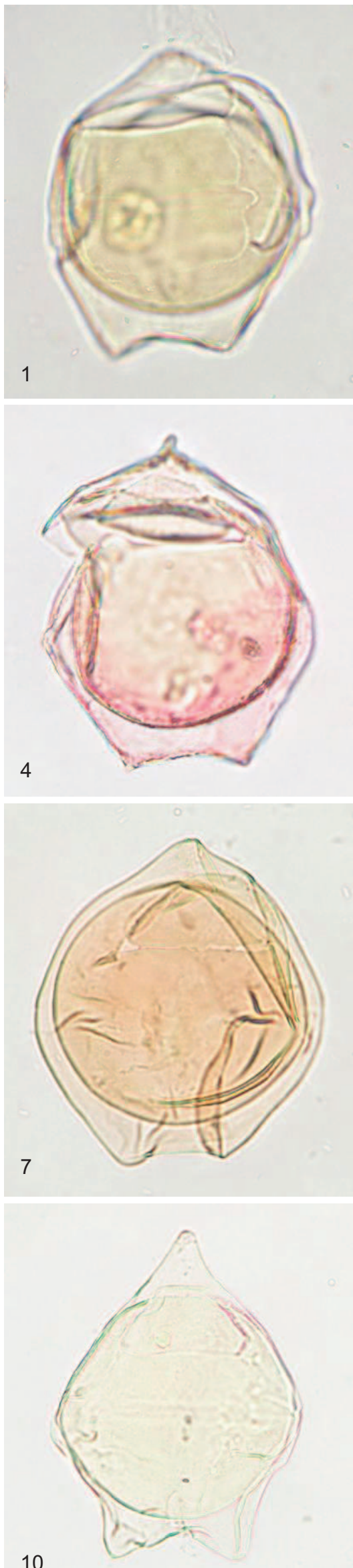
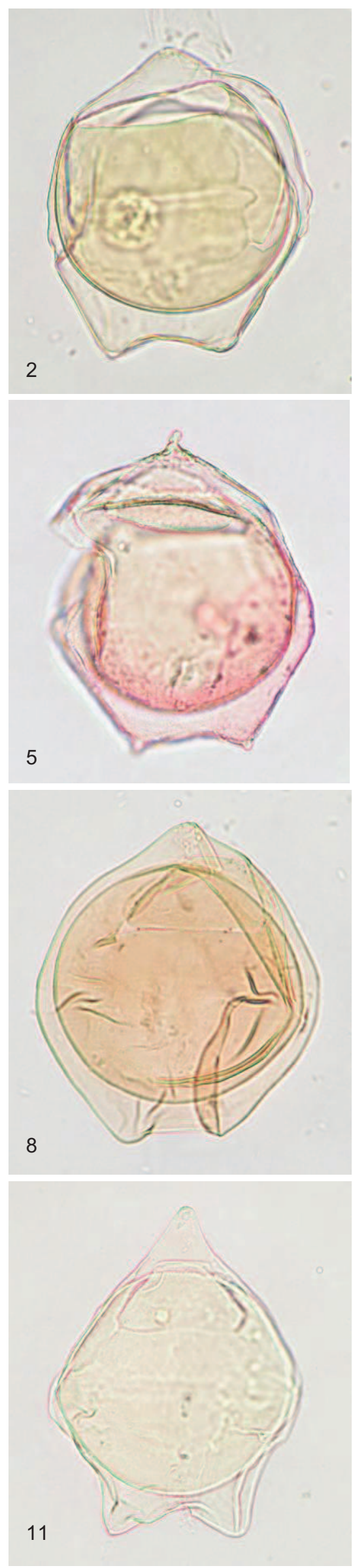

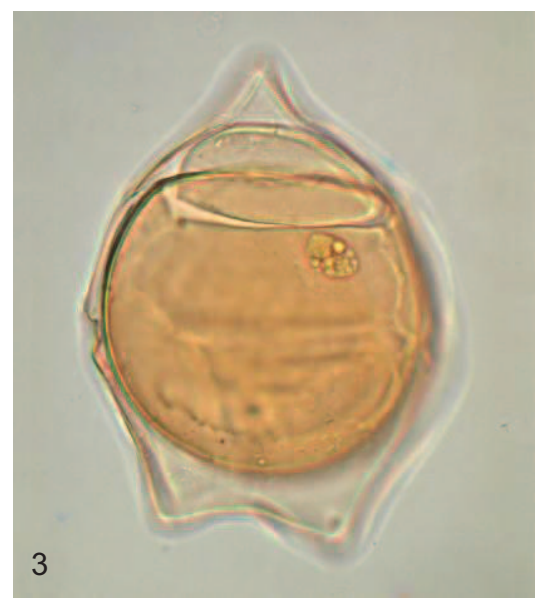

6

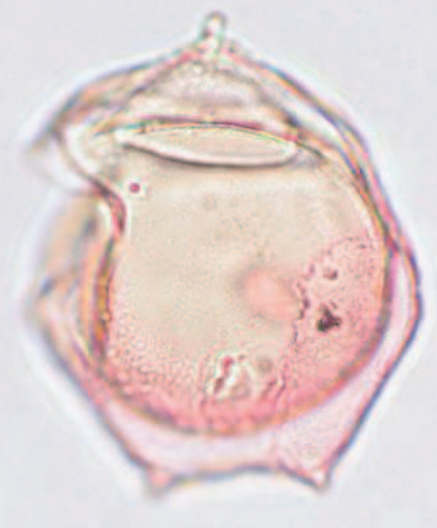

9

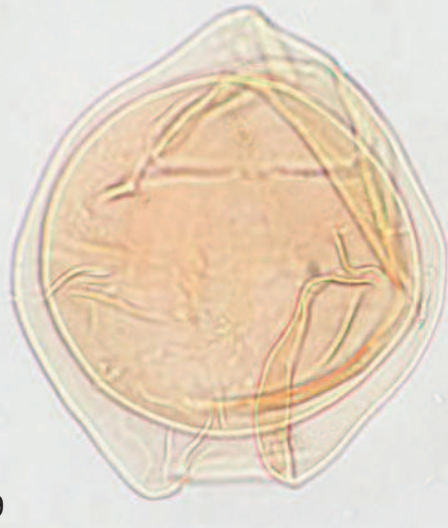

12

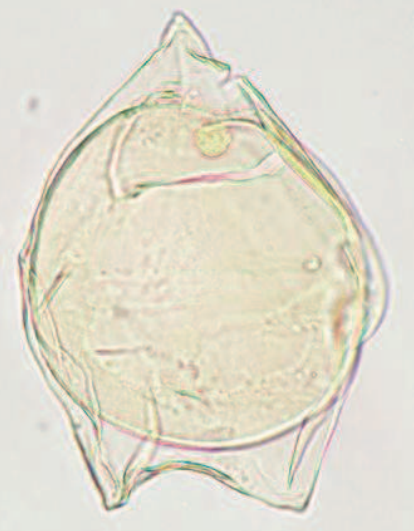




\section{Plate 14}

\section{Deflandrea totara}

Figure 1 Sample J42/f096, slide L10951/SM086; Totara Limestone, Kakanui River (early Whaingaroan); x 350; specimen measures 135 × $95 \mu \mathrm{m}$

Figure 2-3 Sample J42/f096, slide L10951/SM093; Totara Limestone, Kakanui River (early Whaingaroan); x 350; specimen measures 130 × $95 \mu \mathrm{m}$

\section{Deflandrea sp. 2}

Figure 4-6 Sample K29/f102, slide L11038/SM002; Kaiata Mudstone, Cape Foulwind Section (Runangan)

\section{Deflandrea sp. not identified}

Figure 7-9 Sample U24/f417, slide L23125/SM003; Wanstead, Te Uri Stream (Porangan)

Alterbidinium cf. acutulum

Figure 10-12 Sample J42/f486, slide L23121/SM001; ?Hampden Formation, Hampden Beach Section

(Porangan-Bortonian); x 825; specimen measures 57 x $45 \mu \mathrm{m}$ 


\section{Plate 14}
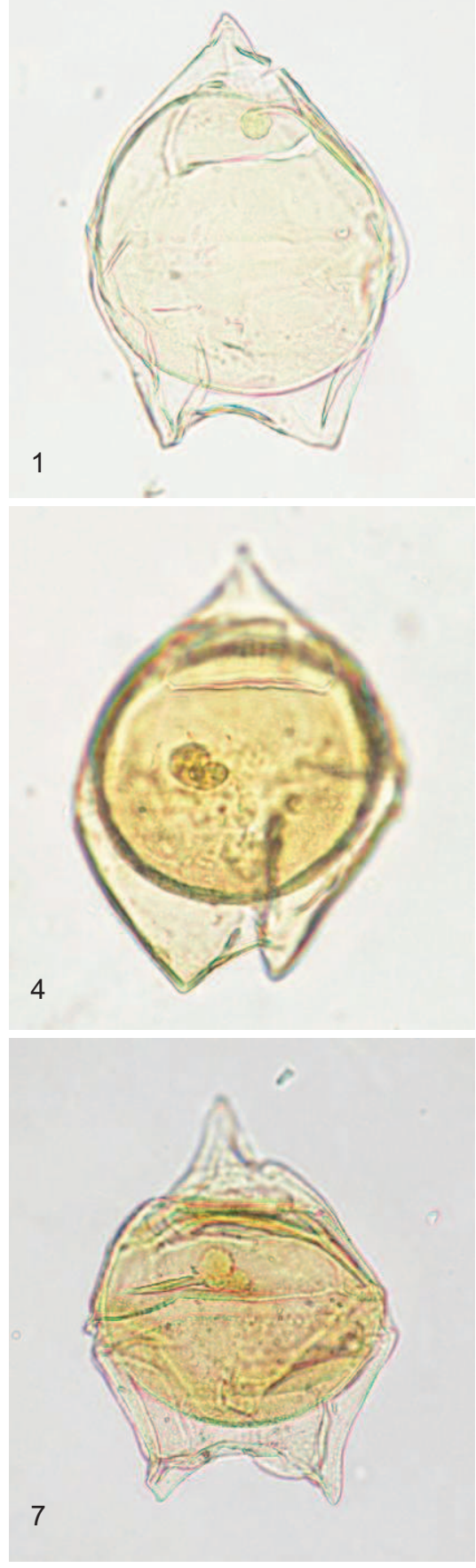

5

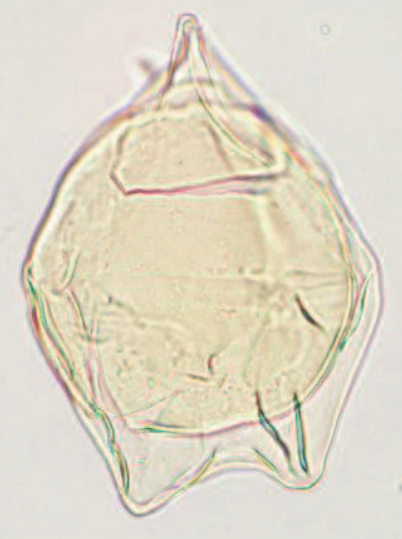

2

3
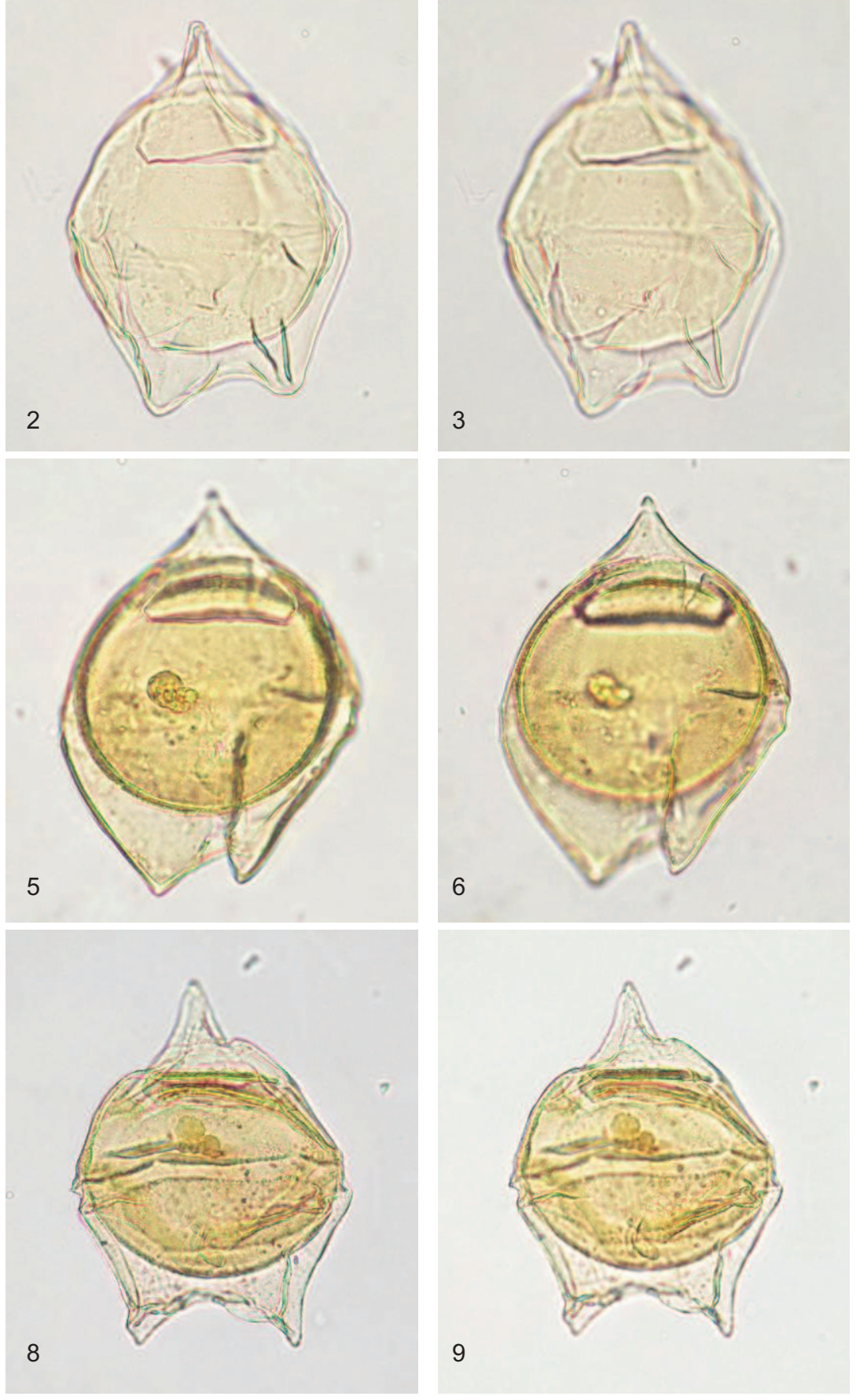

9
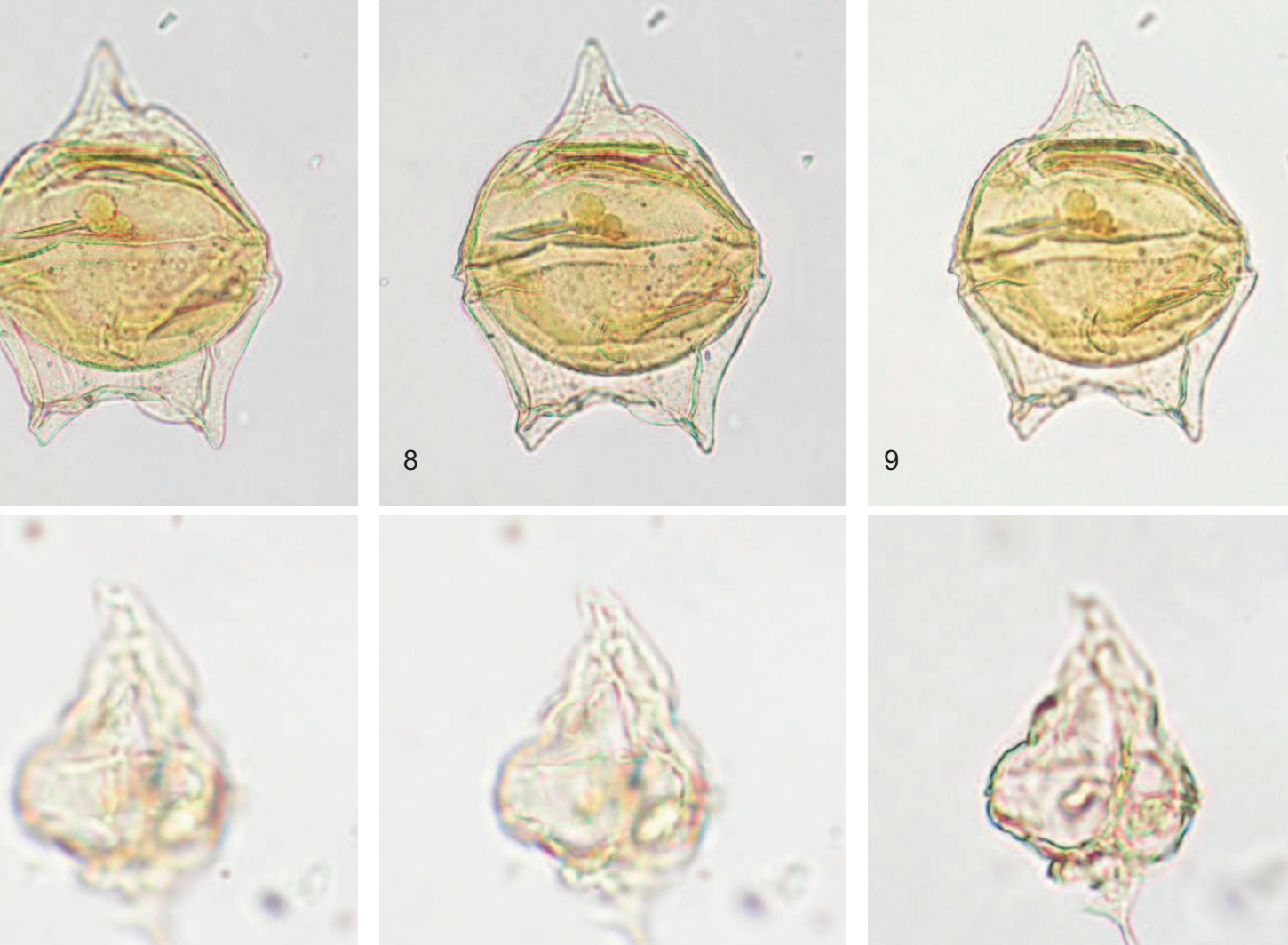

11

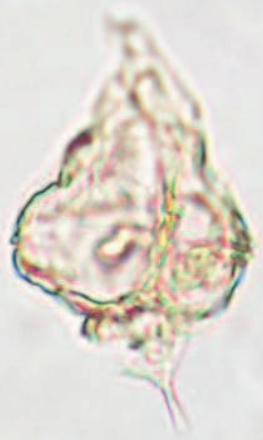

12 


\section{Plate 15}

\section{Cerodinium medcalfii}

Figure 1-3 Sample U24/f419, slide L23127/SM061; Wanstead, Te Uri Stream (Porangan); x 300; specimen measures $155 \times 72 \mu \mathrm{m}$

Figure 4-6 Sample U24/f419, slide L23127/SM074; Wanstead, Te Uri Stream (Porangan); x 350; specimen measures $135 \times 80 \mu \mathrm{m}$

\section{Isabelidinium cf. bakeri}

Figure 7-9 Sample J42/f063, slide L09220/2-1422-215; Mokihi Formation, Hampden Beach Section (Kaiatan); x 275; specimen measures 165 x $96 \mu \mathrm{m}$

\section{Planoperidinium gracile}

Figure 10-12 Sample K29/f097, slide L10914/SM044; Port Elizabeth Member, Cape Foulwind Section (early Whaingaroan); x 600; specimen measures 78 x $65 \mu \mathrm{m}$ 


\section{Plate 15}
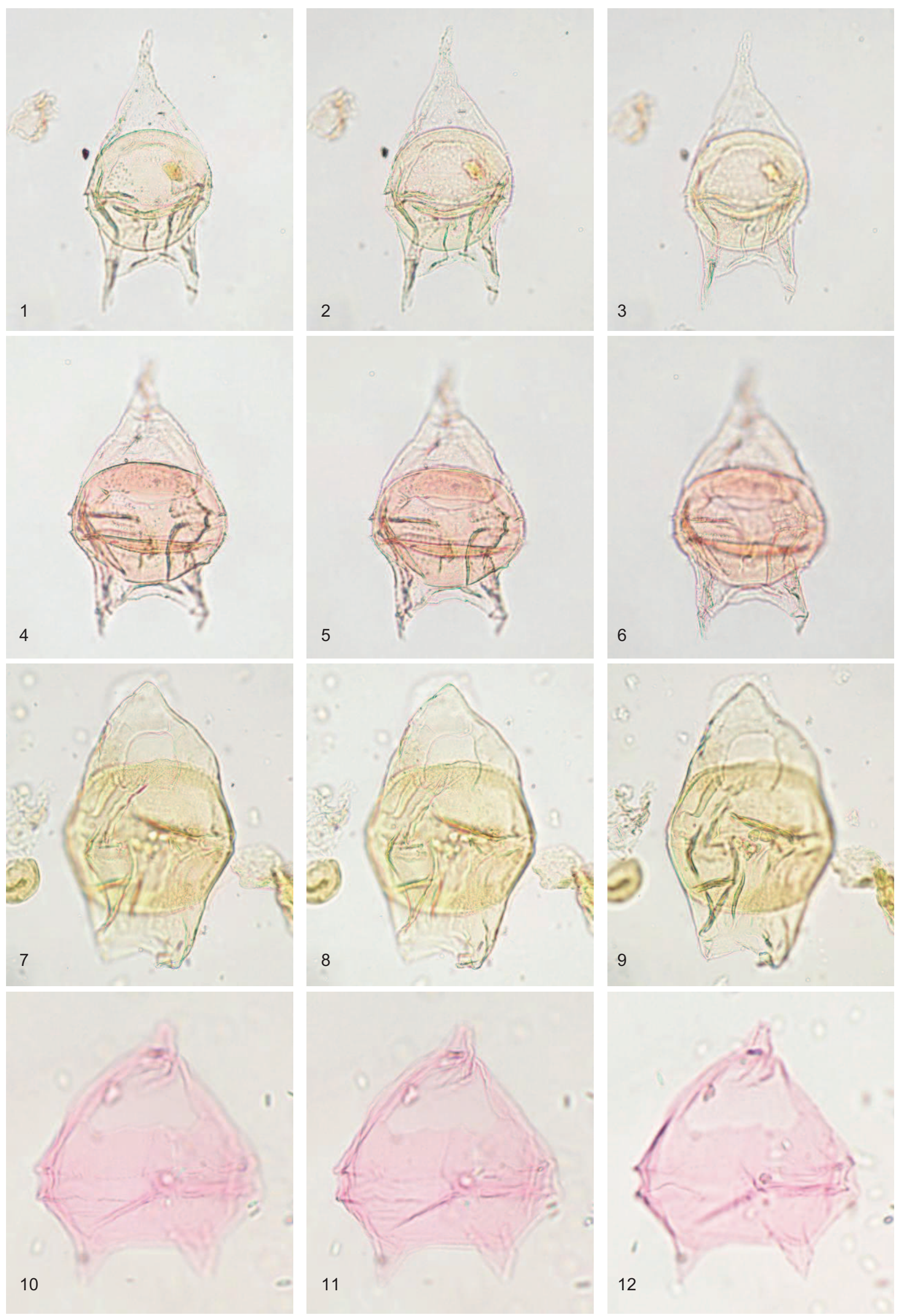


\section{Plate 16}

\section{Planoperidinium gracile}

Figure 1-3 Sample K29/f097, slide L10914/SM045; Port Elizabeth Member, Cape Foulwind Section (early Whaingaroan); x 550; specimen measures 87 x $67 \mu \mathrm{m}$

\section{?Planoperidinium sp. 2}

Figure 4-6 Sample K29/f097, slide L10914/SM002; Port Elizabeth Member, Cape Foulwind Section (early Whaingaroan); x 625; specimen measures 75 x $55 \mu \mathrm{m}$

Figure 7-9 Sample K29/f097, slide L10914/SM042B; Port Elizabeth Member, Cape Foulwind Section (early Whaingaroan); x 650; specimen measures 72 x $50 \mu \mathrm{m}$

\section{Spinidinium cf. styloniferum}

Figure 10-12 Sample 144/f080, slide L08947/SM024; Burnside Formation, Burnside Marl Pit (Bortonian); x 850; specimen measures 56 x $47 \mu \mathrm{m}$ 


\section{Plate 16}
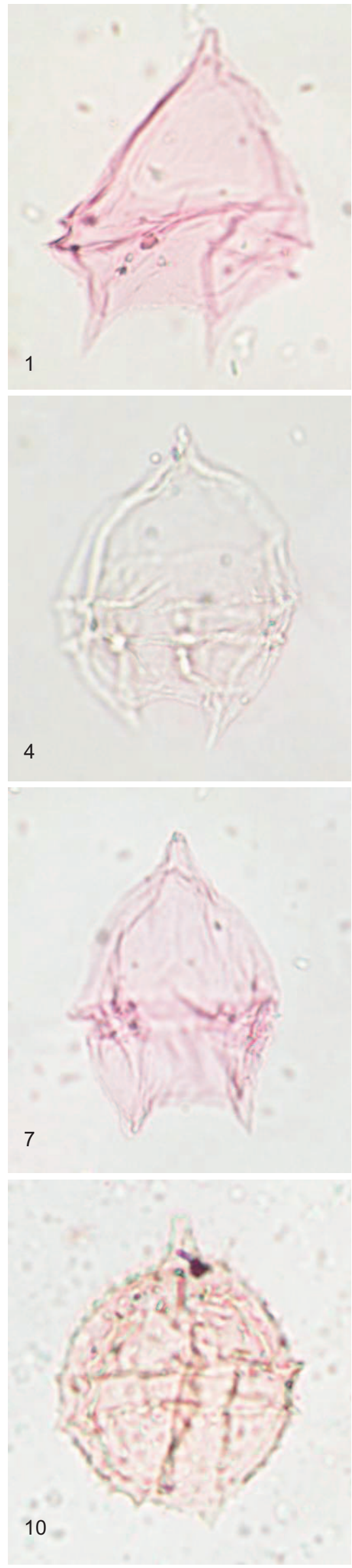
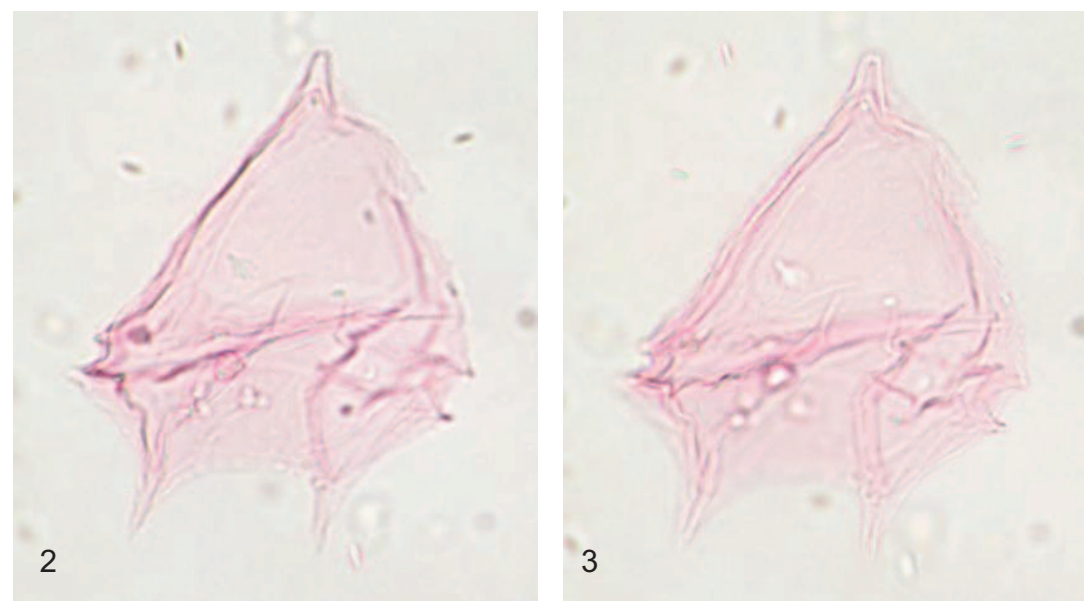

5
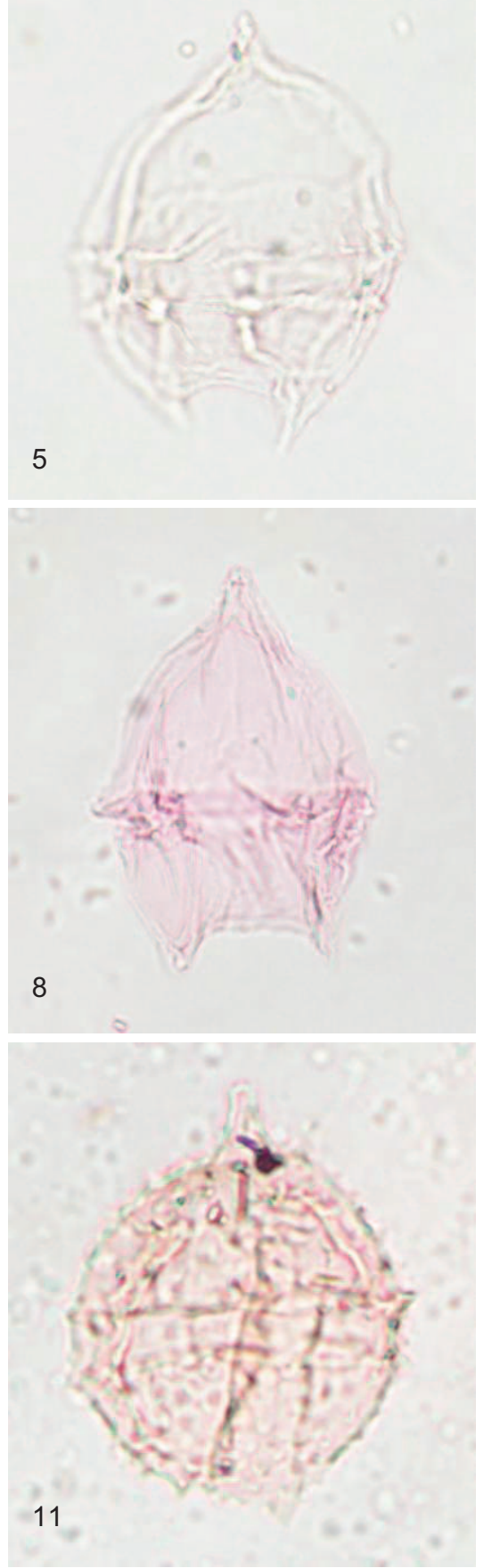
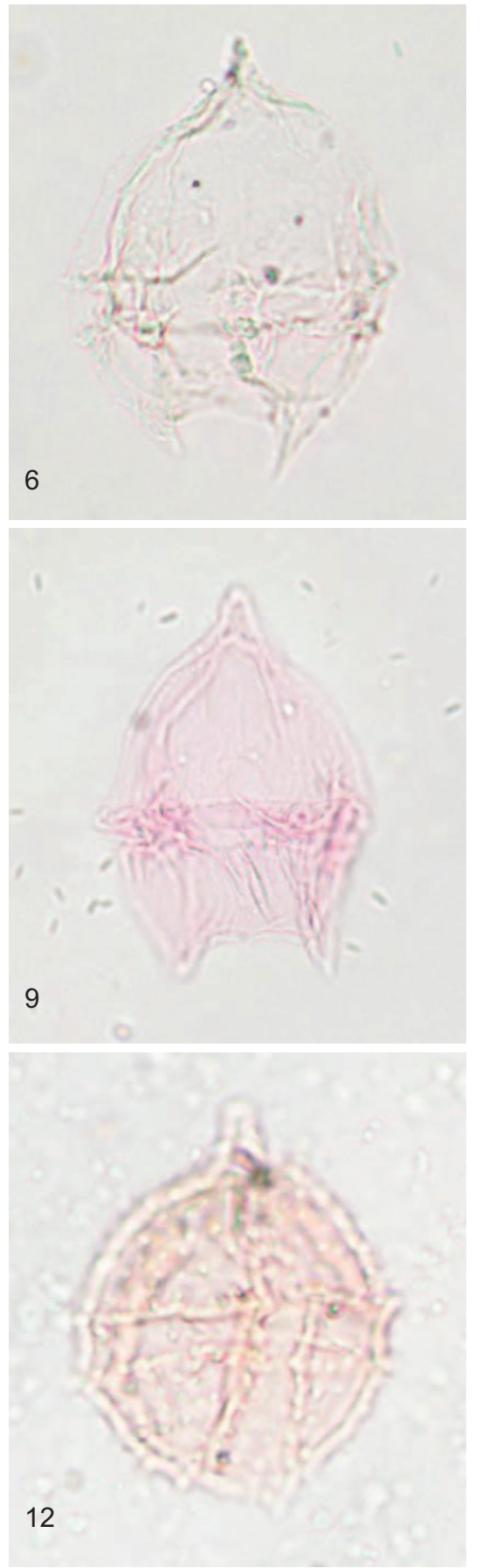


\section{Plate 17}

\section{Spinidinium colemanii}

Figure 1-3 Sample U24/f417, slide L23125/SM028; Wanstead, Te Uri Stream (Porangan); x 1000; specimen measures $47 \times 42 \mu \mathrm{m}$

Figure 4-9 Sample J42/f488, slide L23123/SM007; Hampden Formation, Hampden Beach Section (Bortonian); x 775; specimen measures $60 \times 37 \mu \mathrm{m}$

\section{Spinidinium essoi}

Figure 10-11 Sample U24/f419, slide L23127/SM057; Wanstead, Te Uri Stream (Porangan); x 850; specimen measures $55 \times 42 \mu \mathrm{m}$

\section{Spinidinium macmurdoense}

Figure 12 Sample J42/f485, slide L23120/SM005; ?Hampden Formation, Hampden Beach Section (Porangan-Bortonian); x 850; specimen measures 55 x $46 \mu \mathrm{m}$ 


\section{Plate 17}
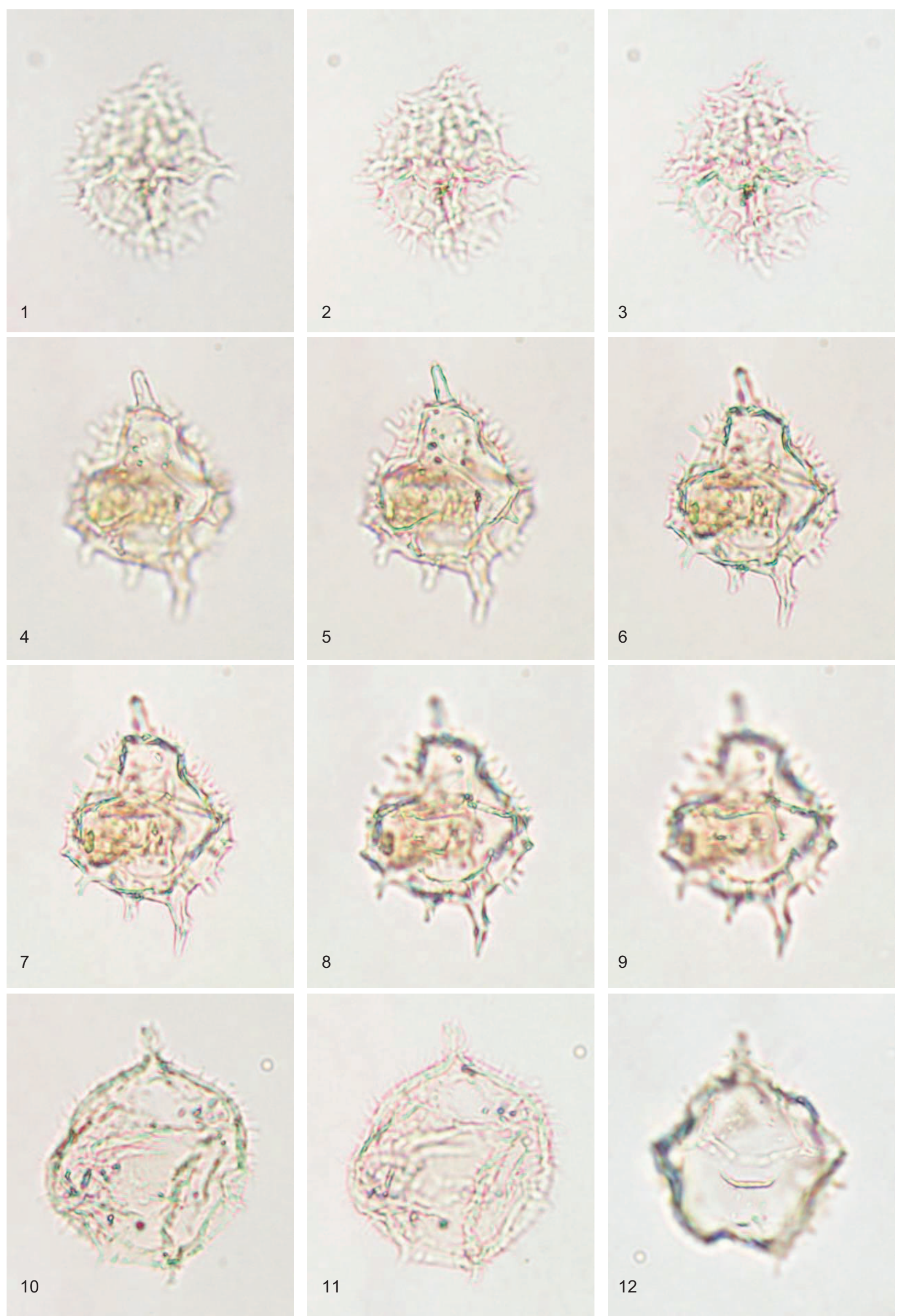

9

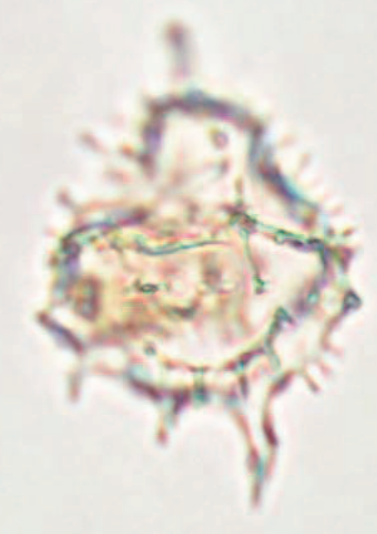




\section{Plate 18}

\section{Spinidinium macmurdoense}

Figure 1-3 Sample J42/f485, slide L23120/SM005; ?Hampden Formation, Hampden Beach Section (Porangan-Bortonian); x 850; specimen measures 55 x $46 \mu \mathrm{m}$

\section{Vozzhennikovia apertura}

Figure 4-6 Sample I43/f092, slide L16340/1-1431-224; Burnside Formation, Puketeraki Core (Bortonian); x 1125; specimen measures 42 x $31 \mu \mathrm{m}$

Figure 7-9 Sample 143/f092, slide L16340/1-1304-197; Burnside Formation, Puketeraki Core (Bortonian); x 1050; specimen measures 45 x $33 \mu \mathrm{m}$

Figure 10-12 Sample J42/f301, slide L23131/SM030; Hampden Formation, Hampden Beach Section (Porangan-Bortonian); specimen measures $38 \times 35 \mu \mathrm{m}$ 


\section{Plate 18}
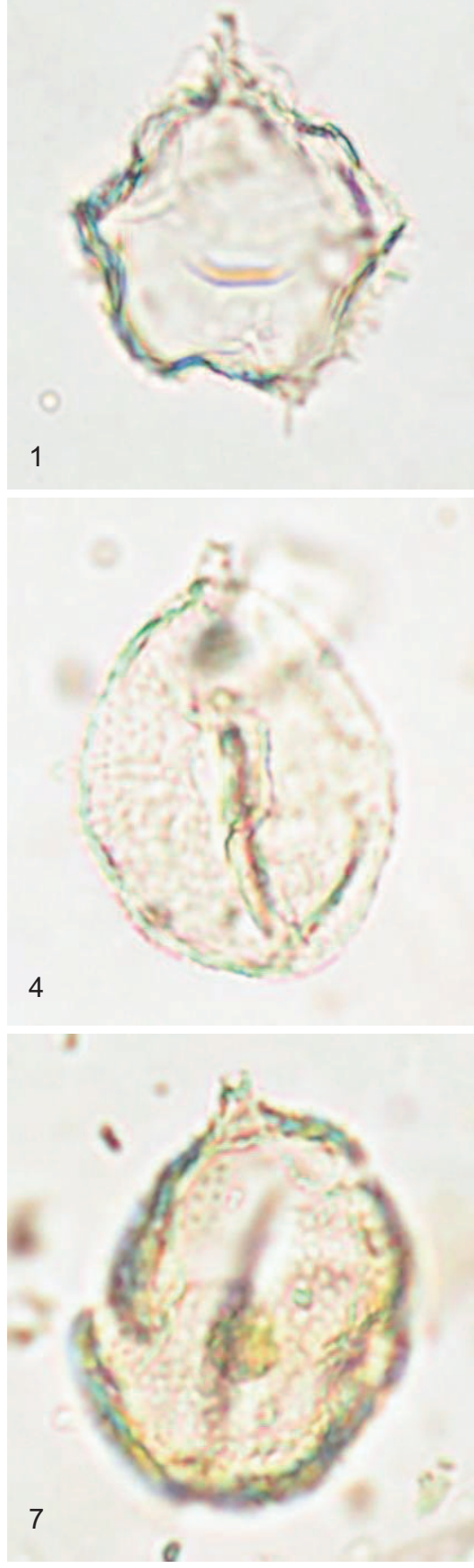

5

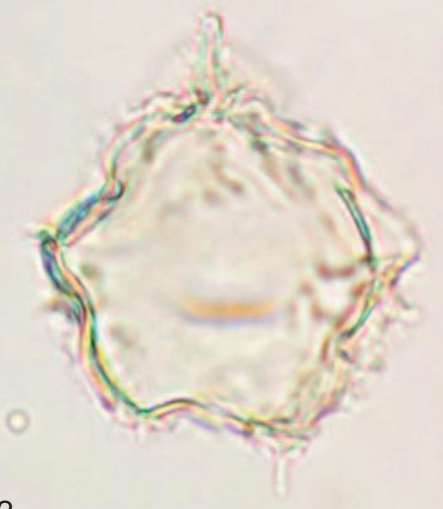

2
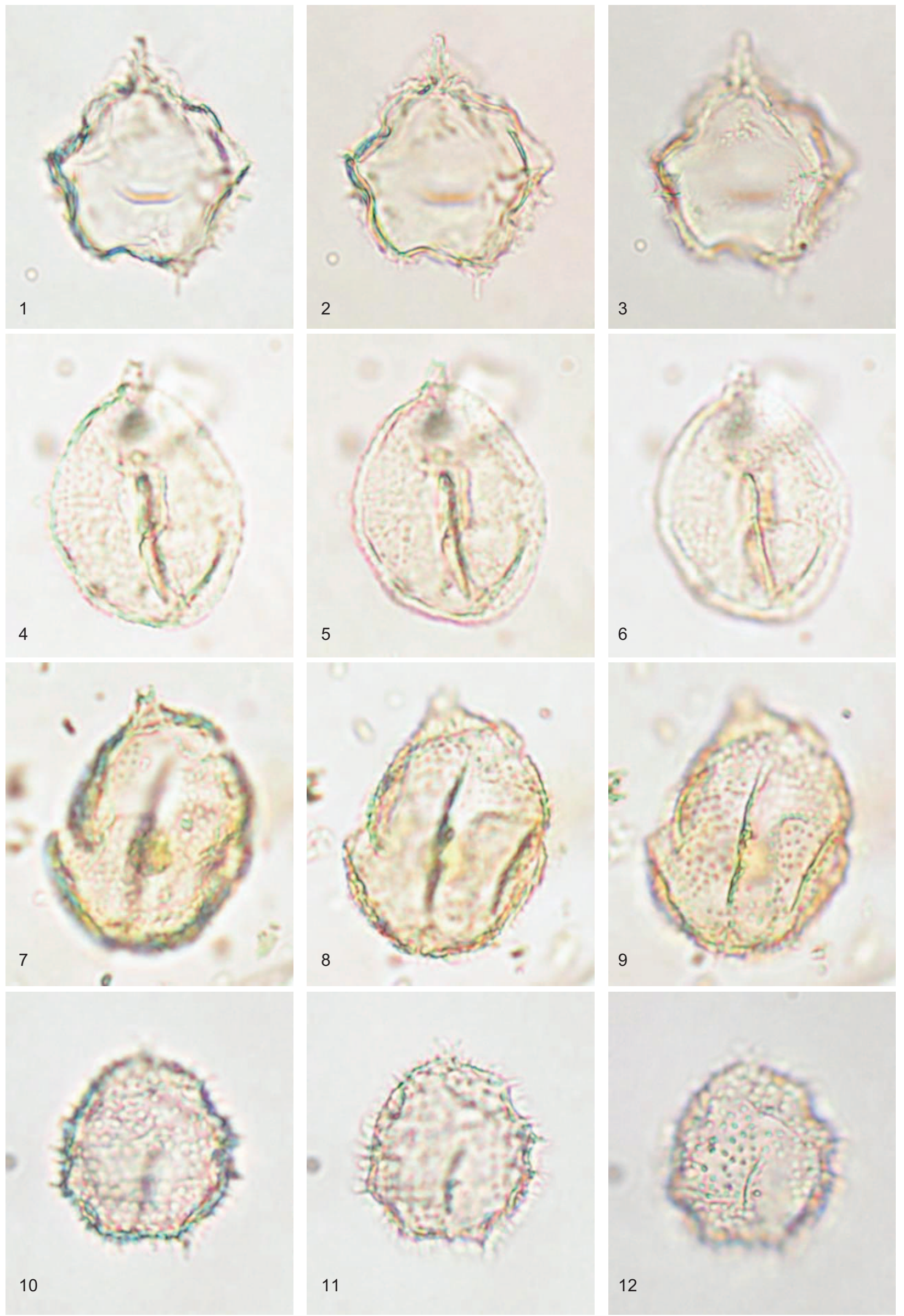

10

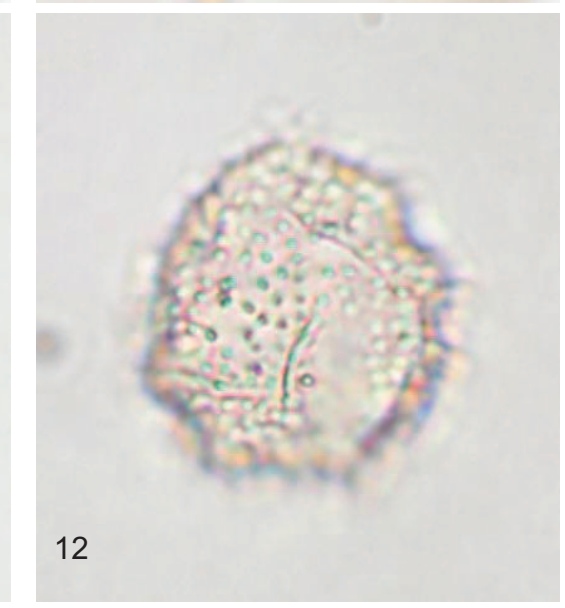




\section{Plate 19}

\section{Phthanoperidinium ?crenulatum}

Figure 1-3 Sample 143/f090, slide L16338/SM007; Burnside Formation, Puketeraki Core (Bortonian); x 775; specimen measures 61 x $53 \mu \mathrm{m}$

Figure 4-6 Sample 143/f089, slide L16337/2-1418-106; Burnside Formation, Puketeraki Core (Bortonian); x 1000; specimen measures $47 \times 39 \mu \mathrm{m}$

\section{Phthanoperidinium dentatum}

Figure 7-12 Sample J42/f8690, slide L06958/SM0382; Hampden Formation, Hampden Beach Section (Bortonian); x 1175; specimen measures 40 x $34 \mu \mathrm{m}$ 


\section{Plate 19}
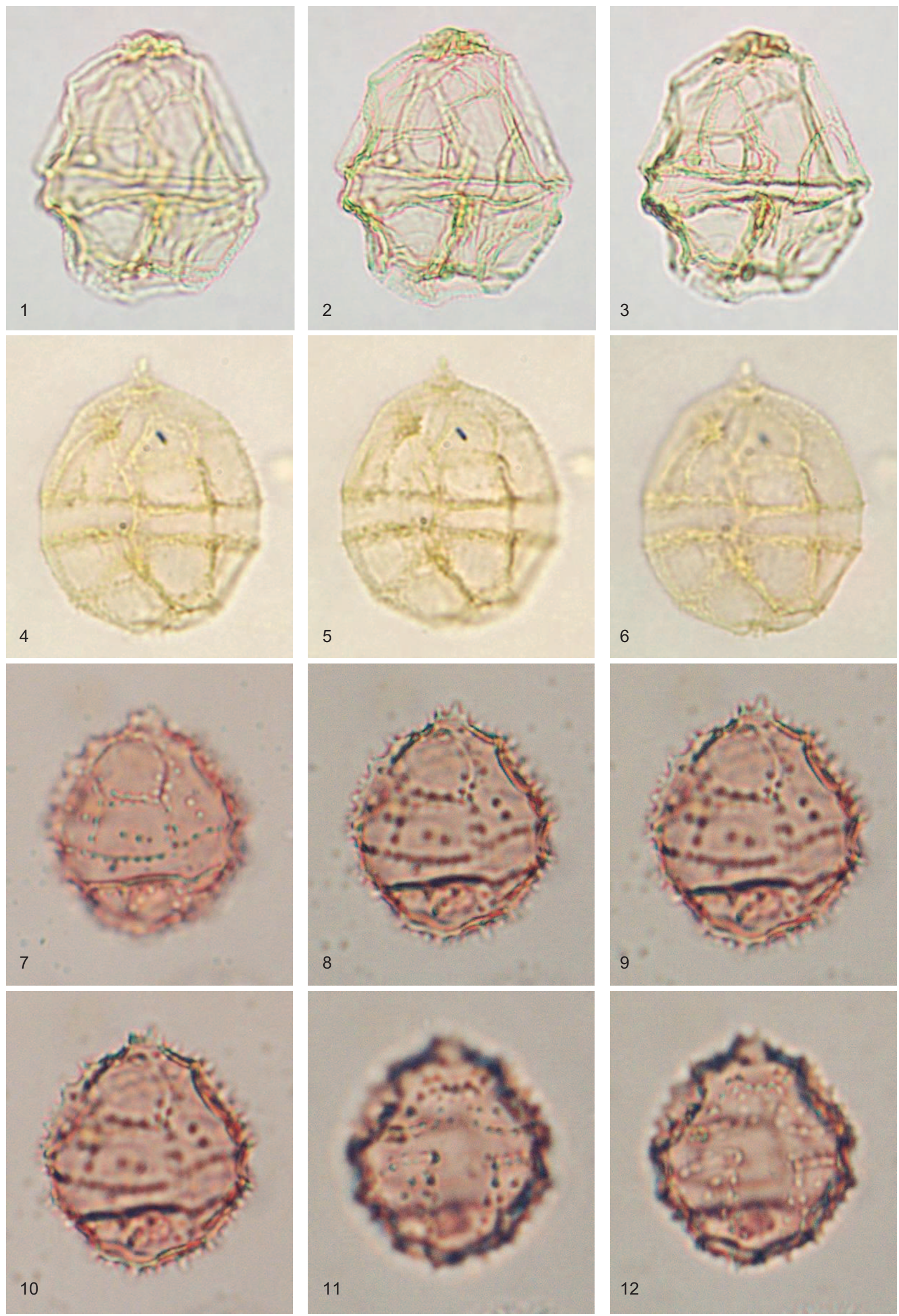


\section{Plate 20}

\section{Phthanoperidinium dentatum}

Figure 1-3 Sample J42/f8690, slide L06958/SM0392; Hampden Formation, Hampden Beach Section (Bortonian); x 1050; specimen measures $43 \times 40 \mu \mathrm{m}$

\section{Phthanoperidinium echinatum}

Figure 4-6 Sample 143/f093, slide L16341/SM077; Burnside Formation, Puketeraki Core (Bortonian); x 950; specimen measures 49 x $39 \mu \mathrm{m}$

Figure 7-12 Sample 143/f093, slide L16341/SM133; Burnside Formation, Puketeraki Core (Bortonian); x 900; specimen measures 52 × $38 \mu \mathrm{m}$ 


\section{Plate 20}
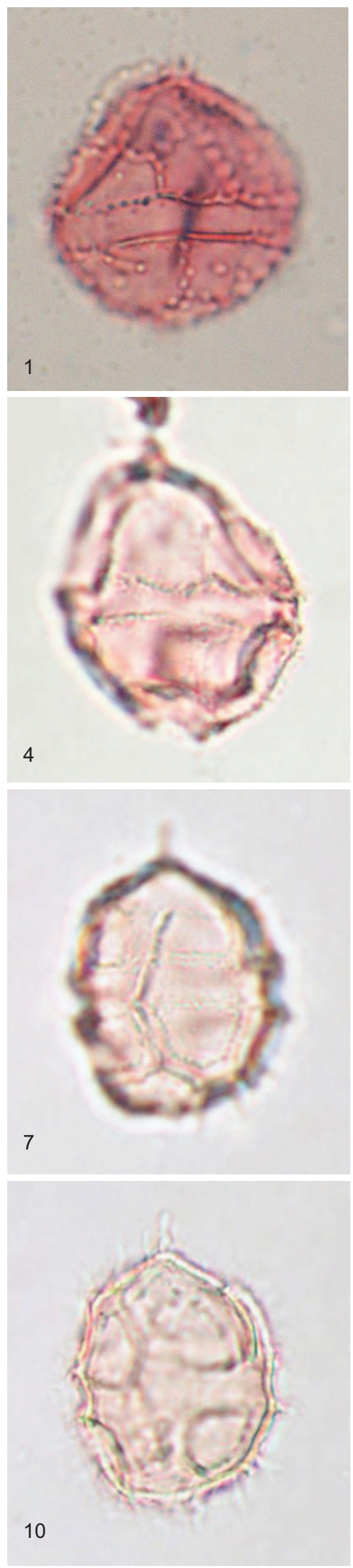
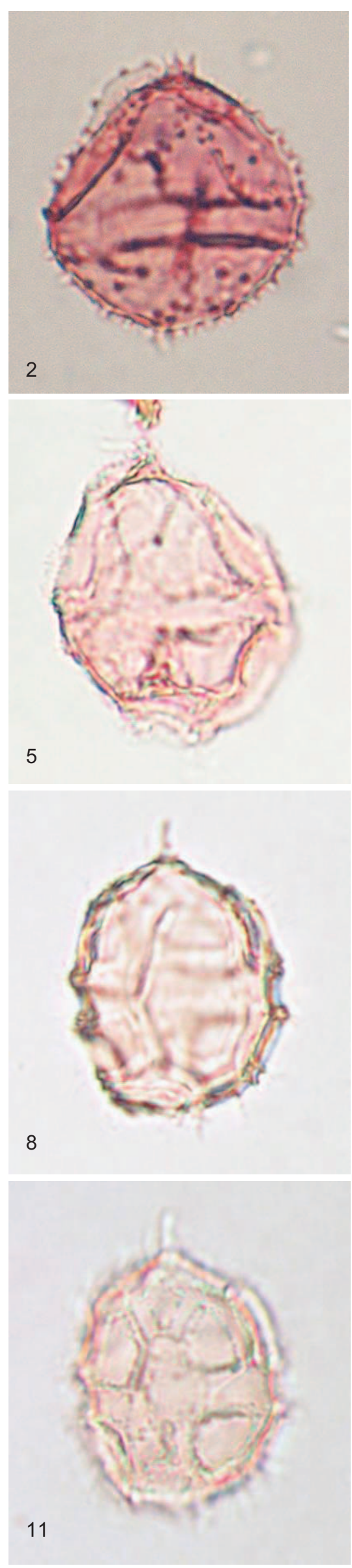
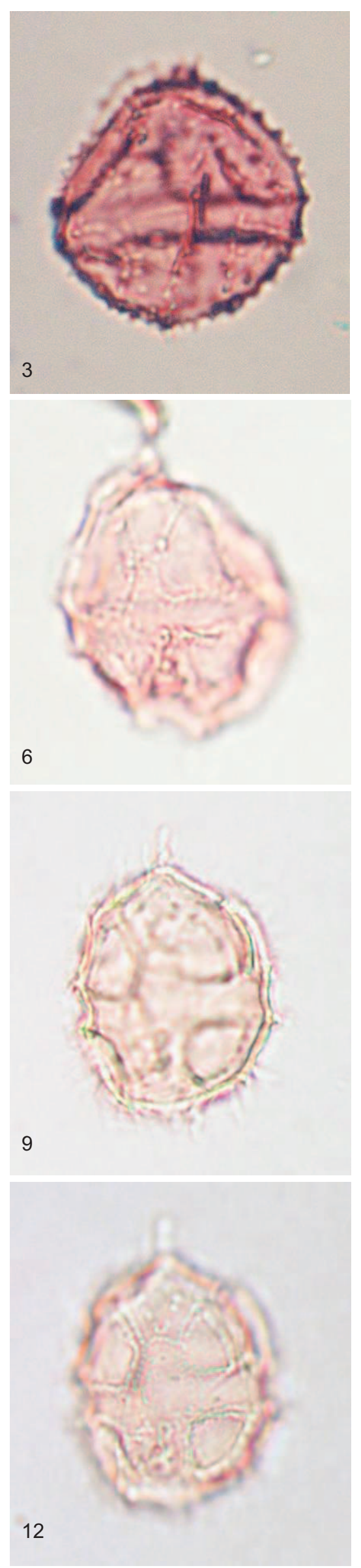


\section{Plate 21}

\section{Phthanoperidinium eocenicum}

Figure 1-3 Sample 143/f093, slide L16341/SM012; Burnside Formation, Puketeraki Core (Bortonian); x 925; specimen measures 51 x $35 \mu \mathrm{m}$

Figure 4-6 Sample J41/f8914, slide L04979/SM1084; Waiareka Volcanics, Jacksons Paddock (KaiatanRunangan); x 725; specimen measures 64 x $45 \mu \mathrm{m}$

\section{Phthanoperidinium geminatum}

Figure 7-12 Sample 143/f093, slide L16341/SM107; Burnside Formation, Puketeraki Core (Bortonian); x 1125; specimen measures 42 × $32 \mu \mathrm{m}$ 


\section{Plate 21}
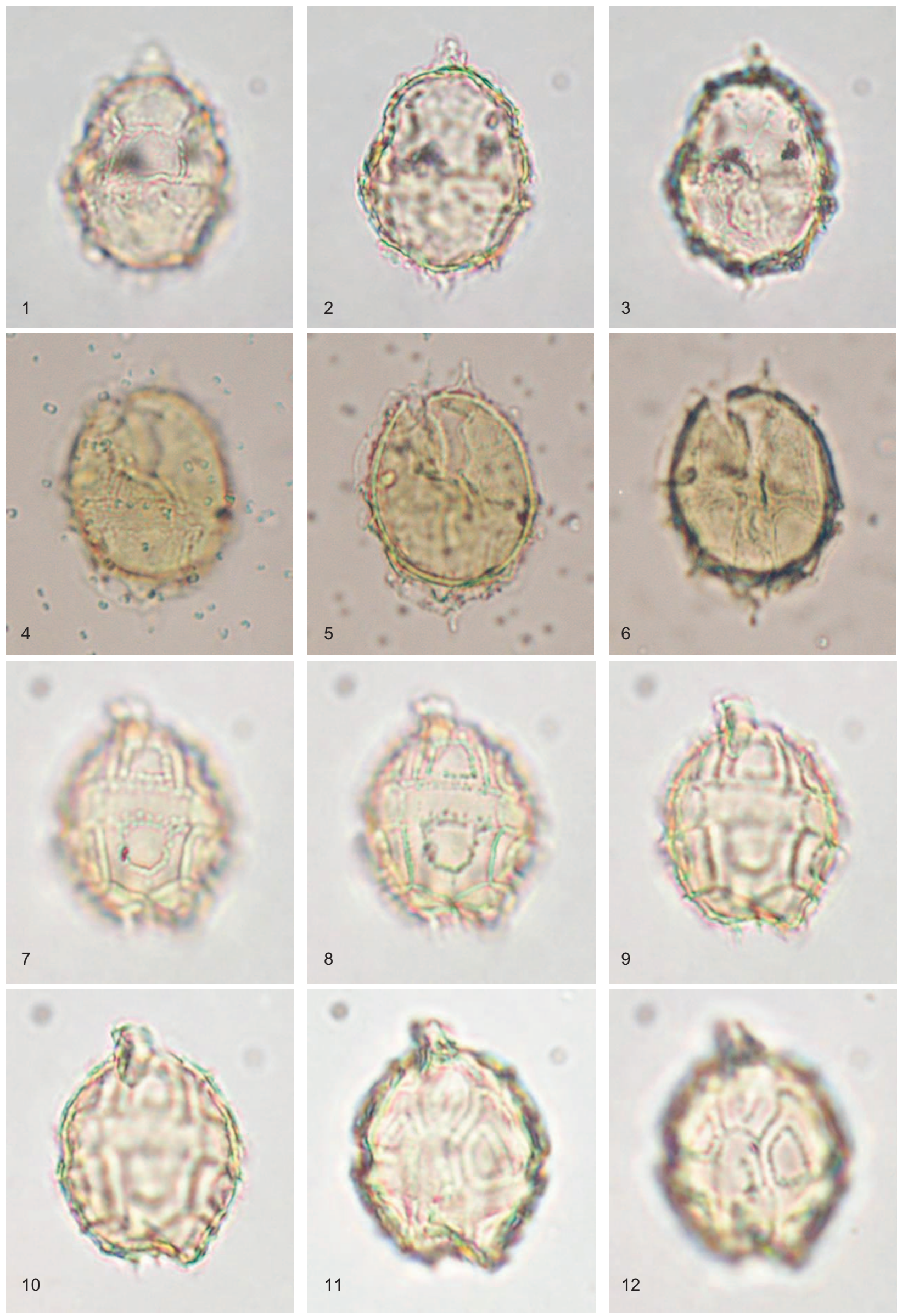


\section{Plate 22}

\section{Phthanoperidinium granulatum}

Figure 1-6 Sample 143/f108, slide L16358/SM4832; Burnside Formation, Tumai (Runangan); x 825; specimen measures $57 \times 41 \mu \mathrm{m}$

\section{Phthanoperidinium ?resistente}

Figure 7-9 Sample 143/f093, slide L16341/SM061; Burnside Formation, Puketeraki Core (Bortonian); x 975 ; specimen measures 48 x $35 \mu \mathrm{m}$

\section{Phthanoperidinium spumosum}

Figure 10-12 Sample 143/f093, slide L16341/SM078; Burnside Formation, Puketeraki Core (Bortonian); x 1050; specimen measures $45 \times 37 \mu \mathrm{m}$ 


\section{Plate 22}
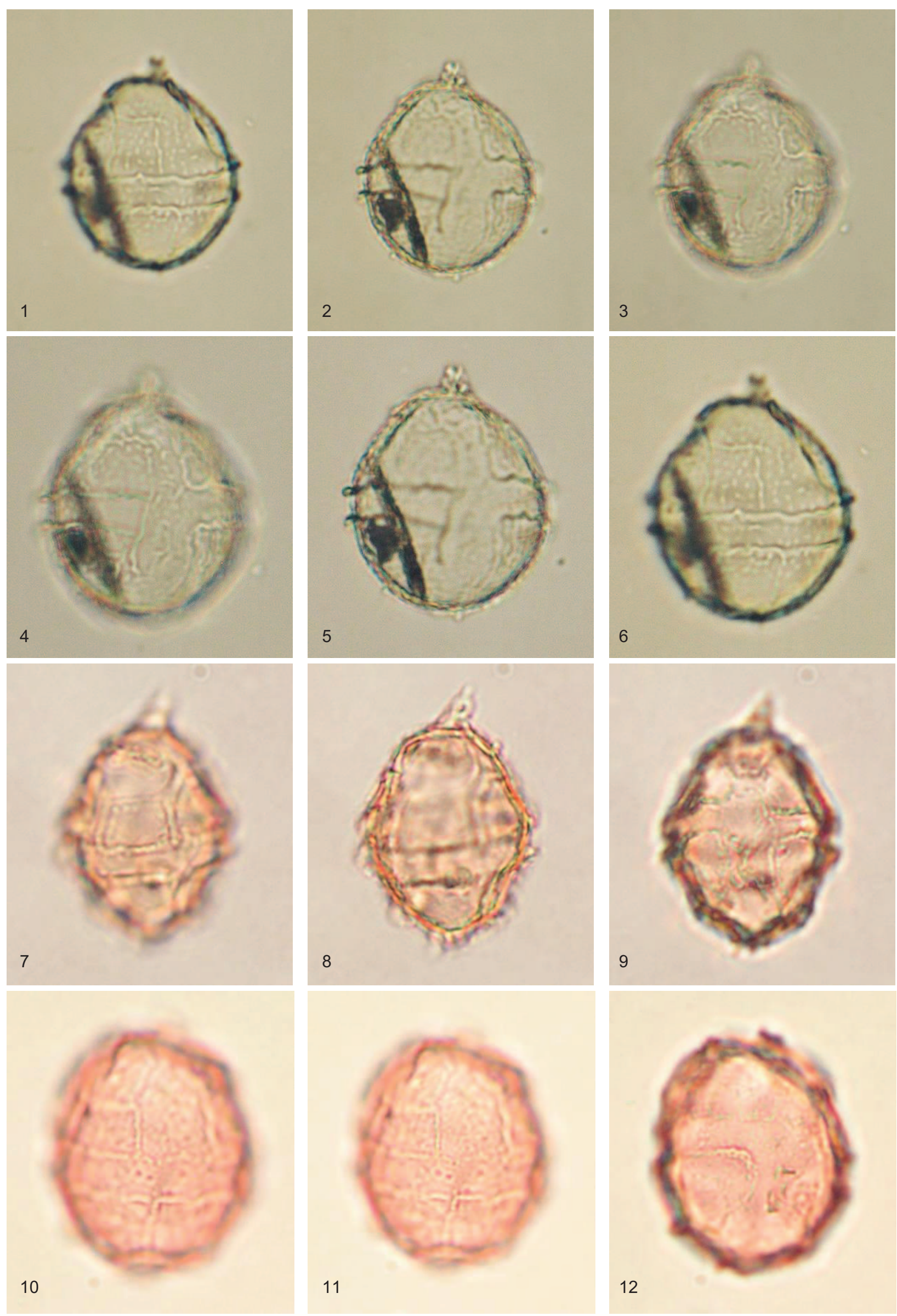


\section{Plate 23}

\section{Phthanoperidinium spumosum}

Figure 1-3 Sample 143/f093, slide L16341/SM078; Burnside Formation, Puketeraki Core (Bortonian); x 1050; specimen measures $45 \times 37 \mu \mathrm{m}$

\section{Phthanoperidinium aculeatum}

Figure 4-9 Sample 143/f093, slide L16341/SM082A; Burnside Formation, Puketeraki Core (Bortonian); x 900; specimen measures 52 × $42 \mu \mathrm{m}$

\section{Phthanoperidinium tenuimurum}

Figure 10-12 Sample S14/f8599, slide L10662/SM014; Waikato Coal Measures, Old Mountain Road (Runangan-early Whaingaroan); x 700; specimen measures 63 × $60 \mu \mathrm{m}$ 


\section{Plate 23}
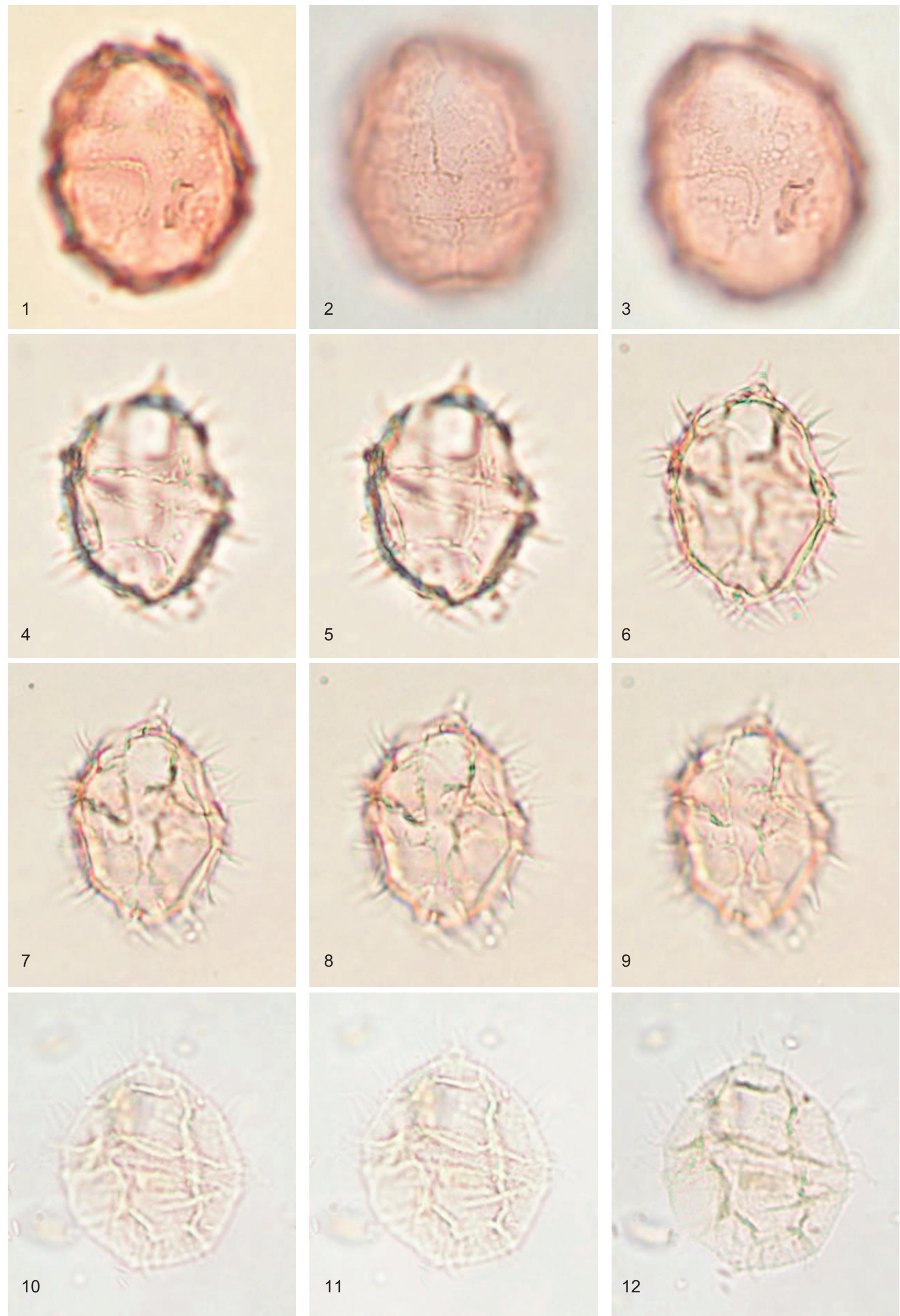


\section{Plate 24}

\section{Phthanoperidinium tritonium}

Figure 1-3 Sample 143/f093, slide L16341/SM103; Burnside Formation, Puketeraki Core (Bortonian); x 750; specimen measures $62 \times 45 \mu \mathrm{m}$

\section{Phthanoperidinium sp. 4}

Figure 4-6 Sample 143/f090, slide L16338/1-1273-187; Burnside Formation, Puketeraki Core (Bortonian); x 1050; specimen measures 45 x $33 \mu \mathrm{m}$

Figure 7-12 Sample 143/f090, slide L16338/SM002; Burnside Formation, Puketeraki Core (Bortonian); x 975; specimen measures $48 \times 35 \mu \mathrm{m}$ 


$$
\begin{array}{lll}
0 & 0 & 0 \\
0 & 0 & 0 \\
0 & 0 & 0 \\
0 & 0 & 0
\end{array}
$$




\section{Plate 25}

\section{Wetzeliella hampdenensis}

Figure 1-3 Sample J42/f055, slide L09212/6-1486-045; Hampden Formation, Hampden Beach Section (Bortonian); x 400; specimen measures 97 × $102 \mu \mathrm{m}$

\section{Charlesdowniea coleothrypta}

Figure 4-6 Sample U24/f418, slide L23126/SM002; Wanstead, Te Uri Stream (Porangan); x 425; specimen measures $105 \times 97 \mu \mathrm{m}$

\section{Dracodinium granulatum}

Figure 7-9 Sample 143/f094, slide L16342/1-1252-070; Burnside Formation, Puketeraki Core (Bortonian); x 450; specimen measures 87 x $95 \mu \mathrm{m}$

\section{Rhombodinium glabrum}

Figure 10-12 Sample 143/f093, slide L16341/SM131; Burnside Formation, Puketeraki Core (Bortonian); x 400; specimen measures $115 \times 108 \mu \mathrm{m}$ 


\section{Plate 25}
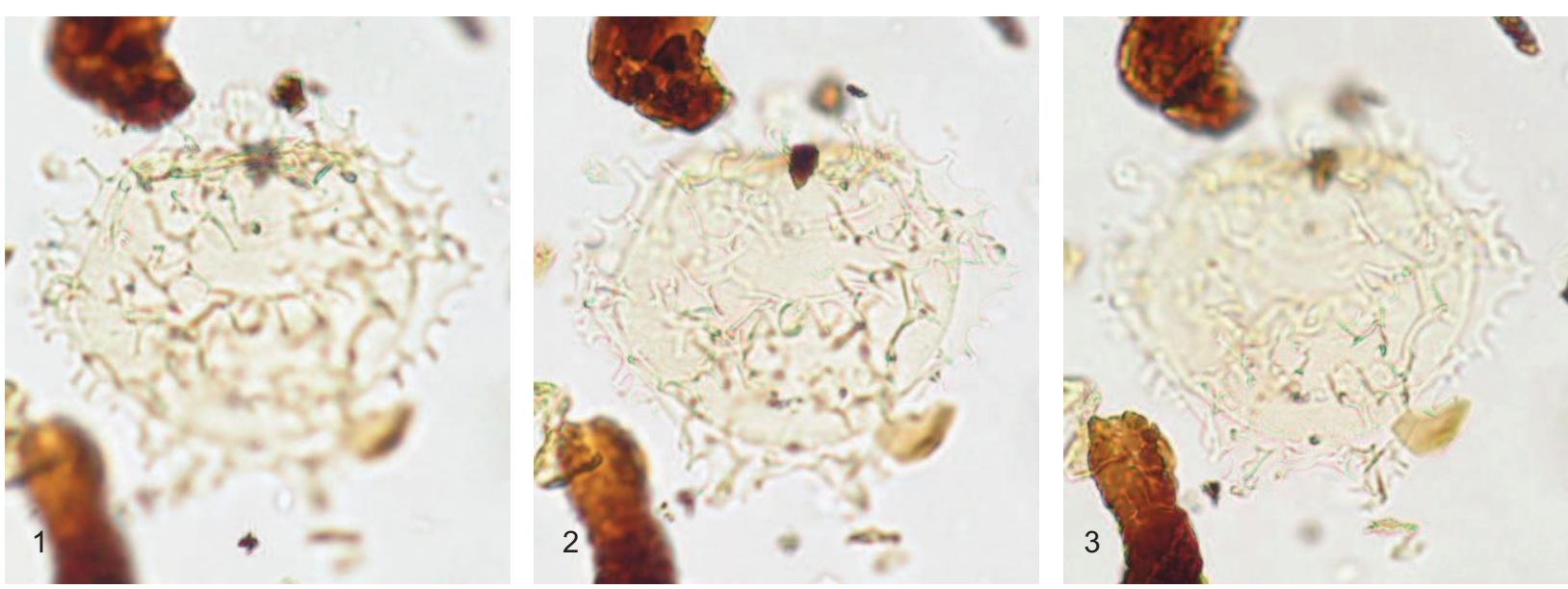

4
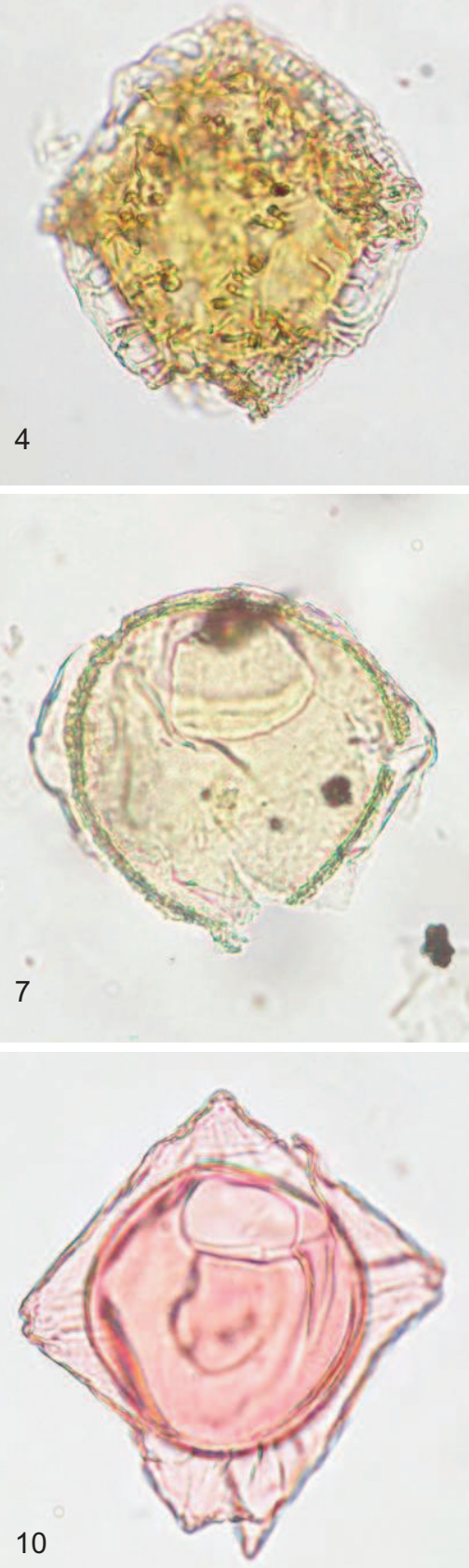

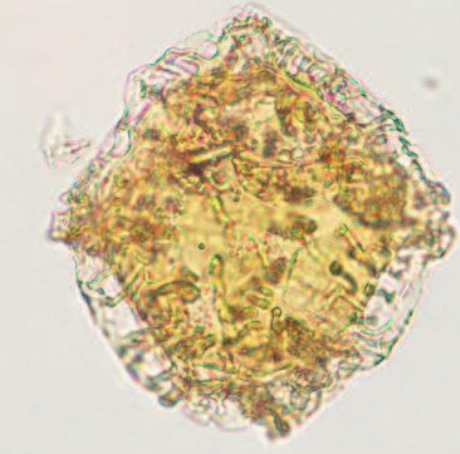

5
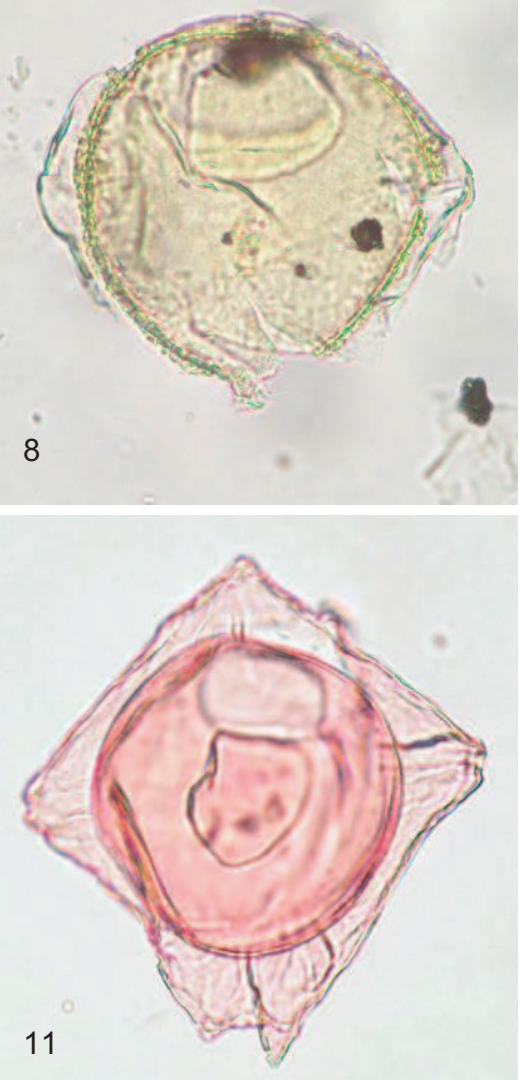
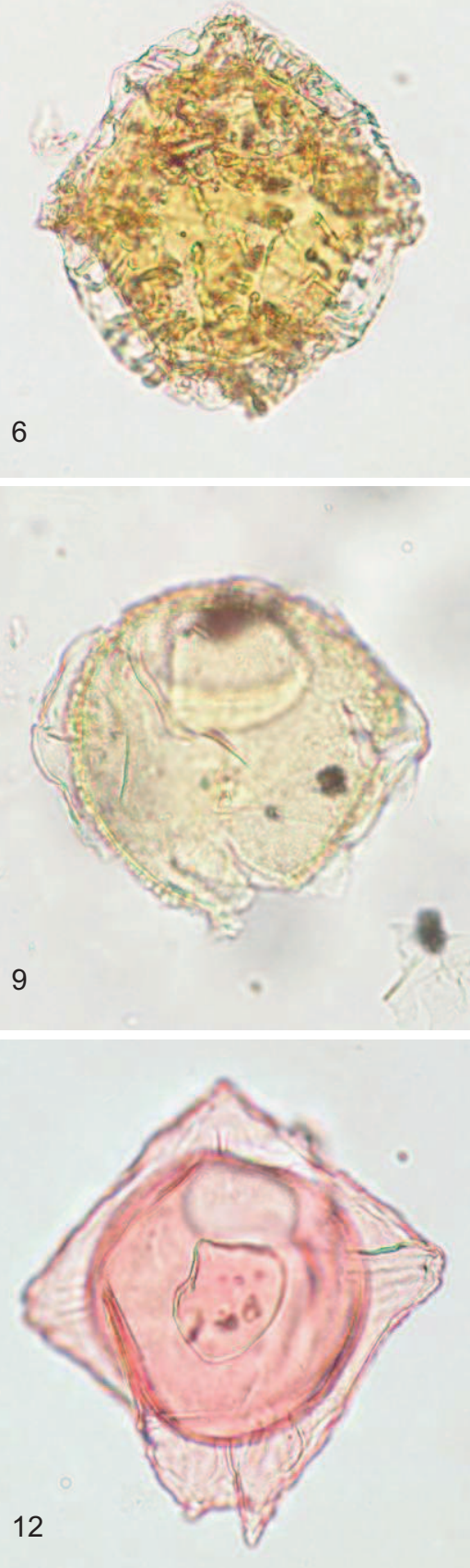


\section{Plate 26}

\section{Rhombodinium glabrum}

Figure 1-2 Sample 144/f080, slide L08947/SM027; Burnside Formation, Burnside Marl Pit (Bortonian); x 250; specimen measures $181 \times 146 \mu \mathrm{m}$

Figure 3 Sample 143/f090, slide L16338/SM018; Burnside Formation, Puketeraki Core (Bortonian); x 375; specimen measures $128 \times 115 \mu \mathrm{m}$

Wilsonidium cf. echinosuturatum

Figure 4-6 Sample J42/f303, slide L23133/SM003; Hampden Formation, Hampden Beach Section (Bortonian); x 450; specimen measures 94 × $92 \mu \mathrm{m}$

\section{Wilsonidium lineidentatum}

Figure 7-9 Sample J42/f055, slide L09212/6-1471-031; Hampden Formation, Hampden Beach Section (Bortonian); x 350; specimen measures 135 x $95 \mu \mathrm{m}$

\section{Lejeunecysta ?fallax}

Figure 10-12 Sample K29/f114, slide L11050/SM014; Port Elizabeth Member, Cape Foulwind Section (early Whaingaroan); x 600; specimen measures 72 x $69 \mu \mathrm{m}$ 


\section{Plate 26}
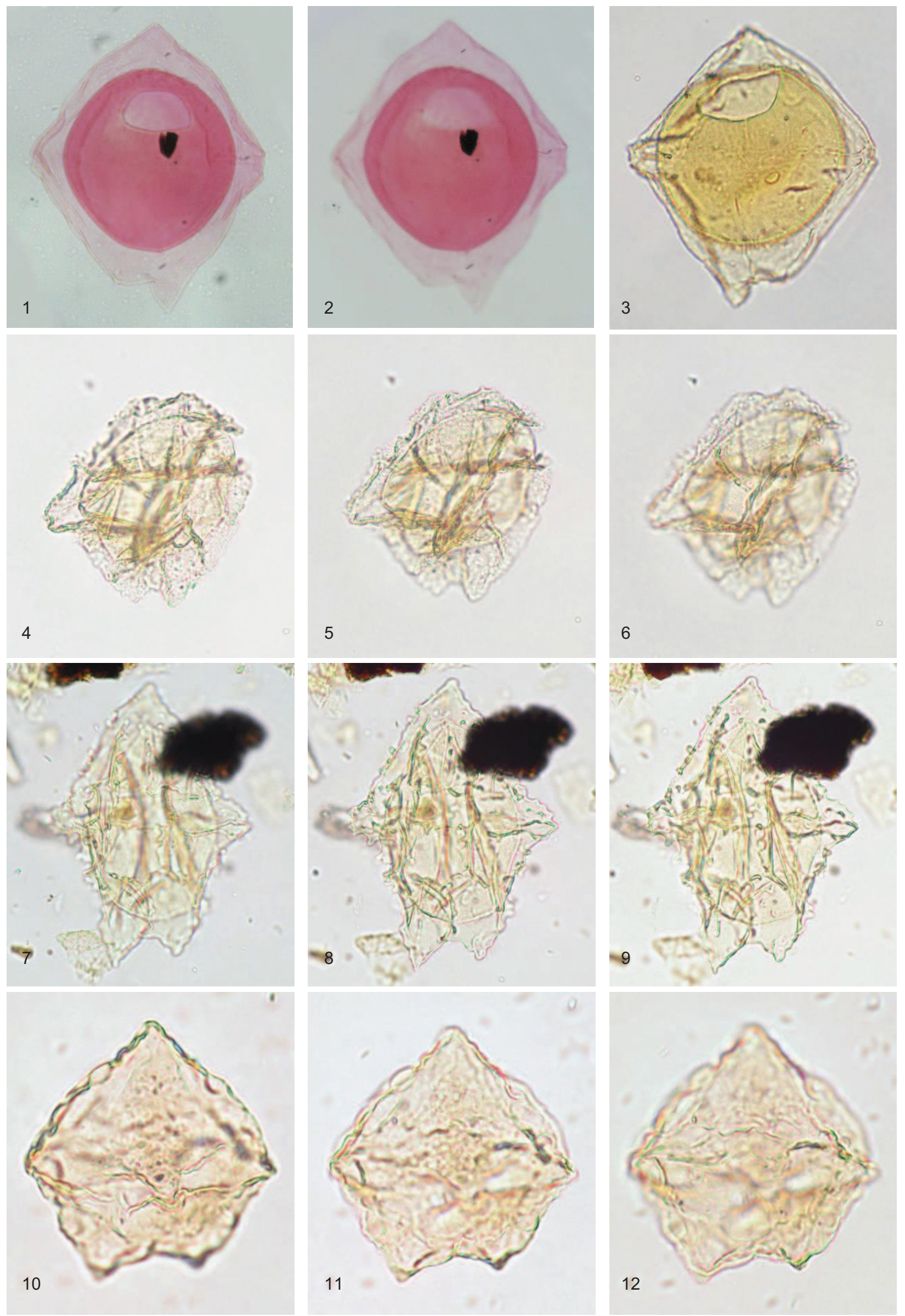


\section{Plate 27}

\section{Spiniferites ramosus}

Figure 1-3 Sample J42/f096, slide L10951/SM050; Totara Limestone, Kakanui River (early Whaingaroan); x 450; specimen measures $105 \times 92 \mu \mathrm{m}$

Figure 4-6 Sample J42/f489, slide L23124/SM010; Hampden Formation, Hampden Beach Section (Bortonian); x 425; specimen measures 100 x $97 \mu \mathrm{m}$

Spiniferites ramosus subsp. gracilis

Figure 7-8 Sample 143/f089, slide L16337/SM066B; Burnside Formation, Puketeraki Core (Bortonian); x 700; specimen measures 60 x $60 \mu \mathrm{m}$

Figure 9 Sample 143/f093, slide L16341/SM006; Burnside Formation, Puketeraki Core (Bortonian); x 775; specimen measures 53 x $55 \mu \mathrm{m}$

\section{Spiniferites aff. mirabilis}

Figure 10-12 Sample 143/f093, slide L16341/1-1269-068; Burnside Formation, Puketeraki Core (Bortonian); x 525; specimen measures 91 x $79 \mu \mathrm{m}$ 


\section{Plate 27}
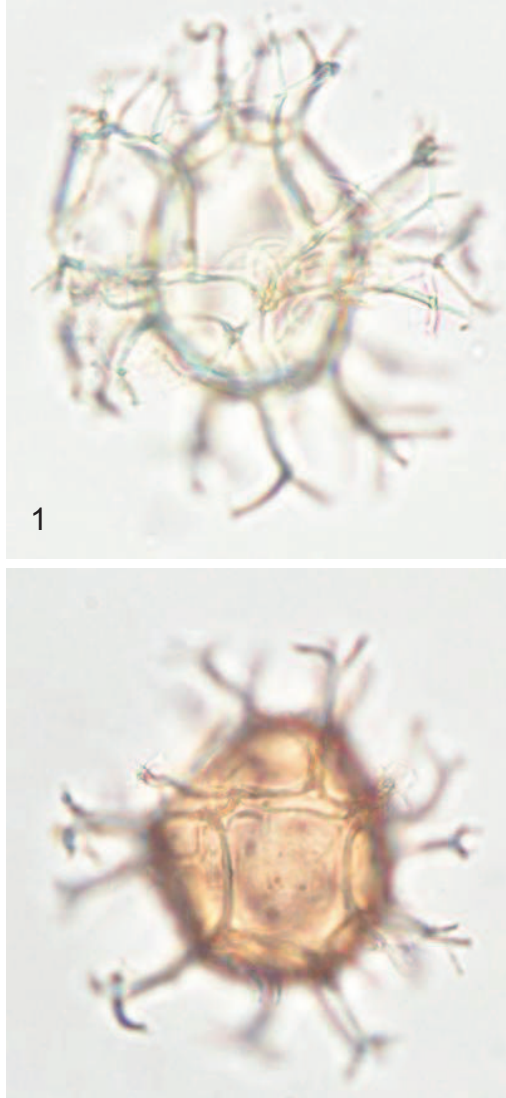

4
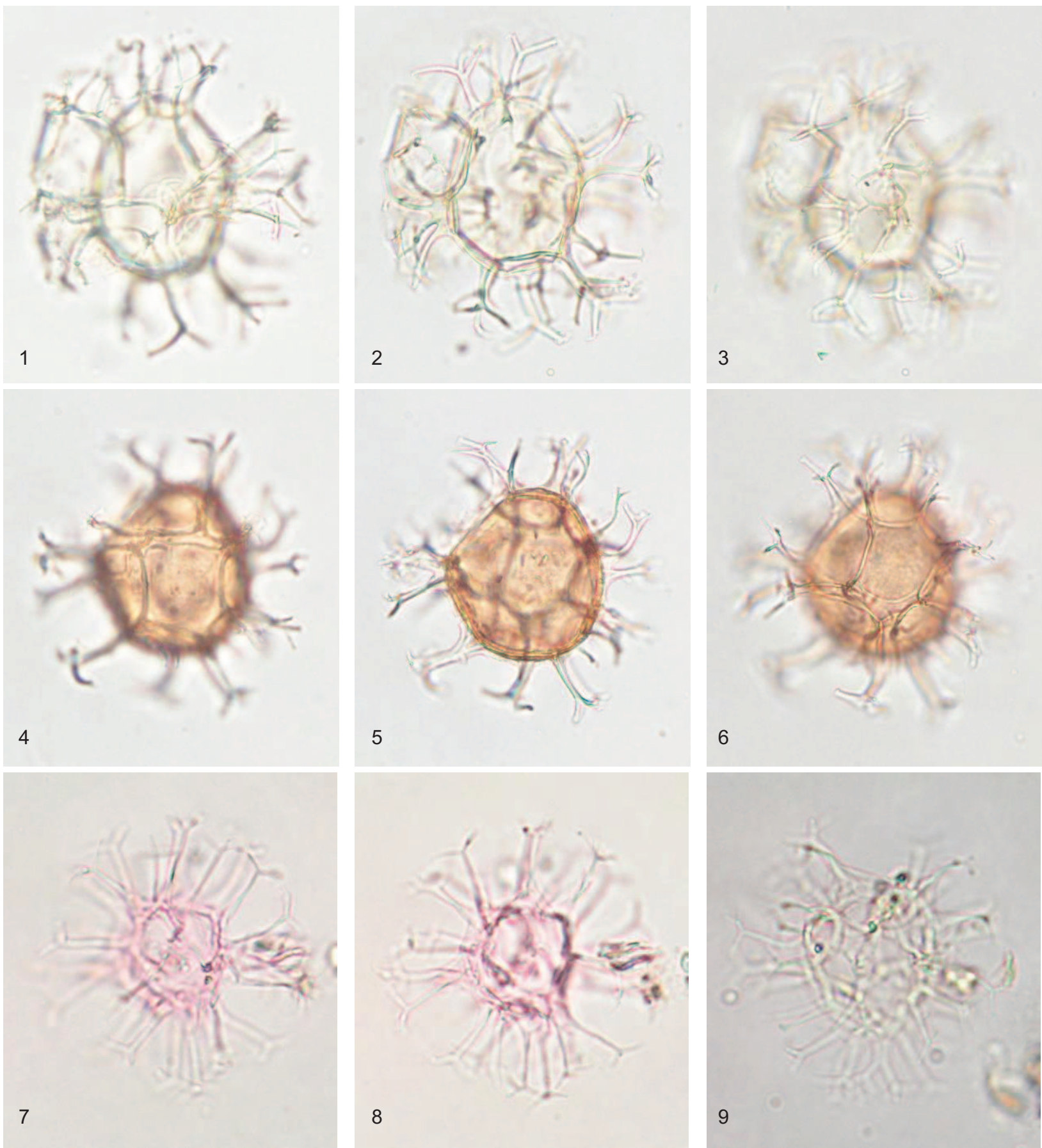

5

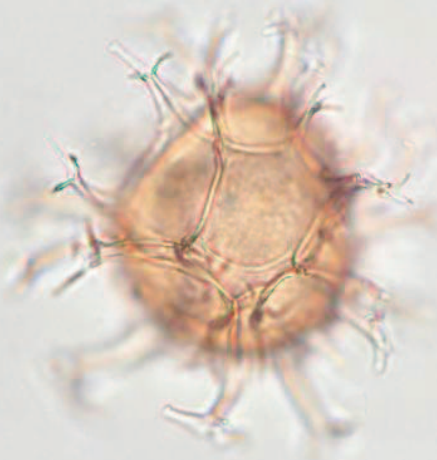

6

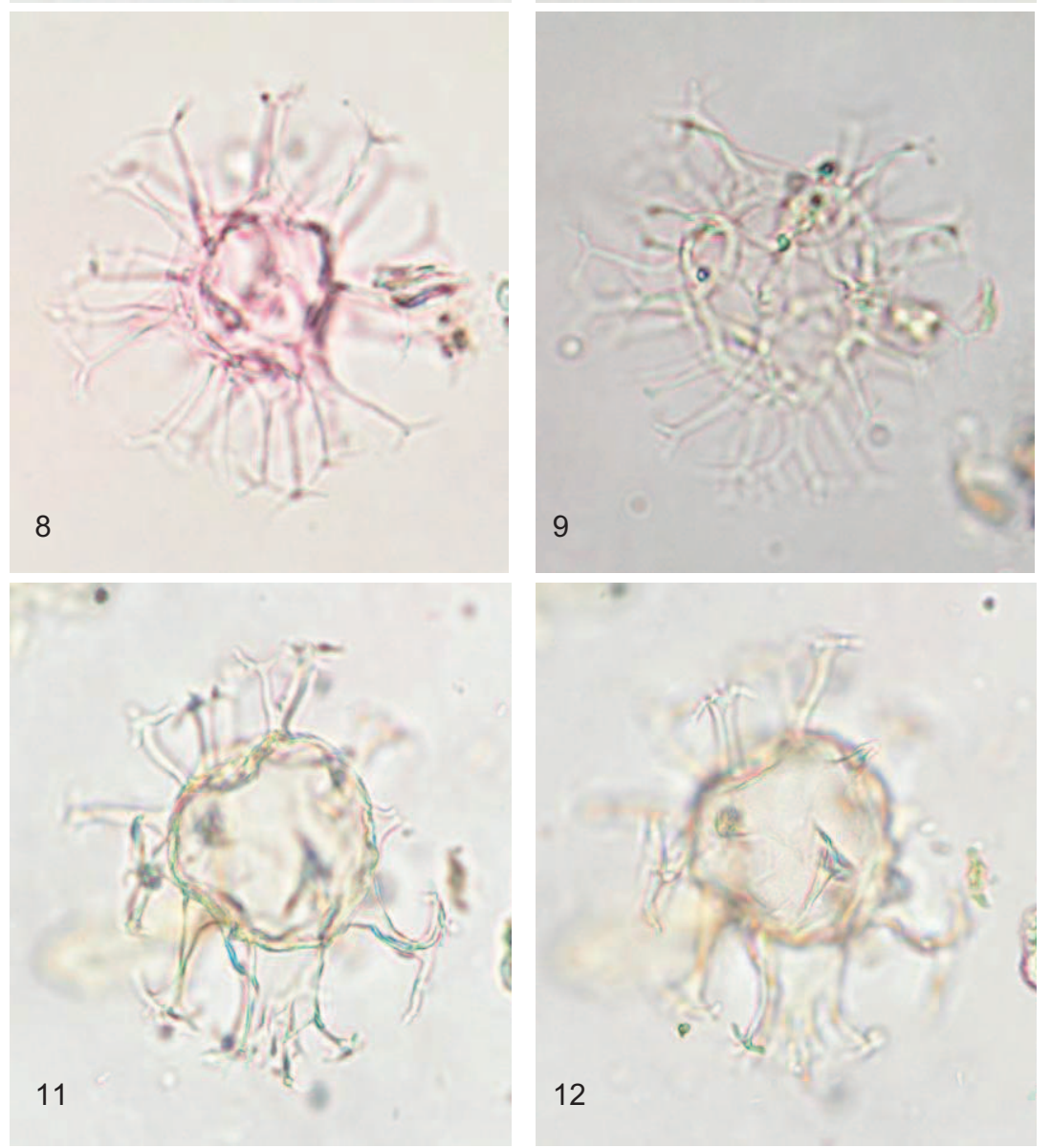




\section{Plate 28}

\section{Achomosphaera alcicornu}

Figure 1-6 Sample 143/f093, slide L16341/SM147; Burnside Formation, Puketeraki Core (Bortonian); x 500; specimen measures $95 \times 75 \mu \mathrm{m}$

\section{Hafniasphaera ?septata}

Figure 7-9 Sample U24/f419, slide L23127/SM082; Wanstead, Te Uri Stream (Porangan); x 675; specimen measures $70 \times 62 \mu \mathrm{m}$

\section{Hystrichostrogylon membraniphorum}

Figure 10-12 Sample 143/f093, slide L16341/SM053; Burnside Formation, Puketeraki Core (Bortonian); x 525; specimen measures 80 × $80 \mu \mathrm{m}$ 


\section{Plate 28}
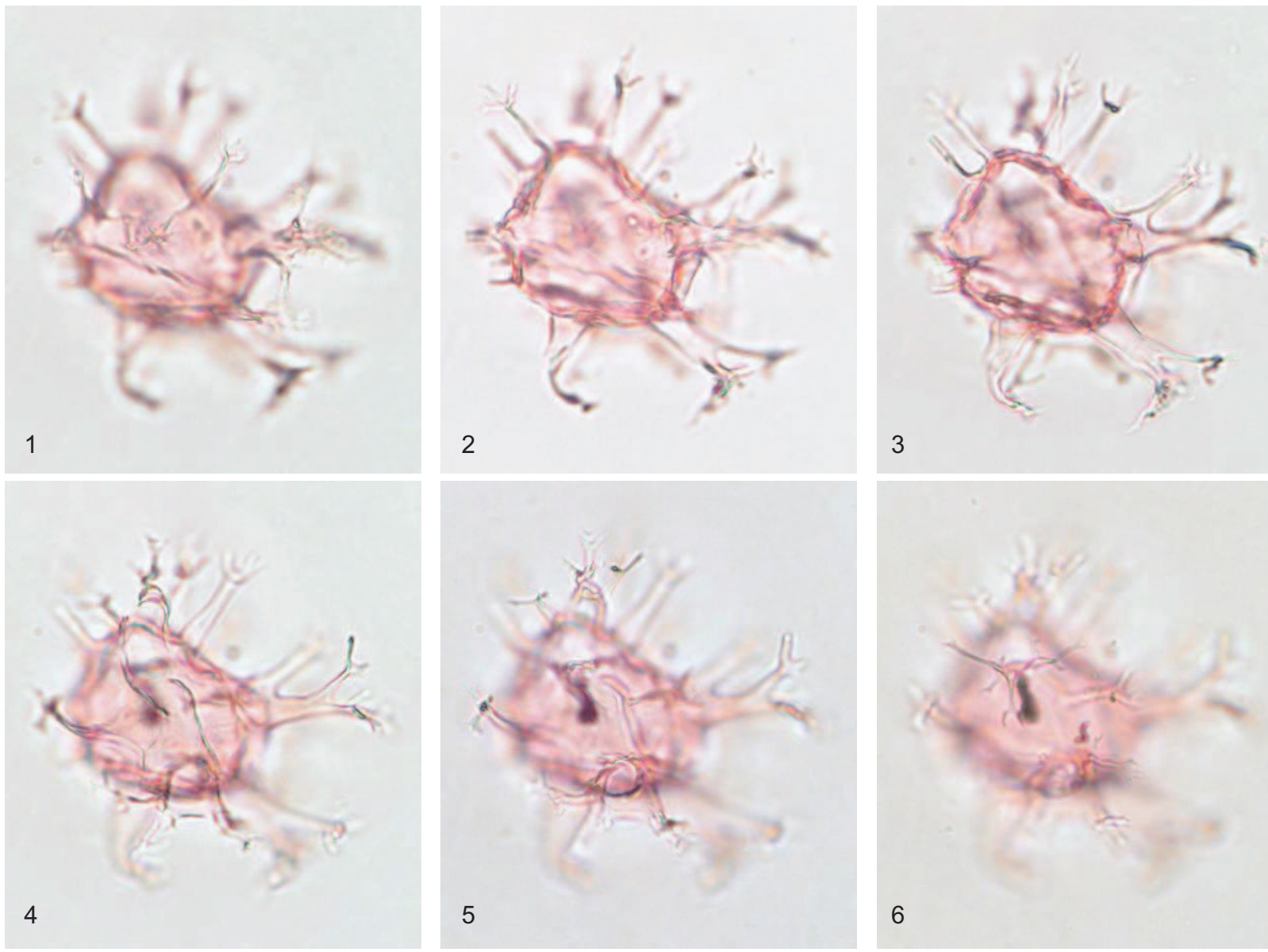

3
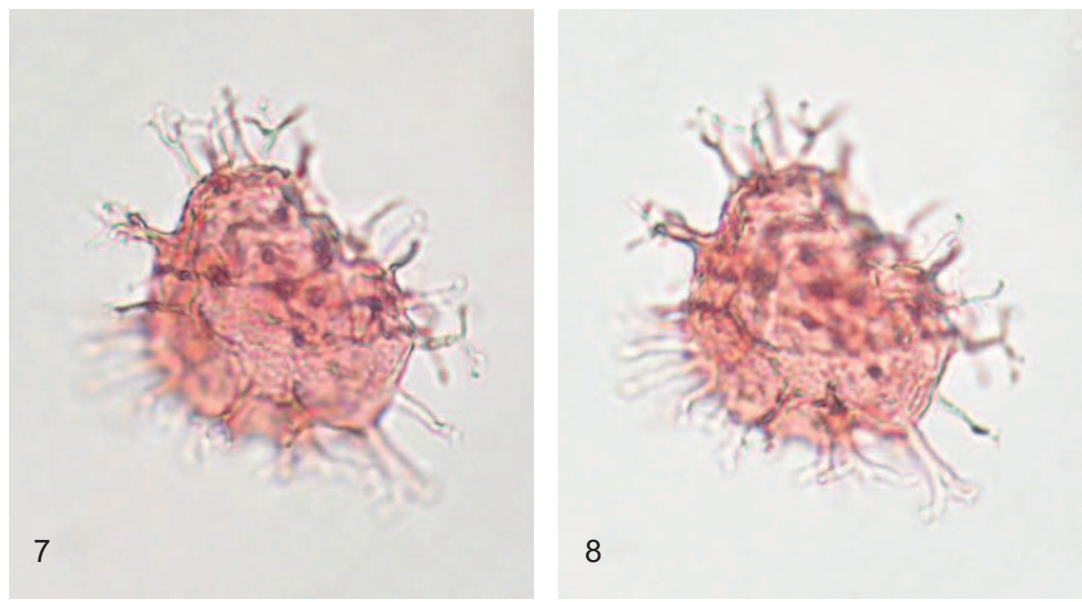

6
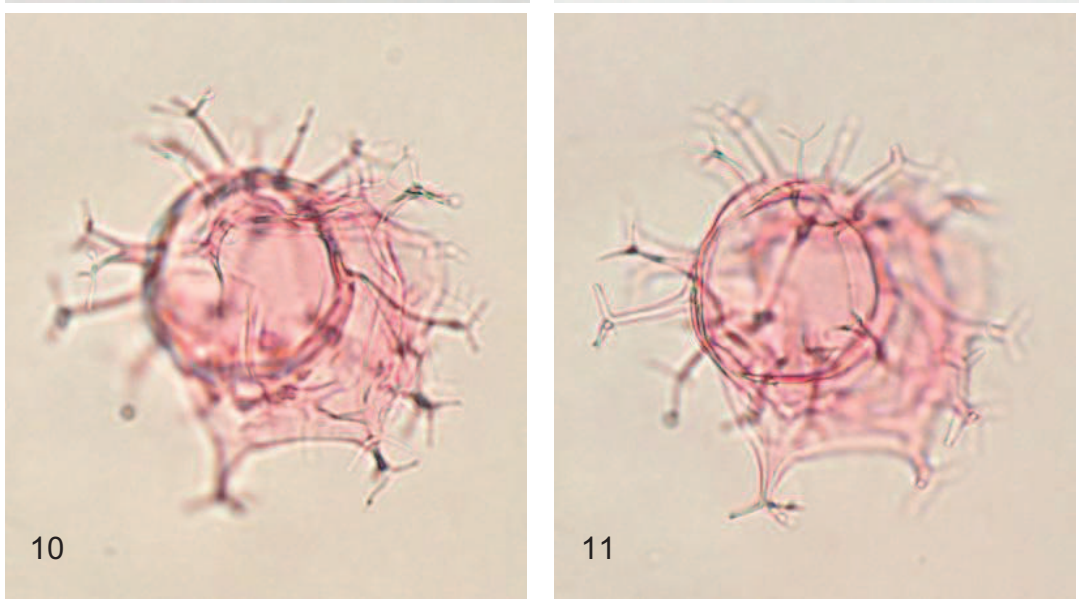

9
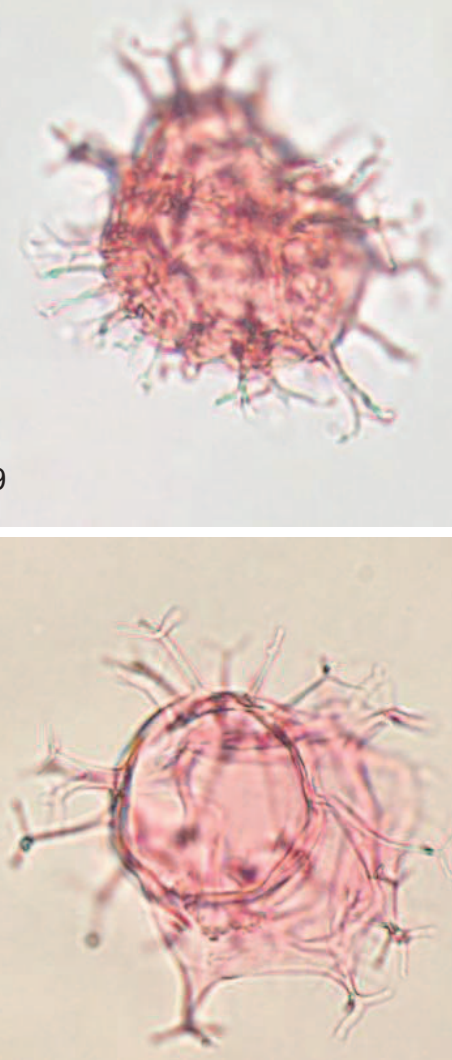

12 


\section{Plate 29}

\section{Nematosphaeropsis balcombiana}

Figure 1-3 Sample J42/f096, slide L10951/SM044; Totara Limestone, Kakanui River (early Whaingaroan); specimen measures $39 \times 40 \mu \mathrm{m}$

Figure 4-6 Sample J42/f096, slide L10951/SM047; Totara Limestone, Kakanui River (early Whaingaroan); x 925; specimen measures 47 x $45 \mu \mathrm{m}$

\section{Rottnestia borussica}

Figure 7-12 Sample 143/f093, slide L16341/SM115; Burnside Formation, Puketeraki Core (Bortonian); x 525; specimen measures 90 x $54 \mu \mathrm{m}$ 


\section{Plate 29}
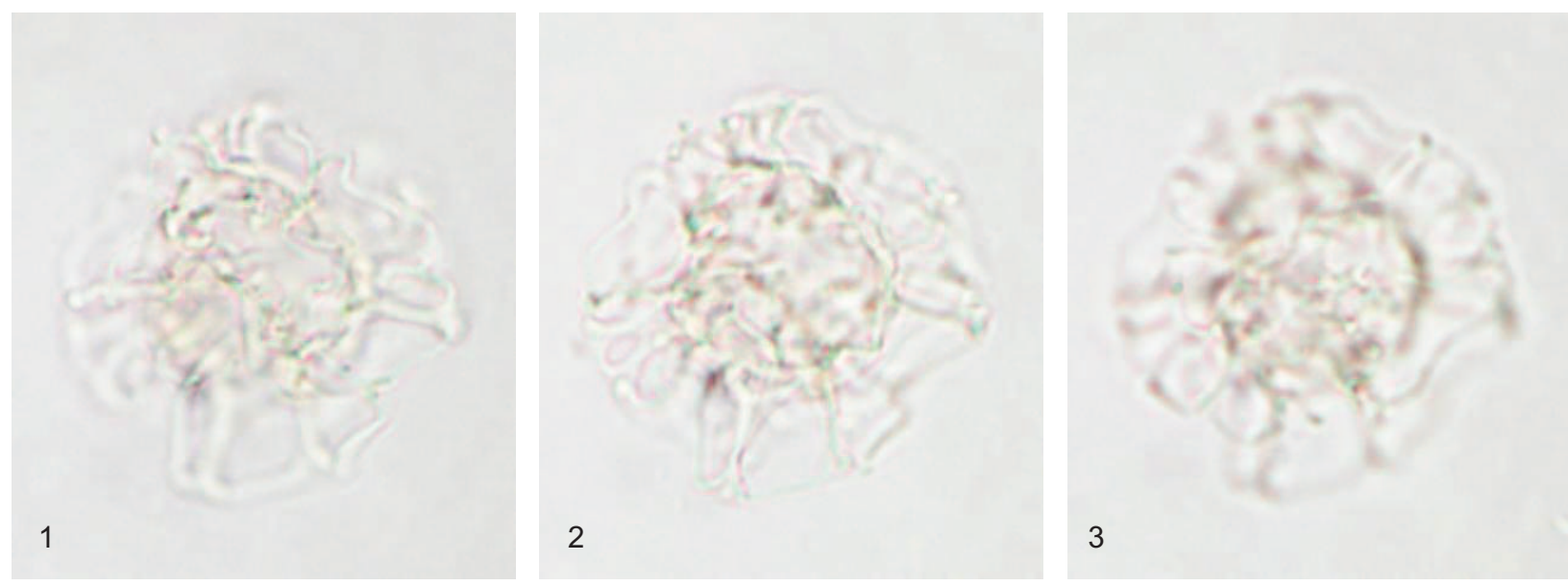

4

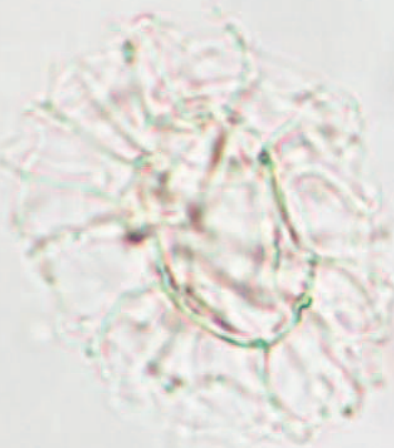

5

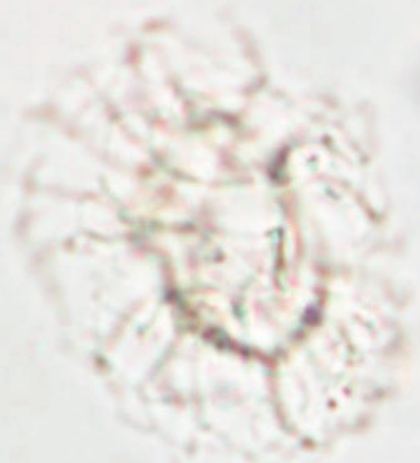

6

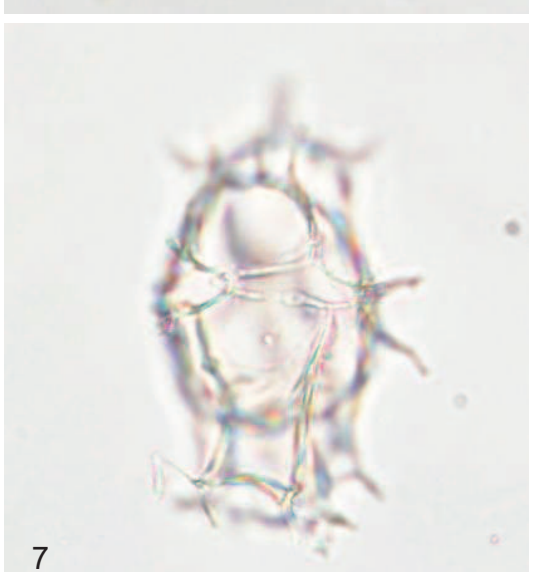

8
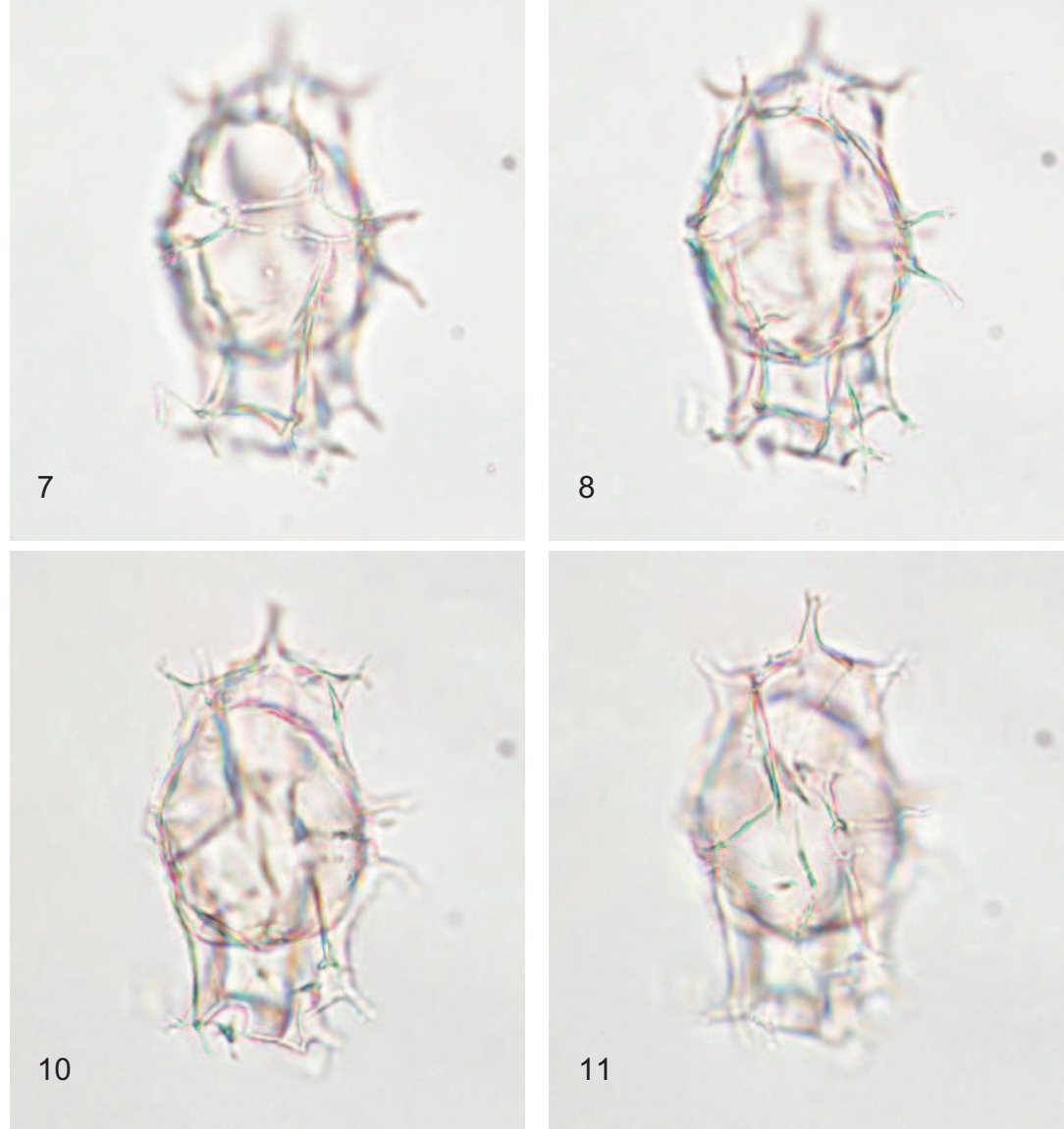

9

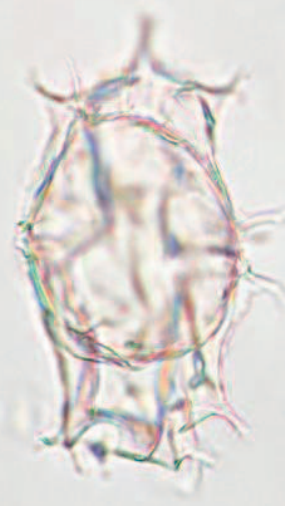

12 


\section{Plate 30}

\section{?Cannosphaeropsis sp. 1}

Figure 1-3 Sample 143/f093, slide L16341/SM015; Burnside Formation, Puketeraki Core (Bortonian); x 800; specimen measures 59 x $53 \mu \mathrm{m}$

\section{Corrudinium incompositum}

Figure 4-6 Sample K29/f116, slide L11052/SM4890; Port Elizabeth Member, Cape Foulwind Section (early Whaingaroan); x 925; specimen measures $51 \times 42 \mu \mathrm{m}$

\section{Corrudinium bujakii}

Figure 7-9 Sample 143/f090, slide L16338/SM053; Burnside Formation, Puketeraki Core (Bortonian); specimen measures $32 \times 33 \mu \mathrm{m}$

\section{Corrudinium eyrense}

Figure 10-12 Sample L34/f7538, slide L06997/SM2572; View Hill Volcanics, Upper Eyre River (Mangaorapan); x 800; specimen measures 53 x $53 \mu \mathrm{m}$ 


\section{Plate 30}
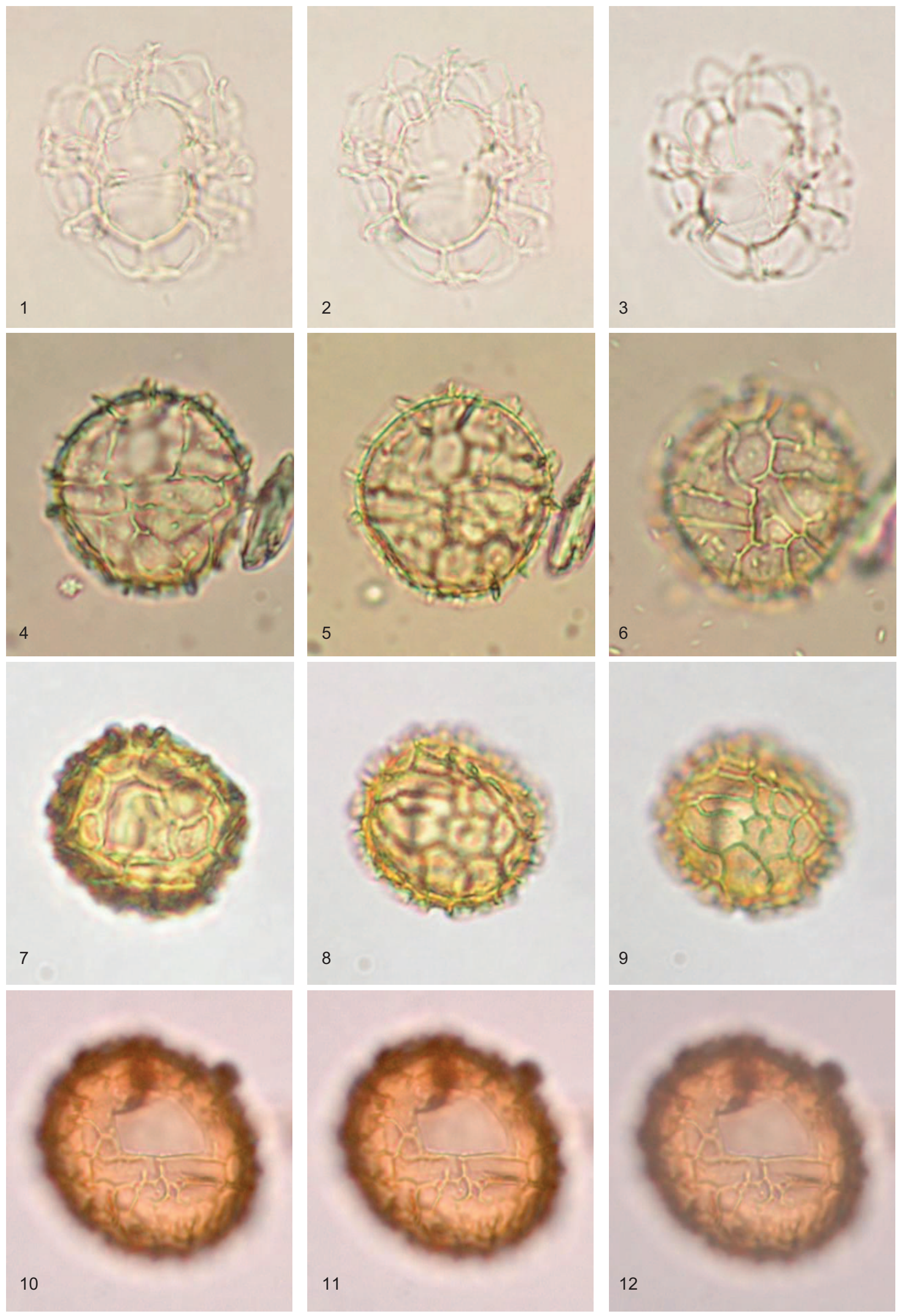


\section{Plate 31}

\section{Corrudinium eyrense}

Figure 1-3 Sample L34/f7538, slide L06997/SM2572; View Hill Volcanics, Upper Eyre River (Mangaorapan); x 800; specimen measures $53 \times 53 \mu \mathrm{m}$

\section{Corrudinium obscurum}

Figure 5-6, Sample J42/f299, slide L23129/SM010; Hampden Formation, Hampden Beach Section 8-9 (Porangan); x 775; specimen measures 55 x $55 \mu \mathrm{m}$

\section{Corrudinium otagoense}

Figure 4, 7, Sample 143/f089, slide L16337/SM117; Burnside Formation, Puketeraki Core (Bortonian); 10 x 800; specimen measures 52 x $53 \mu \mathrm{m}$

Figure 11-12 Sample U24/f419, slide L23127/SM012; Wanstead, Te Uri Stream (Porangan); x 775; specimen measures $56 \times 55 \mu \mathrm{m}$ 


\section{Plate 31}
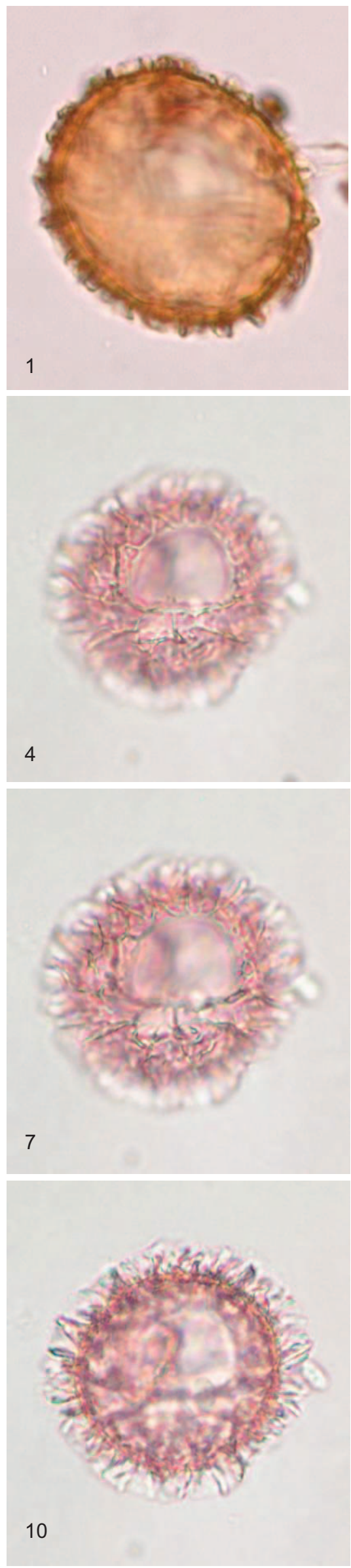
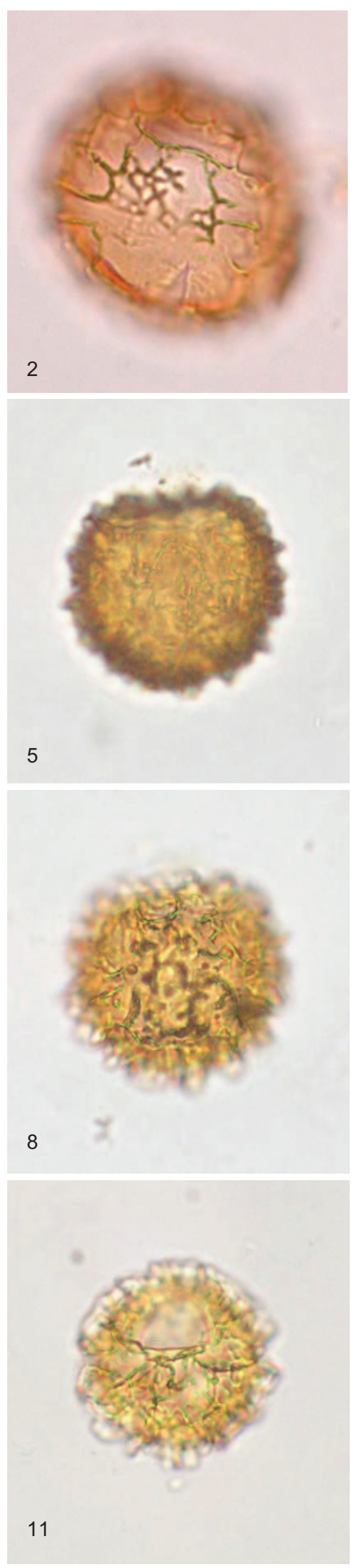
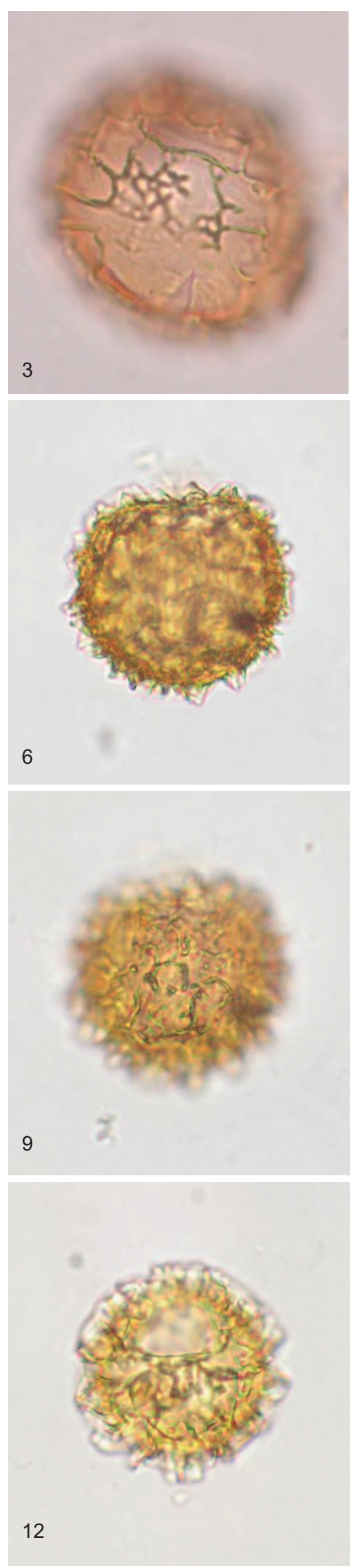


\section{Plate 32}

\section{Corrudinium otagoense}

Figure 1-3 Sample U24/f419, slide L23127/SM012; Wanstead, Te Uri Stream (Porangan); x 775; specimen measures $56 \times 55 \mu \mathrm{m}$

\section{Corrudinium regulare}

Figure 4-6 Sample 144/f080, slide L08947/SM4886; Burnside Formation, Burnside Marl Pit (Bortonian) Figure 7 Sample 144/f080, slide L08947/SM4885; Burnside Formation, Burnside Marl Pit (Bortonian); x 825; specimen measures 51 x $51 \mu \mathrm{m}$

Figure 8-9 Sample 144/f080, slide L08947/SM4887; Burnside Formation, Burnside Marl Pit (Bortonian) Impagidinium dispertitum

Figure 10-12 Sample U24/f417, slide L23125/SM022; Wanstead, Te Uri Stream (Porangan); specimen measures $38 \times 36 \mu \mathrm{m}$ 


\section{Plate 32}
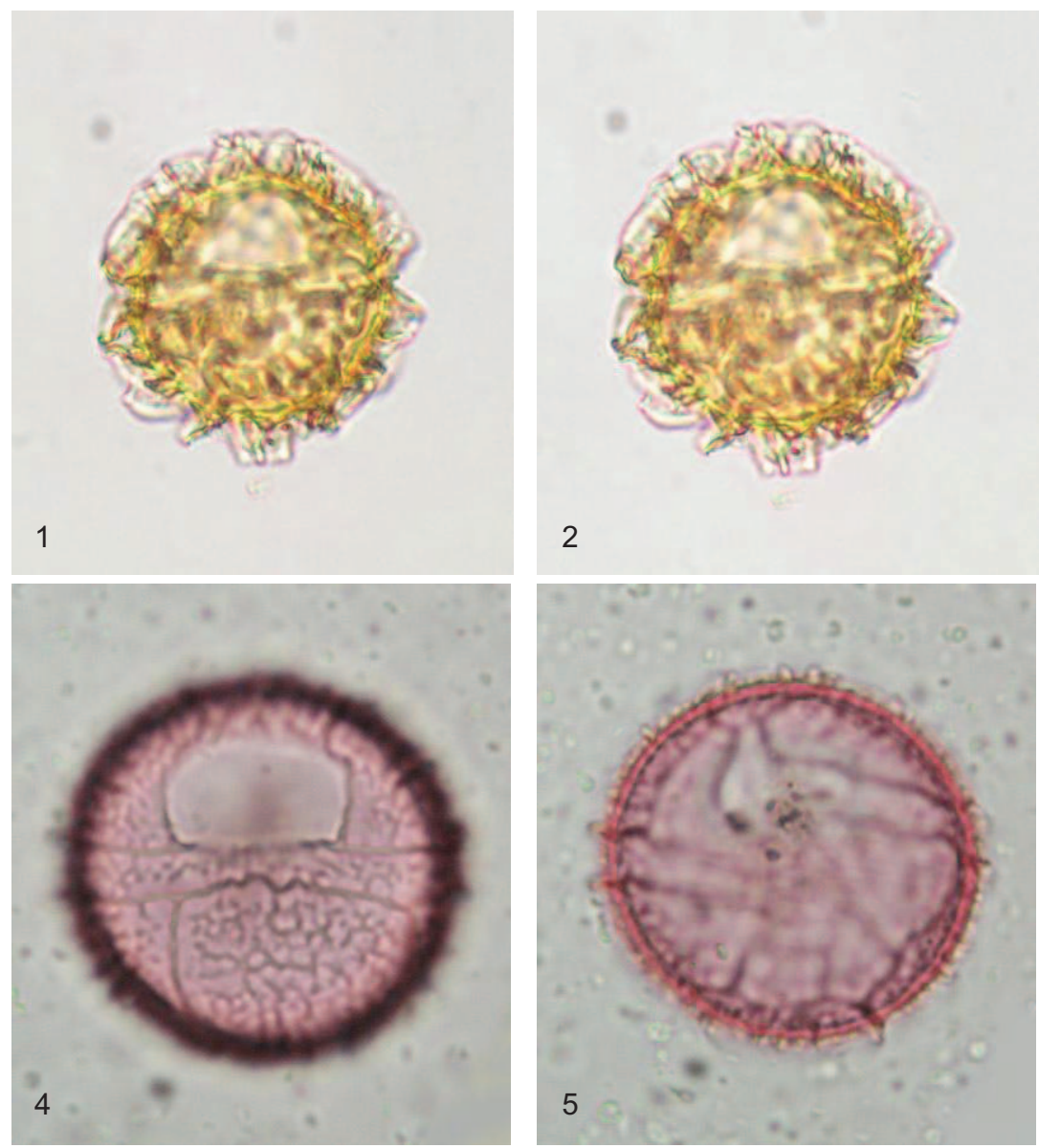

3
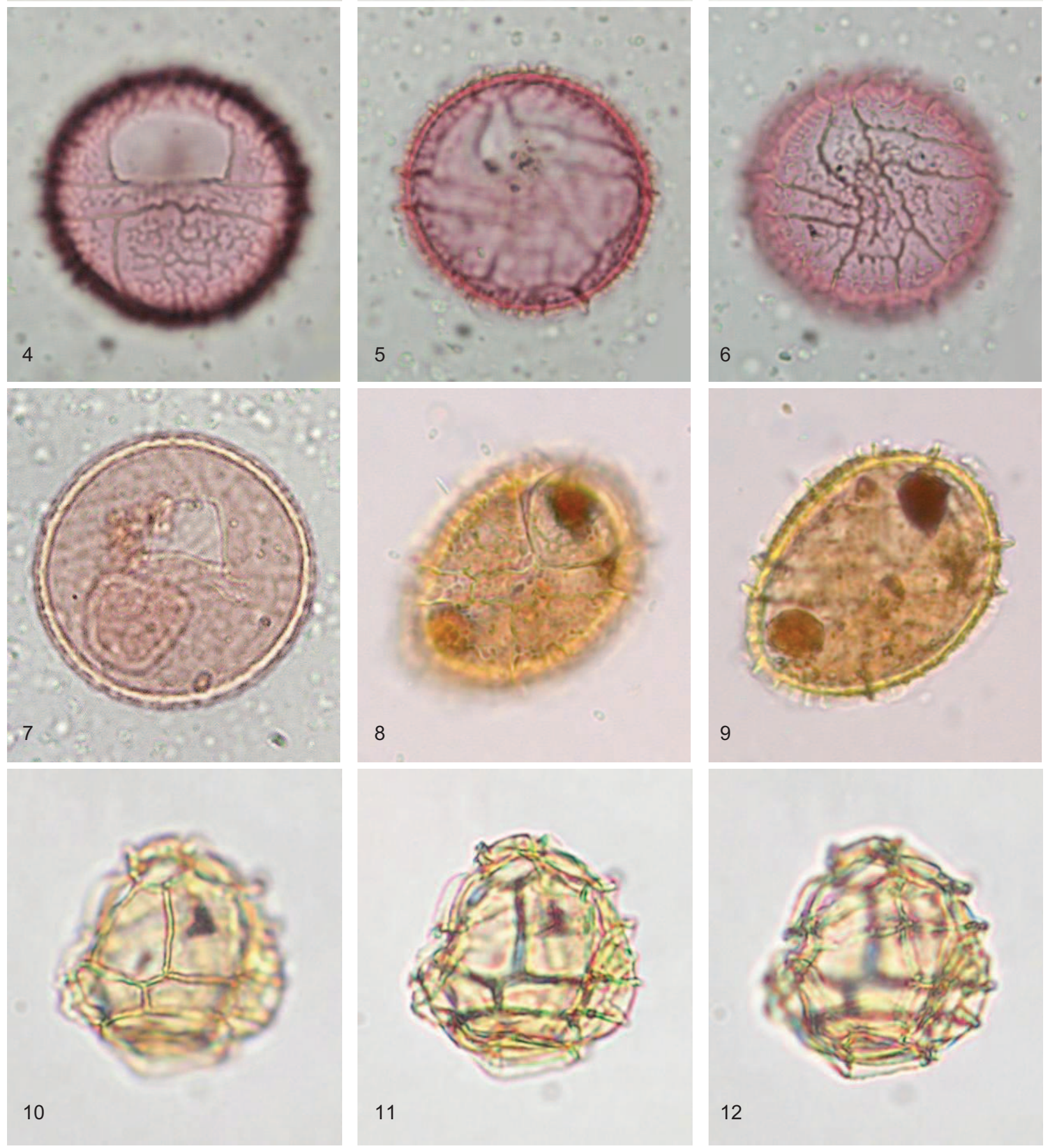


\section{Plate 33}

\section{Impagidinium victorianum}

Figure 1-3 Sample J42/f096, slide L10951/SM2955; Totara Limestone, Kakanui River (early Whaingaroan); x 550; specimen measures 82 × $78 \mu \mathrm{m}$

Figure 4-6 Sample J42/f096, slide L10951/SM2956; Totara Limestone, Kakanui River (early Whaingaroan); x 575; specimen measures 82 × $72 \mu \mathrm{m}$

Figure 7-9 Sample J42/f096, slide L10951/SM110; Totara Limestone, Kakanui River (early Whaingaroan); x 625; specimen measures 70 x $68 \mu \mathrm{m}$

\section{Impagidinium aculeatum}

Figure 10-12 Sample 143/f089, slide L16337/SM051; Burnside Formation, Puketeraki Core (Bortonian); x 850; specimen measures 43 x $49 \mu \mathrm{m}$ 


\section{Plate 33}
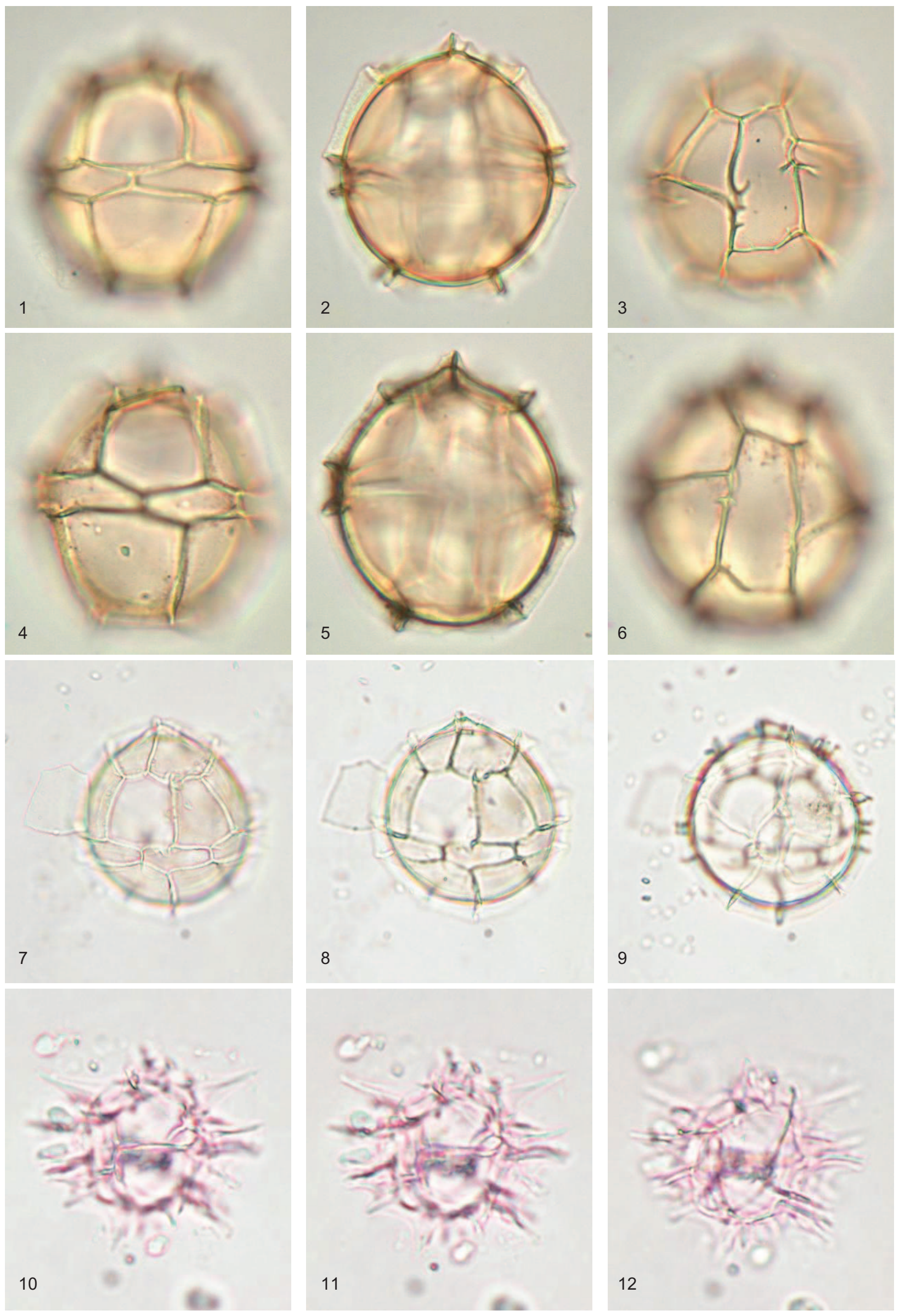


\section{Plate 34}

\section{Impagidinium aculeatum}

Figure 1-3 Sample 143/f092, slide L16340/1-1340-100; Burnside Formation, Puketeraki Core (Bortonian); x 900; specimen measures 51 x $47 \mu \mathrm{m}$

\section{Impagidinium elegans}

Figure 4-6 Sample J42/f125, slide L11625/SM014; Totara Limestone, Kakanui River (Runangan-early Whaingaroan); x 375; specimen measures 117 × $112 \mu \mathrm{m}$

Figure 7-9 Sample 143/f093, slide L16341/SM020; Burnside Formation, Puketeraki Core (Bortonian); x 425; specimen measures 101 x $100 \mu \mathrm{m}$

Figure 10-12 Sample 143/f093, slide L16341/SM093; Burnside Formation, Puketeraki Core (Bortonian); x 450; specimen measures 85 x $95 \mu \mathrm{m}$ 


\section{Plate 34}
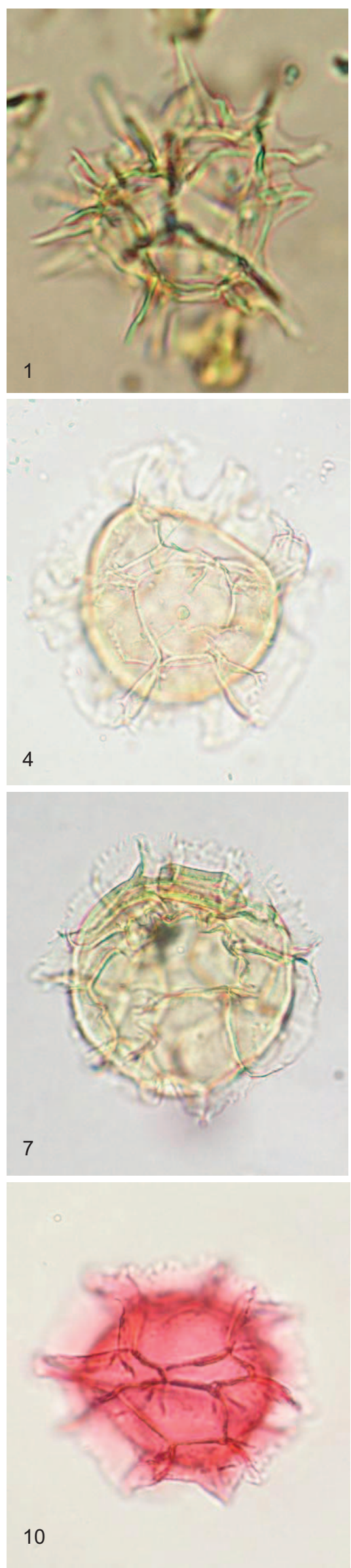
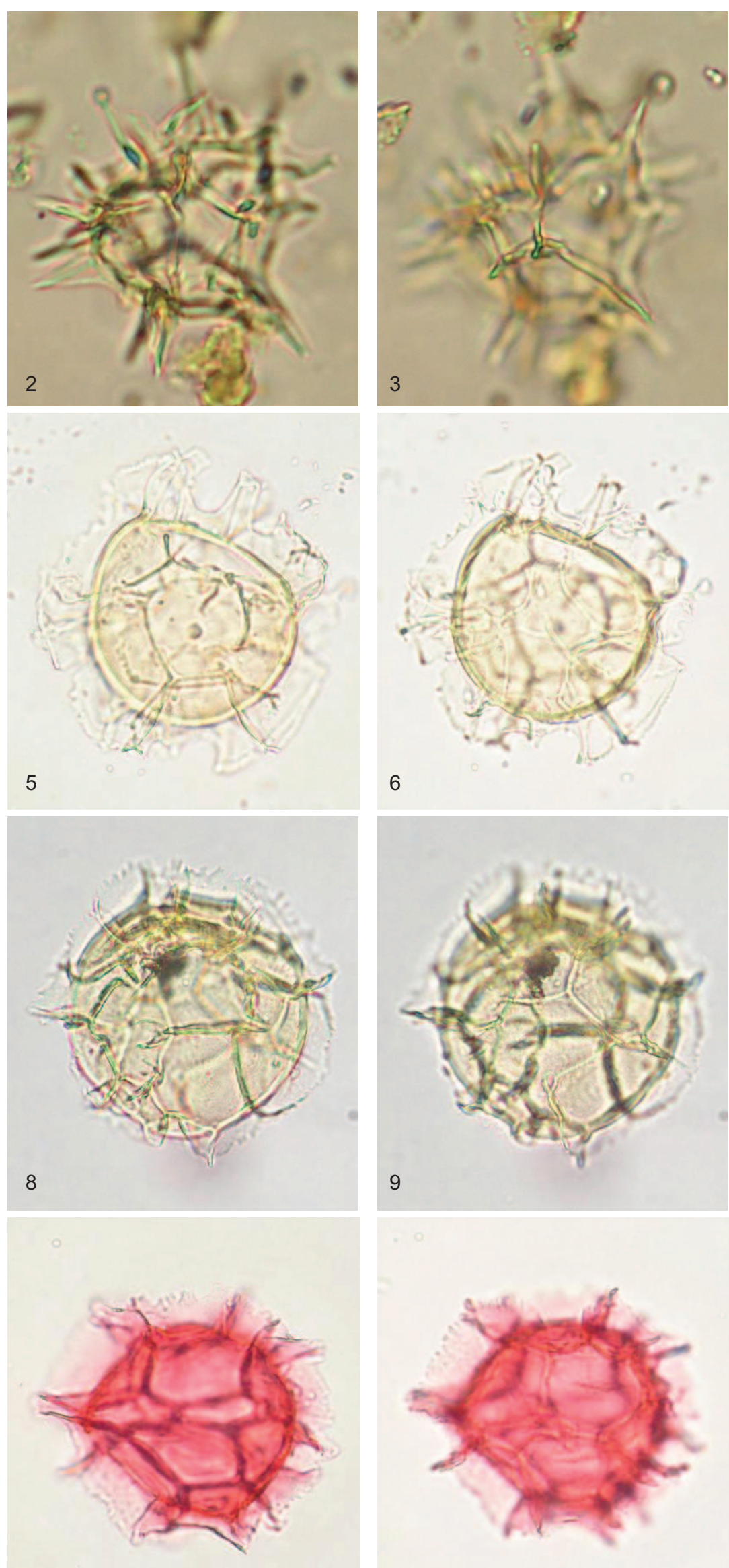

11
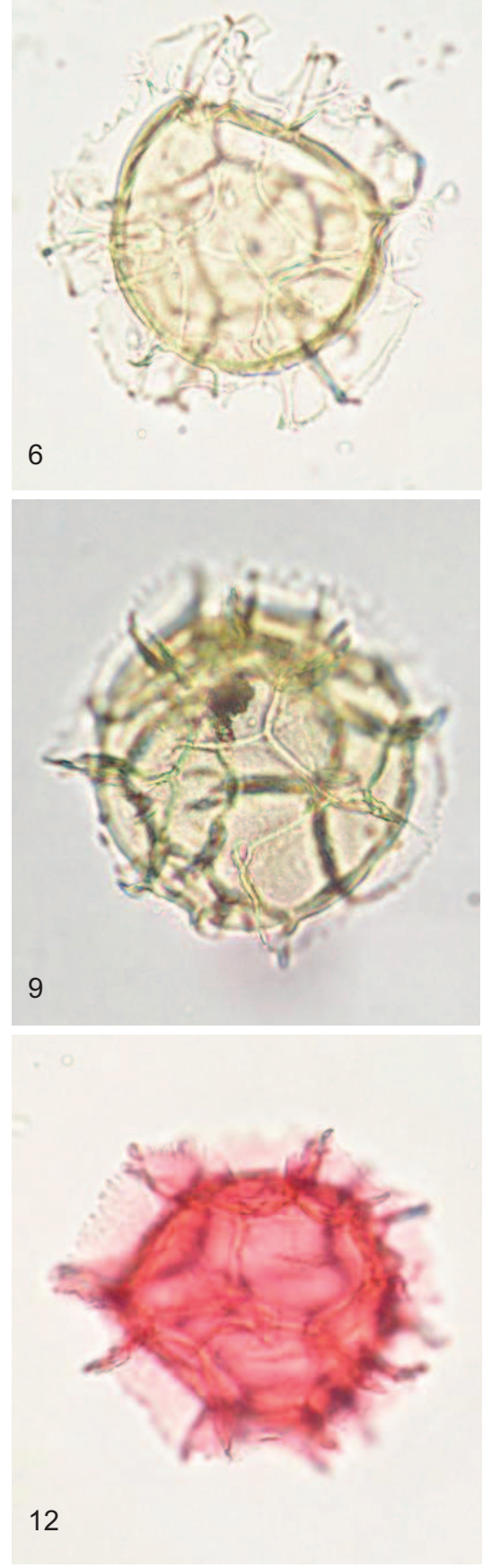


\section{Plate 35}

\section{Impagidinium elegans}

Figure 1-3 Sample 143/f096, slide L16344/SM027; Burnside Formation, Puketeraki Core (Kaiatan); x 400; specimen measures $113 \times 105 \mu \mathrm{m}$

\section{Impagidinium maculatum}

Figure 4-9 Sample J42/f485, slide L23120/SM038; ?Hampden Formation, Hampden Beach Section (Porangan-Bortonian); x 1000; specimen measures 45 x $42 \mu \mathrm{m}$

Figure 10-12 Sample U24/f419, slide L23127/SM068; Wanstead, Te Uri Stream (Porangan); x 1050; specimen measures $45 \times 37 \mu \mathrm{m}$ 


\section{Plate 35}
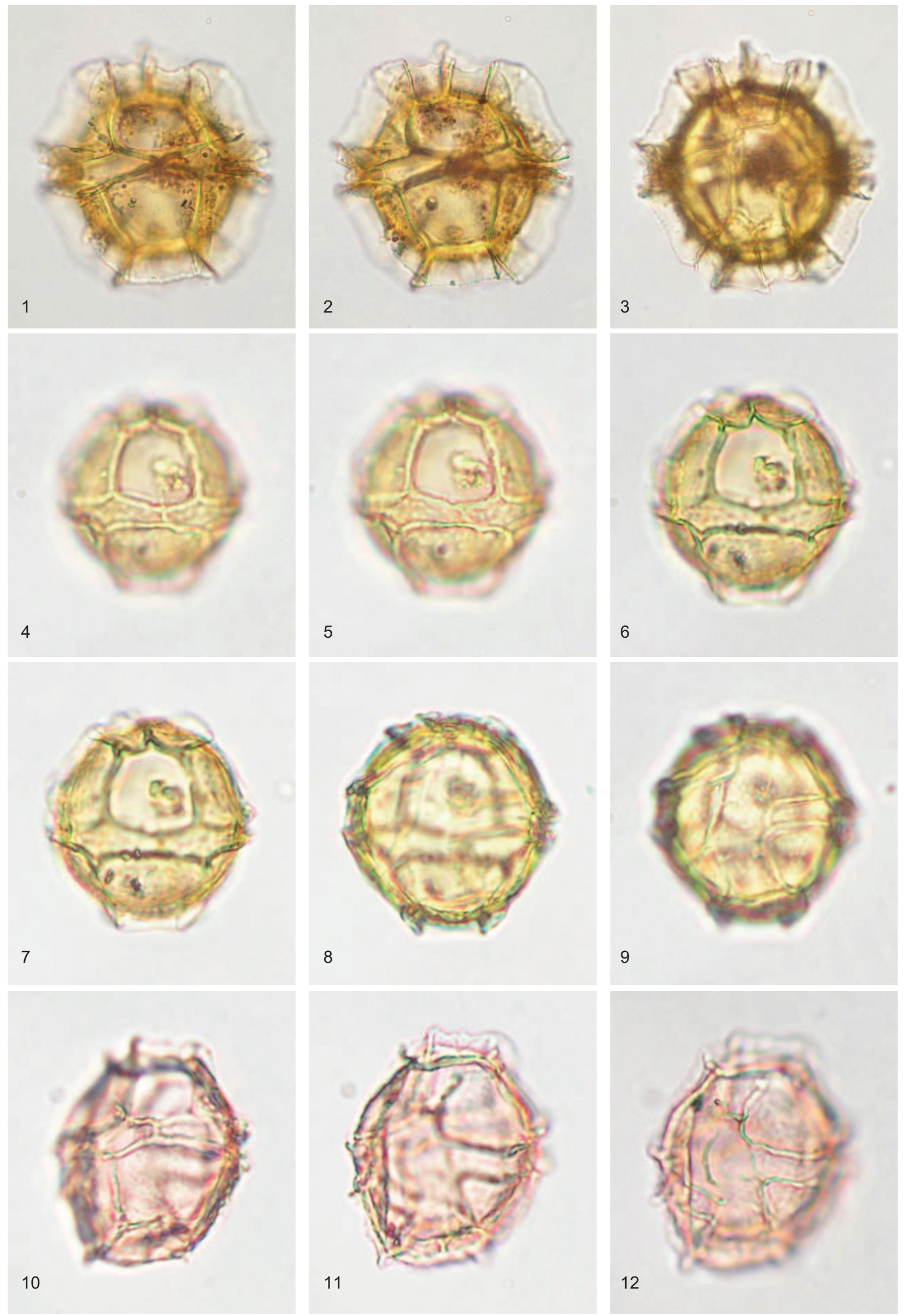


\section{Plate 36}

\section{Impagidinium cf. maculatum}

Figure 1-3 Sample U24/f419, slide L23127/SM071; Wanstead, Te Uri Stream (Porangan); x 1000; specimen measures $45 \times 42 \mu \mathrm{m}$

Figure 4-6 Sample J42/f302, slide L23132/SM007; Hampden Formation, Hampden Beach Section (Porangan-Bortonian); x 675; specimen measures 65 x $63 \mu \mathrm{m}$

\section{Impagidinium waipawaense}

Figure 7-9 Sample U24/f418, slide L23126/SM025; Wanstead, Te Uri Stream (Porangan); x 625; specimen measures $75 \times 60 \mu \mathrm{m}$

\section{Pentadinium sp. 1}

Figure 10-12 Sample J42/f485, slide L23120/SM037; ?Hampden Formation, Hampden Beach Section (Porangan-Bortonian); x 600; specimen measures 62 x $70 \mu \mathrm{m}$ 


\section{Plate 36}
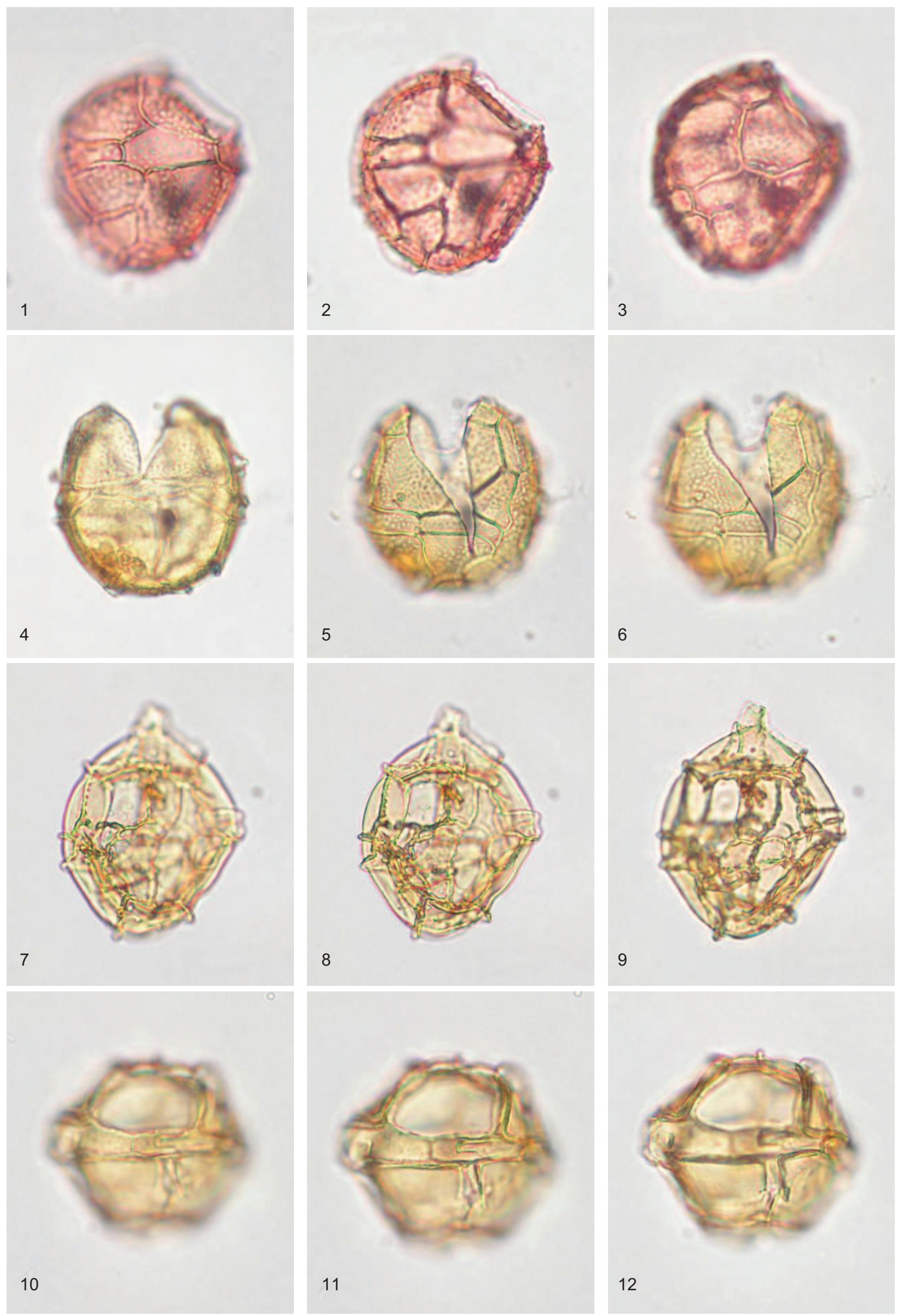


\section{Plate 37}

\section{Pentadinium sp. 1}

Figure 1-3 Sample J42/f485, slide L23120/SM037; ?Hampden Formation, Hampden Beach Section (Porangan-Bortonian); x 600; specimen measures 62 × $70 \mu \mathrm{m}$

\section{Tectatodinium pellitum}

Figure 4-6 Sample J42/f096, slide L10951/SM067; Totara Limestone, Kakanui River (early Whaingaroan); x 1050; specimen measures 43 × $40 \mu \mathrm{m}$

Figure 7-9 Sample J42/f096, slide L10951/SM065; Totara Limestone, Kakanui River (early Whaingaroan); x 800; specimen measures 48 × $52 \mu \mathrm{m}$

Tectatodinium sp. 1

Figure 10-12 Sample J42/f098, slide L10953/SM006; Totara Limestone, Kakanui River (Runangan); x 700; specimen measures $60 \times 60 \mu \mathrm{m}$ 


\section{Plate 37}

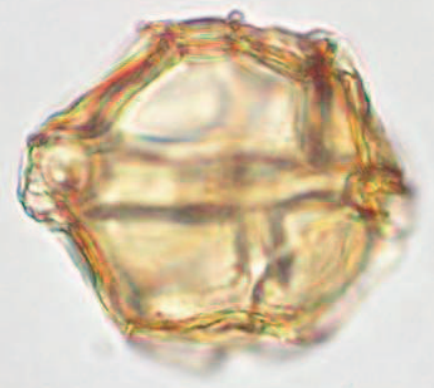

1

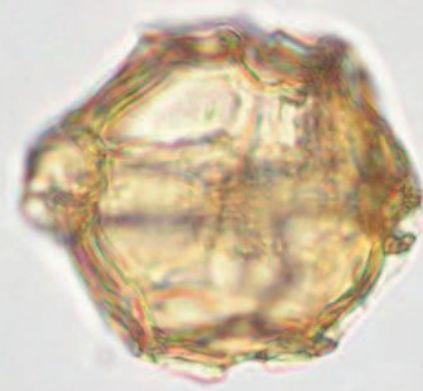

2

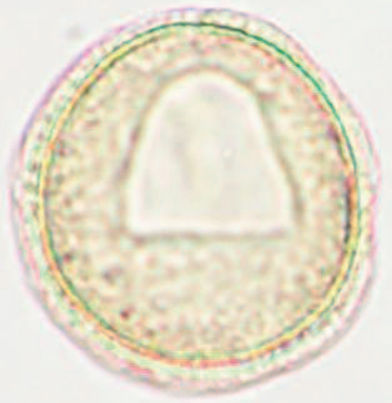

5

4
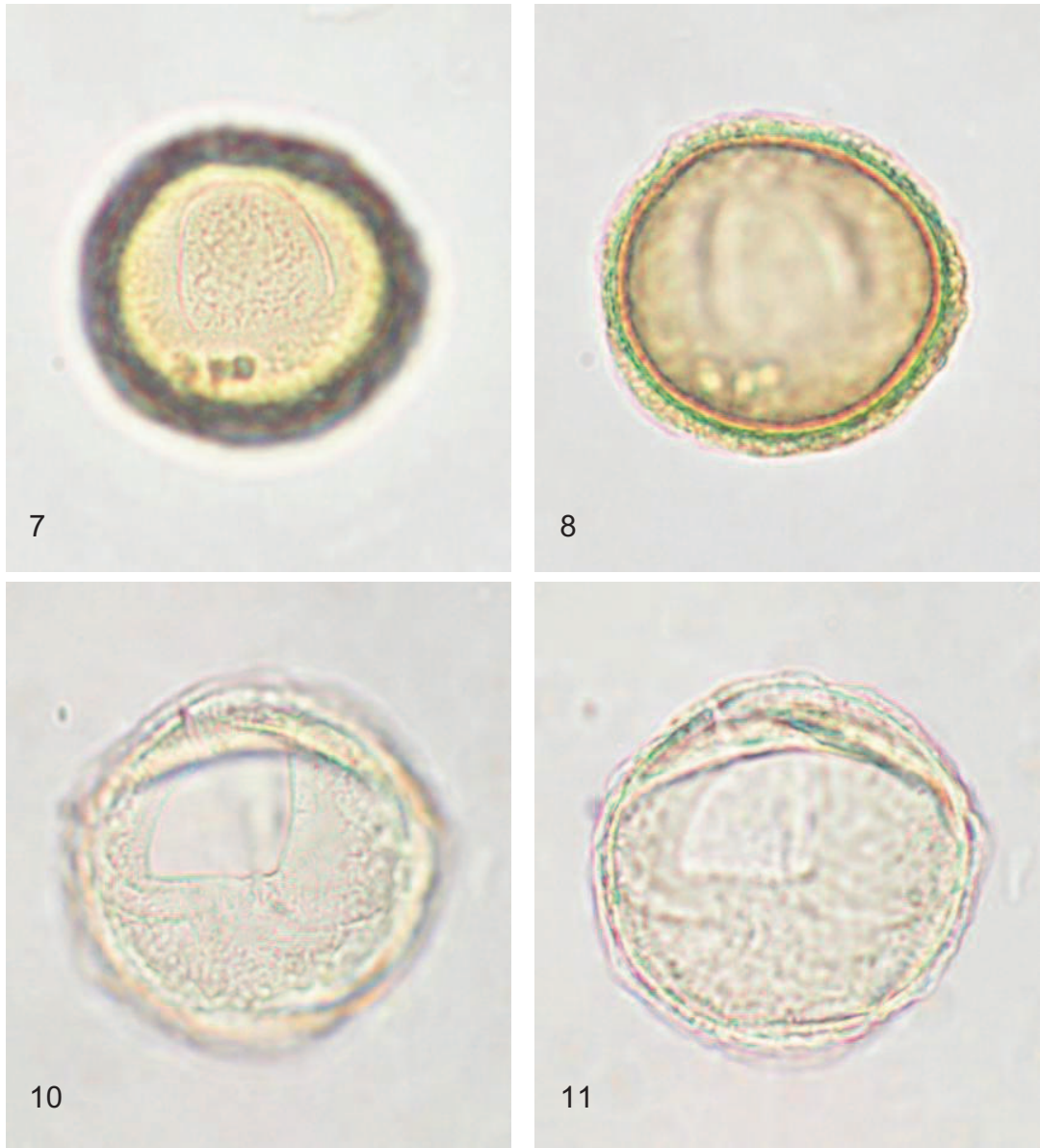

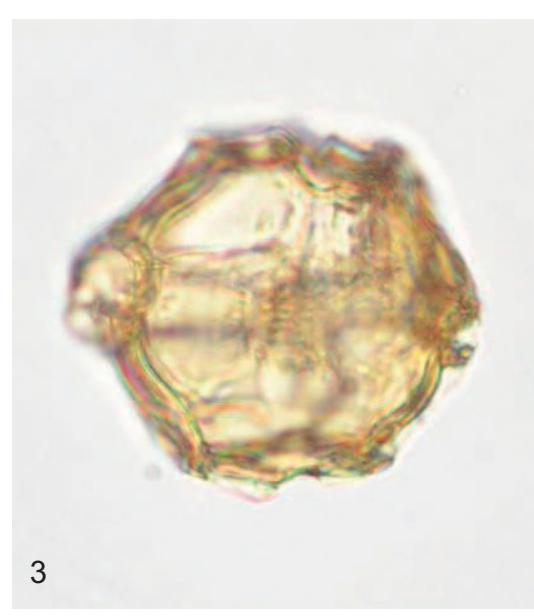

3

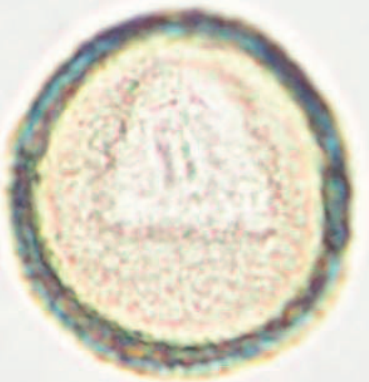

6
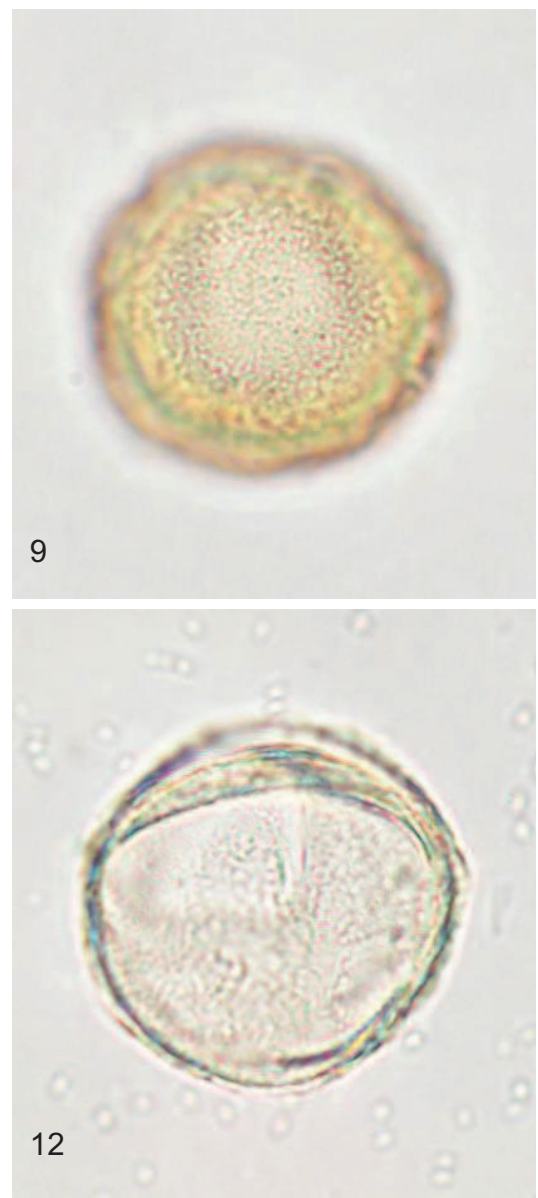


\section{Plate 38}

\section{Tectatodinium sp. 2}

Figure 1-3 Sample J42/f098, slide L10953/SM010; Totara Limestone, Kakanui River (Runangan); x 1150; specimen measures $41 \times 30 \mu \mathrm{m}$

Figure 4-6 Sample J42/f098, slide L10953/SM009; Totara Limestone, Kakanui River (Runangan); specimen measures $38 \times 32 \mu \mathrm{m}$

\section{Filisphaera sp. 3}

Figure 7-9 Sample J42/f098, slide L10953/SM011; Totara Limestone, Kakanui River (Runangan); specimen measures $38 \times 36 \mu \mathrm{m}$

\section{'Apteodinium' australiense}

Figure 10-12 Sample J42/f096, slide L10951/SM2958; Totara Limestone, Kakanui River (early Whaingaroan); x 450; specimen measures 94 x $91 \mu \mathrm{m}$ 


\section{Plate 38}
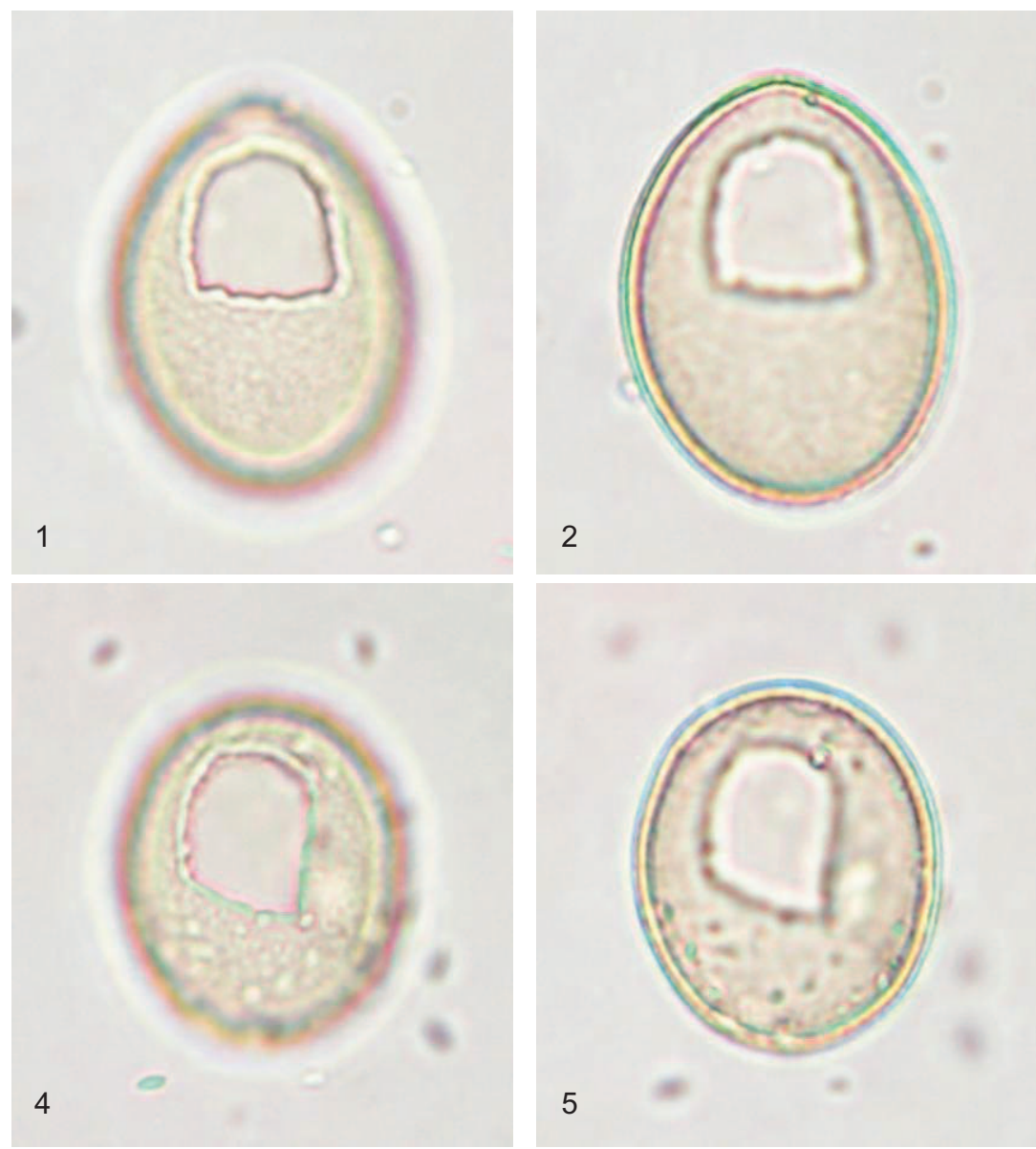

3
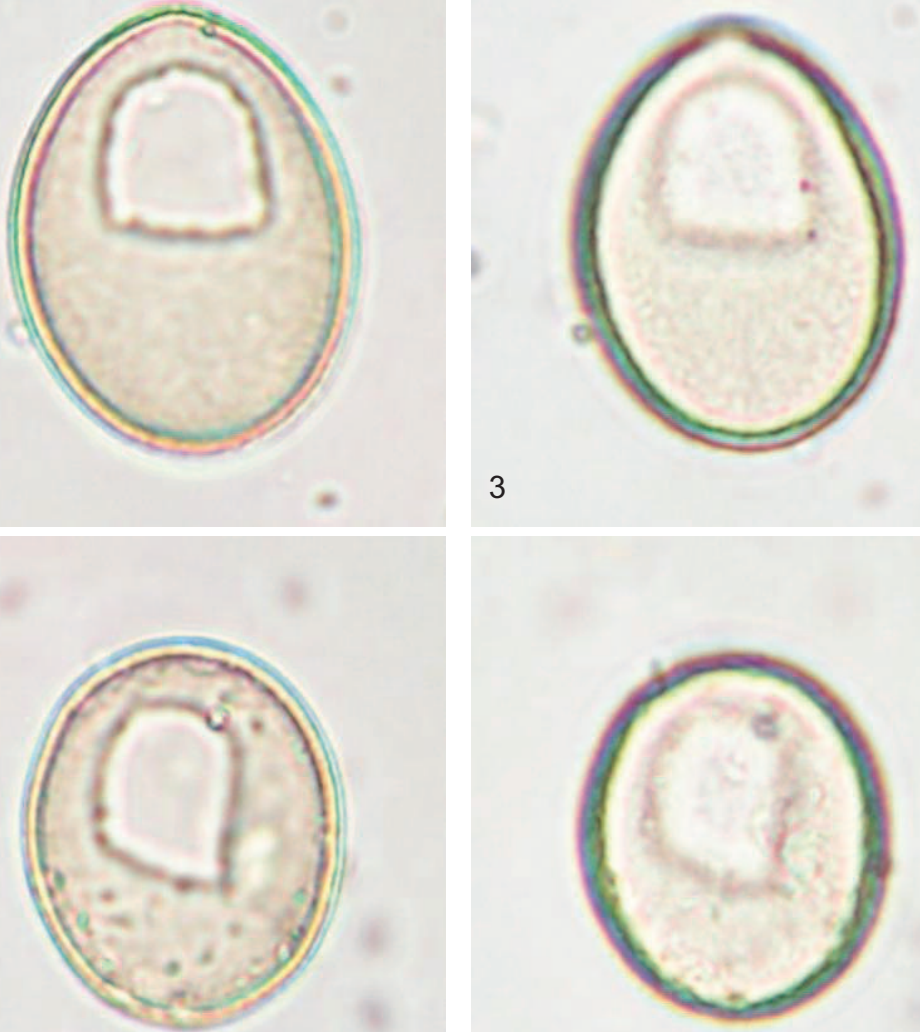

5
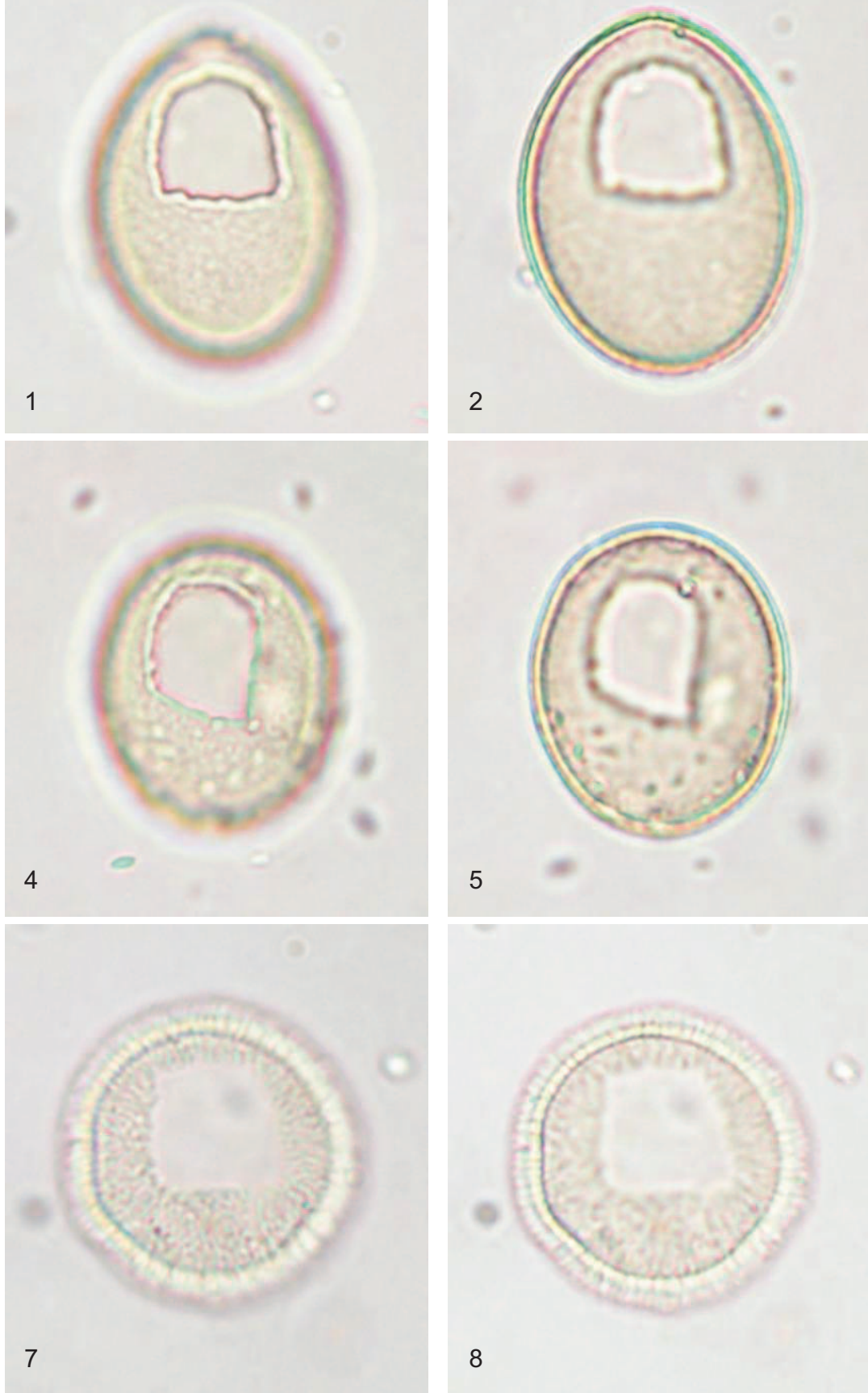

8

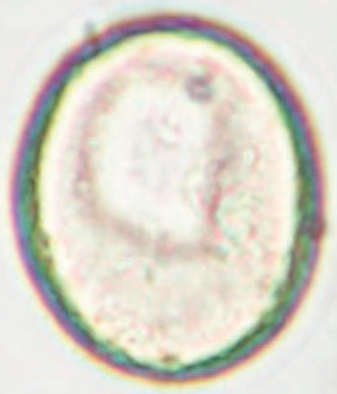

6

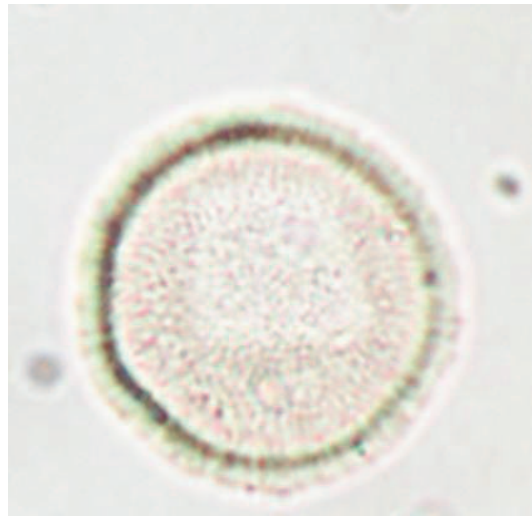

9
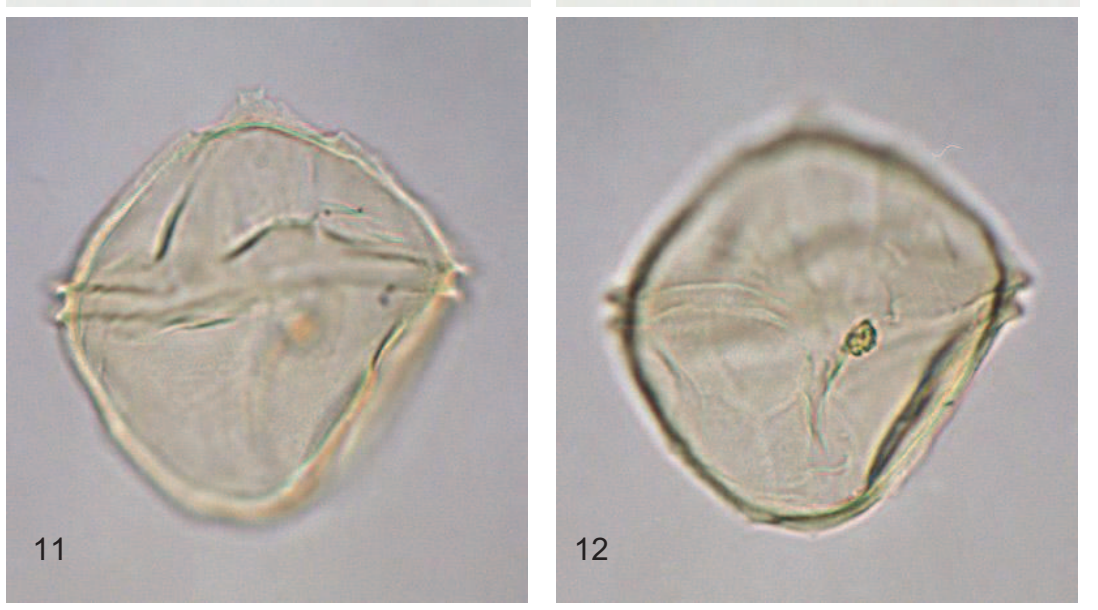


\section{Plate 39}

\section{'Apteodinium' ?tenuitabulatum}

Figure 1-4 Sample I43/f089, slide L16337/SM087A; Burnside Formation, Puketeraki Core (Bortonian); x 575; specimen measures $73 \times 73 \mu \mathrm{m}$

Figure 5-6 Sample 143/f090, slide L16338/SM055; Burnside Formation, Puketeraki Core (Bortonian); x 575; specimen measures $70 \times 74 \mu \mathrm{m}$

Figure 7-9 Sample 143/f090, slide L16338/SM054; Burnside Formation, Puketeraki Core (Bortonian); x 675; specimen measures $63 \times 63 \mu \mathrm{m}$

Achilleodinium biformoides

Figure 10-12 Sample J42/f483, slide L23118/SM026; Kurinui Formation, Hampden Beach Section (Heretaungan); x 425; specimen measures 110 x $88 \mu \mathrm{m}$ 


\section{Plate 39}
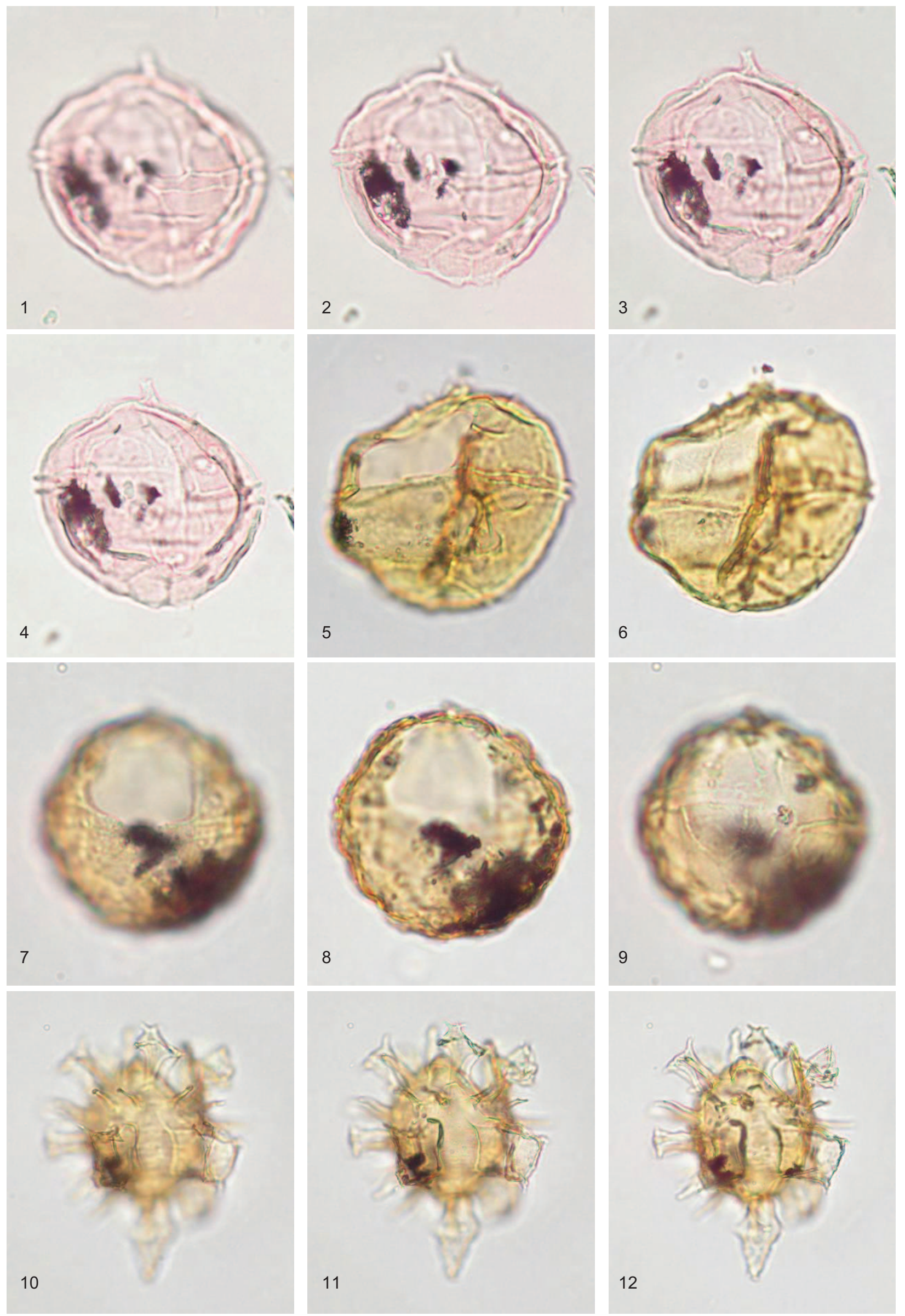


\section{Plate 40}

\section{Achilleodinium biformoides}

Figure 1-3 Sample J42/f483, slide L23118/SM026; Kurinui Formation, Hampden Beach Section (Heretaungan); x 425; specimen measures $110 \times 88 \mu \mathrm{m}$

Figure 4-6 Sample J42/f483, slide L23118/SM025; Kurinui Formation, Hampden Beach Section (Heretaungan); x 500; specimen measures 80 × $84 \mu \mathrm{m}$

\section{Achilleodinium cf. biformoides}

Figure 7-9 Sample 144/f240, slide L15506/SM4820; Abbotsford Formation, M26 Core (HeretaunganBortonian); x 450; specimen measures 107 x $96 \mu \mathrm{m}$

\section{Achilleodinium echinatum}

Figure 10-12 Sample J42/f485, slide L23120/SM026; ?Hampden Formation, Hampden Beach Section (Porangan-Bortonian); x 425; specimen measures $97 \times 100 \mu \mathrm{m}$ 


\section{Plate 40}
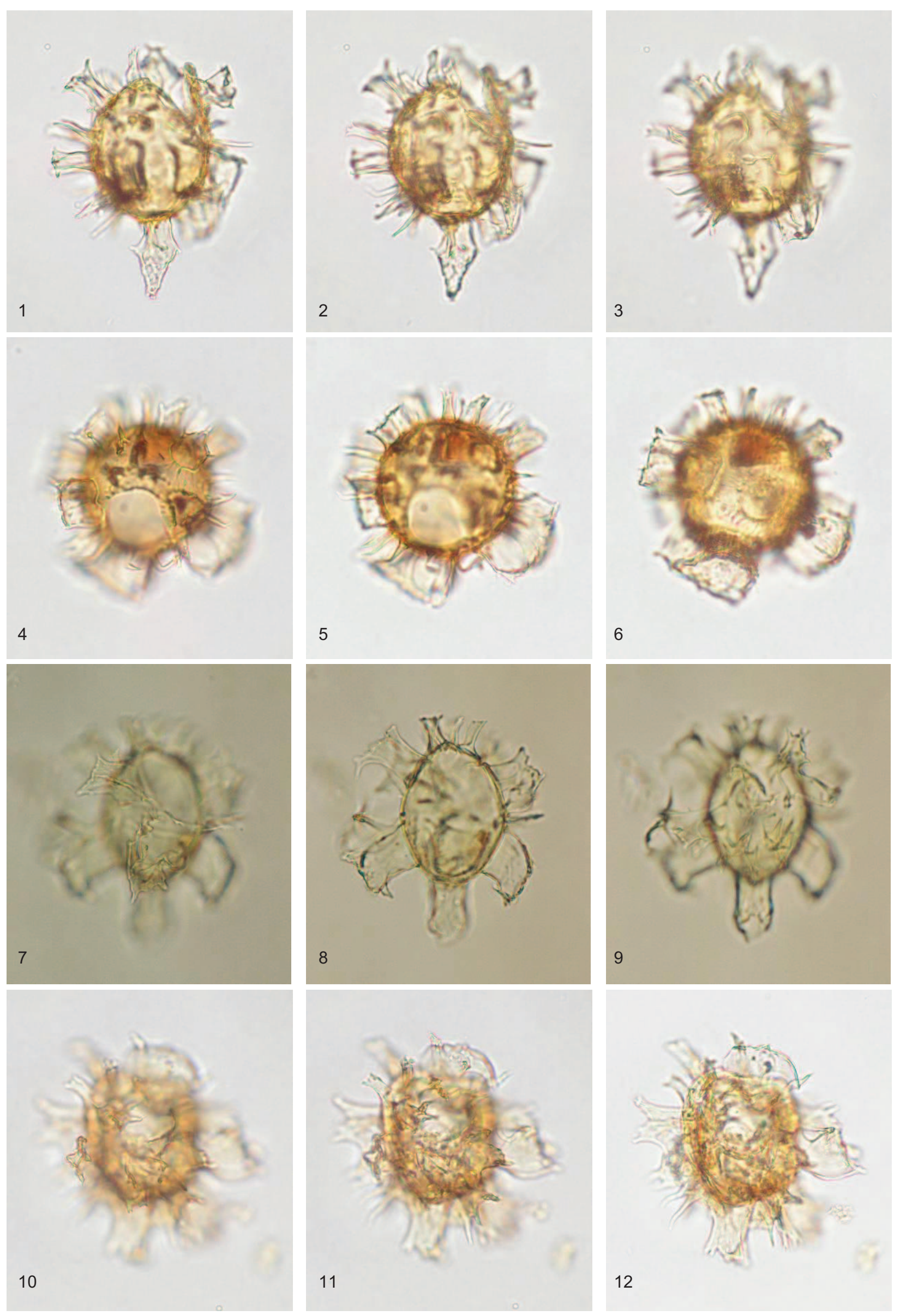


\section{Plate 41}

\section{Achilleodinium echinatum}

Figure 1-3 Sample J42/f485, slide L23120/SM026; ?Hampden Formation, Hampden Beach Section (Porangan-Bortonian); x 425; specimen measures $97 \times 100 \mu \mathrm{m}$

\section{Achilleodinium improcerum}

Figure 4-6 Sample J42/f484, slide L23119/SM020; Kurinui Formation, Hampden Beach Section (Heretaungan); x 650; specimen measures 72 × $55 \mu \mathrm{m}$

Figure 7-9 Sample 143/f090, slide L16338/SM4829; Burnside Formation, Puketeraki Core (Bortonian); x 450; specimen measures 104 x $88 \mu \mathrm{m}$

Figure 10-12 Sample 143/f090, slide L16338/SM4830; Burnside Formation, Puketeraki Core (Bortonian); x 375; specimen measures $126 \times 112 \mu \mathrm{m}$ 


\section{Plate 41}
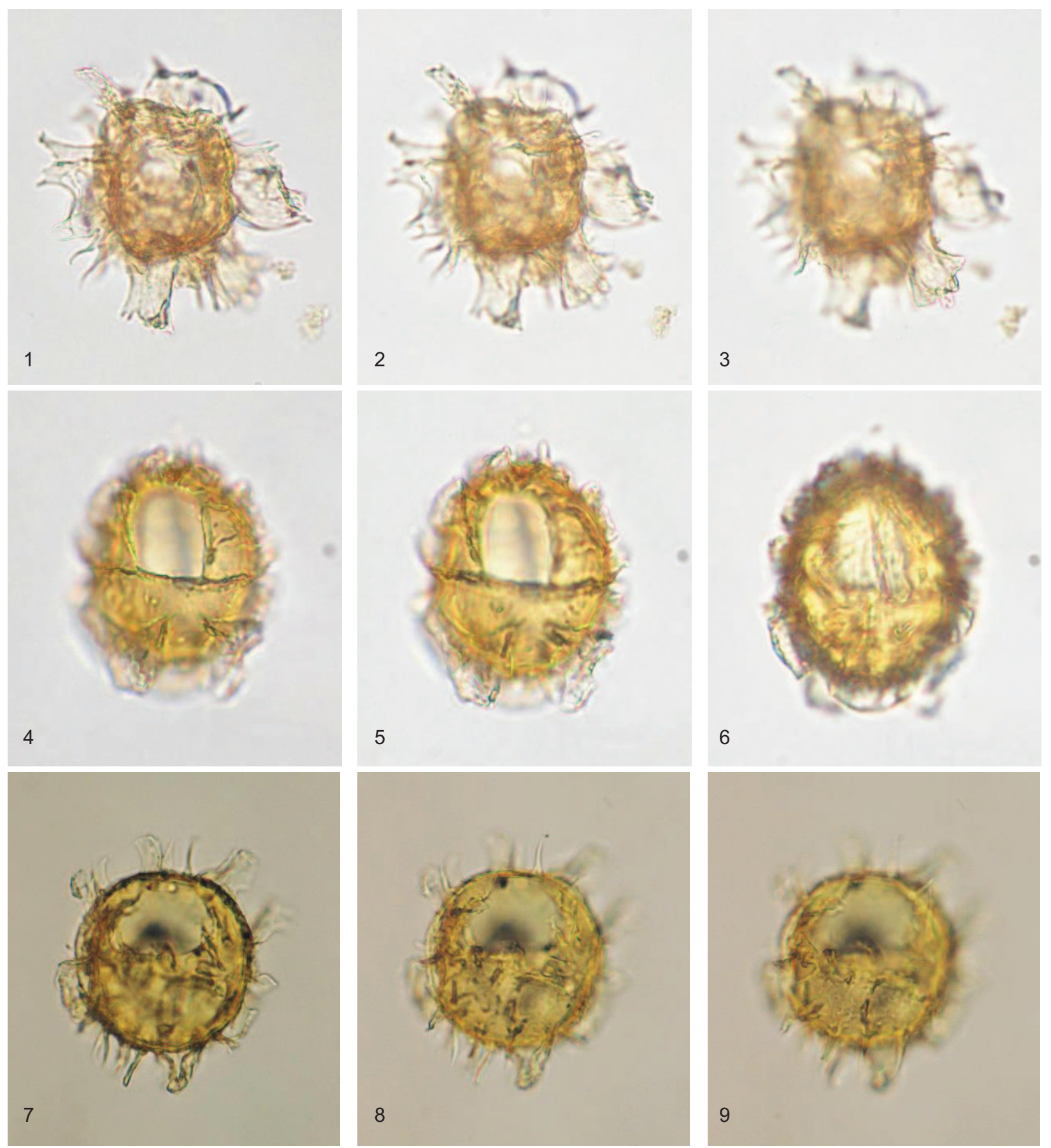

6
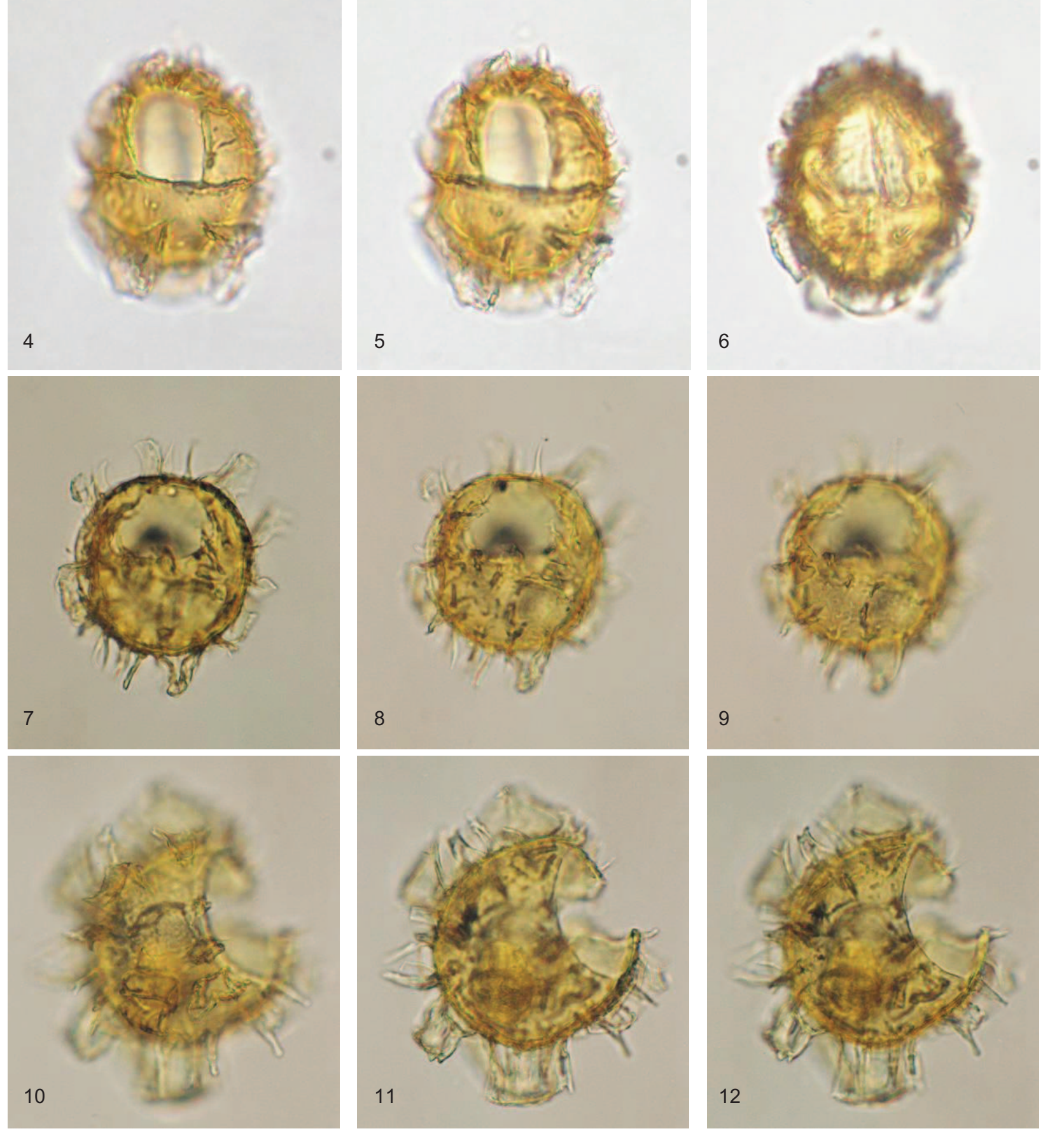


\section{Plate 42}

\section{Achilleodinium improcerum}

Figure 1-6 Sample 143/f093, slide L16341/SM085; Burnside Formation, Puketeraki Core (Bortonian); x 450; specimen measures $105 \times 96 \mu \mathrm{m}$

\section{'Araneosphaera' stephanophora}

Figure 7-10 Sample J42/f486, slide L23121/SM011; ?Hampden Formation, Hampden Beach Section (Porangan-Bortonian); x 1000; specimen measures 47 x $40 \mu \mathrm{m}$

Figure 11-12 Sample J42/f486, slide L23121/SM012A; ?Hampden Formation, Hampden Beach Section (Porangan-Bortonian); specimen measures $39 \times 37 \mu \mathrm{m}$ 


\section{Plate 42}
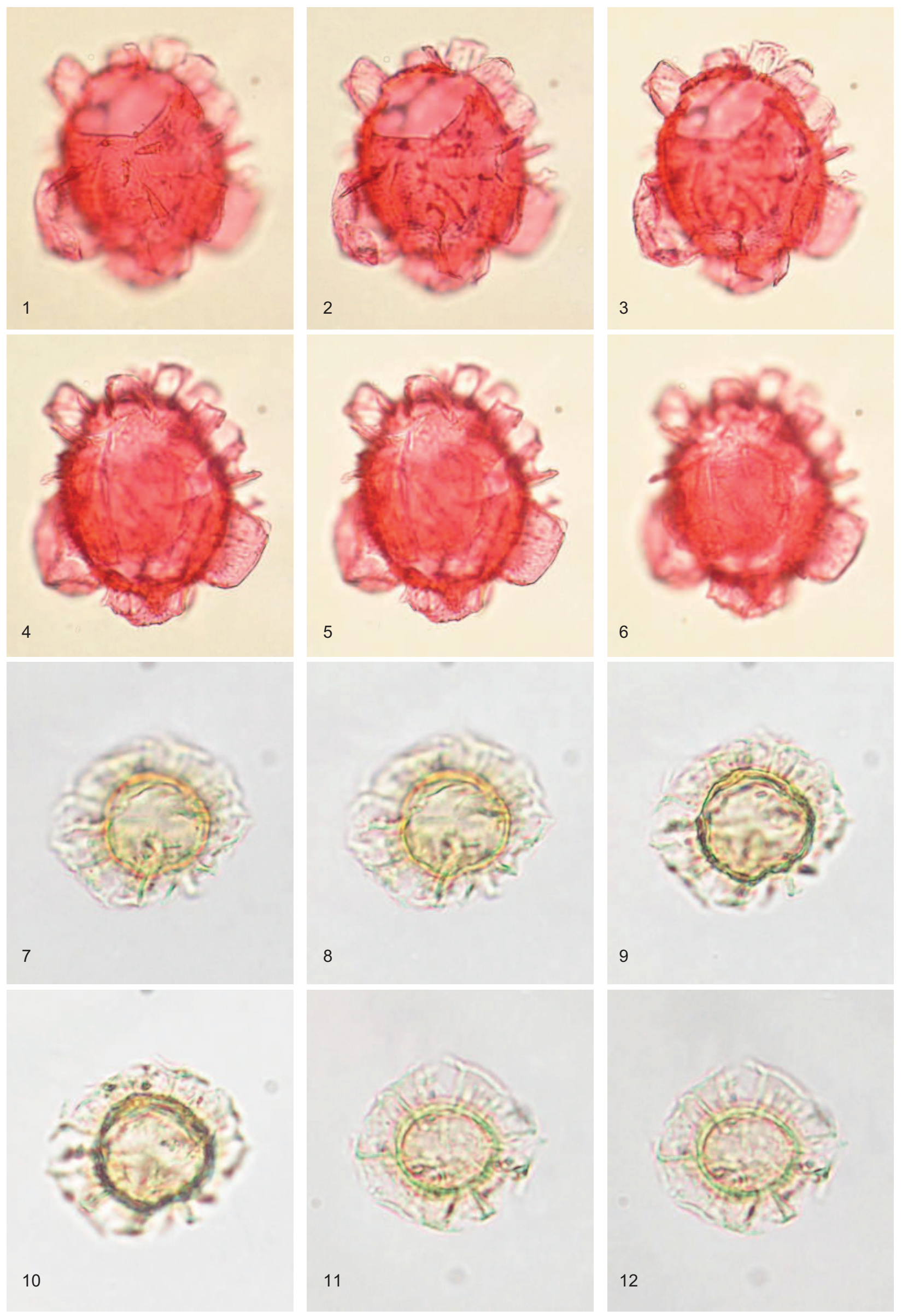


\section{Plate 43}

\section{'Araneosphaera' stephanophora}

Figure 1-3 Sample 143/f089, slide L16337/SM087B; Burnside Formation, Puketeraki Core (Bortonian); x 1050; specimen measures $40 \times 40 \mu \mathrm{m}$

Figure 4-6 Sample 143/f089, slide L16337/SM072B; Burnside Formation, Puketeraki Core (Bortonian); x 1125; specimen measures $42 \times 32 \mu \mathrm{m}$

\section{Cordosphaeridium inodes}

Figure 7-12 Sample J42/f483, slide L23118/SM022; Kurinui Formation, Hampden Beach Section (Heretaungan); x 450; specimen measures 100 x $95 \mu \mathrm{m}$ 


\section{Plate 43}

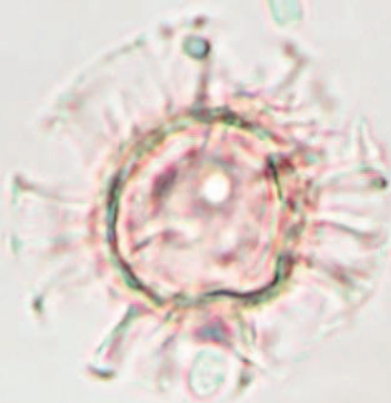

1

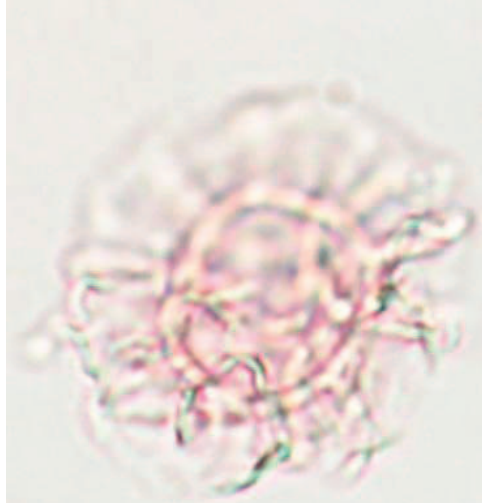

4
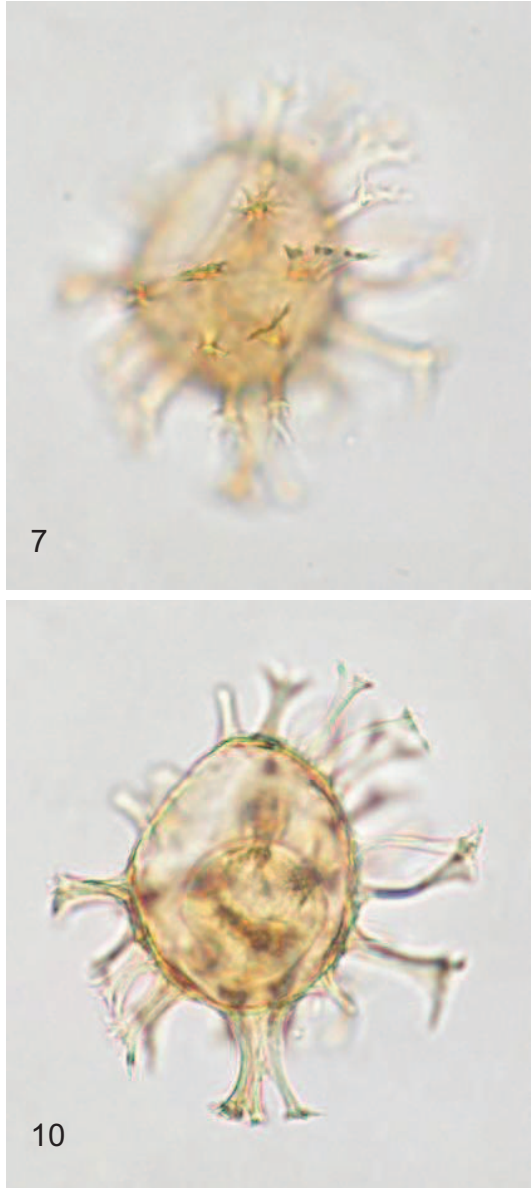

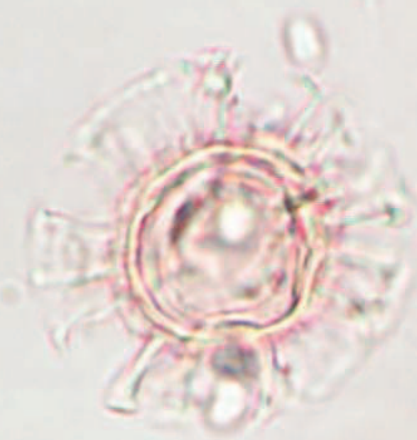

2

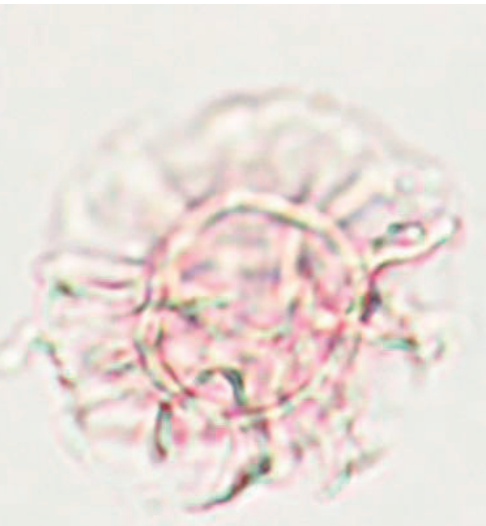

5
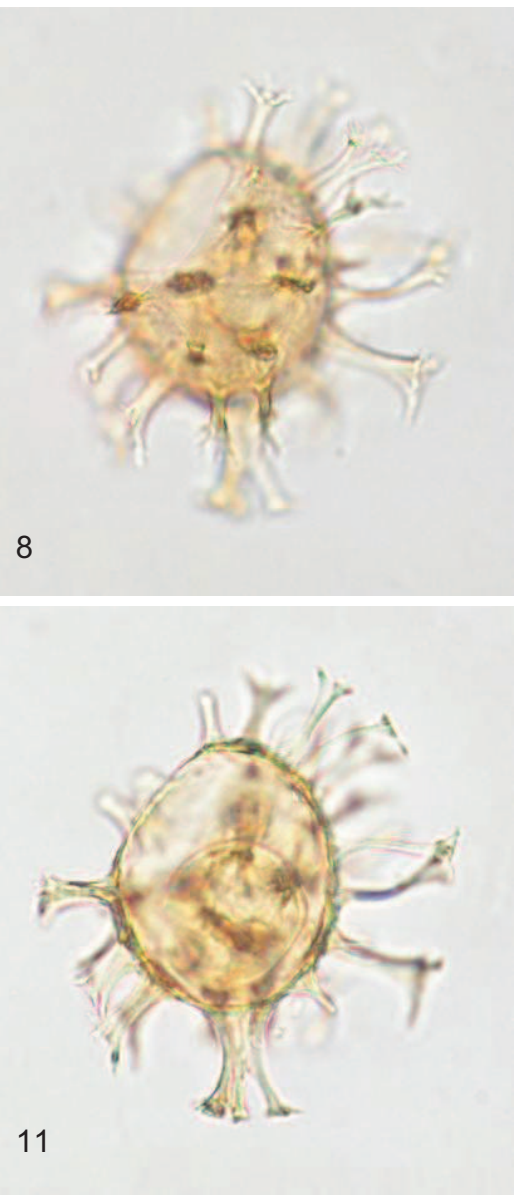
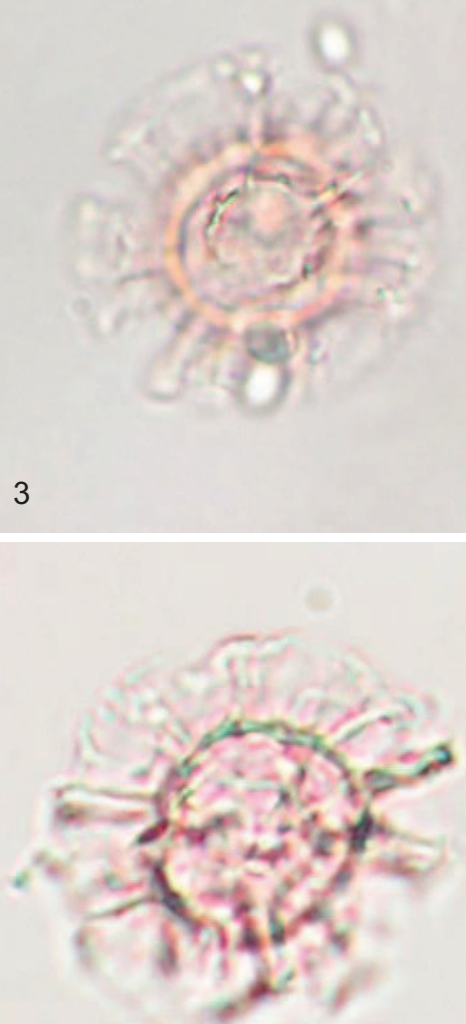

6
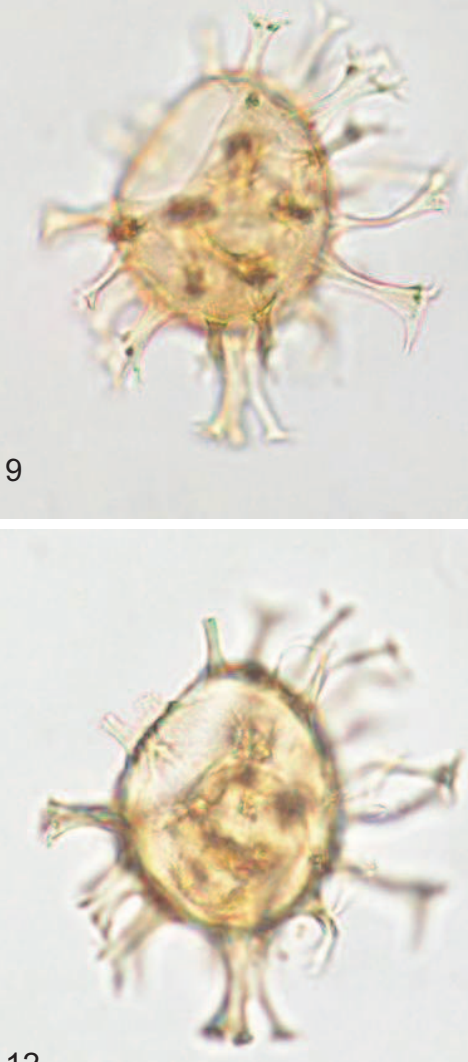

12 


\section{Plate 44}

\section{Cordosphaeridium inodes}

Figure 1-3 Sample J42/f301, slide L23131/SM016; Hampden Formation, Hampden Beach Section (Porangan-Bortonian); x 500; specimen measures 85 x $84 \mu \mathrm{m}$

\section{Cordosphaeridium gracile}

Figure 4-5 Sample 143/f096, slide L16344/SM016; Burnside Formation, Puketeraki Core (Kaiatan); x 250; specimen measures $143 \times 160 \mu \mathrm{m}$

Figure 6 Sample 143/f093, slide L16341/SM037; Burnside Formation, Puketeraki Core (Bortonian); x 300; specimen measures $163 \times 117 \mu \mathrm{m}$

\section{Cordosphaeridium fibrospinosum}

Figure 7-9 Sample 143/f090, slide L16338/SM039; Burnside Formation, Puketeraki Core (Bortonian); x 400; specimen measures $115 \times 105 \mu \mathrm{m}$

Figure 10-12 Sample 143/f093, slide L16341/SM089; Burnside Formation, Puketeraki Core (Bortonian); x 350; specimen measures 85 × $120 \mu \mathrm{m}$ 


\section{Plate 44}

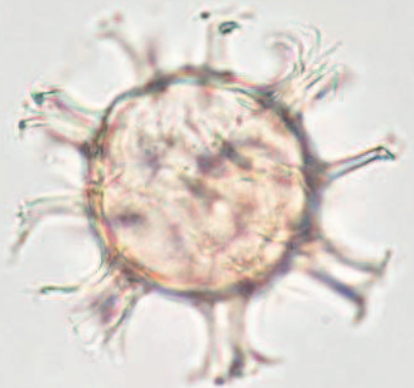

1

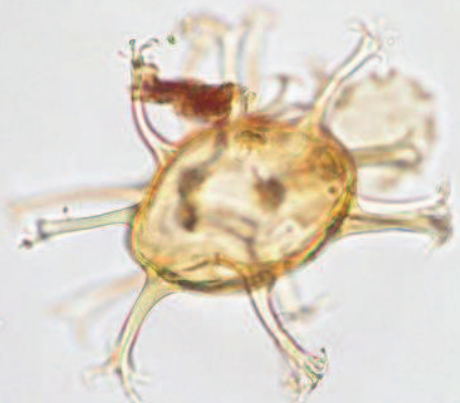

4
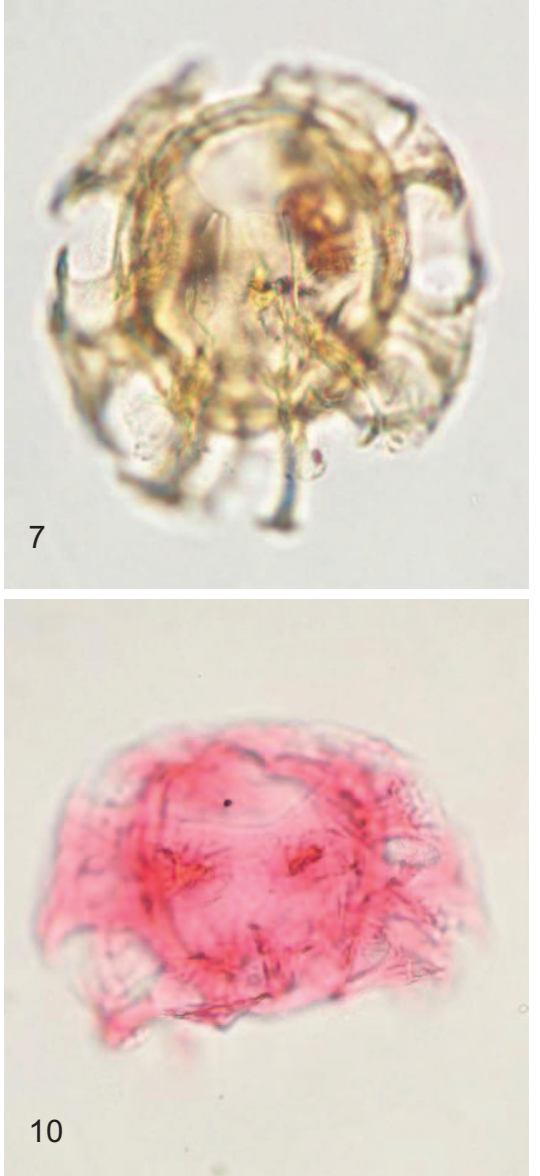

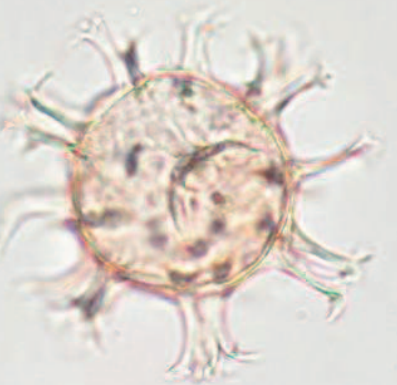

2
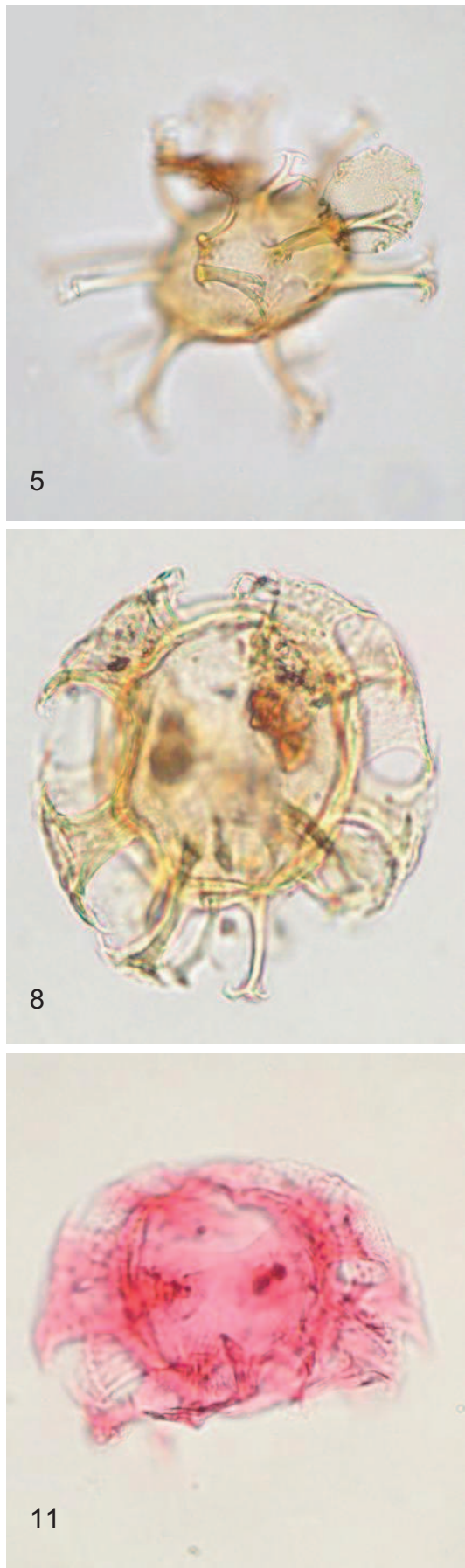
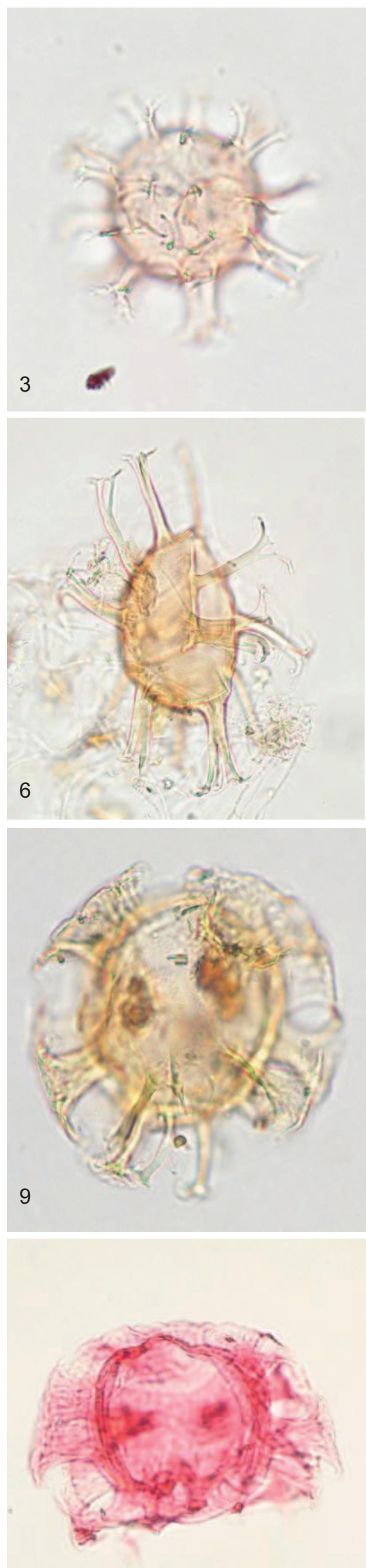

12 


\section{Plate 45}

\section{Cordosphaeridium aff. funiculatum}

Figure 1-6 Sample K29/f114, slide L11050/SM009; Port Elizabeth Member, Cape Foulwind Section (early Whaingaroan); x 350; specimen measures $125 \times 122 \mu \mathrm{m}$

Figure 7-8 Sample K29/f114, slide L11050/SM005; Port Elizabeth Member, Cape Foulwind Section (early Whaingaroan); x 225; specimen measures $175 \times 177 \mu \mathrm{m}$

Figure 9 Sample K29/f114, slide L11050/SM010; Port Elizabeth Member, Cape Foulwind Section (early Whaingaroan)

Figure 10-12 Sample K29/f114, slide L11050/SM039; Port Elizabeth Member, Cape Foulwind Section (early Whaingaroan); x 375; specimen measures $125 \times 112 \mu \mathrm{m}$ 


\section{Plate 45}
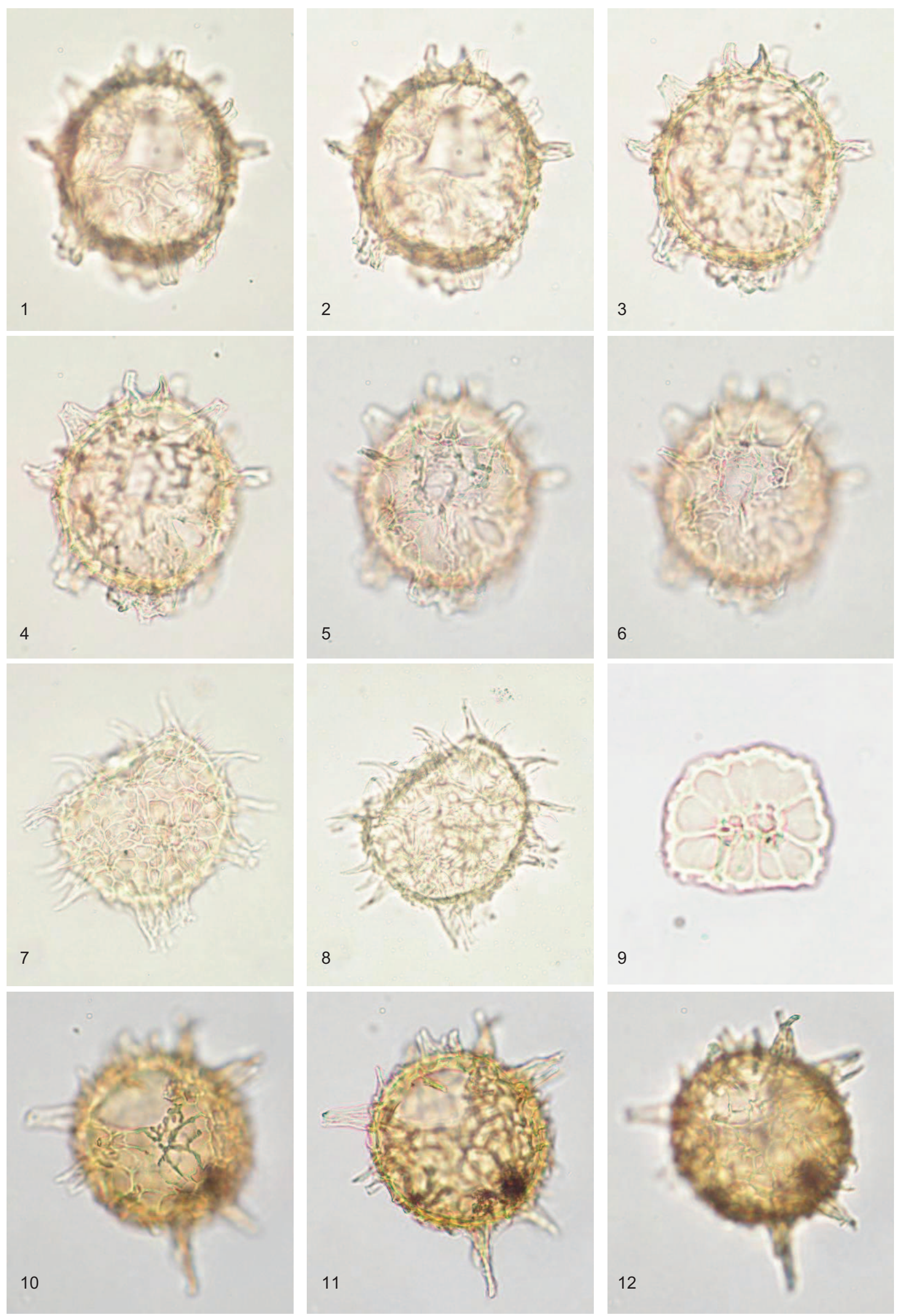

9

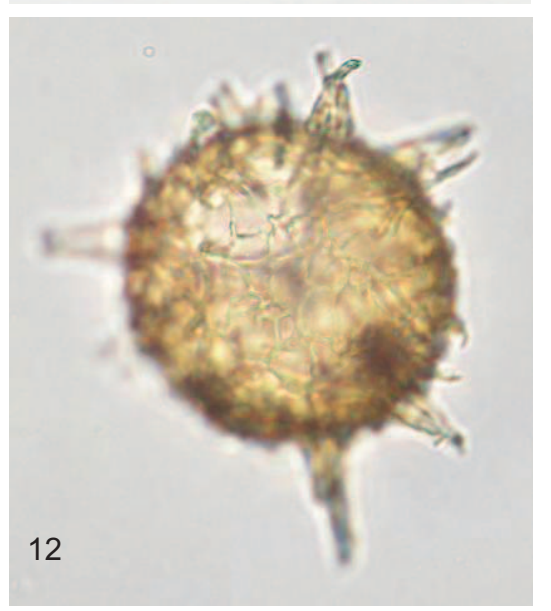




\section{Plate 46}

\section{Cordosphaeridium minimum}

Figure 1-2 Sample J42/f300, slide L23130/SM027; Hampden Formation, Hampden Beach Section (Porangan); specimen measures 34 × $33 \mu \mathrm{m}$

Figure 3 Sample J42/f485, slide L23120/SM029B; ?Hampden Formation, Hampden Beach Section (Porangan-Bortonian); x 1100; specimen measures $40 \times 38 \mu \mathrm{m}$

Figure 4-6 Sample J42/f483, slide L23118/SM024; Kurinui Formation, Hampden Beach Section (Heretaungan); specimen measures $38 \times 37 \mu \mathrm{m}$

Figure 7-9 Sample 143/f090, slide L16338/SM040; Burnside Formation, Puketeraki Core (Bortonian); specimen measures $37 \times 40 \mu \mathrm{m}$

\section{Turbiosphaera filosa}

Figure 10-12 Sample U24/f418, slide L23126/SM017B; Wanstead, Te Uri Stream (Porangan); x 350; specimen measures $137 \times 110 \mu \mathrm{m}$ 


\section{Plate 46}
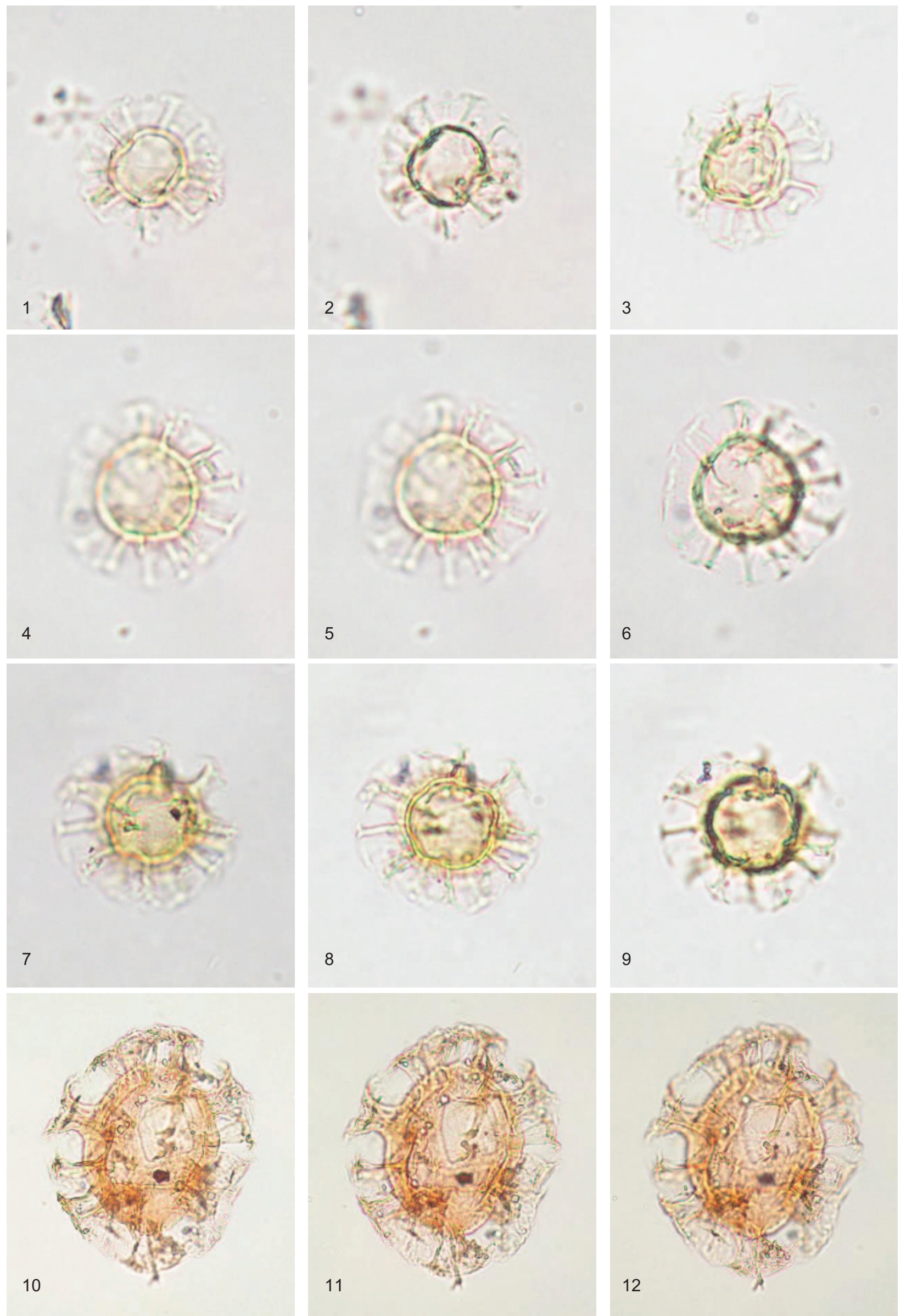

9

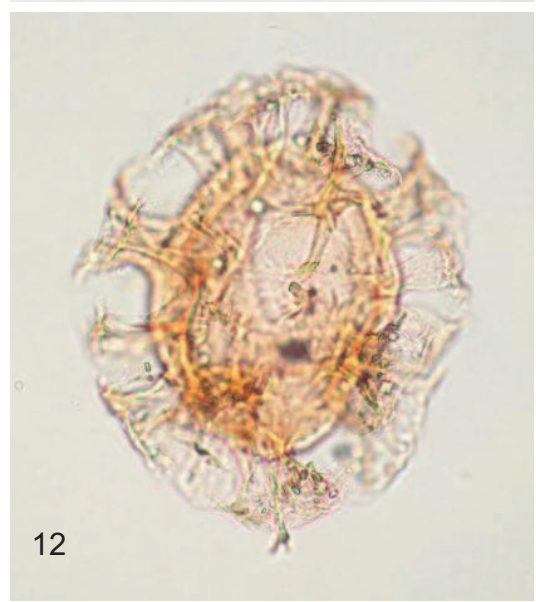




\section{Plate 47}

\section{Turbiosphaera filosa}

Figure 1 Sample U24/f418, slide L23126/SM017B; Wanstead, Te Uri Stream (Porangan); x 350; specimen measures $137 \times 110 \mu \mathrm{m}$

Figure 2-3 Sample U24/f418, slide L23126/SM021; Wanstead, Te Uri Stream (Porangan); x 425; specimen measures $109 \times 98 \mu \mathrm{m}$

\section{Turbiosphaera sp. 1}

Figure 4-12 Sample J42/f485, slide L23120/SM030; ?Hampden Formation, Hampden Beach Section (Porangan-Bortonian); x 425; specimen measures $102 \times 97 \mu \mathrm{m}$ 


\section{Plate 47}
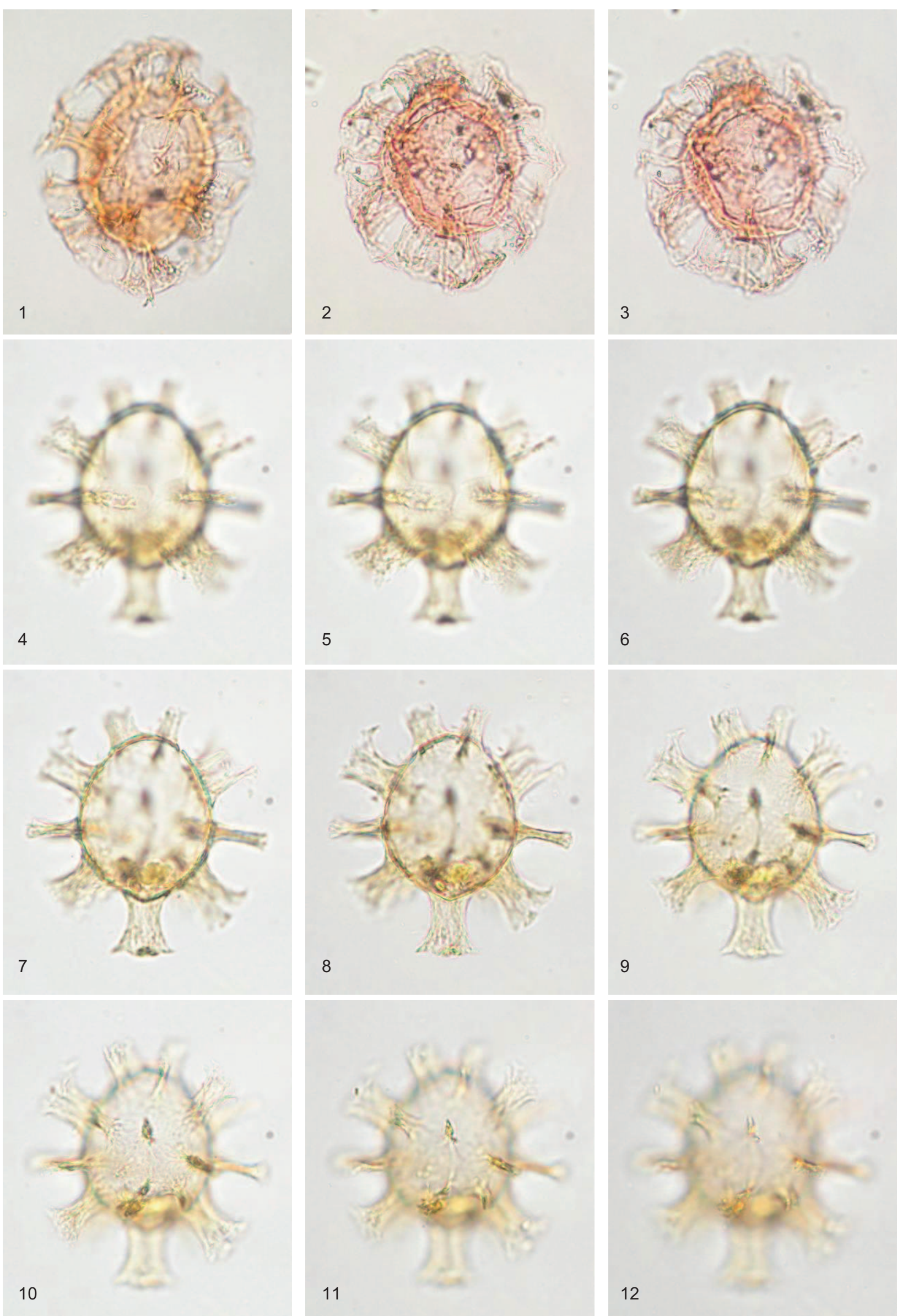

8
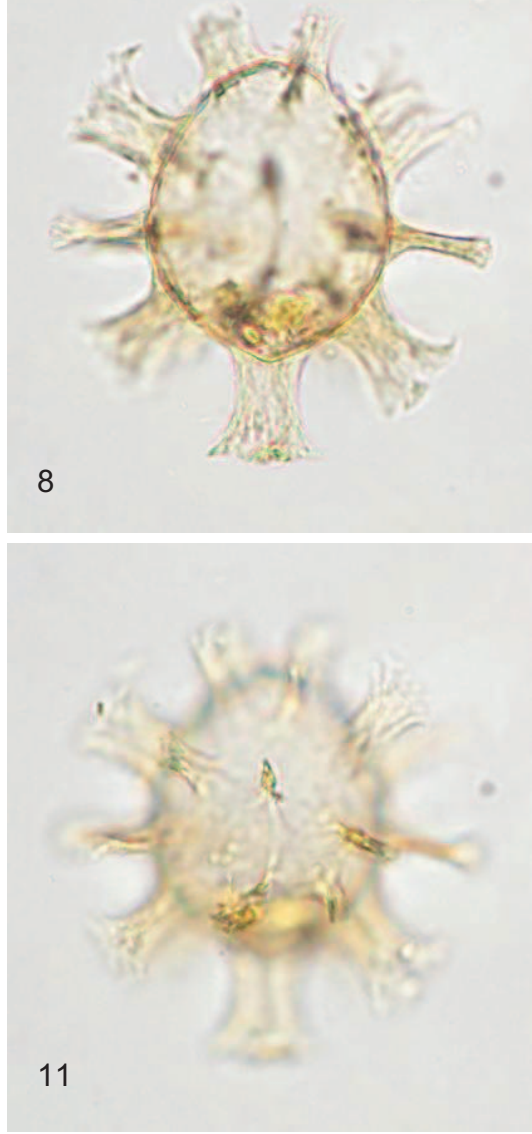

9
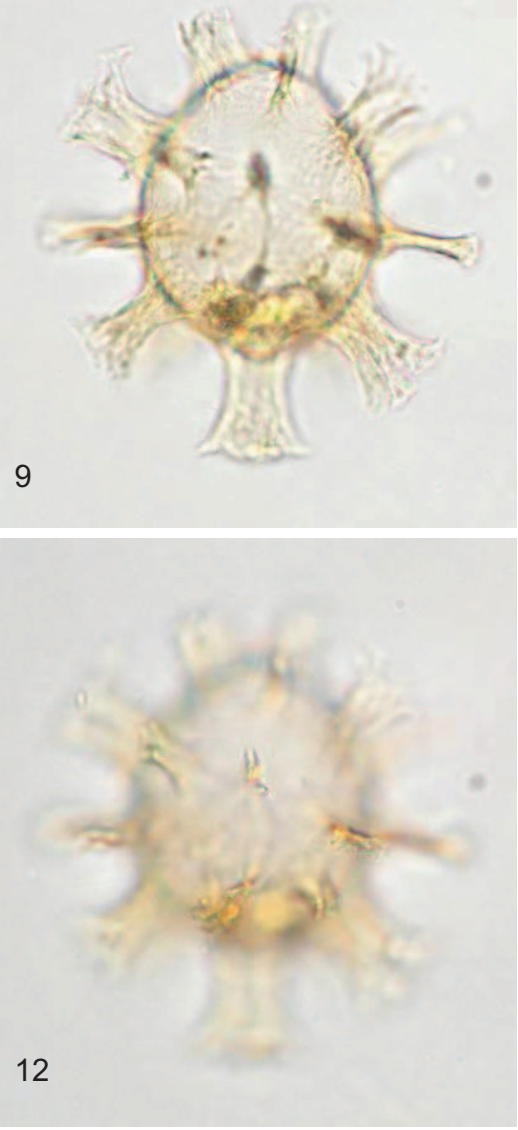


\section{Plate 48}

\section{Disphaerogena morgansii}

Figure 1-6 Sample J42/f486, slide L23121/SM015; ?Hampden Formation, Hampden Beach Section (Porangan-Bortonian); x 425; specimen measures 103 x $99 \mu \mathrm{m}$

Figure 7-9 Sample J42/f300, slide L23130/SM016; Hampden Formation, Hampden Beach Section (Porangan); x 425; specimen measures $103 \times 97 \mu \mathrm{m}$

Figure 10-12 Sample J42/f485, slide L23120/SM027; ?Hampden Formation, Hampden Beach Section (Porangan-Bortonian); x 425; specimen measures 110 x $85 \mu \mathrm{m}$ 


\section{Plate 48}
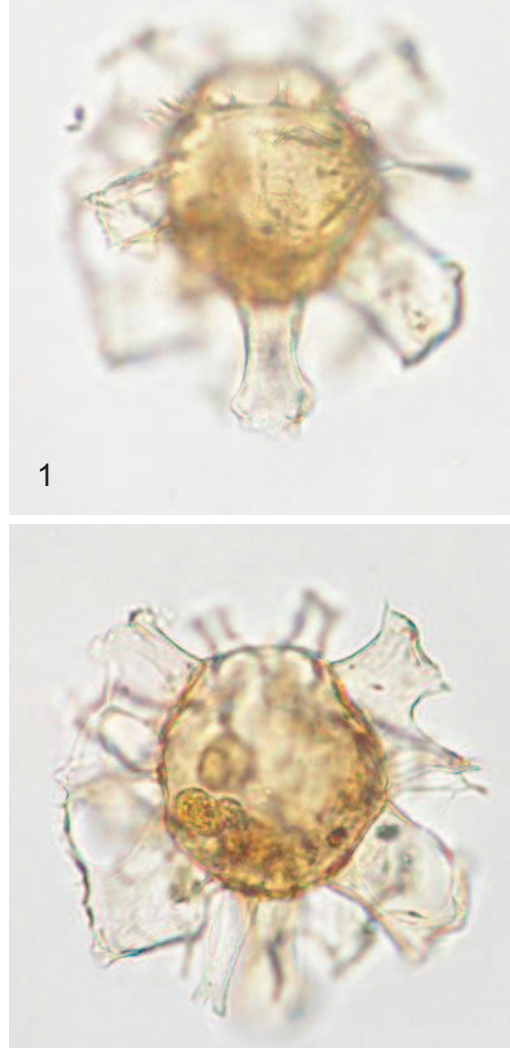

4
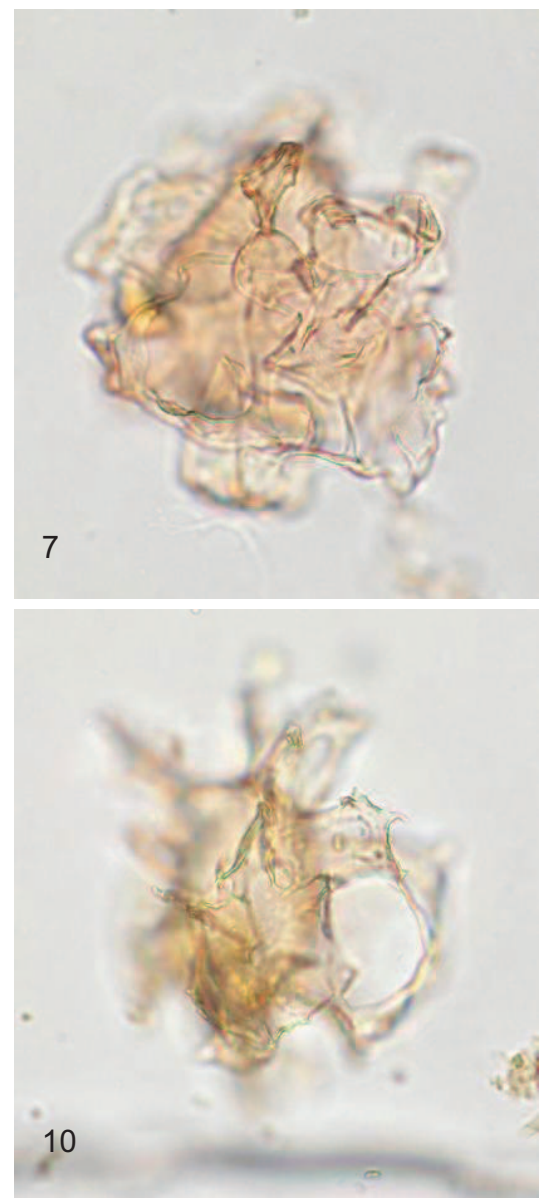
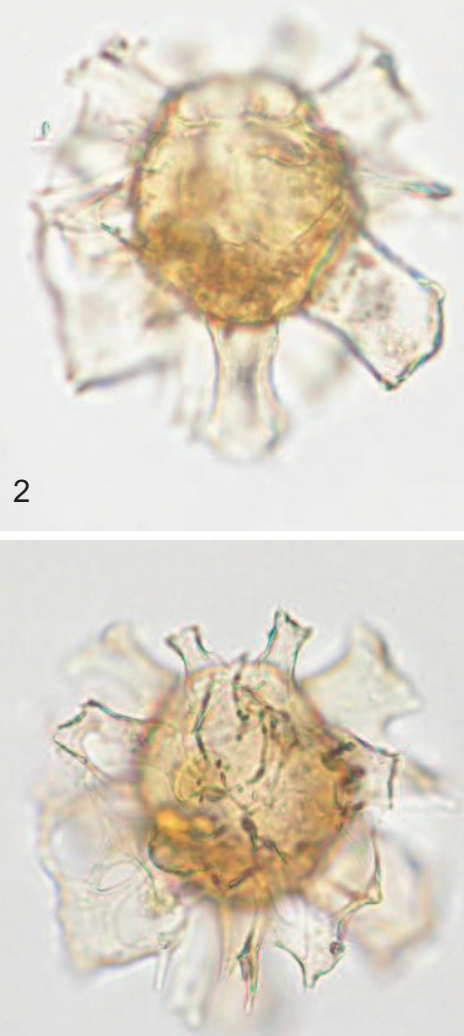

5

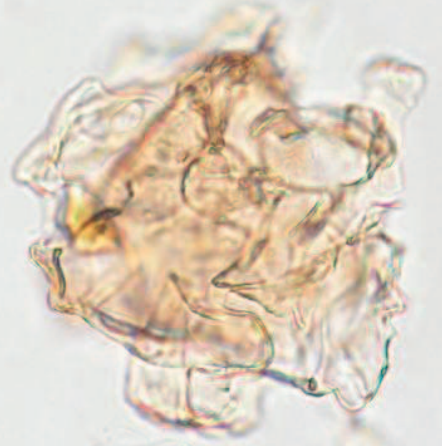

8
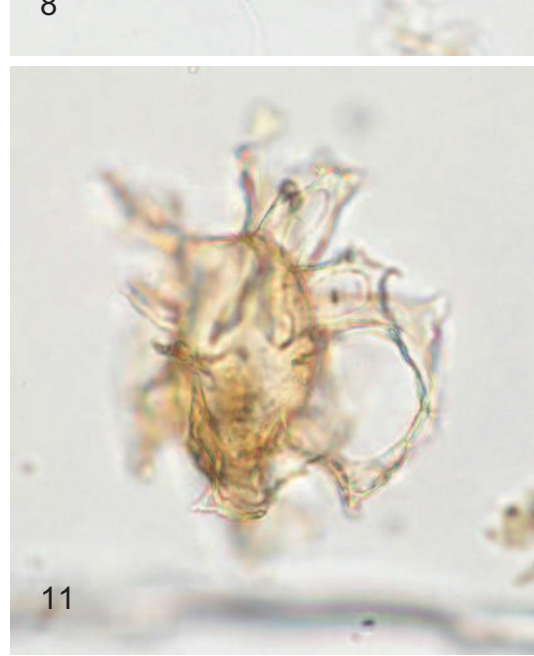
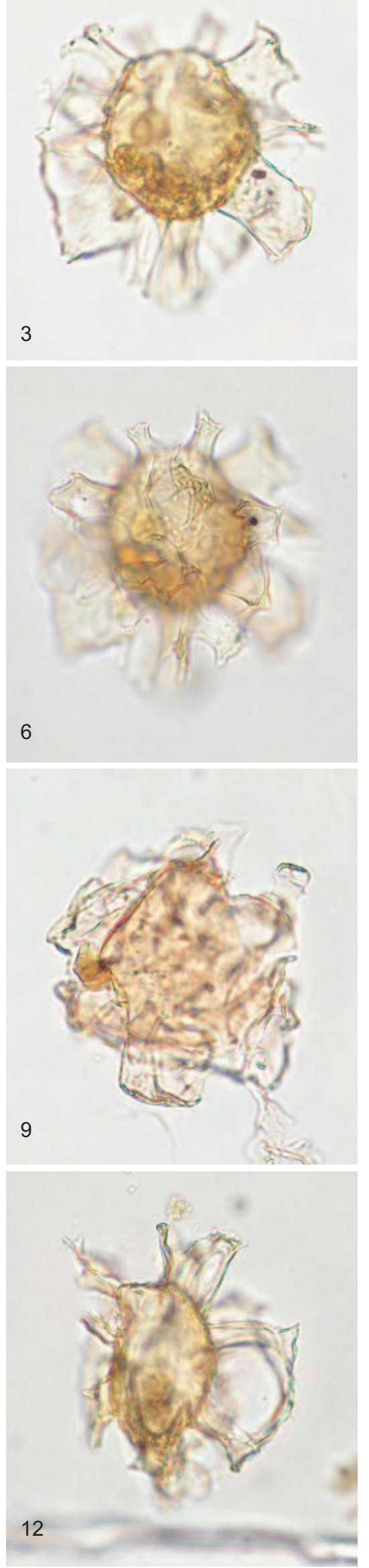


\section{Plate 49}

\section{Hystrichokolpoma cinctum}

Figure 1-3 Sample K29/f101, slide L11037/SM002; Kaiata Mudstone, Cape Foulwind Section (Runangan)

\section{Hystrichokolpoma rigaudiae}

Figure 4-6 Sample J42/f125, slide L11625/SM004; Totara Limestone, Kakanui River (Runangan-early Whaingaroan); x 525; specimen measures $85 \times 79 \mu \mathrm{m}$

Figure 7-9 Sample K29/f114, slide L11050/SM002; Port Elizabeth Member, Cape Foulwind Section (early Whaingaroan); x 450; specimen measures 105 x $83 \mu \mathrm{m}$

Hystrichokolpoma sp. 3

Figure 10-12 Sample I43/f093, slide L16341/SM092; Burnside Formation, Puketeraki Core (Bortonian); x 750; specimen measures 55 x $56 \mu \mathrm{m}$ 


\section{Plate 49}
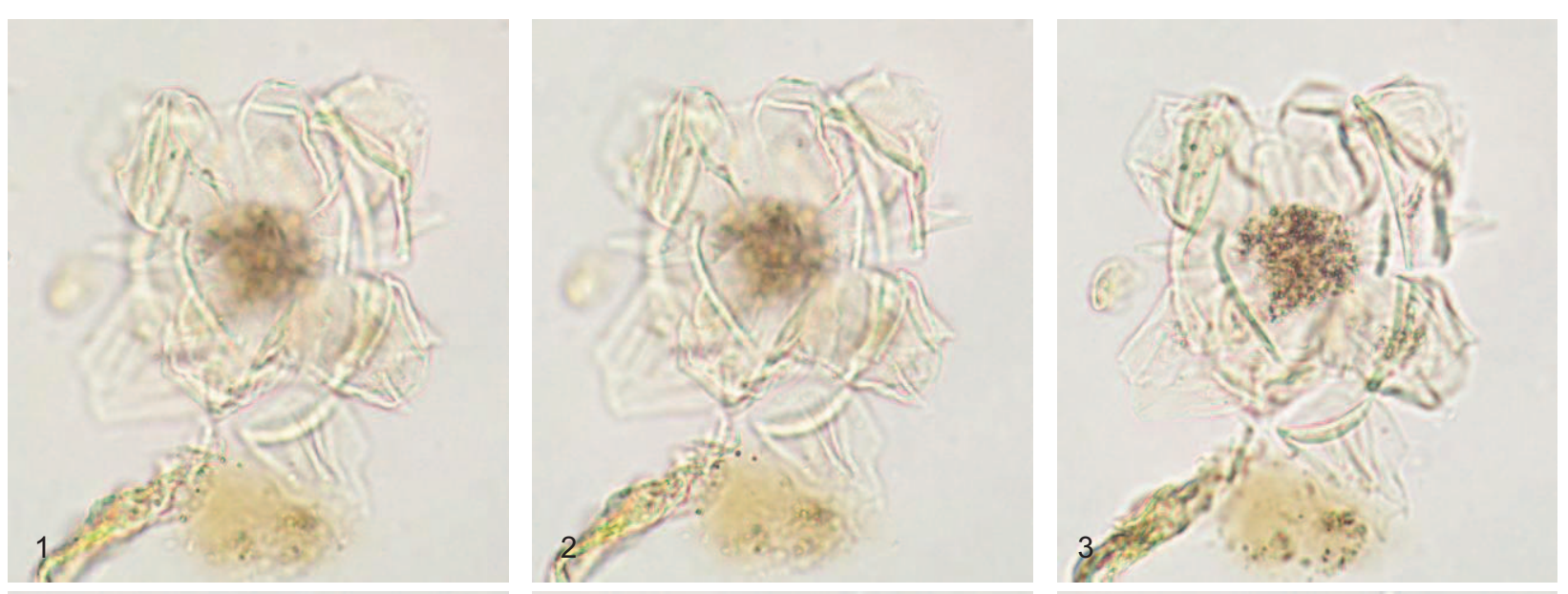

4
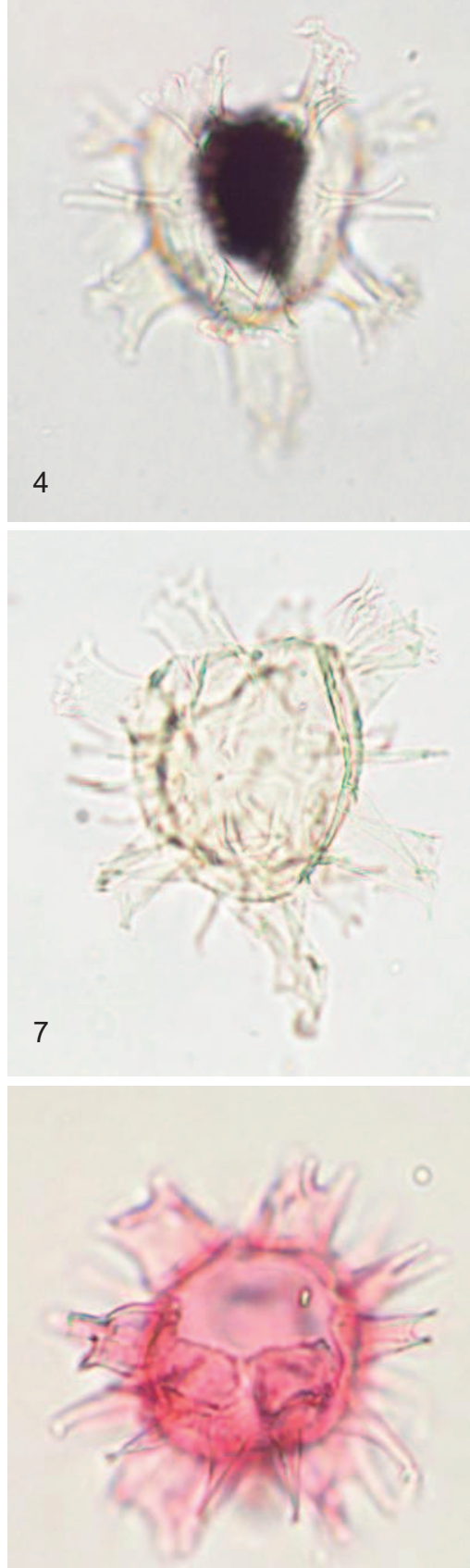

10
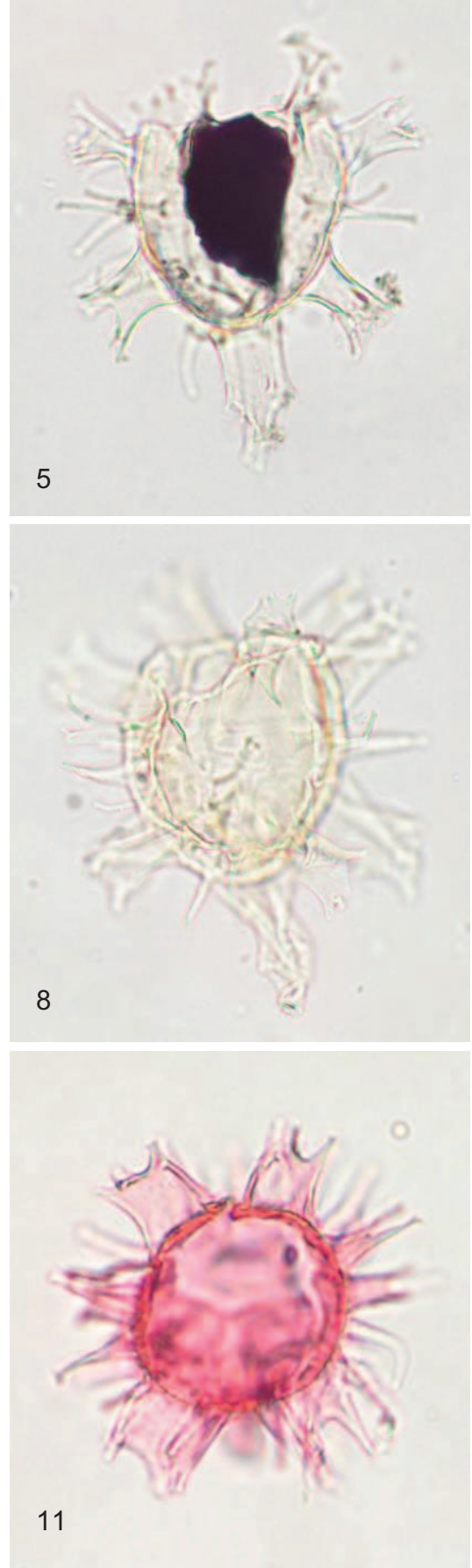
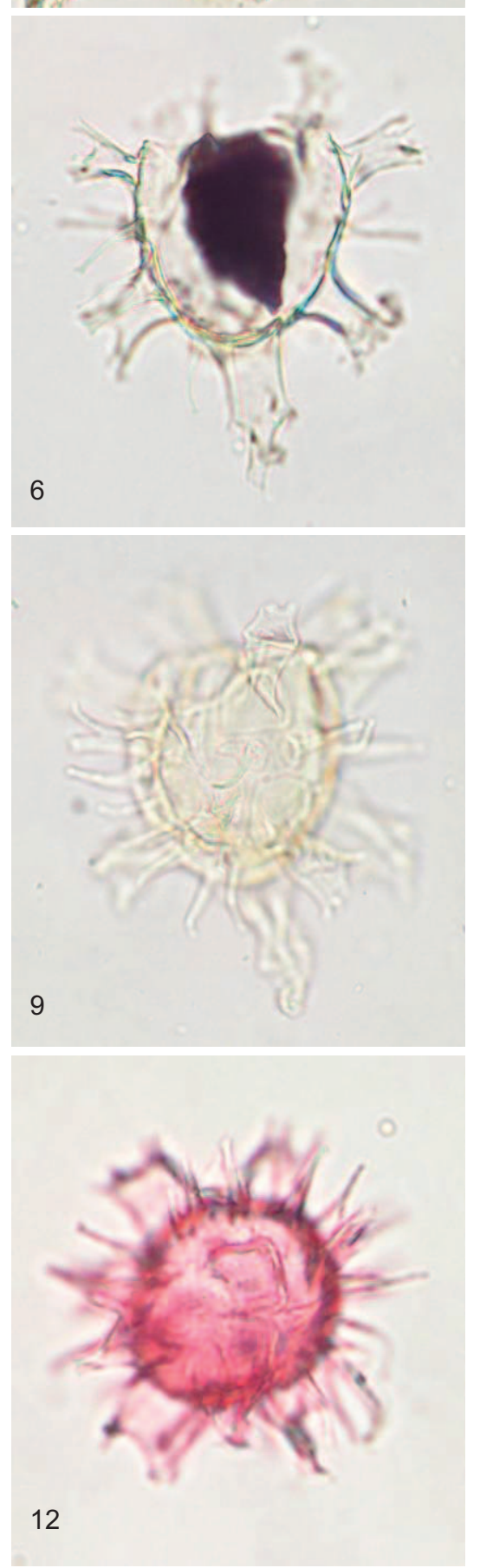


\section{Plate 50}

\section{Hystrichokolpoma sp. 3}

Figure 1-3 Sample 143/f093, slide L16341/SM158; Burnside Formation, Puketeraki Core (Bortonian); x 450; specimen measures 58 x $94 \mu \mathrm{m}$

\section{Hystrichokolpoma spinosum}

Figure 4-9 Sample J42/f486, slide L23121/SM013; ?Hampden Formation, Hampden Beach Section (Porangan-Bortonian); x 600; specimen measures 58 x $71 \mu \mathrm{m}$

Figure 10-12 Sample J42/f483, slide L23118/SM019; Kurinui Formation, Hampden Beach Section (Heretaungan); x 650; specimen measures 70 x $65 \mu \mathrm{m}$ 


\section{Plate 50}
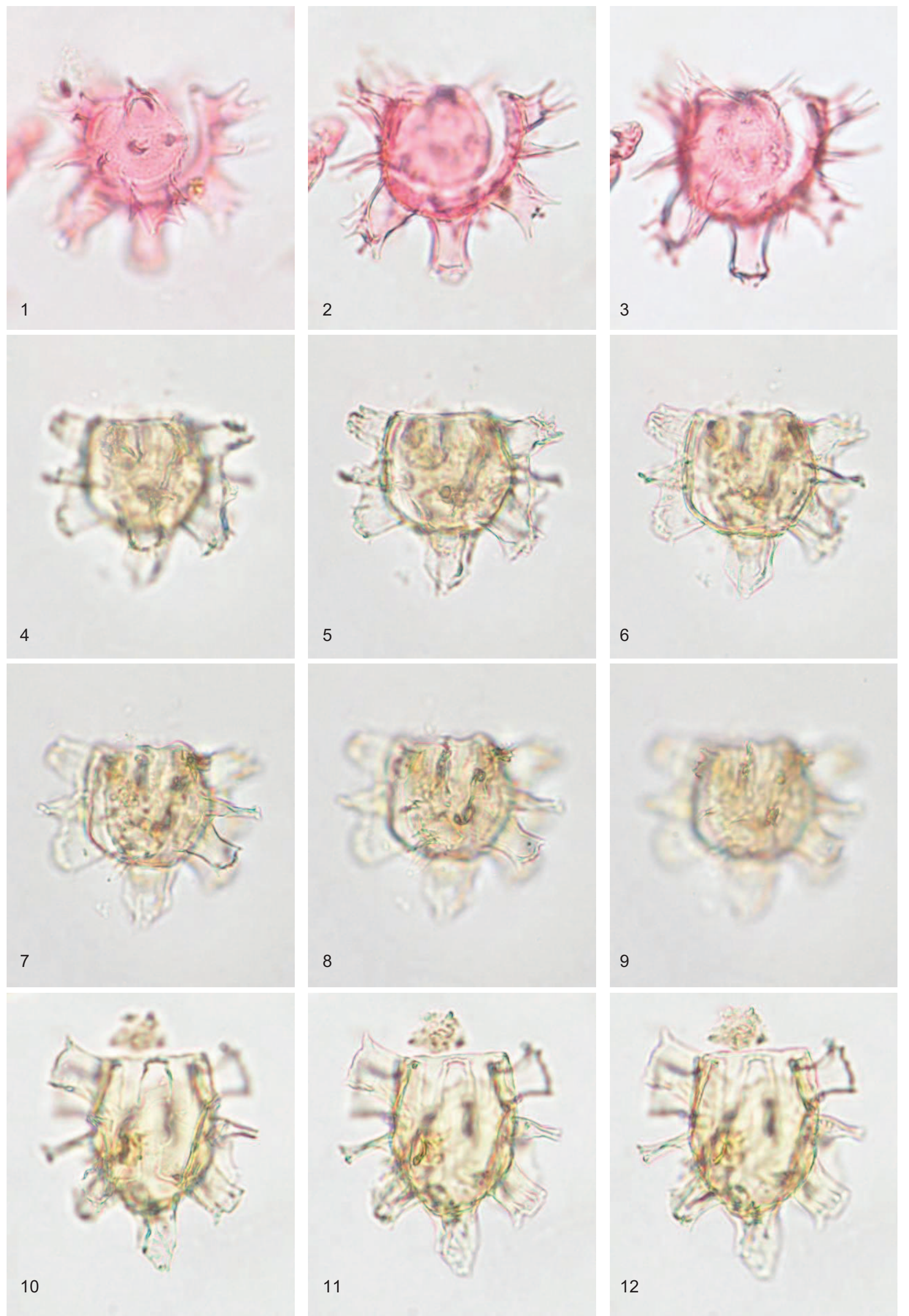


\section{Plate 51}

\section{Hystrichokolpoma spinosum}

Figure 1-3 Sample J42/f483, slide L23118/SM019; Kurinui Formation, Hampden Beach Section (Heretaungan); x 650; specimen measures 70 x $65 \mu \mathrm{m}$

\section{Diphyes colligerum}

Figure 4 Sample 143/f093, slide L16341/SM007; Burnside Formation, Puketeraki Core (Bortonian); x 725; specimen measures 64 x $54 \mu \mathrm{m}$

Figure 5 Sample 143/f093, slide L16341/SM008A; Burnside Formation, Puketeraki Core (Bortonian); x 600; specimen measures 58 x $69 \mu \mathrm{m}$

Figure 6 Sample J42/f483, slide L23118/SM012; Kurinui Formation, Hampden Beach Section (Heretaungan); x 650; specimen measures 58 x $65 \mu \mathrm{m}$

Figure 7-9 Sample J42/f302, slide L23132/SM023; Hampden Formation, Hampden Beach Section (Porangan-Bortonian); x 675; specimen measures $61 \times 62 \mu \mathrm{m}$

\section{Diphyes aff. colligerum}

Figure 10-12 Sample I43/f093, slide L16341/SM171; Burnside Formation, Puketeraki Core (Bortonian); x 600; specimen measures $52 \times 69 \mu \mathrm{m}$ 


\section{Plate 51}
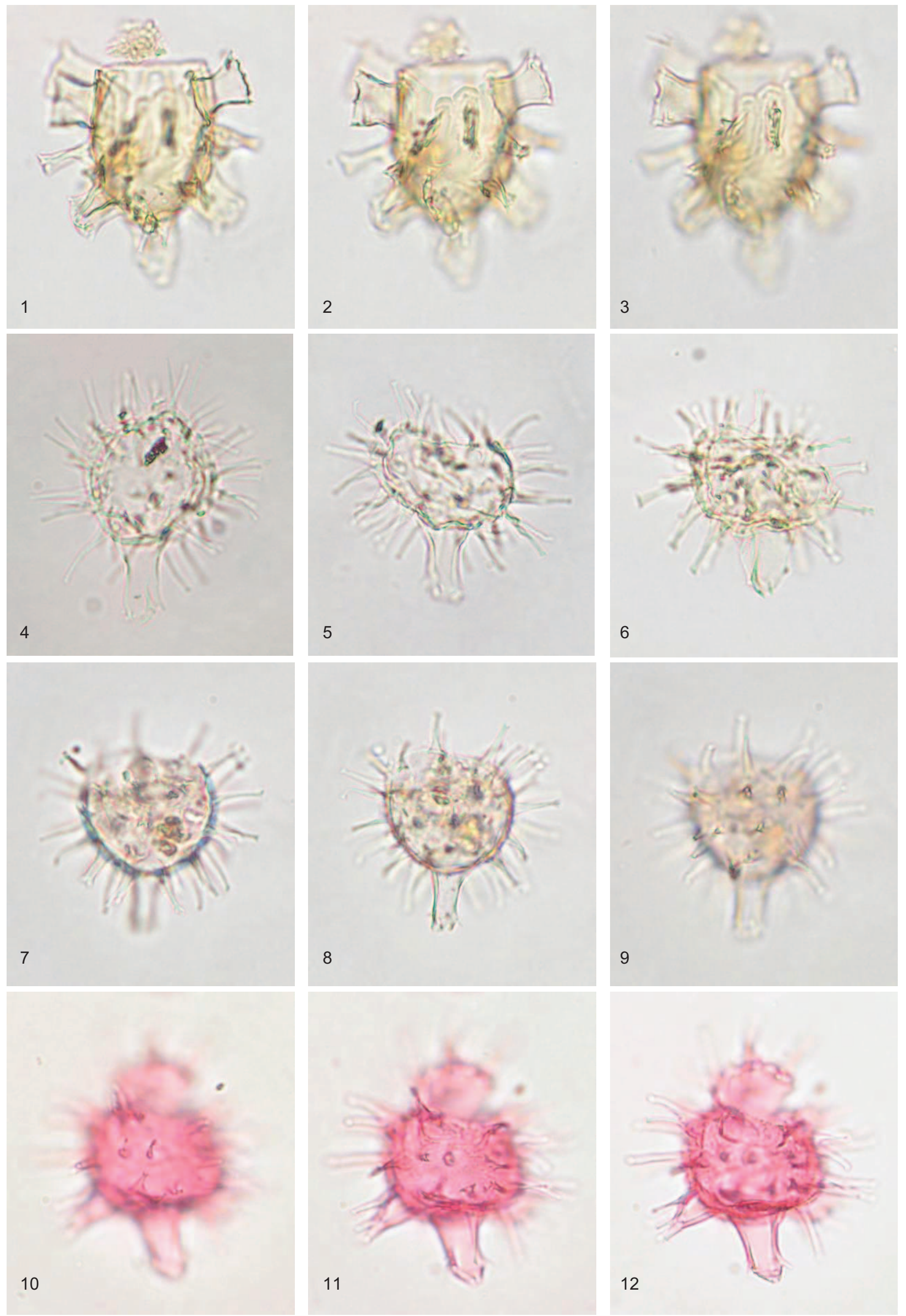


\section{Plate 52}

\section{Diphyes aff. colligerum}

Figure 1-3 Sample 143/f093, slide L16341/SM171; Burnside Formation, Puketeraki Core (Bortonian); x 600; specimen measures 52 x $69 \mu \mathrm{m}$

Figure 4-9 Sample 143/f093, slide L16341/1-1424-176; Burnside Formation, Puketeraki Core (Bortonian); x 725; specimen measures 62 × $58 \mu \mathrm{m}$

\section{Diphyes ficusoides}

Figure 10-12 Sample J41/f8914, slide L04979/SM1085; Waiareka Volcanics, Jacksons Paddock (KaiatanRunangan); x 550; specimen measures 69 × $75 \mu \mathrm{m}$ 


\section{Plate 52}
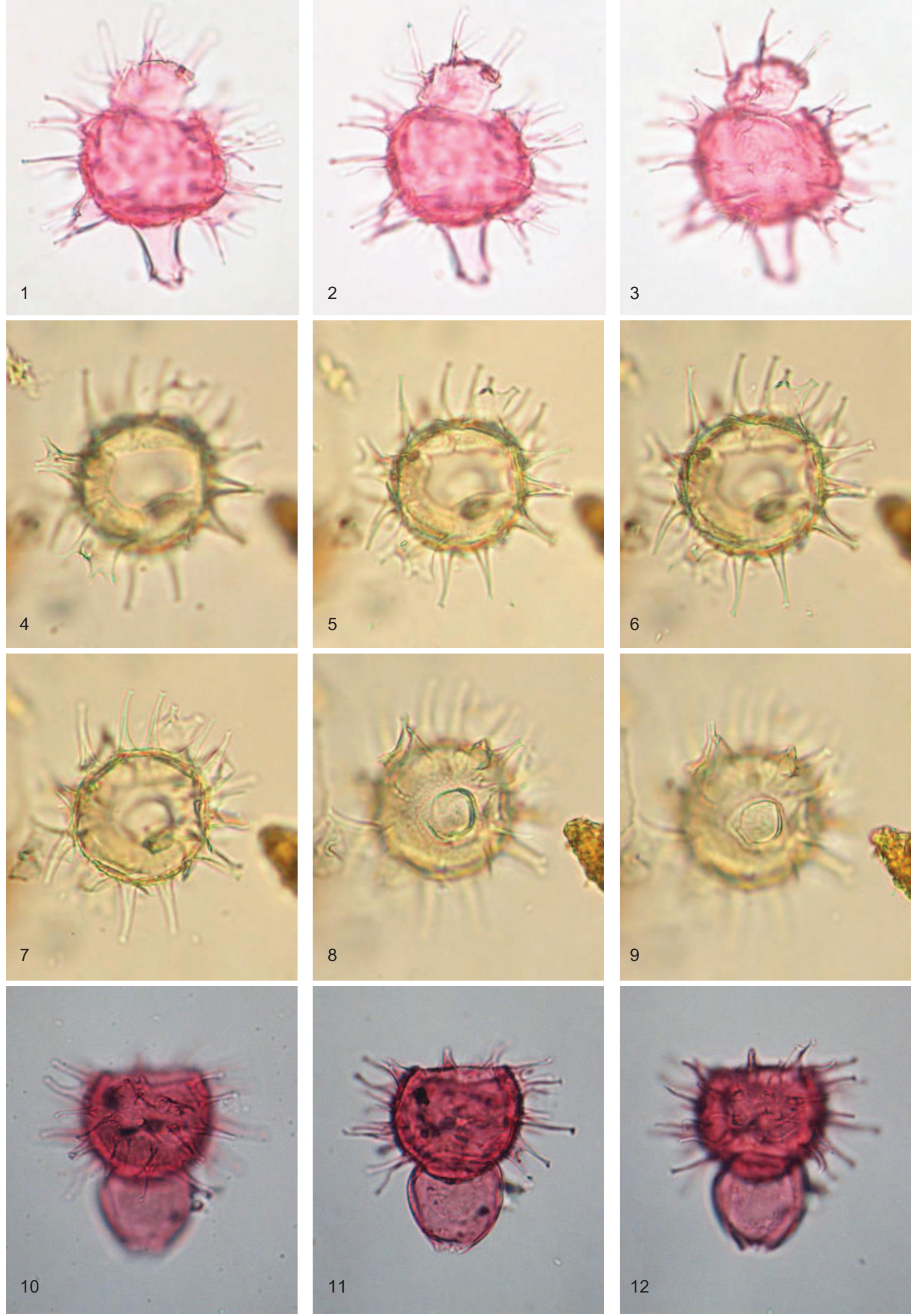


\section{Plate 53}

\section{Diphyes brevispinum}

Figure 1-3 Sample 143/f096, slide L16344/1-1329-020; Burnside Formation, Puketeraki Core (Kaiatan); x 775; specimen measures $60 \times 55 \mu \mathrm{m}$

\section{Lingulodinium ?machaerophorum}

Figure 4-9 Sample 143/f093, slide L16341/SM168; Burnside Formation, Puketeraki Core (Bortonian); x 575; specimen measures $78 \times 73 \mu \mathrm{m}$

Operculodinium ?centrocarpum

Figure 10-12 Sample J42/f096, slide L10951/SM074; Totara Limestone, Kakanui River (early Whaingaroan); x 675; specimen measures 60 × $62 \mu \mathrm{m}$ 


\section{Plate 53}
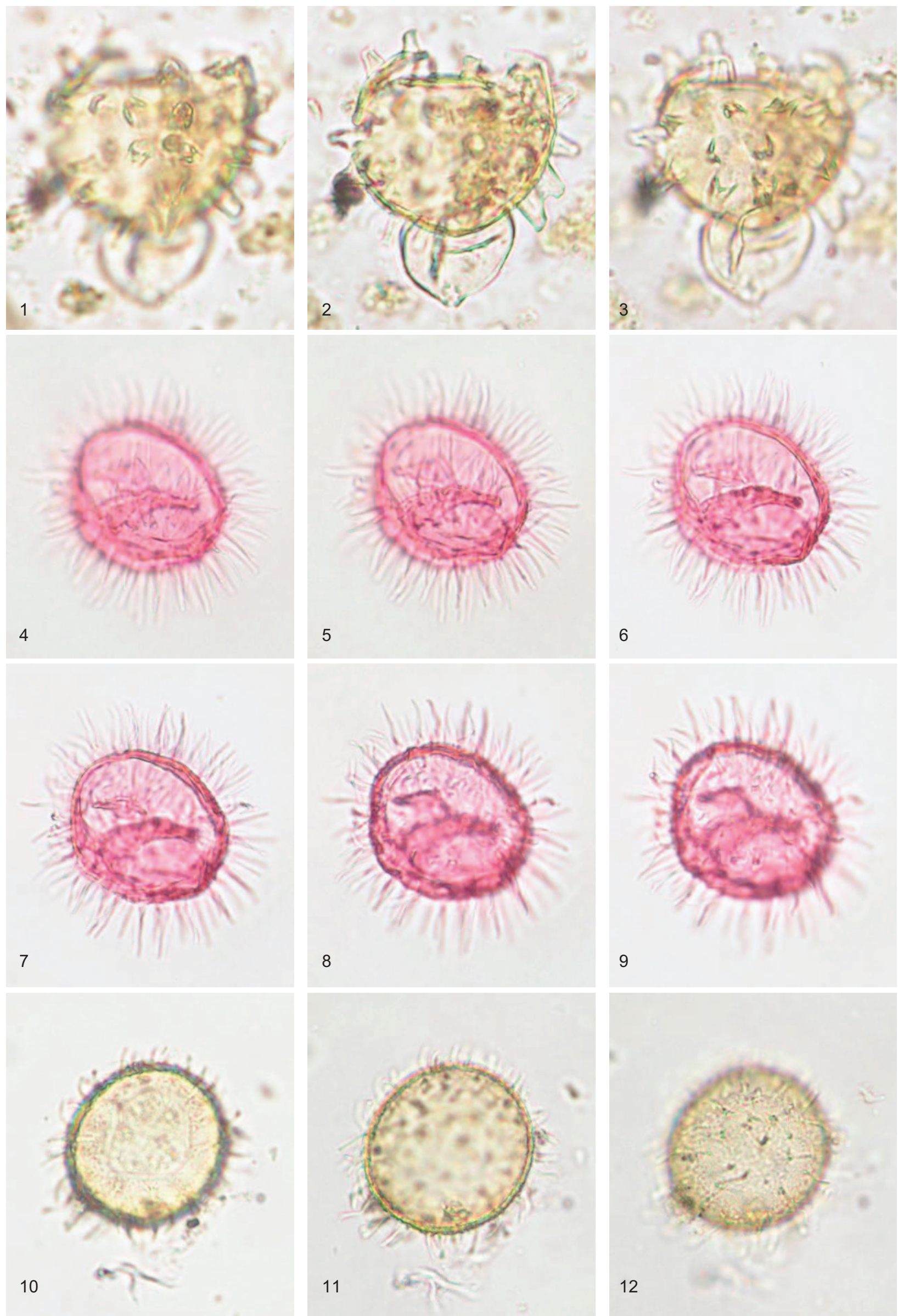


\section{Plate 54}

\section{Operculodinium ?centrocarpum}

Figure 1-3 Sample J42/f096, slide L10951/SM075; Totara Limestone, Kakanui River (early Whaingaroan); x 675; specimen measures $58 \times 63 \mu \mathrm{m}$

\section{Operculodinium schioleri}

Figure 4-9 Sample K29/f097, slide L10914/SM031; Port Elizabeth Member, Cape Foulwind Section (early Whaingaroan); x 325; specimen measures $133 \times 127 \mu \mathrm{m}$

Figure 10-12 Sample K29/f097, slide L10914/SM027; Port Elizabeth Member, Cape Foulwind Section (early Whaingaroan); x 375; specimen measures $116 \times 110 \mu \mathrm{m}$ 


\section{Plate 54}
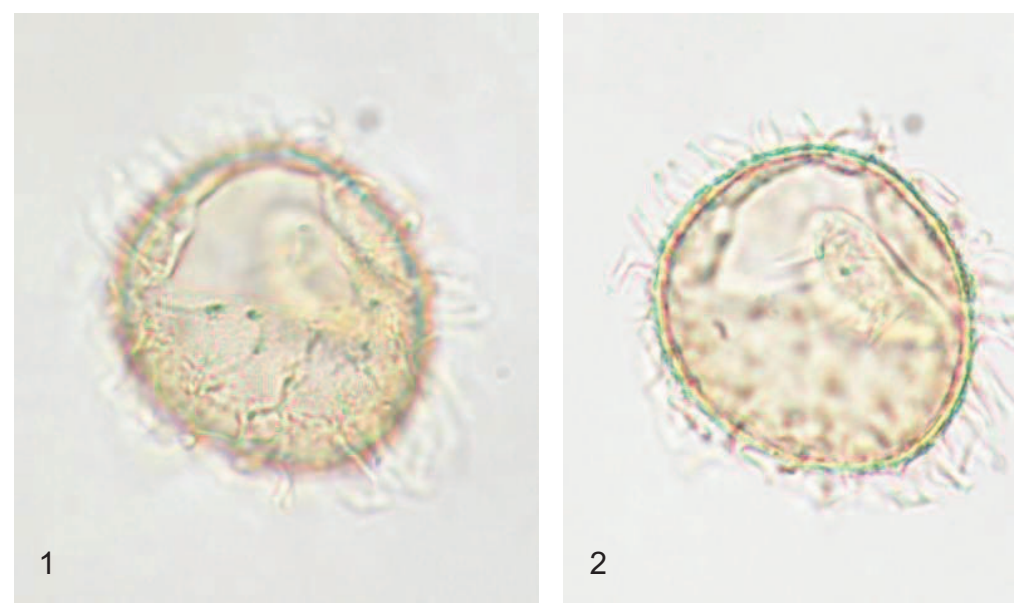

2
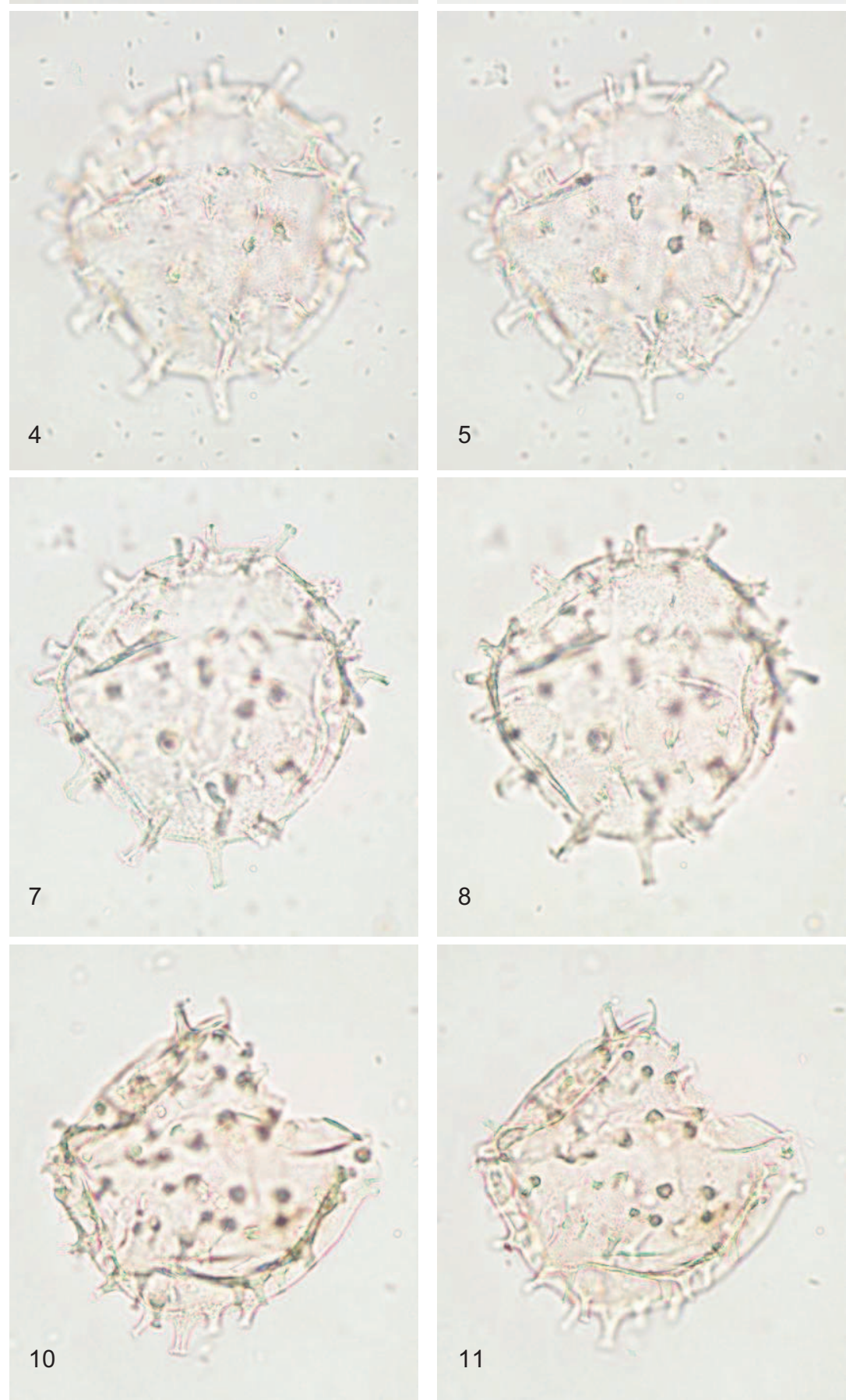

9

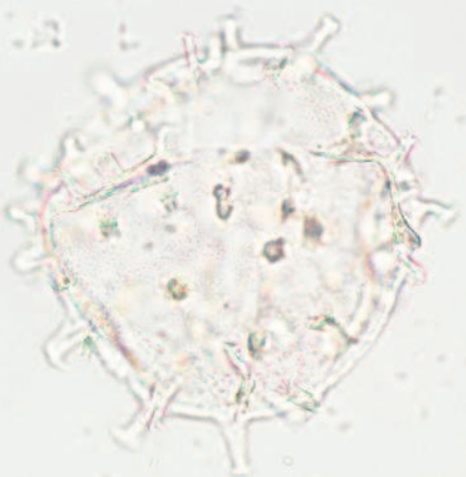

6
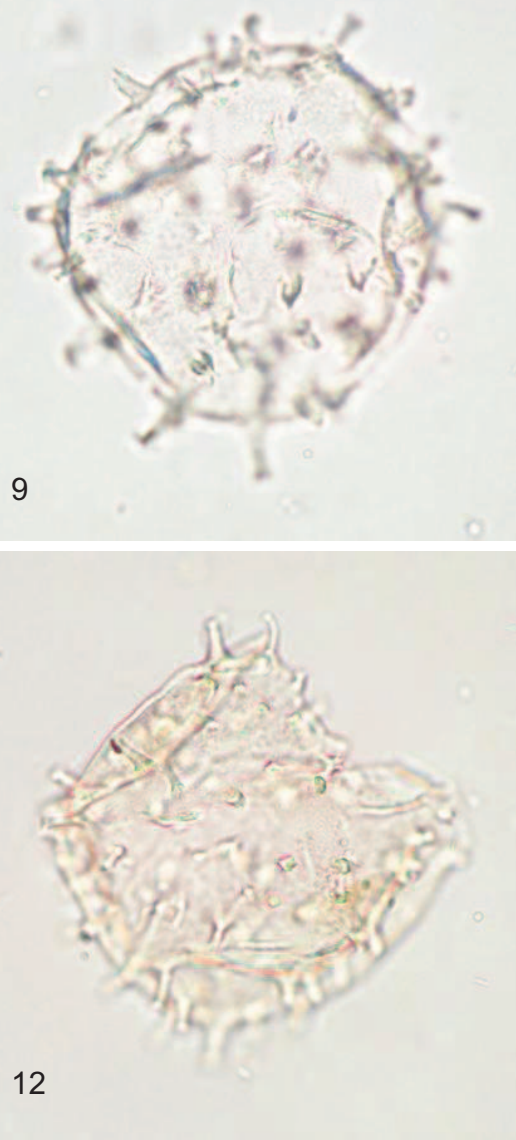


\section{Plate 55}

\section{Operculodinium sp. 10}

Figure 1-3 Sample K29/f097, slide L10914/SM033; Port Elizabeth Member, Cape Foulwind Section (early Whaingaroan); x 350; specimen measures 125 x $122 \mu \mathrm{m}$

\section{Operculodinium vulgare}

Figure 4-6 Sample 143/f093, slide L16341/SM066; Burnside Formation, Puketeraki Core (Bortonian); x 500; specimen measures 81 × $82 \mu \mathrm{m}$

Figure 7-9 Sample K29/f097, slide L10914/SM025; Port Elizabeth Member, Cape Foulwind Section (early Whaingaroan); x 300; specimen measures $150 \times 135 \mu \mathrm{m}$

Operculodinium ?janduchenei

Figure 10-12 Sample J42/f302, slide L23132/SM013; Hampden Formation, Hampden Beach Section (Porangan-Bortonian); x 850; specimen measures 48 x $49 \mu \mathrm{m}$ 


\section{Plate 55}
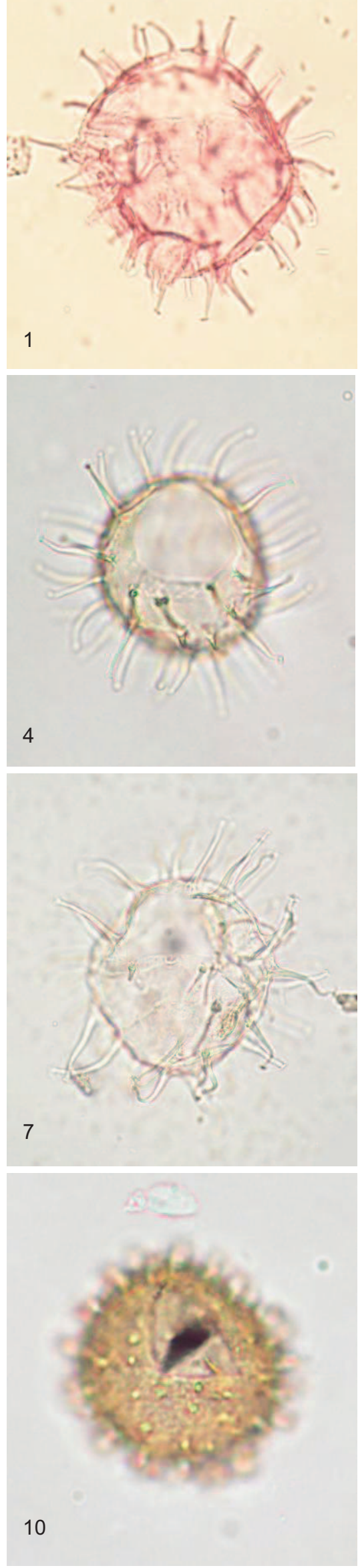
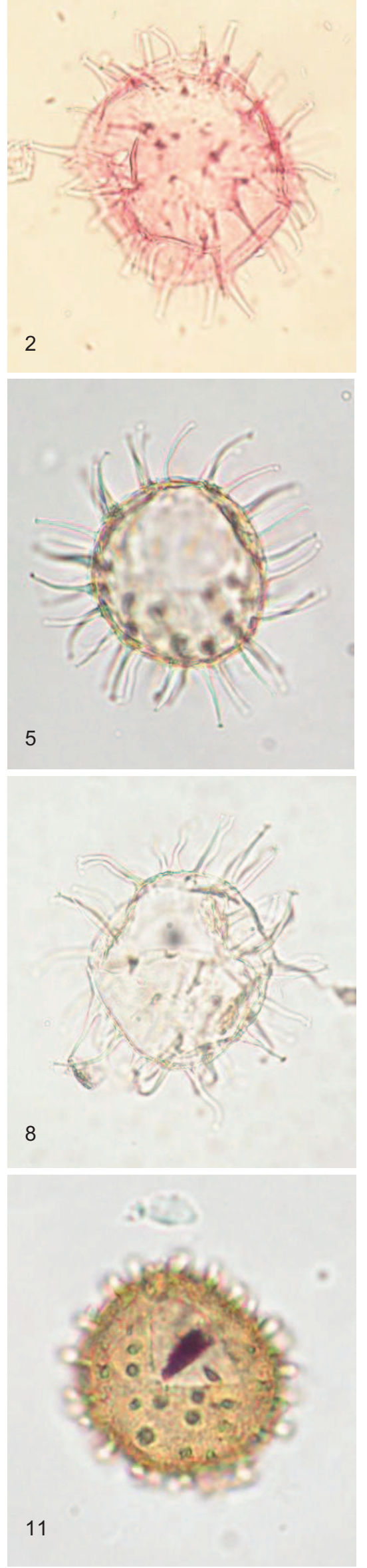
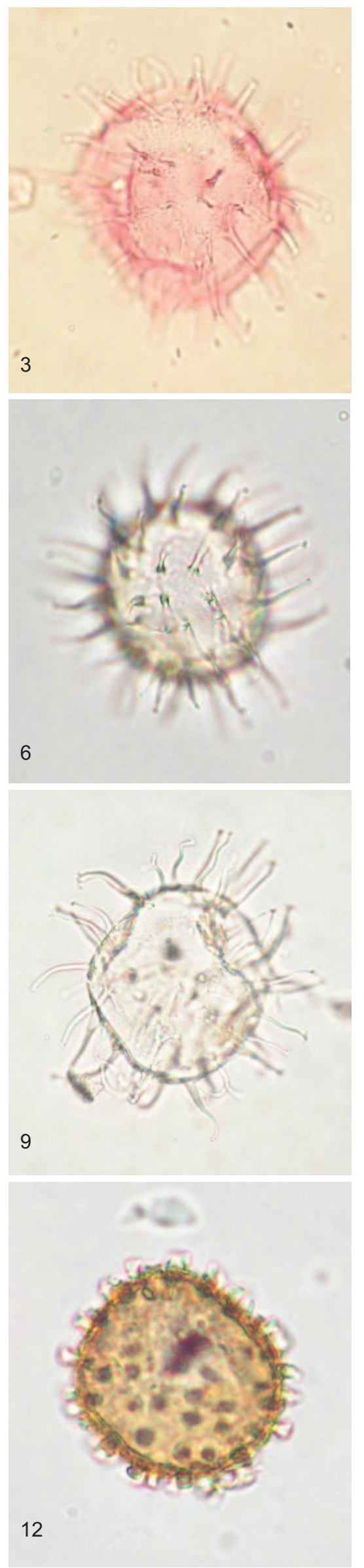


\section{Plate 56}

\section{Operculodinium ?janduchenei}

Figure 1-2 Sample J42/f302, slide L23132/SM013; Hampden Formation, Hampden Beach Section (Porangan-Bortonian); x 850; specimen measures 48 x $49 \mu \mathrm{m}$

\section{Operculodinium pulcher}

Figure 3 Sample I43/f093, slide L16341/SM109; Burnside Formation, Puketeraki Core (Bortonian); x 725; specimen measures $53 \times 57 \mu \mathrm{m}$

Figure 4-6 Sample 143/f093, slide L16341/SM042; Burnside Formation, Puketeraki Core (Bortonian); x 700; specimen measures 58 x $59 \mu \mathrm{m}$

Figure 7-9 Sample 143/f093, slide L16341/SM065; Burnside Formation, Puketeraki Core (Bortonian); x 775; specimen measures 55 x $55 \mu \mathrm{m}$

Figure 10-12 Sample 143/f093, slide L16341/SM048; Burnside Formation, Puketeraki Core (Bortonian); x 775; specimen measures 53 × $55 \mu \mathrm{m}$ 


\section{Plate 56}

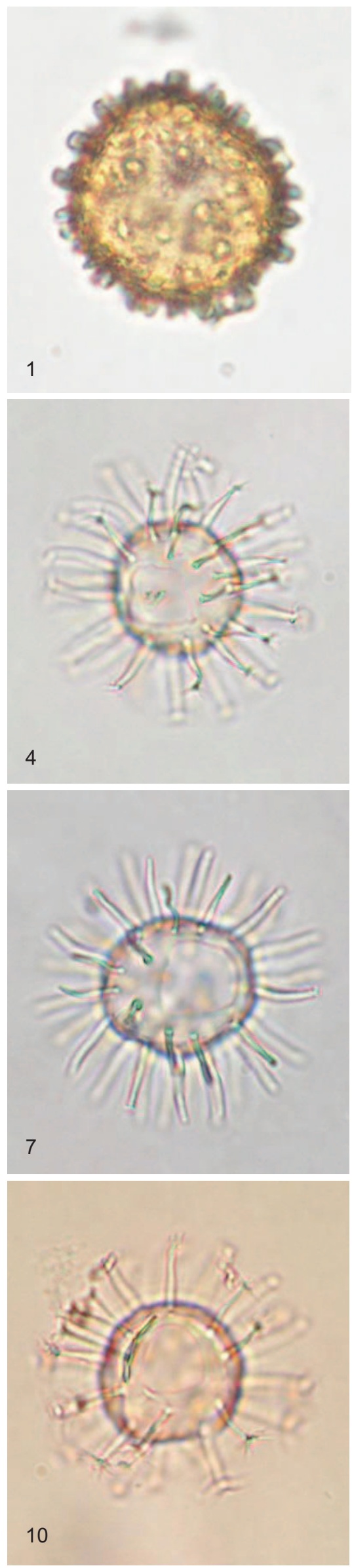

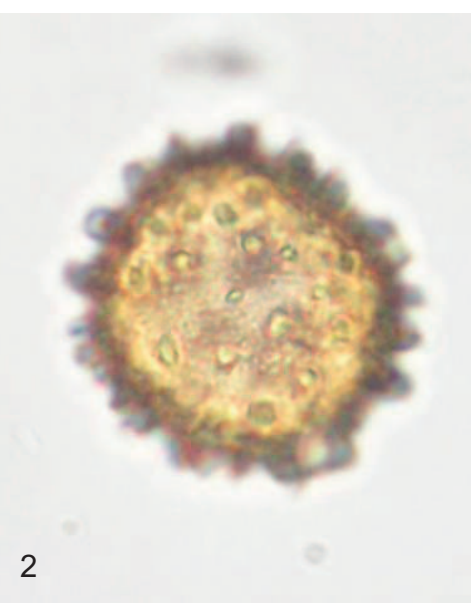
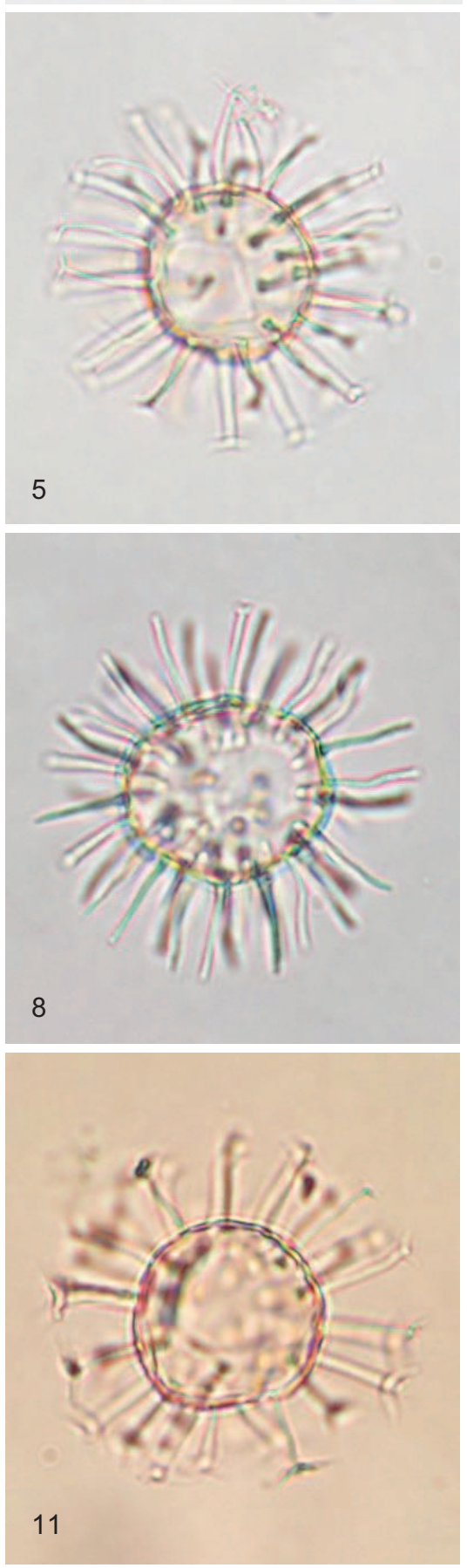
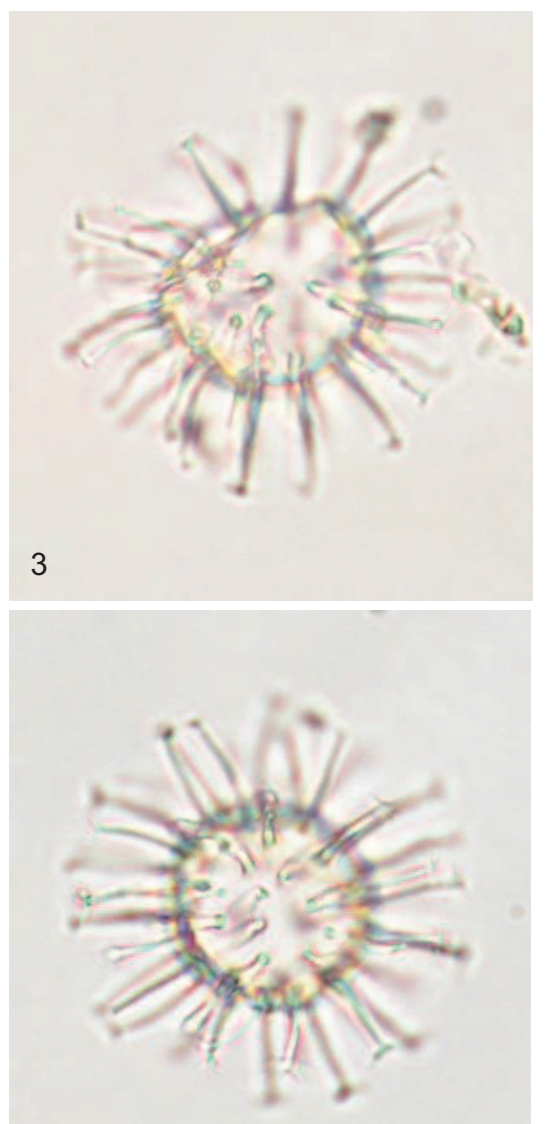

6
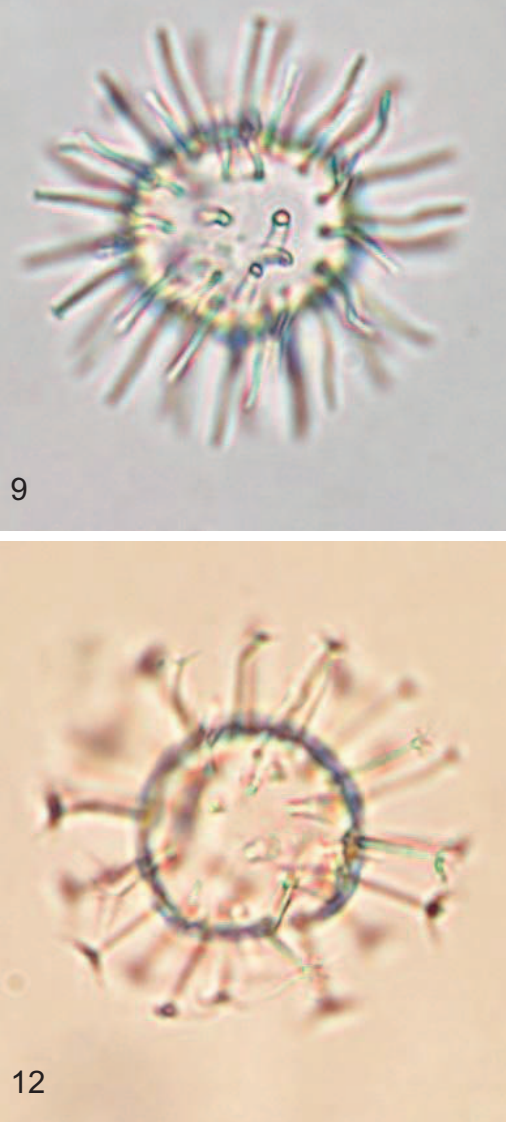


\section{Plate 57}

\section{Operculodinium sp. 5}

Figure 1-3 Sample U24/f419, slide L23127/SM042; Wanstead, Te Uri Stream (Porangan); x 850; specimen measures $55 \times 45 \mu \mathrm{m}$

Figure 4-6 Sample U24/f419, slide L23127/SM043; Wanstead, Te Uri Stream (Porangan); x 800; specimen measures $51 \times 52 \mu \mathrm{m}$

\section{Operculodinium sp. 7}

Figure 7-12 Sample 143/f092, slide L16340/1-1332-041; Burnside Formation, Puketeraki Core (Bortonian); x 875; specimen measures 44 x $48 \mu \mathrm{m}$ 


\section{Plate 57}
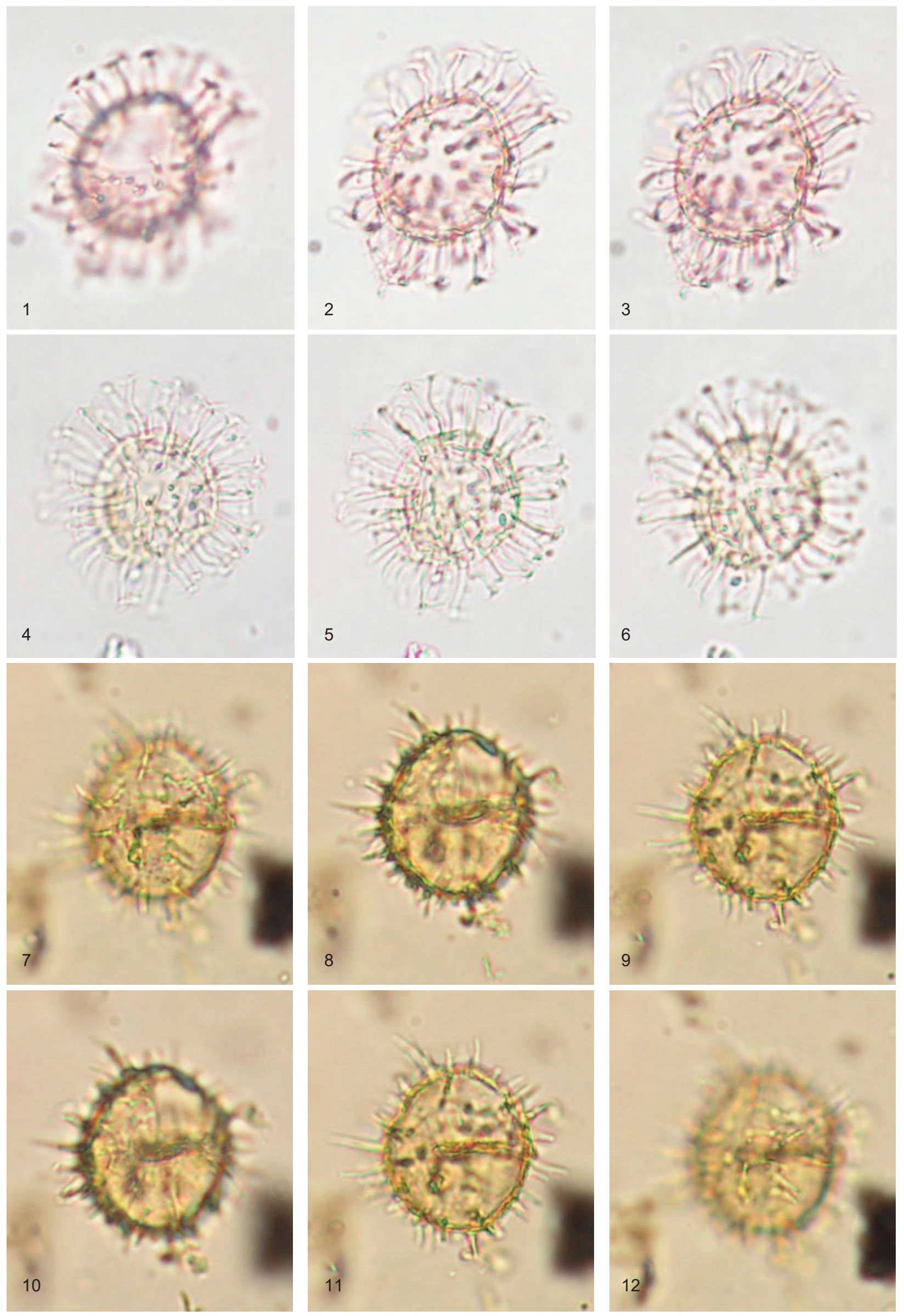


\section{Plate 58}

\section{Operculodinium ?xanthium}

Figure 1-3 Sample 143/f089, slide L16337/2-1349-101; Burnside Formation, Puketeraki Core (Bortonian); x 775; specimen measures 54 x $54 \mu \mathrm{m}$

\section{Operculodinium sp. 3}

Figure 4-6 Sample J42/f096, slide L10951/SM076; Totara Limestone, Kakanui River (early Whaingaroan); x 650; specimen measures $70 \times 65 \mu \mathrm{m}$

Operculodinium sp. 6

Figure 7-9 Sample J42/f483, slide L23118/SM017; Kurinui Formation, Hampden Beach Section (Heretaungan); x 625; specimen measures 63 x $67 \mu \mathrm{m}$

Operculodinium crouchii

Figure 10-12 Sample J42/f302, slide L23132/SM019; Hampden Formation, Hampden Beach Section (Porangan-Bortonian); x 625; specimen measures 75 x $60 \mu \mathrm{m}$ 


\section{Plate 58}
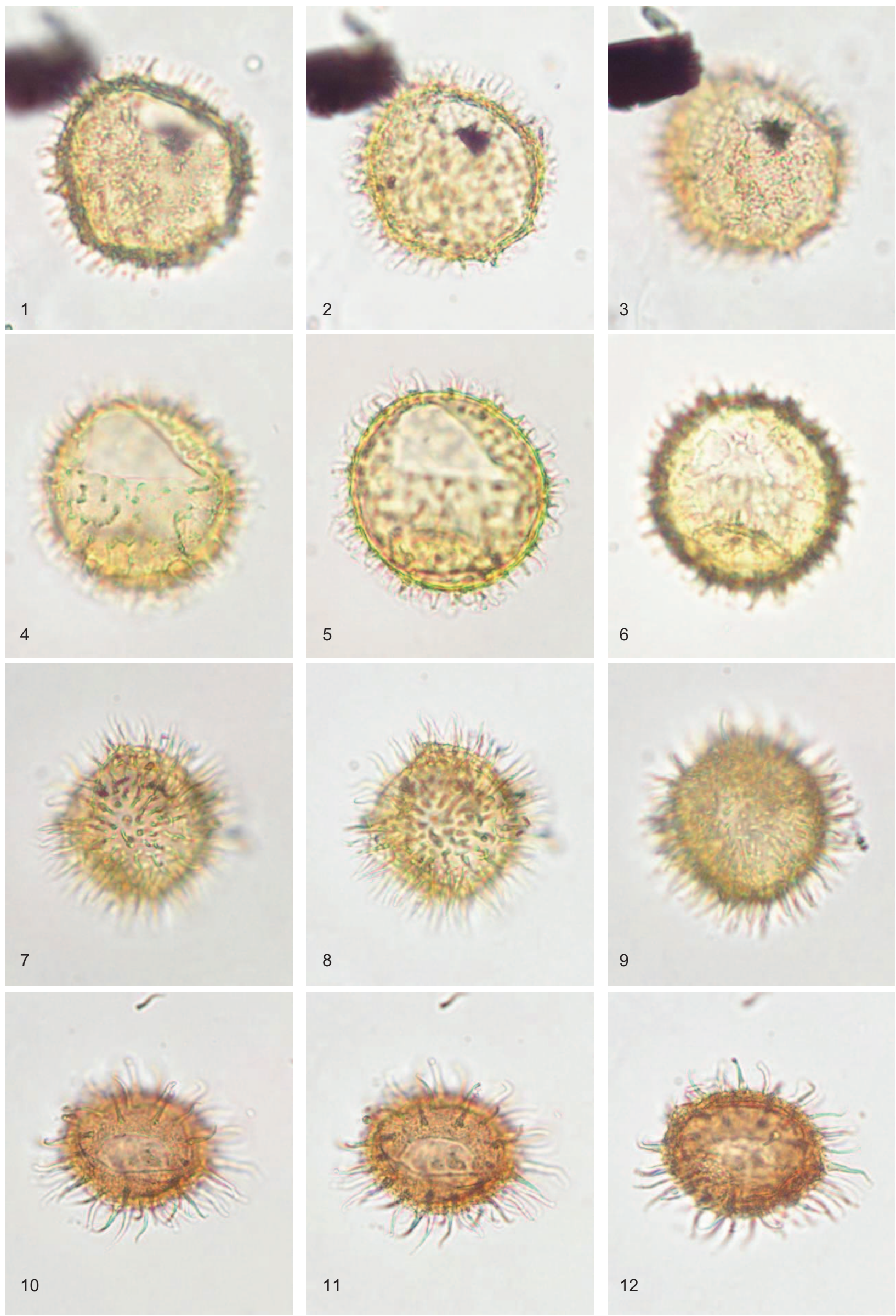


\section{Plate 59}

\section{Operculodinium crouchii}

Figure 1-3 Sample J42/f302, slide L23132/SM018; Hampden Formation, Hampden Beach Section (Porangan-Bortonian); x 500; specimen measures 82 × $85 \mu \mathrm{m}$

Figure 4-6 Sample J42/f302, slide L23132/SM017; Hampden Formation, Hampden Beach Section (Porangan-Bortonian); x 600; specimen measures 78 x $65 \mu \mathrm{m}$

Figure 7-9 Sample J42/f303, slide L23133/SM006; Hampden Formation, Hampden Beach Section (Bortonian); x 675; specimen measures 57 x $62 \mu \mathrm{m}$

Figure 10-12 Sample J42/f301, slide L23131/SM011; Hampden Formation, Hampden Beach Section (Porangan-Bortonian); x 575; specimen measures 70 x $72 \mu \mathrm{m}$ 


\section{Plate 59}
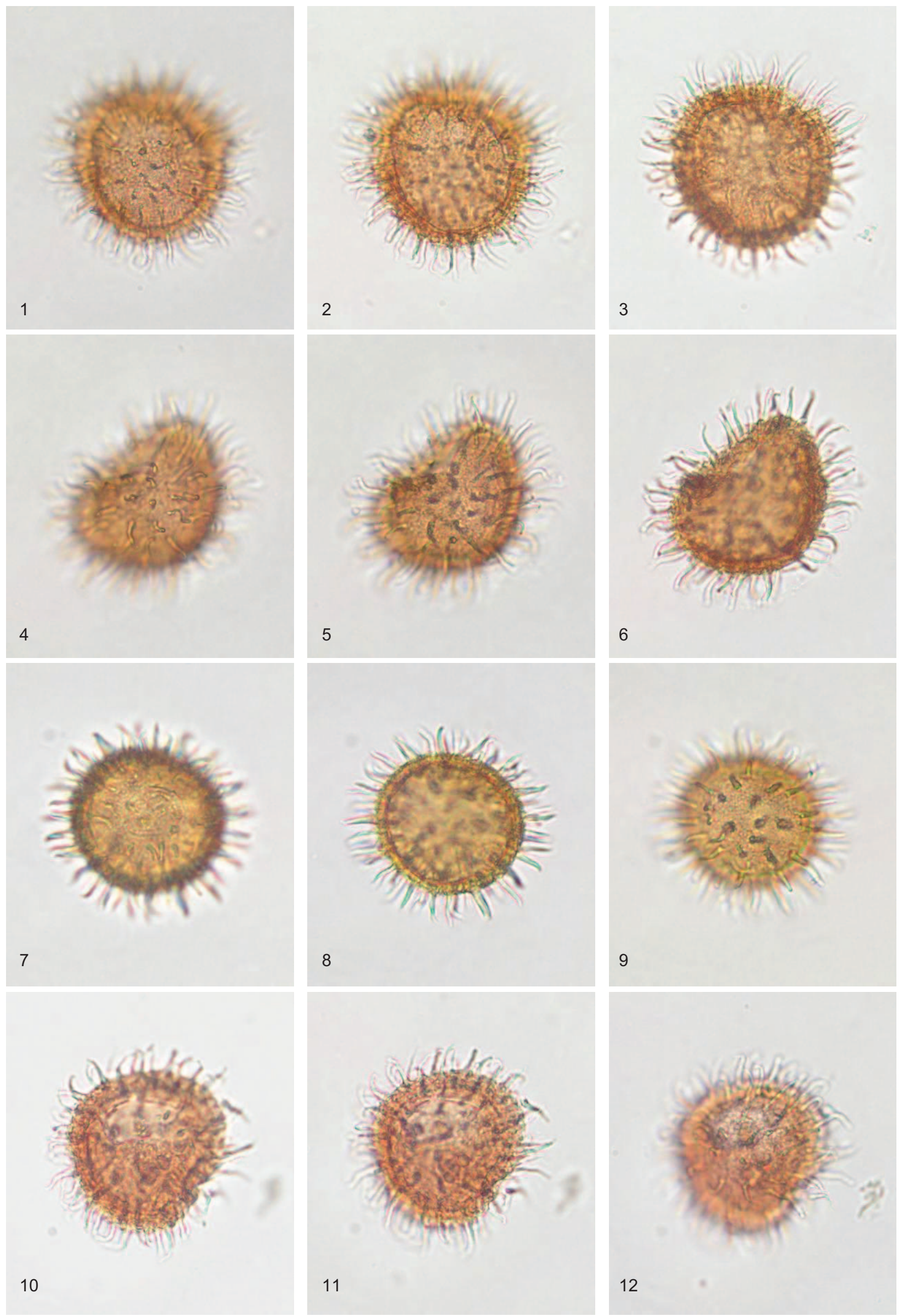


\section{Plate 60}

\section{Operculodinium sp. 11}

Figure 1-6 Sample 143/f090, slide L16338/SM035; Burnside Formation, Puketeraki Core (Bortonian); x 525; specimen measures $82 \times 80 \mu \mathrm{m}$

\section{Operculodinium sp. 12}

Figure 7-9 Sample J42/f488, slide L23123/SM011; Hampden Formation, Hampden Beach Section (Bortonian); x 725; specimen measures 65 × $50 \mu \mathrm{m}$

Figure 10-12 Sample U24/f417, slide L23125/SM007; Wanstead, Te Uri Stream (Porangan); x 625; specimen measures $70 \times 68 \mu \mathrm{m}$ 


\section{Plate 60}
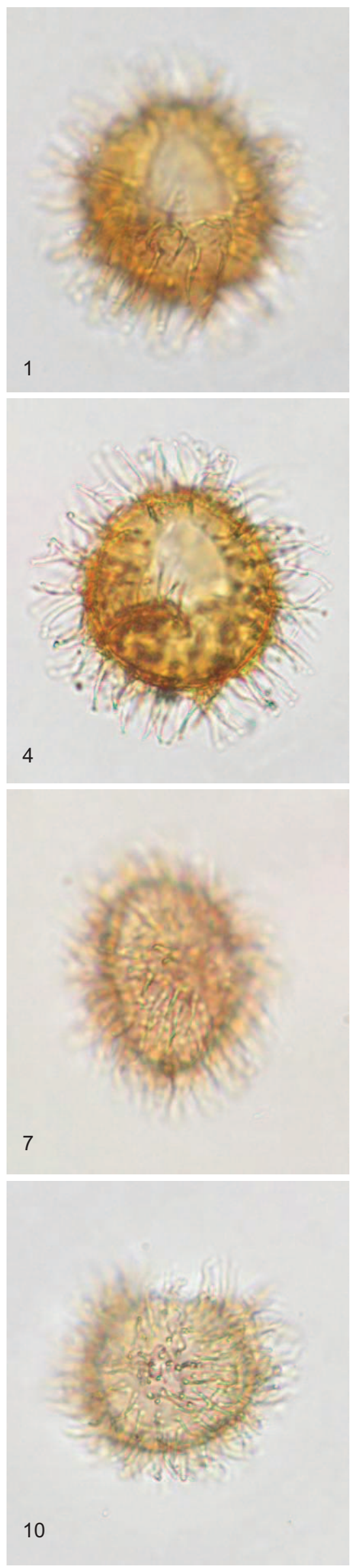
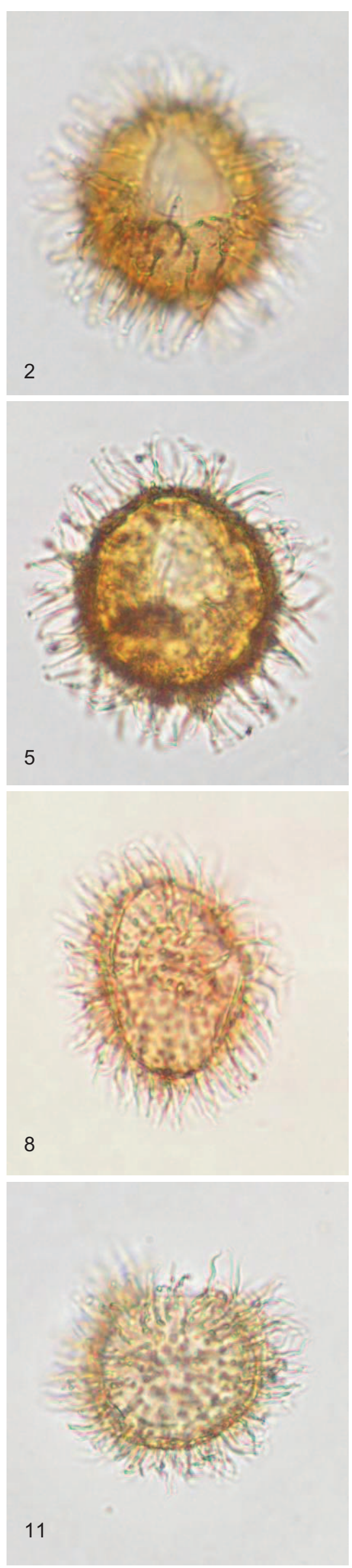
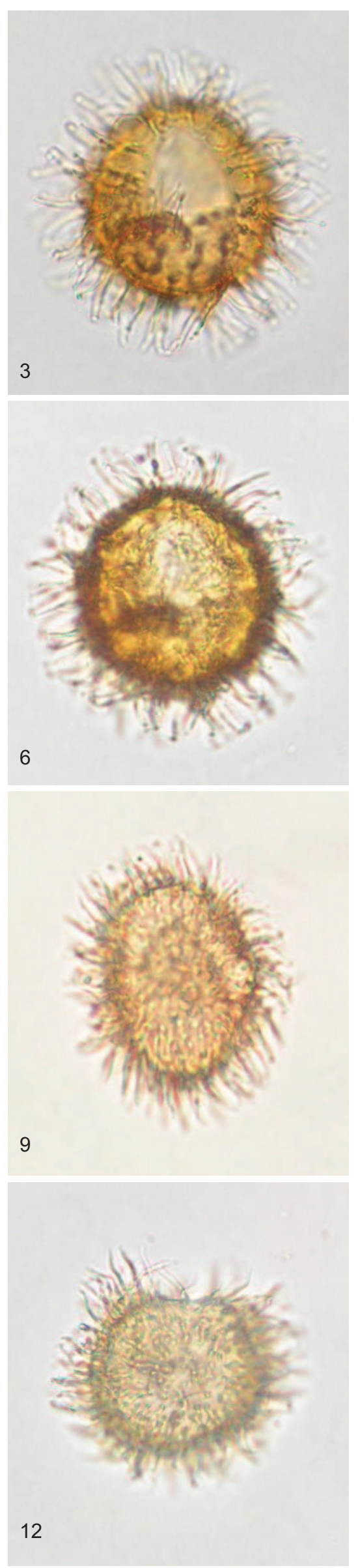


\section{Plate 61}

\section{Samlandia reticulifera}

Figure 1-3 Sample 143/f093, slide L16341/SM003; Burnside Formation, Puketeraki Core (Bortonian); x 450; specimen measures $106 \times 77 \mu \mathrm{m}$

Figure 4-6 Sample J42/f097, slide L10952/SM2963; Totara Limestone, Kakanui River (?early Whaingaroan); $x$ 450; specimen measures $102 \times 78 \mu \mathrm{m}$

\section{Samlandia tenuis}

Figure 7-12 Sample K29/f097, slide L10914/SM019; Port Elizabeth Member, Cape Foulwind Section (early Whaingaroan); x 375; specimen measures 122 × $100 \mu \mathrm{m}$ 


\section{Plate 61}
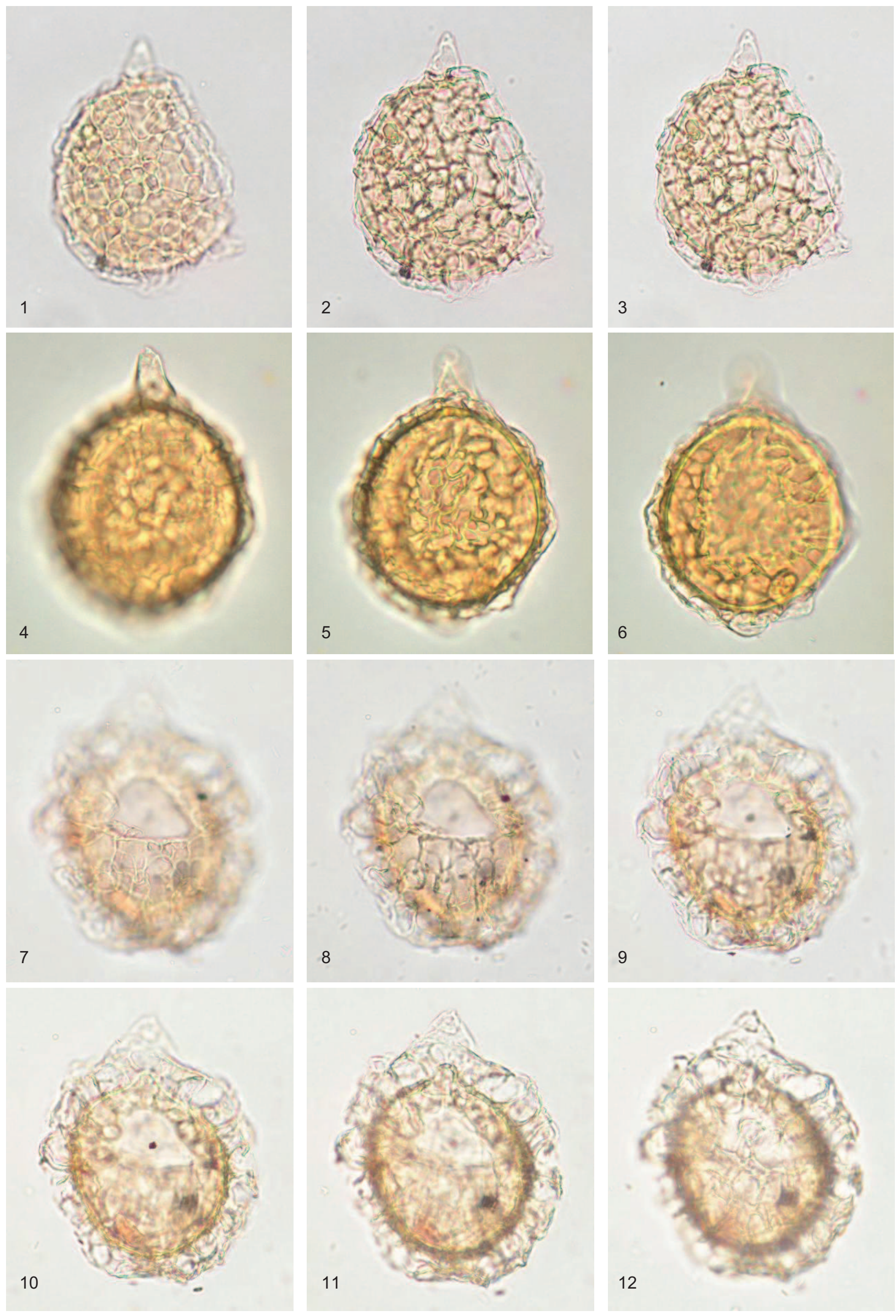


\section{Plate 62}

\section{Samlandia tenuis}

Figure 1-3 Sample 143/f093, slide L16341/SM166; Burnside Formation, Puketeraki Core (Bortonian); x 450; specimen measures $107 \times 90 \mu \mathrm{m}$

\section{Stoveracysta kakanuiensis}

Figure 4-6 Sample J42/f096, slide L10951/SM014; Totara Limestone, Kakanui River (early Whaingaroan); x 700; specimen measures 65 × $60 \mu \mathrm{m}$

\section{Stoveracysta ?ornata}

Figure 7-9 Sample K29/f104, slide L11040/SM001; Kaiata Mudstone, Cape Foulwind Section (Runangan); x 700; specimen measures 49 × $60 \mu \mathrm{m}$

\section{Thalassiphora pelagica}

Figure 10-12 Sample K29/f097, slide L10914/SM022; Port Elizabeth Member, Cape Foulwind Section (early Whaingaroan); x 225; specimen measures $200 \times 150 \mu \mathrm{m}$ 


\section{Plate 62}
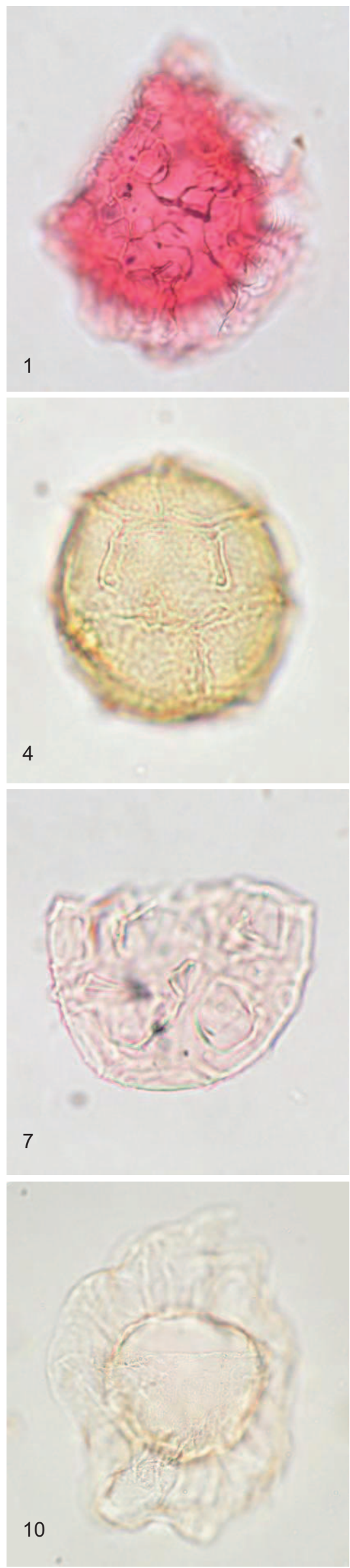
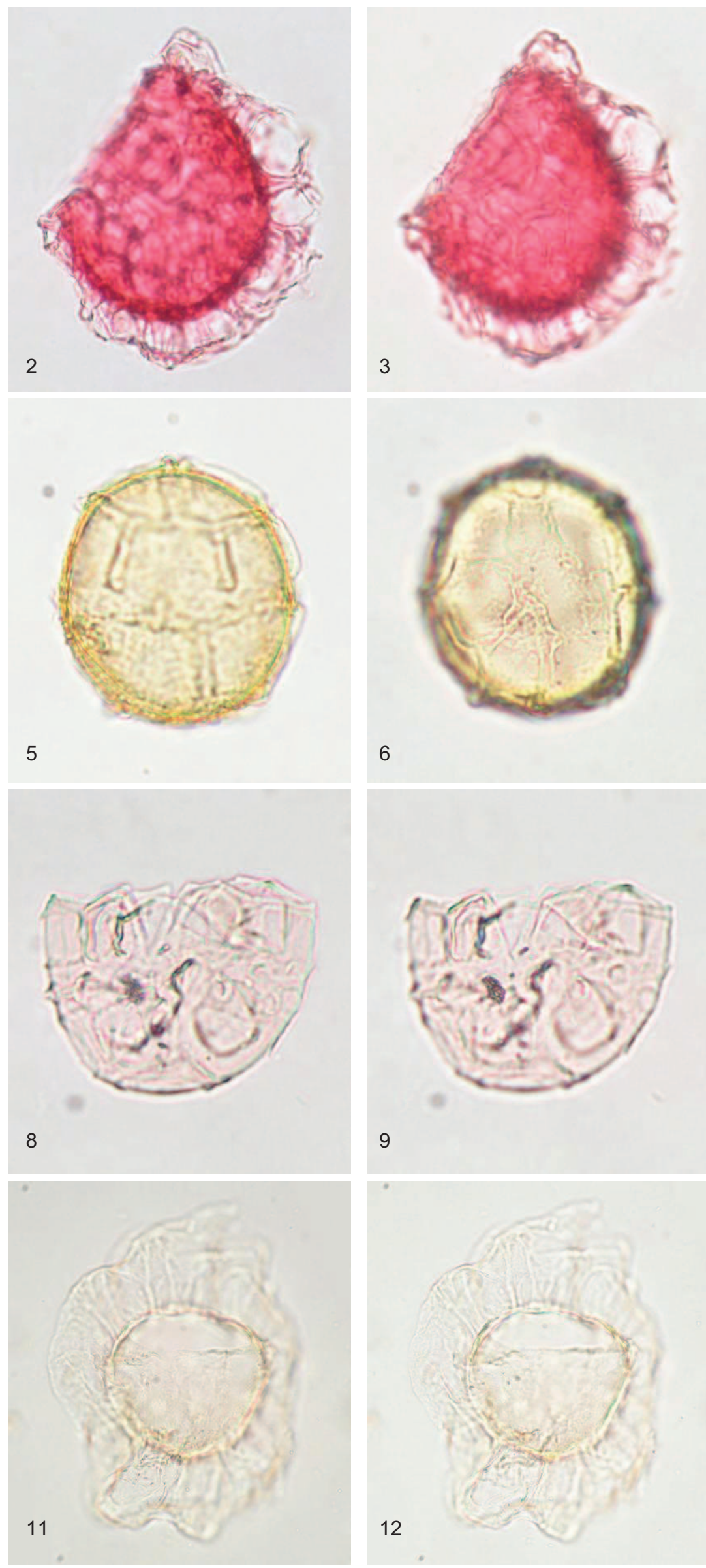
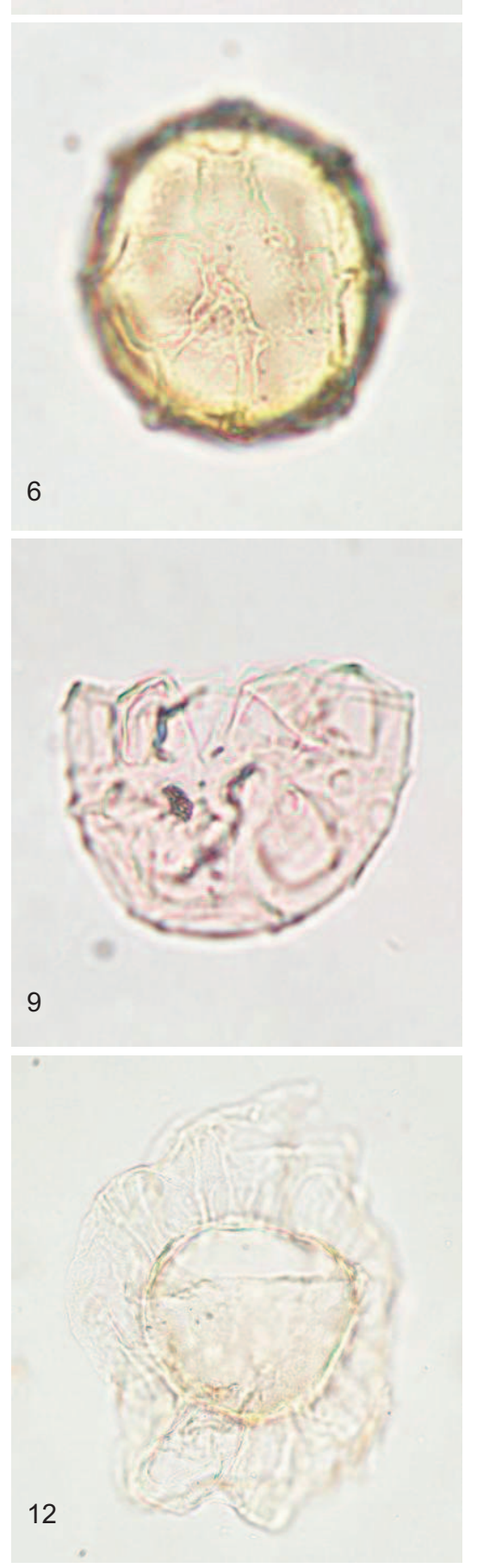


\section{Plate 63}

\section{Thalassiphora pelagica}

Figure 1-2 Sample K29/f097, slide L10914/SM022; Port Elizabeth Member, Cape Foulwind Section (early Whaingaroan); x 225; specimen measures $200 \times 150 \mu \mathrm{m}$

Figure 3-6 Sample 143/f093, slide L16341/SM095; Burnside Formation, Puketeraki Core (Bortonian); x 175; specimen measures 177 x $225 \mu \mathrm{m}$

Figure 7-9 Sample J42/f484, slide L23119/SM024; Kurinui Formation, Hampden Beach Section (Heretaungan); x 250; specimen measures 122 × $165 \mu \mathrm{m}$

Figure 10-12 Sample J42/f485, slide L23120/SM032; ?Hampden Formation, Hampden Beach Section (Porangan-Bortonian); x 375; specimen measures 122 × $115 \mu \mathrm{m}$ 


\section{Plate 63}
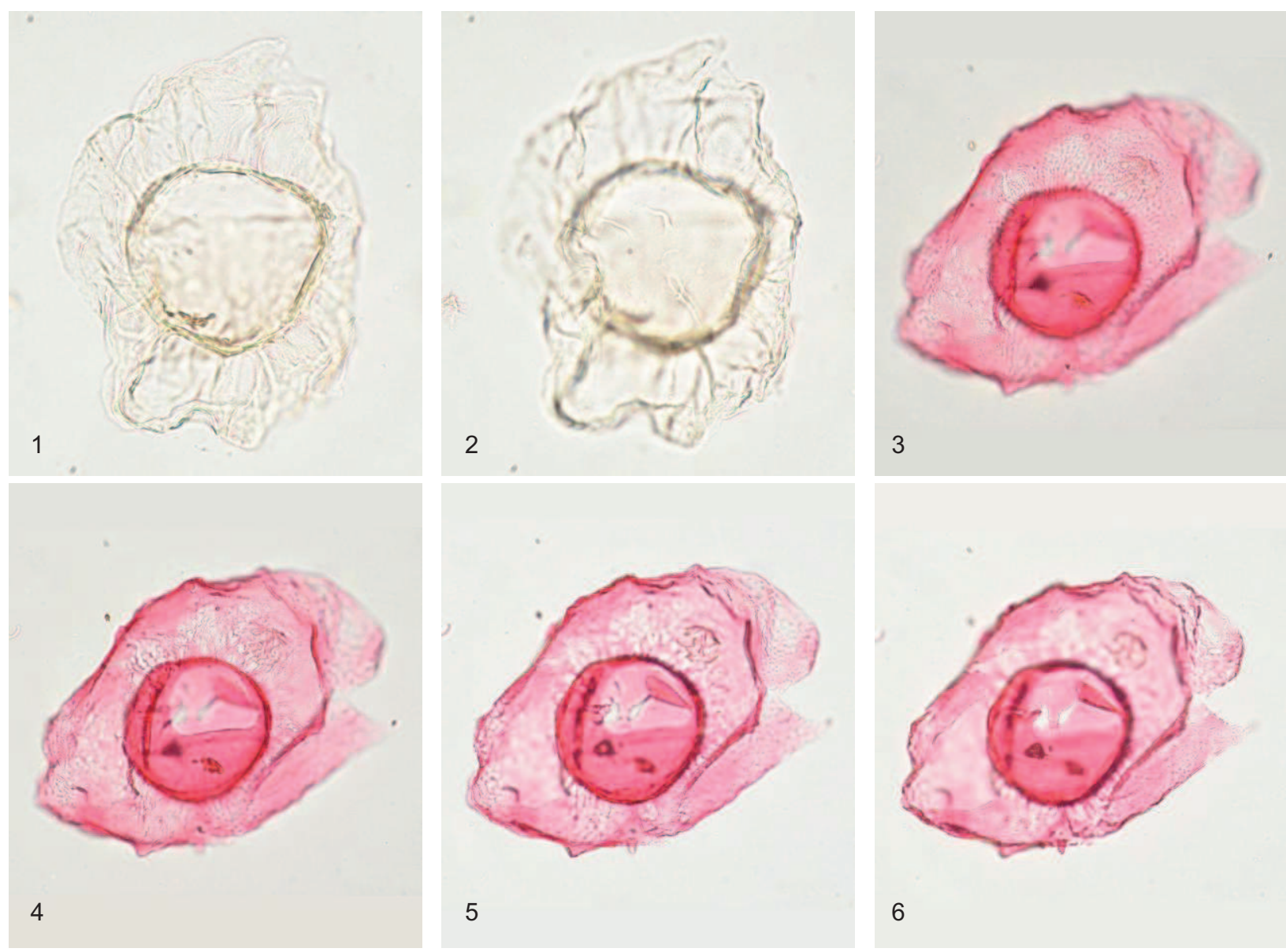

5

6

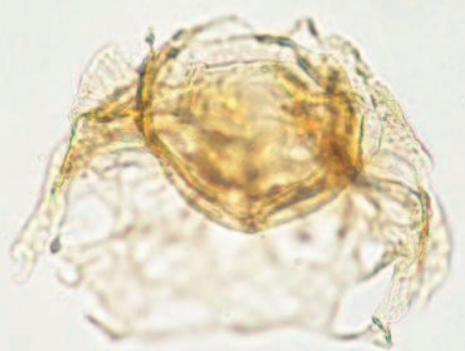

7

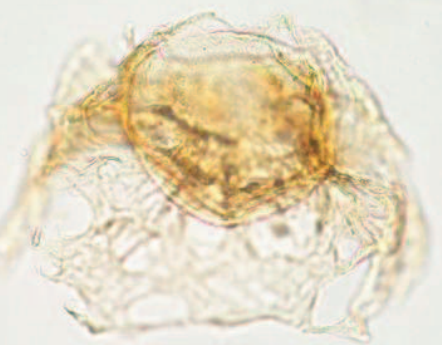

8

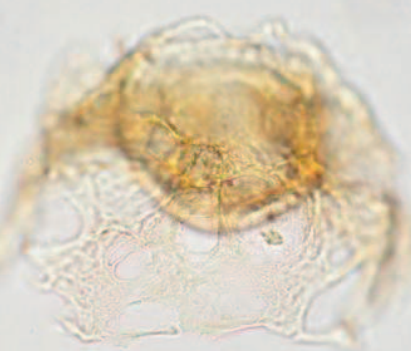

9
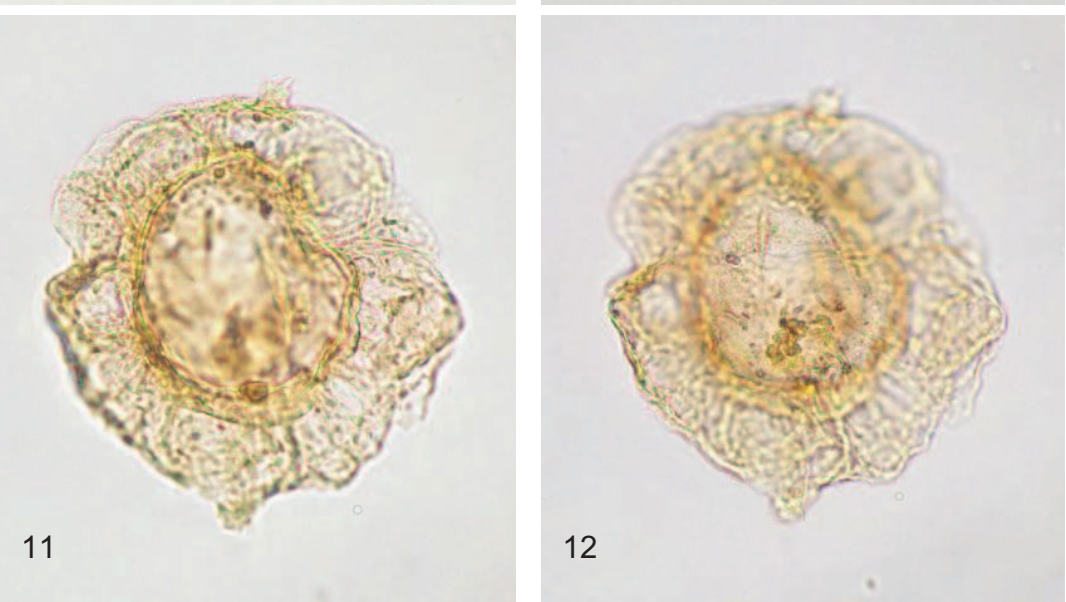


\section{Plate 64}

\section{?Tityrosphaeridium cantharellus}

Figure 1-3 Sample J42/f096, slide L10951/SM034; Totara Limestone, Kakanui River (early Whaingaroan); x 725; specimen measures $60 \times 58 \mu \mathrm{m}$

Figure 4-6 Sample J42/f125, slide L11625/SM012; Totara Limestone, Kakanui River (Runangan-early Whaingaroan); x 600; specimen measures $70 \times 70 \mu \mathrm{m}$

Figure 7-10 Sample J42/f096, slide L10951/SM036; Totara Limestone, Kakanui River (early Whaingaroan); $x$ 800; specimen measures 55 x $53 \mu \mathrm{m}$

Figure 11-12 Sample J42/f096, slide L10951/SM037; Totara Limestone, Kakanui River (early Whaingaroan); x 700; specimen measures $68 \times 55 \mu \mathrm{m}$ 


\section{Plate 64}
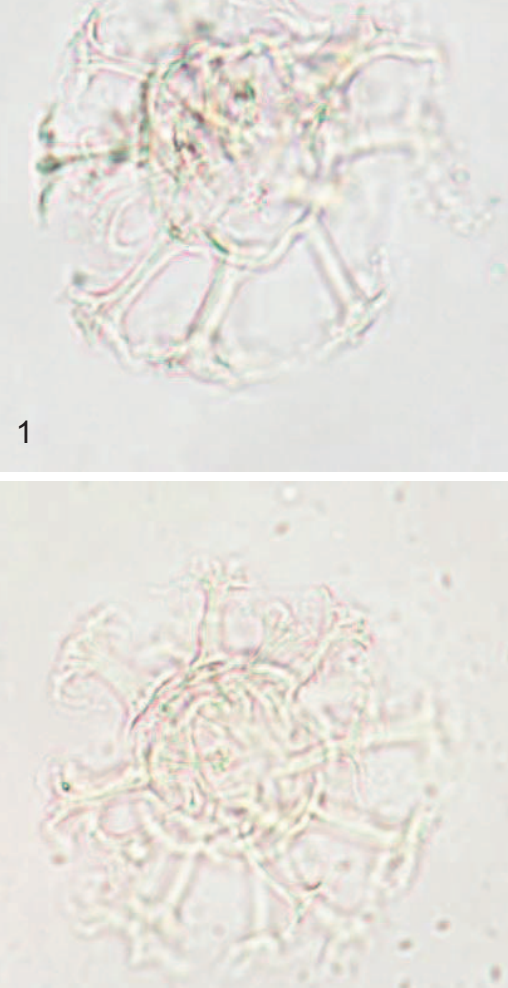

4
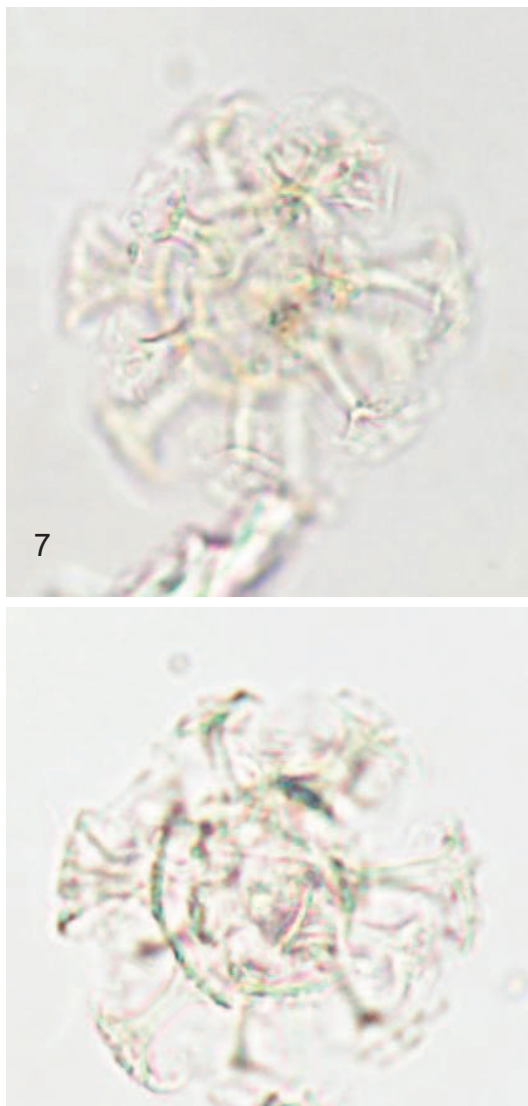

10

oxy

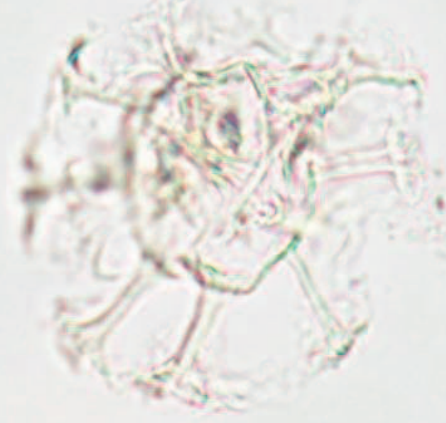

2

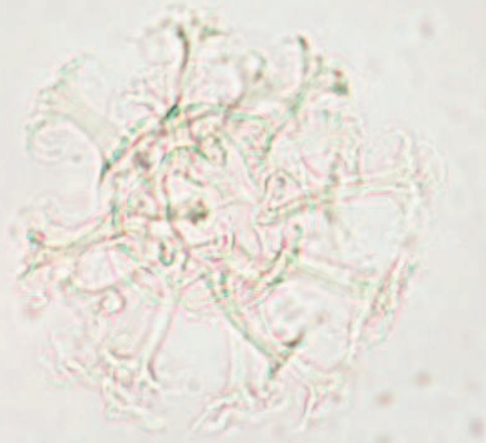

5
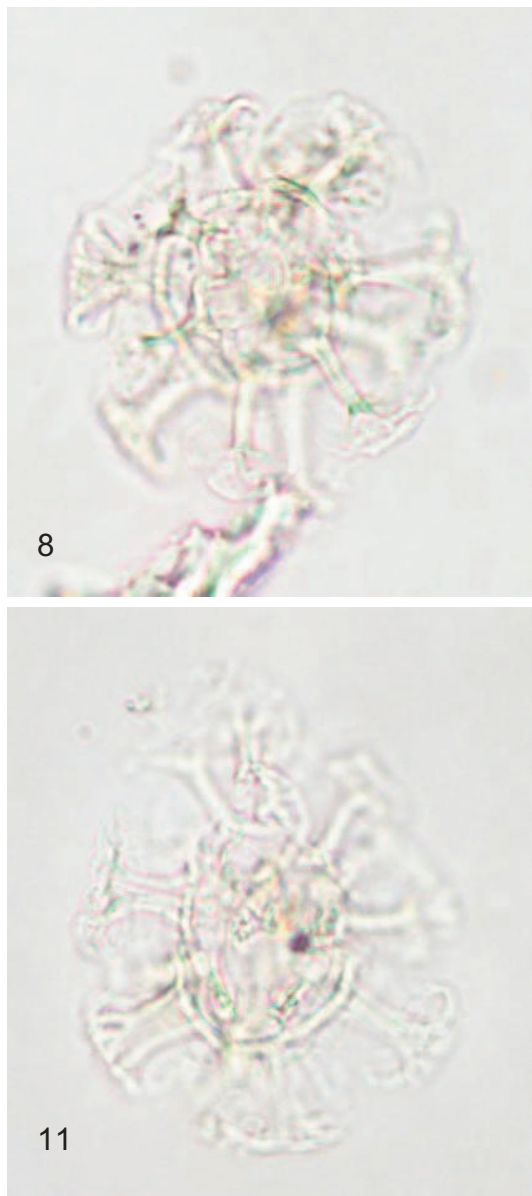
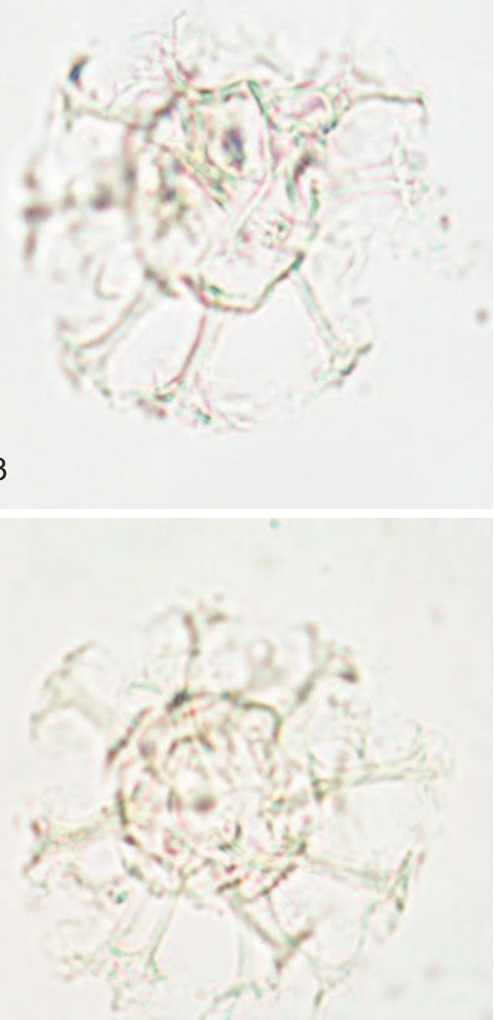

6
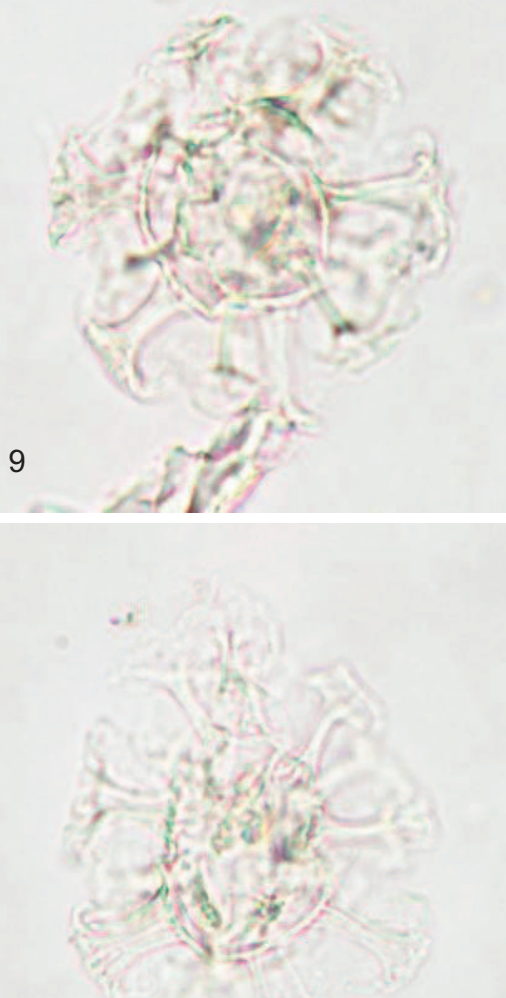

12 


\section{Plate 65}

\section{?Tityrosphaeridium cantharellus}

Figure 1 Sample J42/f096, slide L10951/SM037; Totara Limestone, Kakanui River (early Whaingaroan); $x$ 700; specimen measures $68 \times 55 \mu \mathrm{m}$

Figure 2-3 Sample U24/f419, slide L23127/SM073C; Wanstead, Te Uri Stream (Porangan); x 1025; specimen measures $46 \times 40 \mu \mathrm{m}$

\section{Areosphaeridium dictyostilum}

Figure 4-9 Sample 143/f096, slide L16344/SM005; Burnside Formation, Puketeraki Core (Kaiatan); x 500; specimen measures $77 \times 85 \mu \mathrm{m}$

Figure 10-12 Sample 143/f096, slide L16344/SM008; Burnside Formation, Puketeraki Core (Kaiatan); x 525; specimen measures $90 \times 80 \mu \mathrm{m}$ 


\section{Plate 65}
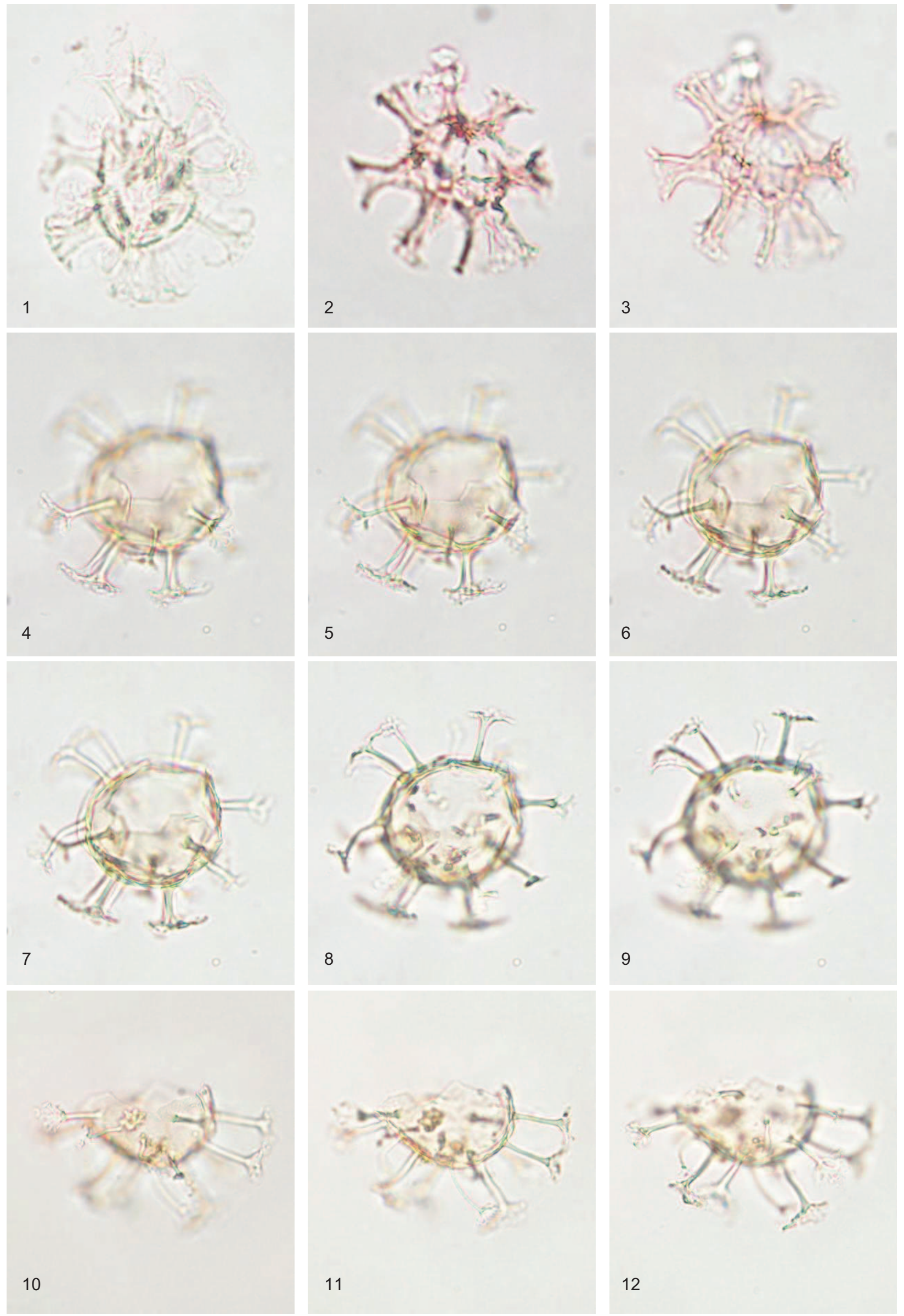


\section{Plate 66}

\section{Areosphaeridium dictyostilum}

Figure 1-3 Sample 143/f089, slide L16337/SM107; Burnside Formation, Puketeraki Core (Bortonian); x 400; specimen measures $105 \times 102 \mu \mathrm{m}$

\section{Areosphaeridium ebdonii}

Figure 4-9 Sample J42/f303, slide L23133/SM009; Hampden Formation, Hampden Beach Section (Bortonian); x 575; specimen measures $67 \times 72 \mu \mathrm{m}$

\section{Areosphaeridium multicornutum}

Figure 10-12 Sample 143/f090, slide L16338/SM029; Burnside Formation, Puketeraki Core (Bortonian); x 525; specimen measures 65 × $80 \mu \mathrm{m}$ 


\section{Plate 66}
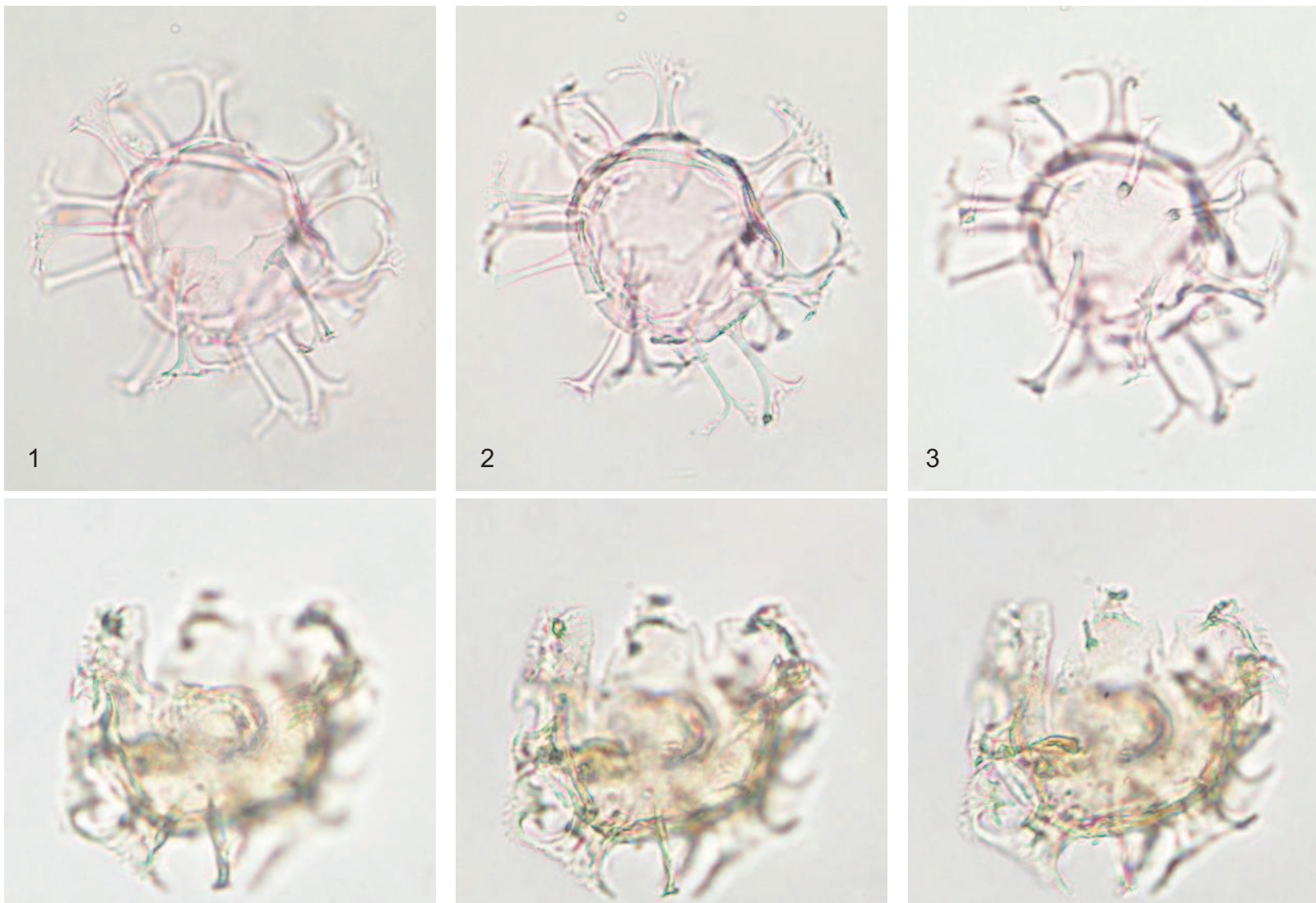

4

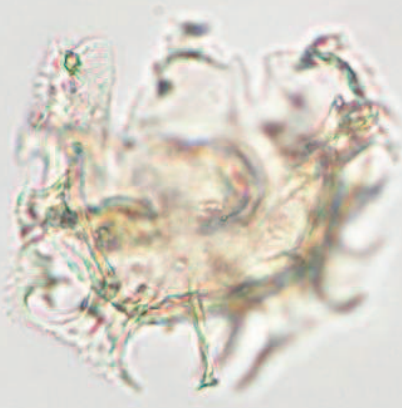

5

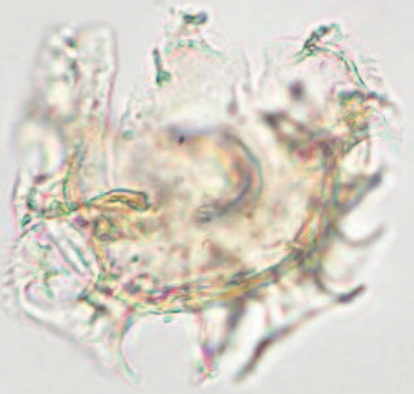

6
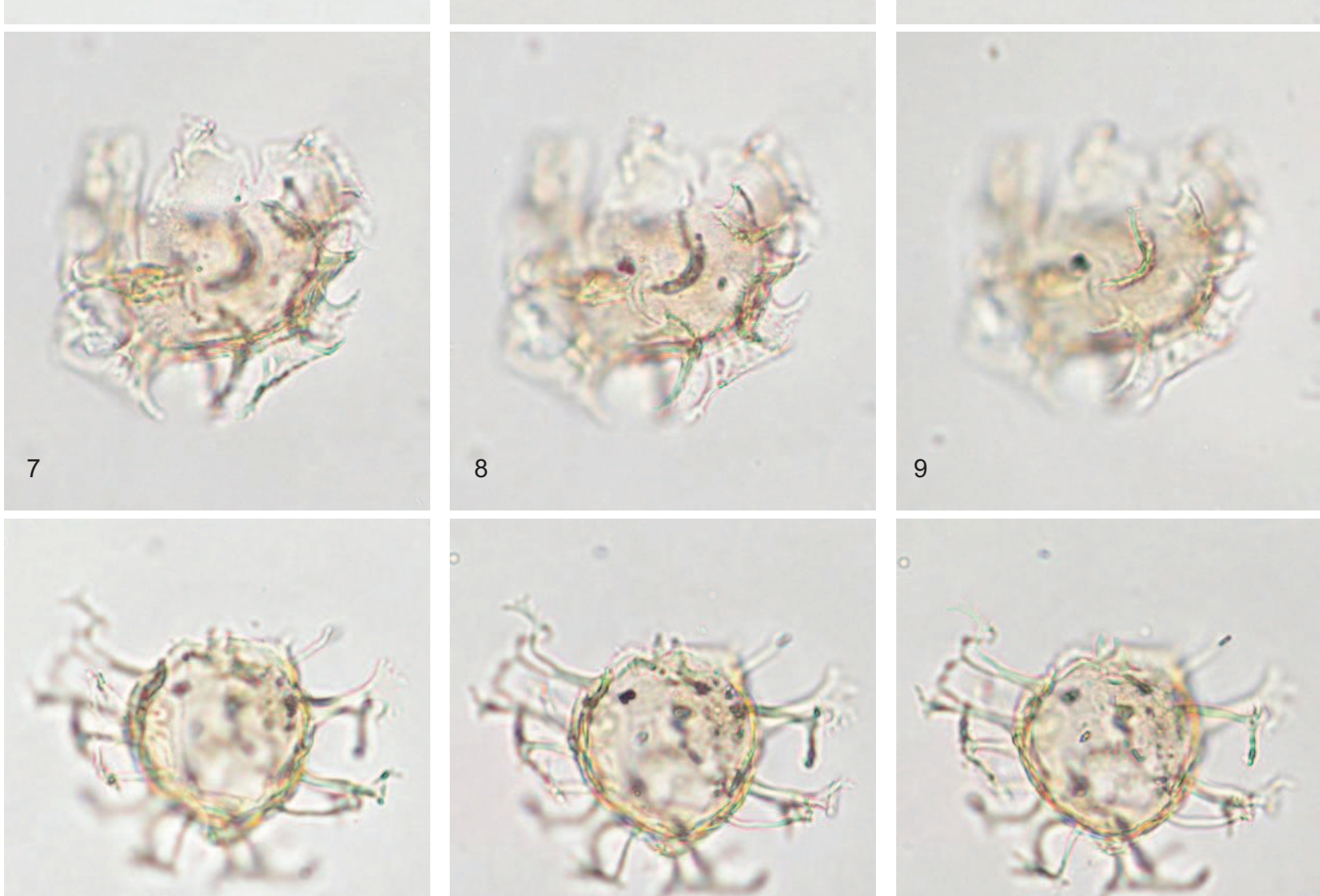

10

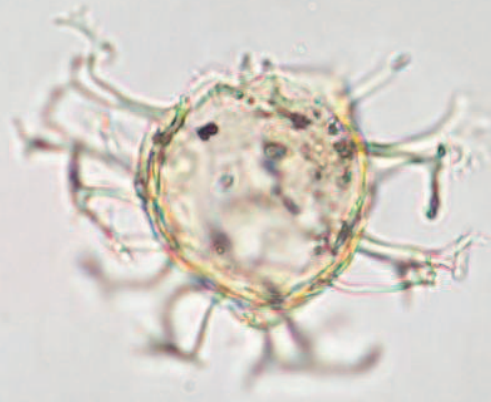

11

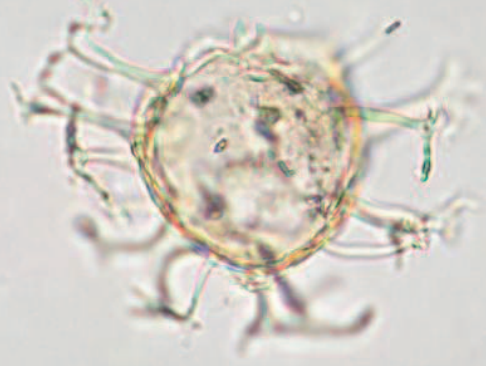

12 


\section{Plate 67}

\section{Areosphaeridium multicornutum}

Figure 1-3 Sample I43/f090, slide L16338/SM029; Burnside Formation, Puketeraki Core (Bortonian); x 525; specimen measures $65 \times 80 \mu \mathrm{m}$

\section{Areosphaeridium pectiniforme}

Figure 4-6 Sample I43/f089, slide L16337/SM092; Burnside Formation, Puketeraki Core (Bortonian); x 475; specimen measures 100 x $83 \mu \mathrm{m}$

Figure 7-9 Sample I43/f089, slide L16337/SM093; Burnside Formation, Puketeraki Core (Bortonian); x 425; specimen measures $102 \times 97 \mu \mathrm{m}$

Figure 10-12 Sample 143/f093, slide L16341/SM167; Burnside Formation, Puketeraki Core (Bortonian); x 375; specimen measures $110 \times 112 \mu \mathrm{m}$ 


\section{Plate 67}
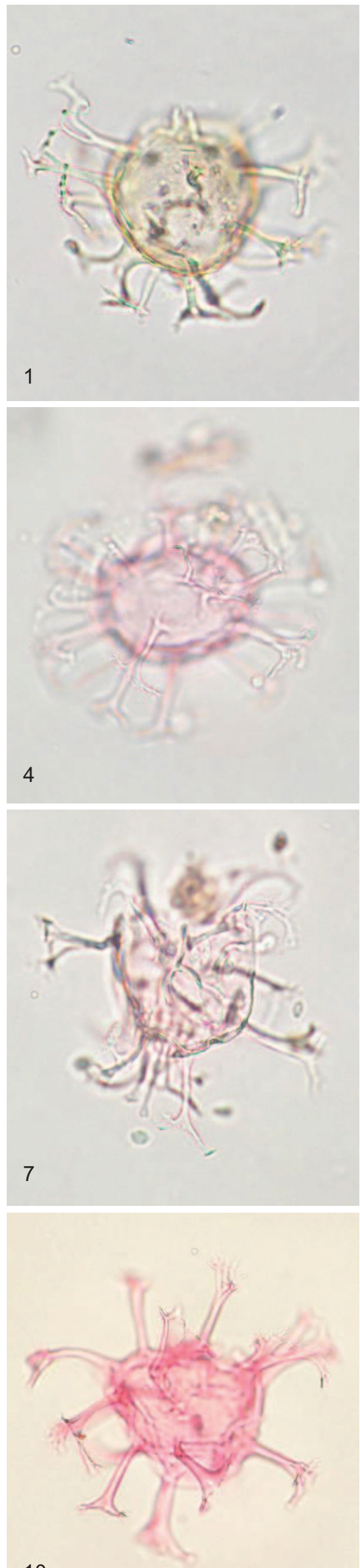

10
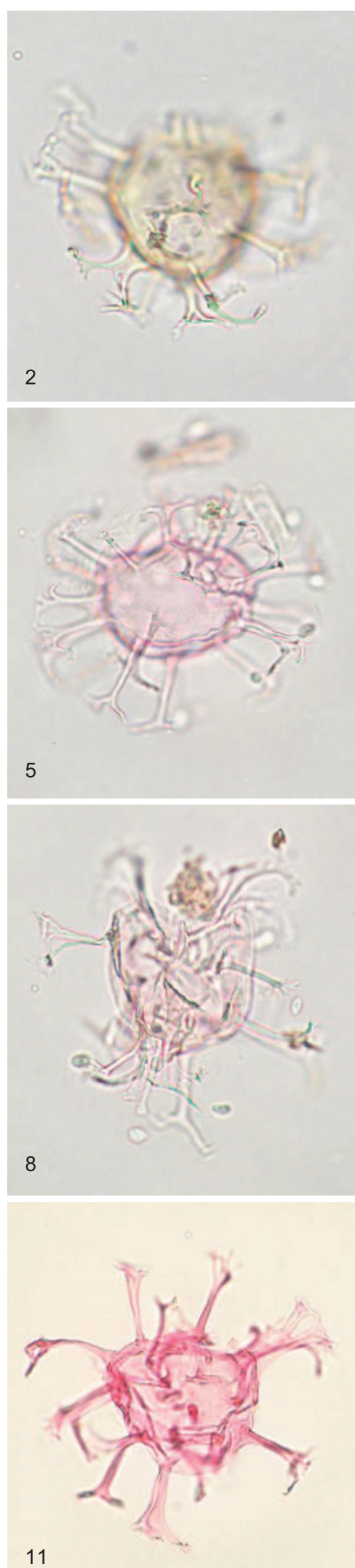
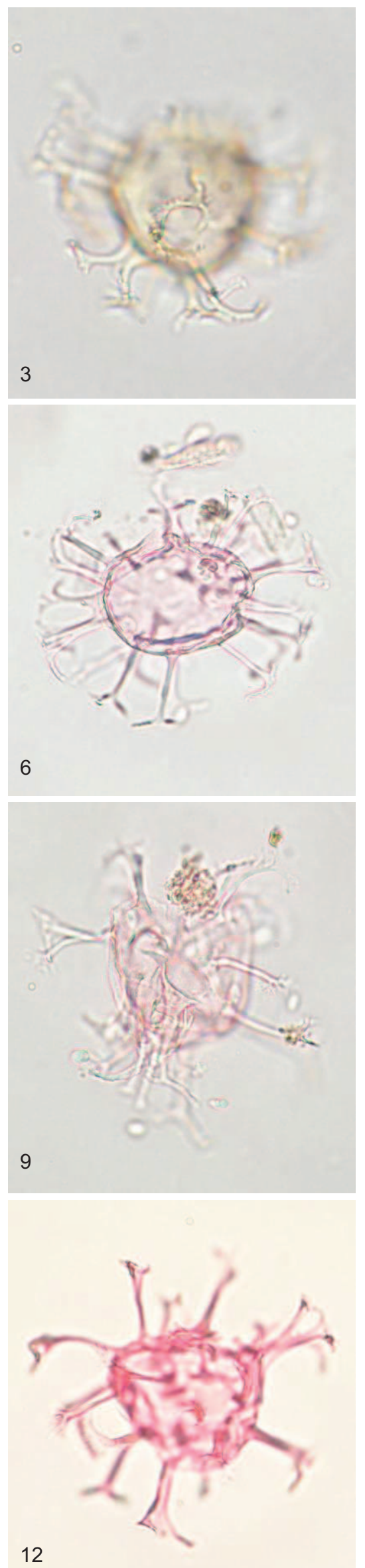


\section{Plate 68}

\section{Cooksonidium capricornum}

Figure 1-3 Sample 143/f096, slide L16344/SM004; Burnside Formation, Puketeraki Core (Kaiatan); x 725; specimen measures $52 \times 57 \mu \mathrm{m}$

\section{Graptodinium inconditum}

Figure 4-9 Sample 143/f090, slide L16338/SM060; Burnside Formation, Puketeraki Core (Bortonian); specimen measures $28 \times 32 \mu \mathrm{m}$

Figure 10-12 Sample J42/f097, slide L10952/SM014; Totara Limestone, Kakanui River (?early Whaingaroan); x 1175; specimen measures 40 × $35 \mu \mathrm{m}$ 


\section{Plate 68}

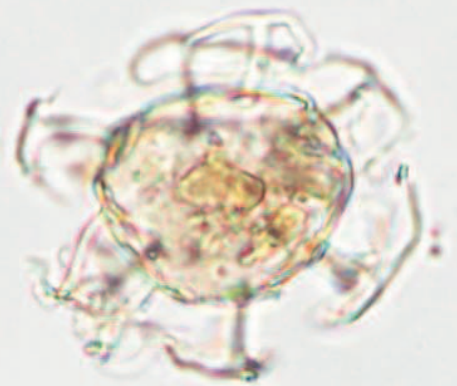

1

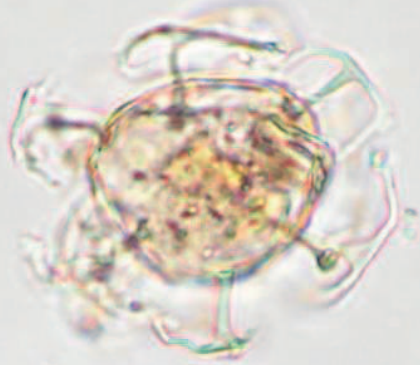

2

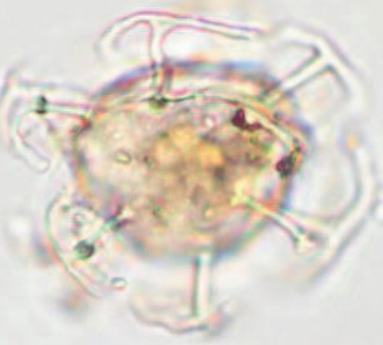

3
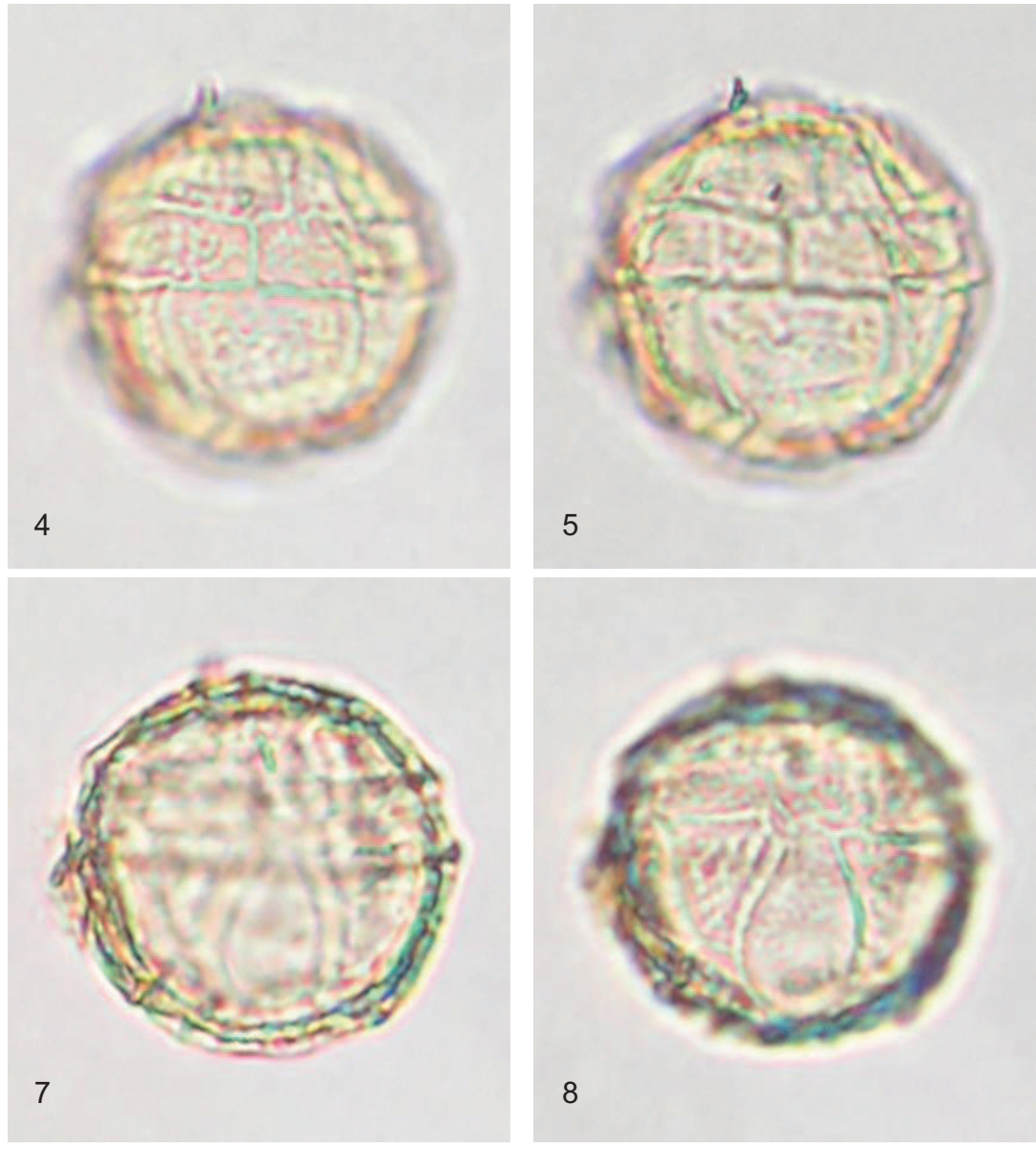

6
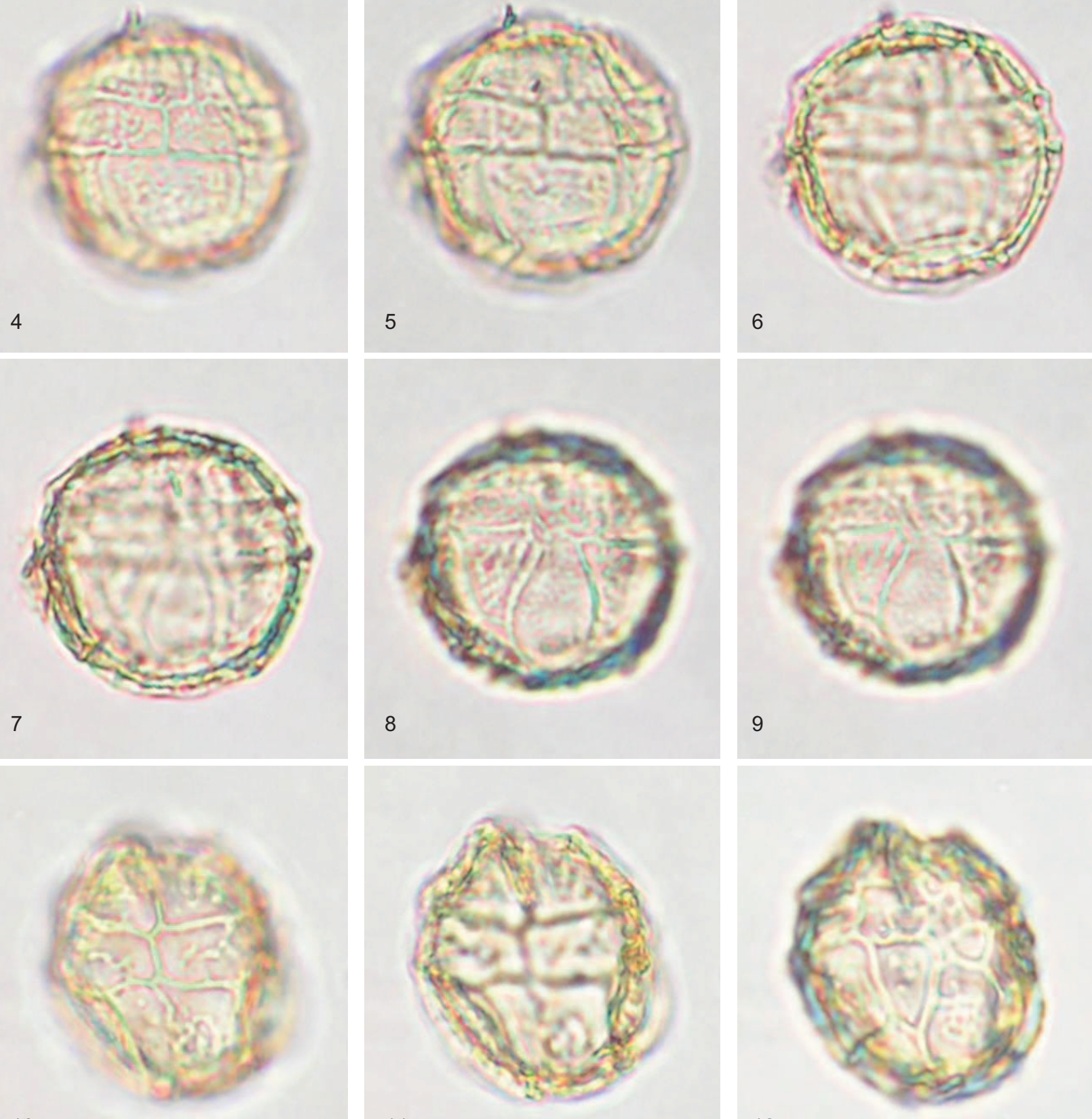

10

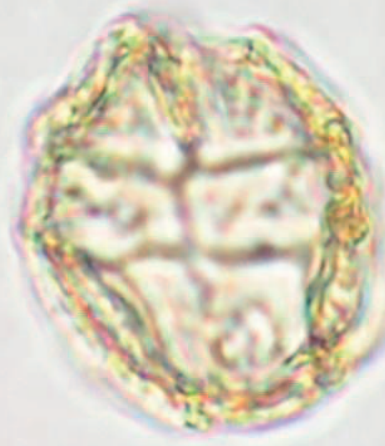

11

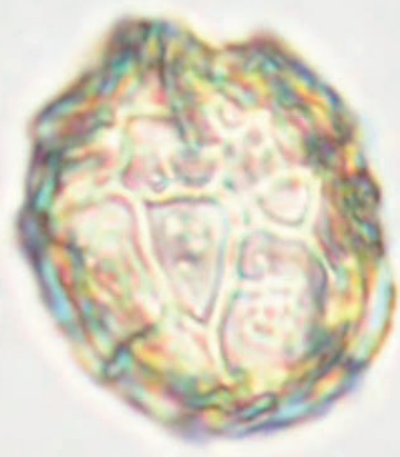

12 


\section{Plate 69}

\section{Graptodinium inconditum}

Figure 1-6 Sample 143/f093, slide L16341/SM075; Burnside Formation, Puketeraki Core (Bortonian); specimen measures $35 \times 34 \mu \mathrm{m}$

\section{Graptodinium reticulatum}

Figure 7-12 Sample 143/f093, slide L16341/SM071; Burnside Formation, Puketeraki Core (Bortonian); specimen measures $36 \times 37 \mu \mathrm{m}$ 


\section{Plate 69}
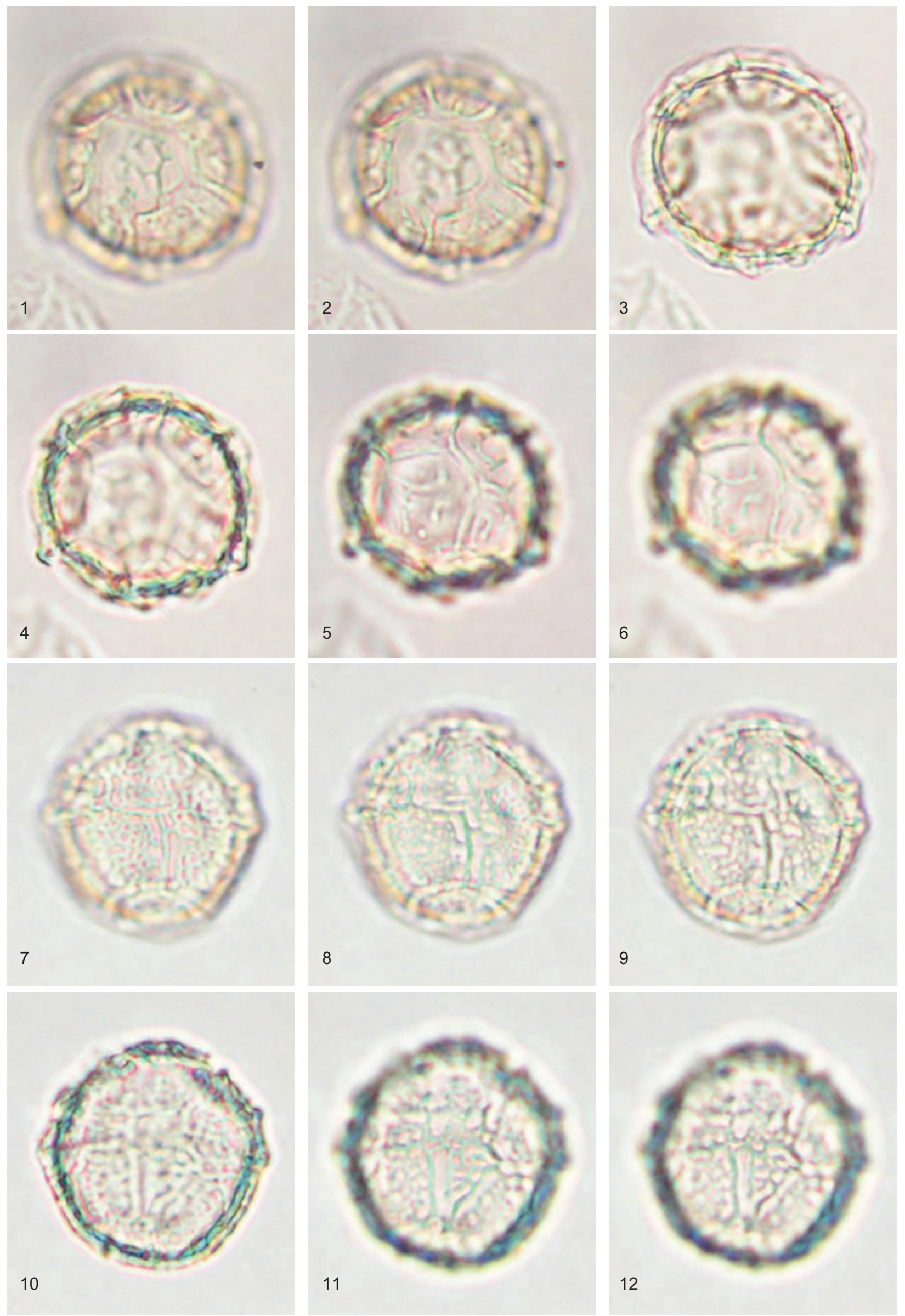


\section{Plate 70}

\section{Graptodinium reticulatum}

Figure 1-3 Sample 143/f090, slide L16338/SM059; Burnside Formation, Puketeraki Core (Bortonian); specimen measures $34 \times 26 \mu \mathrm{m}$

\section{cf. Kleithriasphaeridium sp. 1}

Figure 4-6 Sample S14/f8599, slide L10662/SM018; Waikato Coal Measures, Old Mountain Road (Runangan-early Whaingaroan); x 375; specimen measures 125 x $98 \mu \mathrm{m}$

Figure 7-9 Sample S14/f8599, slide L10662/SM019; Waikato Coal Measures, Old Mountain Road (Runangan-early Whaingaroan); x 400; specimen measures 103 × $107 \mu \mathrm{m}$

\section{Lophocysta ?sulcolimbata}

Figure 10-12 Sample 143/f089, slide L16337/SM094; Burnside Formation, Puketeraki Core (Bortonian); x 775; specimen measures $60 \times 42 \mu \mathrm{m}$ 


\section{Plate 70}
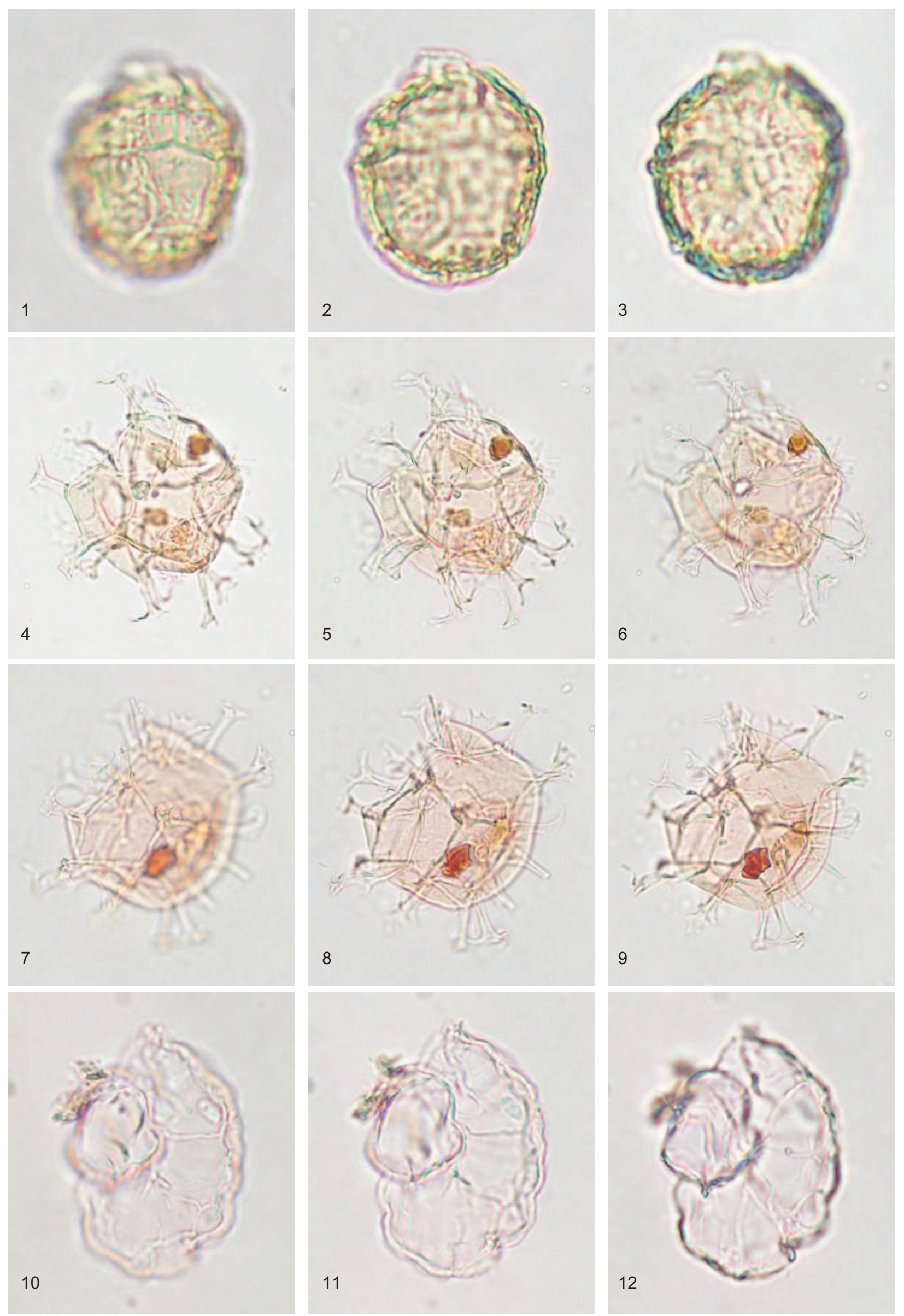


\section{Plate 71}

\section{Lophocysta ?sulcolimbata}

Figure 1-3 Sample 143/f089, slide L16337/SM115; Burnside Formation, Puketeraki Core (Bortonian); x 850; specimen measures 56 x $40 \mu \mathrm{m}$

\section{Aireiana salicta}

Figure 4-6 Sample 143/f090, slide L16338/SM045; Burnside Formation, Puketeraki Core (Bortonian); x 375; specimen measures $122 \times 102 \mu \mathrm{m}$

Figure 7-9 Sample 143/f090, slide L16338/1-1318-117; Burnside Formation, Puketeraki Core (Bortonian); x 325; specimen measures 95 x $128 \mu \mathrm{m}$

\section{Fibrocysta bipolaris}

Figure 10-12 Sample I43/f090, slide L16338/SM041; Burnside Formation, Puketeraki Core (Bortonian); x 350; specimen measures 137 x $97 \mu \mathrm{m}$ 


\section{Plate 71}
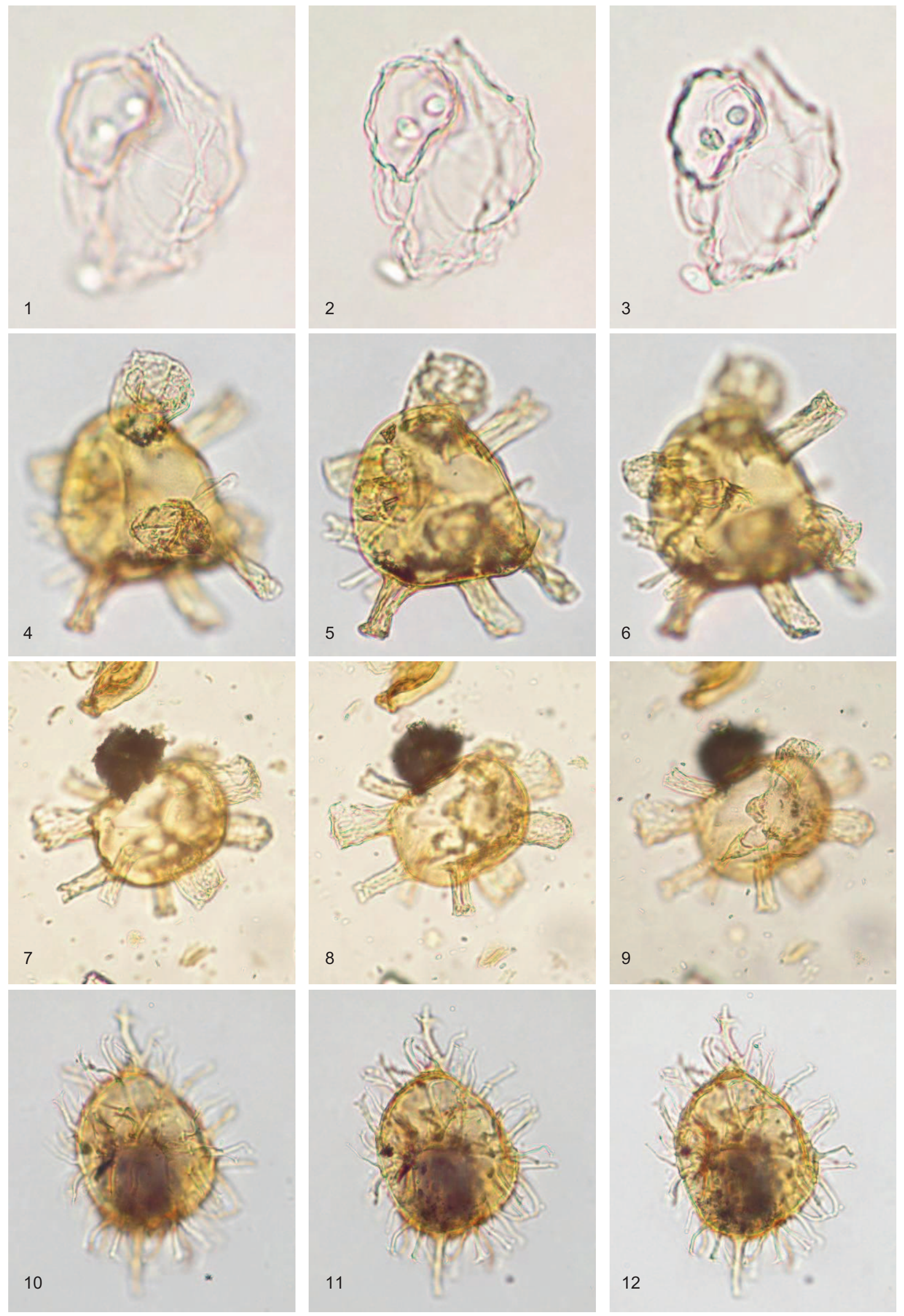


\section{Plate 72}

\section{Fibrocysta bipolaris}

Figure 1-3 Sample 143/f090, slide L16338/SM042; Burnside Formation, Puketeraki Core (Bortonian); x 425; specimen measures $108 \times 95 \mu \mathrm{m}$

\section{Pyxidinopsis crassimurata}

Figure 4-6 Sample U24/f418, slide L23126/SM040; Wanstead, Te Uri Stream (Porangan); x 725; specimen measures $58 \times 58 \mu \mathrm{m}$

\section{Pyxidinopsis teuriensis}

Figure 7-9 Sample J42/f484, slide L23119/SM031; Kurinui Formation, Hampden Beach Section (Heretaungan); x 575; specimen measures 80 × $72 \mu \mathrm{m}$

Figure 10-12 Sample J42/f484, slide L23119/SM029; Kurinui Formation, Hampden Beach Section (Heretaungan); x 550; specimen measures $75 \times 77 \mu \mathrm{m}$ 


\section{Plate 72}
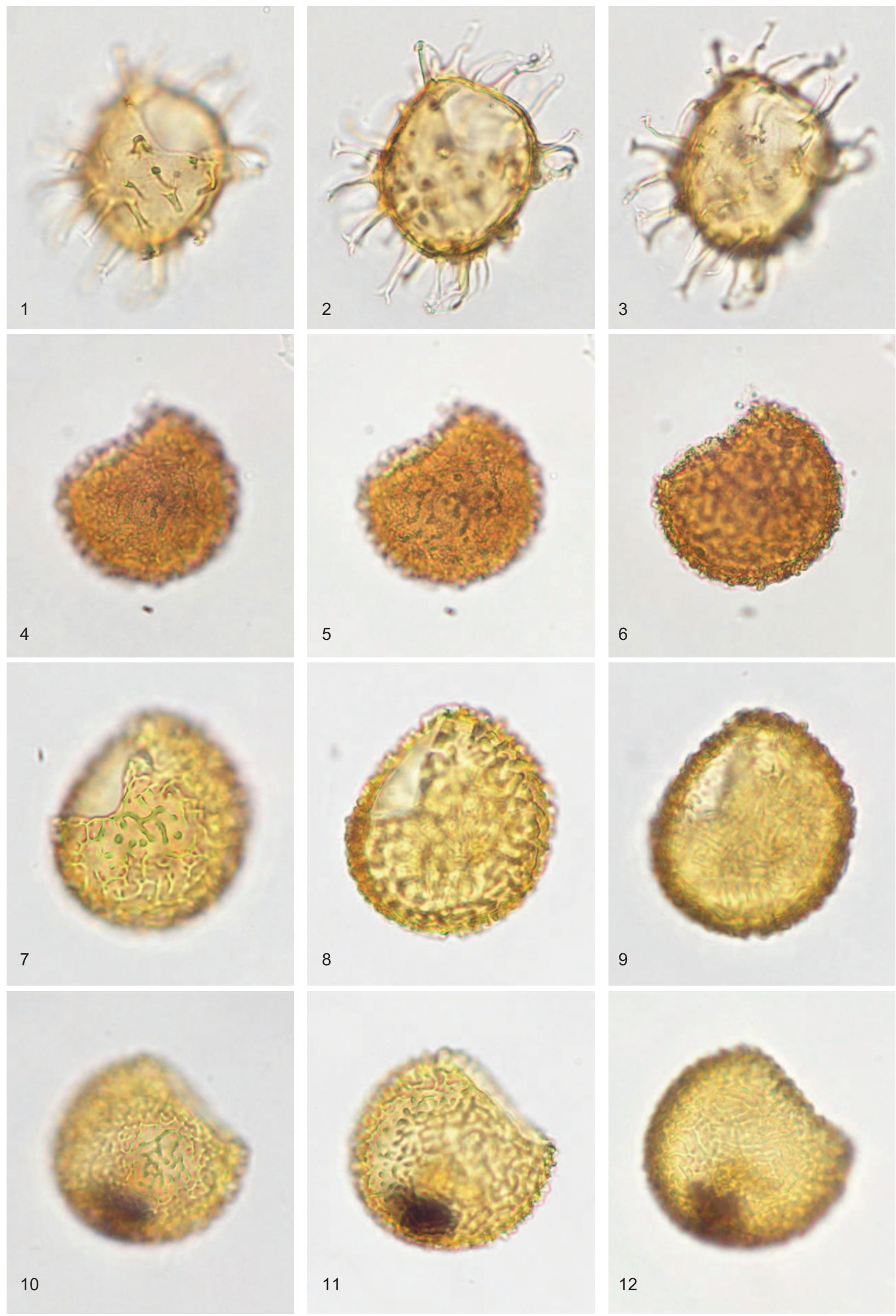


\section{Plate 73}

\section{Pyxidinopsis teuriensis}

Figure 1-3 Sample J42/f299, slide L23129/SM017; Hampden Formation, Hampden Beach Section (Porangan); x 675; specimen measures $61 \times 62 \mu \mathrm{m}$

Figure 4-6 Sample U24/f419, slide L23127/SM088; Wanstead, Te Uri Stream (Porangan); x 600; specimen measures $70 \times 70 \mu \mathrm{m}$

\section{Pyxidinopsis cf. delicata}

Figure 7-12 Sample 143/f090, slide L16338/SM062; Burnside Formation, Puketeraki Core (Bortonian); x 800; specimen measures 47 x $52 \mu \mathrm{m}$ 


\section{Plate 73}
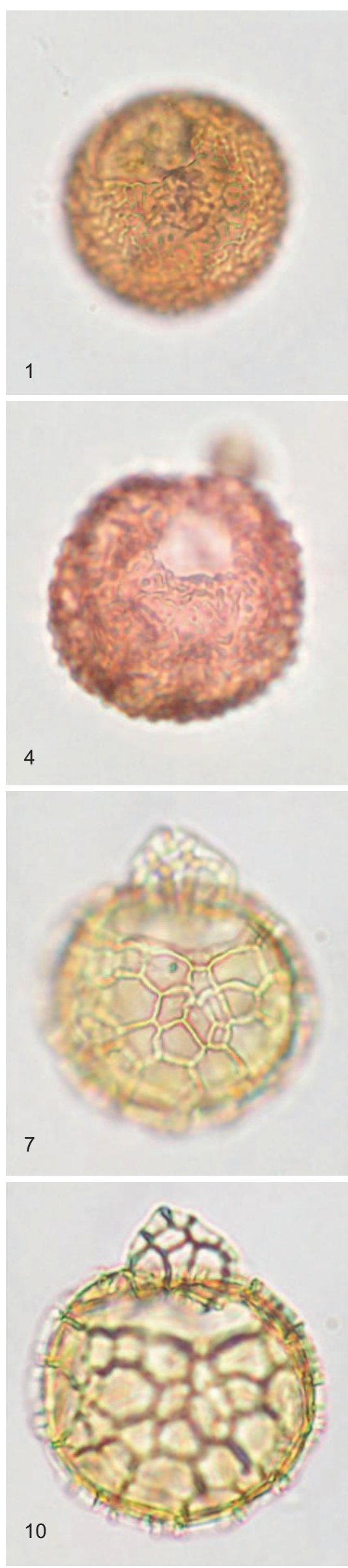
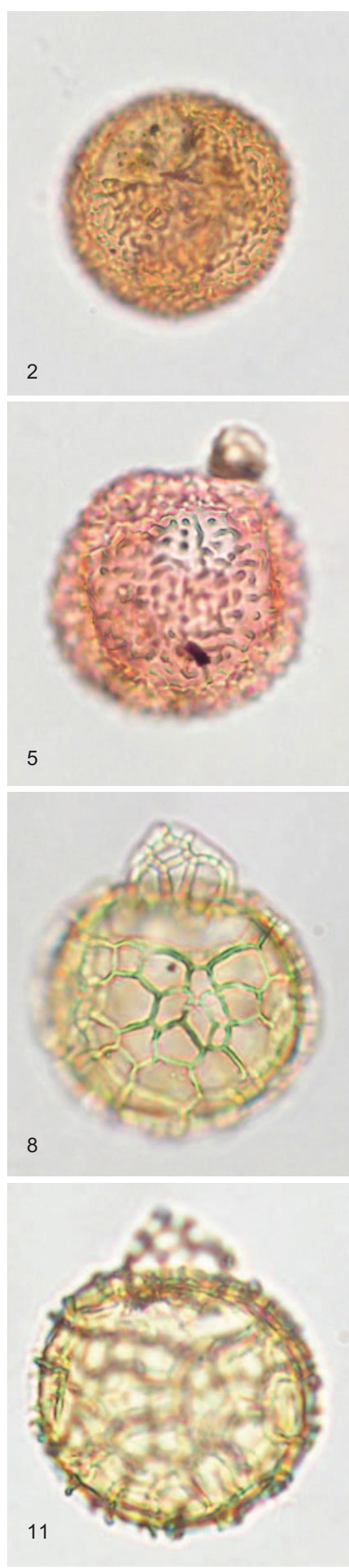
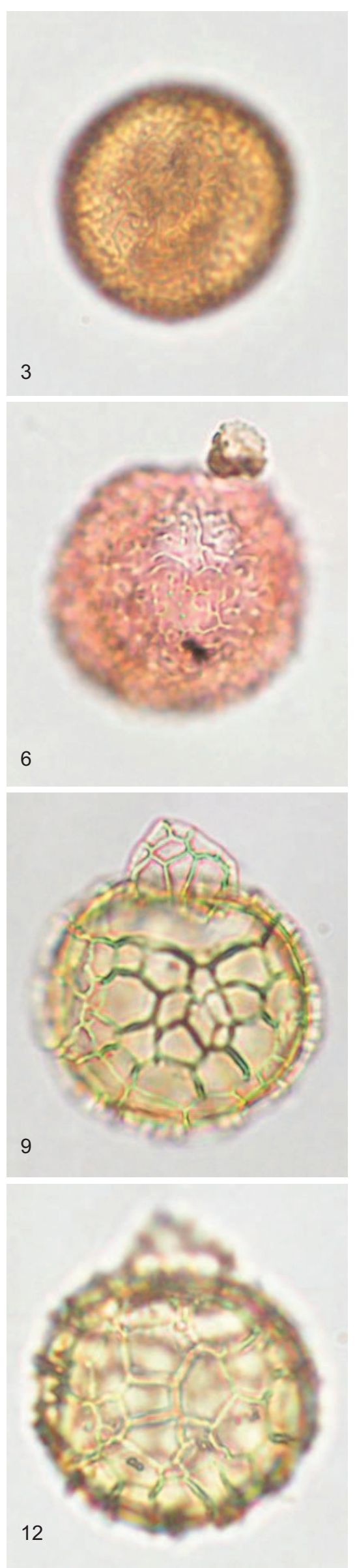


\section{Plate 74}

\section{Pyxidinopsis sp. 3}

Figure 1-3 Sample U24/f419, slide L23127/SM087B; Wanstead, Te Uri Stream (Porangan); x 775; specimen measures $57 \times 55 \mu \mathrm{m}$

\section{Pyxidinopsis mundus}

Figure 4-6 Sample U24/f419, slide L23127/SM020; Wanstead, Te Uri Stream (Porangan); x 850; specimen measures $52 \times 50 \mu \mathrm{m}$

Figure 7-9 Sample J42/f483, slide L23118/SM031; Kurinui Formation, Hampden Beach Section (Heretaungan); x 775; specimen measures 55 x $54 \mu \mathrm{m}$

Figure 10-12 Sample U24/f419, slide L23127/SM032; Wanstead, Te Uri Stream (Porangan); x 950; specimen measures $50 \times 43 \mu \mathrm{m}$ 


\section{Plate 74}
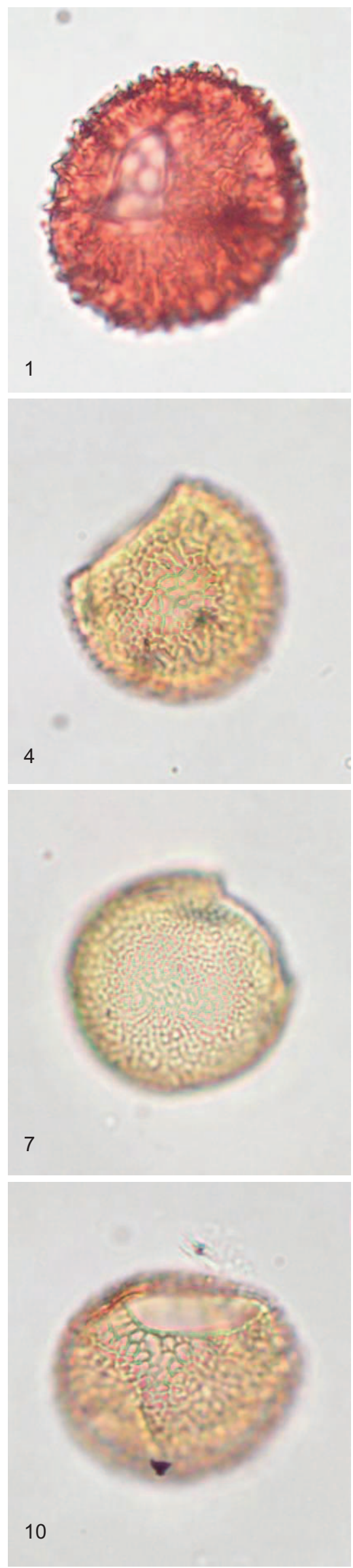
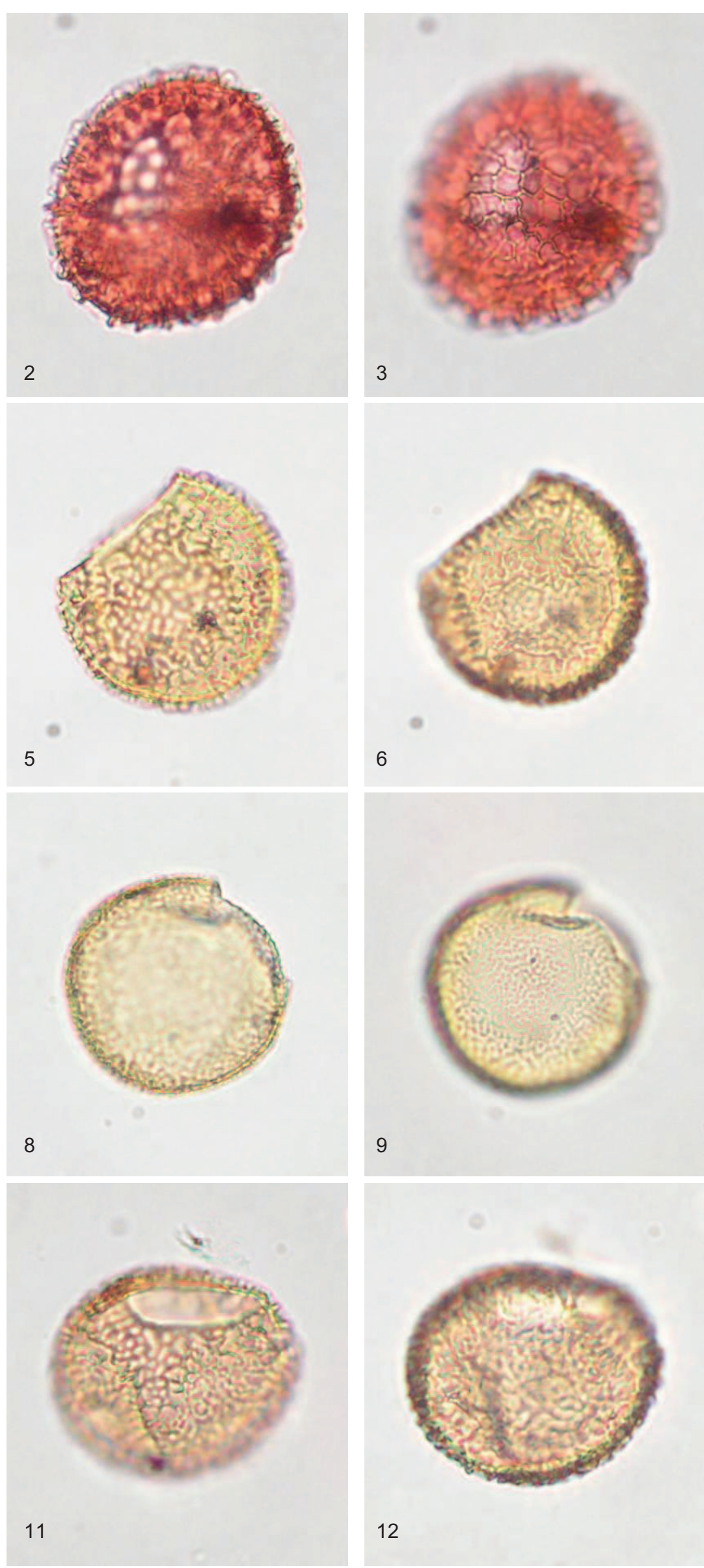
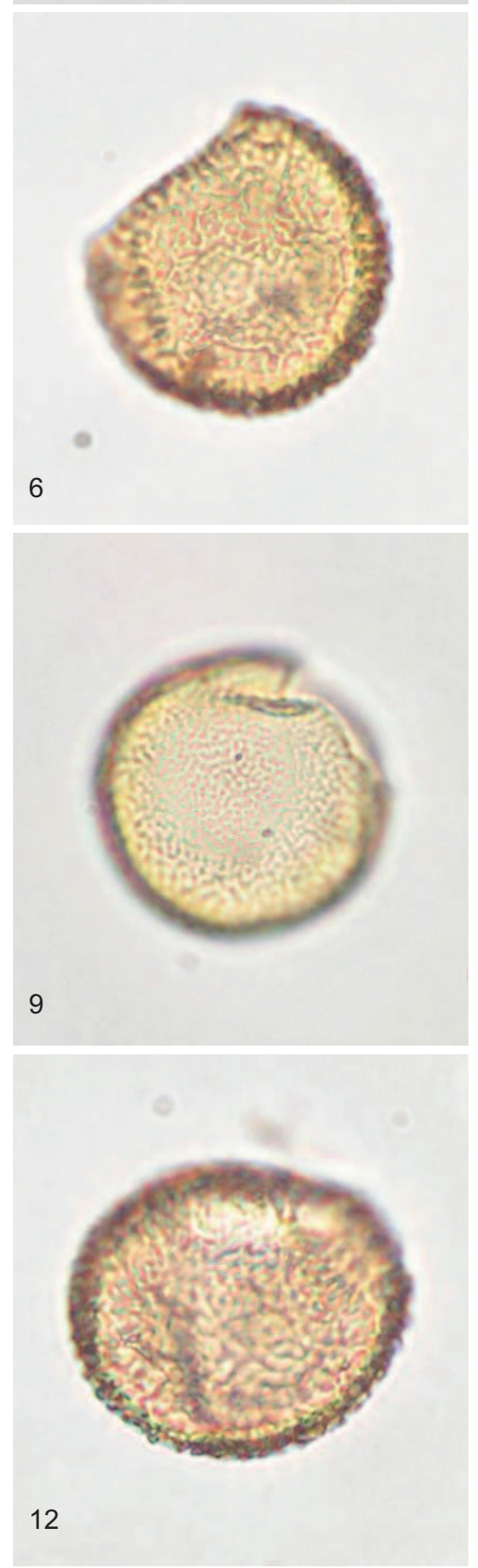


\section{Plate 75}

\section{Pyxidinopsis waipawaensis}

Figure 1-3 Sample V22/f8994, slide L12118/SM3329; Waipawa Section (Heretaungan); x 750; specimen measures $58 \times 56 \mu \mathrm{m}$

Figure 4-5 Sample 144/f080, slide L08947/SM4888; Burnside Formation, Burnside Marl Pit (Bortonian)

Figure 6 Sample 144/f080, slide L08947/SM4926; Burnside Formation, Burnside Marl Pit (Bortonian); x 500; specimen measures $80 \times 82 \mu \mathrm{m}$

?Areoligera hampdenensis

Figure 7-12 Sample J42/f483, slide L23118/SM005; Kurinui Formation, Hampden Beach Section (Heretaungan); x 525; specimen measures $75 \times 80 \mu \mathrm{m}$ 


\section{Plate 75}
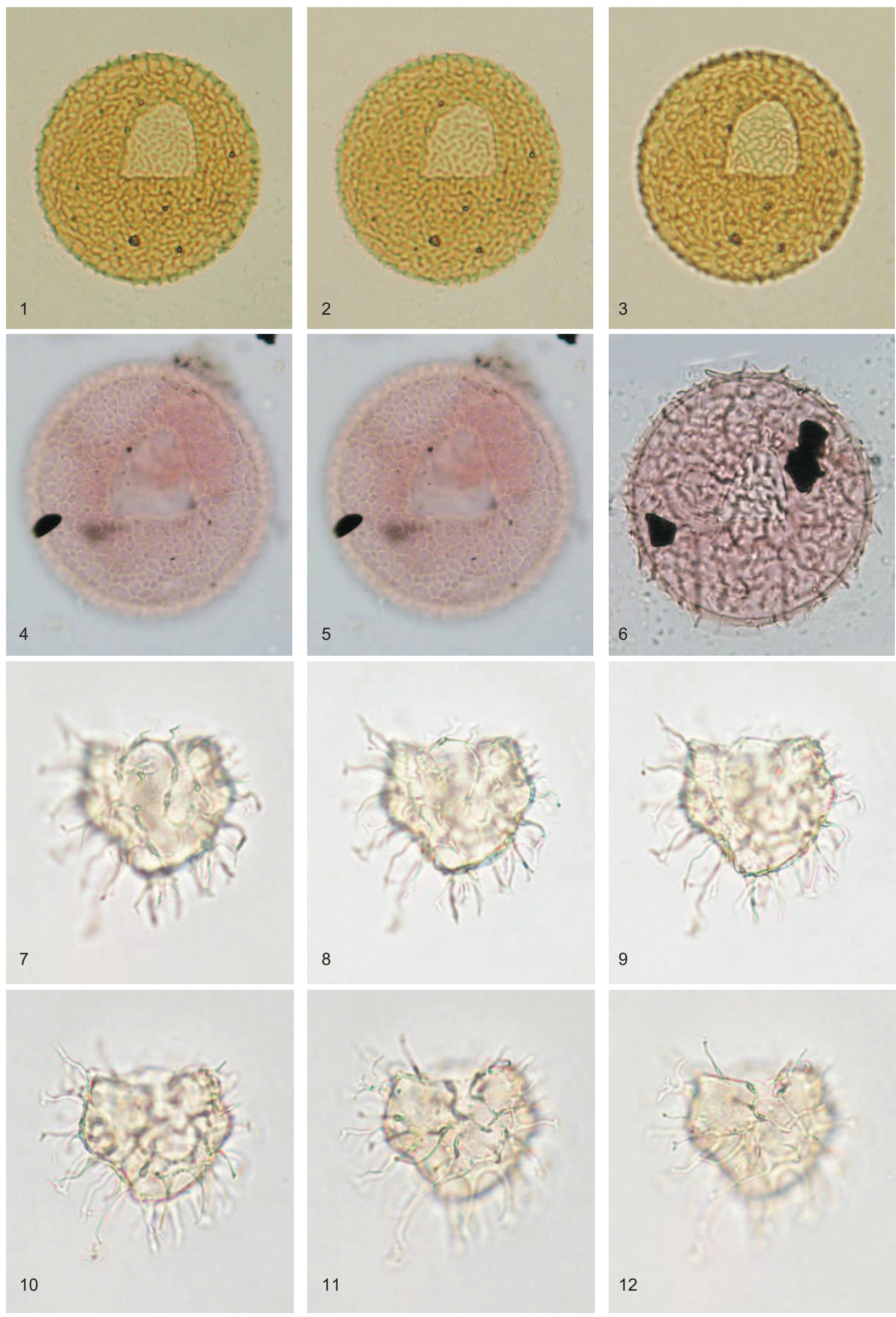

9

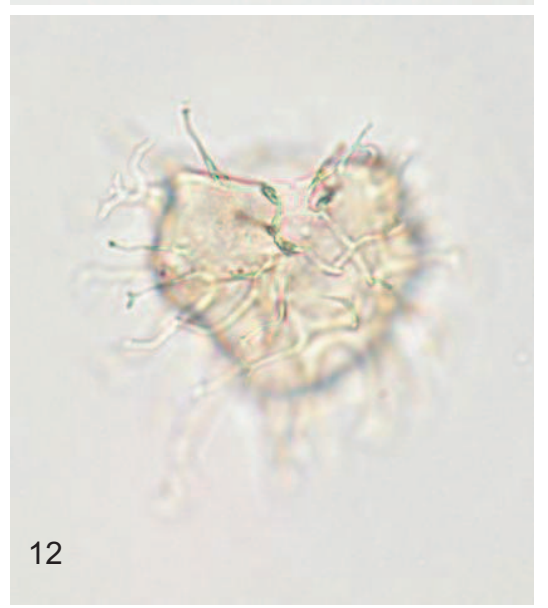




\section{Plate 76}

\section{?Areoligera hampdenensis}

Figure 1-5 Sample J42/f483, slide L23118/SM006; Kurinui Formation, Hampden Beach Section (Heretaungan); x 425; specimen measures $110 \times 97 \mu \mathrm{m}$

Figure 6 Sample J42/f484, slide L23119/SM033B; Kurinui Formation, Hampden Beach Section (Heretaungan)

Figure 7-9 Sample J42/f300, slide L23130/SM034; Hampden Formation, Hampden Beach Section (Porangan); x 375; specimen measures 125 x $84 \mu \mathrm{m}$

Figure 10-12 Sample J42/f484, slide L23119/SM005; Kurinui Formation, Hampden Beach Section (Heretaungan); x 475; specimen measures 98 x $88 \mu \mathrm{m}$ 


\section{Plate 76}
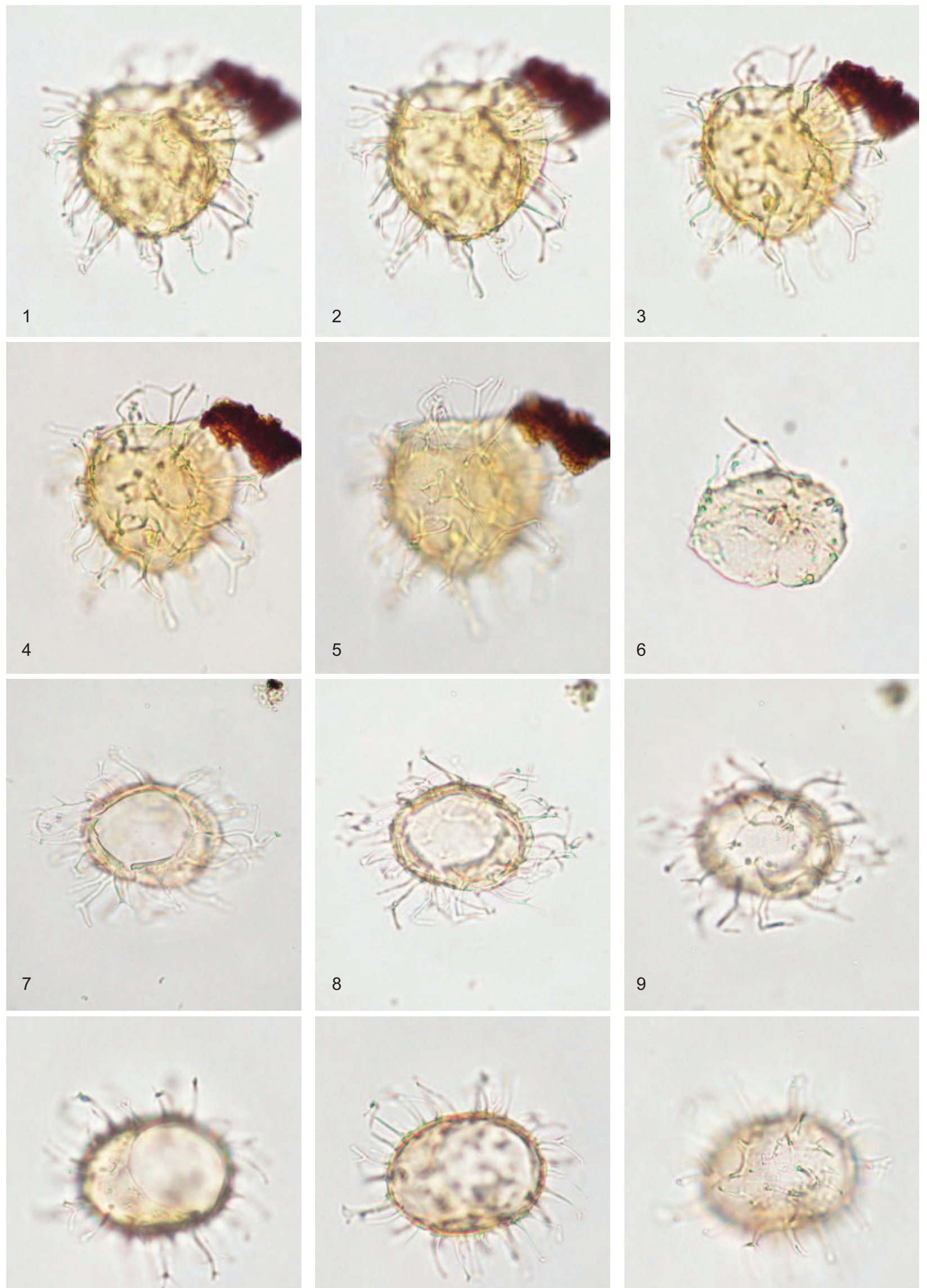


\section{Plate 77}

\section{?Areoligera sp. 2}

Figure 1-6 Sample J42/f300, slide L23130/SM010; Hampden Formation, Hampden Beach Section (Porangan); x 550; specimen measures $79 \times 77 \mu \mathrm{m}$

Figure 7-9 Sample J42/f299, slide L23129/SM022; Hampden Formation, Hampden Beach Section (Porangan); x 450; specimen measures 87 x $91 \mu \mathrm{m}$

\section{Cleistosphaeridium diversispinosum}

Figure 10-12 Sample I43/f093, slide L16341/SM004; Burnside Formation, Puketeraki Core (Bortonian); x 575; specimen measures $72 \times 74 \mu \mathrm{m}$ 


\section{Plate 77}
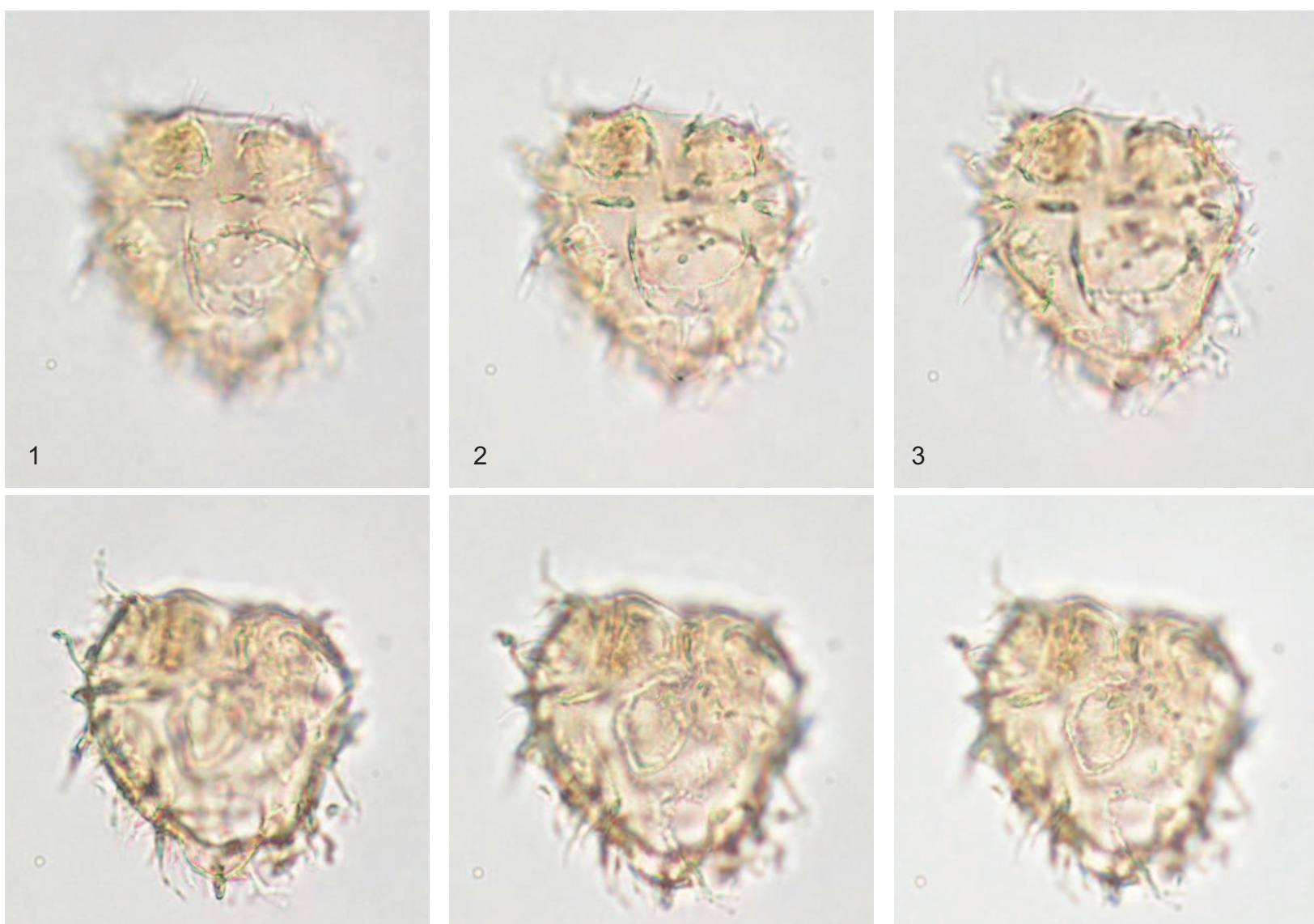

4
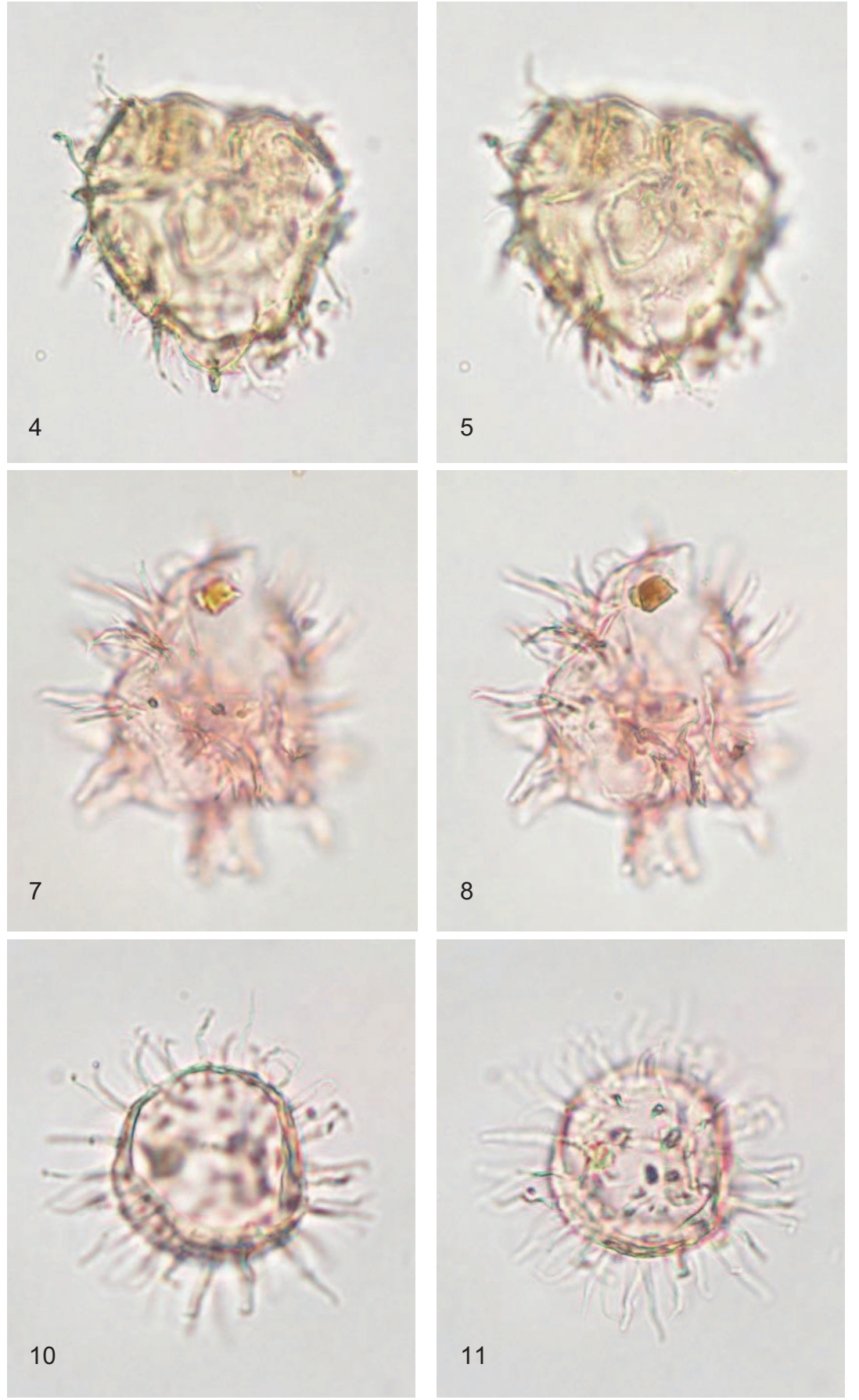

9
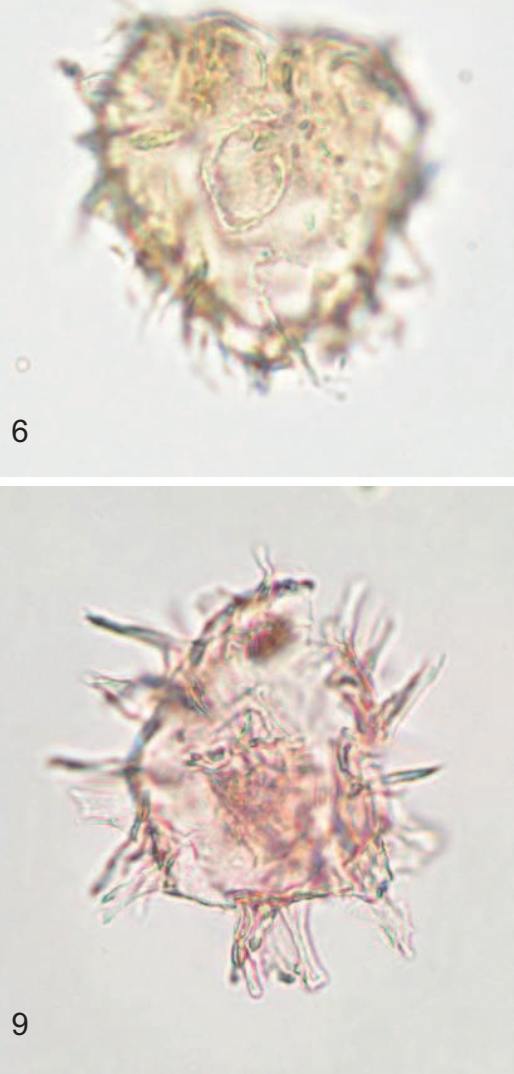

6

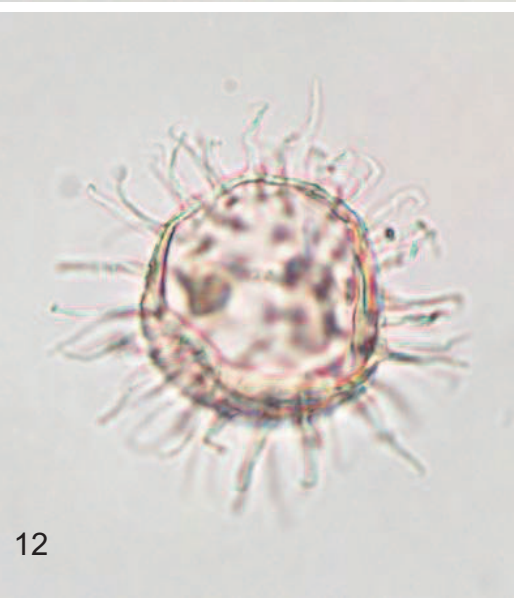




\section{Plate 78}

\section{Cleistosphaeridium ancyreum}

Figure 1-6 Sample J42/f483, slide L23118/SM009; Kurinui Formation, Hampden Beach Section (Heretaungan); x 725; specimen measures 65 x $43 \mu \mathrm{m}$

\section{Cleistosphaeridium placacanthum}

Figure 7-9 Sample K29/f106, slide L11042/SM003; Kaiata Mudstone, Cape Foulwind Section (Runangan-early Whaingaroan); x 450; specimen measures 84 x $93 \mu \mathrm{m}$

Cleistosphaeridium sp. 1

Figure 10-12 Sample 143/f089, slide L16337/SM100; Burnside Formation, Puketeraki Core (Bortonian); x 700; specimen measures 67 x $60 \mu \mathrm{m}$ 


\section{Plate 78}
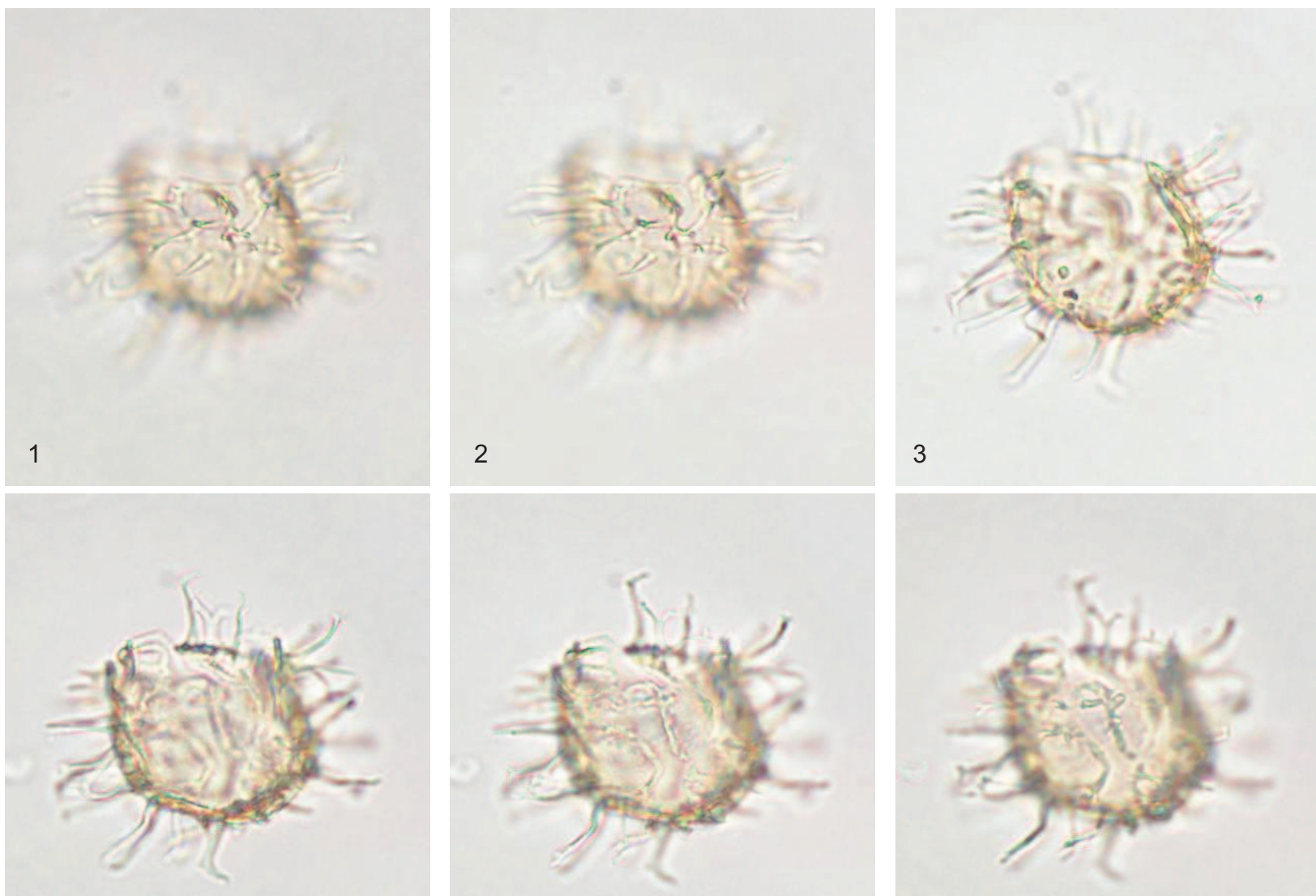

4
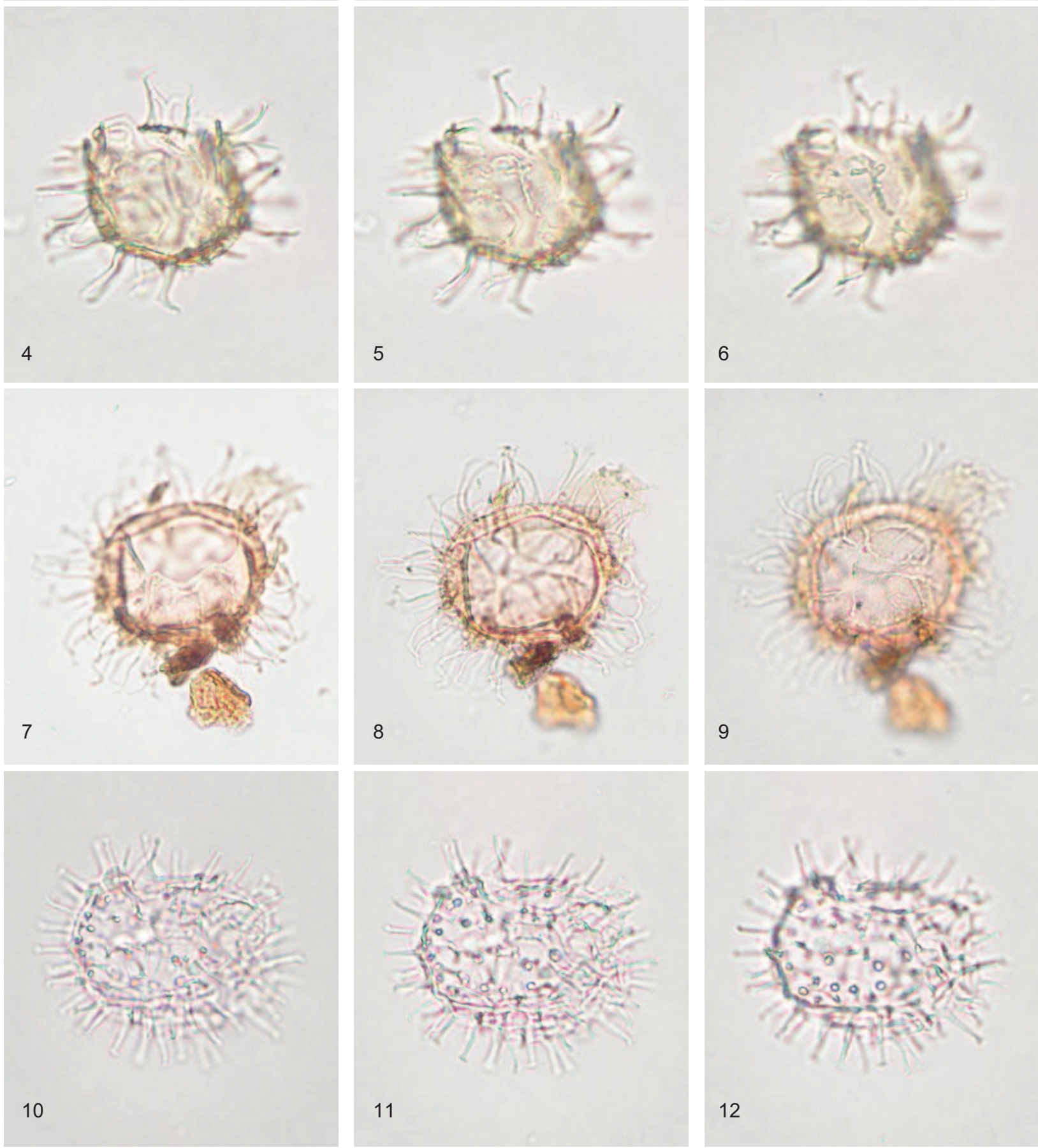

8
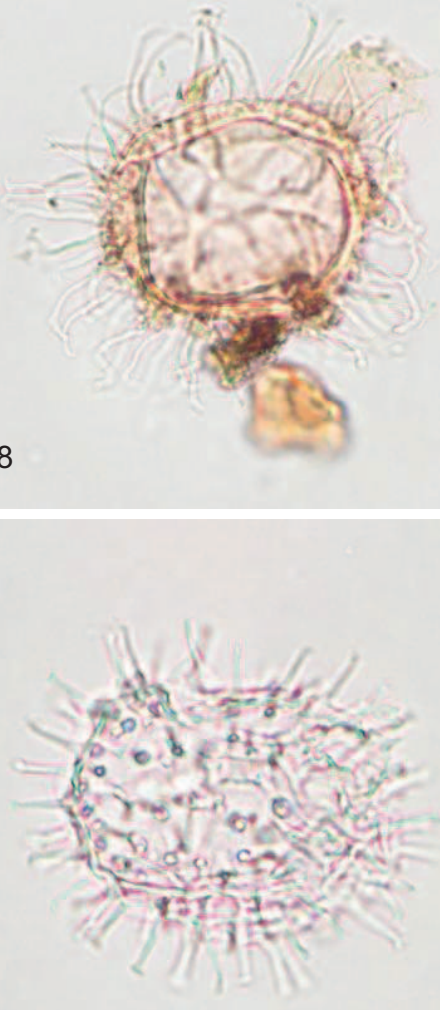

11
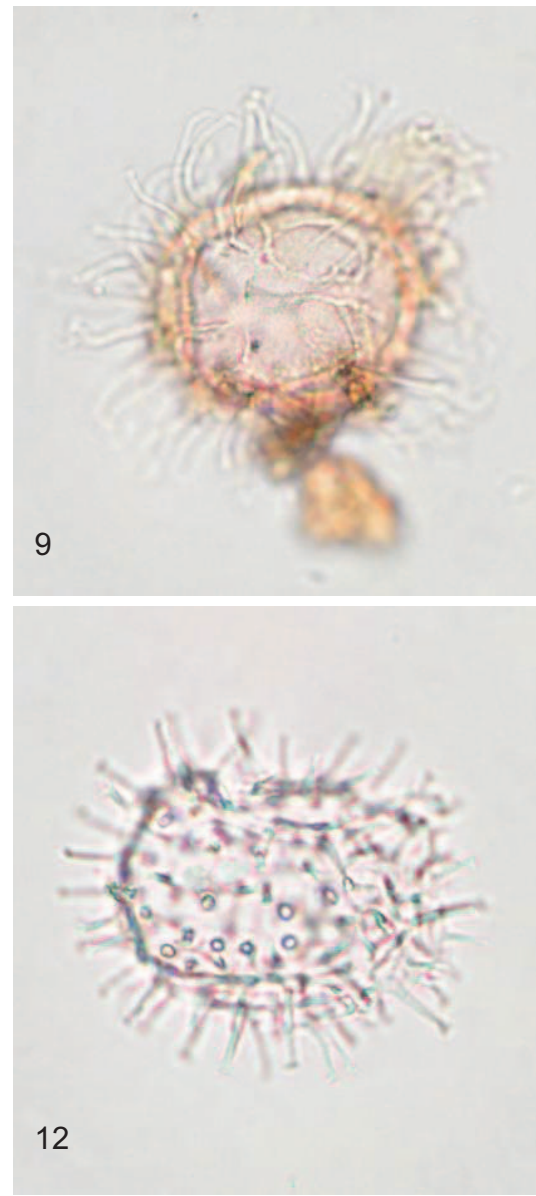


\section{Plate 79}

\section{Cleistosphaeridium sp. 3}

Figure 1-6 Sample 143/f092, slide L16340/1-1438-072; Burnside Formation, Puketeraki Core (Bortonian); x 650; specimen measures 58 × $65 \mu \mathrm{m}$

\section{Cyclonephelium membranophorum}

Figure 7-9 Sample 143/f090, slide L16338/1-1268-107; Burnside Formation, Puketeraki Core (Bortonian); x 450; specimen measures 87 x $95 \mu \mathrm{m}$

\section{Glaphyrocysta cf. retiintexta}

Figure 10-12 Sample J42/f486, slide L23121/SM005; ?Hampden Formation, Hampden Beach Section (Porangan-Bortonian) 


\section{Plate 79}
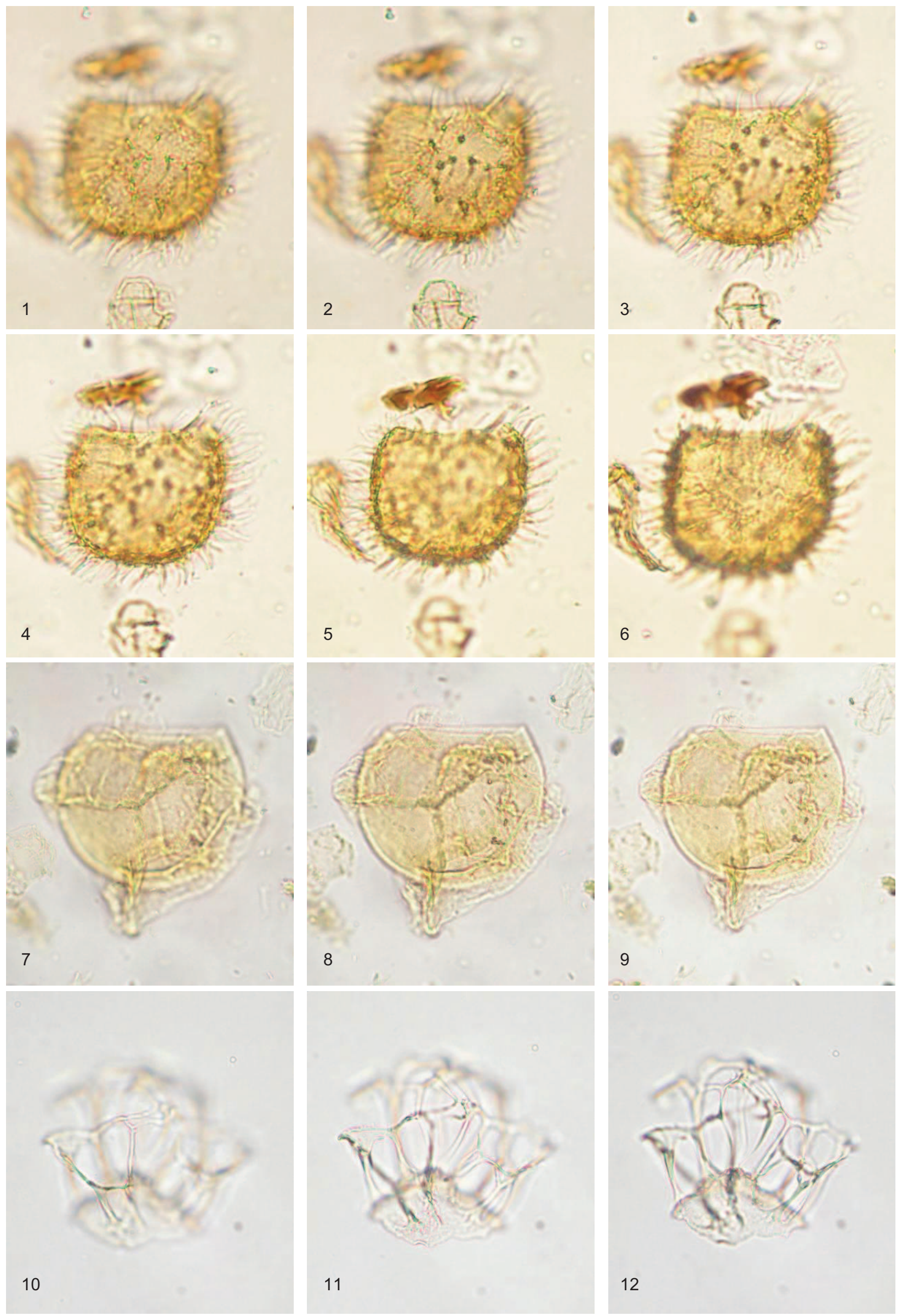


\section{Plate 80}

\section{Glaphyrocysta cf. retiintexta}

Figure 1-2 Sample J42/f486, slide L23121/SM005; ?Hampden Formation, Hampden Beach Section (Porangan-Bortonian)

Figure 3 Sample J42/f485, slide L23120/SM017; ?Hampden Formation, Hampden Beach Section (Porangan-Bortonian)

Figure 4-9 Sample J42/f300, slide L23130/SM012; Hampden Formation, Hampden Beach Section (Porangan); x 375; specimen measures $90 \times 115 \mu \mathrm{m}$

Figure 10-12 Sample J42/f485, slide L23120/SM019; ?Hampden Formation, Hampden Beach Section (Porangan-Bortonian); x 450; specimen measures 102 × $95 \mu \mathrm{m}$ 


\section{Plate 80}

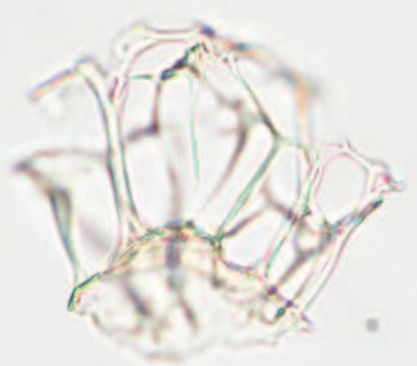

1

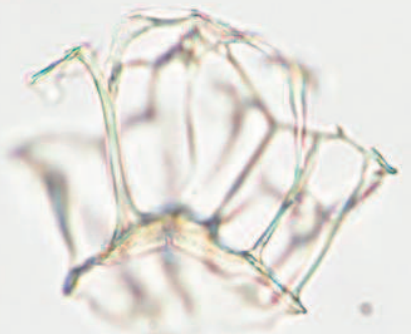

2
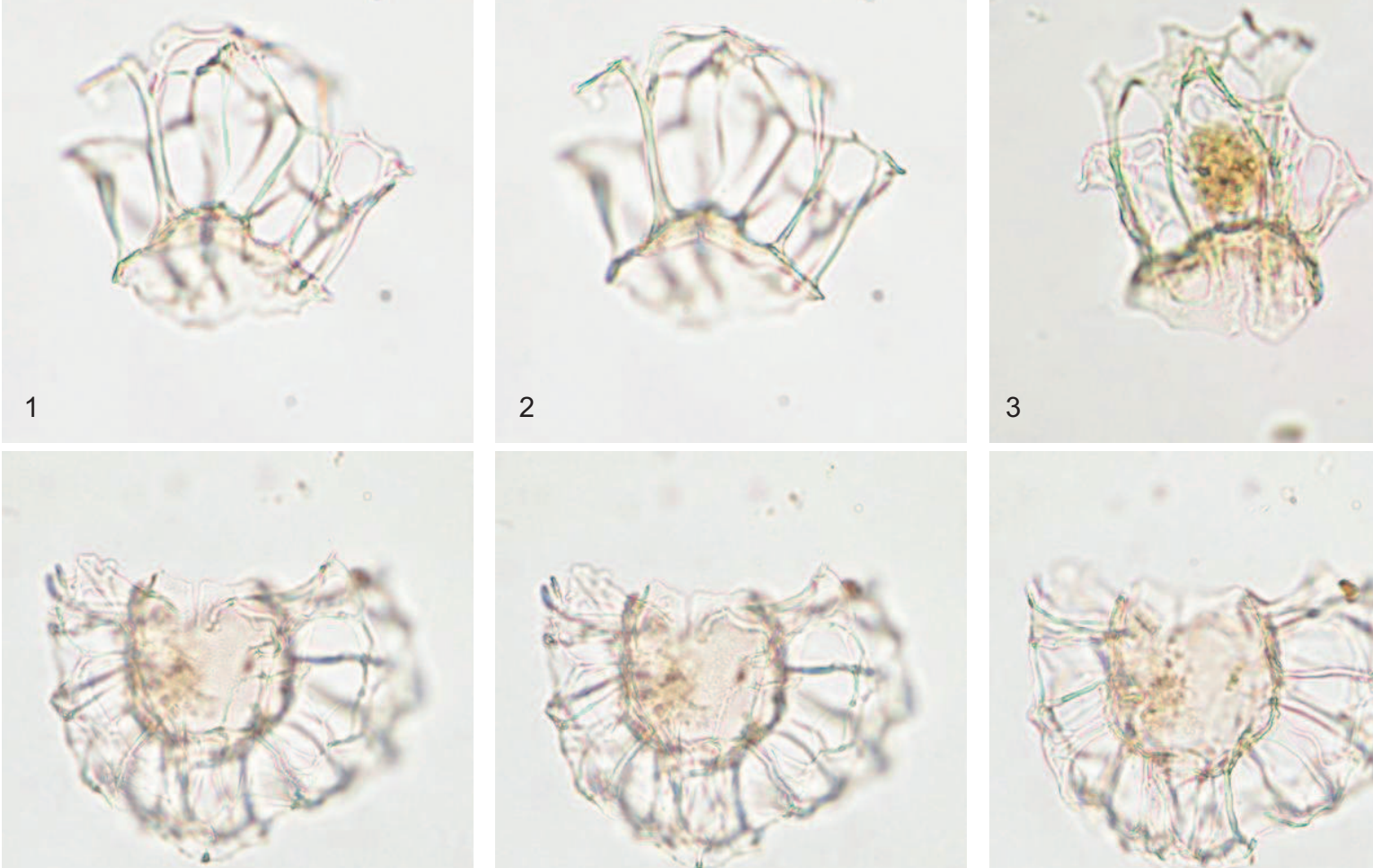

4

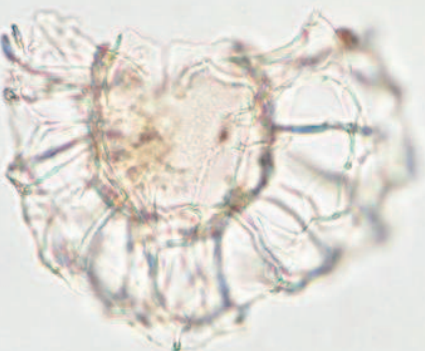

5

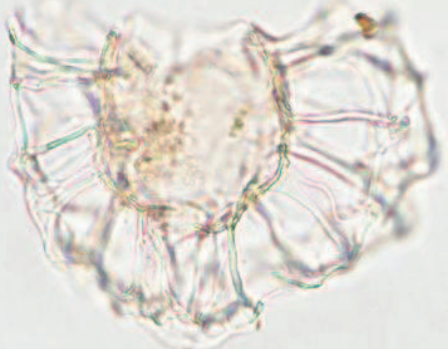

6
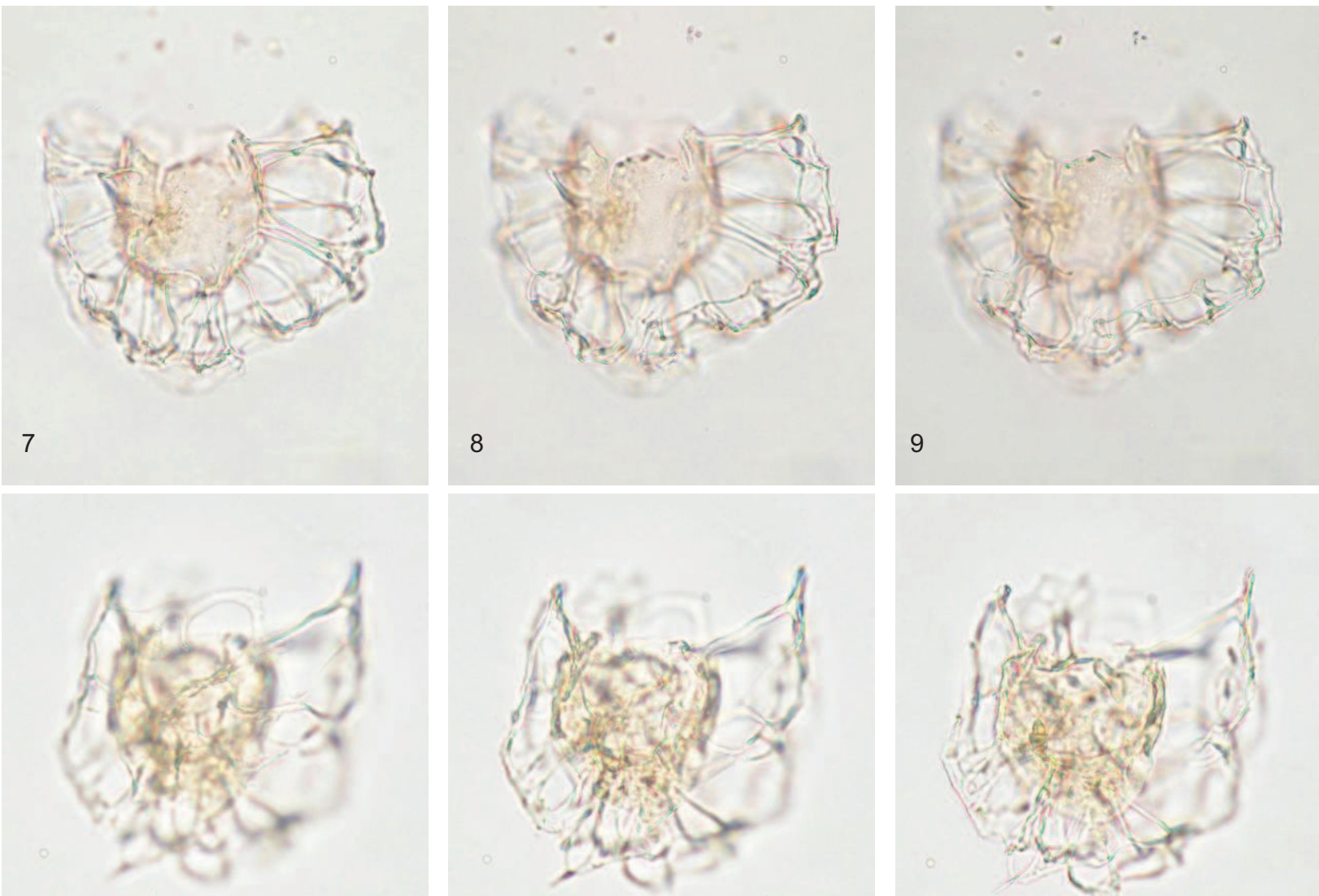

10
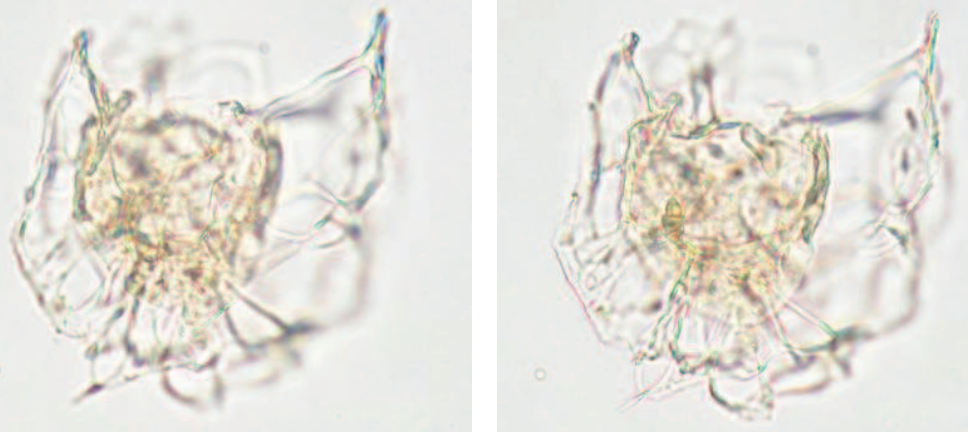

12 


\section{Plate 81}

\section{Glaphyrocysta cf. retiintexta}

Figure 1-3 Sample J42/f485, slide L23120/SM019; ?Hampden Formation, Hampden Beach Section (Porangan-Bortonian); x 450; specimen measures 102 x $95 \mu \mathrm{m}$

Figure 4-9 Sample J42/f485, slide L23120/SM020; ?Hampden Formation, Hampden Beach Section (Porangan-Bortonian); x 450; specimen measures 75 x $96 \mu \mathrm{m}$

\section{Membranophoridium perforatum}

Figure 10-12 Sample J42/f301, slide L23131/SM027; Hampden Formation, Hampden Beach Section (Porangan-Bortonian); x 400; specimen measures 83 x $102 \mu \mathrm{m}$ 


\section{Plate 81}

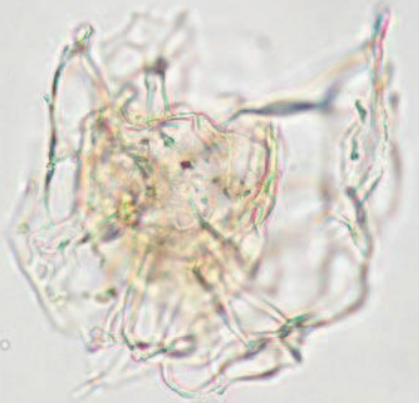

1
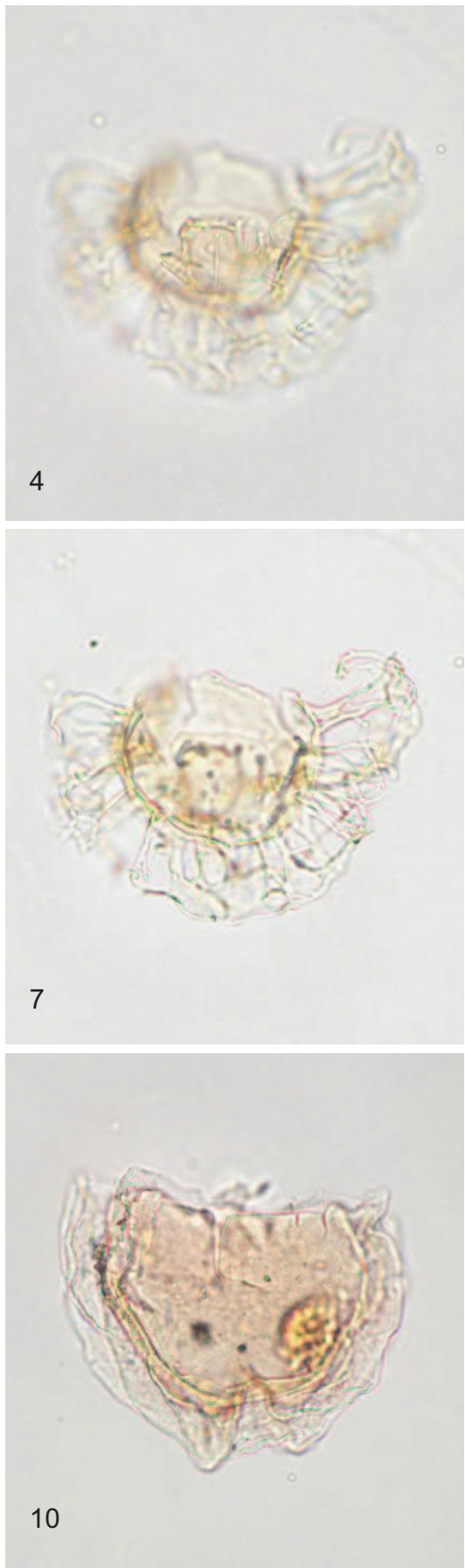

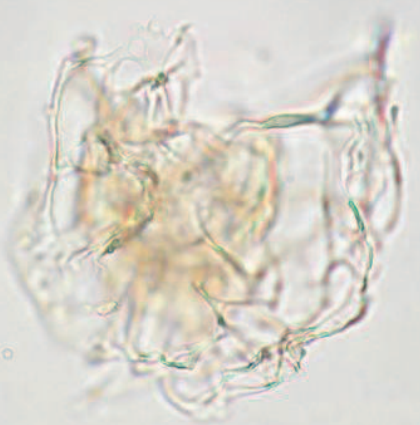

2
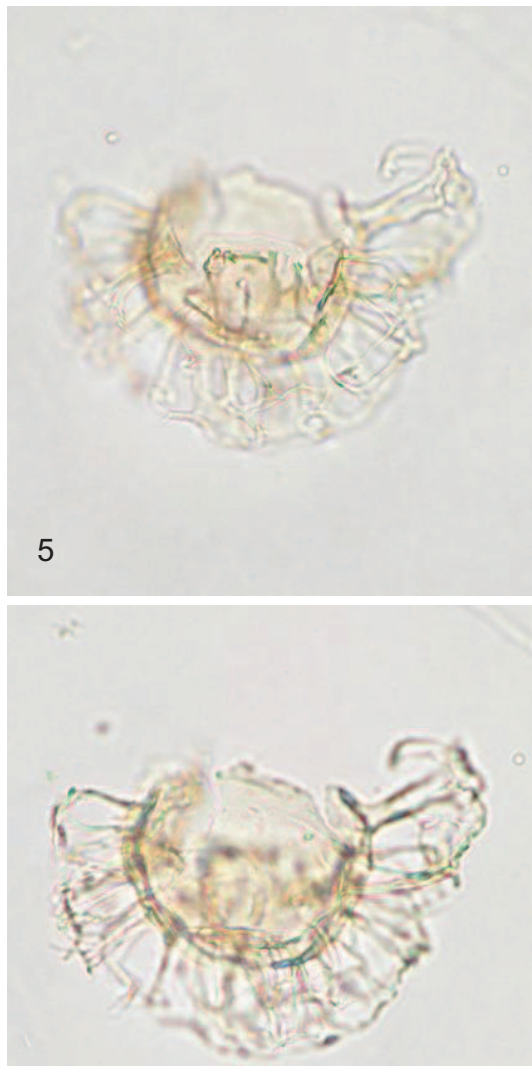

8

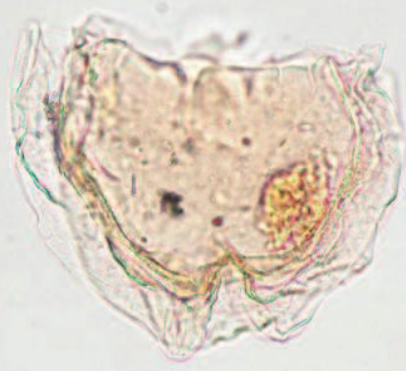

11
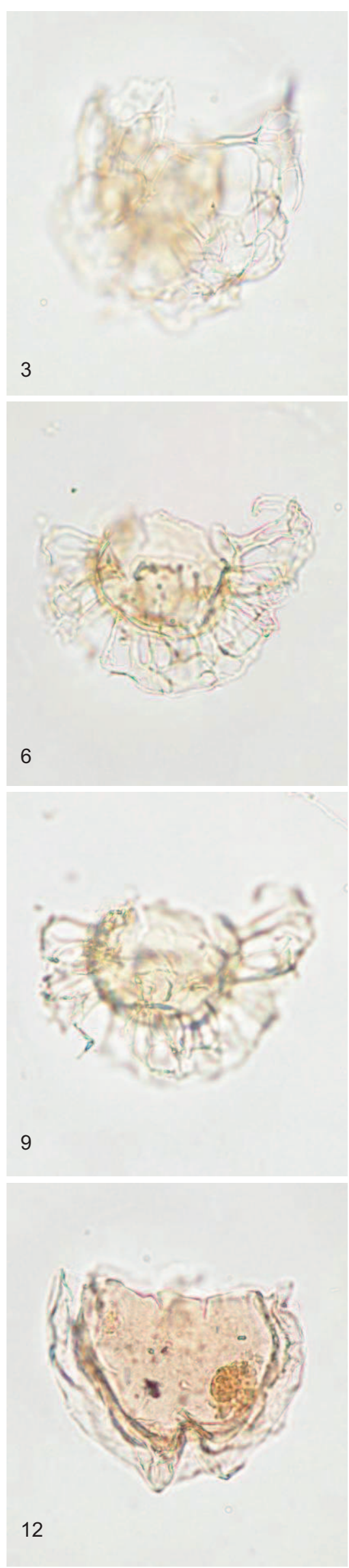


\section{Plate 82}

\section{?Riculacysta sp. 1}

Figure 1-3 Sample J42/f488, slide L23123/SM009; Hampden Formation, Hampden Beach Section (Bortonian)

Figure 4-6 Sample U24/f417, slide L23125/SM021; Wanstead, Te Uri Stream (Porangan); x 500; specimen measures $94 \times 82 \mu \mathrm{m}$

Figure 7-9 Sample U24/f417, slide L23125/SM017; Wanstead, Te Uri Stream (Porangan); x 400; specimen measures $95 \times 102 \mu \mathrm{m}$

Figure 10-12 Sample U24/f417, slide L23125/SM019; Wanstead, Te Uri Stream (Porangan); x 500; specimen measures $79 \times 86 \mu \mathrm{m}$ 


\section{Plate 82}
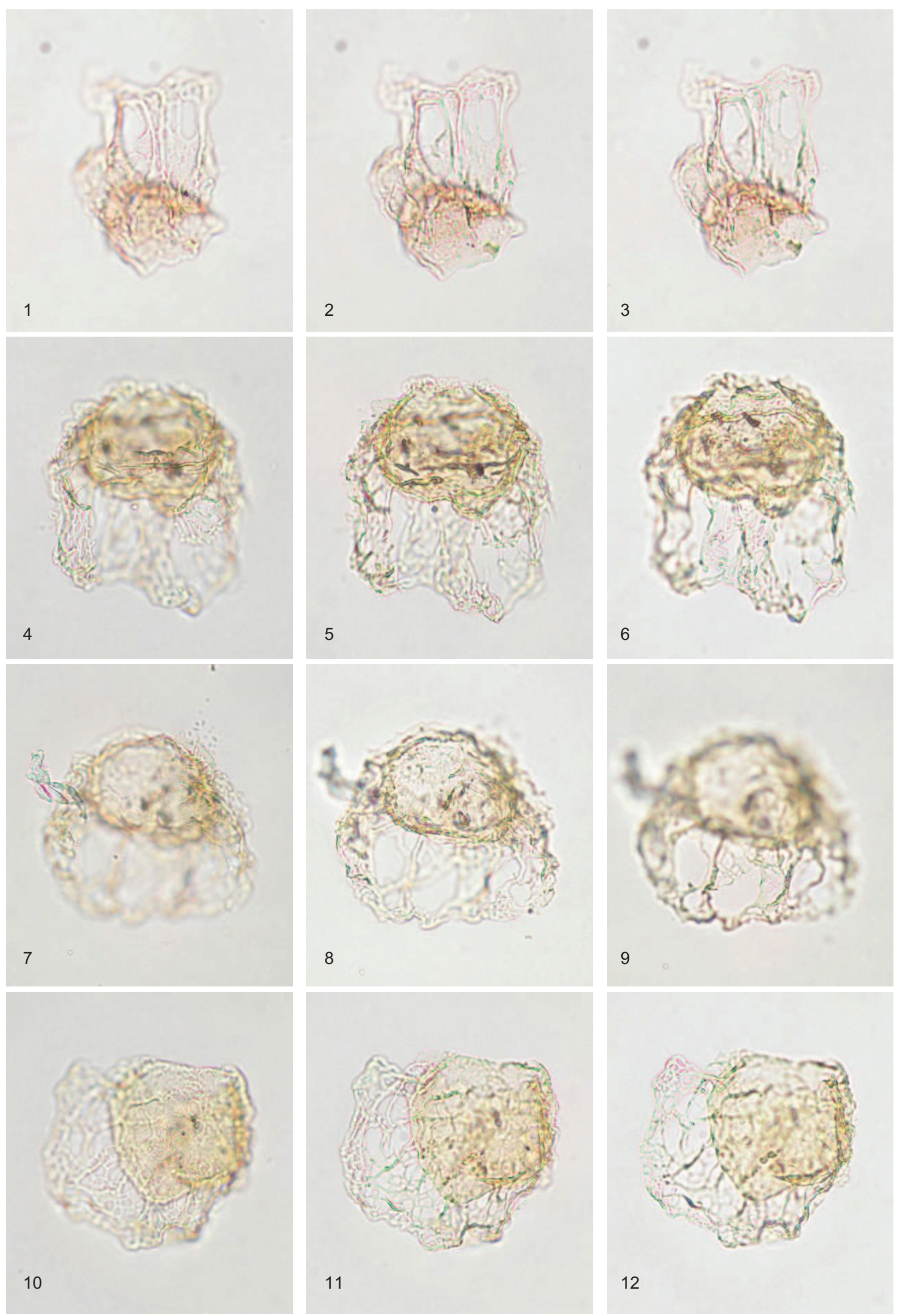


\section{Plate 83}

\section{Eisenackia aff. circumtabulata}

Figure 1-3 Sample 143/f092, slide L16340/1-1434-128; Burnside Formation, Puketeraki Core (Bortonian); x 775; specimen measures 60 x $48 \mu \mathrm{m}$

Figure 4-6 Sample 143/f092, slide L16340/1-1307-137; Burnside Formation, Puketeraki Core (Bortonian); x 775; specimen measures $60 \times 53 \mu \mathrm{m}$

Figure 7-11 Sample 143/f093, slide L16341/SM121; Burnside Formation, Puketeraki Core (Bortonian); x 750; specimen measures $62 \times 56 \mu \mathrm{m}$

?Eisenackia cf. circumtabulata

Figure 12 Sample 143/f089, slide L16337/SM037; Burnside Formation, Puketeraki Core (Bortonian); x 675; specimen measures 70 x $61 \mu \mathrm{m}$ 


\section{Plate 83}
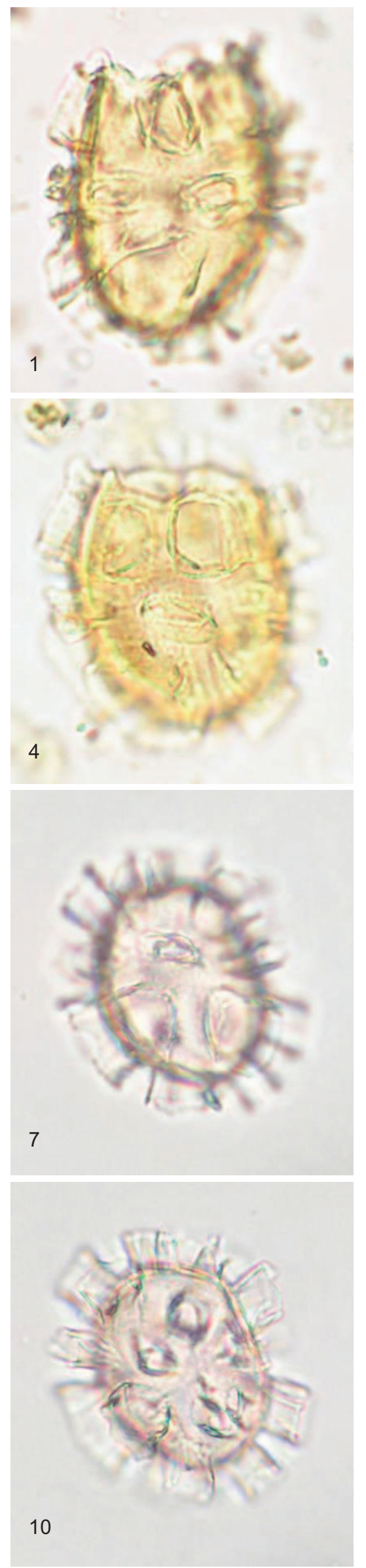
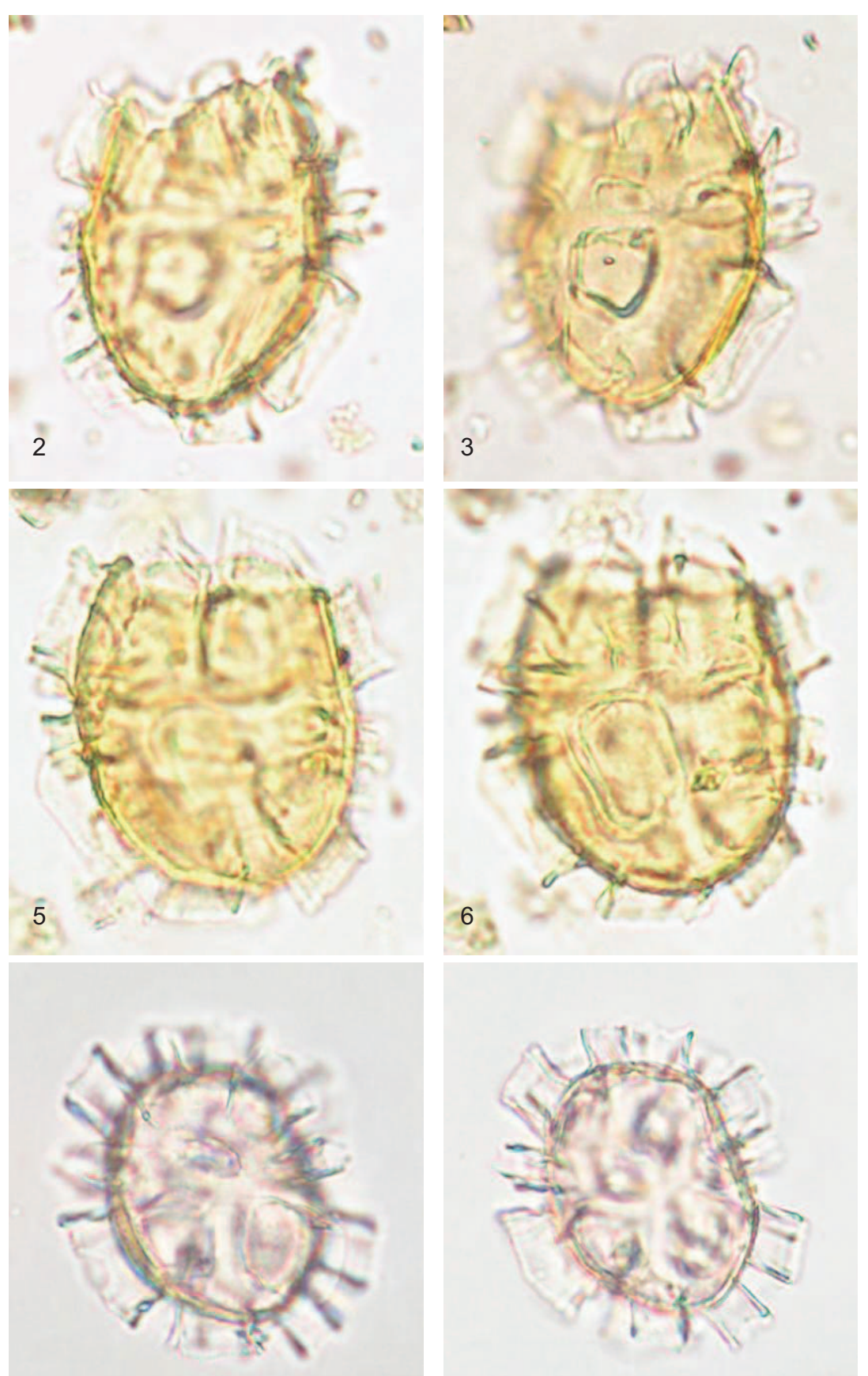

8

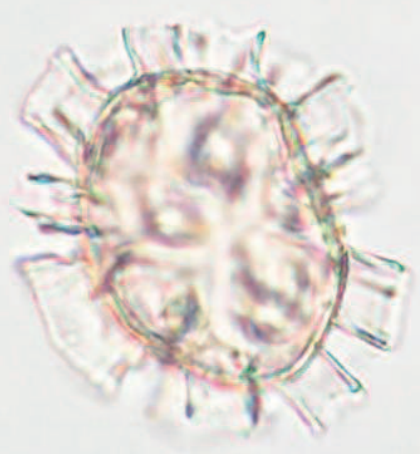

9

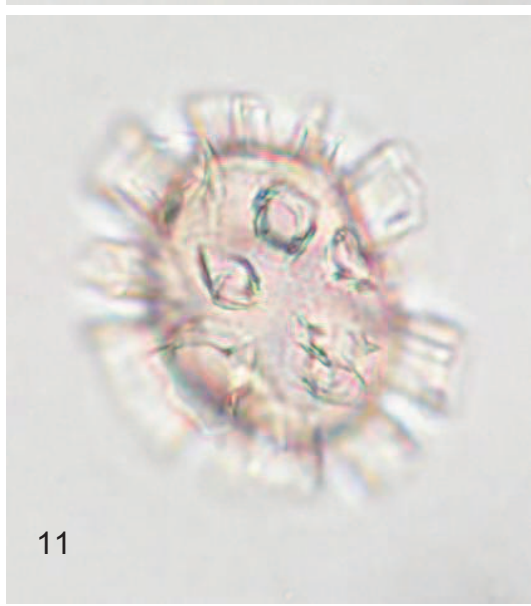

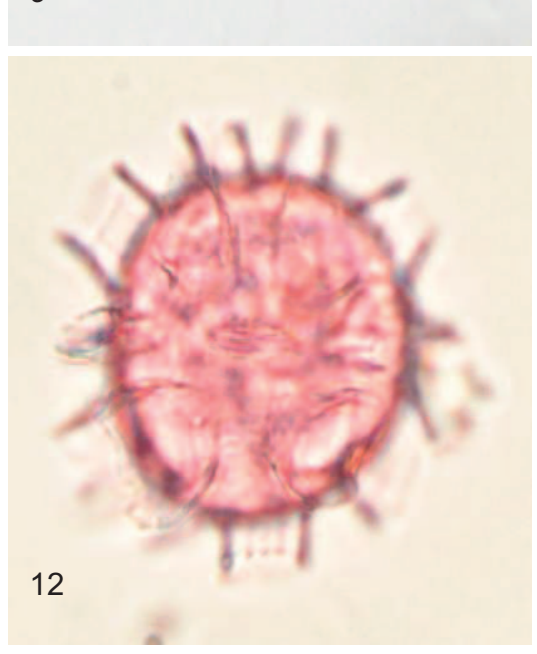




\section{Plate 84}

\section{?Eisenackia cf. circumtabulata}

Figure 1-3 Sample 143/f089, slide L16337/SM037; Burnside Formation, Puketeraki Core (Bortonian); x 675; specimen measures 70 x $61 \mu \mathrm{m}$

?Eisenackia cf. H. wilsonii

Figure 4-9 Sample J42/f489, slide L23124/SM014; Hampden Formation, Hampden Beach Section (Bortonian); x 825; specimen measures 57 x $51 \mu \mathrm{m}$

Figure 10-12 Sample U24/f419, slide L23127/SM024; Wanstead, Te Uri Stream (Porangan); x 850; specimen measures $50 \times 50 \mu \mathrm{m}$ 


\section{Plate 84}
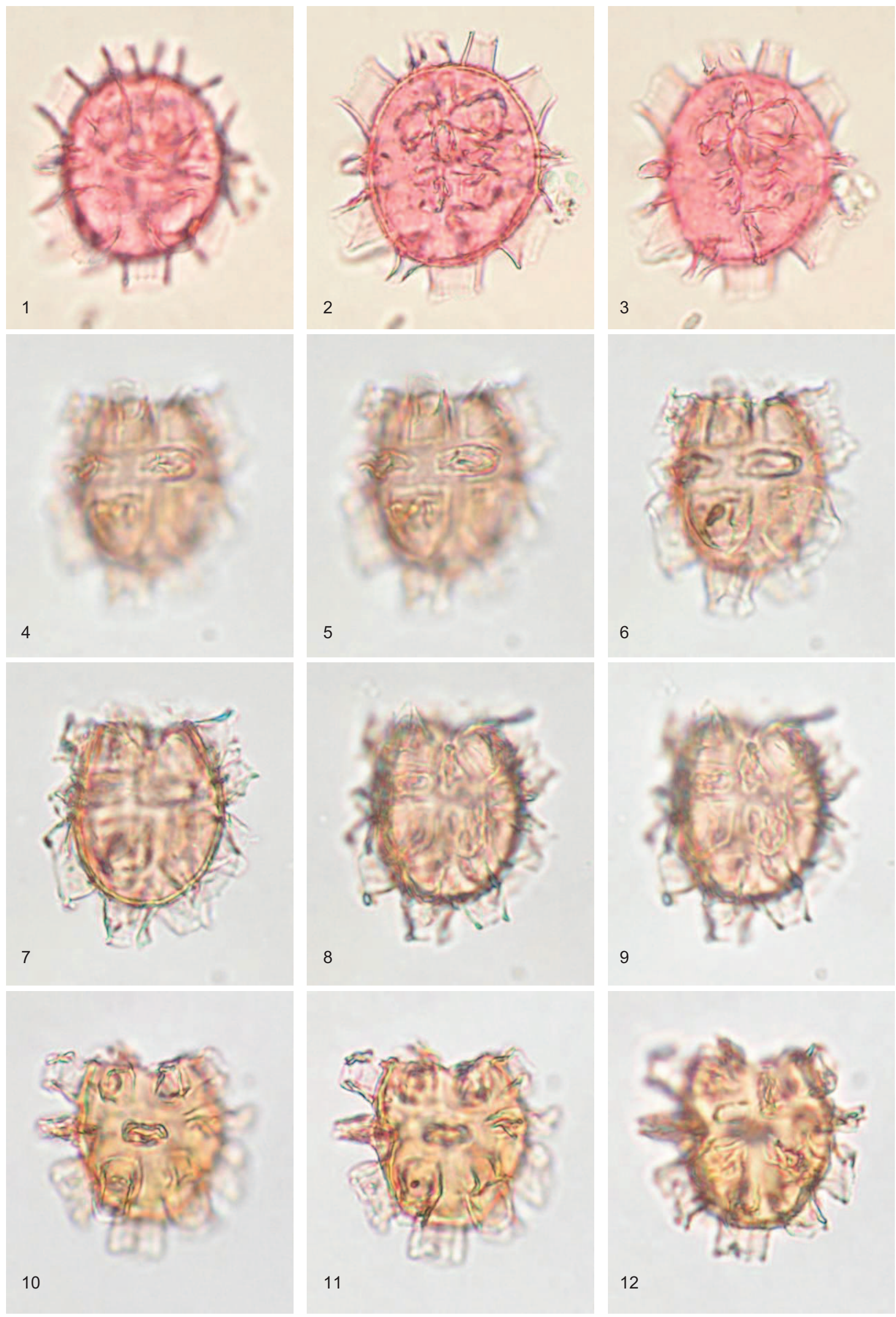


\section{Plate 85}

?Eisenackia cf. H. wilsonii

Figure 1-3 Sample U24/f419, slide L23127/SM065A; Wanstead, Te Uri Stream (Porangan); x 925; specimen measures $45 \times 45 \mu \mathrm{m}$

\section{Homotryblium sp. 2}

Figure 4 Sample 143/f089, slide L16337/SM066A; Burnside Formation, Puketeraki Core (Bortonian)

Figure 5-6 Sample 143/f092, slide L16340/1-1402-180; Burnside Formation, Puketeraki Core (Bortonian); x 925; specimen measures 50 x $45 \mu \mathrm{m}$

\section{Hystrichosphaeridium tubiferum}

Figure 7-12 Sample J42/f485, slide L23120/SM006B; ?Hampden Formation, Hampden Beach Section (Porangan-Bortonian); x 500; specimen measures 79 × $85 \mu \mathrm{m}$ 


\section{Plate 85}
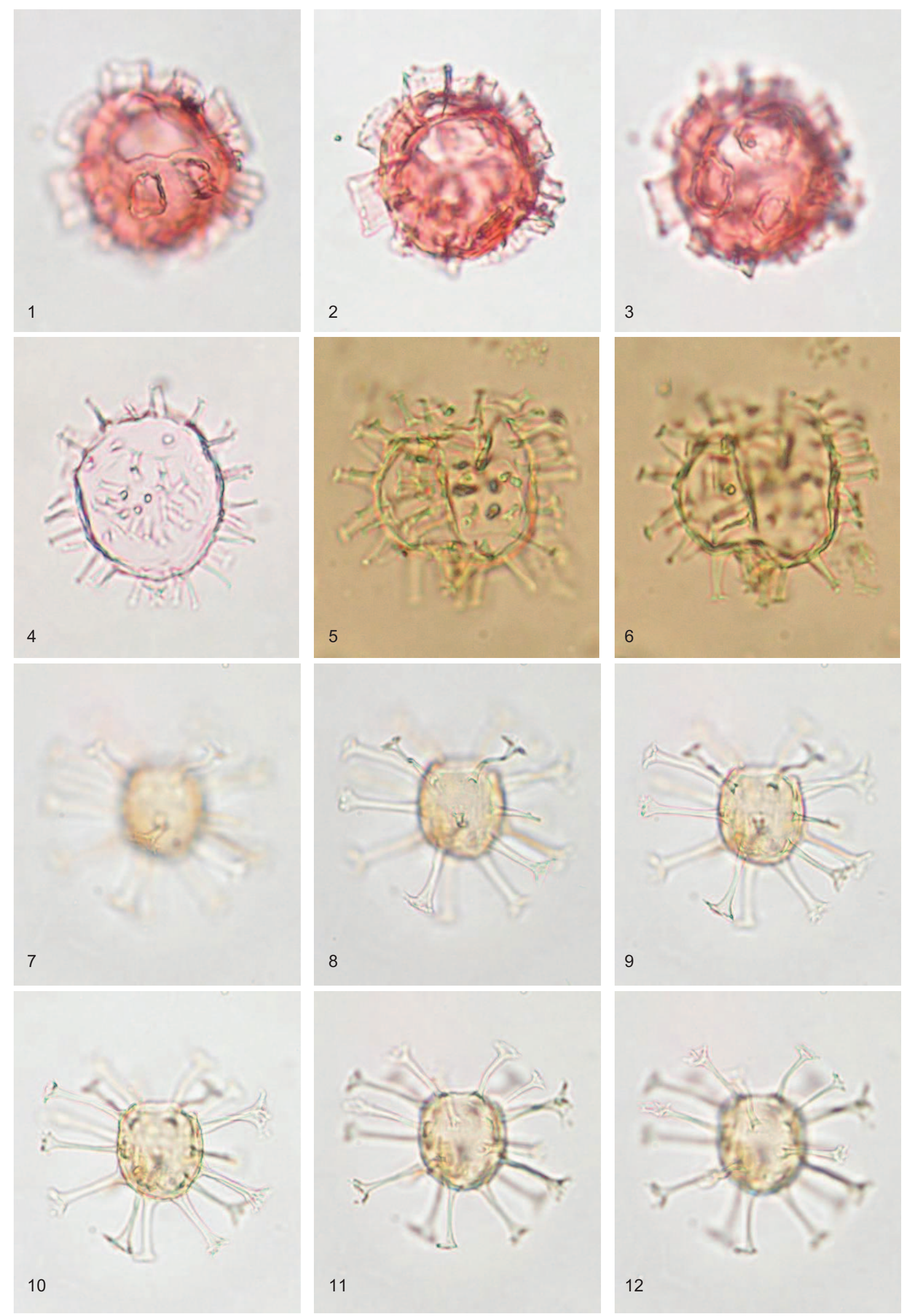


\section{Plate 86}

\section{Hystrichosphaeridium salpingophorum}

Figure 1-3 Sample J42/f302, slide L23132/SM020; Hampden Formation, Hampden Beach Section (Porangan-Bortonian); x 525; specimen measures 87 x $81 \mu \mathrm{m}$

Figure 4-6 Sample J42/f302, slide L23132/SM004B; Hampden Formation, Hampden Beach Section (Porangan-Bortonian); x 600; specimen measures 73 x $70 \mu \mathrm{m}$

\section{Hystrichosphaeridium brevispinum}

Figure 7-12 Sample 143/f093, slide L16341/SM056; Burnside Formation, Puketeraki Core (Bortonian); x 550; specimen measures $67 \times 77 \mu \mathrm{m}$ 


\section{Plate 86}
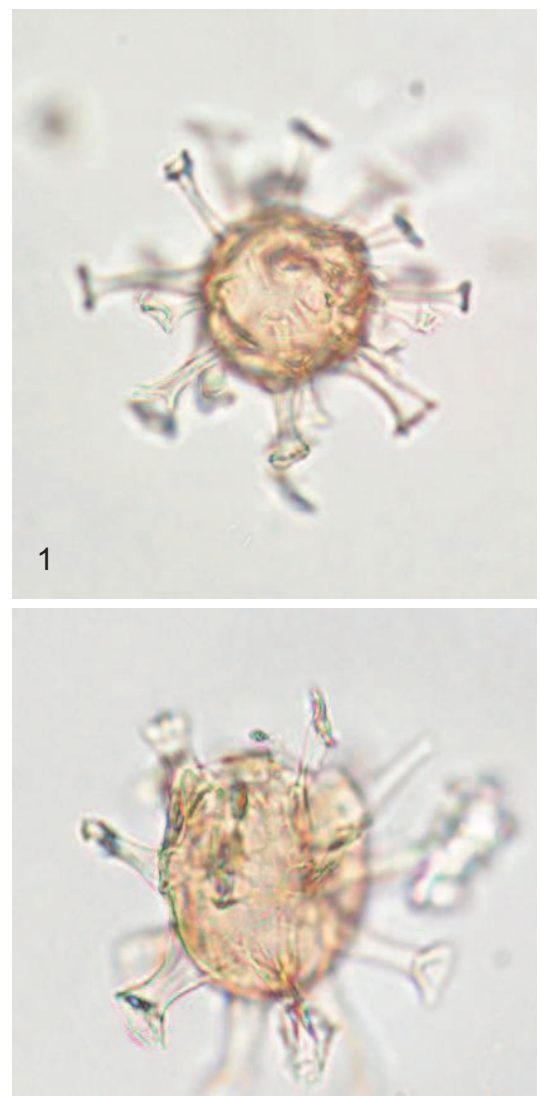

4
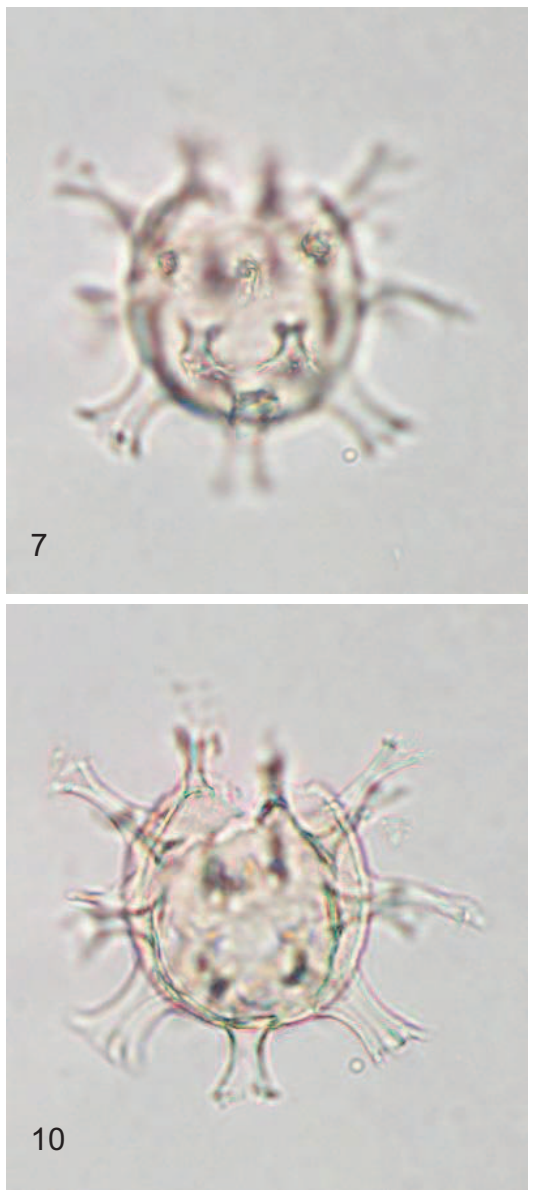
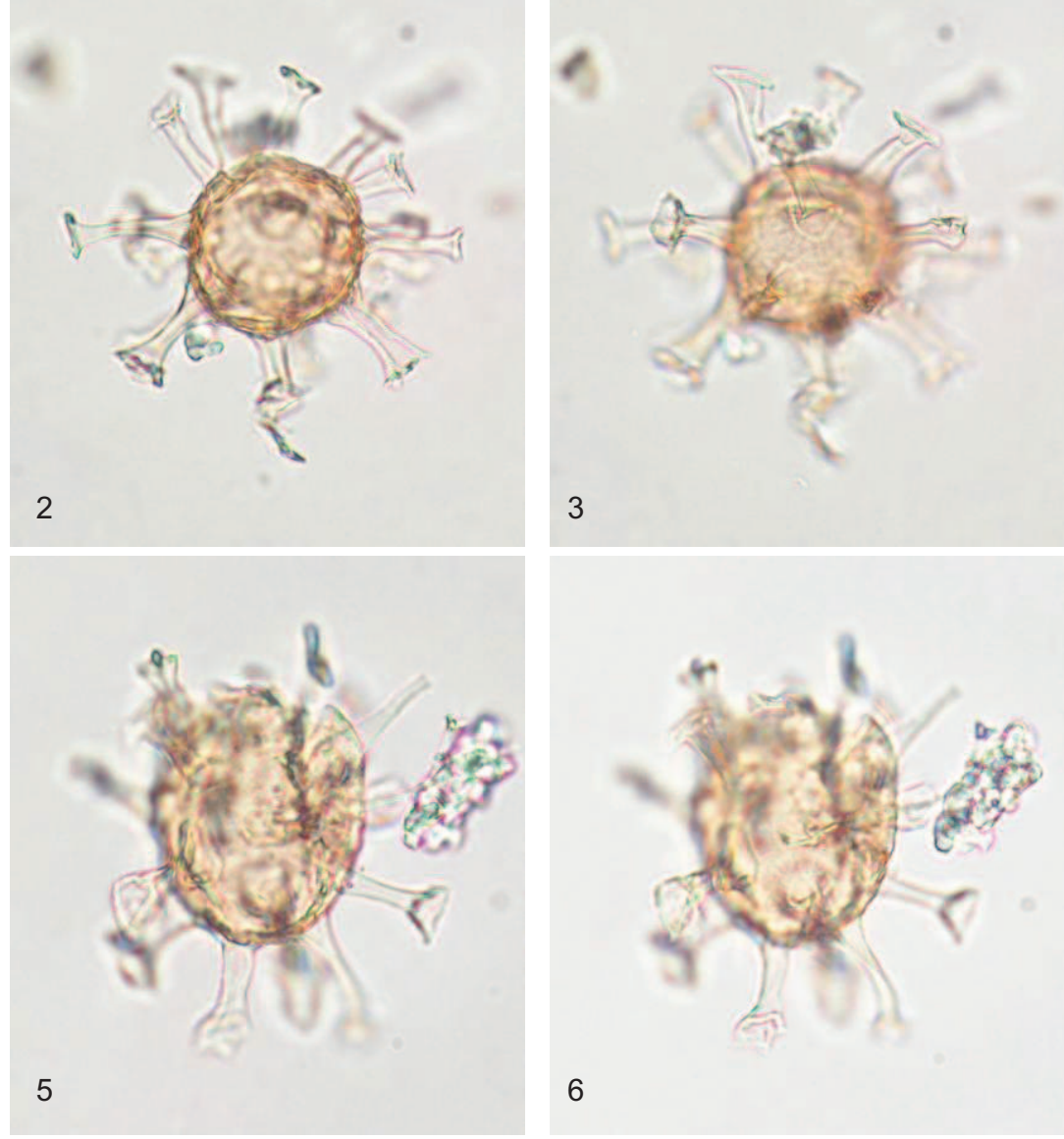

6

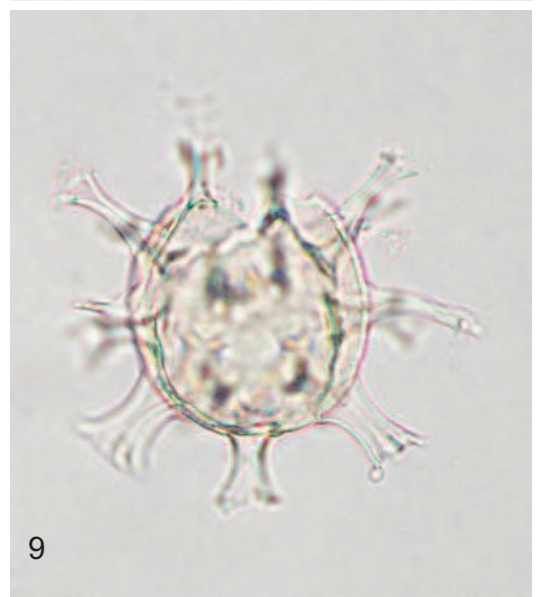

8
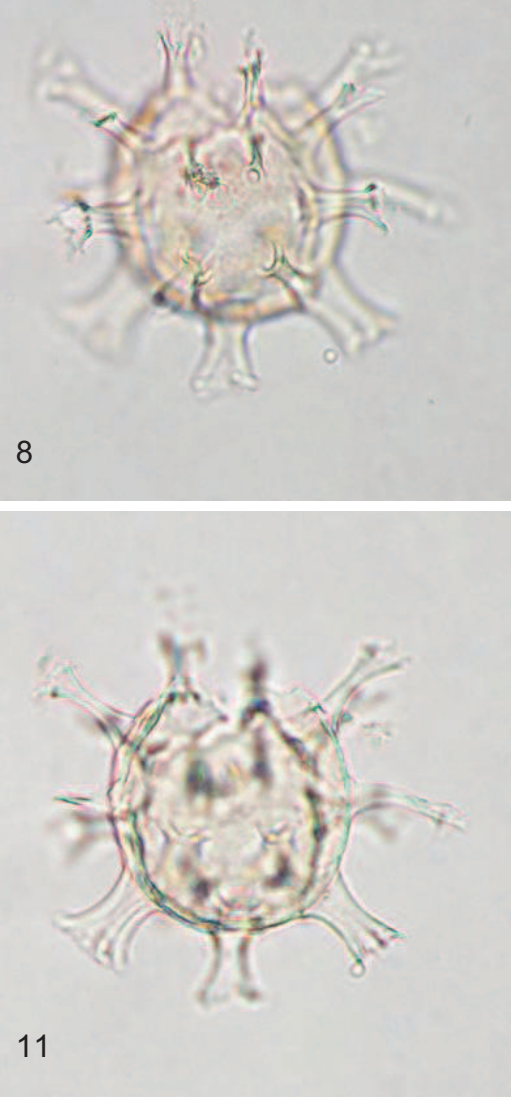

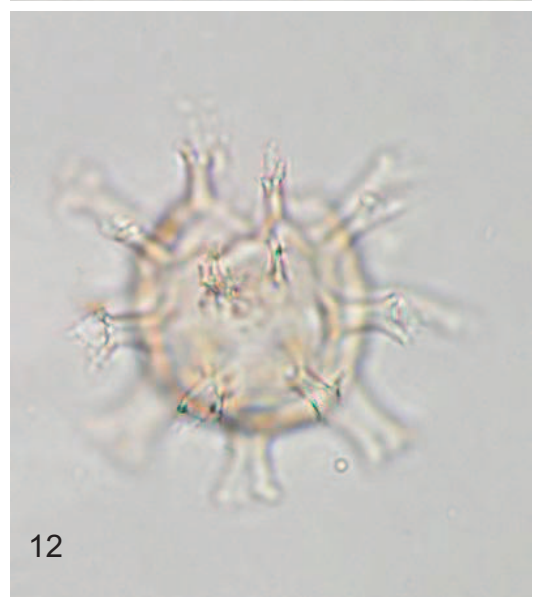




\section{Plate 87}

\section{Hystrichosphaeridium brevispinum}

Figure 1-3 Sample 143/f090, slide L16338/1-1247-116; Burnside Formation, Puketeraki Core (Bortonian); x 550; specimen measures $70 \times 78 \mu \mathrm{m}$

\section{Batiacasphaera perforata}

Figure 4-9 Sample I43/f089, slide L16337/SM102; Burnside Formation, Puketeraki Core (Bortonian); x 725; specimen measures 55 x $57 \mu \mathrm{m}$

Figure 10-12 Sample J41/f8914, slide L04979/SM1086; Waiareka Volcanics, Jacksons Paddock (KaiatanRunangan) 


\section{Plate 87}
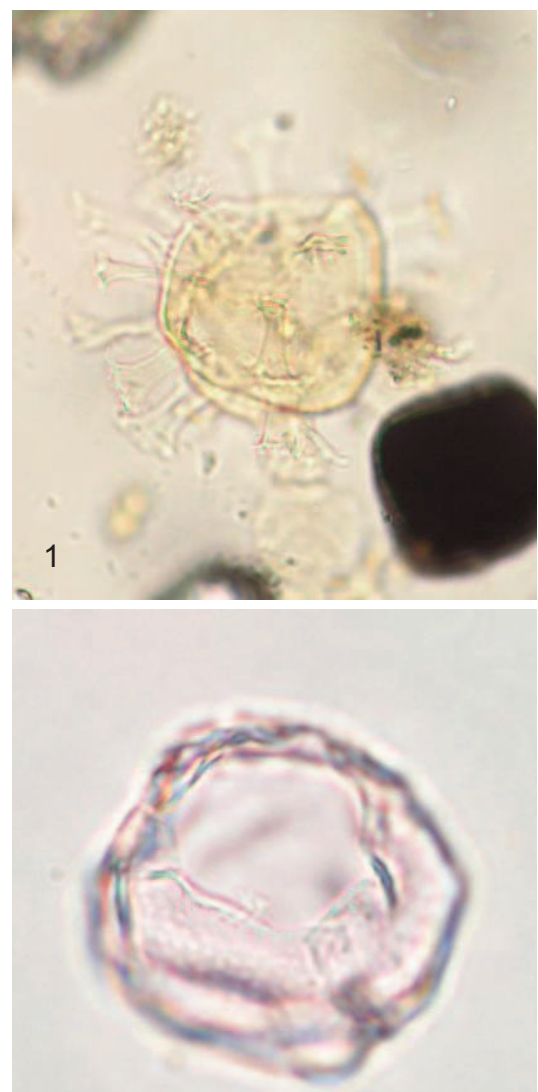

4

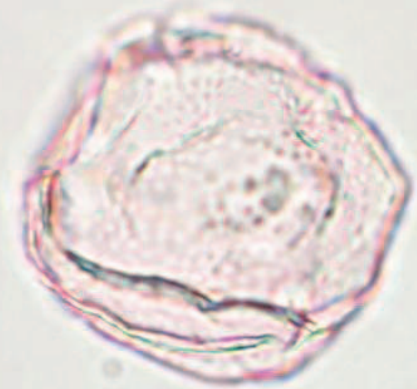

7

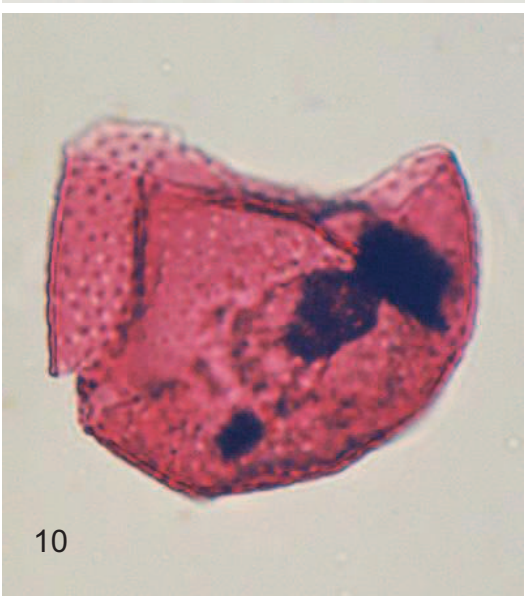

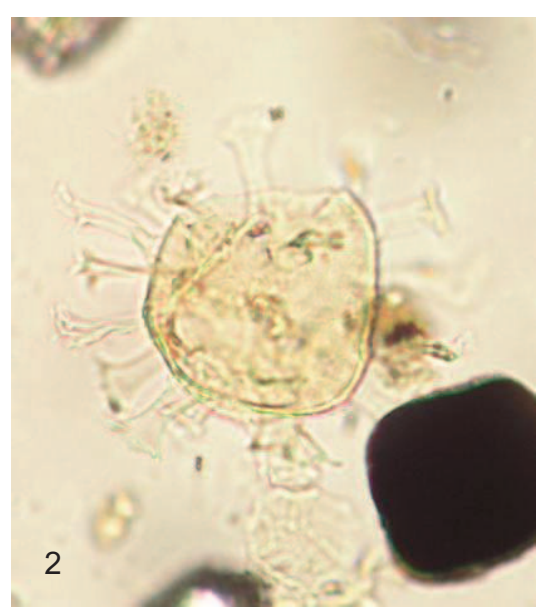

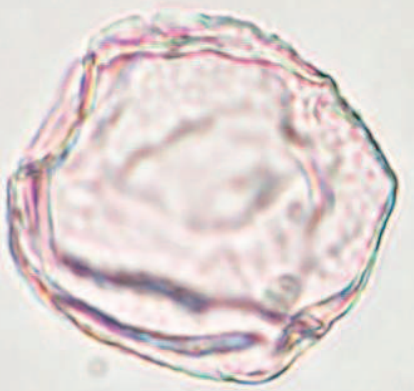

5
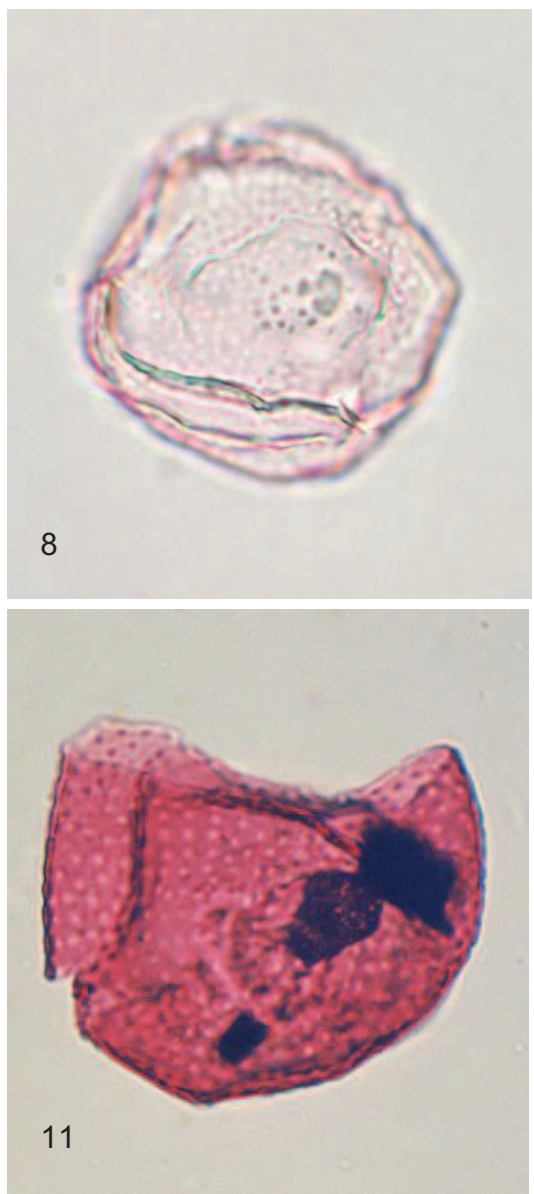
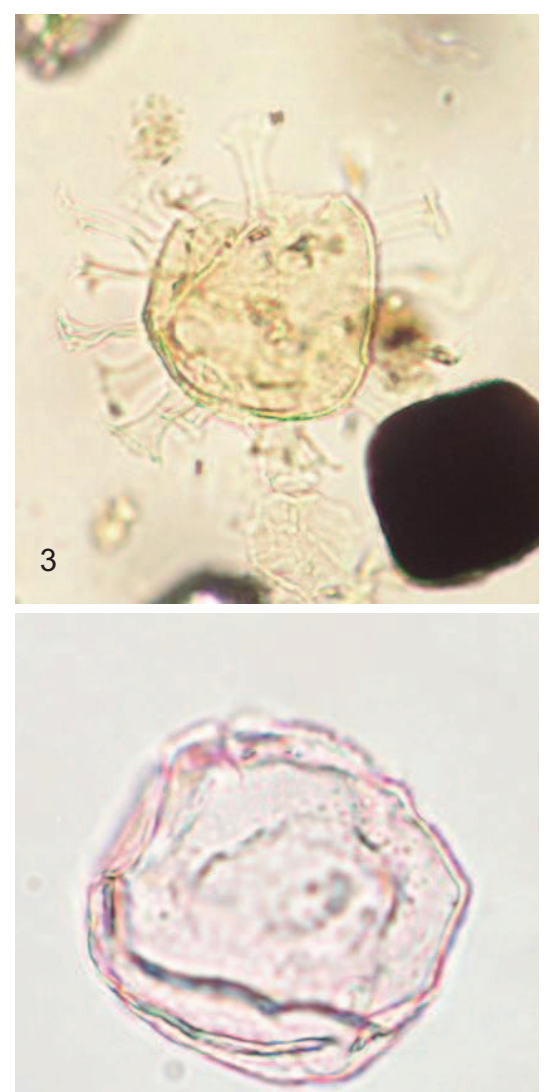

6
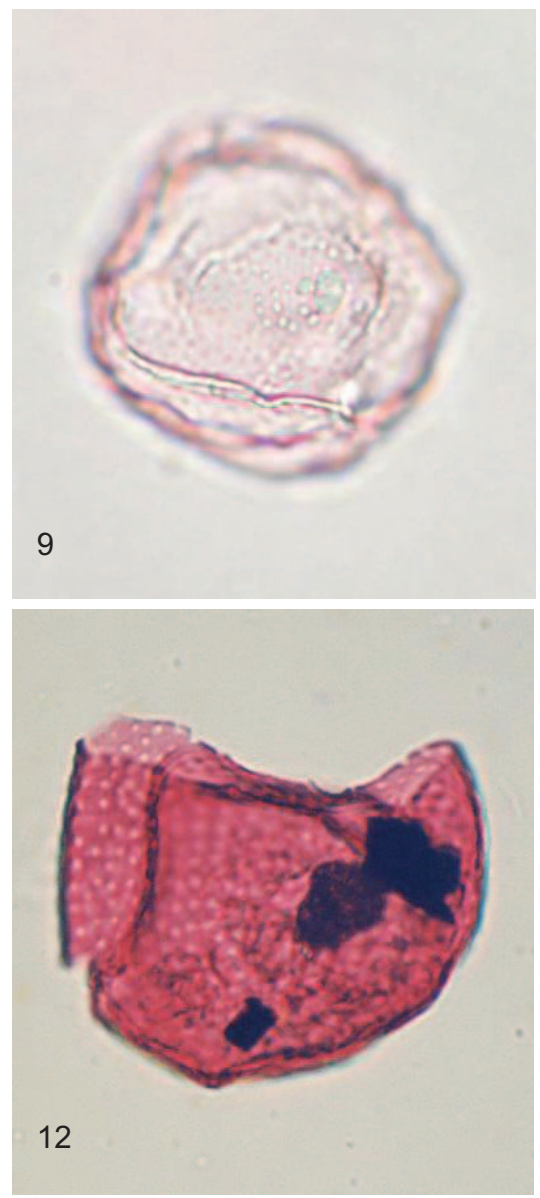


\section{Plate 88}

\section{Batiacasphaera perforata}

Figure 1-2 Sample J41/f8914, slide L04979/10-1179-070; Waiareka Volcanics, Jacksons Paddock (Kaiatan-Runangan)

Figure 3 Sample J41/f8914, slide L04979/SM1105; Waiareka Volcanics, Jacksons Paddock (KaiatanRunangan); x 625; specimen measures 53 x $67 \mu \mathrm{m}$

\section{Cerebrocysta sp. 1}

Figure 4-6 Sample I43/f093, slide L16341/SM174; Burnside Formation, Puketeraki Core (Bortonian); specimen measures $29 \times 29 \mu \mathrm{m}$

Figure 7-9 Sample 143/f089, slide L16337/SM049; Burnside Formation, Puketeraki Core (Bortonian); specimen measures $27 \times 22 \mu \mathrm{m}$

\section{Cerebrocysta ?sp. 2}

Figure 10-12 Sample 144/f080, slide L08947/SM003; Burnside Formation, Burnside Marl Pit (Bortonian); x 775; specimen measures $60 \times 55 \mu \mathrm{m}$ 


\section{Plate 88}
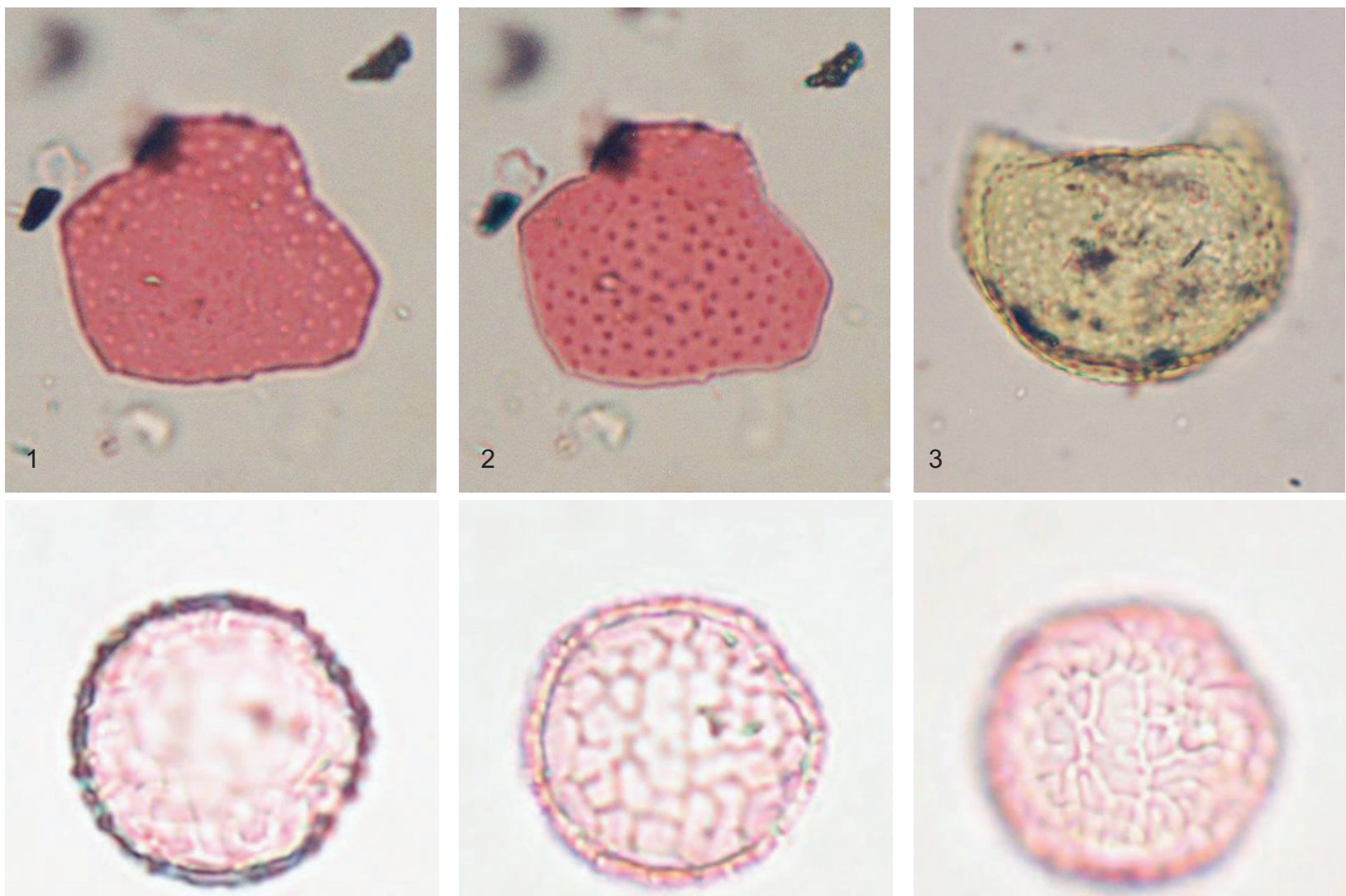

4

5
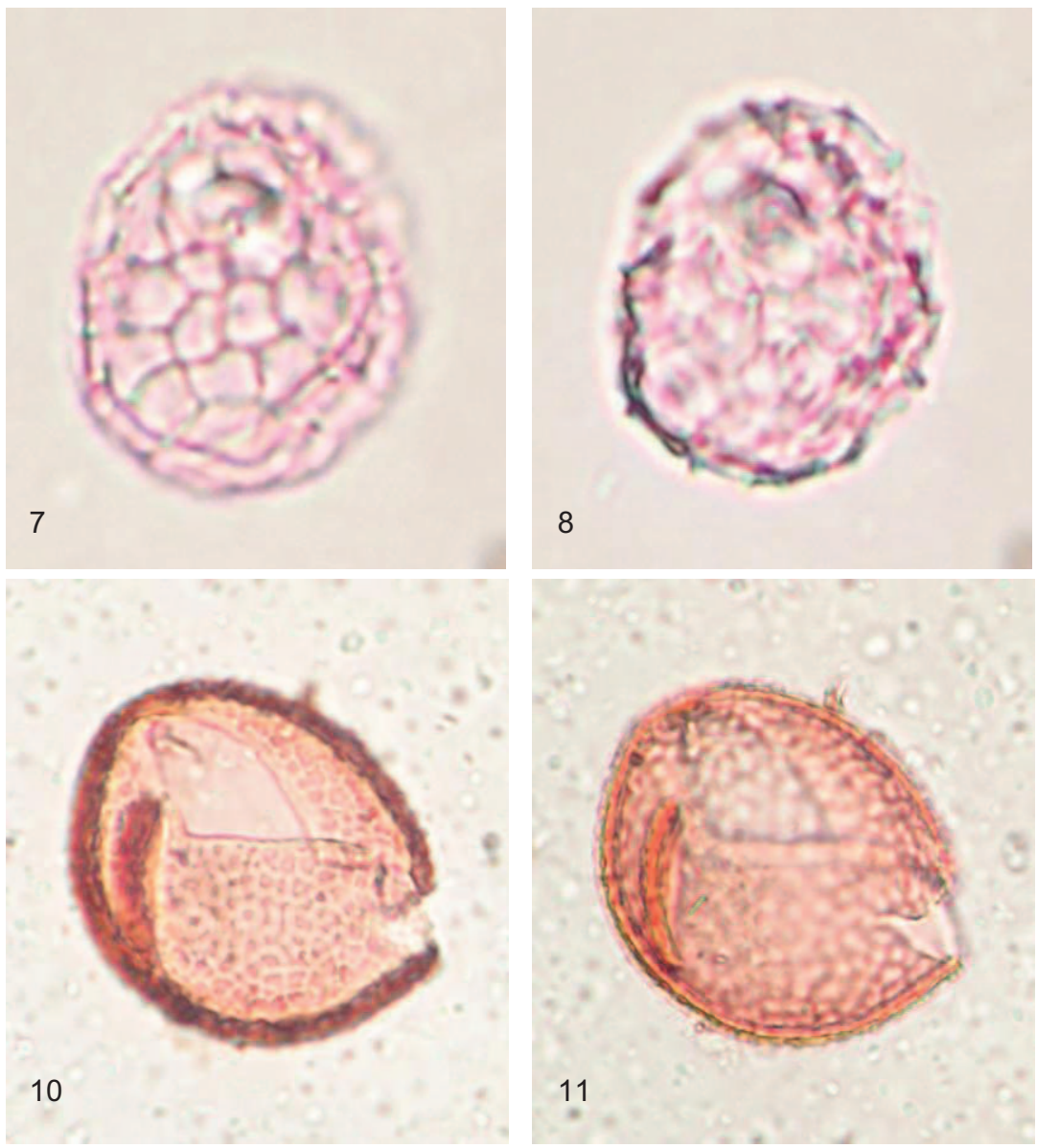
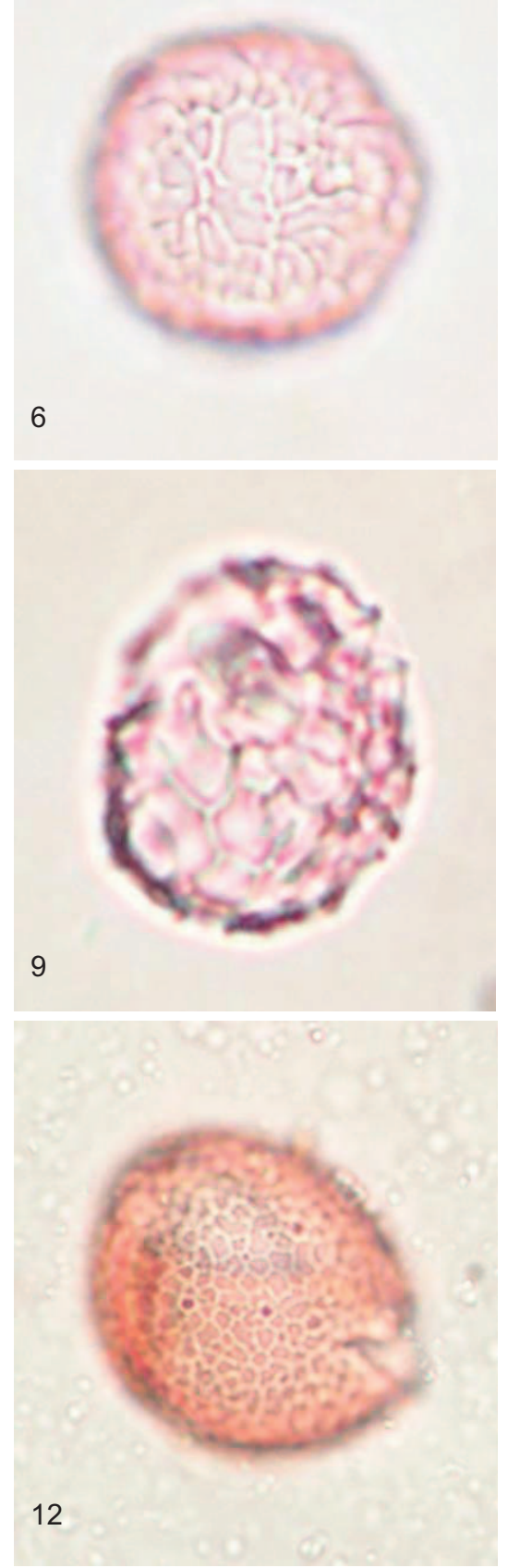


\section{Plate 89}

\section{Chlamydophorella neopilata}

Figure 1-4 Sample J42/f096, slide L10951/SM2952; Totara Limestone, Kakanui River (early Whaingaroan); specimen measures $35 \times 34 \mu \mathrm{m}$

Figure 5-6 Sample J42/f096, slide L10951/SM041; Totara Limestone, Kakanui River (early Whaingaroan); specimen measures $32 \times 28 \mu \mathrm{m}$

Figure 7-12 Sample J42/f097, slide L10952/SM020; Totara Limestone, Kakanui River (?early Whaingaroan); specimen measures $32 \times 28 \mu \mathrm{m}$ 


\section{Plate 89}
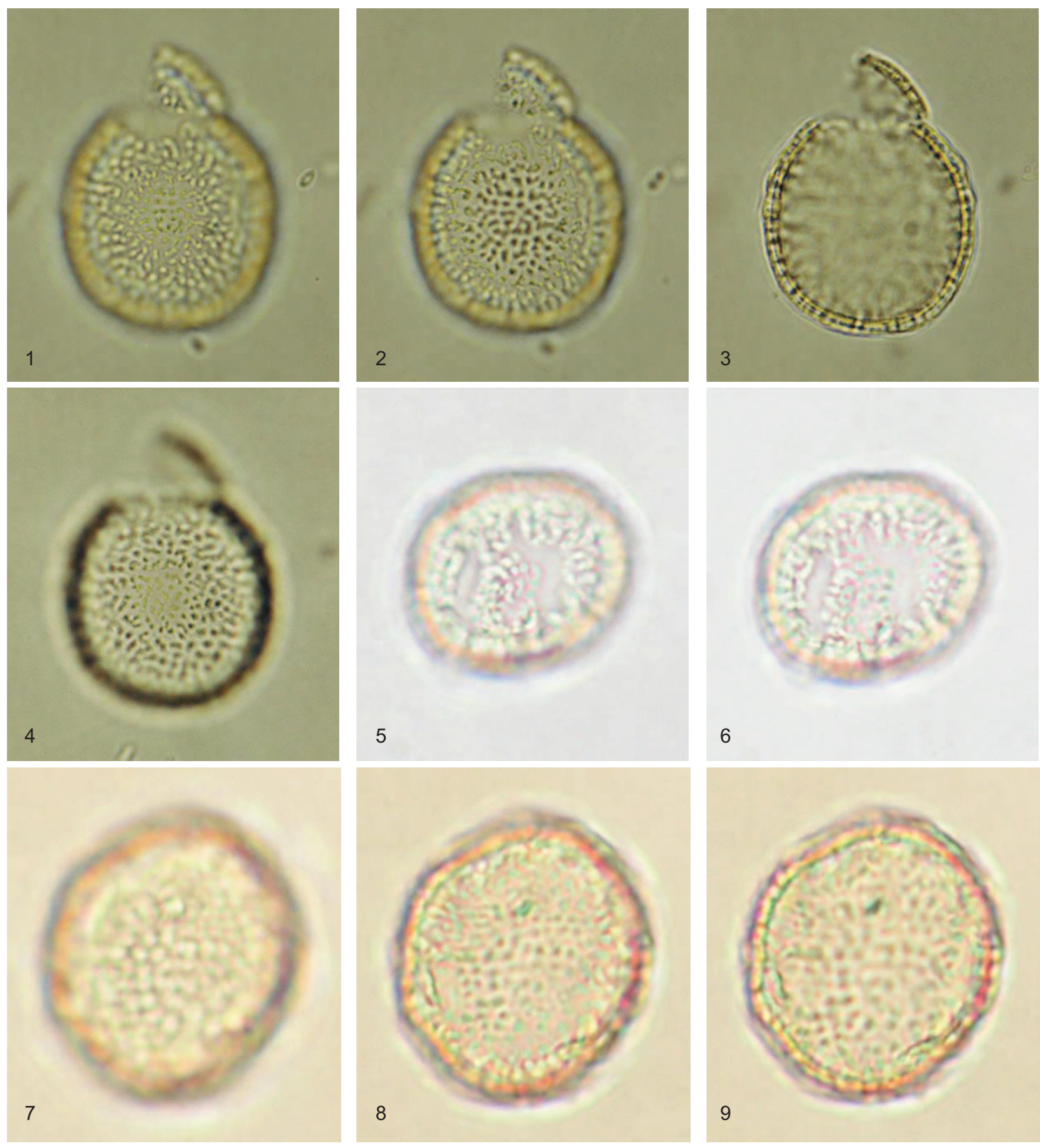

6
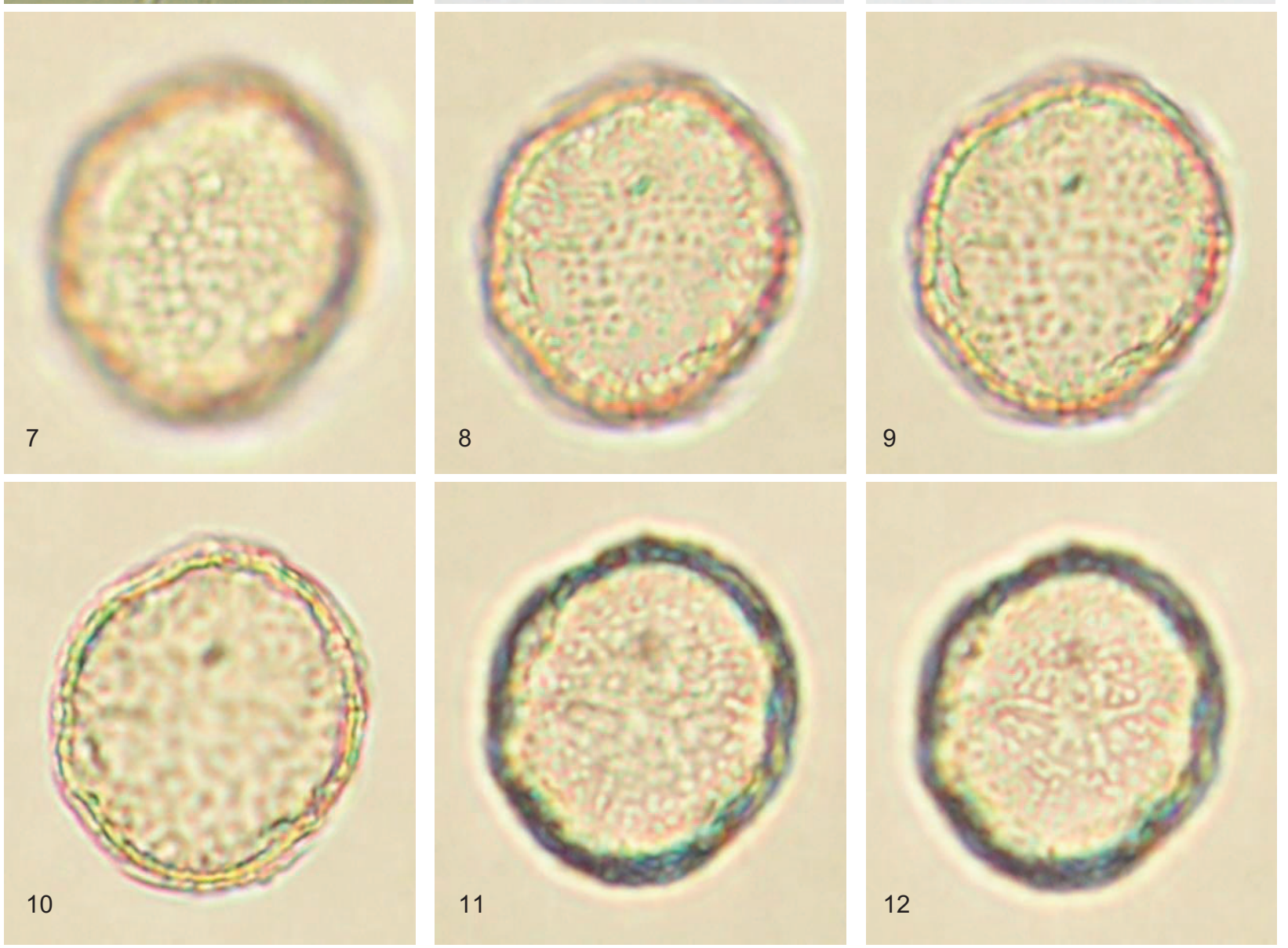


\section{Plate 90}

\section{Chlamydophorella pilata}

Figure 1-6 Sample J42/f485, slide L23120/SM046; ?Hampden Formation, Hampden Beach Section (Porangan-Bortonian); x 850; specimen measures 56 × $33 \mu \mathrm{m}$

Figure 7-12 Sample J42/f485, slide L23120/SM044; ?Hampden Formation, Hampden Beach Section (Porangan-Bortonian); x 1075; specimen measures 44 x $35 \mu \mathrm{m}$ 


\section{Plate 90}
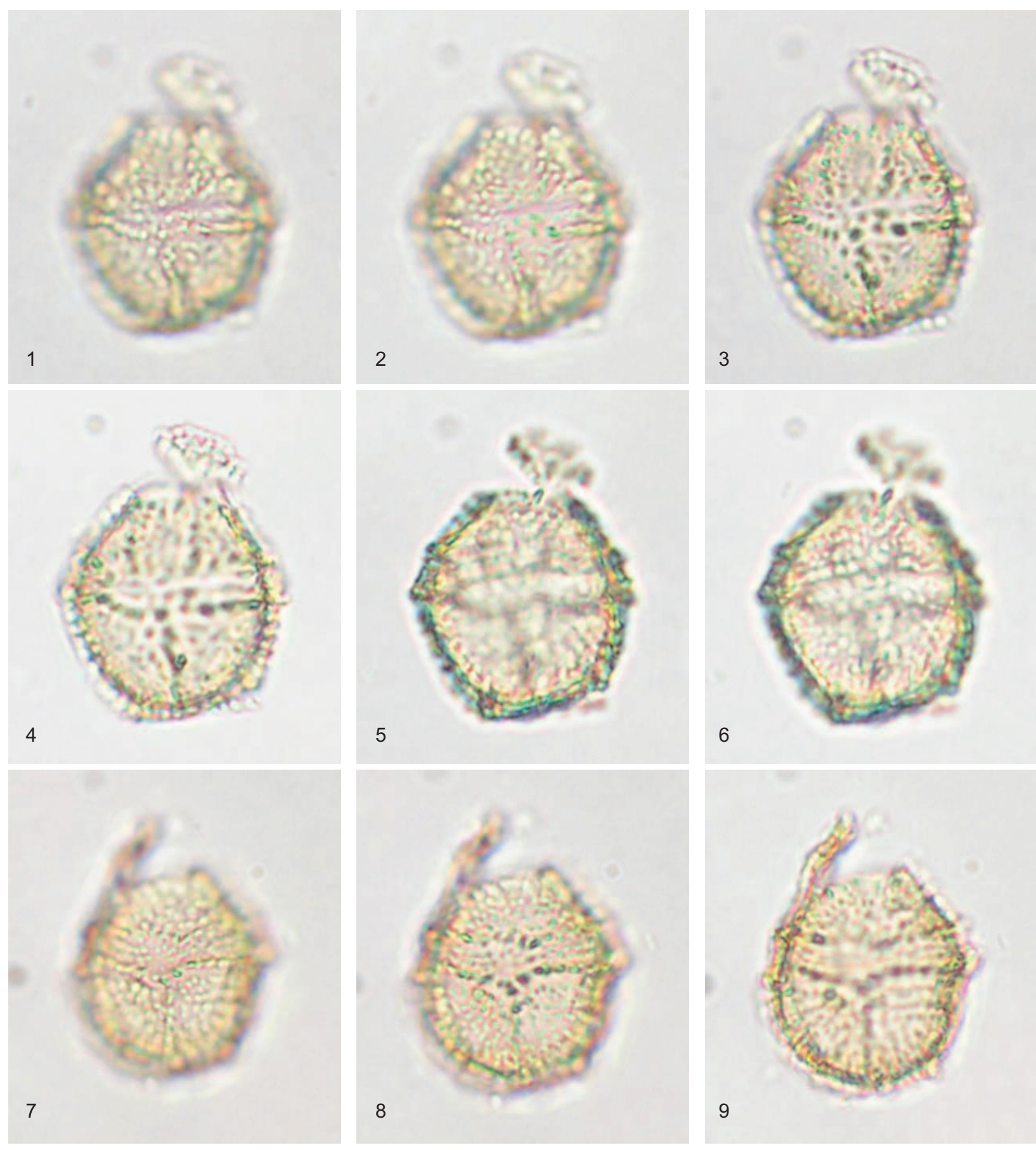

\section{5}
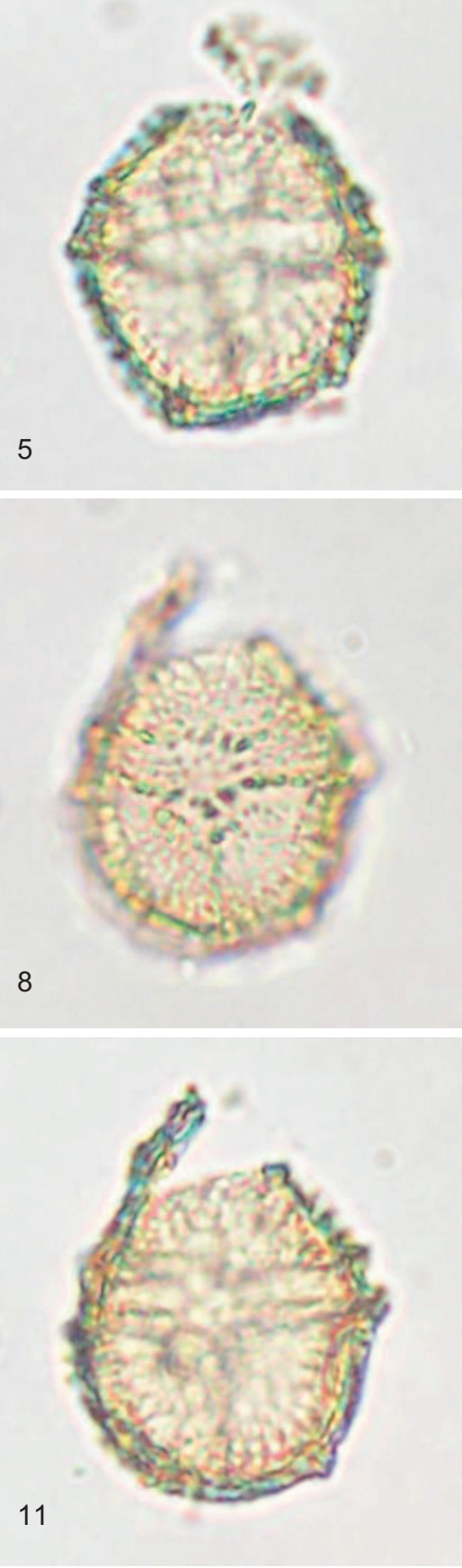

6

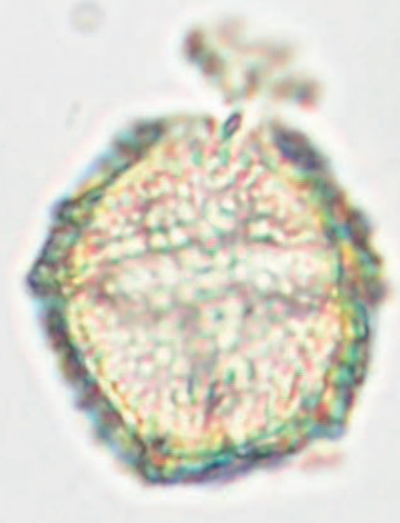

9

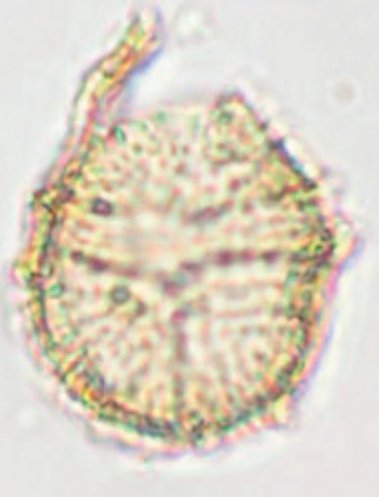

12 


\section{Plate 91}

\section{Dapsilidinium pseudocolligerum}

Figure 1-5 Sample 143/f093, slide L16341/SM086; Burnside Formation, Puketeraki Core (Bortonian); x 550; specimen measures $72 \times 75 \mu \mathrm{m}$

Figure 6 Sample 143/f093, slide L16341/SM116; Burnside Formation, Puketeraki Core (Bortonian); x 625; specimen measures 58 x $67 \mu \mathrm{m}$

\section{Distatodinium apenninicum}

Figure 7-9 Sample I43/f091, slide L16339/1-1420-223; Burnside Formation, Puketeraki Core (Bortonian); x 425; specimen measures $110 \times 77 \mu \mathrm{m}$

\section{?Labyrinthodinium sp. 1}

Figure 10-12 Sample I43/f089, slide L16337/SM070; Burnside Formation, Puketeraki Core (Bortonian); specimen measures $35 \times 37 \mu \mathrm{m}$ 


\section{Plate 91}
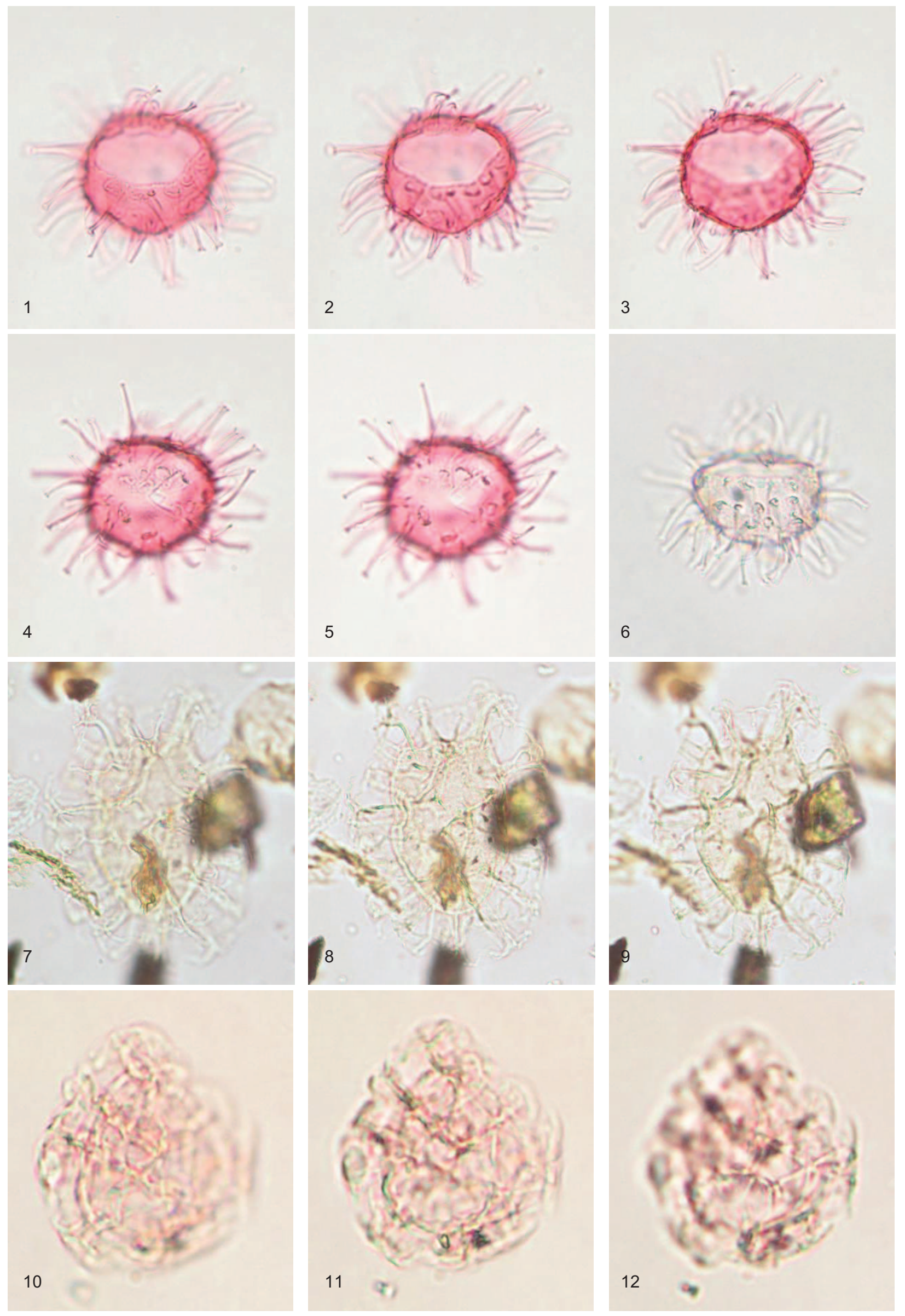


\section{Plate 92}

\section{?Labyrinthodinium sp. 1}

Figure 1-3 Sample 143/f089, slide L16337/2-1401-126; Burnside Formation, Puketeraki Core (Bortonian); specimen measures $38 \times 31 \mu \mathrm{m}$

\section{?Paucisphaeridium inversibuccinum}

Figure 4-6 Sample I43/f093, slide L16341/1-1445-145; Burnside Formation, Puketeraki Core (Bortonian); x 800; specimen measures 58 × $53 \mu \mathrm{m}$

Indet 3 sp. 1

Figure 7-10 Sample J42/f484, slide L23119/SM011; Kurinui Formation, Hampden Beach Section (Heretaungan); x 600; specimen measures 76 × $70 \mu \mathrm{m}$

Figure 11-12 Sample J42/f484, slide L23119/SM012; Kurinui Formation, Hampden Beach Section (Heretaungan); x 650; specimen measures 68 x $64 \mu \mathrm{m}$ 


\section{Plate 92}
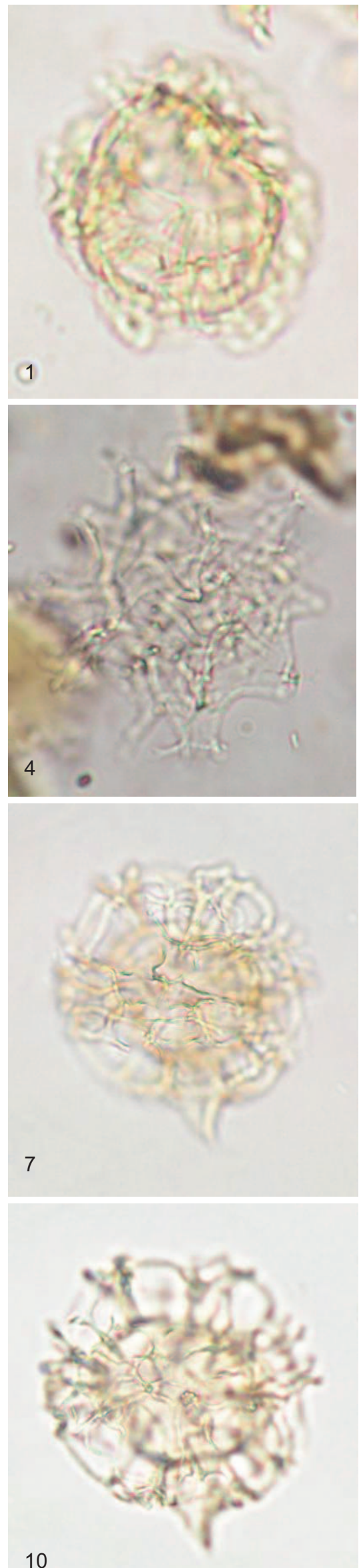
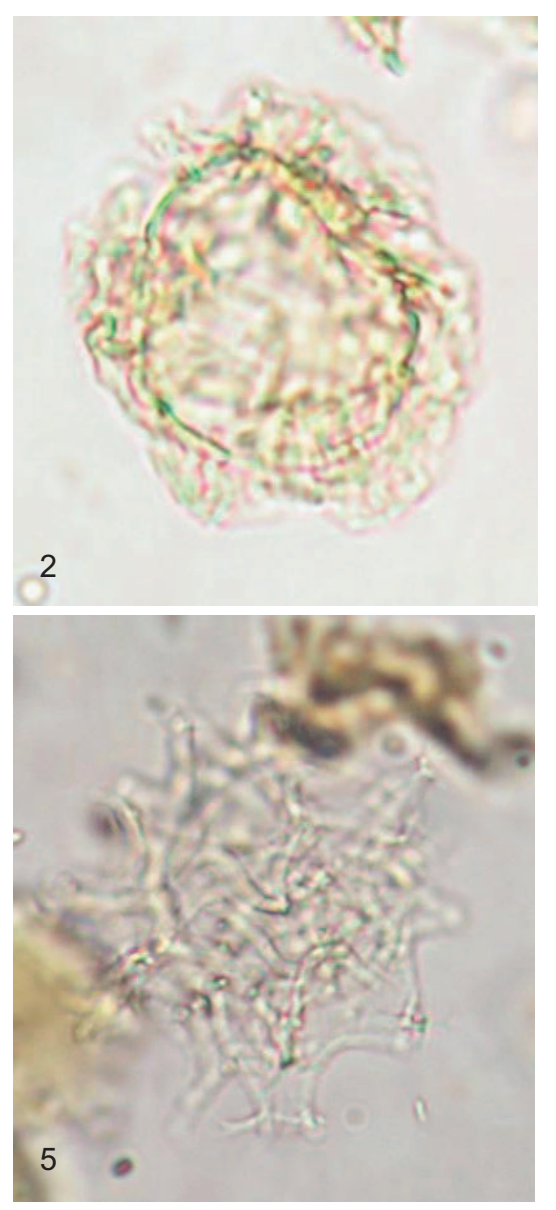

8
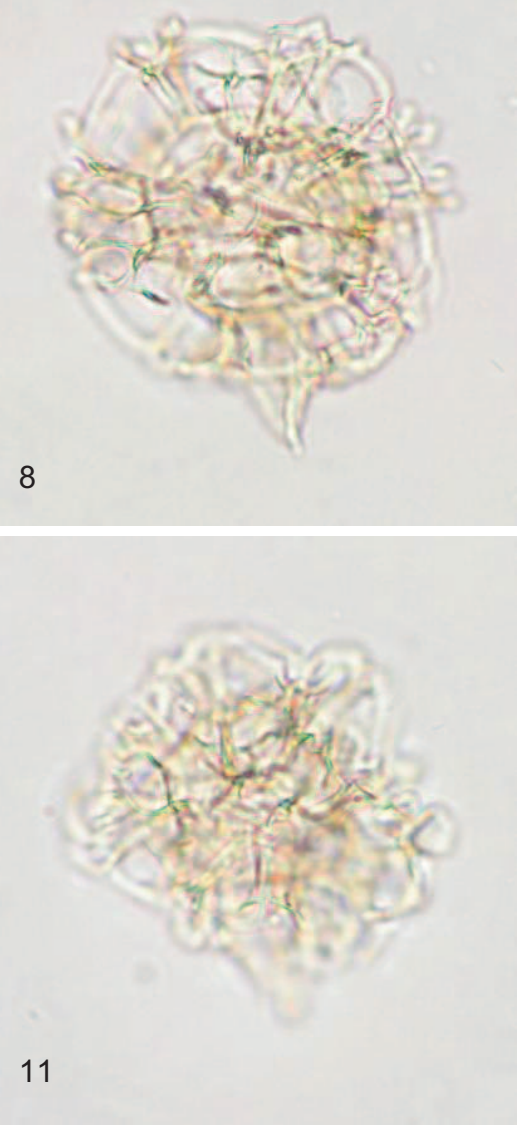

3
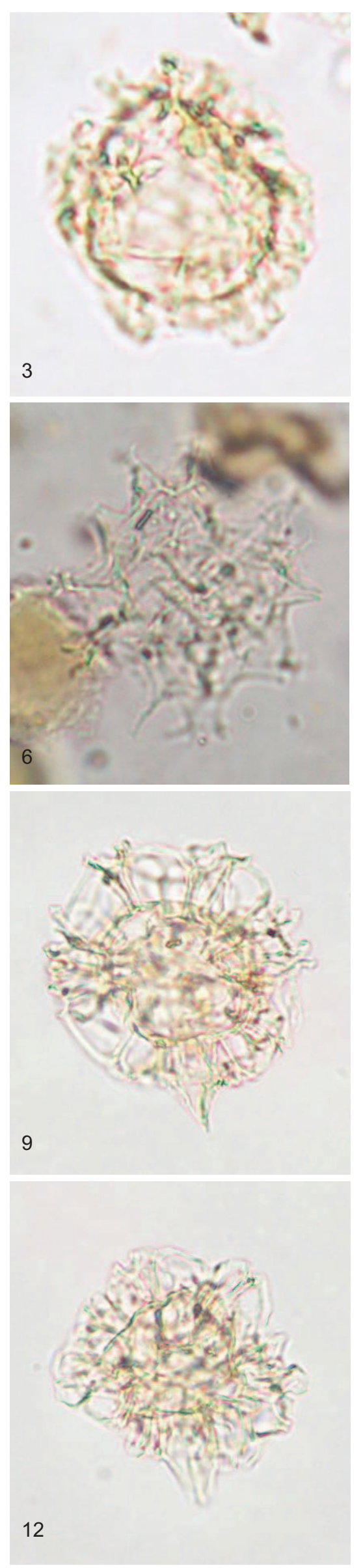


\section{Plate 93}

\section{Indet $4 \mathrm{sp} .1$}

Figure 1-8 Sample 143/f089, slide L16337/SM103; Burnside Formation, Puketeraki Core (Bortonian); x 625; specimen measures 75 x $55 \mu \mathrm{m}$

Figure 9 Sample 143/f096, slide L16344/SM041; Burnside Formation, Puketeraki Core (Kaiatan); x 850; specimen measures 55 x $50 \mu \mathrm{m}$

Figure 10-12 Sample 143/f089, slide L16337/SM050; Burnside Formation, Puketeraki Core (Bortonian); x 700; specimen measures 66 × $60 \mu \mathrm{m}$ 


\section{Plate 93}
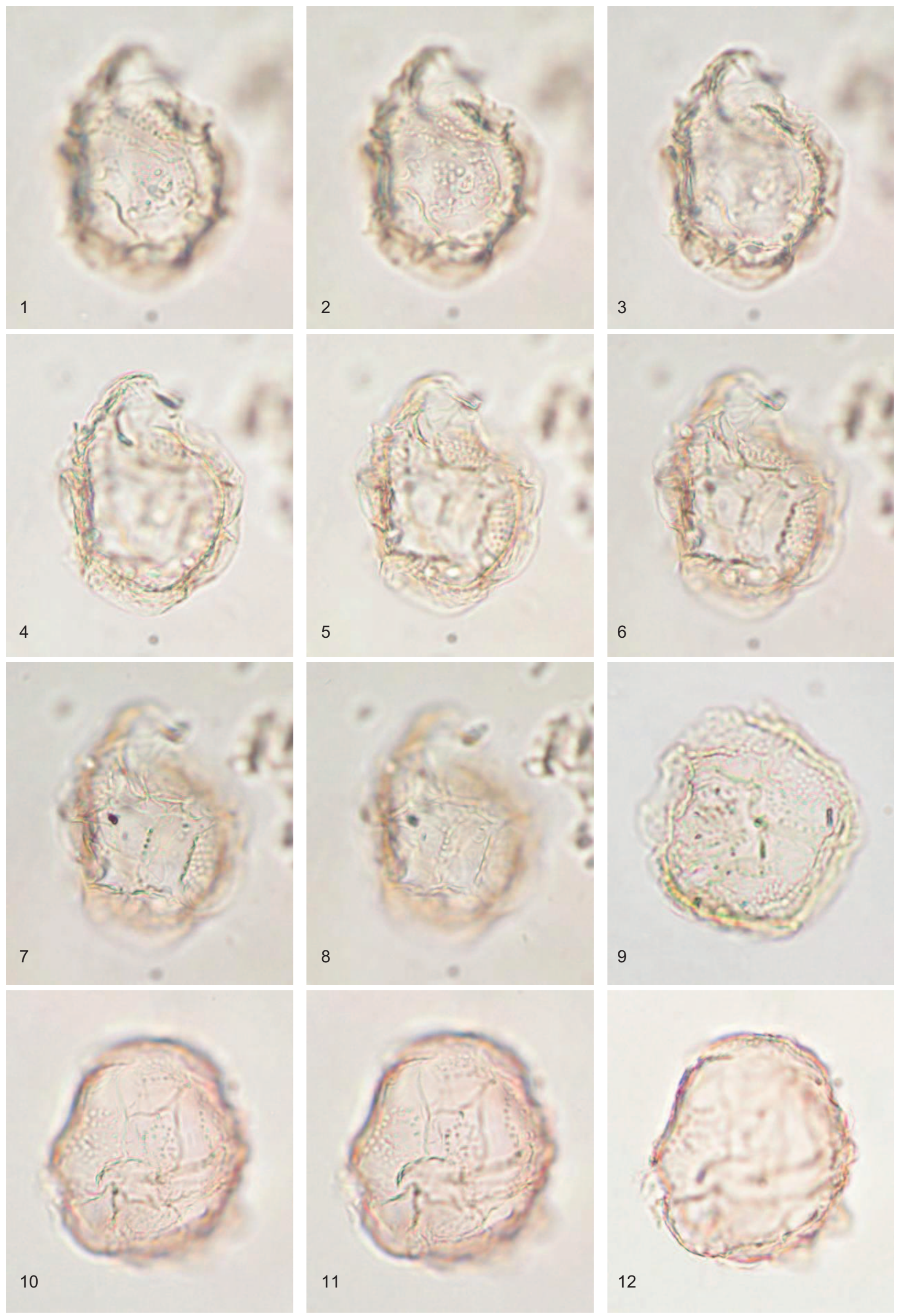


\section{Plate 94}

\section{Indet 4 sp. 1}

Figure 1-3 Sample 143/f089, slide L16337/SM050; Burnside Formation, Puketeraki Core (Bortonian); x 700; specimen measures 66 × $60 \mu \mathrm{m}$

\section{?Cymatiosphaera sp. 1}

Figure 4-6 Sample I43/f089, slide L16337/2-1453-133; Burnside Formation, Puketeraki Core (Bortonian); specimen measures $30 \times 29 \mu \mathrm{m}$

?Cymatiosphaera sp. 2

Figure 7-9 Sample K29/f097, slide L10914/SM040; Port Elizabeth Member, Cape Foulwind Section (early Whaingaroan); x 675; specimen measures 58 x $62 \mu \mathrm{m}$

\section{Pterospermella sp. 1}

Figure 10-12 Sample U24/f419, slide L23127/SM098; Wanstead, Te Uri Stream (Porangan); x 425; specimen measures $110 \times 87 \mu \mathrm{m}$ 


\section{Plate 94}
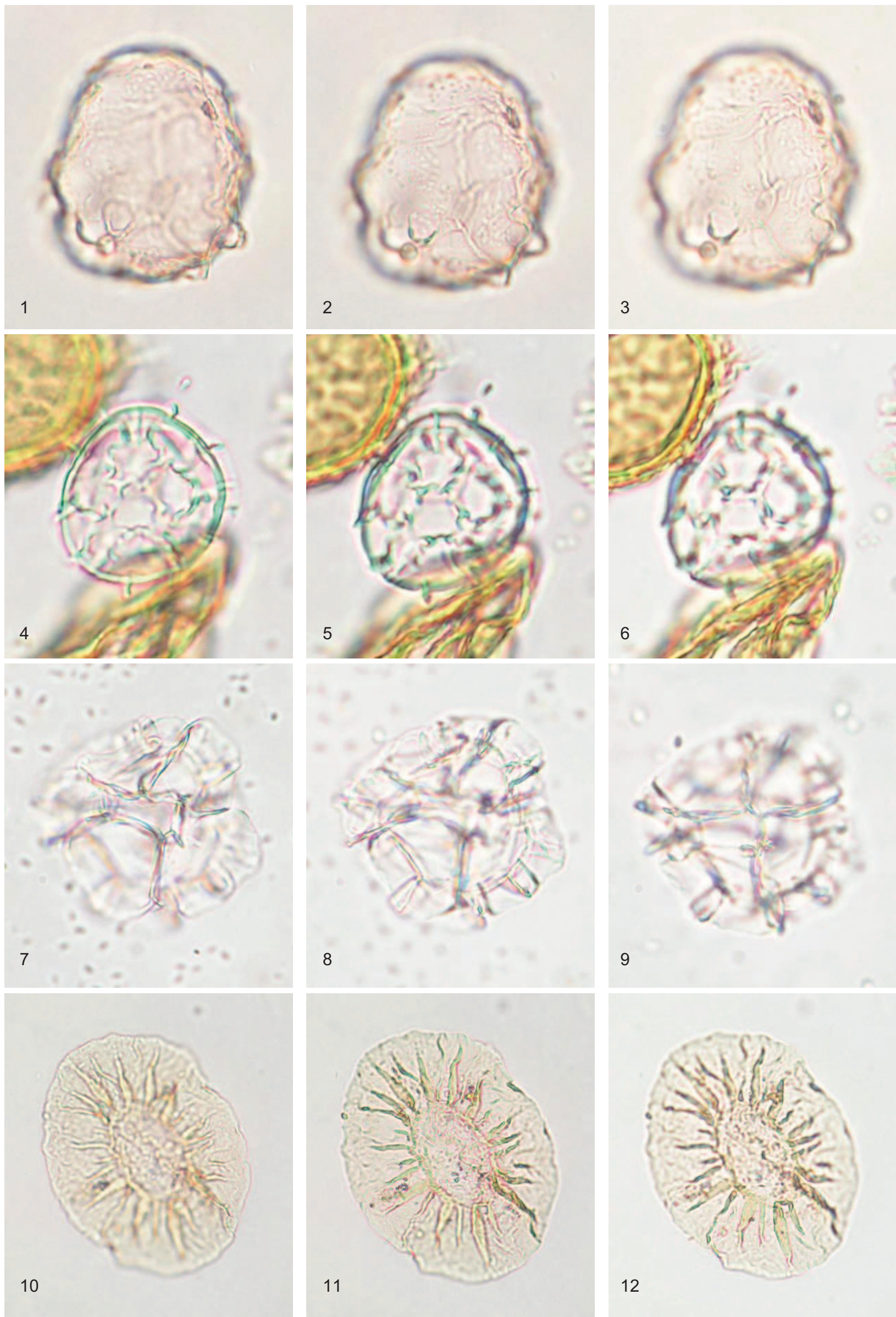

9
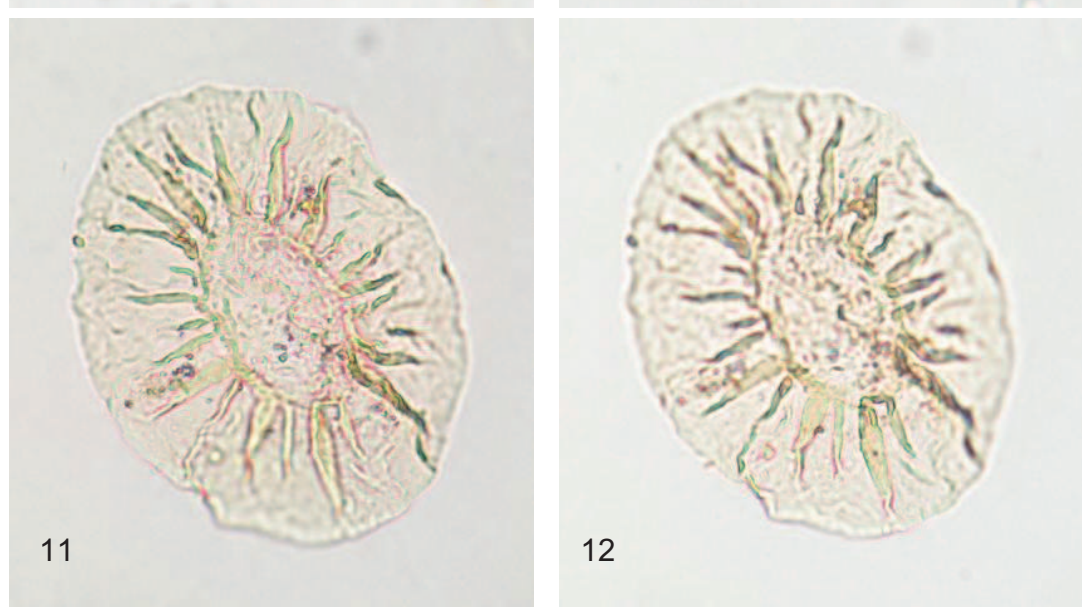